


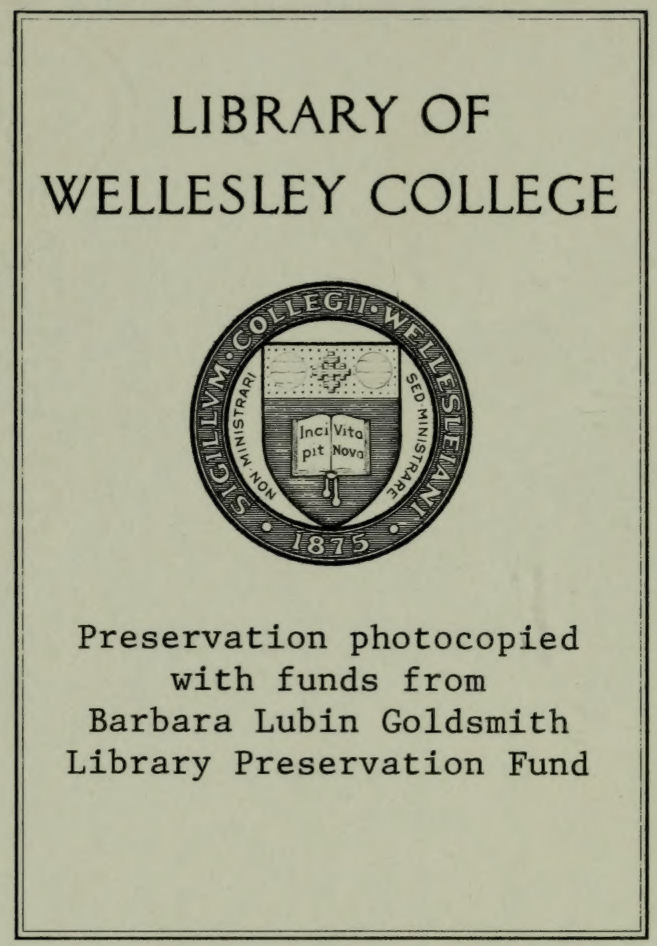






1

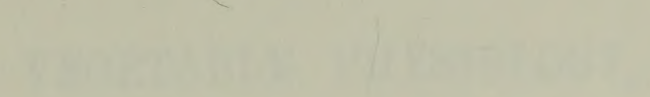

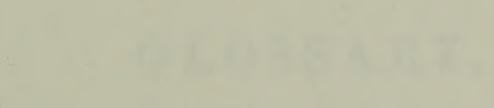

- 



\section{G R A Y'S}

\section{LESSONS IN BOTANY \\ AND}

\section{VEGETABLE PHYSIOLOGY,}

ILLUSTRATED BY OVER 360 WOOD ENGRAVINGS, FROM ORIGINAL DRAWINGS, BY ISAAC SPRAGUR.

TO WHICH IS ADDED A COPIOUS

G L O S S A R Y,

OR

\section{DICTIONARY OF BOTANICAL TERMS.}

B y A S A R A Y,

MSHER PROFESSOR OF NATURAL HISTORY IN HARVARD UNIVERSITY.

IVISON, BLAKEMAN, TAYLOR \& CO., NEW YORK AND CHICAGO

1881. 
Science library

$$
\begin{aligned}
& \text { QR } \\
& 117 \\
& .675 \\
& 1881 a
\end{aligned}
$$




\section{P R E F A C E.}

Tris book is intended for the use of beginners, and for classes in the common and higher schools, - in which the elements of Botany, one of the most generally interesting of the Natural Sciences, surely ought to be taught, and to be taught correctly, as far as the instruction proceeds. While these Lessons are made as plain and simple as they well can be, all the subjects treated of have been carried far enough to make the book a genuine Gramınar of Botany and Vegetable Physiology, and a sufficient introduction to those works in which the plants of a country - especially of our own - are described.

Accordingly, as respects the principles of Botany (including Vegetable Physiology), this work is complete in itself, as a school-book for younger classes, and even for the students of our higher seminaries. For it comprises a pretty full account of the structure, organs, growth, and reproduction of plants, and of their important uses in the scheme of creation, - subjects which certainly ought to be as generally understood by all educated people as the elements of Natural Philosophy or Astronomy are; and which are quite as easy to be learned.

The book is also intended to serve as an introduction to the author's Manual of the Botany of the Northern United States (or to any similar work describing the plants of other districts), and to be to it what a grammar and a dictionary are to a crassicai author. It consequently con. tains many terms and details which there is no necessity for young students perfectly to understand in the first instance, and still less to commit to menory, but which they will need to refer to as occasions arise, when they come to analyze flowers, and ascertain the names of our wild plants.

To make the book complete in this respect, a full Glossary, or Dictionary of Terms used in describing Plants, is added to the volume. This contains very many words which are not used in the Manual of Bolany; but as they occur in eommon botanical works, it was thought best to introduce and explain them. All the words in the Glossary which seemed to require it are accented. 
It is by no means indispensable for students to go through the volume before commencing with the analysis of plants. When the proper season for botanizing arrives, and when the first twelve Lessons have been gone over, they may take up Lesson XXVIII, and the following ones, and proceed to study the various wild plants they find in blossom, in the manner illustrated in Lesson XXX., \&c., - referring to the Glossary, and thence to the pages of the Lessons, as directed, for explanations of the various distinctions and terms they meet with. Their first essays will necessarily be rather tedious, if not diflicult; but each successful attempt smooths the way for the next, and soon these technical terms and distinctions will become nearly as familiar as those of ordinary language.

Students who, having mastered this elementary work, wish to extend their acquaintance with Vegetable Anatomy and Physiology, and to consider higher questions about the structure and classification of plants, will be prepared to take up the author's Botanical Text-Book, an Introduction to Structural Botany, or other more detailed treatises.

No care and expense have been spared upon the illustrations of this volume; which, with one or two exceptions, are all original. They were drawn from nature by Mr. Sprague, the most accurate of living botanical artists, and have been as freely introduced as the size to which it was needful to restrict the volume would warrant.

To append a set of questions to the foot of each page, although not unusual in school-books, scems like a reflection upon the competency or the faithfulness of teachers, who surely ought to have mastered the lesson before they undertake to rearh it; nor ought facilities to be afforded for teaching, any more than learning, lessons by rote. A full analysis of the contents of the Lessons, however, is very convenient and advantageous. Such an Analysis is here given, in place of the ordinary table of contents. This will direct the teacher and the learner at once to the leading ideas and important points of each Lesson, and serve as a basis to ground proper questions on, if such should be needed.

\section{ASA GRAY.}

\section{Harvard University, Cambridge,} January 1, 1857.

\footnotetext{
** Revised August, 1868, and alterations made adapting it to the new edition of Mranual, and to Field, fivest, and Garden Botany, to which this work is the proper introduction and companion.
}

A. G. 


\section{ANALYSIS OF THE LESSONS.*}

IESSON I. - Botany as a Branci of Naturat. Ilistory. . p. 1.

1. Natnral History, its stubjects. 2. The Inorganic or Mincral Kingdom, what it is : why called Inorganic. 3. The Organic world, or the world of Organized beings, why so called, and what its peculiarities. 4. What kingdoms it comprises. 5, 6. Differences between plants and animals. 7. The use of plants : how vegetables are nourished; and how animals.

8. Botany, how defined. 9. Physiology, and Physiological Botany, what hey relate to. 10. Systematic Botany, what it relates to: a Flora, what it is. 11. Geographical Botany, Fossil Botany, \&c., what they relate to.

\section{ZESSON II. - The Growti of tin Prant from tire Send. p. 4.}

12. The Course of Vegetation: general questions proposed. 13. Plants formed on one general plan. 14. The Germinating Plantlet: 15. exists in miniature in the seed : 16. The Embryo; its parts: 17, 18. how it develops. 19. Opposite growth of Root and Stein : 20. its object or results : 21, 22. the different way each grows.

Legson III. Growth of the Plant from the Seed; continued. p. 9.

23. Recapitulation: Ascending and Descending Axis. 24, 25. The Germinating Plantlet, how nourished. 26. Deposit of food in the embryo, illustrated in the Squash, \&c.: 27. in the Almond, Apple-seed, Beech, \&c.: 28. in the Bean : 29. in the Pea, Oak, and Buckeye : peculiarity of these last. 30, 31. Deposit of food outside of the embryo: Albumen of the sced: various shapes of embryo. 32, 33. Kinds of embryo as to the number of Cotyledons: dicotyledonous: monocotyledonous : polycotyledonous. 34, 35. Plan of vegeta tion. 36. Simple-stemmed vegetation illustrated.

\section{Lesson IV. The Growtri of Plants from Buds and Branches. p. 20.}

37, 38. Branching: difference in this respect between roots and stems. 39. Buds, what they are, and where situated: 40. how they grow, and what they become. 41. Plants as to size and duration: herb, annual, biennial, perennial : shrub: tree. 42. Terminal Bud. 43. Axillary Buds. 44. Scaly Buds. 45. Naked Buds. 46. Vigor of vegetation from buds illustrated. 47-49. Plan and arrangement of Branches : opposite: alternate. 50. Symmetry of Branches,

* The numbers in the analysis refer to the paragraphs. 
; what it depends on: 51. how it becomes incomplete: 51-59. how varied. 53 Definite growth. 54. Indefinite growth. 55. Deliquescent or dissolving stems, how formed. 56. Excurrent stems of spire-shaped trees, how produced. 57. Latent Buds. 58. Adventitions Buds. 59. Accessory or supernumerary Buds. 60. Sorts of Buds recuvitulated and defined.

\section{LESSON V. MORPHOLOGY OF Rootg. . . . . . . . . p. 28.}

$61-64$. Morphology; what the term means, and how applied in Botany. 65. Primary Root, simple; and, 66. multiple. 67. Rootlets; how roots absorh: time for transplantation, \&e. 68. Gruat amount of surface which a plant spreads out, in the air and in the soil; reduced in winter, increased in spring. 69. Absorbing surface of roots increased by the root-hairs. 70. Fibrous roots for absorption. 71. Thickened or fleshy roots ats storchouse of food. 72, 73. Their principal forms. 74. Biennial roots; their economy. 75. Perennial thickened roots. 76. Potatoes, \&c. are not roots. 77. Secondary Roots, their economy. 78. Sometimes striking in open air, when they are, 79. Aerial Roots ; illustrated in Indian Corn, Mangrove, Screw Pine, Banyan, \&c. 80. Acrial Rootlets of Ivy. 81. Epiphytes or Air-Plants, illustrated. 82. Parasitic 1'lants, illustrated by the Mistletoe, Dodder, \&c.

\section{LESSON VI. Morphology of Stems and Branches. . . . p. 36.}

83-85. Forms of stems and branches above ground. 86. Their direction or habit of growth. 87. Culm, Caudex, \&c. 88. Suckers : propagation of plauts by division. 89. Stolons: propagation by layering or laying. 90. Otfsets. 91. Runners. 92. Tendrils; how plants climb by them : their disk-like tips in the Virginia Creeper. 93. T'endrils are sometimes forms of leaves. 94. Spines or 'Thorns; their nature : P'rickles. 95. Strange forms of stems. 96. Subterrancun stems and branches. 97. 'The Rootstock or Rlizoma, why stem and not root. 98. Why ruming rootstocks are so troublesome, and so hard to destroy. 99-101. Thickened rootstocks, as depositories of food. 102. Their life and growth. 103. 'The 'Tuber. 104. Economy of the Potato-plant. 105. Gradations of tubers into, 106. Corms or solid bulbs : the nature and economy of these, as in Crocus. 107. Gradation of these into, 108. the Bulb: nature of bulbs. 109, 110. Their economy. 111. Their two principal sorts. 112. Bulblets. 113. How the foregoing sorts of stems illustrate what is meant by morphology. 114. They are imitated in some plants above ground. 115. Consolidated forms of vegetation, illustruted by Cactuses, \&c. 116. Their econony and adiptation to dry regions.

\section{LESSON VII. Monphology of Leaves. . . . . . . . p. 49.}

117. Remarkable states of leaves already noticed. 118, 119. Foliage the natural form of leaves: others are special forms, or transformations; why so called. 120. Leaves as depositories of food, especially the seed-leaves; and, 121. As Bulb-scales. 122. Ieaves as Bud-scales. 123. As Spines. 124. As Tendrils. 125. As Pitchers. 126. As Fly-traps. 127-129. The same leaf serving various purposes. 
LESSON VIII. Morphology of Leaves as Foliage. . . p. 54.

130. Foliage the natural state of leares. 131. Leaves a contrivance for increasing surface: the vast surface of a tree in leaf. 132, 133. The parts of a leaf. 134. The blade. 135. Its pulp or soft part and its framework. 136. The latter is wood, and forms the ribs or veins and veinlets. 137. Division and use of these. 138. Venation, or mode of veining. 139. Its two kinds. 140. Netted-veined or reticulated. 141. Parallel-veined or nerved. 142. The socalled veins and nerves essentially the same thing; the latter not like the nerves of animals. 143. How the sort of veining of leaves answers to the number of cotyledons and the kind of plant. 144. Two kinds of parallel-veined leaves. 145, 146. Two kinds of netted-veined lenves. 147. Relation of the veining to the shape of the leaf. 148-151. Forms of leaves illustrated, as to general outline. 152. As to the base. 153. As to the apex.

LESSON IX. Morphology of Leaves as Foliage; continued. p. 61.

154, 155. Leaves either simple or compound. 156-162. Simple leaves illustrated as to particular outline, or kind and degree of division. 163. Compound leaves. 164. Leaflets. 165. Kinds of compound leaves. 166, 167. The pinnate, and, 168. the palmate or digitate. 169. As to number of leaflets, \&c. 170. Leaflets, as to lobing, \&c. 171, 172. Doubly or trebly compound leaves of both sorts. 173. Peculiar forms of leaves explained, such as : 174. Perfoliate: 175. Equitant: 176. Those without blade. 177. Phyllodia, or flattened petioles. 178. Stipules. 179. Sheaths of Grasses; Ligule.

\section{LeSSON X. The Arrangement of Leaves. . . . . . . p. 71.}

181. Phyllotixy, or arrangement of leaves on the stem : general sorts of arrangement. 182. Lenves arise only one from the same place. 183. Clustered or fascicled leáves explained. . 184. Spiral arrangement of alternate leaves. 185. The two-ranked arrangement. 186. The three-ranked arrangement. 187. The five-ranked arrangement. 188. The fractions by which these are expressed. 189. The eight-ranked and the thirteen-ranked arrangements. 190. The series of these fractions, and their relations. 191. Opposite and whorled leaves. 192. Symmetry of leaves, \&c. fixed by mathematicanl rule. 193. Vernation, or arrangement of leaves in the bud. 194. The principal modes.

\section{LESSON XI: The Arrangement of Flowers on the Stem, OR INFLORESCENCE. . . . . . . . . . p. 76.}

195. Passage from the Organs of Vegetation to those of Fructification or Roproduction. 196. Inflorescence : the arrangement of flowers depends on that of the leaves. 197. They are from either terminal or axillary buds, 198. Indeterminate Inflorescence. 199. Its sorts of flower-clusters. 200. Flowerstalks, viz. peduncles and pedicels, bracts and bractlets, \&c. 201. Raceme. 202. Its gradation into (203) a Corymb, and that (204) into (205) an Umbel. 206. Centripetal order of development. 207. The Spike. 208. The Hea 
209. Spadix. 210. Catkin or Ament. 211, 212. Compound inflorescence of the preceding kinds. 213. Panicle. 214. Thyrsus. 215. Determinate In. florescence explained. 216, 21\%. Cyme: centrifugal order of development. 218. Fascicle. 219. Glomerule. 221. Analysis of tlower-clusters. 222. Com. bination of the two kinds of inflorescence in the same plant.

\section{LeSSON XiI. The Flower: its Parts or Organs. . . . p. 84.}

223. The Flower. 224. Its nature and use. 225. Its organs. 226. The Floral Envelopes or leaves of the flower. Calyx and Corolla, together called (227) Perianth. 228. Petals, Sepals. 229. Neutral and "double" flowers, those destitute of, 230. The Essential Organs: Stamens and Pistils. 231, 232. The parts of the flower in their succession. 233. The Stamen : its parts. 234. The Pistil : its parts.

\section{Lesson Xili. The Plan of the Flower. . . . . . . . p. 88.}

235. Flowers all constructed upon the same plan. 236. Plan in vegetation referred to. 237-239. Typical or pattern flowers illustrated, those at once perfect, complete, regular, and symmetrical. 241. Imperfect or separated flowers. 242. Incomplete flowers. 243. Symmetry and regularity. 244. Irregular flowers. 245. Unsymmetrical flowers. 246. Numerical plan of the flower. 247. Alternation of the successive parts. 248. Occasional obliteration of certain parts. 24?. Abortive organs. 250. Multiplication of parts.

\section{LESSON XiV. Morphology of tile Flower. . . . . . . p. 96.}

251. Recapitulation of the varied forms under which stems and leaves appear. 252. 'These inay be called metamorphoses. 253. Flowers are altered branches; how shown. 254. Their position the same as that occupied by buds. 255, 256. Leaves of the blossom are really leaves. 257. Stamens a different modification of the same. 258. Pistils another modification; the botanist's idea of a pistil. 259. The arrangement of the parts of a flower unswers to that of the leaves on a branch.

\section{LeSSON XV. Morphology of the Calyx and Corolla. . p. 99.}

260. The leaves of the blossom viewed as to the various shapes they assume; as, 261. by growing together. 262. Union or cohesion of parts of the sume sort, rendering the flower, 263. Monopetalous or monosepalous; various shapes defincd and named. 265. The tube, and the border or limb. 266. The claw and the blade, or lamina of a separate petal, \&c. 267. When the parts are distinct, polysepalous, and polypetalous. 268. Consolidation, or the growing together of the parts of different sets. 269. Insertion, what it means, and what is meant by the terms Free and Hypogynous. 270. Perigynous insertion. 271, 272. Coherent or adherent calyx, \&c. 273. Epigynous. 274. Irregularity of parts. 275. Papilionaceous flower, and its parts. 276. Labiate or bilabiato flowers. 277. 278. Ligulate flowers: the so-called compound flowers. 


\section{LESSON XVI. Fetivation, or tme Arrangement of tine Calyx and Corolea in the Bud. . . . p 108.}

279. Fstivation or Prafloration defined. 280. Its principal morles illustrated, viz. the valvate, induplicate, reduplicate, convolute or twisted, and imbricated. 282, 283. Also the open, and the plaited or plicate, and its modification, the supervolute.

\section{LESSON XVII. Morphologt of the Stamens. . . . . p. 111}

284. Stamens considered as to, 285. Their insertion. 286. Their union with each other. 287, 288. Their number. 289. Their parts. 290. The Filament. 291. The Anther. 292, 293. Its attachment to the filament. 294. Its structure. 295. Its mode of opening, \&c. 296. Its morphology, or the way in which it is supposed to be constructed ont of a leaf; its use, viz. to produce, 297. Pollen. 298. Structure of pollen-grains. 299. Some of their forms.

\section{LESSON XVIII. Morrholog}

300. Pistils as to position. 301. As to number. 302. Their parts; Ovary, style, and stigma. 303, 304. I'lan of a pistil, whether simple or compound. 305, 306. The simple pistil, or Carpel, and how it answers to a leaf. 307. Its sutures. 308. The Placenta. 309. The Simple Pistil, one-cellerl, 310. and with one style. 311, 312. The Compound Pistil, how composed. 313. With two or more cells : 314. their placentx in the axis : 315. their dissepiments or partitions. 316, 317. Onc-celled compound pistils. 318. With a free central placenta. 319, 320. With parietal placentr. 321. Ovary superior or inferior. 322. Open or Gymnospermons pistil : Naked-seeded plants. 323. Ovules. 324. Their structure. 325, 326. Their kinds illustrated.

LESSON XIX. Morphology of time Receptacle. • . . p. 124.

327. The Receptacle or Torts. 328-330. Some of its forms illustrated. 331. The Disk. 332. Curious form of the receptacle in Nelumbium.

LESSON XX. The Fruit. . . . . . . . . . . . . p. 126.

333. What the Fruit consists of. 334. Fruits which are not such in a strict botanical sense. 335. Simple Fruits. 336, 337. The Pericarp, and the changes it may undergo. 338. Kinds of simple fruits. 339. Fleshy fruits. 340. The Berry. 341. The Pepo or Ground-fruit. 342. The Pome or Apple-fruit. $343-$ 345. The Drupe or Stone-fruit. 346. Dry fiuits. 347. The Achenium : nature of the Strawberry. 348. Raspberry and Blackberry. 349. Fruit in the Composite Family : Pappus. 350. The Utricle. 351. The Caryopsis or Grain. 352. The Nut : Cupule. 353. The Samara or Key-fruit. 354. 'The Capsule or Pod. 355. The Follicle. 356. The Legume and Loment. 357. The true Capsule. 358, 359. Dehiscence, its kinds. 361. The Silique. 362. The Silicle. 363. The Pyxis. 364. Mnltiple or Collective Fruits. 365. The Strobile or Cone. 
LESSON XXI. The Seed. . . . . . . . . . . . . p. 134.

366. The Seed; its origin. 367. Its parts. 360, 369. Its coats. 370. The Aril or Arillus. 371. Names applied to the parts of the seed. 372. The Kernel or Nucleus. 373. The Albumen. 374, 375. The Embryo. 376. The Radicle. 377. The Cotyledons or Seed-leaves : the monocotyledonous, dicotyledonous, and polycotyledonous embryo. 378. The Plumule. 379. The circle of vegetable life completed.

Lesson XXiI. How Plants grow. . . . . . . . . p. 138.

380,381 . Growth, what it is. 382. For the first formation or beginning of a plant dates further back than to, 383. the embryo in the ripe seed, which is already a plantlet. 384. The formation and the growth of the embryo itself. 385. Action of the pollen on the stigma, and the result. 386. 'The Embryoual Vesicle, or first cell of the embryo. 387. Its growth and development into the embryo. 388. Growth of the plantlet fiom the seed. 389. The plant built up of a vast number of cells. 390. Growth consists of the increase in size of cells, and their multiplication in number.

lesson XXiII. Vegetable Fabric: Cellular Tissue. . . p. 142.

391, 392. Organic Structure illustrated : Cells the units or elements of plants. 393. Cellular 'I'issue. 394,395, 397. How the cells are put together. 396. Intercellular spaces, air-passages. 398 Size of cells. 399. Rapidity of their production. 400. 'Their walls colorless; the colors owing to their contents. 401. 'The walls sometimes thickened. 402. Cells are closed and whole; yet sap flows from one cell to another. 403. 'Their varied shapes.

LESSON XXIV. Vegetable Fabric: Wood. . . . . . p. 145.

404. All plants at the beginning formed of cellular tissue only; and some never have anything else in their composition. 405. Wood soon appears in most plants. 406. Its nature. 408. Wood-cells or Woody Fibre. 409. Hard wood and soft wood. 410. Wood-cells closed and whole; yet they convey sap. 411. They communicate through thin places: Pine-wood, \&e. 412. Bast-cells or fibres of the bark. 413. 1)ucts or Vessels. 414. The principal kinds. 415. Milk-vessels, Oil-receptacles, \&e.

LESSON XXV. Anatomy of the Root, Stem, and Leaves. p. 149.

416. The materials of the vegetable fabric, how put together. 417-419. Structure and action of the rootlets. 420. Root-hairs. 421. Structure of the stem. 422. The two sorts of stem. 423. The Endogenous. 423. The Exogenous : 425. more particularly explained. 426. Parts of the wood or stem itself. 427. Parts of the bark. 428. Growth of the exogenous stem year after year. 429. Growth of the bark, and what becomes of the older parts. 431. Changes in the wood; Sap-wood. 432. Heart-wood. 433. This no longer liv. 
ing. 434. What the living parts of a tree are; their annnal renewal. 435. Cambium-layer or zone of growth in the stem; connected with, 436. new rootlets below, and new shoots, buds, and leaves above. 437. Structure of a leaf: its two parts, the woody and the cellular, or, 438. the pulp ; this contains the green matter, or Chlorophyll. 439, 440. Arrangement of the cells of green pulp in the leaf, and structure of its epidermis or skin. 441. Upper side only endures the sunshine. 442. Evaporation or exhalation of moisture from the leaves. 443. Stomates or Breathing-pores, their structure and use. 444. Their numbers.

\section{LESSON XXVt. The Plant in Action, doing the Work of Vegetation. . . . . . . . . p. 157.}

446. The office of plants to produce food for animals. 447. Plants feed upon earth and air. 449. Their chemical composition. 450. Two sorts of matcrial. 451, 452. The earthy or inorganic constituents. 453. The organic constituents. 454. These form the Cellulose, or substance of vegetable tissue; composition of cellulose. 455. The plant's food, from which this is made. 456. Water, furnishing hydrogen and oxygen. 458. Carbonic acid, furnishing, 457. Carbon. 459. The air, containing oxygen and nitrogen; and also, 460. Carbonic acid; 461. which is absorbed by the leaves, 462 . and by the roots. 463. Water and carbonic acid the general food of plants. 464. Assimilation the proper work of plants. 465. Takes place in green parts alone, under the light of the sun. 466-468. Liberates oxygen gas and produces Cellulose or plant-fabric. 469. Or else Starch; its nature and use. 470. Or Sugar; its nature, \&c. The transformations starch, sugar, \&c. undergo. 471. Oils, acids, \&c. The formation of all these products restores oxygen gas to the air. 472. Therefore plants purify the air for animals. 473. While at the same time they produce all the food and fabric of animals. The latter take all thcir food ready made from plants. 474. And decompose starch, sugar, oil, \&c., giving back their materials to the air again as the food of the plant; at the same time producing animal heat. 475. But the fabric or flesh of animals (fibrine, gelatine, \&c.) contains nitrogen. 476. This is derived from plants in the form of Proteine. Its nature and how the plant forms it. 477. Earthy matters in the plant form the enrthy part of bones, \&c. 478. Dependence of animals upon plants ; showing the great object for which plants were created.

\section{LESSON XXVII. Plant-Life. . . . . . . . . . . . p. 166.}

479. Life; manifested by its effects; viz. its power of transforming matter: 480. And by motion. 481, 482. Plants execute movements as well as animals. 483. Circulation in cells. 484. Frec movements of the simplest plants in their forming state. 485. Ahsorption and conveyance of the sap. 486. Its rise into the leaves. 487. Explained by a mechanical law; Endosmose. 488. Set in action by evaporation from the leaves. 489. These movements controlled by the plant, which directs growth and shapes the fabric by an inherent power. 490492. Special movements of a conspicuous sort; such as seen in the bending, twining, revolving, and coiling of stems and tendrils; in the so-called sleeping and waking states of plants; in movements from irritation, and striking spon. taneous motions. 
493. Cryptogamous or Flowerless Plants. 494. What they comprise; why so called. 495. To be studied in other works.

LESSON XXVIII. Species aND Kinds. . . . . . . . p. 173.

496. Plants viewed as to their relationships. 497. Two characteristics of plants and animals : they form themselves, and, 498. They exist as Individuals. The chain of individuals gives rise to the idea of, 499, 500. Species: aysemblages of individuals, so like that they are inferred to have a common ancestry. 501. Varicties and Races. 502. Tendency of the progeny to inherit all the peculiarities of the parent; how taken advantage of in developing and inxing races. 503. Diversity and gradation of species; these so comnected as to show all to be formed on one plan, all works of one hand, or realizations of the conceptions of one mind. 504. Kinds, what they depend upon. 505. Genera. 506. Orders or Families. 507. Suborders and Tribes. 508. Classes. 509. The two great Series or grades of plants. 510. The way the various divisions in classification are ranked.

LESSON XXIX. Botanical Names and Characters. • . p. 178.

511, 512. Classification; the two purposes it subserves. 513. Names : plan of nomenclature. 514, 515. Generic names, how formed. 516. Specific names, how formed. 517. Names of Varieties. 518, 519. Names of Orders, Suborders, Tribes, \&c. 520, 521. Characters.

LESSONS XXX.-XXXII. How to study Plants. pp. 181, 187, 191.

$522-567$. Illustrated by several examples, showing the mode of analyzing and ascertaining the name of an unknown plant, and its place in the system, \&c.

LESSON XXXIII. Botanical Systems. . . . . . . . p. 195.

568-571. Natural System. 572, 573. Artificial Classification. 574. Artificial System of Linnæus. 575. Its twenty-four. Classes, enumerated and defined. 576. Derivation of their names. 577, 578. Its Orders.

LESSON XXXIV. How to Collect SPEcimens aNd Make an Herbarium. . . . . . . . p. 199.

579-582. Directions for collecting specimens. 583, 584. For drying and preserving specimens. 585, 586 For forming an Herbarium.

GLOSSARY, or Dictionary of Botanical Terms. • . • p. 203 


\title{
FIRST LESSONS
}

\author{
IN
}

\section{BOTANY AND VEGETABLE PHYSIOLOGY.}

\author{
LESSON I. \\ BOTANY AS A BRANCH OF NATURAI, IISTORY.
}

1. Tre subjects of Natural History are, the earth itself and the beings that live upon it.

2. The Inorganic World, or Mineral Kingdom. The earth itself, with the air that surrounds it, and all things naturally belonging to them which are destitute of life, make up the mineral kingdom, or inorganic world. These are called inorganic, or unorganized, because they are not composed of organs, that is, of parts which answer to one another, and make up a whole, such as is a horse, a bird, or a plant. They were formed, but they did not grow, nor proceed from previous bodies like themselves, nor have they the power of producing other similar bodies, that is, of reproducing their kind. On the other hand, the various living things, or those which have pos sessed life, compose

3. The Organic World, - the world of organized beings. These consist of organs; of parts which go to make up an individual, a being. And each individual owes its existence to a preceding one like itself, that is, to a parent. It was not merely formed, but produced. At first small and imperfect, it grows and develops by powers of its own; it attains maturity, becomes old, and finally dies. It was formed of inorganic or mineral matter, that is, of earth and air, indeed; but only of this matter under the influence of life : and after life departs, sooner or later, it is decomposed into earth and air again. 
4. The organic world consists of two kinds of beings; namely, 1. Plants or Vegetables, which make up what is called the Vegetable Kingdom; and, 2. Animals, which compose the Animal Kingdom.

5. The Differences between Plants and Animals seem at first sight so obvious and so great, that it would appear more natural to inquire how they resemble rather than how they differ from each other. What likeness does the cow bear to the grass it feeds upon? The one moves freely from place to place, in obedience to its own will, as its wants or convenience require: the other is fixed to the spot of earth where it grew, manifests no will, and makes no movements that are apparent to ordinary olservation. The one takes its food into an internal cavity (the stomach), fiom which it is absorbed into the system: the other absorbs its food directly by its surface, by its roots, leaves, \&c. Both possess organs; but the limbs or members of the animal do not at all resemble the roots, leaves, blossoms, \&e. of the plant. All these distinctions, however, gradually disappear, as we come to the lower kinds of plants and the lower animals. Many animals (such as barnacles, coral-animals, and polyps) are fixed to some support as completely as the plant is to the soil; while many plants are not fixed, and sone move firom place to place by powers of their own. All animals move some of their parts freely; yet in the extent and rapidity of the motion many of them are surpasised by the common Sensitive Plant, by the Venus's Fly-trap, and by some other vegetables; while whole tribes of aquatic plants are so freely and briskly locomotive, that they have until lately been taken for animals. It is among these microscopic tribes that the animal and vegetable kingdoms most nearly approach each other, - so nearly, that it is still uncertain where to draw the line between them.

6. Since the difficulty of distinguishing between animals and plants occurs only, or mainly, in those forms which from their ininuteness are beyond ordinary observation, we need not further concern ourselves with the question here. Cne, and probably the most absolute, difference, however, ought to be mentioned at the outset, because it enables us to see what plants are made for. It is this:-

7. Vegetables are nourislied by the mineral kingdom, that is, by the ground and the air, which supply all they need, and which they are adapted to live upon; while animals are entirely nourished by vegetables. The great use of plants therefore is, to take portions of 
earth and air, upon which animals cannot subsist at all, and to convert these into something upon which animals can subsist, that is, into food., All food is produced by plants. How this is done, it is the province of Vegetable Physiology to explain.

8. Botany is the name of the science of the vegetable kingdom in general.

9. Physiology is the study of the way a living being lives, und grows, and performs its various operations. The study of plants in this view is the province of Vegetable Physiology. 'The study of the form and structure of the organs or parts of the vegetable, by which its operations are performed, is the province of Structural Botany. The two together constitute Physiological Botany. With this department the study of Botany should begin; both because it lies at the foundation of all the rest, and because it gives that kind of knowledge of plants which it is desirable every one should possess; that is, some knowledge of the way in which plants live, grow, and fulfil the purposes of their existence. To this subject, accordingly, a large portion of the following Lessons is devoted.

10. The study of plants as to their kinds is the province of Systematic Botany. An enumeration of the kinds of vegetables, as far as known, classified according to their various degrees of resemblance or difference, constitutes a general System of plants. A similar acvount of the vegetables of any particular country or district is called a Flora of that country or district.

11. Other departments of Botany come to view when - instead of regarding plants as to what they are in themselves, or as to their relationship with each other - we consider them in their relations to other things. Their relation to the earth, for instance, as respects their distribution over its surface, gives rise to Geographical Botany, or Botanical Geography. The study of the -vegetation of former times, in their fossil remains entombed in the crust of the earth, gives rise to Fossil Botany. The study of plants in respect to their uses to man is the province of Agricultural Botany, Medical Botany, and the like. 


\section{LESSON II.}

\section{THE GROWTH OF THE PLANT FROM THE SEED.}

12. The Course of Vegetation. We see plants growing from the seed in spring-time, and gradually developing their parts : at length they blossom, bear fruit, and produce seeds like those from which they grew. Shall we comnence the study of the plant with the full-grown herb or tree, adorned with flowers or laden with fiuit? Or shall we commence with the seedling just rising from the ground? On the whole, we may get a clearer idea of the whole life and structure of plants if we begin at the beginning, that is, with the plantlet springing from the seed, and follow it throughout its course of growth. 'This also agrees best with the season in which the study of Botany is generally commenced, namely, in the spring of the year, when the growth of plants from the seed can hardly fail to attract attention. Indeed, it is this springing forth of vegretation from seeds and buds, after the rigors of our long winter, clothing the earth's surface almost at once with a mantle of fieshest verdure, - which gives to spring its greatest charm. Even the dullest beholder, the least observant of Nature at other seasons, can then hardly fail to ask: What are plants? Ilow do they live and grow? What do they live upon? What is the object and use of vegetation in general, and of its particular and wonderfully various forms? These questions it is the object of the present Lessons to answer, as far as possible, in a simple way.

13. A reflecting as well as observing person, noticing the resemblances between one plant and another, might go on to inquire whether plants, with all their manifold diversities of form and appearance, are not all constructed on one and the same general plan. It will become apparent, as we proceed, that this is the ease; - that one common plan may be discerned, which each particular plant, whether herb, shrub, or tree, has followed much more closely than would at first view be supposed. The differences, wide as they are, are merely incidental. What is true in a general way of any ordinary vegetable, will be found to be true of all, only with great variation in the details. In the same language, though in varied phrase, the hundred thousand kinds of plants repeat the same 
story, - are the living witnesses and illustrations of one and the same plan of Creative Wisdom in the vegetable world. So that the study of any one plant, traced from the seed it springs from round to the seeds it produces, would illustrate the whole subject of vegetable life and growth. It matters little, therefore, what particular plant we begin with.

14. The Germinating Plantlet. Take for example a seedling Maple. Sugar Maples may be found in abundance in many places, starting from the seed (i. e. germinating) in early spring, and Red Maples at the beginning of summer, shortly after the fruits of the season have ripened and fallen to the ground. A pair of narrow green leaves raised on a tiny stem make up the whole plant at its first appearance (Fig. 4). Soon a root appears at the lower end of this stemlet; then a little bud at its upper end, between the pair of leaves, which soon grows into a second joint or stem bearing another pair of leaves, resembling the ordinary leaves of the Red Maple, which the first did not. Figures 5 and 6 represent these steps in the growth.

15. Was this plantlet formed in the seed at the time of germination, something as the chick is formed in the egg during the process of incubation? Or did it exist before in the seed, ready formed? To decide this question, we have only to inspect a sound seed, which in this instance requires no microscope, nor any other instrument than a sharp knife, by which the coats of the seed (previously snaked in water, if dry) may be laid open. We find within the seed, in this case, the little plantlet ready formed, and nothing else (Fig. 2);- namely, a pair of leaves like those of the earliest seedling (Fig. 4), only smaller, borne on a stemlet just like that of the seedling, only much shorter, and all snugly coiled up within the protecting seed-coat. The plant then exists beforehand

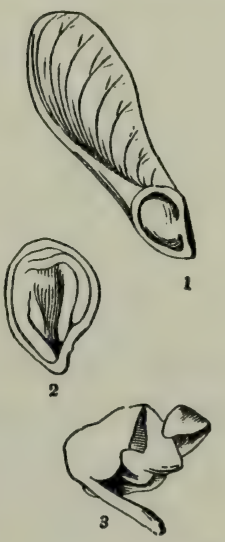
in the seed, in miniature. It was not formed, but only devel-

FIG. 1. A wingod fruit of Red Maple, with tho seed-hearing portion cut open, to show the seed. 2. This seed cut open to show the embryo plantlot within, enlarged. 3. The embryo taken out whole, and partly unfolded. 4. The same after it has begin to grow; of the natural size. 
oped, in germination; when it had merely to unfold and grow, -

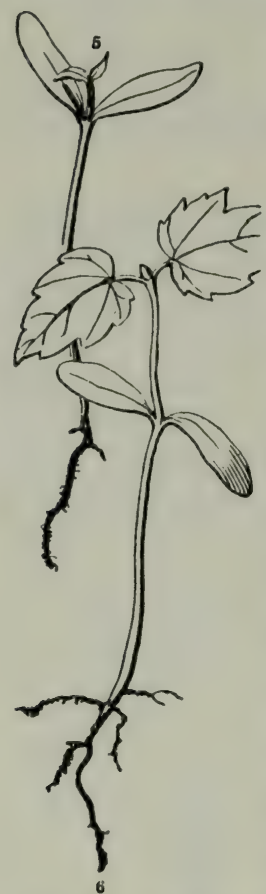
to elongate its rudimentary stem, which takes at the same time an upright position, so as to bring the leaf-bearing end into the light and air, where the two leaves expand; while from the opposite end, now pushed farther downwards into the soil, the root begins to grow. All this is true in the main of all plants that spring from real seeds, although with great diversity In the particulars. At least, there is hardly an exception to the fact, that the plantlet exists ready formed in the seed, in some shape or other.

16. The rudimentary plantlet contained in the seed is called an Embryo. Its little stem is named the Radicle, because it was supposed to be the root, when the difference between the root and stem was not so well known as now. It were better to name it the Caulicle (i. e. little stem); but it is not expedient to change old names. The seed-leaves it bears on its summit (here two in number) are technically called Cotylèdons. The little bud of undeveloped leaves which is to be found between the cotyledons before germination in many cases (as in the l'ea, Bean, Fig. 17, \&c.), has been named the Plumule.

17. In the Maple (Fig. 4), as also in the Morning-Glory (Fig. 28 ), and the like, this bud, or plumule, is not seen for some days after the seed-leaves are expanded. But soon it appears, in the Maple as a pair of minute leaves (Fig. 5), erelong raised on a stalk which carries them up to some distance above the cotyledons. The plantlet (Fig. 6) now consists, ahove ground, of two pairs of leaves, viz.: 1. the cotyledons or seed-leaves, borne on the summit of the original stemlet (the radicle); and 2. a pair of ordinary leaves, raised on a second joint of stem which has grown from the top of the first. Later, a third pair of leaves is formed, and raised on a third joint of stem, proceeding from the summit of the second (Fig. 7), just as that did from the fir'st; and so on, until the germinating plantlet becomes a tree.

FIG. 5. Germinating Red Maple, which has produced its root beneath, and is developing a second pair of leaves above. 6. Samo, further advanced. 
18. So the youngest seedling, and eren the embryo in the seed. is already an epitome of the herb or tree. It has a stem, from the lower end of which it strikes root : and it has leares. The tree itself in its whole vegetation has nothing more in kind. To become a tree, the plantlet has only to repeat itself upwardly by producing more similar parts, - that is, new portions of stem, with new and larger leaves, in succession, - while beneath, it pushes its root deeper and deeper into the soil.

19. The Opposite frowth of Root and Stem began at the beginning of germination, and it continues through the whole life of the plant. While yet buried in the soil, and perhaps in total darkness, as soon as it begins to grow, the stem end of the embryo points towards the light, - curving or turning quite round if it happens to lie in some other direction, - and stretches upwards into the free air and sunshine; while the root end as uniformly avoids the light, bends in the opposite direction

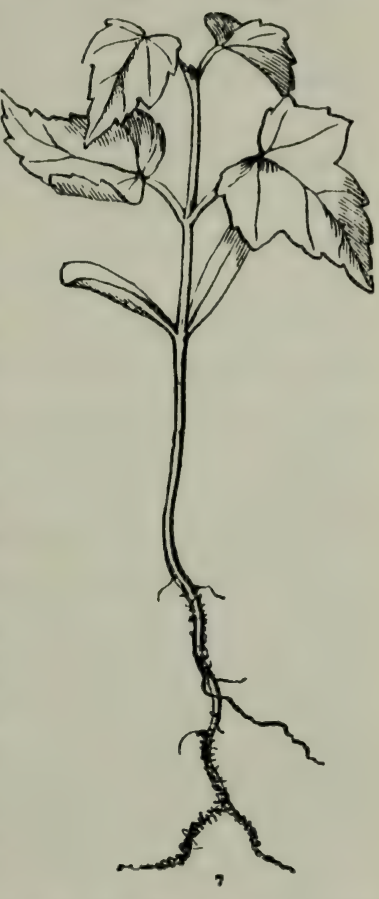
to do so if necessary, and ever seeks to bury itself more and more in the eartli's bosom. How the plantlet makes these movements we cannot explain. But the object of this instinct is obvious. It places the plant from the first in the proper position, with its roots in the moist soil, from which they are to absorb nourishment, and its leaves in the light and air, where alone they can fulfil their office of digesting what the roots absorb.

20. So the seedling plantlet finds itself provided with all the organs of regetaiion that even the oldest plant possesses, - namely, root, stem, and leaves; and has these placed in the situation where each is to act, - the root in the soil, the foliage in the light and air. Thus established, the plantlet has only to set about its proper work.

21. The different Mode of Growtl. of Root and Stem may also be here mentioned. Each grows, not only in a different direction, but in a different way. The stem grows by producing a set of joints, each from

FIG. 7. Gormmatıng Red Maple, further doveluvod. 
the summit of its predecessor; and each joint elongates throughout every part, until it reaches its full length. The root is not composed of joints, and it lengthens only at the end. The stem in the embryo (viz. the radicle) has a certain length to begin with. In the pumpkin-seed, for instance (Fig. 9), it is less than an eighth of an inch long: but it grows in a few days to the length of one or two inches (Fig. 10), or still more, if the seed were deeper covered by the soil. It is by this elongation that the seed-leaves are raised out of the soil, so as to expand in the light and air. The length they acquire varies with the depth of the covering. When large and strong seeds are too deeply buried, the stemlet sometimes grows to the length of several inches in the endeavor to bring the seed-leaves to the surface. The lengthening of the succeeding joints of the stem serves to separate the leaves, or pair's of leaves, from one another, and to expose them more fully to the light.

22. 'The root, on the other hand, begins by a new formation at the base of the embryo stem; and it continues to increase in length solely by additions to the extremity, the parts once formed scarcely elongating at all afterwards. This mode of growth is well adapted to the circunstances in which roots are placed, leaving every part undisturbed in the soil where it was formed, while the ever-advancing points readily insinuate themselves into the crevices or looser portions of the soil, or pass around the surface of solid obstacles.

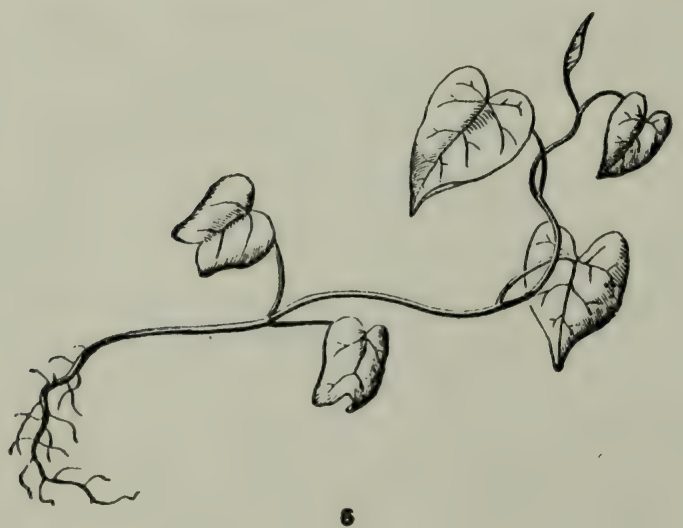




\section{LESSON III.}

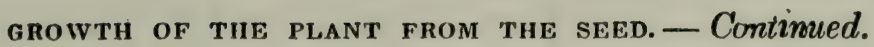

23. So a plant consists of two parts, growing in a different manner. as well as in opposite directions. One part, the root, grows downwards into the soil: it may, therefore, be called the descending axis. The other grows upwards into the light and air: it may be called the ascending axis. The root grows on continuously from the extremity, and so does not consist of joints, nor does it bear leaves, or anything of the kind. The stem grows by a succession of joints, each bearing one or more leaves on its summit. Root on the one hand, and stem with its foliage on the other, make up the whole plantlet as it springs from the seed and the full-grown herb, shrub, or tree has nothing more in kind, - only more in size and number. Before wo trace the plantlet into the herb or tree, some other cases of the growth of the plantlet from the seed should be studied, that we may observe how the same plan is worked out under a variety of forms, with certain differences in the details. The materials for this study are always at hand. We have only to rotice what takes place all around us in spring, or to plant some con.mon seeds in pots, keep them warm and moist, and watch their germination.

24. The Germinating Plantlet feeds on Nourishment provided beforehand. The embryo so snugly ensconced in the seed of the Maple (Fig. 2, $3,4)$ has from the first a miniature stem, and a pair of lcaves already green, or which become green as soon as brought to the light. It has only to form a root by which to fix itself to the ground, when it becomes a perfect though diminutive vegetable, capable of providing for itself. This root can be formed only out of proper material : neither water nor anything else which the plantlet is imbibing from the earth will answer the purpose. The proper material is nourishing matter, or prepared food, more or less of which is always provided by the parent plant, and stored up in the seed, either in the embryo itself, or around it. In the Maple, this nourishment is stored up in the thickish cotyledons, or seed-leaves. And there is barely enough of it to make the beginning of a root, and to provide for the lengthening of the stemlet so as to bring up the unfolding seed-leaves where they may expand to the light of day. But when this is done, 
the tiny plant is already able to shift for itself; - that is, to live and continue its growth on what it now takes from the soil and from the air, and elaborates into nourishment in its two green leaves, under the influence of the light of the sun.

25. In most ordinary plants, a larger portion of nourishment is provided beforchand in the seed; and the plantlet consequently is not so early or so entirely left to its own resources. Let us examine a number of cases, selected from very common plants. Sometimes, as has just been stated, we find this

26. Deposit of Food in the Embryo itself. And we may observe it in every gradation as to quantity, from the Maple of our first illus-

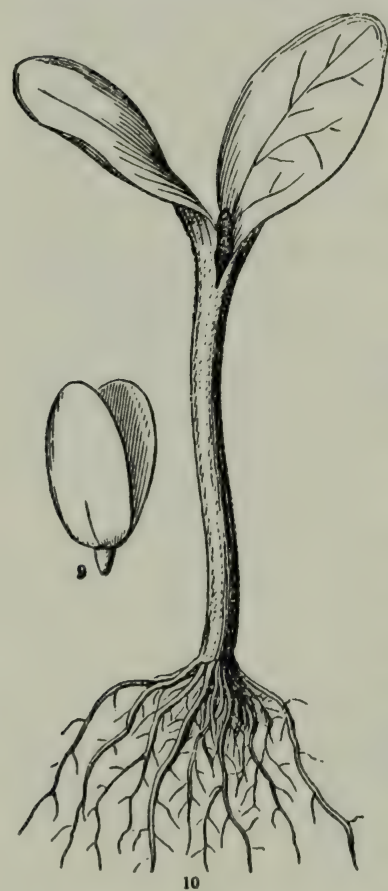
tration, where there is very little, up to the Pea and the Horsechestnut, where there is as much as there possibly can be. If we strip off the coats from the large and flat seed of a Squash or Pumpkin, we find nothing but the embryo within (Fig. 9); and almost the whole bulk of this consists of the two seed-leaves. That these contain a good supply of nourishing matter, is evident from their sweet taste and from their thickness, although there is not enough to obscure their leaf-like appearance. It is by feeding on this supply of nourishment that the germinating Squash or Pumpkin (Fig. 10) grows so rapidly and so vigorously from the seed, lengthening its stemlet to more than twenty times the length it had in the seed, and thickening it in proportion, sending out at once a number of roots from its lower end, and soon developing the plumule (16) from its upper end into a third leaf: meanwhile the two cotyledons, relieved from the nourishment with which their tissue was gorged, have expanded into useful green leaves.

27. For a stronger instance, take next the seed of a Plum or Peach, or an Almond, or an Apple-seed (Fig. 11, 12), which shows

FIG. 9. Embryo of a Pumpkin, of the natural size; the cotyledons a little opened 10. The same, when it has germinated. 
the same thing on a smaller scale. The embryo, which here also

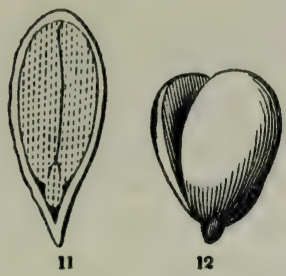
makes up the whole bulk of the kernel of the seed, differs from that of the Pumpkin only in having the seed-leaves more thickened, by the much larger quantity of nourishment stored up in their tissue, - so large and so pure indeed, that the almond becomes an article o food. Fed by this abundant supply, the second, and even the third joints of the stem, with their leaves, shoot forth as soon as the stemlet comes to the surface of the soil. The Beech-nut (Fig. 13), with its sweet and eatable kernel, consisting mainly of a pair of seed-leaves folded together, and gorged with nourishing matter, offers another instance of the same sort: this ample store to feed upon enables the germinating plantlet to grow with remarkable vigor, and to develop a second joint of stem, with its pair of leaves (Fig. 14), before the first pair has expanded or the root has obtained much foothold in the soil.

28. A Bean affords a similar and more familiar illustration. Here the cotyledons in the seed (Fig. 16) are so thick, that, although they are raised out of ground in the ordinary way in germination (Fig. 17), and turn greenish, yet they never succeed in becoming leaflike, - never display their real nature of leaves, as they do so plainly in the Maple (Fig. 5), the Pumpkin (Fig. 10), the Morning-Glory (Fig. 8, 26-28), \&c.

- Turned to great account as magazines of food for the germinating plantlet, they fulfil this special office admirably, but

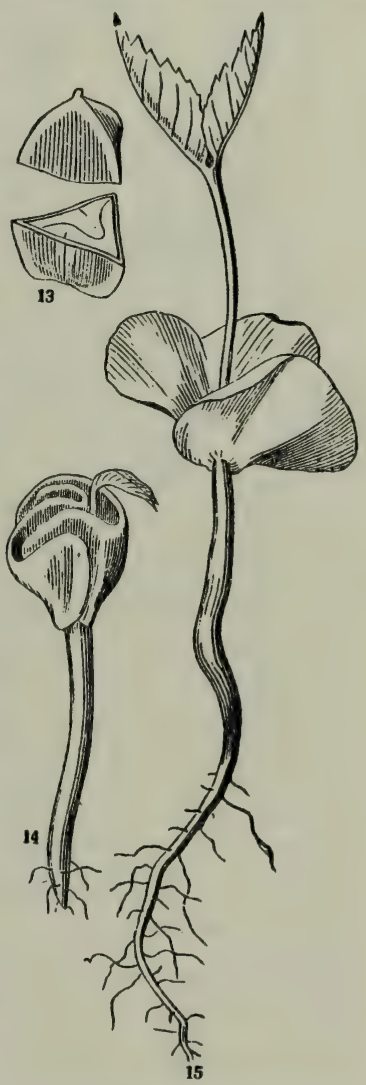

FIG. 11. An Apple-seed cut through lengthwise, showing the embryo with its thickenea cotyledons, 12. The embryo of the Apple, taken out whole, its cotyledons partly separated.

FIG. 13. A Beech-nut, cut across. 14. Beginning germination of the Beech, showing the plumule growing before the cotyledons have opened or the root has scarcely formed. 15. The same, a little later, with the second joint lengthened. 
they were so gorged and, as it were, misshapen, that they became

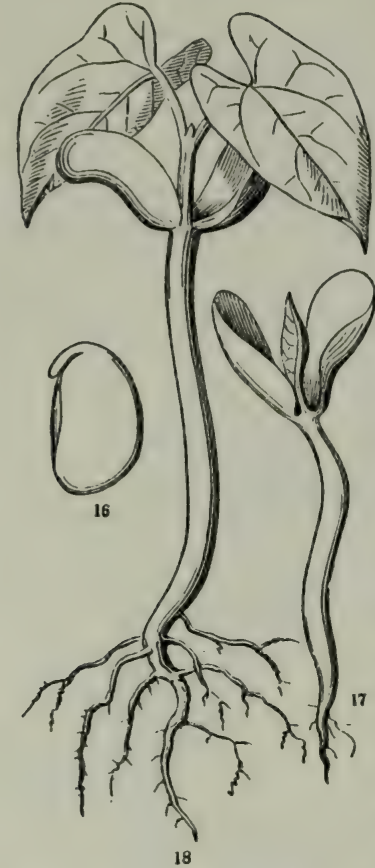
quite unfitted to perform the office of foliage. This office is accordingly first performed by the succeeding pair of leaves, those of the plumule (Fig. 17, 18), which is put into rapid growth by the abundant nourishment contained in the large and thick seed-leaves. The latter, having fulfilled this office, soon wither and fall away.

29. This is carried a step farther in the Pea (Fig. 19, 20), a near relative of the Bean, and in the Oak (Fig. $21,22), \quad$ a near relative of the Beech. The difference in these and many other similar cases is this.

The cotyledons, which make up nearly the whole bulk of the seed are excessively thickened, so as to become nearly hemispherical in shape. They have lost all likeness to leaves, and all power of ever fulfilling the office of leaves. Accordingly in germination they remain unchanged within the husk or coats of the seed, never growing themselves, but supplying abundant nourishment to the plumule (the loud for the forming stem) between them. This pushes forth from the seed, shoots upward, and gives rise

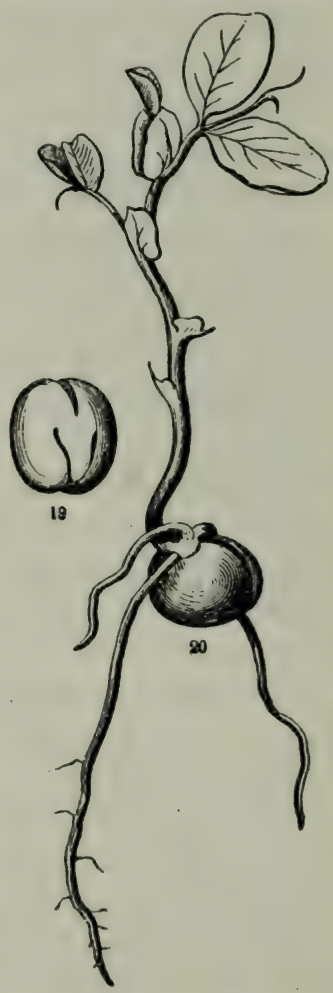

FIG. 16. A Beau : the embryo, from which seed-costs have been removed: the small stem is seen above, bent down upon the edge of the thick cotyledons. 17. The same in early germination; the plumule growing from between the two seed-leaves. 18. The germination more advanced, the two leaves of the plumule unfulded, and raised on a short joint of stem.

FIG. 19. A Pea: the embryo, with the seed-coats taken off. 20. A Pea in germination. 
to the first leaves that appear. In most cases of the sort, the radicle, or short original stemlet of the embryo below the cotyledons (which is plainly shown in the Pea, Fig. 19), lengthens very little, or not at all; and so the cotyledons remain under ground, if the seed was covered by the soil, as every one knows to be the case with Peas. In these (Fig, 20), as also in the Oak (Fig. 22), the leaves of the first one or two joints are imperfect, and mere small scales; but genuine leaves immediately follow. The Horsechestrut and Buckeye (Fig. 23, 24) furnish another instance of the same sort. These trees are nearly related to the Maple; but while the seedleaves of the Maple show themselves to be leaves, even in the seed (as we have already seen), and when they germinate fulfll the office of ordinary leaves, those of the Buckeye and of the Horsechestnut (Fig. 23), would never be suspected to be the same organs. Yet they are so, only in another shape, - exceedingly thickened by the accumulation of a great quantity of starch and other nourishing matter in their substance; and besides, their contiguous faces stick together more or less firmly, so that they never open. But the stalks of these seed-leaves grow, and, as they lengthen, push the radicle and the plumule

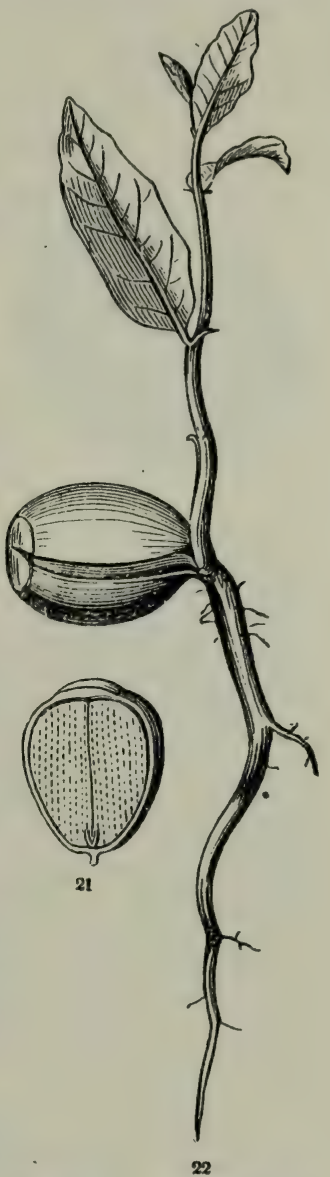
out of the seed, when the former develops downwardly the root, the latter upwarlly the leafy stem and all it bears (Fig. 24).

30. Deposit of Food outside of the Embryo. Very often the nourishment provided for the seedling plantlet is laid up, not in the embryo itself, but around it. A good instance to begin with is furnished by the common Morning-Glory, or Convolvulus. The embryo, taken out of the seed and straightened, is shown in Fig. 26. It consists of a short stemlet and of a pair of very thin and delicate green leaves, having no stock of nourishment in them for sustaining the

FIG. 21. An acorn divided lengthwise. 22. The germinating Oak. 
earliest growth. On cutting open the seed, however, we find this embryo (considerably crumpled or folded together, so as to occupy

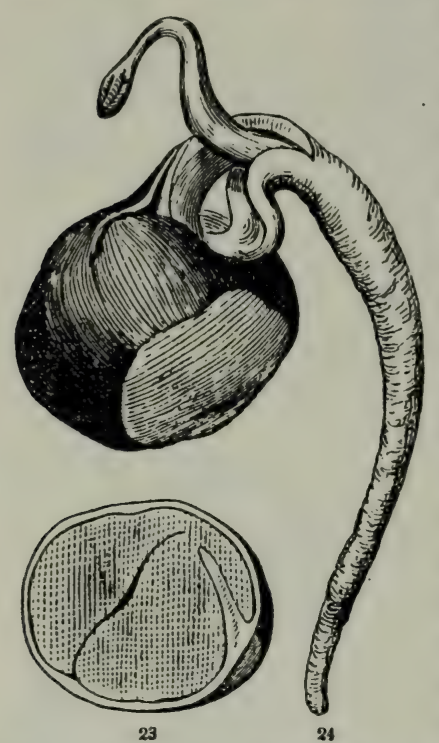
less space, Fig. 25) to be surrounded by a mass of rich, mucilaginous matter (becoming rather hard and solid when dry), which forms the principal bulk of the seed. Upon this stock the embryo feeds in ger. mination; the seed-leaves absorbing it into their tissue as it is rendered soluble (through certain chemical changes) and dissolved by the water which the germinating seed im: bibes from the moist soil. Having by this aid lengthened its radicle into a stem of considerable length, and. formed the beginning of a root at its lower end, already imbedded in the soil (Fig. 27), the cotyledons now disengage themselves from the seed-coats, and expand in the light as the first pair of leaves (Fig. 28). These immediately begin to elaborate, under the sun's influence, what the root imbibes from the soil, and the new nourishment so produced is used, partly to increase the size of the little stem, root, and leaves already existing, and partly to produce a second joint of stem with its leaf (Fig. 29), then a third with its leaf (Fig. 8); and so on.

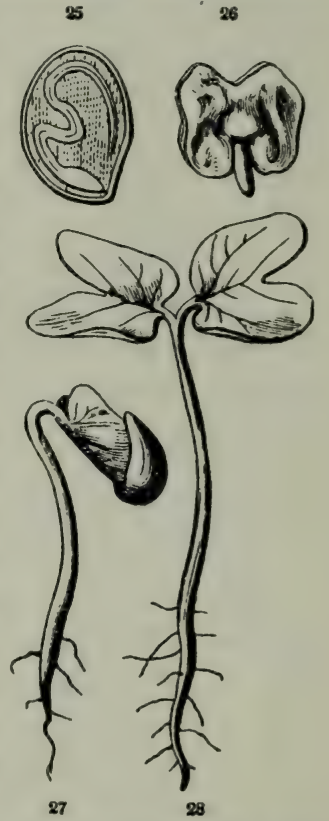

31. This maternal store of food, deposited in the seed along with the embryo (but not in its substance), the old botanists likened to

FIG. 23. Buckeye : a seed divided. 24. A similar seed in gemination.

FIG. 25. Seed and embryo of Mornug-Glury, cut across. 26. Embryo of the same, de. tached and straightened. 27. Germinating Morning-Glory. 28. The same further advancedi tts two thiu socd-loaves expanded. 
the albumen, or white of the egg, which encloses the yolk, and therefore gave it the same name, - the albumen of the seed, - a name which it still retains. Food of this sort for the plant is also food for animals, or for man ; and it is this albumen, the floury part of the seed, which forms the principal bulk of such important grains as those of Indian Corn (Fig. 38-40), Wheat, Rice, Buckwheat, and of the seed of Four-o'clock, (Fig. 36, 37), and the like. In all these last-named cases, it may be observed that the embryo is not enclosed in the albumen, but placed on one side of it, yet in close contact with it, so that the embryo may absorb readily from it the nourishment it requires when it begins to grow. Sometimes

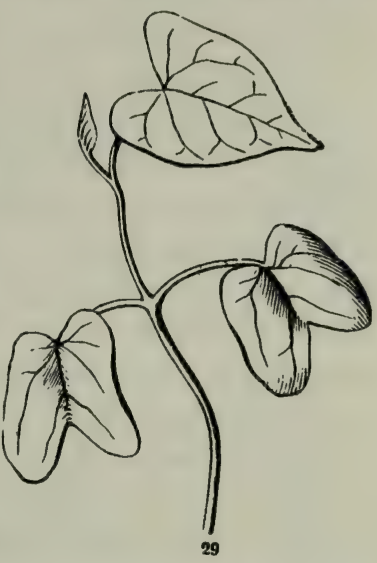
the embryo is coiled around the outside, in the form of a ring, as in the Purslane and the Four-o'clock (Fig. 36, 37); sometimes it is coiled within the albumen, as in the Potato (Fig. 34, 35); sometimes it is straight in the centre of the albumen, occupying nearly its
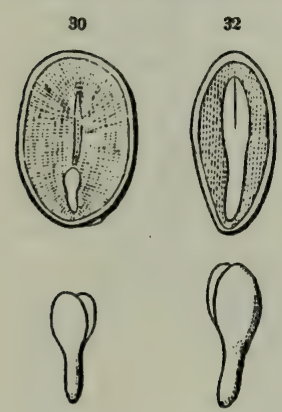

33
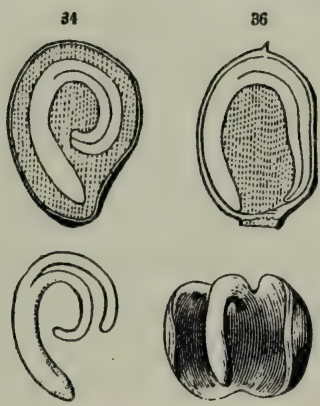

35

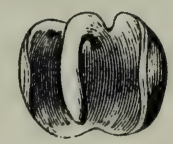

37 whole length, as in the Barberry (Fig. $32,33)$, or much smaller and near one end, as in the Iris (Fig. 43 ) ; or sometimes so minute, in the midst of the albumen, that it needs a magnifying-glass to find it, as in the But-

FIG. 29. Germination of the Morning Glory more advanced : the upper part only ; showing the leafy cotyledons, the kecond joint of stem with its leaf, and the third with its leaf just developing.

FIG. 30. Section of a seed of a Peony, showing a very small embryo in the albumen, near one end. 31. This embryo detached, and more magnified.

FIG. 32. Section of a seed of Barberry, showing the straight embryo in the middle of the albumen. 33. Its enibryo detached.

FIG. 34. Section oi a Potato-seed, showing the embryo coiled in the albumen. 35. Ito einhryo detached.

FIG. 36. Section of the seed of Four-o'clock, showing the embryo coiled round the outside of the albumen. 37. Its embryo detached. 
tercup or the Columbine, and in the Peony (Fig. 30, 31), where, however, it is large enough to be distinguished by the naked eye. Nothing is more curious than the various shapes and positions of the embryo in the seed, nor more interesting than to watch its development in germination. One point is still to be noticed, since the botanist consider's it of much importance, namely :-

32. The Kinds of Embryo as to the Number of Cotyledons. In all the figures, it is easy to see that the embryo, however various in shape, is constructed on one and the same plan; - it consists of a radicle or stemlet, with a pair of cotyledons on its summit. Butanists therefore call it dicotyledonous, - an inconveniently long word to express the fact that the embryo has two cotyledons or seed-leaves. In many cases (as in the Buttercup), the cotyledons are indeed so minute, that they are discerned only by the nick in the upper end of the little embryo; yet in gernination they grow into a pair of seed-leaves, just as in other cases where they are plain to be seen, as leaves, in the seed. But in Indian Corn (Fig. 40), in Wheat, the Onion, the Iris (Fig. 43), \&c., it is well known that only one
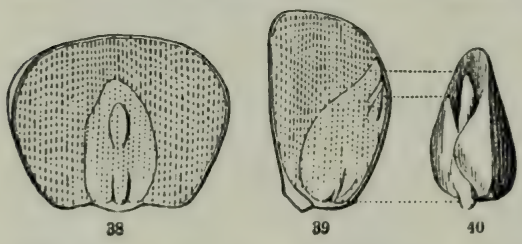
leaf appears at tirst from the sprouting seed: in these the embryo has only one cotyledon, and it is therefore termed by the botanists monocotyledonous; - an extremely long word, like the other, of Greek derivation, which means one-cotyledoned. The rudiments of one or more other leaves are, indeed, commonly present in this sort of embryo, as is plain to see in Indian Corn (Fig. 38-40), but they form a bud situated above or withir. the cotyledon, and enclosed by it more or less completely; so tha they evidently belong to the plumule (16); and these leaves appear in the seedling plantlet, each from within its predecessor, and therefore originating higher up on the forming stem (Fig. 42, 44). 'This will readily be understood from the accompanying figures, with their explanation, which the student may without difficulty verify for him-

FIG. 38. A grain of Indian Corn, flatwise, cut away a little, so as to show the embryo, lying on the albumen, which makes the principal bulk of the seed.

FIG. 39. Anether grain of Corn, cut through the widdle in the opposite direction, dividing the embryo through its thick cutyledon and its plumule, the latter consisting of two leaves, one enclosing the other.

FIG. 40. 'The embryo of Corn, taken out whole: the thick mass is the cotyledon; the narrow body partly enclosed by it is the plumule; the littlo projection at its hase is the very shorr radicle enclosed in the slocathing hase of the first loat of the plumule. 
self, and should do so, by examining grains of Indian Corn, soaked in water, before and also during germination. In the Onion, Lily, and the Iris (Fig. 43), the monocotyledonous embryo is simpler, consisting apparently of a simple oblong or cylindrical body, in which no distinction of parts is visible : the lower end is radicle, and from it grows the root; the rest is a cotyledon, which has wrapped up in it a minute plumule, or bud, that shows itself when the seeds sprout in germination. The first leaf which appears above ground in all these cases is not the cotyledon. In all seeds with one cotyledon to the embryo, this remains in the seed, or at least its upper part, while its lengthening base comes out, so as to extricate the plumule, which shoots upward, and develops the first leaves of the plantlet. 'These appear one

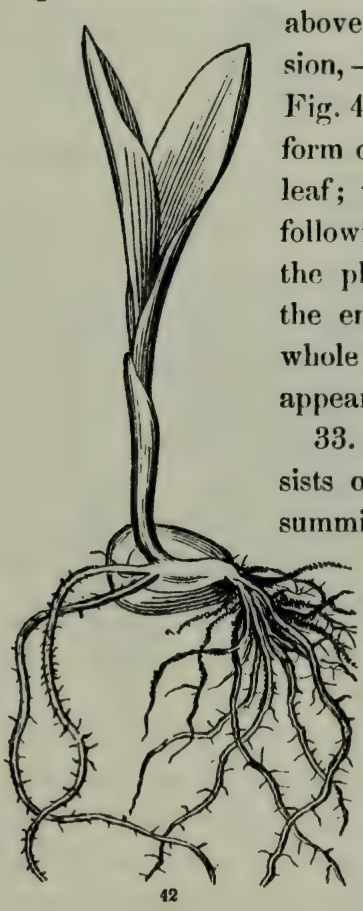
above or within the other in succession, - as is shown in Fig. 42 and Fig. 44, - the first commonly in the form of a little scale or imperfect leaf; the second or third and the

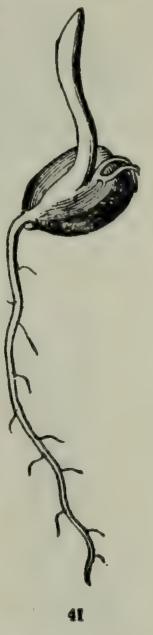
following ones as the real, ordinary leaves of the plint. Meanwhile, from the root end of the embryo, a root (Fig. 41, 44), or soon a whole cluster of roots (Fig. 42), makes its ppearance.

33. In Pines, and the like, the embryo conists of a radicle or stemlet, bearing on its summit three or four, or often from five to ten slender cotyledons, arranged in a circle (Fig. 45), and expanding at once into a circle of as many green leaves in germination (Fig. 46). Such embryos are said to be polycotyledonous, that is, as the word denotes, many. cotyledoned. '

34. Plan of Vegetation. The student who has understandingly followed the growth of the embryo in the seed into the seedling plantlet, - composed of a root, and a stem of two or three joints, each bearing a

FIG. 41. Grain of Indian Corn in germination.

FIG. 42. The same, further advanced 
leaf, or a pair (rarely a circle) of leaves, - will have gained a correct idea of the plan of vegetation in general, and have laid a good foundation for a knowledge of the whole structure and physiology

43

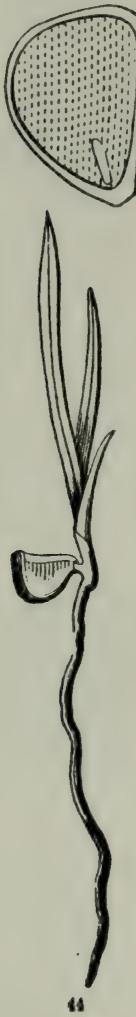
of plants. For the plant goes on to grow in the same way throughout, by mere repetitions of what the early germinating plantlet displays to view, - of what was contained, in miniature or in rudiment, in the seed itself. So far as vegetation is concerned (leaving out of view for the present the flower and fruit), the full-grown leafy herb or tree, of whatever size, has nothing, and does nothing, which the seedling plantlet does not have and do. The whole mass of stem or trunk and foliage of the complete plant, even of the largest forest-tree, is composed of a succession or multiplication of similar parts, - one arising from the summit of another, each, so to say, the offspring of the preceding and the parent of the next. \&

35 . In the same way that the earliest portions of the seedling stem, with the leaves they bear, are successively produced, so, joint by joint in direct succession, a single, simple, leafy stem is developed and carried up. Of such a simple leafy stem many a plant consists (before flowering, at least), - many herbs, such as Sugar-Cane, Indian Corn, the Lily, the tall Banana, the Yucca, \&c.; and among trees the Palms and the Cycas (wrongly called Sago Palm) exhibit the same simplicity, their stems, of whatever age, being unbranched columns

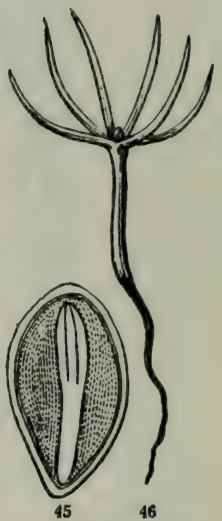
(Fig. 47). (Growth in diameter is of course to be considered, as well as growth in length. That, and the question how growth of any kind takes place, we will consider hereafter.) But more commonly, as soon as the plant has produced a main stem of a certain length, and displayed a certain amount of foliage, it begins to

FIG. 43. Section of a seed of the Iris, or Flower-de-Luce, showing its small embryo in the albumen, near the bottom.

FIG. 44. Germinating plantlet of the Iris.

FIG. 45. Section of a seed of a Pine, with its embryo of several ccityledons. 46. Early seedling P'ine, with its stemlet, displaying its six seed-leaves. 
produce additional stems, that is, branches. The branching plant we will consider in the next Lesson.

36. The subjoined figures (Fig. 47) give a view of some forms of simple-stemmed vegetation. The figure in the foreground on the left represents a Cycas (wrongly called in the conservatories Sago Palm). Behind it is a Yucca (called Spanish Bayonet at the South) and two Cocoanut Palm-trees. On the right is some Indian Corn, and behind it a Banana.

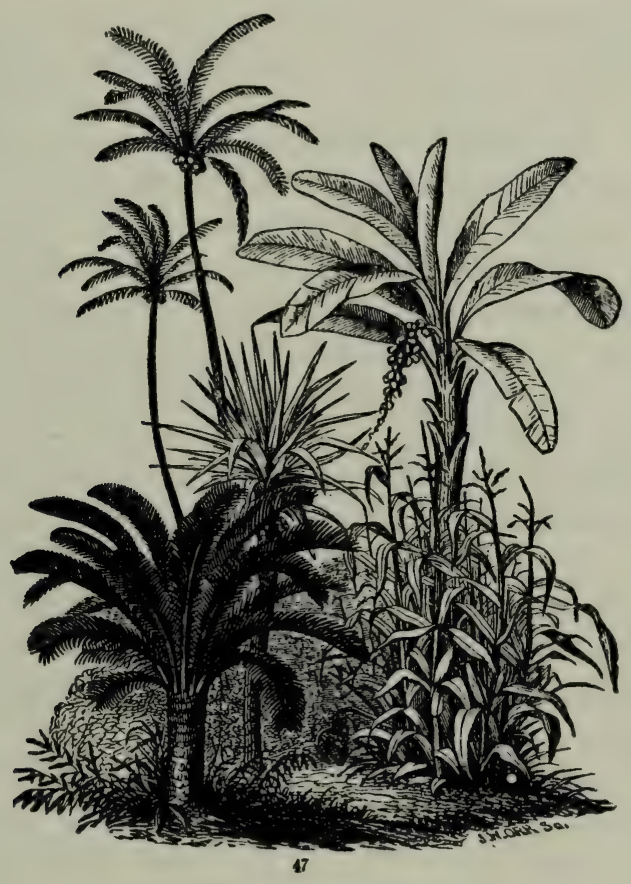




\section{LESSON IV.}

\section{THE GROWTH OF PLANTS FROM BUDS AND BRANCHES.}

37. WE have seen how the plant grows so as to produce a root, and a simple stem with its foliage. Both the root and stem, however, generally branch.

38. The branches of the root arise without any particular order. There is no telling beforehand from what part of a main root they will spring. But the branches of the stem, except in some extraordinary cases, regularly arise from a particular place. Branches or shoots in their undeveloped state are

39. Buds. These regularly appear in the axils of the leaves, that is, in the angle formed by the leaf with the stem on the upper side; and as leaves are symmetrically arranged on the stem, the luds, and the branches into which the buds grow, necessarily partake of this symmetry.

40. We do not confine the name of bud to the scaly winter-buds which are so conspicuous on most of our shrubs and trees in winter and spring. It belongs as well to the forming branch of any herb, at its first appearance in the axil of a leaf. In growing, buds lengthen into branches, just as the original stem did from the plumule of the embryo (16) when the seed germinated. Only, while the original stem is implanted in the ground by its root, the branch is implanted on the stem. Branches, therefore, are repetitions of the main stem. They consisi of the same parts, - namely, joints of stem and leaves, - growing in the same way And in the axils of their leaves another crop of buds is naturally produced, giving rise to another generation of branches, which may in turn produce still another generation; and so on, - until the tiny and simple seedling develops into a tall and spreading lierb or shrub; or into a massive tree, with its hundreds of amually increasing branches, and its thousands, perhaps millions, of leaves.

41. The herb and the tree grow in the same way. The difference is only in size and duration.

An Herb dies altogether, or dies down to the ground, after it has ripened its fruit, or at the approach of winter. 
An annual herb flowers in the first year, and dies, root and all, after ripening its seed : Mustard, Peppergrass, Buckwheat, \&c., are examples.

A biennial herb - such as the Turnip, Carrot, Beet, and Cabbage - grows the first season without blossoming, survives the winter, flowers after that, and dies, root and all, when it has ripened its seed.

A perenninl herb lives and blossoms year after year, but dies down to the ground, or near it, annually, - not, however, quite down to the root: for a portion of the stem, with its buds, still survives; and from these buds the shoots of the following year arise.

A Shrub is a perennial plant, with woody stems which continue alive and grow year after year.

A Tree differs from a shrub only in its greater size.

42. The Terminal Bud. There are herbs, shrubs, and trees which do not branch, as we have already seen (35); but whose stems, even when they live for many years, rise as a simple shaft (Fig. 47). These plants grow by the continued evolution of a bud which crowns the summit of the stem, and which is therefore called the terminal bud. This bud is very conspicuous in many branching plants also; as on all the stems or shoots of Maples (Fig. 53), Horsechestnuts (Fig. 48), or Hickories (Fig. 49), of a year old. When they grow, they merely prolong the shoot or stem on which they rest. On these same shoots, however, other buds are to be seen, regularly arranged down their sides. We find them situated just over broad, flattened places, which are the scars left by the fall of the leaf-stalk the autumn previous. Before the fall of the leaf, they would Fave been seen to occupy their axils (39): so they are named

43. Axillary Buds. They were formed in these trees early in the summer. Occasionally they grow at the time into branches: at least, some of them are pretty sure to do so, in case the growing terminal bud at the end of the shoot is injured or destroyed. Otherwise they lie dormant until the spring. In many trees

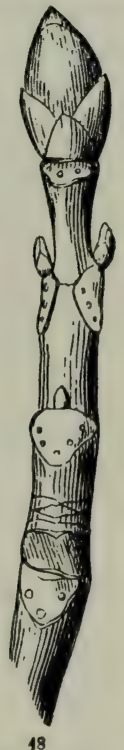
or shrubs (such for example as the Sumach and Honey-Locust) these axillary buds do not show themselves until spring; but if

FIG. 48. Shoot of Horsechestnut, of one year's growth, taken in autumn after the leaves bave fallen. 
searched for, they may be detected, though of small size, hidden under the bark. Sometimes, although early formed, they are con-

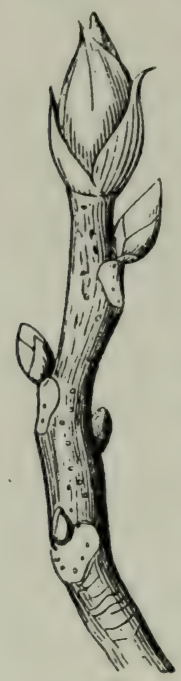
cealed all summer long under the base of the leafstalk, hollowed out into a sort of inverted cup, like a candle-extinguisher, to cover them; as in the Locust, the Yellow-wood, or more strikingly in the Button. wood or Plane-tree (Fig. 50).

44. Such large and conspicuous buds as those of the Horsechestnut, Hickory, and the like, are scaly; the scales being a kind of imperfect leaves. The use of the bud-scales is obvious; namely, to protect the tender young parts beneath. To do this more effectually, they are often coated on the outside with a varnish which is impervious to wet, while within they, or the parts they enclose, are thickly clothed with down or wool; not really to keep out the cold of winter, which will of course penetrate the bud in time, but to shield the interior against sudden changes from warm to cold, or from cold to warm, which are equally injurious. Scaly buds commonly belong, as would be expected, to trees and shrubs of northern elimates; while naked buds are usual in tropical regions, as well as in herbs everywhere which branch during the summer's growth and do not endure the winter.

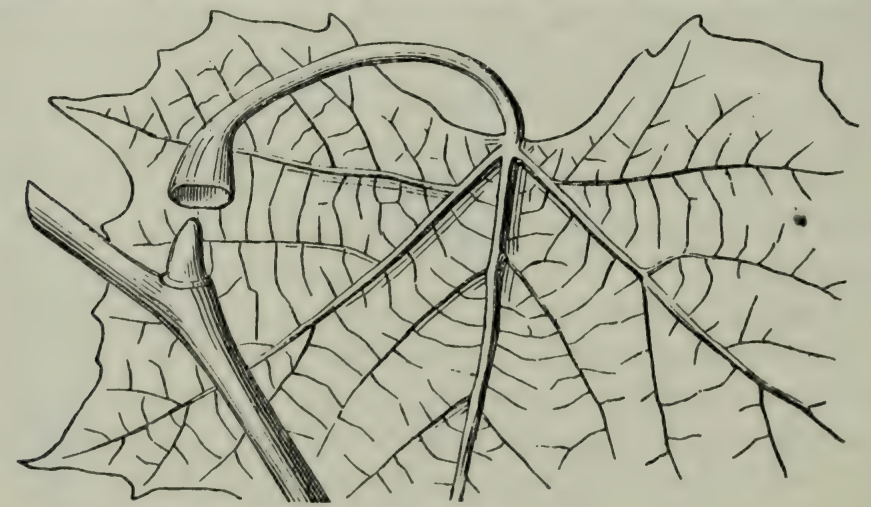

50

45. But nuked buds, or nearly naked, also occur in several of out own trees and shrubs; sometimes pretty large ones, as those of Hob

FIG. 49. Aunual shoot of the shagbark Hickery.

Pli. 50. Bud and leaf of the Buttumwod, or American Plane-tree. 
blebush (while those of the nearly-related Snowball or High BushCranberry are scaly); but more commonly, when naked buas occur in trees and shrubs of our climate, they are small, and sunk in the bark, as in the Sumac; or even partly buried in the wood until they begin to grow, as in the IIoney-Locust.

46. Vigor of Vegetation from Buds. Large and strong buds, like those of the Horsechestnut, Hickory, and the like, on inspection will be found to contain several leaves, or pairs of leaves, ready formed, folded and packed away in small compass, just as the seed-leaves are packed away in the seed : they even contain all the blossoms of the ensuing season, plainly visible as small buds. And the stems npon which these buds rest are filled with abundant nourishment, which was deposited the summer before in the wood or in the bark. Under the surface of the soil, or on it, covered with the fallen leaves of autumn, we may find similar strong buds of our perennial herbs, in great variety; while beneath are thick roots, rootstocks, or tubers, charged with a great store of nourishment for their use. As we regard these, we shall readily perceive how it is that vegetation shoots forth so vigorously in the spring of the year, and clothes the bare and lately frozen surface of the soil, as well as the naked boughs of trees, almust at once with a covering of the freshest green, and often with brilliant blossoms. Everything was prepared, and even formed, beforehand: the short joints of stem in the bud have only to lengthen, and to separate the leaves from each other so that they may unfold and grow. Only a small part of the vegetation of the season comes directly from the seed, and none of the earliest vernal vegetation. This is all from buds which have lived through the winter.

47. This growth from buds, in manifold variety, is as interesting a subject of study as the growth of the plantlet from the seed, and is still easier to observe. We have only room here to sketch the general plan; earnestly recommending tho student to examine attentively their mode of growth in all the common trees and shrubs, when they shoot forth in spring. The gुrowth of the terminal bud prolongs the stem or branch: the growth of axillary hiuds produces branches.

48. The Arrangement of Branches is accordingly the same as of axillary buds; and the arrangement of these buds is the same as that of the leaves. Now leaves are arranged in two principal ways: th'y are either opposite or allernate. Leaves are opposite when 
there are two borne on the same joint of stem, as in the Horsechestnut, Maple (Fig. 7), Honeysuckle (Fig. 132), Lilac, \&c.; the two leaves in such cases being always oppusite each other, that is, on exactly opposite sides of the stem. Ilere of course the buds in their axils are opposite, as we observe in Fig. 48, where the leaves have fallen, but their place is shown by the scars. And the branches into which the buds grow are likewise opposite each other in pairs.

49. Leaves are alternate when there is only one from each joint of stem, as in the Oak (Fig. 22), Lime-tree, Moplar, Buttonwood (Fig. 50), Morning-Glory (Fig. 8), - not counting the seed-leaves, which of course are opposite, there being a pair of them; also in Indian Corn (Fig. 42), and Iris (Fig. 44). Consequently the axillary buds are also alternate, as in Ilickory (Fig. 49); and the branches they form alternate, - making a different kind of spray from the other mude, - one branch shooting on the one side of the stem and the next on some other. For in the alternate arrangement no leaf is on the same side of the stem as the one next above or next below it.

50. Branches, therefore, are arranged with symmetry; and the mode of branching of the whole tree may be foretold by a glance at the arrangement of the leaves on the seedling or stem of the first year. This arrangement of the branches according to that of the leaves is always plainly to be recognized; but the symmetry of branches is rarely complete. This is owing to several causes; mainly to one, viz.:-

51. It never happens that all the budz grow. If they did, there would be as nany hranches in any year as there were leaves the year before. And of those which do begin to grow, a large portion perish, sooner or later, for want of nourishment or for want of light. Those which first begin to grow have an advantage, which they are apt to keep, taking to themselves the nourishment of the stem, and starving the weaker buds.

52. In the Horsechestnut (Fig. 48), Hickory (Fig. 49), Magnolia, and most other trees with large scaly buds, the terminal bud is the strongest, and has the advantage in growth, and next in strength are the upper axillary buds: while the former continues the shoot of the last year, some of the latter give rise to branches, while the rest fail to grow. In the Lilac also, the upper axillary buds are stronger than the lower; but the terminal bud rarely 
appears at all ; in its place the uppermost pair of axillary buds grow, and so each stem branches every year into two; making a repeatedly two-forked ramification.

53. In these and many similar trees and shrubs, most of the shoots make a definite annual growth. That is, each shoot of the season develops rapidly from a strong bud in spring, - a bud which generally contains, already formed in miniature, all or a great part of the leaves and joints of stem it is to produce, - makes its whole growth in length in the course of a few weeks, or sometimes even in a fow days, and then forms and ripens its buds for the next year's similar rapid growth.

54. On the other hand, the Locust, Honey-Locust, Sumac, and, among smaller plants, the Rose and Raspberry, make an indefinite annual growth. That is, their stems grow on all summer long, until stopped by the frosts of autumn or some other cause; consequently they form and ripen no terminal bud protected by scales, and the upper axillary buds are produced so late in the season that they have no time to mature, nor has the wood time to solidify and ripen. Such stems therefore commonly die at the top in winter, or at least all their upper buds are small and feeble; and the growth of the succeeding year takes place mainly from the lower axillary buds, which are more mature. Most of our perennial herbs grow in this way, their stems dying down to the ground every year: the part beneath, however, is charged with vigorous buds, well protected by the kindly covering of earth, ready for the next year's regetation.

55. In these last-mentioned cases there is, of course, no single main stem, continued year after year in a direct line, but the trunk is soon lost in the branches; and when they grow into trees, these commonly have rounded or spreading tops. Of such trees with deliquescent stems, - that is, with the trunk dissolved, as it were, into the successively divided branches, the common American Elm (Fig. 54) furnishes a good illustration.

56. On the other hand, the main stem of Pines and Spruces, as it begins in the seedling, unless destroyed by some injury, is carried on in a direct line throughout the whole growth of the tree, by the development year after year of a terminal bud: this forms a single, uninterrupted shaft, - an excurrent trunk, which can never be confounded with the branches that proceed from it. Of such spiry or spire-shaped trees, the Firs or Spruces are the most perfect and 
familiar illustrations (Fig. 54); but some other trees with strong terminal buds exhibit the same character for a certain time, and in a less marked degree.

57. Latent Buds. Some of the axillary buds grow the following year into branches; but a larger number do not (51). These do not necessarily die. Otten they survive in a latent state for some years, visible on the surface of the branch, or are smaller and concealed pnder the bark, resting on the surface of the wood: and when at any time the ocher buds or branches happen to be killed, these older latent buds grow to supply their place; - as is often seen when the foliage and young shoots of a tree are destroyed by insects. The new shoots seen springing directly out of large stems may sometimes originate from such latent buds, which have preserved their life for years. But commonly these arise from

58. Adventitious Buds. These are buds which certain shrubs and trees produce anywhere on the surface of the wood, especially where it has been injured. They give rise to the slender twigs which often feather so beautifully the sides of great branches or trunks of our American Elms. They sometimes form on the root, which naturally is destitute of buds; and they are sure to appear on the trunks and roots of Willows, Poplars, and Chestnuts, when these are wounded or mutilated. Indeed Osier-Willows are pollarded, or cut off, from time to time, by the cultivator, for the purpose of producing a crop of slender adventitious twigs, suitable for basket-work. Such branches, being altogether irregular, of course interfere with the natural symmetry of the tree (50). Another cause of irregularity, in certain trees and shrubs, is the formation of what are called

59. Accessory or Supernumerary Buds. There are cases where two,

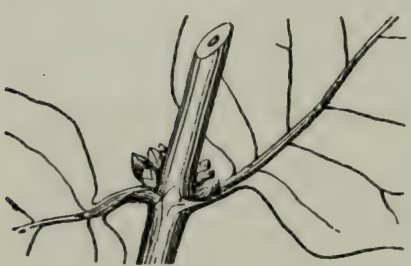

51 three, or more buds spring from the axil of a leaf, instead of the single one which is ordinarily found there. Sometimes they are placed one over the other, as in the Aristolochia or Pipe-Vine, and in the Tartarian Honeysuckle (Fig. 51); also in the Honey-Locust, and in the Walnut and Butternut (Fig. 52), where the upper stpertumerary bud is a good way out of the axil and above the others. And this is here stronger

FIG. 51. Tartarian Honcysuckle, with three accessory buds in one axil. 
than the others, and grows into a branch which is considerably out or the axil, while the lower and smaller ones commonly do not grow at

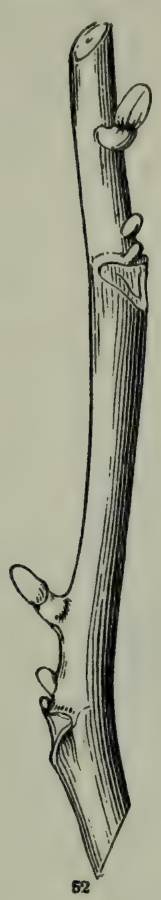
all. In other cases the three buds stand side by side in the axil, as in the Hawthorn, and the Red Maplo (Fig. 53). If these were all to grow into branches. they would stifle or jostle each other. But some of them are commonly flower-buds : in the Red Maple, only the middle one is a leaf-bud, and it does not grow until after those on each side of it have expanded the blossoms they contain.

60. Sorts of Buds. It may be useful to enumerate the kinds of buds which have now been mentioned, referring back to the paragraphs in which the peculiarities of each are explained. I3uds, then, are either terminal or lateral. They are

Terminal when they rest on the apex of a stem (42). The earliest terminal bud is the plumule of the embryo (16).

Lateral, when they appear on the side of a stem : - of which the only regular kind is the

Axillary (43), namely, those which are situated in the axils of leaves.

Accessory or Supernumerary (59), when two or more occur in addition to the ordinary axillary bud.

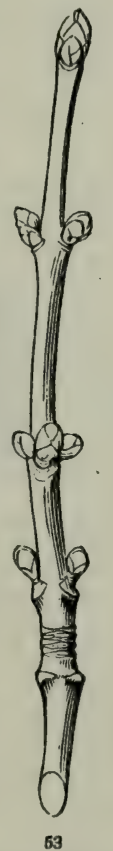

Adventitious (58), when they occur out of the axils and without order, on stems or roots, or even on leaves. Any of these kinds may be, either

Naked, when without coverings; or scaly, when protected by scales $(44,45)$.

Latent, when they survive long without growing, and commonly without being visible externally $(57)$.

Leaf-buds, when they contain leaves, and develop into a leafy shoot.

Flower-buds, when they contain blossoms, and no leaves, as the

FIG. 52. Butternut branch, with accessory buts, the uppormost above the axil.

FIG. 52. Red-Maple branch, with accessory buds placed side by side. 
side-buds of the Red-Maple, or when tliey are undeveloped blossoms. These we shall have to consider hereafter.

Figure 54 represents a spreading-topped tree (American Elm), the stem dividing off into branches; and some spiry trees (Spruces on the right hand, and two of the Arbor-Vitie on the left) with excurrent stems.

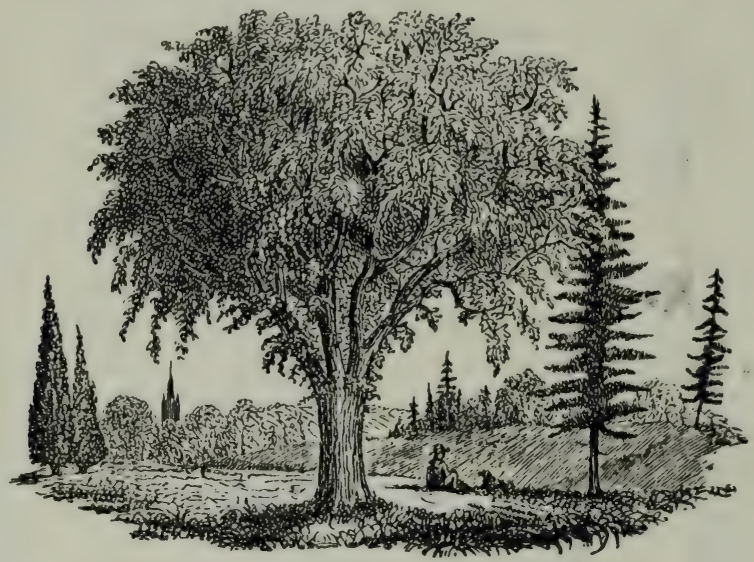

54

\section{LESSON V.}

MORPHOLOGY (i.e. VARIOUS SORTS AND FORNS) OF ROOTS.

61. Mlorplologv, as the name (derived from two Greek words) denotes, is the doctrine of forms. In treating of forms in plants, the botanist is not confined to an enumeration or description of the shapes or sorts that occur, - which would be a dull and tedious business, - but he endeavors to bring to view the relations between one form anci another; and this is an interesting study.

62. Botanists give particular names to all the parts of plants, and also particuiar terms to express their principal varieties in form. They use these terms with great precision and advantage in describing the species or kinds of plants. They must therefore be defined and explained in our books. But it would be a gieat waste of time 
for the young student to learn them by rote. The student should rather consider the connection between one form and another; and notice how the one simple plan of the plant, as it has already been illustrated, is worked out in the greatest variety of ways, through the manifold diversity of forms which each of its three organs of vege. tation - root, stem, and leaf - is made to assume.

63. This we are now ready to do. That is, having obtained a $g$ neral idea of vegetation, by tracing the plant from the seed and the bud into the herb, shrub, or tree, we proceed to contemplate the principal forms under which these three organs occur in different plants, or in different parts of the same plant; or, in other words, to study the morphology of the root, stem, and leaves.

64. Of these three organs, the root is the simplest and the least varied in its modifications. Still it exhibits some widely different kinds. Going back to the beginning, we commence with

65. The simple Primary Root, which most plants send down from the root-end of the embryo as it grows from the seed; as we have seen in the Maple (Fig 5-7), Morning-Glory (Fig. 8 and 28), Beech (Fig. 14, 15), Oak and Buckeye (Fig. 22-24), \&c. This, if it goes on to grow, makes a main or tap root, from which eidebranches here and there proceed. Some plants keep this mair root throughout their whole life, and send off only small side brar ches; as in the Carrot (Fig. 58) and Radish (Fig. 59): and in some trees, like the Oak, it takes the lead of the side-branches for many years, unless accidentally injured, as a strong tap-root. But commonly the main root divides off very soon, and is lost in the branches. We have already seen, also, that there may be at the beginning

66. Multiple Primary Roots. We have noticed them in the Pump. kin (Fig. 10), in the Pea (Fig. 20), and in Indian Corn (Fig. 42). That is, several roots have started all at once, or nearly so, from the seedling stem, and formed a bundle or cluster (a fascicled root, as it is called), in place of one main root. The Bean, as we observe in Fig. 18, begins with a main root, but some of its branches soon overtake it, and a cluster of roots is formed.

67. Absorption of Moisture by Roots. The branches of roots as they grow commonly branch again and again, into smaller roots or rootlets; in this way very much increasing the surface by which the plant connects itself with the earth, and absorbs moisture from it. The whole surface of the root absorbs, so long as it is fresh and new; and the newer the roots and rootlets are, the more freely do they 
imbibe. Accordingly, as long as the plant grows above ground, and expands fresh foliage, fiom which moisture much of the time largely escapes into the air, so long it continues to extend and multiply its roots in the soil beneath, renewing and increasing the fresh surface for absorbing moisture, in proportion to the demand from above. And when growth ceases above ground, and the leaves die and fall, or no lunger act, then the roots generally stop growing, and their soft and tender tips harden. From this period, therefore, until growth begins anew the next spring, is the best time for transplanting; especially for trees and shrubs, and herbs so large that they cannot well be removed without injuring the roots very mnch.

68. We see, on considering a moment, that an herb or a tree consists of two great surfaces, with a narrow part or trunk between them, - one surface spread out in the air, and the other in the soil. These two surfaces bear a certain proportion to each other; and the

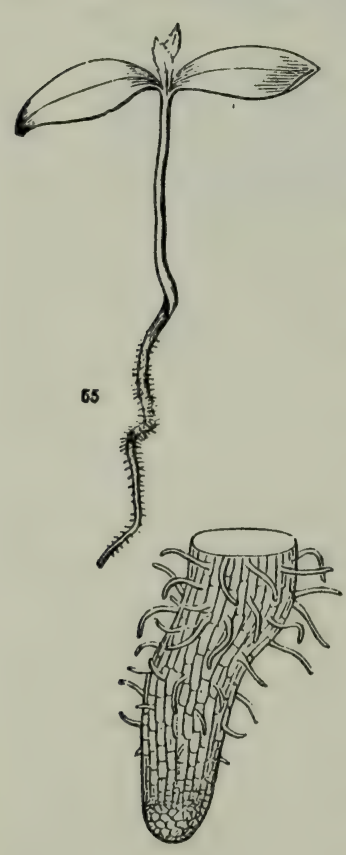

56

upper draws largely on the lower for moisture. Now, when the leaves fall from the tree in autumn, the vast surface exposed to the air is reduced to a very small part of what it was before; and the remainder, being covered with a firm bark, cannot lose much by evaporation. In common herbs the whole surface above ground perishes in autumn; and many of the rootlets die at the same time, or soon afterwards. So that the living vegetable is reduced for the time to the smallest compass, - to the thousandih or hundred-thousandth part of what it was shortly before, - and what remains alive rests in a dormant state, and may now be transplanted without much danger of harm. If any should doubt whether there is so great a difference between the summer and the winter size of plants, let them compare a lily-bulb with the full-grown Lily, or calculate the surface of foliage which

FIG. 55. Seedling Maple, of the natural size, showing the root-hairs. 56. A bit of the oud of the root magnitied. 
a tree exposes to the air, as compared with the surface of its twigs.

69. The absorbing surface of roots is very much greater than it appears to be, on account of the root-hairs, or slender fibrils, which abound on the fresh and new parts of roots. These may be seen with an ordinary magnifying-glass, or even by the naked eye in many cases; as in the root of a seedling Maple (Fig. 55), where the surface is thickly clothed with them. They are not rootlets of a smaller sort; but, when more magnified, are seen to be mere elongations of the surface of the root into slender tubes, which through their very delicate walls imbibe moisture from the soil with great avidity. They are commonly much longer than those shown in Fig. 56 , which represents only the very tip of a root moderately magnified. Small as they are individually, yet the whole amount of absorbing surface added to the rootlets by the countless numbers of these tiny tubes is very great.

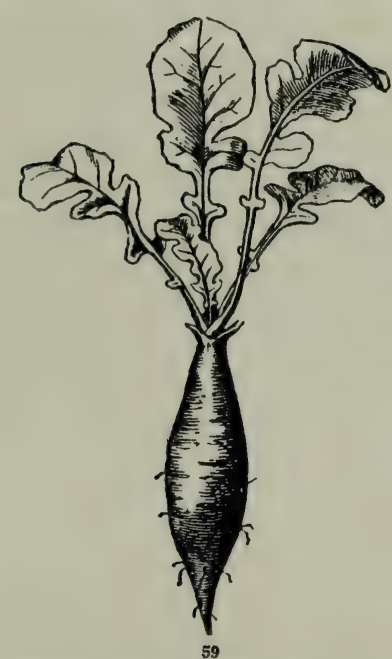

70. Roots intended mainly for absorbing branch free. ly, and are slender
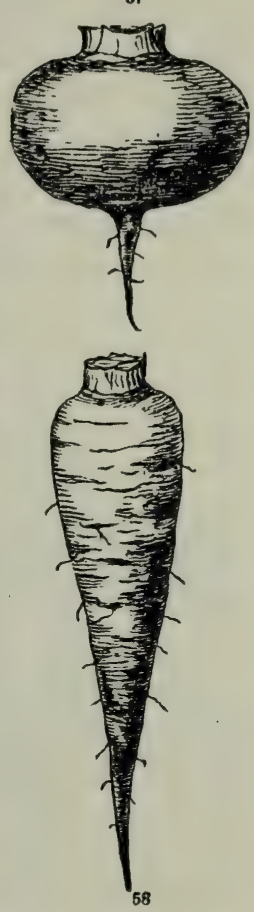
or thread-like. When the root is principally of this character it is said to be fibrous; as in Indian Corn (Fig. 42), and other grain, and to some extent in all annual plants (41).

71. The Root as a Storehouse of Fond. In biennial and many perennial herbs (41), the root answers an additional purpose. In the course of the season it becomes a storehouse of nourishment, and enlarges or thickens as it receives the accumulation. Such roots are said to be fleshy; and different names are applied to them according to 
their shapes. We may divide them all into two kinds; 1 st, those consisting of one main root, and $2 \mathrm{~d}$, those without any main root.

72. The first are merely different shapes of the tap-root; which is

Conical, when it thickens most at the crown, or where it joins the stem, and tapers regularly downwards to a point, as in the Common Beet, the Parsnip, and Carrot (Fig. 58) :

Tumip-shaped or napiform, when greatly thickened above; but abruptly becoming slender below ; as the Turnip (Fig. 57): and,

Spindle-shaped, or fusiform, when thickest in the middle and tapering to both ends; as the common Radish (Fig. 59).

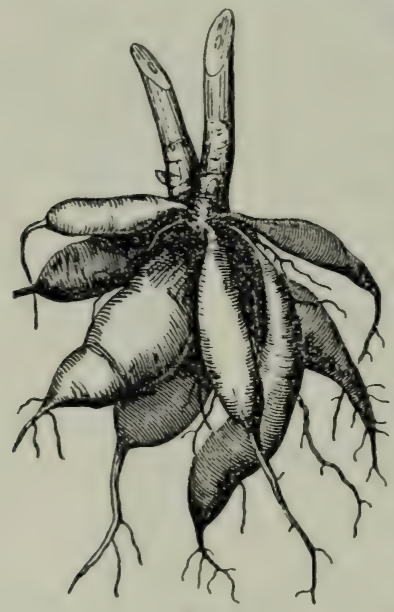

60

73. In the second kind, where there is no main root, the store of nourishing matter may be distributed throughout the branches or cluster of roots generally, or it may be accumulated in some of them, as we see in the tuberous roots of the Sweet Potato, the common Peony, and the Dahlia (Fig. 60).

74. All but the last of these illustratrations are taken from biennial plauts. These grow with a large tuft of leaves next the ground, and accumulate nourishment all the first summer, and store up all they produce beyond what is wanted at the time in their great root, which lives over the winter. We know very well what use man and other animals make of this store of food, in the form of starch, sugar, jelly, and the like. From the second year's growth we may learn what use the plant itself makes of it. The new shoots then feed upon it, and use it to form with great rapidity branches, flower-stalks, blossoms, fruit, and seed; and, having used it up, the whole plant dies when the seeds have ripened.

75. In the same way the nomrishment contained in the separate tuberous roots of the Sweet Potato and the Dahlia (Fig 60) is fed upon in the spring by the buds of the stem they belong to ; and as they are emptied of their contents, they likewise die and decay. But meanwhile similar stores of nourishment, produced by the second year's vegetation, are deposited in new roots, which live through the

FIG. 60. Clustered tuberous ruots of the Dathlia, with the bottom of the stem they belung to. 
next winter, and sustain the third spring's growth, and so on;these plants being perennial (41), or lasting year after year, though each particular root lives little more than one year.

76. Many things which commonly pass for roots are not really roots at all. Common potatoes are tuberous parts of stems, while sweet potatoes are roots, like those of the Dahlia (Fig. 60). The difference between them will more plainly appear in the next Lesson.

77. Secondary Roots. So far we have considered only the original or primary root, - that which proceeded from the lower end of the first joint of stem in the plantlet springing from the seed, - and its subdivisions. We may now remark, that any other part of the stem will produce roots just as well, whenever favorably situated for it ; that is, when covered by the soil, which provides the darkness and the moisture which is congenial to them. For these secondary roots, as they may be called, partake of the ordinary disposition of the organ: they avoid the light, and seek to bury themselves in the ground. In Indian Corn we see roots early striking from the second and the succeeding joints of stem under ground, more abundantly than from the first joint (Fig. 42). And all stems that keep up a connection with the soil - such as those which creep along on or beneath its surface - are sure to strike root from almost every joint. So will most branches when bent to the ground, and covered with the soil : and even cuttings from the branches of most plants car. be made to do so, if properly managed. Propagation by buds depends upon this. That is, a piece of a plant which has stem and leaves, either developed or in the bud, may be made to produce roots, and so become an independent plant.

78. In many plants the disposition to strike root is so strong, that they even will spring from the stem above ground. In Indian Corn, for example, it is well known that roots grow, not only from all those joints round which the earth is heaped in hoeing, but also from those several inches above the soil : and other plants produce them from stems or branches high in the air. Such roots are called

79. Acrial Roots. All the most striking examples of these are met with, as we might expect, in warmer and damper climates than ours, and especially in deep forests which shut out much of the light; this being unfavorable to roots. The Mangrove of tropical shores, which occurs on our own southern borders; the Sugar Cane, from which roots strike just as in Indian Corn, only from higher up the stem; the Pandanus, called Screw Pine (not from its resemblance to a 
Pine-tree, but because it is like a Pine-apple plant); and the fumous Banyan of India, and some other Fig-trees, furnish the most remarkable examples of roots, which strike from the stem or the branches in the open air, and at length reach the ground, and bury themselves, when they act in the same mamer as ordinary roots.

80. Some of our own common plants, however, produce small aerial rootlets; not for absorbing nourishment, but for climbing. By these rootlets, that shoot out abundantly from the side of the stems and branches, the 'Trumpet Creeper, the Ivy of Europe, and our Poison Rhus, - liere called Poison Ivy, - fasten themselves firmly to walls, or the trunks of trees, often ascending to a great height. Here roots serve the same purpose that tendrils do in the GrapeVine and Virginia Creeper. Another form, and the most aerial of all roots, since they never reach the ground, are those of

81. Epiphytes, or Air-Plants. These are called by the first name (which means growing on plants), because they are generally found upon the trunks and branches of trees; - not that they draw any nourishment from them, for their roots merely adhere to the bark, and they flourish just as well upon dead wood or any other convenient support. They are called air-plants because they really live altogether upon what they get from the air, as they have no comnection with the soil. Hundreds of air-plants grow all around us without attracting any attention, because they are small or humble. Such are the Lichens and Mosses that abound on the trunks or boughs of trees, especially on the shaded side, and on old walls, fences, or rocks, from which they obtain no nourishment. But this name is commonly applied only to the larger, flower-bearing plants which live in this way. These belong to warm and damp parts of the world, where there is always plenty of moisture in the air. The greater part belong to the Orchis family and to the Pine-Apple family; and among them are some of the handsomest flowers known. We have two or three flowering air-plants in the Southern States, though they are not showy ones. One of them is an Epidendrum growing on the boughs of the Great-flowered Magnolia: another is the Long-Moss, or Black Moss, so called, - although it is no Moss at all, - which hangs from the branches of Oaks and Pines in all the warm parts of the Southern States. (Fig 61 represents both of these. The upper is the Epidendrum conopseum; the lower, the Black Moss, Tillandsia usneoides.)

82. Parasitic Plants exhibit roots under yet another remarkable 
aspect. For these are not merely fixed upon other plants, as airplants are, but strike their roots, or what answer to roots, into them, and feed on their juices. Not only Monlds and Blights (which are plants of very low organization) live in this predacious way, but many flowering herbs, and even shrubs. One of the latter is the Mistletoe, the seed of which germinates on the bough of the tree where it falls or is left by birds; and the forming root penetrates the hark and engrafts itself into the wood, to which it becomes united as firmly as a natural branch to its parent stem; and indeed the parasite lives just as if it were a branch of the tree it grows and feeds on. A most common parasitic herb is the Dodder; which abounds in low grounds everywhere in summer, and coils its long and slender leafless, yellowish stems - resembling tangled threads of yarn round and round the stalks of other plants; wherever they touch piercing the bark with minute and very short rootlets in the form of suckers, which draw out the nourishing juices of the plants laid hold of. Other parasitic plants, like the Beceh-drops and P'ine-sap, fasten their roots under ground upon the roots of neighboring plants, and rob them of their rich juices.

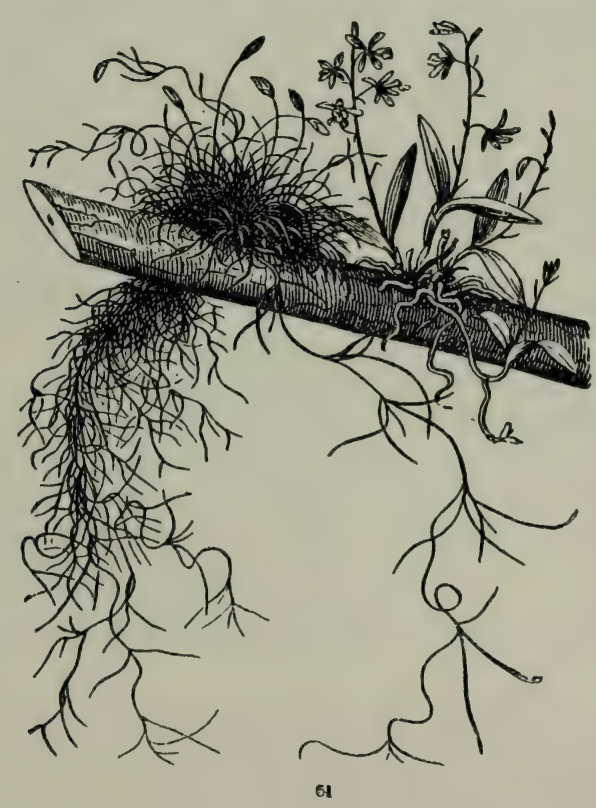




\section{LESSON VI.}

MORPHOLOGY OF STEMS AND BRANCHES.

83. Tire growth of the stem in length, and the formation of branches, have been considered already. Their growth in thickness we may study to more advantage in a later Lesson. The very various forms which they assume will now occupy our attention, beginning with

84. The Forms of Stems and Branches above ground. The principal differences as regards size and duration have been mentioned before (41); namely, the obvious distinction of plants into herbs, shrubs, and trees, which depends upon the duration and size of the stem. The stem is accordingly

Herbaceous, when it dies down to the ground every year, or after blossoming.

Suffrutescent, when the bottom of the stem above the soil is a little woody, and inclined to live from year to year.

Suffruticose, when low stems are decidedly woody below, but herbaceous above.

Fruticose, or shrublny, when woody, living from year to year, and of considerable size, - not, however, more than three or four times the height of a man.

Arborescent, when tree-like in appearance, or approaching a tree in size.

Arboreous, when forming a proper tree trunk.

85. When the stem or branches rise above ground and are apparent to view, the plant is said to be caulescent (that is, to have at caulis or true stem). When there is no evident stem above ground, but only leaves or leaf-stalks and flower-stalks, the plant is said to be acculescent, i. e. stemless, as in the Crocus, Bloodroot, common Violets, \&c., and in the Beet, Carrot, and Radish (Fig. 59), for the first season. There is a stem, however, in all such cases, only it remains on or beneath the ground, and is sometinies very short. Of course leaves and flowers do not arise from the root. These concealeal sorts of stem we will presently study.

86. The direction taken by stems, \&c., or their mode of growth, 
gives rise to several terms, which may be briefly mentioned:such as

Diffuse, when loosely spreading in all directions.

Declined, when turned or bending over to one side.

Decumbent, reclining on the ground, as if too weak to stand.

Assurgent or ascending, when rising obliquely upwards.

Procumbent or prostrate, lying flat on the ground from the first.

Crepping, or repent, when prostrate stems on or just beneath the ground strike root as they grow; as does the White Clover, the little Partridge-berry, \&c.

- Climbing, or scandent, when stems rise by clinging to other objects for support, - whether by tendrils, as do the Pea, GrapeVine, and Virginia Creeper (Fig. 62) ; by their twisting leaf-stalks, as the Virgin's Bower; or by rootlets, like the Ivy, Poison Ivy, and Trumpet Creeper (80).

Twining, or voluble, when stems rise by coiling thernselves spirally around other stems or supports ; like the Morning-Glory und the Bean.

87. Certain forms of stems have received distinct names. The jointed stem of Grasses and Sedges is called by botanists a culm; and the peculiar scaly trunk of Palms and the like (Fig. 47) is sometimes called a caudex. A few forms of branches the gardener distinguishes by particular names; and they are interesting from their serving for the natural propagation of plants from buds, and for suggesting ways by which we artificially multiply plants that would not propagate themselves without the gardener's aid. These are suckers, offsets, stolons, and runners.

88. Suckers are ascending branches rising from stems under ground, such as are produced so abundantly by the Rose, Raspberry, and other plants said to multiply "by the root." If we uncover them, we see at once the great difference between these subterranean branches and real roots. They are only creeping branches under ground. Remarking how the upright shoots from these branches become separate plants, simply by the dying off of the connecting under-ground stems, the gardener expedites the result by cutting them through with his spade. That is, he propagates the plant "by division."

89. Stolons are trailing or reclining branches above ground, which strike root where they touch the soil, and then send up a vigorous shoot, which has roots of its own, and becomes an independent plant when the connecting part dies, as it does after a while. The Currant 
and the Gooseberry naturally multiply in this way, as well as by buckers (which we sce are just the same thing, only the connecting part is concealed under ground). They must have suggested the operation of layering, or bending down and covering with earth branches which do not naturally make stolons ; and after they have taken root, as they almost always will, the gardener cuts though the comecting stem, and so converts a rooting branch into a separate plant.

90. Offsets, like those of the Houseleck, are only short stulons, with a crown of leaves at the end.

91. Runners, of which the Strawberry presents the most familias example, are a long and slender, tendril-like, leadless form of crecping branches. Each runner, after having grown to its full length, strikes root from the tip, and fixes it to the ground, then forms a bud there, which develops into a tuft of leaves, and so gives rise to a new plant, which sends out new rumers to act in the same way. In this manner a single Stiawberry plant will spread over a large space, or prodnce a great number of plants, in the course of the sumner; - all connected at first by the slender runners, but these die in the following winter, if not before, and leave the plants as so many separate individuals.

92. Tendrils are branches of a very slender sort, like runners, not lestined like them for propagation, and therefure always destitute

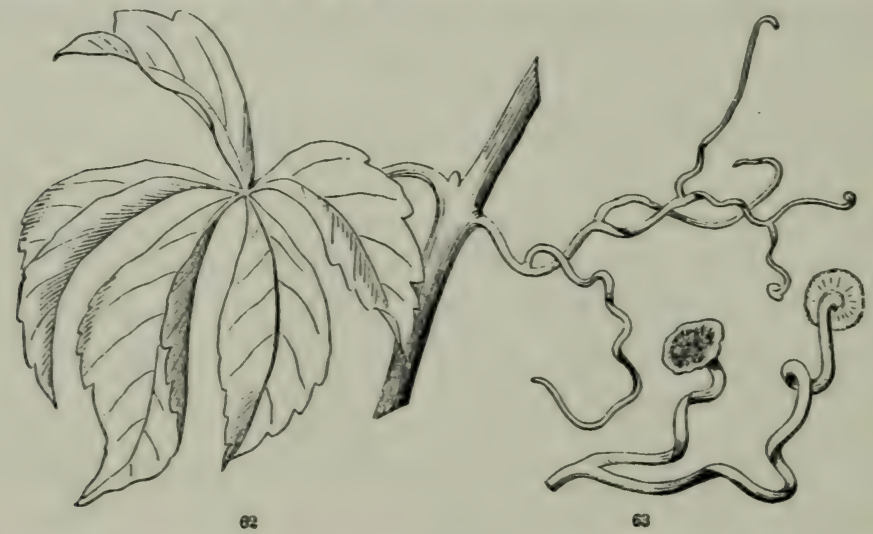

of buds or leaves, but intended for climbing. 'Those of the GrapeVine, of the Virginia Creeper (Fig. 62), and of the Cucumber and

FIG. 62. Piece of the stem of Virgiua Creoper, bearing a leaf and a tendril. C3. Tipa wi a tehdril, about the natural size, shuwing the disks by which they hold fast w walls, \&cc. 
Squash tribe are familiar illustrations. The tendril commonly grows straight and outstretched until it reaches some neighboring support, such as a stem, when its apex hooks around it to secure a hold , then the whole tendril shortens itself by coiling up spirally, and so draws the shoot of the growing plant nearer to the supporting object. When the Virginia Creeper climbs the side of a building or the smooth bark of a tree, which the tendrils cannot lay hold of in the usual way, their tips expand into a flat disk or sucker (Fig. 62, 63), which adheres very firmly to the wall or bark, enabling the plant to climb over and cover such a surface, as readily as the Ivy does by means of its sucker-like little rootlets. The same result is effected by different organs, in the one case by branches in the form of tendrils; in the other, by roots.

93. Tendrils, however, are not always branches; some are leaves, or parts of leaves, as those of the Pea (Fig. 20). Their nature in each case is to be learned from their position, whether it be that of a leaf or of a branch. In the same way

94. Spines or Thorns sometimes represent leaves, as in the Barberry, where their nature is shown by their situation outside of an axillary bud or branch. In other words, here they have a bud in their axil, and are therefore leaves; so we shall have to mention them in another place. Most commonly spines are stunted and hardened branches, arising from the axils of leaves, as in the Hawthorn and Pear. A neglected Pear-tree or Plum-tree shows every gradation between ordinary branches and thorns. Thorns sometimes branch, their branches partaking of the same spiny character: in this way those on the trunks of Honey-Locust trees (produced from adventitious buds, 58) become exceedingly complicated and horrid. The thorns on young shoots of the Honey-Locust may appear somewhat puzzling at first view; for they are situated some distance above the axil of the leaf. Here the thorn comes from the uppermost of several supernumerary buds (59). Prickles, such as those of the Rose and Blackberry, must not be confounded with thorns: these have not the nature of branches, and have no connection with the wood; but are only growths of the bark. When we strip off the bark, the prickles go with it.

95. Still stranger forms of stems and branches than any of these are met with in some tribes of plants, such as Cactuses (Fig. 76). These will be more readily understood after we have considered some of the commoner forms of 
96. Subterranean Stems and Branches. These are very numerous and various; but they are commonly overlooked, or else confounded with roots. From their situation they are out of the sight of the superficial observer: but if sought for and examined, they will well repay the student's attention. For the vegetation that is carried on under ground is hardly less varied, and no less interesting and im. portant, than that which meets our view above ground. All their forms may be referred to four principal kinds; namely, the Rhizo$m a$ or Rootstock, the Tuber, the Corm, and the Bulb.

97. The Rootstock, or Rlizoma, in its simplest form, is merely a creeping stem or branch (86) growing beneath the surface of the soil, or partly coyered by it. Of this kind are the so-called creeping, running, or scaly roots, such as those by which the Mint (Fig. 64), the Scotch Rose, the Couch-grass. or Quick-grass, and many other plants, spread so rapidly and widely, "by the root," as it is said.

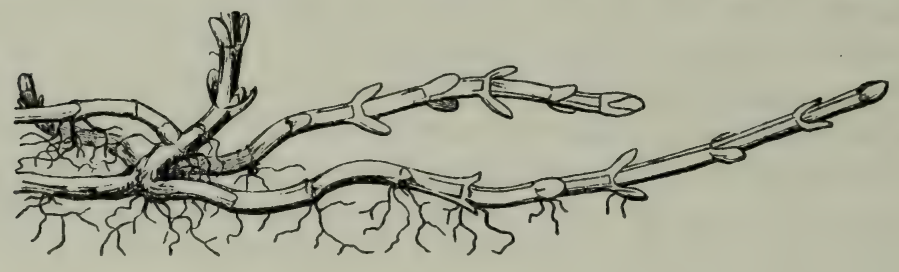

64

That these are really stems, and not roots, is evident from the way in which they grow; from their consisting of a succession of joints; and from the leaves which they bear on each joint (or node, as the botanist calls the place from which leaves arise), in the form of small scales, just like the lowest ones on the upright stem next the ground. Like other stems, they also produce buds in the axils of these scales, showing the scales to be leaves; whereas real roots bear neither leaves nor axillary buds: Placed, as they are, in the damp and dark soil, such stems naturally produce roots, just as the creeping stem does where it lies on the surface of the ground; but the whole appearance of these roots, their downward growth, and their mode of branching, are very different from that of the subterranean stem they spring from.

98. It is easy to see why plants with these rumning rootstocks take such rapid and wide possession of the soil, - often becoming great pests to farmers, - and why they are so hard to get rid of. They are

FIG. 64. Ruotstocks, or creoping subterranean branches, of the Peppermint. 
always perennials (41); the subterranean shoots live over the first winter, if not longer, and are provided with vigorous buds at every joint. Some of these buds grow in spring into upright stems, bearing folinge, to elaborate the plant's crude food into nourishment, and at length produce blossoms for reproduction by seed; while many others, fed by nourishment supplied from above, form a new generation of subterranean shoots; and this is repeated over and over in the course of the season or in succeeding years. Meanwhile as the subterranean shoots increase in number, the older ones, connecting the series of generations into one body, die off year by year, liberating the already rooted side-branches as so many separate plants; and so on indefinitely. Cutting these running rootstocks into pieces, therefore, by the hoe or the plough, far from destroying the plant, only accelerates the propagation; it converts one many-branched plant into a great number of separate individuals. Even if you divide the shoots into as many pieces as there are joints of stem, each piece (Fig. 65) is already a plantlet, with its roots and with a bud in the axil of its scale-like leaf (either latent or apparent), and having prepared nourishment enough in the bit of stem to develop this bud into a leafy stem; and so a single plant is all the more speedily converted into a multitude. Such plants as the Quickgrass accordingly realize the fable of the $\mathrm{Hy}$ dra; as fast as one of its many branches is cut

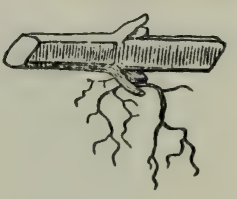

65 off, twice as many, or more, spring up in its stead. Whereas, when the subterranean parts are only roots, cutting away the stem completely destroys the plant, except in the rather rare cases where the root produces adventitious buds (58).

99. The more nourishnent rootstocks contain, the more readily do separate portions, furnished with buds, become independent plants. It is to such underground stems, thickened with a large amount of starch, or some similar nourishing matter stored up in their tissue, that the name of rhizoma or rootstock is commonly applied; - such, for example, as those of the Sweet Flag or Calanus, of Ginger, of Iris or Flower-de-luce (Fig. 133), and of the Solomon's Seal (Fig. 66).

100. The rootstocks of the common sorts of Iris of the gardens usually lie on the surface of the ground, partly uncovered; and they bear real leaves (Fig. 133), which closely overlap each other;

FIf. 65. A piece of the running rootstock of tj:0 Peppermint, with its node or joint, and an axillary bul ready to grow. 
the joints (i. e. the internodes, or spaces between each leaf) being very short. As the leaves die, year by year, and decay, a scar left in the form of a ring marks the place where each leaf was attached. Instead of leaves, rootstocks buried under ground commonly bear scales, like those of the Mint (Fig. 64), which are imperfect leaves.

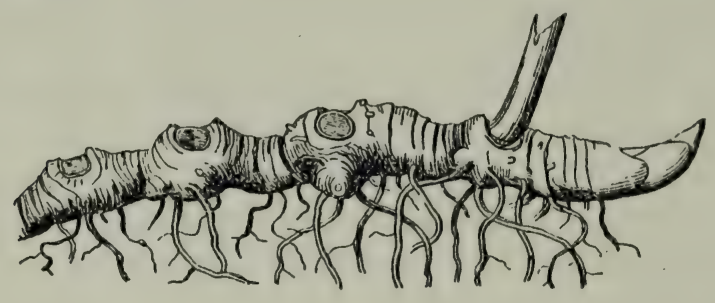

66

101. Some rootstocks are marked with large round scars of a different sort, like those of the Solomon's Seal (Fig. 66), which gave this name to the plant, from their looking something like the impression of a seal upon wax. Ifere the rootstock sends up every spring an herbaceous stalk or stem, which bears the foliage and flowers, and dies in autumn; and the seal is the circular scar left by the death and separation of the dead stalk from the living rootstock. As but one of these is formed each year, they mark the limits of a year's growth. 'The bud at the end of the rootstock in the figure, which was taken in summer, will grow the next spring into the stalk of the season, which, dying in autumn, will leave a similar scar, while another bud will be formed farther on, crowning the ever-advancing summit or growing end of the stem.

102. As each year's growth of stem, in all these cases, makes its own roots, it soon becomes independent of the older parts. And after a certain age, a portion dies off behind, every year, about as fast as it increases at the growing end; - death following life with equal and certain step, with only a narrow interval between. In vigorous plants of Solomon's Seal or Iris, the living rootstock is several inches or a foot in length; while in the short rootstock of

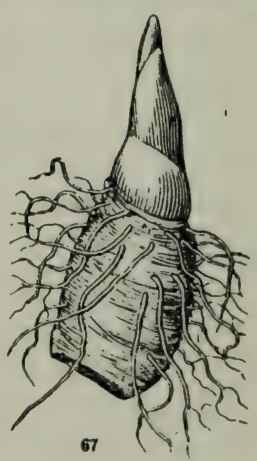

FIG. 66. Rootstock of Solomon's Sual, with the bottom of the stalk of the season, and the huil for tho noxt year's growth.

Fil.. 67. 'J'ho very short routstock and bud of a Trillium or Birthrout. 
Trillium or Birthroot (Fig. 67) life is reduced to a very narrow span, only an inch or less intervening between death beneath and young life in the strong bud annually renewed at the summit.

103. A Tuber is a thickened portion of a rootstock. When slender subterranean branches, like those of the Quick-grass or Mint (Fig. 64), become enlarged at the growing end by the accumulation there of an abundance of solid nourishing matter, tubers are produced, like those of the Nut-grass of the Southern States (which accordingly becomes a greater pest even than the Quick-grass), and of the Jerusalem Artichoke, and the Potato. The whole formation may be seen at a glance in Figure 68, which represents the subterranean growth of a Potato-plant, and shows the tubers in all their stages, from shoots just beginning to enlarge at the tip, up to fully-formed potatoes. And Fig. 69, - one of the forming tubers moderately magnified, plainly shows the leaves of this thickening shoot, in the form of little scales. It is under these scales that the eyes appear (Fig. 70): and these are evidently axillary buds (43).

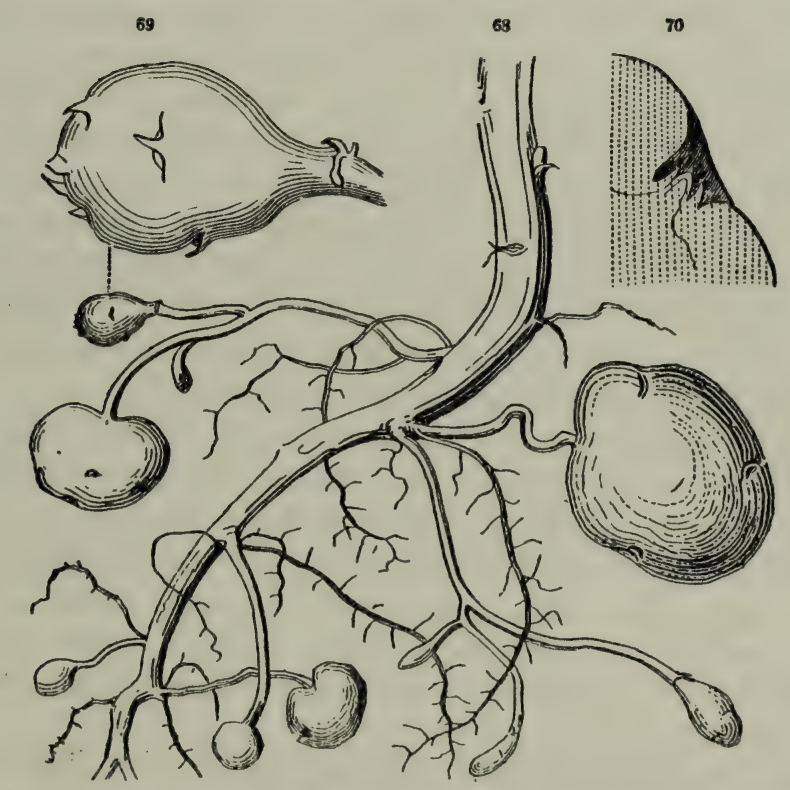

104. Let us glance for a moment at the economy or mode of life of the Potato-plant, and similar vegetables, as shown in the mor-

FIG, 68. Forming tubers of the Potato. 69. One of the very young potatoes, moderately magnified. 70. Slice of a portion through an eye, more magnified. 
phology of the branches, - that is, in the different forms they appear under, and the purposes they serve. The Potato-plant has three principal forms of branches:-1. Those that bear ordinary leaves, expanded in the air, to digest what they gather from it and what the roots gather from the soil, and convert it into nourishment. 2. After a while a second set of branches at the summit of the plant bear flowers, which form fruit and secd out of a portion of the nourishment which the leaves have prepared. 3. But a larger part of this nourishment, while in a liquid state, is carried down the stem, into a third sort of branches under ground, and accumulated in the form of starch at their extremities, which become tubers, or depositories of prepared solid food; - just as in the Turnip, Carrot, Dahlia, \&c. (Fig. 57-60), it is deposited in the root. The use of the store of food is obvious enough. In the autumn the whole plant dies, exeept the seeds (if it formed them) and the tubers; and the latter are left disconnected in the ground. Just as that small portion of nourishing matter which is deposited in the seed (3, and Fig. 34) feeds the embryo when it germinates, so the much langer portion deposited in the tuler nourishes its buds, or eyes, when they likewise grow, the next spring, into new plants. And the great supply enables them to shoot with a greater vigor at the beginning, and to produce a greater anount of vegetation than the seedling plant could do in the same space of time; which vegetation in turn may prepare and store up, in the course of a few weeks or montlis, the largest quantity of solid nourishing material, in a form most available for food. Taking advantage of this, man has transported the Potato from the cool Andes of South America to other cool climates, and makes it yield him a copious supply of food, especially in countries where the season is too short, or the summer's heat too iittle, for profitably cultivating the principal grain-plants.

105. All the sorts of subterranean stems or branches distinguished by botanists pass into one another by gradations. We have seen how nearly related the tuber is to the rootstock, and there are many cases in which it is difficult to say which is the proper name to use. So likewise,

106. The Corm, or Solid Bulb, like that of the Indian Turnip and the Crocus (Fig. 71), is just a very short and thick rootstock; as will be seen by comparing Fig. 71 with Fig. 67 . Indeed, it grows so very little in length, that it is often much broater than long, as in the Indian Turnip, and the Cyclamen of our greenhouses. Corms 
are usually upright, producing buds on their upper surface and roots from the lower. But (as we see in the Crocus here figured) buds may shoot from just above any of the faint cross lines or rings, which are the scars left by the death and decay of the sheathing bases of former leaves. That is, these are axillary buds. In these extraordinary (just ns in ordinary) stems, the buds are either axillary or terminal. 'The whole mode of growth is just the same, only the corm does not increase in length faster than it does in thickness. After a few years some of the buds grow into new corms at the expense of the old one; the young ones taking the nourishment from the parent, and storing up a large part of it in their own tissue. When exhausted in this way, as well as by flowering, the old corm dies, and its shrivelled

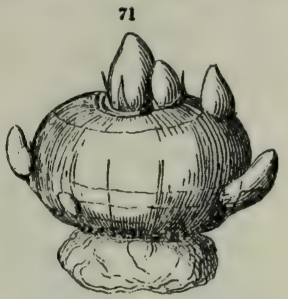
and decaying remains may be found at the side of or beneath the present generation, as we see in the Crocus (Fig. 71).

107. 'The corm of a Crocus is commonly covered with a thin and dry, scaly or fibrous husk, consisting of the rlead remaius of the bases of former leaves. When this husk consists of many scales, there is scarcely any distinction left between the corm and

108. The Bulb. This is an extremely short subterranean stem, usually much broader than high, producing roots from underneath, and covered with leaves or the bases of leaves, in the form of thickened scales. It is, therefore, the same as a corm, or solid bulb, only it bears an abundance of leaves or scales, which make up the greater part of its bulk. Or we may regard it as a bud, with thick and fleshy scales. Compare a Lily-bulb (Fig. 73) with the strong scaly buds of the Hickory and Horsechestnut (Fig. 48 and 49), and the resemblance will be apparent enough.

109. Bulbs serve the same purpose as tubers, rootstocks, or corms. The main difference is, that in these the store of food for future growth is deposited in the stem; while in the bulb, the greater part is deposited in the bases of the leaves, changing them into thick scales, which closely overlap or enclose one another, because the stem does not elongate enough to separate them. That the scales

FIG. 71. Corm or solid bulb of a Crocus. 72. The same, cut throngh lengthwise. 
of the bulb are the bases of leaves may be seen at once by following any of the ground-leaves (root-leaves as they are incorrectly

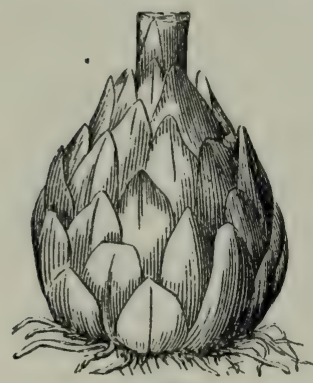

73

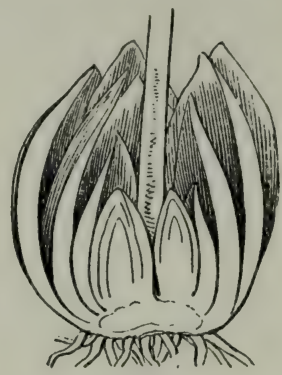

74 called) duwn to their origin in the bulb. Fig. 75 represents one of them from the White Lily; the thickened base, which makes a scale, being cut off below, to show its thickness. After having lasted its time and served its purpose as foliage, the green leaf dies, down to the thickened base, which remains as a scale of the bulb. And year after year, as the bulb grows from the centre, to produce the vegetation and the flowers of the season, the outer scales yicld up their store of nourishment for the purpose, and perish.

110. Each scale, being a leat, may have a bud in its axil. Some of these buds grow into leafy and flowering stems above ground: others grow into new bulbs, feeding on the parent, and at length destroying it, in the same way that corms do, as just described (106).

111. When the scales are broad and enwrap all that is within so as to form a succession of coats, one over another, the bulb is said to be tunicated or coated. The Tulip, Hyacinth, Leek, and Onion afford such familiar examples of coated bulbs that no figure is needed. When the scales are narrow and separate, as in the Lily (Fig. 73), the bulb is said to be scaly.

112. Bulblets are small bulbs formed above ground on some plants; as in the axils of the leaves of the coinmon bulbiferous Lily of the gardens, and often in the flower-clusters of the Leck and Onion. They are plainly nothing but bulbs with thickened scales. They never grow into branches, but detach themselves when

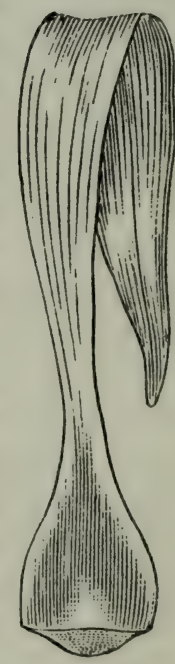

75 iull grown, and fall to the ground, to take root there and form new plants.

113. From the few illustrations already given, attentive students

FIG. 73. Bulb of the Meadow or Canada I.ily. 74. The same, rut through lengthwise.

FIG. 75. A lower leaf of White Lily, with its base under ground thickened inte a bulb. scale. 
can hardly fail to obtain a good idea of what is meant by morphnlogy in Botany; and they will be able to apply its simple principles for themselves to all forms of vegetation. They will find it very interesting to identify all these various subterraiean forms with the common plan of vegetation above ground. There is the same structure, and the same mode of growth in reality, however different in appearance, and however changed the form, to suit particular conditions, or to accomplish particular ends. It is plain to see, already, that the plant is constructed according to a plan, - a very simple one, which is exhibited by all vegetables, by the extraordinary no less than by the ordinary kinds; and that the same organ may appear under a great many different shapes, and fulfil very different offices.

114. These extraordinary shapes are not confined to subterranean vegetation. They are all repeated in various sorts of fleshy plants ; in the Ilouseleek, Aloe, $\Lambda$ gave (Fig. 82), and in the many and strange shapes which the Cacetus family exhibit. (Fig. 76); shapes which imitate rootstocks, tubers, corms, \&c. above ground. All these we may regard as

115. Consolidated Forms of Vegctation. While ordinary plants are constructed on the plan of great spread of surface (131), these are formed on the plan of the least possible arnount of surface in proportion to their bulk. The Cereus genus of Cactuses, for example, consisting of solid columnar trunks (Fig. 76, b), may be likened to rootstocks. A green rind serves the purpose of foliage; but the surface is as nothing compared with an ordinary leafy plant of the same bulk. Compare, for instance, the largest Cactus known, the Giant Cereus of the Gila River (Fig. 76, in the background), which rises to the height of fifty or sixty fect, with a common leafy tree of the same height, such as that in Fig. 54, and estimate how vastly greater, even without the foliage, the surfice of the laiter is than that of the former. Compare, in the same view, an Opuntia or Prickly-Pear Cactus, its stem and branches formed of a succession of thick and flattened joints (Fig. 76, $a$ ), which may be likened to tubers, or an Epiphyllum $(d)$, with shorter and flatter joints, with an ordinary leafy shrub or herb of equal size. And finally, in Melon-Cactuses or Echinocactus (c), with their globular or bulb-like shapes, we have plants in the compactest shape; their spherical figure being such as to expose the least possible amount of its bulk to the air.

116. These consoliduted plants are evidently adapted and designed 
for very dry regions; and in such only are they found. Similarly, bulbous and corm-bearing plants, and the like, are examples of a form of vegetation which in the growing season may expand a large surface to the air and light, while during the period of rest the living vegetable is reduced to a globe, or solid form of the least possible surface; and this is protected by its outer coats of dead and dry scales, as well as by its situation under ground. Such plants exhibit another and very similar adaptation to a season of drought. And they mainly belong to countries (such as Southern Africa, and parts of the interior of Oregon and California) which have a long hot season during which little or no rain falls, when, their stalks and foliage above and their roots beneath being early cut off by dronght, the plants rest securely in their compact bulbs, filled with nourishment, and retaining their moisture with great tenacity, until the rainy season comes round. Then they shoot forth leaves and flowers with wonderful rapidity, and what was perhaps a desert of arid sand becomes green with foliage and gay with blossoms, almost in a day. This will be more perfectly understood when the nature and use of foliage have been more fully considered. (Fig. 76 represents several furms of Cactus vegetation.)

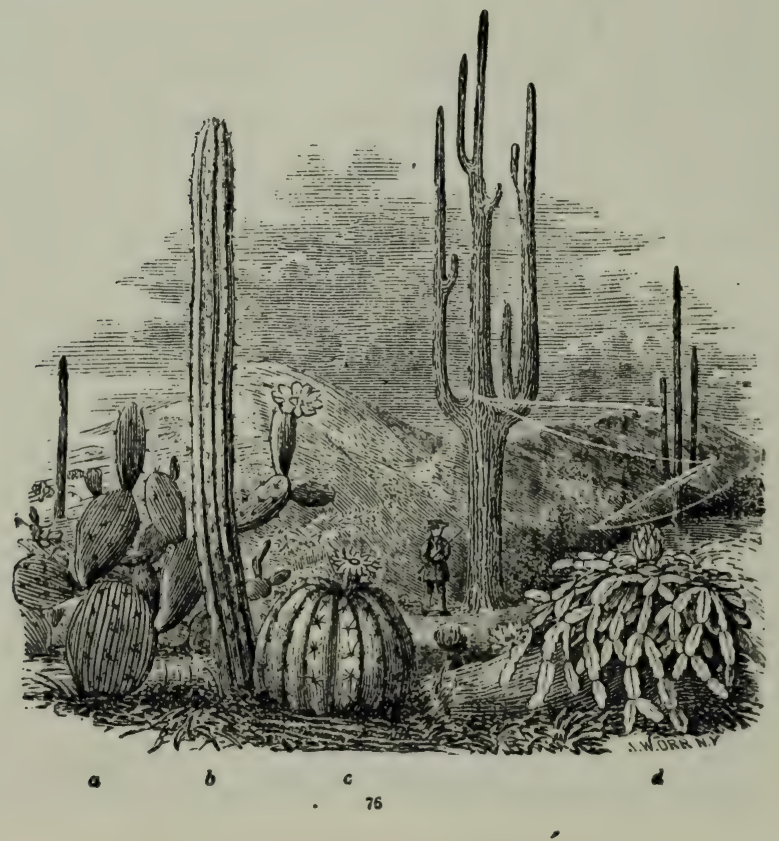




\section{LESSON VII.}

\section{MORPHOLOGY OF LEAVES.}

117. In describing the subterranean forms of the stem, we have been led to notice already some of the remarkable forms under which leaves occur; namely, as scales, sometimes small and thin, as those of the rootstocks of the Quick-grass, or the Mint (Fig. 64), sometimes large and thick, as those of bulbs (Fig. 73-75), where they are commonly larger than the stem they belong to. We have seen, too, in the second Lesson, the seed-leaves (or cotyledons) in forms as unlike foliage as possible ; and in the third Lesson we have spoken of bud-scales as a sort of leaves. So that the botanist recognizes the leaf under other forms than that of foliage.

118. We may call foliage the natural form of leaves, and look upon the other sorts as special forms, - as transformed leaves: by this term meaning only that what would have been ordinary leaves under other circumstances (as, for instance, those on shoots of Mint, Fig. 64, had these grown upright in the air, instead of creeping under ground) are developed in special forms to serve some particular purpose. For the Great Author of Nature, having designed plants upon one simple plan, just adapts this plan to all cases. So, whenever any special purpose is to be accomplished, no new instruments or organs are created for it, but one of the three general organs of the vegetable, root, stem, or leaf, is made to serve the purpose, and is adapted to it by taking some peculiar form.

119. It is the study of the varied forms under this view that constitutes Morphology (61), and gives to this part of Botany such great interest. We have already seen stems and roots under a great variety of forms. But leaves appear under more various and widely different forms, and answer a greater variety of purposes, than do both the other organs of the plant put together. We have to consider, then, leaves as foliage, and leaves as something else than foliage. As we have just been noticing cases of leaves that are not foliage, we may consider these first, and enumerate the principal kinds.

120. Leaves as Depositories of Food. Of these we have had plenty of instances in the seed-leaves, such as those of the Almond, Apple- 
seed (Fig. 11), Beech (Fig. 13-15), the Bean and Pea (Fig. 1620), the Oak (Fig. 21, 22), and Ilorsechestnut (Fig. 23, 24); where the food upon which the plantlet feeds when it springs from the seed is stored up in its cotyledons or first leaves. And we have noticed how very unlike foliage such leaves are. Y et in some cases,

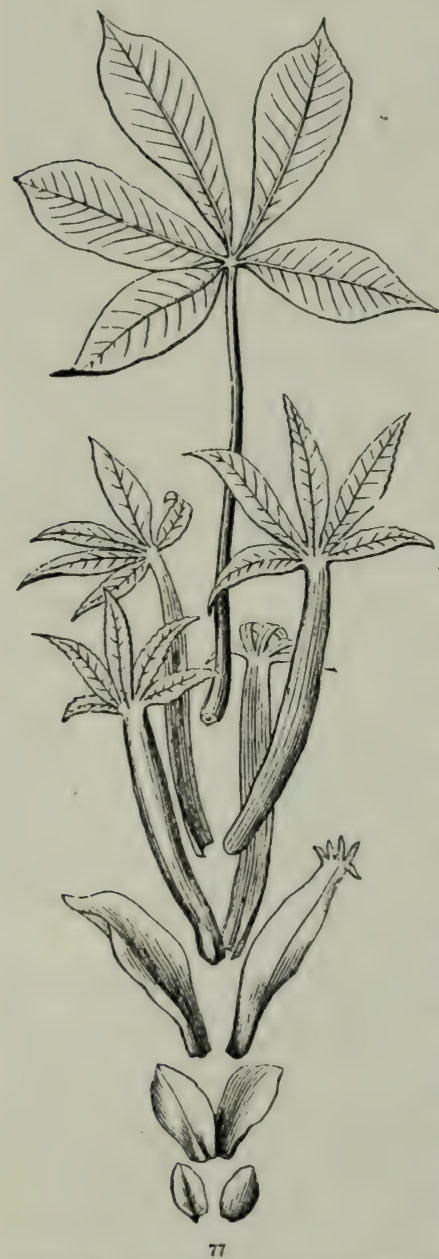
as in the P'umpkin (Fig. 10), they actually grow into green leaves as they get rid of their burden.

121. Bulb-Scules (Fig. 73-75) offer another instance, which we were considering at the close of the last Lesson. Here a part of the nourishment prepared in the foliage of one year is stored up in the scales, or subterranean thickened leaves, for the early growth and flowering of the next year; and this enables the flowers to appear before the leaves, or as soon as they do ; as in Hyacinths, Snow-drops, and many bulbous plants.

122. Leaves as Bud-seales, \&c. True to its nature, the stem produces leaves even under ground, where they cannot serve as foliage, and where often, as on rootstocks and tuber's $(97-103)$, they are not of any use that we know of. In such cases they usually appear as thin scales. So the first leaves of the stems of herbs, as they sprout from the ground, are generally mere scules, such as those of an Asparagus shoot; and such are the first leaves on the stem of the seedling Oak (Fig. 22) and the Pea (Fig. 20). Similar scales, however, often serve an important purpose; as when they form the covering of buds, where they protect the tender parts within (44). That bud-scales are

FIG. 77. Leaves of a deveioping bud of the Low Sweet Buckeye (A :culus parviftora), showing a nearly complete set of gradations fruin a scale to a compound leaf of five leafiets. 
leaves is plainly shown, in many cases, by the gradual transition between them and the first foliage of the shoot. The Common Lilac and the Shell-bark Hickory are good instances of the sort. But the best illustration is furnished by the Low Sweet Buckeye of the Southern States, which is often cultivated as an ornamental shrub. From one and the same growing bud we may often find all the gradations which are shown in Fig. 77.

123. Leaves as Spines occur in several plants. The most familiar instance is that of the Common Barberry. In almost any summer shoot, most of the gradations may be seen between the ordinary leaves, with sharp bristly teeth, and leaves which are reduced to a branching spine or thorn, as shown in Fig. 78. The fact that the spines of the Barberry produce a leaf-bud in their axil also proves them to be leaves.

124. Letves as Tendrils are to be seen in the Pea and the Vetch (Fig. 20, 127), where the upper part of each leaf becomes a tendril, which

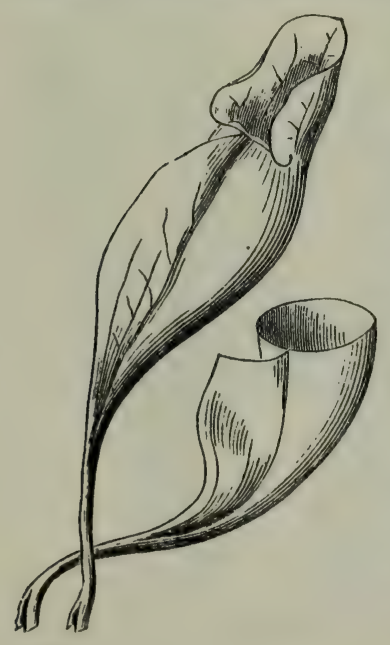

79 the plant uses to climb by; and in

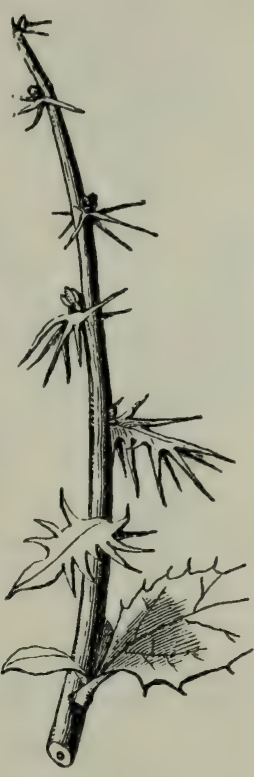
one kind of Vetch the whole leaf is such a tendril.

125. Leaves as Pitchers, or hollow tubes, are familiar to us in the common Pitcherplant or Side-saddle Flower (Sarracenia, Fig. 79) of our bogs. These pitchers are generally half-full of water, in which flies and other insects are drowned, often in such numbers as to make a rich manure for the plant, no doubt; though we can hardly imagine this to be the design of the pitcher. Nor do we perceive here any need of a contrivance to hold water, since the roots of these plants are always well supplied by the wet bogs where they grow.

FIG. 78. Summer shoot of Barherry, showing the transition of leaves into spines.

FLG. 79. Leaf of Earracenia purpurea, entire, and another with the upper part cut off. 
126. Leaves as Fly-1raps. Insects are caught in another way, and more expertly, by the most extraordinary of all the plants of this

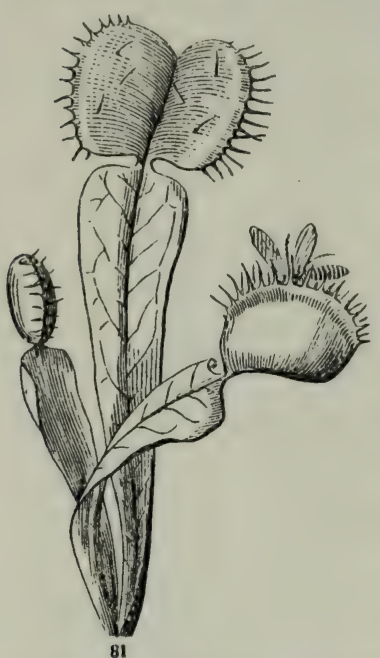
country, the Dionæa or Venus's Flytrap, which grows in the sandy bogs around Wilmington, North Carolina. Here (Fig. 81) each leaf bears at its summit an appendage which opens and shuts, in shape something like a steeltrap, and operating much like one. For when open, as it commonly is when the sun shines, no sooner does a fly alight on its surface, and brush against any one of the several long bristles that grow there, than the trap suddenly closes, often capturing the intruder, pressing it all the harder for its struggles, and corrmonly depriving it of life. If the fly escopes, the trap soon slowly opens, and is ready for another capture. When retained, the insect is after a time moistened by a secretion from minute glands of the iuner surface, and is apparently digested! How such and various other movements are made by plants, - some as quick as in this case, other's very slow, but equally wonderful, must be considered in a future Lesson.

127. Leaves serving both 0rdinary and Spccial Purposes. Let us now remark, that the same leaf frequently answers its general purpose, as foliage, and some special purpose besides. For example, in the Dionaa, the lower part of the leaf, and probably the whole of it, acts as foliage, while the appendage serves its mysterious purpose as a fly-catcher. In the Pea and Vetch (Fig. 20, 127), the lower part of the leaf

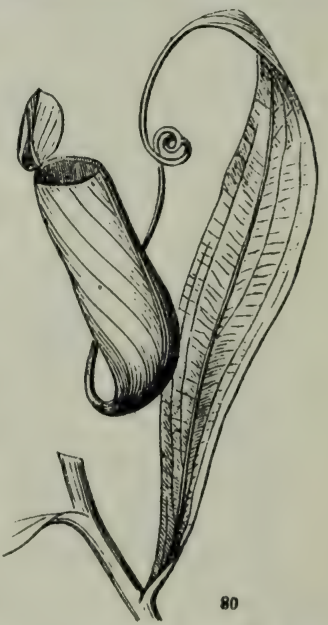
is foliage, the upper a tendril. In the Pitcher-plants of the Indian Archipelago (Nepenthes, Fig. 80) which are not rare in conservatories, the lower part of the leaf is expanded and acts as foliage;

FIG. 80. Leaf of Nepenthes: leaf, tendril, and pitcher combineil.

FIG. 81. Leaves of Dintea the trap in one of them open, in the others closed. 
farther on, it is contracted into a tendril, enabling the plant to climb; the end of this tendril is then expanded into a pitcher, of five or six inches in length, and on the end of this is a lid, which exactly closes the mouth of the pitcher until after it is full grown, when the lid opens by a hinge! But the whole is only one leaf.

128. So in the root-leaves of the Tulip or the Lily (Fig. 75), while the green leaf is preparing nourishment throughout the growing season, its base under ground is thickened into a reservoir for storing up a good part of the nourishment for next year's use.

129. Finally, the whole leaf often serves both as foliage, to prepare nourishment, and as a depository to store it up. This takes place in all fleshy-leaved plants. such as the Houseleek, the Iceplant, and various sorts of Mesembryanthemum, in the Live-for-ever of the gardens to some extent, and very strikingly in the Aloe, and in the Century-plant. In the latter it is only the green surface of these large and thick leaves (of three to five feet in length on a strong plant, and often three to six inches thick near the base) which acts as foliage; the whole interior is white, like the interior of a potato, and almost as heavily loaded with starch and other nourishing matter. (Fig. 82 represents a young Century-plant, Agave Americana.)

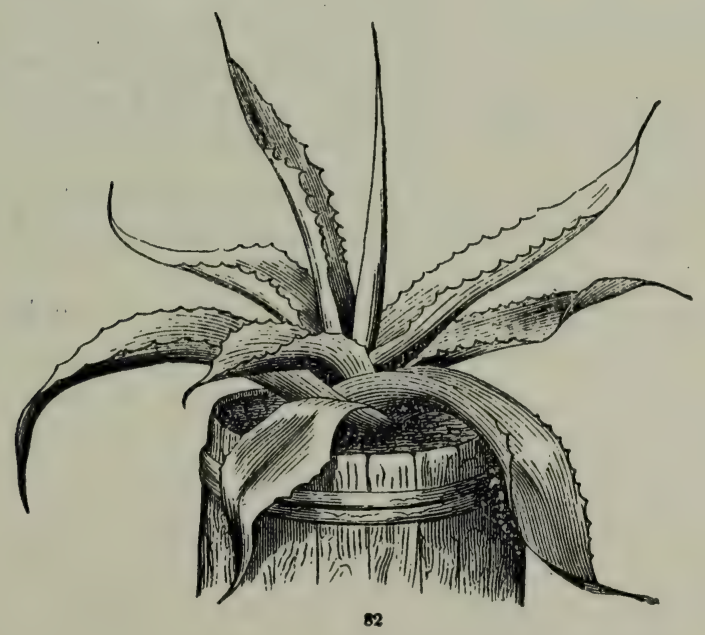




\section{LESSON VIII.}

\section{MORPHOLOGY OF LEAVES AS FOLIAGE.}

130. HAving in the last Lesson glanced at some of the special or extraordinary forms and uses of leaves, we now return to leaves in their ordinary condition, namely, as foliage. We regard this as the natural state of leaves. For although they may be turned to account in other and very various ways, as we have just seen, still their proper oflice in vegetation is to serve as foliage. In this view we may regard

131. Leaves as a Coutrivance for Increasing the Surface of that large part of the plant which is exposed to the light and the air. This is shown by their expanded form, and ordinarily slight thickness in comparison with their length and breath. While a Melon-Cactus (115, Fig. 76) is a st:iking example of a plant with the least possible amount of surface for its bulk, a repeatedly branching leafy herb or tree presents the largest possible extent of surface to the air. The actual amount of surface presented by a tree in full leat is much larger than one would be apt to suppose. Thus, the Washington Elm at Cambridge - a tree of no extraordinary size - was some year's ago estimated to produce a crop of seven millions of leaves, exposing a surface of 200,000 square feet, or about five acres, of foliage.

132. What is done by the foliage we shall have to explain in another place. Under the present head we are to consider ordinary leaves as to their parts and their shapes.

133. The Parts of the Leaf. The principal part of a leaf is the blade, or expanded portion, one face of which naturally looks toward the sky, the other towards the earth. The blade is often raised on a stalk of its own, and on each side of the stalk at its base there is sometimes an appendage called a stipule. A complete leaf, therefore consists of at blade (Fig. 83, b), a foot-stalk or leaf-stalk, called the petiole $(p)$, and a pair of stipules (st). See also Fig. 136.

134. It is the blade which we are now to describe. This, as being the essential and conspicuous part, we generally regard as the leaf: and it is only when we have to particularize, that we speak of the blade, or lamina, of the leaf. 
135. Without here entering upon the subject of the anatomy of the leaf, we may remark, that leaves consist of two sorts of material, viz.: 1. the green pulp, or parenchyma; and 2. the fibrous framework, or skeleton, which extends throughout the soft greer: pulp and supports it, giving the leaf a strength and firmness which it would not otherwise possess. Besides, the whole surface is covered with a transparent skin, called the epidermis, like that which covers the surface of the shoots, \&c.

136. The framework consists of wood, - a fibrous and tough material which runs from the stem through the leaf-stalk, when there is one, in the form of parallel threads or bundles of $b$ fibres; and in the blade these spread out in a horizontal direction, to form the ribs and veins of the leaf. The stout main branches of the framework (like those in Fig. 50) are called the ribs. When there is only one, as in Fig. 83 , \&c., or a middle one decidedly larger than the rest, it is called

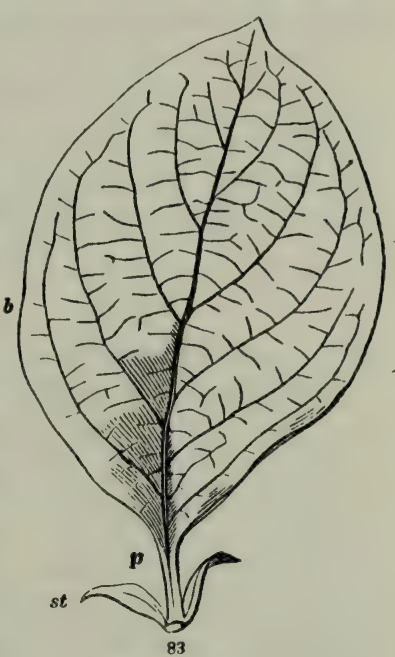
the midrib. The smaller divisions are termed veins; and their still smaller subdivisions, veinlets.

137. The latter subdivide again and again, until they become sn fine that they are invisible to the naked eye. The fibres of which they are composed are hollow; forming tubes by which the sap is brought into the leaves and carried to every part. The arrangement of the framework in the blade is termed the

138. Venation, or mode of veining. This corresponds so completely with the general shape of the leaf, and with the kind of division when the blade is divided or lobed, that the readiest way to study and arrange the forms of leaves is first to consider their veining.

139. Various as it appears in different leaves, the veining is all reducible to two principal kinds; namely, the parallel-veined and the netted-veined.

140. In netted-veined (also called reticulated) leaves, the veins branch off from the main rib or ribs, divide into finer and finer 
veinlets, and the branches unite with each other to form meshes of network. That is, they anastomose, as anatomists say of the veins and arteries of the body. 'The Quince-leaf, in Fig. 83, shows this kind of veining in a leaf with a single rib. The Maple, Basswood, und Buttonwood (Fig. 50) show it in leaves of several ribs.

i41. In parallel-veined leaves, the whole framework consists of slender ribs or veins, which run parallel with each other, or nearly so, from the base to the point of the leaf, not dividing and sub. dividing, nor forming meshes, except by very minute cross-veinlets, The leaf of any grass, or that of the Lily of the Valley (Fig. 84) will furnish a good illustration.

142. Such simple, parallel veins Linnaus, to distinguish them,

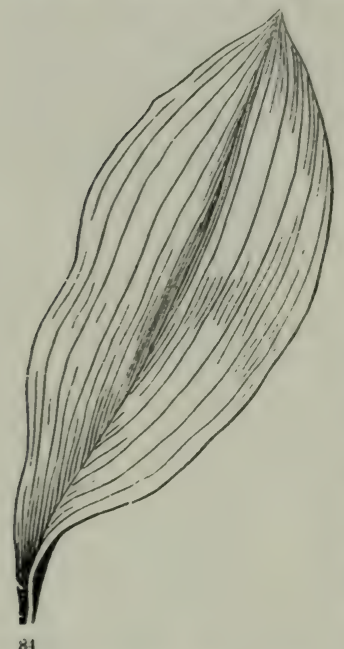
called nerves, and parallel-veined leaves are still commonly called nerved leaves, while those of the other kind are said to be veined; - terms which it is convenient to use, although these " nerves" and "veins" are all the same thing, and have no likeness to the nerves of animals.

143. Netted-veined leaves belong tc. plants which have a pair of seed-leaves or cotyledons, such as the Maple (Fig. 1 -7 ), Beech (Fig. 15), Pea and Bear: (Fig. 18, 20), and most of the illustrations in the first and second Lessons. While parallel-veined or nerved leavee belong to plants with one cotyledon or true seed-leaf; such as the Iris (Fig. 134) and Indian Corn (Fig. 42). So that a mere glance at the leaves of the tree or lierb enables one to tell what the structure of the embryo is, and to refer the plant to one or the other of these two grand classes, - which is a great convenience. For generally when plants differ from each other in some one important respect, they differ correspondingly in other respects as well.

144. Parallel-veined leaves are of two sorts; one kind, and the commonest, having the rilss or nerves all rumning from the base to the point of the leat', as in the examples alrealy given; while in another kind they run from a midrib to the margin; as in the com-

FIG. 84. A (parallel-veined) leaf of the Lily of the Valley. 
mon Pickerèl-weed of our ponds, in the Banana (Fig. 47), and many similar plants of warm climates.

145. Netted-veined leaves are also of two sorts, as is shown in the examples already referred to. In one case the veins all rise from a single rib (the midrib), as in Fig. 83 . Such leaves are called feather-veined or pinnately-veined; both terms meaning the same thing, namely, that the veins are arranged on the sides of the rib like the plume of a feather on each side of the shaft.

146. In the other case (as in the Buttonwood, Fig. 50, Maple, \&c.), the veins branch off from three, five, seven, or nine ribs, which spread from the top of the leaf-stalk, and run through the blade like the toes of a web-footed bird. Hencè these are said to be palmately or digitately veined, or (since the ribs diverge like rays from a centre) radiate-veined.

147. Since the general outline of leaves accords with the framework or skeleton, it is plain that feather-veined leaves will incline to elongated shapes, or at least will be longer than broad; while in radiate-veined leaves more rounded forms are to be expected. A glance at the following figures shows this. Whether we consider the veins of the leaf to be adapted to the shape of the blade, or tho green pulp to be moulded to the framework, is not very material. Either way, the outline of each leaf corresponds with the mode of spreading, the extent, and the relative length of the veins. Thus, in oblong or elliptical leaves of the feather-veined sort (Fig. 87, 88), the principal veins are nearly equal in length; while in ovate and heart-shaped leaves (Fig. 89, 90), those below the middle are longest; and in leaves which widen upwards (Fig. 91-94), the veins above the middle are longer than the others.

148. Let us pass on, without particular reference to the kind of veining, to enumerate the principal

149. Forms of Leaves as to Gencral Outline. It is necessary to give names to the principal shapes, and to define them rather precisely, since they afford the easiest marks for distinguishing species. The same terms are used for all other flattened parts as well, such as the petals of the flowers; so that they make up a great part of the descriptive language of Botany. We do not mention the names of common plants which exhibit these various shapes. It will be a good exercise for young students to look them up and apply them.

150. Beginning with the narrower and proceeding to the broadest forms. a leaf is said to be 
Linear (Fig. 85), when narrow, several times longer than wide, and of the same breadth throughout.

Lanceolate, or lance-shaped, when several times longer than wide, and tapering upwards (Fig. 86), or both upwards and downwards.

Oblong (Fig. 87), when nearly twice or thrice as long as broad.

Elliptical (Fig. 88 ) is oblung with a flowing outline, the two ends alike in width.

Oval is the same as broadly elliptical, or elliptical with the breadth considerably more than half the length.

Ovate (Fig. 89), when the outline is like a section of a hen's-egg lengthwise, the broader end downward.

Orbiculur, or rotund (Fig. 102), circular in outline, or nearly so.

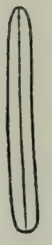

85

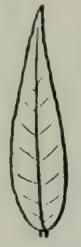

86

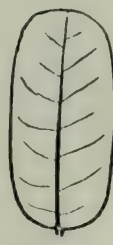

87

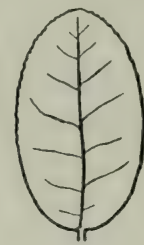

89

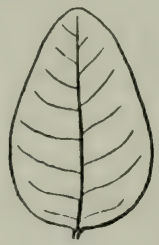

89

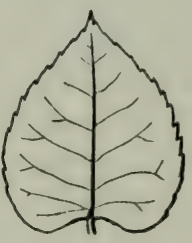

90

151. When the leaf tapers towards the base, instead of upwards, it may be

Oblanceolate (Fig. 91), which is lance-shaped, with the more
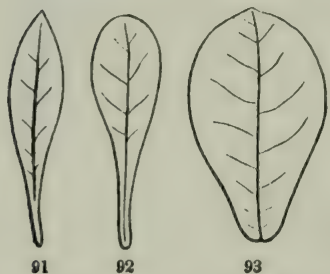

93

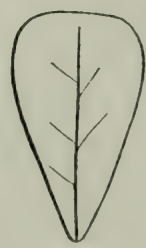

84 tapering end downwards;

Spatulate (Fig. 92), rounded above and long and narrow below, like a spatula;

Obovate (Fig. 93), or in. versely ovate, that is, ovate with the narrower end down; or

Cuneate, or cuneiform, that is, wedge-shaped (Fig. 94), broad above and tapering by straight lines to an acute angle at the base.

152. As to the Base, its shape characterizes several forms, such as

Cordate, or heart-shaped (Fig. 90, 99, 8), when a leaf of an ovate form, or something like it, has the outline of its rounded base turned in (forming a notch or sinus) where the stalk is attached.

Reniform, or kidney-shaped (Fig. 100), like the last, only rounder and broader than long.

FIG. 85-90. Various forms of feather-veined leaves.

FIG. 91. Oblancedate, 92. spatulate, 93. ubovate, 91. wedge-shaped, feather-veined leaves. 
Auriculute, or eared, having a pair of small and blunt projections, or ears, at the base, as in one species of Magnolia (Fig. 96).

Sagittate, or arrow-shaped, where such ears are pointed and turned downwards, while the main body of the blade tapers upwards to a point, as in the common Sagittaria or Arrow-head, and in the Arrow-leaved Polygonum (Fig. 95).

Hastate, or halberdshaped, when such

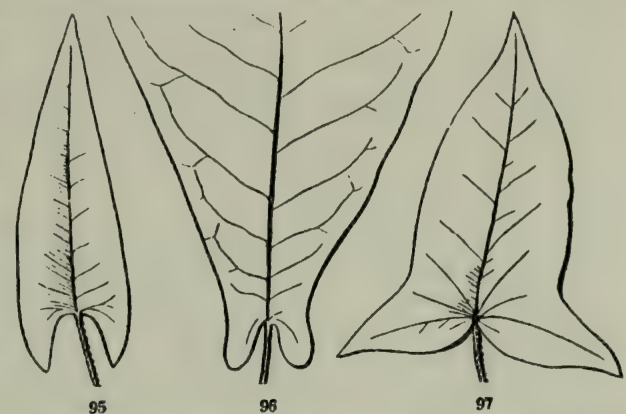
lobes at the base point outwards, giving the leaf the shape of the lialberd of the olden time, as in another Polygonum (Fig. 97).

Peltate, or shield-shaped, (Fig. 102,) is the name applied to a curious modification of the leaf, commonly of a rounded form, where the footstalk is attached to the lower surface, instead of the base, and

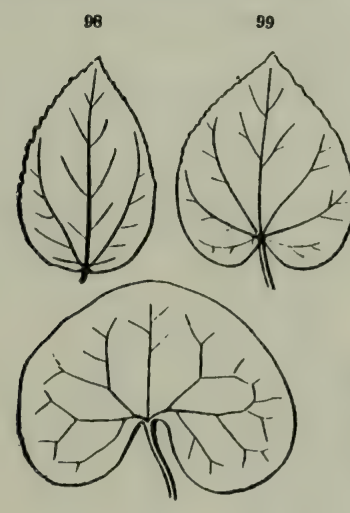

100

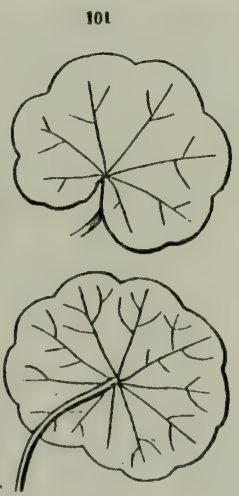

ing

therefore is naturally likened to a shield borne by the outstretched arm. The common Watershield, the Nelumbium, and the White Water-lily, and also the Mandrake, exhibit this sort of leaf. On comparing the shield-shaped leaf of the common Marsh Pennywort (Fig. 102) with that of another common species (Fig. 101), we see at once what this peculiarity means. A shield-shaped leaf is like a

FIG. 95. Sagittate, 96. auriculate, 97. halberd-shaped, leaves.

FIG. 98-102. Various forms of radiate-veined leaves. 
kidney-shaped (Fig. 100) or other rounded leaf, with the margins at the base brought together and united.

153. As to the Apex, the following terms express the principal variatious.

Acuminate, pointed, or taper-pointed, when the summit is more or less prolonged into a narrowed or tapering point, as in Fig. 97.

Acute, when ending in an acute angle or not prolonged point, as in Fig. 104, 98, 95, \&c.

Obtuse, when with a blunt or rounded point, as in Fig. 105, 89, \&c.

T'runcate, with the end as if cut off square, as in Fig. 106, 94.

Retuse, with the rounded summit slightly indented, forming a very shallow notch, as in Fig. 107.

Emarginate, or notched, indented at the end more decidedly, as in Fig. 108.

Obcordate, that is, inversely heart-shaped, where an obovate leaf is more deeply notched at the end (Fig. 109), as in White Clover and Wood-sorrel; so as to resemble a cordate leaf (Fig. 99) inverted.

Cuspidate, tipped with a sharp and rigid point; us in Fig. 110.

Mucronute, abruptly tipped with a small and short point, like a projection of the midrib ; as in Fig. 111.

Aristate, awn-pointed, and bristlc-pointed, are terms used when this mucronate point is extended into a longer bristle-form or other slender appendage.

The first six of these terras can be applied to the lower as well as to the apper end of a leaf or other organ. The others belong to the apex only.

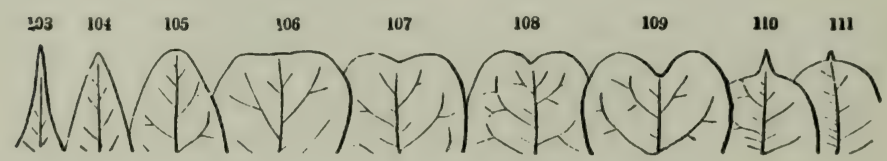

FIG. 103-111. Fiorns of the apex of leaves. 


\section{LESSON IX.}

MORPIOLOGY OF LEAVES AS FOIIAGE.- SIMPLE AND COMPOUND IIEAVES, STIPUIES, FTC.

154. In the foregoing Lesson leaves have been treated of in their simplest form, namely, as consisting of a single blade. But in many cases the leaf is divided into a number of separate blades. That is,

155. Leaves are either Simple or Compound. They are seid to be simple, when the blade is all of one piece : they are compound, when the blade consists of two or more separate pieces, borne upon a common leaf-stalk. And between these two kinds every intermediate gradation is to be met with. This will appear as we proceed to notice the principal

156. Forms of Leaves as to particular Outline or degree of division. In this respect, leaves are said to be

Entire, when their general outline is completely filled out, so that the margin is an even line, without any teeth or notches; as in Fig. $83,84,100, \&$ c.

Serrate, or saw-toothed, when the margin only is cut into sharp teeth, like those of a saw, and pointing forwards; as in Fig. 112; also 90, \&c.

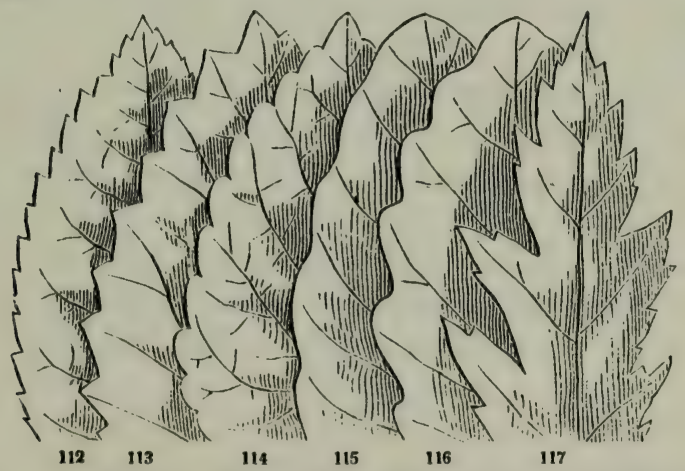

Dentate, or toothed, when such teeth point outwards, instead of forwards ; as in Fig. 113.

FIG. 112-117. Kinds of margin of leaves. 
Crenate, or scalloped, when the teeth are broad and rounded; as in Fig. 114, 101.

Repand, andulute, or wary, when the margin of the leaf forms a wavy line, bending slightly inwards and outwards in succession; as in Fig. 115.

Sinuute, when the margin is more strongly sinuous, or turned inwards and outwards, as in Fig. 116.

Incised, cut, or juyged, when the margin is cut into sharp, deep, and irregular teeth or incisions, as in Fig. 117.

157. When leaves are more deeply cut, and with a definite number of incisions, they are said, as a general term, to be lobed; the parts being called lobes. Their number is expressed by the phrase tuvlobed, three-lobed, five-lobed, nany-lobed, \&c., as the case may be. When the depth and character of the lobing needs to be more particularly specified, - as is often the case, - the following terus are employed, viz.:

Lobed, when the incisions do not extend deeper than about halfway between the margin and the centre of the blade, if so far, and are more or less rounded; ats in the leaves of the L'ost-Oak, l'ig. 118 , and the 1lepatica, Fig. 122.

Cleft, when the incisions extend half-way down or more, and especially when they are sharp, as in Fig. 119, 123. And the phrascs two-cleft, or, in the Lattin form, bifid; three-cleft, or trifid; four-cleft, or quadrifid; five-cleft, or quinquefid, \&c.; or many-cleft, in the Latin form multifid, - express the number of the segments, or portions.

Parted, when the incisions are still deeper, but yet do not quite reach to the midrib or the base of the blade; as in Fig. 120, 124. And the terms two-parted, three-parted, \&c. express the number of such divisions.

Divided, when the incisions extend quite to the nidrib, as in the lower part of Fig. 121 ; or to the leaf-stalk, as in Fig. 125 ; which makes the leat compound. INere, using the Latin form, the leaf is said to be bisected, trisected (Fig. 125), dce, to express the number of the divisions.

158. In this way the degree of division is described. We may likewise express the mode of division. The notches or incisions, being places where the green pulp of the blate has not wholly filled up the framework, correspond with the veining; as we perceive on comparing the figures 118 to 121 with figures 122 to 125 . The 
upper row of figures consists of feather-veined, or, in Latin form, pinnately-veined leaves $(145)$; the lower row, of radiate-veined or palmately-veined leaves (146).

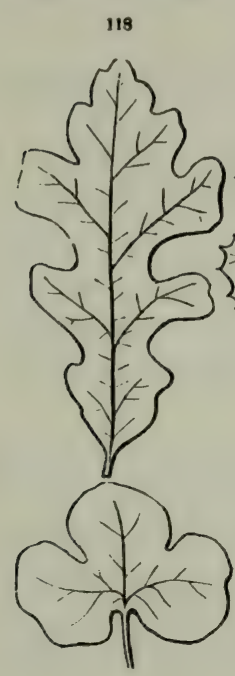

122

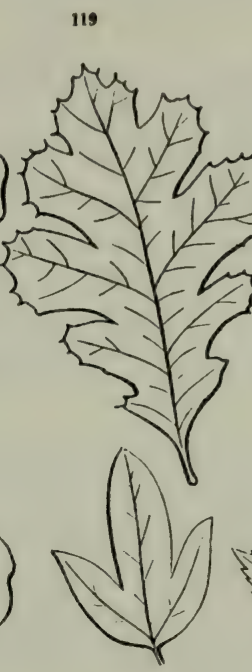

123

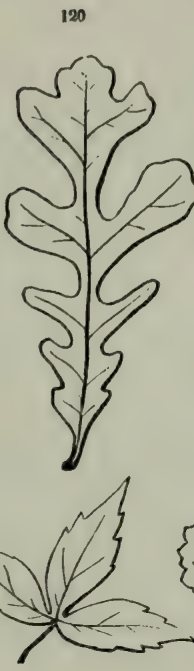

124
121
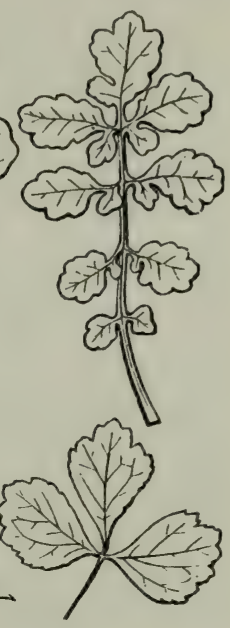

125

159. In the upper row the incisions all point towards the midrib, from which the main veins arise, the incisions (or sinuses) being between the main veins. That is, being pinnately veined, such leaves are pinnately lobed (Fig. 118), pinnately cleft, or pinnatifid (Fig. 119), pinnately parted (Fig. 120), or pinnately divided (Fig. 121), according to the depth of the incisions, as just defined.

160. In the lower row of figures, as the main veins or ribs all proceed from the base of the blade or the summit of the leaf-stalk, so the incisions all point in that direction. That is, palmately-veined leaves are palmately lobed (Fig. 122), palmately cleft (Fig. 123), palmately parted (Fig. 124), or palmately divided (Fig. 125). Sometimes, instead of palmately, we say digitately cleft, \&c., which means just the same.

161. To be still more particular, the number of the lobes, \&c. may come into the phrase. Thus, Fig. 122 is a palmately threelobed ; Fig. 123, a palmately three-cleft ; Fig. 124, a palmately threeparted; Fig. 125, a palmately three-divided, or trisected, leaf. The

FIG, 118-121. Pinnately lobed, cleft, parted, and divided leaves.

FIG. 122-125. Palmately or digitately lobed, cleft, parted, and divided leaves. 
Sugar-Maple and the Buttonwood (Fig. 50) lave palmately fivelobed leaves; the Soft White-Maple palmately five-parted leaves; and so on. And in the other sort, the Post-Oak has pinnately sevento nine-lobed leaves; the Red-Oak commonly has pinnutely seven- to nine-cleft leaves, \&c., \&c.

162. The divisions, lobes, \&c. may themselves be entire (without teeth or notches, 156), as in Fig. 118, 122, \&c.; or serrate (Fig. 124), or otherwise toothed or incised (Fig. 121); or else lobed, cleft, parted, \&c.: in the latter cases making twice pinnatifid, twice palmately or pinnately lobed, parted, or divided leaves, \&c. Fron these illustrations, the student will perceive the plan by which the botanist, in two or three words, may describe any one of the almost endlessly diversified shapes of leaves, so as to convey a perfectly clear and definite idea of it.

163. Compound Leaves. These, as already stated (155), do not differ in any absolute way from the divided form of simple leaves. A compound leaf is one which has its blade in two or more entirely separate parts, each usually with a stalk let of its own : and the stalklet is often jointed (or articulated) with the main leaf-stalk, just as this is jointed with the stem. When this is the case, there is no

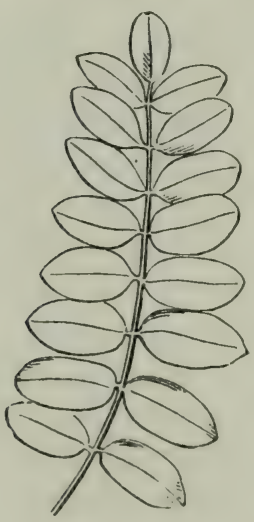

126

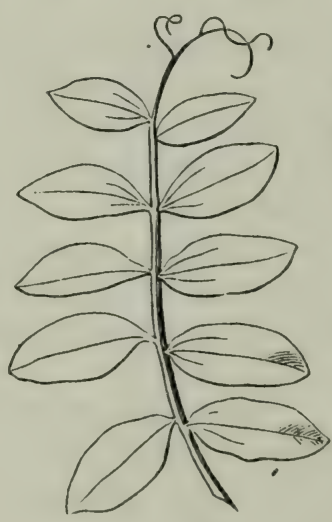

127

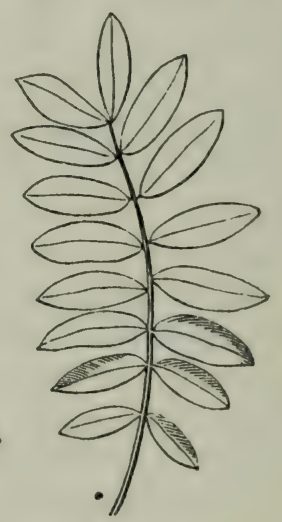

128

doubt that the leaf is compound. But when the pieces have no stalklets, and are not jointed with the main leaf-stalk, the leaf may be considered either as simple and divided, or compound, according to the circumstances.

FIG. 126. Pinnate with an odd leaflet, or odd-pimnate. 127. Pinnate witl: a tendrit 128. Abruptly pinnato leaf. 
164. The separate pieces or little blades of a compound leaf are called leaflets.

165. Compound leaves are of two principal kinds, namely, the pinnate and the palmate; answering to the two modes of veining in reticulated leaves $(145-147)$, and to the two sorts of lobed or divided leaves $(158,159)$.

166. Pinnate leaves are those in which the leaflets are arranged on the sides of a main leaf-stalk; as in Fig. 126-128. They answer to the feather-veined (i. e. pinnately-veined) simple leaf; as will be seen at once, on comparing Fig. 126 with the figures 118 to 121. The leaflets of the former answer to the lobes or divisions of the latter; and the continuation of the petiole, along which the leaflets are arranged, answers to the midrib of the simple leaf.

167. Three sorts of pinnate leaves are here given. Fig. 126 is pinnate with an odd or end leafet, as in the Common Locust and the Ash. Fig. 127 is pinnate with a tendril at the end, in place of the odd leaflet, as in the Vetches and the Pea. Fig. 128 is almuptly pinnate, having a pair of leaflets at the end, like the rest of the leaflets ; as in the Honey-Locust.

168. Palmate (also named digitate) leaves are those in which the leaflets are all borne on the very tip of the leaf-stalk, as in the Iupine, the Common Clover (Fig. 136), t.e Virginia Creeper (Fig. 62), and the Horsechestnut and Buckeye (Fig. 129). They answer to the radiate-veined or palmatelyveined simple leaf; as is seen by comparing Fig. 136 with the figures 122 to 125 . That is, the Cloverleaf of three leaflets is the same as a palmately three-ribbed leaf cut into three separate leaflets. And such a simple five-lobed leaf as that of the Sugar-Maple, if more cut, so as to separate the parts, would produce a palmate leaf of five leaflets,

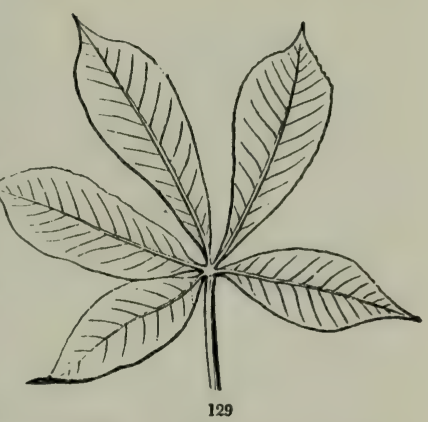
like that of the Horsechestnut or Buckeye (Fig. 129).

169. Either sort of compound leaf may have any number of leaflets; though palmate leaves cannot well have a great many, since they are all crowded together on the end of the main leaf-stalk.

FIG. 129. Palmate leaf of five leaflets, of the Sweet Buckeye. 
Some Lupines have nine or eleven; the Horsechestnut has seven, the Sivect Buckeye more commonly five, the Clover three. A pinnate leaf often has only seven or five leaflets, as in the Wild Bean or Groundnut; and in the Common Bean it has only three; in

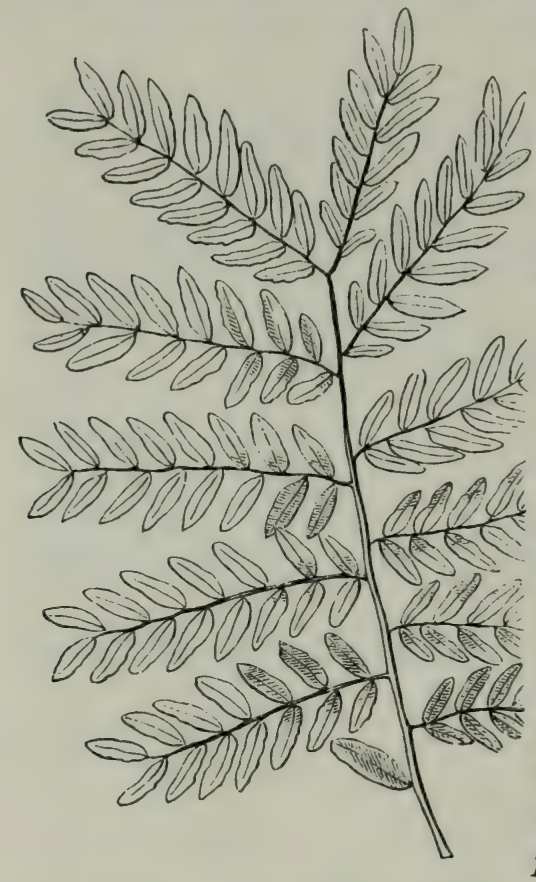

130 some rarer cases only two ; in the Orange and Lemon only one! The joint at the place where the leaflet is united with the petiole alone distinguishes this last case from a simple leaf.*

170. The leaflets of a compound leaf may be either entire (as in Fig. 126-128), or serrate, or lobed, cleft, parted, \&c. : in fact, they may present all the variations of simple leaves, and the sane terms equally apply to them.

171. When this division is carried so far as to separate what would be one leaflet into two, three, or several, the leaf becones doubly or twice compound, either pinnately or palmately, as the case may be. For example, while some of the leaves of the IIoney-Locust are simply pinnate, that is, once pinnate, as in Fig. 128, the greater part

* When the botanist, in descriling leaves, wishes to express the number of leaflets, he may use terms like these :-

Unifolivalc, for a compound leaf of a single leaflet; from the Latin unum, ono. and fuliulum, leaflet.

Bifoliolate, of two leaftets, from the Latin bis, twiec, and foliolum, lenflet.

Trifoliolate (or ternate), of three leaflets, as the Clover; and so on.

When he would express in one phrase both the number of leaflets and the way the leaf is compound, he writes :-

Palmately bifuliulate, trifuliolute, plurifoliolate (of several leaflets), \&c., or else

Pimately bi-, tri-, quadiri-, or pluri-foliolate (that is, of two, three, four, five, or sereral leaflets), as the case may be. 
are bipinnate, i. e. twice pinnate, as in Fig. 130. If these leaflets were again divided in the same way, the leaf would become thrice pinnate, or tripinnate, as in many Acacias. The first divisions are called pinna; the others, pinnules; and the last, or little blades, leaflets.

172. So the palmate leaf, if again compounded in the same way, becomes twice palmate, or, as we say when the divisions are in threes, twice ternate (in Latin form biternate) ; if a third time compounded, thrice ternate or triternate. But if the division goes still further, or if the degree is variable, we simply say that the leaf is decompound; either palmately or pinnately so, as the case may be. Thus, Fig. 138 represents a four times ternately compound, in other words a ternately decompound, leaf of our common Meadow Rue.

173. So exceedingly various are the kinds and shapes of leaves, that we have not yet exhausted the subject. We have, however, mentioned the principal terms used in describing them. Many others will be found in the glossary at the end of the volume. Some peculiar sorts of leaves remain to be noticed, which the student might not well understand without some explanation; such as

174. Perfolinte Leaves. A common and simple case of this sort is found in two species of Uvularia or Bellwort, where the stem appears to run through the blade of the leaf, near one end. If we look at this plant in summer, after all the leaves are formed, we may see the meaning of this at a glance. For then we often find upon the same stem such a series of leaves as is given in Fig. 131 : the lower leaves are perfoliate, those next above less so; then some (the fourth and fifth) with merely a heart-shaped clasping base, and finally one that is merely sessile. The leaf, we perceive, becomes perfoliate by the union of the edges of the base with each other around the stem ; just as the shield-shaped leaf, Fig.

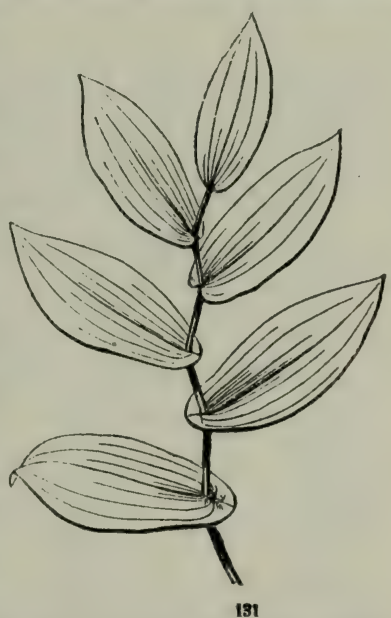
102, comes from the union of the edges of the base of such a leaf as Fig. 101. Of the same sort are the upper leaves of most of

FIG. 131. Leaves of Uvularia (Bellwort); the lower ones perfoliate, the othery merely clasping, or the uppermost only sessile. 
the true IIoneysuckles (Fig. 132): but here it is a pair of opposite leaves, with their contiguons broad hases grown together, which makes what seems to be one round leaf, with the stem running through its centre. This is seen to be the case, by comparing together the upper and the lowest leaves of the same branch. Leaves of this sort are said to be connate-perfoliate.

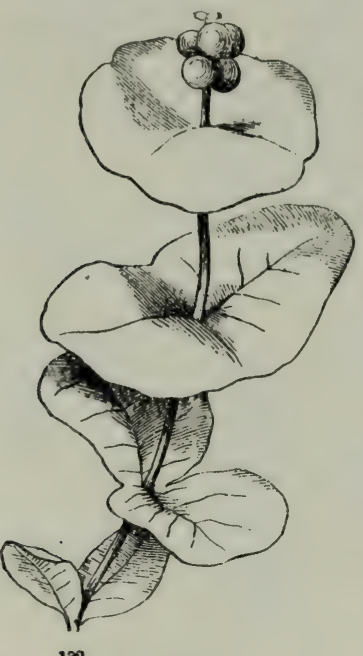

175. Equitaut Lutres. While ordinary leaves spread horizontally, and present one face to the sky and the other to the earth, there are some that present their tip to the sky, and their faces right and left to the horizon. Among these are the equitant leaves of the Iris or Flower-de-Luce. On careful inspection we shall find that each leaf was formed folded together lengthwise, so that what would be the upper surface is within, and all grown together, except next the bottom, where each leaf covers the next younger one. It was from their straddling over each other, like a man on horseback (as is seen in the cross-section, Fig. 134), that Linnous, with his lively fancy, called these equitant leaves.

176. Leaves with 10 distinction of Petiole and Blade. The leaves of Iris just mentioned show one form of this. 'The flat but narrow leaves of Jonquils, Daffodils, and the like, are other instances. Needle-shaped leaves, like those of the Pine (Fig. 140), Larch (Fig. 139), and Spruce, and the awl-shaped as well as the scale-shaped leaves of Junipers, Red Ce-

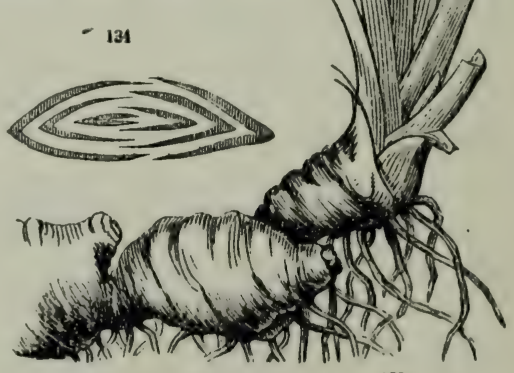

133

FIG. 132. Branch of a Yollow Honeysuckle, with connate-perfoliate leaves.

FIG. 133. Roctstock and equitant leaves of Iris. 134. A soction across the cluster of leaves at the bottum. 
dar, and Arbor-Vita (Fig. 135), are different examples. These last are leaves serving for foliage, but having as

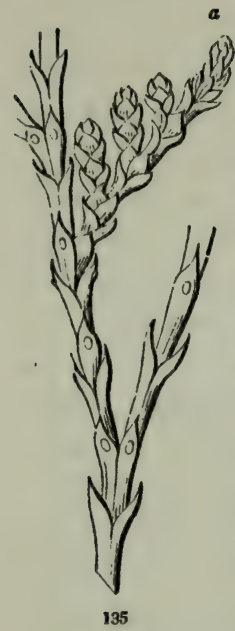
little spread of surface as possible. They make up for this, however, by their immense numbers.

177. Sometimes the petiole expands and flattens, and takes the place of the blade; as in numerous New IIolland Acacias, some of which are now common in greenhouses. Such counterfeit blades are called phyllodia, - meaning leaf-like bodies. They may be known from true blades by their standing edgewise, their margins being directed upwards and downwards; while in true blades the faces look upwards and downwards; excepting in equitant leaves, as alrearly explained, and in those which are turised edgewise by a twist, such as those of the Callistemon or Bottle-brush Flower of our greenhouses, and other Dry Myrtles of New Holland, \&c.

178. Stipules, the pair of appendages which is found at the base of the petiole in many leaves (133), should also be considered in respect to their very varied forms and appearances. More commonly they appear like little blades, on each side of the leaf-stalk, as in the Quince (Fig. 83), and more strikingly in the Hawthorn and in the Pea. Here they remain as long as the rest of the leaf, and serve for the same purpose as the blade. Very commonly they serve for bud-scales, and fall off when the leaves expand, as in the Fig-tree,

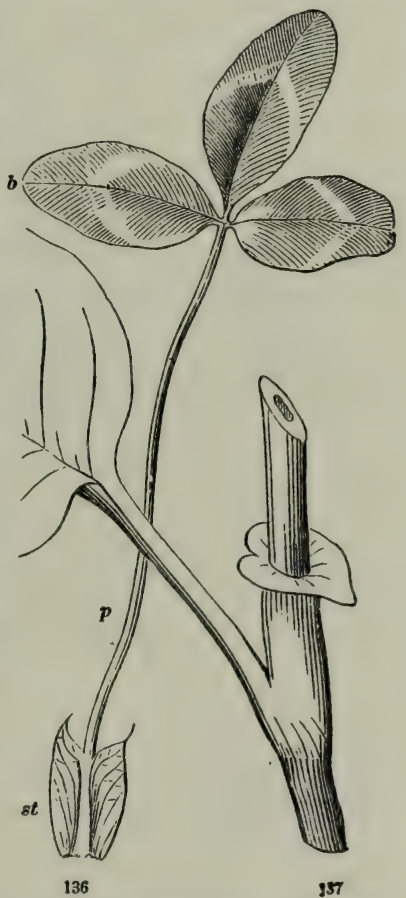
and the Magnolia (where they are large and conspicuous), or soon

FIG. 135. Twig of Arbor-Vitre, with its two sorts of leaves: viz. some awl-shaped, the others scale-like; the latter on the branchlets, $a$.

FIG. 136. Leaf of Red Clover : st, stipules, adhering to the base of $p$, the petiole : $b$, blade of three leaflets.

FIG. 137. Part of stem and leaf of Prince'g-Feather (Polygonum orientale) with the united sheathing etupules forming a sherth. 
afterwards, as in the Tulip-tree. In the Pea the stipules make a very conspicuous part of the leaf; while in the Bean they are quite small; and in the Locust they are reduced to bristles or prickles. Sometimes the stipules are separate and distinct (Fig. 83): often they are united with the base of the leaf-stalk, as in the Rose and the Clover (Fig. 136): and sometimes they grow together by both margins, so as to form a sheath around the stem, above the leaf, as in the Buttonwood, the Dock, and almost all the plants of the Polygonum Family (Fig. 137).

179. The sheaths of Grasses bear the blade on their summit, and therefore represent a form of the petiole. The small and thin appendage which is commonly found at the top of the sheath (called a ligule) here answers to the stipule.

FIG. 138. 'Ternately-ilecompound leaf of Moadow Rue (Thalictrum Cornuti).

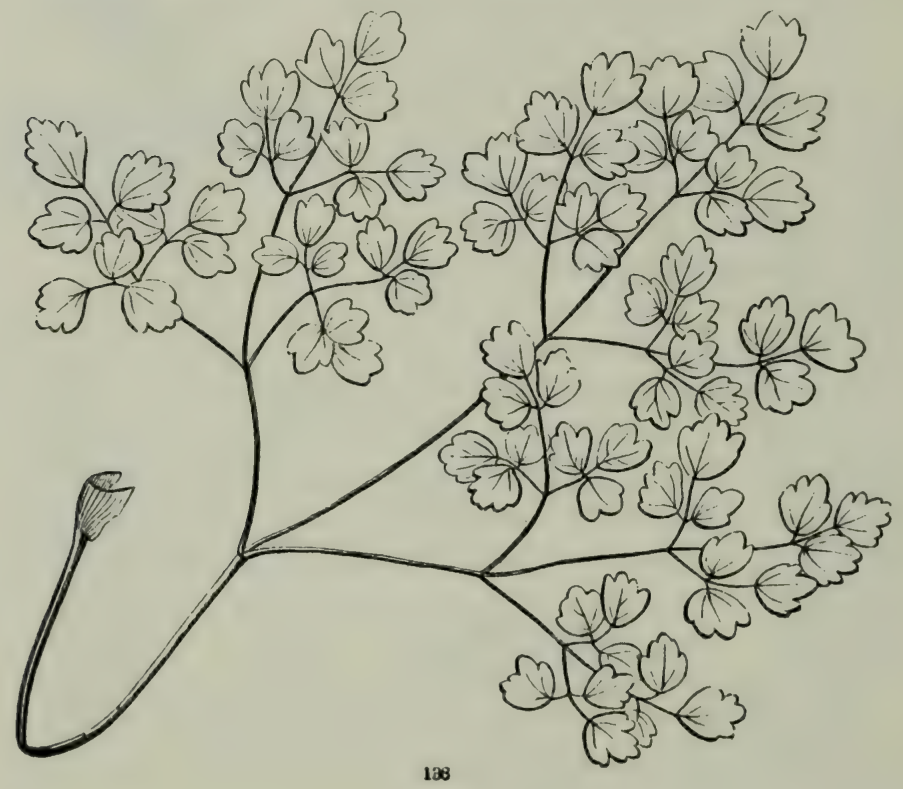




\section{LESSON $\mathrm{X}$.}

\section{THF ARRANGEMENT OF LFAVES.}

180. UNDre this head we may consiler, - 1. the arrangement of leaves on the stem, or what is sometimes called PryLtotaxy (from two Greek words meaning leaf-order); and 2. the ways in which they are packed together in the bud, or their vernation (the word meaning their spring state).

181. Phyllotaxy. As already explained (48, 49), leaves are arranged on the stem in two principal ways. 'They are either

Alternate (Fig. 131, 143), that is, one after another, only a single leaf arising from each node or joint of the stem; or

Opposite (Fig. 147), when there is a pair of luaves on each joint of the stem; one of the two leaves being in this case always situated exactly on the opposite side of the stem from the other. A third, but uncommon arrangement, may be added ; namely, the

Whorled, or verticillate (Fig. 148), when there are three or more leaves in a circle (whorl or verticil) on one joint of stem. But this is only a variation of the opposite mode; or rather the latter arrangement is the same as the whorled, with the number of the leaves reduced to two in each whorl.

182. Only one leaf is ever produced from the same point. When two are borne on the same joint, they are always on opposite sides of the stem, that is, are scparated by half the circumference; when in whorls of three, four, five, or any other number, they are equally distributed around the joint of stem, at a distance of one third, one fourth, or one fifth of the circumference from each other, according to their number. So they always have the greatest possible divergence from each other. Two or more leaves belonging to the same joint of stem never stand side by side, or onc above the other, in a cluster.

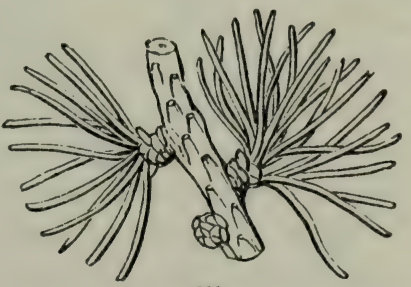

139

183. What are called clustered or fascicled leaves, and which 
appear to be so, are always the leaves of a whole branch which remains so very short that they are all crowded together in a bundle or rosette; as in the spring leaves of the Barberry and of the Larch (Fig. 139). In these cases an examination shows them to be nothing else than alternate leaves, very much crowded on a short spur; and some of these spurs are seen in the course of the season to lengthen into ordinary shoots with scattered alternate leaves. So, likewise, each cluster of two or three needle-shaped leaves in Pitch P'ines (as in Fig. 140), or of five leaves in White Pine, answers to a similar, extremely short branch, springing fiom the axil of a thin and slender scale, which represents a leaf of the main shoot. For Pines produce two kinds of leaves; -1 . primary, the proper leaves of the shoots, not as foliage, but in the shape of delicate scales in spring, which soon fall away; and 2. secondary, the fascicled leaves, from buds in the axils of the former, and these form the actual foliage.

184. Spiral Arringement of Leares. If we examine any alternate-leaved stem, we shall find that the leaves are placed upon it in symmetrical order, and in a way perfectly uniform for each species, but different in different plants. If we draw a line from the insertion (i. e. the point of attachment) of one leat to that of the next, aum so on, this line will wimd spirally around the stem as it rises, and in the same species will always have just the same number of leaves upon it for each turn round the stem. That is, any two suceessive leaves will always be separated from each other by just an equal portion

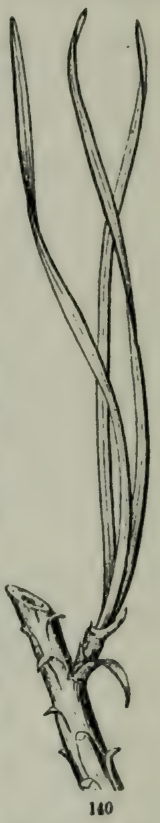
of the circumference of the stem. The distance in lecight between any two leaves may vary greatly, even on the same shoot, for that depends upon the length of the internodes or spaces between each leaf; but the distance as measured around the circumference (in other words, the angulur divergence, or angle formed by any two successive leaves) is uniformly the same.

185. The greatest possible divergence is, of course, where the second leaf stands on exactly the opposite side of the stem from the first, the third on the side opposite the second, and therefore over the

FIG. 140. Piece of a branchlet of Pitch Pine, with three leaves in a fancicle or hundle, in the axil of a thin scale wlich answers to a primary leaf. Tho bundle is surrounded at the base by a short sheath, formed of the delicate scales of the axillary bud. 
first, and the fourth over the second. This brings all the leaves into two ranks, one on one side of the stem and one on the other; and is therefore called the two-ranked arrangement. It occurs in all Grasses, - in Indian Corn, for instance; also in the Spiderwort, the Bellwort (Fig. 131) and Iris (Fig. 132), in the Basswood or Limetree, \&c. This is the simplest of all arrangements.

186. Next to this is the three-ranked arrangement, such as we sce in Serlges, and in the Veratrum or White IIellebore. The plan of it is shown on a Sedge in Fig. 141, and in a diagram or crosssection underneath, in Fig. 142. Here the second leaf is placed one third of the way round the stem, the third leaf two thirds of the way round, the fourth leaf accordingly directly over the first, the fifth over the second, and so on. That is, three leaves occur in each turn round the stem, and they are separated from each other by one third of the circumference.

187. The next and one of the most common is the five-ranked arrangement; which is seen in the Apple (Fig. 143), Cherry, Poplar, and the greater part of our trees and shrubs. In this case the line traced from leaf to leaf will pass twice round the stem before it reaches a leaf situated directly over any below (Fig. 144). Here the sixth leaf is over the first; the leaves stand in five perpendicular ranks, equally distant from each other; and the distance between any two successive leaves is just two fifths of the circumference of the stem.

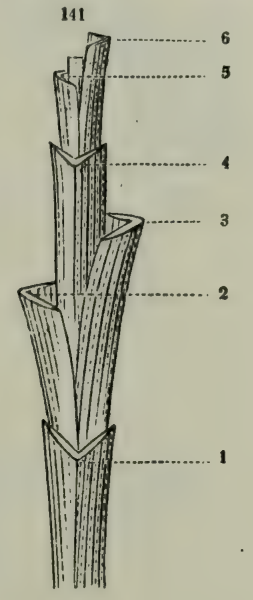

188. The five-ranked arrangement s expressed by the fraction $\frac{2}{5}$. This fraction denotes the divergence of the successive leaves, $i . e$. the angle they form with each other: the numerator also expresses the number of turns made round the stem by the spiral line in completing one cycle or set of leaves, namely $\tilde{a}$; and the denominator gives the number of leaves in each cycle, or the number of perpendicular

FIG. 141. Piece of the atalk of a Eedge. with the leaves cut away, leaving their bases: the leaves are numbered in order. from: to 6. 142. Diagram or cross-section of the same, all in one plane; the :eaves frumlarly numbered. 
ranks, namely 5 . In the same way the fraction $\frac{1}{2}$ stands for the two-ranked morle, and $\frac{1}{f}$ for the three-ranked: and so theso different
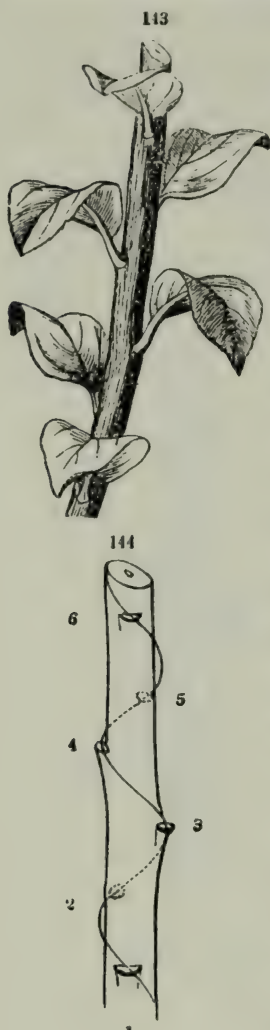

1

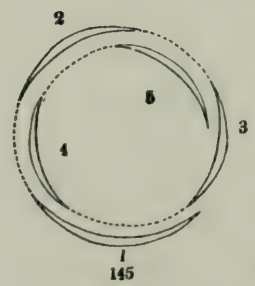
sorts are expressed by the series of fractions $\frac{1}{2}$, $\frac{1}{3}$, $\frac{2}{5}$. And the other cases known follow in the same numerical progression.

189. The next is the eight-ranked arrangement, where the ninth leaf stands over the first, and three turns are made around the stem to reach it; so it is expressed by the fraction $\frac{3}{8}$. This is seen in the Holly, and in the common Plantain. Then comes the thirteen-ranked arrangement, in which the fourteenth leaf is over the first, after five turns around the stem. Of this we have a good example in the common IIouscleck (Fig. 146).

190. The series so far, then, is $\frac{1}{2}, \frac{1}{3}, \frac{2}{5}, \frac{3}{8}, \frac{5}{13}$; the numerator and the denominator of each fraction being those of the two next preceding ones added together. At this rate the next higher slould be $\frac{8}{2}$, then $\frac{1}{3} \frac{3}{3}$, and so on; and in fact just such

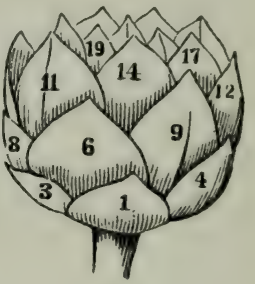

146 cases are met with, and (commonly) no others. These higher sorts are found in the Pine Family, both in the leaves and the cones (Fig. 324), and in many other plants with small and crowded leaves. But the number of the ranks, or of leaves in each cycle, can here rarely be made out by direct inspection: they may be ascertained, however, by certain simple mathematical computations, which are rather too technical for these Lessons.

FIG. 143. Sloot with its loaves 5-ranked, the sixth leaf over the first ; as in the Apple-troe. I'l(s. 144. Diagran of the arrangenent, with a spiral line drawn from the attachment of. one leaf to the noxt, and so on; the parts on the side turned from the eye are fainter.

FIG. 145. A gromul-plan of the same; the section of the leaves similarly numbered; a dotfed line drawn from the edge of one leaf to that of the next completes the spiral.

rils. 146. A young plant of the Honseleek, with the leaves (not yet expanded) numbered, and exhibuing the 13-ranked arrangement 
191. The nrrangement of opposite leaves (181) is usually very simple. The second pair is placed over the intervals of the first; the third over the intervals of the second, and so on (Fig. 147); the successive pairs thus crossing each other, commonly at right angles, so as to make four upright rows. And whorled leaves (Fig. 148) follow a similar plan.

192. So the place of every leaf on every plant is fixed beforehand by unerring mathematical rule. As the stem grows on, leaf after leaf appears exactly in its predestined place, producing a perfect symmetry; - a symmetry which manifests itself not in one single monotonous pattern for all plants, but in a definite number of forms exhibited by different species, and arithmetically expressed by the series of frac-

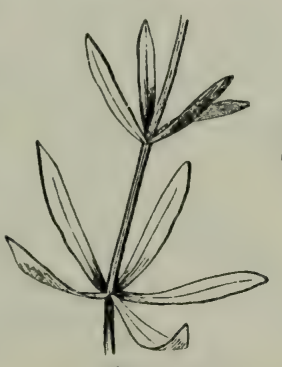

148

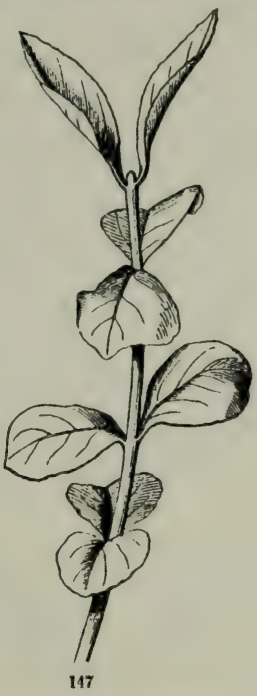
tions, $\frac{1}{2}, \frac{1}{3}, \frac{2}{5}, \frac{3}{8}, \frac{5}{13}, \frac{8}{2} 1$, \&c., according as the formative energy in its spiral course up the developing stem lays down at corresponding intervals $2,3,5,8,13$, or 21 ranks of alternate leaves.

193. Vernation, sometimes called Prafoliation, relates to the way in which leaves are disposed in the bud (180). It comprises two things ; -1 st, the way in which each separate leaf is folded, coiled, or packed up in the bud; and $2 d$, the arrangement of the leaves in the bud with respect to one another. The latter of course depends very much upon the phyllotaxy, i. e. the position and order of the leaves upon the stern. The same terms are used for it as for the arrangement of the leaves of the flower in the flower-bud: so we may pass them by until we come to treat of the flower in this respect.

194. As to each leaf separately, it is sometimes straight and open in vernation, but more commonly it is either bent, folded, or rolled up. When the upper part is bent down upon the lower, as the young blade in the Tulip-tree is bent upon the leafstalk, it is said to be inflexed or reclined in vernation. When folded

FIG. 147. Opposite leaves of the Epindle-tree or Burning-bush.

FIf. 148. Whorled or verticillate leaves of Galium or Bedstraw. 
by the midrib so that the two halves are placed face to face, it is conduplicute (Fig. 149), as in the Magnolia, the Cherry, and the Oak : when folded back and forth like the plaits of a fan, it is plicate or plaited (Fig. 150), as in the Maple and Currant. If rolled, it may be so either from the tip downwards, as in Ferns and the Sundew (Fig. 154), when in unrolling it resembles the head of a crosier, and is said to be circinate; or it may be rolled up parallel with the axis, either from one edge into a coil, when it is convolute (Fig. 151), as in the Apricot and Plum, or rolled f:om both edges towards the midrib; - sometimes inwards, when it is involute (Fig. 152), as in the Violet and Water-Lily; sometimes outwards, when it is revolute (Fig. 153), in the Rosemary and Azalea. The figures are diagrams, representing sections through the leaf, in the way they were represented by Linnæus.

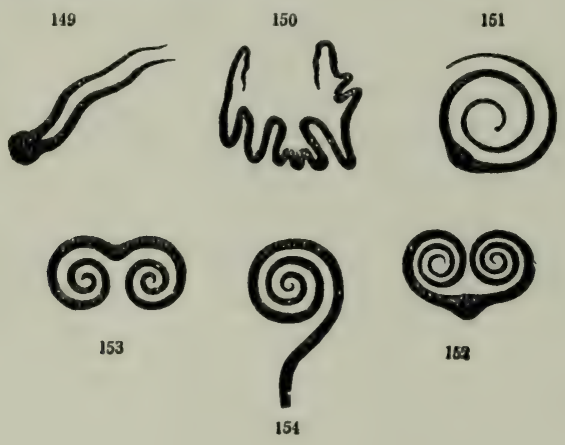

LESSON XI.

THE ARR.ANGEMENT OF FLOWLRS ON THE STEM, OR INFLO.

RESCENCE.

195. Thus far we have been considering the vegetation of the plant, and studying those parts, viz. root, stem, and leaves, by which it increases in size and extent, and serves the purpose of its individual life. But after a time each plant produces a different set of organs, - viz. flowers, fruit, and seed, - subservient to a different purpose, that is, the increase in numbers, or the continuance of the 
species. The plant reproduces itself in new individuals by seed. Therefore the seed, and the fruit in which the seed is formed, and the flower, from which the fruit results, are named the Organs of Reproduction or Fructification. These we may examine in succession. We begin, of course, with the flower. And the first thing to consider is the

196. Inflorescence, or the mode of flowering, that is, the situation and arrangement of blossoms on the plant. Various as this arrangement may seem to be, all is governed by a simple law, which is easily understood. As the position of every leaf is fixed beforehand by a mathematical law which prescribes where it shall stand (192), so is that of every blossom; - and by the same law in both cases. For flowers are buds, developed in a particular way; and flowerbuds occupy the position of leaf-buds, and no other As leaf-buds are either terminal (at the summit of a stem or branch, 42), or axillary (in the axil of a leaf, 43), so likewise

197. Flowers are either terminal or axillary. In blossoming as in regetation we have only buds terminating (i. e. on the summit of) stems or branches, and buds from the axils of leaves. But while the same plant commonly produces both kinds of leaf-buds, it rarely bears flowers in both situations. These are usually either all axillary or all terminal; - giving rise to two classes of inflorescence, viz. the determinate and the indeterminate.

198. Indeterminate Inflorescence is that where the flowers all arise from axillary buds; as in Fig. 155, 156, 157, \&c.; and the reason why it is called indeterminate (or indefinite) is, that while the axillary buds give rise to flowers, the terminal bud goes on to grow, and continues the stem indefinitely.

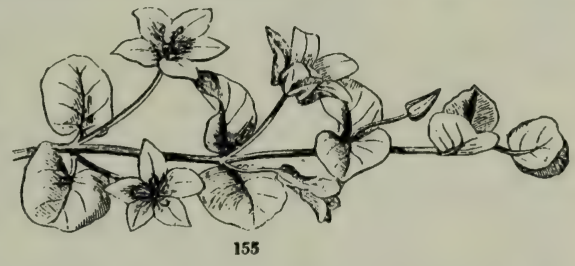

199. Where the flowers arise, as in Fig. 155, singly from the axils of the ordinary leaves of the plant, they do not form flower, clusters, but are axillary and solitary. But when several or many flowers are produced near each other, the accompanying leaves are usually of smaller size, and often of a different shape or character: then they are called bracts; and the flowers thus brought together 
form one cluster or inflorescence. The sorts of inflorescence of the indeterminate class which have received separate names are chiefly the following: viz. the Raceme, the Corymb, the Umbel, the Spike, the Head, the Spadix, the Catkin, and the Panicle.

200. Before illustrating these, one or two terms, of common occurrence, may be defined. A flower (or vilier body) which has no stalk to support it, but which sits directly on the stem or axis it proceeds from, is said to be sessile. If it has a stalk, this is called its peduncle. If the whole flower-cluster is raised on a stalk, this is called the peduncle, or the common peduncle (Fig. 156, $p$ ); and the

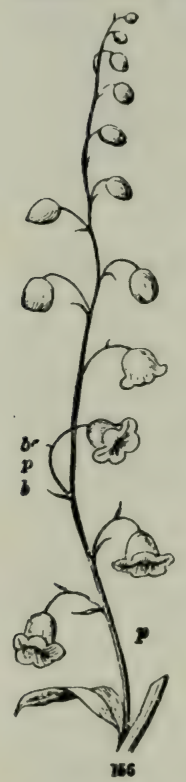
stalk of each particular flower, if it have any, is called the pedicel or partial peduncle $\left(p^{\prime}\right)$. The portion of the general stalk along which flowers are disposed is called the axis of inflorescence, or, when covered with sessile flowers, the rhachis (back-bone), and sometimes the receptacle. The leaves of a flowercluster generally are termed bracts. But when we wish particularly to distinguish them, those on the peduncle, or main axis, and which have a flower in their axil, take the name of bracts (Fig. 156, b) ; and those on the pedicels or partial flower-stalks, if any, that of bractlets (Fig. 156, $b^{\prime}$ ).

201. A Raceme (Fig. 156,157) is that form of flowercluster in which the flowers, each on their own footstalk or pedicel, are arranged along a common stalk or axis of inflorescence; as in the Lily of the Valley, Currant, Choke-Cherry, Barberry, \&c. Each flower comes from the axil of a small leaf, or bract, which, however, is often so small that it might escape notice, and which sumetimes (as in the Mustard Family) disappears altogether. The lowest blossoms of a raceme are of course the oldest, and therefore open first, and the order of blossoming is ascerding, from the bottom to the top. The summit, never being stopped by a terminal flower, may go on to grow, and often does so (as in the common Shepherd's Purse), producing lateral flowers one after another the whole summer long.

202. All the various kinds of flower-clusters pass one into another

FIG. 156 A Raceme, with a general pedunclo $(p)$, pedicels $\left(\mu^{\prime}\right)$, bracts $(b)$, and bractbets $\left(b^{\prime}\right)$. 
by intermediate gradations of every sort. For instance, if we (lengthen the lower pedicels of a raceme, and keep the main axis rather short, it is converted into

203. A Corymb (Fig. 158). This is the same as a raceme, except that it is flat and broad, either convex, or level-topped,) as in the Hawthorn, owing to the lengthening of the lower pedicels while the uppermost remain shorter.

204. The main axis of a corymb is short, at least in comparison with the lower pedicels. Only suppose it to be so much contracted that the bracts are all brought into a cluster or circle, and the corymb becomes

205. An Umbel (Fig. 159), - as in the Milkweed and Primrose, - a sort of flower-cluster where the pedicels all spring apparently from the same point, from the top of the peduncle, so as to resemble, when spreading, the rays of an umbrella, whence the name.) Here the pedicels are sometimes called the rays of the umbel. And the bracts, when brought in this way into a cluster or circle, form what is called an involucre.

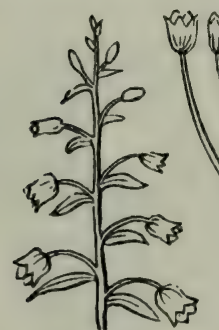

157

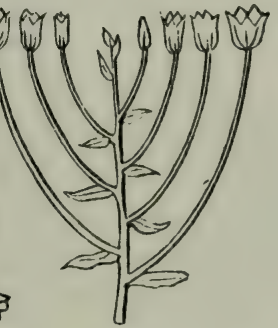

158

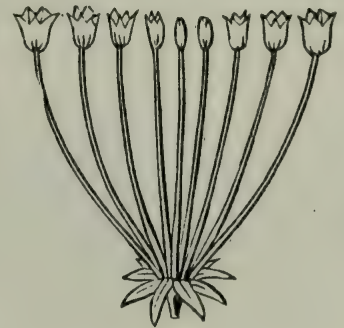

159

206. For the same reason that the order of blossoming in a ra. ceme is ascending (201), in the corymb and umbel it is centripetal, that is, it proceeds from the margin or circumference regularly towards the centre; the lower flowers of the former answering to the outer ones of the latter. Indeterminate inflorescence, therefore, is said to be centripetal in evolution. And by having this order of blossoming, all the sorts may be distinguished from those of the other, or the determinate class. In all the foregoing cases the flowers are raised on pedicels. These, however, are very short in many instances, or are wanting altogether; when the flowers are sessile $(200)$. They are so in

F1G. 157. A raceme. 158 A corymh. 159. An umbed. 
207. The Spilie. This is a flower-cluster with a more or less lengthened axis, along which the flowers are sessile or nearly so tas in the Mullein and the Plantain (Fig. 160). It is just the same as a raceme, therefore, without any pedicels to the flowers.

208. The llead is a round or roundish cluster of flowers which are sessile on a very short axis or receptacle) as in the Button-ball, Button-bush (Fig. 161), and Red Clover. It is just what a spike would become if its axis were shortened; or an umbel, if its pedicels were all shortened until the flowers became sessile or apparently so. The head of the Button-bush (Fig. 161) is naked; but that of the Thistle, of the Dandelion, the Cichory (Fig. 221), and the like, is surrounded by empty bracts, which form an involucre. Two particular forms of the spike and the head have received particular names, namely, the Spadix and the Catkin.

209. A Spadix is nothing but a fleshy spike or head, with small and often imperfect flowers, as in the Calla, the Indian Turnip
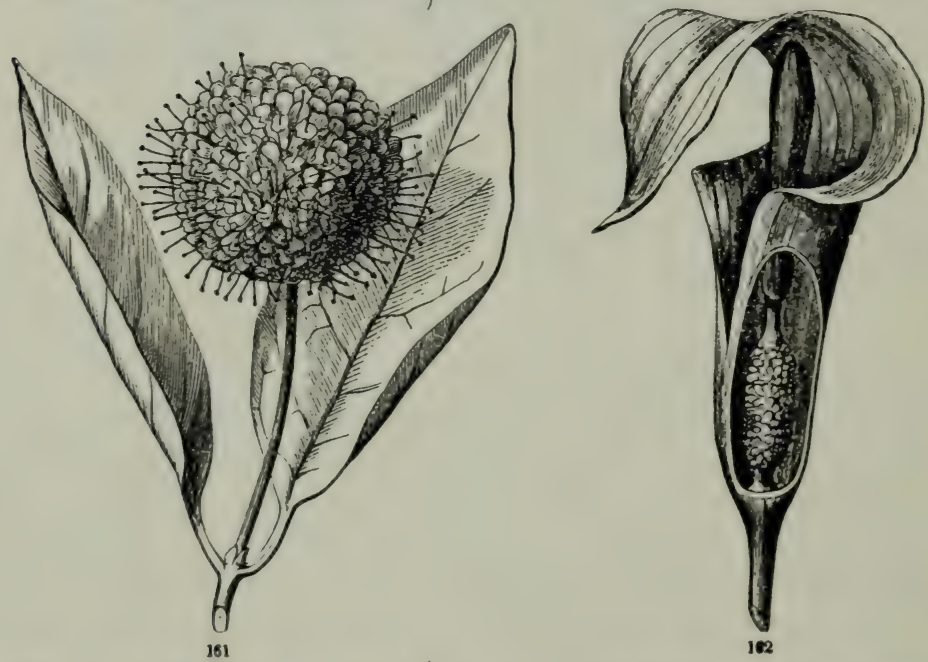

(Fig. 162), Sweet Flag, \&c. ' It is commonly covered by a peculias enveloping leaf, called a spathe.

FIG. 160. Spike of the common Plantain or Ribwort.

FIG. 161. Head of the Button-bush (Cephalanthus).

FIG. 162. Spadix and spathe of the Indian Turnip; the latter cut through below. 
210. A Catkin or Ament is the name given to the scaly sort of spike of the Birch and Alder, the Willow and Poplar, and one sort of flower-clusters of the Oak, Hickory, and the like; - on which account these are called Amentaceous trees.

211. Sometimes these forms of flower-clusters become compound. For example, the stalks which, in the simple umbel such as has been described (Fig. 159), are the pedicels of single flowers, may themselves branch in the same way at the top, and so each become the support of a smaller umbel; as is the case in the Parsnip, Caraway, and almost the whole of the great family of what are called Umbelliferous (i. e. umbel-bearing) plants. Here the whole is termed a compound umbel; and the smaller or partial umbels take the name in English of umbellets. The general involucre, at the base of the main umbel, keeps that name; while that at the base of each umbellet is termed a partial involucre or an involucel.

212. So a corymb (Fig. 158) with its separate stalks branching

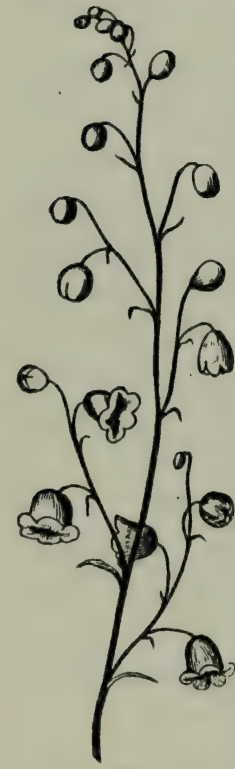

163 again, and bearing smaller clusters of the same sort, is a compound corymb; of which the Mountain Ash is a good example. A raceme where what would be the pedicels of single flowers become stalks, along which flowers are disposed on their own pedicels, forms a compound raceme, as in the Goat's-beard and the False Spikenard. But when what would have been a raceme or a corymb branches irregularly into an open and more or less compound flower-cluster, we have what is called

213. A Punicle (Fig. 163); as in the Oat and in most common Grasses. Such a raceme as that of the diagram, Fig. 156, would be changed into a panicle like Fig. 163, by the production of a flower from the axil of each of the bractlets $b^{\prime}$.

214. A Thyrsus is a compact panicle of a pyramidal or oblong shape; such as a bunch of grapes, or the cluster of the Lilac or IIorsechestnut.

215. Determinate Inflorescence is that in which the flowers are from terminal buds. The simplest case is where a stem bears a solitary, terminal flower, as in Fig. $163^{a}$. This stops the growth of 
the stem; for its terminal bud, being changed into a blossom, can no more lengthen in the manner of a leaf-bud. Any further growth
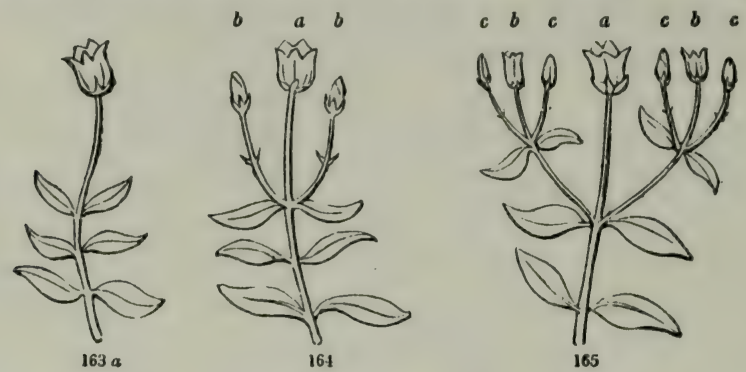

must be from axillary buds developing into branches. If such branches are leafy shoots, at length terminated by single blossoms, the inflorescence still consists of solitary flowers at the summit of the stem and branches. But if the flowering branches bear only bracts in place of ordinary leaves, the result is the kind of Hower-cluster called

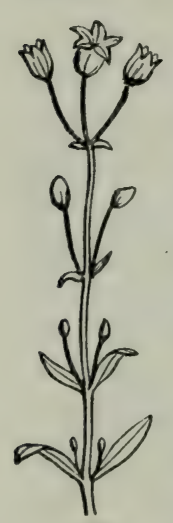

166

216. A Cyme. This is commonly a flat-topped or convex flower-cluster, like a corymb, only the blossoms are from terminal buds.) Fig. 164 illustrates the simplest cyme in a plant with opposite leaves, namely, with three flowers. The middle flower, $a$, terminates the stem; the two others, $b$ b terminate short branches, one from the axil of each of the uppermost leaves; and being later than the middle one, the flowering proceeds fiom the centre outwards, or is centrifugal; - just the opposite of the indeterminate mode, or that where all the flower-buds are axillary. If flowering branches appear from the axils below, the lower ones are the later, so that the order of blossoming continues centrifugal or descending (which is the same thing), as in Fig. 166, making a sort of reversed raceme; - a kind of cluster which is to the true raceme just what the flat cyme is to the corymb.

217. Wherever there are liacts or leaves, buds may be produced from their axils and appear as flowers. Fig. 165 represents the case where the branches, $b$, of Fig. 164, each with a pair of small

FIG. 163 a. Diagran of an opposite-leaved plant, with a single terminal flower. 164 Same, with a cyme of threo flowers; $a$, the first flower, of the main axis ; $b$, those of hranches 165. Same, with tluwers of the third order, c c. 166. Same, with flowers only of the second order from all the axils; the central or uppermost opening first, and so on downwards. 
leaves or bracts about their middle, have branched again, and produced the branchlets and flowers $c c$, on each side. It is the continued repetition of this which forms the full or compound cyme, such as that of the Laurustinus, Hobblebush, Dogwood, and Hydrangea (Fig. 167).

218. A Fascicle, like that of the Sweet-William and Lychnis of the gardens, (is only a cyme with the flowers much crowded, as it were, into a bundle.)

219. A Glomerule is a cyme still more compacted, so as to form a sort of head.) It may be known from a true head by the flowers not expanding centripetally, that is, not from the circumference towards the centre, or from the bottom to the top.

220. The illustrations of determinate or cymose inflorescence have been taken from plants with opposite leaves, which give rise to the most regular cymes. But the Rose, Cinquefoil, Buttercup, and the like, with alternate leaves, furnish equally good examples of this class of flower-clusters.

221. It may be useful to the student to exhibit the principal sorts of inforescence in one view, in the manner of the following

\section{Aualysis of Flower-Clusters.}

I. Indeterminate or Centripetal. (198.)

Simple; and with the

Flowers borne on pedicels,

Along the sides of a lengthened axis, RAceme, 201.

Along a short axis; lower pedicels lengthened, Convмв, 203.

Clustered on an extremely short axis, UMBEL, 205.

Flowers sessile, without pedicels (206),

Along an elongated axis, SPIKe, 207

On a very short axis, HeAd, 208.

Branching irregularly,

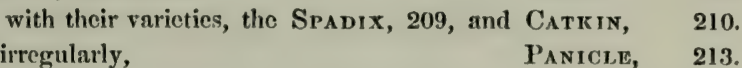

with its variety, the Tirnsus, 214.

II. Determinate or Centrifugat. (215.)

Open, mostly flat-topped or convex, Cуме, 216.

Contracted into a bundle, Fascicle, 218.

Contracted into a sort of head, Glomerule, 219.

222. The numbers refer to the paragraphs of this Lesson. The various sorts run together by endless gradations in different plants. The botanist merely designates the leading kinds by particular names. Even the two classes of inflorescence are often found com. bined in the same plant. For instance, in the whole Mint Family, 
the flower-clusters are centrifugal, that is, are cymes or fascicles; but they are themselves commonly disposed in spikes or racemes, which are centripetal, or develop in succession from below upwards.

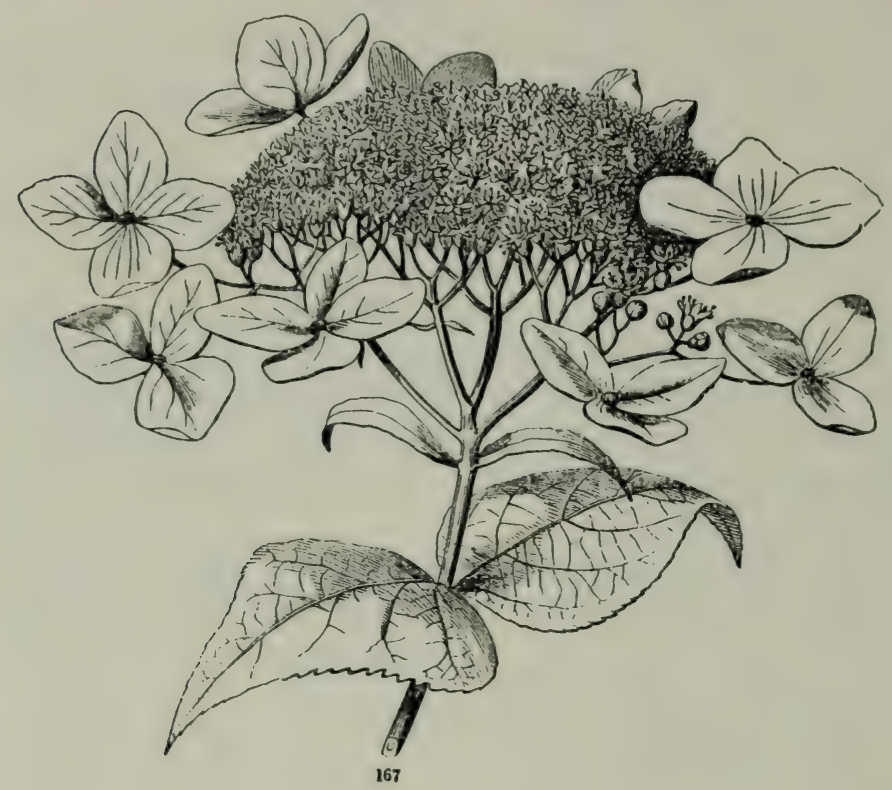

\section{LESSON XII.}

THE FLOWER: ITS PARTS OR ORGANS.

223. Having considered, in the last Lesson, the arrangement of flowers on the stem. or the places from which they arise, we now direct our attention to the flower itself.

224. Nature and Use of the Flower. The olject of the flower is the production of seed. The flower consists of all those parts, or organs, which are subservient to this end. Some of these parts are necessary to the production of seed. Other's serve merely to protect or support the more essential parts.

FIG. 167. Cyme of the Wild Hydrungea (with neutral flowers in the border). 
225. The Organs of the Flower are therefore of two kinds; namely, first, the protecting organs, or leaves of the flower, - also called the floral envelopes, - and, second, the essential organs. The latter are situated within or a little above the former, and are enclosed by them in the bud.

226. The Floral Envelopes in a complete flower are double ; that is, they consist of two whorls (181), or circles of leaves, one above or within the other. The outer set forms the Calyx; this more commonly consists of green or greenish leaves, but not always. The inner set, usually of a delicate texture, and of some other color than green, and in most cases forming the most showy part of the blossom, is the Corolla.

227. The floral envelopes, taken together, are sometimes called the Perianth. This name is not much used, however, except in cases where they form only one set, at least in appearance, as in the Lily, or where, for some other reason, the limits between the calyx and the corolla are not easily made out.

228. Each leaf or separate piece of the corolla is called a Petal; each leaf of the calyx is called a Sepal. The sepals and the petals - or, in other words, the leaves of the blossom - serve to protect, support, or nourish the parts within. They do not themselves make a perfect flower.

229. Some plants, however, naturally produce, besides their perfect flowers, others which consist only of calyx and corolla (one or both), that is, of leaves. 'These, destitute as they are of the essential organs, and incapable of producing seed, are called neutral flowers. We have an example in the flowers round the margin of the cyme of the Hydrangea (Fig. 167), and of the Cranberry-Tree, or Snowball, in their wild state. By long cultivation in gardens the whole cluster' has been changed into showy, but useless, neutral flowers, in these and some other cases. What are called double flowers, such as full Roses (Fig. 173), Buttercups, and Camellias, are blossoms which, under the gardener's care, have developed with all their essential organs changed into petals. But such flowers are always in an unnatural or monstrous condition, and are incapable of maturing seed, for want of

230. The Essentinl Organs. These are likewise of two kinds, placed one above or within the other; namely, first, the Stamens or fertilizing organs, and, second, the Pistils, which are to be fertilized and bear the seeds. 
231. Taking them in succession, therefore, beginning from below, or at the outside, we have (Fig. 168, 169), first, the calyx or outer

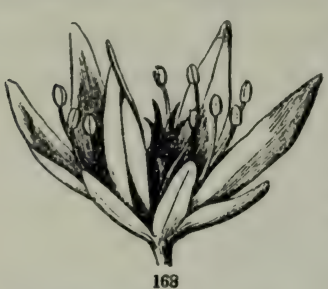
circle of leaves, which are individually termed sepuls $(a)$; secondly, the corolla or inner circle of delicate leaves, called petals $(b)$; then a set of stumens $(c)$; and in the centre one or more pistils $(d)$. The end of the flower-stalk, or the short axis, upon which all these parts stand, is called the Torus or Receptacle.

232. We use here for illustration the flower of a species of Stonecrop (Sedum ternatum), - which is a common plant wild in the Middle States, and in gardens almost everywhere, - because, although small, it exhibits all

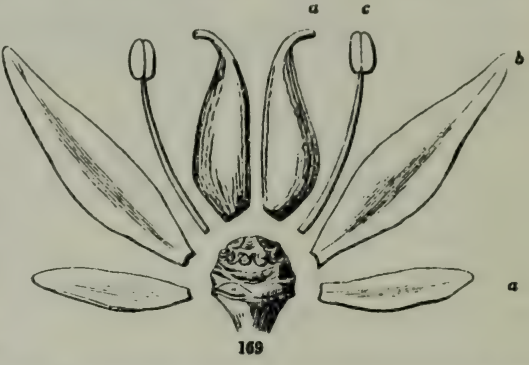
the parts in a perfectly simple and separate state, and so answers for a sort of pattern flower, better than any larger one that is common

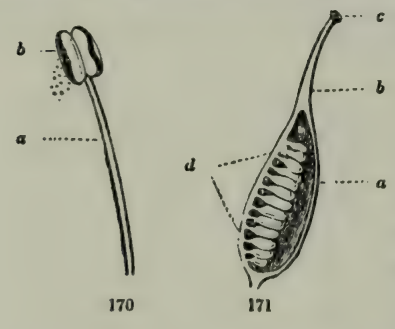
$c$ and well known.

233. A Stamen consists of two parts, namely, the Filament or stalk (Fig. 170, $a)$, and the Anther (b). The latter is a the only essential part. It is a case, commonly with two lobes or cells, each opening lengthwise by a slit, at the proper time, and discharging a powder or dust-like substance, usually of a yellow color. This powder is the Pollen, or fertilizing matter, to produce which is the sole oflice of the stamen.

234. A Pistil is distinguished into three parts; namely, - beginning from below, - the Ovary, the Style, and the Stigma. 'The Ovary is the hollow case or young pod (Fig. 171,a), containing rudimentaiy seeds, called Ovules $(d)$. Fig. 172, representing a pistil like that of

FIG. 168. Flower of a Sisnecrop: Sedım ternatum.

Fia. 169. 'Two partin of each kind of the same fluwor, displayed and enlarged.

FIG. 170. A stamen: $a$, the filament; $b$, the anther, discharging pollen.

FIG. 171. A pistil divided lengthwise, showing the interior of the ovary, $a$, and ite ovules, $d ; b$, the style; $c$, stigma.

FIG. 172. A pistil, enlarged the ovary cut across to shuw the ovules within.

FIG. 173. "Double" Ruse; the essential organs all roplaced by petals. 
Fig. 169, $d$, but on a larger scale, and with the ovary cut across, shows the ovules as they appear in a transverse section. The style (Fig. $171, b$ ) is the tapering part above, sometimes long and slender, sometimes short, and not rarely altogether wanting, for it is not an essential part, like the two others. The stigma $(c)$ is the tip or some other portion of the style (or of the top of the ovary when there is no distinct style), consisting of loose tissue, not covered, like the rest of the plant, by a skin or epidermis. It is upon the stigma that the pollen falls; and the result is, that the ovules contained in the ovary are fertilized and become seeds, by having an embryo (16) formed in them. To the pistil, therefore, all the other organs of the blossom are in some way or other subservient: the stamens furnish pollen to fertilize its ovules; the corolla and the calyx form coverings which pro-

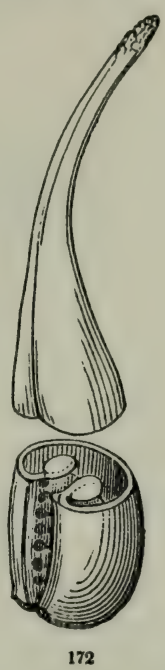
tect the whole.

$234^{n}$. These are all the parts which belong to any flower. But these parts appear under a variety of forms and combinations, some of them greatly disguising their natural appearance. 'To understand the flower, therefore, under whatever guise it may assume, we must study its plan.

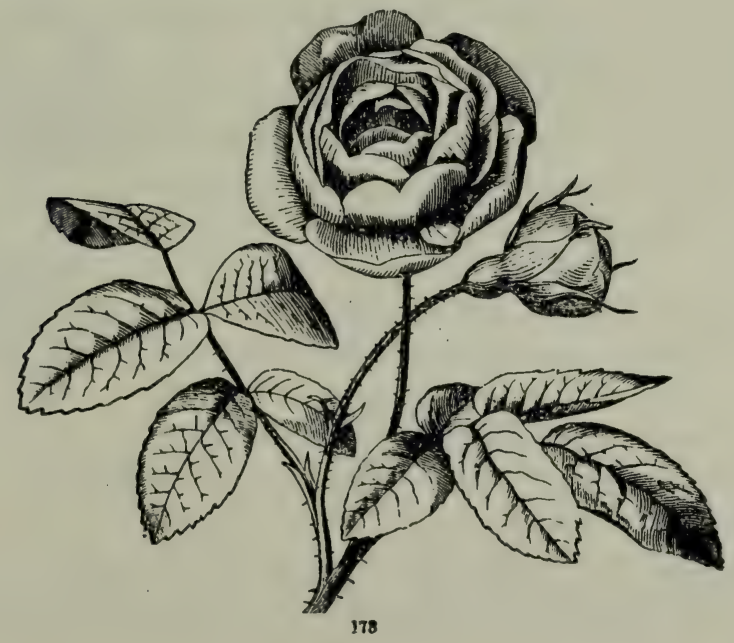




\section{LESSON XIII.}

\section{THE PLAN OF THE FLOWER.}

235. The Flower, like every other part of the plant, is formed upon a plan, which is essentially the same in all blossoms; and the otudent should early get a clear idea of the plan of the flower. Then the almost endless varieties which different blossons present will be at once understood whenever they occur, and will be regarded with a higher interest than their most beautiful forms and richest colurs are able to inspire.

236. We have already become familiar with the plan of the vegetation; - with the stem, consisting of joint raised upon joint, each bearing a leaf or a pair of leaves; with the leaves arranged in symmetrical order, every leaf governed by a simple arithmetical law, which fixes beforehand the precise place it is to occupy on the stem; and we have lately learned (in Lesson 11) how the position of each blossom is determined beforehand by that of the leaves; so that the shape of every flower-cluster in a bouquet is given by the same simple mathematical law which arranges the foliage. Let us now contemplate the flower in a similar way. Having just learned what parts it consists of, let us consider the plan upon which it is made, and endeavor to trace this plan through some of the various forms which blossoms exhibit to our view.

237. In order to give at the outset a correct idea of the blossom, we took, in the last Lesson, for the purpose of explaining its parts, a perfect, complete, regular, and symmetrical flower, and one nearly as simple as such a flower could well be. Such a blossom the botanist regards as

238. A Typical Flower, that is, a pattern flower, because it well exemplifies the plan upon which all flowers are made, and serves as what is called a type, or standard of comparison.

239. Another equally good typical flower (except in a single respect, which will hereafter be mentioned), and one readily to be obtained in the summer, is that of the Flax (Fig. 174). The parts differ in shape from those of the Stonecrop; but the whole plan is evidently just the same in both. Only, while the Stonecrop has ten stamens, or in many flowers eight stamens, - in all cases just twice 
as many as there are petals, - the Flax has only five stamens, of just as many as the petals. Such flowers as these are said to be

Perfect, because they are provided with both kinds of essential organs (230), namely, stamens and pistils ;

Complete, because they have all the sorts of organs which any flower has, namely, both calyx and corolla, as well as stamens and pistils ;

Regular, because all the parts

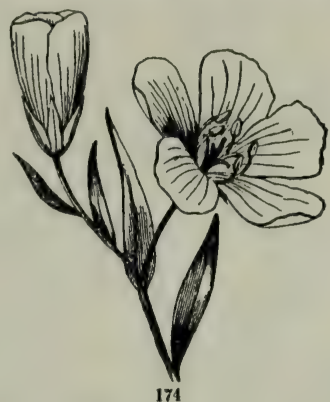
of each set are alike in shape and size; and

Symmetrical, because they have an equal number of parts of each sort, or in each set or circle of organs. That is, there are five sepals, five petals, five stamens, or in the Stonecrop ten stamens (namely, two sets of fire each), and five pistils.

240. On the other hand, many flowers do not present this perfect symmetry and reg-
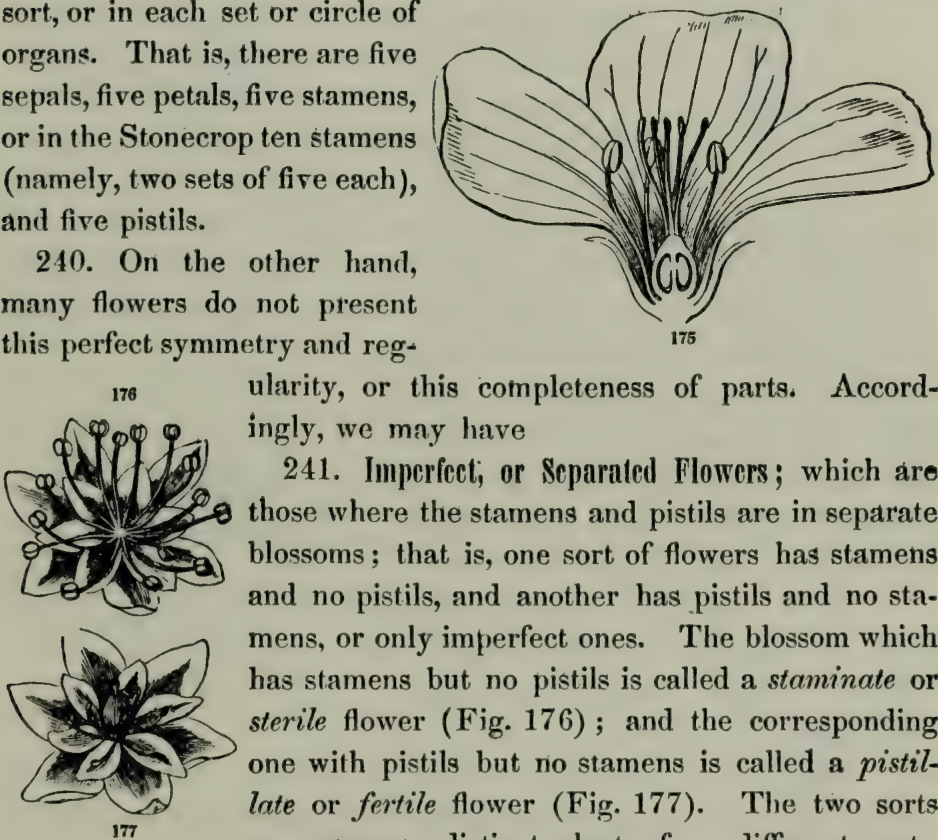
ularity, or this completeness of parts. Accordingly, we may have

241. Imperfect; or Separated Flowers; which are those where the stamens and pistils are in separate blossoms; that is, one sort of flowers has stamens and no pistils, and another has pistils and no stamens, or only imperfect ones. The blossom which has stamens but no pistils is called a staminate or sterile flower (Fig. 176); and the corresponding one with pistils but no stamens is called a pistillate or fertile flower (Fig. 177). The two sorts may grow on distinct plants, from different roots, as they do in the Willow and Poplar, the Hemp, and the Moonseed

FIG. 174. Flowers of the common Flax: a perfect, coinplete, regular, and symmetrical blossom, all its parts in fives. 175. Half of a Flax-flower divided lengthwise, nud enlarged.

FIG. 176. Staminate flower of Moonseed (Menispermum Canadense). 177. Pistillate flower of the same. 
(Fig. 176, 177); when the flowers are said to be diceious (from two Greek words meaning in two households). Or the two may occur

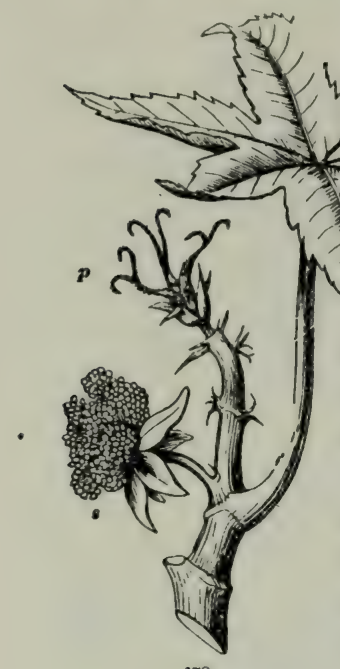

178

on the same plant or the same stem, as in the Oak, Walnut, Nettle, and the Castor-oil Plant (Fig. 178); when the flowers are said to be monocious (that is, in one houseliold). A flower may, however, be perfect, that is, have both stamens and pistils, and yet be incomplete.

242. Incomplete Flowers are those in which one or both sorts of the floral envelopes, or leaves of the blossom, are wanting. Sometimes only one sort is wanting, as in the Castor-oil Plant (Fig. 178) and in the Anemone (Fig. 179). In this case the missing sort is aiways supposed to be the inner, that is, the corolla; and accordingly such flowers are said to be apetalous (meaning without petals). Occasionally both the corolla and the calyx are wanting, when the flower has no proper coverings or floral envelopes at all. It is then said to be naked, as in the Lizard'stail (Fig. 180), and in the Willow.

243. Our two pattern flowers (Fig. 168,174 ) are regular and symmetrical

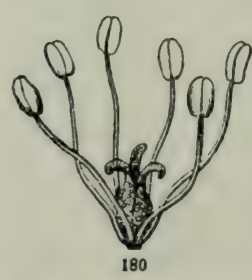
(239). We commonly expect this to be the case in living things. The corresponding

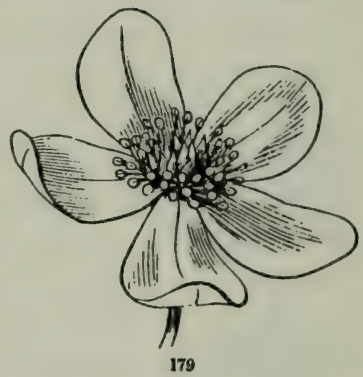
parts of plants, like the limbs or members of animals, are generally alike, and the whole arrangement is symmetrical. This symmetry pervades the Mossom, especially. But the student may often fail to perceive

FIC 178. Noncecious flowers, i. ค. one staminate (s) and one pistillate $(p)$ flower, of the Cie ytor-oil l'lant, growing on the same stem.

1'I(:. 179). Apefilous (incomploto) flower of Anemone Penusylvanica.

Flli. 180. A naked (but perfoct) tlow or of the Lizard'd-tail. 
it, at first view, at least in cases where the plan is more or less obscured by the leaving out (obliteration) of one or more of the members of the same set, or by some inequality in their size and shape. The latter circumstance gires rise to

244. Irregnlar Flowers. This name is given to blossoms in which the different members of the same sort, as, for example, the petals or the stamens, are unlike in size or in form. We have familiar
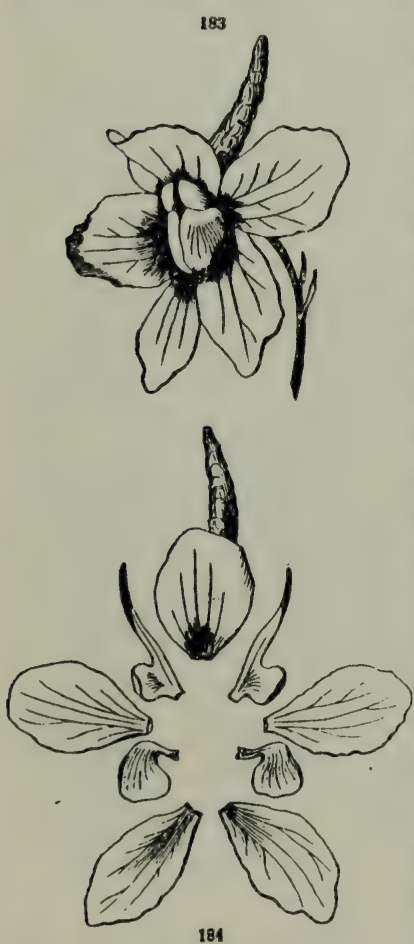

cases of the sort in the Larkspur

(Fig. 183, 184), and Monkshood (Fig. 185, 186); also in the Vio-
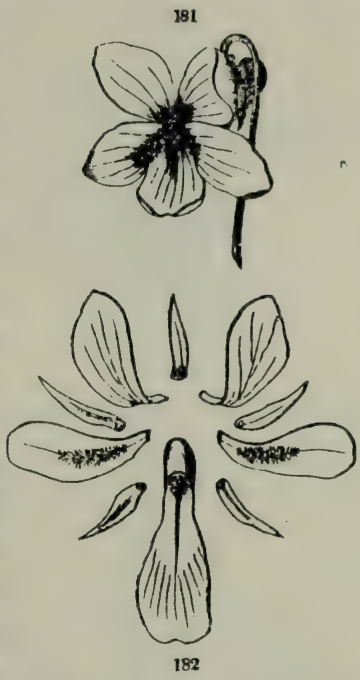

let (Fig. 181, 182). In the latter it is the corolla principally which is irregular, one of the petals being larger than the rest, and extended at the base into a hollow protuberance or spur. In the Larkspur (Fig. 183), both the calyx and the corolla partake of the irregularity. This and the Monkshood are likewise good examples of

245. Unsymmetrical Flowers. We call them unsymmetrical, when the different sets of organs do not agree in the number of their parts. The irregular calyx of Larkspur (Fig. 183, 184) consists of five sepals, one of which, larger than the rest, is prolonged behind into a large spur; but the corolla is made of only four petals (of two shapes);

FIG. 181. Flower of a Violet. 182. Its caly $x$ and corolla displayed : the five smaller parts are the sepals; the five intervening larger ones are the petals.

FIG. 188. Flower of a Larkspur. 184. Its caly $\mathrm{x}$ and corolla displayed; the five larger peces are the sepals; the four smaller, the petals. 
the fifth, needed to complete the symmetry, being left out. And the Monkshood (Fig. 185, 186) has five very dissimilar sepals,

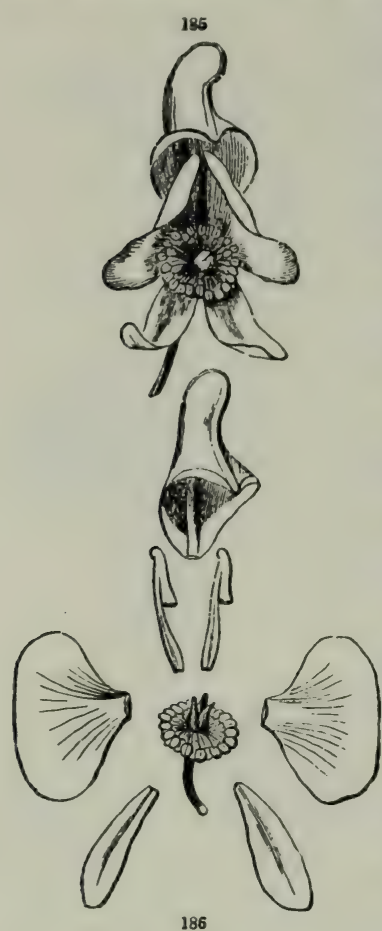
runs through all or most of its parts. And a principal thing which a botanist notices when examining a flower is its numerical plan. It is upon this that the symmetry of the blossom depends. Our two pattern flowers, the Stonecrop (Fig. 168) and the Flax (Fig. 174), are based upon the number five, and a corolla of only two, very small, curiously-shaped petals; the thr ee need. ed to make up the symmetry being left out. For a flower which is unsymmetrical but regular, we may take the com. mon Purslane, which has a calyx o. only two sepals, but a corolia of five petals, from seven to twelve stamens, and about six styles. The Mustard, and all flowers of that family, are unsymmetrical as to the stameris, these being six in number (Fig. 188, while the leaves of the blossom (sepals and petals) are each only four (Fig. 187). Here the stamens are irregular also, two of them being shorter than the other four.

246. Numcrical Plan of the Flower. Although not easy to make out in all cases, yet generally it is plain to see that each blossom is based upon a particular number, which which is exhibited in all their parts. Some flowers of this same Stonecrop have their parts in fours, and then that number runs throughout; namely, there are four sepals, four petals, eight stamens (two sets), and four pistils. The Mustard (Fig. 187, 188), Radish,

FIG. 185. Flower of a Monkshood. 186. Its parts displayed : the five larger pieces are the sepals; the two small ones under the hood are petals; the stamens and pistils are in tI centre.

FIG. 187. Flower of Mustard. 188. Its stamens and pistil separate and enlarged. 
\&c., also have their flowers constructed on the plan of four as to the calyx and corolla, but this number is interfered with in the stamens, either by the leaving out of two stamens (which would complete two sets), or in some other way. Next to five, the most common number in flowers is three. On this number the flowers of Lily, Crocus, Iris, Spiderwort, and Trillium (Fig. 189) are constructed. In the Lily and Crocus the leaves of the flower at first view appear to be six in one set; but the bud or just-

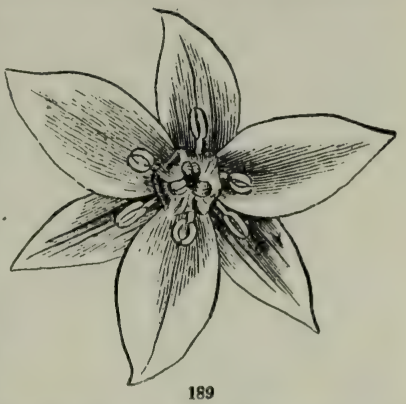
opening blossom plainly shows these to consist of an outer and an inner circle, each of three parts, namely, of caly $\mathrm{x}$ and corolla, both of the same bright color and delicate texture. In the Spiderwort and Trillium (Fig. 189) the three outer leaves, or sepals, are green, and different in texture from the three inner, or the petals; the stamens are six (namely, two sets of three each), and the pistils three, though partly grown together into one mass.

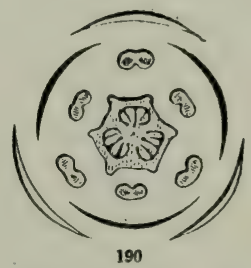

247. Alternation of Parts. The symmetry of the flower is likewise shown in the arrangement or relative position of successive parts. The rule is, that the parts of successive circles alternate with one another. That is, the petals stand over the intervals between the

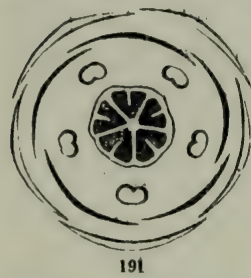
sepals; the stamens, when of the same number, stand over the intervals between the petals; or when twice as many, as in the Trillium, the outer set alternates with the petals, and the inner set, alternating with the other, of course stands before the petals; and the pistils alternate with these. This is shown in Fig. 189, and in the diagram, or cross-section of the same in the bud Fig. 190. And Fig. 191 is a similar diagram or ground-plan (in the form of a

FId. 189. Flower of 'Trilli'um erectum, or Birthroot, sprend out a little, and viewed frouti nhove.

FIG. 190. Dingram or ground-plan of the same, as it would appear in a cross-sectlon of the bud; - the parts all in the sane relative position

F1G. 191. Diagram, or ground-plan, of the Flax-flower, Fig. 174. 
section made across the bud) of the Flax blossom, the example of a pattern symmetrical flower taken at the beginning of this Lesson, with its parts all in fives.

248. Knowing in this way just the position which each organ should occupy in the flower it is readily understood that flowers often become unsymmetrical through the loss of some parts, which

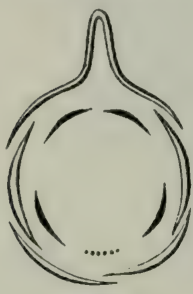

192

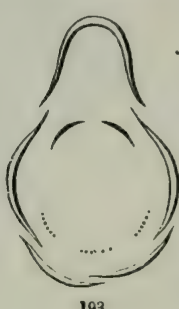

193 belong to the plan, but are obliterated or left out in the execution. For example, in the Larkspur (Fig. 183, 184), as there are five sepals, there should be five petals likewise. We find only four; but the vacant place where the fifth belongs is plainly recognized at the lower side of the flower. Also the similar plan of the Monkshood (Fig. 186) equally calls for. five petals; but three of them are entirely obliterated, and the two that remain are reduced to slender bodies, which look as unlike ordinary petals as can well be imagined. Yet their position, answcring to the intervals between the upper sepals and the side ones, reveals their true nature. All this may perhaps be more plainly shown by corresponding diagrams of the calyx and corolla of the Larkspur and Monkshood (Fig. 192, 193), in which the places of the missing petals are indicated by faint dotted lines. The obliteration of stamens is a still more common case. For example, the Snapdragon, Foxglove, Gerardia, and almost all flowers of the large Figwort family they belong to, have the parts of the calyx and corolla five each, but only four stamens (Fig. 194); the place on the upper side of the flower where the fifth stamen belongs is vacant. That there is in such cases a real obliteration of the missing part is shown by the

249. Abortive 0rgans, or vestiges which are sometimes met with; - bodies which stand in the place of an organ, and represent it, although wholly incapable of fulfilling its office. 'Thus, in the Figwort family, the fifth stamen, which is altogether missing in Gerardia (Fig. 194) and most others, appears in the Figwort as a little scale, and in Pentstemon (Fig. 195) and Turtlehead as a sort of filanent without any anther; - a thing of no use whatever to the plant, but

FIG. 192. Diagram of the calyx and corolla of a Iarkspur. 193. Similar diagram of Munkshood. The dotted lines show where the petals are wanting; one in the former, three in tho latter. 
very interesting to the botanist, since it completes the symmetry of the blossom. And to show that this really is the lost stamen, it now and then lesars an anthere, of the rudiment of one. So tho flower of Catalpa should likewise have five stamens; but we seldom find more than two good ones. Still we may generally discern the three others, as vestiges or half-obliterated stamens (Fig. 196). In separated flowers the rudiments of pistils are often found in the sterile blossom, and rudimentary stamens in the fertile blossom, as in Moonseed (Fig. 177).

250. Mulliplicatiors of Park. Quite in the opposite way, the simple plan of the flower is often more or less obscured by an increase in the number of parts. In the White Water-Lily, and in many Cactus-flowers (Fig. 197), all the parts are very numerous, so that it is hard to say upon what number the blossom is constructed. But more com-
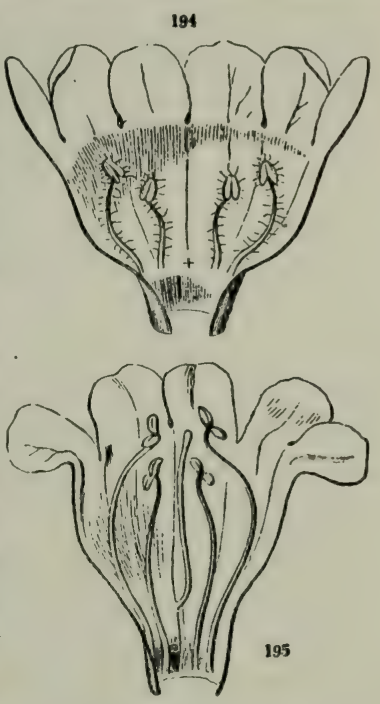
morly snite of the sets are few and definite in the number of their parts. The Buttercup, for instance, has five sepals and five petals, but many stamens and pistils; so it is built upon the plan of five. The flowers of Magnolia have indefinitely numerous stamens and pistils, and rather numerous floral

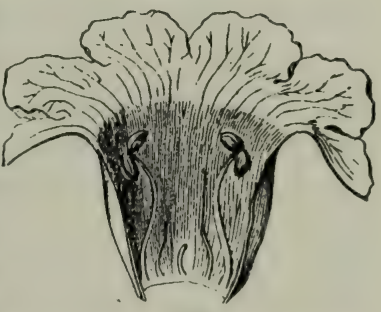
envelopes; but these latter are plainly distinguishable into sets of three; namely, there are three sepals, and six petals in two circles, or nine in three circles, - showing that these blossoms are constructed on the number three.

FIG. 194. Corolla of a purple Gerardia laid open, showing the four stamens ; the cross shows where the fifth stamen would be, if present.

FIG. 195. Corolla, laid open, and stamens of Pentstemon grandiflorus of Iowa, \&c., with a sterile flament in the place of the fifth stamen, and representing it.

FIG. 196. Corolla of Catalpa laid open, displaying two good stanens and three abortive vestiges of stamens 


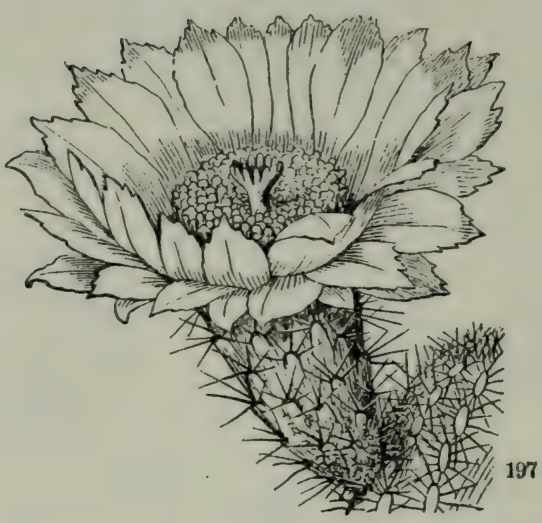

LESSON XIV.

MIORPHOLOGY OF THE FLOWER.

251. In all the plant till we came to the blossom we found nothing but root, stem, and leaves $(23,118)$. However various or strange their shapes, and whatever their use, everything belongs to one of these three organs, and everything above ground (excepting the rare case of aerial roots) is either stem or leaf. We discern the stem equally in the stalk of an herb, the trunk and branches of a tree, the trailing or twining Vine, the straw of Wheat or other Grasses, the columnar trunk of Palms (Fig. 47), in the flattened joints of the Prickly-Pear Cactus, and the rounded body of the Mielon Cactus (Fig. 76). Also in the slender runners of the Strawberry, the tendrils of the Grape-vine and Virginia Creeper, the creeping subterranean shoots of the Mint and Couchgrass, the tubers of the Potato and Artichoke, the solid bulb of the Crocus, and the solid part or base of scaly bulbs; as is fully shown in Lesson 6. And in Lesson 7 and elsewhere we have learned to recognize the leaf alike in the thick secd-leaves of the Almond, Bean, IIorsechestnut, and the like (Fig. 9-21), in the scales of buds (Fig. 77), and the thickened

FIG. 107. A Cactus-flower, viz, of Maunillaria caspitonsa of the Upoer Mlissoum 
scales of bulbs (Fig. 73-75), in the spines of the Barberry and the tendrils of the Pen, in the fleshy rosettes of the Houseleek, the strange fly-trap of Dionæa (Fig. 81), and the curious pitcher of Sarracenia (Fig. 79).

252. Now the student who understands these varied forms or metamorphoses of the stem and leaf, and knows how to detect the real nature of any part of the plant under any of its disguises, may readily trace the leaf into the blossom also, and perceive that, as to their morphology,

253. Flowers are altered Branches, and their parts, therefore, altered leaves. That is, certain buds, which might have grown and lengthened into a leafy branch, do, under other circumstances and to accomplish other purposes, develop into blossoms. In these the axis remains short, nearly as it is in the bud; the leaves therefore remain close together in sets or circles; the outer ones, those of the calyx, generally partake more or less of the character of foliage; the next set are more delicate, and form the corolla, while the rest, the stamens and pistils, appear under forms very different from those of ordinary leaves, and are concerned in the production of seed. This is the way the scientific botanist views a flower; and this view gives to Botany an interest which one who merely notices the shape and counts the parts of blossoms, without understanding their plan, has no conception of.

254. That flowers answer to branches may be shown first from their position. As explained in the Lesson on Inflorescence, flowers arise from the same places as branches, and from no other; flowerbuds, like leaf-buds, appear either on the summit of a stem, that is, as a terminal bud, or in the axil of a leaf, as an axillary bud (196). And at an early stage it is often impossible to foretell whether the bud is to give rise to a blossom or to a branch.

255. That the sepals and petals are of the nature of leaves is evident from their appearance ; persons who are not botanists commonly call them the leaves of the flower. The calyx is most generally green in color, and foliaceous (leaf-like) in texture. And though the corolla is rarely green, yet neither are proper leaves always green. In our wild Painted-Cup, and in some scarlet Sages, common in gardens, the leaves just under the flowers are of the brightest red or scarlet, often much brighter-colored than the corolla itself. And sometimes (as in many Cactuses, and in Carolina Allspice) there is such a regular gradation from the last leaves of the 
plant (bracts or bractlets) into the leaves of the calyx, that it is impossible to say where the one ends and the other begins. And if sepals are leaves, so also are petals; for there is no clearly fixed limit between them. Not only in the Carolina Allspice and Cactus (Fig. 197), but in the Water-Lily (Fig. 198) and a variety of flowers with more than one row of petals, there is such a complete transition between calyx and corolla that no one can surely tell how many of the leaves belong to the one and how many to the other.

256. It is very true that the calyx or the corolla often takes the form of a cup or tube, instead of being in separate pieces, as in Fig. 194-196. It is then composed of two or more leaves grown together. This is no objection to the petals being leaves; for the same thing takes place with the ordinary leaves of many plants, as, for instance, in the upper ones of Honeysuckles (Figr 132).

257. That stamens are of the same general nature as petals, and therefore a modification of leaves, is shown by the gradual transitions that oceur between the one and the other in many blossoms; especially in cultivated flowers, such as Roses and Camellias, when they begin to double, that is, to change their stamens into petals. Some wild and natural flowers show the same interesting transitions. The Carolina Allspice and the White Water-Lily exhibit complete gradations not only between sepals and petals, but between petals and stamens. The sepals of the Water-Lily are green outside, but white and petal-like on the inside; the petals, in many rows, gradually grow narrower towards the centre of the flower; some of these are tipped with a trace of a yellow anther, but still are petals; the next are more contracted and stamen-like, but with a flat petal-like filament; and a further narrowing of this completes the genuine stamen. A series of these stages is shown in Fig. 198.

258. Pistils and stamens now and then change into each other in some Willows; pistils often turn into petals in cultivated flowers; and in the Double Cherry they occasionally change directly into small green leaves. Sometimes a whole blossom changes into a cluster of green leaves, as in the "green roses" which are occasionally noticed in gardens, and sometimes it degenerates into a leafy branch. So the botanist regards pistils also as answering to leaves. And his idea of a pistil is, that it consists of a leaf with its margins curved inwards till they meet and unite to form a closed cavity, the oviry, while the tip is protonged to form the style und bear the stigma; as will be illustrated in the Lesson upon the Pisti!. 
259. Moreover, the arrangement of the parts of the flower answers to that of leaves, as illustrated in Lesson 10, - either to a succession of whorls alternating with each other in the manner of whorled leaves, or in some regular form of spiral arrangement.

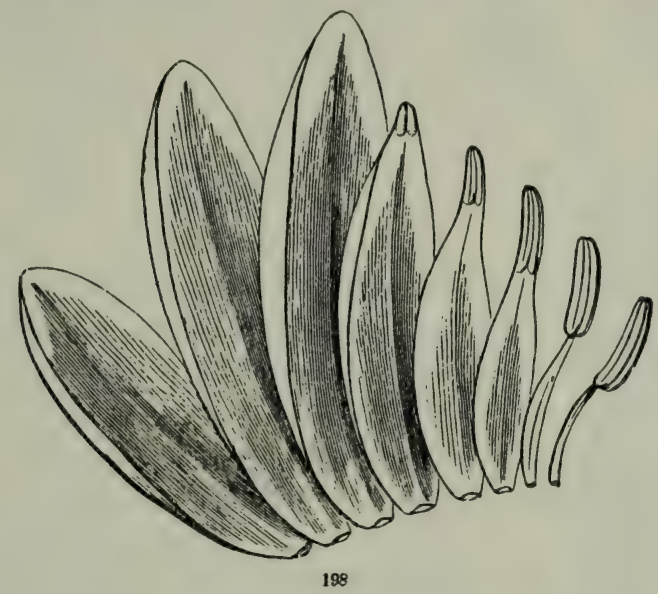

\section{LESSON XV.}

MORPHOLOGY OF THE CALYX AND COROLLA.

260. Having studied the flower as a whole, we proceed to consider more particularly its several parts, especially as to the principal differences they present in different plants. We naturally begin with the leaves of the blossom, namely, the calyx and corolla. And first as to

261. The Growing together of Parts. It is this more than anything else which prevents one from taking the idea, at first sight, that the flower is a sort of very short branch clothed with altered leaves. For most blossoms we meet with have some of their organs grown tc gether more or less. We have noticed it as to the corolla of Ge. rardia, Catalpa, \&c. (Fig. 194-196), in Lesson 13. This growing 
together takes place in two ways: either parts of the same kind, or parts of different kinds, may be united. The first we may call

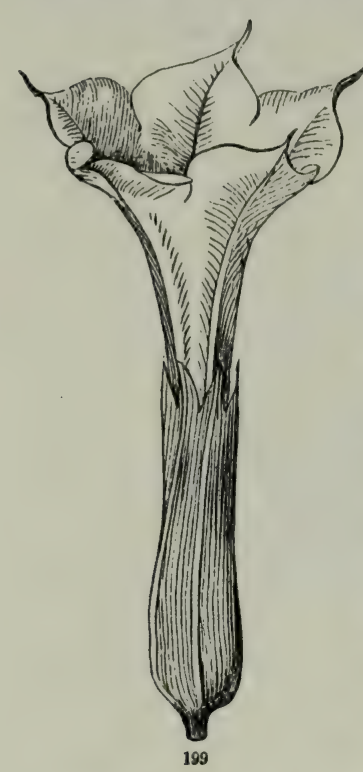
simply the union, the second the consoli. dation, of parts.

262. Union or Cohesion with one another of parts of the same sort. We very commonly find that the calyx or the corolla is a cup or tube, instead of a set of leaves. Take, for example, the flower of the Stramonium or 'Thorn-Apple, where both the calyx and the corolla are so (Fig. 199); likewise the common Morning-Glory, and the figures 201 to 203 , where the leaves of the corolla are united into one piece, but those of the calyx are separate. Now there are numerous cases of real leaves growing together much in the same way, - those of the common Thoroughwort, and the upper pairs in Woodbines or Honeysuckles, for example (Fig. 132); so that we might expect it to occur in the leaves of the blossom also. And that this is the right view to take of it plainly appears firom the transitions everywhere met with in different plants, between a calyx or a corolla of separate pieces and one forming a perfect tube or cup. Figures 200 to 203 show one complete set of such gradations in the corolla, and Fig. 204 to 206 another, in short and open corollas. IIow many leaves or petals each corolla is formed of may be seen by the number of points or tips, or of the notches (called sinuses) which answer to the intervals between them.

263. When the parts are united in this way, whether much or little, the corolla is said to be monopetalues, and the calyx monosepalous. These terms mean "of one petal," or "of one sepal"; that is, of one piece. Wherefore, taking the corolla or the caly $x$ as a whole, we say that it is parted when the parts are separate almost to the base, as in Fig. 204 ; cleft or lobed when the notches do not extend below the middle or thereabouts, as in Fig. 205 ;

FIC. 199. Flower of the common Stramonium; both the caly $x$ and the corolla with theit parts united into a tube. 
toothed or dentate, when only the tips are separate as short points entire, when the border is even, without points or notches, as in the

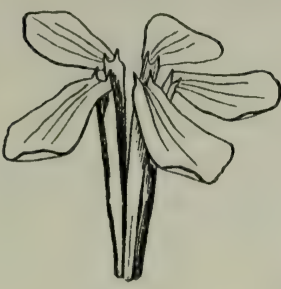

200

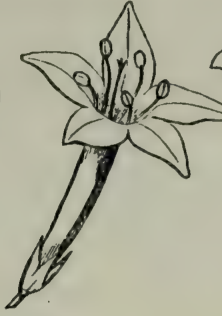

201

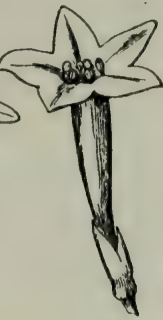

202

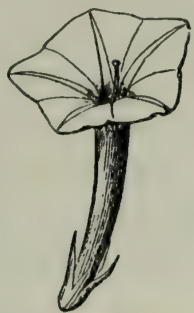

203

common Morning-Glory, and very nearly so in Fig. 203; and eo on; - the terms being just the same as those applied to leaves and all other flat bodies, and illustrated in Lessons 8 and 9 .

264. There is a set of terms applied particularly to calyxes, corollas, or other such bodies of one piece, to express their general shape, which we see is very various. The following are some of the principal :-

Wheel-shaped, or rotate; when spreading out at once, without a tube or with a very short one, something in the shape of a wheel or of its diverging spokes, as in the corolla of the Potato and Bittersweet (Fig. 204, 205).

Salver-shaped, or salver-form; when a flat-spreading border is raised on a narrow tube, from which it diverges at right angles,

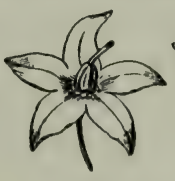

204

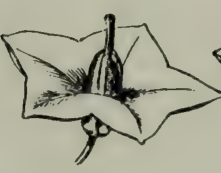

205

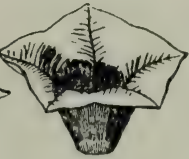

208

like the salver represented in old pictures, with a slender handle beneath. The corolla of the Phlox (Fig. 208) and of the Cypress. Vine (Fig. 202) are of this sort.

FIG. 200. Corolla of Soapwort (the same in Pinks, \&c.), of 5 separate, long-clawed petals.

FIG. 201. Flower of Gilia or Ipomopsis coronopifolia; the parts answering to the clawa of the potals of the last figure here all united into a tube.

FI(x. 202. Flower of the Cypress-Vine; the petals a little farther united into a five-lobed spreading border.

FIG. 203. Flower of the sinall Searlet Morning-Glory, the five petals it is composed of perfectly united into a trumpet-shaped tube, with the spreading horder nearly even (or entire).

FIG. 204. Wheel-shaped and five-parted corolla of Bittersweet (Solanum Dulcamara).

FIG. 205. Wheel-shaped and five-cleft corolla of the common Potatn.

F1G. 206. Almost entire and very open bell-shaped corolla of a Ground Cherry (Physalis) 
Bell-shaped, or campanulute; where a short and broad tute widens upward, in the shape of a bell, as in Fig. 207.

H'unnel-shaped, or funnel-form; gradually spreading at the summit of a tube which is narrow below, in the shape of a funnel or tunnel, as in the corolla of the common Morning-Glory, and of the Stramonium (Fig. 199).

Tubular; when prolonged into a tube, without much spreading at the border, as in the corolla of the Trumpet Honeysuckle, the calyx of Stramonium (Fig. 199), \&c.

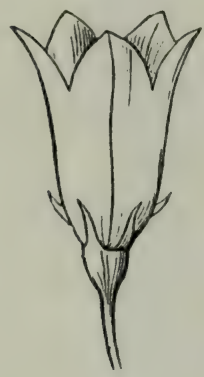

207

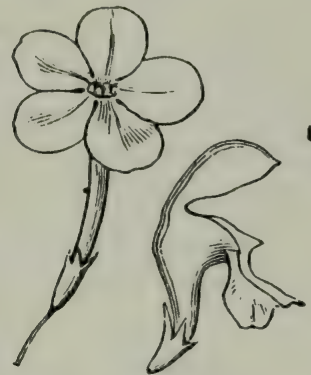

209

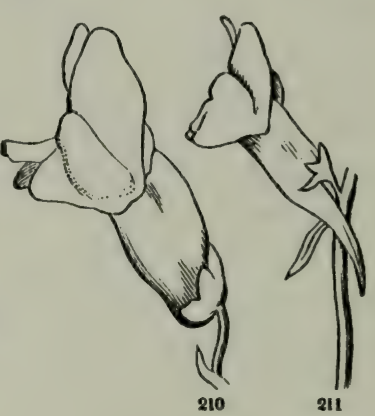

211

265. In most of these cases we may distinguish two parts; namely, the tube, or the portion all in one piece and with its sides upright or nearly so; and the border or limb, the spreading portion or summit. The limb may be entire, as in Fig. 203, but it is more commonly lubed, that is, partly divided, as in Fig. 202, or parted down nearly to the top of the tube, as in Fig. 208, \&c.

266. So, likewise, a separate petal is sometimes distinguishable into two parts; namely, into a narrowed base or stalk-like part (as in Fig. 200, where this part is peculiarly long), called the claw, and a spreading and enlarged summit, or body of the petal, called the lamina or blade.

267. When parts of the same set are not united (as in the Flax, Cherry, \&c., Fig. 212-215), we call them distinct. Thus the sepals or the petals are distinct when not at all united with each other. As a caly $\mathrm{x}$ with sepals united into one body is called monosepalous (263, that is, one-sepalled), or sometimes monophyllous, that is, one-leaved; so, on the other hand, when the sepals are distinct, it is said to be

FIG. 207. Flower of the Harebell, with a campanulate or bell-shaped corolla. 208. Of a Phlox, with salver-shaped corollit. 209. Of Dead-Nettle (Lamium), with labiate ringent (or gaping) corolla. 210. Of Suapdragon, with labiate personate corolla. 211. Of Toad-Flax, with a similar corolla spurred at the base. 
polysepalous, that is, composed of several or many sepals. And a corolla with distinct petals is said to be polypetalous.

268. Consolidation, the growing together of the parts of two or more different sets. In the most natural or pattern flower (as explained in Lessons 13 and 14), the several parts rise from the receptacle or axis in succession, like leaves upon a very short stem; the petals just above or within the sepals, the stamens just above or within these, and then the pistils next the summit or

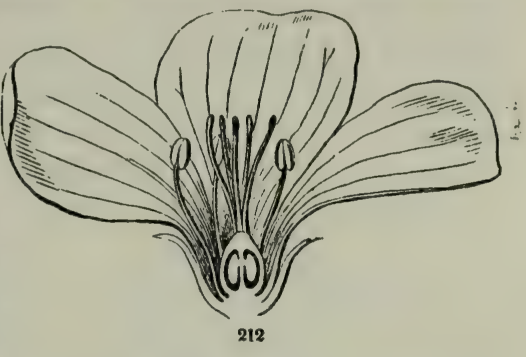
centre. Now when contiguous parts of different sorts, one within the other, unite at their base or origin, it obscures more or less the plan of the flower, by consolidating organs which in the pattern flower are entirely separate.

269. The nature of this consolidation will be at once understood on comparing the following series of illustrations. Fig. 212 represents a flower of the common Flax, cut through lengthwise, so as to show the attachment (or what the botanist calls the insertion) of all the parts. Here they are all inserted on, that is grow out of, the receptacle or axis of the blossom. In other words, there is no union at all of the parts of contiguous circles. So the parts are said to be free.

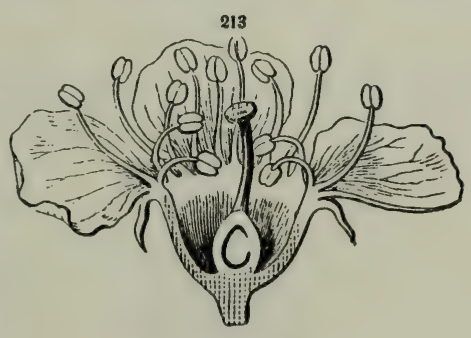
And the sepals, petals, and stamens, all springing of course from beneath the pistils, which are on the very summit of the axis, are said to be hypogynous (a term composed of two Greek words, mean. ing " under the pistil").

FIG. 212. A Flax-flower, cut through lengthwise.

FIG. 213. Flower of a Cherry, divided in the same way.

FIG. 214. Flower of the common Purslane, divided lengthwise. 
270. Fig. 213 is a flower of a Cherry, cut through lengthwise in the same way. Here the petals and the stamens grow out of, that is, are inserted on, the calyx ; in other words they cohere or are consolidated with the base of the calyx up to a certain height. In such cases they are said to be perigynous (from two Greek words, meaning around the pistil). The consolidation in the Cherry is confined to the calyx, corolla, and stamens : the calyx is still free from the pistil. One step more we have in

271. Fig. 214, which is a similar section of a flower of a Purslane.

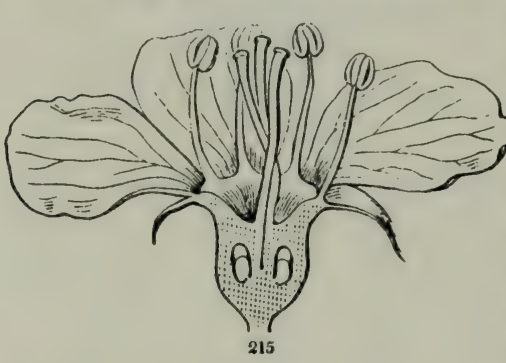
Here the lower part of the calyx (carrying with it of course the petals and stamens) is colerent with the surface of the whole lower half of the ovary. Therefore the calyx, seeming to rise from the middle of the ovary, is said to be half superior, instead of being inferior, as it is when entirely free. It is better to say, however, calyx half-adherent to the ovary. Every gradation occurs between

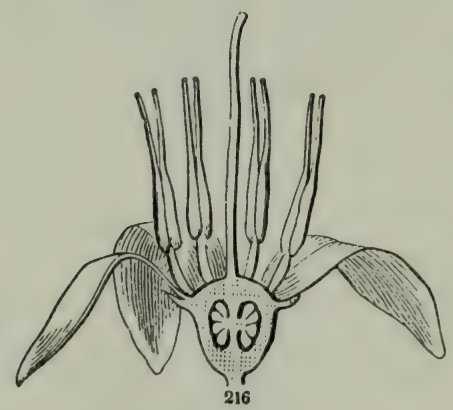
such a case and that of a calyx altogether free or inferior, as we see in different Purslanes and Saxifrages. The consolidation goes farther,

272. In the Apple, Quince, Hawthorn (Fig. 215), \&c. Here the tube of the calyx is consolidated with the whole surface of the ovary; and its limb, or free part, therefore appears to spring from its top, instead of underneath it, as it naturally should. So the calyx is said to be superior, or (more properly) adherent to, or coherent with, the ovary. In most cases (and very strikingly in the Evening Primrose), the tube of the calyx is continued on more or less beyond the ovary, and has the petals and stamens consolidated with it for some distance; these last, therefore, being borne on the calyx, are said to be perigynous, as before $(270)$.

FIG. 215. Flower of a IIawthori, divided lengthwiso.

FIG. 216. Flower of the C'runliorry, dividod longliwise. 
273. But if the tube of the calyx ends immediately at the summit of the ovary, and its lobes as well as the corolla and stamens are as it were inserted directly on the ovary, they are said to be epigynous (meaning on the pistil), as in Cornel, the Huckleberry, and the Cranberry (Fig. 216).

274. Irregularity of Parts in the calyx and corolla has already been noticed (244) as sometimes obstructing one's view of the real plan of a flower. There is infinite variety in this respect; but what has already been said will enable the student to understand these irregularities when they occur. We have only room to mention one or two cases which have given rise to particular names. A very common kind, among polypetalous (267) flowers, is

275. The Papilionaceous flower of the Pea, Bean, and nearly all that family. In this we have an

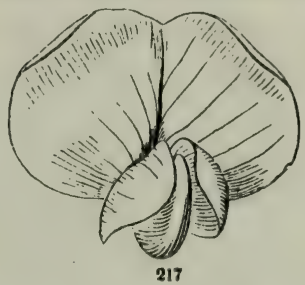
irregular corolla of a peculiar shape, which Linnæus likened to a butterfly (whence the term, papilio being the Latin name for a butterfly); but the resemblance is not very obvious. The five petals of a papilionaceous corolla (Fig. 217) have received different names taken from widely different objects. The upper and larger petal (Fig. 218, s), which is generally wrapped round all the rest in the bud, is called the standard or banner: The two side petals $(w)$ are called the wings. And the two anterior ones $(k)$, the blades of which commonly stick together a little, and which en-
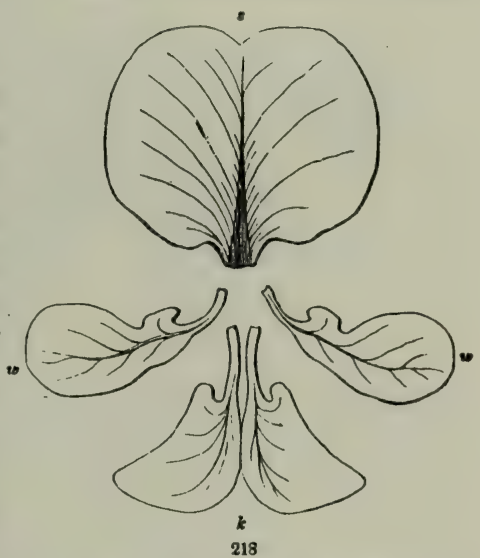
close the stamens and pistil in the flower, from their forming a body shaped somewhat like the keel, or rather the prow, of an ancient boat, are together named the keel.

276. The Labiate or bilabiate (that is, two-lipped) flower is a very common form of the monopetalous corolla, as in the Snapdragon

FIG. 217. Front view of the papilionaceous corolla of the Locust-tree. 218. The parts of the same, displayed. 
(Fig. 210), Toad-Flax (Fig. 211), Dead-Nettle (Fig. 209), Catnip, Horsemint, \&c.; and in the Sage, the Catalpa, \&c., the caly $x$ also is two-lipped. This is owing to unequal union of the different parts of the same sort, as well as to diversity of shape. In the corulla two of the petals grow together higher than the rest, sometimes to the very top, and form the upper lip, and the three remaining ones join on the other side of the flower to form the lower lip, which therefore is more or less three-lobed, while the upper lip is at most only twolobed. And if the calyx is also two-lipped, as in the Sage, - since the parts of the calyx always alternate with those of the corolla (247), - then the upper lip, has three lobes or teeth, namely, is composed of three sepals united, while the lower has only two; which is the reverse of the arrangement in the corolla. So that all these flowers are really constructed on the plan of five, and not on that of two, as one would at first be apt to suppose. In Gerardia, \&c. (Fig. $194,195)$, the number five is evident in the caly $\mathrm{x}$ and corolla, but is more or less obscured in the stamens (249). In Catalpa this number is masked in the calyx by irregnlar union, and in the stamens by abortion. A diflerent kind of irregular flower is seen in



277. The Ligulate or strapshaped corolla of most compound flowers. What was called the compound flower of a Dandelion, Succory (Fig. 221), Thistle, Sunflower, Aster, Whiteweed, \&c., consists of many distinct blossons, closely crowded together into a head, and surrounded by an involucre (208). People who are not botanists commonly take the whole for one flower, the involucre for a calyx, and corollas of the outer or of all the flowers as petals. And this is a very natural mistake when the flowers around the edge have flat and open or strap-shaped corollas, while the rest are regular and tubular, but small, as in the Whiteweed, Sunflower, \&c. Fig. 219 represents such a case in a Coreopsis, with the head, or so-called compound flower, eut through ; and in Fig. 220 we see one of the perfect flowers of the centre or disk, with a regular tubular corolla $(a)$, and with the slender bract $(b)$ from whose

FIG. 219. Head of flowers (the so-called "compound flower ") of Coreopsis, divided lengthwise. 
axil it grew; and also one belonging to the margin, or ray, with a strap-shaped corolla $(c)$, borne in the axil of a leaf or bract of

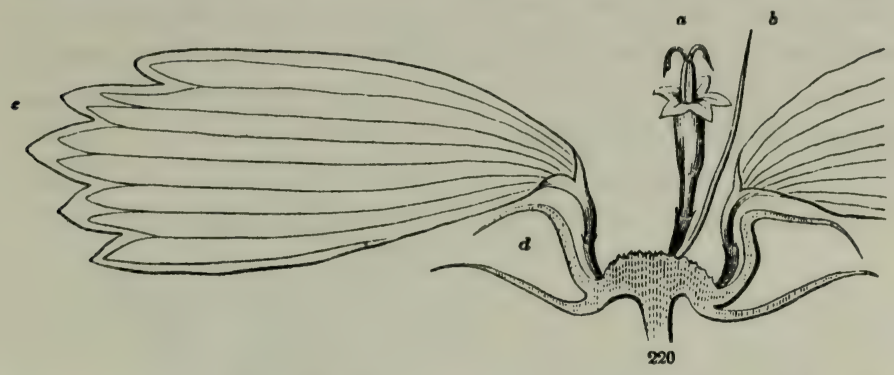

the involucre $(d)$. Here the ray-fower consists merely of a strapshaped corolla, raised on the small rudiment of an ovary; it is therefore a neutral flower, like those of the ray or margin of the cluster in Hydrangea (229, Fig. 167), only of a different shape. More commonly the flowers with a strap-shaped corolla are pistillate, that is, have a pistil only, and produce seed like the others, as in Whiteweed. But in the Dandelion, Succory (Fig. 221, 222),

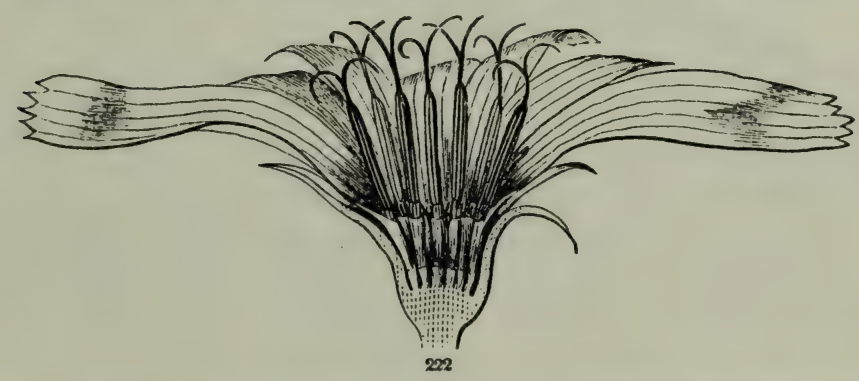

and all of that tribe, these flowers are perfect, that is, bear both stamens and pistils. And moreover all the flowers of the head are strap-shaped and alike.

278. Puzzling as these strap-shaped corollas appear at first view, an attentive inspection will generally reveal the plan upon which they are constructed. We can make out pretty plainly, that each one consists of five petals (the tips of which commonly appear as five teeth at the extremity), united by their contiguous edges, except on

FIf. 220. A slice of Fig. 219, more enlarged, with one tubular perfect flower (a) left standing on the receptacle, with its bractlet or chaff $(b)$, one ligulate, neutral ray-flower $(c)$, and part of another: $d$, section of bracts or leaves of the involucre.

FIG. 222. Head of flowers of Succory, cut through lengtliwise and enlarged 
one side, and spread out flat. To prove that this is the case, we have only to compare such a corolla (that of Coreopsis, Fig. 220, c, or one from the Succory, for instance) with that of the Cardinal-flower, or of any other Lobelia, which is equally split down along one side; and this again with the less irregular corolla of the Woodbine, partially split down on one side.

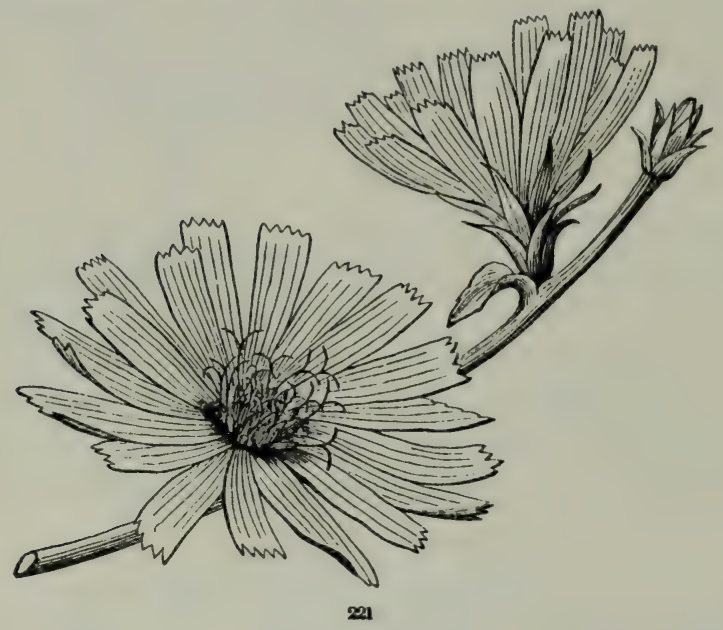

\section{LESSON XVI.}

astivation, or the arrangement of the Calyx and Co ROLLA IN THE BUD.

279. Astrvation or Prafloration relates to the way in which the leaves of the flower, or the lobes of the calyx or corolla, are placed with respect to each other in the bud. This is of some importance in distinguishing different families or tribes of plants, being generally very uniform in each. The æstivation is best seen

FIG. 221. Compound fluwers, i. o. heads of flowers, of Succory. 
by making a horizontal slice of the flower-bud when just ready to open ; and it may be expressed in diagrams, as in Fig. 223, 224.

280. The picces of the calyx or the corolla either overlap each other in the bud, or they do not. When they do not, the æstivation is commonly

Valvate, as it is called when the pieces meet each other by their abrupt edges without any infolding or overlapping; as the caly $x$ of the Linden or Basswood (Fig. 223) and the Mallow, and the corolla of the Grape, Virginia Creeper, \&c. Or it may be

Induplicate, which is valvate with the margins of each piece projecting inwards, or involute (like the leaf in Fig. 152), as in the caly $\mathrm{x}$ of Virgin's-Bower and the corolla of the Potato, or else

Reduplicate, like the last, but the margins projecting outwards

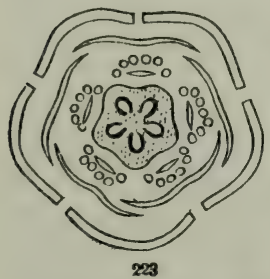
instead of inwards; these last being mere variations of the valvate form.

281. When the pieces overlap in the bud, it is in one of two ways : either every piece has one edge in and one edge out; or some pieces are wholly outside and others wholly inside. In the first case the rstivation is

Convolute or twisted, as in the corolla of Geranium (most commonly, Fig. 224), Flax (Fig. 191), and of the Mallow Family.

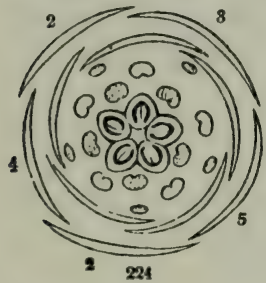

Here one edge of every petal covers the next before it, while its other edge is covered by the next behind it. In the second case it is

Imbricated or imbricate, or breaking joints, like shingles on a roof, as in the calyx of Geranium (Fig. 224) and of Flax (Fig. 191), and the corolla of the Linden (Fig. 223). In these cases the parts are five in number; and the regular way then is (as in the calyx of the figures above cited) to have two pieces entirely external ( 1 and 2), one (3) with one edge covered by the first, while the other edge covers that of the adjacent one on the other side, and two (4 and 5) wholly within, their margins at least being covered by the rest. That is, they just represent a circle of five leaves spirally arranged on the five-ranked or $\frac{2}{5}$ plan $(187,188$, and Fig. 143-145), only with the stem shortened so as to bring the parts close together. The spiral arrangement of the parts of

FIG. 223. Section across the flower-bud of Linden.

FIG. 224. Section across the flower-bud of Leranium : the sepals numbered in theil: orcler 
the blossom is the same as that of the foliage, - an additional evidence that the flower is a sort of branch. The petals of the Linden, with only one outside and one inside, as shown in Fig. 223, exhibit a gradation between the imbricated and the convolute modes. When the parts are four in number, generally two opposite ones overlap the other two by both edges. When three in number, then one is outermost, the next has one edge out and the other covered, and the third is within, being covered by the other two; as in Fig. 190. This is just the three-ranked $\left(\frac{1}{3}\right)$ spiral arrangement of leaves $(186$, and Fig. 171).

282. In the Mignonette, and some other flowers, the restivation is open; that is, the calyx and corolla are not closed at all over the other parts of the flower, even in the young bud.

283. When the calyx or the corolla is tubular, the shape of the tube in the bud has sometimes to be considered, as well as the way the lobes are arranged. For example, it may be

Plaited or plicate, that is, folded lengthwise; and the plaits may either be turned outwards, forming projecting ridges, as in the corolla of Campanula ; or turned inwards, as in the corolla of the Gentian, \&c. When the plaits are wrapped round all in one direction, so as to cover one another in a convolute manner, the æstivation is said to be

Supervolute, as in the corolla of Stramonium (Fig. 225) and the Morning-Glory; and in the Morning-Glory it is twisted besides.

FIG. 225. Upper part of the corolla of a Stramonium (Datura meteloides), in the bud. Cinderneath is a cross-section of the same.

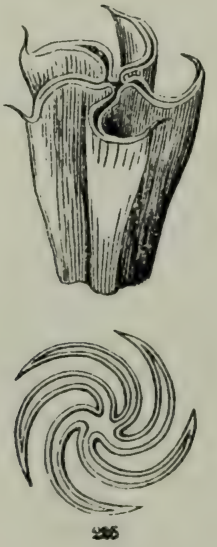




\section{LESSON XVII.}

\section{MORPHOLOGY OF THE STAMENS.}

284. The Stamens exhibit nearly the same kinds of variation in different species that the calyx and corolla do. They may be distinct (that is, separate from each other, 267) or united. They may be free (269), or else coherent with other parts : this concerns

285. Their Insertion, or place of attachment, which is most commonly the same as that of the corolla. So, stamens are

Hypogynous (269), when they are borne on the receptacle, or axis of the flower, under the pistils, as they naturally should be, and as is shown in Fig. 212.

Perigynous, when borne on (that is coherent below with) the calyx ; as in the Cherry, Fig. 213.

Epigynous, when borne on the ovary, apparently, as in Fig. 216. To these we may add

Gynandrous (from two Greek words, answering to "stamens and pistil united"), when the stamens are consolidated with the style, so as to be borne by it, as in the Lady's Slipper (Fig. 226) and all the Orchis Family. Also

Epipetalous (meaning on the petals), when they are borne by the corolla; as in Fig. 194, and in most monopetalous blossoms. As to

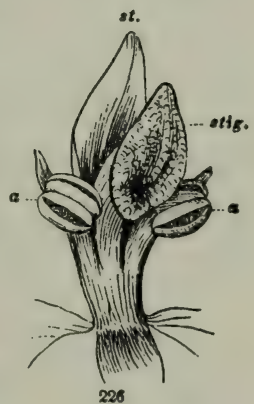

286. Their Union with each other, the stamens may be united by their filaments or by their anthers. In the former case they are

Monadelphous (from two Greek words, meaning " in one brotherhood"), when united by their filaments into one set, usually into a ring or cup below, or into a tube, as in the Mallow Family, the Passion-flower, and the Lupine (Fig. 228).

Diadelphous (in two brotherhoots), when so united in two sets, as in the Pea and almost all papilionaceous flowers (275): here the stamens are nine in one set, and one in the other (Fig. 227).

FIG. 226. Style of a Lady's Slipper (Cypripedium), and stamens united with it: $a, a$, tho anthers of the two good stamens; st., an abortive stamen, what should be its anther changed into a petal-like body ; stig., the stigma. 
Triadelphous, in three sets or parcels, as in the common St. Johnswort ; or

Polyadelphous, when in more numerous sets, as in the Loblolly
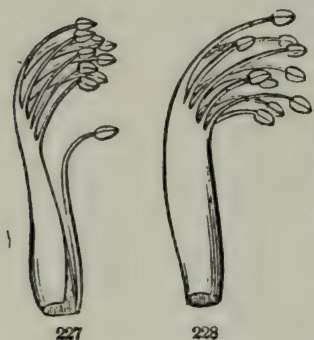

228 Bay, where they are in five clusters. On the other hand, stamens are said to be

Syngenesious, when united by their anthers (Fig. 229, 230), as they are in Lobelia, in the Violet (slightly), and in what are called compound flowers, such as the Thistle, Sunflower, Coreopsis (Fig. 220), and Succory (Fig. 222). In Lobelia, and in the Squash and Pumpkin, the stamens are united both by their anthers and their filaments.

287. Their Number in the flower is sometimes expressed by terms compounded of the Greek numerals and the word used to signify stamen; as, monandrous, for a flower having only one stamen; diandrous, one with two stamens; triandrous, with three stamens; tetrandrous, with four stamens; pentandrous, with five stamens; and so on, up to polyandrous (meaning with many stamens), when there are twenty or a larger number, as in a Cactus (Fig. 197). All such terms may be found in the Glossary at the end of the book.

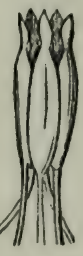

229

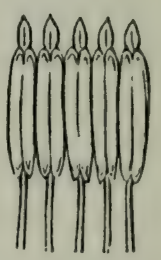

230

288. Two terms are used to express particular numbers with un. equal length. Namely, the stamens are didynamous when only four in number, two longer than the other two, as in the Mint, Catnip, Gerardia (Fig. 194), Trumpet-Creeper, \&c.; and tetradynamous, when they are six, with four of them regularly longer than the other two, as in Mustard (Fig. 188), and all that fumily.

289. Their Parts. As already shown (233), a stamen consists of two parts, the Filament and the Anther (Fig. 231).

290. The Filament is a kind of stalk to the anther: it is to the anther nearly what the petiole is to the blade of a leaf. Therefore it is not an essential part. As a leaf may be without a stalk, so the anther may be sessile, or without a filament. When present,

FIG. 227. Diadelphous stamens of the Pea, \&c. 228. Monadelphous stamens of the Lupine.

FIG. 229. Syngenesious stamens of Coreopsis (Fig. 220, a), \&c. 230. Sane, with the tube of anthers split duwn on one side and sprear open. 
the filament may be of any shape ; but it is commonly thread-like, as in Fig. 231, 234, \&c.

291. The Anther is the essential part of the stamen. It is a sort of case, filled with a fine powder, called Pollen, which serves to fertilize the pistil, so that it may perfect seeds. The anther may be considered, first, as to

292. Its Attachiment to the filament. Of this there are three ways; namely, the anther is

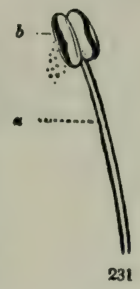

Innate (as in Fig. 232), when it is attached by its base to the very apex of the filament, turning neither inwards nor outwards; or

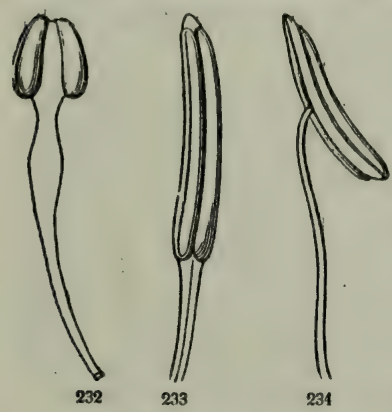

Adnate (as in Fig. 233), when attached by one face, usually for its whole length, to the side of the filament; and

Versatile (as in Fig. 234), when fixed by its middle only to the very point of the filament, so as to swing loosely, as we see it in the Lily, in Grasses, \&c.

293. In both the last-named cases, the anther either looks inwards or outwards. When it is turned inwards, or is fixed to that side of the filament which looks towards the pistil or centre of the flower, the anther is incumbent or introrse, as in Magnolia and the Water-Lily. When turned outwards, or fixed to the outer side of the filament, it is extrorse, as in the Tulip-tree.

294. Its Structure, \&c. There are few cases in which the stamen bears any resemblance to a leaf. Nevertheless, the botanist's idea of a stamen is, that it answers to a leaf developed in a peculiar form and for a special purpose. In the filament he sees the stalk of the leaf ; in the anther, the blade. The blade of a leaf consists of two similar sides; so the anther consists of two lobes or cells, one answering to the left, the other to the right, side of the blade. The two lobes are often connected by a prolongation of the filament, which answers to the midrib of a leaf - this is called the connective. It is very conspicuous in Fig. $\mathbf{z} 32$, where the connective is so broad that it separates the two cells of the anther to some distance from each other.

FIG. 231. $\Lambda$ stamien : $a$, flament ; $b$, anther discharging pollon.

FIG. 232. Stamen of Isopyrum, with innate anther. 233. Of Tulip-tree, with adnate (and extrorse) anther. 234 Of Evening Primrose; with versatile anther. 
295. To discharge the pollen, the anther opens (or is dehiscent)

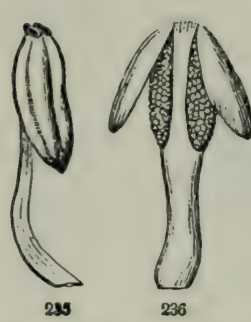
at maturity, commonly by a line along the whole length of each cell, and which answers to the margin of the leaf (as in Fig. 231); but when the anthers are extrorse, this line is often on the outer face, and when introrse, on the inner face of each cell. Sometimes the anther opens only by a chink, hole, or pore at the top, as in the Azalea, Pyrola or False Wintergreen (Fig. 235), \&c. ; and sometimes a part of the face separates as a sort of trap-door (or valve), hinged at the top, and opening to allow the escape of the pollen, as in the Sassafras, Spice-bush, and Baberry (Fig. 236). Most anthers are really four-celled when young; a slender partition running lengthwise through each cell and dividing it into two compartments, one answering to the upper, and the other to the lower, layer of the green pulp of the leaf. Occasionally the anther becomes one-celled. This takes place mostly by confluence, that is, the two cells running together into ${ }^{\circ}$ one, as they do

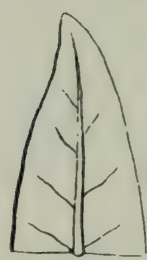
slightly in Pentstemon (Fig. 237)

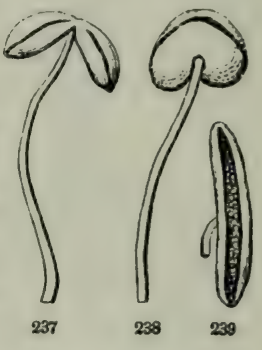
and thoroughly in the Mallow Family (Fig. 238). But sometimes it occurs by the obliteration or disappearance of one half of the anther, as in the Globe Amaranth of the gardens (Fig. 239).

296. The way in which a stamen is supposed to be constructed out of a leaf, or rather on the plan of a

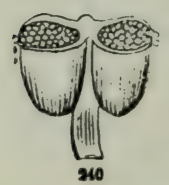
leaf, is shown in Fig. 240, an ideal figure, the lower part representing a stamen with the top of its anther cut away; the upper, the corresponding upper part of a leaf. - The use of the anther is to produce

297. Pollen. This is the powder, or fine dust, commonly of a yellow color, which fills the cells of the anther, and is discharged during blossoming, after which the stamens generally fall off or wither away.

FIG. 235. Stamen of Pyrola ; the anther opening by holes at the top.

FIG. 236. Stamen of Barlierry; tho auther opening hy uplifted valves.

FIG. 237. Stamon of P'entstomon puliescens; anthor-colls slightily coufluent.

FIG. 238. Stamen of Mitlow ; the two cells contluent into one, opening round the margin.

FIG. 239. Anther of Globe Amaranth, of only one cell ; the other cell wanting.

FIG. 240 Diagrain of the lower part of an anther, cut across above, and the upper part of a leaf, to show how the one answers to the other. 
Under the microscope it is found to consist of grains, usually round or oval, and all alike in the same species, but very different in different plants. So that the plant may sometimes be recognized from the pollen alone.

293. A grain of pollen is made up of two coats; the outer coat thickish, but weak, and frequently adorned with lines or bands, or studded with points; the inner coat is extremely thin and delicate, but extensible, and its cavity is filled with a thickish fluid, often rendered turbid by an immense number of minute grains that float in it. When wet, the grains absorb the water and swell so much that many kinds soon burst and discharge their contents.

299. Figures 241-250 represent some common sorts of pollen, magnified one or two hundred diameters, viz.:-A pollen-grain of the Musk Plant, spirally grooved. One of Sicyos, or One-seeded Cucumber, beset with bristly points and marked by smooth bands. One of the Wild Balsam-A pple (Echinocystis), grooved lengthwise. One of Hibiscus or Rose-Mallow, studded with prickly points. One of Succory, many-sided, and dotted with fine points. A grain of the curious compound pollen of Pine. One from the Lily, smooth and oval. One from Enchanter's Nightshade, with three small lobes on the angles. Pollen of Kalmia, composed of four grains united, as in all the Heath family. A grain from an Evening Primrose, with a central body and three large lobes. The figures number from left to right, beginning at the top.
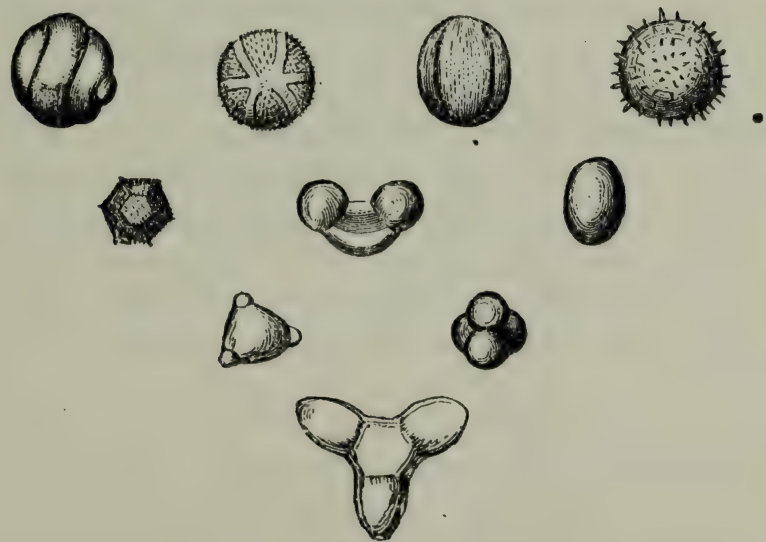


\section{LESSON XVIII.}

\section{MORPHOI.OGY OF PISTILS.}

300. The Pistil, when only one, occupies the centre of the flower; when there are two pistils, they stand facing each other in the centre of the flower; when several, they commonly form a ring or circle; and when very numerous, they are generally crowded in rows or spiral lines on the surface of a more or less enlarged or elongated receptacle.

301. Their number in a blossom is sometimes expressed, in Systematic Botany, by terms compounded of the Greek numerals and the Greek word used to signify pistil, in the following way. A flower with one pistil is said to be monogynous; with two, digynous; with three, trigynous ; with four, tetragynous; with five, pentagynous, and so on; with many pistils, polygynous, _ terms which are explained in the Glossary, but which there is no need to commit to memory.

302. The Parts of a Pistil, as already explained (234), are the veary, the Style, and the Stigma. The ovary is one essential part: * contains the rudiments of seeds, called Ovules. The stigma at the summit is also essential: it receives the pollen, which fertilizes the ovules in order that they may become secds. But the style, the tapering or slemter column commonly borne on the summit of the ovary, and bearing the stigma on its apex or its side, is no more necessary to a pistil than the filanent is to the stamen. Accordingly, there is no style in many pistils : in these the stigma is sessile, that is, rests directly on the ovary. The stigma is very various in shape and appearance, being sometimes a little knob (as in the Cherry, Fig. 213), sometimes a small point, or small surface of bare, moist tissue (as in Fig. 254-256), and sometimes a longitudinal crest or line (as in Fig. 252, 258, 267, 269), and also exhibiting many other shapes.

303. The pistil exhibits an almost infinite variety of forms, and many complications. 'To understand these, it is needful to begin with the simple kinds, and to proceed gradually to the complex. And, first of all, the student should get a clear notion of

304. The Plan or Ident Structure of the Pistil, or, in other words, of the way in which a simple pistil answers to a leaf. Pistils are eilher. 
simple or compound. A simple pistil answers to a single leaf. A compound pistil answers to two or more leaves combined, just as a monopetalous corolla (263) answers to two or more petals, or leaves of the flower, united into one body. In theory, accordingly,

305. The Simple Pistil, or Carpel (as it is sometimes called), consists of the blade of a leaf, curved until the margins meet and unite, forming in this way a closed case or pod, which is the ovary. So that the upper face of the altered leaf answers to the inner surface of the ovary, and the lower, to its outer surface. And the ovules are borne on what answers to the united edges of the leaf. The tapering summit, rolled together and prolonged, forms the style, when there is any; and the edges of the altered leaf turned outwards, either at the tip or along the inner side of the style, form the stigma. To make this perfectly clear, compare a leaf folded together in this way (as in Fig. 251) with a pistil of a Garden Prony, or Larkspur, or with that in Fig. 252; or, later in the season, notice how these, as ripe pods, split down along the line formed by the united edges, and open out again into a sort of leaf, as in the MarshMarigold (Fig. 253). In the Doubleflowering Cherry the pistil occasion ally is found changed back again into

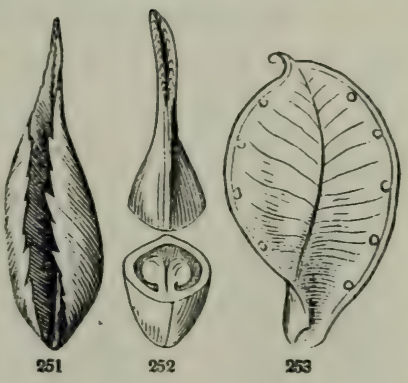
a small green leaf, partly folded, much as in Fig. 251.

306. Fig. 172 represents a simple pistil on a larger scale, the orary cut through to show how the ovules (when numerous) are attached to what answers to the two margins of the leaf. The Stonecrop (Fig. 168) has fire such pistils in a circle, each with the side where the ovules are attached turned to the centre of the flower.

307. The line or seam down the inner side, which answers to the united edges of the leaf, and bears the ovules, is called the ventral or. inner Suture. A corresponding line down the back of the ovary, and which answers to the middle of the leaf, is named the dorsal or outer Suture.

308. The ventral suture inside, where it projects a little into the

FIG. 251. A Inaf rolled up inwards, to show how the pistil is supposed to he formed.

FIf. 252. Pstil of Isopyrum biternatum cut across, with the inner suture tumed towarda the eye.

FIG. 253. Pod or ripe pistil of the Caltha, or Marsh-Marigold, after opening. 
cavity of the ovary, and bears the ovules, is called the Placenta. Obviously a simple pistil can have but one placenta; but this is in its nature double, one half answering to each margin of the leaf. And if the ovules or seeds are at all numerous, they will be found to occupy two rows, one for each margin, as we see in Fig. 252, 172, in the Marsh-Marigold, in a Pea-pod, and the like.

309. A simple pistil obviously can have but one cavity or cell; except from some condition out of the natural order of things. But the converse does not hold true: all pistils of a single cell are not simple. Many compound pistils are one-celled.

310. A simple pistil necessarily has but one style. Its stigma, however, may be double, like the placenta, and for the same reason (305); and it often exhibits two lines or crests, as in Fig. 252, or it may even be split into two lobes.

311. The Compound Pistil consists of two, three, or any greater

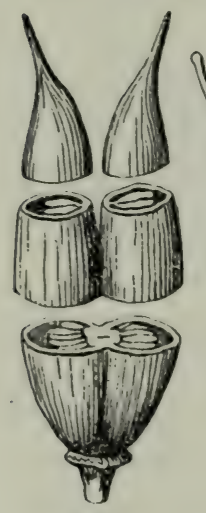

254

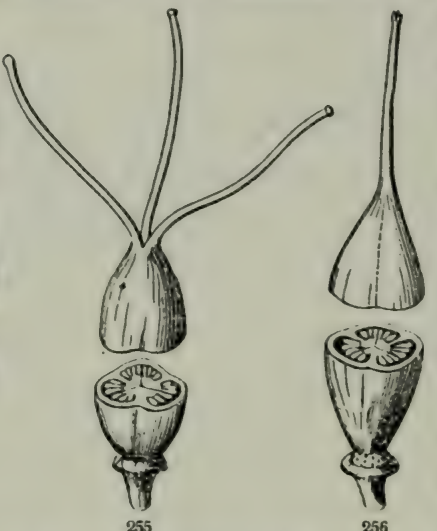

number of pistil-leaves, or carpels (305), in a circle, united into one body, at least by their ovaries. The Cultivated Flax, for example (Fig. 212), has a compound pistil composed of five simple ones with their ovaries united, while the five styles are separate. But in one of our wild species of Flax, the styles are united into one also, for about half their length. So the Common St. John's-wort of the fields has a compound ovary, of three united carpels, but the three styles are separate (Fig. 255), while some of our wild, shrubby species laave the styles also combined into one (Fig. 256 ), although in the fruit they often split into three again. Even the ovaries may only partially combine with each other, as we see in different species of Saxifrage, some having their two pistils nearly separate, while in others they

FIG. 254. Pistil of a Saxifrage, of two simple carpels or pistil-leaves, united at the base only, cut across both above and beliw.

FIG. 255. Compround pistil of common St. John's-wort, cut across : styles separate.

FIG. 256. The same of shrubby St. Juhn's-wort; the three styles united iuto one- 
are joined at the base only, or else below the middle (as in Fig. 254), and in some they are united quite to the top.

312. Fven when the styles arc all consolidated into one, the stigmas are often separate, or enough so to show by the number of their lobes how many simple pistils are combined to make the compound one. In the common Lily, for instance, the three lobes of the-stigma, as well as the three grooves down the ovary, plainly tell us that the pistil is made of three combined. But in the Day-Lily the three lobes of the stigma are barely discernible by the naked eye, and in the Spiderwort (Fig. 257) they are as perfectly united into one as the ovaries and styles are. Here the number of cells in the ovary alone shows that the pistil is compound. These are all cases of

313. Compound Pistils with two or more Cells, namely, with as many cells as there are simple pistils, or carpels, that have united to compose the organ. They are just what would be formed if the simple pistils (two, three, or five in a circle, as the case may be), like those of a Prony or Stonecrop, all. pressed together in the centre of the flower, were to cohere by their contiguous parts.

314. As each simple oviry has its placenta, or seedbearing line (308), at the inner angle, so the resulting compound ovary has as many axile placente (that is, as

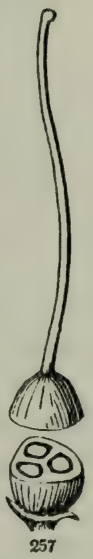
many placentre in the axis or centre) as there are pistil-leaves in its composition, but all more or less consolidated into one. This is shown in the cross-sections, Fig. 254-256, \&c.

315. The partitions (or Dissepiments, as they are technically named) of a compound ovary are accordingly part of the walls or the sides of the carpels which compose it. Of course they are double, one layer belonging to each carpel; and in ripe pods they often split into the two layers.

316. We have described only one, though the commonest, kind of compound pistil. 'There are besides

317. Onc-celled Compound Pistils. These are of two sorts, those with axile, and those with parietal placenta. That is, first, where the ovules or seeds are borne in the axis or centre of the ovary, and, secondly, where they are borne on its walls. 'The first of these cases, or that

FIG. 257. Pistil of Spiderwort (Tradescantia): the three-celled ovary cut acrnss. 
318. With a Free Central Placenta, is what we fiud in Purslane (Fig. 214), and in most Chickweeds (Fig. 258, 259) and P'inks. The difference between this and the foregoing case is only that the delicate partitions have very early vanished; and traces of them

${ }_{258}$ may often be detected. Or sometimes this is a variation

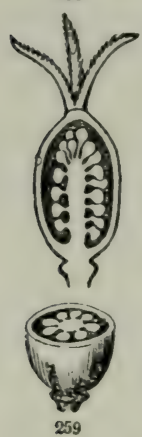
of the mode

319. With Parictal Placentit, namely, with the ovules and seeds borne on the sides or wall (parietes) of the ovary. The pistil of the Prickly Poppy, Bloodroot, Violet, Frost-weed (Fig. 261), Gooseberry, and of many IIypericums, are of this sort. 'Tu understand it perfectly, we have only to inagine two, three, or any number of carpel-leaves (like that of Fig. 251 ), arranged in a circle, to unite by their contiguous edlges, and so form one ovary or pod (as we have endeavored to show in Fig. 260); - very much as in the Stramonium (Fig. 199) the five petals unite by their edges to compose a monopetalous corolla, and the five sepals to form a tubular calyx. Here each carpel is an open leaf, or partly open, bearing orules along its margins; and each placenta consists of the contiguous margins of two pistil-leaves grown together.

320. All degrees occur between this and the several-celled ovary with the placenta in the axis. Com-
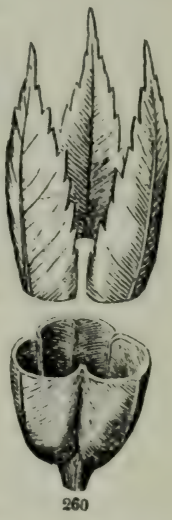
pare, for illustration, the common St. Jolm's-worts, Fig. 255 and 256 , with Fig. 262, a cross-section of the ovary of a different species, in which the three large placenta meet in the axis, but scarcely unite, and with Fig. 263, a similar section of the ripe pod of the same plant, showing three parietal placentæ borne on imperfect partitions projecting a little way into the general eell. Fig. 261 is the same in plan, but with laardly any trace of partitions; that

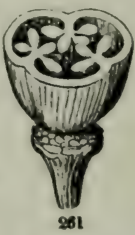
is, the united edges of the leaves only slightly project into the cell.

FIG. 258. Pistil of a Sandwort, with the ovary divided lengthwise; and 259 , the same divided transversely, to show the free contral placenta.

FIG. 260. P'an of a one-celled ovary of three carpel-leaves, with parietal placentæ, cut across below, where it is complete; the upper part showing the top of the three leaves it is compred of, approacling, but not united.

FIG. 261. Cruss-sertion of tho ovary of frust-woed (llohauthoumun), with three parietal placenta. bearing ovules. 
321. The ovary, especially when compound, is often covered by and united with the tube of the calyx, as has already been explained (272). We describe this by saying either "ovary adherent," or "calyx adherent," \&c. Or we say "ovary inferior," when the tube of the calyx is adherent throughout to the surface of the ovary, so that its lobes, and all the rest of the flower, appear to be borne on its summit, as in Fig. 215 and Fig. 216 ; or "halfinferior," as in the Purslane (Fig. 214),

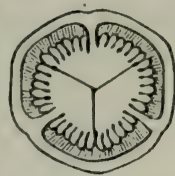

262

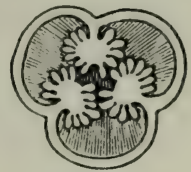

269

where the calyx is adherent part way up ; or "superior," where the calyx and the ovary are not combined, as in the Cherry (Fig. 213) and the like, that is, where these parts are free. The term "ovary superior," therefore, means just the same as "calyx inferior"; and "ovary inferior," the same as "calyx superior."

322. Open or Gymnospermons Pistil. 'This is what we have in the

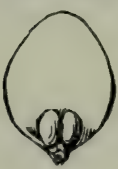
whole Pine family, the most peculiar, and yet the simplest, of all pistils. While the ordinary simple pistil in the eye of the botanist represents a leaf rolled together into a closed pod (305), those of the Pine, Larch (Fig. 264), 264 Cedar, and Arbor-Vita (Fig. 265, 266) are plainly open leaves, in the form of scales, each bearing two or more ovules on the inner face, next the base. At the time of blossoming, these pistil-leaves of the young cone diverge, and the pollen, so abundantly shed from the staminate blossoms, falls directly upon the exposed ovules. Afterwards the scales close over each other until the seeds are ripe. Then they separate again,

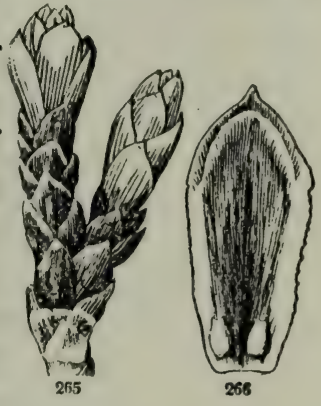
that the seeds may be shed. As their ovules and seeds are not enclosed in a pod, all such plants are said to be Gymnospermous, that is, naked-seeded.

FIG. 262. Cross-fection of the ovary of Iypericum gravenlens. 263. Simılar gection of the ripe pod of the same.

FIG. 264. A pistil, that is, a scale of the cone, of a Larch, at the time of flowering; inside view, showing its pair of naked ovules.

FIQ. 265. Branchlet of the American Arbor-Vite, considerably larger than in nature, terminated by its pistillate flowers, each consisting of a single scale (an open pistil), together forming a small cone.

FIG. 266. One of the scales or pistils of the last, removed and more enlarged. the ibis:lo exposed to view, showing a pair of ovules on its base. 
323. Ovules (234). These are the bodies which are to become seeds. They are either sessile, that is, stalkless, or else borne on a stalk, called the Funiculus. 'They may be produced along the whole length of the cell, or only at some part of it, generally either at the top or the bottom. In the former case they are apt to be numerous; in the latter, they may be few or single (solitary, Fig. 267-26y). As to their direction, ovules are said to be

Horizontal, when they are neither turned upwards nor downwards, as in Fig. 252, 261 ;

Ascending, when rising obliquely upwards, usually from the side of the cell, not from its very base, as in the Buttercup (Fig. 267).

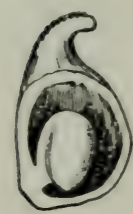

267

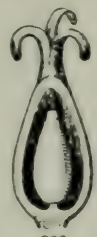

268

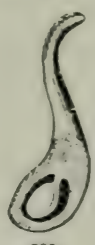

269 and the Purslane (Fig. 214);

Erect, when rising upright from the base of the cell, as in the Buckwheat (Fig. 268);

P'endulous, when hanging from towards the top, as in the Flax (Fig. 212); and

Suspended, when hanging perpendicularly from the very summit of the cell, as in the Anemone (Fig. 269), Dogwood, \&c. All these terms equally apply to seeds.

324. An ovule consists of a pulpy mass of tissue, the Nucleus or kernel, and usually of one or two coats. In the nucleus the embryo is formed, and the coats become the skin or coverings of the seed. There is a hole (Orifice or Furamen) through the coats, at the place which answers to the apex of the ovule. The part by which the ovule is attached is its base; the point of attachment, where the ripe seed breaks away and leaves a scar, is named the Hilum. The place where the coats blend. and cohere with each other and with the nucleus, is named the Chaluza. We will point out these parts in illustrating the four principal kinds of ovule. These are not ditic ult to understand, although ovules are usually so small that a good magnifying-glass is needed for their examination. Moreover, their names, all taken from the Gireek, are unfortunately rather formidable.

325. The simplest sort, although the least conimon, is what is called the

Orthotropous, or strciight ovule. The Buckwheat affords a good

FIG. 267. Section of the ovary of a Buttercup, lengthwise, showing its ascending ovula.

TIG. 268. Section of the ovary of lbuckwheat, shuwing the eruct orule.

F'IG 219. Section of the ovary of Amemone, showing its suspended ovule 
instance of it: it is shown in its place in the ovary in Fig. 268, also detached in Fig. 270, and a much more magnified diagram of it in Fig. 274. In this kind, the orifice $(f)$ is at the top, the chalaza and the hilum $(c)$ are blended at the base or point of attachment, which is at the opposite end ; and the axis of the ovile is straight.
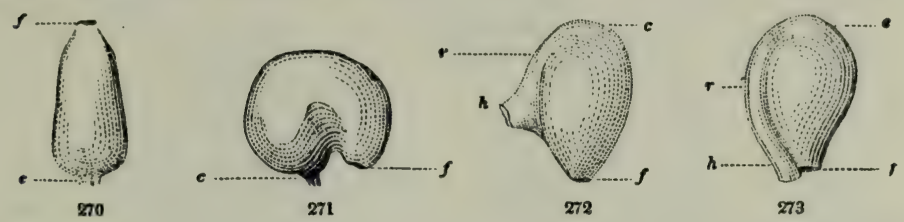

If such an ovule were to grow on one side more than on the other, and double up, or have its top pushed round as it enlarges, it would become a

Campylotropous or curved ovule, as in Cress and Chickweed (Fig. 271). Here the base remains as in the straight kind, but its apex with the orifice is brought round close to it. - Much the most common form of all is the

Anatropous or inverted ovule. This is shown in Fig. 267, and 273 ; also a much enlarged section lengthwise, or diagram, in Fig. 275. 'To understand it, we have only to suppose the first sort (Fig. 270 ) to be inverted on its stalk, or rather to have its stalk bent round, applied to one side of the ovule lengthwise, and to grow fast to the coat down to near the orifice $\left(f^{\prime}\right)$; the hilum, therefore, where the seed-stalk is to break away (h), is close to the orifice; but the chalaza $(c)$ is here at the top of the ovule; between it and the lilum runs a ridge or cord, called the Rhaphe $(r)$, which is simply that part of the stalk which, as the ovule grew and turned over, adhered to its surface. - Lastly, the

Amphitropous or half-anatropous ovule (Fig. 272) differs from the last only in having a shorter rhaphe, ending about half-way between the chalaza and the orifice. So the hilum or attachment is not far from the middle of one side, while the chalaza is at one end and the orifice at the other.

326. The internal structure of the ovule is sufficiently displayed in the subjoined diagrams, representing a longitudinal slice of two

FIG. 270. Orthotropous ovule of Buckwheat : $c$, hilum and chalaza ; $f$, orifice.

FIG. 271. Campylotropous ovule of a Chickweed : $c$, hilum and chalara; $f$, orifice.

FIG. 272. Amphitropous ovule of Mallow : $f$, orifice; $h$, hilum ; $r$, rhaphe; $c$, chalaza

FIG. 273. Anatropous ovule of a Violet; the parts lettered as in the last. 
ovules; Fig. 274, an orthotropous, Fig. 275, an anatropous ovule. The letters correspond in the two; $c$, the chalaza; $f$, the orifice; $r$, rhaphe (of which there is of course none in Fig. 274); $p$, the outer coat, called primine; $s$, inner coat, called secundine; $n$, nucleus or bernel.

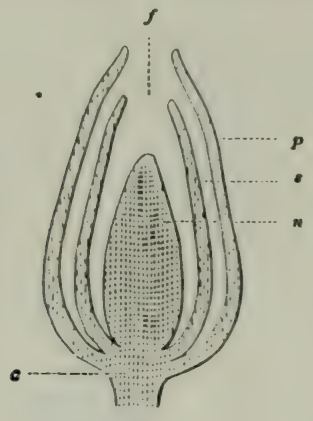

274

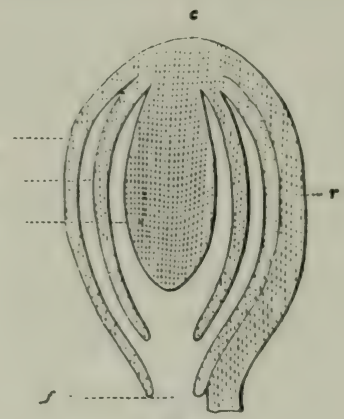

275

\section{LESSON XIX.}

MORPHOLOGY OF THE RECEPTACLE.

327. Tire Receptacle (also called the Torus) is the axis, or stem, which the leaves and other parts of the blossom are attached to (231). It is commonly small and short (as in Fig. 169); but it sometimes occurs in more conspicuous and remarkable forms.

328. Occasionally it is elongated, as in some plants of the Caper family (Fig. 276), making the flower really look like a branch, having its circles of leaves, stamens, \&c., separated by long spaces or internodes.

329. The Wild Geranium or Cranesbill has the receptacle prolonged above and between the insertion of the pistils, in the form of a slender beak. In the blossom, and until the fruit is ripe, it is concealed by the five pistils united around it, and their flat styles covering its whole surface (Fig. 277). But at maturity, the five small and one-seeded fruits separate, and so do their styles, from the beak, and hang suspended from the summit. They split off elasti- 
cally from the receptacle, curving upwards with a sudden jerk, whioh scatters the seed, often throwing it to a considerable distance.

330. When a flower bears a great many pistils, its receptacle is generally enlarged so as to give them room; sometimes becoming broad and flat, as in the Flowering Raspberry, sometimes elongated, as in the Blackberry, the Magnolia, \&c. It is the receptacle in the Straw-
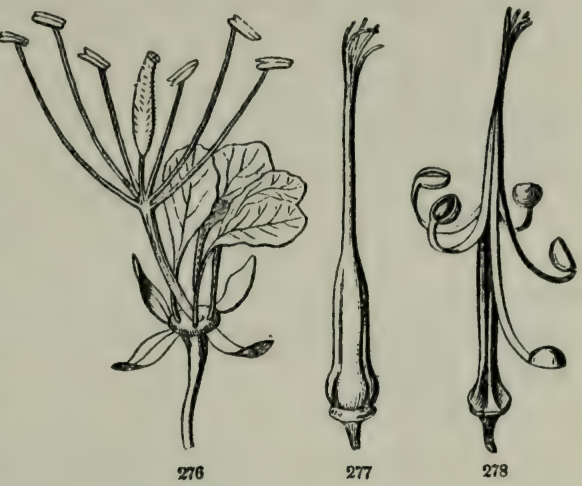
berry (Fig. 279), much

enlarged and pulpy when ripe, which forms the eatable part of the

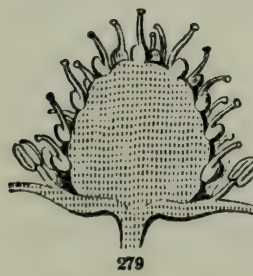
fruit, and bears the small seed-like pistils on its surface. In the Rose (Fig. 280), instead of being convex or conical, the receptacle is deeply concave, or urn-shaped. Indeed, a Rose-hip may be likened to a strawberry turned inside out, like the finger of a glove reversed, and the whole covered by the adherent tube of the calyx, which

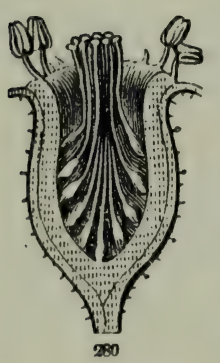
remains beneath in the strawberry.

331. A lisk is a part of the receptacle, or a growth from it, enlarged under or around the pistil. It is hypogynous (269), when free from all union either with the pistil or the calyx, as in the Rue and the Orange (Fig. 281). It is perigynous $(270)$, when it alheres to the

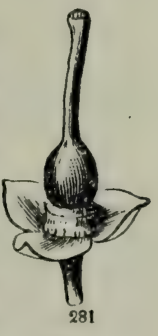

base of the calyx, as in the Bladder-nut and Buckthorn (Fig. 282,

FIC. 276. Flower of Gynanilropsis, the rereptarle enlarged and fittened where it bears the sepals and petals, then elongated into a slender stalk, bearing the stamens (in appearance, but they are monadelphous) above its middle, and a compound ovary on its sunmit.

FIG. 277. Young fruit of the common Wild Cranesbill.

FIG. 278. The same, ripe, with the five pistils splitting away from the long beak or recep tacle, and hanging from its top by their styles.

FTG. 279. Longitudinal section of a young strawberry, enlarged.

FIG. 280. Similar section of a young Rose-hip.

FIG. 281. Pistil of the Orange, with a large hypogynous disk at its base. 
283). Often it adheres both to the calyx and to the ovary, as in New Jersey 'Tea, the Apple, \&c., consolidating the whole together. In such cases it is sometimes carried up and expanded on the top of

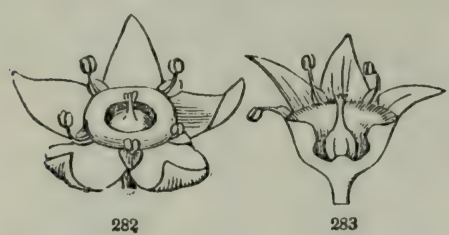
the ovary, as in the Parsley and the Ginseng families, when it is said to be epigynous (273).

332. In Nelumbium, - a large Water-Lily, abounding in the waters of our Western States, - the singular and greatly enlarged receptacle is shaped like a top, and bears the small pistils immersed in separate cavities of its flat upper surface (Fig. 284).

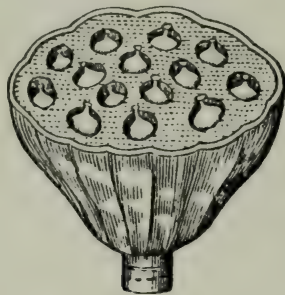

281

\section{LESSON XX.}

THE FRUIT.

333 The ripened ovary, with its contents, becomes the Fruit. When the tube of the calyx adheres to the ovary, it also becomes a part of the fiuit: sometimes it even forms the principal bulk of it, as in the apple and pear.

334. Some fruits, as they are commonly called, are not fruits at all in the strict botanical sense. A strawberry, for example (as we have just seen, 330, Fig. 282), although one of the choicest fruits in the common acceptation, is only an enlarged and pulpy receptacle, bearing the real fruits (that is, the ripened pistils) scattered over its

FIt. 282. Fluwer of a Buckthurn, with a largo perigynous disk. 283. The same, divided.

FIG. 284. Receptacle of Nolumbium, in fruit. 
surface, and too small to be much noticed. And mulberries, figs, and pine-apples are masses of many fruits with a pulpy flower-stalk, \&c. Passing these by for the present, let us now consider only

335. Simple Fruits. These are such as are formed by the ripening of a single pistil, whether simple (305) or compound (311).

336. A simple fruit consists, then, of the Seed-vessel (technically called the Pericarp), or the walls of the ovary matured, and the seeds, contained in it. Its structure is generally the same as that of the ovary, but not always; because certain changes may take place after flowering. The commonest change is the obliteration in the growing fruit of some parts which existed in the pistil at the time of flowering. The ovary of a IIorsechestnut, for instance, has three cells and two ovules in each cell; but the fruit never has more than three seeds, and rarely more than one or two, and only as many cells. Yet the vestiges of the seeds that have not matured, and of the wanting cells of the pod, may always be detected in the ripe fruit. This obliteration is more complete in the Oak and Chestnut. 'The ovary of the first likewise has three cells, that of the second six or seven cells, each with two ovules hanging from the summit. We might therefore expect the acorn and the chestnut to have as many cells, and two seeds in each cell. Whereas, in fact, all the cells and all the ovules but one are uniformly obliterated in the forming fruit, which thus becomes one-celled and one-seeded, and rarely can any vestige be found of the missing parts.

337 . On the other hand, a one-celled ovary sometimes becomes several-celled in the fruit by the formation of false partitions, commonly by cross-partitions, as in the jointed por of the Sea-Rocket and the Tick-Trefoil (Fig. 304).

338. Their Kinds. In defining the principal kinds of simple fruits which have particular names, we may classify them, in the first place, into,-1. Fleshy Fruits; 2. Stone Fruits; and 3. Dry Fruits. The first and second are of course indehiscent ; that is, they do not split open when ripe to discharge the seeds.

339. In fleshy fruits the whole pericarp, or wall of the ovary, thickens and becomes soft (fleshy, juicy, or pulpy) as it ripens. Of this the leading kind is

340. The Berry, such as the gooseberry and currant, the blueberry and cranberry, the tomato, and the grape. Ilere the whole flesh is equally soft throughout. The orange is merely a berry with a leathery rind. 
341. The Pepo, or Gourd-fruit, is the sort of berry which belongs to the Gourd fumily, mostly with a lard rind and the inner portion softer. The pumpkin, squash, cucumber, and melon are the prin. cipal examples.

342. The Pone is a name applied to the apple, pear, and quince; fleshy fruits like a berry, but the principal thickness is calyx, only the papery pods arranged like a star in the core really belonging to the pistil itself (333).

343. Secondly, as to fruits which are partly fleshy and partly hard, one of the most familiar kinds is

344. The Drupe, or Stone-fruit; of which the cherry, plum, and

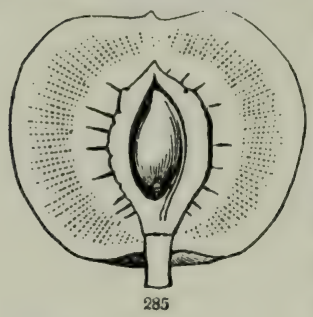
peach (Fig. 285) are familiar examples. In this the outer part of the thickness of the pericarp becomes fleshy, or softens, like a berry, while the inner hardens, like a nut. From the way in which the pistil is constructed (305), it is evident that the fleshy part here answers to the lower, and the stone to the upper, side of the leaf; - a leaf always consisting of two layers of green pulp, an upper and an under layer, which are considerably different (439).

345. Whenever the walls of a fruit are separable into two layers, the outer layer is called the Exocarp, the inner, the Endocarp (fiom Greek words meaning "outside fruit" and "inside fruit"). But in a drupe the outer portion, being fleshy, is likewise called Sarcocarp (which means "fleshy fruit"), and the inner, the Putamen or stone. The stone of a peach, and the like, it will be perceived, belongs to the fruit, not to the seed. When the walls are separable into three layers, the outer layer is named either exocarp or Epicarp; the middle one is called the Mesocarp (i. e. middle fruit); and the innermost, as before, the Endocarp.

346. Thirdly, in dry fruits the seed-vessel remains herbaceous in texture, or becomes thin and membranaceous, or else it hardens throughout. Some forms remain closed, that is, are indehiscent (338); others are dehiscent, that is, split open at maturity in some regular way. Of indehiscent or closed dry fiuits the principal kinds are the following.

347. The Achenium, or Akene, is a small, one-seeded, dry, indehis-

FIG. 285. Longitudinal section of a peach, showing the flesh, the stone, and the seed. 
cent frnit, such as is popularly taken for a naked seed : but it is plainly a ripened ovary, and shows the remains of its style or stigma, or the place

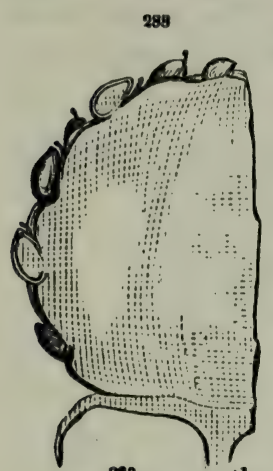

from which it has

fallen. Of this sort are the fruits of the buttercup (Fig. 286,

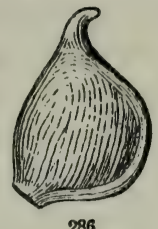

286

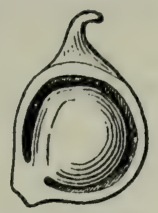

287 287), the Cinque-foil, and the Strawberry (Fig. $279,288)$; that is, the real fruits, botanically speaking, of the latter, which are taken for seeds, not the large juicy receptacle on the surface of which they rest (330). Here the akenes are simple pistils (305), very numerous in the same flower, and forming a head of such fruits. In the Nettle, Hemp, \&c., there is only one pistil to each blossom.

348. In the raspberry and blackberry, each grain is a similar pistil, like that of the strawberry in the flower, but ripening into a miniature stone-fruit, or drupe. So that in the strawberry we eat the receptacle, or end of the flower-stalk; in the raspberry, a cluster of stone fruits, like cherries on a very small scale; and in the blackberry, both a juicy receptacle and a cluster of stone-fruits covering it (Fig. 289, 290).

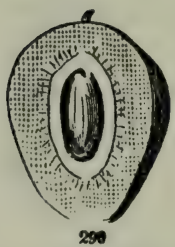

349. The fruit of the Composite family is also an achenium. Here the surface of the ovary is covered by an adherent calyx-tube, as is evident from the position of the corolla, apparently standing on its summit (321, xnd Fig. 220,a). Sometimes the limb or divisions of the calyx are entirely wanting, as in Mayweed (Fig. 291) and Whiteweed. Sometimes the limb of the calyx forms a crown or cup on the top of the achenium, as in Succory (Fig. 292); in Coreopsis, it often takes the form of two blunt teeth or scales; in the Sunflower (Fig. 293), it consists of two

FIG. 286. Achenium of Buttercup. 287. Same, cut through, to show the seed within.

FIs. 288. Slice of a part of a ripe strnwherry, enlarged; some of the achenin shown cut through.

FIG. 289. Elice of a part of a blackberry. 290. One of the grains or drupes divided, more enlarged; showing the flesh, the stone, and the seed, as in Fig. 285. 
thin scales which fall off at the touch ; in the Sneezeweed, of about five very thin scales, which look. more like a calyx (Fig. 294); and in the 'Thistle, Aster, Sow-'Thistle (Fig. 295), and hundreds of others, it is cut up into a tuft of fine bristles or hairs. This is called the Pappus; - a name which properly means the down like that of the Thistle; but it is applied to all these forms, and to every other under which the limb of the calyx of the "compound flowers" appears. In Lettuce, Dandelion (Fig. 296), and the like, the achenium as it matures tapers upwards into a slender beak, like a stalk to the pappus.

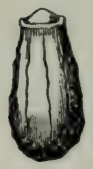

291

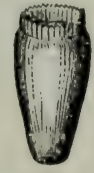

282

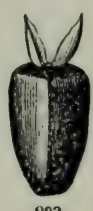

293

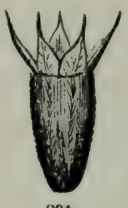

291
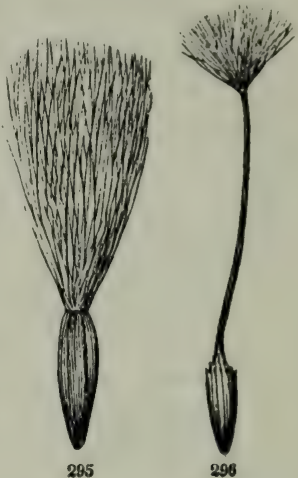

350. A Utricle is the same as an achenium, but with a thin and bladdery loose pericarp; like that of the Goosefoot or Pigweed

297

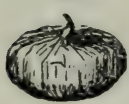

谈

298 (Fig. 297). When ripe it bursts open irregularly to discharge the seed; or sometimes it opens by a circular line all round, the upper part falling off like a lid ; as in the Amaranth (Fig. 298).

351. A Caryopsis, or Grain, differs from the last only in the seed adhering to the thin pericarp ihroughout, so that fruit and seed are incorporated into one body; as in wheat, Indian corn, and other kinds of grain.

352. A Nut is a dry and indehiscent fruit, commonly one-celled and one-seeds $i$, with a hard, crustaceous, or bony wall, such as the cocoanut, hazelnut, chestnut, and the acorn (Fig. 21, 299). Here the

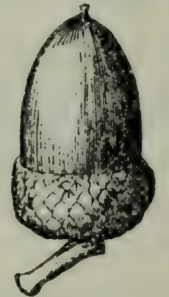

280 involucre, in the form of a cup at the base, is called the Cupule. In the Chestnut it forms the bur; in the Hazel, a leafy husk.

FIG. 291. Achenium of Mayweed (no pappus). 292. That of Succory (its pappus a shal low cup). 293. Of Sunflower (pappus of two deciduous scales). 294. Of Sueezeweed (Ilelenium), with its pappus of five scales. 295. Of Sutv-T'hixtle, with its pappus of delicate downy hairs. 296. Of the Dandelion, its pappus raised on a long beak.

IG. 297. Utricle of the conmon Pigweed (Chenopodium album).

FIG. 298. Utricle (pjxis) of Amaranth, opening all round (circumcisailes.

FIG. 2a9. Nut (acorn) of the Oak, with its cup (or cupule). 
353. A Snmarn, or Key-frnil, is either a nut or an achenium, or any other indehiscent fruit, furnished with a wing, like that of the Mapls (Fig. 1), Ash (Fig. 300), and Elm (Fig. 301).

354. The Capsulc, or Pod, is the general name for dry seed-vessels which split or burst open at maturity. But several sorts of pod are distinguished by particular names. Two of them belong to simple pistils, namely, the Follicle and the Legume.

355. The Follicle is a fruit of a simple pistil opening along the inner suture (307). The pods of the Prony, Columbine, Larkspur, Marsh-Marigold (Fig. 302), and Milkweed are of this kind. 'The seam along which the follicle opens answers to the edges of the pistil-leaf (Fig. 251, 253).

356. The Legume or true Pod, like the Pea-pod (Fig.
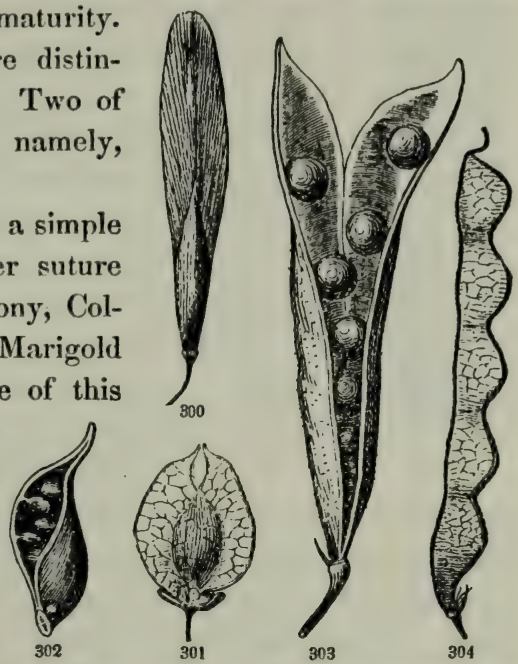
$303)$, is similar to the follicle, only it opens by the outer as well as the inner or ventral suture (307), that is, by what answers to the midrib as well as by what answers to the united margins of the leaf. It splits therefore into two pieces, which are called valves. The legume belongs to plants of the Pulse family, which are accordingly termed Leguminosa, that is, leguminous plants. So the fruits of this family keep the name of legume, whatever their form, and whether they open or not. A legume divided across into one-seeded joints, which separate when ripe, as in Tick-Trefoil (Fig. 304), is named a

\section{Loment.}

357. The true Capsule is the pod of a compound pistil. Like the ovary it resulted from, it may be one-celled, or it may have as many cells as there are carpels in its composition. It may discharge its seeds through chinks or pores, as in the Poppy, or burst irregularly in some part, as in Lobelia and the Snapdragon; but commonly it splits open (or is dehiscent) lengthwise into regular pieces, called valves.

FIG. 300. Samarn or key of the White Ash. 301. Samara of the Amorican Elm.

FIG. 302 Follicle of Marsh-Marigold (Caltha palustris).

FIG. 303. Legune of a Siveet Pea, opened.

FIG 304. Ioment or jointed legume of Tick-'Trefoil (Desmodium). 
358. Dehiscence of a pod resulting from a compound pistil, when regular, takes place in one of two principal ways, which are best shown in pods of two or three cells. Either the pod

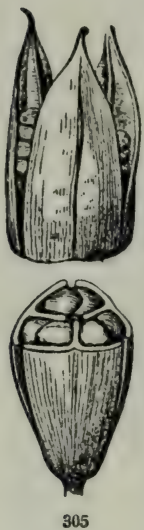
splits open down the middle of the back of each eell, when the dehiscence is loculicidal, as in Fig. 305 ; or it splits through the partitions, after which each cell

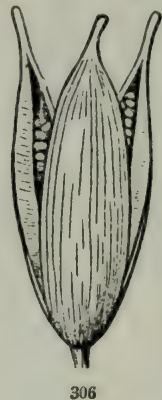

306

generally opens at its inner angle, when it is septicidul, as in Fig. 306 . These names are of Latin derivation, the first meaning "cutting into the cells"; the second, "cutting through the partitions." Of the first sort, the Lily and Iris (Fig. 305) are good examples; of the second, the Rhododendron, Azalea, and St. John's-wort. From the structure of the pistil $(305-311)$ the student will readily see, that the line down the back of each cell answers to the dorsal suture of the carpel; so that the pod opens by this when loculicidal, while it separates into its component carpels, which open as follicles, when septicidal. Some pods open both ways, and so split into twice as many valves as the carpels of which they are formed.

359. In loculicidal dehiscence the valves naturally bear the partitions on their middle; in the septicidal, half the thickness of a partition is borne on the margin of each valve. See the diagrams, Fig. 307-309. A variation of either mode sometimes occurs, as
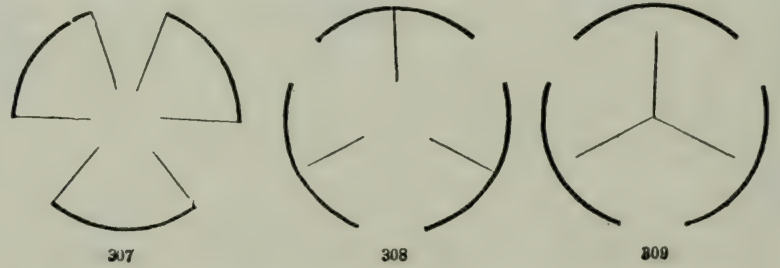

shown in the diagram, Fig. 309, where the valves break away from the partitions. This is called seplifragal dehiscence; and may be seen in the Morning-Glory.

360. Three remaining sorts of pods are distinguished by proper names, viz. :-

FI(3. 305. Capsule of Iris (with loculicidal dehiscence), bolow cut across.

FIG. 306. Pod of a Marsh St. Jolun'y-wort, with septicidal dehiscenco.

FIQ. 307. Diagram of septicidal; 308, of loculicidal; and 300, of septifragal dehiscence. 
361. The Silique (Fig. 310), the peculiar pod of the Mustard family; which is two-celled by a false partition stretched across between two parietal placentæ. It generally opens by two valves from below upwards, and the placenta with the partition are left behind when the valves fall off.

362. A Silicle or Pouch is ouly a short and broad silique, like that of the Shepherd's Purse, of the Candy-tuft, \&ce.

363. The Pyxis is a pod which opens by a circular horizontal line, the upper part forming a lid, as

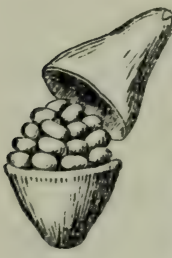

311 in Purslane (Fig. 311), the Plantain, Henbane, \&c. In these the dehiscence extends all round, or is circumcissile. So it does in Fig. 298, which represents a sort of one-

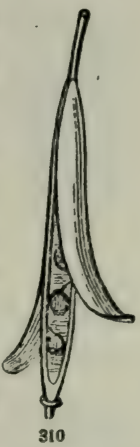
seeded pyxis. In Jeffersonia or Twin-leaf, the line does not separate quite round, but leaves a portion to form a hinge to the lid.

364. Multiple or Collcctive Fruits (334) are, properly speaking, masses of fruits, resulting from several or many blossoms, aggregated into one body. The pine-apple, mullberry, Osage-orange, and the fig, are fruits of this kind. This latter is a peculiar for $\mathrm{m}$, however, being to a mulberry nearly what a Rose-hip is to a strawberry (Fig. 279, 280), namely, with a hollow receptacle bearing the flowers concealed inside; and the whole eatable part is this puipy common receptacle, or hollow thickened flower-stalk.

365. A Strobile, or Cone (Fig. 314), is the peculiar multiple fruit of Pines, Cypresses, and the like; hence named Conifera, viz. conebearing plants. As already shown (322), these cones are made of open pistils, mostly in the form of flat scales, regularly overlying each other, and pressed together in a spike or head.

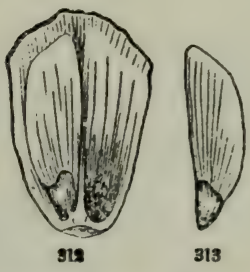
Each scale bears one or two naked seeds on its inner face. When the cone is ripe and dry, the scales turn back or cliverge, and the seed peels off and falls, generally carrying with it a wing, which was a part of the lining of the scale, and which facilitates the dispersion of the seeds by the wind (Fig. 312, 313). In Arbor-Vitæ, the scales

FIक. 310. Silique of Fpring Cress (Carlaminn rhomboidea), opening.

FIG. 311. The pyxis, or pod, of the common Purslane

FIf. 312. Inside view of a scale from the cone of Pitch-Pine; with one of the seeds (Fig. 313) detached; the other in its place on the scale. 
of the small cone are few, and not very unlike the leaves (Fig. 265). In Cypress they are very thick at the top and narrow at the base, so as to make a peculiar surt of clused cone. In Juniper and Red C'edar, the few scales of the very small cone become fleshy, and ripen into a fruit which might be taken for a berry.

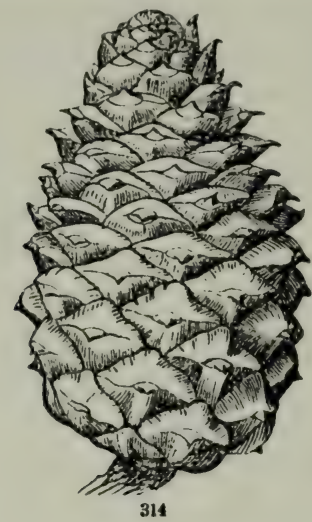

\section{LESSON XXI.}

THE SEED.

366. The ovules (323), when they have an embryo (or undeveloped plantlet, 16) formed in thew, become seeds.

367. The Seed, like the ovule from which it originates, consists of its coats, or integuments, and a kernel.

368. The Seed-coats are commonly two (324), the outer and the

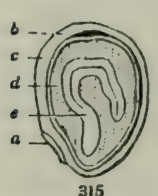

315 inner. Fig. 315 shows the two, in a seed cut through lengthwise. 'The outer coat is often hard or cruslaceous, whence it is called the Testa, or shell of the seed; the inner is thin and delicate.

369. The shape and the markings, so various in different seeds, depend mostly on the outer coat. Sometimes it lits

FIG. 314. Cone of Pitch-Pine (Pinus rigida).

FIG. 315. Seed of Basswood cut through lengthwise: $a$, the hilum or scar; $b$, the outer coat; $c$, the inner : $d$, the albumen; $e$. the embryo. 
the kernel closely; sometimes it is expanded into a wing, as in the Trumpet-Creeper (Fig. 316), and occasionally this wing is cut up into shreds or tufts, as in the Catalpa ; or instead of a wing it may bear a coma, $\mathrm{r}$ tuft of long and soft hairs, such as we find in the Milkweed or Silkweed (Fig. 317). The object of wings or downy tufts is to render the seeds buoyant, so that they may be widely dispersed by the winds. This is clear, not only from their evident adaptation to this purpose, but also from the interesting fact

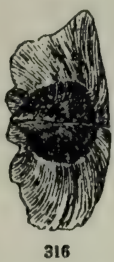
that winged and tufted seeds are found only in fruits that split open at maturity, never in those that remain closed. The coat of some seeds is beset with long hairs or wool. Cotton, one of the most important vegetable products, - since it forms the principal clothing of the larger part of the human race, - consists of the long and woolly hairs which thickly cover the whole surface of the seed. Certain seeds have an additional, but more or less incomplete covering, outside of the real seed-coats, called an

370. Aril, or Arillus. The loose and transparent bag which encloses the seed of the White Water-Lily (Fig.

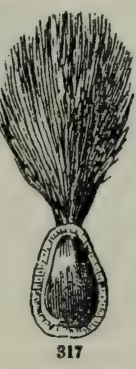
318 ) is of this kind. So is the mace of the nutmeg; and also the

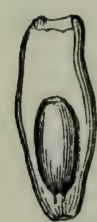
scarlet pulp around the seeds of the Waxwork (Celastrus) and Strawberry-bush (Euonymus), so ornamental in autumn, after the pods burst. The aril is a growth from the extremity of the seed-stalk, or the placenta.

371. The names of the parts of the seed and of its kinds are the same as in the ovule. The scar left where the seedstalk separates is called 。 the Hilum. The orifice of the ovule, now closed up, and showing only a small point or mark, is

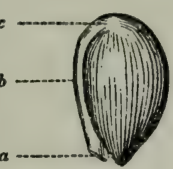

319

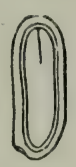

322

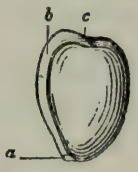

820

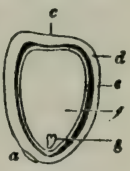

321 named the Micropyle. The terms orthotropous, anatropous, \&c.

FIG. 316. - A winged seed of the Trumpet-Creeper.

FIG. 317. Seed of Milkweed, with a coma or tuft of long silky hairs at one end.

FIG. 318. Seed of White Water-Iily, enclused in its aril.

FIG. 319. Seed of a Violet (anatropous): $a$, hilum; $b$, rhaphe; $c$, chalaza.

FIG. 320. Seed of a Jarkspur (also anatropons); the parts letfered as in the last.

FIG. 321. The same, cut throngh longthwise: $a$, the hilum; $c$, chalaza ; $d$, onter seedcoat ; $e$, inner seed-coat ; $f$, the albumen; $g$, the minute embryo.

FIG. 322. Seed of a St. Juhn's-wort, divided lengthwiso; here the whole kemel is embryo. 
apply to seeds just as they do to ovules (325); and so do those terms which express the direction of the ovule or the seed in the cell ; such as erect, ascending, horizontul, pendulous, or suspended (323): therefore it is not necessary to explain them anew. The accompanying figures (Fig. $319-322$ ) show all the parts of the most common kind of seed, namely, the anatropous.

372. The Kernel, or Nucleus, is the whole body of the seed within the coats. In many seeds the kernel is all Embryo; in others a large part of it is the Albumen.

373. The Albumen of the seed is an accumulation of nourishing matter (starch, \&c.), commonly surrounding the embryo, and destined to nourish it when it begins to grow, as was explained in the earlier Lessons $(30-32)$. It is the floury part of whent, corn (Fig. 38, 39), buckwheat, and the like. But it is not always mealy in texture. In Poppy-seeds it is oily. In the seeds of Patony and Barberry, and in the cocoanut, it is fleshy; in coffee it is corneous (that is, hard and tough, like horn); in the Ivory Palm it has the hardness as well as the general appearance of ivory, and is now largely used as a substitute for it in the fabrication of small objects. However solid its texture, the albumen always softens and partly liquefies during germination; when a considerable portion of it is transformed into sugar, or into other forms of fluid nourishment, on which the growing embryo may feed.

374. The Embryo, or Germ, is the part to which all the rest of the seed, and also the fruit and the flower, are subservient. When the embryo is small and its parts little developed, the albumen is the more abundant, and makes up the principal bulk of the seed, as in Fig. 30, 321, 325. On the other hand, in many seeds there is no albumen at all; but the strong embryo forms the whole kernel; as in the Maple (Fig. 2, 3), Fumpkin (Fig. 9), Almond, Plum, and Apple (Fig. 11, 12), Beech (Fig. 13), and the like. 'Then, whatever nourishment is needed to establish the plantlet in the soil is stored up in the body of the embryo itself, mostly in its seed-leaves. And these accordingly often become very large and thick, as in the almond, bean, and pea (Fig. 16, 19), acorn (Fig. 21), chestnut, and horsechestnut (Fig. 23, 24). Besides these, Fig. 25, 26, 30 to 37, 43 , and 45 exhibit various common forms of the embryo; and also some of the ways in which it is placed in the albumen; being sometimes struight, and sometimes variously coiled up or packed away. 
375. The embryo, being a rudimentary plantlet, ready formed in the seed, has only to grow and develop its parts to become a young plant (15). Even in the seed these parts are generally distinguishable, and are sometimes very conspicuons; as in a Pumpkin-seed, for example (Fig. 323, 324). They are, first,

376. The Radicle, or rudimentary stemlet, which is sometimes long and slender, and sometimes very short, as we may see in the numerous figures already referred to. In the seed it always points to the micropyle (371), or what answers to the foramen of the ovule (Fig. 325, 326). As to its position in the fruit, it is said to be inferior when it points to the base of the pericarp, superior when it points to its summit, \&c. The base or free end of the radicle gives rise to the root; the other extremity bears

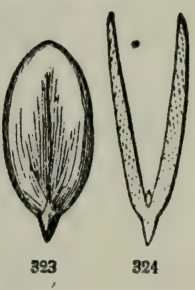

377. The Cotyledons or Secd-Leaves. With these in various forms we have already become familiar. The number of cotyledons has also been explained to be important (32, 33). In Corn (Fig. 40), and in all Grasses, Lilies, and the like, we have a

Monocotyledonous embryo, namely, one fur-

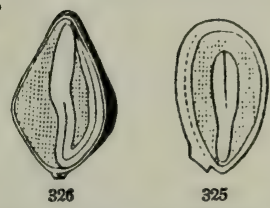
nished with only a single cotyledon or seed-leaf. - Nearly all the rest of our illustrations exhibit various forms of the

Dicotyledonous embryo; namely, with a pair of cotyledons or seedleaves, always opposite each other. In the Pine family we find a

Polycotyledonous embryo (Fig. 45, 46); that is, one with several, or more than two, seed-leaves, arranged in a circle or whorl.

378. The Plumule is the little bud, or rudiment of the next leaf or pair of leaves after the seed-leaves. It appears at the summit of the radicle, between the cotyledons when there is a pair of them, as in Fig. 324, 14, 24, \&c.; or the cotyledon when only one is wrapped round it, as in Indian Corn, Fig. 40. In germination the plumule develops upward, to form the ascending trunk or stem of the plant, while the other end of the radicle grows downward, and becomes the root.

FIC. 323. Finhryo of the Pumpkin, seon flatwise. 324. Same cht through and viewed ellgowise, enlarged; the small plumule scen between the cotyledens at their base.

FIG. 325. Seed of a Violet (Fig. 319) cut through, showing the einbryo in the section, edgewise; being an anatropous seed, the radicle of the straight embrye points down to the base noar the hilum.

FIG. 326. Similar section of the orthotropous seed of Buck wheat. Ilere the radicle points directly away from the hilum, and to the apex of the seed; also the thin cotylodons happen In thia plant to be bent round into the same direction. 
379. This completes the circle, and brings our vegetable history round to its starting-point in the Second Lesson; namely, The Growth of the Plant from the Seed.

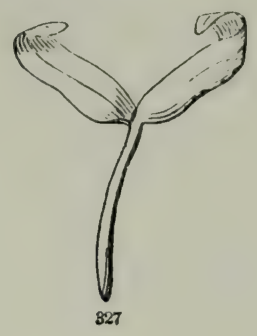

\title{
I.ESSON XXII.
}

\author{
HOW PLANTS GROW.
}

380. A plant grows from the seed, and from a tiny embryo, like that of the Maple (Fig. 327), becomes perhaps a large tree, producing every year a crop of seeds, to grow in their turn in the same way. But how does the plant grow? A little seedling, weighing only two or three grains, often doubles its weight every week of its early growth, and in time may develop into a huge bulk, of many tons' weight of regetable matter. How is this done? What is vegetable matter? Where did it all come from? And by what means is it increased and accumulated in plants? Such questions as these will now naturally arise in any inquiring mind; and we must try to answer them.

381. Growth is the increase of a living thing in size and substance. It appears so natural to us that plants and animals should grow, that people rarely think of it as requiring any explanation. They say that a thing is so because it grew so. Still we wish to know how the growth takes place.

382. Now, in the foregoing Lessons we explained the whole structure of the plant, with all its organs, by begimning with the seedling pluntlet, and following it onward in its development through the 
whole course of vegetation $(12, \& c$.$) . So, in attempting to learn$ how this growth took place, it will be best to adopt the same plan, and to commence with the commencement, that is, with the first formation of a plant. This may seem not so easy, because we have to begin with parts too small to be seen without a good microscope, and requiring much skill to dissect and exhibit. But it is by no means difficult to describe them; and with the aid of a few figure : we may hope to make the whole matter clear.

383. The embryo in the ripe seed is already a plant in miniature, as we have learned in the Second, Third, and Twenty-first Lessons. It is already provided with stem and leaves. To learn how the plant began, therefore, we must go back to an earlier period still ; namely, to the formation and

384. Growth of the Embryo itself. For this purpose we return to the orule in the pistil of the flower (323). During or soon after blossoming, a cavity appears in the kernel or nucleus of the ovule (Fig. 274, o), lined with a delicate membrane, and so forming a closed sac, named the cmbryo-sac $(s)$. In this sac or cavity, at its upper end (viz. at the end next the orifice of the ovule), appears a roundish little vesicle or bladder-like body $(v)$, perhaps less than one thousandth of an inch in

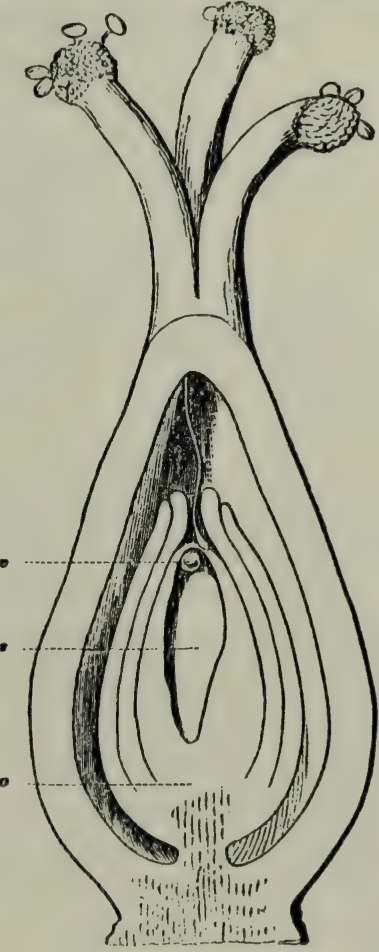

329 diameter. This is the embryo, or rudimentary new plant, at its very beginning. But this vesicle never becomes anything more than a grain of soft pulp, unless the ovule has been acted upon by the pollen.

FIC. 328. Magnified pistil of Buckwheat; fle ovary and nvule divided lengtluwiso: anme pollen on the stigmas, one grain distinctly showing its tuhe, which penefrates the style, reappears in the cavity of the ovary, enters the mouth of the ovule $(0)$, and reaches the surface of the embryo-sac ( $s$ ), near the embryonal vesicle (v). 
385. The pollen (297) which falls upon the stigma grows there in a peculiar way: its delicate inner coat extends into a tube (the pollen-tube), which sinks into the loose tissue of the stigma and the interior of the style, something as the root of a seedling sinks into the loose soil, reaches the cavity of the ovary, and at length penetrates the orifice of an ovule. The point of the pollen-

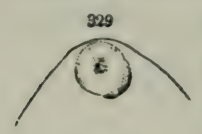
tube reaches the surface of the embryo-sac, and in some uncxplained way causes a particle of soft pulpy or mucilaginous matter (Fig. 328) to form a mem-

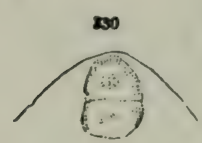
branous coat and to expand into a vesicle, which is the germ of the embryo.

386. 'This vesicle (shown detached and more magnified in Firg. 329) is a specimen of what botanists call

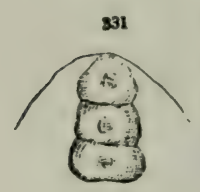
a Cell. Its wall of very delicate membrane encloses a mucilaginous liquid, in which there are often some minute grains, and commonly a larger soft mass (called its nucleus).

387. Growth takes place by this vesicle or cell,

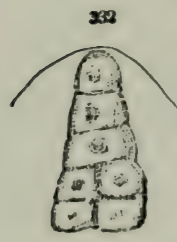
after enlarging to a certain size, dividing by the formation of a cross partition into two such cells, cohering together (Fig. 330); one of these into two more (Fig. 331); and these repeating the process by partitions formed in both directions (Fig. 332); furming a cluster or mass of cells, essentially like the first, and all proceeding from it. After increasing in number for some time in this way, 233 and by a continuation of the same process, the embryo begins to shape itself; the upper end forms the radicle or root-end,

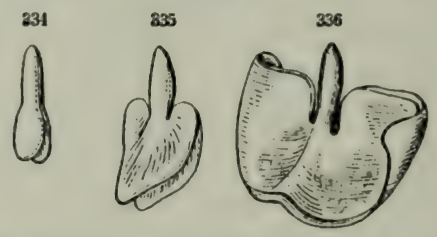
while the other end shows a noteh between two lobes (Fig. 333), these lobes become the cotyledons or seed-leaves, and the embryo as it exists in the seed is at length completed (Fig. 336)

FIG. 329. Vesicle or first cell of the embryo, with a portion of the sunmit of the embryo. sac, detached. 330. Same, more advanced, divided into two cells. 331. Same, a little farther advanced, consisting of threo cells. 332. Same, still more advanced, consisting of a littie mass of young cells.

FIG. 333. Forming embryo of Buckwheat, moderately magnified, showing a nick at the end where the cotyledons are to ho. 33.1. Same, more advaluced in growth. 335. Same,

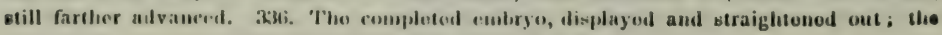
same us show 1 in a vection whon folded toguther in Fig. Batj. 
388. The Growth of the Plantlet when it springs from the seed is only a continuation of the same process. The bladder-like cells of which the embryo consists multiply in number by the repeated division of each cell into two. And the plantlet is merely the aggregation of a vastly larger number of these cells. This may be clearly ascertained by magnifying any part of a young plantlet. The young root, being more transparent than the rest, answers the purpose best. Fig. 56 , on page 30 , represents the end of the rootlet of Fig. 55, magnified enough to show the cells that form the surface. Fig. 337 and 338 are two small bits of the surface more highly magnified, showing the cells still larger. And if we make a thin slice through the young root both lengthwise and crosswise, and view it under a good microscope 'Tig. 340), we may per-

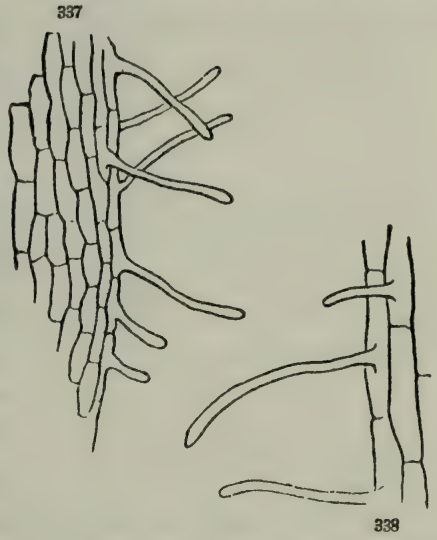
ceive that the whole interior is made up of just such cells. It is the same with the young stem and the leaves (Fig. 355, 357). It is essentially the same in the full-grown herb and the tree.

389. So the plant is an aggregation of countless millions of little vesicles, or cells (Fig. 339), as they are called, essentially like

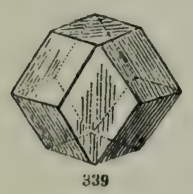
the cell it began with in the formation of the embryo (Fig. 329); and this first cell is the foundation of the whole structure, or the ancestor of all the rest. And a plant is a kind of structure built up of these individual cells, something as a house is built of bricks, - only the bricks or cells are not brought to the forming plant, but are made in it and by it; or, to give a better comparison, the plant is constructed much as a honeycomb is built up of cells, - only the plant constructs itself, and shapes its own materials into fitting forms.

390. And vegetable growth consists of two things; -1 st, the expansion of each cell until it gets its full size (which is commonly not more than $\frac{1}{d} \frac{1}{d}$ of an inch in diameter) ; and $2 \mathrm{~d}$, the multiplication

FIC. 337. Tissue from the rootlet of a seedling Maple, magnified, showing root-hairs 838. A smiall portion, more magnified.

F1G. 339. A regularly twelve-sided cell, like those of Fig. 340, detached. 
of the cells in number. It is by the latter, of course, that the principal increase of plants in bulk takes place.

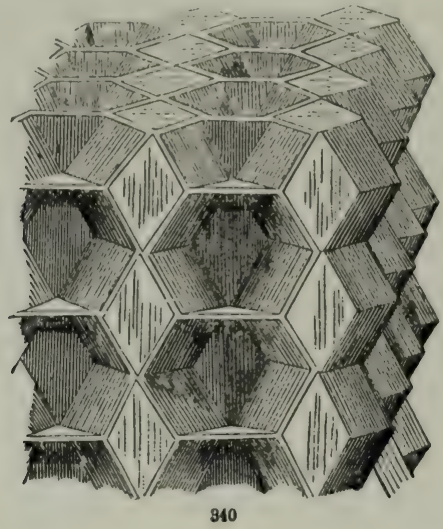

\section{LIESSON XXIII.}

VEGETABLE FABRIC： CELLULAR TISSUE.

391. Organic Strucitle. A mineral - such as a erystal of spar, or a piece of matble - maty be divided into smaller and still smaller pieces, and yet the minutest portion that can be seen with the microscope will have all the characters of the larger body, and be capable of still further subdivision, if we had the means of doing it, into just such particles, only of smaller size. A plant may also be divided into a number of similar parts: first into branches; then each branch or stem, into joints or similar parts (34), each with its lleaf or pair of leaves. But if we divide these into pieces, the pieces are not all alike, nor have they separately the properties of the whole; they are not whole things, but fragments or slices.

392. If now, under the microscope, we subdivide a leaf, or a piece of stem or root, we come down in the same way to the set of similar things it is made of, - to cavities with closed walls, - to Cells, as we call them (386), essentially the same every where, however they maty vary in shape. These are the units, or the elements of which every part consists; and it is their growth and their multiplication which 
make the growth of the plant, as was shown in the last Lesson. We cannot divide them into similar smaller parts having the prop erties of the whole, as we may any mineral borly. We may cut them in pieces; but the pieces are only mutilated parts of a cell. This is a peculiarity of organic things $(2,3)$ : it is organic structure. Being composed of cells, the main structure of plants is called

393. Cellular Tissue. The cells, as they multiply, build up the tissues or fabric of the plant, which, as we have said (389), may be likened to a wall or an edifice built of bricks, or still better to a honeycomb composed of ranges of cells (Fig. 340).

394. The walls of the cells are united where they touch each other; and so the partition appears to be a simple membrane, although it is really double; as may be shown by boiling the tissue a few minutes and then pulling the parts asunder. And in soft fruits the cells separate in ripening, although they were perfectly united into a tissue, when green, like that of Fig. 310.

395. In that figure the cells tit together perfectly, leaving no interstices, except a very small space at some of the corners. But in most leaves, the cells are loosely heaped together, leaving spaces or passages of all sizes (Fig. 356); and in the leaves and stems of aquatic and marsh plants, in particular, the cells are built up into narrow partitions, which form the sides of large and regular canals or passages (as shown in Fig. 341). These passages form the holes or cavities so conspicuous on cutting aeross any of these plants, and which are always filled with air. They may be likened to a stack of chimneys, built up of cells in place of bricks.

396. When small and irregular, the interstices are called inter. eellular spaces (that is, spaces between the cells). When large and regular, they are named intercellular passages or air-passages.

397. It will be noticed that in slices of the root, stem, or any tissue where the cells are not partly separate, the boundaries of the cells are usually more or less six-sided, like the cells of a honeycomb; and this is apt to be the case in whatever direction the slice is made, whether crosswise, lengthwise, or obliquely. The reason of this is easy to see. The natural figure of the cell is globular Cells which are not pressed upon by others are generally round or roundish (except when they grow in some particular direction), as we see in the green pulp of many leaves. When a quantity of spheres (such, for instance, as a pile of (annon-balls) are heaped up, each one in the interior of the heap is touched by twelve others. If the spheres be 
soft and yielding, as young cells are, when pressed together they will become twelve-sided, like that in Fig. 339. And a section in any direction will be six-sided, as are the meshes in Fig. 340 .

398. The size of the common cells of plants varies from about the thirtieth to the thousandth of an inch in diameter. An ordinary

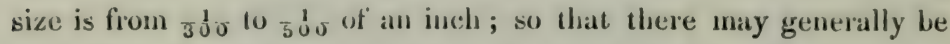
from 27 to 125 millions of ectls in the compass of a cubie inch!

399. Now when it is remembered that many stems shoot up at the rate of an inch or two a day, and sometimes of three or four inches, knowing the size of the cells, we may form some conception of the rapidity of their formation. 'The giant Puff-ball has been known to enlarge fiom ain inch or so to nearly a foot in diameter in a single night ; but much of this is probably owing to expansion. We take therefore a more decisive, but equally extraordinary case, in the huge flowering stem of the Century-Plant. After waiting many years, or even for a century, to gather strength and materials for the effort, Century-Plants in our conservatories send up a flowering stalk, which grows day afier day at the rate of a foot in twentyfour hours, and becomes about six inches in diameter. This, supposing the cells to average $\frac{1}{300}$ of an inch in diameter, requires the formation of over twenty thousand millions of cells in a day!

400. The walls of the cells are almost always colorless. The green color of leaves and young vark, and all the brilliant hues of flowers, are due to the contents of the cells, seen through their more or less transparent walls.

401. At first the walls are always very thin. In all soft parts they remain so; but in other cases they thicken on the inside and harden, as we see in the stone of stone-firuits, and in all hard wood (Fig. 345) Sometimes this thickening continues until the cell is nearly filled up solid.

402. The walls of cells are perfectly closed and whole, at least in all young and living cells. Those with thickened walls have thin places, indeed; but there are no holes opening from one cell into another. And yet through these closed cells the sap and all the juices are conveyed from one end of the plant to the other.

403. Vegetable cells may vary widely in shape, particularly when not combined into a tissue or solid fabric. The hairs of plants, for example, are cells drawn out into tubes, or are composed of a row of cells, growing on the surface. Cotton consists of simple long hairs on the coat of the sced; and these hairs are single cells. The hair- 
like bodies which abound on young roots are very slender projections of some of the superficial cells, as is seen in Fig. 337. Even the fibres of wood, and what are called vessels in plants, are only peculiar forms or transformations of cells.

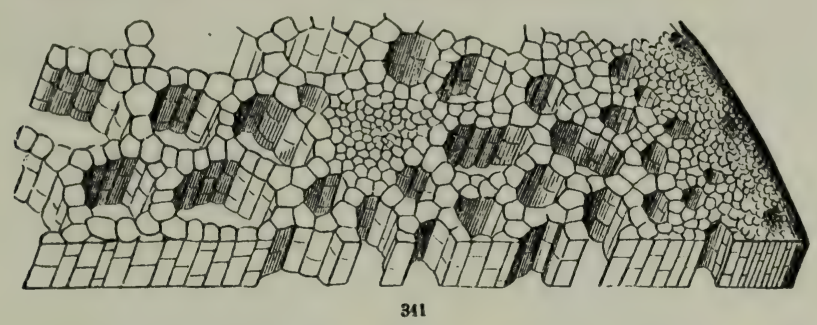

\section{LESSON XXIV.}

VEGFTABLE FABRIC: WOOD.

404. Cellular tissur, such as described in the last Lesson, makes up the whole structure of all very young plants, and the whole of Mosses and other vegetables of the lowest grarle, even when full grown. But this fabric is too tender or too brittle to give needful strength and toughness for plants which are to rise to any considerable height and support themselves. So all such plants have also in their composition more or less of

405. Wood. This is found in all common herbs, as well as in shruls and trees; only there is not so much of it in proportion to the softer cellular tissue. It is formed very early in the growth of the root, stem, and leaves; traces of it appearing in large embryos even while yet in the seed.

406. Wood is likewise formed of cells, - of cells which at first are just like those that form the soft parts of plants. But early in their growth, some of these lengthen and at the same time thicken their walls; these are what is called Woody Fibre or Wood-Cells; others grow to a greater size, have thin walls with various markings upon them, and often run together end to end so as to form pretty 
large tubes, comparatively; these are called Ducts, or sometimes Vessels. Wood almost always ionsists of bolh woody fibres and ducts,

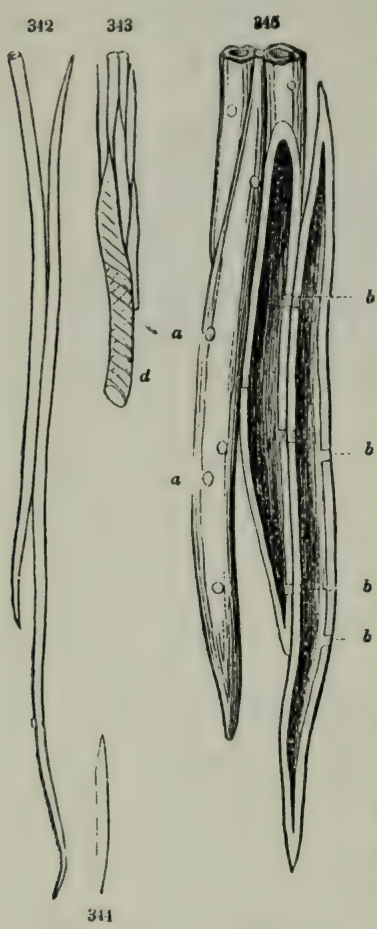
variously intermingled, and combined into bundles or threads which run lengthwise through the root and stem, and are spread out to form the framework of the leaves (136). In trees and shrubs they are so numerous and crowded together, that they make a bolid mass of wood. In herbs they are fewer, and often scattered. That is all the difference.

407. The porosity of some kinds of wood, which is to be seen by the naked eye, as in mahogany and Oak-wood, is owing to a large sort of ducts. 'These generally contain air, except in very $b$ young parts, and in the spring of the year, when they ares often gorged with sap, as we see in a wounded Grapevine, or in the trunk of a Sugar-Maple at that time. But in woody plants through the season, the sap is usually carried up from the roots to the leaves by the

408. Wood-f'clls, or Woody Fibre. (Fig. $342-345$.) 'These are small tubes, commonly between one and two thousandths, but in Pine-wood sometimes two or three hundredths, of an inch in dianeter. Those fiom the tough bark of the Basswood, shown in Fig. 342 , are only the fifteen-hundredth of an inch wide. Those of Buttonwood (Fig. 345) are larger, and are here highly magnified besides. They also show the way wood-cells are commonly put together, namely, with their tapering ends overlapping each other,spliced together, as it were, - thus giving more strength and toughness to the stem, \&c.

FIG. 342. Two woul-cells frum the inuer or fibrous bark of the Jinden or Bangwout. 34. Sone tissue of the wood of the same, viz. Ivoud-cells, and below $(d)$ a portion of a Epirally marked duct. 344. A separate wood-cell. All equally magnified.

FIf. 31.5. Sutue wood-cells of Buttomwerol, highly magnifed : $a$, thin spofs in the

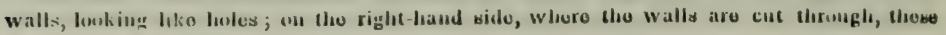
ib) aro susu in protilu. 
409. In hard woods, such as Hickory, Oak, and Buttonwood (Fig. $345)$, the walls of these tubes are very thick, as well as dense; while in soft woods, such as White-Pine and Basswood, they are pretty thin.

410. Wood-cells, like other cells (at least when young and living), have no openings; each has its own cavity, closed and independent. They do not form anything like a set of pipes opening one into another, so as to convey an unbroken stream of sap through the plant, in the way people generally suppose. The contents can pass from one cell to another only by getting through the partitions in some way or other. And so short are the individual woodcells generally, that, to rise a foot in such a tree as the Basswood, the sap has to pass through about two thousand partitions!

411. But although there are no holes (except by breaking away when old), there are plenty of thin places, which look like perforations; and through these the sap is readily transferred from one cell to another, in a manner to be explained further on (487). Some of them

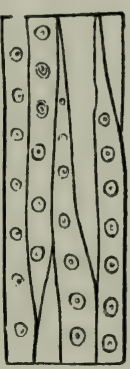

346

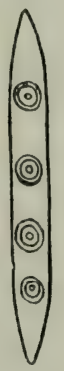

347 are exhibited in Fig. 345, both as looked direetly down upon, when they appear as dots or holes, and in profile where the cells are cut through. The latter view shows what they really are, namely, very thin places in the thickness of the wall; and also that a thin place in one cell exactly corresponds to one in the contiguous wall of the next cell. In the wood of the Pine family, these thin spots are much larger, and are very conspicuous in a thin slice of wood under the microscope (Fig. 346, 347); - forming stamps impressed as it were upon each fibre of every tree of this great family, by which it may be known even in the smallest fragment of its wood.

412. Wood-cells in the bark are generally longer, finer, and tougher than those of the proper wood, and appear more like fibres. For example, Fig. 344 represents a cell of the wood of Basswood, of average length, and Fig. 342 one (and part of another) of the fibrous bark, both drawn to the same scale. As these long cells form the principal part of fibrous bark, or bast, they are named Bastcells or Bast-fibres. These give the great toughness to the inner bark of Basswood (i. e. Bast-wood) and of Leatherwood ; and they

FIO. 346. A bit of Pine-slaving, highly magnified, showing the large circular thin spota of the wall of the wood-cells. 347. A separate wood-cell, inore magnifled, the varying thick. aess of the wall at these spots showing as ring*. 
furnish the invaluable fibres of flax and hemp; the wood of the stem being tender, brittle, and destroyed by the processes which separate for use the tough and slender bast-cells.

413. Ducts (Fig. $348-350$ ) are larger than woud-cells, some of them having a calibre large enough to be seen by the naked eye,

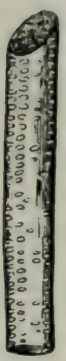

348

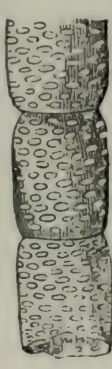

319

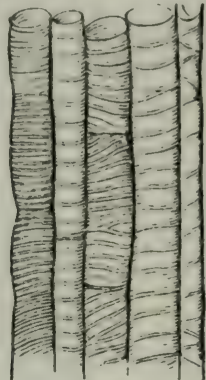

350 when cut across (407), although they are usually much too small for this. They are either long single cells, or are formed of a row of cells placed end to end. Fig. 349 , a piece of a large dotted duct, and two of the ducts in Fig. 350, show this by their joints, which mark the boundaries of the several cells they are composed of.

414. The walls of ducts under the microscope display various kinds of markings. In what are called

Dotted Ducts (Fig. 348, 349), which are the commonest and the largest of all, - their cut ends making the visible porosity of Oakwood, - the whole wall is apparently riddled with holes: but until they become old, these are only thin places.

Spiral Ducts, or Spiral Vessels, also the varieties of these called Annular or Banded Ducts (Fig. 350), are marked by a delicate fibre spirally coiled, or by rings or bands, thickening the wall. In the genuine spiral duct, the thread may be uncoiled, tearing the transparent wall in pieces; - as may be seen by breaking most young shoots, or the leaves of Strawberry or Amaryllis, and pulling the broken ends gently asunder, uncoiling these gossamer threads in abundance. In Fig. 355, some of these various sorts of ducts or vessels are shown in their place in the wood.

415. Milk-Vessels, Turpentine-Vessels, Oil-Receptacles, and the iike, are generally canals or cavities formed between or among the cells, and filled with the particular products of the plant.

FIG. 348. Part of a dofled duct from a Grape-vine. 349. A similar one, evidently coinposed of a row of cells. 350. Part of a bundle of spiral and anmular ducts from the stem of Polygonuun orientale, or Princes' Feather. All highly magıified. 


\title{
LESSON XXV.
}

\author{
ANATOMY OF THE ROOT, STEN, AND LEAVES.
}

416. IIAving in the last preceding Lessons learned what the materials of the vegetable fabric are, we may now briefly consider how they are put together, and how they act in carrying on the plant's operations.

417. The root and the stem are so much alike in their internal structure, that a description of the anatomy of the latter will answer for the former also.

418. The Structure of the Rootlets, however, or the tip of the root, demands a moment's attention. 'The tip of the root is the newest part, and is constantly renewing itself so long as the plant is active (67). It is shown magnified in Fig. 56, and is the same in all rootlets as in the first root of the seedling. The new roots, or their new parts, are mainly concerned in imbibing moisture from the ground; and the newer they are, the more actively do they absorb. 'The abkorhing ends of roots are entirely composed of soft, new, and very thin-walled cellulur tissue; it is only farther back that some woodcells and ducts are found. The moisture (and probably also air) presented to them is absorbed through the delicate walls, which, like those of the cells in the interior, are destitute of openings or pores visible even under the highest possible magnifying power.

419. But as the rootlet grows older, the cells of its external layer harden their walls, and form a sort of skin, or epidermis (like that which every where covers the stem and foliage above ground), which greatly checks absorption. Roots accordingly cease very actively to imbibe moisture almost as soon as they stop growing (67).

420. Many of the cells of the surface of young rootlets send out a prolongation in the form of a slender hair-like tube, closed of course at the apex, but at the base opening into the cavity of the cell. These tubes or root-hairs (shown in Fig. 55 and 56 , and $a$ few of them, more magnified, in Fig. 337 and 338), sent out in all directions into the soil, vastly increase the amount of absorbing surface which the root presents to it.

421. Structure of the Stem (also of the body of the root). At the beginning, when the root and stem spring from the seed, they consist 
almost entirely of soft and tender cellular tissue. But as they grow, wood begins at once to be formed in them.

422. This woody material is arranged in the stem in two very different ways in different plants, making two sorts of wood. One sort we see in a l'alm-stem, a rattan, and a Corn-stalk (Fig. 351); the other we are familiar with in Oak, Maple, and all our common kinds of wood. In the first, the wood is made up of separate threads, scattered here and there throughout the whole diameter of the stem. In the second the wond is all collected to form a layer (in a slice across appearing as a ring) of wood, between a central cellular part which has none in it, the P'ith, and an outer cellular part, the Bark. This last is the plan of all our Northern trees and shrubs, and of the greater part of our herbs. The first kind is

423. The Eindogenous Stem; so named fiom two Greek words meaning "inside-growing," because, when it lasts from year to year, the

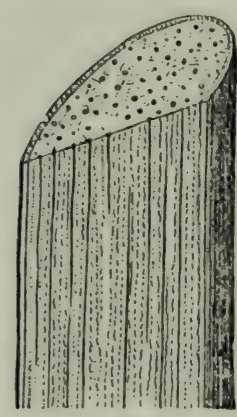

351 new wood which is added is interspersed among the older threads of wood, and in old stems the hardest and oldest wood is near the surface, and the youngest and softest towards the eentre. All the plants represented in Fig. 47, on p. 19, (except the anomalous Cycas,) are examples of Endogenous stems. And all such belong to plants with only one cotyledon or seed-leaf to the embryo (32). Botanists therefore call them Endogenous or Monocotylerdonous Plants, using sometimes one name, and sometimes the other. Endogenous stems have no separate pith in the centre, no distinct bark, and no layer or ring of wood between these two; but the threads of wood are scattered throughout the whole, without any particular order. This is very different from

424. The Exogenous Stem, the one we have most to do with, since all our Northern trees and shrubs are constructed on this plan. It belongs to all plants which have two cotyledons to the embryo (or more than two, such as l'ines, 33); so that we call these either Exogenous or Dicotyledonous Plunts (16), accordingly as we take the name from the stem or from the embryo.

425. In the Exogrenous stem, as alrearly stated, the wood is all collected into one zone, surroundiner a pith of pure cellular tissue in the centue, and surrounded by a distinct and separable bark, the

FIG. 351. Soction of a Curn-stalk (an endugonous stom), both cruaswise and length'wisa 
outer part of which is also cellular. This structure is very familiar in common wood. It is really just the same in the stem of an herb,

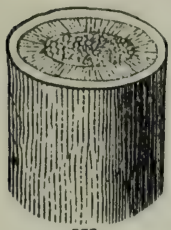
only the wood is much less in quantity. Compare, for instance, a cross-section of the stem of Flax (Fig. 352) with that of a shoot of Maple or IIorsechestnut of the same age. In an herb, the wood at the beginning consists of separate threads or little wedges of wood; but these, however few and scattered they may be, are all so placed in the stem as to mark out a zone (or in the cross-section a ring) of wood, dividing the pith within from the bark without.

426. The accompanying figures (which are diagrams rather than exact delineations) may serve to illustrate the anatomy of a woorly exogenous stem, of one year old. The parts are explained in the references below. In the centre is the Pith. Surrounding this is the layer
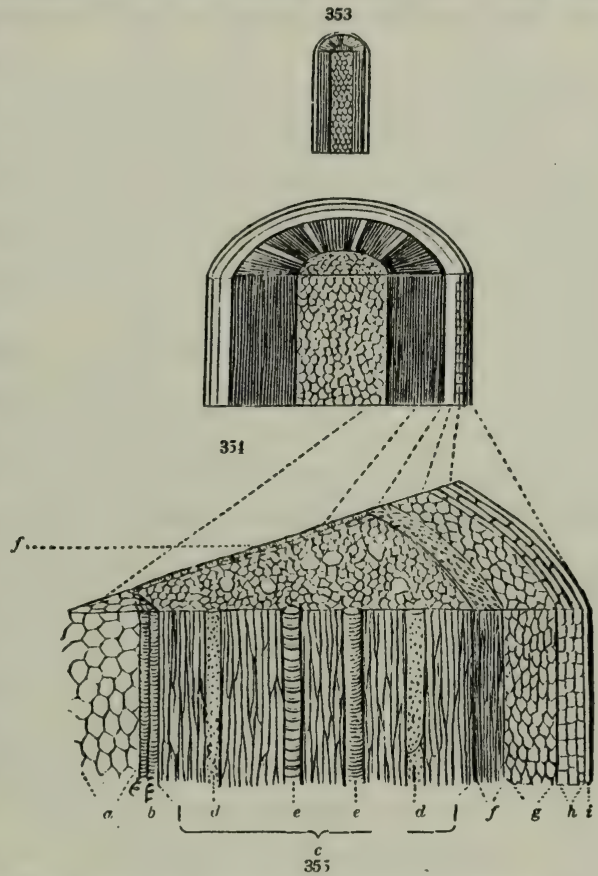
of Wood, consisting both of wood-cells and of ducts or vessels. From the pith to the bark on all sides run a set of narrow plates of cellular tissue, called Medullary Rays : these make the silver-grain of wood. On the cross-section they appear merely as narrow lines; but in wood cut lengthwise parallel to them, their faces show as glimmer-

FIG. 352. Cross-section of the stem of Flax, showing its bark, woud, and pith.

FIG. 353. Piece of a stem of Soft Maple, of a year old, cut crosswise and lengthwise. FIG. 354. A portion of the same, magnified.

FIG. 355. A small piece of the samn, taken from one sidn, rnching from the hark to the pith, and highly magnified : $a$, a small hit of the pith; $b$, spiral ducts of what is called the medullary sheath; $c$, the wood ; $d, d$, dotted ducts in the wood ; $c, c$, annular ducts ; $f$, the liher or inner bark; $g$, the green bark; $h$, the corky layer; $i$, the skin, or epidermis ; $f$, one of the medullary rays, or plateg of silver-grain, seen on the cross-section. 
ing plates, giving a peculiar appearance to Oak, Maple, and other wood with large medullary rays.

427. The Burk covers and protects the wood. At first it is all cellular, like the pith; but soon some slender woody fibres, called bast-cells (Fig. 342), generally appear in it, next the wood, forming

The Liber, or Fibrons Burk, the inner bark; to which belongs tles fine fibrous bast or buss of Basswood, and the tough and slender fibres of flax and hemp, which are spun and woven, or made into cordage. In the Birch and Beech the inner bark has few if any bast-cells in its composition.

The Cellulur or Outer Bark consists of cellular tissue only. It is distinguished into two parts, an iuner and an outer, viz. :-

The Green Burk, or Green Layer, which consists of tender cells, containing the same green matter as the leaves, and serving the same purpose. In the course of the first season, in woody stems, this becomes covered wilh

The Corky Layer, so named because it is the same substance as cork; common cork being the thick corky layer of the bark of the Cork-Oak, of Spain. It is this which gives to the stems or twigs of shrubs and trees the aspect and the color peculiar to each; namely, light gray in the Ash, purple in the Red Maple, red in several Dogwoods, \&c. Lastly,

The Epidermis, or skin of the plant, consisting of a layer of thicksided empty cells, covers the whole.

428. Growth of the Stem year after yenr. So much for an exogenous stem only one year old. The stems of herbs perish at the end of the season. But those of shrubs and trees make a new growth every year. It is from their mode of growth in diameter that they take the name of exogenous, i. e. outside-growing. The second year, such a stem forms a second layer of wood outside of the first; the third year, another outside of that; and so on, as long as the tree lives. So that the trunk of an exogenous tree, when cut off at the base, exhibits as many concentric rings of wood as it is years old. Over twelve hundred layers have actually been counted on the stump of an aged tree, such as the Giant Cedar or Redwood of California; and there are doubtless some trees now standing in various parts of the world which were already in existence at the beginning of the Christian era.

429. As to the bark, the green layer seldom grows much after the first season. Sometimes the corky layer grows and forms new layers, inside of the old, for a good many years, as in the Cork-Ouk, 
the Sweet Gum-tree, and the White and the Paper Birch. But it all dies after a while; and the continual enlargement of the wood within finally stretches it more than it can bear, and sooner or later cracks and rends it, while the weather acts powerfully upon its surface; so the older bark perishes and falls away piecemeal year by year.

430. But the inner bark, or liber, does make a new growth annually, as long as the tree lives, inside of that formed the year before, and next the surface of the wood. More commonly the liber occurs in the form of thin layers, which may be distinctly counted, as in Basswood: but this is not always the case. After the outer bark is destroyed, the older and dead layers of the inner bark are also exposed to the weather, are riven or split into fragments, and fall away in succession. In many trees the bark acquires a considerable thickness on old trunks, although all except the innermost portion is dead; in others it falls off more rapidly; in the stems of Honeysuckles and Grape-vines, the bark all separates and hangs in loose shreds when only a year or two old.

431. Sap-wood. In the wood, on the contrary, - owing to its growing on the outside alone, - the older layers are quietly buried under the newer ones, and protected by them from all disturbance. All the wood of the young sapling may be alive, and all its cells or woody tubes active in carrying up the sap from the roots to the leaves. It is all Sap-wood or Alburnum, as young and fresh wood is called. But the older layers, removed a step farther every year from the region of growth, - or rather the zone of growth every year removed a step farther from them, - soon cease to bear much, if any, part in the circulation of the tree, and probably have long before ceased to be alive. Sooner or later, according to the kind of tree, they are turned into

432. Ileart-wood, which we know is drier, harder, more solid, and much more durable as timber, than sap-wood. It is generally of a different color, and it exhibits in different species the hue peculiar to each, such as reddish in Red-Cedar, brown in Black-Walnut, black in Ebony, \&c. The change of sap-wood into heart-wood results from the thickening of the walls of the wood-cells by the deposition of hard matter, lining the tubes and diminishing their calibre; and by the deposition of $-\mathrm{a}$ regetable coloring-matter peculiar to each species.

433. The heart-wood, being no longer a living part, may decay $S$ \& $F-8$ 
and often does so, without the least injury to the tree, except by impairing the strength of the trunk, and so rendering it more liable to be overthrown.

43.4. The Living Parts of a Tree, of the exogenous kind, are only these: first, the rootlets at one extremity; second, the buds and leaves of the season at the other; and third, a zone consisting of the newest wood and the newest bark, connecting the rootlets with the buds or leaves, however widely separated these may be, - in the largest trees from two to four hundred feet apart. And these parts of the tree are all renewed every year. No wonder, therefore, that trees may live so long, since they annually reproduce everything that is essential to their life and growth, and since only a very small part of their bulk is alive at once. The tree survives, but nothing now living has existed long. In it, as elsewhere, life is a transitory thing, ever abandoning the old, and displaying itself afresh in the new.

435. Cumbium-Layer. The new growth in the stem, by which it increases in diameter year after year, is confined to a narrow line between the wood and the inner bark. Cambium is the old name for the mucilage which is so abundant between the bark and the wood in spring. It was supposed to be poured out there, and that the bark really separated from the wood at this time. This is not the case. The newest bark and wood are still united by a delicate tissue of young and forming cells, - called the Cambitm-layer, loaded with a rich mucilaginous sap, and so tender that in spring the bark may be raised from the wood by the slightest force. Here, nourished by this rich mucilage, new cells are rapidly forming by division $(387-390)$; the inner ones are added to the wood, and the outer to the bark, so producing the annual layers of the two, which are ever renewing the life of the trunk.

436. At the same time new rootlets, growing in a similar way, are extending the roots beneath; and new shoots, charged with new buds, annually develop fresh crops of leaves in the air above. Only, while the additions to the wood and bark remain as a permanent portion of the tree, or until destroyed by decay, the foliage is temporary, the crop of leaves being annually thrown off after they have served their purpose.

437. Strutture of the Leaf. Leaves also consist both of a woody and a cellular part (135). The woody part is the framework of rils and veins, which have already been described in full $(136-147)$. 
They serve not only to strengthen the leaf, but also to bring in the ascending sap, and to distribute it by the veinlets throughout every part. The cellular portion is the green pulp, and is nearly the same as the green layer of the bark. So that the leaf may properly enough be regarded as a sort of expansion of the fibrous and green layers of the bark. It has of course no corky layer ; but the whole is covered by a transparent skin or epidermis, resembling that $o^{2}$ the stem.

438. The green pulp consists of cells of various forms, usually loosely arranged, so as to leave many irregular spaces, or air-pas. sages, communicating with each other throughout the whole interior of the leaf (Fig. 356). The green color is owing to a peculiar green matter lying loose in the cells, in form of minute grains, named Chlorophyll (i. e. the green of leaves). It is this substance, seen through the transparent walls of the cells where it is accumulated, which gives the common green hue to vegetation, and especially to foliage.

439. The green pulp in most leaves forms two principal layers; an upper one, facing the sky, and an under one, facing the ground. The upper one is

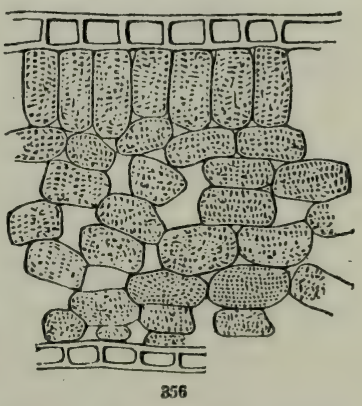
always deeper green in color than the lower. This is partly owing, perhaps, to a greater amount of chlorophyll in the upper cells, but mainly to the more compact arrangement of these cells. As is seen in Fig. 356 and 357, the cells of the upper side are oblong or cylindrical, and stand endwise to the surface of the leaf, usually close together, leaving hardly any vacant spaces. Those of the lower part of the leaf are apt to be irregular in shape, most of them with their longer diameter parallel to the face of the leaf, and are very loosely arranged, leaving many and wide air-chambers. The green color underneath is therefore diluted and paler.

440. In many plants which grow where they are subject to drought, and which hold their leaves during the dry season (the Oleander for example), the greater part of the thickness of the leaf consists of layers of long cells, placed endwise and very much com-

FIn. 356. Section through the thickness of a leaf of the Star-Anise (Illicium), of Florlda, magnified. The upper and the lower layers of thick-walled and empty cells represent the epidermis or skin. All those between are cells of the green pulp, cuntaining grains of chlurophyll. 
pacted, so as to expose as little surface as possible to the direct action of the hot sun. On the other hand, the leaves of marsh plants, and if others not intended to survive a drought, have their cells more loosely arranged throughout. In such leaves the epidermis, or skin, is made of only one layer of cells; while in the Oleander, and the like, it consists of three or four layers of hard and thick-walled cells. In all this, therefore, we plainly see an arrangement for tempering the action of direct sunshine, and for restraining a too copious evapr oration, which would dry up and destroy the tender cells, at least when moisture is not abundantly supplied througli the roots.

441. That the upper side of the leaf alone is so constructed as to bear the sunshine, is shown by what happens when their position is reversed: then the leaf soon twists on its stalk, so as to turn again its under surface away from the light; and when prevented from doing so, it perishes.

412. A large part of the moisture which the roots of a growing plant are constantly absorbing, after being carried up through the stem, is evaporated fiom the leaves. A Sunflower-plant, a little over three feet high, and with between five and six thonsand stuare inches of surface in foliage, \&ce, has been found to exhale twenty or thirty ounces (between one and two pints) of water in a day. Some part of this, no doubt, flies off through the walls of the epidermis or skin, at least in sunshine and dry weather; but no considerable portion of it. The very olject of this skin is to restrain evaporation. The greater part of the moisture exhaled escapes from the leaf through the

443. Stomates or Breathing-pores. These are small openings through the epidermis into the air-chambers, establishing a direct communication between the whole interior of the leat and the external air. Through these the vapor of water and air can freely escape, or enter, as the case may be. The aperture is guarded by a pair of thin-walled cells, - resembling those of the green pulp within, which open when moist so as to allow exhalation to go on, but promptly close when dry, so as to arrest it before the interior of the leaf is injured by the dryness.

444. Like the air-chamber's, the breathing-pores belong mainly to the under side of the leaf. In the White Lily, - where they are unusually large, and easily seen by a simple microscope of moderate power, - there are about 60,000 to the square inch on the eppidermis of the lower surface of the leaf, and only about 3,000 in 
the same space of the upper surface. More commonly there are few or none on the upper side; direct sunshine evidently being unfavorable to their operation. Their immense numbers make up for their minuteness. They are said to vary from less than 1,000 to 170,000 to the square inch of surface. In the Apple-tree, where they are under the average as to number, there are about 24,000 to the square inch of the lower surface; so that each leaf has not far from 100,000 of these openings or mouths.

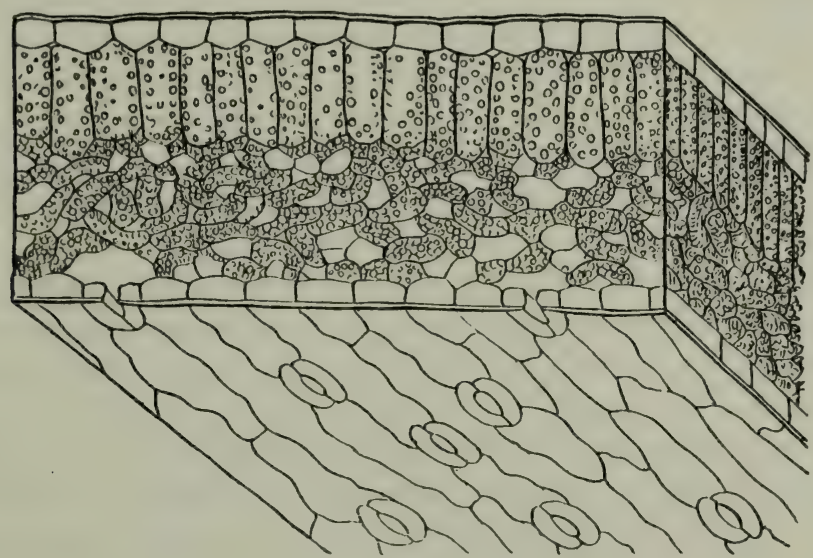

957

\section{LESSON XXVI.}

THE PLANT IN ACTION, DOING THE WORK OF VEgETATION.

445. BeIng now acquainted with the machinery of the plant, we naturally proceed to inquire what the use of it is, and how it works.

446. It has already been stated, in the first of these Lessons (7), that the great work of plants is to change inorganic into organic matter ; that is, to take portions of earth and air, - of mineral matter, - upon which animals cannot live at all, and to convert them

FIG. 367. Portion of a White-Lily leaf, cut through and magnified, showing a section of the thickness, and also a part of the skin of the lower side, with some breathing-pores- 
into something upon which they can live, namely, into food. All the food of all animals is produced by plants. Animals live upon vegetables; and vegetables live upon earth and air, principally upon the air.

447. Plants fecl upon Earth and Air. This is evident enough from the way in which they live. Many plants will flourish in pure sand or powdered chalk, or on the bare face of a rock or wall, watered merely with rain-water. And almost any plant may be made to grow from the seed in pure sand, and increase its weight many times, even if it will not come to perfection. Many naturally live suspended from the branches of trees high in the air, and nourished by it alone, never laving any connection with the soil (81); and some which naturally grow on the ground, like the Live-for-ever of the gardens, when pulled up by the roots and hung in the air will often flourish the whole summer long.

448. It is true that fast-growing plants, or those which produce considerable vegetable matter in one season, - especially in such a concentrated form as to be useful as food for man or the higher animals, - will come to maturity only in an emriched soil. But what is a rich soil? One which contains decomposing vegetable matter, or some decomposing animal inatter; that is, in either case, some decomposing organic matter formerly produced by plants; aided by this, grain-bearing and other important vegetables will grow more rapidly and vigorously, and make a greater amount of nourishing matter, than they could if left to do the whole work at once from the beginning. So that in these cases also all the organio matter was made by plants, and made out of earth and air.

449. 'Jheir l'hemical Composition shows what Plants are made of. The soil and the air in which plants live, and by which they are everywhere surrounded, supply a variety of materials, some likely to be useful to the plant, others not. To know what elements the plant makes use of, we must first know of what its fabric and its products are composed.

450, We may distinguish two sorts of materials in plants, one of which is absolutely essential, and is the same in all of them; the other, also to some extent essential, but very variable in different plants, or in the sanne plant under different circumstances. The former is the organic, the latter the inoryunic or earthy materials.

451. The Eariliy or Inorganic Constituents. If we burn thoroughly a lewe, a piece of wood, or any other part of a vegetable, almost all of 
it is dissipated into air. But a little ashes remain : these represent the earthy constituents of the plant.

452. They consist of some potash (or soda if a marine plant was used), some silex (the same as flint), and probably a little lime, alumine, or magnesia, iron or manganese, sulphur or phosphorus, \&c. Some or all of these elements may be detected in many or most plants. But they make no part of their real fabric ; and they form only from one or two to nine or ten parts out of a hundred of any "vegetable substance. The ashes vary according to the nature of the soil. In fact, they consist, principally, of such materials as happened to be dissolved, in small quantity, in the water which was taken up by the roots ; and when that is consumed by the plant, or flies off pure (as it largely does, 447) by exhalation, the earthy matter is left behind in the cells, _ just as it is left incrusting the sides of a teakettle in which much hard water has been boiled. As is very natural, therefore, we find more earthy matter (i. e. more ashes) in the leaves than in any other part (sometimes as much as seven per cent, when the wood contains only two per cent); because it is through the leaves that most of the water escapes from the plant. These earthy constituents are often useful to the plant (the silex, for instance, increases the strength of the Wheat-stalk), or are useful in the plant's products as furnishing needful elements in the food of man and other animals; and some must be held to be necessary to vegetation, since this is never known to go on without them.

453. The Organic Constituents. As has just been remarked, when we burn in the open air a piece of any plant, nearly its whole bulk, and from 88 to more than 99 parts out of a hundred by weight of its substance, disappear, being turned into air and vapor. These are the organic constituents which have thus been consumed, - the actual materials of the cells and the whole real fabric of the plant. And we may state that, in burning, it has been decomposed into exactly the same kinds of air, and the vapor of water, that the plant used in its making. The burning has merely undone the work of vegetation, and given back the materials to the air just in the state in which the plant took them.

454. It will not be difficult to understand what the organic constituents, that is, what the real materials, of the plant are, and how the plant obtains them. The substance of which vegetalle tissue, viz. the wall of the cells, is made, is by chemists named Cellulose. It is just the same thing in composition in wood and in soft cellular tis- 
sue,-in the tender pot-herb and in the oldest tree. It is composed of earbon, hydrogen, and oxygen, 6 parts of the first to 10 of the second and 5 of the third. 'These, accordingly, are necessary materials of vegetable growth, and must be received by the growing plant.

455. The Plaut's Food must contain these three elements in some shape or other. Let us look for them in the materials which the plant is constantly taking from the soil and the air.

456. Water is the substance of which it takes in vastly more than of anything else: we well know how neeessary it is to vegetable life. The plant imbibes water by the roots, which are specially constructed for taking it in, as a liquid when the soil is wet, and probably also in the form of vapor when the soil is only damp. That water in the form of vapor is absorbed by the leaves likewise, when the plant needs it, is evident from the way partly wilted leaves revive and freshen when sprinkled or placed in a moist atmosphere. Now water is composed of hydrogen and oxyyen, two of the three elements of cellulose or plant-fabric. Moreover, the hydrogen and the oxygen exist in water in exactly the same proportions that they do in cellulose : so it is clear that water furnishes these two elements.

457. We inquire, therefore, after the third element, carbon. This is the same as pure charcoal. Charcoal is the carbon of a vegetable left behind after charring, that is, heating it out of contact of the air until the hydrogen and oxygen are driven off. The charcoal of wood is so abundant in bulk as to preserve perfectly the shape of the cells after charring, and in weight it amounts to about half that of the original material. Carbon itself is a solid, and not at all dissolved by water : as such, therefore, it cannot be absorbed into the plant, however minute the particles; only liquid and air can pass through the walls of the cells $(402,410)$. It must therefore come to the plant in some combination, and in a fluid form. The only substance within the plant's reach containing carbon in the proper state is

458. Carbonic Acid. This is a gas, and one of the components of the atmosphere, everywhere making about $\frac{1}{250 \sigma}$ part of its bulk, - enough for the food of plants, but not enough to be injurious to animals. For when mixed in any considerable proportion with the air we breathe, carbonic acid is very poisonous. The air produced by burning charcoal is carbonic acid, and we know how soon burning charcoal in a close room will destroy life.

459. The air around us consists, besides this minute proportion of carbonic acid, of two other gases, mixed together, viz. oxygen 
and nitrogen. The nitrogen gas does not support animal life : it only dilutes the oxygen, which does. It is the oxygen gas alone which renders the air fit for breathing.

460. Carbonic acid consists of carbon combined with oxygen. In breathing, animals are constantly forming carbonic acid gas by uniting carbon from their bodies with oxygen of the air ; they inspire oxygen into their lungs; they breath it out as carbonic acid. So with every breath animals are diminishing the oxygen of the air, so necessary to animal life, - and are increasing its carbonic acid, so hurtful to animal life ; or rather, which would be so hurtful if it were allowed to accumulate in the air. The reason why it does not increase in the air beyond this minute proportion is that plants feed upon it. They draw their whole stock of carbon from the carbonic acid of the air.

461. Plants take it in by their leaves. Every current, or breeze that stirs the foliage, brings to every leaf a succession of fresh atoms of carbonic acid, which it absorbs through its thousands of breathingpores. We may prove this very easily, by putting a small plant or a fresh leafy bough into a glass globe, exposed to sunshine, and having two openings, causing air mixed with a known proportion of carbonic acid gas to enter by one opening, slowly traverse the foliage, and pass out by the other into a vessel proper to receive it: now, examining the air chemically, it will be found to have less carbonic acid than before. A portion has been taken up by the foliage.

462. Plants also take it in by their roots, some probably as a gas, in the same way that leaves absorb it, and much, certainly, dissolved in the water which the rootlets imbibe. The air in the soil, especially in a rich soil, contains many times as much carbonic acid as an equal bulk of the atmosphere above. Decomposing vegetable matter or manures, in the soil, are constantly evolving carbonic acid, "and a large part of it remains there, in the pores and crevices, among 'which the absorbing rootlets spread and ramify. Besides, as this gas is dissolved by water in a moderate degree, every rain-drop that falls from the clouds to the ground brings with it a little carbonic acid, dissolving or washing it out of the arr as it passes, and bringing it down to the roots of plants. And what flows off into the streams and ponds serves for the food of water-plants.

463. So water and carbonic acid, taken in by the leaves, or taken in by the roots and carried up to the leaves as crude sap, are the general food of plants, - are the raw materials out of which at least 
the fabric and a part of the general products of the plant are made. Water and carbonic acid are mineral matters: in the plant, mainly in the foliage, they are changed into organic matters. This is

464. The Plant's proper Work, Assimilation, viz. the conversion by the vegetable of foreign, dead, mineral matter into its own living substance, or into organic matter eapable of becoming living substance. To do this is, as we have said, the peculiar office of the plant. Ilow and where is it done?

465. It is done in the green parts of plants alone, and only when these are acted upon by the light of the sun. The sun in sone way supplies a power which enables the living plant to originate these peculiar chemical combinations, - to organize matter into forms which are alone capable of being endowed with life. The prool of this proposition is simple; and it shows at the same time, in the simplest way, what the plant does with the water and carbonic acid it consumes. Namely, 1 st, it is only in sunshine or bright daylight that the green parts of plants give out oxygen gas, - then they do; and $2 d$, the giving out of this oxygen gas is just what is required to render the chemical composition of water and carbonic acid the same as that of cellulose (454), that is, of the plant's fabric. This shows why plants spread out so large a surface of foliage.

466. In plants growing or placed under water we may see bubbles of air rising from the foliage; we may collect enough of this air to test it by a candle's burning brighter in it; which shows it to be oxygen gas. Now if the plant is making cellulose or plant-substance, - that is, is making the very materials of its fabric and growth, as must generally be the case, - all this oxygen gas given off by the leaves comes from the decomposition of carbonic acid taken in by the plant.

467. This must be so, because cellulose is composed of 5 parts of oxygen and 10 of hydrogen to 6 of carbon $(454)$ : here the first two are just in the same proportions as in water, which consists of 1 part of oxygen and 2 of hydrogen, - so that 5 parts of water and 0 of carbon represent 1 of cellulose or plant-fabric; and to make it out of water and carbonic acid, the latter (which is composed of carbon and oxygen) has only to give up all its oxygen. In other words, the plant, in its foliage under sunshine, decomposes carbonic acid gas, and turns the carbon together with water into cellulose, at the same time giving off the oxygen of the carbonic acid into the air.

468. And we can readily prove that it is so,-namely, that plants 
do decompose carbonic acid in their leaves and give out its oxygen, - by the expcriment mentioned in paragraph 461 . There the leaves, as we have stated, are taking in carbonic acid gas. We now add, that they are giving out oxygen gas at the same rate. The air as it comes from the glass globe is found to have just as much more oxygen as it has less carbonic acid than before - just as much more oxygen as would be required to turn the carbon re tained in the plant back into carbonic acid again.

469. It is all the same when plants - instead of making fabric at once, that is, growing - make the prepared material, and store it up for future use. The principal product of plants for this purpose is Starch, which consists of minute grains of organic matter, lying lonse in the cells. Plants often accumulate this, perhaps in the root, as in the Turnip, Carrot, and Dahlia (Fig. 57-60); or in subterranean stems or branches, as in the Potato (Fig. 68), and many rootstocks; or in the bases of leaves, as in the Onion, Lily (Fig. $73-75)$, and other bulbs; or in fleshy leaves above ground, as those of the Jce-Plant, House-leek, and Century-Plant (Fig. 82); or in the whole thickened body, as in many Cactuses (Fig. 76); or in the seed around the embryo, as in Indian Corn (Fig. 38, 39) and other grain ; or even in the embryo itself, as in the Ilorsechestnut (Fig. 23, 24), Bean (Fig. 16), Pea (Fig. 19), \&c. In all these forms this is a provision for future growth, either of the plant itself or of some offset from it, or of its offspring, as it springs from the seed. Now starch is to cellulose or vegetable fabric just what the prepared clay is to the potter's vessel, - the same thing, only requiring to be shaped and consolidated. It has exactly the same chemical composition, and is equally made of carbon and the elements of water, by decomposing the same amount of carbonic geid and giving back its oxygen to the air. In using it for growth, the plant dissolves it, conveys it to the growing parts, and consolidates it into fabric.

470. Sugar, another principal vegetable product, also has essentially the same chemical composition, and may be formed out of the same common food of plants, with the same result. The different kinds of sugar (that of the cane, \&c. and of grapes) consist of the same three materials as starch and cellulose, only with a little more water. The plant generally forms the sugar out of starch, changing one into the other with great ease; starch being the form in which prepared material is stored up, and sugar that in which it is ex- 
pended or transferred from one part of the plant to another. In the Sugar-cane and Indian Corn, starch is deposited in the seed; in germination this is turned into sugar for the plantlet to begin its growth with; the growing plant produces more, and deposits some as starch in the stalk; just before blossoming, this is changed into sugar again, and dissolved in the sap, to form and feed the flowers (which cannot, like the leaves, create nourishment for themselves); and what is left is deposited in the seed as starch again, with which to begin the same operation in the next generation.

471. We might enumerate other vegctable products of this class (such as oil, acids, jelly, the pulp of fruits, \&c.), and show how they are formed out of the carbonic acid and water which the plant takes in. But those already mentioned are sufficient. In producing any of them, carbonic acid taken from the air is decomposed, its carbon retained, and its oxygen given back to the air. That is to say,

472. Plants purify the hir for Animals, by taking away the carbonic acid injurious to them, continually poured into it by their breathing, as well as by the burning of fuel and by decay, and restoring in its place an equal bulk of life-sustaining oxygen (160). And by the same operation, combining this carbon with the elcments of water, \&c., and elaborating them into organic matter, - especially into starch, sugar, oil, and the like, -

473. Plants produce all the Food and Fabric of Animals. The herbivorous animals feed directly upon vegetables; and the carnivorous feed upon the herbivorous. Neither the one nor the other originate any organic matter. They take it all ready-made from plants, altering the form and qualities more or less, and at length destroying or decomposing it.

474. Starch, sugar, and oil, for example, form a large part of the food of herbivorous animals and of man. When digested, they enter into the blood; any surplus may be stored up for a time in the form of fat, being changed a little in its nature; while the rest (and finally the whole) is decomposed into carbonic acid and water, and exhaled from the lungs in respiration; - in other words, is given back to the air by the animal as the very same materials which the plant takes from the air as its food (463); - is given back to the air in the same form that it would have been if the vegetable matter had been left to decay where it grew, or if it had been set on fire and burned; and with the same result too as to the heat, the heat in this case producing and maintaining the proper temperature of the animal. 
475. But starch, sugar, and the like, do not make any part of the flesh or fabric of animals. And that for the obvious reason, that they consist of only the three elements carbon, hydrogen, and oxygen; whereas the flesh of animals has nitrogen as well as these three elements in its composition. The materials of the animal body, called Fibrine in the flesh or muscles, Gelatine in the sinews and bones, Cascine in the curd of milk, \&c., are all forms of one and the same substance, composed of carbon, hydrogen, oxygen, and nitrogen. As nitrogen is a large constituent of the atmosphere, and animals are taking it into their lungs with every breath they draw, we might suppose that they take this element of their frame directly from the air. But they do not. Even this is furnished by vegetables, and animals receive it ready-made in their food. And this brings us to consider still another and most important vegetable product, of a different class from the rest (omitted till now, for the sake of greater simplicity); namely, what is called

476. Proteine. This name has been given to it by chemists, because it occurs under such a protean variety of forms. The Gluten of wheat and the Legumine of beans and other leguminous plants . may be taken to represent it. It occurs in all plants, at least in young and growing parts. It does not make any portion of their tissue, but is contained in all living cells, as a thin jelly, mingled with the sap or juice, or as a delicate mucilaginous lining. In fact, it is formed earlier than the cell-wall itself, and the latter is moulded on it, as it were; so it is also called Protoplasm. It disappears from common cells as they grow old, being transferred onward to new or forming parts, where it plays a very active part in growth. Mixed with starch, \&c., it is accumulated in considerable quantity in wheat, beans, and other grains and seeds, especially those-which are most nutritious as food. It is the proteine which makes them so nutritious. Taken by animals as food, it forms their flesh and sinews, and the animal part of their bones, without much change; for it has the same composition, - is just the same thing, indeed, in some slightly different forms. To produce it, the plant employs, in addition to the carbonic acid and water already mentioned as its general food, some ammonia; which is a compound of hydrogen and nitrogen. Ammonia (which is the same thing as hartshorn) is constantly escaping into the air in small quantities from all decomposing vegetable and animal substances. Besides, it is produced in every thunderstorm. Every flash of lightning causes some to be made (in the 
form of nitrate of (ammonia) out of the nitrogen of the air and the vapor of water. 'The reason why it never accumulates in the air so as to be perceptible is, that it is extremely soluble in water, as are all its compounds. So it is washed out of the atmosphere by the rain as fast as it is made or rises into it, and is brought down to the roots of plants, which take it in freely. When assinilated in the leaves along with carbon and water, proteine is formed, the very substance of the flesh of animals. So all flesh is vegetable matter in its origin.

477. Even the earthy matter of the bones, and the iron and other mineral matters in the blood of animals, are derived from the plants they feed upon, with hardly an execption. These are furnished by the earthy or mineral constituents of plants (45\%), and are merely accumulated in the animal frame.

478. Animals, therefore, depend absolutely upon vegetables for their being. The great olject for which the All-wise Creator established the vegetable kingdom evidently is, that plants might stand on the surface of the earth between the mineral and the animal creations, and organize portions of the former for the sustenance of the latter.

\section{LESSON XXVII.}

\section{PLANT-LIFE.}

479. LIFE is known to us only by its effects. We cannot tell what it is ; but we notice some things which it does. One peculiarity of living things, which has been illustrated in the last Lesson, is their power of transforming matter into new forms, and thereby making products never produced in any other way. Life is also manifested by

480. Motion, that is, by self-caused movements. Living things move; those not living are moved. Animals, living as they do upon organized food, - which is not found everywhere, - must needs have the power of going after it, of collecting it, or at least of taking it in; which requires them to make spontaneons movements. But plants, with their wide-spread surface $(34,131)$ always in con- 
tact with the earth and air on which they feed, - the latter and the most important of these everywhere just the same, - have no need of locomotion, and so are generally fixed fast to the spot where they grow.

481. Yet many plants move their parts freely, sometimes when there is no occasion for it that we can understand, and sometimes aceomplishing by it some useful end. The sudden elosing of the leaflets of the Sensitive Plant, and the dropping of its leafstalk, when jarred, also the sudden starting forwards of the stamens of the Barberry at the touch, are familiar examples. Such cases seem at first view so strange, and so different from what we expect of a plant, that these plants are generally imagined to be endowed with a peculiar faculty, denied to common vegetables. But a closer examination will show that plants generally share in this faculty; that similar movements may be detected in them all, only - like those of the hands of a clock, or of the shadow of a sun-dial - they are too slow for the motion to be directly seen.

482. It is perfectly evident, also, that growth requires motion; that there is always an internal activity in living plants as well as in animals, - a power exerted which causes their fluids to move or circulate, and carries materials from one part to another. Some movements are mechanical; but even these are generally directed or controlled by the plant. Others must be as truly self-caused as those of animals are. Let us glance at some of the principal sorts, and see what light they throw upon vegetable life.

483. Circulation in ('ells. From what we know of the anatomy of plants, it is clear that they have no general circulation (like that of all animals except the lowest), through a system of vessels opening into each other $(402,410)$. But in plants each living cell carries on a circulation of its own, at least when young and active. This may be beautifully seen in the transparent stems of Chara and many other water-plants, and in the leaves of the Fresh-water Tape-Grass (Vallisneria), under a good microscope. Here the sap circulates, often quite briskly in appearance, (but the motion is magnified as well as the objects,) in a steady stream, just beneath the wall, around each cell, passing up one side, across the end, down the other, and so round to complete the circuit, carrying with it small particles, or the larger green grains, which make the current more visible. This circulation may also be observed in hairs, particularly those on flowers, such as the jointed hairs of Spiderwort, looking 
under the glass like strings of blue beads, each bead being a cell. But bere a microscope magnifying six or cight hundred times in diameter is needed to see the current distinctly.

484. The movement belongs to the protoplasm (476), or jelly-like matter under the cell-wall. As this substance has just the same composition as the flesh of animals, it is not so strange that it should exhibit such animal-like characters. In the simplest water-plants, of the Sea-weed family, the body which answers to the seed is at first only a rounded little mass of protoplasm. When these bodies escape from the mother plant, they often swim about freely in the water in various directions, by a truly spontancous motion, when they closely resemble animalcules, and are often mistaken for them. After enjoying this active life for several hours, they come to rest, form a covering of cellulose, and therefore become true vegetable cells, fix themselves to some support, germinate, and grow into the perfect plant.

485. Alssorption, C'onveyance of the Sap, \&e. Although contained in cells with closed walls, nevertheless the fluids taken in by the roots are carried up through the stem to the leaves even of the topmost bough of the tallest tree. And the sap, after its assimilation by the leaves, is carried down in the bark or the cambium-layer, and distributed throughout the plant, or else is conveyed to the points where growth is taking place, or is accumulated in roots, stems, or wherever a deposit is being stored up for future use $(71,104,128,469)$.

486. That the rise of the sap is pretty rapid in a leafy and growing plant, on a diy summer's day, is evident firom the amount of water it is continually losing by exhalation from the foliage (47); - a loss which must all the while be supplied from the roots, or else the leaves would dry up and die; as they do so promptly when sepalrated from the stem, or when the stem is cut off from the roots. Of course they do not then lose moisture any faster than they did before the separation; only the supply is no longer kept up from below.

487. The rise of the sap into the leaves apparently is to a great degree the result of a mode of diffusion which has been called Endosmose. It acts in this way. Whenever two fluids of different density are separated hy a membrane, whether of dead or of living substance, or are separated by any porous partition, a flow takes place through the partition, mainly towards the heavier fluid, until that is brought to the same density as the other. A familiar illus- 
tration is seen when we place powdered sugar upon strawberries, and slightly moisten them: the dissolving sugar makes a solution stronger than the juice in the cells of the fruit; so this is gradually drawn out. Also when pulpy fruits are boiled in a strong sirup; as soon as the sirup becomes denser than the juice in the fruit, the latter begins to flow out and the fruit begins to shrivel. But when shrivelled fruits are placed in weak sirup, or in water, they become plump, because the flow then sets inwards, the juice in the cells being denser than the water outside. Now the cells of the living plant contain organic matter, in the form of mucilage, protoplasm, sometimes sugar, \&c.; and this particularly abounds in young and growing parts, such as the tips of roots (Fig. 56), which, as is well known, are the principal agents in absorbing moisture from the ground. The contents of their cells being therefore always much denser than the moisture outside (which is water containing a little carbonic acid, \&c., and a very minute quantity of earthy matter), this moisture is constantly drawn into the root. What makes it ascend to the leaves?

488. To answer this question, we must look to the leaves, and consider what is going on there. For (however it may be in the spring before the leaves are out), in a leafy plant or tree the sap is not forced up from below, but is drawn up from above. Water largely evaporates from the leaves (447); it flies off into the air as vapor, leaving behind all the earthy and the organic matters, - these not being volatile; - the sap in the cells of the leaf therefore becomes denser, and so draws upon the more watery contents of the cells of the stalk, these upon those of the stem below, and so on, from cell to cell down to the root, causing a flow from the roots to the leaves; which begins in the latter, - just as a wind begins in the direction towards which it blows. Somewhat similarly, elaborated sap is drawn into buds or any growing parts, where it is consolidated into fabric, or is conveyed into tubers, roots, seeds, and the like, in which it is condensed into starch and stored up for future use $(74,103, \& c$.$) .$

489. So in absorbing moisture by the roots, and in conveying the sap or the juices from cell to cell and from one part to another, the plant appears to make use of a physical or inorganic force; but it manages and directs this as the purposes of the vegetable economy demand. Now, when the proper materials are brought to the growing parts, growth takes place; and in growth the plant moves 
the particles of matter, arranges them, and shapes the fabric in a manner which we cannot at all explain by any mechanical laws. The organs are not shaped by any external forces; they shape themselves, and take such forms and positions as the nature of each part, or the kind of plant, requires.

490. Special Mlovements. Besides growing, and quite independent of it, plants not only assume particular positions, but move or bend one part upon another to do so. Almost every species does this, as well as what are called sensitive plants. In springing from the seed, the radicle or stem of the embryo, if not in the proper position already, bends itself round so as to direct its root-end downwards, and the stem-end or plunnule upwards. It does the same when covered so deeply by the soil that no light can affect it, or when growing in a perfectly dark cellar. But after reaching the light, the stem bends towards that, as every one knows; and bends towards the stronger light, when the two sides are unequally exposed to the sun. It is now known that the shoot is bent by the shortening of the eells on the more illuminated side; for if we spplit the bending shoot in two, that side curves over still more, while the opposite side inclines to lly back. But how the light causes the cells to shorten on that side, we can no more explain, than we can tell how the will, acting through the nerves, causes the contraction of the filres of the muscles by which a man bends his arm. We are sure that the bending of the shoot has nothing to do with growth, because it takes place after a shoot is grown; and the delicate stem of a young seedling will bend a thousand times faster than it grows. Also because it is yellow light that most favors growth and the formation of vegetable fabric, while the blue and violet rays produce the bending. Leaves also move, even more freely than stems. They constantly present their upper face to the light; and when turned upside down, they twist on their stalks, $\sigma$ curve round to recover their original position. The free ends of twining stems, as of IIop, or Morning Glory, or Bean, which apparently hang over to one side from their weight, are in fict bent over, and, the direction of the bend constantly changing, the shoot is steadily sweeping round the circle, making a revolution every few hours, or even more rapidly in certain cases, until. it reaches a neighboring support, when, by a continuation of the sane movement, it twines around it. Most tendrils revolve in the sane way, bometines even more rapidly; while others only turn from the 
light; this is especially the case with those that cling to walls or trunks by sucker-like disks, as Virginia Creeper, p. 38, fig. 62. When an active tendril comes into contact with a stem or any such extraneous body, it incurves at the point of contact, and so lays hold of the support: the same contraction or tendency to curve affecting the whole length of the tendril, it soon shortens into a coil, part coiling one way, part the other, thus drawing the shoot up to the supporting body; or, if the tendril be free, it winds up in a simple coil. This movement of tendrils is so prompt in the Star-Cucumber (Sicyos) in Echinocystis, and in two sorts of Passion-flower, that the end, after a gentle rubbing, coils up by a movement rapid enough to be readily seen. In plants that climb by their leaf-stalks, such as Maurandia and Tropacolum, the movements are similar, but much too slow to be seen.

491. The so-called sleep of plants is a change of position as night draws on, and in different ways, according to the species, - the Locust and Wood-Sorrel turning down their leaflets, the Honey Locust raising them upright, the Sensitive Plant turning them forwards one over another; and the next morning they resume their diurnal position. One fact, among others, showing that the changes are not cansed by the light, but by some power in the plant itself, is this. The leaves of the Sensitive Plant close long before sunset; but they expand again before sunrise, under much less light than they had when they closed. In several plants the leaves take the nocturnal position when brushed or jarred, - in the common Sensitive Plant very suddenly, in other sorts less quickly, in the Honey Locust a little too slowly for us to see the motion. The way in which blossoms open and close, some when the light increases, some when it diminishes, illustrates the same thing. The stamens of the Barberry, when touched at the base on the inner side, - as by an insect seeking for honey, or by the point of a pin, - make a sudden jerk forward, and in the process commonly throw some pollen upon the stigma, which stands a little above their reach.

492. In many of these cases we plainly perceive that a useful end is subserved. But what shall we say of the Venus's Fly-trap of North Carolina, growing where it might be sure of all the food a plant can need, yet provided with an apparatus for catching insects, and actually capturing them expertly by a sudden motion, in the manner already described (126, Fig. 81)? Or of the leaflets of the 
Desmodium gyrans of the East Indies, spontaneously falling and rising by turns in jerking enotions nearly the whole day long? We can only say, that plants are alive, no less than animals, and that it is a characteristic of living things to move.

\section{* Cryptogahous or Fiowerless Plants.}

493. In all the foregoing Lessons, we have had what may be called plants of the higher classes alone in view. There are other's, composing the lower grades of vegetation, to which some allusion ouglit to be made.

494. Of this sort are Ferns or Brakes, Mosses, Liverworts, Lichens, Sea-weeds, and Fungi or Mushrooms. They are all classed together under the name of Flowerless Plants, or Cryptogamous Plants; the former epithet referring to the fact that they do not bear real blussoms (with stamens and pistils) nor seeds (with an embryo ready-formed within). Instead of seeds they have spores, which are usually simple cells (392). The name Cryptogamous means, of hidden fructification, and intimates that they may have something answering to stamens and pistils, although not the same; and this is now known to be the ea: e with most of them.

495. Flowerless plants are so very various, and so peculiar in each family, that a volume would be required to illustrate them. Curious and attractive as they are, they are too difficult to be studied botanically by the beginner, except the F'erns, Club-Mosses, and Horse-tails. For the study of these we refer the student at once to the Manual of the Botany of the Northern United States, and to the Field, Forest, and Gurden Botany. The structure and physiology of these plants, as well as of the Mosses, Liverworts, Lichens, Seaweeds, and Fungi, are explained in the Structural Botany, or Botanical Text-Book, and in other similar works. When the student has become prepared for the study, nothing can be more interesting than these plants of the lowest orders. 


\title{
LESSON XXVIII.
}

\author{
SPFCIES AND KINDS.
}

196. Untru now, we have been considering plants as to their structure and their mode of life. We have, as it were, been reading the biography of an individual plant, following it from the tiny seedling up to the mature and fruit-bearing herb or tree, and learning how it grows and what it does. The botanist also considers plants as to their relationships.

497. Plants and animals, as is well known, have two great peculiarities: 1st, they form themselves; and $2 \mathrm{~d}$, they multiply themselves. They reproduce themselves in a continued succession of

498. Individuals (3). Mineral things occur as masses, which are divisible into smaller and still smaller ones without alteration of their properties (391). But organic things (vegetables and animals) exist as individual beings. Each owes its existence to a parent, and produces similar individuals in its turn. So each individual is a link of a chain; and to this chain the natural-historian applies the name of

499. Species. All the descendants from the same stock therefore compose one species. And it was from our observing that the several sorts of plants or animals steadily reproduce themselves, - or, in other words, keep up a succession of similar individuals, - that the idea of species originated. So we are led to conclude that the Creator established a definite number of species at the beginning, which have continued by propagation, each after its kind.

500. There are few species, however, in which man has actually observed the succession for many generations. It could seldom be proved that all the White Pine trees or White Oaks of any forest came from the same stock. But observation having familiarized us with the general fact, that individuals proceeding from the same stock are essentially alike, we infer from their close resemblance that these similar individuals belong to the same species. That is, we infer it when the individuals are as much like each other as those are which we know to have sprung from the same stock.

501. We do not infer it from every resemblance; for there is the resemblance of kind, - as between the White Oak and the Red Oak, 
and between the latter and the Scarlet Oak: these, we take for granted, have not originated from one and the same stock, but from three separate slucks. Nor do we deny it on account of every difference; for even the sheep of the same flock, and the plants raised from peas of the same pod, may show differences, and such differences occasionally get to be very striking. When they are pretty well marked, we call them

Varieties. The White Oak, for example, presents two or three varieties in the shape of the leaves, although they may be all alike upon each particular tree. The question often arises, practically, and it is often hard to answer, whether the difference in a particular case is that of a variety, or is specific. If the former, we naty commonly prove it to be so by finding such intermediate degrees of difference in various individuals as to show that no clear line of distinction can be drawn between them; or else by observing the variety to vary back again, if not in the same individual, yet in its offspring. Our sorts of Aples, P'ears, Potatoes, and the like, show us that differences which are permanent in the individual, and continue unchanged through a long series of generations when propagated by division (as by oftiets, cuttings, grafts, bulbs, tubers, \&c.), are not likely to be reproduced by seed. Still they sometimes are so: and such varieties are called

Races. 'These are strongly marked varieties, capable of being propagated by seed. Our different sorts of Wheat, Indian Corn, Peas, Radishes, \&c., are familiar examples : and the races of men offer an analogous instance.

502. It should be noted, that all varieties have a tendency to be reproduced by seed, just as all the peculiarities of the parent tend to be reproduced in the offspring. And by selecting those plants which have developed or inherited any desirable peculiarity, keeping them from mingling with their less promising brethren, and selecting again the most promising plants raised from their seeds, we may in a few generations rendic almost any variety transmissible by seed, so long as we take good care of it. In fact, this is the way the cultivated or domesticated races, so useful to man, have been fixed and preserved. Races, in fact, can hardly, if at all, be said to exist independently of man. I3ut man does not really produce them. Such peculiarities - often surprising enough - now and then originate, we know not how (the plant sports, as the gardeners say); they are only preserved, propagated, and generally further developed, by the culti- 
vator's skilful care. If left alone, they are likely to dwindle and perish, or else revert to the original form of the species.

503. Botanists variously estimate the number of known species of plants at from seventy to one hundred thousand. About 3,850 species of the higher classes grow wild in the United States east of the Mississippi. So that the vegetable kingdom exhibits a very great diversity. Between our largest and highest-drganized trees, such as a Magnolia or an Oak, and the simplest of plants, reduced to a single cell or sphere, much too minute to be visible to the naked eye, how wide the difference! Yet the extremes are connected by intermediate grades of every sort, so as to leave no wide gap at any place; and not only so, but every grade, from the most complex to the most simple, is exhibited under a wide and most beautiful diversity of forms, all based upon the one plan of regetation which we have been studying, and so connected and so answering to each other throughout as to convince the thoughtful botanist that all are parts of one system, works of one hand, realizations in nature of the conception of One Mind. We perceive this, blso, by the way in which the species are grouped into

504. Kinds. If the species, when arranged according to their resemblances, were found to differ from one another about equally, that is, if No. 1 differed from No. 2 just as much as No. 2 did from No. 3, and No. 4 from No. 5, and so on throughout, - then, with all the diversity in the vegetable kingdom there is now, there would yet be no foundation in nature for grouping species into kinds. Species and kinds would mean just the same thing. We should classify them, no doubt, for convenience, but our classification would be arbitrary. The fact is, however, that species resemble each other in very unequal degrees. Some species are almost exactly alike in their whole structure, and differ only in the shape or proportion of their parts; these, we say, belong to one Genus. Some, again, show a more ger: eral resemblance, and are found to have their flowers and seeds constructed on the same particular plan, but with important differences in the details; these belong to the same Order or Fumily. Then, taking a wider survey, we perceive that they all group themselves under a few general types (or patterns), distinguishable at once by their flowers, by tieir seeds or embryos, by the character of the seedling plant, by the structure of their stems and leaves, and by their general appearance: these great groups we call Classes. Finally, we distinguish the whole into two great types or grades; 
the higher grade of Flowering plants, exhibiting the full plan of vegetation, and the lower grade of Flowerless plants, in which vegetation is so simplitied that at length the only likeness between them and our common trees or Flowering plants is that they are both vegetables. From species, then, we rise first to

505. lienera (plural of Crenus). The Rose kind or genus, the Oak genus, the Chestnut genus, \&c., are familiar illustrations. Each genus is a group of nearly related species, exhibiting a particular plan. All the Oaks belong to one genus, the Chestnuts to another, the Beech to a third. 'The Apple, Pear, and Crab are species of one genus, the Quince represents another, the various species of Hawthorn a third. In the animal kingdom the common cat, the wild cat, the panther, the tiger, the leopard, and the lion are species of the cat kind or genus; while the dog, the jackal, the different species of wolf, and the foxes, compose another genus. Some gencra are represented by a vast number of species, other's by few, very many by only one known species. For the genus may be as perfectly represented in one species as in several, although, if this were the case throughuut, genera and species would of course be identical (504). The Beech genus and the Chestnut genus would be just as distinct from the Oak genus even if but one Beech and one Chestnut were known; as indeed was the case formerly.

506. Orders or Families (the two names are used for the same thing in botany) are groups of genera that resemble each other; that is, they are to genera what genera are to species. As familiar illustrations, the Oak, Chestnut, and Beech genera, along with the Hazel genus and the IIornbeams, all belong to one order, viz. the Oak Family; the Birches and the Alders make another family; the Poplars and Willows, another; the Walnuts (with the Butternut) and the Hickories, another. The Apple genus, the Quince and the Hawthorns, along with the Plums and Cherries and the Peach, the Raspberry, with the Blackberry, the Strawberry, the Rose, and many other genera, belong to a large order, the Rose Family.

507. Tribes and Suborders. This leads us to remark, that even the genera of the same order may show very unequal degrees of resemblance. Some may be very closely related to one another, and at the same time differ strikingly from the rest in certain important particulars. In the Rose Fannily, for example, there is the Rose genus itself, with the Rasploerry genus, the Strawberry, tha Cinquefoil, \&c. near it, but by no meitns so much like it as they are like canch 
other: this group, therefore, answers to what is called a Tribe; and the Rose itself stands for another tribe. But we further observe that the Apple genus, the IIawthorns, the Quince, and the Juneberry, though of the same order, and nearly related among them. selves, differ yet more widely from the Rose and its nearest relations; and so, on the other hand, do the Plum and Cherry, the Peach and the Almond. So this great Rose Family, or Order, is composed of three groups, of a more marked character than tribes, - groups which might naturally be taken for orders; and we call them Suborders. But students will understand these matters best after a few lessons in studying plants in a work describing the kinds.

508. Classes. These are great assemblages of orders, as already explained (515). The orders of Flowering Plants are numerous, no less than 134 being represented in the Botany of the Northern United States; but they all group themselves under two great classes. One class comprises all that have seeds with a monocotyledonous embryo (32), endogenous stems (423), and generally parallel-veined leaves (139); the other, those with dicotyledonous embryo, exogenous stems, and netted-veined leaves; and the whole aspect of the two is so different that they are known at a glance.

509. Finally, these two classes together compose the upper Series or grade of Flowering or Phanogamous Plants, which have their counterpart in the lower Series of Flowerless or Cryptogamous Plants, - composed of three classes, and about a dozen orders.

510. The universal members of classification are Class, Order, Genus, Species, always standing in this order. When there are more, they take their places as in the following schedule, which comprises all that are generally used in a natural classification, proceeding from the highest to the lowest, viz.:-

Series,

Class,

Subclass,

Order, or Family,

Suborder,

'Tribe,

Subtribe,

Genus,

Subgenus or Section,

Species,

Variety. 


\section{LESSON XXIX.}

BOTANICAI, NAMLS AND CHARACTERS.

511. Plants are classified, - i. e. are marshalled under their respective classes, orders, tribes, genera, and species, - and they are haracterized, - that is, their principal characteristics or distinguishmarks are described or enumerated, in order that,

First, their resemblances or differences, of various degrees, may be clearly exhibited, and all the species and kinds ranked next to those they are most related to; - and

Secondly, that students may readily ascertain the botanical names of the plants they meet with, and learn their peculiarities, properties, and place in the system.

512. It is in the latter that the young student is chiefly interested. And by his studies in this regard he is gradually led up to a higher point of view, from which he may take an intelligent survey of the whole general system of plants. But the best way for the student to learn the classification of plants (or Botany as a system), is to use it, in finding out by it the name and the peculiarities of all the wild plants he meets with.

513. Names. The botanical name of a plant, that by which a botanist designates it, is the name of its genus followed by that of the species. The name of the genus or kind is like the family name or surname of a person, as Smith, or Jones. That of the species answers to the baptismal name, as John, or James. Accordingly, the White Oak is called botanically Quercus alba; the first word, or Quercus, being the name of the Oak genus; the second, alba, that of this particular species. And the Red Oak is named Quercus rubra; the Black-Jack Oak, Quercus nigra; and so on. The botanical names are all in Latin (or are Latinized), this being the common language of science everywhere; and according to the usage of that language, and of most others, the name of the species comes after that of the genus, while in English it comes before it.

514. Generic Names. A plant, then, is named by two words. The generic name, or that of the genus, is one word, and a substantive. Commonly it is the old classical name, when the genus was known to the Greeks and Romans; as Quercus for the Oak, F'ayus for the 
Beech, Corylus, the IIazel, and the like. But as more genera became known, botanists had new names to make or borrow. Many are named from some appearance or property of the flowers, leaves, or other parts of the plant. 'To take a few examples from tine early pages of the Manual of the Botany of the Northern United Siares, in which the derivation of the generic names is explained. The genus Hepatica, p. 6, comes from the shape of the leaf resembling that of the liver. Myosurus, p. 10, means mouse-tail. Detphinium, p. 12, is from delphin, a dolphin, and alludes to the shape of the flower, which was thought to resemble the classical figures of the dolphin. Zanthorhiza, p. 13, is from two Greek words meaning yellow-root, the common name of the plant. Cimicifuga, p. 14, is formed of two Latin words, meaning, to drive away bugs, the same as its common name of Bugbane, the Siberian species being used to keep away such vermin. Sanguinaria, p. 26, is named from the blood-like color of its juice.

515. Other genera are dedicated to distinguished botanists or promoters of natural science, and bear their names: such are Magnolia, p. 15, which commemorates the early French botanist, Magnol, and Jeffersonia, p. 20, named ufter President Jefferson, who sent the first exploring expedition over the Rocky Mountains. Others bear the name of the discoverer of the plant in question ; as, Sarracenia, p. 23, dedicated to Dr. Sarrazin of Quebec, who was one of the first to send our common Pitcher-plant to the botanists of Europe: and Claytonia, p. 65, first made known by the early Virginian botanist Clayton.

516. Specific Names. The name of the species is also a single word, appended to that of the genus. It is commonly an adjective, and therefore agrees with the generic name in case, gender, \&c. Sometimes it relates to the country the species inhabits; as, Claytonia Virginica, first made known from Virginia; Sanguinaria Canadensis, from Canada, \&c. More commonly it denotes some obvious or characteristic trait of the species; as, for example, in Sarracenia, our northern species is named purpurea, from the purple blossoms, while a more southern one is named flava, because its petals are yellow; the species of Jeffersonia is called diphylla, meaning two-leaved, because its leaf is divided into two leaflets. Some species are named after the discoverer, or in compliment to a botanist who has made them known; as, Magnolia Fraseri, named after the botanist Fraser, one of the first to find this species; Ra 
worthia Michauxii, p. 65, named for the early botanist Michaux; and Polygala Nuttallii, in compliment to Mr. Nuttall, who described it under another name. Such names of persons are of course written with a capital initial letter. Occasionally some old substantive name is used for the species; as Magnolia Umbrella, p. 49, and Ranunculus Flammula, p. 41. These are also written with a capital initial, and need not accord with the generic name in gender, \&c.

517. The name of a variety, when it is distinct enough to require any, is mude on the same plan as that of the species, and is written after it; as, Ranunculus Flammula, variety reptans, p. 41 (i. e. the creeping variety), and $R$. abortivus, variety micranthus, p. 42, or the small-flowered variety of this species.

518. Names of Groups. The names of tribes, orders, and the like, are in the plural number, and are commonly formed by prolonging the name of a genus of the group taken as a representative of it. For example, the order of which the Buttercup or Crowfoot genus, Ranunculus, is the representative, takes from it the name of Ranunculacea (Manual, p. 34); meaning Planta Ranunculacea when written out in full, that is, Ranunculacrous Plants. This order comprises several tribes; one of which, to which Ranunculus itself belongs, takes the name of Ranunculere; another, to which the genus Clematis, or the Virgin's-Bower, belongs, takes accordingly the name of Clematidece; and so on. So the term Rosacece (meaning Rosaccous plants) is the name of the order of which the Rose (Rosa) is the well-known representative; and Rosece is the name of the particular tribe of it which comprises the Rose.

519. A few orders are named on a somewhat different plan. The great order Leguminosa, for instance (Manual, p. 123), is not named after any genus in it ; but the fruit, which is a legume (356), gives the name of Leguminous Plants. So, likewise, the order Umbelliferce (Manual, p. 187) means Umbelliferous or Umbel-bearing Plants; and the vast order Composita (Manual, p. 215) is so named because it consists of plants whose blossoms are crowded into heads of the sort which were called "compound flowers" by the old botanists (277).

520. Characters. The brief description, or enumeration in scientific terms, of the principal distinctive marks of a species, genus, order, or other group, as given in botanical works, is called its Character. Thus, in the Manual, already referred to, at the begin- 
ning, the character of the first great series is given; then that of the first class, of the first subclass, and of the first division under it. Then, after the name of the order, follows its character (the ordinal character) : under the name of each genus (as, 1. Clematis, p. 35) is added the generic character, or description of what essentially distinguishes it ; and finally, following the name of each species, is the specific character, a succinct enumeration of the points in which it mainly differs from other species of the same genus. See, for 'illustration, Clematis Viorna, p. 36, where the sentence immediately following the name is intended to characterize that species from all others like it.

521. Under this genus, and generally where we have several species of a genus, the species are arranged under sections, and these often under subsections, for the student's convenience in analysis, the character or description of a section applying to all the species under it, and therefore not having to be repeated under each species. Under Clematis, also, are two sections with names, or sub-genera, which indicates that they might almost be regarded as two distinct genera. But these details are best understood by practice, in the actual studying of plants to ascertain their nume and place. And to this the student is now ready to proceed.

\section{LESSON XXX.}

HOW TO STUDY PLANTS.

522. Having explained, in the two preceding Lessons, the general principles of Classification, and of Botanical Names, we may now show, by a few examples, how the student is to proceed in applying them, and how the name and the place in the system of an unknown plant are to be ascertained.

523. We suppose the student to be provided with a hand magnifying-glass, and, if possible, with a simple microscope, i. e. with a magnifying-glass, of two or more different powers, mounted on a support, over a stage, holding a glass plate, on which small flowers or their parts may be laid, while they are dissected under the microscope with the points of needles (mounted in handles), or divided 
by a sharp knife. Such a microscope is not necessary, except for very small flowers; but it is a great convenience at all times, and is indispenaable in studying the more difficult orders of plants.

524. We suppose the student now to have a work in which the plants of the country or district are scientifically arranged and described : if in the Southern Atlantic States, Dr. Chapman's Flora of the Scuthern Stutes; if north of Carolina and Tennessee, Gray's Manual of the Botuny of the United States, fifth edition; or, as covering the whole ground as to common plants, and including also all the common cultivated plants, Gray's Field, Forest, and Garden Botany, which is particularly arranged as the companion of the present work; that containing brief botanical descriptions of the plants, and this the explanation of their general structure, and of the technical terms employed in describing them. To express clearly the distinctions which botanists observe, and which furnish the best marks to know a plant by, requires a good many technical terms, or words used with a precise meaning. These, as they are met with, the student should look out in the Glossary at the end of this volume. The terms in common use are not so numerous as they would at first appear to be. With practice they will soon become so familiar as to give very little trouble. And the application of botanical descriptive language to the plants themselves, indicating all their varieties of form and structure, is an excellent discipline for the mind, equal, if not in some respects superior, to that of learning a classical language.

525. The following illustrations and explanations of the way to use the descriptive work are, first, for The Field, Forest, and Garden Botany, that being the one which will be generally used by beginners and classes. This and the Lessons, bound together in a single compact volume, will serve the whole purpose of all but advanced students, teachers, and working botanists. 'Thus equipped, we proceed to

526. The Analysis of a Plant. A Butlercup will serve as well as any. Some species or other may be found in blossom throughout nearly the whole spring and summer; and, except at the very beginning of the season, the fruit, more or less developed, may bo gathered with the blossom. To a full knowledge of a plant the fruit is essential, although the name may almost always be ascertained without it. This common yellow flower being under examination, we are to refer the plant to its proper class and order or 
family. The families are so numerous, and so generally distinguishable only by a combination of a considerable number of marks that the student must find his way to them by means of a contrivance called an Analytical Key. This Key begins on p. 12.

527. It takes note of the most comprehensive possible division of plants, namely those "producing true flowers and seeds," and those "not producing flowers, propagated by spores." To the first of these, the great series of Pindegamous or Flowering Plants, the plant under examination obviously belongs.

528. This series divides into those "with wood in a circle, or in concentric annual circles or layers around a central pith, netted-veined leares, and parts of the flower mostly in fives or fours," - to which might be added the dicotyledonous embryo, but that in the present case is beyond the young student's powers, even if the fruit were at hand; - and into those "with wood in separate threads scattered through the diameter of the stem, not in a circle," also the "leaves mostly parallel-veined, and parts of the flower almost always in threes, never in fives." Although the hollowness of the stem of the present plant may obscure its internal structure, a practised hand, by throwing the light through a thin cross section of the stem under the glass, would make it evident that its woody bundles were all in a circle near the circumference, yet this could hardly be expected of an unassisted and inexperienced beginner. But the two other and very obvious marks, the netted-veined leaves, and the number five in both calyx and corolla, certify at once that the plant belongs to the first class, Exogenous or Dicotyledonous Plants.

529. We should now look at the flower more particularly, so as to make out its general plan of structure, which we shall need to know all about as we go on. We observe that it has a calyx of 5 sepals, though these are apt to fall soon after the blossom opens; that the 5 petals are

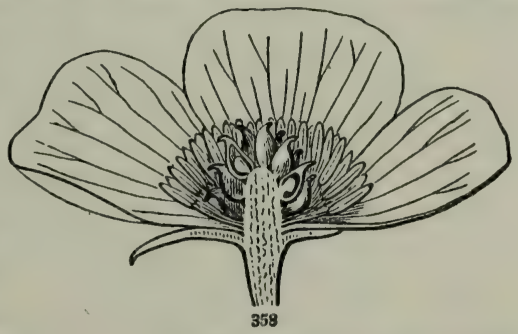
borne on the receptacle (or common axis of the flower) just above the sepals and alternate with them; that there are next borne, a

FIG. 358. A flower of a Buttercup (Ranunculus bulbosus) cut through from top to bottom. and enlarged. 
little higher up on the receptacle, an indefinite number of staraens; and, lastly, covering the summit or centre of the receptacle, an in-

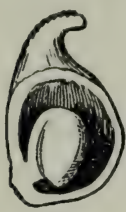

259

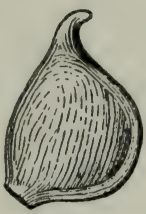

360

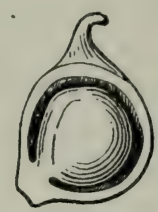

361 definite number of pistils. A good view of the whole is to be had by cutting the flower directly through the middle, from top to bottom (Fig. 358). If this be done with a sharp knife, some of the pistils will be neatly divided, or may be so by a second slicing. Each pistil, we see, is a closed ovary, containing a single ovule (Fig. 359) ascending from near the base of the cell, and is tipped with a very short broad style, which has the stigma running down the whole length of its inner edge. The ovary is little changed as it ripens into the sort of fruit termed an akene (Fig. 360); the ovule becoming the seed and fitting the cell (Fig. 361). Reverting to the key, on p. 13, we find that the class to which our plant belongs has two subclasses, one "with pistil of the ordinary sort, the ovules in a closed ovary"; the other "without proper pistil, the ovules naked on a scale," \&c. The latter is nearly restricted to the Pine Family. The examination already had makes it quite clear that our plant belongs to the first subclass, Angrospermous Exogenous or Dicotyledonous Plants.

530. We have here no less than 110 orders under this subclass. To aid the unpractised student in finding his way among them, they are ranked under three artificial divisions; the Polypetalous, the Monopetalous, and the Apetalous. The plant in hand being furnished, in the words of the key, "with both calyx and corolla, the latter of wholly separate petals," is to be sought under I. PoLYPetalous Division; for the analysis of which, see p. 14.

531. Fully half the families of the class rank under this division. The first step in the key is to the sections A and B; to the first of which, having "stamens more than 10 , and more than twice the number of the sepals or divisions of the calyx," our plant must pertain.

532. Under this we proceed by a series of successive steps, their gradations marked by their position on the page, leading down to the name of the order or family, to which is appended the number

FIG. 359. A pistil taken from a Buttercup (Kanunculus bulbosus), and more magnified; its ovary eut through lengthwise, showing the ovule. 360 . One of its pistils when ripened Into a fruit (achenium or akent). 361. 'The same, cut through, to show the seed in it. 
of the page where that family and the plants under it are described. The propositions of the same grade, two or more, from which determinntion is to be made, not only stand one directly under the other, but begin with the same word or phrase, or with some counterpart, - in the present case again with "Stamens," and with four propositions, with one and only one of which the flower in hand should agree. It agrees with the last of the four: "Stamens not monadelphous."

533. The propositions under this, to which we are now directed, are six, beginning with the word "Pistils" or "Pistil." The one which applies to the flower in hand is, clearly, the fourth: "Pistils numerous or more than one, separate, on the receptacle."

534. The terms of the analysis directly subordinate to this are only two: we have to choose between "Stamens borne on the calyx," and "Stamens borne on the receptacle." The latter is true of our flower. The terms subordinate to this are four, beginning with the word "Leaves." The fourth alone accords: "Leaves not peltate; herbs," - and this line leads out to the Crowfoor FAMily, and refers to p. 33.

535. Turning to that page, a perusal of the brief account of the marks of the Ranunculacese (the technical Latin name) or CrowFoOT FAMIL, assures us that the Key has led us safely and readily to a correct result. Knowing the order or family, we have next to ascertain the genus. Here are twenty genera to choose from; but their characters are analyzed under sections and successive subsections $(\S, *,+,++, \& c$.$) so as to facilitate the way to the desired$ result. Of the two primary sections, we must reject $\S 1$, as it agrees only in respect to the pistils, and differs wholly in the characters furnished by the sepals, the petals, and the leaves. With "§ 2 . Sepals imbricated in the bud: not climbing nor woody," it agrees. It also agrees with the sub-section immediately following, viz.: "* Pis. tils and akenes, several or many in a head, one-seeded." The sub. division following: " + Petals none: sepals petal-like," is inapplicable; but its counterpart, " ++ Petals and sepals both conspicuous, five or more : akenes, naked, short-pointed," suits, and restricts our choice to the three genera, Adonis, Myosurus, and Ranunculus. The determination is soon made, upon noting the naked sepals, the petals with the little scale on the upper face of the short claw, and the akenes in a head: so the genus is, 7. Ranunculus. 
536. The arrangement of the species of Ranunculus is to be found, under the proper number, 7 , on p. 37 and the following. The first section contains aquatic species; ours is terrestrial, and in all other particular's auswers to $\S 2$. The smooth ovary and akene, and the perennial root refer it to the subsection following, marked by the single star. The shape of the leaves excludes it from the "+ Spearwort Crowfoots," the large and showy petals from the "+ + Small-flowered Crowfoots; while all the marks agree with +++ Butrercups or Common Crowfoots. There is still a subdivision, one set marked, "++ Nutives of the country, low or spreading," the other "++++ Introduced weeds from Europe, common in fields, \&.c.: stem erect: leaves much cut,"- - which is the case. We have then only to choose between the two field Crowfoots, and we have supposed the pupil to have in hand the lower, early-flowered one, comınon at the east, which has a solid bulb or corm at the base of the stem, and displays its golden flowers in spring or earliest summer, and which accordingly answers to the description of Ranunculus bulbosus, the Bulbous Buttercur.

537. Later in the season it might have been $R$. acris, the Tall Buttercup, or much earlier $R$. fascicularis, or $R$. repens. IIaving ascertained the genus from any one species, the student would not fail to recognize it again in any other, at a glance.

538. If now, with the same plant in hand, the Manual (Fifth edition) be the book used, the process of analysis will be so similar, that a brief indication of the steps may suffice. Here the corresponding Analytical Key, commencing on p. 21, leads similarly to the first Series, Class, Subclass, and Division; - to A, with numerous stamens; 1, with calyx entirely free and separate from the pistil or pistils, thence to the fourth line beginning with the word Pistils; thence to the third of the three subordinate propositions, viz. to "Stamens inserted on the receptacle"; to the second of the succeeding couplet, or "Filaments longer than the auther"; to the second of the next couplet, " Flowers perfect," \&c., and to the first of the final couplet, "Leaves not peltate ; petals deciduous," - which ends in "Ranunculacese, 34." This is the technical name of the family, and the page where it is described.

539. Turning to that page we read the general description of that order, particularly the portion at the beginning printed in italics, which comprises the more important points. The "Synopsis of the 
Genera" which follows is similar to, but more technical than that of the other, more elementary book; and the names of the tribes or natural groups of genera (507) are inserted. The steps of analysis bring the student to the Tribe III. Ranuncules, and under it to the genus Ranunculus. The number prefixed to the name enables the student to turn forward and find the genus, p. 40. The name, sciertific and popular, is here followed by a full generic charactr $r$ (5\%0). The primary sections here have names: the plant under examination belongs to " $\S 2$. RANUnCULUs proper"; and thence is to be traced, through the subdivisions $*++++,+++$, to the ultimate subdivision $b$, under which, through a comparison of characters, the student reaches the species $R$. Busbosus, $L$.

540. The $L$. at the end of the name is the recognized abbreviation of the name of Linnxus, the botanist who gave it. Then come the common or English names; then the specific character ; after this, the station where the plant grows, and the region in which it occurs. This is followed by the time of blossoming (from May to July); and then by some general descriptive remarks. The expression “ Nat. from Eu." means that the species is a naturalized emigrant from Europe, and is not original to this country. But all these details are duly explained in the Preface to the Manual, which the student who uses that work will need to study.

\section{LESSON XXXI.}

HOW TO STUDY PLANTS: FURTHER ILI.USTRATIONS.

541. Beginners should not be discouraged by the slow progress they must needs make in the first trials. By perseverance the various difficulties will soon be overcome, and each successful analysis will facilitate the next. Not only will a second species of the same genus be known at a glance, but commonly a second genus of the same order will be recognized as a relative at sight, by the family likeness. Or if the family likeness is not detected at the first view, it will be seen as the characters of the plant are studied out.

542. To help on the student by a second example, we will take the common cultivated Flax. Turning to the Key, as before, on 
p. 12, the student is led to ask, first, is the plant Phanogamous or Flowering? Of cour:e it is; the blossom, with its

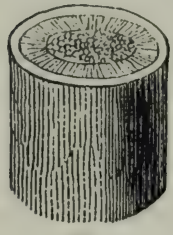
stamens and pistils, answers that question. Next, to which of the two clasies of Flowering Plants does it belong? If we judge hy the stem, we ask whether it is exogenous or endogenous (422-424). A section of the stem, considerably magnified, given on page 151, we may here repeat (Fig. 362); it plainly shows a ring of wood between a central pith and a bark. It is therefore exogenous. Mortover, the leavey are netted-veined, though the veins are not conspicuous. IVe might even judge from the embryo; for there is little difficulty in dissecting a flax-seed, and in finding that almost the whole interior is occupied by an embryo with two cotyledons, much like that of an apple-seed (Fig. 11, 12), and this class, as one of its name denotes, is dicotyledonous. If we view the parts of the blossom, we perecive they are five throughout (Fig. 363, 365), a number which occurs in that class only. All these marks, or as many of them as the student is able to verify, show that the plant belongs to Class I. Exoginouy or Dicotrlenonous Plants. 543. To which subclass, is the next. inquiry. The single but several-celled ovary in the centre of the flower, enclosing the ovules, assures us that it belongs to the Angrospermous subclass, p. 13.

544. To get a good idea of the general plan of the flower, before
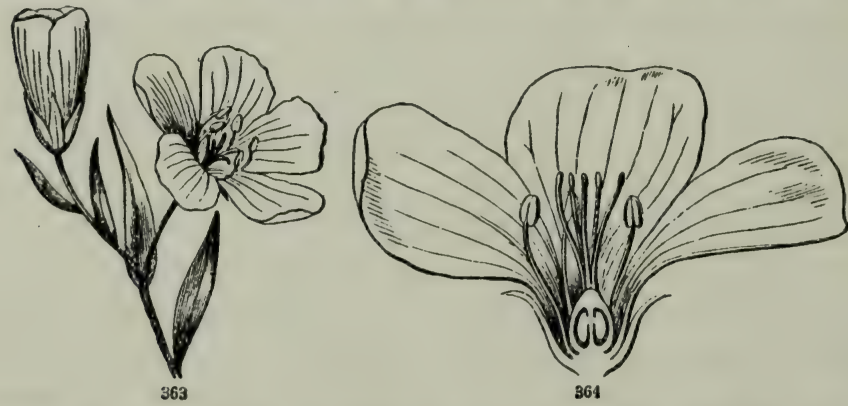

proceeding farther, cut it through the middle lengthwise, as in Fig. 364 , and also take a slice across a flower-bud, which will bring to view an arrangement somewhat like that of Fig. 365. Evidently the blossom is regularly constructed upon the number five. It has a calyx of five sepals, a corolla of five petals, five stamens, and five

FIG. 362. Section of the stem of F'lax, mugnifed. 333. Summit of a branch of the common Elax, with two Howors. 3it. A llower divided lengthwise and eularged. 
styles, with their ovaries all combined into one compound ovary. We note, also, that the several parts of the blossom are all free and unconnected, - the leaves of the calyx, the petals, and the stamens all rising separately one after another from the receptacle underneath the ovary; but the filaments, on close inspection, may show a slight union among themselves, at the base.

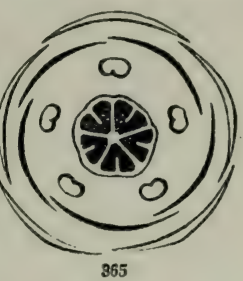

545. So our plant, having 5 separate petals, is of the PolypetaLous division of the first class, for the analysis of which see page 14 .

546. But it does not belong to the primary division $A$, which has more than 10 stamens. The student passes on, therefore, to the counterpart division $\mathrm{B}$, on page 16 , to which the few stamens, here only five, refer it.

547. Of the three subdivisions, with numerals prefixed, only the second answers; for the calyx is free from the ovary, and there is only one ovary, although the styles are five.

548. The divisions subordinate to this form a couplet; and our plant agrees with the second member of it, having "Stamens of the same number as the petals" [5] and "alternate with them." The division under this is a triplet, of which we take the third member; for the "Leaves are not punctate with pellucid dots." Under this, in turn, is a triplet beginning with the word Ovary, and the five, if not ten cells, determine our choice of the third member of it, "Ovary compound." Under this we have no less than nine choices, dependent upon the structure of the ovary, the number of ovules and seeds, \&c. But the 5-celled ovary with a pair of ovules in each cell, separated by a false partition projecting from the back (Fig. 365), so that the pod becomes in fact 10-celled, with a solitary seed in each cell, is described only in the ninth and last of the set, p. 18. Under this, again, we have to choose among five propositions relating to the seeds. Here the fifth - "Seeds and ovules only one or two in each cell"-alone meets the case. Under this, finally, we have to choose from six lines, beginning with the words 'Tree, Shrubs, or IIerbs. The fifth alone agrees, and leads to the Flax Famir, p. 77.

549. There is only one genus of it in this country, namely, the Flax genus itself, or Linum. To determine the species, look first

FIG. 365. Cross-section of an unexpanded flower of the same, a sort of diagram. 
at the three sections, marked with stars. The second answers to our plant; and the annual root, pointed sepals, and blue petals determine it to be the Common Flax, Linum usitatissimum.

550. By the Manual, the same plant would be similarly traced, along a somewhat different order of steps, down to the genus on p. 104, and to the species, which being a foreign cultivated one, and only by chance spontaneous, is mercly mentioned at the close.

551. After several analyses of this kind, the student will be able to pass rapidly over most of these steps; should ordinarily recognize the class and the division at a glance. Suppose a common Mallow to be the next subject. Having flowers and seeds, it is Phanogamous. The netted-veined leaves, the structure of the stem, and the leaves of the flower in fives, refer it to Class I. The pistils, of the ordinary sort, refer it to Subclass I. The five petals refer it to the Polypetalous division. Turning to the Key in the Field, Forest, and Garden Botany, and to the analysis of that division, commencing on p. 14, the numerous stamens fix it upon $A$, under which the very first line, "Stamens monadelphous, united with the base of the corolla; anther's kidney-shaped, one-celled," exactly expresses the structure of these organs in our plant, which is thus determined to be of the Mallow Famly, - for which see page 70 .

552. After reading the character of the family, and noting its agreement in all respects, we fix upon $\S 1$, in which the anthers are all borne at the top, and not down the side of the tube of filaments. We pass the subdivision with a single star, and choose the alternative, with two stars, on account of the ring of ovaries, \&c.; fix upon the division + , on account of the stigmas running down one side of the slender style, instead of forming a little head or blunt tip at their apex; and then have to choose anong five genera. The three separate bracts outside of the calyx, the obcordate petals, and the fruit determine the plant to be a Marva. Then, referring to p. 71 for the species, the smatl whitih flowers point to the first division, and a comparison of the character's of the two species under it, assures us that the plant in hand is Matra rotundeolia.

553. For the sake of an example in the Monopetalous Division, we take a sort of Morning-Glory which is often met with climbing over shrubs along the moist banks of streams. Its netted-veined leaves, the sepals and the stamens being five, - also the structure of the stem, if we choose to examine it, and the embryo with two leafy 
entyledons (as in Fig. 26), readily inspected if we have seerls, show it belongs to Class I. Its pistil refers it of course to Subclass I. The corolla being a short funnel-shaped tube, theoretically regarded as formed of five petals united up to the very summit or border, renders the flower a gond illustration of the Monopetalous Division, the analysis of which begins on p. 20 , in the work we are using.

554. The calyx free from the ovary exclules it from the section $\Lambda$, and refers it to section 13 . This is subdivided, in the first place, by the number of the stamens, and their position as respects the lobes of the corolla. Now, as the petals of the corolla in this flower are united up to the very border, the student may at first be puzzled to tell how many lobes it should have, or, in other words, how many petals enter into its composition. But the five leaves of the caly $x$ would lead one to expect a corolla of five parts allo. And, although there are here really no lobes or notehes to be seen, yet the five plaits of the corolla answer to the notehes, and show it to consist of five petals perfectly united. Since the stamens are of the same number as the plaits of the corolla, and are placed before them (as may be best seen by splitting down the corolla on one side and spreading it out flat), it follows that they alternate with the lobes or petals; therefore our plant falls under the third subdivision: "Stamens as many as the lobes or parts of the corolla and alternate with them." This subdivides by the pistils. Our plant, having a pistil with two stigmas and two cells to the ovary, must be referred to the fifth and last category: "Pistil one, with a single compound ovary," \&c. We are then directed to the stannens, which here are "plainly borne on the corolla"; next to the leaves, which are on the stem (not all at the root), also alternate, without stipules; the stamens 5 , and the ovary 2-celled, - all of which accords with the seventh of the succeding propositions, and with no other. The middle one alone under this agrees as to the ovary and seeds, and all is confirmed by the twining stem. It is the Convolvulus Family, p. 262.

555. The proper Convolvulus Family has green foliage, as has our plant. Its style is single and entire, as in $\S 1$. Its caly $x$ has a pair of large leafy bracts, as in the subdivision with two stars. So we reach the genus Calysteria, or Bracted Bindwed.

556. Under this genus two species are described : the twining stem, and the other particulars of our plant, direct us to the first C. SEPIUn, which in England is named Hedge BindweEd, and here is one of the various Convolvulaceous plants known as Morning-GLory. 


\section{LESSON XXXII.}

\section{HOW TO STUDY PLANTS: FURTHER ILLUSTRATIONS.}

557. True foregoing illustrations have all been of the first or Exogenous class. We will take one from the other class, and investigate it by the Munual.

558. It shall be at rather common plant of our woods in spring, the Three-leaved Nightshade, or Birthroot. With specimens in hand, and the Manual open at the Analytical Key, p. 21, seeing that the plant is of the Plaxnoganous series, we proceed to determine the class. The netted-veined leaves would seem to refer the plant to the first class; while the blossom (Fig. 366, 367), constructed on the number three, naturally directs us to the second

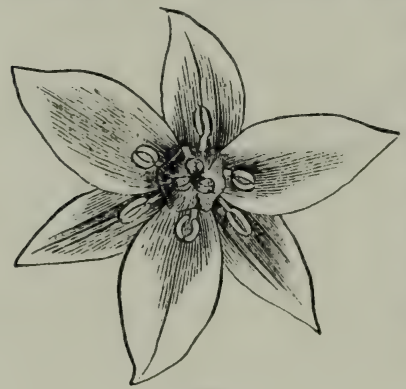

366 class, in which this number almost universally prevails. IIere the student will be somewhat puzzled. If the seeds were ripe, they might be examined, to see whether the embryo has one cotyledon only, or a pair. But the seeds are not to be had in spring, and if they were, the embryo would not readily be made out. We must judge, therefore, by the structure of the stem. Is it exogenous or endogenous? If we cut the stem through, or take off a thin slice crosswise and lengthwise, we shall perecive that the woody matter in it consists of

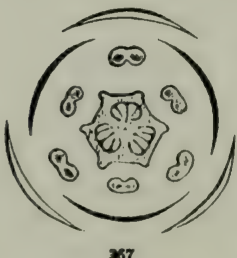
a number of threads, interspersed throughout the soft cellular part without regularity, and not collected into a ring or layer. In fact, it is just like the Corn-stalk (Fig. 351), except that the woody threads are fewer. It is therefore endogenous (422); and this decides the question in favor of Class II. Monocotrlevonous or ENDOGNous P'Lan's (page 30 ), notwithstanding the branching veins of the leatves. For neither this character, nor the number of parts in 
the blossom, holds good universally, while the plan of the stem does.

559. The single flower of our plant with distinct calyx and corolla takes us over the Spadiceous to the Petaloideous Division: the Petaloideous Division of Endogens there begins on p. 28. These parts being free from and beneath the ovary, refer us to the third subdivision, viz: "3. Perianth wholly free from the ovary."

$559^{\mathrm{n}}$. The pistil is next to be considered: it accords with the third of the triplet: "Pistil one, compound (cells or placentr 3); anthers 2-celled." Under this follows a triplet, of which the initial word is "Perianth": our choice falls upon the first, as there is nothing "glumaceous" about this flower.

560. The succeeding triplet relates to the stamens; here 6 , so we take the first alternative. The next refers to mode and place of growth : our plant is "Terrestrial, and not rush-like." The next again to the perianth: the second number of the triplet: "Perianth of 3 foliaceous and green sepals, and 3 colored withering-persistent petals" (as would be seen after flowering-time), brings us to a particular group in the great Lily family, or Lilia CE

561. Reading over the family character, and collating the five tribes comprised, we perceive that our plant belongs to the group, quite peculiar among Liliaceous plants, here ranked as Tribe $I$. Triblidex, the Trillium tribe. And the next step, leading to a choice between two genera, determines the genus to be Trillium.

562. Turning to this, on p. 522, and reading the full description of it, we proceed to the easy task of ascertaining the species. The "flower is raised on a peduncle," as in $\S 2$. This peduncle is slender and nearly erect, and all the other particulars accord with the subdivision marked by a single star. And, finally, the ovate, acutish, widely-spreading, dark dull-purple petals mark the species as the Purple Birthroot, Trillium erectum, L.

563. By the Field, Forest, and Garden Botany, the analysis is similar, only more simple. The details need not be particularly recapitulated.

564. The student residing west of New England will also be likely to find another species, with similar foliage, but with larger, pure white, and obovate petals, turning rose-color when about to fade. 'This will at once be identified as 1 '. grandiflorum. And towards the north, in cold and damp woods or swamps, a smaller 
species will be met with, having dull-green and petioled leaves rounded at the base, and rather narrow, wavy, white petals, marked with pink or purple stripes at the base: this the student will refer to $T$. erythrocarpum. But the species principally found in the eastern parts of the country has a short peduncle recurved under the leaves, so as nearly to conceal the much less handsome, dull white flower: this, it will be seen, is T. cernuum, the Nodding Trillium or Wuke Robin.

565 . Whenever the student has fairly studied out one species of a genus, he will be likely to know the others when he sees them. And when plants of another genus of the same order are met with, the order may generally be recognized at a glance, from the family resemblance. For instance, having first become acquainted with the Convolvulus family in the genus Calystegia (555), we recognize it at once in the common Morning-Glory, and in the Cypress-Vine, and even in the Dodder, although these belong to as many different genera. Having examined the common Mallow (552), we immediately recognize the Mallow family (Mulvacece) in the Marsh-Mallow, sparingly naturalized along the coast, in the Glade Mallow, and the Indian Mallow, in the Hibiscus or Rose-Mallow, and so of the rest: for the relationship is manifist in their general appearance, and in the whole structure of the flowers, if not of the foliage also.

566. So the study of one plant leads naturally and easily to the knowledge of the whole order or family of plants it belongs to:which is a great advantage, and a vast saving of labor. For, although we have about one hundred and thirty orders of Flowering Plants represented in our Botany of the Northern States by about 2,540 species, yet half of these species belong to nine or ten of these orders; and more than four fifths of the species belong to forty of the orders. One or two hundred species, therefore, well examined, might give a grood general idea of our whole botany. And students who will patiently and thoroughly study out twenty or thirty wellchosen examples will afterwards experience little difficulty in determining any of our Flowering Plants and Ferus, and will find the pleasure of the pursuit largely to increase with their increasing knowledge.

567. And the interest will be greatly enhanced as the student, rising to higher and wider views, begins to discern the System of Botany, or, in other words, comprehends more and more of the Plan of the Creator in the Vegetable Kingdom. 


\title{
LESSON XXXIII.
}

\author{
BOTANICAL SYSTEMS.
}

568. Natural System. The System of Botany consists of the orders or families, duly arranged under their classes, and having the tribes, the genera, and the species arranged in them according to their relationships. This, when properly carried out, is the Natural System; because it is intended to express, as well as we are able, the various degrees of relationship among plants, as presented in nature; - to rank those species, those genera, \&c. next to each other in the classification which are really most alike in all respects, or, in other words, which are constructed most nearly on the same particular plan.

569. Now this word plan of course supposes a planner, - an intelligent mind working according to a system : it is this system, therefore, which the botanist is endeavoring as far as he can to exhibit in a classification. In it we humbly attempt to learn something of the plan of the Creator in this department of Nature.

570. So there can be only one natural system of Botany, if by the term we mean the plan according to which the vegetable creation was called into being, with all its grades and diversitics among the species, as well of past as of the present time. But there may be many natural systems, if we mean the attempts of men to interpret and express the plan of the vegetable creation, - systems which will vary with our advancing knowledge, and with the judgment and skill of different botanists, - and which must all be very imperfect. They will all bear the impress of individual minds, and be shaped by the current philosophy of the age. But the endeavor always is to make the classification a reflection of Nature, as far as any system can be which has to be expressed in a series of definite propositions, and have its divisions and subdivisions following each other in some single fixed order.*

* The best classification must fail to give more than an imperfect and considerably distorted reflection, not merely of the plan of creation, but even of our knowledge of it. It is often obliged to make arbitrary divisions where Naturo shows only transitions, and to consider genera, \&c. as equal units, or groups of equally related species, while in fact they may be very unequal, - to assume, on 
571. The Natural System, as we receive it, and as to that portion of it which is represented in the botany of our country, is laid before the student in the Manual of the Botany of the Northern United States. The orders, however, still require to be grouped, according to their natural relationships, into a considerable number of great groups (or alliances); but this cannot yet be done throughout in any easy way. So we have merely arranged them somewhat after a custonary order, and have given, in the Artificial Key, a contrivance for enabling the student easily to find the natural order of any plant. This is a sort of

572. Artificial Classification. The object of an artificial classification is merely to furnish a convenient method of finding out the name and place of a plant. It makes no attempt at arranging plants according to their relationships, but serves as a kind of dictionary. It distributes plants according to some one peculiarity or set of peculiarities (just as a dictionary distributes words according to their first Jetter's), disregarding all other considerations.

573. At present we need an artificial classification in Botany only as a Key to the Natural Orders, - as an aid in referring an unknown plant to its proper family; and for this it is very needful to the student. Formerly, when the orders themselves were not clearly made out, an artificial classification was required to lead the student down to the genus. Two such classifications were long in vogue. First, that of 'Tournefort, founded mainly on the leaves of the flower, the calyx and corolla: this was the prevalent system throughout the first half of the eighteenth century; but it has long since gone by. It was succeeded by the well-known artificial system of Linnæus, which has been used until lately; and which it is still worth while to give some account of.

574. The Artificial System of Linnatus was founded on the stamen and pistils. It consists of twenty-four classes, and of a variable number of orders, which were to take the place temporarily of the natural classes and orders; the genera being the same under all classifications.

paper at least, a strictly definito limitation of genera, of tribes, and of orders, although observation shows so much blending here and there of natural groups, sufficiently distinct on the whole, as to warrant us in assuming the likelihood that the Creator's plan is one of gradation, not of definite limilation, oven perhape io the species themsolves. 
575. The twenty-four classes of Linnaus were founded upon something about the stamens. The following is an analysis of them. The first great division is into two great series, the Phe-. nogamous and the Cryptogamous, the same as in the Natural System. The first of these is divided into those flowers which have the stamens in the same flower with the pistils, and those which have not; and these again are subdivided, as is shown in the following tabular view.

Series I. PIIENOGAMIA; plants with stamens and pistils, i. e. with red flowers.

L. Stamens in the same flower as the pistils:

* Not united with them,

+ Nor with one another.

\# Of equal length if either 6 or 4 in number.

One to each flower,

Two " "

Three " "

Four " "

Five " "

Six " "

Seven " "

Eight " "

Nino " "

Ten " "

Eleven to nineteen to ench flower,

Twenty or more inserted on the caly $\mathrm{x}$,

" " on the receptacle,

\# +Of unequal length and either 4 or 6 .

Four, 2 long and 2 shorter,

Six, 4 long and 2 shorter,

+ + United with each other,

By their filaments,

Into one set or tube,

Into two sets,

Into three or more sets,

By their anthers into a ring,

* * United with the pistil,

2. Stamens and pistils in separate flowers,

Of the same individuals, Of different individnals,

Some flowers perfect, others staminate or pistillate either in the same or in different individuals,
Class 1. Monantria.

2. I)IANDRIA.

3. TrinNDRIA.

4. Tetrandria.

5. Pentandria.

6. Hexandria.

7. Heptandria.

8. Octandria.

9. Finieanitria.

10. DECANDRIA.

11. DODECAN DRIA.

12. Icosandria.

13. Polyandria.

14. Didynamia.

15. Tetradynama

16. Monadelphia.

17. J) DELLIHA.

18. Polyadelpuia

19. Syngenesia.

20. GYNandria.

22. Diøecia.

23. Polygamia.

Series II. CRYPTOG $\Lambda$ MIA. No stamens and pistils, therefore no proper flowers,

24. Cryptogami 
576. The names of these classes are all compounded of Greek words. The first eleven consist of the Greek numerals, in succession, from 1 to 11, combined with audria, which here denotes stamens;- e. g. Mfonandria, with one stamen; and so on. The 11th has the numeral for twelve stamens, although it includes all which have from eleven to nineteen stamens, numbers which rarely occur. The $12 \mathrm{th}$ means "with twenty stamens," but takes in any higher number, although only when the stamens are borne on the culyx. The 13th means "with many stamens," but it takes only those with the stamens borne on the receptacle. The 14 th means "two stamens powerful," the shorter pair being supposed to be weaker; the 15th, "four powerful," for the same reason. The names of the next three classes are compounded of adelphia, brotherhood, and the Greek words for one, two, and many (Monadelphia, Diadelphia, and Polyudelphia). The 19th means "united in one household." The 20th is compounded of the words for stamens and pistils united. The 21 st and $22 \mathrm{~d}$ are composed of the word meaning house and the numerals one, or single, and two: Monacia, in one house, Dixcia. in two houses. The $23 \mathrm{~d}$ is funcifully formed of the words meaning plurality and marriage, from which the English word polygamy is derived. The 2 th is from two words meaning concealed nuptials, and is opposed to all the rest, which are called Phanogamous, because their stamens and pistils, or parts of fructification, are evident.

577. IIaving established the classes of his system on the stamens, Linnæus proceeded to divide them into orders by marks taken from the pistils, for those of the first thirteen classes. These orders depend on the number of the pistils, or rather on the number of styles, or of stigmas when there are no styles, and they are named, like the classes, by Grerk numerals, prefixed to gynia, which means pistil. Thus, flowers of these thirteen classes with

\begin{tabular}{|c|c|c|c|c|}
\hline & \multirow{3}{*}{$\begin{array}{r}\text { Order } 1 . \\
2 . \\
3 .\end{array}$} & \multirow{3}{*}{$\begin{array}{l}\text { Monogynia. } \\
\text { Digynia. } \\
\text { Trigynia. }\end{array}$} \\
\hline \multicolumn{3}{|c|}{$\begin{array}{l}\text { One style or sessile stigma belong to } \\
\text { Two styles or sessilc stigmas, to }\end{array}$} & & \\
\hline Three & “ & " & & \\
\hline Four & “ & “ & 4 & Tetrag ynia. \\
\hline Five & “ & “ & 5. & Pentagynia. \\
\hline Six & “ & “ & 6. & Hexag Ynia. \\
\hline Seven & “ & " & 7. & HePtagYaia. \\
\hline Eight & “ & “ & 8. & OCTOGYNIA. \\
\hline Nine & “ & “ & 9. & EnNeagrita. \\
\hline Ten & “ & “ & 10. & Decagynia. \\
\hline Eleven & velve & $“$ & 11. & Dodecagraia. \\
\hline More $\mathrm{t}$ l & welve & “ & 13. & POLYGYNIA. \\
\hline
\end{tabular}


578. The orders of the remaining classes are founded on various considerations, some on the nature of the fruit, others on the number and position of the stamens. But there is no need to enumerate them here, nor farther to illustrate the Linnæan Artificial Classification. For as a system it has gone entirely out of use; and as a Key to the Natural Orders it is not so convenient, nor by any means so certain, as a proper Artificial Key, prepared for the purpose, sucle as we have been using in the preceding Lessons.

\section{LESSON XXXIV.}

\section{HOW TO COLLECT SPECIMENS AND MAKE AN HERBARIUM.}

579. For Collecting specimens the needful things are a large knife, strong enough to be used for digging up bulbs, small rootstocks, and the like, as well as for cutting woody branches; and a botanical $b o x$, or a portfolio, for holding specimens which are to be carried to any distance.

580. It is well to have both. The botanical box is most useful for holding specimens which are to be examined fresh. It is made of tin, in shape like a candle-box, only flatter, or the smaller sizes like an English sandwich-case; the lid opening for nearly the whole length of one side of the box. Any portable tin box of convenient size, and capable of holding specimens a foot or fifteen inches long, will answer the purpose. The box should shut close, so that the specimens may not wilt: then it will keep leafy branches and most flowers perfectly fresh for a day or two, especially if slightly moistened.

581. The portfolio should be a pretty strong one, from a foot to twenty inches long, and from nine to eleven inches wide, and fastening with tape, or (which is better) by a leathern strap and luckle at the side. It should contain a quantity of sheets of thin and smooth, unsized paper; the poorest printing-paper and grocers' tea-paper are very good for the purpose. The specimens as soon as gathered are to be separately laid in a folded sheet, and kept under moderato pressure in the closed portfolio. 
582. Botanical specimens should be either in flower or in fruit. In the case of herbs, the same specimen will often exhibit the two; and both should by all means be secured whenever it is possible. Of small herbs, especially annuals, the whole plant, root and all, should be taken for a specimen. Of larger ones branches will suffice, with some of the leaves from near the root. Enough of the root or subterranean part of the plant should be collected to show whether the plant is an anuual, biennial, or perennial. Thick roots, bulbs, tubers, or branches of specimens intended to be preserved, should be thinned with a knife, or cut into slices lengthwise.

583. For drying Specimens a good supply of soft and unsized paper - the more bibulous the better - is wanted; and some convenient means of applying pressure. All that is recunisite to make good dried botanical specimens is, to dry them as rapidly as possible between many thickuesses of paper to absorb their moisture, under as much pressure as can be given without crushing the more delicate parts. This pressure may be given by a botanical press, of which various forms have been contrived; or by weights placed upon a board, from forty to eighty or a hundred pounds, according to the quantity of specimens drying at the time. For use while travelling, a good portable press may be made of thick binders' boards for the sides, holding the drying paper, and the pressure may be applied by a cord, or, much better, by strong straps with buckles.

584. For drying paper, the softer and smoother sorts of cheap wrapping-paper answer very well. This paper may be made up into driers, each of a dozen sheets or less, according to the thickness, lightly stitched together. Specimens to be dried should be put into the press as soon as possible after gathering. If collected in a portfolio, the more delicate plants should not be disturbed, but the sheets that hold them should one by one be transferred from the portfolio to the press. Specimens brought home in the botanical box must be laid in a folded sheet of the same thin, smooth, and soft paper used in the portfolio; and these sheets aro to hold the plants until they are dry. They are to be at once laid in between the driers, and the whole put under pressure. Every day (or at first even twice a day would be well) the specimens, left undisturbed in their sheets, are to be shifted into well-dried fresh driers, and the pressure renewed, while the moist sheets are spread out to dry, that they may take their turn again at the next shifting. This course must be continued until the specimens are no longer moist to the touch, - 
which for most plants requires about a week; then they may be transferred to the sheets of paper in which they are to be preserved. If a great abundance of drying-paper is used, it is not necessary to change the sheets every day, after the first day or two.

585. Ilerbarium. The botanist's collection of dried specimens, ticketed with their names, place, and time of collection, and systematically arranged under their genera, orders, \&c., forms a Hortus Siccus or Herbarium. It comprises not only the specimens which the proprietor has himself collected, but those which he acquires through friendly exchanges with distant botanists, or in other ways. The specimens of an herbarium may be kept in folded sheets of neat, and rather thick, white paper; or they may be fastened on half-sheets of such paper, either by slips of gummed paper, or by glue applied to the specimens themselves. Each sheet should be appropriated to one species; two or more different plants should never be attached to the same sheet. The generic and specific name of the plant should be added to the lower right-hand corner, either written on the sheet, or on a ticket pasted down at that corner; and the time of collection, the locality, the color of the flowers, and any other information which the specimens themselves do not afford, should be duly recorded upon the sheet or the ticket. The sheets of the herbarium should all be of exactly the same dimensions. The herbarium of Linnæus is on paper of the common foolscap size, about eleven inches long and seven wide. But this is too small for an herbarium of any magnitude. Sixteen and a half inches by ten and a half, or eleven and a half inches, is an approved size.

586. The sheets containing the species of each genus are to be placed in genus-covers, made of a full sheet of thick, colored paper (such as the strongest Manilla-hemp paper), which fold to the same dimensions as the species-sheet; and the name of the genus is to be written on one of the lower corners. These are to be arranged under the orders to which they belong, and the whole kept in closed cases or cabinets, either laid flat in compartments, like large "pigeonholes," or else placed in thick portfolios, arranged like folio volumes, and having the names of the orders lettered on the back. 



\section{G L O S S A R Y}

OR

\section{DICTIONARY OF TERMS USED IN DESCRIB- ING PLAN'TS,}

\section{COMBINED WITH AN INDEX.}

$A$, at the beginning of words of Greek derivation, commonly signifies a negative, or the absence of something; as apetalous, without petals; aphyllous, leafless, \&c. If the word begins with a vowel, the prefix is an; as ananther. ous, destitute of anther.

Abnormal: contrary to the usual or the natural structure.

Ahoriginal : original in tho strictest sense; same as indigenous.

Alortive: imperfectly formed, or rudimentury, as one of the stamens in fig. 195 sul three of them in fig. 196, p. 95.

Alention: the imperfect formation, or non-formation, of some part.

Abrupt : suddenly terminating; as, for instance,

Alruptly pinnate: pinnate without an odd lenflet at the end; fig. 128, p. 65.

Acaulescent (acaulis) : apparently stemless; the proper stem, bearing the leaves and flowers, being very short or subterranean, as in Bloodroot, and most Violets; p. 36.

Accéssory: something additional ; as Accessory buds, p. 26.

Accrescent : growing larger after flowering, as the calyx of Physalis.

Accumbent: lying against a thing. The cotyledons are accumbent when they! lie with their edges against the radicle.

Acerose: needle-shaped, as the leaves of Pines; fig. 140, p. 72.

Acetábuliform: saucer-shaped.

Achenium (plural achenia) : a one-seeded, seed-like fruit; fig. 286, p. 129.

Achlamyidcous (flower) : without floral envelopes; as Lizard's-tail, p. 90, fig. 180. Acicular: needle-shaped; more slender than acerose.

Acináciform : scymitar-shaped, like some bean-pods.

Acines: the separate grains of a fruit, such as the raspberry; ing. 289.

Acorn: the nut of the Oak; fig. 299, p. 130.

Acotylédonous: destitute of cotyledons or seed-leaves.

Acrogenous: growing from the apex, as the stems of Ferns and Mosses.

Acrogens, or Acrogenous Plants: the higher Cryptogamous plants, such as Ferns, \&c., p. 172. 
Acrileate: armed with prickles, i. e. aculei; as the Rose and Brier.' Acuilealyfe: armed with sonall prickles, or slightly prickly. Acúminate: taper-pointed, as the leaf in fig. 97 and tig. 103.

Acule: mercly sharp-jointud, or ending in a point less than a right angle.

Adelphous (stanens): joined in a fraternity (adelphia): see monudelphous and diculelyloous.

Adlierent: sticking to, or, more commonly, growing fast to another body; p. 104. Adnate: growing fast to; it meuns born adherent. The anther is adnate when fixed by its whole length to the filament or its prolongation, as in Tulip. tree, fig. 233.

Adpressed, or appressed: brought into contact, but not united.

Adscendent, ascendent, or ascending: rising gradually upwards.

Adsuryent, or assuryent : same as uscending.

Adientitious: out of the proper or usual place; e. g. Adventitious buds, p. 26, 27. Adventive: applied to furcign plants accidentally or sparingly spontancous in a country, but hardly to be called naturalized.

Equilateral: equul-sided ; opposed to oblique.

Estivation: the arrangement of parts in a flower-bud, p. 108.

Air-cells or Air-passages: spaces in the tissue of leaves and some stems, p. 143.

Air-Plants, p. 34.

Akénium, or akene. See achenium.

Ale (plural ale $)$ : a wing; the sidie-petals of a papiliouaceous corolla, p. 105, lig. $218, w$.

Alubcistrum: a flower-bud.

Alar: situated in the forks of a stem.

Alute: winged, as the sceds of Trumpet-Crecper (fig. 316) the fruit of the Maple, Elm (fig. 301), \&c.

Albescent: whitish, or turning white.

Alsorption, p. 168.

Allumen of the seed: nourishing matter stored up with the embryo, but not within it ; p. 15, 136.

Albúmen, a vegetable product; a form of proteine, p. 165.

Alluminous (sceds) : furnished with albumen, as the seeds of Indian corn (fig. 38, 39), of Buckwheat (fig 326), \&c.

Alturnum: young wood, sap-wood, p 153.

Alpine: belonging to high mountains above the limit of forests.

Aliernate (leaves): one after another, p. 24, 71. Petals are altcrnate with the sepals, or stamens with the petals, when they stand over the intervals botween them, p. 93.

Alvedate: honeycomb-like, as the receptacle of the Cutton-Thistle.

Ament: a catkin, p. 81. Amentaceous : eatkin-like, or catkin-bearing.

Amorphous: shapeless; withont any definite form.

Amphigástrium (plural amphigastria): a peculiar stipule-like leaf of certain Liverworts.

Amphútropous or Amphítropal ovules or seeds, p. 123, fig. 272.

Amplectant : embracing. Amplexicaul (leaves) : clasping the stem by the base.

Ampulláceous : swilling out like a bottle or bludder.

$\Delta$ myluiceous : composed of starch, or starch-like. 
Andintherous : withont anthers. Anumthous : destitute of flowers ; flowerless.

Anristomosing : forming a net-work (anustomosis), as the veins of leaves.

Anailropous or Anátropal ovules or sceds ; p. 123, fig. 273.

Ancipital (anceps) : two-edged, as the stern of Blue-eyed Grass.

Androcium : a name for the stamens taken together.

Androgynous: having both staminate and pistillate flowers in the same eluster or inflorescence, as many species of Carcx.

Ándrophore: a column of united stamens, as in a Mallow; or the support on which stamens are raised.

Anfraictuose: bent hither and thither, ns the anthers of the Squash, \&c.

Angiosperme, Angiospermous Plants : with their seeds formed in an ovary or pericarp, p. 183.

Angular divergence of leaves, p. 72.

Anmual (plant) : flowering and fruiting the year it is raised from the seed, and then dying, p. 21.

Annular: in the form of a ring, or forming a circle.

Ánnulate: marked by rings; or furnished with an

Ánnulus, or ring, like that of the spore-case of most Ferns (Manual Bot. N.

Stutes, plate 9, fig. 2): in Mosses it is a ring of cells placed between the mouth of the spore-case and the lid, in many species.

Anterior, in the blossom, is the part next the bract, i. e. external :- while the posterior side is that next the axis of inflorescence. Thus, in the Pea, \&c. the keel is anterior, and the standard posterior.

Anther: the essential part of the stamen, which contains the pollen; p. 86, 113.

Antherdium (plural antheridict): tho organ in Mosses, \&c. which answers to the nnther of Flowering plants.

Antheriferous : anther-bearing.

Anthesis : the period or the act of the expansion of a flower

Anthocairpous (fruits) : same as multiple fruits; p. 133.

Ánticons: same as anterior.

Antrorse: directed upwards or forwards.

Apetalous : destitute of petals ; p. 90, fig. 179.

Aphillous : destitute of leaves, at least of foliage.

Ápical : belonging to the apex or point.

Apiculate: pointletted ; tipped with a short and abrupt point.

Apocarpous (pistils): when the several pistils of the same flower are separate, as in a Buttercup, Sedum (fig. 168), \&c.

Apophysis: any irregular swelling; the enlargement at the base of the sporecase of the Umbrella-Moss (Manual, plate 4), \&c.

Appendage any superadded part.

Appendiculate: provided with appendages.

Appressed: where branches are close pressed to the stem, or leaves to the branch, \&c.

Apterous : wingless.

Aquetir: living or growing in water; npplied to plants whether growing under water, or with all but the base raised out of it.

Arichnoid: cobwebhy ; clothed with, or consisting of, soft dorvny fibres.

Arbòreous, Arborescent : tree-like, in size or form ; p. 36. 
Arcnegonium (plural archegonia) : the organ in Mosses, \&c., which is analogous to the pistil of Flowering P'lants.

Árcunte: bent or curved like a how.

Aréolute: marked out into little spaces or areolee.

Árillate (sceds) - furnished with an

Aril or Arillus: a fleshy growth forming a false coat or appendage to a seod; p. 135, fig. 318.

A ristate: awned. i. e. furnished with an arista, like the beard of Barley, \&c.

A ristulate: diminutive of the last ; short-awned.

Llrow-shaped or Arrow-headed: same as sayittate; p. 59, fig. 95.

'Articulated: jointed ; furnished with joints or urticulations, where it separates or inclines to do so. Articulated leaves, p. 64.

Aitificial Classification, p. 196.

Ascending (stems, \&c.), p. 37 ; (seeds or ovules), p. 122.

Asperyilliform: shaped like the brush used to sprinkle holy water; as the stignm of many Grasses.

Assimilution, p. 162.

Assurgent: same as ascending, p. $\mathbf{3 7}$.

Atropous or Atropal (ovules): same as orthotropous.

Auriculate: furnished with auricles or ear-like appendages, p. 59.

Awl-shaped: sharp-pointed from a broader base, p. 68.

Awn: the bristle or beard of Barley, Oats, \&c.; or any similar bristle-like appendage.

Awned: furnished with an awn or long bristle-shaped tip.

Axil: the angle on the upper side between a leaf and the stem, p. 20.

Axile: belonging to the axis, or occupying the axis; p. 119, \&c.

Axillary (buds, \&c.) : occurring in an axil, p 21, 77, \&c.

Axis : the central line of any body ; the organ round which others are attuched; the root and stem. Ascending Axis, p. 9. Descending Axis, p. 9.

Baccate: berry-like, of a pulpy nature like a berry (in Latin bacca) ; p. 127.

Barbate: bearded; bearing tufts, spots, or lines of hairs.

Burbed: furnished with a barb or double hook; as the apex of the bristle on the fruit of Echinospermum (Stickseed), \&c.

Barbellate: said of the bristles of the pappus of some Composita (species of Liatris, \&c.), when beset with short, stiff hairs, longer than when denticulate, but shorter than when plumose.

Barbellulate: diminutive of barbellate

Bark: the covering of a stem outside of the wood, p. 150, 152.

Busal : belonging or attached to the

Base : that extremity of any organ by which it is attached to its support.

Bast, Bast-fibres, p. 147.

Beaked: ending in a prolonged narrow tip.

Bearded: see berbute. Batud is sometimes used popularly for awn, moro com. monly for long or stiff hairs of any sort.

Bell-shaped : of the shape of a bell, as the corolla of Harebell, fig. 207, p. 102.

Berry : a fruit pulpy or juicy throughout, as a grape; p. 127.

$B$ i- (or Bis), in compound words : twice; as 
Biarticulate : twice jointed, or two-jointed ; separating into two pieces.

Biaurculate: having two ears, as the leaf in fig. 96.

Bicallose : having two callosities or harder spots.

Bicarinate: two-keeled, as the upper palea of Grasses.

Bicipital (Biceps) : two-headed; dividing into two parts at the top or bottom.

Biconjugate: twice paired, as when a petiole forks twice.

Bidentate: having two teeth (not twice or doubly dentate).

Bicinnial: of two yents' continuance; springing from the seed one scason, flowering nnd dying the next; p. 21.

Bifárious : two-ranked; arranged in two rows.

Bifid: two-cleft to about the middle, as the petals of Mouse-ear Chickweed.

Bifoliolate: a compound leaf of two leaflets; p. 66 .

Bifircate: twice forked; or, more commonly, forked into two branrhes.

Bijugate: bearing two pairs (of leaflets, \&c.).

Bilabiate: two-lipped, as the corolla of sage, \&c , p. 105, fig. 209.

Bilámellate: of two plates (lamella), as the stigma of Mimulus.

Bilobed: the same as two-lobed.

Bilocular: two-celled; as most anthers, the pod of Foxglove, most Saxifrages

(fig. 254), \&c.

Binate: in couples, two together.

Bipartite: the Latin form of two-parted; p. 62.

Bipinnate (leaf) : twice pinnate ; p. 66, fig. 130.

Bipinnatifid: twice pinnatifid, p. 64; that is, pinnatifid with the lobes again pinnatifid.

Biplicate: twice folded together.

Biserial, or Biseriate : occupying two rows, one within the other.

Biserrate: doubly serrate, as when the teeth of a leaf, \&c. are themselves serrate.

Biternate: twice ternate; i. e. principal divisions 3, each bearing 3 leaflets, \&c.

Bladdery: thin and inflated, like the calyx of Silene inflata.

Blade of a leaf: its expanded portion ; p 54.

Boat-shaped: concave within and keeled without, in shape like a small boat.

Bráchiate: with opposite branches at right angles to each other, as in the Maple and Lilac.

Bract (Latin, bractea). Bracts, in general, are the leaves of an inflorescence, more or less different from ordinary leaves. Specially, the bract is the small leaf or scale from the axil of which a flower or its pedicel proceeds : p. 78 ; and a

Bractlet (bracteola) is a bract seated on the pedicel or flower-stalk; p. 78, fig. 156. Branch, p. 20, 36.

Brislles: stiff, sharp hairs, or any very slender bodies of similar appearance.

Bristly: beset with bristles.

Brush-shaped: see aspergilliform.

Bryology : that part of Botany which relates to Mosses.

Bud: a branch in its earliest or undeveloped state; p. 20.

Bud-scales, p. 22, 50.

Bulb: a lcaf-bud with fleshy scales, usually subterranean; p. 45, fig. 73.

Bulliferous : bearing or producing bulbs.

Bulbose or bulbou: : hulb-like in shape, \&c. 
Bulblets: small bulbs, borne above ground, as on the stems of the bulb-bearing Lily and on the fronds of Cistopteris bulbifica and some other Ferns; p. 46. Bulb-scales, p. 50.

Bullate: appearing as if blistered or bladdery (from bulla, a bubble).

Cadicous: dropping off very early, compared with other parts; as the calyx in the Poppy Family, falling when the flower opens.

Cespitose, or Céspitose: growing in turf-like patches or tufts, like most sedges, \&c. Cálcarate: furnished with a spur (calcar), as the flower of Larkspur, fig. 183, and Violet, fig. 181 .

Calcéolute or Cúlceiform: slipper-shaped, like one petal of the Lady's Slipper.

Cállose: hardened; or furnished with callositics or thickened spots.

Calycine: belonging to the calyx.

Calyculate: furnished with an outer accessory calyx (culyculus) or set of bracts looking like a calyx, as in true Pinks.

Calyptra: the hood or veil of the capsule of a Moss: Manual, p. 607, \&c.

Calyptriform: shaped like a calyptra or candle-extinguisher.

Calyx : the outer set of the floral envelopes or leaves of the flower; p. 85.

Cambium and Cambium-layer, p. 154.

Campámulate: bell-shajed; p. 102, fig. 207.

Campylótropous, or Campylotropal; curved ovules and seeds of a particular sort; p. 123, fig. 271.

Campylospermous: applied to fiuits of Umbellifera when the seed is curved in at the edges, forming a groove down the inner face; as in Sweet Cicely.

Canaliculate: channelled, or with a deep longitudinal greove.

Cáncellate: latticed, resembling lattice-work.

Canéscent: grayish-white; hoary, usually because the surface is covered with fine white hairs. Incenous is whiter still.

Capilláceous, Cápillary: hair-like in shape; as fine as hair or slender bristles.

Capitate: having a globular apex, like the head on a pin; as the stigma of Cherry, fig. 213; or forming a head, like the flower-cluster of Button-bush, fig. 161 .

Capitellate: diminutive of capitate; as the stignas of fig. 255.

Capítulum (a little head): a close rounded dense cluster or head of sessilo flowers; p. 80, fig. 161.

Capréolate: bearing tendrils (from capreolus, a tendril).

Cupsule: a pod; any dry dehiscent secd-vessel ; p. 131, fig. 305, 306.

Cápsular : relating to, or like a capsule.

Carina: a keel; the two anterior petals of a papilionaccous flower, which are combined to form a body shaped somewhat like the keel (or rather tho prow) of a vessel ; p. 105, fig. 218, $k$.

Cárinate: keeled; furnished with a sharp ridge or projection on the lower side.

Cariopsis, or Caryópsis : the one-seeded fruit or grain of Grusses, \&c., p. 351.

Cárneous: flush-colored; pale red.

Cúrnose: fleshy in texture.

Cárpel, or Carpidium : a simplo pistil, or one of the parts or leaves of which a compound pistil is composed; p. 117.

Cárpellary: pertuining to a carpel. 
Carpolony: that department of Botany which relates to fruits.

Carpophore: the stalk or support of a fruit or pistil within the flower; as in ig. $276-278$.

Cartiláginous, or Cartilagíneous : firm and tough, like cartilage, in texture.

Cairuncle: an excrescence at the scar of some seeds; as those of Polygala.

Carinculate: furnished with a caruncle.

Caryophylláceous : pink-like : applied to a corolla of 5 long-clawed petals; fig. 200.

Cutkin : a scaly deciduous spike of flowers, an ament; p. 81.

Candute: triled, or tail-pointed.

Cinudex : a sort of trumk, such as that of Pnlms ; an upright rootstock ; p. 37.

Cauléscent: having an obvious stem; p. 36.

Caúlicle: a little stem, or rudimentary stem; p. 6.

Cauline: of or belonging to a stem (caulis, in Latin), p. 36.

Cell (diminutive Cellule) : the cavity of an anther, ovary, \&c., p.113,119; one of the elements or vesicles of which plants are composed; p. 140, 142.

Cellular tissue of plants; p. $142 . \quad$ Cellular Bark, p. 152.

Cellulose, p. 159.

Centrifigal (inflorescence): produced or expanding in succession from the centre outwards; p. 82. The radicle is centrifugal, when it points away from the centre of the fruit.

Centripetal: the opposite of centrifugal ; p. 79, 83.

Cereal: belonging to corn, or corn-plants.

Cernuous : nodding; the summit more or less inclining.

Chaff: small membranous scales or bracts on the receptacle of Compositæ; the glumes, \&c. of Grasses.

Chaffy: furnished with chaff, or of the texture of chaff.

Chalaza: that part of the ovule where all the parts grow together; p. 122.

Channelled: hollowed out like a gutter; same ns canaliculate.

Character: a phraso expressing the essential marks of a species, genus, \&c. which distinguish it from all others; p. 180.

Chartaceous : of the texture of paper or parchment.

Chlorophyll: the green grains in the cells of the leaf, and of other parts exposed to the light, which give to herbage its green color; p. 155.

Chromule: coloring matter in plants, especially when not green, or when liquid.

Cicatrix: the scar left by the fall of a leaf or other organ.

Celiate: beset on the margin with a fringe of cilia, i. e. of hairs or bristles, like the eyelashes fringing the eyelids, whence the name.

Cinéreous, or Cineraiceous : ash-grayish ; of the color of ashes.

Círcinate: rolled inwards from the top, like a crosier, as the shoots of Ferns; p. 76, fig. 154 ; the flower-clusters of Heliotrope, \&c.

Circunscissile, or Circumcissile: divided by a circular line round the sides, as the pods of Purslane, Plantain, \&c. ; p. 133, fig. 298, 311.

Circumscription : the gencral outline of a thing.

Cirrhiferous, or Cirrhose: furnished with a tendril (Latin, cirrhus) ; as the Grape. vine. Cirrhose also menns resembling or coiling like tendrils, as the leaf. stalks of Virgin's-bower; p. 37.

Class, p 175, 177.

Classificution, p. 173. 
Cuáthrate: latticed; same as cancellate.

Clavate: club-shaped; slender below and thickened upwards.

Claw: the narrow or stalk-like base of some petals, as of Pinks; p. 102, fig. 200.

Climbing : rising by clinging to other objects; p. 37.

Club-shuped: see clavate.

Clustered: leaves, flower's, \&c. aggregated or collected into a bunch

Clypeate : buckler-shaped.

Coúdunate: same as connute; i. e. united.

Couléscent : growing together.

Coárclate : contracted or brought close together.

Coated Bulbs, p. 46.

Colnelby: same as arachnoid; bearing hairs like colbwebs or gossamer.

Coccus (plural cocci): anciently a berry; now mostly used to denote the carpens of a dry fruit which are separable from each other, as of Euphorbia.

Cochleáriform : spoon-shajed.

Cóchleute : coiled or shaped like a snail-shell.

Celospermous: applied to those fruits of Umbellifera which have the seed hollowed on the inuer face, by the curving inwards of the top and bottom; as in Coriander.

Coherent, in Botany, is usually the same as connate; p. 104.

Collective fruits, p. 133.

Collum or Collar : the neck or line of junction between the stem and the ront.

Columella : the axis to which the carpels of a compound pistil are often attuched, as in Geranium (fig. 278), or which is left when a pod opens, as in Azalea and Rhododendron.

Column : the united stamens, as in Mallow, or the stamens and pistils united into one body, as in the Orchis fumily, fig. 226.

Columnar: shaped like a column or pillar.

Coma : a tuft of any sort (literally, a head of hair); p. 135, fig. 317.

Cómose: tufted; bearing a tuft of hairs, as the seeds of Milkweed ; fig. 317.

Cómmissure: the line of junction of two carpels, as in the fruit of Umbelliferæ, such as Parsnip, Caraway, \&c.

Common : used as "general," in contradistinction to "partial "; e. g. " common involucre," p. 81.

Complanute: flattenced.

Compound leaf, p. 64. Compound pistil, p. 118. Compound umbel, \&c., p. 81 .

Complete (flower), p. 89.

Complicate : folded upon itself.

Compressed : flattened on two opposite sides.

Conduplicate : folded upon itself lengthwise, as are the leaves of Magnolia in the bud, p. 76.

Cone: the fruit of the Pine famil $j$; p. 133, fig. 314.

Confluent : blended together; or the same as coherent.

Conforned: similar to another thing it is associated with or compared to ; or closely fitted to it, as the skin to the kernel of a seed.

Congésted, Conglómerute: crowded together.

Cónjugate: coupled ; in single pairs.

Connate: united or grown together from the first. 
Connective, Connretimum : the part of the anther connecting its two cells; p. 113.

Connfvent : converging, or brought close together.

Consolidated forms of vegetation, p. 47.

Continuous : the reverse of interrupted or articulated.

Contorted: twisted together. Contorted restivation : same as convolute; p. 109.

Contortuplicate : twisted hack upon itself.

Contracted: either narrowed or shortened.

Contrary : turned in an opposite direction to another organ or part with which it is compared.

Convolute : rolled up lengthwise, as the leaves of the Plum in vernation; p. 76, fig. 151. In restivation, same as contorted; p. 109.

Cordate: heart-shaped ; p. 58, fig. 90, 99.

Coriaceous: resembling leather in texture.

Corky : of the texture of cork. Corky linger of bark, p. 152.

Corm, Cormus : a solid bulb, like that of Crocus; p. 44, fig. 71, 72.

Corneous : of the consistence or appearance of horn, as the albumen of the seed of the Date, Coffec, \&c.

Cornfculate: furnished with a snall horn or spur.

Cormate: horned; bearing a horn-like projection or appendage.

Cordlla: the leaves of the flower within the ealyx ; p. 86.

Corollaceous, Corolline: like or belonging to a corolla.

Conna : a coronet or crown; an appendage at the top of the claw of some petals, as Silene and Soapwort, fig. 200, or of the tube of the corolla of Hound's-Tongue, \&c.

Corsnate: crowned; furnished with $\Omega$ crown.

Cortiral: belonging to the bark (cortex).

Corymb : a sort of flat or convex flower-cluster; p. 79, fig. 158.

Corymbdse: approaching the form of a corymb, or branched in that way; arranged in corymbs.

Costa : a rib; the midrib of a leaf, \&e. Costate: ribbed.

Cotyleitons : the first leaves of the embryo; p. 6, 137.

Crateriform: goblet-shaped; broadly cup-shaped.

Creeping (stems) : growing flat on or beneath the ground and rooting; p. 37 .

Crémocarp: a half-fruit, or one of the two carpels of Umbelliferse.

Crenate, or Crenelled : the edge scalloped into rounded teeth; p. 62, fig. 114

Crested, or Cristate: bearing any elevated appendage like a crest.

Cribrose : pierced like a sieve with small apcrtures.

Crinite: bearded with long hairs, \&c.

Crown : sce convan.

Crowning: borne on the apex of anything.

Criciate, or Criciform: cross-shaped, as the four spreading petals of the Mus. tard (fig. 187), and all the flowers of that family.

Crustaceous : hard, and brittle in texture ; crust-like.

Cryptofyamous, or Cryptogamic : relating to Cryptogamia; p. 172, 197.

Cucuillate: hooded, or hood-shaped, rolled up like a cornet of paper, or a hood

(cucullus), as the spathe of Indian Turnip, fig. 162.

Culm : a straw ; the stem of Grasses and Sedges.

Chinsate, Cuineiform: wedge-shaped; p. 58, fig. 94. 
Cup-shaped: same as cyathiform, or near it.

Cuipule: a little cup ; the cup to the acorn of the Oak, p. 130, fig. 299.

Chipulate: provided with a cupule.

Chispidute: tipped with a sharp and stiff point.

Cut : same as incised, or applied generally to any sharp and deep division.

Cúticle: the skin of plants, or more strictly its exterual pellicle.

Cyathiform : in the shape of a cup, or particularly of a wine-glass.

Cýcle: one complete turn of a spire, or a circle; p. 73.

Cýclical: rolled up cirenlarly, or coiled into a complete circle.

Cyclosis : the circulation in closed cells, p. 167.

Cylindraceous : approaching to the

Cylindrical form; as that of stems, \&e., which are round, and gradually if at all

tapering.

Cymbeform, or Cymbiform : same as boat-shuped.

Cyme: a cluster of centrifugal iuflorescence, p 82, fig. 165, 167.

Cymose: furnished with cymes, or like a cyme.

Deca- (in composition of words of Greek derivation) : ten ; as

Decáfynous : with 10 pistils or styles. Decándious : with 10 stamens.

Deciduous : falling off, or subject to fall, said of leaves which fall in autumn, and of a calyx and corolla which fall before the fruit forms.

Declined : turned to one side, or downwards, as the stumens of Azalea nudiflora.

Decompound: several times compounded or divided; p 67, fig. 138.

Decumbent : reclined on the ground, the summit tending to rise; p. 37 .

Decurrent (leaves) : prolonged on the stem beneath the insertion, as in Thistles.

Decuissate: arranged in pairs which successively cross each other; fig. 147.

Definite: when of a uniform number, and not above twelve or so.

Deflexed: bent downwards.

Deflorate: past the flowering state, as an anther after it has discharged its pollen.

Dehiscence: the mode in which an anther or a pod regularly bursts or splits open ; p. 132.

Dehiscent : opening by regular dehiscence.

Deliquescent : branching off so that the stem is lost in the branches, p. 25.

Deltoid: of a triangular shape, like the Greek capital $\Delta$.

Demersed: growing below the surface of water.

Dendroid, Dendritic : tree-like in form or appearance.

Dentate: toothed (from the Latin dens, a tooth), p. 61, fig. 113.

Denticulate: furnished with denticulations, or very small teeth: diminutive of the last.

Depauperate (impoverished or starved): below the natural size.

Depressed : flattened, or as if pressed down from above; flattened vertically.

Descending : tending gradually downwards.

Determinate Inflorescence, p. 81, 83.

Dextrorse : turned to the right hand.

$D i$ - (in Greek compounds) : two, as

Diádelphous (stamens): united by their filaments in two sets; p. 111, fig. 227.

Diándrous: having two stamens, p. 112.

Diaynosis. a short distinguishing character, or descriptive phrase. 
Didphanots : transparent or translucent.

Dichlamýdeous (flower) : having both calyx and corolla.

Dichotomons : two-forked.

Diclinous: having the stamens in ono flower, the pistils in another; p. 89, fig. 176, 177.

Dicoccous (fruit) : splitting into two cocci, or closed carpels.

Dicotylédonous (embryo) : having a pair of cotyledons; p. 16, 137.

Dirotyledonous Plants, p. 150, 182.

Didlymans: twin.

Didynamous (stamens); having four stamens in two pairs, one pair shorter than the other, as in fig. 194, 195.

Diffuse: spreading widcly and irregularly.

Digitate (fingered): where the leaflets of a compound leaf are all borne on the apex of the petiole; p. 65, fig. 129.

Digynous (flower): having two pistils or styles, p. 116.

Dimerous : made up of two parts, or its organs in twos.

Dimidiate: halved; as where a leaf or leaflet has only one side developed, or a stamen has only one lobe or cell ; fig. 239.

Jimniphous : of two forms.

Dieccious, or Dinicous: where the stamens and pistils are in separate flowers on different plants ; p. 89.

Dipetalous: of two petals. Diphyllous : two-leaved. Dipterous : two-winged.

Disciform or Disk-shaped: flat and circular, like a disk or quoit.

Disk: the face of nuy flat body ; the eentral part of a hear of flowers, like the Sunflower, or Coreopsis (fig. 224), as opposed to the ray or margin; a fleshy expansion of the receptacle of a flower; p. 125.

Dissected: cut deeply into many lohes or divisions.

Dissépiments : the partitions of an ovary or a fruit; p. 119.

Distichous : two-rankerl; p. 73.

Distinct: uncombined with each other; p. 102.

Diváricate: straddling; very widely divergent.

Divided (leaves, \&c.) : cut into divisions extending about to the base or the midrib; p. 62, fig. 125.

Dodeca- (in Greck compounds): twelve; as

Dodecágynous: with twelve pistils or styles.

Dodecandrous : with twelve stamens.

Dolabriform: axe-shaped.

i)orsal: pertaining to the back (dorsum) of an organ.

Dorsal Suture, p. 117.

Dotted Ducts, p. 148.

Double Flowers, so called : where the petals are multiplied unduly ; p. 85, 98.

Downy: clothed with a coat of soft and short hairs.

Drupe: a stone-fruit; p. 128, fig. 285.

Drupaceous: like or pertaining to a drupe.

Ducts : the so-called vessels of plants; p. 146, 148.

Dumose: bushy, or rolating to bushes.

Duramien: the heart-wood, p. 153.

Duarf: remarkably low in stature. 


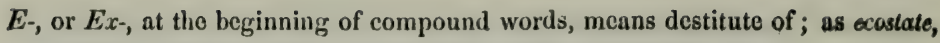
without a rib or inidrib; exalluminous, without ulbumen, \&c.

Eared: see auriculate; p. 59, fig. 96.

Elraicteate; destitute of bracts.

Echinute: armed with prickles (like a hedgehog). Echinulate: a diminutive of it. Edentate : toothless.

Effete : past bearing, \&ce; said of anthers which have discharged their pollen. Eglandulose : destitute of glands.

Elâters: threads mixed with the spores of Liverworts. (Manual, p. 682.) Ellipsoidal: approaching an elliptical figure.

Elliptical : oval or oblong, with the ends regularly rounded; p. 58, fig. 88.

Emárginate: notched at the summit; p. 60, fig. 108.

Embryo: the rudimentary undeveloped plantlet in a seed; p. 6, fig. 9, 12, 26, $31-37$, \&c., and p. $136 . \quad$ Embryo-sac, p. 139.

Emersed : raised out of water.

Endecaiyynous: with eleven pistils or styles. Endecándrous : with eleven stamens. Endocarp : the inner layer of a pericarp or fiuit; p. 128.

Éndochrome: the coloring matter of Algat and the like.

E'ndóyenous Stenes, p. 150. Éndoyenous P'lants, p. 150.

Endosmose : p. 168.

Éndosperm: another name for the albumen of a seed.

Éndostome: the orifice in the inner coat of an ovule.

Ennea-: nine. Enneáyynous: with nine petals or styles.

Enneändrous: with nine stamens.

Ensiform: sword-shaped; as the leaves of Iris, fig. 134.

Entire: the margins not at all toothed, notched, or divided, but even; p. 61.

Ephemeral: lasting for a day or less, as the corolla of Purslane, \&c.

Epi-, in composition : upon; as

Epicarp: the outermost layer of a fruit ; p. 128.

Epidermal: relating to the Epidermis, or the skin of a plant; p. 152, 155.

Epiggeous: growing on the earth, or close to the ground.

Epigynous: upon the ovary; p. 105, 111.

Epipetalous: borne on the petals or the corolla.

Epriphýllous: borne on a leaf.

Epiphyle: a plant growing on another plant, but not nourished by it; p. 34 .

Epiphýtic or Epiphítal: relating to Epiphytes; p. 34.

Episperm : the skin or coat of a seed, especially the outer coat.

Equal: same as regulur; or of the same number or length, as the case may be,

of the body it is compared with.

Equally pinnate: same as abruptly pinnate; p. 65.

Équitant (riding straddle); p. 68, fig. 133, 134.

Erose: eroded, as if gnawed.

Erostrate: not beaked.

Essential Organs of the flower, p 85.

Estivátion: see cestivation.

Etiolated: blanched by excluding the light, as the stalks of Celery.

Everypeen : holding the leaves over winter and until new ones appear, or longer.

Exxulbuminous (soed) : destitute of albumen; p. 136. 
Excirrent : running out, as when a midrib projects beyond the apex of a leaf, or a trunk is continued to the very top of a tree.

Exhalation, p. 156, 169.

Exdgenous Stems, p. 150. Exogenous Plants, p. 182.

Exostome: the orifice in the outer coat of the ovule; p. 122.

Explanate: spread or flattened out.

Exserted: protruding out of, as the stamens out of the comlla of fig. 201.

Exstípulate: destitute of stipules.

Extra-axillary: said of a branch or bud a little out of the axil; as the upper accessory buds of the Butternut, p. 27, fig. 52.

Extrorse: turned outwards; the anther is extrorse when fastened to the filament on the side next the pistil, and opening on the outer side, as in Iris; p. 113.

Falcate: scythe-shaped; a flat body curved, its edges parallel.

Fitmily: p. 176.

Furinaceous: mealy in texture. Fárinose: covered with a mealy powder.

F'risciute: banded; also applied to monstrous stems which grow flat.

Friscicle: a close cluster ; p. 83.

Fiscicled, Fasciculuted: growing in a bundle or tuft, as the leaves of Pine and Larch (fig 139, 140), the roots of Prony and Dahlia, fig. 60.

Fastigiate: close, parallel, and upright, as the branches of Lombardy Poplar.

Faux (plural, fuuces) : the throat of a calyx, corolla, \&c.

Faveolate, Fávose: honcycombed; same as alveolate.

Feather-veined: where the veins of a leaf spring from along the sides of a mid rib ; p. 57, fig. 86-94.

Female (flowers) : with pistils and no stamens.

Fenestrute: pierced with one or more large holes, like windows.

Ferrugineous, or Ferruginous : resembling iron-rust ; rerl-grayish.

Fertile: fruit-bearing, or capable of producing fruit; also said of anthers when they produce good pollen.

Fertilization: the process by which pollen causes the embryo to be formed.

Fibre, p. 145. Filwous: containing much fibre, or composed of fibres.

Fibrillose: formed of small fibres.

Fibrine, p. 165.

Fiddle-shaped: obovate with a deep recess on cach side.

Filament: the stalk of a stamen; p. 86, fig. 170, $a$; also any slender thread. shaped appendage.

Filameintose, or Filamentous : bearing or formed of slender threads.

Filiform: thread-shaped ; long, slender, and cylindrical.

Fimbriate: fringed ; furnished with fringes ( fimbria).

Fistular or Fistulose: hollow and cylindrical, as the lcaves of the Onion.

Flabelliform or Flabellate: fan-shaped; broad, rounded at the summit, and narrowed at the base.

Flaigellate, or Flagelliform e long, narrow, and flexible, like the thong of a whip. or like the runners (flugellex) of tho Strawberry.

Flavescent : yellowish, or turning yellow.

Flrshy: composed of firm pulp or flesh.

Fleshy Plants, p. 47. 
Fléxuose, or Fléxuous: bending gently in opposite directions, in a zigzag way.

Floating: swimming on the surface of water.

Flocriose : composed, or bearing tufts, of woolly or long and soft hairs.

Flora (the goddess of flowers): the plants of a country or district, taken together, or a work systematically describing them; p. 3 .

Floral: relating to the blossom.

Floral Envelopes: the leaves of the flower; p. 85, 99.

Floret: a diminutive flower; one of the flowers of a head (or of the so-called compound flower) of Composita, p. 106.

Flower : the whole organs of reproduction of Phanogamous plants; p. 84.

F'lower-bud: an unopened flower.

Flowering Plants, p. 177. Flowerless Plants, p. 172, 177.

Foliaceous : belonging to, or of the texture or nature of, a leaf (folium).

Fóliose: leafy; abounding in leaves.

Fóliolute: relating to or bearing leaflets (foliola).

Follicle: a simple pod, opening down the inner suture; p. 131, fig. 302.

Follicular: resembling or belonging to a follicle.

Food of Plants, p. 160.

Foramen : a hole or orifice, as that of the ovule; p. 122.

Fornix: little arched scales in the throat of some corollas, as of Comfrey.

Fornicate: over-arched, or arehing over.

Fovente: deeply pitted. Fovecolute: diminntive of foveate.

Free: not united with any other parts of a different sort ; p. 103.

Fringed: the margin beset with slender appendages, bristles, \&e.

Frond: what answers to leaves in Ferns; the stem and leaves fused into one body, as in Duckweed and many Liverworts, \&c.

Frondescence : the bursting into leaf.

Fróndose: frond-bearing; like a frond : or sometimes used for leafy.

Fructification: the state of fruiting. Organs of, p. 76.

Fruit : the matured ovary and all it contains or is connected with; p. 126.

Frutéscent: somewhat shrubby ; becoming a shrub (frutex).

Fruticulose: like a small shrub. Frúticose: shrubby; p. 36.

Fugacious: soon falling off or perishing.

Fulvous: tawny; dull yellow with gray.

Funiculus: the stalk of a seed or ovule; p. 122.

Funnel-form, or Fumel-shaped: expanding gradually upwards, like a funnel or tunnel; p. 102.

Fircute: forked.

Furfuráceous: covered with bran-like fine scurf.

Furrowed: marked by longitudinal channels or grooves.

Fuscous: deep gray-brown.

Fúsiform: spindle-shaped; p. 32.

Gáleate: shaped like a helmet (galea); as the upper sepal of the Monkshood, fig. 185, and the upper lip of the corolla of Dead-Nettle, fig. 209.

Gianopétulous: of united petals; same as monopetalous, and a better word; p. 102. Giamoplinjlons: formed of united leaves. Gumosépulous : formed of united sepuls. Cielutine, p. 165. 
Géminate: twin; in pairs; as the flowers of Linnæa.

Gemma : a bud.

Gemmation: the state of budlding, or the arrangement of parts in the bud.

Gémmule: a small bud ; the buds of Mosses; the plumule, p. 6.

Genículate: bent abruptly, like a knee (genu), as many stems.

Genus : a kind; a rank above species; p. 175, 176.

Generic Names, p. 178. Generic Character, p. 181.

Geographical Botany: the study of plants in their gengraphical relations, p. 3.

Germ: a growing point; a young bud; sometimes the same as embryo; p. 136.

Germen: the old name for ovary.

Germination: the development of a plantlet from the sced ; p. 5, 137.

Giblous : more tumid at one place or on one side than the other.

Glahrate: becoming glabrous with age, or almost glabrous.

Glatrous : smooth, i. e. having no hairs, bristles, or other pubescenc.

Gladiate: sword-shaperl; as the leaves of Iris, fig. 134.

Glands: small cellular organs which secrete oily or aromatic or other products : they are sometimes sunk in the leaves or rind, as in the Orange, Prickly Ash, \&c. ; sometimes on the surface as small projections; sometimes raised on hairs or bristles (glimdular hairs, $f c$.), as in the Sweetbrier and Sundew. The name is also given to any small swellings, \&c., whether they secrete anything or not.

Glandular, Glandulose: furnished with glands, or gland-like.

Glans (Gland) : the acorn or mast of Oak and similar fruits.

- Glaucescent: slightly glaucous, or bluish-grny.

Glancons: covered with a blonm, viz. with a fine whito powiler that rubs off, like that on a fresh plum, or $\mathrm{n}$ cabbage-leaf.

Globose: spherical in form, or nearly so. Globular : nearly globose.

Glochidiate (hairs or bristles): barbed, tipped with barbs, or with a double hooked point.

Glomerate: closely aggregated into a dense cluster.

Glomerule : a dense head-like cluster; p. 83.

Glossology : the department of Botany in which technical terms are explained.

Glumaceous : glume-like, or glume-bearing.

Glume: Glumes are the husks or floral coverings of Grasses, or, particularly, the outer husks or bracts of each spikelet. (Manual, p. 535.)

Glumelles: the inner husks, or palcx, of Grasses.

Gluten: a vegetable product containing nitrogen; p. 165.

Granular: composed of grains. Granule: a small grain.

Growth, p 138.

Grumous or Grumose : formed of coarse clustered grains.

Guttate: spotted, as if by drops of something colored.

Gymnocárpous : naked-fruited.

Gymnospermous : naked-sceded; p. 121.

Gymnosperma, or Gymnospermous Plants, p. 184 ; Manual, p. xxiii.

Gynandrous : with stamens horne on, i. e. united with, the pistil ; p. 111, fig. 226.

Gyncrium : a name for the pistils of a flower taken altogether.

Gynobase : a particular receptacle or support of the pistils, or of the carpels of a compound ovary, as in Geranium, fig. 277, 278. 
Gynophore: a stalk raising a pistil above the stamens, as in the Cleome Family, p. 276.

Gyrale: coiled in a circle: same as circinate.

Gyrase: strongly bent to and fro.

Habit : the general aspect of a plant, or its mode of growth.

Habitat : the situation in which a plant grows in a wild stato.

Hairs : hair-like projections or appendages of the surfuce of plants.

Hairy : beset with hairs, especially longish ones.

Halberd-shaped, or Halberd-hauded: see hastate.

Halved: when appearing as if one half of the body were cut away.

Humate or Hamose: hooked ; the end of a slender body bent round.

Hámulose : bearing a small hook; a diminutive of the last.

Hastate or Ilustile: shaped like a halberd; furnished with a spreading lobe on each side at the base; p. 59, fig. 97.

Heart-shaped: of the shape of a heart as commonly painted; p. 58, fig. 90.

Heart-wood: the older or matured wood of exogenous trees; p. 153.

Helicoid: coiled like a helix or snail-shell.

Helmet: the upper sepal of Monkshood in this shape, fig. 185, \&c.

Hemi- (in compounds from the Grcek) : half; e. g. Hemispherical, \&c.

Hémicarp: half-fruit, or one carpel of an Umbelliferous plaut.

Hemítropous or Ilemátropul (ovule or seed): nearly same as amphitropous, p. 123.

Hepta- (in words of Greek origin): seven; as,

Ileptaiygnous: with seven pistils or styles.

IIeptrimerous : its parts in sevens. Heptándrous: having seven stamens.

Herl, p. 20.

IIertaceous: of the texture of common herbage; not woody ; p. 36.

llerbarium: the botanist's arranged collection of dried plants; p. 201.

Ilermaphrodite (flower): having both stanens and pistils in the same blossom; same as perfect; p. 89.

Heterocípous: bearing fiuit of two sorts or shapes, as in Amphicarpæa.

Heteroyamous: bearing two or more sorts of flowers as to their stamens and pistils; as in Aster, Daisy, and Coreopsis.

Heteromorphous: of two or more shapes.

Heterotropous, or IIeterotropal (ovule) : the same as amphitropous; p. 123.

Hexa- (in Greek compounds) : six ; as

Hexaigonal: six-angled. Hexágynous : with six pistils or styles.

Hexamerous: its parts in sixes. Hexándrous: with six stunens.

Hexcípterous : six-winged.

Hilar: belonging to the hilum.

Hilum : the scar of the seed; its place of attachment; p. 122, 135.

Hippocrépiform: horseshoe-shaped.

Hirsute: hairy with stiffish or beard-like hairs.

Hispid: bristly; beset with stift hairs. Mispidulous is a diminutive of it.

Hoary : grayish-white; see canescent, \&c.

Honógamous : a heud or cluster with flowers all of one kind, as in Eupatorium.

Homogéneous: uniform in nature; all of one kind.

Homomállous (leaves, \&c.): originating all round a stem, but all bent or curved round to one side. 
Momomorphous : all of one shnpe.

Homotropous or Homotropal (embryo) : curved with the seed; curved one way.

Hood: same as helmet or galea. IIonded: hood-shaped ; see cucullate.

Hooked: same as hamate.

Horn: a spur or some similar appendage. Horny: of the texture of horn.

IIortus Siccus : an herbarium, or collection of dricl plants ; p. 201.

IIumifiuse: spread over the surface of the ground.

Mỵaline: transparent, or partly so.

Hybrid: a cross-breed between two allied species.

IIypocratériform: salver-shaped; p. 101, fig. 202, 208.

Hiypogúan: produced under ground.

Mypogynous: inserted under the pistil; p. 103, fig. 212.

Icosaindrous: having 12 or more stamens inserted on the calyx.

Imbricate, Imbricated, Imbricutive: overlapping one another, like tiles or shingles on a roof, as the scales of the involucre of Zinnia, \&c., or the bud-scales of Horsechesnut (fig. 48) and Hickory (fig. 49). In astivation, where some leaves of the calyx or corolla are overlapped on both sides by others; p. 109.

Immarginate: destituto of $\mathrm{n}$ rim or border.

Immersed: growing wholly under water.

Impari-pinnate: pimnato with a singlo leaflet at the npex; p. 65, fig. 126.

Imperfect flowers: wanting either stamens or pistils ; p. 89.

Inaquilateral: unequal-sided, as the leaf of a Begonia.

Incanous: hoary with whitc pubescence.

Incised: cut rather decply and irregularly ; p. 62.

Included: cnclosed ; when the part in question does not project beyond another.

Incomplete Flower: wanting calyx or corolla; p. 90.

Incrassated: thickened.

Incumbent: leaning or resting upon: the cotyledons aro incumbent when the back of one of them lies against the radicle; the anthers are incumbent when turned or looking inwards, p. 113.

Incurved: gradually curving inwards.

Indefinite: not uniform in number, or too numerous to mention (over 12).

Indefinite or Indeterminate Inflorescence: p. 77.

Indehiscent : not splitting open ; i. e. not dehiscent; p. 127.

Indigenous: native to the country.

Individuals: p. 173.

Indiplicate: with the edges turned inwards; p. 109.

Indisium: the shicld or covering of a fruit-dot of a Fern. (Manual, p 588.)

Inferior: growing below some other organ; p. 104, 121.

Inflated: turgid and bladdery.

Inflexed: bent inwards.

Inflorescence: the arrangement of flowers on the stem; p. 76.

Infra-axillary: situnted beneath the axil.

Infundibuliform or Infundíbular: funnel-shaped; p. 102, fig. 199.

Inete (anther) : attached by its base to the very npex of the filament; p. 113.

Innovation: an incomplete young shoot, especially in Mosses.

Inorganic Constituents, p. 160. 
Insertion: the place or the mode of attachment of an organ to its support; p. 72. Intercellular Passayes or Syaces, p. 143, fig. 341.

Internode: the part of a stein botween two nodes; p. 42.

Interruptedly pinnate: pinnate with small leaflets intermixed with larger ones, as in Water Avens.

Intrafuliaceous (stipules, \&c.): placed between the leaf or petiole and the stem.

Introrse: turned or facing inwards, i. e. towards the axis of the flower; p. 113.

Inverse or Inverted: where the apex is in the direction opposite to that of the organ it is compared with.

Involucel: a partial or small involucre; p. 81 .

Incolicellate: furnished with an involucel.

Involúcrate: furnished with an involucre.

Involucre: a whorl or set of bracts around a flower, umbel, or head; p. 79.

Involute, in vernation, p. 76 : rolled inwards from the edges.

Irregular Flowers, p. 91.

Jointed: separate or separable at one or more places into pieces; p. 64, \&c.

Keel: a projecting ridge on a surface, like the keel of a boat; the two anterior petals of a papilionaceous corolla ; p. 105, fig. 217, 218, $k$.

Keeled: furnished with a keel or sharp longitudinal ridge.

Kernel of the ovule and seed, p. 122, 136.

Kidney-shaped: resembling the outline of a kidney; p. 59, fig. 100.

Labellum: the odd petal in the Orchis Family.

Iabiate: same as bilubiate or two-lipped; p. 105.

Lacíniate: slashed; cut into deep narrow lobes (called lacinia).

Lactescent: producing milky juice, as does tho Milkweed, \&c.

Lácunose : full of holes or gaps.

Lavigate: smooth as if polished.

Lámellar or Lamellate: consisting of flat plates (lamella).

Lámina: a plate or blade: the blade of a leaf, \&c., p 54.

Lanute: woolly; clothed with long and soft entangled hairs.

Lanceolate: lance-shaped; p. 58, fig. 86.

Lanuginous: cottony or woolly.

Latent buds: concealed or undeveloped buds ; p. 26, 27.

Lateral: belonging to the side.

Latex: the milky juice, \&e. of plants.

Lax: loose in texture, or sparse; the opposite of crowded.

Leaf, p. 49. Leaf-buds, p. 20, 27.

Leaflet: one of the divisions or blades of a compound leaf; p. 64.

Leaf-like: same as foliaceous.

Leathery : of about the consistence of leather; coriaceous.

Leyume: a simple pod, dehisent into two pieces, like that of the Pea, p. 131, fig. 303 ; the fruit of the l'ea Family (Lerguminos(e), of whatever shape.

Legumine, p. 165.

Leguminous : bclonging to legumes, or to the Leguminous Family.

Lenticular: lens-shaped; i. e. flattish and convex on both sides. 
Lepidote: leprons; covered with scurfy scalcs.

Liber: the inner, fibrous bark of Exogenous plants ; p. 152.

Ligneous, or Lignose: woody in texture.

Ligulate: furnished with a ligule; p. 106.

Ligule: the strap-shaped corolla in many Compositx, p. 106, fig. 220; the

little membranous appendage at the summit of the leaf-sheaths of most Grasses.

Limb: the blade ot n leaf, petrl, \&c.; p. 54, 102.

limear: narrow and flat, the margins parallel; p. 58, fig. 85.

Lineute: marked with parallel lines. Lineolate: marked with minute lines.

Lingulate, Linguiform : tongue-shaped.

Lip : the principal lobes of a bilabiate corolla or calyx, p. 105 ; the odd and peculiar petal in the Orchis Family.

Iole: any projection or division (especially a rounded onc) of a leaf, \&c.

Iocellus (plural locelli) : a small cell, or compartment of a cell, of an ovary or anther.

Lscular : relating to the cell or compartment (loculus) of an ovary, \&c.

Loculicidal (dehiscence) : splitting down through the middle of the back of each cell; p. 132, fig 305.

Locusta: a name for the spikelet of Grasses.

Ioment : a pod which separates transversely into joints; p. 131, fig. 304 .

Lomentáceous : pertaining to or resembling a loment.

Lorate: thong-shaped.

Linate: crescent-shaped. Lunulate: diminutive of lunate.

Lyrate: lyre-shnped; a pinnatifid leaf of an obovate or spatulate outline, the end-lobe large and roundish, and the lower lobes small, as in WinterCress and Radish, fig. 59.

Mace: the aril of the Nutmeg; p. 135.

Máculate : spotted or blotched.

Male (flowers) : having stamens but no pistil.

Mámmose: breast-shaped.

Marcescent : withering without falling off.

Marginal: belonging to the edge or margin.

Marginate: margined, with an edge different from the rest.

Masked: see personate.

1.Median: belonging to the middle.

Medillary: belonging to, or of the nature of pith (medulla); pithy.

Merhullary Rays : the silver-grain of wood; p. 151.

Medullary Sheath: a set of ducts just around the pith ; p. 151.

Membranaceous or Membranous: of the texture of membrane; thin and more or less translucent.

Meniscoid : crescent-shaped.

Mericarp : one carpel of the fruit of an Umbelliferous plant.

Merismatic: separating into parts by the formation of partitions within.

Mésocarp: the middle part of a pericarp, when that is distinguishable into three layers; p. 128.

Mesophloeum : the middle or green bark. 
Micropyle: the closed orifice of the seed; p. 135.

Midrib: the middle or main rib of a leaf; p. 55 .

Milk-Vessels : p. 148.

Miniate: vermilion-colored.

Mitriform: mitre-shaped; in the form of a peaked cap.

Monadelphous : stamens united by their filanents into one set; p. 111.

Monáudrous (flower) : having only one stamen; p. 112.

Moníliform: necklace-shaped; a cylindrical body contracted at intervals.

Monochlamýdeous : having only one floral envelope, i. e. calyx but no corolla, as Anemone, fig. 179, and Castor-oil Plant, fig. 178.

Monocotylédonous (embryo): with only one cotyledon; p. 16, 137.

Monocutyledonous Plants, p. 150, 192.

Moncecious, or Monoicous (flower): having stamens or pistils only ; p. 90.

Monógynous (flower) : having only one pistil, or one style; p. 116.

Monopétalous (flower): with the corolla of one piece; p. 101.

Monoplyillous: one-leaved, or of one piece; p. 102.

Monoséfalous: a calyx of one piece; i. e. with the sepals united into one body; p. 101.

Monospérmous : one-seciled.

Monstrosity: an unnatural deviation from the usual structure or form.

Morpholoyy : the departinent of botany which treats of the forms which an organ (say a leaf) may assume; p. 28.

Múcronate: tipped with an abrupt short point (mucro); p. 60, fig. 111.

Mucrónulate: tipped with a minute abrupt point; a diminutive of the last.

Multi-, in composition: many; as

Multangular: many-angled. Multicípital: many-headed, \&c.

Multifurious: in many rows or ranks. Millifid: many-cleft; p. 62.

Mfultilócular: many-celled. Multiserial: in many rows.

Multiple Fruits, p. 133.

Múricate: beset with short and hard points.

Múriform : wall-like; resembling courses of bricks in a wall.

Muscology: the part of iescriptive hotany which treats of Mosses (i. e. Musci).

Múticous : pointless; beardless; unarmed.

Jycélium: the spawn of Fungi; i. e. the filaments from which Mushrooms, \&c. originate.

Nápiform: turnip-shaped; p. 31, fig. 57.

Natural System: p. 195.

Naturalized: introduced from a foreign country, but growing perfectly wild and propagating freely by seel.

Naviular: boat-shaped, like the glumes of most Grasses.

Necklace-shaped: looking like a string of beads; see moniliform.

Nectar : the honey, \&c. secreted by glands, or by any part of the corolla.

Necterifforous : honcy-bearing; or having a nectary.

Nectery: the old name for petals and other parts of the flower when of unusual shape, especially when honey-bearing. So the hollow spur-shaped petals of Columbine were called nectaries; also the curious long-clawed petals of Monkshood, fig. 186, \&c. 
Needle-shaped: long, slender, nnd rigid, like the leares of Pines; p. 68, fig. 140. Nerve: a namo for the ribs or veins of leaves, when simple and parallel; p. 56. Nerved: furnisher with nerves, or simple and parallel ribs or veins ; p. 56, fig. 84. Netted-veined: furnished with branching veins forming network; p. 56, fig. 83. Nodding (in Latin form, Nutant) : bending so that the summit hangs downward. Node: a knot; the "joints" of a stem, or the part whence a leaf or a pair of leaves springs; p. 40.

Noinse: knotty or knobhy. Nodulose: furnished with little knohs or knots.

Normal : according to rule; the pattern or natural way according to some law, I Notate: marked with spots or lines of a different color.

Nucumentaceous : relating to or resembling a small nut.

Niciform: nut-shaped or nut-like. Núcule : a small nut.

Nucleus: the kernel of an ovule (p. 122) or seed (p. 136) of a cell ; p. 140.

Nut : a hard, mostly one-secded indehiscent fruit; as a chestnut, butternut, acorn ; p. 130, fig. 299.

Nitlet: a little nut; or the stone of a drupe.

$O b$ - (mcaning over against) : when prefixed to words, signifies inversion; as,

Olcompressed: flattened the opposite of the usual way.

Obcordute: heart-shaped with the broad and notehed end at the apex instead of the base; p. 60, fig. 109.

Oblanceolute: lance-shaped with the tapering point downwards; p. 58, fig. 91.

Oblique: applied to leaves, \&c. means unequal-sided.

Oblong: from two to four times as long as broad, and moro or less elliptical in outline; $p: 58$, fig. 87.

Obriate: inversely ovate, tho broad end upward; p. 58, fig. 93.

Obtuse: blunt, or round at the end; p. 60, fig. 105.

Obverse: same as inverse.

Obeolute (in the buil): when the margins of ono leaf alternntely overlup those of the opposite one.

Óchreate: furnished with ochrex (boots), or stipules in the form of sheaths; as in Polygonum, p. 69, fig. 137.

Ochrolevicous: yellowish-white; dull cream-color.

Octo-, eight, enters into the composition of

Octágynous : with eight pistils or styles.

Oclámerous: its parts in eights. Octándrous : with eight stamens, \&c.

Offset: short branches next the ground which take root; p. 38.

One-ribhed, One-nerved, \&c. : furnished with only a single rib, \&c., \&c.

Opaque, applied to a surface, means dull, not shining.

Operculate: furnished with a lid or cover (operculum), as the capsules of Mosses.

Opposite: said of leaves and branches when on opposite sides of the stem from each other (i. e. in pairs); p. 23, 71. Stamens are opposite the petals, \&c. when they stand before them.

Orbícular, Orbiculate: circular in outline or nearly so; p. 58.

Organ: any member of the plant, as a leaf, a stamen, \&c.; p. 1.

Organs of Vegrtation, p. 7 ; of Reproduction, p. 77.

Organized, Organic: p. 1, 158, 159, 162.

Organic Constitucnts, p. 160. Organic Structure, p. 142. 
Orthotropous or Oithotropal (ovule or seed) : p. 122, 135, fig. 270, 274.

Osseous: of a bony texture.

Oval: broadly elliptical; p. 88.

Óvary : that part of the pistil containing the ovules or future seeds; p. 86, 116.

Ovate: shaped like an egg with the broader end downwards, or, in plane sur-

faces, such as leaves, like the section of an egg lengthwise ; p. 58, fig. 89.

Óvoid: ovate or oval in a solid form.

Óvule: the body which is destined to become a seed; p. 86, 116, 122.

Paleu (plural palece) : chaff; the inner husks of Grasses; the chaff or bracts on the receptacle of many Compositie, as Coreopsis, fig. 220, and Sunflower.

Paleaceous : furnished with chaff, or chatfy in texture.

Palmate: when leaflets or the divisions of a leaf all spreal from the apex of the petiole, like the hand with the outspread fingers; p. 167, fig. 129, \&c.

Palmately (veined, lobed, \&c.) : in a palmate manner; p. 57, 63, 65.

Pandíiform: fiddle-shaped (which see).

Pánicle: an open cluster; like a raceme, but more or less compound; p. 81, fig. 163.

P'aniclel, P'aniculate: arranged in panicles, or like a panicle.

Papery: of ubout the consistence of letter-puper.

Papilionaceous : butterfly-shaped; applied to such a corolla as that of the Pea and the Locust-tree; p. 105, fig. 217.

Papilla (plural papille) : little nipple-shaped protuberances.

Papillate, Papillose: covered with papilla.

Pappus: thistle-down. The down crowning the achenium of the Thistle, and other Compositx, represents the calyx ; so the scales, teeth, chaff, us well as bristles, or whatever takes the place of the calyx in this family, are called the pappus; fig. 292-296, p. 130.

Parallel-veined, or nerved (leaves) : p. 55, 56.

Paraphyses: jointed filaments mixed with the antheridia of Mosses. (Manual, p. 607.)

Parenchyma : soft cellular tissue of plants, like the green pulp of leaves.

Parietal (placentæ, \&c.): attached to the walls (parietes) of the ovary or percarp ; p. 119, 120.

Parted: separated or cleft into parts almost to the base; p. 62.

Partial involucre, same as an imolucel : partial petiole, a division of a main leafstalk or the stalk of a leaflet : partial peduncle, a branch of a peduncle : partial umbel, an umbellet, p. 81.

Patent : spreading; open. Patulous : moderately spreading.

Pauci-, in composition: few ; as pauciflorous, few-flowered, \&c.

Pear-shaped: solid obovate, the shape of a pear.

Péctinate: pinnatifid or pimnately divided into narrow and close divisions, like the teeth of a comb.

Pedate: like a bird's foot; palmate or palmately cleft, with the side divisions again cleft, as in Viola pedata, \&c.

Pedately cleft, lobed, \&c. : cut in a pedate way.

Pédicel: the stalk of each particular flower of a cluster; p. 78, fig. 156.

Pédicillute, Pélicelled: furmished with a pedicel. 
Pediencle : n flower-stnlk, whether of a single flower or of a flower-eluster; p. 78. Péduncled, Pedinculate: furnished with a peduncle.

Peltate: shield-shaped: said of a leaf, whatever its shape, when the petiole is attached to the lower side, somewhere within the margin ; p. 59, fig. 102, 178.

Pendent : hanging. Pendulous: somewhat hanging or drooping.

Pentcillate: tipped with a tuft of fine hairs, like a painter's pencil ; as the stigmas of some Grasses.

Penta- (in words of Greek composition) : five; as

Pentrígynous : with five pistils or styles; p. 116.

Pentámerous : with its parts in fives, or on the plan of five.

Pentándrous : having five stamens; p. 112. Pentástichous : in five ranks.

Pepo: a fruit like the Melon and Cucumber; p. 128.

Perennial: lasting from year to year; p. 21.

Perfect (flower): having both stamens and pistils; p. 89.

Perfoliate: passing through the leaf, in appearance; p. 67, fig. 131, 132.

Pérforate: pierced with holes, or with transparent dots resembling holes, as an Orange-leaf.

Perianth: the leaves of the flower generally, especially when we cannot readily distinguish them into calyx and corolla; p. 85.

Pericarp: the ripened ovary; the walls of the fruit ; p. 127.

Pericarpic: belonging to the pericarp.

Perichreth : the cluster of peculiar leaves at the base of the fruit-stalk of Mosses.

Perichatial: belonging to the perichath.

Perigónium, Perigone: same as perianth.

Perigymium : hodies around the pistil ; applied to the closed cup or bottle-shaped body which encloses the ovary of Sedges, and to the bristles, little scales, \&c. of the flowers of some other Cyperaceæ.

Perigynous: the petals and stamens borne on the calvx ; p. 104, 111.

Peripheric: around the outside, or periphery, of any organ.

Perisperm : a name for the albumen of a seed ( $p .136$ ).

Peristome: the fringe of teeth, \&c. around the orifice of the capsule of Mosses. (Manual, p. 607.)

Persistent : remaining beyond the period when such parts commonly fall, as the leaves of evergreens, and the calyx, \&c. of such flowers as remain during the growth of the fruit.

Personate: masked; a bilabiate corolla with a projection, or polote: in the throat. as of the Snapdragon; p. 106, fig. 210, 211.

Petal: a leaf of the corolla; p. 85.

Petaloid: petal-like; resembling or colored like petals.

Pétiole: a footstalk of a leaf; a leaf-stalk, p. 54.

Petioled, Petiolate: furnished with a petiole.

Petiolulate: said of a lenflet when raised on its own partial leafstalk.

Phanogamous, or Phanerógamous: plants bearing flowers and producing seeds: same as Flowering Plants ; p. 177, 182.

Phyllodium (plural phyllodia) : a leaf where the blade is a dilated petiole, as in New Holland Acacias; p. 69.

Phyllotáxis, or Phyllotaxy : the arrangement of leaves on the stem ; p. 71.

Physiological Botany, Physiology, p. 3. 
Plyton : a name used to designate the pieces which by their repetition make up

a plant, theoretically, viz. u joint of stem with its leuf or pair of leaves.

Piliferous: bearing as slenter bristlo or hair (

Pílose : hairy ; clothed with soft slender hairs.

Pinna: a primary branch of the petiole of a bipinnate or tripinnate leaf, as fig. 130, p. 66.

Pinnule: a secondary branch of the petiole of a bipinnate or tripinnate leaf ; p. 66 .

Pinnate (leaf) : when the leaflets are arranged along the sides of a common petiole ; p. 65, fig. $126-128$.

Pinnately lobed, cleft, parted, divided, \&c., p. 63.

Pinnálifid: same as pinnately cleft; p. 63, fig. 119.

Pistil: the seed-bearing organ of the flower; p. 86, 116.

Pistillidium : the body which in Mosses, Liverworts, \&c. answers to the pistil.

Pitchers, p. 51, fig. 79, 80.

Pith : the cellular centre of an exogenous stem; p. 150, 151.

Pitted: having small depressions or pits on the surface, as many seeds.

Placenta: the surface or part of the ovary to which the ovules are attached; p. 118.

Plaited (in the bud); p. 76, fig. 150 ; p. 110, fig. 225.

Plane: flat, outspread.

Plicate: same as plaited.

Plumose: feathery; when any slender body (such as a bristle of a prppus) is besct with hairs along its silles, like the plumes or the beard on a feather.

Plamule: the little bud or first shoot of a germinating plantlet abovo the cotyle. dons; p. 6, fig. 5 ; p. 137.

Pluri-, in composition : many or several ; as

Plurifoliolate: with several leaflets; p. 66.

Pod: specially a legume, p. 131 ; also applied to any sort of capsule.

Podosperm: the stalk of a seed.

Pointless : destitute of any pointed tip, such as a mucro, awn, acumination, \&c.

Pollen : the fertilizing powder of the anther; p. 86, 114.

Pollen-mass : applied to the pollen when the grains all cohere into a mass, as in Milkweed and Orchis.

Poly- (in compound words of Greek origin) : same as multi- in those of Iatin origin, viz. many ; as

Polyadelphous: having the stamens united by their filaments into several bundles; p. 112.

Polyaindrous: with numerous (more than 20) stamens (inserted on the receptacle); p. 112.

Polycotylédonous: having many (more than two) cotyledons, as Pines; p. 17, 137, fig. 45, 46.

Polyyamous : having some perfeet and some separated flowers, on the same or ou different individuals, as the Red Maple.

Polyyonal: many-angled.

Polygynous : with many pistils or styles; p. 116.

Polymerous : formed of many parts of each set.

Polymorphous : of several or varying forms.

Polypétclous: when the petals are distinct or separate (whether few or many); p. 103. 
Polyphyllous : many-leared; formed of several distinct pieces, as the calyx of Sedum, fig. 168, Flax, fig. 174, \&c.

Polysepalous: same as the last when applied to the calyx; p. 103.

Polyspérmous: many-secded.

Pome: the apple, pear, and similar fleshy fruits; p. 128.

Porous: full of holes or pores.

Pouch : the silicle or short pod, as of Shepherd's Purse; p. 133.

Prafloration : same as astivation ; p. 108.

Prefoliation: same as vernation; p. 75.

Promorse: ending abruptly, $n$ if bitten off.

Prickles : sharp elevations of the bark, coming off with it, as of the Rose; p. 39.

Prickly: bearing prickles, or sharp projections like them.

Primine: the outer cont of the covering of the ovule ; p. 124.

Primordinl : earliest formed; primordial leaves are the first after the cotyledons.

Prismátic : prism-shaped ; having three or more angles bounding flat or hollowed sides.

Process : any projection from the surface or edge of a body.

Procumbent: trailing on the ground; p. 37 .

Produred : extended or projecting, as the upper sepal of a Larkspur is produced above into a spur; p. 91, fig. 183.

Prolffernus (literally, bearing offspring) - where $a$ new branch rises from an older one, or one head or cluster of flowers out of another, as in Filago Germanica, \&c.

Prostrate: lying flat on the ground.

Proteine: a vegetable product containing nitrogen ; p. 165.

Prótoplasm : the soft nitrogenous lining or contents of cclls; p. 165.

Pruinose, Pruinate: frosted ; covered with a powder like hoar-frost.

Puberulent : covered with fine and short, almost imperceptible down.

Pubéscent : hairy or downy, especially with fine and soft hairs or pubescence.

Pulverulent, or Pulveraceous : dusted; covered with fine powder, or what looks like such.

Pulvinate : cushioned, or shaped like a cushion.

Punctate : dotted, either with minute holes or what look as such (as the leaves of St. John's-wort and the Orange), or with minute projecting dots.

Pungent : very hard, and sharp-pointed; prickly-pointed.

Putamen: the stone of a drupe, or the shell of a nut; p. 128.

Pyramidul : shaped like a pyramid.

Pyréne, Pyréna: a seed-like nutlet or stone of a small drupe.

Pyxis, Pyxídium : a pod opening round horizontally by a lid; p. 133, fig. 298, 311.

Quadri-, in words of Latin origin : four ; as

Quadiangular : four-angled. Quadrifoliate: four-leaved.

Quaidrifid: four-cleft; p 62.

Quaternate: in fours. Quinate: in fives.

Quincuincial: in a quincunx; when the parts in restivation are five, two of them outside, two inside, and one half out and half in, as shown in the calyx, fig. 224.

Quintuple : five-fold. 
Race: a marked variety which may be perpetuated from seed; p. 174.

Raceme: a flower-cluster, with one-flowered pedicels arranged along the sides of a general perluncle; p. 78, fig. 156.

liacemose: bearing racemes, or raceme-like.

Riuchis : see rhachis.

Riculial: belonging to the ray.

Rádiate, or Radiant: furnished with ray-flowers; p. 107.

Rádical: belonging to the root, or apparently coming from the root.

Rúdicant : rooting, taking root on or alpove the ground, like the stems of Trumpet-Creeper and Poison-Ivy.

Rádicels : little roots or rootlets.

Radicle: the stem-part of the embryo, the lower end of which forms the root; $p$. 6, fig. 4, \&c. ; p. 137.

Rameal : belonging to a branch. Ramose : full of branches (rami).

Rámulose: full of branchlets (ramuli).

Ruphe: see rhaphe.

liay: the marginal flowers of a head (as of Coreopsis, p. 107, fig. 219) or eluster

(as of IIydrangea, fig. 167), when different from the rest, especially when ligulate, and diverging (like rays or sunbeams); the branches of an umbel, which diverge from a centre; p. 79.

Receptacle: the axis or support of a flower; p. 86, 124 ; the common axis or support of a head of flowers; fig. 230.

Reclined: turned or curved downwards; nearly recumbent.

Recurved: curved outwards or backwards.

Reduplicate (in restivation) : valvate with the margins turned outwards, p. 109.

Reflexed : bent outwards or backwards.

Refracted: bent suddenly, so as to appear broken at the bend.

Regular : all the parts similar; p. 89.

Réniform: kidney-shaped; p. 58, fig. 100.

Repánd: wavy-margined; p. 62, fig. 115.

Répent: creeping, i. e. prostrate and rooting underneath.

Réplum : the persistent frame of some pods (as of Prickly Poppy and Cress), after the valves fall away.

Reproduction, organs of : all that pertains to the flower and fruit; p. 76.

Resúpinate: inverted, or appearing as if upside down, or reversed.

Reticulated: the veins forming network, as in fig. 50,83 .

Retroflexed: bent backwards; same as reflexed.

Retuise: blunted; the apex not only obtuse, but somewhat indented; p. 60, fig. 107.

Revolute: rolled backwards, as the margins of many leaves; p. 76.

Rhachis (the backbone): the axis of a spike, or other body; p. 78.

Rhaphe: the continuation of the seed-stalk along the side of an anatropous orule

(p. 123) or seed ; fig. 273, r, 319 and $320, b$.

Rháphides: erystals, especially needle-slitped ones, in the tissues of plants.

Rhizoma: a rootstock; p. 40, fig. 64-67.

Rhombic: in the shape of a rhomb. Rhomboidul: approaching that shape.

Rib : the principal picee, or one of the principal pieces, of the framework of a leaf, p. 55 ; or any similar elevated line along a body. 
Ring : an elastic band on the spore-crses of Ferns. (Manual, p. 587, plate 9. fig. 2, 3.)

Ringent : grinning; gaping open ; p. 102, fig. 209.

Root, p. 28.

Root-hairs, p. 31, 149.

Rootlets : small roots, or root-branches; p. 29.

Rootstock : root-like trunks or portions of stems on or under ground; p. 40.

Rosaceous : arranged like the petals of a rose.

Rostellate: hearing a small heak (rostellum).

Rostrate: benring a benk (rostrum) or a prolonged appendage.

Rosulate: in a regular cluster of spreading leaves, resembling a full or doablo rose, as the leaves of Houseleek, \&c.

Rotate: wheel-shaped : p. 101, fig. 204, 205.

Rotund: rounded or roundish in ontline.

Rudimentary : imperfectly developed, or in an early state of development.

Rugose: wrinkled, roughened with wrinkles.

Ruminated (albumen) : penetrated with irregular channels or portions filled with softer matter, as a nutmeg.

Ruincinate: coarsely saw-toothed or cut, the pointed teeth turned towards the base of the leaf, as the lenf of a Dandclion.

Runner: a slender and prostrate branch, rooting at the end, or at the joints, as of a Strawberry, p. $\mathbf{3 8}$.

Sac : any closed membrane, or a dcep purse-shaped cavity.

Sígittate : arrowhead-shaped; p. 59, fig. 95.

Salver-shaped, or Salver-form : with a border spreading at right angles to a slender tube, as the corolla of Phlox, p. 101, fig. 208, 202.

Samára : a wing-fruit, or key, as of Maple, p. 5, fig. 1, Ash, p. 131, fig. 300, and Elm, fig. 301.

Sámaroid: like a samara or key-fruit.

Sap : the juices of plants generally. Ascending or crude sap; p. 161, 168. Elaborated sap, that which has been digested or assimilated by the plant; p. $162,169$.

Sircocarp : the fleshy part of a stone-fruit, p. 128.

Sarmentáceous : bearing long and flexible twigs (sarments), either spreading or procumbent.

Saiv-toothed : see serrate.

Scábrous : rough or harsh to the touch.

Scalairiform : with cross-bands, resembling the steps of a ladder.

Scales : of buds, p. 22, 50 ; of bulbs, \&c., p. 40, 46, 50.

Scaly : furnished with scales, or scale-like in texture; p. 46, \&c.

Scandent : climbing; p. 37.

Scape : a peduncle rising from the ground, or near it, as of the stemless Violets, the Bloodroot, \&c.

Scapiform : scape-like.

Scar of the seed, p. 135. Leaf-scars, p. 21.

Scarious or Scariose : thin, dry, and membranous.

Scrbiform: resembling sawdust. 
Scorpioid or Scorpioidal : curved or circinate at the end, like the tail of a scorpion, as the inflorescence of Ifeliotrope.

Serodicalute: pitted ; excavated into shallow pits.

Scurf, Scurfiness: minute scales on the surface of many leares, as of Goosefoot, Buffalo-berry, \&c.

Scuitute : buckler-shapied.

Scutellate, or Scutelliform: sancer-shuped or platter-shaped.

Sécund: one-sided; i. e. wlicre fluwers, leaves, \&ce. are all tarned to one side.

Secuindine: the inner coat of the ovule; p. 124.

Seed, p. 134. Seed-caats, p. 134. Seed-vessel, p. 127.

Seyment : a subdivision or lobe of any cleft body.

Seyregute: separated from each other.

Seni- (in compound words of Latin origin) : half; as

Semi-adherent, as the calyx or ovary of Purslane, fig. 214. Semicordate: halfheart-shaped. Semilunar : like a half-moon. Semiovate: half-ovate, \&c.

Senninal: relating to the seed. Seminiferous: seed-bearing.

Sempervirent : evergreen.

Sepal : a leaf or division of the calyx ; p. 85.

Sépuloid: sepal-like. Sepaline: relating to the sepals.

Separated Fluvers: those having stamens or pistils ouly ; p. 89.

Septate: divided by partitions (septa).

Septenate: with parts in sevens.

Septicidul: where a pod in dehiscence splits through the partitions, dividing each into two layers; p. 132, fig. 306.

Sepliferous: bearing the partition.

Septifragal: where the valves of a pod in dehiscence break away from the partitions; p. 132.

Septum (plural septa) : a partition, as of a pod, \&c.

Sérial, or Seriate: in rows; as biserial, in two rows, \&c.

Sericeous: silky; clothed with satiny pubescence.

Serótinous: happening late in the season.

Serrate, or Serrated: the margin cut into teeth (serratures) pointing forwards; p. 61 , fig. 112.

Serrulate: same as the last, but with fine teeth.

Sessile: sitting; without any stalk, as a leaf destitute of petiole, or an anther destitute of filament.

Seta : a bristle, or a slender body or appendage resembling a bristle.

Setaceous : bristle-like. Sétiform: bristle-shaped.

Settijerous : bearing bristles. Sctosę: beset with bristles or bristly hairs.

Sex: six; in composition. Sexangular: six-angled, \&e.

Sheath: the base of such leaves as those of Grasses, which are

Sheathing: wrappred round the stem.

Shield-shuped: same as scutate, or as peltate, p. 59.

Shoul, p. 21.

Signoid: curved in two directions, like the letter S, or the Greck sigma.

Siliculose : bearing a silicle, or a fruit resembling it.

Silicle: a pouch, or short pod of the Cress Family; p. 133.

Siliyue: a longer poil of the Cress Family; p. 133, fig. 310. 
Siliquose: bearing siliques or pods which resemble siliques.

Silky : glossy with a coat of fine and soft, close-pressed, straight hairs.

Silver-grain of wood ; p. 151.

Silvery: shining white or bluish-gray, usually from a silky pubescence.

Simple: of one picce; opposed to compound.

Sinistrorse: turned to the left.

Sinute: strongly wavy; with the margin alternately bowed inwards and outwards; p. 62 , fig. 116.

Sinus: a recess or bay ; the re-entering angle or space between two lobes or projections.

Sleep of Plants (so called), p. 170.

Soboliferous: hearing shoots from near the ground.

Solitary: single; not associated with others.

Sorus (plural sori) : the proper name of a fruit-dot of Ferns.

Spadix: a fleshy spike of tlowers; p. 80, fig. 162.

Spathaceous: resembling or furnished with a

Spathe: a bract which inwraps an inforescence; p. 80, fig. 162.

Spátulate, or Spathulate: shaped like a spatula; p. 58, fig. 92.

Special Morements, p. 170.

Sprecies, p. 173.

Specific Character, p. 181. Specific Names, p. 179.

Spicote: belonging to or disposed in a spike.

Spiciform : in shape resembling a spike.

Spike: an inflorescence like a raceme, only the flowers are sessile; p. 80, fig. 160.

Spikalut : a stmall or $n$ secondary spike: the inflorescence of Grasses.

Spine: a thorn; p. 39.

Spindle-shoped - tapering to each end, like a radish; p. 31 , fig. 59.

Spinescent : tipped by or degenerating into a thorn.

Spinose, or Spinifersus: thorny.

Spiral arrangement of leaves, p. 72. Spiral vessels or ducts, p. 148.

Sporaingia, or Sporocarps : spore-cases of Ferns, Mosses, \&c.

Spore: a body resulting from the fructification of Cryptogamous plants, in them taking the place of a sced.

Sporule: same as a spore, or a small sporc.

Spur: any projecting appendage of the flower, looking like a spar, as that of Larkspur, fig. 183.

Squamate, Squamose, or Squamaceous: furnished with scales (squamo).

Squamelhate or Squámulose: furnished with little scales (squamelloe or squamuloe).

Squaimiform: shaped like a scale.

Squarnose: where scales, leaves, or any appendages, are spreading widely from the axis on which they are thickly set.

Squérrulase: diminutive of squarrase; slightly squarrose.

Stalk : the stem, petiole, peduncle, \&c., as the case may be.

Stamen, p. 86, 111.

Staminate: furnished with stamens; p. 89. Staminerl: relating to the stamens Stamindium. an abortive stamen, or other body resembling a sterile stamen.

Slandard: the upper petal of a papilionaceous corolla ; p. 105, fig. 217, 218, s

Slarch : a well-known vegetable product; p. 163. 
Stution: the particular place, or kind of situation, in which a plant naturally occurs.

Stellate, Stellular: starry or star-like; where several similar parts spread out from a common centre, like a star.

Stem, p. 36, \&c.

Slemless : destitute or apparently destitute of stem.

Sterile: barren or imperfect; p. 89.

Stigma : the part of the pistil which receives the pollen; p. 87.

Stigmátic, or Stigmatose : belonging to the stigma.

Stipe (Latin stipes) : the stalk of a pistil, \&c., when it has any ; the stem of a Mushroom.

Stipel: a stipule of a leaflet, as of the Bean, \&c.

Stipeillate: furnished with stipels, us the Bean and some other Leguminous plants.

Stipitate: furnished with a stipe, as the pistil of Cleome, fig. 276.

Stipulate: furnished with stipules.

Stipules: the appendages one each side of the base of certain leaves ; p. 69.

Stolons: trailing or reclined and rooting shoots; p. 37.

Siclomiferous: producing stolons.

Slomale (Latin stoma, plural stomata) : the breathing-pores of leaves, \&c.; p. 156.

Strap-shaped: long, flat, and narrow; p. 106.

Striate, or striutul: marked with slender longitudinal grooves or channels (Latiu strice).

Strict: close and narrow; straight and narrow.

Strigillose, Striyase: beset with stout and appressed, scale-like or rigid bristles.

Strobilactous: relating to, or resembling a

Strolile: a multiple fruit in the form of a cone or head, as that of the Hop and of the Pine; fig. 314, p. 133.

Ströphiole: same as caruncle. Strophiolate: furnished with a strophiole.

Struma: a wen; a swelling or protuberance of any organ.

Style: a part of the pistil which bears the stigma; p. 86.

Stylopódium : an epigynous disk, or an enlargement at the base of the style, found in Unbelliferous and some other plants.

Sub-, as a prefix : about, nearly, somewhat; as subcordate, slightly cordate : subserrate, slightly serrate: subaxillary, just beneuth the axil, \&ic., \&c.

Siberose: corky or cork-like in texture.

Subclass, p. 177, 183. Sulorder, p. 176. Sultribe, p. 177.

Subulate: awl-shaped; tapering from a broadish or thickish base to a shary point ; p. 68.

Succulent: juicy or pulpy.

Suckers: shoots from subterranean branches; p. 37.

Suffrutéscent: slightly shrubby or woody at the base only; p. $\mathbf{3 6}$.

Sugar, p. 163.

Sulcate: grooved longitudinally with deep furrows.

Supernumerary Buds: p. 26.

Supérvolute: plaited and convolute in bud; p. 110, fig. 225.

Supra-axillary: borne ahove the axil, as some buds; p. 26, fig. 52.

Supra-decompound: many times compounded or divided. 
Sirculose : producing suckers, or shonts resembling them.

Suspended: hanging down. Suspended ovules or seeds hang from the very summit of the cell which contains them ; p. 122, fig. 269.

Situral: belonging or relating to a suture.

Suiture: the line of junction of contiguous parts grown together; p. 117.

Sumd-shaped: vertical leaves with acute parallel edges, tapering above to a point; as those of Iris, fig. 133.

Symmetrical Flower: similar in the number of parts of each set; p. 89.

Synaintherous, or Syngenesious: where stamens are united by their anthers; p. 112, fig. 229.

Syncarpous (fruit or pistil) : composed of several carpcls consolidated into one. System, p. 195.

Systematic Botany: the study of plants after their kinds; p. 3.

Taper-pointed: same as acuminate; p. 60, fig. 103.

Tap-root: a root with a stout tapering body; p. 32 .

Tawny: dull yellowish, with a tinge of brown.

Taxonomy: the part of Botany which treats of classification.

Ténmen: a name for the inner seed-coat.

Tendril: a thread-shaped body used for climbing, p. 38 : it is either a branch, as in Virginia Creeper, fig. 62 ; or a part of a leaf, as in Pea and Vetch, fig. 127 .

Térefe: long and round; same as cylindrical, only it may taper.

Terminal : borne at, or belonging to, the extremity or summit.

Terminslony: the part of the science which trents of technical terms; snme as glosomlongy.

Térnnte: in threes; p. 66. Ternately: in a ternate way.

Trsta: the outer (and usually the harder) coat or shell of the sced; p. 134.

Tdra- (in words of Greck composition) : four ; ns,

Tetracoccous: of four cocci or carpels.

Tetradiynamous: where a flower has six stamens, two of them shorter than the other four, as in Mustard, p. 92, 112, fig. 188.

Tetraigonal: four-angled. Tetraigynous: with four pistils or styles; p. 116.

Tetrimerous : with its parts or sets in fours.

Tetrindrons: with four stamens; p. 112.

Theca: a case; the cells or lobes of the anther.

Thorn: see spine; p. 39.

Thread-shaped: slender and round, or roundish like a thread ; as the filament of stamens generally.

Throat: the opening or gorge of a monopetalous corolln, \&c., where the border and the tube join, and a little below.

Thyrse or Thyrsus : a compact and pyramidal panicle; p. 81.

Tomentose: clothed with matted woolly hairs (tomentum).

Tongue-shaped: long, flat, but thickish, and blunt.

Toothed: furnished with teeth or short projections of any sort on the margin, used especially when these are sharp, like saw-tceth, and do not point for, wards ; p. 61, fig. 113.

Top-shaped: shaped like a top, or a cone with its apex downwards. 
Tórose, Tórulose: knobby ; where a cylindrical body is swollen at intervals.

Torus: the receptacle of the flower; p. 86, 124.

Tree, p. 21.

Iri-, in composition : three; as

Triadelphous: stamens united by their filaments into three bundles; p. 112.

Triándrous: where the flower has three stamens; p. 112.

Tribe, p. 176.

Trichotomous : three-forked. Tricóccous : of three cocci or roundish carpels.

Tricolor: having three colors. Tricostate: having three ribs.

T'ricuispidate: three-pointed. Tridéntate: three-toothed.

Triénnial: lasting for three years.

Trifárious: in three vertical rows; looking three ways.

Trifid: three-cleft ; p. 62.

Trifoliate: three-leaved. Trifoliolate: of three leaflets; p. 66.

Trifürcate: three-forked. Trígonous : three-angled, or triungular.

Trígynous: with three pistils or styles; p. 116. Trijugate: in three pairs (jugi).

Trilubed, or Trilubate: three-lobed; p. 62.

Trilocular: three-eelled, as the pistils or pods in fig. 225-227.

Trimerous: with its parts in threes, as 'Trillium, fig. 189.

Trinervate: three-nerved, or with three slender ribs.

Triócious: where there are three sorts of flowers on the sume or different individuals; as in Red Maple.

Tripartible: scparable into three pieces. Tripátile: three-parted; p. 62.

Tripetalous : having three petals; as in fig. 189.

Triphyillous: three-leaved; composed of three pieces.

Tripinnate: thrice pinnate; p. 66 . Tripinnátifid: thrice pinnately cleft ; p. 64.

Triple-ribled, Triple-nerved, \&c.: where a midrib branches into three near the base of the leaf, as in Sunflower.

riquétrous : sharply three-angled; and especially with the sides concave, like a bayonet.

Triserial, or Triseriate: in three rows, under each other.

Tristichous : in three longitudinal or perpendicular ranks.

Tristigmálic, or Tristígnatose: having three stigmas.

Trisulcute: three-grooved.

Triternate: three times ternate; p. 67.

Trivial Name: the specific name.

Trochlear: pulley-shaped.

Trumpet-shaped: tubular, enlarged at or towards the summit, as the corolla of Trumpet-Crecper.

Truncate: as if cut off at the top; p. 60, fig. 106.

Tube, p. 102.

Trunk: the main stem or general body of a stem or tree.

Tuber: a thickened portion of a subterranean stem or branch, provided with eye (buds) on the sides; as a potato, p. 43, fig. 68.

Túbercle: a small excrescence.

Tubercled, or Tuberculate : bearing excrescences or pimples.

Thiberous: resembling a tuber. Tuberiferous: bearing tubers.

Tíbular: hollow and of an elongated form; hollowed like a pipe. 
Tumid: swollen; somewhat inflated.

Tuinicate: conted; invested with layers, as an onion ; p. 46.

Turbinate: top-shaped. Turgid: thick as if swollen.

Túrio (plural turwnes) : young shoots or suckers springing out of the ground; as Asparagus-shoots.

Turnip-shaped: broader than high,

Twin: in pairs (see geminate), as the flowers of Linnæa

Twining: ascending by coiling round a support, like the Hop; p. 37 .

- Typical : well expressing the characteristics of a species, genus, \&c.

Úmbel : the umbrella-like form of inflorescence; p. 79, fig. 159.

Umbellate: in umbels. Umbelliferous : bearing umbels.

Úmbellet : a secondary or partial umbel ; p. 81 .

Umbilicate: depressed in the centre, like the ends of an apple.

Úmbonate: bossed ; furnished with a low, rounded projection like a boss (umbo).

Umbraiculiform ; umbrella-shaped, like a Mushroom, or the top of the style of Sarracenia.

Unarmed: destitute of spines, prickles, and the like.

Úncinate: hook-shaped; hooked over at the end.

Under-shrub : partially shrubhy, or a very low shrub.

Úndulate: wavy, or wavy-margined; p. 62.

Unequally pinnate: pinnate with an odd number of leaflets; p. 65.

Unguiculate: furnished with a claw (unguis); p. 102, i. e. a narrow base, as the petals of $n$ Rose, where the claw is very short, and those of Pinks (fig. 200), where the claw is very long.

Uni-, in compound words: one; as

Uniflorous : one-flowered. Unifoliate : one-leaved.

Unifoliolate: of one leaflet; p. 66. Unijugate: of one pair.

Unilabiate: one-lipped. Unilateral : one-sided.

Unilocular: one-celled, as the pistil in fig. 261, and the anther in fig. 238, 239.

Uniovulate: having only one ovule, as in fig. 213, and fig. 267-269.

Uniserial : in one horizontal row.

Uniséxual : having stamens or pistils only, as in Moonseed, fig. 176, 177, \&c.

Únivalved: a pod of only one piece after dehiscence, as fig. 253.

Urcéolate : urn-shaped.

Útricle: a small, thin-walled, one-seeded fruit, as of Goosefoot ; p. 130, fig. 350.

Utricular : like a small bladder.

Viginate: sheathed, surrounded by a sheath (vagina).

Valve: one of the pieces (or doors) into which a dehiscent pod, or any similar body, splits; p. 131, 114.

Valvate, Valvular: opening by valves. Valvate in æstivation, p. 109.

Variety, p. 174, 177.

Váscular: containing vessels, or consisting of vessels, such as ducts; p. 146, 148.

Vaulted: arched; same as fornicate.

Vegetable Physiology, p. 3.

Veil : the calyptra of Mosses. (Manual, p. 607)

Veins : the small ribs or branches of the framework of leaves, \&c. : p. 55. 
Veined, Veiny : furnished with evident veins. Veinless : destitute of veins.

Veinlets : tho smaller ramilications of veins.

Velute: furnished with a veil.

Veluitinous: velvety to the touch.

Venation: the veining of leaves, \&c.; p. 55.

Vénose: veiny; furnished with conspicuous veins.

Ventral: belonging to that side of a simple pistil, or other organ, which looks towards the axis or centre of the flower; the opposite of dorsal; as the

Ventral Suture, p. 117.

Véntricose: inflated or swelled out on one side.

Vénulose: furnished with veinlets.

Vermícular: shaped like worms.

Vernation: the arrangement of the leaves in the bud; p. 75.

Vernicose: the surface appearing as if varnished.

Verrucose: warty ; beset with little projections like warts.

Versatile: attached by one point, so that it may swing to and fro, as the anthers of the Lily and Evening Primrose; p. 113, fig. 234.

Vertex: same as the apex.

Vértical : upright; perpendicular to the horizon, lengthwise.

Verticil: a whorl; p. 71. Verticillate: whorled; p. 71, 75, fig. 148

Vésicle: a little bladder. Embryonal Vesicle, p. 139. Vesicular: bladdery.

Vessels: ducts, \&c. ; p. 146, 148.

Vexillary, Vexillar: relating to the

Vexfllum: the standard of a papilionaceous flower; p. 105, fig. 218, s.

Villose: shaggy with long and soft hairs (villosity.)

Vimineous: producing slender twigs, such as those used for wicker-work.

Vine: any trailing or climbing stem; as a Grape-vine.

Viréscent, Viridescent: greenish; tụning green.

Virgate: wand-shaped, as a long, straight, and slender twig.

Viscous, Viscid: having a glutinous surface.

Vitta (plural vittie): the oil-tubes of the fruit of Unbelliferæ.

Vóluble: twining, as the stem of Hops and Beans; p. 37.

Wany: the surface or margin alternately convex and concave; p. 62.

Waxy: resembling beeswax in texture or appearance.

Wedge-shaped: broad above, and tapering by straight lines to a narrow base. p. 58, fig. 94.

Wheel-shaped: see rotute; p. 102, fig. 204, 205.

Whorl, Whorled: when leaves, Se. are aranged in a circle round the stens p. 71,75 , fig. 148 .

Wing: any membranous expansion. Wings of papilionaceous flowers, p. 105

Winged: furnished with a wing; as the fruit of Ash and EIm, fig. 300, 301.

Wood, p. 145. Woody: of the texture or consisting of wood.

Woody Fibre, or Wood-Cells, p. 146.

Woolly: clothed with long and entangled soft hairs; as the leaves of Mullein. 


\section{B O ' T A N Y}

or

\section{TIIE NORTIERN UNITED STATES.}





\section{A N U A L}

or

B O T A N Y

OF

\section{THE NORTIIERN UNITED STATES,}

INCLUDING THE DISTRICT EAST OF TIIE MISSISSIPPI AND NORTH OF NORTH CAROLINA AND TENNESSEE,

ARRANGED ACCORDING TO THE NATURAL SYSTEM.

\section{BY A S A GRAY,}

FISHER PROFESSOR OF NATURAL, IISTORY IN IIARVARD UNIVERSITY.

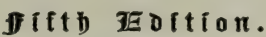

EIGHTH ISSUR.

WITH TWENTY PLATES, ILlostrating THE SEDGES, GRASSES, FERNS, ETC.

IVISON, BLAKEMAN, TAYLOR \& CO. NEW YOIK AND CIICAGO. 
Entered according to $A$ ct of Congress, in the year 1867 , by IVISON, PHINNEY, BLAKLMAN, \& Co.,

in the Clerk'y Office of the District Court of the United Stibley for the Sunthern Distriet of New York. 


\section{JOHN TORREY, LL.D.}

Almost twenty years have passed since the first edition of this work was dedicated to you, - more than thirty, since, as your pupil, I began to enjoy the advantage of being associated with you in botanical pursuits, and in a lasting friendship. The flow of time has only decpened the sense of gratitude due to you from your attached friend,

CAmbridge, May 30, 1867.

ASA GRAY. 


\section{N O T E.}

IN the present issue many small corrections, typographical and other, have been made throughout the volume, as well as more considerable alterations on pages $479,480,564$; an omission of the proper acknowledgment for the article on Sparganium is supplied on page 481 ; and additional species, with a few more extended emendations, are given on pages $679-682$.

Самвidige, January 30, 1868. 


\section{O N T E N TS.}

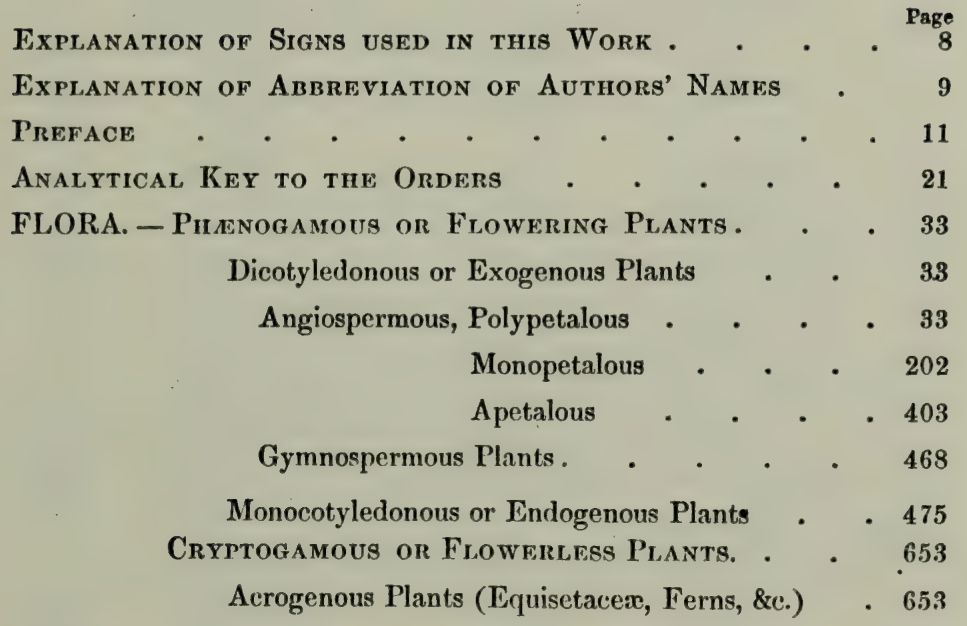

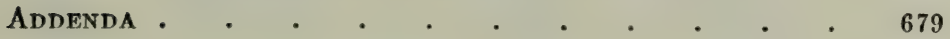

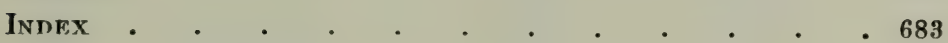

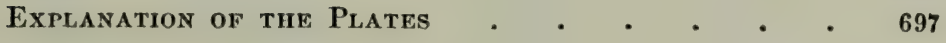




\section{SIGNS USED IN THIS WORK.}

(1) An annual plant.

(2) A biennial plant.

4 A perennial plant.

? A mark of doubt.

! A mark of affirmation or authentication.

These signs are, however, very rarely employed in this volume.

$1^{\circ}, 2^{\prime}, 3^{\prime \prime}$. To save space, the sign of degrees $\left(^{\circ}\right)$ is used for feet; of minutes ('), for inches; of seconds ('I), for lines, - the (English) line being the twelfth part of an inch.

The dash - between two figures, as " $5-10$," means from 5 to 10 , \&c. 


\section{PRINCIPAL ABBREVIATIONS}

OF THF NAMES OF AUTHORS CITED IN THIS VOLUME.

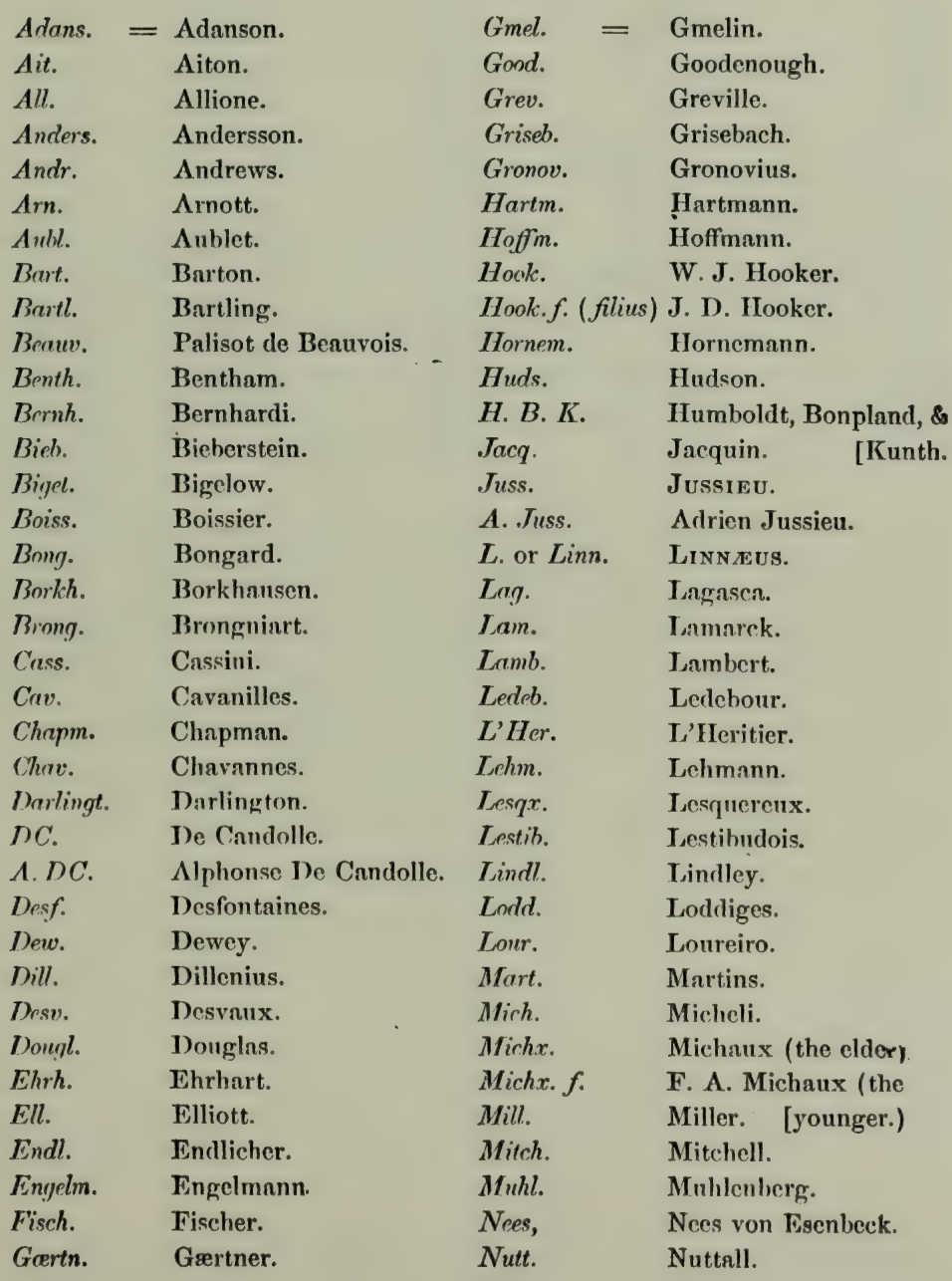




\begin{tabular}{|c|c|c|c|}
\hline $\begin{array}{l}\text { Puv. } \\
\text { Pers. }\end{array}$ & $\begin{array}{l}\text { Pavon. } \\
\text { P'ersoon. }\end{array}$ & $\begin{array}{l}\text { Steud. }= \\
\text { Sulliv. }\end{array}$ & $\begin{array}{l}\text { Steudel. } \\
\text { Sullivant. }\end{array}$ \\
\hline Pluk. & Plukenet. & T'hunb. & 'Thunberg. \\
\hline Plum. & Plumier. & Torr. & Torrey. \\
\hline Poir. & Poiret. & Torr. \& Gr. & Torrey and Gray \\
\hline R. $B r$. & Roнект Brown. & T'ourn. & Touruefort. \\
\hline liuf. & Rafinesque. & T'rautv. & 'T'rautvetter. \\
\hline lieichenb. & Reichenbach. & Tirev. & Treviranus. \\
\hline Rich. & Richard. & Trin. & Trinius. \\
\hline Richards. & Richardson. & Tuckerm. & Tuckerman. \\
\hline Ricm. & Ruemer. & Tuicz. & Turczaninow. \\
\hline Rottb. & Rottbüll. & Vaill. & Vaillant. \\
\hline Salisb. & Salisbury. & Vent. & Ventenat. \\
\hline Schk. & Sclikuhr. & Vill. & Villars. \\
\hline Schlecht. & Schlechtendal. & Wahl. & Wahlenberg. \\
\hline Schrad. & Schrader. & Walp. & Walpers. \\
\hline Schreb. & Schrcber. & Walt. & Walter. \\
\hline Scluult. & Schultes. & Wanyh. & Wangenheim. \\
\hline Schw. or Schwein. & Schwcinitz. & Wedd. & Weddell. \\
\hline Scop. & Scopoli. & Willd. & Willdenow. \\
\hline Ser. & Seringe. & With. & Withering. \\
\hline Soland. & Solander. & Wulf. & Wulfen. \\
\hline Spreng. & Sprengel. & Zucc. & Zuccarini. \\
\hline
\end{tabular}




\section{P REF A CE.}

This work is designed as a compendious Flora of the Northern portion of the United States, for the use of students and of practical botanists.

The first edition (published in 1848) was hastily prepared to supply a pressing want. Its plan, having been generally approved, has not been altered, although the work has been to a great extent twice rewritten, and the geographical range extended. The second edition, much altered, appeared in 1856 . The third and fourth were merely. revised upon the stereotype plates, and some pages added, especially to the latter.

The Garden Botany, an Introduction to a Knowledge of the Common Cultivated Plants, which was prefixed to this fourth edition in 1863 , is excluded from the present edition, and is to be incorporated into a simpler and more elementary work, but of wider scope, designed especially for school instruction, and for those interested in cultivation, - entitled Field, Forest, and Garden Botany.

In the present edition it has been found also expedient to remand to a supplementary volume the Mosses and Liverworts, so carefully and generously elaborated for the previous editions of this work by my friend, Wм. S. Sullivant, Esq. It is hoped that the Lichenes; if not all the other orders of the Lower Cryptogamia, may be added to this supplementary volume, so that our students may extend their studies into these more recondite and difficult departments of Botany.*

* The following important aids, moreover, are alrearly provided, viz. The Icones Musconum, or Figures and Descriptions of most of those Mosses peculiar to 
Six plates, illustrating the genera of the Cyperacea or Sedge Family, are now added to the eight which illustrate the Graminea or Grasses, and the six which illustrate the Filices or Ferns and their allies: all are from original drawings by Mr. Isaac Sprague; and they should render the study of these families comparatively easy, even to the beginner.

In other respects the changes in this edition are only in details, and such as the progress of botanical knowledge, and the longer experience of the author and his associates or correspondents in teaching, have scemed to render necessary or advisable.

I am newly indebted to Dr. George Engemane, of St. Louis, for a revision of the account of Cuscuta and Sagittaria, \&c., formerly prepared by him, and for the complete re-elaboration of the genera Callitriche, Euphorbia, Pinus, Juncus, and Isoetes. I have also to express my special ackuowledgments to my friends, Dr. J. W. Robins, of Uxbridge, Massachusetts, who contributed the whole article on the diflicult genus Potamogeton; - to Mr. Cos F. Austin, of Closter, New Jersey, who furnished that on the Lemuncea ; - and to Prof. Danicl Cady Eaton, of Yale College, who has entirely re-elaborated the Ferns for the present edition. The Sulicacere and the genus Carex, as is well known, were contributed to the first edition by my old friend and associate, Jonn Carer, Esq., now of London. Deprived of his further and important assistance, I have

Eastern North America which have not been heretofore figured, by War. S. SulliVANT, LL. D. Imp. 8vo, with 129 copper-plates.

Musci-Boreali-Americana, sive Specimina Exsiccata, etc. - A second and enlarged edition of the arranged collection of Mosses of the United States, published by Messrs. Sullivant and Lesquereux, of which the first issue was noticed in the preface to former editions of the Manual. The present edition comprises 536 species or varieties of Mosses, and is supplied by Mr. Leo Lesquereux, of Columbus, Olio, for $\$ 35$ in gold, or $£ 7$ sterling.

Eichenes Exsiccati, by Professur Edwand Trickerman, of Amherst College; - of which four vols. (small 4 to) have already been issued. A small volume on the Genera of North American Lichenes is now in preparation by the same author.

Nereis Borcali-Americana, - an account of the Marine Algae of the United States, by the late Professor WM. II. HaRver, a large quarto volume with fifty colored plates, - published by the Smithsonian Institution. 
myself revised these articles as well as $I$ could, in advance of the publication of Andersson's work on the Salicacea in the forthcoming volume of De Candolle's Prodromus, and of the posthumous volume of the late Dr. Boott's Illustrations of Carex. In the latter genus, however, I have been essentially aided by Willinм Bootт, Esq., of Boston, and S. T. Olney, Esq, of Providence, who have made the Carices a special study. To render due acknowledgments to the correspondents who have contributed to the value of the Manual by the communication of specimens, notes, and corrections, would require me to enumerate all the cultivators and numerous amateurs of botany in this country. In special instances their names will be found scattered throughout the pages of the work. The necessity of economizing space to the utmost, so as to keep the volume within the dimensions of a manual, alone has debarred me from fuller citations of the names of collectors and of particular stations of rare or local plants. For the same reason I have generally omitted synonymes, except in case of some original or recent changes in nomenclature.

There is abundant reason, I doubt not, for me to renew the request that those who use this book will kindly furnish information of all corrections or additions that may appear to be necessary, so that it may be made more accurate and complete hereafter, and maintain the high character which it has earned.

Some explanations are needful in respect to details of typography, reference, and arrangement.

Grographical Limitation, Distribution, \&c. As is stated on the title-page, this work is intended to comprise the plants which grow spontaneously in the United States north of North Carolina and Tennessee and east of the Mississippi. A Flora of the whole national domain, upon a similar plan (the issue of which I may now hope will not be delayed many years longer), would be much too bulky and expensive for the main purpose which this Manual fulfils. 
For its purpose, the present geographical limitation is, on the whole, the best, - especially since the botany of the States south of our district has been so well provided for by my friend Dr. Chapman's F'lora of the Southern States, issued by the same publishers. The southern boundary here adopted coincides better than any other geographical line with the natural division between the cooler-temperate and the warm-temperate vegetation of the United States; very few characteristically Southern plants occurring north of it, and those only on the low coast of Virginia, in the Dismal Swamp, \&c. Our western limit, also, while it includes a considerable prairie vegetation, excludes nearly all the plants peculiar to the great Western woodless plains, which approach our borders in Iowa and Missouri. Our northern boundary, being that of the United States, varies through about five degrees of latitude, and nearly embraces Canada proper on the east and on the west, so that nearly all the plants of Canada East on this side of the St. Lawrence, as well as those of the deep peninsula of Canada West, will be found in this volume.*

I have here endeavored to indicate, briefly and generally, the district in which each species occurs, or in which it most abounds, in the following manner: 1 . When the principal area of a species is southward rather than northward, I generally give first its northern limit, so far as known to me, if within the United States, and then its southern limit if within our boundaries, or add that it extends southward, meaning thereby that the species in question occurs in the States south of Virginia or Kentucky. Thus Magnolia glanca, p. 49, a prevailingly Southern species, but which is sparingly found as far north as Massachusetts, is recorded as growing "near Cape Ann and New York southward, near the coast"; M. acuminata, "W. New York to Ohio and southward," \&c. While in species of northern

* For the geographical statistics of our botany, see three articles in The American Journal of Science and Arts, Second Series, Vol. XXII. and Vol. XXIII. $1856-57$. 
range, the southern limits are mentioned; as Anemone Pennsylvanica, "W. New England to Illinois and northwestward." And so of Western plants; e. g. Isopyrum biternatum, p. 44, "Ohio to Illinois, Kentucky, and westward"; Amorpha canescens, p. 130, "Michigan to Wisconsin and southwestward." But this rule has not always been closely adhered to. 2. Where no habitat or range is mentioned, the species is supposed to be diffused over our whold area, or nearly so, and usually beyond it. 3. When the species is quite local or rare, the special habitat is given; e. g. Vesicaria Shortii, p. 73, and Alyssum Lescurii, p. 72 ; Sullivantia Ohionis, p. 169, \&c. Except in such cases, or when the known geographical range of a species has been recently extended, the want of space has generally demanded the omission of particular stations, which are so appropriately given in local Floras and in more detailed works, but for which there is no room in a manual like this.

For the same reason, I could not here undertake to specify the range of those species which extend beyond the geographical limits of this work, or beyond the United States. Nevertheless, to facilitate the comparison of our American flora with that of Europe, I have appended the mark (Eu.) to those species which are indigenous to both.

\section{Distinction between Introduced and Indigenous Spe-} cres. Foreign plants which have become denizens of the soil have to be described along with the genuine indigenous members of our flora; but the introduced species are distinguished by the specifio name being printed in a different type, namely, in small capitals, ${ }^{*}$ while the names of the indigenous species are in heavier, antique letter. $\dagger$ Moreover, the country from which they came is specified (mostly Europe), as well as the nature of the denizenship. That is, following the suggestions of M. Alphonse De Candolle, I have classified our introduced plants as well as I could into two sorts, the

* For example, under Ranunculus, R. Bulbosus, ACRis, \&c., p. 43.

$\dagger$ For example, R. repens, on the same page. 
thoroughly naturalized, and the adventive; the first comprising those species which have made themsetves perfectly at home in this country, propagating themselves freely by seed beyond the limits of cultivated grounds; the second, those which are only locally spontaneous, and perhaps precarious, or which are spontaneous only in cultivated fields, around dwellings, or in manured soil, and which, still directly or indirectly dependent upon civilized man, would probably soon disappear if he were to abandon the country. (I here rank with the adventive plants those weeds of cultivation which De Candolle terms plunts cultivated without or agaiust man's will.) Accordingly the species naturalized from Eurrope are indicated, at the close of the paragraph, by the phrase "(Nat. from Eu.)": those adventive, or less estublished, by the phrase "(Adv. from Eu.)," \&c.

Distinction or Cirade of Vameties. Vain is the attempt to draw an absolute liue between varieties and species. Yet in systematic works the distiuction has to be made absulute, and each particular form to be regarded as a species or a variety, according to the botanist's lest judgment. Varieties, too, exhibit all degrees of distinctness. Such as are marked and definite enough to require names are distinguished here into two sorts, according to their grade: 1. Those which, I think, cannot be doubted to be varieties of the species they are referred to, have the name printed in small capitab.* These varieties make part of the common paragraph. 2. Those so distinct and peculiar that they have been, or readily may be, taken for species, and are some of them not unlikely to establish the claim : of these the name is printed in the same type as that of the species; and they are allowed the distinction of a separate paragraph, $†$-except where the variety itself is the only form in the country, as in the first species of Anemone. $\ddagger$

* As, for instance, the thrue varieties of Lesjodeza violacea, p. 137, viz. DIVERcisis, sessilifolia, and anigotizolia. Sec ulso, under Ranunulus Flammula, var. INTERMedius, p. 41.

$\dagger$ As, Var. reptans, of the above-mentioned species.

\$. patens, I., var. Nuttalliana, p. 36. 
Accentuation of Names. As a guide to correct pronunciation of botanical names (in which great carelessness prevails), I have marked the accented syllable; and have also (following Loudon's convenient mode) indicated what is called the long sound of the vowel by the grave (') and the short sound by the acute (') accentmark.

Indication of Prominent Cinaracters is made by the use of Italic type, for the leading distinctions of the orders, and for those points in the specific descriptions hy which two or more species of the same division may be most readily or surely discriminated, the latter a plan adopted from Koch's Flora Germanica.

The ready discrimination of the genera is provided for by a Synopsis, in small type, of the leading characters of all the genera, when more than two, under each order. In this the genera are analytically disposed under their proper sub-orders, tribes, or other such natural groups, of whatever rank, properly characterized; and then, to save room, all these subordinal or tribal names and characters are left out of the body of the order, the genera following each other without a break.

Whenever a genus comprises several species, pains have been taken to render important differences conspicuous, and to abridge the labor of analysis, by proper grouping, and when needed by a series of rightly subordinated divisions and subdivisions. Divisions of the highest rank, or Subgenera, have the sectional mark (§) followed by the subgeneric name.* 'Those less important are indicated by the $\S$, without a name; subsections or divisions of lower grade are marked by stars (*); their divisions, if any, by the + , and theirs again by the + , \&c.

Having in view the needs of students rather than of learned botanists, I have throughout endearored to smooth the beginner's way by discarding many an unnecessary technical word or phrase, and

* As § 1. ATRAGENF, under Clematis, p. 35, and § 1. PULSATLLLA, under Anemone, p. 36. 
by casting the languagre somewhat in a vernacular mould, - perhaps at some sacrifice of brevity, but not, I trust, of the precision for which botanical language is distinguished.

Arrangement of the Orders. The Natural Orders are disposed in a serjes which nearly corresponds, in a geueral way, with De Candolle's arrangenent (varied somewhat more in this edition, to come nearer to that adopted thus far in Bentham and Ilooker's new Genera Plantarkm), beginning with the highest class and ending with the lowest; and commencing this first and far the largest clats (of Dicotyledonous or Exogenous Plants) with those order's in which the flowers are mostly provided with double floral envel. opes, viz. with both calyx and corolla, and in which the corolla consists of separate petals (the Polypetalous division); beginning this series with those orders in which the : everal organs of the flower are most distinct and separate (hypogynous), and proceeding to those which have the parts mo:t combined anong themselves and consolidated with each other (perigynous and epigynous); then follow those with the petals combined into a monopelalons corolla (the Monopetalous dirision; and finally, those destinte of a corolla or destitute of all floral envelopes (the Apetalous division). The class of Monocotyledonous or Endogenous Plunts opens with orders exhibiting one form of simplified flowers, passes to those with the organs most combined and consolidated, then to those less combined by adnation of parts, and closes with other simplificd and reduced forms. The present problem in Botany is to group the numerous Natural Orders in each class into natural alliances. But this has not yet been done in such a manner as to he available to the ordinary student. I do not here attempt, therefore, to group the orders naturally, but let them follow one another in what secins to be on the whole: a natural and inanageable sequence. And, by means of an artificial

Analytical Key to the Orokes (p. 21), I enable the student to refer readily to its proper order any of our plants, upon taking the pains to ascertuin the structure of its flowers, and sometimes of 
the fruit, and following out a series of easy steps in the analysis. This key is founded upon the most obvious distinctions which will well answer the purpose, and is so contrived as to provide for all the exceptional instances and variant cases I could think of. I shall be disappointed if the attentive student is not able by it to refer to its proper order any to him unknown plant of the Northern States of which he has flowering specimens in haud. Referring to the Order which the Key leads him to, the student will find its most distinctive points, - which he has chiefly to consider, - brought together and printed in italics in the first sentence of the ordinal description, and thus can verify his results.

The Synopsis which follows will then lead him to the genus, to be verified in turn by the full generic description in its place; and the progress thence to the species, when there are several to clioose from, is facilitated by the arrangement under divisions and subdivisions, as already explained.

It will be seen that the Key directs the inquirer to ascertain, first, the Class of the plant under consideration, - which, even without the seeds, is revealed at once by the plan of the stem, as seen in a cross-section, and usually by the veining of the leaves, and is commonly confirmed by the numerical plan of the flower; - then, if of the first class, the sub-class is at once determined by the pistil, whether of the ordinary kind, or an open scale bearing naked ovules. If the former, then the choice between the three divisions is determined by the presence or absence of the petals, and whether separate or united. Each division is subdivided by equally obvious characters, as, p. 21, first the number of stamens, then, whether the caly $x$ is free from or connected with the surface of the ovary. And, finally, a series of successively subordinated propositions, each set more indented upon the page than the preceding, leads to the name of the order sought for, followed by the number of the page upon which that order is described in the body of the work. 
More particular instructions for the use of this book in the study of our plants are lice superfluous; as these, as woll as the needful preliminary knowledge, will be acquired from the author's Introduction to Structural and Systematic Botany (Botanical Text-Book), or foom the simpler First Lessons in Botany, - one or the uther of which must needs be previously studied, and be the inseparable companion of The Munuch. 


\section{A N A L YTIC A L K E Y}

TO TIIF ORDERS OF ALL THE PLANTS DESCRIBED IN THIS WORK.

Serres I. PIIANOGAMOUS on FLOWERING PLANTS, those producing real flowers and seeds.

\section{Class I. DICOTYLEDONOUS on EXOGENOUS PLANTS.}

Stems formed of bark, wood, and pith; the wood forming a zone between the other two, and increasing, when the stem continues from year to year, by the annual addition of a new layer to the outside, next the bark. Leaves netted-veined. Embryo with a pair of opposite cotylerlons, or in Subclass II. often three or more in a whorl. Parts of the flower mostly in fours or fives.

Subclass I. ANGIOSPERMA. Pistil consisting of a closed ovary which contains the ovules and the seeds.

Jivision I. POLYPETALOUS: the calyx and corolla both present; the latter of separate petals.

A. Stamens numerous, at least more than 10, and more than twice the sepals.

1. Calyx entirely free and separute from the pistil or pistils.

Pistils numerous but cohcring over each other in a solid mass on an elongated receptacle. . . . MAgnoliaced, 48

Pistils numerous, scparate, but concealed in a hollow receptacle.

Leaves opposite, entire: no stipules. . . . . Calycantirace 162

Leaves alternate, with stipules. . . . . Rosa, in Rosaces, 146

Pistils several, immersed in hollows of the upper surface

of a large top-shaped receptacle. Nelumbium, in NYMPH雨e 54

Pistils more than one, separate, not enclosed in the receptacle.

Stamens inserted on the calyx, distinct. . . . . RosıCE 2,146

Stamens united with the base of the petals, monadelphous. Malvacee, 98

Stamens inserted on the receptacle.

Filanents much shorter than the anther: trees. . . Anonace e, 50

Filaments longer than the anther.

Flowers dioecious: twincrs with alternate leaves. Menispermaces, 51

Flowers perfect: if elimbers, the leaves opposite.

Leaves not peltate: petals deciduous. . . . Ranunculdce 2,34

Leaves peltate : petals persistent. Brasenia, in NYMPHжACEA, 54 
Pistils several-lobed, the ovaries united below the midlle. Resedaces, 76 Pistils several, their ovaries cohering in a ring around an axis. Malvaces, 98 I'istils strictly one as to the ovary: the styles or stignas may be several.

leaves punctate under a lens with transparent dots. HYPkncacke, 83 Leaves not punctate with trausparent dots.

Ovary simple, l-celled, 2-ovuled. . . . . . Rosaces, 146 Ovary simple, l-celled, with one parietal many-ovuled placenta.

Leaves 2-3-ternately compound or dissected. RANunCULACE 2,34 Leaves peltate, simply lobed. Podophyllum, in Bкивекіраска, 52 Ovary compound, 1-celled, with a central placenta. Pontulacacke, 97 Ovary compound, 1-celled, with 2 or more parictal placente.

Calyx caducous. Juice milky or colored. . P Papaveraces, 58 Calyx deciduous, of 4 sepals. . . . . Capparidaces, 75 Calyx persistent, of 3 or 5 sepals. . . . . . Cistacek, 80 Ovary compound, several-eclled.

Calyx valvate in the bud, and

Persistent: stamens monadelphous : anthers 1-celled. Malvace Deciduous : anthers 2-celled. . . . . Tiliaced, 103 Calyx inbricated in the bud, persistent.

Shrubs: stamens borne on the base of the petals. Camellacese, 103 Aquatic or marsh herbs: ovules many,

On 5 placenta in the axis. . . . Sarraceniacede, 57

On the 8-24 partitions. . . . . Nrmpizaces, 54

2. Calyx more or less coherent with the surface of the (compound) ovary.

Ovary 10-30-celled : ovules many, on the partitions: aquatic. NrmpI Ovary 10-celled : cells 1-ovuled. . . . Amelanchier, in Rosackas, 146 Ovary 2-5-celled.

Leaves alternate, with stipules. . . . Pomere, in Rosaces, 146

Leaves opposite, without stipules. Philadelphus, in Saxifragacede, 163

Leaves alternate, without stipules. . . . . Strracace.e, 309

Ovary one-celled, with the ovules parietal.

Fleshy plants with no true foliage : petals many. - - CACtacex, 184

Rough-leaved plants : petals 5 or 10. . . . . IOASACEN, 184

Ovary one-celled, with the ovules rising from the base. Pontulacaces, 97

B. Stamens of the same number as the petals and opposite them.

Pistils 3-6, separate. Flowers diocious. Woody vines. Mnisperancede, 51 Pistil only ane.

Ovary one-eelled : anthers opening by uplifted valves. Bermeridaces, 52 Ovary one-celled : anthers not opening by uplifted valves.

Style and stigma one: ovules more than one.

Primulace 313

Style one: stigmas 3 : scpals 2 : ovules several. Portulacacea, 97

Styles 5: ovule und seed only one. . . . Plumbaginacke, 312

Ovary 2-4-eelled.

Calyx-lobes minute or obsolete : petals valvate. . . Vitaces, 112

Calyx 4-5-cleft, valvate in the bud: petals involute. Rinsмaces, 113 
C. Stamens not more than twice as many as the petals, when of just the number of the petuls then alternate with them.

1. Calyx free from the ovary, i. e. the ovary wholly superior.

* Ocaries 2 or more, separate.

Stamens united with each other and with a large and

thick stigma common to the two ovaries.

AsCreptadaces, 394

Stamens unconnected, on the receptacle, free from the calyx.

Leaves punctate with pellucid dots. . . . . . Rutrees, 109

Leaves not pellurid-punctale.

'Tree, with pinnate leaves. . . Ailanthus, in Srmarubacex, 110

Low shrub with pinnate leaves. Zanthorhiza, in RANuncumaces, 34

Herbs, not fleshy. . . . . . . . Ranunculacese, 34

Herbs, with thick fleshy leaves. . . . . Cnassulaces, 171

Stumens unconnected, inserted on the calyx,

Just twice as many as the pistils (flower symmetrical). Crassucacene, 171

Not just the number or twice the number of the pistils.

Leaves without stipules. . . . . . . SAxifragacex, 163

Leaves with stipules. . . . . . . . ROSACEA, 140

* Ovaries 2-5, somewhat united at the base, separate above.

Leaves punctate with pellucid dots. . . . . . RutACEx, 109

Leaves not pellucid-punctate.

Shrubs or trees with opposite leaves. . . . . SAPINDACBE, 116

Terrestrial herbs : the carpels fewer than the petals. SAxifuagAeE, 163

Oraries or lobes of ovary 3 to 5, with a common style. Geraniacex, 105 *** * Ovary only one, and

- Simple, with one parietal placenta. LEguminos. 123

$\leftarrow+$ Compound, as shown by the number of cells, placenta, styles, or stigmas.

Ovary onc-celled.

Corolla irregular: petals 4 : stamens 6. - . . Fumaricese, 60

Corolla irregular: petals and stamens 5. . . . VIOLACEA, 76

Corolla regular or nearly so.

Ovule solitary: shrubs or trees: stigmas 3 . ANac̀ndices, 111

Ovules solitary or few : herbs. . . Some anomalous Crucifers, 62

Ovules more than one, in the centre or bottom of the cell.

Petals not inserted on the calyx. . . . . CAr yopíyllacese, 87

Petals on the throat of $\boldsymbol{\Omega}$ bell-shapel or tubular calyx. LyтнRaces, 182

Ovules several or many, on two or more parietal placenta.

Leaves punctate with pellucid and dark dots. HYPericnces, 83

Leaves beset with reddish gland-tipped hristles. DroserAcese, 82

Leaves neither punctate nor bristly-glandular.

Sepals 5, very unequal or only 3. . . . Crstaces, 80

Sepals and petals 4 : stamens $6 . \quad$ Anomalous Cruciferde, 62

Sepals and petals 5 : stamens 5 or 10.

Ovary and stamens raised on a stalk. . PAssiflonacen, 185

Ovary sessile. $\quad$ - . . . . . SAxifragacen, 163 
Ovary 2-several-elled.

Flowers irregular.

Anthers opening at the top,

Six or cight and 1-celled : ovary 2-celled. . . Polygalacex, 120

Ten and 2-celled : ovary 5-celled. . . Rhodora, in Ëicace 286 Anthers opening lengthwise.

Stamens 12 and petals 6 on the throat of a tubu-

lar inflated or gibbous calyx. Cuphea, in Lyturaces, 182

Stamens $5-8$ or 10 , and petals hypogynous, or nearly so.

Ovary 3-celled. . . . . . . . . Sapindace 2116

Ovary 5-celled. $\quad . \quad \cdot \quad$ Impatiens, \&e. in Geraniacede, 105

Flowers regular or nearly so.

Stamens neither just as many nor twice as many as petals,

'Triadlelphous : petals 5. $\quad$. $\quad . \quad$. $\quad . \quad$. HYPericacex, 83

Tetradynamous (or rarely only 2 or 4 ) : petals 4 :

pungent herbs. - . . . . . CRucifeke, 62

Distinet and fewer than the 4 petals. . . OLeacka, 400

Distinct and nore numcrous than the petals. . SAPIndaces, 116

Stamens just as many or twice as many as the petals.

Ovules and secels only 1 or 2 in cuch cell.

Herbs: flowers moncecious or difecious. EUPHORBIACEA, 430

Herbs: flowers perfect and symmetrical.

Cells of the ovary as many as the sepals, \&c. Geraniacese, 105

Cells of the ovary (divided) twice as many as

the styles, sepals, \&c. . . . . . Linacex, 104

Shrubs or trees.

Leaves 3-foliolate, pellucid-punctate. P'telea, in Rutaces, 109

Leaves palmately veined : fruit 2-winged. SAPINDACE 116

Leaves pinnately veined, simple, not punctate.

Calyx not minute: pod colored, dehiscent:

seeds enclosed in a pulpy aril.

Celastracene, 115

Calyx minute: fruit a berry-like drupe. Aquifoliaces, 305

Ovules (and usually sceds) several or many in each cell.

Stipules between the opposite and simple leaves. Elatinacea, 86

Stipules between the opposite and compound leaves

(but they are caducous). Staphylea, in SaPindacede, 116

Stipules none when the leaves are opposite.

Stamens 5, monadelphous in a 10-toothed tube

or cup : leaves simple, all radical.

Galacineat, 305

Stamens 10, monadelphous at the base. Leaf-

lets 3, inversely heart-shaped. Oxalis in Geraniacex, 105

Stamens distinct, free from the calyx.

Style 1, undiviled. . . . . . Enicaces, 286

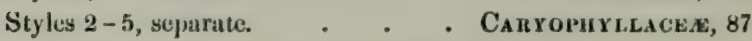

Stamens distinct, inserted on the calyx.

Styles 2 (or 3), or splitting into 2 in fruit. Saxifragaceer, 163

Style 1 : pod in the calyx, 1-celled at maturity. LYTHRACEx, 182 
2. Calyx-tube adherent to the ovary, at least to its lower half.

Tendril-bearing and often succulent herbs. . . . Cucurbitaces, 186

Not tendril-bearing.

Ovules and sceds more than one in each cell.

Ovary 1-celled, many-ovuled from the base. . . TORTUlacaces, 97

Ovary 1-celled, with 2 or 3 parietal placentæ. - SAxifragaCEA, 163

Ovary 2-several-celled.

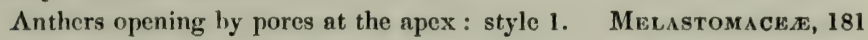

Anthers not opening by pores.

Stamens on a flat disk which covers the ovary. Cenastracese, 115

Stamens inserted on the calyx,

Eight or four (rarely five) : style 1. . . ONAGRACEe, 176

Five or ten : styles 2-3, distinct. . . SAxifragacen, 163

Ovulesand seeds only one in each cell.

Stamens 10 or 5 (instead of many), - rarely in Cratægus, in Ros ACE E, 146

Stamens 2 or 8 ; style 1 : stigma 2-4-lobed: herbs. Onagrace 176

Stamens 4 or 8 : aquatics: styles or sessile stigmas 4 . HALORAGEX, 174

Stamens 8 : styles 2 : shrub. . . . . Hamamelace 173

Stanens 4: style and stigma 1: chicfly shrubs. Cornacex, 199

Stamens 5 : flowers in unbels, or rarely in heads.

Fruit dry, splitting in two at maturity : styles 2. UMRELlfFere, 187

Fruit berry-like : styles 2-5, separate, or united. Araliaces, 198

Drvision II. MONOPETALOUS : calyx and corolla both present; the latter with its petals united more or less into one piece.

A. Stamens more numerous than the lobes of the corolla.

Ovary 1-celled with ono parietal placenta. . . . ILGUMinosA, 123

Ovary 1-celled, with 2 parictal placentæ. Adlumia, \&c. in Fumariacex, 60

Ovary 1-celled with the ovules at the centre or base. STrracaces, 309

Ovary 2-celled with a single ovule in each cell. . . Polygalaces, 120

Ovary 3-many-celled.

Stamens free or nearly free from the corolla: style single. Ericaces, 286

Stamens free from the corolla: styles 5. Oxalis, in Geraniace e, 105

Stamens inserted on the base or tube of the corolla.

Filaments monadelphous : anthers 1-celled, kidney-shaped. MaLvacn, 98

Filaments 1-5-adelphous at base : anthers 2-celled.

Calyx free from the ovary. . . . . CAmethices, 103

Calyx coherent with the ovary or with its base. . Styracaces, 309

Filaments wholly distinct : calyx free, persistent. . . Enenace 2,30 ?

B. Stamens (fertile ones) as many as the lobes of the corolla and onposite them.

Ovary 5-celled : corolla nppendaged with scales inside. SAPOtaces, 30*

Ovary 1-celled : pod several-many-seeded : style 1. . Primulacex, 313

Orary 1-celled: utricle 1-geeded : styles 5. . . Puumagraces, 312

(1) it - ? 
C. Stamens as many as the lobes of the corolla and alternate with them, or fewer.

1. Overy adherent to the callyx-lube (inferior).

Tendril-bearing herbs: anther's often united. . . Cucuristaces, 186 Tendrils none.

Stanens united by their anthers into a ring or tube.

Flowers in an involuerate heal. . . . .

Flowers separate, not involucrate: corolla irregular. LOßELACEA, 282

Stamens separate, free from the corolla or nearly so, as

many as its lobes: stipules none: juice milky. Campanulacea, 285

Stamens separate, inserted on the corolla.

Une to three, always fewer tham lobes of the corolla. Valerianacea, 213

Four or five: leaves opposite or whorled.

Flowers in a dense head, with an involucre: no stipules. Dipsacese, 215 Flowers if in heads not involucrate.

Leaves whorled und without stipules.

Leaves opposite or whorled, and with stipules.

RUBIACEA, 208

Leaves opposite without stipules (but some-

times with appendages to the petioles imitat-

ing them).

- Caprifoliaceis, 202

2. Ovary free from the calyx (superior).

* Corolla irreyuler : stamens (with anthers) 4 and didynamous, or only 2.

Ovules and seeds solitary in the $(1-4)$ cells.

Ovary 4-lobed, the style rising from between the lobes.

Ovary not lobed, the style from its apex. . . .

Ovules numerous or at least as many as 2 in each cell.

Ovary and pod l-celled,

With a free central placenta: stamens 2 : aquatics. Lentibulaces, 317

With 2 or more parictal very many-seeded placentæ :

stamens 4

. Оrobanchaces, 322

Ovary and fruit more or less 4-5-celled. Martynia,

Ovary and pod 2-eelled, but the 2 placentix parietal.

BIGNONIACEN, 320

Ovary and pod 2-celled: placenta in the axis.

Sceds rarely few, not on hooks, with albumen. Scropiulariaces, 324

Seeds few, borne on hook-like or other projections

of the placenta: no albumen. - . . Acantuaces, 338

* *orolla snmewhut irregular : stamens (with anthers) 5.

Stamens free from the corolla: anthers with their cells

opening by a liole or chink at the top. Azalea, in Ericaces, 286

Stanens inserted on the corolla.

Ovary deeply t-lubed around the style. Echim, in Bonmainaced, 360

Ovary not lobed : poil inany-secded.

Filaments or some of them woolly. Verbactum, Scropmeirartace.e, 32.t

Filaments not woolly. . . . . Hyoscyamus, Solinacea, 380 
* * Corolla regular.

+ Stamens as many as the lobes of the corollo.

Ovaries 2, aeparate; their

Styles and stigmas also wholly separnte. Dichondra, in Convolvulacex, 374

Stigmas and sometimes styles united into one.

Filuments distinct : pollen in ordinary grains.

A POCYNACE

Filaments monadelphous : pollen in masses. . - ASCleptadace 394 ()vary one, but deeply 4-lobed around the style.

Letves alternate. - Borraginace $\mathbf{3}, \mathbf{3 6 0}$

Leaves opposite. . . . . . . Mentha, in LАвІАт ж, 341

Ovary one: porl 2-lobed or 2-horned at the summit. . LOGANIACEA, 391 Ovary one, not divided nor decply lobed,

One-celled, with ovules parictal or on 2 parietal placentx.

Leaves (or in Menyanthes three leaflets) entire.

Gentianacex, 384

Leaves toothed, lobed or pinnately compound. HydrornyLlaces, 367

Two- to ten-celled.

Leafless parasitic twining plants. Cusenta, in Convouvulaces, 374

Leaves opposite, their bases or petioles connected

by stipules or a stipular line . . . . Log ANiace $x, 391$

Leaves when opposite without stipules.

Stamens frce from the corolla or nearly so : style 1. Ericacex, 286

Stamens almost free from the corolla: style nonc. Aquifolincese, 305

Stamens insertel on the tube of the corolla,

Four : pod 2-celled, circumcissile. - . Plantaginaces, 310

Four: ovary 2-4-celled: ovules solitary. . VERBenACEx, 339

Five or rarely more.

Fruit of two or four secd-like nutlets. . Bonraginacese, 360

Fruit a few-seeded pod.

Style 3-cleft : seeds small.

Style single or 2-cleft, or again 2-cleft: seeds

large, only one or two in a cell. . Convolvulacex, 374

Fruit a very many-seeded pod or herry.

Styles 2. - . . IIydrolea, in HYDROPHYLACE 367

Style single. . . . . . . . SolanaCefa, 380

++ Stamens fewer than the lobes of the corolla.

Stamens 4, didynamous.

Ovary 2-celled; the cells scveral-sceded. . . . ACANturace $\mathbb{E}, 338$

Ovary 2-4-celled; the cells 1-secded. . . . Verisenace. 339

Stamens only 2 with anthers : ovary 4-lobed. . Lycopus, in Labrate, 342

Stamens 2, rarely 3 : ovary 2 -celled.

Low herbs: corolla scarions, withering on the pod. PLantaginacese, 310

llerbs: corolla rotate, or somewhat funnelform, and

slightly irregular . . . Veronica, in Scrorirulariace $x, 324$

Shrubs or trees : corolla perfectly regular. . . . . OLEACEN, 400 
Divrsion III. APETALOUS: corolla (and sometimes calyx) wanting.

A. Flowers not in catkins.

1. Ovary or its cells containing many ovules.

Ovary and pod inferior (i. e. calyx-tube adherent to the ovary),

Six-celled : stamens 6-12. . . . . Anistolochinces, 403

Four-celled : stamens 4. . . . . Ludwigia, in Onagraces, 176

One-celled, with parietal placentiv. Chrysusplenium, in Saxifragaces, 163 Ovary and pod wholly naked (there being no calyx),

Two-celled, 2-beaked : flowers capitate: tree. . . HАмamelacede, 173

Two-celled, many-ribbed : aquatic herb. . . Podostemaces, 429 Ovary and pod superior, i. e. free from the calyx,

Five-celled and 5-beaked, opening across the beaks, which

fall off at maturity : stamens 10. Penthorum, in Crassulacese, 171

Three-5-celled, opening round the middle. Sesuvium, in Portulacacere, 97

Three-eelled and 3-valved. . . Mollugo, in Caryopirylacke, 87

Two-celled or one-celled : placenta central.

Stamens inserted on the throat or tube of the calyx. Lytriraces, 182

Stamens inserted on the receptacle or the base of the calyx,

Alternate with the 5 sepals. . . Glaux, in Primulacex, 313

Opposite the sepals when of the same number. Caryonirldacede, 87

One-celled, with one parictal placenta.

Ovaries 2 or more, separate, simple. $\}$. . : Ranunculaceas, 34

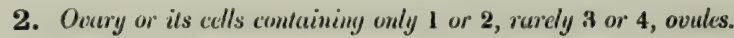

* Pistils more than one, and distinct or ncarly so.

Stamens inserted on the calyx. Leaves with stipules. . . Rosacks, 146 Stamens inserted on the receptacle.

Leaves punctate with pellucid dots. . Zanthoxylum, in Rutace.s, 109 Leaves not dottud.

Calyx present, and ustally colored or petal-like. Ranunculace 2,34

Calyx absent. Flowers entirely naked, perfect, spiked. Saururacede, 427

* Pistil one, either simple or compound.

Ovary partly inferior, the ealyx colerent to its lower half,

2-eelled: styles 2 : stamens many. . . . Hamamelacex, 173

Ovary wholly inferior (in perfect or pistillate flowers).

Aquatic herbs: ovary 3-4 celled, or (Hippuris) 1-celled. Haloragee, 174 Woody plants : style or stigma one, entire : ovary 1-celled.

Stigma rumning down one side of the style. Nyssa, in Cornaces, 199

Stigma terminal, with or without a style.

Parasitic on the branches of trees : anther's sessile. Tonanthace.e, 426

Not parasitic above ground: anthers on tilameuts. "Santalacea, 425 
Ovary renlly free from the calyx, but permanently invested by its tube, or the base of it, so as to scem inferior.

Shrubs, with scurfy leaves: flowers mostly diœcious. ELAEANACEX, 424 Herbs: with the calyx colored like a corolla.

Leaves opposite, simple. . . . . . Nrctaginace 2,404

Leaves alternate, pinnate. . . . . Poterium, in Rosacese, 146

Ovary plainly free from the calyx, which is sometimes wanting.

Stipules (ochrex) sheathing the stem at the nodes.

Tree: the calyx none: flowers monocious, in heads. PLATANacex, 446

IIerbs: the calyx present and commonly petal-like. PoLxGonacese, 414

Stipules not sheathing the stem, or none.

Aquatic herbs, submersed or nearly so.

Leaves whorled and dissected: style single. Ceratopirtuace 427

Leaves opposite, entire : styles 2 : ovary 4-celled. CALLITricinCEA, 427 Not aquatics, herbs.

Ovary 10-celled: berry 10-seeded. . . . PIIytolacCACEe, 405 Ovary 3- (rarely 1-2-) celled : juice usually milky. EUPHORBiace 4,430 Ovary one-celled : juice not milky.

Style, if any, and stigma only one: leaves simple:

no scarious bracts around the flowers. . . URTICACE 1 , 44C

Style or stigmas 2 or 3 : embryo coiled or curved.

Stipules not scarious; leaves palmately cleft or

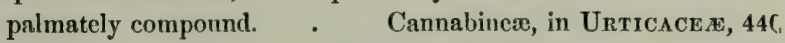
Stipules scarious. - . Illecebrex, in Caryophy illacede, 8 -

Stipules and scarious bracts none: strmens inserted high up on the tube of the calyx. Scleranthus, in CAnYopHy LuACFe, 87

- Stipules none : but flowers with scarious bracts. AMARANTACEA, 411 Shrubs or trees.

Stipules and scarious bracts none . . Cinnopobiacede, 405

Ovules a pair in each cell of the ovary.

Fruit 2-celled, a double samara. Accrinex, in SAPindace 116

Fruit a 1-celled and 1-seeded samara or a drupe. Olencese, 406

Ovules single in each cell of the

Three-nine-celled ovary : leaves heath-like. . EMPEtrace 2,440

Three-celled ovary : leaves broad. . . . RHAMnACEAc, 113

One-two-celled ovary : styles or stigmas 2-cleft. URTICACEA, 440

One-celled ovary : style and stigma single and entire.

Anthers opening longitudinally . . . Thymeleaces, 424

Anthers̄ opening by uplifted valves. . . . LA URACEאE, 422

B. Flowers (monocious or diocious) one or both sorts in catkins.

1. Only one sort of flowers in catkins or catkin-like heads.

Fertile flowers in a short catkin, head, or strohile. . . Untics CEx, 440 Fertile flowers single or clustered : sterile ones in slencler eatkins.

Leaves pinnate: fertile flowers and fruit naked. . JUG IANDACEA, 447

Leaves simple: fertile flowers -3 in an involucre or cup. Cupulifers, 449 
2. Both sterile and fertile flowers in cutkins or catkin-like heads.

Ovary and pod 2-celled, many-seeded. Tiquidambar, in Hamamelaces, 173 Ovary and pod 1-celled, many-seceled; seeds furnished with

a downy tuft at one end. . . . . . . SAlicaces, 461

Ovary 1 -2-celled, only one ovule in each cell : fruit 1-seeded.

Parasitic on trees : fruit a bery. . . . . Lorantuacex, 426

Trees or shrubs, not parisitic.

Calyx regular, in the fertile flower succulent in fruit. Untraces, 440

Calyx none, or rudimentary and scale-like.

Style and stigura one, simple : the flowers in heads. Platanacede, 446 Styles or long stigmas 2.

Fertile flowers 2 or 3 under each scale of the catkin. Betulace e, 458 Fertile flowers single under each scale: nutlets

naked, waxy-coated or drupe-like. . . . MYricdCEA, 457

Fertile flowers in pairs at each scale, each in a mem-

branous sac or with leafy bractlets. Carpinea, in Cupulifere, 449

Subclass II. GYMNOSPERMA. Pistil an open scale or altered leaf, bearing naked ovules on its margin or its upper surface, or in 'T'axus entirely wanting. I'lowers monocious or dicecious.

Represented in the Northern United States only by the order Conifens, 468

\section{Class II. MONOCOTYLEDONOUS or ENDOGENOUS PLANTS.}

Stems with the wood collected into separate bundles or threads, "rkich are irregularly dispersed throughout the whole diameter, leaving no distinct pith in the centre; not forming annual layers. (A transverse slice of the stem therefore exhibits the woody threads as dots scattered throughout the cellular tissue.) Leaves mostly parallel-veined (occasionally more or less reticulated). Embryo with a single cotyledon, and the first leaves in germination alternate. Parts of the flower generally in threes, never in fives.

A. Spadiceons Division. Flowers aggregated on a spadix or fleshy axis, or - sometimes scattered, destitute of calyx and corolla (excepling some Aracese and Naiadaces, where, however, they are on a spadix), and also without glumes (husky scules). Leares sometimes with nettal veins.

Little floating ayuatics, with no distinction of stem and foliage. Lennacex, 478 Immersed aquatics, branching and leafy. . . . . NA1DACE $x, 482$

Reed-like or Flag-like marsh herbs, with linear and sessile nerved leaves : flowers in spikes or heads.

Flowers moncecions, and quite destitute of thoral envelopes. Trphace 4,480

Flowers perfect, on al lateral spadix : sepals 6. Acorus, )

Terrestrial or mursh plants : leaves mostly with a distinct netted-veined blade, petioled.

ARACEA, 475 
B. Petalomeous Division. Flowers not collected on a spadix, furnished with floral envelopes (perianth) answering to calyx or to both calyx and corolla, either herbaceous or colored and petal-like.

1. Perianth adherent to the whole surface of the ovary.

Flowers diœcious or polygamous, regular.

Aquatics: ovules and seeds several or numcrous. HY drocunidide $x, 494$

Twiners : ovules and seeds one or two in each cell. DrosconenCE

Flowers perfect : ovules and seeds usually numerous.

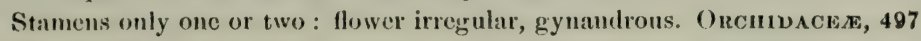
Stamens three.

Anthers introrse, opening transversely. . . BURmanniaCE. 496

Anthers introrse or versatile, opening lengthwise. Hemodorace 1514

Anthers extrorse, opening lengthwise. - . . . IRIDACEe, 515

Stamens 6 : flowers usually on a scape from a bulb. Amaryllidaede, 512

2. Perianth adherent only to the base or lower half of the ovary.

Perianth woolly or roughish-mealy : the leaves equitant. HAmonoraces, 514

Perianth smooth : the leaves grass-like. Stenanthium, \&c., in LiLiacex, 520

3. Perianth wholly, fire from the ovary.

Pistils numerous or fow in a heal or ring. . . . Alsmace e, 490

Pistil one : anthers 1-celled : flowers dioecious. Tendril-bearing. SMILACEA, 518 Pistil one, compound (cells or placenta mostly 3 ) : anthers 2-celled.

Perianth not glumaceous or chaffy : flowers not in dense heads.

Stamens 6 (in one Smilacina 4), similar and perfect.

Scurfy-leaved epiphyte : sceds hairy-tufted. . . Bromelacex, 515

Rush-like marsh-herbs : carpels separating closed from the axis : seed without albumen. Triglochin, in $\Lambda_{\text {LISMACE }} \mathbf{L}, 490$

Terrestrial, not rush-like: seeds with albumen.

Perianth of similar divisions or lobes, mostly colored.

Perianth of 3 foliaccous and green sepals and 3 col- $\}$ LiLincese, 520 ored withering.persistent petals. Trillium in

Perianth of 3 persistent green sepals, and 3 ephemeral deliquescent petals . . . . . COMmeLYNACE 25,546

Stamens 6, dissimilar, or only three with perfect anthers.

Perianth of 3 herbaccous sepals and 3 unequal and ephemeral petals. . . . . Commelynacese, 546

Perianth tubular, 6-lobed. . . . . . Pontederinces, 544

Stamens 3, similar. Moss-like aquatic. Mayaca, under Xrridice 547

Perianth wholly glumaccous, of 6 similar divisions. Rushes. JunCACEA, 536

Perianth partly glumaceous or chaff-like: flowers in very

dense heads. Rush-like or aquatic.

Flowers perfect : inner perianth of three yellow petals : perfect stamens and plumose sterile filaments each

3: pod 1 - celled, many-seeded on 3 parictal placenta. X y rub ACE 5,547

Flowers monocious or dicecious, whitish-bearded : sta-

mens 4 or 3 : pod 2-3-celled, 2-3-sceled. Eriocaulonaces, 549 
C. Glumiceous Division. Flowers destitute of any proper perianth, except sometimes smull scales or bristles, but covered by glumes, i. e. husk-like or scalelike bracts.

Glume a single scalc-like bract with a flower in its uxil. . Crperacede, 550 Glumes in pairs, of two sorts. $. \quad . \quad . \quad . \quad . \quad$ Graminea, 602

\section{Series II. CRYPTOGAMOUS or FLOWERLESS PLANTS:} those destitute of stamens and pistils, in fructification producing spores instead of seeds.

\section{Class III. ACROGENOUS PLANTS.}

Plants with a stem containing woody tissue and vessels, as does the foliage when there is any (in the form of veins).

Fructification of several spore-cases borne on the under side of the shield-shaped stalked seales of a terminal spike or cone. Leaves none, except a whorl of teeth at each joint of tho stem.

Equisetacean, 653

Fructification borne on the leaves (fronds), commonly on their backs or margins. . . .

Fructification of spore-cases in the axil of simple leaves or bracts.

- Lycopodiacen, 672

Fructification on the branches or petioles. . . HYDropterides, 677 


\section{B O T A N Y}

OF IIE

\section{NORTHERN UNITED STATES.}

\section{SERIES I.}

\section{PHANÓGAMOUS OR FLOWERING PLANTS.}

Vegetables bearing proper flowers, that is, 'having stamens and pistils, and producing seeds, which contain an embryo.

CLASS I. DI COTYLÉDONOUS OR EXÓGENOUS PLANTS.

Stems formed of bark, wood, and pith; the wood forming a layer between the other two, increasing, when the stem continues from year to year, by the annual addition of a new layer to the outside, next the bark. Leaves nettedveined. Embryo with a pair of opposite cotyledons, or rarely several in a whorl. Flowers having their parts usually in fives or fours.

\section{SUBCLASS I. ANGIOSPÉRM A.}

Pistil consisting of a closed ovary, which contains the ovules and forms the fruit. Cotyledons only two. 


\section{Drvision I. POLYPÉTALOUS EXÓGLNOUS PLANTS.}

Floral envelopes consisting of both calyx and corolla; the petals not united with each other. (Several gencra or species belonging to Polypetalous Order's are destitute of petals.)

\section{Order 1. hanunculàcea. (Crowfoot Famley.)}

Iterbs or woody climbers, rurely undershrubs, with a colorless acrid juice, polypetalous, or apetaluess with the caly. ofien culored like a corolla, hyporgynons; the sepals, peluls, numerous stamens, and many or few (rurely single) pistils all distinct and unconnected. - Flowers regular or irregular. Sepals 3-15. Petals $3-15$, or wanting. Stamens indefinite, rarely few : anthers short. Fruits vither dry pods, or seed-like (achenia), or berries. Seeds anatropous (when solitary and suspended the rhaphe dorsal), with fleshy albunen and a minute embryo. - Stipules none. Leaves often dissected, their staths dilated at the base. (A large family, mostly of acrid plants, some of them acrid-narcotic poisons.)

\section{Syuopsis of the Genera.}

Tribe I. CLEMATIDEAE. Sepals valvate in the bud, or with the edges bent inwards, Petals none, or small. Achcuia numerous, tailed with the feathery or hairy styles. Seeds solitary, suspended. - Leaves all opposite.

1. Clematis. Climbing by the leaistalks, or erect herbs.

Tribe II. ANEMONEF. Sepals imbricuted in the bud. Petals none or very small and stamen-like. Achenia numerous or several. Seed solitary. - Stem-leaves often opposite or whorled, forming an involucre.

* Seed suspended. Sepals 4-20.

2. Anemone. Achenia numerous, in a head, pointed or tailed, not ribbed nor inflated. Involucre leaf-like and remote from the flower

3. Iepatica. Achenia several, not ribled. Involucre close to the flower, of 3 simple leavey, and resembling is calyx.

4. Thalictrum. Achenia 4-10, ribbed, grooved, or inflated. Involucre none, or leaflike, and remote from the flowers.

* Seed erect. Sepals 3-5, caducous.

5. Trautvetteria. Achenia inflated and 4-angled. Involucre none.

Tribe II. RANUNCULEA:. Sepals imbricatel in the bud. Petals evident, often with a scale or pore iuside. Achenia numerous Seed solitary.

6. Ranumeulus. Sepals not appendaged. Achenia in a head. Seed erect.

7. Mуо osurus. Sepals sporred at the base. Achenia in a long spike. Seed suspended.

Tribe IV. HELLEBORINEAS. Sepals imbricated in the bud, deciduous, rarely persistent, petal-like. Petals (uectaries of the early lotinists) tubular, irregular, or 2lippet, often wone. Pods (follicles) few, rarely siugle, few-several-seeded. - Leaves all alternate.

* Flower regular. Pods several-seeded. Merbs.

8. Isopyrum. Petals none (in our species). Poils fer. Leaves compound.

9. Caltha. Petals none. Pods several. Leaves kidney-shapel, undivided. 
10. Trolllus. Petals many, minute and stamen-like, hollowed near the base. Pods 8-15, sessile. Leaves palmately divided.

11. Coptis. Petals 5-6, small, hollowed at the apex. Pods 3-7, long-stalked. Sepals deciduous. Leaves trifolinlate.

12. Helleborus. Petals $8-10$, small, tubular, 2-lipped. Pods several, sessile. Sepals 5 , persistent, turning green with age.

13. Aquilegia. Petals 5, spur-shaped, longer than the 5 deciduous sepals. Pods 5

* Flower unsymmetrical and irregular. Pods several-seeded.

14. Delphinfum. Upper sepal spurred. Petals 4, of two forms; the upper pair with long spurs, enclosed in the spur of the calyx.

15. A conitum. Upper sepal hooded, covering the two long-clawed small petals.

* * Flower symmetrical. Pods ripening only one seed. Shrubby.

16. Zanthorhiza. Petals 5, small, 2-lobed, with claws. Stamens $5-10$. Flowers in drooping compound racemes.

Tribe V. CIMICIFUGEA. Sepals imbricated, falling off as the flower opens. Petals small and flat, or none. Pistils 1 -several. Fruit a 2 -several-seeded pod or berry. All the leaves alternate.

17. Hydrastis. Flower solitary. Pistils several in a head, becoming berries in fruit, 2 seeded. Leaves simple, lobed. Petals none.

18. Actren. Flowers in a single short raceme. Pistil single, forming a many-seeded berry. Icaves 2 - 3-ternately compound. Petals manifest, but small.

19. Cimicifuga. Flowers in long spiked racemes. Pistils $1-8$, in fruit forming dry and several-seeded pods. Leaves 2-3-ternately compound

\section{CLÉm A Tis, L. Virgin's-Bower.}

Sepals 4 , or rarely more, colored, the valvate margins turned inwards in the bud. Petals none, or small. Achenia numerous in a head, hearing the persistent styles ns naked, hairy, or plumose tails. P'erennial herbs or vines, mostly a little woody, and climbing by the bending or clasping of the leafstalks, rarely low and erect. Leaves opposite. (K $\lambda \eta \mu a r i s$, a name of J)ioscorides for a climbing plant with long and lithe branches.)

§ 1. ATR AGENE, L. Some of the outer filaments enlarged and gradually passing into small spatulate petals: peduncles bearing single large flowers : the thin sepals widely spreading.

1. C. verticillàris, DC. Woody-stemmed climber, almost glabrous; leaves trifoliolate, with slenderecommon and partial petioles; leaflets ovate or slightly heart-shaped, pointed, entire, or on sterile stems 1-3-toothed or lobed; flower bluish-purple, $2^{\prime}-3^{\prime}$ across ; tails of the fruit plumose. ( $\Lambda$ tragene Americana, Sims.) - Rocky places in mountainous districts, Maine and Western New England to Virginia, Wisconsin, and northwestward: rare. May. $-\mathbf{A}$ pair of leaves with a peduncle between them, developed in spring from each of the opposite buds, gives the appearance of a whorl, whence the specific name.

\$2. CLLM $A$ TIS proper. Petals ontively wanting.

* Peduncles benring single large notdling fowers: caly. leathery: anthers linear. + Stem low, erect and mostly simple: calyx silky outside, greenish.

2. C. ochroleùca, Ait. Leaves simple and entire, ovate or sometimes 3-lohed, almost sessile, silky beneath ; tails of the fruit very plumose. - Copses, Long Island, Staten Island (Dr. Allen), Pennsylvania, and Virginia : rare. May. 
+ +- Stems climbing: leaves pinnate: calyx (and foliage) glabrous or puberulent.

3. C. Vióna, L. (Leatuer-hower.) Calyx ovate and at length bellshaped; the purplish sepals very thick and leathery, tipped with short recurval points; the long tails of the fruit very plumose; leaflets $3-7$, ovate or oblong, sometimes slightly cordate, 2-3-lubed or entire; uppermost leaves often simple. - Rich soil, Pennsylvania, Ohio, and southward. May-Aug.

4. C. Pítcheri, Torr. \& Gray. Calyxbell-shaped; the dull purplish sequals with narrow and slightly margined recurved points; tails of the finit filijorm and bardy pubescent; leaflets 3-9, ovate or somewhat cordate, entire or 3-lobed, much reticulated; uppermost leaves often simple. - Illinois on the Mississippi, and southward. June.

5. C. cylindrica, Sims. Calyx cylindraceous below, the upper half of the bluish-purple scpals dilated and widely spreading, with broad and uavy thin margins; tails of the fruit silky; leaflets 5-9, thin, varying from oblong-ovato to lanceolate, entire or 3-5-parted. - Virginia near Norfolk, and southivard. May-Aug.

* * Flowers in panicled clusters, polygamo-dixcious : sepals thin : anthers oblong.

6. C. Virginiàna, I. (Comaron Vircin's-Bower.) Smooth; leaves bearing 3 ovate acute lcaflets, which are cut or lobed, and somewhat heart-shaped at the base; tails of the fruit plumose. - River-banks, \&c., common ; climbing over shrubs. July, Angust. - The axillary peduncles bear clusters of numerous white flowers (sepals obovate, spreading); the fertile succeeded in autumu by the conspicuous feathery tails of the fruit.

\section{A N EMÒNE, L. ANÉmone. WIND-Flower.}

Sepals few or many, petal-like. Petals none, or in No. 1 resembling abortivo stamens. Achenia pointed or tailed, flattened, not ribbed. Seed suspended.Perennial herbs with radical leaves; those of the stem 2 or 3 together, opposite or whorled, and forming an involucre remote from the flower. (Name from

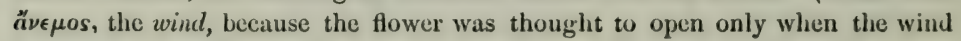
blows.)

§1. PULSATfLLA, Tourn. Carpels numerous in a head, with long and hairy styles which in fruit form feathery tails, as in Clematis: flower large, usually with some ylandular bodies like abortive stamens answering to petals, but minute or indistinct.

1. A. pàtens, L., var. Nuttalliàna. (Pasque-flower.) Villous with long silky hairs; flower ereet, developed before the leates; which are ternutely divided, the lateral divisions 2-parted, the middle one stalked and 3-parted, the segments deeply once or twice cleft into narrowly linear and acute lobes; lobes of the involucre like those of the leaves, at the base all united into a shallow cup; sepals $5-7$, pupplish or whitish $\left(1^{\prime}-1 \frac{1}{2} \prime\right.$ long), spreading when in full anthesis. (A. Nuttalliana, $D C$. Pulsatilla Nuttalliana, ed. 2. P. patens, var. Wolfgangiana, Trautv.) - Prairies, Illinois (Bebb), Wisconsin (Lapham), thence northward and westward. March-April. - A span high. Tail of carpels $2^{\prime}$ long. (Eu. Siberia.) 
§ 2. Carpels very numerous in a dense head, tipped with short and nearly naked styles, thickly clothed with very lony and matted wool when ripe.

* Low or slender plants, somewhat pubescent, always simple-stemmed, with a mostly sessile 2-3-leaved involucre far below the flower.

2. A. Caroliniana, Walt. (Canolina Anemone.) Stem $3^{\prime}-6^{\prime}$ high from a round tuber; root-lcaves once or twice 3-parted or cleft; involucre 3parted, its wedge-shaped divisions 3-eleft; sepals 10-20, oblong-linear, purple or whitish; heal of fruit oblong. - Illinois (O. Everett, J. W. Jowell, M. S. Bebb, E. IIall, T.J. IIale, \&c.) and southward. May. $\Lambda_{\text {pparently passes into the }}$ South American A. decapetala.

3. A. parviflora, Michx. (Small-flowerev A.) Stem $3^{\prime}-12^{\prime}$ high from a slender rootstock ; root-leaves 3 -parted, their broadly wedge-shaped divisions crenate-incised or lobed; involucre 2-3-leaved; sepals 5 or 6, oval, white; head of fruit globular. - Lake Supcrior, northward and westward. May, June.

*. Taller, commonly branching above or producing two or more peduncles: sepals $5-8$, silky or downy beneath $\left(4^{\prime \prime}-6^{\prime \prime}\right.$ long), oval or oblong.

4. A. multífida, DC. (MANy-Cleft A.) Silky-hairy $\left(6^{\prime}-12^{\prime}\right.$ high); principal involucre 2-3-leaved, bearing one naked and one or two 2-leaved peduncles; leaves of the involucre short-petioled, similar to the root-leaves, twice or thrice 3-parted and cleft, their divisions linear; sepals 5-8, obtuse, red, sometimes greenish-yellow or whitish ; head of fruit spherical or oval. - Rocks, Western Vermont and Northern New York, Lake Superior, \&c. : rare. June.

5. A. cylíndrica, Gray. (Long-fruited A.) Slender ( $2^{\circ}$ high), clothed with silky hairs; flowers 2-6, on very long and upright naked peduncles; leaves of the inevoluere long-petioled, twice or thrice as many as the flowerstalks, 3-divided; their divisions wedge-shaped, the lateral 2-parted, the middle one 3-cleft; lobes cut and toothed at the apex; sepals 5, rather obtuse, greenishwhite; head of fruit cylindrical (1' long). - Sandy. or dry woods, Massachusetts and Rhode Island to Illinois and northwestward. May. - Peduncles $7^{\prime}-12^{\prime}$ long, all appearing together from the same involucre, and naked throughout, or sometimes part of them with involucels, as in the next.

6. A. Virginiàna, L. (VIRGinian A.) Hairy; principal involucre 3leaved; the leaves long-petioled, 3-parted; their divisions ovatr-lanceolate, pointed, cut-serrate, the lateral 2-parted, the middle 3-cleft; peduncles clongated, the earliest naked, the others with a 2-lcaved involucel at the middle; sepals 5, acute, greenish (in one varicty white and obtuse); head of fruit oval or oblong. - Woods and meadows; common. June-August. - Plant $2^{\circ}-3^{\circ}$ high; the upright peduncles $6^{\prime}-12^{\prime}$ long. In this and the next species the first flowerstalk is leafless; but from the same involucre soon proceed one or two lateral ones, which are 2-leaved at the middle; these partial involucres in turn giving rise to similar peduncles, thus producing a succession of flowers through the summer.

§ 3. Carpels fewer, the achenia and the short slender styles mercly pubescent.

7. A. Pennsylvánica, L. (Pennsyuvanina A.) Hairy, rather low; imvolucres sessile; the primary ones 3-leaved, bearing a naked peduncle, and soon a pair of branches or peduncles with a 2-leaved involucre at the middle, which branch similarly in turn; their leaves broadly wedge-shaped, 3-cleft, cut and 
toothed; radical leaves 5-7-parted or cleft; sepals 5, obovate, white $\left(6^{n}-9^{n}\right.$ long); head of fruit spherical; the carpels flat, orlbicular. - W. New England to Illinois and northwestward. Junc-Aug.

8. A. nemorosa, L. (Wind-reuwer. Woon A.) Low, smoothish; sten perfictly simple, from a filiform rootstock, slender, leafless, except the involucie of 3 long-petivled trifoliolate leares, their leatlets wedge-shaped or oblong, und toothed or cut, or the litcral ones (var. Qtireverolia) 2-parted; a similar radicall leaf in sterile plants solitary from the rootstock; peduncle not longer than the involucre: sepals $4-7$, oval, white, sometimes tinged with purple outside; carpels only 15-20, oblong, with a hooked beak. - Margin of woods. April, May. - A delicate verual species; the flower l' broad. (Eu.)

\section{H F Pá TI C A, Dill. Liveli-leak. Heitica.}

Involuere simple and 3-leaved, very close to the Hower, so as to resemble a calyx; otherwise as in Anemone (of which this genus should strictly be vicwed as only a section). - Leaves all radical, heart-shalped and 3-lobed, thickish and persistent through the winter, the new ones appearing later than the fluwers, which are single, on hairy scapes. (Name firom a fancied resemblance to the liver in the shape of the leaves.)

1. H. tríloba, Chaix. (Round-Loned Hepatica.) Leaves with 3 ovate obtuse or rounded lohes; those of the involucre also obtuse. - Woods ; common eastward; flowering soon after the snow leaves the groumd in spring. Sepals 6-9, blue, purplish, or nearly white. Achenia several, in a small loose head, ovate-oblong, pointed, hairy. (Eu.)

2. H. acutíloba, J)C. (Silarp-Lomid Hepatica.) Leaves with 3 ovate and pointed lobes, or sometimes 5-lobed; those of the involucre acute or acutish. - Woods, Vermont and New York to Wisconsin. Sepals 7-12, pale purple, pink, or nearly white. Perhaps runs into the other.

\section{THA LÍ T T U M, Tourn. Meadow-Rue.}

Sepals 4 or more, petal-like or greenish. Petals none. Achenia 4-15, grooved or ribbed, or else inllated. Seed suspended. - Perennials, with 2-3ternately compound leaves, the divisions and the leaflets stalked. Flowers in corymbs or panicles, often polygamous or dicecions. (1)erivation obscure.)

§1. SYNI)ÉSMON, Iloffin. Between Thalictrum and Anemone, having all its stem-lcaves in the form of an incolucie at the top, and the stamens shorter than the 5-10 white and conspicuous stpuls; but the stigma depressid-truncute, and

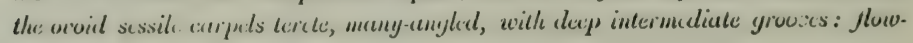
er's perfect.

1. T. anemonoides, Mirlix. (Riv-Anestone.) Glabrous; stem and slender petiole of ratical late (a span high) rising from a cluster of thickened tuberous roots; the latter 2-3-ternately componml; leatlets romolish, somewhat 3-lobed at the end, cordate at the base, long-petiolulate, those of the 2 -3-leaved 1 - 2-ternate involucre similar; flowers several in an umbel ; sepals oval ( $\frac{1}{2}$ long, rarcly pinkish) not carly deciduous. - Woods, common, flowering in early 
spring, along with and considernbly resembling $\Lambda$ nemone nemorosa. Rarely the sepals are 3 -lobed like the leaflets.

§ 2. Leaves alternate along the stem: no involuere: ronts filmous: flowers comparatively small and numerous, panicled: seperls 4 or 5, usually, falling early.

* Flowers dicrious or sometimes polygumous, in ample pumicles: filaments slender: stigmas elongated, linear or subulute, mostly unilateral: achenia sessile or shortstipitate, ovoid, pointed, strongly several-angled and grooved.

2. T. dioleum, I. (EARLy Mesnow-Ruv.) Smooth and pale or glancous, $1^{\circ}-2^{\circ}$ high; leaves all with general petioles; leaflets dimping, rounded and 3-7-lobed; flowers purplish and greenish; the yellowish anthers linear, mucronate, drooping on fine capillary filaments. - Rocky woods, \&c.; common. April, May.

3. T. purpuráscens, L. (Perpusn M.) Taller $\left(2^{\circ}-4^{\circ}\right.$ high, the stem usually purplish); sten-lenves sessile (without general petiole) or nearly so; leaflets roundish or oblong and more or less 3-lobed, thickish, pale and usually minutely pubescent beneath, the margin mostly revolute and the veining conspicuous; panicles compound ; flowers (sepals, filaments, \&c.) greenish and purplish; anthers linear or oblong-linear, mueronulate, drooping on capillury filaments which are manifestly broadened at the summit. ('T. Virginiumum elatius, \&c., Moris. T. rugìsum, Ait.? T. puhéscens, Pursh. 'T. revolìtum, DC.) I)ry uplands and rocky hills, S. New England to Michigan, Illinois and south. ward. May, June. - Sometimes nearly glabrous thronghout, often minutely pubescent, and in

Var. cerfferum, C. F. Austin, mss., with the lower surface of the leaves, scpals, and mostly the fruit thickly beset with waxy atoms. Plant often growing with the other, and exhaling a peculiar odor.

4. T. Cornuti, L. ('TALL M.) Smooth or obscurely pubeseent, $4^{\circ}-8^{\circ}$ high; stem-leaves sessile; leaflets nearly as in the last, but usually thinner and less revolute and veiny and the lobes more acute; panicles very compound; fowers white, the fertile ones with some stamens; anthers not drooping, small, oblong, blunt, the white filaments decidedly thickened upwards. ('T. rugosum, $F^{3}$ ursh., ICC. T. corynéllum, DC.) - Wet meadows and aloug rivulets, common, especially castward. July-Sept.

* * Flowers all perfect, corymbed; the filaments strongly club-shaped or inflated under the small and short anther: stigme short and unilateral: achenia long-stipitate.

5. T. clavatum, DC. Size and appearance of No. 2, but leaves only twice ternate; flowers white and fewer; achenia 5-10, flat, somewhat crescentsliaped, tapering into the slender stipe. - Mountains of S. Virginia and southward. June.

\section{TRAUTVETtìria, Fischer \& Meyer. False Bugbane.}

Sepals 3-5, usually 4, concave, petal-like, very caducous. Petals none. Achenia numerous, in a head, membranaceous, compressed-4-angled and inflated. Seed erect. $-\Lambda$ perennial herb, with palmately-lobed leaves, all alternate, and corymbose white flowers. (Dedicated to Prof. Trautvetter, a Russian botanist.) 
1. T. palmàta, Fischer \& Meyer. (Cimicifuga palmata, Michx.) Woods, along streams, Virginia and Kentucky along the mountains: also sparingly in Ohio and Illinois. July, Aug. - Rout-leaves lange, 5-9-lobed; the lobes toothed and cut. Stems $2^{\circ}-3^{\circ}$ high.

\section{R A N Ú N C U L U S, L. Crowfoot. Butrencup.}

Sepals 5. Petals 5, flat, with a little pit or seale at the base inside. Achenia numerous, in a head, mostly flattened, pointed; the seed erect. - Anumals or perennials: stem-leaves alternate. Flowers solitary or somewhat corymbed, yellow, rarely white. (Sepals and petals rarely only 3, the latter often more than 5. Stamens occasionally few in number.) - (A Latin name for a little frog ; applied by Pliny to these plants, the aquatic species growing where frogs abound.)

§ 1. BA'TRA CHIUM, DC. - Petals with a spot or naked pit at the base, white, or only the claw yellow: achenia marginless, trunsversely wrinkled: aquatic perennials, with the immersed fuliuge repeutedly dissected (mostly by threes) into capillury divisions: peduncles 1-flowered.

1. R. divaricàtus, Schrink. (Stifr Watek-Cnowfoot.). Leaves all under water and sessile or nearly so, the divisions and subdivisions short, spreading in one roundish plane, rigid, keeping the i, form without collapsing when withdrawn fiom the wuter. (R. circinàtus, Silthorp.) - Ponds and slow streans, northward and westward, nuch rarer than the next. June-Aug. (Eu.)

2. R. aquátilis, L., var. trichophýllus, Chaix. (Common Wurte Waten-Chowroot.) leaves all under water and mostly petioled, their capillary divisions and subdivisions ruther long and soft, usually collapsing more or less when withdiawn fiom the water. - Common, especially in slow-flowing waters. June-Aug. (Eu.)

Var. heterophýllus, DC. (Frosting W.) Uppermost leaves flouting, rounded and 3-5-lobed, the lobes wedye-shaped. (R. aquatilis, Bigel, ed. 3.) Roxbury and Newton, near Boston, Bigelow; but not met with for many years: was possibly introduced from Europe, where this form is common.

§ 2. IRANUNCULUS proper. Petals with a little scale at the base (ycllow).

* Achcnia smooth.

- Aquatic, perennial: immersed leaves filiformly dissecled, as in the preculing.

3. R. multífidus, P'ursh. (Yeisow Watrke-Crownoot.) Stema floating or immersed, with the leaves all repeatedly 3-forked into long filiform divisions, or sometimes ereeping in the mud, the emersed leaves with shorter and linear or wedge-shatped divisions, or else kidney-shajed and sparingly lobed ( $r$ toothed; flower deep bright yellow, $\frac{1}{2}-I^{\prime}$ in dianeter; petals $5-8$, much larger than the calyx ; carpels in a round head, pointed with a straight beak. (R. lacustris, Beck \&. Trucy, and R. I'urshii, Richards, both in the year 1823. R. Gmelini, $D C^{\prime} \cdot(1818)$ is an older name, belonging to a small northern form of the species; but R. multifidus, P'ursh, is the oldest, 1814, and apparently fiee for use.) E. New Lingland to S. Penn., Illinois, and nortiward. May - July. - Out of water it is often pubeseent, especially in 
Var. terréstris, which differs from the ordinary emersed forms by the stems ascending from the base and paniculately several-flowered at the summit, where the leaves are reducel to oblong or linear bracts; no immersed dissected leaves. - Ann Arbor, Michigan, on muddy banks, Miss Clark.

+ + Terrestrial but growing in very wet places, glabrous or nearly so: root perennial: leaves all entire or ixarely toothed, all or else all but the lowest lanceolate or linear; curpels forming a globular head. (SPEAnivont.)

4. R. alismæfollius, Geyer. (Whter Puntain Spennwont.) Stems hollow, ascending $\left(1^{\circ}-2^{\circ}\right.$ high $)$, often rooting from the lower joints; leaves lanceolate or the lowest oblong, mostly denticulate $\left(3^{\prime}-5^{\prime}\right.$ long $)$, contracted into a margined petiole which expands into a membranaceous clasping base; petals 5-7, bright yellow, much longer than the ealyx $\left(3^{\prime \prime}-4^{\prime \prime}\right.$ long); carpels fluttened, large, pointed with a long and straight narrow subulate beak. - Common, especially northward. June-Aug. - Intermediate in appearance between $\mathbf{R}$. Flammula and Lingua, and has been confounded with both, but most resembles the latter.

5. R. Flámmula, L. (Smatefr Spenrwort.) Stem reclining or ascending, rooting below; leaves lanccolate or linear, or the lowest oblonglanceolate, entire or nearly so, mostly petioled ( $1^{\prime}-2^{\prime}$ long); petals $5-7$, much longer than the caly $\mathrm{x}$, bright yellow ; carpels futtish but turgid, mucronate with a short abrupt point. - Shore of $\mathrm{L}$. Ontario and northward : rare, and only a small form (var. INTERMènuUs) met with in this country, a span high, with flowers $3^{\prime \prime}$ in diameter, passing into

Var. réptans. (Creeping S.) Small, slender, the fliform crerping stems rowing at all the joints $\left(3^{\prime}-6^{\prime}\right.$ long; leaves linear, spatulate, or oliongr. $\left(1^{\prime}-1^{\prime}\right.$ long).-Gravelly or sandy shores and inmulated banks; very common northward. June-Sept. (En.)

6. R. oblongifolius, Ell. Stem erect or ascending, often pubescent below, slender (10 high), diffusely branched above and mnny-flowered; leaves serrate or dinticulate; the lower long-petioled, ovate or oblong $\left(\frac{1}{2}^{\prime}-1 \frac{1}{2}^{\prime}\right.$ long $)$; the uppermost linear; flowers $3^{\prime \prime}-5^{\prime \prime}$ broad ; petals 5 , twice the longth of the calyx, bright yellow ; stamens numerous; carpels minute, almost glolular, tipped with a very small sessile stigma. (R. pusillus, var. Torr. \& Gr. Fl. R. Texensis, Engelm.) Wet prairies, Salem, Illinois, Behl, and in S. States. June.

7. R. pusíllus, Poir. Stem ascending, weak, loosely branching $\left(6^{\prime}-18^{\prime}\right.$ long) ; leares entire or olsscurely denticulate ; the lowest round-ovate or heartshaped ( $\frac{1^{\prime}}{2}$ long), long-petioled, the upper oblong or lanceolate $\left(1^{\prime}-1 \frac{1}{2}^{\prime}\right.$ long); flowers very smail; petals $\mathbf{1 - 5}$, yellowish, scarcely exceding the calyx and the 310 stamens; carpels very turgid, tipped with a minute sessile stigma. - Wet places, S. New York and southward along the coast. June- Ang.

+ + + Terrestrinl, with annual root, spronding by runners, glubous : leaves all rounded and undivided but conrsely crenute: carpels in fivit forming an oblong head.

8. R. Cymbalaria, Pursh. (Sra-Rinf Crowroor.) Flowering stems leafless $\left(3^{\prime}-6^{\prime}\right.$ high), 1-7-flowered; leaves clustered at the root and on the joints of the long rooting runners, roundish-heart-shaped or kidney-shaped, 
rather fleshy, long-petioled; petals 5-8; carpels striate on the sides. - Sandy shores, from New Jersey northward, and along the Great Lakes to Illinois and westward : also at salt springs. June-Aug.

++++ Terrestrial, but often in uet pluces: root perennial: some or all of the lanes cleft or divided.

+- Rioot-leaves not divided to the very base.

9. R. rhomboideus, Goldie. Dwarf; huiry; rool-leaves roundish or rhombic-ovute, rarely subcurdate, toothed or crenate; lovest stem-leaves similar or 3-5-lobed; the upper 3-5-parted, almost sessile, the lobes linear; carpels orbicular with a mimute teak, in a spherical head; petuls harge, exceeding the caly.x. (Also R. Brevicaulis \& ovalis, Ilook:) - P'rairies, Michigan to Illinois and northward. April, May. - Stems $3^{\prime}-6^{\prime}$ high, sometimes not louger than the root-leaves. Flower decp yellow, as large as in No. 14.

10. R. abortivus, L. (SMall-kloweked C.) Gilabrous and erry smooth; primary root-leaves round heart-shaped or hidney-form, barcly crenate, the suceecding ones often 3-Jobed or 3-parted; those of the stem and branches 3-5-parted or divided, subsessile; their divisions oblong or narrowly wedgeform, mostly toothed; carpels in a ylobular hend, mucronate with a minute curved, beak; petuls shorter than the reftexd calyx. - Shady hillsides and along brooks, common. April -June. - Stem erect, $6^{\prime}-2^{\circ}$ high, at length branched above, the pale yellow flowers very small in proportion.

Var. micránthus. Pubescent; root-leaves seldom at all heart-shaped, some of them 3-parted or 3-divided; divisions of the upper sten-leaves moro linear and entire; perluncles more slender. (R. micranthus, Nutt.) - Massachusetts (near Boston, C'. J. Syrague), Michigan, Illinois, and westward.

11. R. sceleràtus, L. (Cursed C.) Smooth and glabrous; root-leaves 3-labed, rounded; lover stem-leaves 3-parted, the lobes obtusely cut and toothed, the uppermost ahmost sessile, with the lobes oblong-linear and nearly entire; carpels barely mucronulule, very numerous, in oblony or cylindical heads; petals scurcely exceeding the calyx. - Wet ditches.: appeuring as if introduced. JuneAug. - Stem thick and hollow, $1^{\circ}$ high. Leaves thickish. Juice acrid and blistering. Flowers small, pale yellow. (Eu.)

12. R. recurvàtus, Poir. (Hоокер C.) Hirsute; leaves of the root and stem nearly alike, long-peliolid, dieply 3-cleft, large; the lobes broadly wedgeshaped, 2-3-cleft, cut and toothed towards the apex; caipels in a globular hend, flat and margined, conspicuously beaked by the long and recurved hooked styles; petals shorter than the reflcicd calyx, pale. - Woods, common. May, June. Stem $1^{\circ}-2^{\circ}$ high.

++ ++ All the leaves ternutcly divided to the very buse, or compound, and the divisions cleft or cut: acherict flat.

a. Ilcad of carpels oblong: petals pale, not exceeding the calyx.

13. R. Pennsylvánicus, I. (Bristly C.) Hirsute with rough spreading bristly lasirs; stem stout, erect; divisions of the leaves stalked, somewhat ovate, meequally 3-cleft, sharply eut and toothed, acute; carpels pointed with a sharp straight beak. - Wet places, common. June-Aug. A coarse plant, $2^{\circ}-3^{\circ}$ high, with inconspicuous flowers. 
b. Head of carpels globular; petals bright yellow, much larger than the calyx.

14. R. fasciculàris, Muhl. (EARLy C.) Low, pubescent with closepressed silky hairs; root a cluster of thickened fleshy fibres; radical leaves appearling pinnute, the long-stalked terminal division remote from the sessile lateral ones, itself 3-5-divided or parted and 3-5-cleft, the lobes oblong or linear; stems ascending; petals spatulate-oblong, twice the length of the spreading calyx ; carpels scarcely margined, tipped with a slender straight or rather curved benk. - Rocky hills. April, May. - Plant 5'-9' high; the bright yellow flower 1 ' broad : petals rather distant, the base scarcely broader than the scale, often 6 or 7 .

15. R. rèpens, L. (Creeping C.) Low, hairy or nearly glabrous; stems ascending, and some of them forming long runners; leaves 3-divided; the divisions all stalked (or at least the terminal one), broadly wedge-shaped or ovate, unequally 3-cleft or parted and varionsly cut; peduncles furrowed; petals obovate, much larger than the spreading calyx ; carpels strongly margined, pointed by a stout straightish beak. - Moist or shady places, wet meadows, \&c., May - Aug. - Extremely variable in size and foliage, commencing to flower by upright stems in spring before the long runners are formed. Flowers as large as those of No. 14, or often larger. (Eu.)

16. R. Bulbòsus, L. (Bulbous C. Buttercurs.) Hairy ; stem erect -f from a bulb-like base; radical leaves 3 -divided ; the lateral divisions sessile, the terminal stalked and 3-parted, all wedge-shaped, cleft and toothed; peduncles fur-

trowed; petals round, wedge-shaped at the base, much longer than the reflexed scalyx; carpels tipped with $n$ very short beak. - Ficlds; very abuudant only in 8. New England; rare in the interior. May-July. $-A$ foot high. Leaves appearing as if pinnate. Petals often 6 or 7 , deep glossy yellow, the corolla more than an inch broad. (Nat. from Eu.)

17. R. ACris, L. (TAlL C. or Buttercups.) Hairy; stem erect $\left(2^{\circ}-3^{\circ}\right.$ high) ; lenves 3 divided ; the divisions all sessile and 3-cleft or parted, their segments cut into lanceolate or linear crowded lobes; peduncles not furrowed; petals obovate, much longer than the spreading calyx. - Fields; common eastward. June-Ang. - Plant twice the height of the preceding; the flower nearly as large, but not so deep yellow. - The Buttercups are avoided by cattle, on account of their very acrid or even blistering juice, which, however, being volatile, is dissipated in drying, when these plants are cut with hay. (Nat. from Eu.)

\section{* Achenia beset with rongh points or small prickles : annuals.}

18. R. murichtus, L. Nearly glabrous; lower leaves roundish or reniform, 3-lobed, coarsely crenate; the upper 3-cleft, wedge-form at the base; petals longer than the calyx; carpels flat, spiny-tuberculate on the sides, strongly beaked, surrounded with a wide and sharp smooth margin. - Eastern Virginia and southward. (Nat. from Eu.)

19. R. Panviflónus, L. Hairy, slender, and diffuse; lower leaves roundish-cordate, 3-cleft, coarsely toothed or cut; the upper 3-5-parted; petals not longer than the calyx; carpels minutely hispid and rough, beaked, narrowly margined. - Norfolk, Virginia, and southward. (Nat. from Eu.) 


\section{M Y OS Ù R S, Dill. Mouse-tali.}

Sepals 5, spurred at the base. Petals 5, small and narrow, raised on a slen. der claw, ut the summit of which is a nectariferous hollow. Stamens 5-20. Achenia numerous, somewhat 3 -sided, crowded on a very long and slender spike-like receptacle (whence the name, from $\mu \hat{v}$, a mouse, and oúpá, a tail), the seed suspended. - Little annuals, with tufted narrowly linear-spatulate root-leaves, and naked l-flowered scapes. Flowers small, greenish.

1. M. mínimus, L. Carpels blunt. - Alluvial ground, Illinois and Kentucky, thence south and west; apparently indigenous. (Eu.)

\section{I SOPÝ R U M, L. (ĹNÉMION, Raf.)}

Sepals 5, petal-like, deciduous. Petals 5, minute, wanting in the American species. Stamens $10-40$. Pistils $3-6$ or more, pointed with the styles. Pods ovate or oblong, 2-several-seeded. - Slender smooth herbs, with 2-3-ternately compound leaves; the leaflets 2-3-lobed. Flowers axillary and terminal,

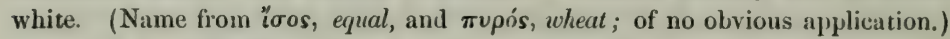

1. I. biternàtum, Torr. \& Gray. Petals none ; pistils 3-6 (commonly 4), divaricate in fruit, 2-3-seeded; seeds even. 4-Moist shady places, Ohio to Illinois, Kentucky, and westward. May. - Fibres of the root thickened here and there into little tuber's. Aspect and size of the plant much as in Thalictrum anemonoides.

\section{Ca L T H A, L. Marsir Marigold.}

Sepals 5-9, petal-like. Petals none. Pistils 5-10, with scarcely any styles. Pods (follicles) compressed, spreading, many-seeded. Glabrous perenuials, with round and heart-shaped or kidney-form, large, undivided leaves. (Name

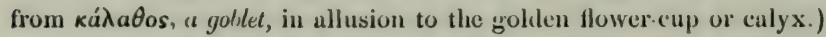

1. C. palústris, L. (Marsir Marigold.) Stem hollow, furrowed; leaves round or kidney-shaped, either crenate or nearly entire; sepals broadly oval (bright yellow). - Swamps and wet neadows, common northward. A pril, May. - This well-kuown plant is used as a pot-herb in spring, when coming into flower, under the name of Cowsurs ; but the Cowslip is a totally different plant, namely, a species of Primrose. The Caltha should bear with us, as in England, the popular nane of Marsh Marigold. (Eu.)

\section{TRÓLIIUS, L. GLOBE-Flower.}

Sepals 5-15, petal-like. P'etals numerous, small, 1-lipped, the concavity near the base. Stamens and pistils numerous. Pods 9 or more, sessile, suanyseeded. - Smooth pereunials with palmately parted and cut leaves, like Ranunculus, and large solitary terminal flowers. (Name thought to be derived from the old German word troll, a globe, or something round.)

1. T. láxus, Salisb. (Srreading Glone-flower.) Sepals 5-6, spreading; petals $15-25$, inconspicuous, much shorter than the stamens. Deep swamps, New Hampshire to Delaware and Michigan. May. - Flowers twice the size of the common Buttercup; the sepals spreading, so that tho 
name is not appropriate, as it is to the European Globe flower of the gardens, nor is the blossom showy, being pale greenish-yellow, or nearly white.

\section{Có PTIS, Salisb. Goldturead.}

Sepals 5-7, petal-like, deciduous. Petals 5-7, small, club-shaped, hollow at the apex. Stamens 15-25. Pistils 3-7, on slender stalks. Pods divergent, membranaccons, pointed with the style, 4 - 8-secled. - Low smooth percnnials, with ternately divided root-leaves, and small white flowers on scapes.

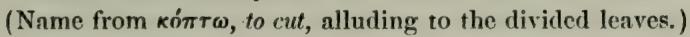

1. C. trifolia, Salisb. (Turee-Leaved Goldthread.) Leaflets $\mathbf{3}$, obovate-wedge-form, sharply toothed, obscurely 3-lobed; scape 1-flowered. Bogs, abundant northward; extending south to Maryland along the mountains. May. - Root of long, bright yellow, bitter fibres. Leaves evergreen, shining. Scape naked, slender, $3^{\prime}-5^{\prime}$ high. (Eu.)

\section{HELLÉboRUS, L. Hellebore.}

Sepals 5, petnl-like or greenish, persistent. Petals 8-10, very small, tubular, 2-lipped. Pistils 3-10, sessile, forming coriaceous many-seeded pods. Perennial herbs of the Old World, with smple palmate or perlate leaves, and large, solitary, nodding, early vernal flowers. (Name from $\dot{\epsilon} \lambda \hat{\epsilon} \boldsymbol{\nu}$, to injure, and Bopá, food, from their well-known poisonous properties.)

1. H. viridis, L. (Green Hellebore.) Root-leaves glabrous, pedate, calyx spreading, greenish. - Near Brooklyn and Jamaica, Long Island, and Bucks Co., Peun., Mertindale. ( $\Lambda$ dv. from Eu.)

\section{A Q U I L E $\mathbf{E} \mathbf{A}$, Tourn. Columbine.}

Sepals 5, regular, colored like the petals. Petals 5, all alike, with a short spreading lip, produced backwarls into large hollow spurs, much longer than the calyx. Pistils 5, with slender styles. Pods erect, many-seeded. - Perennials, with 2-3-ternatcly compound leaves, the leaflets lobed. Flowers large and showy, terminating the branches. (Name from aquila, an eagle, from some - fancied resemblance of the spurs to talons.)

1. A. Canadénsis, L. (IVIld Columbine.) Spurs nearly straight; stamens and styles longer than the ovate sepals. - Rocks, common. April June. - Flowers 2 ' long, scarlet, yellow inside (or rarely all over), nodding, so that the spurs turn upward, but the stalk becomes upright in fruit. - More graceful than the

A. vulgiris, L., the common Garden Columbine, of Europe, with hooked spurs, which is beginning to escape from cultivation in some places.

\section{DELPHÍ NI U M, Tourn. Larkspur.}

Sepals 5, irregular, petal-like; the upper one prolonged into a spur at the hase. Petals 4, irregular, the upper pair continued hackwards into long spurs which are enclosed in the spur of the calyx, the lower pair with short claws: 
rarely only 2 united into one. Pistils $1-5$, forming many-sceded pods in fruit. - Ieaves palmately divided or cut. Flowers in terminal racemes. (Name from Delphin, in allusion to the shape of the flower, which is sometimes not unlike the classical figmes of the dolphin.)

$$
\text { * Perennials, indigenous; pistils 3-5. }
$$

1. D. exaltàtum, Ait. ('Tall Lakíspur.) Leaves deeply 3-5-cleft; the divisions narrow wedge-form, diverging, 3-cleft at the apex, acute; racemes wand.like, panicled, many-flowered; spur straight; pods 3, erect. - Rich soil, Penn. to Michigan and southward. July. - Stem $2^{\circ}-5^{\circ}$ high. Flowers purplish-blue, downy.

2. D. tricórne, Michx. (Dwarf L.) Leaves deeply 5-parted, their divisions unequally 3-5-cleft; the lobes linear, acutish ; ruceme few-flowertel, loose; spur straightish, ascending; pods stiongly diverging. - W. P'enn. to Illinois und southward. April, May. - Root a tuberous cluster. Stem simple, 6'-12' high. Flowers bilight blue, sometimes white.

3. D. azùreum, Michx. (Azure L.) Leaves deeply 3-5-parted, the divisions 2-3 times cleft; the lobes all narrowly linear; raceme strict; spur ascending, usually curved upwards; pods erect. - Wisconsin, Illinois, and southward. May, June. - Stem $1^{\circ}-2^{\circ}$ high, slender, often softly pubescent. Flowers sky-blue or whitish.

** Annual, introduced: pistil single.

4. D. Consólida, L. (Fited L.) Leaves dissected into narrow linear lobes; racemes rather few-flowered, loose; pedicels shorter than the bracts; petals all combined into one boly. - Pennsylvania und Virginia, escaped from grain-fields or gardens; and sparingly along roadsides farther north. (Nat. from Eu.)

\section{A CONit U M, Tourn. Aconite. Monkshood. Wolfsine.}

Sepals 5, petal-like, very irregular; the upper one (helmet) hooded or helmet-shaped, larger than the others. Petals 2 (the 3 lower wanting entirely, or very minute rudiments among the stamens), consisting of small spur-shatped bodies raised on long claws and concealed under the helmet. I'istils 3-5. Pods several-seeded. Seed-coat usually wrinkled or scaly. - Perennials, with palmately cleft or dissected leaves, and showy flowers in racemes or panicles. (The ancient Greek and Latin name, said to be derived from Arone, in Bithynia.)

1. A. uncinàtum, L. (WILd Monksiood.) Glabrous; stem slender, erect, but weak and dispesed to climb; leaves deeply 3-5-lubed, petioled; the lobes ovate-lanceblate, contrsely toothed; flowers blue; helmet erect, obtusely conical, compressed, slightly pointed or beaked in front. - Rich shady soil along streams, S. W. New York, and southward along the mountains. June-Aug.

2. A. reclinatum, Gray. (Trailing Wolfsibane.) Glabrous; stems trailing $\left(3^{\circ}-8^{\circ} \mathrm{lom}-\mathrm{s}\right)$; lraves deeply $3-7$-cleft, petioled, the lower orbicular in outline; the divisions ivedge-form, incised, often $2-3$-lobed; flovers white, in very loose panicles; helmet soon horizontal, flonguted-conical, with a straight beak in front. - Cheat Mountain, Virginia, and southward in the Alleghanies. Aug.

- Lower loaves $5^{\prime}-6^{\prime}$ wide. Flowers $9^{\prime \prime}$ long, nearly glabrous. 


\section{Z A N THORH ìzA, Marshall. Sirun Yellow-root.}

Sepnls 5, regular, spreading, decidnons. Petals 5, much smaller than the sepals, concave and obscurely 2-lobed, raised on a claw. Stamens 5 to 10. Pistils 5-15, bearing 2 pendulous ovules. I'ols 1 -seeled, oblong, the short style becoming dorsal in its growth. $-\Lambda$ low shrubby plant; the bark and the long ronts decp yellow and bitter. Flowers polygamous, brown purple, in compound drooping racemes, nppearing, aloner with the 1-2-pinnate leaves, from large terminal buds in carly spring. (Name compounded of $\xi a v \theta$ s, yollow, arid pí(a, root.)

1. Z. apiifolia, L'Her. - Shady banks of streams, Sherhurne, New York, Dr. Douglass, and from the mountains of Pennsylvania southward. - Stems clustered, $1^{\circ}-2^{\circ}$ high. Leaflets cleft and toothed. - The rootstocks of this, and also of the next plant, were used as a yellow dye by the aborigines.

\section{H Y D R Á TIS, L. Orange-rout. Yellow puccoon.}

Sepals 3, petal-like, falling away when the flower opens. Petals none. Pistils 12 or more in a head, 2-ovuled : stigina flat, 2-lipped. Ovaries becoming a head of erimson $1-2$-seeded berrics in fruit. $-\Lambda$ low perennial herb, sending up in early spring, from a thick and knotted yellow rootstock, a single radical leaf, and a simple hairy stem, which is 2-leaved near the summit, and terminated by a single grecnish-white flower. (Name perhaps from $\ddot{\delta} \omega \rho$, water, and $\delta \rho \dot{a} \omega$, to act, alluding to the active properties of the juice.)

1. H. Canadénsis, L. - Rich woods, New York to Wisconsin and southward : rare. - Leaves rounded, heart-shaped at the base, 5-7-lobed, doubly serrate, veiny, when full grown in summer $4^{\prime}-9^{\prime}$ wide.

\section{A CT 罡A, L. BANEBERry.}

Sepals 4 or 5, falling off when the flower expands. Petals 4-10, small, flat, spatulate, on slender claws. Stamens numerous, with slender white filaments. Pistil single: stigma sessile, depressed, 2-lobed. Fruit a many-seciled berry. Seeds smooth, flattened, and packed horizontally in 2 rows. - Perennials, with ample 2-3-ternately compound leaves, the ovate lenflets sharply eleft and toothed, and a short and thick terminal raceme of white flowers. (Name from ákт $\hat{\eta}$, the Elder, from some resemblance in the leaves.)

1. A. spicata, L., var. rubra, Michx. (Red BAneberny.) Raceme ocate; petals rhombic-spatulate, much shorter than the stamens; pedicels slender; berries cherry-rd, oval. (A. brachypétala, DC.)-Rich woods, common, especially northward. April, May. - Plant $2^{\circ}$ high. (Eu.)

2. A. alba, Bigel. (Wnite BANeberRy.) Taller and rather smoother than the preceding; raneme oblong; petals slender, mostly truncate at the end, appearing to be transformed stamens; pedicels thirkened in fruit, as large as the peluncle and red, the globular-oval berries white. ( $\Lambda$. spicata, var. alba, Michx., and ed. 2. A. pachýpoda, Ell.) - Rich woods, flowering a weck or two later than the other, and more common westward and southward. - White berries rarely occur with slender pedicels, also red berrics with thick pedicels: but these are perhaps the result of crossing. 


\section{CIMI IÍ $\mathbf{I}$ U A, L. Bughane.}

Sejals 4 or 5 , falling off soon after the flower expands. Petals, or rather transformed stanens, $1-8$, small, on claws, 2-horued at the apex. Stamens as in Actea. Pistils 1-8, forming dry dehisecent pods in fruit. - Perennials, with 2-3-ternately-divided leaves, the leatlets ent-serrate, and white flowers in elongated wand-iike racemes. (Nane fiom cimee, a bug, and fiugo, to drive away; the Siberian species being used as a bugbane.)

§ 1. MACRÒTYS, Rat. Pistil solitary, sometimes 2-3: seeds smooth, flattened and packed horizonlally in the pod in turo rows, as in Actasa: stigna broud and flat.

1. C. racemósa, kill. (Bцаск Snakenoot.) Racemeg very long; pods ovoid, sessile. - Rich woods, Maine and Vermont to Wisconsin, and southward. July. - Stem $3^{\circ}-8^{\circ}$ high, from a thick knotted rootstock; the racenes in firuit becoming $1^{\circ}-3^{\circ}$ long.

§2. CIMICIFUGA, L. Pistils 3-8: seeds flattened laterally, covered with chatfy scules, and occupying one row in the membianaceous pods: style antshaped: stigma minute.

2. C. Americana, Michx. (American Bugbank.) Racemes slender, panieled; ovaries mostly 5, glabrous; pods stalked, flattened, veiny, 6-8seeded. - Mountains of Southern Pennsylvania and southward throughout the Alleghanies. Aug. - Sept. - Plant $2^{\circ}-4^{\circ}$ high, more slender than the preceding.

Adònis autuanalis, L., the Pheasant's Eye of Europe, has been found growing spontaneously in Western New York, and in Kentucky.

Nigélla Damascèna, L., the FenNel-fiower, which offers a remarkable exception, in having the pistils partly united into a compound ovary, so as to form a several-celled pod, grows ncirly spontaneously around gardens.

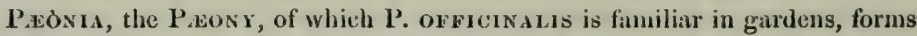
a sixth tribe of this order, distinguished by a leafy persistent calyx, and a fleshy disk surrounding the base of the follicular pistils.

\section{Order 2. Imagnolícede. (Maginolia Family.)}

Trees or strubs, with the leaf-buds covered by membranous stipules, polypetalons, hypogynous, polyandrous, polygynous; the calyx and corolla colored alike, in three or more rows of three, and imbricated (rarely convolute) in the bual. - Sepals and petals deciduous. Anthers adnate. Pistils many, mostly packed together and covering the prolonged receptacle, colsering with each other, and in fruit forming a sort of fleshy or dry cone. Seeds 1 or 2 in each carpel, anatropous: albumen fleshy : embryo minute. - Leaves alternate, not toothed, marked with minute transparent dots, feather-veined. Flowers single, large. Bark aromatic and bitter. - There are only two Northern genera, Magnolia and Liriodendron. 


\section{MA G N OLIA, L. Magnolia.}

Sepals 3. Petals 6-9. Stamens imbricated, with very short filaments, and long anthers opening inwards. Pistils aggregated on the long receptacle and coherent in a mass, together forming a fleshy and rather woody cone-like red fruit; each carpel at maturity opening on the back, from which the 1 or 2 herry-like seeds hang by an extensile thread composed of unrolled spiral vessels. Inner seed-coat bony. - Buds conical, the coverings formed of the successive pairs of stipules, each pair enveloping the leaf next above, which is folded lengthwise, and applied straight against the side of the next stipular sheath, and so on. (Named after Magnol, Professor of Botany at Montpellier in the 17 th century.)

* Leuves all scattered along the branches: leaf-buds silky.

1. M. glaùca, L. (Smatl or Laurel Magnolia. Sweet Bay.) Jeares oblong or oval, obtuse, white beneath; flower globular, white, $2^{\prime}$ long, very fiagrant; petals broad; cone of fruit small, oblong. - Swamps, from near Cape $\Lambda \mathrm{nn}$ and New York southward, near the coast; in Pennsylvania as far west as Cumberland Co. Juno- 1 ng. - Shrub $4^{\circ}-20^{\circ}$ high, with thickish leaves, which farther south are evergreen, and sometimes oblong-lanceolate.

2. M. acuminata, L. (Cucumiser-Tres.) Leaves oblong, pointed, green and a little pubescent bencath; flower oblong bell-shuped, glaucous-green tinged with yellow, $2^{\prime}$ long; cone of fruit small, cylindrical. - Rich woods, W. New York to Ohio and southward. May, June. - Tree 60-90 feet high. Leaves thin, $5^{\prime}-10^{\prime}$ long. Fruit $2^{\prime}-3^{\prime}$ long, when young slightly resembling a small cucumber, whence the common name.

3. M. macrophýlla, Michx. (Grent-lenved Magnolia.) Leaves obovate-oblong, cordute at the narrowed base, pubescent and white beneath; flower open bell-shaped, white, with a purple spot at the base, petals ovate, $6^{\prime}$ long; cone of fruit ovoid. - Rockeastle and Kentucky Rivers, S. F. Kentucky and southward. Occasionnlly planted farther north. May, Junc. - 'Trce $20^{\circ}-40^{\circ}$ high. Leaves $22_{2}^{\circ}-3 \frac{1}{2}^{\circ}$ long.

* * Leates crowded on the summit of the flowering branches in an umbrella-like circle: leaf-buds glabrous: flowers white, slightly scented.

4. M. Umbrélla, Lam. (Umbrella-tree.) Leaves vbovate-lanceolate; pointed at bo'h inds, soon glabrous, petals obovate-oblong, $4^{\prime}-5^{\prime}$ long. (M. tripétala, L.) - York and Lancaster counties, Penn. (Prof. Porter), to Virginia and Kentucky along the Alleghanies. May. - A small tree. Leaves $1^{\circ}-3^{\circ}$ long: Fruit rose-color, $4^{\prime}-5^{\prime}$ long, ovoid-oblong.

5. M. Fràseri, Walt. (Ear-Leaven Umbrelia-tree.) Lenves oblongdovate or spatulate, auriculate at the base, glabrous; petals obovate-spatulate, with narrow claws, $4^{\prime}$ long. (M. auriculata, Lam.) - Virginia and Kentucky. along the Alleghanies, and southward. April, May. - Tree $30^{\circ}-50^{\circ}$ high. Leaves $8^{\prime}-12^{\prime}$ long. Flower more graceful and cone of fruit smaller than in the preceding.

M. condita, Michx., the Yeliow Cucumber-tree, of Gengin, and the

M. grandifora, L., the Great Inunet Magnolis, of the Southern States (a noble tree, remarkable for its deliciously fragrant great flowers, and G $M-3$ 
thick evergreen leaves, which are shining and deep green above and rustycolored beneath), are the only remaining North American species. The former is hardy as far north as Cambridge. One tree of the latter bears the winter and blossoms near Philadelphia. The Umbrella-tree attains only a small size in New England, where M. macrophylla is precarious.

\section{LIR I O D E N D O N, L. 'TULIP-TRE.}

Sepals 3, reflexed. Petals 6 , in two rows, making a bell-shaped corolla. Anthers linear, opening outwards. P'istils flat and scale-form, long and narrow, imbricating and cohering together in an elongated cone, dry, separating from each other und from the long and slender axis in fruit, and falling away whole, like a samara or key, indehiscent, 1-2-seeded in the small cavity at the base. Buds flat, sheathed by the successive pairs of flat and broad stipules joined at their edges, the folded leaves bent down on the petiole so that their apex points

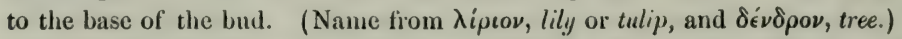

1. L. Tulipifera, L. - Rich soil, S. New England to Michigan, Illinois, and southward. May, June. - A most beautiful tree, sometimes $140^{\circ}$ high and $8^{\circ}-9^{\circ}$ in diameter in the Western States, where it is wrongly called Poplar. Leaves very smooth, with 2 lateral lobes near the base, and 2 at the apex, which appears as if cut off abruptly by a broad shallow notch. Petals $2^{\prime}$ long, greenish-yellow marked with orange. Cone of fruit $3^{\prime}$ long.

\section{Order 3. anonàceate. (Custard-Apple family.)}

Trees or shrubs, with naked buds and no slipules, a calyx of 3 sepals, and a corolla of 6 petals in two rows, valvate in the bud, hypogynous, polyandrous. - Petals thickish. Anthers adnate, opening outwards : filaments very short. Pistils several or many, separate or cohering in a mass, fleshy or pulpy in fruit. Seeds anatropous, large, with a crustaceous seed-coat, and a minute embryo at the base of the ruminated albumen. - Leaves alternate, entire, feather-veined. Flowers axillary, solitary. Bark, \&e. acril-aromatic or fetid. - A tropical family, except one genus in the United Staties, viz.:

\section{A S Ím I N A, Adans. Nontri American Papaw.}

Petals 6, increasing after the bud opens; the outer set larger than the inner. Stamens numcrous in a globular mass. Pistils few, ripening $1-4$ large and oblong pulpy several-secded fruits. Seeds horizontal, flat, enclosed in a fleshy aril. - Shrubs or small trees, with unpleasant odor when bruised; the lurid flowers solitary from the axils of last year's leares. (Name from Asiminier, of the French colonists.)

1. A. triloba, Dunal. (Common Papaw.) Leaves thin, obovate-lanceolate, pointed; petals dull-purple, veiny, round-ovate, the outer ones 3-4 times as long as the calyx. - Banks of streams in rich soil, W. New York and l'enn. to Illinois and southward. April, May. - Tree $10^{\circ}-20^{\circ}$ high; the 
young shoots and expanding leaves clothed with a rusty down, soon, glabrous. Flowers appearing with the leaves, $1 \frac{1}{2}^{\prime}$ wide. Fruits $3^{\prime}-4^{\prime}$ long, yellowish, swect and cdible in antumn.

A. PARvifúrı, a smaller-flowered and small-fruited low species, probably does not grow so far north as Virginia.

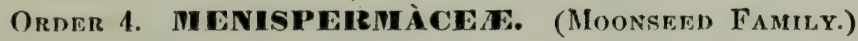

Wooly climbers, with palmate or peltate alternate leaves, no stipules; the sepals and petals similar, in three or more rows, imbricated in the bud; hypogynous, dicecious, 3-6-gynous; fruit a 1-seeded drupe, with a large or long curved embryo in scanty albumen. - Flowers small. Stamens several. Ovaries nearly stritight, with the stigma at the apex, but often incurved in fruiting, so that the seed and embryo are bent into a crescent or ring. Properties bitter-tonic and narcotic. - Chiefly a tropical family; there are only three species, belonging to as many genera, in the United States.

1. Cocenlus. Stamens, petals, and sepals each 6 . Anthers 4-celled.

2. Menispermum. Stamens $12-2 t$, slender. Petals $6-8$. Anthers 4-celled.

3. Colycocarpum. Stamens in the sterile flowers 12 ; in the fertile flowers 6 , abortive. Petals none. Anthers 2-celled.

\section{Có CCULUS, DC. Coceurus.}

Sepals, petals, and stamens 6, the two latter short. Anthers 4-celled. Pistils 3-6 in the fertile flowers: style pointed. Drupe and sced as in Moonseed. Cotyledons narrowly linear and flat. - Flowers in axillary racemes or panicles. (An old name, from coccun, a berry.)

1. C. Carolinus, DC. Minutely pubescent; leaves downy benea, ovate or cordate, entire or sinuate-lobed, variable in shape; flowers greenish; the petals in the sterile ones auriculate-inflexed below around the filaments, drupe red (as large as a small pea). - River-banks, S. Illinois, Virginia, and southward. July, Aug.

\section{M E N I S P É R M U M, L. Moonsén.}

Sepals 4-8. Petals 6-8, short. Stamens $12-20$ in the sterile flowers, as long as the sepals : anthers 4-celled. Pistils $2-4$ in the fertile flowers, raised on a short common recptacle: stigma broad and flat. Drupe globular, the mark of the stigma near the base, the ovary in its growth after flowering being strongly incurved, so that the (wrinkled and grooved) laterally flattened stone (putamen) takes the form of a large crescent or a ring. The slender embryo therefore is horseshoe-shaped : cotyledons filiform. - Flowers white, in axillary panicles. (Name from $\mu \dot{\eta} \nu \eta$, moon, and $\sigma \pi \dot{\epsilon} \rho \mu a$, seed.)

1. M. Canadénse, I. (Canadian Moonseed.) Leaves peltate near the edge, 3-7-angled or lobed.-Banks of streams; common. June, July. Drupes black with a bloom, ripe in September, looking like frost grapes. 


\section{C A L Y C O C Á R P U M, Nutt. Cupseed.}

Sepals 6. Petals nouc. Stumens 12 in the sterile flowers, short: anthers 2-celled. Pistils 3, spindle-shaped, tipped with a radiate many-cleft stigma. Drupe not incurved; but the thin crustaceous putamen hollowed out like a cup on one side. Embryo fuliaceous, heart-shaped. - Flowers greenish-white, in

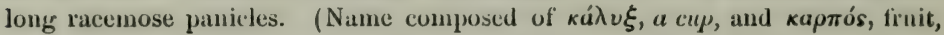
from the shape of the shell.)

1. C. Lyoni, Nutt. (Menispermum Lyoni, Pursh.) - Rich soil, S. Ken. tucky and sonthward. May. - Stems climbing to the tops of trees. Leaves large, thin, decply $3-5$-lobed, cordate at the base; the lobes acuminate. 1)rupe an inch long, globular, greenish; the shell crested-toothed on the edge of the cavity.

\section{Order 5. HERIBERIDÀCEAE. (BarberRy Family.)}

Sthuls or herbs, with the sepals and pelals both imbricated in the bud in two or more rows of 2-4 each; the hypogynous stamens as many as the petals and opposite to them: authers opening by 2 valves or lids hinged at the top. (Podophyllum is an exception, and Jeffersonia as respects the sepals in one row.) P'istil single. Filaments short. Style short or none. Fruit a berry or a pod. Seeds few or several, anatropous, with albumen. Embryo small, except in Berberis. Leaves alternate.

* Petals and stamens 6. Fruit fer-seeded.

1. Berberis. Shrubs, with yellow tlowers and wood; a pair of glaudular spots on the base of each petal. Fruit a berry.

2. Cumloplayllum. Heri), with greenish flowers: petuls thick, much shorter than the sepals. Ovary seon lursting ; the two seevls left naked.

3. Diphylleia. Herb with white flowers; petals much longer than sepals. Berry 2-4. seeded.

* Petals 6-9. Stamens 8-18. Fruit many-seeded. Herbs.

4. Jeffersomia. Petals and stameus usually 8 : anthers opening by uplifted valves. Pod opening by a lid.

5. Poulophyllum. Petals 6-9. Stamens 12-18: anthers not opening by uplifted valres. Fruit a large berry.

\section{BÉRBERIS, L. BarberRy.}

Sepals 6, roundish, with 2-6 bractlets ontside. Petals 6, obovate, concave, with two ghamblular spots inside above the short claw. Stamens 6 . Stigma circular, depressed. Fruit a 1-fiew-seeded berry. Seeds erect, with a crustaceous integument. - Shrubs, with yellow wood and inner bark, yellow flowers in drooping racemes, som berries, and 1 -9-foliolate leaves. Stamens irritable. (Derived from Berberys, the Arabic name of the fruit.)

1. B. vulgaris, L. (Common Barierry.) Jeaves scattered on the fresh shoots of the season, mostly reduced to sharp triple or branched spines; from which the next season procecd rosettes or fascicles of olovate-oblong closely bristly-toothed leaves (the short petiole jointed!), and drooping many-flowered racemes; petals entire; berries oblong, scarlet. - T'lickets and waste grounds in 
E. New England, where it has become thoronghly wild : elsewhere occasionally spontaneous. May, June. (Nat. from Eu.)

2. B. Canadénsis, Pursh. (Amertcan Barberry.) Lenves repandly tonthed, the teeth less bristly-pointed; racemes few-flowered: petals notehed at the apex; berries oval (otherwise as in No. 1). - Alleghanies of Virginia and southward: not in Canada. June. - Shrub $1^{\circ}-3^{\circ}$ high.

\section{C A UL O PH X́ LL U M, Michx. Buv Comon.}

Sepals 6, with 3 small bractlets at the base, ovate-oblong. P'etals 6 thick and gland-like somewhat kidney-shaped or hooded bodics, with short claws, much sinaller than the sepals, one at the base of each of them. Stamens 6 : anthers oblong. Pistil gibbous: style short: stigma minute and unilateral: ovary bursting soon after flowering by the pressure of the 2 erect, enlarging seeds, and withering away; the spherical seeds naked on their thick seed-stalks, looking like drupes; the fleshy integument turning blue: albumen of the texture of horn. $-\Lambda$ perennial glabrous herb, with matted knotty rootstocks, sending up in early spring a simple and naked stem, terminated by a small raceme or panicle of yellowish-green flowers, and a little below bearing a large triternately compound lenf, without any common petiole (whence the name, from kaviós, stem, and $\phi \dot{u} \lambda \lambda \lambda^{\circ}$, leaf; the stem sceming to form a stalk for the great leaf). Leaflets obovate wedge-form, $2-3$-lobed.

1. C. thalictroldes, Michx. (Also called Pappoose-root.) Leóntice thalictroides, L. - Deep rich woods; common westward. April, May. - Stens $11^{\circ}-2 \frac{1}{2}^{\circ}$ high. Flowers appearing while the leaf is yet sinall. A smaller biternate leaf often at the base of the panicle. Whole plant glaucous when young, also the seeds, which are as large as peas.

\section{DI PH Y LL L I A, Michx. Umbrella-tenf.}

Sepals 6, fugacious. Petals 6, oval, flat, larger than the sepals. Stamens 6 : anthers oblong. Ovary oblong: style hardly any : stigma depressed. Ovules 5 or 6 , attached to one side of the cell below the middle. Berry few-seeded. Seeds oblong, with no aril. - A perennial glabrous herb, with thick horizontal rootstocks, sending up each year either a huge centrally peltate and cut-lobed, rounded, umbrella-like, radical leaf, on a stout stalk, or a flowering stem bearing two similar (but smaller and more 2-cleft) alternate leaves which are peltate near one margin, and terminated by a cyme of white flowers. (Name composed of Sis, twice, and $\phi u ́ \lambda \lambda o v$, lenf.)

1. D. cymósa, Miclix. Wet or springy places, mountains of Virginia and southwart. May. - Root-lenves $1^{\circ}-2^{\circ}$ in diameter, 2-cleft, each division 5-7-lobed; lobes toothed. Berries blue.

\section{JEFFERSÒ N I A, Barton. Twin-leaf.}

Sepals 4, fingacious. l'etals 8, oblong, flat. Stamens 8 : antliers ohlonglinear, on slender filaments. Ovary ovoid, soon gibbous, pointed: stigina 2lobed. Pod pear-shaped, opening half-way round horizontally, the upper part 
making a lid. Seeds inany in several rows on the lateral placenta, with a fleshy lacerate aril on one side. - A perennial glabrous herb, with matted fibrous roots, long-petioled root-leaves, parted into 2 hall-ovate leaflets, and simple naked 1flowered scapes. (Named in honor of Thomus Jefferson.)

1. J. diphýlla, Pers. - Woods, W. New York to Wisconsin and southward. April, May.- Low. Flower white, $\mathbf{I}^{\prime}$ broad: the parts rarely in threes or fives. - Called likenumatism-root in some plates.

\section{PODOPHÝLLUM, L. MaY-Apple. Mandrake.}

Flower-bud with 3 green bractlets, which early fall away. Sepals 6, fugacious. Petals 6 or $y$, obovate. Stamens as many as the petals in the Himalayan species, twice as many in ours: anthers linear-oblong, not opening by upiifted valves. Ovary ovoid : stigma sessile, large, thick, and undulate. Fruit a large fleshy berry. Sceds covering the very large lateral placenta, in many rows, each seed enclosed in a pulpy aril, all forming a mass which fills the cavity of the tiuit. - Perennial herbs, with crecping rootstocks and thick fibrous

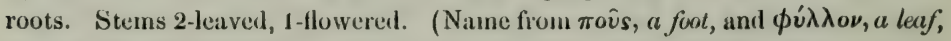
from a fanced resemblatice of the 5-7-parted leaf to the foot of some webfooted animal.)

1. P. peltatum, \&. Stamens 12-18; leaves 5-9-parted; the lobes oblong, rather wedge-shatped, somewhat lobed and toothed at the apex. - Rich woods, common. Mav. - Flowerless stems terminated by a large round 7 -9lobed leaf, peltate in the middle like an umbrella. Flowering stems bearing two one-sided leaves, with the stalk fixed near their inner edge; the nodding white flower from the fork nearly $2^{\prime}$ broad. Fruit ovoid, $1^{\prime}-2^{\prime}$ long, ripe in July, sweet and slightly acid, edible. The leaves and roots are drastic and poisonous!-Found occasionally with from 2 to 6 carpels!

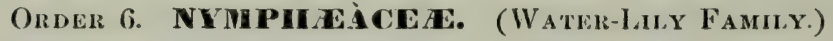

Aquatic perennial herls, with horizonlal rootstocks and pellate or sometimes only cordate leaves flouting or emersed; the ovules borne on the sides or back (or when solitary hanging from the summit) of the cells, not on the veritral suture; the embryo enclosed in a little bag at the end of the albumen next the hilum, except in Nelumbium, which has no albumen. Rarlicle hardly any : cotyledons thick and fleshy, enclosing a well-developed plumule. Flowers axillary, solitary. Leaves rolled inwards in vernation. Rootstocks very obscurely exogenous in structure. - Comprises a few genera, which differ so much in the flower and fruit, that, for the sake of convenient definition, we have formerly treated as separate orders the following suborders:

\section{Suborder I. Camóm Bate. (Water-Shield Family.)}

Sepals and petals each 3 or sometimes 4 , hypogynous and persistent. Stamens definite $(6-18)$. Pistils $2-18$, free and distinct, coriaceous and 
indehiscent, 1-3-seeded on the dorsal suture.-Stems slender, leafy, coated with mucilage. Flowers small.

1. Irngenia. Stameng 12-18: flaments sleniler. Leaves all peltate.

\section{Suborder II. NeLUMibònez. (Nelumbo Family.)}

Sepals and petals numerous in several rows, passing gradually into each other, and with the indefinitely numerous stamens hypogynous and deciduous. Pistils several, 1-ovuled, separately immersed in the obconical receptacle, which is much enlarged and broadly top-shaped at maturity, the imbedded nut-like fruits resembling small acorns. Embryo large; no albumen. - Petioles and peduncles all from the tuberous rootstock, the centrally peltate leaves and the flowers large.

2. Nelumbium. Character of the Suborder.

\section{SUBORDER III. NYMPIIAACEAE PROPER. (WATER-Lily F.)}

Sepals 4-6, and petals numerous in many rows, persistent or decaying away, either hypogynous or variously adnate to the surface of the compound 8-30-eelled ovary, which is formed by the union of as many carpels; the numerous ovules inserted over the whole inner face of the cells, except at the ventral suture. Stigmas radiate as in Poppy. Fruit baccate, with a firm rind. Petioles and peduncles from a thick rootstock.

3. Nymphren. Petals adnate to the ovary, large; the stamens on its summit.

4. Nuphar. Petals, very small and stamen-like, and stamens inserted under the ovary.

\section{B R A S E I A, Schreber. WAter-Simbld.}

Serals 3 or 4 . Petals $3-4$, linear, sessilc. Stamens $12-18$ : filaments filiform: anthers innate. Pistils 4-18, forming little club-shaped indehiscent pods : stigma linear. Sceds 1-2, pendulous on the dorsal suture !- Rootstock creeping. Leaves alternate, long-petioled, centrally peltate, oval, floating on the water. Flowers axillary, small, dull-purple. (Name of uncertain origin.)

1. B. peltàta. Pursh. (IJydropéltis purpiuren, Michr.) - Ponds and slow strcams. June-Ang. - Leaves entire, $2^{\prime}-3^{\prime}$ ncross. (Also n native of Puget Sound, Japan, Anstralia, and Eastern India!

Саво́мвA, the other genus of the group, occurs from N. Carolina southward.

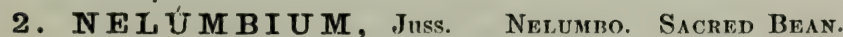

The only gen as of the suborder. (Nrlumbo is the Ceylonese name of the East Indian species, the pink-flowered N. speciosum.)

1. N. lùteum, Willd. (Yeliow Nelumbo, or Water Chinquepin.) Corolla pale yellow : anthers tipped with a slender hooked appendage. - Waters of the Western and Sonthern States; rare in the Middle States: introduced into the Delaware below Philadelphin. Nenr Woodstown and Sussex Co., Now Jersey. Big Sorlus Buy, I. Onturio, and in the Connecticut nenr Lvme; perhaps introduced there by the aborigines. Junc- $\Lambda$ ng. - Leaves ust:ally raised high out of the water, circular in outline, with the centre de- 
pressed or cupped, $1^{\circ}-2^{\circ}$ in diameter. Flower $5^{\prime}-10^{\prime}$ broad. Tubers furinaceous and edilile. Sieds also cutuble. Limbryo like that of Nymphoa on a large scale. Cotyledons thick and theshy, enclosing a plumule of 1 or 2 wellformed young leaves, enclosid in a delicate stipule-like sheath.

\section{NYMPH庯A, Tourn. WATER-Nymph. WATER-Lily.}

Sepals 4, green outside, nearly free. Petals numerous, in many rows, the innermost gradually passing into stamens, imbricately inserted all over the surface of the ovary. Stamens indetinite, inserted on the ovary, the outer with dilated tilaments. Ovary 18 - 30-celled, the concave summit tipped with a glubular projection at the centre, around which are the radiate stigmas; these project at the margin, ant are extended into linear and incurved sterile appendages. Fruit depressed-globular, corered with the bases of the decaycd petals, maturing under water. Seeds enveloped by a sac-like aril. - Flowers white, rose-color, or blue, very showy. (Dedicated by the Greeks to the WaterNymphs.)

1. N. odoràta, Ait. (Sweet-scente1, Water-LiLy.) Leaves orlic- $f($ ) ular, cortate-eleft at lle hase to the petiole $\left(5^{\prime}-9^{\prime}\right.$ wide), the margin entire; stipules broadly triangular or almost kidney-shaped, notehed at the apex, appressed to the rootstock ; flower white, very sweet scented (uften as much as 5 in diameter when fully expanded, opening early in the morning, closing in the afternoon); petals obtuse; aril much longer than the distinctly stipitate oblong seeds (these about $1 \frac{1}{2}$ " long; anthers blunt). - Ponds and still or slow-flowing water : common eastward and southward. June-Sept. - Varies with pinkishtinged and rarely with bright pink-red flowers (especially at Barnstable, Mass.), the leaves often crimson underneath, - and in size by gradations into

Var. minor, Sims (N. minor, DC., \&c.), with leaves only $2^{\prime}-5^{\prime}$ and flowers $2^{\prime}-3^{\prime}$ broad. - Shallow water, in cold bogs and in sandy soil.

2. N. tuberósa, Paine, Cat. Pl. Oneida, 1865. (Tuber-uedring W.) Leaves reniform-orbicular, mostly larger $\left(8^{\prime}-15^{\prime}\right.$ wide) and more prominently ribbed than the last, green buth sides; rootstock bearing numenous spontunevuly detaching ofien compound tubers; flower scentless (or with a slight odor as of apples, white, never pinkish, $4_{\frac{1}{2}}^{\prime}-9^{\prime}$ in diameter, the petals, as in N. alba, proportionally broader and blunter than in No. 1); the fruit more depressed, and with fewer but nuch larger (i. e. twice as broad) glubular-oioid seals which when imature are barely enclosed by the aril, and not stipitate. (N. alba, Nutt. Gen. N. reniformis, $I C$. ? starcely of Walter, which is very obseure.) - Lakes, sluw rivers, \&c., W. New York (from Oneida Lake, Puine) and near Meadville, P'enu. ( W. L. Chuffin) to Michigan, Hlinois, and probably in the Southern States. July - Sept.

\section{N Ù P H A R, Smith. Yellow Pond-Lily. Spatter-Dock.}

Sepals 5, 6, or sometimes more, colored, or partly green outside, roundish. Petals numerous, small and thickish, stamen-like or scale-like, inserted with the very numerous and short stamens on the receptacle under the ovary, not 
surpassing the disk-like 8-24-rayed sessile stigma. Fruit ovoid, naked, ustually ripening above water. Aril none.-Leaves with a deep sinus at the base. Flowers yellow or sometimes tinged with purple, produced all summer. (Nov́pap of Jioscorides, from the Egyptian name.) - Our various forms scem to include only two species.

1. N. advena, Ait. (Соммом Y.) Sepals 6, unequal ; petals shorter than the stamens and resembling them, thick and fleshy, truncate; stigma 12 24-rayed; ovary and fruit not contracted into a narrow neck under the stigma; thin submersed leaves seldom appearing; floating or cmersed and erect leaves thick, varying from roundish to ovate or almost oblong in outline, the sinus open, or (var. VARiEgAтUM, Engelm., flower often partly purplish) closed or narrow. - Very common, in still or stagnant water.

2. N. lùteum, Smith. (SMaller Y.) Sepals 5, nearly equal; petals longer and diloted upwards; stigma 12-16-rayed; fruit globular, with a short narrow neck; earlicr and submersed leaves very thin and delicate, roundish, the flonting ones oval and usually with n narrow or closed sinus. - The only specimen seen like the European (expanded flower fully $2^{\prime}$ across) is from "Manayunk, 7 miles from Philalelphia," in herb. Collins, now Durand. (Eu.)

Var. pùmilum. (Small Y.) Flower $\frac{1^{\prime}}{2}-\mathbf{l}^{\prime}$ across when outspread; leaves $1^{\prime}-5^{\prime}$ long. (N. pumilum, Hoppe. N. Kalmiàna, Pursh.)-Ponds, N. England to Penn. and northward. (Eu.)

N. Polysépalum, Engelm., with very large flowers and numerous sepals, occurs far west.

N. Sagitrifotia, Pursh, of N. Carolina and southward, has narrow and long leaves. Both perhaps run into No. 1 .

\section{Order 7. Samraceniàceat. (Pitchen-Plants.)}

Polyandrous and hypogynous bog-plants, with hollow pilcher-form or trumpet-shaped lenves, - comprising one plant in the mountains of Guiana, another (Darlingtonia, Torr.) in California, and the following genus in the Atlantic United States.

\section{SA R R A CEN I A, Tourn. SiDe-SAdde Flower.}

Sepals 5, with 3 bractlets at the base, colored, persistent. Petals 5, oblong or obovate, incurved, deciduous. Stamens numerous, hypogynous. Ovary compound, 5-celled, globose, crowned with a short style, which is expanded at the summit into a very broad and petal-like, 5-angled, 5-rayed, umbrella-shaped body; the 5 delicate rays terminating under the angles in as many little hooked stigmas. Copsule with a granular surface, 5-celled, with many-secded placentre in the axis, 5-valved. Seeds anatropous, with a small embryo at the base of fleshy albumen. - Perennials, yellowish-green and purplish; the hollow leaves all radical, with a wing on one side, and a rounded arching hood at the apex. Scape naked, 1-flowered : flower nodding. (Numed by 'l'ournefort in honor of Ir. Sarrazin of Qucbec, who first sent our Northern species, and a botanical account of it, to Europe.) 
1. S. purpùrea, L. (Side-sande Flower. Pitcher-Plant. HuntsMaN's CUP.) Leaves pitchr-shaped, ascending, curved, broadly winged; the hood erect, open, round heart-shaped ; flower deep purple; the fiddle-shaped petals arched over the (greenish-yellow) style. - Varies rarely with greenishyellow flowers, and without purple veins in the foliagre. (S. heterophylla, Eaton.) - Peat-bogs ; common from N. Lingland to Minnesota, N. Illinois, and southward east of the Alleghanies. June. - The curious leaves are usually half filled with water and drowned insects : the imner face of the hood is clothed with stiff bristles pointing downward. Flower globose, nodding on a scape a foot high : it is difficult to fancy any resemblance between its shape and a sidesaddle, but it is not very unlike a pillion.

2. S. flàva, L. ('Trumets.) Leaves long $\left(1^{\circ}-3^{\circ}\right)$ and trumpet-shaped, erect, with an open month, the erect hood rounded, narrow at the base; wing almost none; flower yellow, the petals becoming long and drooping. - Bugs, Virginia and southward. April.

\section{Order 8. Papavericede. (Porpy Family)}

Herbs with milky or colored juice, regular flowers with the parts in twos or fours, fugacious scpuls, polyandrous, hypogynous, the ovary 1-celled with 2 or more parictal placenta. - Sepals 2 , rarely 3 , falling when the flower expands. Petals 4-12, spreading, imbricated and often crumpled in the bud, early deciduous. Stamens rarely as fiew as 16 , distinct. Fruit a dry 1-celled pod (in the Poppy imperfectly many-celled, in Glaucium 2celled). Seeds numerous, anatropous, often crested, with a minute embryo at the base of fleshy and oily albumen. - Leaves alternate, without stipules. Peduncles mostly 1-flowered. Juice narcotic or acrid.

* Ovary incompletely several-celled by the projecting placents.

1. Papaver. Stigunas united into a radiate crown on the summit of the ovary. Pod opening by chinks or pores. Petals crumpled in the nodding flower-bud.

* Ovary strictly 1-celled. Pod opening by valves, leaving the 2-6 filiform parietal placenteo as a framework.

- Petals twice as many as the sepals, usually more or less crumpled in the flower-bud.

2. Argemone. Stigmas (sessile) anil placentæ 4-6. Pod and leaves prickly.

2. Stylophorum. Stigmas and placenta 3-4. Style distinct. Pod bristly.

4. Chelidonium. Stigmas and placenta 2. Pod linear, gmooth.

+ Petals 4-6 times as many as the 2 sepals, not crumpled in the erect flower-bud.

- Sangularia. Stigua 2-grooved. Placeutie 2. Petals white.

* * Ovary and elougated pod 2-celled by a spougy partition.

6. Glauclum. Stigua 2-lobed or 2-horued. Petals 4.

\section{PAPA VER, L. Porpy.}

Sepals mostly 2. I'etals mostly 4. Stigmas united in a flat 4-20-rayear crown, resting on the summit of the ovary and capsule; the latter short and turgid, with 4-20 many-seeded placenta projecting like imperfect partitions, opening by as many pores or chinks under the edge of the stigma. - Herbs 
with a white juice; the flower-buds nodding. (Derivation obscure.) - Three annual species of the Old World are sparingly adventive; viz. :

1. P. somfferum, I. (Common Poppy.) Smooth, glaucons ; leaves clasping, wavy, incised and toothed ; pod globose; corolla mostly white or purple. - Near dwellings in some places. ( $\Lambda \mathrm{dv}$. from Eu.)

2. P. dúbium, L. (Smootri-fnuted Conn-Porpy.) Pinnatifid leaves and the long stalks bristly; pods club-shaped, smooth; corolla light scarlet. Cult. grounds, Westchester, Penn. and southward: rare. (Adv. from Eu.)

3. P. argemóne, L. (Rougir-fruited C.) Sinaller, with finer-cut leaves and paler flowers than the last; pods club-shaped and bristly. - Waste

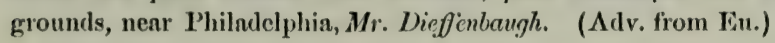

\section{A R G M Ò N E, L. Prickly Poppy.}

Sepals 2 or 3 , often prickly. Petals $4-6$. Style almost none : stigmas 3 6, radiate. Pod oblong, prickly, opening by $3-6$ valves at the top. Seeds crested. - Annuals or biennials, with prickly bristles and yellow juice. Leaves sessile, sinuate-lobed, and with prickly teeth, often blotched with white. Flowerbuds erect, short-peduncled. (Name from á $\rho \gamma \hat{\epsilon} \mu a$, a disease of the eye, for which the juice was a supposed remedy.)

1. A. Mexicdna, L. (Mexican P.) Flowers yellow, rarely white.Waste places, southward. July - Oct. (Adv. from trop. Amer.)

\section{S Ty L Ó PHOR U M, Nutt. Cenchnine Poppy.}

Sepals 2, hairy. Petals 4. Style distinct, columnar : stigma 2-4-lobed. Pods bristly, 2-4-valved to the base. Seeds conspicuously crested. - Perennial low herbs, with stems naked below and oppositely 2-leaved, or sometimes 1-3-leaved, and umbellately 1 -few-flowered at the summit; the flower-buds and the pods nodding. Leaves pinnately parted or divided. Juice yellow.

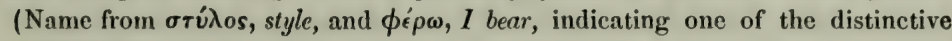
characters.)

1. S. diphyllum, Nutt. Leaves pale or glaucous beneath, smoothish, decply pinnatifid into 5 or 7 oblong sinuate-lobed divisions, and the root-leaves often with a pair of smaller and distinct leaflets; peduncles equalling the petioles; flower deep yellow ( $2^{\prime}$ broad); stigmas 3 or 4 ; pod oval. - Damp woods, W. Penn. to Wisconsin, and southward. May. - Foliage and flower resembling Celandine.

\section{CHEII D Ò N I U M, L. Celandine.}

Sepals 2. Tetals 4. Stamens 16-24. Style nearly none: stigma 2-lobed. I'od linear, slender, smooth, 2-valved, the valves opening from the bottom upwards. Seeds crested - Perennial herb with brittle stems, saffron-colored acrid juice, pinnately divided or 2-pinnatifid and toothed or cut leaves, and small yellow flowers in a pedunculate umbel; the buds nodding. (Name from $\chi \in \lambda \iota \delta \omega \nu$, the Swallow, because, according to Dioscorides, it begins to flower at the time the swallows appear.) 
1. C. majus, L. (Celandine.) Waste grounds near dwellings. MayAug. (Adv. from Eu.)

\section{S A N G U I N À R I A, Dill. Blood-root.}

Sepals 2. Petals 8-12, spatulate-oblong, the inner narrower. Stamens about 24. Style slort; stigma 2-grooved. P'od oblong, turgid, 1-celled, 2 valved. Seeds with a large crest. - A low perenuial, with thick prostrate rootstocks, surcharged with red-orange acrid juice, sending up in earliest spring a rounded palmate-lobed leaf, and a 1 -flowered naked scape. Flower white, handsome, the bud erect, the petals not crumpled. (Name from the color of the juice.)

1. S. Canadénsis, L. - Open rich woods; common. April, May.

\section{G I A Ù C I U M, Tourn. Horn-Porpy.}

Sepals 2. Petals 4. Style none: stigma 2-lobed or 2-horned. Pod vers long and lincar, cumpletely 2-celled by a spongy false partition; seeds crestless. - Annuals or biennials, with saffron-colored juice, clasping leaves, and solitary yellow tlowers. (The Greck name, $\gamma \lambda$ aúkı

1. G. Lùteua, Scop. Lower leaves pinnatifid; upper ones sinuate-lobed and toothed, cordate-clasping; pods rough, $\left(6^{\prime}-10^{\prime}\right.$ long $) .-$ Waste places s. E. New England, Maryland, and Virginia; not common. (Adv, from Lu.)

\section{Order 9. Fumatiàcede. (Fumitory Family.)}

Delicate smooth herbs, with watery juice, compound dissected leaves, irregular flowers, with 4 somewhat united petuls, 6 diadelphous stamens, and 2-merous pods and secels like those of the P'oppy Fimily. - Sepals 2, small and scale-like. Corolla flattened, closerl; the 4 petals in two pairs; the outer with spreading tips, and one or both of them spurred or saccate at the base; the inner pair narrower, and with their callous crested tips united over the stigma. Stamens in two sets of 3 each, placed opposite the larger petals, hypogynous; their filaments often united; the midlle anther of each set 2-celled, the lateral ones 1-celled. Pod 1-celled, either 1-seeded and indeliscent, or several-seeded with 2 parietal placenta. - Leaves usually alternate, without stipules. (Slightly bitter, innocent plants.)

* Poil slender : the 2 valves separating from the persistent filiform placentse.

1. AdIиmia. Corolla heart-shitjul, persistent; petals all united. Seeds crestless.

2. Dicentra. Corolla heart-shaped or 2 -spurred at the base. Seeds crested.

3. Corydalis. Corolla 1-spurred at the base. Seeds crested or arilled.

* * Pod fleshy, indehiscent, globular, 1-seeded.

4. Fumaria. Corolla 1-spurred at the base. Seed crestless.

\section{A DL Ù MIA, Raf. Chiming Fumitory.}

Petals all permanently united in a cordate-ovate corolla, becoming spongycellular and persistent, enclosing the small, few-seeded pod. Seeds not crested. 
Stigma 2-crested. Filaments monadelphous below in a tube which is adherent to the corolla, diadelphous at the summit. - A climbing biennial, with thricepinnate leaves, cut-lobed delicate leaflets, and ample panicles of drooping white or purplish flowers. (Dedicated by Rafinesque to Miajor Adlum.)

1. A. cirrhosa, Raf. - Wet woods; common westward. June-Oct. A handsome vine, with delicate foliage, climbing by the slender young leafstalks over high bushes; cultivated for festoons and bowers in shaded places.

\section{DI CÉ N R A, Bork. DuтсимаN's Breaches.}

Petals slightly cohering into a heart-shaped or 2-spurred corolla, either deciduous or withering-persistent. Stigma 2-crested and sometimes 2-horned. Filaments slightly united in two sets. Pod 10-20-secded. Seeds crested. - Low, stemless perennials (as to our wild species) with ternately compound and dissected leaves, and racemose nodding flowers. Pedicels 2-bracted. (Name from

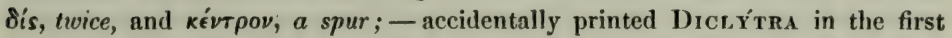
instance, which by an erroneous conjecture was afterwards changed into DrÉLYTRA.)

1. D. Cucullària, DC. (Dutchman's Breecues.) Scape and slender-petioled leaves from a sort of granulate bulb; lobes of the leaves linear; raceme simple, fow-flowered; corolla with 2 divergent spurs longer than the pedicel; crest of the inner petals minute. - Rich woods, especially westward. - A very delicate plant, sending up in early spring, from the cluster of grain-like tubers crowded together in the form of a scaly bulb, the finely cut leaves and the slender scape, hearing 4-10 pretty, but odd, white flowers tipped with cream-color.

2. D. Canadénsis, DC. (Sounnel Cons.) Subterranean shoots bearing senttered grain-like tubers (resembling peas or grains of Indian corn, yellow); leaves and raceme as in No. 1; corolla merely heart-shaped, the spurs very short and rounded; crest of the inner petals conspicuous, projecting. - Rich woods, Maine to Wisconsin and Kentucky, especially northward. April, May. - Flowers greenish-white tinged with rose, with the fragrance of Hyacinths.

3. D. exímia, DC. Sulsterranean shoots scaly; divisions and lobes of the leaves broadly oblong; raceme compound, clustered; corolla oblong, 2-saccate at the base; crest of the inner petals projecting. - Rocks, W. New York, rare (Thomns, Sartwell); and Alleghanies of Virginia. May - Aug. - Coarser-leaved than the others; scapes $6^{\prime}-10^{\prime}$ high.

\section{CORÝDAIIS, Vent. Corydals.}

Corolla 1-spurred at the base (on the upper side), deciduous. Style persistent. Pod many-seeded. Seeds crested or arilled. Flowers in racemes. Our species are biennial, leafy-stemmed, and pale or glaucous. ('The ancient Greek name for the Fumitory.)

1. C. glaùca, Pursh. (Pale Corydalis.) Stem upright; racemes panicled; spur of the purplish and yellow-tipped corolla very short and rounded; pods erect, slender, elongated. - Rocky places : conmon: $6^{\prime}-2^{\circ}$ high: May - Aug.

2. C. fláviula, Raf. Corollu pale-yellow, $3^{\prime \prime}-4^{\prime \prime}$ long; spur very short; tips of the outer petals pointed; wing-crested on the back, longer than the inner; seeds 
acutely margined, rugose-reticulated; aril loose: otherwise as in the next. Pennsylvania to Wisconsin and southward.

3. C. aùrea, Willd. ((ioldiver C.) Sicms low or decumbent; racemes simple; corolla golden-yellow, I' long; slightly decurved spur somewhat shorter than the pedicel, not half the length of the rest of the flower; tips of outer petals blunt, crestless and naked on the back, little longer thitu the inner; pods usually pendent; seeds smooth and even, or sometimes very minutely reticulated, turgiel, marginless, partly covered by the scale-shaped aril. - Rocky places, Vermont to Penn., Wisconsin, and northward. April-July. - Var. micnántia, Engelı., is a state with minute spurless flowers (probably fertilized in the bud), and ascending pods, on very short podicels. - IV. Illinois and St. Louis, Riehl.

(C. montana, Engelm., or perhajs rather C. auiks, var. occidentalis, Engelm., Missouri to 'Texas and westward, differs from the Eastern C. aurea in the often ascending spur nearly equalling the rest of the corolla and longer than the pedicel, erect or ascending pods, and seeds lenticular with acutish margin. - C. curvisfliqua, Engelm., of Southwest, differs from this in longer 4-angular pods asecnding on very short pedicels, the acute-margined seed muricate! - C. Cirstálina, Engelin., of Sonthwest, differs from this in the very bruad but short wing on tip of outer petals, short few-seeded pod covered with crystalline vesicles, and sharper-margined tubercular-reticulated seeds.)

\section{FU M Á R A, I. Fontory.}

Corolla 1-spurred at the base. Style decidnous. Fruit indehiscent, small, globular, 1-seceled. Seeds erestless. - Branched and leafj-stennned annuals, with finely dissected compound leaves, and small flowers in dense racemes or spikes. (Name from fumus, smoke.)

1. F. officinalis, L. (Common Fumitory.) Sepals ovate-lanceolater acute, sharply toothed, narrower and shorter than the corolla (which is fleshcolor tipped with crimson); fruit slightly notehed. - Waste places, about dwellings. (Adv. from Eu.)

\section{Order 10. Chucíferat. (Mustard Family.)}

Herbs, with a pungent watery juice and cruciform tetradynamous flowers: fruit a silique or silicle. - Sepals 4, deciduous. Petals 4, hypogynous, regular, placed opposite each other in pairs, their spreading limbs forming a cross. Stamens 6, two of them inserted lower down and shorter (rarely only 4 or 2). Pod 2-celled by a thin partition stretched between the two marginal placenta, fiom which when ripe the valves separate, either much longer than broad (a silique), or short (a silicle or pouch), sometimes indehiscent and nut-like (nucumentaceous), or separating acruss into 1-seeded joints (lomentaceous). Seeds campylotropous, without albumen, filled by the large embryo, which is curved or folded in various ways: i. e. the colyledons accumbent, viz. their margins on one side applied to the radicke, so that the cross-section of the seed appears thus $\theta$; 
or else incumbent, viz. the back of one cotyledon applied to the radicle, thus of 0 . In these cases the cotyledons are plane; but they may be folded upon themselves and round the radicle, as in Mustard, where they

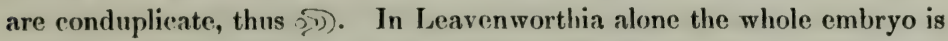
straight. - Leaves alternate, no stipules. Flowers in terminal racemes or corymbs: pedicels rarely bracted. - A large and very natural family, of pungent or acrid, but not poisonous plants. (Characters of genera taken from the pods and seeds; the flowers being nearly alike in all.)

I SIIIQUOSA. Poll long, a silique, opening by valves.

Tribe I. A A BIDEAE. Pod elongated (except in Nasturtium). Seeds orbicular or oval, more or less flattened. Cotyledons accumbent, plane.

* Seeds small and turgid, selilom half the brealth of the turgid pod.

1. Nasturtium. Pod terete, linear, oblong or even globular. Flowers white or yellow.

* Seeds flat or flattish, scarcely narrower than the partition, except in some of No. 5.

2. Leavenworthla. Pod oblong, flat; the valves nerveless. Seeds winged: embryo straight! Flowers white or purplish, with a yellowish base. Leaves all radical.

3. Dentaria. Pod flat, lanceolate; the valves nerveless, opening elastically from the base. Seeds wingless, on broad seedstalks. Flowers white or purple. Stem naked below.

4. Cardamine. Por flat, linear or lanceolate; the valves nerveless, opening elastically. Seeds wingless, on sleniler stalks. Flnwers white or purple. Stem lenfy, at least below.

5. Arnbis. Pod linear, elongated, flat or flattish, rarely almost terete; the valves commoniy with a prominent midrib, or veiny, not opening elastically. Flowers white, whitish, or purple. Stems leafy, at least below.

6. Bnrbarea. Pod linear, more or less 4 -sided, the rigid valves being keeled by a prominent midrib. Seeds wingless. Flowers yellow.

Tribe II. SISYM BRIEAE. Pod elongated. Seeds thickish, mostly oblong. Cotyledons incumbent, narrow, plane.

7. Frysimum. Pod sharply 4-angled, linear. Flowers yellow.

8. Sisy mbrium. Pods terete, 4-6-angled, or flattish. Flowers white or yellow.

Tribe II. BRAsstCEA. Pod linear or oblong. Seeds globular. Cotyledons incumbent and conduplicate, folded round the radicle.

9. Brassica (including Sinapis). Pod beaked or pointed beyond the end of the valves, or tipped with a rigid style, nearly terete, or 4-sided. Flowers yellow or whitish.

II. SILICULOSA. Pod short, a silicle or pouch, opening by valves.

Tribe IV. A LYSEINEA. Pod oval or oblong, flattened parallel to the broad partition, or glohular. Cotyledons accumbent, plane

1. Nasturtium. Pod terete or globular with many small seeds.

10: Draba. Pod flat, oval, oblong, or even linear, many-seeded.

11. A 1 у ssum. Pod flat, orbicular, 2-4-seederl.

12. Vesicaria. Pod globular-inflated, 4 -several-seeded.

Tribe V. CAMELINEAE. Pod turgid or somewhat flattened parallel with the broad partition. Cotyledons incumbent, narrow.

13. Camellna. Pod peur-shaped, many-seeded : style slender. Flowers yellow.

14. Subularin. Pod globular, few-seerled : style none. Flowers white.

Tribe VI. LEPIDINEAE and THIA SIDEAE. Pod short; the boat-shaped valves conduplicate or much flattened contrary to the narrow partition. Flowers white.

15. Capselln. Pod many-seeded, obcordate-triangular, wingless. Cotyledons incumbent.

16. ThInspl. Pod several-seeded, obovate or obcoriate, wingerl. Cotyledons accumbent.

17. Lepidinm. Pod 2-seeded, flat, scale-shaped. Cotyledons incumbent or accumbent.

13. Seneblera. Pod 2-seeded, dilymous ; the valves rugose, separating at maturity from the little partition as two closed one-seeded nutlets. Cotyledons incumbent, narrow. 
III. LOMENTACEAE. Pod articulated, separating across into joints.

Tribe VII. CA KIIINEAE. Cotyledons plane and accumbent, as in Tribe 1.

19. Cak1lo. Pod short, 2 jointud: the juints 1-celled and 1-seeded.

rribe VII I. IR A II A E Hc. (cotyledons conduplicate and incumbent, as in Tribe 3. 20. Raphanus. Pod elongated, geveral-secded, trausversely inturcepted.

\section{N A S T Ú R I U M, R. Br. Waten-Chess.}

Pod a short silique or a silicle, varying from oblong-linear to globular, terete or nearly so. Seeds small, turgid, marginless, in 2 irregular rows in each cell (except in No. 2). Cotyledons accumbent. - Aquatic or marsli plants, with yellow or white flowers, and commonly pinnate or pinnatifid leaves, usually glabrous. (Name from Nusus tortus, a convulsed nuse, alluding to the efliect of its pungent qualities.)

§1. Petals white, twice the length of the calyx: pods linear: leaves pinnate.

1. N. Ofricindle, R. Br. ('True Watek-Cress.) Stems spreading and rooting; leaflets $3-11$, roundish or oblong, nearly entire; pods ( $6^{\prime \prime}-8^{\prime \prime}$ long) ascending on slender widely spreading pedicels. 4-Brooks and ditches: escaped from cultivation. (Nat. from Eu.)

\$2. Petuls yellow or yellowish, seldom much excecding the calyx: pods linear, oblong, or even ovoid or ylobular: leaves mostly pinnatifid.

* Perennial from creeping or subternancun shoots: flowers ruther large, bright yellow.

2. N. sylvésthe, R. Br. (Ylloow Čress.) Stems ascending; leaces pinnately parted, the divisions toothed or eut, lanceolate or linear ; pods ( $\frac{1}{2}$ long) on slender pedicels, linear and narrow, bringing the seeds into one row; style very short. - Wet meadows, Massachusetts to Virginia : rare. (Nat. from Lu.)

3. N. sinuàtum, Nutt. Stems low, diffuse; leaves pinnately cleft, the short lobes nearly entire, linear-oblong; pods linear-oblong ( $4^{\prime \prime}-6^{\prime \prime}$ long), on slender pedicels; style slender. - Banks of the Mrississippi and westward. June. * * Annual or biennial, rarely perennial? with simple fibrous roots : flowers small or minute, greenish or yellowish: leaves somewhat lyrate.

4. N. sessiliflorum, Nutt. Stems erect, rather simple; leaves obtusely incised or toothed, obovate or oblong; flowers minute, nearly sessile; pods elongated-oblong ( $5^{\prime \prime}-6^{\prime \prime}$ long), thick; style very short. - W. Illinois to Teunessee and southward. April-June.

5. N. obtùsum, Nutt. Stens much branched, diffusely spreading; leaves pinnatly parted or divided, the divisions roundish and obtusely toothed or repand; flowers minute, short-predicelled; pods longer than the pedicels, varying from linearoblong to short-oval; style short. - With No. 3 und 4.

7. N. palústre, I)C. (Marsir Cress.) Stem erect; leaves pinnately cleft or purted, or the upper laciniate; the lobes oblong, cut-toothed; pedicels about as long as the small flowers and mostly longer than the oblong, ellipsoid, or ovoid pods; style short. - Wet places or in shallow water; cominon. JuneSept. - Flowers only $1^{\prime \prime}-1 \frac{1}{2}$ long. Stems $1^{\circ}-3^{\circ}$ high. - The typical form with oblong pods is rare (W. New York, Dr. Surtwell). Short pods and hirsute stems and leaves are common. Var. Hispidoum (N. hispidum, $D C$.) is a form, with ovoid or globular pods. (Eu.) 
\$ 3. Petals white, much longer than the caly $x$ : pod's ovoid or globular : leaves undivided, or the lower ones pinnatifid: root perennial, ( $\Lambda$ rmoracia.)

7. N. lacùstre, Gray, Gen, Ill. 1, p. 132. (LAkf Creas.) Aquatic; immerset leaves 1-3-pinnately dissected into numerous capillary divisions; emersel leaves oblong, entire, serrate, or pinnatifid; pedicels widely sprending; pods ovoid, one-celled, a little longer than the style. (N, natans, var. Americanum, Gruy. Armoracia Americann, Arn.) - Lakes and rivers, N. E. New York to Illinois and sonthwestward. July - Aug. - Near N. amphibium.

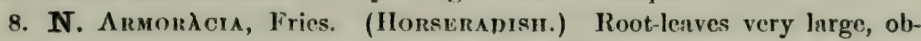
long, crenate, rarely pinnatific ; those of the stem lanceolate; fruiting pelicels ascending; pods globular (seldom formed); style very short. (Cochleària Armoracia, L.) - Roots large and long; - a well-known condiment. Fscaped from cultivation into moist ground. (Adv. from Fu.)

\section{LEA V E N W Ó R T H I A, Torr, Lenvenwortilia.}

Pod broadly linear or oblong, flat; the valves nerveless, but minutely reticulate-veined. Seeds in a single row in each ecll, flat, surrounded by a wing. Embryo straight! or the short radicle only slightly bent in the direction which if continuer would make the orbicular cotyledons accumbent. - Iittle biennial or hyemal annuals, glabrous and stemless, with lyrate root-leaves and short one-few-flowered scapef. (Named in honor of the late M. C. Ieavenworth.)

1. L. Michaúxir, Torr. - On flat rocks and barrens, S. E. Kentucky and southwestward : rare. March-May. - Scapes $2^{\prime}-4^{\prime}$ high. Petals purple, rose color, or nearly white, with a golden yellow or yellowish base, or rarely yellow throughout? (L. aurea, Torr.), cuncate-obcordate or emarginate; the flowers rather large for the size of the plant,

\section{DENTÀ R I A, I. Toothwort. Perper-root.}

Pod lanceolate, fiat, as in Cardamine, but broader. Scedstalks broad and flat. Cotyledons petioled, their margins somewhat infolding each other. Perennials, with long, horizontal, fleshy, sometimes interrupted, scaly or toothed rootstocks, of a pleasant pungent taste; the simple stems leafless below, bearing 2 or 3 petioled compound leaves about the middle, and terminated by a single corymb or short raceme of large white or purple flowers. (Name from dens, a tooth.)

1. D. diphylla, L. Rontstock long and continuous, toothed; stem-leaves 2, similar to the rudicul ones, close together, of 3 rhombic-ovate conrsely toothed leaflets; petals white. - Rich woods, Maine to Kentucky. May. - Rootstocks $5^{\prime}-10^{\prime}$ long, crisp, tasting like Water-Cress.

2. D. máxima, Nutt. Rootstock interrupted, forming a string of thick toothed tubers; stem-leaces $(2-7)$ mostly 3 and allernate; lraflets 3, ovate, obtuse, coarsely toothed and incised, often 2-3-cleft; petals pink. (I). laciniata, var. \&, Torr. \&. $G r_{\text {. }}$ - Northern New York (Watertown, Crawe; Utica, Painc) to Penn.: rare. May. - Seldom taller, but the leaves often smaller, than in No. 1.

3. D. heterophylla, Nutt. Routstoclo a chuiu of 2 or 3 narrow-oblong and obscurely toothed tulers; stem-leaves 2 or 3 , allernate (rarely opposite), dividod into L \& $\mathrm{M}-23$ 
3 lanceolate or lineur-dbony somewhat toothed (sometimes incised or 2-eleft) leaflets; root-leaves of 3 roumled or cunrate-imate incised lenflets; petals purple. - Penn.

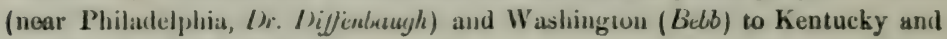
southward. April, May.

4. D. laciniàta, Mull. Ruotstock as in the last; stem-leaves 3 in a whorl, 3 paited; the leciflets lincur or lanccolate, irregularly cut or cleft into prominent narrow teeth, the lateral ones decply 2-lobed; routleaves similuily dissected; petuls pale purple or nearly white. - Rich soil alung streans, W. New Eugland to Wisconsin and Kentucky. April, May.

5. D. multífida, Muhl. More slender and delicate than the last; rootstock similar ; stem-leuics 3 or sometimes 2 , alteruate, opjusite, or whorled, finely 2-3-ternulely dividal, or the subdivisions parted, inte ecry nurrowly leneur labes; root-leaves similarly 3 -t-ternately divided; flowers $(4-7)$ white. - Suuthern Kentucky (duubtless) and sunthward. - This appears to pass into No. 4; and all these species execpt the first probably run together.

\section{Ca r d á mine, L. Bitter Cress.}

Pod linear, flattened, usually opening elastically from the base; the valves nerveless and veinless, or nearly so. Secels in a single row in each cell, wingless; their stalks slender. Cotyledons accumbent. - Elowers white or purple. (A Greek name, in D)ioscorides, for some Cress, from the cordial or cardiacal qualities.) - Runs into Dentaria on the one hand, into Arabis on the other.

* Root peremiul: leaves simple or 3-foliolate.

1. C. rhomboídea, 1)C. (SPring CкEss.) Stems upright fiom a tuberiferous base, simj le; rout-leaves round and rather heart-shaped; lower stem-leaves ovate or rhombic-obiong, somewhat petioled, the upper almost lanceolate, all soinewhat angled or sparingly toothed; pods linear-lanceulate, pointed with a slender style tipjed with a conspicuous stigma; seeds round-oval. - Wet meadows and springs; common. Flowers large, white. A pril-June.

Var. purpùrea, 'T'urr. Lower $\left(t^{\prime}-6^{\prime}\right.$ high $)$, and slightly pubescent; leaves rounder; flowers rose-purple, appearing earlier. - Along streams in rich soil, W. New York and S. Pennsylvania to Wisconsin and northward.

2. C. rotundifolia, Michx. (Molintain Watek-Cress.) Stemsbranchiny, weak or decumbent, making long runne's; root fibrous; leaves all much alike, romilish, sonewhat angied, often heart-shaped at the base, petioled, the lowest frepuently 3-folsed or of 3 leaflets; prols linear-awl-shaped, pointed with the style; stigma minute; secds occul-oblong. - f'ool shaded springs, P'ennsylvania and southward a!ong the menutains. May, Junc. - Leaves with just the taste of the true Water-Cress. Flowers white, smaller than in No. 1.

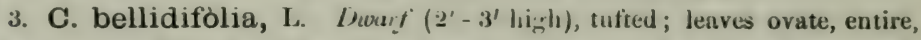
or sometimes 3 -lolsed ( $t^{\prime \prime}$ long), on long petioles; pods upright, linear; style nearly wone. - Alpine summits of the White Mountains und Katahdin, Maine (.J. W. C'hickering). July. - Elowers 1-5, white. I'uds I' long, turgid, the convex valves l-uerved. (Eu.)

* Root perenuial: laves pinnate: fluwers showy.

4. C. praténsis, L. (Cuckuo Fluwex.) Stem ascending from a short 
rootstock, simple ; leaflets $7-13$, those of the lower lenves rounded and stalked; of the upper ones oblong or linear, entire, or slightly angled-toothed; petals (white or rose-color) thrice the length of the calyx. - Wet places and bogs, Vermont to New Jersey, Wisconsin, and northward: rare. May. (Eu.)

* * Rnot mostly biennial or annual: leaves pinnate: flowers small, white.

5. C. hirsuta, L. (Smate Bitter Cress.) Beset with scattered hairs, or glabrous ; stems $\left(3^{\prime}-12^{\prime}\right.$ high $)$ erect or ascending from the spreading cluster of root-leaves; their leaflets rounded, those of the upper leaves oblong or linear and often confluent, all either toothed, angled, or entire; pods linear, slender, erect or asconding in line with the pedicel; style very short or almost none. (C. Pennsylvanica, Muhl.; usually taller and more leafy-stemmed than the true European C. hirsuta, the stamens always 6, and the pods less erect.) - Wet places: common. May-July. (Eu.)

Var. sylvática (C. sylvatica, Link., C. Virginica, Michx.) grows in drier places, is more slender, and has pods more erect than their ascending or spreading pedicels, the style evident. - Commoner sonthward. (Eu.)

\section{5. Á R A B I S, L. Rock Cress.}

Pod linear, flattened; the valves plane or convex, more or less 1-nerved in the middle, or longitudinally veiny. Seeds usually margined or winged. Cotyledons accumbent. - Leaves seldom divided. Flowers white or purple. (Name from the country, Arabia. See Linn. Phil. Bot. § 235.)

§ 1. Seeds in one row in each cell, being nearly as broad as the partition.

* Low, chirfly biennials, diffuse or spreading fiom the base.

1. A. Ludoviciana, Meyer. Nearly glabrous, often annual ; leaves all pinnately parted into oblong or linear few-toothed or entire divisions, those of the lower leaves numerous; flowers small, white; pods rather broadly linear and spreading, flat; seeds wing-margined. (Cardamine Ludoviciann, Hook.) Open grounds, Virginia? to Illinois and southward.

2. A. lyrata, L.' Root biennial; plant mostly glabrons, except the lyratepinnatifid root-leaves, stem-leaves scattered, spatulate or linear with a tapering base, sparingly toothed or entire; petals white, much longer than the yellowish calyx; pods long and slender, flat, ascending or spreading; the seeds marginless. - On rocks, New England to Kentucky along the mountains, Minnesota and northward. April - July. - Radicle sometimes oblique, or even dorsal.

A. Thamina, L., resembles the last, but the root-leaves are hardly if at all lyrate, the stem more strict, flowers smaller, and the cotyledons uniformly incumbent; so it is referred to Sisyıbrium, p. 70.

3. A. petræa, Lam. Root prenmial, multicipital; leaves sparingly pinnatifid-toothed or incised, sometimes entire; petals rose-color or nearly white; pods shorter and less flat than in A. lyrata: otherwise similar. - Rocks, I. Superior? Willoughby Mountain, Vermont, M. Mamn.

4. A. dentàta, Torr. \& Gray. Roughish-pubescent, slender $\left(1^{\circ}-2^{\circ}\right.$ ligh); leaves oblong, very ohtuse, unequally and sliarply toothed; those of the stem numerous, half-clusping and cared at the base, of the root broader and tapering into short petiole; petals (whitish) scarcely exceeding the calyx, 
pods widely spreading, very slender, short-stalked; style scarcely any; seeds marginless. - New York and Illinois to Virginia and Kentucky. May, June.

* * Erect and simple lerıfy-stemmed biennials, with white or whitish flowers, narrovo but flattened uscending or erect pods, and wingless seeds.

5. A. patens, Sulliv. Downy with spreading hairs, erect $\left(1^{\circ}-2^{\circ}\right.$ high $)$; stem-leaves oblong-ovate, acutish, coarsely toothed or the uppermost entire, partly clasping by the heart-shaped base; petals (bright white, $4^{\prime \prime}$ long) twice the length of the calyx; pedicels slender, spreading; pods spreading or ascinding, tipped with a distinct style. - Central Ohio (rocky banks of the Scioto, Sullivant), Pennsylvania (Huntingdon Co. to the Schuylkill, Porter); also in E. Tennessee. April, May.

6. A. hirsùta, Scop. Rough-hairy, sometimes smoothish, strictly erect $\left(1^{\circ}-2^{\circ}\right.$ high $)$; stem-leaves ol)lung or lanceolate, entire or toothed, partly clasping by a somewhat arrow-shaped or heart-shaped base; petals (greenish-white) small, but longer than the calyx ; pedicels and pods strictly upright; style scarcely any. - Rocks, common, especially northward. May, June. (Eu.)

*** Erect and simple leafy-stemmed biennials $\left(1^{\circ}-3^{\circ}\right.$ high $)$, with small whitish flowers, recurved-spitading or pendulous flat pods $\left(3^{\prime}-4^{\prime}\right.$ long), and broadly winged seeds, their stalks adherent to the partition.

7. A. lævigàta, DC. Simooth and glaucous, upright; stem-leaves partly clasping by the arrow-shined base, lanceolate or linear, sparingly cut-toothed or entire; petals searely longer than the calyx ; pods long and nurrow, recurvedspreading on ascending or merely spreading pedicels. ('This is also A. heterophylla, Nutt.) - Rocky places, Maine to Wisconsin and Kentucky. May.

8. A. Canadénsis, L. (SickLE-PO1.) Stem upright, smooth above; stem-leaves pubescent, point d at bolh ends, oblong-lanceolate, sessile, the lower toothed; petals twice the length of the calyx, oblong-linear; porls very flat, scythe-shaped, hanging on rough-hairy pedicels (2" wide). - (A. fillcàta, Michx.) Woods and ravines; not rare, especially westward. June-Aug.

**** Tall and leafy-stemmed biennials or perennials, with rather showy flowers, the pink-purple petals long-clawed; anthers sayittate and when old arcuaterecurved; the widely spreading and ruther short pods nearly terete; seeds marginless. (Iodantuis, Turr. \&. Gray.) - Transition to Thelypodium and Streptanthus.

9. A. hesperidoldes. Glabrous $\left(1^{\circ}-3^{\circ}\right.$ high $)$, often branched above; root-leaves round or heart-shaped, on slender petioles; stem-leaves ovate-oblong and ovate-lanceolate $\left(2^{\prime}-6^{\prime}\right.$ long $)$, nembranaceous, veiny, sharply and often doubly tootled, tapering to each end, the lower into a winged petiole, sometimes bearing a pair or two of small lateral lobes; pods on short diverging pedicels, pointed by a short style. (Hésperis pinnatifida, Michx. Iodanthus hesperidoides, Torr. \& (hray.) - Alluvial river-banks, Ohio, Kentucky aud southwestwird. May, June.

§ 2. TURRITIS, Dill. Seerls not so broad as the partition, occupying two more or less distinct rows in each cell, at least when young: strict and very lcafy-stemmed biennials; the cauline leaves parlly clasping by a sayillub base. (Very. gus- 
brous in the following species, except the base of the stem and the lower or tuft of radical leaves, these mostly hirsute.)

10. A. perfoliàta, Lam. (Tower Mustard.) Tall $\left(2^{\circ}-4^{\circ}\right.$ high); glancous; stem-leaves oblong or ovate-lanccolate, entire, half-clasping by the sagittrte base; petals yellowish-white, little longer than the calyx; pods very narrow ( $3^{\prime}$ long) and pedicles strictly erect. (Turritis glabra, L.) - Rocks and fields, scarce and perhaps introduced southward; more common northward. (Eu.)

11. A. Drummóndii, Gray. Scarcely glaucous, $1^{\circ}-2^{\circ}$ high ; stemleaves lincenlate or oblong-linear and sagittate $\left(1^{\prime}-2^{\prime}\right.$ long) with narrow auricles, or the lowest spatulate; petals white or rose-color, fully twice the length of the calyx; pericels and flat pods loosely erect, or ascending, or even spreading; seeds wingmargined, when mature little narrower than the partition. ('Turritis stricta, Groham.) - Rocky places, from the St. Lawrence in Canada East, to Lewiston (Clinton), Lake Superior, and northwestward; also "Chenango Co. New York," Northern Illinois, Vusey. - Pods $2 \frac{1}{2}$ ' $-3 \frac{1}{2}$ ' long, or in var. (T. brachycarpa, Torr. \& Gray) only $1^{\prime}-2^{\prime}$ long.

\section{B. B A R B A R ì A, R. Br. Winter Cress.}

Pod linear, terete or somewhat 4-sided; the valves being keeled by a midnerve. Seeds in a single row in each cell, marginless. Cotyledons accumbent. - Mostly biennials resembling Nasturtium ; flowers ycllow. (Ancicntly called The Herb of St. Barbara.)

1. B. vulgàris, R. Br. (Common Winter Cress. Yellow Rocket.) Smooth; lower leaves lyrate, the terminal division round and usually large, the lateral 1-4 pairs or rurely wanting; upper leaves obovate, cut-toothed, or pinnatifid at the base; pods erect or slightly sprealing; or in var. STRICTA, appressed; in var. ARCUATA, ascending on spreading pediccls. - Low grounds and roadsides : apparently introduced, but indigenous from L. Superior northward and westward. (Eu.)

2. B. PRìcox, R. Br. (EARLY Winten C.), with 5-8 pairs of lateral lobes to the leaves, and longer pods on very thick pedicels, - yet probably only a variety of the other, - somewhat cultivated from New York southward as a winter salad, under the name of Scurvy-Grass, - is beginning to run wild. (Eu.)

\section{7. · E Ý S I M U M, L. Treacle Mustard.}

Pod linear, 4-sided; the valves keeled with a strong midrib. Seeds in a single row in each cell, oblong, marginless. Cotyledons (often obliquely) incum. bent. Calyx erect. - Chicfly biennials, with yellow flowers; the leaves not clasping. (Name from é $\rho \dot{\omega} \omega$, to draw blisters.)

1. E. cheiranthoides, L. (Worm-seed Mustand.) Minutely roughish, branching, slender; leaves lanceolate, scarccly toothed; flowers small ; pods small and short (7" $-12^{\prime \prime}$ long), very obtusely angled, ascending on slender divergent pedicels. - Banks of streams, New York, Penn., Illinois, and northward. July. (Eu.)

2. E. ásperum, DC., var. Arkansànum, Nutt. (Wratern WALLrLowEr.) Minutely roughish-hoary ; stem simple; leaves lanceolate, some- 
what toothed; porls nearly erect on very short perlicels, elongated (3'-4' long), exactly 4-sided; stigma 2-lohed. - Ohio (on limestone cliffs) to Illinois, and southwesivard. June, July. - $1^{\prime}$ laut stout, $1^{\circ}-2^{\circ}$ high; the crowded bright orange-yellow flowers as latige as those of the Wall-flower. Petals orbicular, on very slender claws.

\section{Sis Ým B R I U M, L. Hedge Mustard.}

Pod terete, flattish, or 4-6-sided; the valves 1-3-nerved. Seeds oblong, marginless. Cotyledons incumbent. Calyx open. - Flowers small, white or yellow. (An ancient Greek name for some plant of this family.) Ours are annuals or biemnials.

1. S. officinale, Scop. (Hedge Mustarb.) Leaves runcinate; flowers very small, pale yellow; pods awl-shaped, close pressed to the stem, scarcely stalked. - Waste places. May - Sept. - An unsightly branched weed, $2^{\circ}-3^{\circ}$ high. (Nat. from Eu.)

2. S. Thalidna, Gaud. (Mouse-ear Cress.) Leaves obovate or ablong, entire or barely toothed; flowers white; pods linear, somewhat 4-sided, longer thin the slender spreading pedicels. (Arabis 'Thaliana, L.; the plant resembles $\mathbf{A}$. lyrata.) - Old fields and rocks, Massachusetts to Kentucky. April, May. A span high, slender, branched, hairy at the base. (Nat. from Eu.)

3. S. canéscens, Nutt. (TANsy Mustard.) Leaves 2-pinnatifid, often hoary or downy, the divisions small and toothed; flowers yellowish, very small; pods in long racenes, oblong-club-shaped or oblong-linear, shorter than their mostly horizontal pedicels; secds 2-ranked in each eell. - Penn. and New York (Lucifer Falls, Tompkins Co., J. W. Chickering) to Lake Superior, thence southward and westward. June-Aug.

S. Soruta, L., with slender linear pods nearly erect on ascending pedicels, and one-ranked sechls is nat. from Eu. in Canada Liast. - S. Incisus, Eingelm, differing only in the shorter pods widely spreading on horizontal pedicels, is wild beyond the Mississippi.

\section{B R Á S S I C A (Brassica and Sinùpis), Tourn.}

Pod linear or oblong, nearly terete or 4 -sided, with a stout $\mathbf{1}$-seeded beak or a rigid style; valves 1 - 5-nerved. Seeds globose, one-rowed. Cotyledons incumbent, folded around the radicle.-Annuals or biennials, with yellow flowers. Lower leaves mostly lyrate, incised, or pinnatifid. (The Latin name of Cabbage. Sinapis is the Greck Sivarı, which is said to come from the Celtic nup, a turnip.)

1. B. Sinarfarium, Boissice (or Sinapis arvénsis, I., the English CuarLOCK), with knotty porls, filly one third ocenpied by a stout 2-edged beak (which is either empty or onc-seceded), the upper leaves barely toothed, is a noxious weed in grain-ficlds, from Pennsylvania and New York westward. (Adv. from Eu.)

2. B. (or Sinapis) ália. (Winte Mustani).) Puds bristly, ascending on spreading pedicels, more than half its length oceupied by the sword-shaped oneseeded beak; leaves all pinnatifid; seeds pale. (Cult. and adv. from Eu.) 
3. B. (or Sindpis) nigra. (Brack Mustarn.) Pods smooth (党'long), 4-cornered (the valves only I-nerved), erect on appressed pedicels forming a slender raceme, tipped with a stout persistent style; seeds dark brown, smaller and more pungent than in the last; lower leaves with a large terminal lobe and $a$ few small lateral ones. - Fields and waste places, or cultivated. (Adv. from Eu.)

B. campéstris, L., in the form of the Rutabara and the Turnir, sometimes persists a year or two in neglected grounds.

\section{DRÀ B A, L. Wutrow-Grass.}

Pouch oval, oblong, or even linear, flat; the valves plane or slightly convex ; the partition broad. Secds several or numerous, in 2 rows in cach cell, marginless. Cotyledons accumbent. Calyx equal. Filaments not toothed. - Low herbs with entire or toother leaves, and white or yellow flowers; the pubeseence often stellate. (Name from $\delta \rho a \dot{\beta} \eta$, acrid, in allusion to the pungency of the leaves.)

§1. DRABA, DC. Petals not notched nor cleft.

* Perennial or biennial, leafy-stemmed: flowiers white: pods twisted when ripe.

1. D. ramosissima, Desv. Diffustly much branched and forming many radical tufts, perennial $\left(5^{\prime}-8^{\prime}\right.$ high), pubescent; leaves luciniute-loothed, linearlanceolate, the lower oblanceolate; racemes corymbosely-branched; pods hairy, oval-oblong or lanceolate $\left(2^{\prime \prime}-5^{\prime \prime} \mathrm{long}\right)$, on slender spreading pedicels, tipped with a long style. - Cliffs, Harper's Ferry, Natural Bridge, \& $\dot{c}$., Virginia to Kentucky River, and southward. April, May.

2. D. arábisans, Michx. Slightly pubescent, the perennial root bearing rather numerous radical tufts; flowering stems $\left(6^{\prime}-10^{\prime}\right.$ high) erect and mostly simple; leaves oblong-lancenlate, linear, or the lower spatulate, sparingly toothed; racemes short, usually simple; pods glabıous. oblong-lanccolate (5'-6' long), acute, on rather short and spreading pedicels, pointed with a short but distinct style. - Rocky banks, N. Vermont and New York towards the St. Lawrence, also Akron, Ohio (Clinton), and shores of I. Huron and L. Superior. May, June. - Petals rather large. Too near some forms of the next.

3. D. incana, L. Hoary-mehescent, biennial or somewhat perennial, the radical tuft seldom branching; leaves shorter, raceme more strict, petals smaller, and pods shorter and blunter than in the last, of en pubescent, on short erect pedicels; style very short or none. - Dry rocks, Willoughby Mountain, Vermont, Tuckerman, H. Mann.; also high northward. (Eu.)

* Annual or biennial: lenf!! stems short: Anvers white, or in No. 5 yellow: style none. (Ieaves oblong or obovate, hairy, sessile.)

4. D. brachycárpa, Nutt. Low $\left(2^{\prime} \bullet 4^{\prime}\right.$ high $)$, minutely pubescent; stems leafy to the base of the dense at length elongated raceme; leaves narrowly oblong or the lowest ovate $\left(2^{\prime \prime}-4^{\prime \prime}\right.$ long), few toothed or entire; flowers small; pods smooth, narrowly oblong, acutish (2" long), about the length of the ascending or spreading pedicels. - Dry hilla, Illinois, Kentucky, Virginia, A. II. Curtiss, and southward. $\Lambda$ pril. - Petals sometimes minute, sometimes none. 
5. D. nemorosa, I. Leares oblong or somewhat lanceolate, more or less toothed; racemes elonguted $\left(4^{\prime}-8^{\prime}\right.$ long in fruit); petals emarginate, small; pods elliptical-oblong, half the length of the horizontal or widely-spreading pedicels, pubescent (I). nemoràlis, Elih.), or smooth (D. lutea, $D C^{\prime}$.). - Fort Gratiot, Michigan, and northwestward. (Eu.)

6. D. cuneifolia, Nutt. Leaves obovate, wedge-shaped, or the lowest spatulate, toothed; raceme somochat elongated in fimit $\left(1^{\prime}-3^{\prime}\right)$, at length cqualling the naked peduncle; petals enarginate, mucls longer than the calyx; pods oblong-lincar, minutely huiry, longer than the horizontul pedicels. - Grassy places, Illinois, Kentucky, and southward. March, April.

7. D. Caroliniàna, Walt. Small $\left(1^{\prime}-5^{\prime} h i g h\right)$; leaves obovate, mostly entire; peduncles scape-like; petals usually twice the length of the calyx; ruceme short or corymlose in fruit $\left(\frac{1^{\prime}}{2}-1^{\prime} \mathrm{long}\right)$; pods broudly linear, snooth, much longer than the ascending pedicels. - Sandy and waste ficlds, Rhode Island to Wisconsin, and southward. March-May. - Petals often wanting in the luter racemes, especially in the

Var. micrántha (D. micrantha, Nutt.), with minutely rough-hairy pods. With the other, westward, Bebl, \&c.

§ 2. ERÓPIILA, 1)C. Petuls 2-cleft. (Annual or biennial: flowers white.)

8. D. vérna, L. (Wnitlow-Grass.) Small (scapes $1^{\prime}-3^{\prime}$ high); leaves all radical, oblong or lanceolate; racemes elongated in fruit; pods varying from round-oval to oblong-lanceolate. smooth, shorter than the pedicels. - Sandy waste places and róadsides. April, May. - Not found north of Lower Canada : perhaps introduced. (E⿺r.)

\section{ALÝ S U M, Tourn. AlYssum.}

Like Vesicaria but with a flat pouch : only one or two seeds in a cell : flower yellow or white. Filaments often toothed. (Greek name of a plant reputed to check the hiccup, as the etvmology denotes.) They are plants of the Old World, two adventive species deserving a mere mention, and one indigenous, rare and doubtful.

1. A. marf́timum, L. (Swrze Alyssum), with green or slightly huary linear leaves, honey-scented small white flowers, and 2-seeded pods, commonly cult., begins to be spontaneous southward. (Adv. from Eu.)

2. A. calycinum, L., a dwarf hour, annual, with linear-spatulate leaves, pale yellow or whitish petals little exceedingr the persistent caly $\mathrm{x}$, and orbicular sharp margined $t$-seeded porl, the style minute. oceurs in grass-land at Amberst, Mass., Tuckerman. (Adv. from IEn.)

3. A. Lescùrii. (Vesicaria? Lescurii, ed. 2.) Somewhat pubescent, but green; stems diffusely ascending from a biennial mot: leaves oblong or uval, sparingly toothed, those of the stem hulf-clasping by ". sagittate base; racemes elongated, many-flowered; pedicels ascending; filancerte inflated at the base; style half the lengeh of the hispid orbicular or broadly oval flat porl: seeds wing-margined, 1-4 in each cell, on free stalks. - Hills near Nashville. Tennessee, Leo Lesquereux. April, May. - Petals golden yellow, rather large Ambiguous between this genus and the next. 


\section{VESICA AIA, Tourn. Brader-Fod.}

Pouch globular or inflated, with $n$ broad mostly orbicular partition; the hemispherieal or convex thin valves nerveless. Seeds few or several, flat. Cotyledons accumbent. Filaments toothless. - Low herbs, pubescent or hoary with stellate hairs. Flowers mostly yellow. (Name from vesica, a bladder.)

1. V. Shórtii, Torr. \& Grny. Minutely hoary all over; stems spreading or decumbent from an annual or biennial root; leaves oblong or lanceolate with n tapering basc, repand-toothed or nearly entire; raecme nt length elongated, with filiform diverging pedicels; petals light yellow ; style filiform, much longer than the small globose about 4-seeded pod; seeds marginless. - Rocky banks of Elkhorn Creek near Lexington, Kentucky (Short), and Kentucky River near Frankfort, Lesquereux. May, June.

\section{CA M É L I A, Crantz. False Frax.}

Ponch obovoid or pear-shaped, pointed, turgid, flattish parallel to the broad partition: valves 1-nerved. Sceds numerous oblong. Cotyledons incumbent.

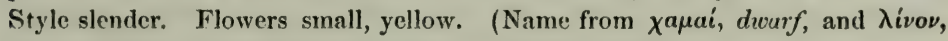
flax. It has been fancied to be a sort of degenerate flax.)

1. C. surtva, Crantz. $\Lambda$ nnual; leaves lanceolate and arrow-shaped; pods margined, large. A weed in flax-fields, \&c. (Adv. from Eu.)

\section{S U B U L À R I , L. Awtwont.}

Pouch ovoid or globular, with a broad partition; the turgid valves 1-nerved. Seeds several. Cotylerlons long and narrow, incumbently folded transversely, i. e. the cleft extending to the radicular side of the curvature Style none. $-\mathbf{A}$ dwarf stemless perennial, nquatic; the tufted leaves awl-shaped (whence the nnme). Senpe naked, few-flowered, $1^{\prime}-3^{\prime}$ high. Flowers minute, white.

1. S. aquática, L. - Margin of lakes in Maine, Nuttall, \&c. Echo Lake, Franconia, New Humpshire, Tuckerman. June, July. (Eu.)

\section{C A PSÉLLA, Vent. Sherherd's Purse.}

Ponch obcordate-triangular, flattened contrary to the narrow partition; the valves boat-shaped, wingless. Seeds numerous. Cotyledons incumbent. Annuals : flowers small, white. (Name a diminutive of cupsula, a pod.)

1. C. Bursa-pastòris, Mœnch. Root-leaves clustered, pinnatifid or toothed; stem-leaves arrow-shaped, sessile. - Waste places; the commonest of weeds. $\Lambda$ pril-Sept. (Nat. from Eu.)

\section{TH L Á S P I, Tourn. Pennycress.}

Pouch orbicular, obovate, or obcordate, flattened contrary to the narrow partition, the midrib or keel of the boat-shaped valres extended into a wing. Seeds 2-8 in each cell. Cotyledons accumbent. 1'etals equal. - Low plants, with root-leaves undivided, stem-leaves arrow-shaped and clasping, and small white or purplish flowers. (Ancient Greek name, from $\theta \lambda a \dot{\omega}$, to crush, of a Cress the seeds of which were bruised and used like Mustard.)

i $\mathrm{M}-4$ 
1. T. arvénse, L. (Field P. or Mituridite Mugfard.) A smooth annual, with broadly winger pod $\frac{1}{2}$ in dianeter, several-seeded, deeply notehed at top; style minute. - Waste places, shore of Lake Huron and in Lower Canada; also Virginia. (Nat. from Eu.)

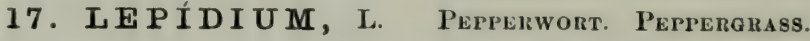

Pouch roundish, much flattened contrary to the narrow partition; the valves hoat-shaped and kecled. Seeds solitary in cach cell, pendulous. ('otyledons incumbent, or in No. 1 aceumbent! Flowers small, white or greenish. (Namo from $\lambda \epsilon \pi i \delta$ iov, a little scale, alluding to the small flat pods.) - Ours are annuals or bieunials, except the last.

* Leaves all with a tapering buse; the upper linear or lanceolate and entire, the lowir and often the midelle ones incised or pinnatifid: pods orbicular or oval, with a small notch at the top: the style minute or none: stamens only 2.

1. L. Virgínicum, L. (Wild Perpergisss.) Cotyledons accumbent and seed minutely margined; pod marginless or obscurely margined at the top; petals present, execpt in some of the later flowers. - June-Sept. A common roadside weed, which has immigrated firom firther South.

2. L. intermedium, Gray. Cotyledons incumbent as in the following; pod minutely wing-maryined at the top; petals sometimes conspicuous, rarely wanting; otherwise nearly as in No. 1. - Dry places, from Northern Michigan and Illinois northward and westward.

3. L. RLDERÀLe, L. More diffuse, the sinaller and oval pods and the seeds marginless; petals always wanting. - Roadsides, near Boston, Philadelphia, \&c.; not common. (Adv. fiom Eu.)

* * Stem-leaves with a sugittute partly clasping base, rather crowded.

4. I. Campéstré, L. Minutely soft downy; leaves arrow-shaped, somewhat toothed; pods oute, winged, rough, the style longer than the narrow notch. Old fields, Mass. and New York to Virginia : rare. (Nat. from Eu.)

5. L. Driвa, L. Perenuial, obscurely hoary; leaves oval or oblong, the upper with broad clasping auricles; flowers corymbose; pods heart-shaped, wingless, thickish, entire, tipped with a conspicuous style. - Astoria, near New York, D. C. Euton. (Ailv. fiom Eu.)

\section{S E N E B I E R A, DC. Wait-Cress. Swine-Cress.}

Pouch flattened contrary to the narrow partition; the two cells indehiscent, but falling away at maturity from the partition as closed nutlets, strongly wrinkled or tubereulate, 1-seeded. Cotyledons narrow and incumbently folded transversely. Low and diffuse or prostrate annuals or biennials, with minute whitish flowers. Stamens often ouly 2 . (I) dicated to .J. Sencbier, a distinguished vegetable physiologist.)

1. S. dídyma, P'ers. Icaves 1-2-pinnately purted; pods notched at the apex, rough-wrinkled. (S. pinnatífida, $D C$. Lepidium didymum, L.) - Waste places, at ports, Philadelphia to Virginia, \&c. : an immigrant from farther South. 
2. S. Coronòpus, IC. Leaves less divided, with narrower lobes; pods not notched at the apex, tubercled. Virginia, Pursh. Newport, Rhode Island, Robbins, \&c. (Adv. from Eu.)

\section{CA K İLE, Tourn. Sen-Rocket.}

Pod short, 2-jointer across, fleshy, the upper joint separating at maturity ; each indehiscent, 1-celled and 1-sceded, or the lower sometimes seedless. Seed erect in the upper, suspended in the lower joint. Cotylerlons obliquely accumbent. - Scaside fleshy annuals. Flowers purplish. ( $\Lambda$ n old $\Lambda$ rabic namc.)

1. C. Americana, Nutt. (American Sea-Rocket.) Leaves obovate, sinuate and toothed; lower joint of the frnit obovoid, emarginate; the upper ovate, flattish at the apex. - Coast of the Northern States and of the Great Lakes. July-Sept. - Joints nearly eren and fleshy when fresh; the upper one 4-angled and appearing more beaked when dry.

\section{R Á P H A U S, L. RaDisir.}

Pods linenr or oblong, tapering upwards, 2-jointed; the lower joint often secdless and stalk-like; the upper necklace-form by constriction between the seeds, with no proper partition. Style long. Seeds spherical as in Cabbage, \&c.- Annuals or biennials. (The ancient Greek name from épá, quickly, and

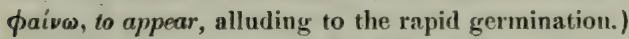

1. R. Raphanfotrum, L. (Wild Ranisif. Jointen Cinarlock.) Pods necklace-form, long-beaked ; leaves lyre-shaped, rongh ; petals yellow, turning whitish or purplish, veiny. - A troublesome weed in fields, E. New Lngland to Pennsylvania. (Adv. from Eu.)

R. sativus, L., GARDEN RADIsir, with pink-purple or whitish flowers, and thick knobby and pointed pods, with irregular fleshy partitions between the seeds, occasionally becomes spontancous for a year or two.

\section{Order 11. Cappatidàcea. (Caper Famuy.)}

Herbs (when in northern regions), with cruciform fowers, but 6 or more not telradynamous stamens, a 1-celled pod with 2 parietal placenta, and kidney-shaped seeds. - Pod as in Cruciferx, but with no partition : seeds similar, but the embryo coiled rather than folded. - Leaves alternate, mostly palmately compound. - Often with the acrid or pungent qualities of Cruciferz (as in capers, the flower-buds of Cápparis spinosa); also commonly bitter and nauseous. Represented within our limits only by

\section{POLA N ISIA, Raf. Polanisia.}

Sepals 4. Petals 4, with claws, notched at the apex. Stamens 8-32, unequal. Receptacle not elongated, hearing a gland behind the base of the ovary. Pod linear or oblong, veiny, turgid, many-seederl. - Fetirl annuals, with glandular or clammy hairs. Flowers in leafy racemes. (Name from $\pi$ on ús, mony, and avioos, unequal, points in which the genus differs in its stamens from Cleome.) 
1. P. gravèolens, Raf: Leaves with 3 oblong leaflets; stamens about 11, scarcely exceeding the petals : style short ; pod slightly stipitate. - Gravelly shores, fiom Conncticut (near Hartiond) and W. Vermont to Wisconsin and Kentucky. June - Aug. - Flowers small: calyx and filaments purplish: petals yellowish-white.

\section{Order 12. IB ESEDACEAE. (Mignonette Family.)}

Herbs, with unsymmetrical 4-7-merous smull flowers, a fleshy one-sided hypogynous disk between the petals and the $(3-40)$ stamens, bearing the latter. Calyx not closed in the bud. Pod 3-6-lobed, 3-6-horred, 1-celled with 3-6 parictul plucinter, opening at the top bejore the seeds (which are as in Order 11) are full grown. - Leaves alternate, with only glands for stipules. Flowers in terminal spikes or racemes. - A small and unimportant family, of the Old WVorld, represented by the Mignonette (Reseda odorata) and the Dyer's Weed.

\section{RES E $\mathbf{E}$ A, L. Mignonette. Dyer's Rocket.}

Petals 4-7, eleft, unequal. Stamens $12-40$, on one side of the flover. (Name from resclo, to calm, in allusion to supposed sedative properties.)

1. R. Lutèul, L. (DYer's Weed or Weld.) Leaves lanceolate; calyx 4-parted; putals 4, greenish-yellow; the upper one 3-5-cleft, the two lateral 3-cleft, the lower one linear and entire; pods depressed. - Roadsides, New York, \&c. $-1^{\prime}$ lant $2^{\circ}$ high. Used for dyeing yellow. (Adv. from Eu.)

\section{Order 13. Viokiceas. (Viulet Famly.)}

Herbs, with a somewhat irregular 1-spurred corolla of 5 petals, 5 hypogynous stamens with adnate introrse anthers conniving over the pistil, and a 1-cellerl 3-valved porl with 3 parietal placenta. - Sepals 5, persistent. Petals imbricated in the bud. Stamens with their short and broad filaments continued beyond the anther-cells, and often coherent with each other. Style usually club-shaped, with the simple stigma turned to one side. Valves of the capsule bearing the several-seeded placenta on their middle: after opening, each valve as it dries folds together lengthwise firmly, projecting the seeds. Seeds anatropous, rather large, with a hard seed-coat, and a large and straight embryo nearly as long as the albumen : cotyledons flat. - Leaves alternate, with stipules. Flowers axillary, nodding. (Roots slightly acrid or emetic.) - Two genera in the Northern United States.

\section{SÒLEA, Ging., DC. Green Violet.}

Sepals not prolonged at the base. Petals nearly equal in length, but the lower one larger and gibbous or saccate at the base, more nutched than the others at the apex. Stanens completely united into a sheath enclos- 
ing the ovary, and bearing a brond gland on the lower side. Style hooked at the summit. - A homely perennial herb, with stems leafy to the top, and $1-3^{\circ}$ small greenish-white flowers in the axils, on short recurved pedicels. (Named in honor of W. Sole, anthor of an essay on the British Mints.)

1. S. cóncolor, Ging. (Viola concolor, Pursh, \&c.) - Woods, New York to Illinois and southward. June. - Plant $1^{\circ}-2^{\circ}$ high. Leaves oblong, pointed at both ends, entire. Pod $1^{\prime}$ long.

\section{Vİ OLA, L. Violet. IIEART's-ease.}

Sepals extended into ears at the base. Petals somewhat unequal, the lower. one spurred at the base. Stamens closely surrounding the ovary, often slightly cohering with each other; the two lower ones bearing spurs which project into the spur of the corolla. Besides these conspicuous blossoms, which appear in spring, others are produced later (especially in the stemless species), on shorter peduncles or on runners, usually concealed under the leaves; these never open nor develop petals, but are fertilized in the young bud, producing pods which are far more fruitful than the ordinary blossoms. ('The ancient Latin name of the genus.)

\$ 1. Stemless Violets: the leaves and scupes all fiom a subterranean rootstock, flowering in early spring, and bearing fruitful apetalous flowers all summer.

* Flowers yellow: rootstock creeping and producing summer runners.

1. V. rotundifòlia, Michx. (Round-Leaved Violet.) Leaves roundovate, heart-shaped, slightly crenate; lateral petals bearded and marked with brown lines; spur very short. - Cold woods, Maine to Michigan, and south along the Alleghanies - Smoothis! : leaves $\mathbf{l}^{\prime}$ broad at flowering, increasing to $3^{\prime}$ or $4^{\prime}$ in the summer, then lying flat on the ground, shining above.

* Flowers white (small, short-spurred) ; lower petals striped with lilac veins : rootstock creeping and producing summer runners or subterraneun filiform branches. (No. 2 and No. 4, however different, seem to be connected by No. 3.)

2. V. lanceolata, L. (Lance-Leaved Violet.) Smooth; leaves lanccolnte, erect, blunt, tapering into a long-margined petiole, almost entire; petals beardless. - Damp soil, Maine to Illinois, Kentucky, and southward; common eastward.

3. V. primulæfolia, L. (Primrose-leaved V.) Sinooth or a little pubescent; leaves oblong or ovate, abrupt or somewhat heart-shaped at the base; petals often acute, the lateral ones usually sparingly bearded. (V. acùta, Bigelow.) - Damp soil ; with No. 2.

4. V. blánda, Willd. (SweEt Wnite V.) Leaves round-heurt-shuped or kidnry-form, minutely puheseent ; petals mostly beardless. - Damp places, everywhere, Maine to Wisconsin and Kentucky. - Flowers faintly sweet-scented.

*** Flowers purplish or violet: rootstocks slender and creeping, often producing numerous summer runners.

V. odorata, L. (SweEt or ENGlisi Violet), cultivated in gardens, from Europe, belongs to this section, and is becoming sparingly spontaneous in some places. 


\section{V. palústris, L. (Marsi V.) Smooth; leaves round-heart-shaped} and kidney-form, olightly erenate; flowers (small) pale lilac with purple streaks, nearly beardless; spur very short and obtuse. - $\Delta$ lpine suminits of the White Mountains, New Ilanpshire, and high northward. June. (Eu.)

6. V. Selkírkii, Pursh, Guldic, 1822. (Great-srunico V.) Simall and delicate; the filiform rootstock filsrose-rooted, no runners alove ground; smooth, except the round-heart-shaped crenate leaves, which are minutely hairy on the upper surface and have a deep narrowed sinus; spur viry lange, thickened at the end, almost as long as the beardless pale violet petals. (V. umbrosi, Fries, 1828. V. Kamtschatica, Gingins, 1826.) - Damp and shady soil, W. Massachusets to Chatauque Co., N. Y. (Clintom), L. Superior (Liobbins), and northward: rare. Scapes and petioles $1^{\prime}-2^{\prime}$, the leaf $\frac{1^{\prime}}{2}-14^{\prime}$ loug, thin ; the spur $3^{\prime \prime}$ long. (Eu.)

**** Flowers violet or purple (or rarely almost white) : rootstocks fleshy and thichened or tuberous, mostly eiect or ascending, producing neither runners nor runnerlike subterranaun branches.

7. V. cucullàta, Ait. (Common Buve V.) Rootstocks thickly dentate with fleshy teeth, branching and forming compact masses ; leaves all long-petioled and upright, heart-shorped with a broad simus, varying to kidney-shaped and dilatedtriangular, smooth, or more or less pubescent, the sides at the base rolled inwards when young, obtusely serrate; lateral and often the lower petals bearded; spur short and thick; stigma slightly beaked or beakless. - Low grounds, common everywhere. - Very variable in size, shape of leaves and sepals, and in the color and size of the flowers, which are deep or pale violet-blue or purple, some: times nearly white, or variegrated with white. Scapes $3^{\prime}-10^{\prime}$ high. Passes by intermediate forms of all sorts into

Var. palmàta. (HAND-LEAF V.) Leaves vuriously 3-i-clefi or parted, or the earlier ones entire on the same individual. (V. palmàta, L.) - Common, especially southivard.

Var. cordáta. Leaves chiefly round-heart-shaped and prostrate, sometimes villous, sometimes nearly glabrous, small. (V. villòsa and V. cordata, Wult. V. soròria, Willd.) - Common southward; a variety growing in drier soil or more exposed situations.

8. V. sagittàta, Ait. (Anuow-Lenved V.) Smoothish or hairy; leaves on short and maryined, or the later often on long and naked petioles, varying from oblong-heart-shaped to halberd-shiped, arrow-shaped, oblong-linnciolate or ovat', denticulate, sometimes cut-toothed near the base, the lateral or occasionally all the (pretty large purple blue) petals bearded; spur short and thick; stigma beaked. (V. ovàta, Nutt., anıl V. conarginàta, Le Conte, are states of this variable speeies.) - Dry or moist open places, New Eingland to Illinois and southward. Rootstock nearly as in the preceling, into which some forms seem to pass.

9. V. delphinifolia, Nutt. (Lakispuk V.) Liaves all palmately or pedately 5-7-parted, divisions 2-3-cleft; lobes linear; lateral petuls bearded; stigma short-benked; otherwise like the next. - Rich prairies, Illinois and westward.

10. V. pedàta, L. (Binv-root V.) Ncarly smooth; rootstock short and very thick, erect, not scaly ; leaves all 3 -5-divided, or the earliest only parted, the lateral divisions 2-3-parted, all linear or narrowly spatulate, sometimes 2 -: 
3-toothed or cut at the apex; petals beardless; stigma nearly beakless. - Sandy or gravelly soil, New England to Illinois and southward. - Flower large, $1^{\prime}$ broad, pale or deep lilac-purple or blue.

Var. bicolor. A very handsome variety, with the two upper petals deep violet, and as it were velvety, like a pansy, occurs sparingly from Massachusetts to Maryland, \&c.

\section{\$ 2. IEAFY-STEMMED Viotets: all but the last peremial from short rootstocks.}

* Leaf-bearing fiom base to summit, "sumlly branching and flowering all summer: stipules entive or barely toothed, not folinceons.

11. V. canína, L., var. sylvéstris, Regel. (1)og V.) Low ( $3^{\prime}-8^{\prime}$ high) ; stems ascending, mostiy simple, from the base at length producing creeping branches; leaves heart-shaped, or the lowest kilney-form, erenate, the uppermost slightly pointed; stipules lanceolate, fringe-toothed; spur cylindrical, half the length of the light violet pelals, the lateral ones slightly bearded; stigma beaked. (V. sylvestris, Lam. V. Muhlenbérgii, Torr., and former ed.) - Damp or wet shady places: common. May - July. (Eu.)

12. V. rostràta, Pursh. (Long-Spurred V.) Stems ascending $\left(3^{\prime}-6^{\prime}\right.$ high); leaves roundish-heart-shaped, serrate, the upper acute; stipules lanceolate, fringed-toothed, large; spur slender ( $\frac{1}{2}$ ' long), longre then the pale violet beardless petals; style straight and slender; stigna terminal, benkless. - Shaded hillsides, Maine to Ohio and Kentucky, and southwards in the Alleghanies: rather rare; June, July.

13. V. striàta, Ait. (PALE V.) Stems angular, ascending $\left(6^{\prime}-10^{\prime}\right.$ higb); leaves heart-shaped, finely serrate, often acute ; stipules oblong-lanceolate, large, strongly fringed-toothed; spur thickish, much shorter than the croam-colored or white petuls, the lateral ones bearded, the lower striped with purplish lines; stigma beaked. - Low grounds; common, especially westward. April-Oct.

14. V. Canadénsis, I. (Canada V.) Upright $\left(1^{\circ}-2^{\circ}\right.$ high); leaves heart-shaped, pointed, serrate; stipules orate-lancerlate, entire; petals white or whitish inside, the upper ones mostly tinged with violet beneath, the lateral bearderl; spur very short; stigma beakless. - Rich woods; common northward and along the Alleghanies. May-Aug.

* Simple stems erect, nalid below, 2-4-leaved above: stipules nearly entire: flowers yellow, in spring and carly summer: stigma bearded on each side.

15. V. pubescéns, Ait. (Downy Yeicow V.) Softly pubescent $\left(6^{\prime}-1\right.$ $12^{\prime}$ high); leaves very broadly heart-shrped, toothed, somewhat pointed; stipules ovate or ovate-lanceolate, large; spur extremely short; lower petals veined with purple. - Woods ; common.

Var. eriocárpa, Nutt. More pubescent, stout, $1^{\circ}-2^{\circ}$ high ; pods woolly. (V. eriocarpa, Schwein.) - Common westward.

Var. scabriuscula, Torr. \& Gray. Smaller and greener, slightly pubescent ; stems often decumbent $\left(4^{\prime}-10^{\prime}\right.$ high). - Rhode Island to Kentucky.

16. V. hastàta, Michx. (HaLrern-tanven V.) Nearly glabrous, slender $\left(4^{\prime}-10^{\prime}\right.$ high); stem-leaves hulberd-shoped or oblong-heart-shaped, slightly serrate, acute; stipules ovate, small; spur very short. - Woods, N. Ohio (near Painesville, Miss Shattuck), mountains of Penn., and southward : rare. 
* * Lenf-bearing throughout from an annual, biennial, or sometimes short-lived perennial root; the stipules large, lenf-like und lyrute-pinnatifid.

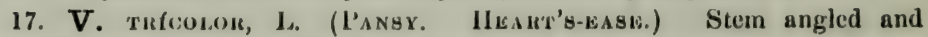
branched; leaves roundish, or the upper oval and the lowest heart-shaped, crenate or entire; petals variable in color or variegated (yellow, whitish, violet-blue and purple); - in var. ARvénsis shorter or little longer than the calyx. - Dry or sandy soil, New York to Illinois and southward: the variety sceming like a native plant. $\Lambda_{\text {pril }- \text { Sept. }}$ (Nat. from Eu.)

\section{Order 14. CISTÁCEA. (Rock-rose Famly.)}

Low shrubs or herbs, with regular flowers, distinct and hypogynous mostly indefinite stamens, a persistent calyx, a 1-celled 3-5-valved pod with as many parietal placente borne on the midlle of the valves, and orthotropous albuminous seeds. - Sepals 5 ; the two external often small, like bracts, or sometimes wanting; the three others a little twisted in the bud. Petals 3 or 5 , convolute in the opposite direction from the calyx in the bud. Anthers short, innate, on slender filaments. Style single or none. Ovules few or many, on slender stalks, with the orifice at their apex. Embryo long and slender, straightish or curved, in mealy albumen : cotyledons narrow. - Leaves simple and mostly entire, the lower usually opposite, and the upper alternate. (Inert plants. A small family: mostly of the Mediterranean region.)

1. Hellanthemum. Petals 5, crumpled in the bud, fugacious. Stamens and ovulea numerous in the petal-bearing flowers.

2. Hudsonia. Petals 5, fugacious. Stamens 9-30. Style long and slender. Pod strictly 1-celled, 2-6-sceded.

3. Lechea. Petals 3, persistent. Stamens 3-12. Style none. Pod partly 3-celled, the imperfect partitions bearing broad 2-seeded placenteo.

\section{HELIÁNTHEMUM, Tourn. Rock-Rose.}

Petals 5, crumbled in the bud, fugacious. Style short or none in our species: stigna 3-lobed. Capsule strictly l-celled. Embrjo curved in the form of a hook or ring. - Flowers in most N. American species of two sorts, viz., 1. the primury or earlier ones, with large petils, indefinitely numerous stamens, and many-seeded pods; 2. secondary, or later ones, which are much smaller and in clusters, with small petals or none, 3-10 stamens, and much smaller 3 -fewseeded pods. The yellow flowers open only once, in sunshine, and cast their

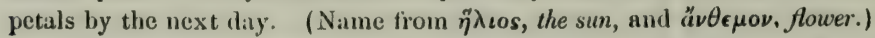

1. H. Canadénse, Michx. (Frost-wév.) Petal-bearing flowers solitary; the small secondury flouers clustered in the axils of the leaves, nearly sessile; calyx of the large flowers hairy-pubescent; of the small ones hoary, like the stem and lower side of the lanceolate-oblong leaves. $-\mathbf{A}$ variety is more hoary, and with a stronger tendency to multiply the minute clustered flowers. - Sandy or gravelly dry soil, Maine to Wisconsin and southward. June-Aug. - Stems at first simple. Corolla of the large flower $1^{\prime}$ wide, producing pods $3^{\prime \prime}$ long: 
pods of the smaller flowers not larger than a pin's head. - Late in autumn, crystals of ice shoot from the cracked bark at the root, whence the popular name.

2. H. corymbosum, Michx. Flowers all clustered at the summit of the stem or branches, the petal-bearing ones at length on slender stalks: calyx woolly. - Pine barrens, New Jersey and southward along the coast.

\section{H U D S Ò I I A, I. Hunsonia.}

Petals 5, fugacious (lanting but " day), much larger than the calyx. Stamens 9-30. Style long and slender: stigma minute. Pod oblong, enclosed in the calyx, strictly 1-celled, with 1 or 2 seeds attached near the base of each nerve-like placenta. Embryo coiled into the form of a closed hook. - Bushy heath-like little shrubs (seldom a foot high), covered all over with the small awl-shaped or scale-like persistent downy leaves, producing numerous (small but showy) bright yellow flowers crowded along the upper part of the branches. (Named in honor of $W m$. Hudson, an early English botanist.)

1. H. ericoldes, L. Downy but greenish; leaves slender, awl-shaped, loose; flowers on slender naked stalks, - Dry sandy soil near the coast, N. Maine to Virginia. May.

2. H. tomentosa, Nutt. Iloary with down; leaves ovul or narrowly oblong, short, close-pressed and imbricated ; flowers sessile (sandy coasts from Maine to Maryland), - or short-peduncled, the leaves also narrower: Maine (at Harrison, $J$. Blake) and along the shores of the Great Lakes to Minnesota. May, June.

\section{L安 CHEA, L. PINweE.}

Petals 3, narrow, flat in the bnd: not longer than the calyx, withering-persistent. Stamens 3-12. Style scarcely any: stigmas 3, plumose. Pod globular, partly 3-celled; the 3 broad and thin placenta borne on imperfect partitions, each bearing 2 seeds on the face towards the valve: in our species, the placenta curve backwards and partly encloge the seeds. Embryo straightish. - Homely perennial lrerhs, with very small greenish or purplish flowers, in summer. (Named in honor of .John Leche, a Swedish botanist.)

1. L. màjor, Michx. Hniry; stem upright $\left(1^{\circ}-2^{\circ}\right.$ high, stout $)$, simple, producing slender prostrate branches from the base ; leaves elliptical, mucronatepointed, alternate and opposite or sometimes whorled; flowe,s densely crowded in panicled clusters; pedicels shorter than the very small globose-triamyular pod; sejuls narrower than its valves. - Sterile grounds : common, especially southward.

2. L. thymifolia, Pursh. Hoary with appressed hairs, especially the decumbent stout leafy shoots from the base ; flowering stems ascending, loosely branched, with the leaves linenr or oblanceolate; those of the shoots elliptical, whorled, crowded; flowers scattered in small and loose clusters; pedicels as long as the globose pods. - Sandy const, Maine to New Jersey and southward. - Scarcely a foot high, tufted, rigid ; the pods larger than in No. 1.

3. L. Novæ-Cæsarè,, C. F. Austin, ined. Intermediate in appearance between No. 1 and the taller forms of No. 4 ; leaves of the former, but 
smaller ( $\frac{1}{2}$ ' long) elliptical or linear-oblorig, often opposite or whorled; flowers in narrow rather close panicles; pedicels longer than the oval pods; the two outer or Gruct-like sepals very stender, mastly longer than the ochers. - Upen dry grounds, N. New Jersey and anjacent part of New York, C'. F'. Austin.

4. L. minor, Lam. Minuely hairy; stems slender, upright or diffuse; leafy shoots densidy tufted at the base; leuves linear; flowers lwasely rucenad on the slender branchlets; perlicels mostly longer than the oval porls. - Dry open soil : common. June-Siph. - I'lant 5'-15' high, slender, running into numberless variations accorling $t$ ) the soil, scasun, and exposure. P'uds smabler than in No. 2.

\section{Order 15. Dirosericea. (Sundew Family.)}

Bog-herbs, mostly glandular-haired, with regular hypogynous flowers, pentamerous and withering-persistent calyx, corclla, and stamens, the anthers fixed by their middle and turned outwards, and a 1-celled pod wich twice as many styles or stignnus as there are parietal placentue - Calys imbricated. Petals convolute. Seeds numerous, anatropous, with a short and miunte embryo at the base of the albumen. - Leaves circinate in the bud, i. e. rolled up firm the apex to the base as in Furns. (A small family, of no known qualities, except a slight bitterness, \&c.; the Sundews impart a purple stain to paper.) Only one genus within our limits, viz.

\section{DRÓsERA, L. Susuew.}

Stamens 5. Styles 3, or sometimes 5, deeply 2-partel so that they are taken for 6 or 10, slender, stigmatose above on the inner fuce. Pod 3- (rarely 5-) valved; the valves bearing the numerous seeds on their middle for the whole length. - Low perennials or biennials; the leaves clothed with reduish glandbearing bristles, in our species all in a tuft at the base; the naked scape bearing the flowers in a 1 -sided raceme-like inflorescence, which nods at the undeveloped apex, so that the fresh-blown flower (which opens only in sunshine) is always highest. (The glauds of the leaves exude drops of a clear glutinous fluid, glittering like slew-llops, whence the name, from $\delta \rho o \sigma \epsilon$ pós, dewy.)

1. D. rotundifolia, L. (Round-Leaved Sunvew.) Laves orticular, abruptly narrowed into the spreuding hairy petioles; sceds spindle-shaped, the coat loose and chatf-like; flowers white, the parts sometimes in sixes. - PeatLogs, common, especially northward. July-Aug. (Eu.)

2. D. longifolia, I. Leucrs spatuhute-oblong, tupering into the long rather erect naked petiviles; seeds otlong, with a rungh cluse cont; flowers white. (D. intermedia, Hayne.) - Bogs; less common. June-Aug.-Plant raised un its prolonged caudex when growing in water. (Eu.)

3. D. lineàris, Guldic. (Shenden Susplw.) Leaies lineur, obtuse, the blate $\left(2^{\prime}-3^{\prime}\right.$ long, scarcely $2^{\prime \prime}$ wide $)$ on nuked erect petivles about the sume length; seeds oblong, with a snooth and perfuctly close cuat; flowers white. - Shore of Iake Superior. July. 
4. D. fllifórmis, Raf. (Turfan-leaven Sundew.) Leaves very long and filform, erect, with no distinction between blade and stalk; seeds spindleshaped; flowers numerous, purple rose-color ( $\frac{1^{\prime}}{2}$ broad). - Wet sand, near the coast, l'lymouth, Massachusetts to New Jersey, and southward. Aug. Scapes $6^{\prime}-12^{\prime}$ high, and the singular leaves nearly as long, from a bulb-like base or corn.

Dronda muscfoula, Ellis, the Venus's Fuy-trap, - so noted for the extraordinary irritahility of its leaves, closing quickly at the touch, - is a native of the sandy savannas of the eastern part of North Carolina. It differs in several respects from the character of the order given above; the stamens being 15 , the styles united into one, and the seeds all at the base of the pod.

\section{Order 16. HYPEIRICÀCEAE. (St. Join's-wort Family.)}

IIerbs or shrubs, with opposite entire dotterl leaves and no stipules, regular hypogynous flowers, the petals mostly oblique and convolute in the bud, and many or few stamens commonly collected in 3 or more clusters or bundles. Pod 1-celled with 2-5 parictal placenta, and as many styles, or 3-7-celled by the union of the placenta in the centre: dehiscence mostly septicidal. Sepals 4 or 5, imbricated in the bud, herbaceous, persistent. Petals 4 or 5, mostly deciduous. Styles persistent, at first sometimes united. Seeds numerous, small, anatropous, with no albumen. Embryo cylindrical. Plants with a resinous juice (acrid and balsamic), dotted with pellucid or dark glands, usually smooth. Leaves mostly sessile. Flowers sclitary or cymose.

1. Ascyrum. Sepals 4 , very unequal. Petals 4 , oblique, convolute, yellow.

2. Hypericuin. Sepals 5. Petals 5, oblique, convolute, yellow.

8. Elodes. Sepals 5. Petals 5 , equal-sided, imbricated, purplish. Glands alternating with the stamen-clusters.

\section{1. Á S C Y R U M, L. St. Peter's-wont.}

Sepals 4 ; the 2 outer very broad and leaf-like; the inner much smaller. Petals 4, oblique, very deciduous, convolute in the bud. Stamens numerous; the filaments distinct and scarcely in clusters. Pod strictly 1-celled, 2-4valved. - Low, rather shrubby, smooth plants, with pale black-dotted leaves, and nearly solitary light yellow flowers. (An ancient Greek name of some plant, from $a$, without, and $\sigma$ kúpos, roughness.)

1. A. stáns, Michx. (St. Peter's-wort.) Stem rather simple, 2-edged, $1^{\circ}-2^{\circ}$ high, stout; leaves oval or oblong, sommhat clnsping, thickish; petals oborate; styles 3 or 4. - Pine barrens, Long Island to P'enn. and southward. July, $\Lambda$ ug. - Flowers showy, almost sessile : outer sepals round-heart-shaped.

2. A. Crux-Ándreæ, L. (ST. Andrew's Cross.) Low, much branched and decumbent; leaves narrowly obovote-oblong, contracted at the base, thin; petals linear.oblong; styles 2, very short; pod flat. - I'ine barrens, New Jersey to Illinois, and southward. July-Sept. - Petals searcely cxcecding the outer sepals, npproaching cach othor in pairs over them, in the form of a St. Andrew's cross. 


\section{H Y P É R I C U M, L. ST. JoHN'8-wORT.}

Sepals 5, somewhat equal. Petals 5, oblique, convolute in the bud. Stamens commonly united or clustered in 3-5 parcels : no interposed glands. Yod 1-celled or 3-5-celled. Seeds usually cylindrical. - Herbs or shrubs, with cymose yellow flowers. (An ancient Greek name, of obscure meaning.)

\$1. Stamens very numerous, 5-adelphous: pod 5-7-celled, with the placentce turned far back into the cells: perennial: flowers very large: styles united.

1. H. pyramidàtum, Ait. (Great Str. John's-wort.) Branches 2-4-angled; leaves ovate-ublong, partly clasping; petals narrowly obovate, not deciduons until after they wither; stigmas capitate. - Banks of rivers: rare. New England and Penn. to IVisconsin and Illinois. July. - Plant $3^{\circ}$ 50 high. Leaves $2^{\prime}-3^{\prime}$ long. Petals $I^{\prime}$ long. Pod 3 long, conical.

§ 2. Stamens very numerous, obscurcly if at all clustered: ryles 3 (No. 2 excepted), more or less uniled into one and the sepuls fuliaceous, except in No. 9.

* Busluy slirubs, $1^{\circ}-6^{\circ}$ high, leafy to the top : pod 3-5-celled.

2. H. Kalmiànum, L. (Kals's ST. John's-wort.) Branches 4angled : branchlets 2-eilged; leaves crowded, glaucous, oblanceolate (1'-2' long); flowers feir in a cluster (1' wide); pods ovale, 5-celled. - Wet rocks, Niagara Falls and Northern lakes. Aug.

3. H. prolíficum, L. (Sirndвв St. Jonn's-wort.) Branchlets 2edged; leaves lanceolate-oblong, mostly obtuse, narrowed at the base; flowers numerous, in single or compound cluster's; pods oblong, 3-celled. - New Jersey to Michigan, Illinois, and southward. July-Sept. - Varies greatly in size, \&c.

Var. densiflorum. Excedingly hranched above, $1^{\circ}-6^{\circ} \mathrm{high}$, the branches slender and crowded with smaller leaves; flowers smaller $\left(\frac{1}{2}{ }^{\prime}-\frac{2}{3}\right.$ in diameter) and more numerous, in crowded compound cymes. (H. densiflorum, \& H. galioides, Pursh.) - Pine barrens of New Jersey to glades of Kentucky, and southward.

* * Peremial herbs or in No. 5 and 6 a little unodly at the base: pod one-celled with 3 parietal placentae, or incompletely 3-4-celled.

4. H. adpréssum, Barton. Stem simple, herbaceous, from a slightly woody crecping base $\left(1^{\circ}-2^{\circ}\right.$ high $)$, obscurcly 4 -angled below and 2 -edged above; lates ascending, lanceolute or linear-oblong, often acute, thin; cyme leafy at the lase, few-flowered; sepuls linear-lanceolnte; pods ovoid-olilong, partly 3-4 celled. Moist places, Rhode Islanil (Ohey), New Jersey, Peunsylvania, and southwestward. July-Aug. - Leaves $1 \frac{1}{2}{ }^{\prime}$ long. Petals bright yellow, $3^{\prime \prime}-5^{\prime \prime}$ long.

5. H. dolabrifórme, Vent. Stems branched froin the decumbent base, woudy below $\left(6^{\prime}-2\right)^{\prime}$ high $\left.h_{1}\right)$, terete; leaves linear-lanceolate, widely spreading, veinless; cyme leafy, few-flowered; sepals oblong or ovate-lanceulate, about the length of the very ublique petals (5" $-6^{\prime \prime}$ long); pods ovate-conical, pointed, strictly 1-celled, the walls very thick and hard. (II. procumbens, Michx.)-Dry hills and rocks, barrens of Kentucky and westward. June-Aug.

6. H. nudiflorum, Michx. Stems branched, woody at the base, sharply 4 -angled or almost winged above $\left(2^{\circ}-4^{\circ}\right.$ high $)$; leaves oblong or oval-lanceolate, obtuse, obscurely veined, pale $\left(2^{\prime}-22^{\prime}\right.$ long $)$; cyme compound, many-flowered, 
nnked ; sepals oblong; pods ovate-conical, pointed, almost 3-celled; seeds slender cylindrical, minutcly pitted. - Low grounds, Pennsylvania, Virginia, and southward. July.

7. H. sphærocárpon, Michx. Stems mostly simple, herbaceous, with a somewhat woody base, angled with 4 very narrow salient lines $\left(1^{\circ}-2^{\circ}\right.$ high $)$; leaves oblong-linear, greener above and narrower than in the preceding; the naked cyme similar; sepals ovute; pods depressed-globular or ovoid-conical, strictly 1-celled; sceds oblong, rough-pitted. - Rocky banks of the Ohio and its tributaries, S. W. Ohio to Illinois and southward. July-Sept. - Flowers small.

8. H. ellifpticum, Hook. Stem simple, herbaccous ( $1^{\circ}$ high), obscurely 4-angled; leaves spreading, elliptical-oblong, obtuse, thin; cyme nearly nuked, rather few-flowered; sepuls oblong; pods ovoid, very obtuse, pmrple, 1-celled. Wet places, New England and Pennsylvania to Lake Superior and northward. July, Aug. - Petals light yellow, 3 " long.

9. H. anguldsum, Michx. Stem slender, strict, simple, sharply 4angled, herbaceous $\left(1^{\circ}-2^{\circ}\right.$ high $)$; leaves ascending, opaque, ovate or oblonglanceolnte, acute $\left(\frac{1^{\prime}}{2}-1^{\prime}\right.$ long), closely sessile by a broad base; cyme compound, naked, the scattered flowers racemose on its ascending branches; sepals herbaceous, erect, enclosing the ovoid 1-celled pod; syles 3, separate. - Wet pine barrens of New Jersey and southward. July-Sept. - Petals copper-yellow, $4^{\prime \prime}-5$ " long, furnished with a tooth on one side.

\$ 3. Stamens very numerous, in $\mathbf{3}$ or $\mathbf{5}$ clusters : styles $\mathbf{3}$ separate and usually diverging: pod 3-celled: calyx erect: petals and anthers with black dots.

10. H. Perforatum, L. (Common St. John's-wort.) Stem much branched and corymbed, somewhat 2-edged (producing runners from the base); leaves elliptical-oblong or linear-oblong, with pellucid dots ; petals (deep yellow) twice the length of the lanceolate acute sepals; flowers numerous, in open leafy cymes. - Fields, \&c. June-Sept. - Too well known as a pernicious weed, which it is difficult to extirpate. Juice very acrid. (Nat. from Fu.)

- 11. H. corymbosum, Muhl. Conspicuonsly marked with both black and pellucid dots: stem terete, sparingly branched; leaves oblong, the base either obtuse or somewhat clasping; flowers crowded (small); petals pale yellow, much longer than the oblong sepuls, styles not longer than the pod. - Damp places; common. July-Sept. - Leaves larger and flowers much smaller than in the last : petals $2^{\prime \prime}-3^{\prime \prime}$ long, marked with black lines as well as dots. - Too near H. maculàtum, Wrilt., of the South, which has more elasping leaves and very long and slender styles.

12. H. gravèolens, Buckley. Like the last, but with larger leaves and fewer much larger bright yellow flowers, lanceolale acute sepals, and long erect styles; common in the mountains of N. Carolina, doubtless also in S. Virginia.

§ 4. Stamens 5-12, distinct or in 3 clusters: pod (brown purple) 1-celled, with 3 strictly parietal placentee: styles short, distinct; petals oblong or linear : sepals narrow, evect: slender annunls, with 4-angular branches; flowering all summer.

13. H. mùtilum, L. Stem flaccid, widely branching $\left(6^{\prime}-10^{\prime}\right.$ high $)$; leaves ovate or oblong, obtuse, partly clasping, 5-nerved; cymes leafy ; pods orateconical, rather longer than the calyx. (H. parviflorum, Muhl.) - Low grounds, every where. - Flowers $2^{\prime \prime}$ broad. 
Var. gymnánthum (H. gymnanthum, Engtlm. \&. Gray), is a form, or perhaps species, with strict sten and branches, or oftur unbranched, more clasping heart-shaped stem-leaves, and a naked cyme, the floral leaves being reduced to small awl-shaped bracts; so that in aspect it approaches the next. - Newcastle Co., Delaware, Canby, and Illinois, E. Hall, thence southward.

14. H. Canadéuse, L. Stem strict $\left(6^{\prime}-15^{\prime}\right.$ high), with the branches ereet; leaves linear, 3-ricivel at the base, obtuse ; cymes naked; porls conical-oblong, usuaily much longer than the culyx. - Wet, sandy soil : common. June - Oct. Flowers deep yellow, $2^{\prime \prime}-3^{\prime \prime}$ broad when expanded.

Var. màjor is a large form, $1^{\circ}-2^{\circ}$ high, with lanceolate leaves $1_{\frac{1}{2}}^{\prime}$ long, 3 " wide, the upper acute. - L. Superior, liublins; S. New York and southward.

15. H. Drummóndii, 'T'vr. \& Gray. Stem and the mostly alternate bushy branches rigid, crect $\left(10^{\prime}-18\right.$ high); leaves linear-subuhate, nearly erect, 1-nerved ( $3^{\prime \prime}-9^{\prime \prime}$ lung); flowers scattered along the upper part of the leafy branches, short-pedicelled; poils ovvid, not longer than the calyx. (Sarothra Drunmondii, Grev. \& (look.) - W. Illinois and southward, in dry soil.

16. H. Salothra, Michx. (Orange-grass. Pink-Wekd.) Stem and bushy branches thread-like, wiry $\left(4^{\prime}-9^{\prime}\right.$ high); leaves minute aul-shaped scules, uppitssed; fluwers minute, mostly sessile and scattered along the ereet branches; pods ovate-lanceolute, acute, much longr.r than the calyx. (Sarothra gentianoides, L.) - Sandy fields: common. June-Oct.

\section{ELÒDES, Adaus. Marsir St. John's-wort.}

Sepals 5, equal, erect. Petals 5, cqual-sided, oblong, naked, imbricated in the bud. Stamens 9 (rarely more), united in 3 sets; the suts separated by as many large orange-colored glands. Pod 3-celled, oblong: styles distinct. Perennial herbs, in marshes or shallow water, with small close clusters of tleshcolored flowers in the axils of the leaves and at the summit of the stem. (Name $\epsilon \lambda \omega \dot{\delta} \eta s$, yrowing in maishes, accidentally changed to EloDÈ by Jussieu, who was followed by Pursh, \&e.)

1. E. Virgínica, Nutt. Leaves closely sessile or clusping by a broud buse, oblong or ovate, very obtuse; filaments united below the middle. (Hypericum Virginicum, L.) - Conmon in swamps. July, Aug.

2. E. petiolàta, l'ursh. Leaves tapering intu a short petiole, oblong: filaments united beyond the middle. - From New Jersey south and westward.

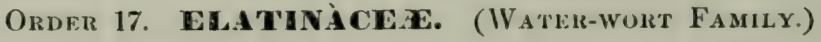

Litlle marsh ammuals, with mombranarcous stipules between the opposile dolless leaves, minule aillary flovers like Chickweeds, but the pod 2-5celled, and the seeds us in St. John's-wort. The principal genus is

\section{ELÁTING, L. WATER-Wort.}

Sepals $2-4$, persistent. Petals $2-4$, hypogynous. Stamens as many, rarely twice as many, as the 1 rtals. Styles, or sessile capitate stigmas, 2-4. Pod $2-$ 4-celled, several-many-seeded, 2-4-valved; the partitions left attached to tho 
nxis, or eranescent. Seeds cylindrical, straightish or curved. ( $\Lambda$ Greck name for some obscure herb.)

1. E. Americana, Arnott. Dwarf ( $1^{\prime}$ high), creeping, rooting in the mud, tufted; leaves obovate ; flowers sessile; sepals, petals, stamens, and stigmas 2, rarely 3 ; seeds 5 or 6 in each cell, rising from the base. (Peplis Americana, Pursh. (Crypta minima, Nutt.) - Margin of ponds, \&c., N. Hampshire, to Illinois, Virginia, and sonthwestward. l'od very thin and delicate; the seeds large in proportion, straightish.

\section{Order 18. CARYOHHYLLACEAE. (Pink Family.)}

Herbs, with opposite entire leaves, symmetrical 4-5-merous flowers, with or without petals; the distinct stamens no more than twice the number of the sepuls, either hypogynous or perigynous; styles 2-5 (or rarely united into one); seeds attached to the base or the central column of the 1-celled (rarely 3-5-celled) pod, with a slender embryo coiled or curved around the outside of mealy albumen, in Dianthus nearly straight. - Bland herbs; the stens usually swollen at the joints; uppermost leaves rarely alternate: Leaves often united at the base. Caly $x$ persistent. Styles stigmatic along the inside. Seeds amphitropous or campylotropous.

Tribe I. SILEN ER. Sepals united into a tube or cup. Petals and stamens borne on the stipe or stalk of the ovary, the former with slender claws, to the base of which the corresponding flaments often adhere, included in the caly $x$-tuhe, mostly convolute in the bud. Seeds numerous. - Stipulez none. Flowers often large and showy.

- Calyx with scaly bractlets or small leuves at the base. Sceila flattened on the back, attached by their face : embryo nearly straight.

1. Dlanthus. Calyx terete, mostly cylindrical. Styles 2 .

* Calyx naked. Seeds globular or kidney-shaped : embryo curved or coiled.

2. Saponaria. Calyx tercte. Styles 2

3. Vucenrla. Caly $\times 5$-angled and in fruit 5-winged. Styles 2.

4. Silene. Calyx 5-toothed. Styles 3 .

5. Iy chnig. Calyx 5 toothed or 5-lobed. Styles 5, rarely 4.

Tribe II. A LSINEAE. Sepuls sepurate to the base or nearly so, imbricated in the bud. Petals when present without claws, inostly imbricated in the bud, and with the stamens inserted at the base of the sessile ovary, or into $a$ little disk which often coheres with the base of the calyx. Pod splitting into valves or teeth, several-many-seeded. Stamens opposite the gepals, when not more numerous than they. - Low herhs. Stipules none.

* Styles opposite the sepak, or, when ferrer, opposite those which are exterior in the bud.

6. Arevaria. Petals entire. Styles usually 3. Pod short, splitting into 3 or 6 valves.

7. Stellnrin. Petals 2-cleft or none. Styles usually 3 Porl short, splitting to the base.

8. Holostemm. Petals denticulate or notched at the end. Styles usually 3. Pod opening at the apex by 6 teeth. Seeds fixed by their face.

9. Cerastium. Petals notched at the end or 2-cleft. Styles 5 or 4 (as many as the petals). Pod usually elongated, opening at the apex by 10 or 8 teeth. Seeds fixed edgewise.

* : Styleg alternate with the sepals : stamens as many as they, sometimes twice as many.

10. Sagina. Petals 4 or 5, undivided, or noue. Styles 4 or 5. Pod 4-5-valved.

Trlbe II. ILLECEBR F.A. Sepals separate or more or less united below. Petald without long claws, or minute. or often none, Inscrted unler the sessile ovary or on the calyx. Pod 1-celled and splitting into valves, or a one-seeded utricle. - Leaves with dry, 
scale-like stipules (except in Scleranthus), the uppermost sometimes alternate. Flowen mostly smatl.

* Poil (cupsule) many-seceled. Styl-s 3 - 5. Petals usually conspleuous.

11. Spergulnrlu. Stylıs 3-6. Javes opposite.

12. Spergulu. Styles 5. Valves of the pod opposite the sepals. Leaves whorled.

* * Pod (utricie) 1-seeded. Styles 2, often united. Petals none or minute.

13. Anychia. Stuneus on the base of the 5 -parted awuless calyx. Style hardly any.

14. Paronychia. Stamens on the base of the 6-parted calyx; the sepals bristle-pointed. Style 1, two-cleft at the top.

15. Seleranthus. Staniens borne on the throat of the indurated 6-eleft and pointless caly $x$. Styles 2. Stipules nove.

Tribe IV. MOLI.UGINERE. Stamens alternate with the sepals when of the same number, when fewer alteruate with the cells of the 3-celled ovary. Partitions of the pod persistent on the valves. Leaves not truly opposite, otherwise as in Tribe II.

16. Molluggo. Petals none. Stameus 3-5. Stigmas 3. Pod many-seeded.

\section{DI Á NTHUS, L. Pink. Carnation.}

Calyx cylindrical, nerved or striate, 5 -toothed, subtended by 2 or more imbricated bractlets. Stamens 10. Styles 2. Pod 1-celled, 4-valved at the apex. Seeds flattish on the back: embryo scarcely curved. - Oruamental plants, of well-known aspect and value in cultivation. (Nane from $\Delta$ cós, of Jupiter, und

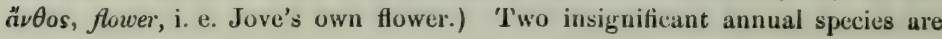
rarely spontaneous.

1. D. Armèria, L. (Depteond Pink.) Flowers in close clusters; bractlets of the calyx and bracts lance-awl-form, herbaceous. downy, as long as the tube; leaves linear, hairy; petals small, rose-color with white dots, crenate. Fields, \&c., Virginia to E. Massachusetts. July. - (Adv. from Eu.)

2. D. Prólifer, L. (Proliferous Pink.) Smouth, slender; flowers clustered ; bractlets ovate, dry, concealing the calyx ; leaves few, narrow, linear, erect; petals small, pink. - Near Philidelphia, C. E. Smith. (Adv. from Lu.)

\section{SA PON A RIA, L. SoAPWORT.}

Calyx tubular, terete, nerveless, 5-toothed, naked at the base. Stamens 10. Styles 2. Pod short-stalked, 1-celled, or partly 2-celled at the base, 4-toothed at the apex.- Flowers clustered. (Name from sapo, soap, the mucilaginous juice forming a lather with water.)

1. S. officinalis, L. (Common Soapwort. Bouncing Bet.) Clusters corymbed; petals crowned with an appendage at the top of the claw; leaves oval-lanceolate. - Roadsides, \&c. July - Sept. - A stout pereunial, with large rose-colored flowers, commonly double. (Adv. fiom L̀u.)

\section{V A C C À R I A, Medik. Cow-Herb.}

Calyx naked at the base, ovoid-pyramidal, 5-angled, 5-toothed, enlarged and wing-angled in fruit. Petals not crowned. Stamens 10. Styles 2. Pod incompletely 4-celled at the base. - A smooth annual, with pale red flowers in corymbed cymes, and ovate-lanceolate leaves. (Name from vacca, a cow.)

1. V. vulgaris, Host. (Saponaria Vaccaria, L.) - Escaped from gardens and becoming spontaneous in some places. (Adv. from Eu.) 


\section{SILÈ E, L. Catcifly. Campion.}

Calyx 5-toothed, 10-many-nerved, naked at the base. Stamens 10. Styles 3, rarely 4. Pod 1-celled, sometimes 3-celled at least at the hase, opening by 3 or 6 teeth at the apex. - Flowers solitary or in cymes. Petals mostly crowned with a scale at the base of the blade. (Name from $\sigma i a \lambda o v$, saliva, from the viscid exudation on the stems and calyx of many species. The English name Catchfly alludes to the same peculiarity.)

* Calyx bludderly-influted : prevennial : Alowers panicled, white, in summer.

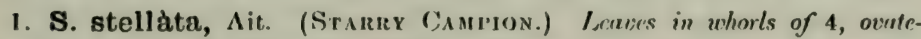
linceolute, taper-pointed; calyx bell-shaped; petals cut into a fringe, crownless. (Cucùbalus stellatus, L.) - Wooded banks, Rhode Island to Wisconsin, and southward. - Stem $3^{\circ}$ high, with a large and open pyramidal panicle. Corolla \$ุ' broad.

2. S. nívea, DC. Leaves opposite, lancelate or oblong, taper-pointed; caly $\mathrm{x}$ oblong; petals wedge-form, 2-cleft, minutely crowned. - Columbia, Pennsylvania, to Ohio and Illinois : rare. - Stem $1^{0}-2^{\circ}$ high, almost sinooth. Flowers few, larger than in the last.

3. S. inflata, Smith. (Bladner Campion.) Gluucons; leaves opposite, ovate-lanceolate; calyx globular, much influted, clegantly veined; petals 2-cleft, nearly crownless. - Fields and roadsilles, E. New England to Penn. - A foot high. Flowers loosely cymose. (Nat. from Eu.)

* Calyx elongated or club-shaped, not inflated except by the enlarying pod: flowers cymose or clustered z perennial, pubescent with viscid huirs, espocially the calyx: petals crowned, red or rose-color.

4. S. Pennsylvánica, Michx. (WrLd Pink.) Stems low $\left(4^{\prime}-8^{\prime}\right.$ high) ; root-leaves narrowly spatulate, nearly glabrous, tapering into hairy petioles; stem-leaves ( 2 or 3 pairs) lanceolute; flowers clustered, short-stalked ; calyx clubshaped; petals wedge-form, slighlly notched and eroded, pink. - Gravelly places, E. New England to Penn., Kentucky, and southward. April-June.

5. S. Virglnica, L. (Fire Pink. Catchfiry.) Stems slender $\left(1^{\circ}-\right.$ $2^{\circ}$ high); leaves thin, sputulate, or the upper oblong-lanceolate; flowers few and loosely cymose, peduncled ; calyx oblong cylindrical, soon obconical ; petals oblong, 2-cleft, deep crimson; the limb I' long.-Open woods, W. New York (Dr. Sartuell) to Illinois and southward, June-Aug.

6. S. règia, Sims. (Royal Catchrity.) Stem roughish, erect $\left(3^{\circ}-4^{\circ}\right.$ high) ; leaws thickish, ovate-lanceolate, acute; flowers numerous, short-stalked, in clusters, forming a strict panicle; caly $\mathrm{x}$ ovoid-club-shaped in fruit; petals spatuInte-lancrolate, mostly undivided, deep scarlet. - Prairies, Ohio to Illinois, and southward. July.

7. S. rotundifolia, Nutt. (Round-Leaven CatchFi,y.) Viscid-hairy; stems weak, branched, decumbent $\left(2^{\circ}\right.$ long); leures thin, romd, almuplly pointed, the lower obovate; flowers few, looscly cymose, stalked; calyx elongated ; petals 2-eleff and cut-toothed, deep scarlet. - Shaled banks of the ()hio, and in Kentucky. June-Aug. - Leaves and flowers large. - The last threc probably run together.

L \& M-24 . 
* * * Calyx not influted, except by the enlarging pod: annuals.

- Glabrous, a portion of cach joint of the stem y/utinous : flowers pink.

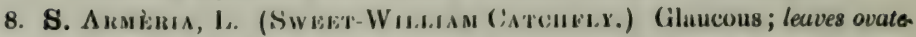
lanceolute; flowers in flat cymes, ope:n in sunsline; calyx club-shuped; jetuls notched, crowned with awl-shaped scalcs. - Escajed from gardens : rare. (Adv. from Eu.)

9. S. antirrhina, L. (Stees'y C.) Stem slender $\left(8^{\prime}-30^{\prime}\right.$ ligh); leaves lanceolote or linere; flowcess smatl, paniculate; culye ocvid; petals obcordate, crowned, opening transiently in sumshine. - Dry soil : common in waste plates. June-Sept.

++ Viscid-pubrscent: fluwers white or nearly so, opening at night, sweet-scented.

10. S. noctúna, L. (Nigit C.) Leaves short, the lower spatulate, the npper lincar; flvevers small, celternate in a 1-sidcd spoke; petals 2-parted. - Introduced sparingly in P'ennsylvania, according to Silueinitz. (Adv. fiom Eu.)

11. S. noctiloba, L. (Nigute-fowering C.) Viscid-huiry, tall (10$3^{\circ}$ high); lower leaves large and spatulate; the upper lanceolate; flowers few, peduncled; calyx-tube elongated (over I'long), som ovoid, with awl-shaped teeth; petals ratlec large, 2-partcel, crowned. - Cultivated grounds. (Nat. fiom Lu.)

**** Ihouif, luftcd, smooth, perennial: flowering shoots 1-flowered.

12. S. acaùlis, L. (Moss Campron.) Tufted like a moss ( $\left(1^{\prime}-2^{\prime}\right.$ high), leaves lincar, crowded; flowers almost sessile, or rarely on a naked peduncle; petals purple or rarely white, notehed or entire, crowned.-Alpine summits of the White Mountains, New IIampshire. July. (Eu.)

\section{L Ý CH N I S, Tourn. Lycinis. Cockle.}

Styley 5 , rarely 4 ; and pod opening by as many or twice as many teeth : otherwise nearly as in Silcne. Calyx in one species with leaf-like lobes. (Ancient Greek name for a scarlet or flaune-colored species, from $\lambda \dot{v} \chi^{\nu}{ }^{2}$, a light or lamp.)

1. L. vespertina, Sibth. (Evening L.) Biennial, usually dicecious, viscid pubescent, in foliage, \&c., like Silene noctiflora; but 5 styles; calyx much shorter, the fertile enlarging and broadly ovoid in fruit, with lance-linear teeth ; flowers white or pinkish, opening at evening. (L. dioica, L. in part.) - Cult. or waste grounds: scarce. (Adv. from Eu.)

2. L. Gıтидio, Lam. (СокN Cockle.) Annual, clothed with long soft appressed hairs; flowers long-peduncled; calyx-lobes similar to the long and linear leaves, surpassing the broad and crownless purple-red petals, falling off in fruit. (Agrostémma (iithago, L., \& ed. 2.) $-\Lambda$ weed in wheat-ficlds, too common, the black seeds of Cockle being injurious to the appearance of the flour. (Adv. from Eu.)

\section{AREI À RIA, L. SANDWORT.}

Sepals 5. I'etals 5, entire, sumetimes barcly notched, rarely wanting. Stamens 10. Styles 3, rarcly more or fewer, opposite as many sepals. Pod short, splitting into as many or twice as many valves as there are styles, few - many- 
soeded. - Low, usunlly tufted herbs, with sessile exstipulate lenves and small white flowers. (Name from arena, sand, in which many of the species grow.) - The following sections are by many botanists taken for gencra, as they were in the former edition.

§ 1. ARENARLA proper. Pod splitfing wholly or pent-wany down into 3 or at length into 6 valves: seeds many, naked at the hilum.

1. A. Serpyllifòlia, L. ('Tiyme-leaved Sandwort.) Diffusely branched, roughish $\left(2^{\prime}-6^{\prime}\right.$ high $)$; leaves ovate, acute, small ; cymes leafy; sepals lanceolate, pointer, 3-5-nerved, about as long as the petals und the 6toothed pod. - A low annual, in sandy waste places. June-Aug. (Nat. from Eu.)

§ 2. AISlNE, (Tourn.) Wahl. Pod splitting to the base into 3 entire valves: seeds many, usually rough, noked at the hilum: flowers solitary and terminal or cymose: root in our species perennial.

* Leaves small, rigid, awl-shaped or bristle-shaped.

2. A. squarrosa, Michx. (Pine-Barren S.) Densely tufted from a deep perpendicular root; leaves closely imbricated, but spreading, awl-shaped, shont, channelled; branches naked and minutely glandular above, several-flowcred; sepals obtuse, ovate, shorter than the porl. ( $\Lambda$ lsine, ed. 2.) - In pure sand, S. New York, New Jersey, and southward along the const May-July.

3. A. stricta, Michx. Erect, or usually diffusely spreading from a small root, smooth ; leaves slender, between awl-shaped and bristle-form, with many others clustered in the axils; cyme diffuse, naked, many-flowered; sepals pointed, 3 ribbed, ovate, as long as the pod. (Alsine Michauxii, Fenzl.) - Rocks and dry wooded banks, Vermont to Wisconsin and Kentucky. July. - The specific name is a bad one, as there is nothing strict about the plant.

* * Leaves soft and herlacrous, filiform-linear: petals retuse or notched.

4. A. pátula, Michx. Diffusely branched from the slender root; stems filiform ( $6^{\prime}-10^{\prime}$ long) ; branches of the cyme diverging; peduncles long; sepals lancrolate, acuminate, 3-5-nerved. (Alsine, ed. 2.) - Cliffs of Kentucky River, mountains of Western Virginia, and southward.

5. A. Grœnlándica, Spreng. (Mountain S.) Densely tufted from slender roots, smooth; flowering stems filiform, erect $\left(2^{\prime}-4^{\prime}\right.$ high), few-flowered; sepals oblong, olituse, nerveless. (Stellaria Gronlandica, Retz. Alsine, ed. 2.) - Summit of the Shawangunk, Catskill, and Adirondack Mountains, New York, of all the higher mountains of New England, and northward; alpine or subalpine. At Bath, Maine, on river-banks near the sea. June-Aug. Leaves and peduncles $3^{\prime \prime}-6$ " long; flowers large in proportion.

A. GLABRA, Michx., of the mountain-tops in Carolina, may occur on those of Virginia, and is perhaps a large form of the above.

§3. M(EHRINGIA, L. Tarts of the flower sometimes in fours: pod as in \$1, but the young ovary 3-celled: serds rnther few, smooth and with a thickish appendage (strophiole) at the hilum: perennials, with faccid brondish leaves.

6. A. lateriflora, L. Sparingly branched, erect, minutely pubescent; leaves oval or oblong obtuse $\left(\frac{1}{}^{\prime}-1^{\prime}\right.$ long) ; peduncles 2 - (rarely $\left.3-4-\right)$ flowered, 
soon becoming lateral; sepals oblong, obtuse. - Gravelly slıores, \&c., Rhode Island to Peunsylvania, Wisconsin, and nortlıward. May, June. (Eu.)

§4. AMMAI) ÈnIA, Guclin. (Ioukénya, Ehrh.) Pod fleshy, splitting into as many valies as there are styles (3, curdy 4 or 5); the ovury more or less 3-(5-) celled: seeds few, smooth, short-beaked at the naked hilum: disk under the ovary more prominent than usual, glandular. 10-lulsed; flowers almost sessile in the axils of fleshy leaves, sometimes divecrous or polygumsus : root perenuial.

7. A. peploides, L. Stems (simple or forking fiom long rootstocks, 6' $10^{\prime}$ high) and ovate partly-clasping leaves $\left(8^{\prime \prime}-10^{\prime \prime}\right.$ lung) very fleshy. (IIonkenya peploides, Ehrh., ed. 2.) - Sands of the sea-shore, New Jersey to Maine and northward. June. (Eu.)

\section{STELLÀ R A, L. Chickwed. Starwort.}

Sepals 4-5. Petals $4-5$, deeply 2-cleft, somctimes none. Stamens 8,10 , or fewer. Styles 3, rarely 4 or 5, opposite as many sejals. Pod ovoid, 1 -celled, opening by twice as many valves as there are styles, several-many-secded. Seeds naked. - Flowers (white) solitary or cynusc, terminal, or appearing lateral by the prolongation of the stem fiom the upper axils. (Name from stella, a star, in allusion to the star-shajed flowers.)

* Stems spreading, fluccid, marked longitudinully with one or two pubescent lines: leaves ovate or oblong, $\frac{1^{\prime}}{2}-2 \frac{1}{2}{ }^{\prime}$ long.

1. S. mèda, Smith. (Сомmon Cйскwéd) Annual or nearly so; lower leaves on hairy petioles; petals shorter than the calyx, 2-parted; stamens 310. - Everywhere in damp grounds. (Nat. from Eu.)

2. S. pùbera, Michx. (Great Chickweed.) Root perennial; leaves all sissile; jetuls longer than the calyx, deeply 2-cleft; stamens 10. - Shaded rocks, Pennsylvania to Kentucky and southward. May.

* *temes erect or spreading: wholly glubrous perennials, with sessile and narrow or small leaves: stamens usually 10 , perigynous.

- Scaly-bracted: petals 2-purted, equalling or surpussing the culyx.

3. S. longifolia, Muhl. (Long-Leaven Stitciwort.) Stem erect, weak, often with rough angles $\left(8^{\prime}-18^{\prime}\right.$ high $)$; leaves linear, acutish at both ends, spreading; cymes naked and at length lateral, peduncled, many-flowered, the slender predicels spreading; petals 2-jarted, longer than the calyx; seeds smooth. Grassy places: common, especially northward. June, July. (Eu.)

4. S. lóngipes, Goldie. (Long-stalked S.) Shining or somewhat glaucous, very smooth; leaves ascending, lanceolute or linear-lancelute, acute, Lroadest at the base, rather rigid; cyme terminal, few-flowered, the long pedicels strictly erect; petals longer than the calyx ; seeds smooth. - Maine to Wisconsin : rare, common further worth. (Eu.)

5. S. uliginòsa, Murr. (Swamp S.) Stems weak, decumbent or diffuse, at length prolonged, leaving the naked and usually sessile cymes lateral; leuors lanceolute or oblong, veiny; petals and ripe pods as long as the culy $x$; seeds roughened. (S. aquatica, Pollich.) - Swamps and rills, Pennsylvania (Durlington, \&c.), New Hampshire (Bluke), and northward in British America. (Eu.) 
a + Leafy-bracted, the flowers terminal or in the forks of the stem or of leafy branches; bracts foliaceous : petals 2-parted, smull or often none: styles 3-4 : pod longer than the calyx.

6. S. crassifolia, Ehrhart. Stems diffuse or erect, flaccid; leaves rather fleshy, varying from linear-lanccolate to oblong; petals longer than the calyx, or wanting; seeds rugose-roughened. - (An apetalous 4-6-androus state is Sagina fontinàlis, Short \&. Peter.) Springy places, E. Kentucky (Short), Ringwood, Illinois (Vasey), and northward. April-June. (Eu.)

7. S. boreallis, Bigelow. (Nontuenn S.) Stems erect or spreading, flaccid, many times forked, at length resolved into a leafy cyme; leaves varying from broadly lanceolate to ovate-oblong; petals 2-5, shorter than the calyx, or oflener none; scpals acute; styles usually 4 ; seeds smooth. - Shaded or wet places, Rhode Island to Wisconsin and northward. June-Aug. Var. Alpéstris (S. alpestris, Fries, S. Fenzlii, Regel) has the later flowers more cymose, and their bracts small and partly scarious, also the seeds obscurcly reticulated or roughish. - Lake Superior, Dr. Robbins. (Eu.)

8. S. humifùsa, Rottboll. Spreading or creeping; stems or branches (2' high) 1-3-flowered; leaves flishy, orate or oblong (2" $-3^{\prime \prime}$ long); petals a little longer than the culyx; sceds smooth. - Northern border of Maine on the St. John's (G. L. Goodale), and high northward. June. (Eu.)

\section{HOLÓSTEU M, L. JAGGed ChickweEd.}

Sepals 5. Petals 5, usually jagged or denticulate at the point. Stamens 35, rarely 10. Styles mostly 3. Pod ovoid, 1-celled, many-seeded, opening at the top by 6 teeth. Seeds rough, flattened on the back, attached by the inner face. - Annuals or biennials, with several (white) flowers in an umbel, borne on

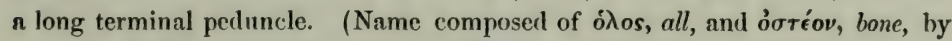
antiphrasis, these plants being soft and tender.)

1. H. UмBеLLAтUM, L. Leaves oblong; peduncle and upper part of the stem glandular-pubescent ; pedicels reflexed after flowering. - Hills around Lancaster, Penn., Prof. Porter, and Morris Co., N. Jersey, C.F. Austin. (Nat. from Eu.)

\section{Cer á s t i U M, L. Mouse-ear Chickteed.}

Sepals 5, rarely 4. Petals as many, 2-lobed or cleft, rarely entire. Stamens twice as many, or fewer. Styles equal in number to the sepals and opposite them. Pod 1-celled, usually elongated, membranaceous, opening at the apex by twice as many teeth as there were styles, many-seeded. Seeds rough. Flowers white, in terminal cymes. (Name from képas, a horn, alluding to the shape of the pods in many species.)

\$1. Petals 2-cleff or ubcordate: parts of the flower in fives: pods (except in No. 5) longer than the calyx, and usually more or less curved.

1. C. velgitum, L. (Mouse-ear Chickween.) Annual, hairy and rather clammy, nearly erect $\left(4^{\prime}-9^{\prime}\right.$ high) ; leaves ovate or oborate; bracts herbaceous; flowers (small) in close clusters at first; prdicels eren in fruit not longer than the acute sepals; petals shorter than the calyx. - Grassy places, eastward and southward: not common. May-July. ('The names of this and the next were 
transposed by Linnæus, and by continental botanists ever since.) - Stamens often 5. - The var.? SEMJDECÁNDRUM, which has more lengthened fruit-bearing pedicels, is here hardly met with. (Nat. from Lu.)

2. C. viscósum, L. (Lakger M.) Perennial; stems clammy-laairy, spreading $\left(6^{\prime}-15^{\prime}\right.$ long $)$; leaves oblong; upper bracts scarious-margined; Howers at first elustered, the firniting pedicels longer, the earlier ones mostly much longer than the obtuse sepals; petals equalling the calyx. - Ficlds and copses: common, perhaps indigenous to the country. May-July. (Nat. from Eu.)

3. C. nùtans, Rat: Anumal, very clammy-pubescent; stems erect, slender, grooved, diffusely branched $\left(6^{\prime}-20^{\prime}\right.$ high) ; cyme loose and open, manyflowered; leaves oblony-lanceolate, acute, the lowest spatulate; peduncles mostly elongated; petals longer than the calyx; pods nodding on the stalks, curved upwards, thrice the length of the calyx. - Moist places, Vermont to Minnesota and southward. May-July. - Var. Bracix́poved, Engelm., W. Illinois and southwestward, has pedicels shorter than the pods.

4. C. oblongifölium, Torr. Perennial; stems ascending, villous (6 $6^{\prime}-$ $12^{\prime}$ high), many-flowered; leaves oblony-lanceolute and ovate; peduncles clammyhairy; petals (2-Jobed) and ripe pods about twice the length of the calyx. - Rocky places, New York to N. Virginia and Illinois: rare. May-July. - Stouter and larger flowered than the following species.

5. C. arvénse, L. (Fízld Cискиеed.) Perennial; stems ascending or ereet, tufted, downy, slender $\left(4^{\prime}-8^{\prime}\right.$ high), naked and few-several-flowered at the summit; leaves lineur; petals obcordate, more than twice the length of tho calyx; pods scaicely longer than the calyx. Dry or rocky places, New England to Wisconsin and northward. May - July. (Eu.)

§ 2. MQÉNCIIIA, Ehrhart. Petals entire or mercly retuse: the parts of the flower commonly in fours : pod ovate, not longer than the calyx.

6. C. Quaternéluda, Fenzl. Smooth and glancous annual; stem simple, erect $\left(2^{\prime}-4^{\prime}\right.$ high), 1 -2-flowered; leaves lanceolate, acute ; petals not execeding the calyx; stamens 4. (Sagina erecta, L. Moenchia quaternella, Ehrh.) - Near Baltimore, in dry ground. (Adv. from Eu.)

\section{SA G İ A , I. Pearlwort.}

Sepals 4 or 5 . Petals 4 or 5, undivided, or often none. Stamens as many as the sepals, rarely twice their number. Styles as many as the sepals and alternate with them. Pod many-seeded, 4-5-valved to the base; valves opposite the sepals. - Little, matted herbs, with thread-like or awl-shaped leaves, no stipules, and small flowers terminating the stems or branches; in summer. (Name from sagine, fittening ; of dubious application.)

* Parts of the flower in fours, rarely with some few in fives.

1. S. procúmbens, L. Perenial, depresserl or spreading on the ground, glabrous; leaves lincar-threarl-shaped; apex of the peduncle often hooked soon after flowering; petuls shorter than the broudly ovate obluse sepuls, sometimes none. - Springy places and damp rocks, coast of Maine to Pennsylvania. (Eu.)

2. S. apétala, L. Annual, erect, with more slender leaves, narrower sepals, and petals none or obsolete. - Dry soil, New York and P'ennsylvania to Illinois: scarce, scemingly native? (Eu.) 
* Parts of the flower in fives, the stamens not rarely 10.

3. S. subulata, Wimmer. Perennial (or apparently annual), ascending; the peduncles and caly $\mathbf{x}$ with the margins of the upper leaves at first glandularpulwsent; leaves short, often bristly-tipped, not fascicled in the axils; peduncles slender; petals equalling or shoiter thin the calyx (S. Elliottii, Fenzl.), - or in var. Sм тиші, a slender form, seemingly annual, npetulous, at least in the later flowers. - Near Philadelphia, in waste gonumd, and sandy fields, \&e., Somers' Point, New Jersey, C: E' Smith. - This form has the aspect of No. 2. Seeds minutely roughened. (P'erhaps nat. from Fin.)

4. S. noddsa, Fenzl. P'erennial, tufted, glalırous, or glandular above: stems ascending $\left(3^{\prime}-5^{\prime}\right.$ high; lower leaves threal-form, the upper short and awl-shaped, with minute ones fuscicled in their axils so thut the branchlets appou knotty; petals much Ionger than the mlyr. (Spergula nodosa, 1.) - Wet sandy soil, along the coast of Maine, New IIampshire, also Lake Superior, and northward. (Eu.)

\section{SPERGUIÀ R A, Pers. SAND-Spurret.}

Sepals 5. Petals 5, entire. Stamens 2-10. Styles and valves of the manyseeded pod 3, very rarely 5 , when the valves alternate with the sepals I $\mathbf{E m -}$ bryo not coiled into a complete ring. - Low herbs, mostly on or near the seaconst, with filiform or linear somewhat fleshy opposite leaves, and smaller ones often clustered in the axils: stipules scaly-membranaceous : flowering all summer. (Name altered from Spergula.) - Genus also known under the name of Lepfgonum, Fries. Our species, which perhaps run together, are here arranged in view of Kindberg's monograph, but with some reduction. 'They are all annuals and subperennials.

1. S. rùbra, Presl., var. campéstris. Ncarly glabrous, except the summit of the prostrate slender stems, peduncles, and sepals, which are usually glandular-pubescent; leaves filiform; stipules triangular-awl-shaped; pods and pinkred corolla small (2"), hardly equalling or exceeding the calyx; seeds rough with projecting points, semi-obovate or gillous-wedge-shaped, wingless. - Sandy or gravelly dry soil, New England to Virginia along and near the coast, but rarely maritime. (Frt.)

2. S. salina, Presl. Larger and more decidedly fleshy than the preceding, with ovate stipules, and peluncles rarely longer than the pod, which is longer than the calyx ( $3^{\prime \prime}$ long); petals pale; seeds obovete-rounded and roughened with points, wingless or narrow-winged. - Brackish sands, \&c., coast of New England to Virginia and southward. (Eu.)

3. S. media, Presl. Distinguished from the last mainly by the smooth sects, either winged or wingless; peduncles equalling or exceeding the pod, which is 2" or 3 " long, and " little exceents the calyx. (Lepigonum medium, Fries. L. leiospermum, Kindberg.) - Salt marshes and sands, with the last. (Eu.)

Var. macrocárpa. (S. macrocarpa, Presl. Lepigonum marinum, Fries.) Root more woody and perennial ; pod $3 \frac{1}{2}$ " $-5^{\prime \prime}$ long, surpassing the calyx; seeds also larger, rounded, broadly winged, or a few wingless. - Sea-beaches, rare northward. (Eu.) 


\section{SPÉ RGULA, I. SPuRRE.}

Stamens 5 or 10. Styles 5. The 5 valves of the pod opposite the sepals. Embryo spirully annular. Leaves in whorls. Otherwise as in Spergularia. (Name from spargo, to scatter, fiom the seeds.)

1. S. arvénsis, L. (Cokn Spukrex.) Annual; leaves numerous in the whorls, thread-shaped ( $1^{\prime}-2^{\prime}$ long); stipules minute; flowers white, in a stalked panicled cyme; seeds rough. - Grain-ficlds. (Adv. from Eu.)

\section{A N Ý CH I A, Michx. Forkev Chíkwéd.}

Sepals 5, scarcely concare, indistinctly mucronate on the back, greenish. Petals none. Stamens 2-3, rarely 5. Stigmas 2, sessile. Utricle 1-seeded, laryer than the calyx. Radicle turned downwards. - Small, many times forked annuals, with small stipules, and minute flowers in the forks, produced all summer. (Same derivation as the next genus.)

I. A. dichótoma, Michx. Erect or spreading; leaves varying from lanceolate to elliptical, somewhat petioled. Varies much; in woods or rich soil being very smooth, erect $\left(6^{\prime}-10^{\prime}\right.$ high $)$ and capillary, with long joints, the leaves broader and thinner $\left(5^{\prime \prime}-10^{\prime \prime} \mathrm{long}\right)$, and the flowers more stalked (A. capillacea, Nutt. and Queria Canadensis L.) : in sterile or parched soil it is pubescent, low and spreading, short-jointed, narrower-leaved, and the flowers nearly sessile and more clustered (A. dichotoma, $D C$.). Common throughout.

\section{PA RO N ÝCH IA, Tourn. Whitlow-wont.}

Sepals 5, linear or oblong concave, awned at the apex. Petals bristle-form, or minute tecth, or none. Stamens 5. Style 2-cleft at the apex. Utricle 1seeded, enclosed in the calyx. Radicle ascending. - Tufted herbs, with dry and silvery stipules, and clustered llowers. (Greck name for a whitow, and for a plant thought to cure it.)

1. P. argyrócoma, Nutt. Forming broad tufts, branched, spreading; leaves linear; flowers densely clustered, surrounded by conspicuous large silvery biacts; calyx hairy, short-awned; petals mere teeth letween the stamens. 14 - Slides in the Noteh of the White Momntains, New Hampshire, and bare summits above. Allcrhany Mountains from Virginia southward. July.

2. P. dichótoma, Nutt. Smooth, tufterl; stems $\left(6^{\prime}-12^{\prime}\right.$ high) ascending from a rather woody base; leaves and bracts awl-shaped; cymes open, many-times forked; scpals short-pointed; minute bristles in place of petals. 4 -Rocks, Harper's Ferry, Virginia, and southwestward. July-Sept.

\section{SCLERÁ NTHUS, L. KNAwEL.}

Sepals 5, united below in an indurated (mp, enclosing the 1-seeded utricle. Petals none. Stanens 10 or 5. Styles 2, distinct. - Homely little weeds, with awl-shaped leaves, obscure greenish clustered flowers, and no stipules. (Name

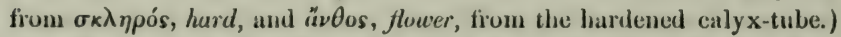

1. S. Áneus, I. Much branched, spreading $\left(3^{\prime}-5^{\prime}\right.$ high) ; flowers sessile in the forks; calyx-lobes scarcely margined. - Waste places. (Nat. from Eu.) 


\section{M O L L Ù G O, L. Indian-ChickweEd.}

Sepals 5, white inside. Petals none. Stamens hypogynous, 5 and alternate with the scpals, or 3 and alternate with the 3 cells of the ovary. Stigmas 3. Pod 3-celled, 3-valved, loculicidal, the partitions breaking away from the manyseeded axis. - Low homely anunals, much branched; the stipules obsolete. (An old Latin nnme for some soft plant.)

1. M. verticillata, L. (CARrET-wern.) I'rostrate, forming patches; leaves spatulate, clustered in whorls at the joints, where the 1-flowered pedicels form a sort of sessile umbel; stamens usually 3. - Sandy river-banks, and cultivated grounds. June-Sept. (An immigrant from farther south.)

\section{Order 19. Portulacàcea. (Purslane Family.).}

IIerbs, with succulent leaves, and regular but unsymmetrical flowers; viz., sepals usually fewer than the petals: the stamens opposite the petals when of the same number, but ofien indefinite: otherwise nearly as Chickweeds. - Sepals 2, rarely 3 or 5 . Petals 5 , or sometimes none. Stanens mostly 5-20. Styles 3-8, united below, or distinct, stigmatic along the inside. Pod 1-5-celled, with few or many campylotropons secrls rising on stalks from the base, or from a central placenta. Embryo curved around mealy albumen. - Insipid and innocent herbs, with entire leaves. Corolla opening only in sunshine, mostly ephemeral, then shrivelling.

* ANOMAlOts PORTULACACEF. Sepals 5, bearing the stamens.

1. Sesurlum. Petals none. Stamens 5-60. Pod 3-5-celled, opening across by a lid.

* * TRUE PORTULACACET. Sepals (2) fewer than the petals : pod I-celled.

2. Portulaca. Stamens $7-20$, on the partly adherent calyx. Pod opening by a lid.

3. Trllnum. Stamens more numerous than the petals, hypogynous Pod many-seeded.

4. Clnytomin. Stamens as many as the hypogynous petals, and attached to their base. Porl 3-6-sected.

\section{S ES Ù V I U M, L. . Sea Purgine.}

Calyx 5-parted, purplish inside, persistent, free. Petals none. Stamens 560, inserterl on the calyx. Styles 3-5, separatc. Pod 3-5-celled, many-seeded, circumscissile, the upper part falling off as a lirl. - Prostrate maritime herbs, with suceulent stems, opposite leaves, and axillary or terminal flowers. (An unexplainer name.)

1. S. Portulacástrum, L. Ront perennial ; leaves lanceolate-oblong. flattish; flowers sessile or short-peduncled; stamens many. - Coast of New Jersey and southward. July-Sept.

\section{POR T U L À A , Tourn. Purslane.}

Calyx 2-cleft; the tube cohering with the ovary helow. Petals 5, rarely 6, inserted on the calyx with the 7-20 stamens, fugacious. Style mostly 3-8parted. Pod 1-celled, glohular, many-seeded, opening transversely, the upper part (with the upper part of the calyx) separating as a lid. - Fleshy annuals, with mostly scattered leaves. (An old Latin name, of unknown meaning.)

G $\mathrm{M}-\mathbf{5}$ 
1. P. orericea, I. (Common Pursine.) Prostrate, very smooth; Jeaves obovate or weige-form; flowers sessile (opening only in sunny inornings); sepals kecled; podials pale yellow; stamens 7-12; style decply 5-6parted; flower-bud flat and acute. - Cultivated and waste grounds : common. (Nat. from Eu.)

P. retusa. Engelın., closely resembling the common Purslane, is indigenons west of the Mississippi.

P. GRANDiflóra, with terete leaves and showy flowers, cult. for ornament, begins to be spontaneous around gardens.

\section{T A L İ N U M, Adans. Talinum.}

Sepals 2, distinct and free, deciduous. Petals 5, ephemeral. Stamens $10-$ 30. Style 3-lobed at the apex. Pod 3-celled at the base when young, 3-valved, with many seeds on a globular staked placenta. (Derivation obscure.)

1. T. teretifolium, Pursh. Leafy stems low, tuberous at the base; leaves linear, cylindrical; peduncle long $\left(3^{\prime}-6^{\prime}\right)$ and naked, bearing an open cyme of pink flowers (3' broall); stamens 15-20. 4 - Serpentine rocks, Westchester, P'mn., Falls of St. Croix River, Wisconsin, and soutliward. June-Aug.

\section{CLA Y T Ò NIA, L. SPring-Beauty.}

Sepals 2, ovate, free, persistent. Stamens 5, adhering to the short elaws of the petals. Style 3-cleft at the apex. Pod 1-celled, 3-valved, 3-6-seciled. Our two species are peremials, sending up simple stems in early spring from a small deep tuber, bearing a pair of opposite leaves, and a loose raceme of pretty flowers. Corolla rose-color with deeper veins, opening for more than one day ! (Named in honor of Di. John Clayton, one of our earliest botauists, who contributed to Gronovius the materials for the Flora Virginica.)

1. C. Virgínica, L. Leaves linear-lanceolate, elongated $\left(3^{\prime}-6^{\prime}\right.$ long).Moist open woods : common, especially westward and southward.

2. C. Caroliniàna, Michx. Leares spatulate-oblong or oval-lanceolate $\left(1^{\prime}-2^{\prime}\right.$ long). - W. New Hampshire, to Wisconsin, and southward along the Alleghanics.

\section{Order 20. malidiceas. (Mallow Family.)}

Herbs or shrubs, with alternate stipulate leaves and regular flowers, the calyx valvate and the corolla convolute in the bud, numerous stamens monadelphous in a column, which is united at the base with the short claws of the petals, 1-celled culhers, and kidney-shaped seeds. - Sepals 5, united at the base, persistent, often involucellate with a whorl of bractlets, forming a sort of exterior calyx. P'etals 5. Anthers kidney-shaped, opening along the top. P'istils several, with the ovaries united in a ring, or forming a several-celled pod. Seeds with little albumen : embryo curved, the leafy cotyledons variously dunbled up. - Mucilaginous, innocent plants, with tongh bark, and paluately-veined leaves. Flowerstalks with a joint, axillary. 
Tribe I. Mr A TEES. Columns of atamens anther-bearing at the top. Ovaries and pods (carpels) 5-20 or more, closely united in a ring around a central axis, from which they separate after ripening.

- 8tigmas occupying the inner face of the atyles : carpels 1-seederl, falling away separately.

1. A lehrea. Involucel of 6 to 9 bractlets.

2. Malva. Involucel of 3 bractlets. Petals obcorlate. Carpels rounded, beakless.

3. Callirrhoe. Involucel of 3 bractlets or none. Petals truncate. Carpels beaked.

4. Na prea. Involucel none. Flowerg dinecious. Stamens few.

* Stigmas terminal, capitate : carpels 1 - few-seceled, usually dehiscent.

5 Mnlvastrum. Inveluecl of 3 bractets or none. Sects solitury in the cells, nscending.

6. Sidn. Involucel none. Seed solitary in the cells, pendulous.

7. Abutilon. Involucel none. Seeils 3 or more in each cell.

8. Modiola. Involucel of 3 bractlets. Seeds 2 in each cell, and with a transverse partition between them.

Tribe II. IIBISCE. Column of stamens anther-bearing for a considerable part of its length, naked and 5-toothed at the very apex. Pod mostly 5.celled, loculicidal, leaving scarcely any axis in the centre after opening.

9. Kosteletzkya. Involucel of several bractlets. Pod 5-celled, 5-seeded.

10. Hibiseus. Involucel of many bractlets. Pod 5-celled, many-seeded.

\section{A L TH 安 A, L. Marsir-Malrow.}

Calyx surrounded by a 6 -9-eleft involucel. Otherwise as in Malva. (Name from $\vec{a} \lambda \theta \omega$, to cure, in allusion to its healing properties.)

1. A. officinilis, L. (Common Mansir-Mallow.) Stem erect; leaves ovate or slightly heurt-shaped, toothed, sometimes 3-lobed, velvety-downy: peduncles axillary, many flowered. - Salt marshes, const of New England and New York. Aug., Sept. - Flowers pale rose-color. Perennial root thick, abounding in mucilage, the basis of the Prites de Guimauve. (Nat. from Eu.)

\section{M Á L V A, L. Mallow.}

Calyx with a 3-leaved involucel at the base, like an outer calyx. Petals obcordate. Styles numerous, stigmatic down the inner side. Fruit depressed, , scparating at maturity into as many $\mathbf{l}$-sceded and inclehiscent round kidneyA shaped blunt carpels as there are styles. Radicle pointing downwards. (An old Latin name, from $\mu \alpha \lambda \hat{a} \chi \eta$, sọf, alluding to the cmollient leaves.)

1. M. rotundfólis, I. (Common Mallow.) Stems procumlent from a deep biennial root; leaves round-licart-shapel, on very long petioles, crenate, olseurely-lobed; petals twice the length of the calyx, whitish; carpels pubescent,

cven. - Waysides and cultivated grounds: common. (Nat. from Eu.)

2. M. SYLVÉstris, L. (IIIGII M.) Biennial; stem erect, branched $\left(2^{\circ}-3^{\circ}\right.$ high); leaves sharply 5-7-lobed; petals thrice the length of the calyx, large, purple and rose-color; carpels wrinkled-veiny. - Waysides. (Adv. from Eu.)

3. M. crfspa. (Curued M.) A tall, erect annual, with round and angled toothed and crisped leaves, and small sessile fowers crowded in the axils, - sparingly escaped from old gardens. (Adv. from Eu.)

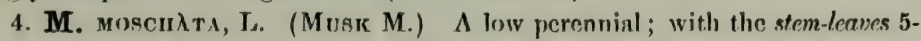
parterl, and the divisions once or twire parted or atef into linear lobes, fnintly inusky-scented, the flowers rose-color or white $\left(1 \frac{1}{2}^{\prime}\right.$ in diameter) on short po- 
duncles crowded on the stem and branches, the fruit downy : has escaped from gardens to waysides. (Adv, from Liı.)

5. M. Áleva, L., with the stem-leaves only once 5-purted or cleft, the lobes incised, large flowers like No. 4, but the fruit smooth, and bractlets of the involucel ovate: has escaped tirom gardens in Chester Co., Penn. (Adv. from Eu.)

\section{CALLÍRRHO ̈̈, Nutt. Callikrö̈.}

Calyx either naked or with a 3-leaved involucel at its base. Petals wedgeshaped and truncate (usually red-purple). Styles, \&e. as in Malva. Carpels 10-20, straightisl, with a short einpty beak, separated within from the 1seeded cell by a narrow projection, indehiscent or partly 2-valved. Radicle pointing downwards. - Flower's perfect.

1. C. triangulàta, Gray. Hairy-pubescent; stens nearly erect $\left(2^{\circ}\right.$ high) from a tuberous root; leaves triangular or halberd-shaped, or the lowest rather heart-shapel, coarsely crenate; the upper incised or 3-5-cleft; flowers panicled, short-pedicelled (purple); involucel as long as the calyx; carpels shortpointed, crestless. (Malva triaugulata, Lenvenworth. M. Iloughtonii, Torr. ff Gray.) - Dry prairies, Wisconsin, Illinois, and sonthward. July.

2. C. alcæoides, Gray. Strigose-pubescent ; stems slender (10 high) from a perennial root; lower leaves triangular-heart-shaped, incised ; the upper 5-7-parted, laciniate, the uppermost divided into linear segments; flowers corymbose, on slender peduncles (rose-color or white); involucel none; carpels obtusely beaked, crested and strongly wrinkled on the back. (Sida alcaoides. Michx.) - Barren oak-lands, S. Kentucky and Tennessee.

\section{N A P 㐫 A, Clayt. Glade Mallow.}

Calyx naked at the base, 5-toothel. Petals entire. Flourers diccious; the staminate flowers destitute of pistils, with 15-20 anthers; the fertile with a short column of filaments but usually no anthers. Styles 8-10, stigmatic along the inside. Fruit depressed-globular, separating when ripe into as many kidney-shaped 1 -seeded beakless and scarcely dehiscent carpels as there are styles. Radicle pointing downwards. - A tall and roughish perennial herb, with very large 9-11-parted lower leaves, the pointed lobes pinnatifid-cut and toothed, and small white flowers in panicled elustered corymbs. (Naned by Clayton from $\nu \hat{a} \pi \eta \eta$, a wooded valley or glade, or, poctically, the nymph of the groves.)

1. N. dióica, I. (Sida dioica, Cav.) - Limestone valleys, Penn. ancl 6outhward to the Valley of Virginia, west to Ohio and Illinois: rare. July.

\section{MALVÁsTRUM, Gray. False Mallow.}

Calyx with an involucel of 2 or 3 bractlets, or none. Petals notchel at the end or entire. Styles 5 or more: stigmas capitate. Carpels as in Malva, or else as in Sida, but the solitary kidney-shaped seed ascending and the rarlicle pointing downwards, as in the former. - Flowers perfect. (Name altered from Malva.) 
1. M. angústum, Gray. Slightly hairy ; stem erect $\left(6^{\prime}-9^{\prime}\right.$ high) from an annual root; leaves lance-oblong or linear, with scattered fine callous teeth; flowers in the upper axils, on peluncles shorter than the broadly ovate-triangular scpals; bractlets and stipules setaceons; petals yellow, scarcely exceeding the calyx; carpels 5, kidney-shaped, with smooth sides, at length 2-valved. Rock Island in the Mississippi, Illinois, Engelmann, Parry. Aug.

2. M. coccíneum, (iray (Sida coccinea, Pursh), a low and hoary perennial, with 5-parted or perlate leaves, and short spikes or racemes of showy pink-red flowers, the petals very much longer than the calyx ; the carpels 10 or more, reticulated on the sides and indehiscent: abounds on the plains from lowa and Minnesota westward.

\section{Sì DA, L. SIDA.}

Calyx naked at the base, 5-cleft. Petals entire, usually oblique. Styles 5 or more, tipped with capitate stigmas: the ripe fruit separating into as many 1sceded carpels, which are closed, or commonly 2 -valved at the top, and tardily separate fiom the axis. Seed pendulous. Embryo abruptly bent; the radicle pointing upwards. - Flowers perfect. (A name used by Thcophrastus.)

1. S. Napæa, Cav. $\Lambda$ smooth, tall $\left(4^{\circ}-10^{\circ}\right.$ high $)$ perennial ; leaves 5 -cleff, the lobes oblong and pointed, toothed; flowers (white) umbellate-corymbed, large; carpels 10, pointed. (Napæa lævis \& hermaphrodita, L.) - Rocky river-banks, Penn., York Co., \&c.; Porter. Kanawha Co., Virginia, Rev. J. M. Brown. (Cultivated in old gardens.)

2. S. Elliobttii, Torr. \& Gray. A smooth, erect perennial $\left(1^{\circ}-4^{\circ} \mathrm{high}\right)$; lenves linerar, serratc, short-petioled; peduncles axillary, 1-flowered, short ; flowers (yellow) rather large; carpels 9-10, slighly and abruptly pointed, forming a depressed fruit. - Sandy soil, S. Virginia and southward. Mny-Aug.

3. S. spinoss, T. Annual weed, mimutely and softly pulsescent, low $\left(10^{\prime}-\right.$ $20^{\prime}$ high), much branched; leaves orate-lunecolnte or ollong, serrate, rather longpetioled; peduncles axillary, 1-flowered, shorter than the petiole; flowers (yellow) small; carpe/s 5, combined into an ovate fruit, ench splitting at the top into 2 beaks. - A little tubercle at the base of the leaves on the stronger plants gives the specific name, but it cannot be called a spinc. - Wastc places: common southward. (Nat. from Trop. Amer. or Afr.)

\section{A B Ù TIL N, Tourn. Indian Mallow.}

Carpels 2-9-seeded, at length 2-valverl. Radicle ascending or pointing inwards. Otherwise as in Sida. (Name of unknown origin.)

1. A. Avicénese, Gartn. (Velvet-Lenf.) Tall annual ( $4^{\circ}$ high); leaves roundish-heart-shaped, taper-pointed, velvety; peduncles shorter than the leafstalks; corolla yellow; pods $12-15$, hairy, beaked. - Waste places, escape. from gardens. (Adv. from India.)

\section{MODİOLA, Manch Moniora.}

Caly $\mathbf{x}$ with a 3-leaved involucel. Petals obovate. Stamens 10-20. Stigmas capitate. Carpels 14-20, kidney-shaped, pointed, and at length 2-valved at the 
top; the cavity divided into two by a cross partition, with a single sced in each cell. - Inumble, procunbent or crecping annuals or biennials, with cut leaves and small purplish flowers solitary in the axils. (Name from modiolus, the broad and depressed fruit resembling in shape the Roman measure of that name.)

1. M. multífida, Muench. Hairy; leaves 3-5-eleft and incised; stamens 15-20; firuit hispid at the top. - Low grounds, Virginia and southward.

\section{KOSTEL Ĺt TZKYA, Presl. hosteletzky.}

Pod depressed, with a single seed in each cell. Otherwise as Hibiscus. (Named after $V \cdot r$. Kustdetzy, a Bohemian botanist.)

1. K. Virgínica, P’resl. loughish-hairy peremnial $\left(2^{\circ}-4^{\circ}\right.$ high) ; leaves halberd-shaped and heart-shaped; the lower 3-lobed. (Hibiscus Virginicus, L.) - Marshes on the coast, New York to Virginia and southward. Aug. - Curollis $2^{\prime}$ wide, rose-color. Columu slender.

\section{HIBÍSCUS, L. Rose-Mallow.}

Calyx involucellate at the hase by a row of numerous bractlets, 5-cleft. Colunn of stancus long, hearing anthers for much of its length. Styles united: stignats 5, catpitate. Frnit a 5-eelled loculicidal pod. Seeds several or many in each cell. - Herbs or shrubs, usually with large and slowy thewers. (An old Greek and Latin name of unkuown meaning.)

\section{* Indigenons, tall perinnials $\left(4^{\circ}-8^{\circ}\right)$ flowering lute in summer.}

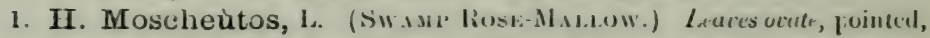
toothed, the heser 3-lobed, whitened underneath with a the suft down, ghalsous or slightly downy bencath; the 1-flowerced peduneles sonetimes united at the base with the petioles; culyx not infhaded; peal and secels smouth or marly so. Brackish marshes along the cuast, sometimes extending up rivers far beyoud the influence of salt water (as above Harrisburg, l'cun.) : al=o Onondaga Lahe, N. Y., and westward, usually within the influence of salt springs. - Corolla $\$ 1-6$ ' in diameter, light rose-color or white, with or without a crimson eye.

2. H. grandifiòus, Michx. Liaces sofl-douny lolh sides, the lower broadly ovate and henit-sheplal; porl viry hirsule; secds smooth; - odherwise resembling - the last. - Illinois (Iawrence Co., Fritchey) and southward.

3. H. militàris, Cav. (HALBEAD-LEAVED R.) Sinvoth throughuut; luwer leaves ovate-heart-shitperl, toothed, 3-lobed; upper leaves halberd-form, the short lateral lobes spreating at the base, the middle one prolonged and taper-pointed; peduncles slender; fimiling calye inflited; steds hairy. - River-banks, l'enu. to Illinois and southward. - Corollit $t^{\prime}-5^{\prime}$ in diameter, flesh-color.

\section{* Escapal from gardens or grounds.}

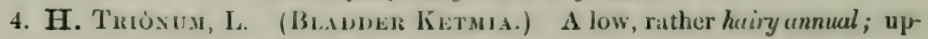
per leaves 3-parted, with lanecolate divisions, the midlle one much the longest; fruiting caly.c influed, nembranuccons, 5-uing d; corolla sulphur-yellow with at blackish eye, ephemeral; henee the name Flouer-of-an-hour. (Adv. from Eu.)

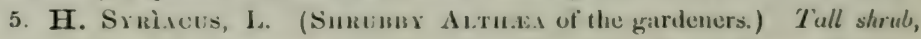

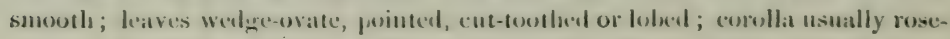

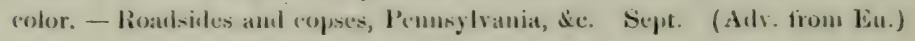




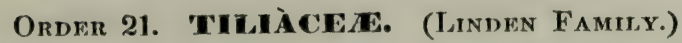

Trees (rarely herbs), with the mucilaginous properties, fibrous bark, valvate calyx, \&c., of the Mallow Family; but the sepals deciduous, petals imbricated in the bud, the stamens usually polyadelphous, and the anthers 2-celled; - represented in Northern regions only by the genus,

\section{TÍt IA, L. Linden. Basswood.}

Sepals 5. Petals 5, spatulate-oblong. Stamens numerous: filaments cohering in 5 clusters with each other (in European species), or with the hase of a sputulate petal-like body placed opposite each of the real petals. Pistil with a 5-celled ovary and 2 half-anatropous ovules in each, a single style, and a 5 toothed stigma. Fruit a sort of woorly globular nut, becoming 1-celled and 12-seeded. Embryo with a taper radicle, and a pair of leaf-like somewhat heartshaped and lobed cotyledons, which are a little folded. - Fine trees, with soft and white wood, more or less heart-shaped and serrate leaves (oblique and often truncate at the base), decirluons stipules, and small cymes of flowers, hanging on an axillary peduncle which is united to a leaf-like bract. Flowers cream-color, honey-bearing, fragrant. (The classical Latin name of the genus.)

1. T. Americana, L. (Basswoon.) Leaves green and glabrous or nearly so, thickish. - Rich wools, May, Junc. - This familiar tree is rarely called Lime-tree, oftener White-uood, commonly Bussurod; the name (now obsolete in England) alluding to the use of the inner bark for mats and corlage.

Var. pubéscens. Leaves softly pubescent underneath, often thin. (T. pubescens, Ait.) - Common from Maryland southward and westward.

2. T. heterophýlla, Vent. (Wuite Busswoon.) Leaves larger, smooth and bright green alove, silvery-whitened with a fine down molerneath. ('T. all)a, Michx.) - Mountains of P'enn. to Kentucky and southward.

T. Europdea, the Europenn Linden, which is planted in and near our cities as an ornamental tree, is at once distinguished from any native species by the absence of the petal-like scales among the stamens. This tree (the Lin) gave the family name to Linnaus.

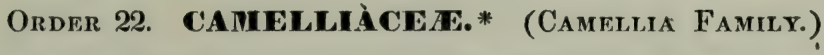

Trees or shrubs, with alternate simple feather-veined leaves, and no stipules; the regular flowers hypogynous and polyandrous, the sepals and petals both imbricated in astivation, the stamens more or less united at the base with each other (monadelphous or 3-5-ndelphous) and with the base of the petals. Anthers 2-celled, introrse. Fruit a woody 3-5-celled loculicidal pod. Seeds few, with little or no albumen. Embryo large, with broad cotyledons. - A family with showy flowers, the types of which are the wellknown Camerisa and the more important Tea Piant, - representer in this country by the two following genera.

* Name of same date as TERNSTR(EMIACE $\not E$, and preferable. 


\section{S Túd Rtia, Catesly. Stuartia.}

Sepals 5, rarely 6, ovate or lanceolate. Petals 5, rarely 6, obovate, crenulate. Stamens monadelphous below. Pod 5-celled. Seeds 1 or 2 in each cell, crustaceous, anatropous, ascending. Embryo straight, nearly as long as the albumen : radicle longer than the cotyledons. - Shrubs with membranaceous deciduous oblong-ovate serrulate leaves, soft-downy beneath, and large short-peduncled flowers solitary in their axils. (Nimed for John Stuart, Lord Bute.)

1. S. Virgínica, Cav. Petals 5 white (1'long); scpals ovate; style 1; stigma 5-toothed; pod globular, blunt; seeds not margined. (S. Malachodéndron, L.) - Woods, Virginia and southward.

S. PEntAGrNa, L'Her., with cream-colored flowers, 5 styles, and an angled and pointed pod, may be found in the Alleghanies of Southern Virginia.

\section{GORDò I A, Ellis. Loblolly Bay.}

Sepals 5, rounded, concave. Petals 5, obovate. Stamens 5-adelphous, one cluster adhering to the base of each petal. Style 1. Pod ovoid, 5-valved; the valves separating fiom the persistent axis; cells $2-8$-seeded. Seeds pendulous. Embryo straightish, with a short radicle, and thm longitudinally plaited cotyledons. - Shrubs or small trees, with large and showy white flowers on axillary peduncles. (Dedicated by Dr. Garden to his "old master, Dr. James Gordon of Aberdeen," and by Lilis to a London nurserymun of the same name.)

1. G. Lasiánthus, E. (Loblolly BAY.) Leaves coriaceous añd persistent, lanceolate-oblong, narrowed at the base, minutely serrate, smooth and shining; pod pointed; seerls winged above. Swamps near the coast. Virginia and southward. May-July. - Petals $1 \frac{1}{2}$ ' long.

\section{Ohder 23. hinàceat. (Flax Famity.)}

Herbs (rarely shrubs) with the regular and symmetrical hypogynous flowers 4-6-merous throughout, strongly inbricated calyx and convolute petals, the 5 stamens monadelphous at the base, and an 8-10-seeded pod, having twice as many cells as there are styles. Represented by the genus,

\section{LínUM, L. Flax.}

Sepals (persistent), petals, stamens, and styles 5, regularly alternate with each Jother. Pod of 5 united carpels (into which it splits in dehiscence) and 5-celled, with 2 seeds hanging from the summit of each; but each cell is partly or completely diviled into two by a false partition which projects from the back of the carpel, thus becoming 10-celled. Seeds anatropous, mueilaginous, flattened, containing a large embryo with plano-convex cotyledous. - Herbs, with a tough fibrous bark, simple and sessile entire leaves (alternate or often opposite), without stipules, but often with glands in their place, and with corymbose or pauicled Howers. Corolla usually ephemeral. ('The classical name of the Flax.)

* Indigenous species, glabrous, $1^{\circ}-3^{\circ}$ high, with yellow flowers, in summer.

1. L. Virginianum, L. Stem erect from the base and with the corymbose spreading or recurving branches terete and even; leaves oblong or lanceolate, 
or the lower spatulate and often opposite; flowers scattered, small (barely 3 " long); sepals ovate, pointed, smooth-edged or nearly so, equalling the depressed 10-celled pod; styles distinct. - Dry woods : common. - Root apparently annual; but the plant propagated by suckers from the base of the stem.

2. I. striàtum, Walt. Stems gregarious, erect or ascending from a creeping or decumbent base, slightly viscid, and with the mostly racemose short brumchrs strinte with about 4 sharp wing-like angles decurrent from the leaves; these bronder than in the last, and mostly oblong, "sually with all the lower ones opposite; flowers more crowded; sepals searecly equalling the very small brownish pod: otherwise nearly as in No. 1. (L. oppositifolium, Engelm.)-Wet or boggy grounds, New England to Virginia and south ward. - Generally confounded with L. Virginianum (figured for it in Reichenb. Ic. Exot.), but well distinguished by Walter, except that the stem-leaves are commonly opposite up to the first branch : here described from the indications given by C.F.Austin.

3. L. sulcatum, Riddell, 1836. Stem strictly erect from an annual root, and with the upright or ascending branches striate-angled or grooved; leaves linear, acute, or the upper subulate, rather rigid; a pair of dark glands in place of slipules: sepals ovate-lanceolate and sharp-pointed, strongly 3-nerved and (like the bracts) with rough-bristly-grandular margins, scarcely longer than the ovoid-globose incompletely 10-celled pod; styles united almost to the middle. (I. Boottii, Planchon, 1848.) - Dry soils, Rhode Island to Illinois and southwestyr. - Flowers and pods twice as large as in the preceding. (I. RfoIDUM, Pursh., of the Western plains, probably in Minnesota, is dwarf, glaucous, and has the styles, united almost to the top.)

* Escuping fiom cultivation, blue-fowered, anmual.

4. L. usitatfsimum, L. (Common Flax), is occasionally spontaneous in ficlds.

\section{Order 24. Getraniàceae. (Geranium Family.)}

Plants (chiefly herbs) with perfect and generally symmetrical hypogynous flowers; the stamens, counting sterile flaments, as many or commonly twice as many, and the lobes or cells (1-few-ovuled) of the ovary as many, as the sepals, an axis of the dry fruit persisting. - Seeds without albumen. except in Oxalis. The flower of Impatiens is partly, and that of Tropæ. olum still more unsymmetrical. Herbage often strong-scented, but neve1 punctate with pellucid dots. - As a whole the order, here recombined as it was founded by Jussieu, is hard to define. Of late it has generally been broken into several small orders: the principal ones here stand as suborlers, with only one or two genera to each. - TropeoLum, the Garden Nasturtium, occupies a position between the first and the second suborder.

\section{Suborder I. Gereanie}

Flowers 5-merous and symmetrical; the persistent sepals imbricated and the petals usually convolute in the bud: 5 glands of the receptacle 
alternate with the petals. Stamens somewhat monadelphous. Ovary deeply 5-lobed, the 5 two-ovuled carpels and the lower part of the long styles adnate to a long and beak-like prolongation of the receptacle, from which, when ripe and dry, the small and membranaceous pods are torn off, and carried away by the styles, - which, as they separate from the beak from the base upwards, are elastically recurved or revolute, the solitary seed falling out. Embryo filling the seed (no albumen); cotyledons folded together and bent down on the short radicle. - Strongseented herbs (or the P'elargoniums, which have somewhat irregular flowers, shrubby plants), with opposite or alternate stipulate leaves, and astringent roots.

1. Gexanium. Stamens with anthers 10 , rarely 5 . The recurving bases of the styles or tails of the carpels in fruit naked insile.

2. Eroclium. Stamens with anthers only 5. Tails of the carpels in fruit bearded inside, often spirally twisted.

\section{Suborder II. Limnantile a. (Limanthes Family.)}

Flowers 3-merous or 5-merous, completely symmetrical and regular; the persistent sepals ovate in the bud : glands of the receptacle alternate with the petals. Stamens distinct. No beak or prolongation of the receptacle beyond the ovary, which consists of 3 or 5 almost distinct, at lengtleshy and separating, indehiscent, 1 -seeded carpels, united by a common style. Seeds without albumen : cotyledons very thick and fleshy, the short railicle included by their heart-shaped bases. - Tender low annuals, with pinnate alternate leaves and no stipules. - Consists of the pretty-flowered Califurnian Limnantiles, and of

3. Floxkea. Sepals, minute petals, and lobes of the ovary 3 : stamens 6.

\section{Suborder III. BaLsamineate. (Balsam Family.)}

Flowers mostly unsymmetrical, 5-merous as to the stamens and pistil; the sepals and petals irregular, usually unsymmetrical and of fewer pieces, imbricated in the bud, all petaloid and deciduous, the larger piece with an ample sac or spur: no glands : filaments distinct, short. Fruit a fleshy 5celled pod or berry: no albumen : the straight embryo with thick cotyledons and a short radicle. - Tender herbs, the succulent stems gorged with a bland watery juice; the leaves simple, mostly alternate, without stipules.

4. Impaclens. Inner or lateral petals unequally 2-lobed. Pod bursting elastically into 5 valves, several-seeded.

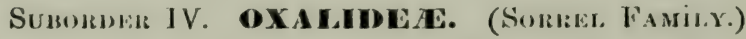

Flowers 5-merous, regular and symmetrical, decandrous; the persistent sepals imbricated and the petals convolute in the bud : no glands alternate with the latter. Stamens often monadelphous at the base. Fruit at 
5-cellerl loculicidal pod or a berry. Secds 2 or few in each cell, with a straight embryo in a little fleshy albumen. - Leaves compound: juice sour.

5. Oxalis. Styles 5, separate. Pod oblong : the valves not falling away. Leaflets usually obcordate.

\section{G E R À N I U M, L. Cranesmill.}

Stamens 10 (sometimes only 5 in No. 2), all with perfect anthers, the 5 longer with glands at their base (alternate with the petals). Styles smooth inside in fruit when they separate from the axis. - Stems forking. Peduncles 1-3-flowered. (An old Greek name, from répavos, a crane; the long fruitbearing beak thought to resemble the bill of that bird.)

\section{* Rootstock perennial.}

1. G. maculàtum, L. (WiLd Cranesbill.) Stem erect, hairy; leaves ahout 5-parted, the wedge-shaped divisions lobed and cut at the end; sepals slender-pointed; petals entire, light purple, bearded on the claw ( $\frac{1}{2}$ long). - Open woods and fields. April-July. - Leaves somewhat blotehed with whitish as they grow old.

\section{* Root biennial or annual: flowers small.}

2. G. Caroliniànum, L. (Carolina C.) Stems at first erect, diffusely branched from the base, hairy; leaves about 5-parted, the divisions eleft and cut into numerous oblong-linear lobes; peluncles and pedicels short; scpals awn-pointed, as long as the emarginate (pale rose-color) petals; carpels hairy; seeds ovoid-oblong, very minutely reticulated. - Barren soil and waste places : common. May-Aug. - Depauperate forms, except by the seeds, are hardly distinguishable from

3. G. disséctum, L. (Cut-lenved C.) More slender and spreading, with narrower lobes to the leaves, and snialler rerl-purple petals notehed at the end; seeds short-ovoid or globular, finely and strongly reficulated. - Waste grounds, scarce. (Nat. from Eu.)

4. G. conumbenu, I. (Long-stalken C.) Minutely hairy, with very slender decumbent stems; leaves $5-7$-parted and ent into narrow linear lobes; prduncles and pedicels fuiform and ciongated; scpals awned, about cqualling the purple petals, cnlarging after flowering; carpels glalirous; secds nearly ns in No. 3. - $\Lambda$ long the Susquehanna, Lancaster Co., \&c., Prof. Porter. Alexandria, Virginia, A. H. Curtiss. Junc, July. (Nat. from Eu.)

5. G. Pusfllum, L. (Smald-Flowered C.) Stems procumbent, slender, minutely pubescent; leaves rounded kidney-form, 5-7-parted, the divisions werge-shaped, mostly 3-loberl; sepals aunless, about as long as the (purplish) jetals; seeds smooth. - Waste places, Massachusetts to Pennsylvania : rarc. (Nat. from $\mathrm{Eu}$.)

6. G. Robertiànum, I. (Hens Ronert.) Sparsely hairy, diffuse; strong-scented, leaves 3-divided or pedetcly 5-divided, the divisions twice pinnatifid: sepals awned, shorter than the (red-purple) petals; pods wrinliled; sends smooth. - Moist woods and shaded ravines: common northward. June-Oct. (Eu.) 


\section{FR Ò D I U M, L'Her. StorksBil.t.}

The 5 shorter stamens sterile or wanting. Styles in fruit twisting spirally, bearded inside. Otherwise as Geranium. (Name from épwóı́s, a heron.)

1. E. cicutanium, L'Her. Annual, hairy ; stems low, spreading; leaves pinnate; the leaflets sessile, 1-2-pinnatifid; peduncles several-flowered. - New York, Pennsylvauia, \&c. : scarce. (Adv. from Èu.)

\section{FL Ó́ RKEA, Willd. False Mermaid.}

Sepals 3. Petals 3, shorter than the calyx, oblong. Stamens 6. Ovaries 3, opposite the sepals, united only at the base; the style rising in the centre: stigmas 3 . Fruit of 3 (or $1-2$ ) roughish fleshy aclienia. Seed anatropous, erect, filled by the large embryo with its hemispherical fleshy cotyledons. - A small and inconspicuous annual, with minute solitary flowers on axillary peduncles. (Named after Flarke, a German botanist.)

1. F. proserpinacoldes, Willd. - Marshes and river-banks, W. New England to Wisconsin and Kentucky. April-June.-Leaflets 3-5, lauceolate, sometimes 2-3-cleft. 'Taste slightly pungent.

\section{I M P À TI $\mathbf{T} \mathbf{N}$, L. Balsam. Jewel-weed.}

Calyx and corolla colored alike and not clearly distinguishable. Sepals apparently only 4 ; the anterior one, which is notehed at the apex, probably consisting of two combined; the posterior one (appearing anterior as the flower hangs on its stalk) largest, and forming a spurred sac. Petals 2, unequal-sided and 2-lobed (each consisting of a pair united). Stamens 5, short: filanents appendaged with a scale on the inner side, the 5 scales comivent and united over the stigma: anthers opening on the inner face. Ovary 5-celled: stigma sessile. Porl with evanescent partitions, and a thick axis bearing the several anatropous seeds, 5-valved, the valves coiling elastically and projecting the seeds in bursting. Embryo straight: albumen none. - Leaves simple, alternate, without stipules, in our species ovate or oval, coarsely toothed, petioled. Flowers axillary or panicled, often of two sorts, viz., - the larger ones, as described above, which scldom ripen seeds; - and very small ones, which are fertilized early in the bud; their floral envelopes never expand, nor grow to their full size, but are forced off by the growing pod and carried upwaris on its apex. (Name from the sudden bursting of the pods when touched, whence also the popular appellation, Touch-me-not, or Snap-weed.)

1. I. pállida, Nutr. (P'ALE Toucu-ne-not.) Flowers pale-yellow, sparingly dotted with browni-1-red; sac dilated and very obtuse, broader than long, tipped with a short incurved spur. - Moist shady places and along rills, in rich soil ; most common northward. July-Sept. - Larger and greener than the next, with larger flowers: a spolless variety in N. Vermont and New Hampshire, Miss Lumbrird.

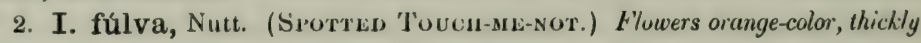
spotted with reddish-brown; sac longer than broad, acutely conical, tapering into a stiongly inflexed spur. - Rills and shady moist places: common, especially 
southward. June-Sept. - Plant $2^{\circ}-4^{\circ}$ high: the flowers loosely panieled at the ends of the branches, hanging gracefully on their slender nodding stalks, the open mouth of the cornucopia-shaped sepal upwarl. $-\Lambda$ varicty is not rare with spotless flowers, which differs from the I. Noli-tungere of Europe in the more inflexed spur and smaller petals. Spur rarely wanting.

\section{5. Ó X A L I S, I. Wood-Sorret.}

Sepals 5, persistent. Petals 5, their bases sometimes united, withering after expansion. Stamens 10, usually monadelphous at the base, alternately shorter. Styles 5, distinct. Pod oblong, membranaceous, 5-celled, more or less 5-lobed, each cell opening on the back; the valves persistent, being fixed to the central column or axis hy the partitions. Secds 2 or more in each cell, pendulous from the axis, anatropous, their outer coat loose and separating. Enbryo large and straight in fleshy albumen: cotyledons flat. - Herbs, with sour watery juice, alternate or radical leaves, mostly of 3 obcordate leaflets, which close and droop at nightfall. Sereral species produce (like Impatiens) small peculiar flowers, which are precocionsly fertilized in the bud and are particularly fruitful; and the ordinary flowers are often dimorphous or even trimorphous in the relative length of the stamens and styles. (Name from ókús, sour.)

* Stemless perennials: leaves and scapes a rootstock or bulb: lenflets broadly obcordate: flowers nearly 1' bruad; cells of the pod few-serded.

1. O. Acetosélla, I. (Соммом Woom-Sonnve.) Rootstock ereeping and scaly-toothed; scape 1 -flowered $\left(2^{\prime}-5^{\prime}\right.$ high); petals white with reddish veins, often notched. - Deep cold woods, Massachusetts to Penn., L. Superior and northward: also sonthward in the Alleghanies. June. (Eu.)

2. O. violàcea, L. (Violet W.) Nearly smooth; bulb scaly; scapes umbellately several-flowered $\left(5^{\prime}-9^{\prime}\right.$ high), longer than the leaves; petals violet. Rocky places; most common southward. May, June.

* : Stems leafy, branching: peduncles axillary: flowers small: cells several-seeded.

3. O. striata, L. (Yellow W.) Annual or perennial by running subterranean shoots; stems at first erect; stipules absent; peduncles 2-6-flowered, longer than the leaves; petals yellow; pods elongated, erect in fruit. - Copses and cultivated grounds : common. May - Sept. - Varies greatly in appearance and in the size of its flowers.

4. O. Cornicurita, L., if in this district, and truly distinct from O. stricta, should be known by the stipules at the base of the petioles. (Eu.)

\section{Order 25. IRU'TÀCEA. (Rue Family.)}

Plants with simple or compound lenves, dolted with pellucid glands, abounding with a pungent or bitter-aromatic acrid volatile oil, producing hypogynous almost always regular 3-5-merous flowers, the stamens as many or twice as many as the sepals (varely more numerous); the $2-5$ pistils separate or combined into a compound ovary of as many cells, raised on a prolongaiion of the receptacle (gynophore) or glandular disk. - Embryo large, curved or 
straight, usually in fleshy albumen. Styles commonly united or cohering, even when the ovaries are distinct. Fruit usually capsular. Leaves alteriate or opposite. Stipules none. - A large family, chiefly of the Old World and the Southern hemisphere; the P'Buper RuTACEs, represented in gardens by the Rue (Ruta gravètens, L.) and Fraxinella (Dictámnus Fraxinella, L.) chietly herbs, but the rest are shrubs or trees. - The AuI:ANTIE: or Orange Family, recently appended to this order, bas baccate firuit, seeds without albumen, and stancens sometimes almost indefinitely numerous. - Our two indigenous genera are

1. Zanthoxylum. Flowers diucious : ovaries $3-5$, separate, forming fleshy pods.

2. Ptelea. Flowers poly gamous : ovary 2-celled, forming a samara, like that of kilm.

\section{ZA NThóxyLUM, Collen. Prickly Asir.}

Flowers diocious. Sepals 4 or 5, obsolcte in one species. Petuls 4 or 5 , im. bricated in the bud. Stamens 4 or 5 in the sterile flowers, alternate with the petals. Pistils 2-5, separate, but their styles comniving or slightly united. Pods thick and fleshy, 2-valved, 1-2-seeded. Seed-coat crustaceous, black, smooth and shining. Embryo straight, with broad cotyledons. - Shrubs or trees, with mostly pinnate leaves, the stems and often the leafstalks prickly. Flowers small, greenish or whitish. (Name from $\xi a v \theta o ́ s$, yellow, and $\xi u ́ \lambda o \nu$, wood: therefore more properly spelled with an initial X.)

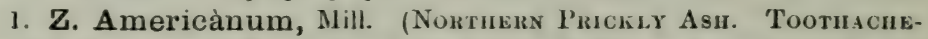
тreE.) Lcaves and fluevers in cxillury clusters; leatlets $4-5$ pairs and an odd one, ovate-ublong, lowny when young; calyx none; petals 5 ; pistils $3-5$, with slender styles; poels short-stulhed. - Rocky woods and river-banks : common northward. April, May. - A prickly shrub, with yellowish-green flowers appearing before the leaves. Bark, leares, and pods very pungent and aromatic.

2. Z. Caroliniànum, Lam. (Soutnens P.) Glabrous; leaflets 3-5 pairs and an odd one, ovite or ovate-lanceolate, oblique, shining above; flowers in a terminal cyme, appearing after the leaves ; sepals and petals 5 ; pistils 3 , with short styles; pods sessile. - Sandy coast of Virginia, and southward. June. A small tree with very sharp prickles.

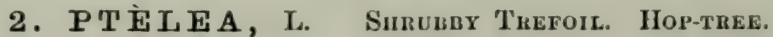

Flowers polygamous. Sepals $3-5$. Petals $3-5$, imbricated in the bud. Stamens as many. Ovary 2-eelled: style short: stigmas 2. Fruit a 2-celled and 2-seceled samatra, winged all round, nearly orbicular. - Shruls, with 3-fuliolate leaves, and greenish-white small flowers in compound terminal cymes. ('The Greek name of the Ehon, here applied to a genus with similax fruit.)

1. P. trifoliàta, L. Leaflets ovate, pointed, downy when young. - Rocky places, Penn. to Wisconsin and southward. June. $-\Lambda$ tall shrulb. Fruit bitter, used as a substitute for hops. Odor of the flowers disagrecable.

Ailántius glandulósus, Desf., called T'ree of Heaven, - but whose blossoms, especially the stuminute onew, are redolent of anything but " airs firous 
heaven," - is much planted us a shade-tree, especially in towns, and is inclining to spread from eeed in P'ennsylvania. It belongs to the order Simarubaces, which differs from Rutaces in the absence of dots in the leaves. The tree is known by its very long pinnate leaves of many leaflets, and small polygamous greenish flowers in panicles, the female producing $2-5$ thin, linear-oblong, veiny samaras. (Adv. from China.)

\section{Order 26. anacatrdicicate. (Cashew Family.)}

Trees or shrubs, with a resinous or milky acrid juice, dotless alternate leaves, and small, oflen polygamous, regular, pentandrous flowers, with a 1celled and 1-ovuled ovary, but with 3 styles or stigmas. - P'etals imbricated in the bud. Seed without albumen, borne on a curved stalk that rises from the base of the cell. Stipules none. Juice or exhalations often poisonous. - Represented here only by the genus

\section{RHÚ $\mathbf{S}$, L. Sumacir.}

Sepals 5. Petals 5. Stamens 5, inserted under the edge or between the lobes of $\Omega$ flattened disk in the bottom of the calyx. Fruit small and indehiscent, $\Omega$ sort of dry drupe. - Leaves (simple in R. Cútiuns, the Smoke-Plant of gardens) usually compound. Flowers greenish-white or yellowish. (The old Greek and I.atin name of the genus.)

§ 1. SÜMAC, DC. Flowers polygamous, in a terminal thyrsoid panicle: fruit globular, clothed with acid crimson hairs; the stone smooth: lcaves odd-pinnate. (Not poisonous.)

1. R. tỳphina, L. (Sтаgiorn Sumach.) Branches and stalks densely velvety-hairy; leaflets $11-31$, pale bencath, oblong-lanceolate, pointed, serrate, rarely laciniate. - Hillsides. Junc. - Shrub or tree $10^{\circ}-30^{\circ}$ high, with ornnge-colored wood.

2. R. glabra, L. ( Вмоотн S.) Smooth, somewhat glaucous; leaflets 11 31, whitened beneath, lanceolate-oblong, pointed, serrate. - Rocky or barren soil. June, July. - Shrub $2^{\circ}-12^{\circ}$ high. A var. has laciniate leaves.

3. R. copallina, L. (DWARF S.) Branches and stalks downy; petioles uing-margined between the 9-21 oblong or ovate-lanceolate (often entire) leaflets, which are oblique or unequal at the base, smooth and shining above. Rocky hills. July. - Shrub $1^{\circ}-7^{\circ}$ high, with running roots.

§2. TOXICODENDRON, Tourn. Flowers polygamous, in loose and slender axillary panicles: fruit globular, glabrous, whitish or dun-colored; the stone striate: leaves odd-pinnute or 3-foliolute, thin. (Poisonous to the touch.)

4. R. venenata, 10C. (Poison S. or Dogwoon.) Smooth, or nearly so ; lenflets 7-13, obovate-oblong, entire. (R. Vérnix, L.)-Swamps. June.Shrub $6^{\circ}-18^{\circ}$ high. The most poisonous species: also called Poison Elder.

5. R. Toxicodéndron, L. (Poison Ivy. Poison Onк.) Climbing by rootlets over rocks, \&c., or ascending trees; leaflets 3, rliombic-ovate, mostly jointed, and rather downy beneath, variously notehed, sinuate, or cut-lobed, - or else entire, then it is R. radicans, $L$. - Thickets, low grounds, \&c. June. 
§3. LOBADIUM, Raf. Fiowers polyyamo-dicecious, in clustered scaly-bracted spikics like oulkins, precrdin! the lenves: disk 5-parted, large: fruit as in $\$ 1$, but flutush : lowes 3-foliculute. (Not poisonous.)

6. R. aromática, Ait. (lisagkant S.) Leaves pubescent when young, thickish when old; leatlets 3 , rhombic-ovate, uncyually cut-toothed, the middle one wedge-shaped at the base; fluwers pale yelluw. - Dry rocky soil, from Vermont westivard and southward. A pril, May. - A straggling bush; the crushed leaves sweet-seented.

\section{ORDER 27. VITACEAE. (VINE Famil.y.)}

Shrubs with watery juice, usually climbing by tendrils, with small regular flowers, a minute or Iruncated calyx, its limb mostly obsolete, and the stamens as many as the valvate petals and opposite them! Berry 2-celled, usually \$seeded. - Petals 4-5, very deciduous, hypogynous or perigynous. Filaments slender: anthers introrse. Pistil with a short style or none, and a slightly 2-lobed stigma: ovary 2-celled, with 2 erect anatropous ovules from the base of each cell. Seeds bony, with a minute embryo at the base of the hard albumen, which is grooved on one sile. - Stipules deciduous. Leaves palmately veined or compound : tendrils and flower-clusters upposite the leaves. Flowers small, greenish. (Young shoots, foliage, \&c., acid.) - Consists of Vitis and one or two nearly allied genera.

\section{VITIS, Tourn. Grape.}

Calyx very short, usually with a nearly entire border or none at all, filled with an adnate fleshy disk which bears the jetals and stamens. - Flowers in a compound thyrsus; pedicels mostly umbellate-clustered. ('The classical Latin name.)

\$1. VITIS proper. Pttuls 5, cohering at the top, sepurating at the base, and so the corolla usually fulls off without expanding: 5 thick glands or lobes of the dixk alternating with the stumens: flowers polygamuns or diacious in all the American species, exhaliny "frugrance like that of Miynonette: leaves simple, rounded and heart-shuped, often variously and variably lobed.

* Leaves woolly beneath, when lobed having obtuse or rounded simuses.

1. V. Labrúsca, L. (Northers Fox-Gkape.) Branchlets and youny leaves very woolly; leaves continuing rusty-woolly beneath; fertile panicles compact; berries large. - Muist thickets: common. June. Eruit ripe in Sept. or Oct., dark purple or amber-color, with a tough musky pulp. Improved by cultivation, it has given rise to the Isabella, Catawba, Concord, and other varieties.

2. V. æstivalis, Miclix. (Sumaer Grapk.) Yuung leaves downy with loose cobwebby hairs bencuth, smoothish when old, green above; fortile panicles compound, long and slender: berries smull, black with a bloom. - Thickets : common. May, June. - Berrie's pleasint, ripe in Oct.

* Leuves smooth or neurly so and bright yreen both sides, commonly pubescent on the veins beneuth, either incisely lobed or undivided.

3. V. cordifolia, Michx. (Winter or Frust Grape.) Leaves thin, 
not shining, heart-shaped, acuminate, sharply and coarsely toothed, often obscurely 3-lobed; panicles compound, large and lonse; berries small, blue or black with a bloom, very acerb, ripening after frosts. - Var, RIPARIA, has the leaves broader and cut-lobed. (V. riparia, Michx.) - Thickets and river-hanks : common. May, June. - Flowers very sweet-scented,

4. V. vulpina, L. (Muscadine or Soutiern Fox-Grape.) Lenves shining both sides, small, rounded with a heart-shaped base, very coarsely toothed with brond and bluntish teeth, scldom lobod; panicles small, densely flowered; berries large ( $\frac{1}{2}-3^{\prime}$ in liameter), musky, purplish without a bloom, with a thick and tough skin, ripe carly in autumn. - River-banks, Maryland to Kentucky and southward, May, - Bark of stem close, not separating in strips as in the other species. Branchlets minutely warty. This is the original of the Scuppernong Grape, \&c.

§ 2. CISSUS, L. Petuls (5 in our species) expanding before or when they fall: disk thick and broad, usually 4-5-lobed: flowers commonly perfect: lendrils feuer.

5. V. indivisa, Will. Nearly glabrous; leaves heart-shaped or truncate at the base, coarsely and slarply toothed, acuminate, not lobed; panicle snall and loose; style slender; berries of the size of a pen, 1-3-seeded. - Riverbanks, West Virginia, Ohio, and sonthward. June.

6. V. bipinnàta, Torr. \& Gray. Nearly glabrous, bushy and rather upright; leaves twice pinnate or ternate, the leaflets cut-toothed; flowers cymose; calyx 5-toothed; disk very thick, adherent to the ovary; berries black, obovate. - Rich soils, Virginia, Kentucky, and southward.

\section{A M PELÓ PSIS, Michx. VIrginin Creeper.}

Calyx slightly 5-toothed. Petals concave, thick, expanding before they fall. Disk none. - Leaves digitate, with 5 oblong-lanceolate sparingly serrate leaflets. Flower-clusters cymose. Tendrils fixing themselves to trunks or walls by dilated sucker-like disks at their tips. (Name from $\ddot{\mu} \mu \pi \epsilon \lambda_{o s}, a$ vine, and ö $\psi \iota s$, appearance.)

1. A. quinquefolia, Michx. - A common woody vine, in low or rich grounds, climbing extensively, sometimes by rootlets ns well as by its diskbearing tendrils, blossoming in July, ripening its small blackish berries in October. Also called American Ivy, and still less appropriatcly, Woodbine. Leuves turning bright crimson in autumn.

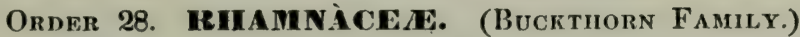

\$hruhs or small trees, with simple leaves, small and regular flowers (sometimes apetalous), with the 4 or 5 perigynous stamens as many as the valvate sepals and alternate with them, accordingly opposite the petals! Drupe or pod with only one erect seed in each cell, not arilled. - I'etals folded inwards in the bud, hooded or concave, inserted along with the stamens into the erge of the fleshy disk which lines the short tube of the calyx and sometimes unites it to the lower part of the 2-5-celled ovary. L \& M-25 
Ovules solitary, anatropous. - Stigmas 2-5. Embryo large, with broad cotyledons, in sparing fleshy altumen. -- Flowers often polygamous, sometimes diecious. Leaves mostly altcriate : stipules small or obsolete. Branches often thorny. (Slightly bitter and astringent: the fruit often mucilaginous, commonly rather nauseous or drastic.)

\section{* Caly $x$ and disk free from the ovary.}

1. Berchemia. l'etals sessile, entire, as long as the calyx. Drupe with thin flesh and a 2 celled bony putamen.

2. Rhamuus. Pctals small, short-clawed, notched, or none. Drupe berry-like, with the 2-4 separate seed-like nutlets concave on the back : cotyledons leaf-like, revolute.

3. Frangula. Yetials, \&c. as in No. 2. Seed-like nutlets couvex on the back: cotyledons flat, fleshy.

* Caly $x$ with the disk adherent to the base of the ovary.

4. Cennothus. Petits long-clawcd, hoviled. Fruit dry, at leugth dehiscent.

\section{BERCHË I A, Necker. Supple-JACK.}

Caljx with a very short and roundish tube; its lobes equalling the 5 oblong sessile acute petals, longer thin the stamens. Jisk very thick and flut, filling the calyx-tule and covering the ovary. 1)rupe oblong, with thin flesh and a bony 2-eelled putanen. - Woody high-climbing twiners, with the pinnate veins of the leaves straight and parallel, the small greenish-white flowers in small panicles. (Name unexplained, probably personal.)

1. B. Volùbilis, 1)C. Gilabrous; leaves oblongrovate, ncuto, scarcely serrulate; style short. - Damp soils, Virginia, and southward. June. - Ascending tall trees. Stems tough and very lithe, whence the popular name.

\section{RH $\mathbf{A} \mathbf{M} \mathbf{N} \mathbf{S}$, Tourn. BuсктиовN.}

Calyx 4-5-cleft; the tube campanulate, lined with the disk. Petals small, short-clawed, notclied at the end, wrapped around the short stamens, or sometimes none. Ovary free, 2-4-celled. Drupe berry-like (black), containing 24 separate seed-like nutlets, of cartilaginous texture, which are grooved on the back, as is the contained seed. Cotyledons foliaceous, the inargins revolute. - Shruls or small trees, with loosely pinnately veined leaves, and greenish polygamous or dioecious flowers; in axillary clusters. ('The ancient Greek name, from the numerous branchlets.)

* Lobes of the calyx, petuls, and stamens 4.

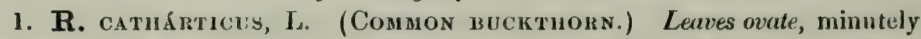
serrate; fiuit 3-4-secalid; branchlets thorny. - Cultivated for hedges; sparingly naturulized cistward. May, June. (Nat. from Lu.)

2. R. lanceolàtus, P'ursh. Lraves ublong-lancevlate and acute, or on flowering shoots oblong and obtuse, fincly serrulate, smooth or minutely downy beneath; petals deeply notched; fiuit 2-sceded. Hills and river-banks, Penn. (Mercerslurg, Prof: (incen) to Illinois, and westward. May. - Shrub tall, not thorny ; the yellowish-green flowers of two forms on distinct plants, both perfect: one with the short pedicels clustered in the axils and with a short included style; the other with the pedicels oftener solitary, the style longer and exserted. 
* Loles of the calyx and stamens 5 : petals wanting.

8. R. alnifolius, L'Iler. A low shrub, lenves oval, acute, serrate, nearly straight-veined : fruit 3-seeded. - Swamps, Maine to Penn., Illinois, and northward. June.

\section{F RÁ N G U LA, Tourn. Alder-Buckthorn.}

Seeds not grooved or concave (but convex) on the back. Cotyledons plane, thick. Flowers perfect; the lobes of the calyx, petils, ard stamens almost always 5. Leaves with nearly straight parallel veins. Otherwise as in Rhannus. (Name from frango, to break, in allusion to the brittleness of the stems.)

1. F. Caroliniàna, Gray. Thornless shrub or small tree; leaves $\left(3^{\prime}-5^{\prime}\right.$ long) oblong, obscurely scrrulate, nearly glabrous, deciduous; flowers in one form umbelled, in another solitary in the axils, short-peduncled; drupe globose, 3-seeded. - Secaucus swamp, New Jersey, Dr. Post, W. H. Leggett, and riverbanks. Virginia to Kentucky and southward. June.

\section{CEA N Ùth US, L. New Jersex Tea. Red-root.}

Calyx 5-lobed; the lobes colored and incurved; the lower part with the thick disk cohering with the ovary, the "pper separating across in fruit. Petals hooded, spreading, on slender claws longer than the calyx. Filaments also elongated. Fruit 3-lobed, dry and splitting into its 3 carpels when ripe. Sced as in Frangula. - Shrubby plants; the flowers in little umbel-like clusters, which are crowded in dense panicles or corymbs at the summit of naked flowerbranches: calyx and pedicels colored like the petals. (An obscure name in Theophrastus, probably misspelled.)

1. C. Americanus, L. (New Jersey Tea.) Leaves ovate or oblong-ovate, 3-ribbed, serrute, downy beneath, often heart-shaped at the base : common peduncles elongated. - Dry woodlands. July. - Stems $1^{\circ}-3^{\circ}$ high from a dark red root: branches downy. Flowers in pretty white clusters. The leaves were used for tea during the American Revolution; and the manufacture has been recently revived in Pennsylvania.

2. C. ovàlis, Bigelow. Leaves narrowly oval or elliptical-lanceolate, finely glandular-serrite, glabrous or nearly so, as well as the short common peduncles. - Dry rocks, W. Vermont to Wisconsin, and westward. May. - The white flowers larger than in No. 1, more corymbed: leaves narrower, smooth, mostly ncute at both ends.

\section{Order 29. Celastiriàcea. (Staff-tree Family.)}

Shrubs with simple leaves, and small regular flowers, the sepals and the petals both imbricated in the bud, the 4 or 5 perig!nous stamens as many as the petals and alternate with them, inserted on a disk which fills the bottom of the calyx and sometimes covers the ovary. Seeds arilled. - Ovules one or few (erect or pendulous) in each cell, anatropous: styles united into one. Fruit 2-5-celled, free from the calyx. Embryo large, in fleshy albumen: cotyledons broad and thin. Stipules minute and fugacious. Pedicels jointed. - Represented by two genera. 


\section{Celá stru $\mathbf{s}$, L. Staff-tree. Shrubby Bitter-sweet.}

Flowers polygumo-diecions. Petuls (crenulate) and stamens 5, inserted on the margin of a cup-shinped disk which lines the base of the ealyx. Pod globose (orange-color and berry-like), 3-celled, 3-valved, loculicidal. Seeds 1 or 2 in each cell, ereet, enclosed in a pulpy scarlet aril. - Leaves alternate. Flowers sinall, greenish, in raceme-like clusters terminating the branches. (An ancient Greek name for some evergreen, which our plant is not.)

1. C. scándens, L. (Wax-wokк. Chimuing Bitter-siveet.) 'T'wining shrub; leaves ovate-oblong, fincly serrate, pointed. - Along streams and thickets. June. - The opening orange-colored pods, displaying the scarlet covering of the seeds, are very ornamental in autumn.

\section{E U Ó N Y M U S , Tourn. Spindle-tree.}

Flowers perfect. Sepals 4 or 5 , united at the hase, forming a short and flat calyx. Petals 4-5, rounded, spreading. Stannens very short. inserted on the edge or face of a broad and flat 4-5-angled disk, which colieres with the calyx and is stretehed over the ovaly, adliering to it more or less. Style short or none. Pod 3-5-lubed, 3-5-valved, loculicidal. Seeds 1-4 in each cell, enclosed in a red aril. - Shrubs, with 4-sided branchlets, opposite serrate leaves, and loose cymes of small Howers on axillary peduncles. (Derivation

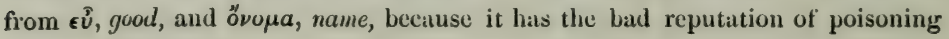
cattle. Tourn.)

1. E. atropurpùreus, Jacq. (Bunning-Bush. WaAnoo.) Shrub tall $\left(6^{\circ}-14^{\circ}\right.$ high) and upright; leaves petioled, oval-oblong, pointed; parts of the (dark-purple) flower commouly in fours ; porls smooth, deeply lobed. - New York to Wisconsin and southward: also cultivated. June. - Ornamental in autumn, by its copions crimson fruit, drooping on long peduncles.

2. E. Americànus, I. (Strawberry Busir.) Shrub low, upright or straggling $\left(2^{\circ}-5^{\circ}\right.$ high) ; leates almost sessile, thickish, bright green, varying from ovate to oblong-lanceolate, acute or pointed; parts of the greenish-purple flowers mostly in fives; pods rough-warty, depressed, crimson when ripe; the aril scarlet. - Wooded river-banks, S. and W. New York to Illinois and suuthward. June.

Var. obovàtus, Torr. \& Gray. Trailing, with rooting branches; flowering stems $1^{\circ}-2^{\circ}$ high; leaves thin and dull, obovate or oblong. (E. obovatus, Nutt.) - Low or wet places : the commoner form.

\section{Order 30. Sapindiceat. (Soapberry Family.)}

Trees, shrubs, with simple or compound leaves, mostly unsymmetrical and often irregular flowers; the 4-5 sepals and petals both imbricated in astivation; the 5-10 stumens inserted on a fleshy (perigynous or hypogynuns) disk; a 2-3-celled and lober ovary, with $1-2$ (or rarely more) ovules in euch cell; and the embryo (except Staphylea) curved or convolute, without altumen. - A large and diverse order, the true Sapindacea principally tropical, here represented only by the Buckeyes. 


\section{Sunorder I. StTapingeacede. Biandfr-Nut Family.}

Flowers (perfect) regular : stamens as many as the petals. Ovules 1-8 in each cell. Seeds bony, with a straight embryo in scanty albumen. Shrubs with opposite pinnately compound leaves, both stipulate and stipellate.

1. Staphy lea. Lohes of the colored calyx and petals 5, erect. Stamens 5. Fruit a 3-celled bladdery-inflated pod.

\section{Suborder II. SAPINDACEA proper (including Hipfocastanew.)}

Flowers (often polygamons) mostly unsymmetrical and irregular; the stamens commonly more numerous than the petals or sepals, but rarely twice as many. Ovules 1 or 2 in each cell. Albumen none. Embryo curved or convolute, rarely straight : cotyledons thick and fleshy. - Leaves alternate or sometimes opposite, destitute of stipules, mostly compound.

2. Tsculus. Caly $\times$ 5-lobed. Fetals 4 or 5. Stamens commonly 7. Fruit a leathery pod. L'aves opposite, ligitate.

\section{Suborder III. ACerineat. Maple Family.}

Flowers (polygamous or diøcious) small, regular, but usually unsymmetrical. Petals often wanting. Ovary 2-lobed and 2-celled, with a pair of ovules in each cell. Winged fruits 1-seeded. Albumen none. Embryo coiled or folded; the cotyledons long and thin. - Leaves opposite, simple or compound.

3. A cer. Flowers polygamous. Leaves simple, or rarely digitately compound.

4. Negnndo. Flowers diœecious. Leaves pinnate, with $3-5$ leaflets.

\section{S T A P H Y LìA, L. Bladder-Nut.}

Calyx deeply 5-parted, the lobes erect, whitish. Petals 5, erect, spatulate, inserted on the margin of the thick perigynous disk which lines the base of the calyx. Stamens 5, alternate with the petals. Pistil of 3 several-ovuled carpels, united in the axis, their long styles lightly cohering. Pod large, membranaceous, inflated, 3-lobed, 3-celled, at length bursting at the summit; the cells containing $1-4$ bony anatropous seeds. Aril none. Embryo large and straight, in scanty albumen; cotyledons broad and thin. - Upright shrubs, with opposite pinnate leaves of 3 or 5 serrate. leaflets, and white flowers in drooping raceme-

1 like clusters, terminating the branchlets. Stipules and stipels deciduous. (Name from $\sigma \operatorname{ra\phi } v \lambda \dot{\eta}, a$ cluster.)

1. S. trifolia, L. (American Blander-nut.) Leaflets 3, ovate, pointed. - Thickets, in moist soil. May. - Slırub $10^{\circ}$ high, with greenish striped branches.

\section{2. 庎 S C U L U S, L. Horse-chestnut. Buckeye.}

Calyx tubular, 5-lobed, often rather oblique or gibbous at the base. Petals 4, sometimes 5, more or less unequal, with claws, nearly hypogynous. Stamens 
7 (rarely 6 or 8 ) : filaments long and slender, often unequal. Style 1: ovary 3-celled, with 2 ovules in each, only one of which, or one in each cell, forms a seed. Seed very large, with a thick and shining cuat, and a large and round pale scar, without albumen. Cotyledons very thick and fleshy, their contiguous faces more or less united, remaining under ground in germination : plumule 2 leaved: radicle curved. - Trees or shrubs. Leaves opposite, digitate: leaflets serrate, straight-veined, like a Chestnut-leaf. Flowers in a terminal thyrsus or dense panicle, often polygamous, the greater portion with imperfect pistils and sterile. Pedicels jointed. Seeds farinaceous, but imbued with a bitter and narcotic principle. ('The ancient name of some Oak or other mast-bearing tree.)

\section{§1. ASSCULUS proper. Fruit covered with prickles when young.}

1. 死. Hippocistanum, L. (Common Honse-chestnut.) Corolla spreading, white spotted with purple and yellow, of 5 petals; stamens declined; leaflets 7. - Commonly planted. (Adv. from Asia via Eu.)

2. 互. glabra, Willd. (Fetri or Onio Buckeye.) Stamens curved, longer than the pale yellow corolla of 4 upright petals; leaflets 5. - Riverbanks, W. Penn. and Virginia to Michigan and líentucky. June. - A largo tree; the bark exhaling an umpleasant odor, as in the rest of the genus. Flowers small, not showy.

§ 2. PAVIA, Bocrhaave. Fruit smooth: petals 4, conniving; the 2 upper smaller and longer than the others, with a sinall and rounded blade on a very long claw.

3. A巴. flàva, Ait. (Siveet Buckeye.) Stamens included in the yellow corolla; calyx oblong-campanulate; leaflets 5 , sometimes 7 , glabrous, or often minutely downy underneath. - Rich woods, Virginia to Ohio, Indiana, and southward. May. A large tree or a shrub.

Var. purpuráscens. Flowers (both calyx and corolla) tinged with fleshcolor or dull purple; leaflets commonly downy beneath. (AE. discolor, Pursh.) - From West Virginia southward and westward.

4. A. Pàvia, L. (Red Buckeye.) Stamens not longer than the corolla, which is bright red, as well as the tubular calyx; leaflets glabrous or softdowny beneath. - Fertile valleys, Virginia, Kentucky, and southward. May. - A shrub or̂ small tree.

\section{A CER, Tourn. MAPLE.}

Flowers polygamo-diacious. Calyx colored, 5- (rarely 4-12-) lobed or parted. Petals either none, or as many as the lobes of the calyx, equal, with short claws if any, inserted on the margin of the lobed disk, which is either perigynous or hypogynous. Stamens 3-12. Ovary 2-eelled, with a pair of ovules in each : styles 2, long and slender, united only below, stigmatic down the inside. From the back of each ovary grows a wing, converting the fruit into two l-seeded, at length separable samaras or keys. Seed without albumen. Embryo variously coiled or folded, with large and thin cotyledons. - Trees, or sometimes shrubs, with opposite palmately-lobed leaves, and small flowers. Prdicels not jointed. ('The classical name, from the Celtic ac, hard.) 
- Flowers in terminal racemes, grecnish, appenring affer the lcauss: stamens 6-8.

1. A. Pennsylvanicum, I. (Striped MArLe.) Leaves 3-lobed at the apex, finely and sharply doubly serrate; the short lobes taper-pointed and also serrnte; racemes dronping, louse; petals obovente; fruit with large diverging wings. (A. striàtum, Lam.) - Rich wools, Maine to Wisconsin, and southward along the Alleghanies to Virginia and Kentucky. Junc. $-\Lambda$ small and slender tree, with light-green bark striped with dark lines, and greenish flowers and fruit. Also called Striped Dogyworl and Moesse- I'

2. A. spicàtum, Lam. (Mountsin M.) J,aves downy underneath, 3- (or slightly 5-) lobed, coarsely serrate, the lohes toper-pointed; racemes upright, dense, somewhat compound; petals linom-sputulufe; fruit with small very

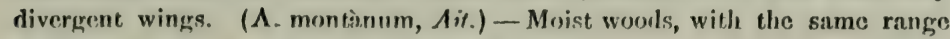
as No. I. June. $-\Lambda$ tall shrub, forming clumps.

* * Flowers umbellate-corymbed, grenish-yellow, appenring with the laves.

3. A. sacchàrinum, Wang. (Sugar or Rock M.) Leaves 3-5-lohel, with rounded sinuses and pointed sparingly sinuate-toothed lobes, either heartshaped or nearly truneate at the base, whitish and smooth or a little downy on the veins beneath; flowers from terminal leaf-bearing and lateral leafless buds, Arooping on very slender harry pedicels; calyx hairy at the apex; petals none; wings of the fruit broad, slightly diverging. - Rich woods, especially northward and along the mountains southward. April, May. - A large and handsome tree.

Var. nigrum. (BцАск Sugsi-M.) Leaves scarcely paler beneath, but often minutely downy, the lobes wider, the sinus at the base often closed. (A. nigrum, Michx.) - With the ordinary form

* * Flowers in umbel-like clusters arising fiom separate lateral buds, and much proceding the leaves: stamens 3-6.

4. A. dasycárpum, Ehrhart. (White or Sirver M.) Leaves very derply 5-lohed with the sinuses rather aeute, silvery-white (and when young downy) underneath, the divisions narrow, cut-lobed and toothed; flowers (greenish-yellow) on short pedicels; petals none; fiuit voolly when young, with large divergent wings. - River-banks; most common southward and westward. March-April. - A fine ornamental tree.

5. A. rubrum, L. (Ren or Swame M.) Inaves $3-5$ lobed, with acuto sinuses, whitish underneath; the lobes irregularly serrate and notched, acute, ' the middle one usually longest; petals linear-oblong; flowers (scarlct, crimson, or sometimes yellowish) on very short pedicels ; but the smnoth fruit on prolonged drooping pedicels. - Swamps and wet woorls. A pril. - A small trec, with reddish twigs; the leaves varying greatly in shape, turning bright crimsom in early autumn.

\section{N EG Ú N D O, Mœnch. Asti-lenved Maple. Box-Eldfr.}

Flowers dioecious. Calyx minute, 4-5-cleft. Petals none. Stamens 4-5. Disk none. - Sterile flowers in clusters on capillary pedicels, the fertile in drooping racemes, from lateral buds. Leaves pinnate, with 3 or 5 leaflets. (Name unmeaning.) 
1. N. aceroides, Monch. (Acer Negundo, L.) Leaflets smoothish when old, very veiny, ovate, pointed, toothed; fruit smooth, with large rather incurved wings. - River-banks. I'ennsylvania to Wisconsin, and southward. $\Lambda$ pril. $-\Lambda$ small but handsome trec, with light-green twigs, and very delicate drooping clusters of small greenish flowers, rather earlier than the leaves.

\section{Order 31. POLyGatacede. (Milkwort Family.)}

Plants with irregular hypogynous flowers, 4-8 diadelphous or monalelphous stamens, their 1+celled anther's opening at the top by a pore or chink; the firuit a 2-celled and 2-seeded pod.-Represented in this country only by the genus

\section{POLÝGALA, Tourn. Minwort.}

Flower very irregular. Caly $x$ persistent, of 5 sepals, of which 3 (the upper and the 2 lower) are small and often greenish, while the two lateral or inner (called wings) are much larger, and colored like the petals. Petals 3 , hypogynous, connected with each other and with the stamen-tube, the middle (lower) one keel-shaped and often crested on the back. Stamens 6 or 8 : their filameuts united below into a split sheath, or into 2 sets, colhering more or less with the petals, free above: anthers 1-celled, often cup-shaped, opening by a hole or broad chink at the apex. Ovary 2-celled, with a single anatropous ovule pendulous in each cell: style prolunged and curved: stigma various. Fruit a small, loculicidal 2-seeded pod, usually rounded and notehed at the apex, much flattened contrary to the very narrow partition. Seeds with a caruncle, or variously shaped appendage, at the hilum. Embryo large, straight, with flat and broal cotyledons, surrounded by a sparing albumen. - Bitter plants (low herbs in temperate regions), with simple entire often dotted leaves, and no stipules: sometimes (as in the last two species) bearing concealed flowers next the ground, which are fertilized in the closed bud. (An old name composed of $\pi 0 \lambda$ ús, much, and $\gamma a ́ \lambda a$, milk, from a fincied property of its increasing this secretion.)

§. Biennials or anmuals, with alternate leaves, and yellow flowers, which are disposcd to birn greenish in drying: crest of the keel (lower petal) small: flowering all summer.

1. P. lùtea, L. Low; flowers (bright orange-yellow) in solitary ovate or oblong heads (4' thick, ) terminating the stem or simple branches; leaves $\left(1^{\prime}-2^{\prime}\right.$ long $)$ obovate or spatulate; lobes of the curuncle nearly as long as the seed. - Sandy swamps, New Jorsey and southward, near the coast.

2. P. ramósa, lill. Floucers (citron-yellow) in numurous short and dense spikelike racemes collected in a llat-topped compound ryme; leaves oblong-linear, the lowest spatulate or obovate; seels ovoid; minutely hairy, twice the length of the caruncle. (P. cymosa, Poir., not of Walt. 1'. coryubosa, Nutt.) - Damp pinebarrens, Delaware and southward. ('The allied P'. crabss, Walt., which is P'. graminifolia, I'oir., I'. attenuata, Nutt. and I'. acutifolia, Torr. \& Gray, known by its simpler cymes, stem naked above, narrower leaves, and globulat seeds with no caruncle, - may occur in S. Virginia.) 
§ 2. Annuals, with all the leaves alternate: flowers in spikes, heads, or racemes terminating the stem or branches, purple or rose-rolor, in summer: none subterranean.

* Corolla conspicuously crestrd on the keel: the claws of the true petals united into a long and slender cleft tube much surpassing the wings.

3. P. incarnata, L. Glancous; stem slender, sparingly hranched; leaves minute and linear-awl-shnped; spike cylindrical; flowers flesh-color; caruncle longer than the narrow stalk of the hairy secd. - Dry soil, Penn. to Wisconsin and southward; rather rare.

* * Corolla minutely or inconspicuously crested; the true petals not longer but mostly shorter than the wings: seed pear-shaped.

: 4. P. sanguínea, L. Stem sparingly branched above, lcafy to the top; lenves oblong-linear; heads glolular, at length oblong, very dense ( 4 " -5 " thick), bright red-purple (rarely paler or even white); pedicels scarcely any; wings broully ovate, closely sessile, longer than the pod; the 2-parted caruncle almost equalling the seed. - Sandy and moist ground: common.

b 5. P. fastigiata, Nutt. Stem slender, at length corymbosely branched; loaves narrouly lineur, small ; spikes short and dense (3" in diameter); the small rose-purple flowers on pedicels of about the length of the pod; wings obovate- or oval-oblong, narrowerl at the hase, scarcely excecling the pod ; brarts deciduous with the flowers or fruits; carmucle as long as and nealy cuveloping the stalklike base of the minutely hairy seed. (P. sanguinen, Torr. \& Gr., excl. syn.; not of Nutt., nor $L$.) - Pine barrens of New Jersey (Nuttall) and Delaware to Kentucky and southward.

6. P. Nuttàllii, Torr. \& Gr. ( $F l .1, p .670$, excl. syn. \& descr.) Resembles the last, but usually lower; spikes more cylindrical ; flowers duller or greenish jurple, on shorter pedicels; the awl-shaped scaly bracts persistent on the axis after the flowers or fruits fall ; sced very hairy, the caruncle smaller. (P. sanguinea, Nutt., not of L. P. Mariana, \&c., Pluk. t. 437. P. ambigua, Torr. \& Gr. Fl., not of Nutt.) - Dry sandy soil, coast of Massachusetts to Kentucky and southward. - Spike sometimes rather loose.

7. P. Curtíssii, n. sp. Slender ( $\left(9^{\prime}\right.$ high $)$; leaves, \&c., as in the two precerling; flowers rose-purple, in elonguted and loose racemrs; the ascending pedicels und the narrow oblong erret wings fully twice the length of the pod ; bracts persistent, those of the lower and remoter flowers foliaccons; caruncle small, on one side of the stalk-like hase of the very hairy serd, which is conspicuonsly apiculate at the biouder end. - Near Alexandria, Virginia, A. H. Curtiss. - Most related to P. Chapmanii of Florida.

8. 3. Annuals with at least the lower stem-leaves whorled in fours, sometimes in fives: spikes terminating the stem and branches; $f$. summer and autumn.

* Spikes shont and thick (4" - 9" in diameter; the axis rough with the squarrose bracts persisting after the full of the (middle-sized) rose or greenish purple flowers : crest of the keel smill.

8. P. cruciàta, I. Stems $\left(3^{\prime}-10^{\prime}\right.$ high) nlmost winged at the angles, with spreading opposite branches; lesves nearly all in fours, linear and somewhat spatulate or oblanceolate; sprikes sessile or nerrly so, wings lrondly deltoid. ovate, slightly heart-shaped, tapering to a bristly point, or rarely pointless ; caruncie

G M-6 
nearly as long as the seed. - Margin of swamps, Maine to Virginia and southward near the coast, and along the Great Lakes.

9. P. brevifolia, Nutt. Ruther slender, brunched above; leaves scattered on the branches, narrower; spikes peduncled; winys lanceolate-ocate, poinuless or lardy mucronate. - Margin of sandy bogs, Rhode Island (Olney), New Jersey, and southward. Too near the last.

* * Spikes slender (about 2" thich), the bracts fulling with the flowers, which are small, grenish-white or burcly tinged with purple, the crest of the keel larger.

10. P. verticillàta, L. Slender $\left(6^{\prime}-10^{\prime}\right.$ high), much branched; stemleaves all whorled, those of the branches scattered, linear, acute; spikes peduncled, dense, acute; wings round, clawed; the 2-lobed caruncle half the length of the seed. - Dry soil : common.

11. P. ambígua, Nutt. Very slender, loosely branched; lowest stem-lunces in fours, the rest scattered; spikes long-peduncled, more slender, the flower's often purplish and scattered; wings oval; caruncle shorter; otherwise nearly as in No. 10, - of which it is probably a mere variety. - Dry soil, from New York and Pennsylvania southward.

\$4. Perennial, with allernate laves thronghout, and white flowers in a solitary close spike: no subterrancan blossoms.

12. P. Sénega, L. (Śleneca Snakeroot.) Stems several from thick and hard knotty rootstocks, simple $\left(6^{\prime}-12^{\prime}\right.$ high $)$; leaves lanceolate or oblonglanccolate, with rough margins; flowers almost sessile; wings round-obovate, concave; crest short; carumcle nearly as long as the seed. - Rocky soil, W. New England to Wisconsin and southward. May, June.

Var. latifolia, Torr. \& Gray. 'Tiller, sometimes branched; leaves ovate or ovate-lanceolate, $2^{\prime}-4^{\prime}$ long, tapering to each end. - Maryland to Kentucky.

§5. Biennials and perenniuls, with showy, rose-purple, conspicuously crested flowers; also bearing colorless und incorspicuous more fertile ones, with imperfect corollas, fertilized in the bud, on sublerranean branches.

13. P. polýgama, Walt. Stems numerous from the biennial root, mostly simple, ascending, very leafy $\left(6^{\prime}\right.$ to $9^{\prime}$ high $)$; leaves clunceolate or oblong, alternate ; terminal racene many-fluwered, the broadly obovate wings longer than the keel; stamens 8 ; radical flowers racemed on short rumers beneath the ground; lobes of the caruncle 2, scale-like, shorter than the secd. - Dry sandy suil ; common eustward. July.

14. P. paucifolia, Willd. Perennial; flowering stems short $\left(3^{\prime}-4^{\prime}\right.$ high), rising from long and slender prostrate or subterrancan shoots, which also bear concealed fertile flowers; lower leaves small and scale-like, scattered: the upper leares ovute, petiolcd, crowded at the summit of the stem; flowers 1-3, large, peduncled; wings obovate, rather shorter than the conspicuously fringe-crested keel; stamens 6 ; caruncle of 2 or 3 awl-shaped lobes longer than the seed. Woods, in light soil, especially uorthward, extending southward along the Alleghanies. May. - A delicate plant, with large and very handsome flowers, $9^{\prime \prime}$ long, rose-purple, or rarely pure white. Sometimes called Flowering Wintergreen, but more appropriately Fringed Polygala. 


\section{Order 32. LeGuminiosat. (Pulge Famity.)}

Plants with papilionacenus or sometimes regular ntrerlers, 10 (rarely 5 and somelimes many) monadelphous, dind,lphous, or rarely distinct stamens, and a single simple free pistil, becoming a leyume in fruit. Seeds mostly without albumen. Leaves alternate, with stipules, usually compound. One of the sepals inferior (i. e. next the bract) ; one of the petals superior (i. e. next the axis of the inflorescence). - A very large orler (nearly free from noxious qualities), of which the principal representatives in northern temperate regions belong to the first of the three suborders it comprises.

\section{Suborder I. Papilionaceat. Profer pulse family.}

Calyx of 5 sepals, more or less uniterl, often unequally so. Corolla perigynous (inserted into the base of the calyx), of 5 irregular petals (or very rarely fewer), imbricated in the bud, more or less distinctly papilionaceous, i. e. with the upper or odd petal, called the vexillum or standard, larger than the others and enclosing them in the bud, usually turned backward or spreading; the two lateral ones, called the wings, oblique and exterior to the two lower petals, which last are comnivent and commonly more or less coherent by their anterior edges, forming a body named the carina or keel, from its resemblance to the keel or prow of a boat, and which usually encloses the stamens and pistil. Stamens 10 , very rarely 5 , inserted with the corolla, monadelphous, diadelphous (mostly with 9 united in one set in a tube which is cleft on the upper side, $i$. e. next the standard, and the tenth or upper one separate), or occasionally distinct. Ovary 1-celled, sometimes 2-celled by an intrusion of one of the sutures, or transversely 2 many-celled by cross-division into joints: style simple: ovules amphitropous, rarely anatropous. Cotyledons large, thick or thickish: radicle incurved. - Leaves simple or simply compound, the earliest ones in germination usually opposite, the rest alternate: leaflets almost always quite entire. Flowers perfect, solitary and axillary, or in spikes, racemes, or panicles.

A. Stamens monadelphous or diadelphous.

Trlbe I. GENISTER. Shruhs or hrobs, never climbing, with simple or palmately compound leaves, and peluncles terminal or opposite the leaves. Stamens monadelphous : anthers of two forma. Pod continuous.

1. Lnpinus. Calyx deeply 2-lipped. Keel scythe-shaped, pointed. Pod flat.

2. Crotalarin. Calyx 5-lobed. Keel scythe-shaped, pointed. Pod inflated. Leaves simple.

3. Geulsta. Keel straight, deflexed. Por uaually flat. Leaves simple.

Tribe II. TRIFOLI I: RE. IIerhs, not climbing, with 3-(rarely 5-7-) foliolate leaves, the veinlets of the leaflets often running into minute teeth, and the stipules united with the base of the petiole. Peduncles axillary. Stamens diadel phous : anthers uniform. Pod emall and 1 -few-seedei, or coiled.

4. Trifollum. Flowers capitatc. Poils membranacenus, 1-6-secded. Petnis adherent to the stamen-tube.

5. Melllotus. Flowers racemed. Pods coriaceous, wrinkled, 1-2-seeded.

6. PIedlcago. Flowers racemel or spiked. Pods curved or coiled, 1-few-seeded 
Tribe III. GA I.EGEAC. Herbs or woody plants (twining only in No. 12), not tendritbearing, with piunate or sometimes palmately compound leuves. Stamens diadelphous of

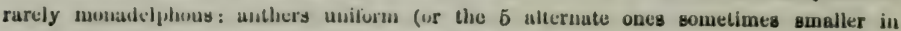
No. 7). Pod contiunuus, at least not transversely jointed.

* PSORALIEj. Glandular-dotted shrubs or herbs. Ovary 1-3 ovuled; the legume small atud indehiseent, 1-sevied, rartly 2-seeded.

7. Psoralea. Corolla truly papilionaceous. Stamens 10 , wore or less diadelphous, half of the anthers often smaller or less perfict. Leaves $3-5$-foliclate.

8. Dalea. Corolla imperfectly papilionaccous. Stamens 9 or 10 , wonadelphous; the cleft tube of filaments bearing 4 of the petals about its midale. Leares pinuate.

9. Petalostemon. Corulla scarcely at all papilionaceuus. Stamens 5 , monadelphous; the cleft tube of tilaments bearing 4 of the petals ou its summit. Leaves pinuate.

10. Amorpha. Surolla of unly oue petal! stameus 10 , monadelphous at the base. Leaves pinuate.

* TEphrosiez. 'Trees, shrubs, or herbs. Ovary several-many-ovuled : pod flattened, several-seteded, 2-varved. Leaves pinnate. Standard large and broud.

11. Robinia. Wings of the corolla free frum the keel. Pod flat, thin, margined on one edge. Trees or shrubs: leaflets stipellate.

12. Wistaria. Wings free frorn the ket. Poil tumid, marginless. Woody twiners : leaflets obscurtly stipellate.

13. Tephrosia. Wings cohering with the keel. Pod flat, marginless. Herbs: leaflets not stipellate.

* * ASTRAgale.E. Chiefly herbs, with pinnate leaves and axillary racemes or spikes. Poil mostly turgid or inflated. Style beardless. Staudard narrow, erect.

14. Astragalus. Anthers distinctly 2-celled. Keel not tipped with a point or sharp appendage. Pod turgid, with one or both the sutures turned in, sometimes dividing the cull lengthwise into two.

15 Oxytropis. Kecl of the corolla tipped with a point : otherwise as Astragalus.

16. GIyeyruhiza. Authers with the two cells confluent. Pod short, few-seeted, nearly indehiscent, glandular-prickly.

Tribe IV. IHEDYSA RAE. Herbs, with pinnate or pinnately 1-3-foliolate leaves, not tendril-bearing. Anthers uniform, except in No. 21. Pod (loment) trausversely 2-several-jointed, the reticulated 1-seeded joints remainiug closed, or sometimes reduced to one such joint.

* Leaves pinnate, with several leaflets, not stipellate.

17. Aschy nomene. Stamens equally diadelphous (5 \& 5). Calyx 2-lipped. Pod severaljointed : joints square.

18. Hedysarum. Stamens unequally diadelphous $(9 \& 1)$. Calyx 5-cleft. Pod severaljointed : juints roundish.

* Ieaves pinnately 3-foliolate, rarely 1-foliolate.

19. Desm odfum. Stamens diatedplons $(9 \& 1)$ or monadelphous below. Calyx zlipped. Pod several-jointed. F'lowers all of one sort and completo. Leaflets stipellate.

20. Lespedeza. Stiancus dialelphous $(9 \& 1)$ : anthers uniform. Porl 1-2-jointed. Flowers often of 2 sorts, the more fertile ones apetalous. Leaflets not stipellate.

21. Stylosunthes. Stamens moutulelphous: authers of 2 sorts. Pod 1 -2-jointed. Caly $x$ deciduous, the tube narrow and stalk-like. Leaflets not stipellate.

Tribe V. VICI EA. Herbs, with abruptly pinuate leaves, usually climbing, the common leafstalk continued into a tendril or bristle. Peduucles axillary. Stamens chiefly diadelphous (9\& 1). Pod continuous, 2-valved, few - several-seeded. Cotyledons very thick, remaining under ground in germination.

22. Vicin. Wings adherent to the keel. Style filiform, bearded with a tuft or ring of hairz at the apex.

23. Lathyrus. Wings nearly free. Style somewhat dilated and flattened upwards, bearded down the inner face. 
Tribe V1. PH A SEOLEAE. Twining or sometimes only trailing plants (herbs in temperate regions), with piunately 3 - (rarely 1- or 5-7.) foliolate leaves, commonly stipellnte. Peduncles or flowers axillary ; the pedicels usually clustered on the thickened nodes of the raceme. Anthers uniform. Pod continuous, not jointed, nor more than 1-celled, except by cellular matter sometimes deposited hetween the seeds, 2 -va!ved. Cotyledons thick, and rising above grousd little changed in germination, or sometimes becoming foliaceous.

\section{* Leaves pinnate.}

12. Wistaria. Wooly tiriner: leaflets 9-13 Keel harely incurved, obtuse.

24. A plos. Herbaceous twiner : leaflets 5-7. Keel slende $r$ and much incurved or coiled.

* Leaves 3-foliolate. Ovules and seeds several. Flowers not yellow.

25. Phaseolus. Keel strongly incurved or coiled: standard recurved-spreading. Style bearled lengthwise.

26. Centrosemn. Calyx short, 5-cheft. Standard with a spur at the base: keel broarl, merely incurved. Style ininutely bearderl next the stigma.

27. Clltoria. Calyx tubular, 5-lobed. Standard erect, spurless : keel scythe-shaped. Style bearded down the inner face.

28. Amplicnrpren. Caly $x$ tubular, 4 -5-toothed. Stanlard erect : keel almost straight. Style beardless. Some nearly apetalous fertile flowers next the ground.

29. Galactin. Caly $\times$ 4-cleft, the upper lobe broadest and entire. Style beardless. Bract and bractlets minute, mostly deciduous.

*** Leaves 1-3-foliolate. Ovules and seeds only one or tiro. Flowers yellow.

30. Rhynchosia. Keel scythe-shaped. Calyx 4-5-parted. Pod short.

B. Stamens all separate.

Trlbe VII. SOPIOREAE and PODALYRIEAG. Stamens 10, distinct; the carolla being truly papilionaceous.

31. Вирtisia. Caly $\times 4-5$-lobed. Pod inflated. IIerhs : leaves nalmately 3-foliolate or simple.

32. Cladrastis. Caly $\times$ 5-toothed. Pod very flat. Tree, with pinnate leaves.

\section{Suborder II. Casalpivie a. Brasiletto Family.}

Corolla imperfectly or not at all papilionaceous, sometimes nearly regular, imbricated in the bud, the upper or odd petal inside and enclosed by the others. Stamens 10 or fewer, commonly distinct, inserted on the calyx. Seeds anatropous, often with albumen. Embryo straight.

* Flowers imperfectly papilionaceous, perfect.

33. Cereis. Calyx campanulate, 5-toothed. Pod flat, wing-margined. Leaves simple.

* Flowers not at all papilionaceous, perfect.

34. Cassia. Caly $x$ of 5 nearly distinct sepals. Leaves simply and abruptly pinnate.

* * Flowers not at all papilionacentr, polygamous or dicecious.

35. Gymnocladus. Tree: leaves all doubly pinnate. Calyx-tube elongated, at its summit hearing 5 petals resembling the calyx-lobes. Stamens 10.

36. Gleditgehln. Trees thorny: leaves simply and doubly pinnate. Calyx-tube short; its lobes, petals, and stamens $3-5$.

\section{Suborder III. Mimosea. Mimosa Family.}

Flower regular. Corolla valvate in æstivation, often united into a 4-5-lobed cup, hypogynous, as are the (often very numerous) exserted stamens. Embryo straight. Leaves twice pinnate.

37. Desmanthus. Petals distinck. Stamens 5 or 10 Porl smonth.

29. Schrankla. Petals united below into a cup. Stamens 8 or 10 . Pod covered with emall prickles or rough projections. 


\section{L U Pİ N U S, Tourn. Luping.}

Calyx very decply 2-lipped. Siles of the standard reflexed: keel scytheshaped, pointed. Sheath of the monadelphous stamens entire: anthers alternately oblong and roundish. Pod oblong, flattened, often knotty by constrictions between the seeds. Cotyleduns thick and fleshy. Iferbs, with palmately 1-15-foliolate leaves, stipules adnate to base of the petiole, and showy flowers in terminal racemes or spikes. (Name from Lupus, a wolf, because these plants were thought to devour the fertility of the soil.)

1. L. perénnis, L. (IVILi) Lurint.) P'eremuial, somewhat hairy; stem erect $\left(1^{\circ}-2^{\circ}\right)$; leaflets $7-11$, oblanceolate; flowers in a long raceme; pods very hairy. - Sandy soil : common. May, Junc. - Nlowers showy, purplishblue, rarely pale.

\section{CROTALÀ RIA, L. Ratthe-box.}

Calyx 5-cleft, scarcely 2-lipped. Standard large, heart-shaped: keel scytheshaped. Sheath of the monadelphous stamens cleft on the upper side: 5 of the anthers smaller and roundish. Pod inflated, oblong, many-seeded. - Herbs with simple leaves. Hlower's yellow. (Name from кро́та入ov, a rattle; the loose seeds rattling in the coriaceous inflated pods.)

1. C. sagittàlis, L. Annual, hairy $\left(3^{\prime}-6^{\prime}\right.$ high $)$; leaves oval or oblong. lanceolate, scarcely petioled; stipules united and decurrent on the sten, so as to be inversely arrow-shaped; peduncles few-flowered; corolla not longer than the calyx. - Sandy soil, Mass. to Virginia near the coast, Illinois and southward. July.

\section{GENÍSTA, L. Woad-Waxen. Whin.}

Calyx 2-lipped. Standard oblong-oval, spreading: keel oblong, straight, deflexed. Stanens mouadelphous, the slieath entire; 5 alternate unthers shorter. Pod mostly flat and scveral-seeded. - Shrubby plants, with simple leaves, and yellow flowers. (Name from the Celtic gen, a bush.)

1. G. tinctória, L. (Dyer's Green-iveen.) Low, not thomy, with striate-angled erect branches; leaves lanceolate; flowers in spiked racemes. Eastern New York and Massachusetts, especially Essex Co., where it is thoroughly established on sterile hills. June. (Adv. from Eu.)

\section{TRIFÒ I U M, I. Chover. 'Treforl.}

Calyx persistent, 5-eleft, the teeth bristle-form. Corolla mostly withering or persistent; the claws of all the petals, or of all except the oblong or ovate standard, more or less united below with the stamen-tube: keel short and obtuse. 'Tenth stamen more or less separate. Pods small and membranous, often includer in the calyx, 1-6-seeded, indehiscent, or opening by one of the sutures. - Tufted or diffuse herbs. Teaves mostly palmately, sometimes pinnately 3-foliolate: Jeaflets often toothed Stipules united with the petiols. Nlowers in heads or spilies. (Name fiom tres, three, and foliun, a leat.)

* Flowers sessile in dense heads: corolla purple or purplish, withering anvey after flowering, tubular below; the petals more or less colertnt with each other. 
- Calyx-teeth silky-plumose, longer than the, whitish corolla: root annual.

1. T. ARvenge, L. (Rabrit-Font or Stone Crover.) Silky, branching $\left(5^{\prime}-10^{\prime}\right.$ high); lenflets oblanceolate; heads becoming very soft-silky and grayish, oblong or cylindrical. - Old fields, \&c. (Nat. from Ku.)

+ + Calyx scarcely hairy except a beurded ring in the thrort, shorter than the rosepurple elongated-tubulur corolla. (Short-lived perennials : fluwers sweet-scented.)

2. T. PRATEnse, L. (RED C.) Stems ascending, somewhat hairy; leaflets oval or obovate, often notched at the end and marked on the upper side with a pale spot; stipules broad, bristle-pointed; heads ovate, sessile. - Fields and meadows ; largely cultivated. (Adv. from Eu.)

3. T. мѐnuм, I. (ZigzAs C.) Stems zigzang, smoothish; lanfets oblong, entire, and spotless; heads mostly stalked; flowers deeper purple, otherwise too like the last. - 1)ry hills, E. Massachusetts. ( $\Lambda d v$. from Fu.)

* Flowers pedicelled in umbel-like round heads on a naked peduncle, their short pedicels reflexd when old: corolla white or rose-color, withering-persistent and turning brownish in fading; the tubular portion short.

4. T. refléxum, L. (Buffalo C.) Annual or biennial; stems ascending, downy; lenflets obovate-oblong, finely toothed; stipules thin, ovate; calyx-teeth lıiry; pods 3-5-seeded. - Western New York (rare) to Illinois and southward. - Heads and flowers larger than in No. 2 : standard rose-red; wings and keel whitish.

5. T. stoloniferum, Muhl. (Running Buffalo-C.) Smooth, perennial; stems with long runners from the base; leaflets broadly obovate or obcordate, minutely toothed; heads loose; pods 2-seeded. - Open woodlands and prairies, Ohio to Illinois, Kentucky, and westward. - Flowers white, tinged with purple. Probably a variety of the last.

6. T. rèpens, L. (Wniтe C.) Smooth, perennial; the slender stems spreading and creeping; leaflets inversely heart-shaped or increly notehed, obscurely toothed; stipules scalc-like, narrow; petioles and especially the peduncles very long; heads small and loose; calyx much shorter than the white corollu; pods about 4-seeded. - Fields and copses, everywhere. Here probably introduced, but indigenous northward.

7. T. Caroliniànum, Michx. (CArourna C.) Somewhat pubescent small perennial, procumbent, in tuffs; leaflets werlge-obovate and slightly notehed; stipules ovate, foliaceons; heads small on slender peduncles; caly.x-teeth lanceolate nearly equalling the purplish corollu; standard pointed; porls 4-secded. Nat. from Southern States in waste grounds below Philadelphia (C. E. Smith); probably wild in S. Virginia. May.

* * Flowers short-pedicelled in clnse heads, reflexed when old: cornlla yellow, persistent, turning dry and chestnut-brown with age, the standard becoming hoodshaped: annuals, $f$. in summer.

7. T. AGRARIUM, I. (YELLOW or Hop-C.) Smonthish, somewhat upright $\left(6^{\prime}-12^{\prime}\right.$ high) ; lenflets obovote-oblong, all three fiom the some point. (palmate) nnd nearly sessile; stipules narrow, cohering with the petinle for more than half its length. - Sandy fields, Massachusetts to Virginia. (Nat. from Eu.) 
8. T. PROCúmuENs, L. (Low Hop-C.) Stems spreading or ascending, pubescent $\left(3^{\prime}-6^{\prime}\right.$ high $)$; leaflets werlyc-drovate, notched at the end ; the leteral at a small distance fiom the other (piminatcly 3-fuliolate); stipules ovate, short. Sandy fields and roadsides, New England to Virginia. Also var. Minus ('I. minus, Relhan), with sualler heads, the standard not much striate with age. With the other; also Kientucky, in cultivated grounds. (Nat. from Eu.)

\section{MeLilòt US, 'Tourn. Melilot. Sweet Clover.}

Flowers much as in Clover, but in spiked racemes, small : corolla deciduous, free from the stamen-tube. Pod ovoid, coriaceous, wrinkled, longer than the culyx, scarcely dehiscent, 1-2-seeded. - Annual or biennial herbs, fragrant in drying, with pinnately 3 -foliolate leaves; leaflets toothed. (Name fiom $\mu \epsilon^{\prime} \lambda_{\epsilon}$, honey, and $\Lambda \omega \tau$ ós, some leguminous plant.)

1. M. Oheicinàlis, Willd. (Yellow Melilot.) Upright $\left(2^{\circ}-4^{\circ}\right.$ high); leaflets obovate-oblong, obtuse; corvlla yellow; the petals nearly of equal length. - Waste or cultivated grounds. (Adv. from Eu.)

2. M. ÁlBa, Lam. (White M.) Leaflets truncate; corolla white; the standard loriger than the other petals. (M. leuéntha, Koch.) - In similar places to the last, and much like it. (Adv. from Eu.)

\section{M E D I À G O, L. Medick.}

Flowers nearly as in Melilotus. Pod 1 -several-secderl, seythe-shaped, incurved, or variously coiled. - Leaves pinnately 3-foliolate. Stipules often cut. (M $\eta \delta \_\eta^{\prime}$, the name of Lucerne, because it came to the Greeks from Media.)

1. M. sativa, L. (Lucerne.) Upright, smooth, perennial; leaflets obovate-oblong, toothed; flowers (purple) racemed; pods spirally twisted. Cultivated for green fodder, rarely spontaneous. (Adv, from Eu.)

2. M. Lupulina, L. (Black Medick. Nonesuch.) Procumbent, pubescent, annual; leaflets wedge-obovate, toothed at the apex; flowers in short spikes (yellow); pods kidney-furm, 1-seeded. - Waste places. (Adv. from Eu.)

3. M. maculata, Willd. (Spotted Medick.) Spreading or procumbent annual, somewhat pubescent; leaflets obcordate, with a purple spot, minutely toothed; peduncles 3-5-flowered; flowers yellow; pods compacily spiral, of 2 or 3 turns, compressed, furrowed on the thick edye, and fringed with a donblo row of curved prickles. - Introduced with wool into waste grounds in some places. (Adv, from Eu.)

4. M. Denticulita, Willd. Nearly glabrous; pods loosely spiral, derply reticulated, and with a thin kecled edge: otherwise like the last; in similar places, eastward. (Adv. from Eu.)

\section{PSORÁLA, L. Psoralea.}

Calyx 5-cleft, persistent, the lower lobe longest. Stamens diadelphous or sometimes monadelphous. P'od selilom longer than the calyx, thick, often wrinkled, indehiseent, 1-seeded. - Peremuial herbs, usually sprinkled all over or roughened (especially the calyx, pods, \&c.) with glandular dots or points. 
Leaves mostly $3 \rightarrow 5$-foliolate. Flowers spiked or racemed, white or mostly

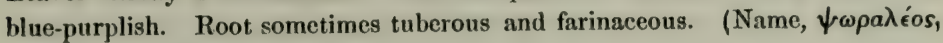
scurfy, from the glands or dots.)

* Leaves pinnately 3-foliolate.

1. P. Onóbrychis, Nutt. Nearly smooth and free from glands, erect $\left(3^{\circ}-5^{\circ}\right.$ high); leaflcts lanceolate-onate, taper-pointed ( $3^{\prime}$ long); stipules and bracts aivl-shrped; racemes elongated; peduncle shorter than the leaves; pods roughened and wrinkled. - River-banks, Ohio to Ill. and southward. July.

2. P. stipulata, 'Torr. \& Gray. Nearly smooth and glandless; slems diffuse; lenflets ovate-ellipticul, reticulated ; stipules ovate; flowers in heads on rather short peduncles; bructs broudly ovate, shaip-pointed. - Rocks, Falls of the Ohio, Kentucky. June, July.

3. P. melilotoldes, Michx. Somewhat pubescent, more or less glandular; stems erent $\left(1^{\circ}-2^{\circ}\right.$ high), slender; leuflets lanceolute or narrowly oblong; spikes oblong, long-peduncled; stipules awl-shaped; bracts orate or lanceolate, taper-pointed; pods strongly wrinkled transverscly. (Also P. eglandulosa, Ell.) -Dry soil, Ohio to Illinois, Virginia, and southward. June.

* * Leaves palmately 3-5-foliolate.

4. P. floribúnda, Nutt. Slender, erect, much branched and bushy $\left(2^{\circ}-\right.$ $4^{\circ}$ high), minutely hoary-pulescent when young; lcaflets varying from linear to obovate-oblong $\left(\frac{1}{2}^{\prime}-1 \frac{1}{2}^{\prime}\right.$ long), glandular-dotted; racemes panicled; lobes of the calyx and bracts ovate, acute; pod glandular. - Prairies of Illinois and southwestward. June-Sept. - Flowers $2^{\prime \prime}$ or $3^{\prime \prime}$ long.

5. P. argophylla, Pursh. Silvery silky-uhite all over, erect, divergently branched $\left(1^{\circ}-3^{\circ}\right.$ high); leaflets elliptical-lanceolate; spiles interrupted; lobes of the calyx and bracts lanceolate. - Iligh plains, N. Wisconsin, and westward. June. - Flowers $4^{\prime \prime}-5$ " long.

6. P. esculénta, Pursh. Ronghısh hairy all over; stem stout $\left(5^{\prime}-15^{\prime}\right.$ high) and erect from a tuberous or turnip-shaped farinaceous root; leaflets 5 , obovate- or lanccolate-oblong; spikes oblong, dense, long-perluncled; lobes of the calyx and bracts lanccolate, nearly equalling the corolla $\left(\frac{1}{2}^{\prime}\right.$ long). - High plains, N. W. Wisconsin, Mr. Spears, T. J. Hale, \&c., and westward. June. 'The Pomme biancie, or Pomme de Prainie, of the Voyageurs.

\section{D À LEA, L. Dalea.}

Calyx 5-cleft or toothed. Corolla imperfectly papilionaccous : petals all on claws: the standard heart-shaperl, inserted in the bottom of the calyx : the keel and wings borne on the middle of the monadelphous sheath of filaments, which is cleft down one side. Stamens 10, rarely 9. Pod membranaceous, 1-seeded, indehiscent, enclosed in the persistent caly x. - Mostly herbs, more or less glandular-dotted with minute stipules; the small flowers in terminal spikes or heads. (Named for Thomas Dale, an English botanist.)

1. D. alopecuroides, Willd. Erect annusl $\left(1^{\circ}-2^{\circ}\right.$ high $)$, glnbrons, except the dense and cylindrical silky-villous spike; leaves pinnate, of many linear-oblong leaflets; corolla whitish. - Alluvial soil, Illinois and southwurd. July. (Numerous species occur farther southwest.) 


\section{9. pethalostèmon, Michx. Pairie Clover.}

Calyx 5-toothed. Corolla indistinctly papilionaccous : petals all on thread. shaped claws, 4 of them ncarly similar and spreading, borne on the top of the monadelphous and cleft sheath of filaments, alternate with the 5 anthers; the fifth (standard) inserted in the bottom of the calyx, heart-shaped or oblong. Pod membranaccous, enclosed in the calyx, indehiscent, 1-2-seeded. - Chiefly perennial herbs, upright, glandular-dotted, with crowded odd-pinnate leaves, minute stipules, and small flowers in very dense terminal and peduncled heads or spikes. (Name combined of the two Gireek words for petal and stamen, alluding to the peculiar union of these organs in this genus.)

1. P. violàceus, Michx. Sinoothish: leuflets 5, narrowly linear; heals globose-ovate, or oblung-cylindrical when old; bracts pointed, not longer than the silky-hoary ealyx; corolla rose-purple. - 1)ry prairies, Michigan to Miunesota and southward. July.

2. P. cándidus, Michx. Smooth; leaflets 7-9, lanceolate or linear-oblong; heads oblong, when old cylindrical; bracts awned, lunger than the nearly glabrous calyx; corolle white. - With No. 1. July.

3. P. villosus, Nutt. Soji-downy or silky all over; leaflets $13-17$, linear or oblong, small ( $4^{\prime \prime}-5^{\prime \prime}$ long) ; spikes cylindrical $\left(1^{\prime}-5^{\prime}\right.$ long), short-peduncled, soft-villous; curvelle ruse-color: - N. Wisconsin (Lake P'epin, \&c. T.J. Hule) and westward.

\section{A M Ó R PHA, L. False Indigo.}

Calyx inversely conical, 5 -toothed, persistent. Standard (the other petals entirely wanting!) wrapped around the stamens and style. Stamens 10, monadelphous at the very base, otherwise distinet. Pod oblong, longer than the calyx, 1 -2-seeded, roughened, tardily dehiscent. - Shruls, with odd-pinnate leaves; the leaflets marked with minute dots, usually stipellate. Flowers violet or purple; crowded in clustered terminal spikes. (Name, ä $\mu \rho \rho \phi \eta$, wanting form, from the absence of four of the petals.)

1. A. fruticosa, L. (FAlse Indigo.) Rather pubescent or smoothish; leaflets 8-12 pairs, oval, scattered; pods 2-sceded. - River-banks S. Penu. to Wisconsin and southward. Jume. - A tall shub: very variable.

2. A. canéscens, Nutt. (Lead-Plant.) Low $\left(1^{\circ}-3^{\circ}\right.$ high), whitend with hoary down; leaflets $15-25$ pairs, elliptical, crowded, small, smoothish alove with age; pods $\mathbf{1}$-seetled. - Prairies and crevices of rocks, Michigan to Wisconsin and southwestward. July. - Supposed to indicate lead-ore.

\section{ROBf IA, I. Locust-Tike.}

Calyx short, 5-toothed, slightly 2-lipped. Standand large and rounded, turned back, scarcely longer than the wings and keel. Stameus diadelphous. Pod linear, flat, several-seeded, margined on the seed-bearing edge, at leagth 2 valved. - T'rees or shrulss, often with prickly spines for stipules. Leaves oddpinnate, the ovate or ublong leatlets stipellate. Flowers showy, in hanging axillary racemes. Base of the leaf-stalks covering the huds of the next year. (Named in honor of John Robin, herbalist to Henry IV. of France, and his son Fisjusian Rubin, who first cultivated the Locust-tree in Europe.) 
1. R. Pseudacàcia, L. (Common Locust or False Acacia.) Branches naked; racemes slender, loose; flowers white, fragrant; pod smooth. - S. Pennsylvania to $\mathrm{S}$. Illinois and sonthward. Commonly cultivated as an ornamental trec, and for its valuable timber: naturalized in many places. June.

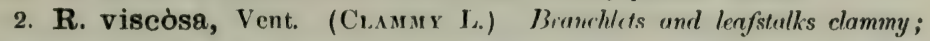
fowers crowdid in oblong racemes, tingerl with mese-color, nearly inodorous; pod glandular-hispidl. - Virginia and sonthward. Cultivated, like the lnst, a smaller tree. Juno.

3. R. híspida, I. (Bristry L. or Rosf Aслсти.) Branchlets and stalks bristly; flowers large and decp rose-color, inodorons; pods glandular-hispid. Varies with less bristly or nearly naked branchlets; also with smaller flowers, \&c. - Mountains of Virginia and southward: commonly cultivated. May, Jnne. - Shrub $3^{\circ}-8^{\circ}$ high.

\section{W I S T A I A, Nutt. Wistaria.}

Calyx campanulate, somewhat 2-lipped; upper lip of 2 short teeth, the lower of 3 longer ones. Standard roundish, large, turned back, with 2 callosities at its base: keel scythe-shaped : wings doubly auricled at the base. Stamens diadelphous. Pod elongated, thickish, kuobby, stipitate, many-seeded, at length 2-valved. Seeds large. - Woody twiners, climbing high, with minute stipules, pinnate leaves of $9-13$ ovate-lanceolate leaflets, with or without minute stipels, and dense racemes of large and showy lilac-purple flowers. (Dedicated to the late Professor Wistar, of Philadelphia.)

1. W. frutéscens, DC. Downy or smoothish when old; wings of the corolla with one short auricle and an awl-shaped one as long as the claw. (W. speciosa, Nutt.) - Alluvial grounds, W. Virginia to Illinois and southward. May. - Sometimes cultivated for ornament, as is the still handsomer Chinese species.

\section{TEPHRÒsi A, Pers. Hoary Pea.}

Calyx about equally 5 -cleft. Standard roundish, usually silky ontsidc, turned back, scarcely longer than the coherent wings and keel. Stamens monadelphous or diadelphous. Fod linear, flat, several-sected, 2-valved.-Hoary perennial herbs, with odd-pinnate leaves, and white or purplish racemed flowers. Leaflets

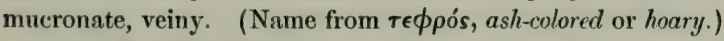

1. T. Virginiàna, Pers. (Gont's Rue. CAtgut.) Silky-villous with whitish hairs when young; stem erect and simple $\left(1^{\circ}-2^{\circ}\right.$ high), leafy to the top ; leaflets 17-29, linear-oblong; flowers large and numerous, clustered in a terminal oblong dense raceme or panicle, yellowish-white marked with purple. - Dry sandy soil. June, July. - Roots long and slender, very tough.

2. T. spicata, Torr. \& Gray. Villous with rusty hairs; stems branched below, straggling or ascending ( $\left.2^{\circ} \mathrm{long}\right)$, few-leaved; leaflets $9-15$, obovate or oblong-wedge-shaped, often notehed; finwers few, in a loose interrupted very longprduncled spike, reddish. - Dry soil, Delaware and southward. July.

3. T. hispidula, Pursh Iniry with some long and rusty or only minute and appressed pubescence; stems slender $\left(9^{\prime}-24^{\prime}\right.$ long), divergently branched, 
straggling; leaflets $5-15$, oblong, varying to obovate-wedge-shaped and oblanceolate; peduncles longer than the leaves, 2-4-flowered; flowers reddish-purple. Dry sandy soil, Virginia and southward.

\section{A S TRÁ GALUS, L. Milk-Vetcir.}

Calyx 5-toothed. Corolla usually long and narrow : standard narrow, equalling or exceeding the wings and blunt keel, its sides reflexed or spreading. Stamens diadelphous. Stigma ininute, terminal. Pod several-many-seeded, various, mostly turgid, one or both sutures usually projecting in to the cell, either slightly or so as to divide the cavity lengthwise into two. Seed-stalks slender. Chictly herbs (ours perennials), with odd-pinnate leaves and spiked or racemed flowers. ('The ancient Greek name of a leguminous plant, as also of ths ankle-bone; but the connection between the two is past all guess.)

\$ 1. Pod very thick and juicy when fiesh, not stulked in the arlyr, 2 celled, indehiscent, or tardily separable into 2 closed portions: stems low, decusnbent or ascending: leaflets numerous.

1. A. caryocárpus, Ker. (Ground Plum.) Pale and minutely appressed-pubescent; luaflets narrowly oblong; floweis in a short spike-like raceme : corolla violet-purple; fiuit glabrous, ovate-ylabslar, more or less pointed. about $\mathbf{3}^{\prime}$ in dianeter, every thick-uculled, cellular or corky when dry. Upper Mississippi River, thence westward and southward. May.

2. A. Mexicànus, A. 1)C. Smoother, or pubescent with looser hairs, larger; leaflets roundish, obovate, or oblong; flowers larger $\left(10^{\prime \prime}-12^{\prime \prime}\right.$ long); calyx softly hairy; corolla cream-color, bluish only at the tip; fruit globular, very obtuse and pointless, $I^{\prime}$ or more in diameter: otherwise like the last: the unrije tiuits of both resemble green plums, - whence the popular name, - and are eaten, raw or cooked, hy travellers. (A. trichocalyx, Nutt.) - Prairies and open plains, from Illinois opposite St. Louis westward and southward.

3. A. Platténsis, Nutt. Loosely villous; stipules conspicuous; leuflets oblong, often glabrous above; flowers crowded in a short spike or oblong head, crean-color often tinged or tipped with purple; fruit ovate, pointeel, and with the calyx villous, - in var. Tennesseénsis (A. Tennesseensis, Gray, in Chapm. S. Fl.) wlong and slightly curved, much less fleshy and thick than in the preceding. - Gravelly or sandy banks of Illinois River (Vasey, Slosson, Bebb), thence southward and westward. May.

\$2. Pod diy and dchiscent, more or less thin-walled, turgid, not stalked in the caly.c, completely 2-celled only in No. 4.

4. A. Canadénsis, L. 'T'ull and erect $\left(1^{\circ}-4^{\circ}\right.$ high $)$, somewhat pubescent ; leaflets $21-27$, oblong; flowers greenish crean-colur, very numerous, in long and close spikes; poels ocvid-oblomy, coriaceous, small, completely 2-celled. - Riverbanks : common from N. New York westward and southward. July-Aug.

5. A. Cooperi, Gray. Nearly smooth, erect $\left(1^{\circ}-2^{\circ}\right.$ high $)$; leaflets $11-$ 21, elliptical or oblong, sumewhat notehed at the end, minutely hoary underneath; flousers white, rather numerous in a short spike; porls influted-ocvid (almost $1^{\prime}$ long), thin-walled, one-celled, the dor'sal suture slightly, the ventral more decidedly projecting inwards. (Phaca neglecta, Torr. \& Gray. Now numed for 
the discoverer, the late $\mathrm{W}^{\prime} \mathrm{m}$. Cooper, there being already an A. neglectus.) Gravelly shores, \&c., W. New York to Wisconsin. June, July.

6. A. distórtus, 'Torr. \& Gray. Low and spreading, branched from the base, smoothish; leaflets 11-23, oblong or obovate; flowers purplish or violet, 10 - 20 in a short spike; the stundard decply noteherl at the summit; pods oblong, turgid, incurved (' ${ }^{\prime}$ ' long), coriaceous, incompletely 2-celled. - Mason Co., Illinois, Dr. Mead. May. (Also in Arkansas and Texлs.)

\$ 3. Pod dry and dehiscent, thin-walled, small, slulliced in the calyx. (stipitate), and with it more or less pubescent with fine bluckish hairs, hanging on short pedicels : raceme short, vather many-flowered, long-prduncled: leaflets oval or oblong.

7. A. alpinus, L. Smooth or slightly hairy; stem diffuse, $6^{\prime}$ to $12^{\prime}$ high ; leaflets 13-25; corolla violet-purple, or at least the kecl tipped with violet or blue (5" $-6^{\prime \prime}$ long); pods black-hairy, oblong, deeply grooved on the hack and partly 2-celled by the intrusion of the dorsal suture, its stipe usually rather exceeding the calyx. - Rocks and banks, Northern Vermont (Willoughby Mountain, J. Blake) and Maine (Dr. Scammon, G. L. Goodale), and northward. June, July. (Eur.)

8. A. Robbinsii, Gray. Nearly smooth and erect (1० high), slender; leaflets 7-11; corolla white ( $4^{\prime \prime}$ long); calyx-tceth short; pods oblong, fattish ( $\frac{1}{2}{ }^{\prime}$ long), membranaceous, almost glabrous, the base suddenly contracted into a stipe s.bout equalling the caly $\mathrm{x}$, one-celled, a thin membrane slightly projecting from the dorsal suture. (Phaca Robhinsii, Oakes.) - Rocky ledges of Onion River, at Colchester, Vermont, Dr. Robbins (1829): the station now obliterated. May.

\section{OXÝTROPIS, DC. OXYTropis.}

Keel of the corolla tipped with a sharp projecting point or appendage : otherwise as in Astragalus. Pod often partly 2-celled by the intrusion of the ventral suture. - Our species, and most others, are low, nearly acaulescent perennials, with tufts of numerous very short stems from a harl and thick root or rootstock, covered with scaly adnate stipules; pinnate leaves of many leaflets; and naked scapes bearing a head or short spike of flowers. (Name indicates the peculiarity

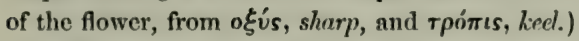

1. O. campéstris, DC. Pubescent or smoothish; lcaflets lanceolate or oblong : flowers yellowish or white, often tinged or tipped with purple or violetblue: pods ovate or oblong-lanceolate, of a thin or papery texture. - Northern border of Maine, on the St. John's, near Seven Isles, G. L. Goodale, and northward. July. (Eu.)

2. O. Lambérti, Pursh. Silky with fine appressed hairs; Ieaflets mostly linear; flowers larger, purple, violet, or sometimes white; pods cartilaginous or firm coriaceous in texturc, strictly erect, cylindraccous-lanceolate and long-pointed, almost 2-celled by intrusion of the ventral suture. - Dry plains, Minnesota and westward. June.

\section{GLYCYRRHIZZA, Tourn. Liquonice.}

Calyx with the two upper lobes shorter or partly united. Anther-cells confluent at the apex, the alternate ones smaller. Pod ovate or oblong-linear, com- 
pressed, often curved, clothed with rough glands or short prickles, scarcely dehiscent, few-sceded. 'The flower, \&c., otherwise as in Astragalus. - Long perennial root sweet (whence the name, from $\gamma \lambda \nu \kappa u ́ s$, sweet, and $\rho i \xi a$, rout); herbage glanclular-viscid; leaves odd-pinnate, with minute stipules; flowers in axillary spikes, white or bluish.

1. G. lepidota, Nutt. (Wild Lrquonice.) Tall $\left(2^{\circ}-3^{\circ}\right.$ high); leaflets 15-19, oblung-linceolate, mucronate-pointed, sprinkled with little scales when young, and with corresponding dots when old; spikes peduncled, short; flowers whitish; pods oblong, beset with hooked prickles, so as to resemble the fruit of Xanthiun on a smaller scale. - Vicinity of Buffalo, New York, on the sands of the shore, probably drifted from its native northwest regions; but perfectly established, $G$. W. Clinton.

\section{7. 死 S C H Y N Ó M E N E, L. Sensitive Joint-Vetch.}

Calyx 2-lipped; the upper lip 2-, the lower 3-cleft. Standard roundish : keel boat-shaped. Stamens diadelphous in two sets of 5 each. Pod Hattened, conposed of several easily separable joints. - Leaves odd-pinnate, with sev eral pairs of leaflets, sometimes sensitive, as if shrinking from the touch (whence the name, from aiơ $\chi v 0 \mu e^{\prime} \eta$, being ashamed).

1. 妮. híspida, Willd. Erect, rough-bristly annual ; leaflets $37-51$, linear; racenes few-flowered; pod stalked, 6-10-jointed. - Along rivers, S. Penn. and southward. Aug. - Flowers yellow, reddish externally.

\section{HEDÝ SARUM, Tomn. IIEdrsarum.}

Calyx 5-cleft, the lobes awl-shaped and nearly equal. Líel nearly straight, obliquely truncate, not appendaged, longer than the wings. Stamens diadelphous, 5 \& 1. Pod flattened, composed of several equal-sided separable roundish joints connected in the middle.-Perennial herbs: leaves odd-pinnate.

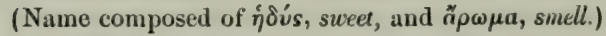

1. H. boreàle, Nutt. Leaflets 13-21, ollong or lanceólate, nearly glabrous; stipules scaly, united oppiosite the petiole; raceme of many deflexed purple flowers; standard shorter than the kece; joints of the pod 3 or 4, smooth, reticulated. - Mountain ahove IVillowghby Iatke, Vermont, A. Woud, \&ce. St. John's River, Maine, Ǵ. L. Givorlale. Also northward.

\section{DESM Ò D U M, DC. Tick-TreForL.}

Calyx usually more or less 2-lipped. Standard obovate: wings adherent to the straight or struightish and usually truncate keel, by neans of a little transverse appendage on each side of the latter. Stamens diadelphons, $9 \& 1$, or monadelphous below. P'od llat, deeply lobed on the lower margin, separating into few or many flat reticulated joints (mostly roughened with minute hooked hairs, by which they adhere to the fleece of animals or to clothing). - P'eremial herbs, with pinnately 3-foliolate (rarcly 1-foliolate) leaves, stipellate. Flowers (in summer) in axillary or terminal racemes, often panicled, and 2 or 3 from each bract, purple or purplish, often turning green in withering. Stipules ard 
bracta serale-like, often striate. (Nane from $\delta \epsilon \sigma \mu o ́ s, a$ bond or chain, from tho connected joints of the pods.)

\$1. Pod raiscd on a stalk within the calyx (stipe) many times longer than the slightly toothed calyx and nerrly as long as the pedicel, straightish on the upper margin, deply sinuate on the lower; the 1-4 joints mostly hulf-oborate and concave on the burk: stamens momadelphons below: plants newly glallrous: stems erect or uscending: rnceme terminul, panicled: stipules bristle-form, deciduous.

1. D. nudiflorum, I). Leaves all crouded at the summit of sterilo stems; leaflets broadly ovate, bluntish, whitish beneath; raceme elongated on an ascending mostly leaffess stalk or scipe from the ront, $2^{\circ}$ long. - Dry wools : common.

2. D. acuminatum, DC. Leares all crouxled at the summit of the stem from which arises the elongated naked raceme or panicle; leaflets round-ovate, taperpointed, green both sides, the end one round $\left(4^{\prime}-5^{\prime}\right.$ long). - Rich woods.

3. D. pauciflorum, 1)C. Leaves scattered along the low $\left(8^{\prime}-15^{\prime}\right.$ high) ascending stems; leaflets rhombic-ovate, bluntish, pale beneath; raceme fewflowered, terminnl. - Woods, W. New York and Pennsylvania to Illinois and sonthward.

§ 2. Pod raised on a stalk (stipe) little if not all surpassing the deeply-cleft calyx: stems long and prostrate or decumbent : racemes axillary and terminal.

* Stipules conspicuous, ovate, taper-pointed, striate, persistent: racemes mostly simple.

4. D. rotundifolium, DC. Soft-hairy all over, truly prostrate; leaflets orhicular, or the odd one slightly rhomboid; flowers purple; pods almost equally sinuate on both edges, 3-5-jointed; the joints rhomboid-oval. - Dry rocky woods: rather common.

Var. glabratum : ulmost glabrous, otherwise nearly as the ordinary form. (Hedysarum humifusum, Muhl. in part, Bige., \&c.)-Mass., New York, \&c.

5. D. ochroleùcum, M. A. Curtis. Stems sparsely huiry, decumbent; leaflets nearly glabrous, ovate, acute or obtuse, transversely reticulated beneath, the lateral ones smaller or sometimes wanting; racemes much elongated; corolle whitish; pods twisted, 2-4-jointed, the large rhomboid joints smooth and reticulated but the margins downy. (Perhaps Muhlenberg's H. humifusum from " (arolina.") - Woodlands, Maryland (W. M. Canby) and sonthivard.

* * Stipules smaller, lanceolate and uul-shaped, less persistent : racemrs pamicled.

6. D. humifùsum, Beck (as to syn.). Glabrous or nearly so, procum. but; lenflets ovate or ointe-oblong, rather obtuse, much smaller than in the two jreceling (1 $f^{\prime}-2^{\prime}$ long); corolla purple; pods 2-4-jointed, flat, the oval-rhom loid joints minutely scabrous throughont. (Hedysarum humifusum, Muhl. Fl. Lincrst. herb., ex Canby.) - Dry sandy soil (Lancaster, Penn., Muhlønherg). Salisbury, Maryland, W. M. Canby.

\$3. Pod slightly if at all stalked in the calyx: racemes panicled.

* Stems tall $\left(3^{\circ}-5^{\circ}\right)$ and erect; the persistent stipules and deciduous bracts largo and conspiruous, ovate or ovute-lemerolate, tuper-pointed: pods of 4-7 unequalsided ,homlic joints, which ane considerably longer than brond, about $\frac{1}{2}$ long. (Flowers rather lu'ge.)

7. D. canéscens, DC. Stem loosely branched, hairy; leaflets ovate, bluntish, about the length of the petioles, whitish and reticulated beneath, both sides 
roughish with a close fine pubescence; joints of the pod very adhesive. - Moist grounds, W. Vermont to Wisconsin and southward, chiefly westward. Branches clothed with both minute and hooked, and longer, spreading, rather glutinous hairs.

8. D. cuspidatum, Torr. \& Gray. Very smooth except the panicle; stem straight; leaflets lanceolate-ovate and taper-pointed, grcen both sides; longer than the petivle $\left(3^{\prime}-5^{\prime}\right)$; joints of the pod rhomboid-oblong, smoothish. - Thickets : common. - The conspicuous bracts and stipules 31 long.

* Sterns $\left(2^{\circ}-5^{\circ}\right.$ high $)$ erect: stipules as well as the bructs mostly deciduous, smuil and inconspicuous: pods of 3-5 trianyular or half-rhombic or very uncqualsided rhomboidul joints, which are longer than broud, d' or less in lenyth. (F'lowers middle-sizad.)

9. D. lævigatum, 1)C. Smooth or nearly so throughout: stem straight; leaflets ovate, bluntish, pale beneath $\left(22^{\prime}-3^{\prime}\right.$ long $)$; panicles minutely roughpubescent. - Pine woods, New Jersey and southward.

10. D. viridiflorum, Beck. Stem very downy, rough at the summit; leuflets broadly ovate, very obtuse, rough ahove, whitened with a soft velvety down underneuth $\left(2^{\prime}-3^{\prime}\right.$ long $)$. - S. New York and southward.

11. D. Dillènii, Darlingt. Stem pubescent; leafluts oblony or oblong-ovate, commonly bluntish, palc beneath, sofily and finely pubescent (mostly thin, $2^{\prime}-3^{\prime}$ long). - Open woodlands : common.

12. D. paniculàtum, 1)C. Narty smooth throughout; stem slender, tall ; leaflets oblong-lunceolute, or narrowly lancwate, tapering to a blunt point, thin $\left(3^{\prime}-5^{\prime}\right.$ long) ; racemes much panicled. - Copses, common.

13. D. stríctum, 1)C. Stem very straight and slender, simple $\left(2^{\circ}-3^{\circ}\right.$ high), the npper part and narrow panicle rough-glandular; leaflets linear, blunt, strongly reticuluted, thickish, very smooth ( $\left(1^{\prime}-2^{\prime}\right.$ long, $f^{\prime}$ wide); joints of the pod $1-3$, semi-obovate or very gibbous (only $2^{\prime \prime}$ long). - P'ine woods of New Jersey, and southward.

*** Stipules small and inconspicuous, mostly deciduous : pods of few roundish or obliquely oval or sometimes roundish-rhomboidal joints, $1 \frac{1}{2} "-2 \frac{1}{2}$ "long.

- Stemis erect: Uracts before flowering conspicuous : racemes densely flowered.

14. D. Canadénse, I)C. Stem hairy $\left(3^{\circ}-6^{\circ}\right.$ high); leaflets ollong-lanceolate, or ovate-lanceolate, olstuse, with numerous straightish veins, much longer then the petisle $\left(12^{\prime}-3^{\prime}\right.$ long) ; flowers showy, larger than in any other species $\left(\frac{f^{\prime}}{2}-f^{\prime}\right.$ long $)$. - Dry, rich woods : common, especially northward.

15. D. sessilifolium, 'Torr. \& Gray. Stem pubescent $\left(2^{\circ}-4^{\circ}\right.$ high $)$; leaves nearly sessile; leaglets limear or lincar-oblong, blunt, thickish, reticulated, rough above, downy bene:ath; branches of the panicle long; flowers small. Copses, Pennsylvania and Michigan to Illinois and southward.

++ Stems ascending $\left(1^{\circ}-3^{\circ}\right.$ high $)$ : bracts small; racemes or panicles elongated und loosely flowered: flowers sinall.

16. D. rígidum, I)C. Stem branching, somewhat hoary, like the lower surface of the leaves, with a close roughish pubescence; leaflets ovate-ablong, blunt, thickish, reticulated-veiny, rather rough above, the lateral ones longer thin the prtiole. - Dry hillsides, Mass. to Michigan, Illinois, and southward. - Intermediate, as it were, between No. 17 and No. 11. 
17. D. ciliare, DC. Stem slender, hairy or rough-pubescent; leaves crouded, on very short hairy prtioles; lenftets mund-ovate or oval, thickish, more or less hairy on the margins and underneath $\left(\frac{1}{2}{ }^{\prime}-1^{\prime}\right.$ long). - Dry hills and sandy fields : common, especially southward.

18. D. Marilándicum, Boott. Nearly smooth throughout, slender; lenflets ouxte or roundish, very obtuse, thin, the Interal ones about the length of the slender petiole: otherwise rescmbling the preceding, (I). obtìsum, DC.) Copses : common.

\section{+++ Stems reclining or prostrate: racemes looscly flowered.}

19. D. lineàtum, DC. Stem minutely pubescent, striate-angled; leaflets orbicular, smoothish $\left(\frac{1^{\prime}}{2}-1^{\prime}\right.$ long), much longer than the petiole; pod scarcely stalked in the calyx. - Dry soil, Maryland (W. M. Canby), Virginia and southward.

\section{LESPED安A, Mich. Busu-Cıovin.}

Calyx 5-cleft; the lobes nearly equal, slender: Stamens diadelphous (9 \& 1): anthers all alike. Pods of a single 1-sceded joint (sometimes 2-jointed, with the lower joint empty and stalk-like), oval or roundish, flat, reticulated. Perennials with pinnately 3 -foliolate leaves, not stipellate. Stipules and bracts minute. Flowers often polygamous, in summer and autumn. (Dedicated to Lespedez, the Spanish governor of Florida in the time of Michaux.)

* Flowers of two sorts, the larger (violet-purple) perfect, but seldon fruitful, panicled or clustered; with smaller pistillate and fertile but mostly apetalous ones intermixd, or in subsessile little clusters.

1. L. procúmbens, Michx. Soft-downy, except the upper surface of the leaves, trailing, slender ; leaflets oval or elliptical ; peduncles slender, mostly simple, few-flowered. - Sandy soil : commonest southward. - The apetalous fertile flowers, as in the rest, have short hooked styles.

2. L. rèpens, Torr. \& Gray. Smooth, except minute close-pressed scattered hairs, prostrute, spreading, very slender; leaflets oval or obovate-elliptical ( $\frac{1}{2}{ }^{\prime}$ long); peduncles slender and few-flowered; pods roundish. - Dry sandy soil, S. New York to Kentucky and southward. - Much like the last.

3. L. violàcea, Pers. Stems upright or spreading, branched ; leaflets varying from oval-oblong to linear, whitish-downy beneath with close-pressed pubescence; peduncles or clusters few-flovered; pods ovate. - The principal varieties are, 1. Divérgens, with oval or oblong leaflets and loosely panicled flowers; this runs into, 2. SEssilifions, with the flowers principally on peduncles much shorter than the leaves, and clustered ; and a more distinct form is 3. ANGUSTIFòr, with closely clustered flowers on straight branches, crowded leaves, and narrowly oblong or linear leaflets, which are often silky. - Dry copses: common. - Pods ripening from both sorts of flowers.

4. L. Stùvei, Nutt. Stems upright-sprending, bushy, dnwmy; leaflets oval or roundish, longer than the petiole, silky or white-woolly beneath (and sometimes above); clusters muny.flowrred crowdel; porls ovate, downy. - Dry hills, and sand, Plymouth, Mass. to Virginia, Michigan, and southward. - Appearing intermediate between No. 3 and No. 5 .

$$
\text { L \& M-26 }
$$


* * Flowers all alike and perfect, in close spikes or heads: corolla whitish or creamcolur with a purple spot on the standard, about the length of the downy calyx: stcms upright, uccull-like $\left(2^{\circ}-4^{\circ}\right.$ high $)$.

5. L. hírta, EII. P'cduncles longer than the leaves; petides slender; leaflets roundish or oval, hairy; spties cylindricul, ruther louse; pods nearly as long as the calyx. (L. polystachia, Muchi.) - Dry hillsides.

6. L. capitàta, Michx. L'eluncles und petiotes short; stems rigid, woolly; leaflets elliptical or ollong, thickish, reticulated and mostly smooth above, silky beneath; spikes or heeuls shorl; pods much shorter thatu the calyx. - Varies greatly, most of all in var. ANGístróla : slender; leaflets linear; peduncles sometimes elongated. - Dry and sandy soil; the narrow variety only finuc near the coust and southward.

\section{STYLOSÁ NTHES, Swartz. Pencil-Flower.}

Calyx early deciduous; the țube slender and stalk-like; the limb unequally 4-5-cleft, the lower lobe more distinct. Corolla and monadelphous stament inserted at the summit of the calyx-tube : standard orbicular: kecl incurved. Anthers 10, the 5 longer ones fixed near their base, and the 5 alternate sliorter ones fixed by the middle. Style filifurm, its upper part falling off after fluwering, the lower part incurved or hooked, and persistent on the apex of the 1 2-jointed small anil short reticulated pod, the lower joint when present enpty and stalk-like. - Low peremuials, branched from the base, with wiry stems, pimately 3-foliolate leaves, the sheathing stipules united to the petiole, no stipels, and small, yelluw fluivers in terminal lieads or short spikes. (Name

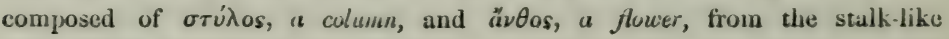
caly $x$-tube.)

1. S. elàtior, Swartz. 'Tufted; leaflets lanceolate, strongly straightveined; heads or elusters sinall and few-flowered. - P'ine barrens, Long Island, New York, to Virginia, Illinois, and southward. July-Oct.

\section{Vícia, Tourn. Vetch. Tare.}

Calyx 5-eleft or 5-toothed, the 2 upper teeth often shorter, or the luwest longer. Wings of the corollia adhering to the middle of the keel. Stamens more or less dialdelphous $(9 \& 1)$; the orifice of the tube oblique. Style filiform, lairy all round or only on the back at the apex. Pod flat, 2-valved, 2several-seeded. Seeds globular. Cotyledons very thick, remaining under ground in germinattion. - IIerbs, nostly climbing more or less by the tendril at the end of the pinnate keaves. Stipuies half-sagittate. Flowers or peduncles uxillary. ('The classical latin name.)

* Amunil: floccrs 1-2 in the axils, neurly sessile, harge, violet-purple.

1. V. sativa, L. (Сомдок Vetcu or 'Take.) Sumewhat pubescent; stem simple; leatlets $5-7$ pairs, varying from obovate obling to linear, notched and mucronate at the apex; pod lincar, several-seeded. - Cultivated fields and waste plices; hoth the common form and the vill. Angustieobia, which has longer and narrow leaflets. (Adv. from Eu.) 
- Annual, sknder : peduncles elongated: flowers small. (Species of Ervum, L.)

2. V. tetrasperma, L. Peduncles 1-2-flowered; leaflets 4-6 pairs, linearoblong, obtuse; calyx-tecth unequal; corolla whitish; pods narrowly oblong, 4seeded, smooth. - Waste or open places, near the coast. (Nat. from Èu.)

3. V. Hirsùta, Koch. Peduncles 3-6-fowered; leaflets 6-8 pairs, truncate; calyx-tceth equal ; corolla bluish ; pols oblong, 2-sceded, hairy.-Massachusetts to Virginin. (Nat. from Liı.)

*** Permnial: queluncles elongated; calyx-tecth unequal: pod several-sseded.

4. V. Crácca, L. Downy-pubescent ; leaflets $20-21$, oblong-lanceolate, strongly murionate; peduncles densely mamy-flowered; calyx-tecth shorter than the tube. - Borders of thickets, New England to Kentucky and northward: rather rare. July. - Flowers blue, turning purple, $6^{\prime \prime}$ long, one-sided in the spike, reflexed. (Eu.)

5. V. Caroliniàna, Walt. Nearly smooth ; leaftets $8-24$, oblong, obtuse, scarcely mucronate; peduncles loosily flowered; calyx-teeth very short. - Riverbanks, \&c. May. - Flowers small, more scattered than in the preceding, whitish, the keel tipped with blue.

6. V. Americàna, Muhl. Glabrous; leaflets 10-14, elliptical or ovateollong, very obtuse, many-veined; peduncles 4-8-flowered.-Moist soil, New York to Kentucky and northward. Junc. - Flowers purplish, 8" long.

\section{LÁt $\mathbf{T} \mathbf{Y} \mathbf{R} \mathbf{S}$, L. Vetchling. Everlasting Pea.}

Style flattish, dilated and flattish (not grooved) above, hairy along the inner side (next the free stamen). Sheath of the filaments scarcely oblique at the apex. Otherwise nearly as in Vicin. ( $A \dot{\theta} \theta$ vpos, a leguminous plant of Theophrastus.) - Our species are perennial and mostly smooth plants.

1. L. marítimus, . Bigclow. (Велсн PeA.) Stem stout $\left(1^{\circ}\right.$ high); leaflets 4-8 pairs, crowded, oval or obovate; stipules broadly halberd-shaped, nearly as large as the leaflets; peduncles 6-10-flowered. - Sea-coast, from New Jersey northward, and shore of the Great Lakes. June-Aug. - Flowers large, purple. Leaflets very veiny, as also in the other species. (Eu.)

2. L. venosus, Muhl. Stem climbing $\left(2^{\circ}-5^{\circ}\right.$ high); leaflets $5-7$ pairs, scattered, oblong-ovate, often downy beneath ; stipules very small and usually slender, half arrow-shaped, rarely larger and broader; peduncles many-flowered; corvlla purple. - Shady hanks, Penn. to Wisconsin, and southward. June.

3. L. ochroleùcus, Hook. Stem slender $\left(1^{\circ}-3^{\circ}\right.$ high $)$; leaflets $3-4$ pairs, ovate or oval, smooth, glancous, thin ; stipules half heart-shrped, about half as large as the leaflets; peduncles 7-10-flowered; corolla yellowish-white, smaller than in the last. - Hillsides, W Vermont to Pennsylvania, Wisconsin, and northward. July.

4. L. palústris, L. (MАnsi Vetching.) Stem slender $\left(1^{\circ}-2^{\circ}\right.$ high), often winged-margined; leaflets 2-4 pairs, lanecolate, linear, or narrowly ohlong, mucronate-pointed ; stipules small, lancrolate, half arrow-shaped, sharppointed at both ends; perluncles 3-5-flowered; corolla blue-purple. - Moist places, N. England to Penn., Illinois, and northward. July. (Eu.)

Var. myrtifolius. Tuller, climbing $2^{\circ}-4^{\circ}$ high ; leaflets oblong or ovate- 
elliptical; upper stipules much larger : corolla pale purple. (L. myrtifolius, Muhl.) - W. New England to Virginia and northward, July. - Ordinarily appears quite distinct fiom L. palustris; but intermediate specimens occur.

5. L. PRATÉnsis, L. Low and straggling; leuflets a single pair, narrow. lanceolate; stipules large; peduncles several-flowered; corolla yellow. - Spon. taneous and abundant along the Connecticut at West Springfield, Mass., A. P. Foster. July. (Adv. from Eu.)

\section{4. ÁPIOS, Bocrhaave. Ground-Nut. Wild Bean.}

Calyx somewhat 2-lipped, the 2 lateral teeth being nearly obsolete, the upper very short, the lower one longest. Standard very broad, reflexed: the long scythe-shaped keel strongly incurved, at length coiled. Stamens diadelphous. Pod straight or slightly curved, linear, elongated, thickish, many-seeded. - A perennial herb (with some milky juice!), bearing edible tubers on underground shoots, twining and climbing over bushes. Leaflets 5-7, ovate-lanceolate, obscurely stipellate. Flower's in dense and short, often branching racemes.

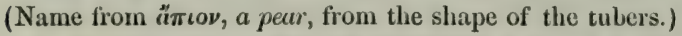

1. A. tuberòsa, Manch. (Glýcine Apios, L.) - Low grounds; common. Aug. - Sept. - Flower's brown purple, or chocolate-color, violet-scented.

\section{PHAS ÈOUUS, L. Kidney Bean.}

Calyx 5-toothed or 5-cleft, the two upper tecth often higher united. Keel of the corolla, with the included stamens and style, spirally coiled or curved into a ring. Stamens diadelphous. Style bearded along the upper side: stigma oblique or lateral. Pod linear or scythe-shaped, several-many-seeded, tipped with the hardened base of the style. Cotyledons thick and fleshy, rising out of the ground nearly unchanged in germination. - Twining or prostrate herbs, with pinnately 3-foliolate stipellate leaves. Flowers often clustered on the knotty joints of the raceme, produced in summer and autunn. ('The ancient name of the Kidney Bean.)

* Pods scymetar-shaped: racemes long and loose, panicled.

1. P. perénnis, Walt. (Wild Besa.) Stem climbing high from a perennial root; leaflets roundish-ovate, short-pointed; pods drooping, strongly curved, 4-5-seeded. - Copses, Connecticut to Illinois, and southward. - Flowers purple, handsome, but small.

* * Pods long and straight, linear, rather terete: flowers few in a short crustereil and long-peduncled raceme. (Strophóstyles, Ell.)

2. P. diversifolius, Pers. Annual ; stem prostrate, spreading, roughhairy ; leaflets ovute-3-lubed, or angled towards the base, or some of them oblongovate and entire; peduncles at length twice the length of the leaves. - Sandy fields and banks, cuast of Massachusetts and along the Great Lakes to Illinois and southward. - Corolla greenish-white, tinged with red or purple. Pod thickish.

3. P. hélvolus, L. Perennial, hairy ; stems diffuse, slender; leaflets ovate or oblong, entire or obscureiy angled; peduncles 3-6 times the length of the leaves. - Sandy fields, S. New York to Illinois and southward. - More slender thau the last: pods narrower : flowers as large and similar. 
- Pods straight and linear, flat: peduncles short, 1 -few-flowered at the summit: flowers smull : keel less incurved.

4. P. pauciflorus, Benth. Annual; stems diffuse, but twining, slender, pubescent; lenflets varying from oblong-lanceolate or ovate-oblong to linear. (P. leiospermus, Torr. \& (ír.) - River-banks, Illinois (Meal) and southwestward. July - Sept. - Flowers 3 " long, purple. Pod 1' long, pubescent.

\section{C E N T R OS E M A, DC. Spured Butterfiy-Pea.}

Calyx short, 5-cleft. Corolla, \&c. much as in Clitoria, but the spreading standard with a spur-shaped projection on the back near the base : keel broad. Style bearded at the apex around the terminal stigma. Pod long and linear, flat, pointed with the awl-shaped style, many-seeded, thickened at the edges, the valves marked with a raised line on each side next the margin. - Twining perennials, with 3 -foliolate stipellate leaves, and large showy flowers. Stipules, bracts, and bractlets striate, the latter longer than the calyx. (Name from

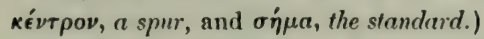

1. C. Virginianum, Benth. Rather rough with minute hairs; leaflets varying from oblong-ovate to lanceolate and linear, very veiny, shining; peduncles 1 -4-flowered ; calyx-teeth lincar-awl-shaped. - Sandy woods, from Maryland southward. July. - Corolla $1^{\prime}$ long, violet. Pods straight, $4^{\prime}-5^{\prime}$ long.

\section{Clit tò i A, L. Butterfly-Pen.}

Calyx tubular, 5-toothed. Standard much larger than the rest of the flower, erect, rounded, notched at the top, not spurred on the back: keel small, shorter than the wings, incurved, acute. Stamens monadelphous below. Style bearded down the inner face. Pod linear-oblong, flattish, knotty, several-seeded, pointed with the base of the style. - Erect or twining pereunials, with mostly pinnately 3-foliolate stipellate leaves, and very large flowers. Peduncles 1-3-flowered: bractlets opposite, striate. (Derivation recondite.)

1. C. Mariàna, L. Smooth; leaflets oblong-ovate or ovate-lanceolate; stipules and bracts awl-shaped; peduncles short, 1-3-flowered. - Dry banks, E. New York to Virginia and southward. July. - Low, ascending or twining; the showy pale-blue flowers $2^{\prime}$ long.

\section{A M P H I A R P 度 A, Ell. Hog Pen-nut.}

Flowers of 2 kinds ; those of the racemes from the upper branches perfect, but scldom ripening fruit; those near the base and on creeping branches with the corolla none or rudimentary, and few free stamens, but fruitful. Calyx about equally 4- (rarely 5-) toothed: bractlets none or minute. Keel and wing-petals similar, almost straight; the standard partly folded round them. Stamens diadelphous. Style beardless. Pods of the upper flowers, when formed, somewhat scymetar-shaped, 3-4-seeded; of the lower ones commonly subterrancan, obovate or pear-shaped, fleshy, ripening usually but one lurge seed. - Low and slender perennials; the twining stems elothed with brownish hairs. Leaves pinnately 3 -foliolate: leaflets rhombic-ovate, stipellate. Flowers small, in clus- 
tered or compound racemes, purplish. Bracts persistent, round, partly elasp-

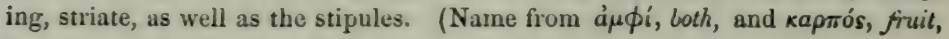
in allusion to the two kinds of pods.)

1. A. monoica, Nutt. Racemes nodding; bracts each supporting 2 or more flowers, shorter than the pedicels; subterranean pods hairy. - Rich woodlands. Aug., Sept.

\section{GA L Á C tia, P. Browne. Milk-Pea.}

Calyx 4-cleft; the lobes acute, the upper one broadest, entire. lieel scarcely incurved. Stamens diadel phous or nearly so. Style beardless. Pod linear, flat, several-seeded (some few of them rarely partly subterranean and fleshy or deformed). - Low, mostly prostrate or twining perennial herbs. Leaflets usually 3, stipellate. Flowers in somewhat interrupted or knotty racemes, purplish ; in

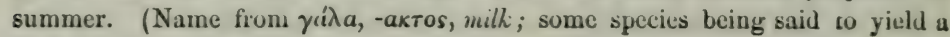
milky juice, which is unlikely.)

1. G. glabélla, Michx. Stems nearly smooth, prostrate; leaflets elliptical or ovate-oblong, sometinues slightly hairy beneath ; racemes short, 4-8-flowered; pods somewhat hairy. - Sandy woods, S. New York, New Jersey and P'enu. to Virginia and southward. - Flowers large for the genus, rose-purple.

2. G. móllis, Michx. Stems (decumbent and somewhat twining) and leaves beneath sof-downy and haary; leaflets oval ; racemes many-flowered; pods very downy. - S. Penusylvania, Maryland, and southward. July.

\section{RHYNCHÒSTA, Lour., DC. Rurnciosia.}

Calyx somewhat 2-lipped, or deeply 4-5-parted. Keel scythe-shaped, or incurved at the apex. Stamens diadelphous. Ovules only 2. Pod 1-2-seeded, short and flat, 2-valved. - Usually twining or trailing perennial herbs, pinnately 3-foliolate, or with a single leaflet, not stipellate. Flowers yellow, racemose or clustered. (Name from pívXos, a beak, from the shape of the keel.)

1. R. tomentosa, 'Torr. \& Gray. More or less downy; leaflets roundish; racemes short or capitate; calyx about as long as the corolla, 4-jarted, the upper lobe 2-cleft; pod oblong. - Very variable: or perhaps the following aro distinct species.

Var. monophýlla, Torr. \& Gray. Dwarf and upright $\left(3^{\prime}-6^{\prime}\right.$ high $)$; leaves mostly of one round leaflet $1^{\prime}-2$ wide. (R. renifórmis, $D C$.) - Virginia and southward, in dry sandy soil. - Flowers earlier than the following.

Var. volùbilis, Torr. \& Gray. Trailing and twining, less downy ; leaflets 3 , roundish; racemes few-flowered, almost sessile in the axils. (R. diffórmis, DC.) - S. Virginia and southward.

Var. erécta, Torr. \& Gray. Upright $\left(1^{\circ}-2^{\circ}\right.$ ligh $)$, soft-downy; leaflets 3, oval or oblung. (R. erecta, $D C$.) - Maryland and southward.

\section{B A PTísia, Vent. False Indigo.}

Calyx 4-5-toothed. Standard not longer than the wings, its sides reflexed: kecl-petals nearly separate, and, like the wings, straight. Stamens 10, distinct. 
Pod stalked in the persistent calyx, roundish or oblong, inflated, pointed, manyseeded. - Perennial herbs, with palmately 3-foliolate (rarely simple) leaves, which generally blacken in drying, and racemed flowers. (Named from $\beta a \pi \tau i \zeta \omega$, to dye, from the cconomical use of some species, which yich a poor indigo.)

1. B. tinctòria, R. Br. (WII.) InnIgo.) Smooth and slender $\left(2^{\circ}-3^{\circ}\right.$ high), rather glancons; leaves almost sessile; leaflets rounded wedge-obovate ( $\left(f^{\prime}\right.$ long) ; stipules and bructs minute, and dreiduous; ruremes fi'm-flowered, terminating the bushy branches; pods oval-globose, on a stalk longer than the calyx. Sandy dry soil : common. June- $\Lambda$ ug.-Corolla yellow, $\frac{1}{2}$ long.

2. B. austràlis, R. Br. (Buve False-Indigo.) Smooth, tall and stout $\left(4^{\circ}-5^{\circ}\right)$; leaflets oblong-wedge-form, olituse; stipules lancrolate, as long as the petioles, ruther persislent ; vareme elongatert $\left(1^{\circ}-2^{\circ}\right)$ and many-ftowered, erert; bracts deciduous; stalk of the ovval-oblong pork alout the length of the culyx. - Alluvial soil, from Pennsylvania westward and southward: often cultivaterl. June. - Flowers 1' long, indigo-blue. Pods $2^{\prime}-3^{\prime}$ long.

3. B. leucántha, Torr. \& Gr. Smooth; stems, leaves, and racemes as in the foregoing ; stipules early decidwous; ports oved-oblong, raisen on a stalk fully twice the length of the calyx. - Alluvial soil, ()hio to Wisconsin and southwestward. July. - Flowers white; the standard short. Pods $2^{\prime}$ long.

4. B. alba, R. Br. Smooth $\left(1^{\circ}-3^{\circ}\right.$ high); the branches slender and widdy spreading; petioles slender; stipules and bructs mimue and deciduous; leaflets oblong or oblanceolate; racemes slender on a long naked peduncle; pods linceroblong $\left(1^{\prime}+1 \frac{1}{2}^{\prime}\right.$ long $)$, short-stalked. - Dry soil, Virginia and southward. May, June. - Flowers white, 6" - 9" long.

5. B. leucophæ̀a, Nutt. Hairy, low (10 high), with divergent branchrs; lenves almost sessilh; leaflets narrowly oblong-obovate or spatulate; stipules and lracts large and leafy, persistent; racemes long, reclined; flowers on elongated pedicels; pods ovoid, hoary. - Michigan to Wisconsin and southward. April, May. - Raceme often $1^{\circ}$, pedicels $1^{\prime}-2^{\prime}$, the cream-colored corolla $1^{\prime}$, in length.

\section{CLA DRÁS TIS, Raf. Yeliow-Woon.}

Calyx 5-toothed. Standard large, roundish, reflexed : the distinct keel-petals and wings straight, oblong. Stamens 10, distinet: filaments slender, incurved ahove. Pod short-stalked above the calyx, linear, flat, thin, marginless, 4-6seeded, at length 2-valved. - A small and handsome tree, with yellow wood, smooth bark, nearly smooth pinnate leaves of $7-11$ oval or ovate leaflets, and ample panicled racemes $\left(10^{\prime \prime}-20^{\prime \prime}\right.$ long) of showy white flowers drooping from the end of the branches. Stipules obsolete. Base of the petioles hollow, and enclosing the leaf-huds of the next ycar. Bracts minute and fugacious. (Name of obscure derivation.)

1. C. tinctória, Raf. (Virgília lutea, Mirhx.f.) Rich hillsides, E. Kentucky and southward along the western base of the Alleghanies. May, June.

\section{CÉris, L. Red-bud. Judas-tree.}

Calyx 5-toothed. Corolla imperfectly papilionaceous: standard smaller than the wings, and enclosed by them in the bud: the keel-petals larger and not 
united. Stamens 10, distinct, declined. Pod oblong, flat, many-seeded, the upper suture with a winged margin. Embryo straight. - Trees, with rounded. heart-shaped simple leaves, caducous stipules, and red-purple flowers in umbellike clusters along the brauches of the last or preceding years, uppearing beforo the leaves, acid to the tuste. ('T'he ancient nane of the Oriental Judus-tret.)

1. C. Canadénsis, L. (RED-Buv.) Leaves pointed; pods nearly sessile above the calyx. - Rich soil, New York to Ohio, Illinois, and southward. March-May. - A small ornamental tree, often cultivated : the blossoms sualler than in the European species.

\section{C ÁS SIA, L. SenNa.}

Sepals 5, scarcely united at the base. Petals 5, little unequal, spreading. Stamens 5-10, unequal, and some of them often imperfect, spreading: anthers opening by 2 pores or chinks at the apex. Pod many-seeded, often with cross partitions. - Herbs (in the United States), with simply and abruptly pinnate leaves, and mostly ycllow flowers. (An ancient name of obscure derivation.)

* Leaflets large: stipules deciduous: the $\mathbf{3}$ upper anthers deformed and imperfect: flowers in short axillury racemes, the upper ones panidul: herbuye glabrous.

1. C. Marilándica, L. (WII.D Senna.) Leajlets 6-9 pairs, lanculateoblong, obluse; petiole with a club-shaped gland near the base; pods linear, slightly curved, flat, at first hairy $\left(2^{\prime}-4^{\prime}\right)$; root perennial. - Alluvial soil. July. - Stem $3^{\circ}-4^{\circ}$ high. Leaves used as a substitute for the officinal Senna.

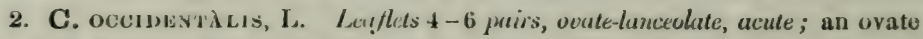
gland at the base of the petiole; pods long-linear ( $5^{\prime}$ long) with a tumid border, glabrous. - Virginia and southward. Aug. (Adv. from Trop. Anner.)

3. C. obtusifolia, L. Leuflets 3 or rarely 2 puirs, obovate, obtuse, with an elongated gland between those of the lower pairs or lowest pair; pods slender, 6' long, curved; root annual. - Banks of the Ohio River, Illinois (Dr. Vuscy), S. Virginia and southward.

* * Leaflets small, somewhat sensitive to the touch: stipules striate, persistent : a cupshaped yland beneath the lowest pair of leaflets: anthers all perject: flowers in small clusters above the axils: pods flat: root annual.

4. C. Chamrecrista, L. (P’artrinol PEA.) Leuflets 10-15 pairs, linear-oblong, oblique at the base; flowers (large) on slender pedicels; anthrers 10 , elviguted, unequal ( $t$ of them yellow, the others purple) style slender. - Sundy fields: common, especially southivard. Aug. - Stems spreading, $1^{\circ}$ long: 2 or 3 of the showy ycllow petals often with a purple spot at the base.

5. C. níctitans, I. (Wild Sensitive-Plant.) Leaflets 10-20 pairs, oblong-linear; flowers (erry small) on very short pedicels; anthers 5, nearly equal; style short. - Sandy ticlds, Now Lingland, near the coast, to Hlinvis and southward. Aug. - Sept.

\section{GY M N Ó CIA D U S, Lam. Kentucky Coffee-tree.}

Flowers dicecious or polygamous, regrular. Calyx elongated-tubular below, 5-cleft. Petals 5, oblong, equal, inserted on the summit of the calyx-tube. Sta: 
mens 10, distinct, short, inserted with the petals. Pod oblong, flattened, hard, pulpy inside, several-seeded. Seeds flattish. - A tall large tree, with rough bark, stout branchlets, not thorny, and large unequally twice-pinnate leaves; the lenflets standing vertically. - Flowers whitish, in terminal racemes. (Name from $\gamma v \mu \nu \operatorname{s}^{\prime}$, naked, and $\kappa \lambda a ́ \delta o s, a$ branch, alluding to the stout branches destitute of sprny.)

1. G. Canadénsis, Lam. Rich woods, along rivers, W. New York and Y'enn. to Illinois and southwestward. June. - Cultivated as an ornamental tree : timber valuable. Leaves $2^{\circ}-3^{\circ}$ long, with several large partial leafstalks bearing 7-13 ovate stalked leaflets, the lowest pair with single leaflets. Pod $6^{\prime}-10^{\prime}$ long, $2^{\prime}$ broud ; the seeds over $\frac{1^{\prime}}{2}$ across. Stipules wanting.

\section{GLEDÍTSCHIA, L. HoneY-Locust.}

Flowers polygamous. Calyx short, 3 -5-cleft, the lobes spreading. Petals as many as the sepals and equalling them, the 2 lower sometimes united. Stamens 3-10, distinct, inserted with the petals on the base of the calyx. Pod flat, 1 - many-sceded. Seeds flat. - Thorny trees, with abruptly once or twice pinnate leaves, and inconspicuous grcenish flowers in small spikes. Thorns above the axils. (Named in honor of $J . G$. Gleditsch, a botanist contemporary with Linnæus.)

1. G. triacánthos, L. (Three-tionned Acacis, or Honey-Locust.) Thorns stout, often triple or compound; leaffits lanceolate-oblong, somewhat serrate; pods linear, elongated $\left(1^{\circ}-1 \frac{1}{2} \circ\right.$ long), often twisted, filled with sweet pulp between the seeds. - Rich woods, Penn. to Virginia, Illinois, and southwestward. June. - Common in cultivation as an ornamental tree, and for hedges.

2. G. monospérma, Walt. (WATer-Locust.) Thorns slender, mostly simple; Iraflets ovate or oblong; pods oval, 1-secded, pulpless. - Swamps, Illinois and southwestward. July. $-\Lambda$ small tree.

\section{DES MA N T H U S, Willd. DesmantuUs.}

Flowers perfect or polygamous, regular. Calyx campanulate, 5-toothed. Petals 5, distinct. Stamens 5 or 10. Pod flat, membranaceous or somewhat coriaceous, several-secded, 2 -valved, smooth. - Herbs, with twice-pinnate leaves of numerous small leaflets, and with one or more glands on the petiole. setaceous stipules, and axillary perluncles bearing a head of small greenish-white flowers.

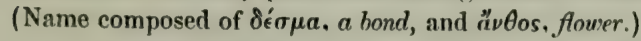

1. D. brachýlobus, Benth. Nearly glahrous perennial, erect $\left(1^{\circ}-4^{\circ}\right.$ high) ; partial petioles 6 - 15 pairs; leaflets $20-30$ pairs; stamens 5 ; porls oblong or lanccolate, curved, scarcely $\mathbf{l}^{\prime}$ long, 2-6-seeded. (Darlingtonia brachyloba \& glandulosa, $D C$.) - Prairies and alluvial banks, Illinois and southwestward.

\section{SCHRÁ NKIA, Willd. Sensitive Briar.}

Flowers polygamons, regular. Calyx minute, 5-toothed. Petals united into a fumnel-form 5-cleft corolla. Stamens 10-12, distinct, or the filaments united at the base. Porls long and narrow, rough-prickly, several-scederl, 4-valved, i. e. G $\mathrm{M}-7$ 
the two narrow valves separating on each side from a thickened margin. - $\mathrm{Pe}$. renuial herbs, nearly related to the true Sensitive Plants (Mimosa); the procumbent stems and petioles prickly, with twice-pinnate sensitive leaves of many small leuflets, and axillary peduncles bearing round heads of small rose-colored flowers. (Named for F.P. Schrank, a German botanist.)

1. S. uncinàta, Willd. Prickles hooked; partial petioles 4-6 pairs; lenflets ellipticul, reticuluted with strong veins bencath ; pods oblung-linear, nearly terete, short-pointed, densely prickly (2' long). - Dry saudy soil, Virginia, Itlinois? and souchward. June-Aug. •

2. S. angustàta, 'Torr. \& Gray. Leaflets oblong-linear, scarcely veined; pods slender, taper-pointed, sparingly prickly (about $4^{\prime}$ long). - With the preculing.

\section{Ordel 33. Rosìceas. (Rose Family.)}

Plants with regular flowers, numerous (rarely few) distinct stamens inserted on the culyi, and 1 -many pistils, which are quile distinct, or (in the Pear tribe) uniled and combined with the calys-tube. Setds (anatropous) 1 - jew in each ovary, almost aluays without albumen. Embryo struight, with large and thick cotyledons. Leaves alternate, with stipules, these sumetimes caducous, rarely obsolete or wanting. - Calyx of 5 or rarely $3-4-$ 8 sepals (the odl one superior), united at the base, often appearing duuble by a row of bractlets outside. Petals as many as the sepals (rarely wanting), mostly inıricated in the bud, and inserted with the stamens on the edge of a disk that lines the calyx-tube. Trees, shrubs, or herbs. - A large and important order, almost destitute of noxious qualities, and producing the most valuable fruits. Very intimately connected with Leguminosa on one hand, and with Saxifragacea on the other.

\section{Suborder I. AMYGDALEAE. (Almond Family.)}

Calyx entirely free from the (usually) solitary ovary, deciduous. Style terminal or nearly so. Fruit a drupe (stone-fruit), 1-seeded, or rarely 2seeded. - Trees or shrubs, with simple leaves, the bark exuding gum, and the bark, leaves, and kerncls yielding the peculiar flavor of prussic acid. Stipules free, often deciduous.

1 Prunus. Flowers perfect. Lobes of the calyx and petals 5. Stone of the drupe bony.

\section{SUBOHDER II. ROSACEA PROPER.}

Calyx free from the ovaries (but sometimes enclosing them in its tube), mostly persistent with the firuit. Pistils few or many, distinct, occasionally single. Stipules commonly united with the petiole.

Tribe I. SPIR AEE E. Pistils mostly 5 and forming folliclis in fruit: styles terwiual. Caly $x$ without bractlets. Secils not rarcly with some alluumen! 
Tribe I1. POTFreI EA. Pistila 1-4, nne-ovuled, beenming achenia, and enclosed in the urn-shaped tuhe of the dry persistent caly $x$, which is constrieted or nearly closed at the throat Petals often wanting

4. Poterium. Petals none. Lohes of the caly $x$ 4, petal-like. Style terminal : atigma tufted.

5. Alehemilla. Petals none. Stamens and pistils 1-4: style lateral.

6. Agrimonia. Petals 5. Stamens 12-15. Pistils 2: style terminal.

Tribe II. DFY A E.A. Pistils numcrous, rarely fow or single, one-ovuled, beeming dry achenla; the calyx open, not flehy in fruit. Petuls present, usually conspicunus.

7. Dryas. Petals and calyx-lubes 8 or 9 . Stamens and carpels uumerons : persistent styles becoming long plunose trils in fruit.

8. Geum. Petals and calyx-lobes 5 , the latter usually with 5 alternating amall bractlets. Stamens and carpels numerous : persistent styles becoming long plumose or hairy, or naked and straight or jointed, tails. Ralicle inforiur.

9. WaldsteluIn. Petals and ealyx-lobes 5 ; no bractlets. Stameus numerous. Achenia 2-6 : styles deciduous from the base. Ralicle inferior.

10. Sibbaldia. Petals minute: stuneus and achenia 5-10: otherwise same as Potentilla.

11. Futentllin. Petals 5 (rirely 4), conspicuous. Culyx-lobes as many, and also with an alternating set of accessory lobes or bractlets. Stamens and achenin numerous; the latter heaped on a dry receptacle. Styles commonly more or less lateral, deciduous or not enlarging in fruit. Malicle superior.

12. Fragarla. Flower as in Potentilla. Receptacle much enlarged and pulpy in fruit.

Trtbe IV. IRUnEA. Pistils numcrous or several, 2-ovuled, becoming herry-like or drupelets in fruit; the 5 -cleft caly $x$ not bracteolate, open, persistent or withering beneath the fruit. Petals conspicuous.

13. Dallibaria. Carpels $5-10$, in the bottom of the caly $x$, almost dry.

14. Rubus. Carpels numerous, henped on the receptacle.

Tribe V. Rosf.R. Pistils numerous, onc-oruled, becoming achenia, contained in the urn-shaped or globular and almost closed fleshy tube of the calyx, or hip : no bractlets. Petals conspicuous.

15. 12osn. Character of the Tribe.

\section{Suborder ili. Pomeze. (Pear Family.)}

Caly $\mathrm{x}$-tube thick and fleshy in fruit, including and combined with the 2-5 ovaries (forming a pome). Stipules free.

* Cells of the compound ovary as many as the styles (2 - 5), each 2- (rarely several-) ovuled.

16. Crntagns. Pome drupe-like, with $1-5$ bony stones or kernels. Usually thorny.

17. Pyxus. Pome containing $2-5$ papery or cartilaginous carpels.

* Cells of the compound ovary becoming twice as many as the styles, each 1-ovuled.

18. Amelanchier. Pome usually of 5 carpels; each becomes incompletely 2-celled by a projection from its back : otherwise as Pyrus.

\section{PR Ù N U S, Tourn. Plum, Cherry, \&c.}

Calyx 5-cleft; the tube bell-shaped, urn-shaped or tubular-obconical, decidnous after flowering. Petals 5, spreading. Stamens 15-20. Ovary solitary, with 2 pendulous ovules. Drupe fleshy, with a bony stone. - Small trees or shrubs, with mostly edible fruit. (The ancient Latin name.)

§1. PRUNUS \& CÉRASUS, 'Tourn. Drupe smonth, and the stone smonth or somexhat ruyged: flowers (usurelly white) from separule, luterel scaly buels in early spring, preceding or coetaneous with the leares; the pedicels few or several in simple umbel-like clusters. - The PuUms of the Old $\mathrm{I}^{\top}$ wld have the leaves 
convolute in the bud, the fruit with a Uloom; its stone oblong, flattened or flattish and acute at both ends: but our wild P'lums are like CHurriss in having the leaves folded bejore cxpansion, litle or no bloom, and some of them in the thickitr or glubular stone, thus conjounding the distinctions.

1. P. Americana, Marshall. (Wild Yellow or Red Plum.) Leaves ovate or somewhat obovate, conspicuously pointed, coursely or doubly serrate, very veiny, glabrous when mature; fruit nearly destitute of bloom, roundish-oval, yellow, orange, or red, $\frac{1}{2}-\frac{y^{\prime}}{}$ in dianeter, with the turgid stone more or less acute on both margins, or in cultivated states $l^{\prime}$ or more in diameter, the flattened stone with broader margins: pleasant-tasted, but with a tough and acerb skin. - Woodlands and river-banks : common. - T'ree thorny, $8^{\circ}-20^{\circ}$ high.

2. P. marítima, Wang. (BEAcr 1'Lum.) Low and straggling $\left(2^{\circ}-\right.$ $\left.5^{\circ}\right)$; leaves ovule or ovul, finely serrate, sofly pubescent underneath; pedicels short, pubescent; fruit globular, purple or crimson with a bloom $\left(\frac{1}{2}{ }^{\prime}-1^{\prime}\right.$ in diameter); the stone very turgid, acute on one edge, rounded and minutely grooved on the other. (P. littoràlis, Bigelow.) - Varies, when at some distance from the coast, with the leaves smoother and thinner, and the fruit smaller. (P. pygmata, Willd.) - Sea-beach and the vicinity, Maine to Virginia; the variety, New Jersey and southward.

3. P. Chicàsa, Michx. (Curckasaw Plum.) Stem scarcely thorny $\left(8^{\prime}-15^{\prime}\right.$ high) ; lawes neculy lanceolute, finely serrulate, glabrous; fruit globular, red, nearly destitute of bloom $\left(\frac{1}{2}{ }^{\prime}-\frac{3}{3}\right.$ ' in diameter); the ovoid stone almost as thick as wide, rounted at both sutures, one of them minutely grooved. - Maryland to Illinois (probably not indigenous) and southwestward.

4. P. spinòsa, L. (Slok. Black Tiroms.) Brinches thorny; leaves obovate-oblong or ovate-lanceolute, sharply serrate, at length ylubrous; pedicels glabrons; fruit small, globular, black with a bloom, the stone turgid, acute on one edge. - Var. insitfía (Buldace-l'luar), is less spiny, the pedicels and lower side of the leaves pubescent. ( $\mathcal{P}^{\text {? }}$. insititia, L.) - Roadsides and waste places, New England, to Penn., \&c. (Adv. fiom Eiu.)

5. P. pùmila, I. (I) wank Cnenrx.) Snooth, depressed, and trailing $\left(6^{\prime}-18^{\prime}\right.$ high $)$; leaves obocule-lanceolate, tapering to the base, somewhat toothed near the apex, pule underneath; flowers $2-4$ together; fruit ovoid, dark red, without bloom; stone ovoid, marginless, of the size of a large pea. - Rocks or sandy banks, Massachusctts northward to Wisconsin, ana south to Virginia aiong the mountains.

6. P. Pennsylvánica, I. (Wird Red Cuerri.) Leaves oblonel-lenceolate, pointed, findly and sharply striate, shiming, green and smooth both sides; flowers many in a cluster, on long pelicels; fruit globose, light red, very small, with thin and sour flesh; stone globular. - Rocky woods: common, especially northward. May. - Tree $20^{\circ}-30^{\circ}$ high, with light red-brown bark.

§ 2. PADUS, Mill. (CиFrrr.) Drupe small, glolwse, withouit blown; the stone turgid-ovale, maryinless: flonvers in ruceness terminating kefy branches, therefore appearing afler the leuves, late in spring.

7. P. Virginiana, I. (С'оке-СпекRу.) Leaves ovul, oblong, or abovate, abruptly pointed, very sharply (often doubly) serrate with slender teeth, thin; racemes 
short and close; petals roundish; fruit red turning to dark crimson; stone smooth. - River-banks : common, especially northward. Mny. $-\mathbf{A}$ tall shrub, seldom a tree, with grnyish hark; the fruit very unstere and nstringent till perfectly ripe. (P. obovìta, Bigelow. I'. serotina, of several authors.)

8. P. serotina, Ehrhart. (Wind Bциск Cherry.) Leaves oblong or lencenlate-nblong, taper-yninted, servate with incurred shent and wollons teeth, thickish, shining above; racemes clongnted; petals obovnte; fruit purplish-black. -

- Woods: common. Junc. $-\Lambda$ fine large tree, with reddish-hrown branches, furnishing valuable timber to the cabinct-maker : nlso abounding castward as a shrub. Fruit slightly bitter, but with a pleasant vinous flavor.

\section{SPIR 怹A, L. Meadow-SweET.}

Calyx 5-cleft, short, persistent. Petals 5, obovate, equal, imbricated in the bud (except in No. 6). Stamens 10-50. Pods (follicles) 2-12, several- (215-) seeded. - Flowers white or rose-color, sometimes diøcious : rarely the parts are 4 instead of 5. (Name probably from $\sigma \pi \epsilon \iota p \dot{\omega} \omega$, to wind, alluding to the fit. ness of the plants to be formed into garlands.)

§ 1. PIIYSOCÁRPOS, Camb. (Nerusa, Don.) Shrubs with simple palmately-lobed leaves and umbl-like corymbs: porls influted and diverging when grown, 2-4-sceded: serds pritty large, roundish, bitter, with a thick cruslaceous seed-cont, and rather copious albumen!

1. S. opulifolia, L. (NINE-BARK.) Leaves roundish, somewhat 3-lobed and heart-shaped; pods 2-5.-Rocky river-banks, especially westward. June. - Shrub $4^{\circ}-10^{\circ}$ high, with long recurved branches, and white flowers, suc ceedel by membranaccous purplish pods: the old bark loose and separating in numerous thin layers.

§2. SPIRAL proper. Shruhs, with simple leave; the stipules olsolcte: porto (mostly 5) not inflated, serrol-seded: serds mosily linear and with a thin or lnose roat and no albumen, in this and the following sections.

2. S. corymbosa, Raf. Nearly sinooth $\left(1^{\circ}-2^{\circ}\right.$ high $)$; leares oval or ovate, cut-toothed towarls the apex; corymbs large, fat, scveral times compound; flumers white. - Alleghanies of P'ennsylvania to Virginia and Kentucky. June. - $\Lambda$ form of $\mathrm{S}$. betulafolia, Pallas.

3. S. salicifolia, L. (Cомmon Meadow-Sweet.) Nearly smooth (2०$3^{\circ}$ high); leaves wedge-lanceolate, simply or donbly serrate; flowers in a creuded prnicle, white or flesh-color; pods smooth. - Wet or low grounds : also cultivated. July. (Eu.)

4. S. tomentosa, L. (Hardick. Strerle-Busir.) Stems and lover surface of the ovate or oblong serrate leares very uoolly; flowers in short racemes crowded in a dense panicle; pods woolly. - Low grounds : commonest in New England. July. - Flowers rose-color, rarely white.

§ 3. ULMARIA, Monch. Perennial herhs, with pinnate leaves and panicled

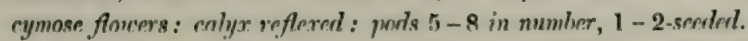

5. S. lobata, Murr. (Q (UEen or twe l'manus) (ilahrous $\left(2^{\circ}-8^{\circ}\right.$ high); leaves interruptedly pinnate; the terminal leaflet very large, 7-9-parted, the lobes incised and tootherl; stipules kidney-form; panicle compound-clustered, 
on a long naked peduncle. - Meadows and Prairies, Penn. to Michigan, Illnois, and Kentucky. June. - Illowers decp peach-blossom color, handsome; the petals and sepals ofien in fours! 'The bruised foliage exhates the odor of Sweet Birch.

\$ 4. ARÚNCUS, Seringe. Perunial herbs, with diacious whitish flowers, in many slender spikes disposed in a long compround panicle: leuves thrice-pinnate: stipules absolete: pods 3-5, several-seeded: pedicels reflexed in fruit.

6. S. Arúncus, L. (Goar's-BEakv.) Smooth, tall; leaflets thin, lanceolate-oblong, or the terminal ones ovate-lanceolite, taper-pointed, sharply cut and serrate. - Rich woods, Caiskill and Alleghany Mountains and westward. Near Baltimore, $P$. V. Leroy. June. (Eu.)

\section{GILLÈ I A, Muench. Indian Pinsic.}

Calyx narrow, somewhat constricted at the throat, 5-toothed; teeth erect. Petals 5, rather unequal, linear-lanceolate, inserted in the throat of the calyx; convolute in the bud. Stunneus 10-20, included. Pods 5, included, at first lightly cohering with each other, 2-4-scerled. Sceds ascending, with a close coriaceous coat, amd some albmucn. - l'eremial herbs, with almost sessile 3-foliolate leares; the thin leaflets doubly serrate and incised. Flowers loosely paniculate-corymbed, pale rose-color or white. (1)edicated to an obscure German botanist or physician, A. Gille, or Gillenius.)

1. G. trifoliàta, Muench. (Bowman's Roor.) Leaflets ovate-oblong, pointerl, cut-serrate; stipules small, awl-shaped, entire. - Rich woods, from W. New York southward, and sparingly in the Western States. July.

2. G. stipulàcea, Nutt. (American Inecac.) Leaflets lanceolate, deeply inciserl; stipules large and leaf-like, doubly incised. - From IV. Peunsylvania and New York to Illinois and Kentucky. June.

\section{POTÉri U M, L. (including Sanguisórba.) Burnet.}

Calyx with a top-shaped tube, constricted at the throat, persistent; the 4 broad petal-like spreating lobes imbricated in the bud, deciduous. Petals none. Stameins 4-12 or more, with flaceid filaments and short anthers. Pistils 1-3: the slender terminal style tipped with a tufted or brush-like stigna. Achunium (commonly solitury) enclosed in the 4-anghted dry and thickish closed callyxtube. Seed suspented. - Chiefly peremnial herbs, with unequally pinnate leaves, stipules colierent with the petiole, and small, often polygamous or dicecious flowers crowded in a dense head or spike at the summit of a long and

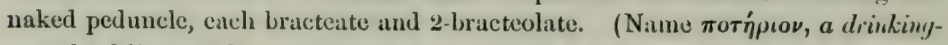
cup, the foliage of Burnet laving been used in the preparation of some medicinal drink.)

1. P. Canadénse. (Canadian Bunnet.) Stimens 4, long-exserted, club-shaped, white, as is the whole of the elongated and cylindrical spike; stem $3^{\circ}-6^{\circ}$ high, leallits numerons, ovatte or oblong-lanceolate, coarsely serrate, oltuse, heart-shapeel at the base, ats if stipellate; stipules serrate. (Sanguisurba

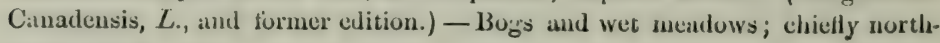
ward. Augr. - Oct. 


\section{ALCHEMILLA, Tourn. LADY's Manter.}

Calyx-tube inversely conical, contracted at the throat; limb 4-parted with as many alternate accessory lobes outside. Petals none. Stamens 1-4. Pistils 1-4; the slender style arising from near the base of the ovary ; the achenia included in the tube of the persistent calyx. - Low herbs, with palmately lobed or compound leaves, and small corymbed greenish flowers. (From Alkemelyeh, the Arabic name.)

1. A. anvéngis, I. (Parsegy Pient.) Small annual $\left(3^{\prime}-8^{\prime}\right.$ high), leafy; leaves 3-parted, with the wedge-shaped lobes 2-3-cleft, pubescent; flowers sessile in the axils. - Eastern and Central Virginia. (Adv. from En.)

A. Alrins, L., is sail by l'ursh to grow on the Green and White Mountains, New England: but there is most probably some mistake about it.

\section{AGRIMÒNIA, Tourn. Agrimonx.}

Calyx-tube top-shaped, contracted at the throat, beset with hooked bristles above, induratea $\times$ fruit and cnclosing the 2 achenia; the limb 5 -cleft, closed after flowering. Petals 5. Stamens 12-15. Styles terminal. Seed suspended. - Perennial herbs, with interruptedly pinnate leaves, and yellow flowers in slender spiked racemes: bracts 3-cleft. (Nane a corruption of Aryemonia, of the same derivation as Argemone, p. 59.)

1. A. Eupatoria, L. (Соммоn Agrimony.) Leaflets 5-7 with minute ones intermixed, oblong-obovate, coarsely toothed; petals twice the length of the calyx. - Borders of woods: common. July-Sept. (Eu.)

2. A. parviflora, Ait. (SMart-Fuwrenen A.) Lraflets crowded, 11 19, with smaller ones intermixed, lanccolate, acute, decply and regularly cut-scrrate, ns well as the stipules; petals small. - Woods and glades, S. New York (C.F. Austin) to Virginia, Kentucky, and southward. July.

\section{D R Ỳ A S, L. DrYAs.}

Calyx open, flattish, 8-9-parted. Petals 8-9, large. Otherwise like Geum $\S$ Sieversia. - Dwarf and matted slightly shrubby plants, with simple toothed leaves, and solitary large flowers. (Name from Dryades, the nymphs of the Oaks, the foliage of the original species resembling oak-leaves in miniature.)

1. D. integrifolia, Vahl. Leaves oblong-ovate, slightly heart-shaped, with revolute margins, nearly entire, white-downy beneath, flowers white. White Mountains, New Hampshire, Prof. Prck, according to Pursh; not since met with : but it grows in Lower Canada. (Eu.)

\section{G E U M, L. Avens.}

Calyx bell-shaped or flattish, decply 5-cleft, usually with 5 small hractlets at the sinuses. Petals 5. Stamens many. Achenia numerous, heaped on a conical or cylindrical dry receptacle, the long persistent styles forming hairy or naked and strnight or jointed tails. Secel crect. - Perennial herhs, with pinnate or lyrate leaves. (Name from yeúw, to give an agreeuble fluvor, the roots being rather aromatic.) 
§1. GEUM proper. Styles jointed and bent near the middle; the lower portion persistent, naked, howked at the end after the deflexed ard mostly somewhat hairy upper joint fulls away: head of fruit sessile in the calyx: calyx-lobrs reflexed. (Flowers somewhat panicled at the summit of a leafy stem: achenia in our species glabrous or nearly so beluw, more or less bristly at the top or along the base of the style.)

* Petuls white or pale greenish-yellow, small, spatulate or oblong: stipules small.

1. G. álbum, Ginclin. Simouthish ur sofily pubescent; stem slender $\left(2^{\circ}\right.$ high $)$; root-leaves of 3-5 leaflets, or simple and rounded, with a few minute leaflets on the petiole below ; those of the stem 3-divided or lobed, or only toothed; petals about the length of the calyx; receptacle of the fruit densely bristly-hirsute. - Borders of woods, \&c. : common. May - Aug. - Too near the European G. urbanum; probably a white or whitish-flowered form of it.

2. G. Virginiànum, L. Bristly-hairy, especially the stout stem; lower and root-leaves pinuate, very various, the upper mostly 3-parted or divided, incised; petals inconspicuous, shorter than the calyx; receptucle of the fruit glabrous or nearly so. - Boriters of woods and low grommls: common. June-Aug. Ileads of fruit larger than in the preceding, on stonter lirsute peduncles.

* * P'als golden-ycllono, conspicuous, broudly oborate, uxceding the calyx: stipules larger and all deeply cut.

3. G. macrophýllum, Willd. Bristly-hairy, stout $\left(1^{\circ}-3^{\circ}\right.$ high) ; rootleaves lyrately and interuptedly pinnate, with the terminal leaftet very hirge and round-heurt-shaped; lateral leatlets of the stem-leaves $2-4$, minute, the terminal roundish, 3-cleft, the lobes wedye-form and roundud; receptacle of the fruit nearly naked. - Around the base of the White Mountains, New Ilampshire, also Northern Michigan, Illinois, and northwestward. June. (Eu.)

4. G. stríctum, Ait. Somewhat hairy $\left(3^{\circ}-5^{\circ}\right.$ high $)$; root-leaves interruptedly pinnate, the leaflets wedge-obovate; leaflets of the stem-leaves $3-5$, rhombic-ovute or oblong, acute; receptacle of fruit downy. - Moist meadows: common, especially northward. July, Aug. (Eu.)

§ 3. STÝLIPUS, Raf. Styles smooth: head of fruit conspicuously stalked in the calyx: bracilets of the calyx none: otherwise nearly as $\$ 1$.

5. G. vérnum, T'orr. \& Gr. Somewhat pubescent ; stems ascending, fewleaved, slender; root-leaves roundish-heart-shaped, 3-5-lobed, or some of them pinnate, with the lobes cat; petals yellow, alout the length of the calyx ; recepr fitaclo smooth. (Stylipus vermus, Kief.) - 'Thickets, Olio to Illinois and Kentucky. April - June.

§3. CARYOPIIYLATA, Tourn. Style jointed and bent in the middle, the upper joint phumose: flowers large: calyx erect or spreculing: petals ereet.

6. G. rivale, L. (Water, or Pumele Avens.) Stems nearly simple, several-flowered $\left(2^{\circ}\right.$ high $)$; root-leaves lyrate and interruptedly pinnate; those of the stem few, 3 -foliolate or 3-lobed; petals dilated-olovate, retuse, contracted into a claw, purplish-orange; head of fruit stalked in the calyx. - Bogs und wet meadows, New England to Penn., Wisconsin, and nortliward. May. - Blossoms nodding, but the feathery fruiting heads upright. Calyx brown-purple. (Eu.) 
84. SIEV ERSIA, Willd. Style not jointed, wholly persistent and straight: hend of finit sessile : flowers large: calyx erect or spreading. (Flowering stems simple, and bearing only bracts or small leaves.)

7. G. triflorum, P'ursh. Low, softly-hairy; root-leaves interruptedly pinnate; the leaflets very numerous and crowded, oblong-wedge-form, deeply cut-toothed; flowers 3 or more on long peduncles; bructlets linear, longer than the purple calyr, as long as the oblong purplish erert petals ; styles very long $\left(2^{\prime}\right)$, strongly plumose in finit - Rocks, N. New Hampshire and N. New York to Wisconsin and westward: rare. April-June.

8. G. radiatum, Michx. IIrsutely hairy or smoothish; root-leaves roundedkidney-shaped, radiate-veined $\left(2^{\prime}-5^{\prime}\right.$ broal $)$, doubly or irregularly cut-toothed and obscurely 5-7-lobed, also a set of minute lenflets down the long petiole; stems $\left(8^{\prime}-18^{\prime}\right.$ high) 1-5-flowered; bractlots minute; petals yellow, round-obovate and more or less obcordate, excecding the calyx ( $\frac{1}{2}$ long), spreading; styles naked except the base. (High mountains of Carolina.)

Var. Péckii. Nenrly glabrous, or the stalks and veins of the leaves sparsely hirsute. (G. Peckii, Pursh.) - Alpine tops of the White Mountains of New Hampshire. July-Sept.

\section{W A LDSTEI N I A, Willd. (Comarópsis, DC.)}

Calyx-tube inversely conical; the limb 5 -cleft, with 5 often minute and decidnous bructlets. Petals 5. Stamens many, inserted into the throat of the calyx. Achenia 2-6, minutely hairy; the terminal slender styles deciduous from the base by a joint. Seed erect. - Low perennial herbs, with chiefly radical 3-5lohed or divided leaves, and small yellow flowers on bractod scapes. (Named in honor of Francis von Wuldstein, a German botanist.)

1. W. fragarioldes, Tratt. (Barren Strawberry.) Low; leaflets 3, broadly wedge-form, cut-tonthed ; scapes several-flowered; petals longer than the calyx. (1)alibarda frugarinides, Michx.) - Wooded hillsides, common northward, and southward along the Alleghanies. Junc.

\section{S I B B Á L D I A, L. Sibbatdia.}

Calyx flattish, 5-cleft, with 5 bractlets. Petals 5, lincar-oblong, minute. Stamens 5 , inserted alternate with the petals into the margin of the woolly disk which lines the base of the calyx. Achenia 5-10: styles lateral. - Low and lepressed mountain perennials, - in fact only reduced Potentillas. (Dedicated to Dr. Robert Sibbald, Prof. at Edinburgh at the close of the 17th century.)

1. S. procúmbens, L. Leaflets 3 , wedge-shaped, 3 -toothed at the apex; petals yellow. - Alpine summits of the White Mountains of New Hampshire, nnd northward. (Eu.)

\section{POTENTítLA, L. Cinque-foll. Five-finger.}

Calyx flat, deeply 5-cleft, with as many bractlets at the sinuses, thus appearing 10-cleft. Petals 5, usually roundish. Stamens many. Achenin many, collected in a head on the dry mostly pubescent or hairy receptacle: styles lat. eral or terminal, deciduous. Radicle superior. - Herbs, or rarely shrubs, with 
compound leaves, and solitary or cymose flowers: their parts rarely in fours. (Name a kind of dininutive from potens, powerful, alluding to the reputed medicinal power, of which in fact these plants pussess very little, being merely mild astringents, like the rest of the tribe.)

\$1. Style terminal, or attuched above the middle of the ovary: achenia glabrous. * Annuals or bienniuls: petuls pale yellow, small, not exceeding the calyx: receptude iो globular, ovoid, or even oblong in fruit.

1. P. Norvègica, L. Hairy, erct, branched above; leaves pulmately 3foliolute; leaflets ubuvate-oblong, cut-tuothed. — Fichls: comnou, especially northward. A homely weed. (Èu.)

2. P. paradóxa, Nutt. Somewhat pubeseent, spreading or decumbent, branched; leaves pinnate; leaflets 5-9, obovate-oblong, cut-toothed; achenia with a thick appeudage at the base. - Banks of the Ohio and Mississippi. Shore of L. Ontario, J. A. Puine; probably an immigrant from the West.

* * Perctmial herbs: petals yellow, commonly longer than the calyx. - Low: leaves palmute, of 3 or 5 leuflels.

3. P. frígida, Vill. Dwaif $\left(1^{\prime}-3^{\prime} h_{i g} h^{\prime}\right)$, tufted, villous when young, stems or scanes mostly 1-flowered; hafles 3, Lrvadly wedge-ohocate, deeply cut into 5-7 oblong approximate teeth. (L'. Roblinsianta, Ouhes.)-Alpine summits of the White Mlountains of New IIampshire (Rubbins, Tuckerman, \&c.). July. - Less villous with age and smaller-flowered than P. frigida of the Alps, but agreeing closer with it than with $\mathbf{P}$. minima, which probably is only another form of the same species. (Lu.)

4. P. Canadénsis, L. (Common Cinque-foil or Five-Finger.) Low or dwarf, silky-hairy; st.ms decumbent, prostrate, or ut length creeping; poduncles axillary, 1-flowerel; ; leaflts 5, obovate-wedge-form, cut-toothed lowards the upex. -Dry soil. A pril-July: producing summer runners (P. sarmentìsa, M Mull.).

Var. símplex, Torr. \& Gr. Less hairy and greener, larger, the ascending stems $\left(1^{\circ}-2^{\circ}\right.$ long, seldom if ever creeping) from a thicker and harder caudex : leaflets obovate-oblong, sometimes almost glabrous. (P. simplex, M Fichx.) Meadows or moister soil. Mity - Sept. - Usually appearing distinct.

5. P. argéntea, I. (Silvery Crogé-roil.) Steins ascending, prniculately branched at the summit, many-fluwered, white-woolly; keaftets, wedge-oblonir, almost pinuatifid, entire towarls the hase, with revolute margins, green above, white with silvery woul bencath. - Dry larren ficlds, \&c. June - Sept. (Eu.)

\section{+ + Leaves pinute, of $3-9$ lectuflets.}

6. P. Pennsylvánica, 1. Stems erect $\left(5^{\prime}-18^{\prime}\right.$ high $)$, hairy or woolly, cymose at the summit, many-flowered; leaflets 5-9, oblong, obtuse, pinuatifid, silky or downy with white hairs, especially beneath, the upper ones larger and crowded; petals seareely longer than the calyx. - Pennsylvania? New IIanpshire (Isle of Shootls, Moddins), Maine (Cape Elizabeth, C. J. Simragne), N. Wisconsin, and northwestward. July-Aug.

\$ 2. Style deeply lateral: prtals yellow or white, deciluons.

* Acheniu glabions: style thichened upeords: receptucle conioal in fruit.

7. P. argùta, Pursh. Stem erect and stout $\left(1^{\circ}-4^{\circ}\right.$ high, $)$ brownish-hairy, clammy above; leaves pinnate, of $3-9$ oval or ovate cut-serrate leufluts, downy 
underneath ; flowers cymose-clustered ; petals yellowish or whitish ; disk thick and glandular. - Rocky hills : common northward and westward. July.

* Achenia (at least below) and the convex rereptacle villous.

8. P. Anserina, L. (Silver-Weed.) Herbaceons, ereeping with slender runners; leaves all radical, pinnate; leaflets $9-19$, with minute pairs interposed, oblong, pinnatificl-serrate, mostly green and nearly smooth ahove, silvery-white with silky doun underneath; stipules many-cleft; flowres solifury (yollow), on long scape-like peduncles. - Brackish marshes, river-banks, \&c., New England to Penn., Wisconsin, and northward. June-Sept. (Eu.)

9. P. fruticosa, I. (Sinumby Cinque-rorr.) Stem erect, shrubly $\left(2^{\circ}-\right.$ $4^{\circ}$ high), very much branched; leaves pinnate; leaftets $5-7$, closely crowded, oblong-lanccolate, entire, silky, especially beneath; stipules scale-like; flowers numerous (yellow), terminating the branchlets. - Wet grounds : common northwards. June-Sept. (Eu.)

10. P. tridentàta, Ait. ('Three-tootmed C.) Stems low $\left(4^{\prime}-6^{\prime}\right.$ high), rather woody at the base, tufted, ascending, cymosely several-flowered; leaves palmate; leaftets 3, wedge-oblong, nearly smooth, thick, coarsely 3-toothed at the apex; petals white; achenia and receptacle very hairy. - Coast of New England, from Cape Cod, and monntain-tops from the Alleghanies, northward: also shores of the upper Great Lakes. June.

§3. Styles moderately lateral: petals (shorter than the calyx, ovatc-lanceolate) and filaments more or less persistent: disk thick and hairy: achenia glabrous : receptacle hairy, convex, at length large and spongy. (Comarum, L.)

11. P. palústris, Scop. (Marsn Five-Finger.) Stems ascending from a creeping perennial base $\left(1^{\circ}-2^{\circ}\right.$ high) ; leaves pinnate, of $5-7$ lanceolate or oblong crowded scrrate leaflets, whitish bencath; flowers somewhat cymose; calyx ( $1^{\prime}$ broad) dark purple inside; petals purple. (Cómarum palıstre, L.) Cool bogs, New England to Penn., Illinois, and northward. June-Aug. (Eu.)

\section{F R A G À R I A, Tourn. Strawberri.}

Flowers nearly as in Potentilla. Styles deeply lateral. Receptacle in fruit much enlarged and conical, becoming pulpy and scarlet, bearing the minute dry achenia scattered over its surface.-Stemless perennials, with runners, and with white cymose flowers on scapes. Leaves radical : leaflets 3, olovate-werge-form, coarsely serrate. Stipules cohering with the base of the petioles, which with the scapes are usually hairy. (Name from the fragrance of the fruit.) - Flowering in spring. (The species are indiscriminately called WILD STRAwberRY.)

1. F. Virginiana, Ehrhart. Achenia imbedded in the deeply pitted fruiting recrptacle, which usually has a narrow neck; calyx becoming erect after flowering and connivent over the hairy receptacle when stcrile or unfructificd; lenflets of a firm or coriaceous texture. (F. Canadensis, Michx.) - Moist or rich woodlands, ficlds, \&c. - In the true F. Virginiana, the hairs of the scopes, and especially of the perlicels, are silky and appressed. It is the original of the Virginian Scarlet strawherrics.

Var. Illinoénsis (F. Grayana, Vilmorin, F. Illinoensis \& F. Iowensis, 
Prince) is a coarser or larger plant, perhaps a distinct species, the flowers more inclined to be polygamo-dicecious, the villous hairs of the scape and pedicels widely spreading, as in F. clatior and $\mathrm{F}$. collina, which it seems to represent in this country. - Common in richer soil, from W. New York to Illinois and beyond the Rocky Muuntiains. The supposed original of Hovey's Seedling, Boston Pine, and other cultivated varieties.

2. F. vésca, L. Acheniu superficial on the glubrous conical or hemisphericul fruiting receptacle (not sunk in pits); calyx remaining sproading or reflexed; hairs on the scape mostly widely spreading, on the pedicels appressed; leaftets thin, even the upper face strongly marked by the veins. - Fields and rocky places: common; certainly indigenous northward. (Eu.)

3. F. Indics, L. (or Duchésnea fragarioides, Smith), - which differs from the true Strawberries in having leafy runners, a calyx with incised leafy bractlets larger than the sepals, yellow petals, and insipid fruit, - has sparingly established itself in copses around Philadelphia (Charles E. Smith, \&c.), and in tho Southern States. (Adv. from Ind.)

\section{DALIBÁRDA, L. Dalibarda.}

Calyx deeply 5-6-parted, 3 of the divisions larger and toothed. Petals 5, sessile, deciduous. Stamens mamy. Ovaries 5-10, becoming nearly dry seedlike drupes: styles terminal, deciduous. - Low perennials, with creeping and densely tufted stems or routstocks, and roundish-heart-shaped crenate leaves on slender petioles. Flowers 1 or 2, white, on scape-like peduncles. (Named in honor of Thomas Lulibard, a French botanist of the time of Linnæus.)

1. D. rèpens, L. Downy; sepals spreading in the flower, converging and enclosing the fruit. - Wooded bauks: common northward. June-Aug. In aspect and foliage resembling a stemless Violet.

\section{RU B Ù S, Tourn. Bramble.}

Calyx 5-parted, without bractlets. Petals 5, deciduous. Stamens numerous. Achenia usually many, collected on a spongy or succulent receptacle, becoming small drupes: styles nearly terninal. - Perennial herbs, or somewhat shrubby plants, with white (rarely reddish) flowers, and edible fruit. (The Roman name, kindred with ruber, red.)

§1. RASPBERRY. Fruit, or collective mass of drupes, fulling off whole from the diy receptacle when ripe, or of few grains which fall separately.

* Leaves simple: flowers large: prichles none: fiuit and receptacle flut and broad.

1. R. odoràtus, I. (I'virife Flowerixg-Raspierry.) Stem shiubly $\left(3^{\circ}-5^{\circ}\right.$ high $)$; brancless, stalks, and calyx bristly with glandular clanmy hairs; leaves 3 -5-lobed, the lobes pointed and minutely toothed, the middle one prolonged; peduncles many-tlowered; calyx-lobes tipped with a long narrow appendage; petals rounded, purple rose-color ; fruit reddish. - Dells, \&c. : common northward. June-Aug. - Flowers showy, 2 ' broad.

2. R. Nutkànus, Moçino. (Wnite F.) Cilandular, scarcely bristly; leaves almost equally 5-lubed, coarsely toothed; peduncles few-fluwered; peluls oval, white (R. parvillorus, Nutt.) - Upper Michigan, and westward. 
3. R. Chamæmorus, L. (Cloun-Berry.) Herbaceous, low, diocious; stem simple, 2-3-leavel, 1-flowered; leaves roundish-kidney-form, somewhat 5lobed, serrate, wrinkled; calyx-lobes pointless; petals obovate, white; fruit of few grains, amber-color. - White Mountrins of New IIampshire at the limit of trees: also on the coast at Lubeck, Mainc, and northward. (Eu.)

* Leuflets (pinurtely) 3-5: petuls smull, erect, white.

+ Stems annut, herbureous, not prickly: fiuit of fow separete grains.

4. R. triflorus, Richardsom. (1) wanr Rasrmskny.) Stems nscending $\left(6^{\prime}-12^{\prime}\right.$ high) or trailing; leaflets 3 (or pedately 5), shombic-ovate or ovatelanceolate, acute at both ends, coarsely doubly serrate, thin, smooth; peduncle 1-3-flowered. - Wooded hillsides, New England to P'ennsylvania, Wisconsin, and northward. June. - Sepals and petals often 6 or 7 .

++ Stems biennial and woody, prickly: receptacle oblong: fruit hemispherical.

5. R. strigosus, Michx. (WiLv Red Raspberry.) Stems upright, and with the stalks, \&c. beset with stiff straight bristles (or a few becoming weak hooked prickles), glandular when young, somewhat glaucous; leaflets 3-5, oblong-ovate, pointed, cut-serrate, whitish-downy underneath; the lateral ones sessile ; petals as long as the scpals; fruit light red. - Thickets and hills : common everywhere, especially northward. June, July. - Fruit ripening all summer, more tender than that of the Garden or European Raspberry (R. IDisus), which it too closely resembles.

6. R. occidentàlis, I. (Brack Raspberry. Timmbererry.) Glancous all over; stems recurved, armed like the stalks, \&c., with hooked prickls, not bristly: leaflets 3 (rarely 5), ornte, pointed, coarscly doubly serrate, whiteneddowny underneath; the lateral ones somewhat stalked; petals shorter than the sepals; fruit purple-black (rarely a whitish varicty), ripe early in July. - Very common northward, especially where ground has been burned over.

§ 2. BLACKBFRRY. Fruit, or collestive drupes, not sparating from the juicy prolonged receptacle, mostly ovate or oblong, blackish.

7. R. villosus, Ait. (Common or Higi Blackrerry.) Shrubby (10$6^{\circ}$ high), furrowed, upright or reclining, armed with stout curved prickles; branchlets, stalks, and lower surface of the leaves hairy and glandular; leaflets 3 (or pedately 5), ovate, pointed, unequally scrrate; the terminal ones somewhat heart-shaped, conspicuously stalked; flowers racemed, numerous; bracts short; sepals linear-pointed, much shorter than the obovate-oblong spreading petals. Var. 1. FRONDósus : smoother and much less glandular; flowers more corymhose, with leafy bracts ; petals roundish. Var. 2. num Fusus : trailing, smaller; peduncles few-flowered. - Borders of thickets, \&c. : common. May, June : the plensant large fruit ripe in $\Lambda$ ug. and Sept. - Plant very variable in size, aspect, and shape of the fruit; - the varieties connecting with

8. R. Canadénsis, L. (Low Blckrerry. Dewrerry.) Shrubby, extensively trailing, slightly prickly; leaflets 3 (or pedately 5-7), oval or ovatelanccolnte, mostly pointed, thin, nearly smonth, sharply cut-sermte ; flowers ra-

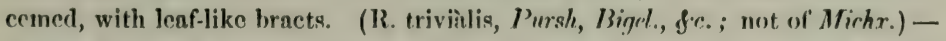
Rocky hills and copses: common. May; ripening its excellent fruit earlier than No. 7. 
9. R. híspidus, L. (Running Swamp-Blackberry.) Stems slender, scarcely uoody, extensively procumbent, beset with small reflexed prickles; leaflets $\mathbf{3}$ (or rarcly pedatcly 5), smooth, thickish, mostly persistent, obovate, obtuse, coarsely serrate, entire towards the base; peduncles leufless, several-flowered, often bristly; flowers small. (R. obovàlis, Michx. R. sempérvirens and R. setòsus, Bigelow.) - Low woods: common northward. June. - Flowering shoots short, ascending ; sterile ones forming long rumners. Fruit of few grains, red or purple, sour.

10. R. cunoifolius, Pursh. (Saxd BLackiserkx.) Shrubly $\left(1^{\circ}-3^{\circ}\right.$ high), upright, armed with stout recured prickles; branchlets and lou:er surfuce of the leaves whitish-uvolly; leallets 3-5, wedge-obovate, thickish, serrate ubove; peduncles 2-4-1luwered; pelats large. - Sindy woods, S. New York, Penu. and southward. May - July; ripening its well-flavored black fruit in August.

11. R. triviàlis, Michı. (Low Busu-Bздскиекит.) Shrubly, procumbent, bristly and prickly ; leaves evergreen, coriaccous, neaily glabrous; leaflets 3 (or pedattely 5), ovate-oblong or lanceolate, sharply serrate; peduncles 1-3-flowered; petals large. - Sandy soil, Virginia and southward. March-May.

\section{RÒSA, Tourn. Rose.}

Calyx-tube urn-shaped, contracted at the mouth, becoming fleshy in fruit. Petals 5, obovate or obcordate, inserted, with the many stamens, into the elge of the hollow thin disk that lines the ealyx-tube and within bears the numerous pistils below. Ovaries hairy, becoming bony achenia in fruit. - Shrubly and prickly, with odd-pinnate leaves, and stipules coliering with the petiole: stalks, foliage, Sc. often bearing aromatic glands. ('The ancient Latin name.)

* Styles cohering in a protruding column, as long as the stamens.

1. R. setigera, Michx. (Cuming or P'ranite Rose.) Stems climbing, armed with stunt naily straight prickles, not bristly; leciflets 3-5, ocate, acute, sharply serrate, smooth or downy beneath; stalks and calyx glandular; flowers corymbed; sepals pointed; petals deep rose-color changing to white; fruit (hip) globular. - Borders of prairies and thickets, W. New York (indigenous?) to Wisconsin and southwestivard: also cultivated. July.-The only Aucrican climbing rose, or with united protruding styles: strong shoots growing $10^{\circ}-20^{\circ}$ in a season.

* * Styles separute, included in the culyx-tube: petals rose-color.

2. R. Carolina, L. (Swasi Rose.) Stems tall $\left(4^{\circ}-7^{\circ}\right.$ high), armed with stout hooked prichles, not bristly; leaftets 5-9, elliptical, often acute, dull above and pale beneath; stipules narrow; flowers numerous, in corymbs; peduncles and calyx (with leaf-like appendiges) glandular-bristly; fruit (hij) depressedglobular, somewhat bristly. - Low grounds: common. June-Sept.

3. R. lùcida, Ehrhart. (I) wakr Wily-liose.) Stems $\left(1^{\circ}-2^{\circ}\right.$ high), armed with unequal brislly prickles, which are mostly decidusus, the stouter persistent ones nearly straight, slender; leaflts 5-9, alliptical or oblong-lanciolate, shining above, sharply scrate; stipules bioud; pedunctes 1-3-flouered, and with the appendaged calyx-lobes glandular-bristly ; fruit depressed-globular, smouth when ripe. - Common in dry soil, or along the borders of swamps. MayJuly. - R. nítida, Willd, is a smooth and narrow-leaved form. 
1 4. R. blánda, Ait. (EARLx Wild-Rose.) Nearly unarmed, or with ( $\rightarrow$ scattered straight deciduous prickles $\left(1^{\circ}-3^{\circ}\right.$ high); leaflets $5-7$, oval or oblong, n' obtuse, pale on both sides and minutely downy or houry beneath, serrate; stipules large; flowors 1-3, the pedunclos and culyx-tulie smouth and glaurous ; fruit globose, crowned with the persistent erect and connivent entire calyx-lobes. Rocks and banks, Vermont to P'enn. and Wisconsin, chiefly northward. May, June. - Petals light rose-color.

5. R. rubiginósu, L. (Swret-Brier.) Climbing high; prickles numerous, the larger ones strong and hooked, the smaller awl-shoped; lenflets doubly serrate, rounded at the base; downy and clothed with fragrant misset glands beneath; fruit pear-shaped or obovate, crowned with the mostly persistent calyx-lobes. - Roadsides and thickets. June-Aug. (Nat. from Eu.)

6. R. micrintin, Smith. (Smaller-fl. S.) Prickles uniform and hooked; fruit elliptical and ovate; calyx-lohes deciduous; flowers smaller: otherwise us the last: a mere variety of it. - E. New England to Virginia. (Nat. from Eu.)

\section{CRA T \&}

Calyx-tube urn-shaped, the limb 5-cleft. Petals 5, roundish. Stamens many, or only 10-5. Styles 1-5. Pome drupe-like, containing 1-5 bony 1-seeded stones. - Thorny shrubs or small trees, with simple and mostly lobed leaves, and white (rarely rose-colored) blossoms. (Name from крáros, strength, on account of the hardness of the wood.)

\section{* Corymbs many-flowered.}

+ Fruit very small, depressed-globose (not lurger than peas), bright red: flowers small : calyx-teeth short and broud: styles 5 : plants glabrous (except No. 1) and glandless.

1. C. Pyrachntina, Pers. (Evergneen Thorn.) Lenves evergreen, shining (1'long), oblong or spatulate-lancoolate, crenulate; the short petioles and young branchlets pubescent; corymbs small. - Shrub, spontancous at Washington, and near Philadelphia, Isanc Murtindale. (Adv. from En.)

2. C. spathulata, Michx. Leaves thickish, shining, but dcciduous, spatulate or oblanceolate, with a long tapering base, crenate above, rarely cut-lobed, nearly sessile. - Virginia and soutlıward. May. - Shrub $10^{\circ}-15^{\circ}$ high.

3. C. cordata, Ait. (W Asnington Thonn.) Leaves brondly ovate or triangulur, mostly truncate or a little heart-shaped at the base, on a slender petiole, variously 3-5-cleft or cut, serrate. - Virginia, Kentucky, and southward. June. - Trunk $15^{\circ}-25^{\circ}$ high.

++ Fruit small $\left(t^{\prime}-\mathbf{b}^{\prime}\right.$ long), ovoid, deep red: flowers rather large: styles $1-3$.

4. C. Oxpachntin, L. (Englisi Hawtuonn.) Smooth; leaves obovate, cut-lobed and toothed, wedge-form at the base; calyx not glandular. May.More or less spontaneous as well as cultivated. ( $\mathrm{\Lambda} d v$. from Eu.)

5. C. apiifolia, Michx. Sottly pubeseent when young; leaves roundish, with a broad truncate or slightly heart-shaped base, pinnalfly 5-7-cleft, the crowded divisions ent-lobed and sharply serrate; petioles slender; calyx-lobes glandular-toothed, slender. - Virginia and southward. March, April. 
++ Fruit large $\left(\frac{1^{\prime}}{2}-\xi^{\prime}\right.$ long), red: flowers large: styles and stones of the fruit even in the sume species $1-3$ (when the fruit is ovoid or pear-shaped), or 4-5 (when the fruit is glubulur): slipules, culyx-teeth, bracts, fcc. often beset with glands.

6. C. coccínea, L. (Scarlet-fruited Thors.) Glabrous throughout; leaves thin, roundish-ovate, sharply toothed and cut, or somewhat cut-lobed, usually abrupt at the base, on slender petivles; flowers white, often with a rosy tinge (3'broad); fruit bright corcal-red, ovoid ( $\frac{1}{2}$ broad), scarcely edible. Thickets and rocky banks : common. May. - A low tree.

7. C. tomentosa, L. (Bцack or Pear Thons.) Downy or villouspubescent at least when young on the peduncles, calyx, and lower side of the leaves; leates thickish, rather large, oval or ovate-oblong, sharply toothed and often cut, abruptly narrowed at the base into a somewhat maryined petiole, the upper surface more or less furrowed along the veins; flowers large (often 1, broad), white ; fiuit scarlet or orange, large $\left(3^{\prime}-\frac{3}{4}\right.$ broad), globular or somewhiat pear-shaped, edible. - Thickets : conmon. May, June. - A tall shrub or luw tree, of many varieties, of which the following are the most marked.

Var. pyrifolia. Leaves sparingly pubeseent bencath when young, soon glabrous, smooth above, and shining often slightly cut-lobed ; fruit large, brightcolored, sparingly dotted, of a pleasant flavor. (C. pyrifölia, Ait.)

Var. punctata. Leaves rather small, mostly wedge-obovate, with a longer tapering and entire base, unequally toothed above, rarcly cut, villous-pubescent when young, smouth but dull wheu old, the numerous veins more strongly impressed on the upper surface and prominent underneath ; fruit globose, usually dull red and yellowish with whitish dots. (C. punctata, Jacq.)

Var. móllis. Lcaves rounded, abrupt or somewhat heart-shaped at the base, soft-downy buth sides, or at least beneath, very sharply doubly-toothed and cut; fruit often duwny, dull red. (C. subvillosa, Sclirader. C. coccinea, var. ? mollis. Torr. \& Gruy.) - Michigan, Illinois, and southwestward.

8. C. Crus-gálli, L. (Cocksper Thons.) Glubrous; leaves thick, shining above, wedge-abovate and oblunceolate, tapering into a very short petiole, serrate above the middle; fruit globular, bright-red ( $f^{\prime}$ broad). - Thickets. June. - Slurub or tree $10^{\circ}-20^{\circ}$ high, with firm dark-green leaves very shining above, and slender thorns often 2 ' long. This is our best species for hedges.

* Corymbs simple, few-(1-6-) flowered: calyx, bracts, \&c. glandular.

9. C. flàva, Ait. (Suмrer Haw.) Somewhat pubescent or glabrous; leaves wedlye-obocate or rhombic-obovate, narrowed into a glandular petiole, unequally touthad and somewhat cut above the middle, vather thin, the teeth glandular; styles 4-5; fruit somewhat pear-shaped, yellowish, greenish, or reddish $\left(\frac{1}{2}{ }^{\prime}-\frac{2}{3}{ }^{\prime}\right.$ broal $)$. - Sandy soil, Virginia and southward. May. - Tree $15^{\circ}-20^{\circ}$ high, with rather large flowers, $2-6$ in a corymb.

Var. pubéscens. Downy or villous-pubescent when young; leaves thickish, usually obtuse or rounded at the summit. (C. elliptica, dit. C. glandulòsa, Michx. C. Virginica, Lodd.) - Virginia and southward.

10. C. parvifolia, Ait. (DWArf Thorn.) Downy; leaves thick, obovatesputulate, crenate-toothed $\left(\frac{1}{2}{ }^{\prime}-1 \frac{1^{\prime}}{2}\right.$ long $)$, almost sessile, the upper surface at length 
shining; flowers solitary or 2-3 together on very short peduncles; calyx-lobes as long as the petals; styles 5; fruit globular or pear-shaped, yellowish. - Sandy soil, New Jersey to Virginia and southward. May. - Shrub $3^{\circ}-6^{\circ}$ high.

\section{Pỳ R U S, L. Pear. Apple.}

Calyx-tube urn-shaped, the limb 5-cleft. Petals roundish or obovate. Stamens numerous. Styles 2-5. Pome fleshy or berry-like; the $2-5$ carpels or cells of a papery or cartilaginous texture, 2-sceded. - Trees or shrubs, with handsome flowers in corymbed cymes. (The classical name of the Pear-tree.)

§ 1. MALUS, Tourn. (ArpLe.) Leaves simple: cymes simple and umbel-like: pome fleshy, globular, sunk in at the attachment of the stulk.

1. P. coronaria, L. (American Crab-Aprle.) Leaves ovate, often rather heart-shaped, cut-serrate or lobed, soon glabrous; styles woolly and united at the base. - Glades, W. New York to Wisconsin and southward. May. - Tree $\mathbf{2 0}^{\prime}$ high, with large, rose-colored, fragrant blossoms, few in the corymb, and fragrant, greenish fruit.

2. P. angustifolia, Ait. (NARRow-Leaved C.) Leaves oblong or lanceolate, often acute at the base, mostly toothed, glabrous ; styles distinct. - Glades, from Pennsylvania southward. April. - Perhaps a variety of No. 1.

§ 2. ADENÒRHACHIS, DC. Leaves simple, the mid-rib glandular along the upper side: cymes compound: styles united at the base: fruit berry-like, small.

3. P. arbutifblia, L. (Choke-Berry.) Leaves oblong or obovate, finely serrate; fruit pear-shaped, or when ripe globular. - Var. 1. ERYTHRocARPA, has the cyme and leaves beneath woolly, and red or purple fruit. Var. 2. MEIANOCARPA, is nearly smooth, with black fruit, - Damp thickets: common. May, June. - Shrub $2^{\circ}-10^{\circ}$ high. Flowers white, or tinged with purple.

§ 3. SÓRBUS, Tourn. Laves odd-pinnale, with rather numerous leaflets: cymes compound: styles siparate: pome berry-like, smull.

4. P. Americana, DC. (Амйichn Mountain-Asir.) Nearlyglabrons or soon becoming so; leaflets $13-15$, lanceolate, taper-pointed, sharply serrate with pointed teeth, bright green; cymes large and flat; berries globose, not larger than peas; leaf-buds pointed, glabrous and somewhat glutinous. - Swamps and mountrin-woods, Maine to Penn. and Michigan, and southward along the whole length of the Alleghanies. June. ( $\mathrm{P}$. microcápa, DC.) - Tree or tall shrub, with leaflets rather shining above and scarcely pale underneath, the rhachis and petiole reddish and elongated: prized in cultivation for the autumnal clusters of bright-red berries.

5. P. sambucifolia, Cham. \& Schlecht. Leaflets oblong. oval, or lanceovate, mostly obtuse or abruptly short-pointed, serrate (mostly doubly) with more spreading teeth, often pale beneath; cymes smaller; flowers and berries larger, the latter ( 4 " broad) when young ovoid, at length globose; leaf-buds sparingly hairy: otherwise nearly as the preceding. (Sorbus aucuparia, var. $\boldsymbol{\beta}$. Mirhx.) - Along the northern fronticrs of the United States, northward and westward to the Pacific, \&c. Perhaps passes into No. 4 : it is sometimes cultivated for it, and nearly connects it with

L \& M-27 
P. aucuparia, Gartn., the Elropean Mountain Asi or Rowan-tree, the one more conmonly planted in grounds: it hats paler, oblong, and obtuse leaflets, their lower surfice downy, larger globose berries, and blunter and tomentose leaf-buds.

\section{A MELÁ NCHIER, Medic. June-rerry.}

Calyx 5-cleft. Petals oblong, elongated. Stamens numerous, short. Styles 5, united below. Ovary 5-eelled, each cell 2-ovuled; but a projection grows from the back of each, and forms a false partition; the berry-like pome thus 10-celled, with one seed in cach cell (when all ripen) : partitions cartilaginous. - Small trees or shrubs, with simple sharply scrrated leaves, and white flowers in racemes. (Ameluncier is the popular nane of $\mathbf{A}$. vulgaris in Savoy.)

1. A. Canadénsis, 'Torr. \& Gray. (Sind-isush. Service-вknky.) Calyx-lobes triangular-lance-forn ; fruit globular, purplish, edible (sweet, ripe in June). - Along streams, \&c. : common, especially northward. April, May. it - Varies exceelingly; the leading forms are, -

Var. Botryàpium; a tree $10^{\circ}-30^{\circ}$ high, nearly or soon glabrous; leaves ovate-oblong, sometimes heart-shaped to the base, pointed, very sharply serrate; flowers in long drooping racemes; the oblong petals 4 times the length of the calyx. (I'yrus Botryapium, Willd.)

Var. oblongifolia; a smaller tree or slurub; leaves oblong, beneath, liko the branchlets white downy when young; racemes and petals shorter.

Var. rotundifolia; with broader leaves and smaller petals than in the first variety; racemes 6 - 10 -flowered.

Var. alnifolia; shrub, with the roundish leaves blunt or notehed at both ends, serrate towards the summit; racenes dense and many-flowered. - Chiefly in the Western States and westward.

Var. oligocárpa; shrub, with thin and smooth narrowly oblong leaves, and 2-4-flowered racemes, the broader petals scarecly thrice the length of the calyx. - Cold and deep mountain swanps, northward.

\section{Order 34. Cakycantimàceas. (Calycantuus Family.)}

Shrubs with opposile entire leaves, no stipules, the sepals and petals similar and indefinite, the anthers adnate and extrorse, and the cotyledons corwolute: the fruil like a rosc-hij. Chicfly represented by the genus

\section{Calycá NThus, L. Carolina Allspice. Siweet. Scented Sillub.}

Calyx of many seprals, united below into a fleshy inversely conical cup (with some leaf-like bractlets growing fiom it); the lobes lanceolate, mostly colored like the petals; which are similar, in many rows, thickish, inserted on the top of the closed calyx-tube. Stanens numerous, inserted just within the petals, short; some of the inner ones sterile (destitute of anthers). Pistils several or many, enclused in the calyx-tube, inserted on its base and inner face, resembling those of the Rose; but the enlarged hip dry when ripe, enclosing the uchenia 
- The lurid purple flowers terminating the lenfy branches. Bark and folinge aromatic; the crushed flowers exhaling more or less the fragrance of strawber-

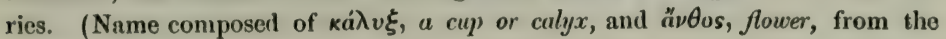
closed cup which contains the pistils.)

1. C. flóridus, L. Leaves oval, sọf-downy underneath. - Virginia? and southward, on hillsides in rich soil. Common in gardens. April-Aug.

2. C. løvigatus, Willı. Leaves oblong, thin, either blunt or taper-pointed, bright green and glabrous or nearly so on both sides, or rather pale beneath ; flowers smaller. - Mountains of Franklin Co., Penn. (Prof. Porter), and southward along the Alleghanies. May-Aug.

3. C. glaùcus, Willd. Leaves oblong-ovate or ovate-lanceolate; conspicuously taper-pointerl, glaucous-white bencuth, roughish alove, glabrous, large $\left(4^{\prime}-7{ }^{\prime}\right.$ long); probably a variety of the preceding. - Virginia? near the mountains and southward. May-Aug.

\section{Order 35. Saxifràgacea. (Saxifrage Family.)}

IIerbs or shrubs, of various aspect, distinguishable from Rosaceæ by having copious albumen in the seeds, opposite as well as alternate leaves, and usually no stipules when the leaves are alternate; the stamens mostly definite, and the carpels commonly fewer than the sepals, either separate or partly so, or all combined into one compound pistil. Calyx either free or adherent, usually persistent or withering away. Stamens and petals almost always inserted on the calyx. Ovules anatropous. - A large family, to which Parnassia, formerly associated with Drosera, is commonly referred, - now made to include Ribes also.

Tribe I. GROSSULARIEAE. Shrubs, with alternate and palmately veined and lobed leaves : stlpules none or united with the hase of the petiole. Calyx-tube coherent with the one-celled ovary, which has 2 parictal placentro and forms a many-seeded berry. Seed-coat externally gelatinous. Fmbryo minute at the base of the hard albumen.

1. Ribes. Character of the tribe. Stamens and small petals 5 .

Tribe II. FSCALLONIEA. Shrubs or trees, with alternate and simple pinnately veined leaves, and no stipules. Ovary 2-5-celled.

2. Itea. Calyx 5-cleft, free from the 2-celled ovary, which becomes a septicidal pod.

Tribe II. HYDR ANGIER. Shrubs or trees, with opposite simple leaves, and no stipules. Ovary 2-5-celled; the calyx coherent at least with its base. Fruit (in the following) a many-seeded pod.

3. Hy drangea. Lobes of the calyx minute in complete flowers. Petals valvate in the bud. Stamens 8 or 10.

4. Phlladelphus. Lobes of the calyx and petals conspicuous; the former valvate, the latter convolute in the burl. Stamens 20-40.

Tribe IV. SAXIFRAGEA. Herbs, without stipules, except perhaps a membranous dilatation of the base of the petiole. Petals imbricated or rarely convolute in the bud. Fruit dry, capsular or follicular.

- A cluster of sterile or gland-tipped filaments at the base of each petal. Stigmas 3 or 4 , situr ated directly over as many parietal placentæ !

6. Parnassia. Sepals, petals, and proper stamens 5. Peduncle a scape or scape-like, 1 . Aowered. 
* No sterile stamens or bodies resembling them.

- Pod 2-3-celled and 2-3-beaked, or of as many distinct follicles.

6. Astllbe. Flowers polyganuus. Stameas twice as, wany as the small petals. Seeds few. Leaves decumpound.

7. Saxifragu. Fluwers perfect. Stamens twice as many as the petals. Seeds numerous, with a close coat.

8. Boy Kinia. Flowers perfect. Stamens only as many as the petals, which are convolute in the bud and deciduous. Caly $x$-tube adherent to the ovary. Seed-coat close.

9. Sullivancia. Flowers perfect. Stanens 5. Calyx nearly free. Seeds wing-wargined. - + Pod one-celled with 2 parietal placenta.

++ Stamens as many as the lobes of the calyx, namely 5 .

10. Heuchera. Caly $x$ bell-shaped, coherent with the ovary below. Petals small, entire.

+++ Stamens twice as many as the lobes of the calyx, namely 8 or 10.

11. Mitella. Calyx partly coheriug with the depressed ovary. Petals small, pinuatifid.

12. Tiarella. Caly $x$ nearly free from the slender ovary. Petals eutire.

13. Chrysosplenium. Calyx-tube cuherent with the ovary. Petals none.

\section{R I B E S, L. Currant. Goosebeirr.}

Calyx 5-lobed, often colored; the tube coherent with the ovary. Petals 5, inserted in the throat of the calyx, small. Stamens 5 , alternate with the petals. Ovary l-celled, with 2 parietal placentex and 2 distinct or united styles. Berry crowned with the shrivelled remains of the calyx; the surface of the numerous seeds swelling into a gelatinous outer coat invese a crustaceous one. Embryo minute at the base of hard albumen. - Low, sometimes prickly shrubs, with alternate and palmately-lobed leaves, which are plaited in the bud (except in one species), often clustered in the axils; the small flowers from the same clusters, or from separate lateral buds. (An Arabic name, properly belonging to a species of Rheum. Grossuluria was the proper name to have been adopted for the genus.)

§ 1. GROSSULARIA, Tourn. (Gooseberry.) Stems mostly bearing thorns at the base of the leafstalks or clusters of leaves, and often with scattered bristly prickles: berries prickly or smooth. (Our species are indiscriminately called WILD Gooseiskri : the fluwers greenish.)

* Peduncles 1-3-flowered: leaves roundish-heart-shuped, 3-5-lobed.

1. R. Cynósbati, L. Leaves pubescent; peduncles slender, 2-3-flowered; stamens and undivideal style not longer than the broad calyx. - Rocky woods: common, especially northivard. May. - Spines sinall or obsolete. Berry large, armed with long prickles like a burr, or rarely smooth.

2. R. hirtéllum, Michx. Leaves somewhat pubescent beneath; peduncles, very short, 1-2-tlowered, deflexed; stamens and 2-cleft style scarcely longer than the bell-shaped calyx; fruit smooth, small, purple, sweet. - Moist grounds, New Lingland to Illinois, common. May. - Stems either smooth or prickly, and with very short thorns, or none. - This yields the commonest smooth gooselerry of New England, \&c., and usually passes for R. tritòrun, Willd., which name belongs to the next.

3. R. rotundifolium, Michx. Leaves smooth or downy; peduncles slender, 1-3-flowered; stamens and 2-parted style slender, longer thar the narrow cylindrical calyx; fiuit smooth, pleasant. - Rucks, W. Massachusetts to Wisconsin, and southward along the mountains to Virginia, \&e. June. 
* Racemes 4-9-flowered, slender, nodding.

4. R. lacústre, Poir. Young stems clothed with bristly prickles, and with weak thorns; leaves heart-shaped, 3-5-parted, with the lobes deeply cut; calyx broad and flat; stamens and style not longer than the petals; fruit bristly (small, unpleasant). - Cold woods and swamps, New England to Wisconsin and northward; south to Pennsylvania. June.

§ 2. RIBÈSIA, Berl. (CURRANT.) Stems neither prickly nor thorny: flowers (grenish) in racemes: bervies never frickly.

5. R. prostràtum, L'Hier. (Fetid Currant.) Stems reclined; leaves deeply heart-shaped, 5-7-lobed, smooth; the lobes ovate, acute, doubly serrate; racemes erect, slender; calyx fluttish; perlicels and the (pale red) fruit glandularbristly. - Cold damp woods and rocks, from N. England and Penn. northward. May. - The bruised plant and berries exhale an unpleasant odor.

6. R. flóridum, L. (Winn Buck Curnant.) Leaves sprinkled with resinous dots, slightly heart-shaped, sharply $3-5$-lobed, doubly serrate; racemes drooping, downy; bructs longer than the pedicels; caly $\mathrm{x}$ tubular-bell-shaped, smooth ; fruit round-oioid, llack, smooth. - Woods: common. May. - Much like the Bluck Currant of the gardens, which the berrics resemble in smell and flavor. Flowers large, whitish.

7. R. rubbum, L. (RED CuRrant.) Stems straggling or reclined; leaves somewhat heart-shaped, obtusely 3 -5-lobed, serrate, downy beneath when young; racemes from lateral buds distinct, from the leaf-buds, drooping; calyx flat (grcen or purplish); fruit globose, smooth, red; on our wild plant apt to turn upwards in the drooping raceme: the veins of the leaves are whitish bencath (whence the name R. alhinérvium, Mich.x.) : but apparently not distinct from the garden Red Currant of the Old World. - Cold bogs and damp woods, New Hampshire to Minnesota and northward. May, June. (Eu.)

R. aureum, Pursh, the Buffalo or Missouri Currant, remarkablo for the spicy fragrance of its yellow blossoms in carly spring, is widely cultis vated for ornament. Its leaves are convolute (instead of plaited) in the bud.

\section{2. İ TEA, L. ITEA.}

Calyx 5-cleft, free from the ovary or nearly so. Petals 5, i.anceolate, much longer than the calyx, and longer than the 5 stamens. Pod oblong, 2-grooved, 2-celled, tipped with the 2 united styles, 2-parted (septicidal) when mature, several-seeded. - Shrubs, with simple, alternate, petioled leaves, without stipules, and small white flowers in simple racemes. (Greek name of the Willow.)

1. I. Virgínica, L. Leaves deciduous, oblong, pointed, minutely serrate; seeds oval, flattish, with a crustaceous coat. - Wet places, New Jersey and southward, near the coast. June.

\section{H Y D R A N G E A, Gronov. HrdrANGeA. -}

Calyx-tube hemispherical, 8-10-ribbed, coherent with the ovary; the limb 4-5-toothed. Petals ovate, valvate in the bud. Stnmens 8-10, slender. Pod crowned with the 2 diverging styles, 2-celled below, many-seeded, opening by a hole between the styles. - Shrubs, with opposite petioled leaves, no stipulos, 
and numerous flowers in compound cymes. The marginal flowers are usually sterile and radiunt, consisting merely of a membranaceous and colored flat and

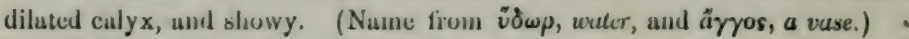

1. H. arboréscens, L. (WiLd Hxurangea.) Glabrous or nearly so; leaves ovate, rarcly heart-shaped, pointed, serrate, green both sides; cymes flat. - Rocky banks, N. Jersey to Illinois, and southward. July. - Flowers often all fertile, rarcly all radiant, like the Garden Hydrangex.

\section{PHiladétidus, L. Mock Orange or Srringa.}

Calyx-tube top-shaped, coherent with the ovary; the limb 4-5-parted, spreading, persistent, valvate in the bud. Putals rounded or obovate, large, convolute in the bud. Stamens 20-40. Styles $3-5$, united below or nearly to the top. Stigmas oblong or linear. Pod 3-5-celled, splitting at length into as many pieces. Seeds very numerous, on thick placenta projecting from the axis, pendulous, with a loose membranaceous coat prolonged at both ends. - Shrubs, with opposite often toothed leaves, no stipules, and solitary or cymose-clustered showy white flowers. (An ancient name, applied by Linnæus to this genus for no obvious reason.)

1. P. inodorus, L. Glabrous; leaves ovate or ovate-oblong, pointed, entire or with some spreading teeth; flowers single or few at the ends of the diverging branches, pure white, scentless; calyx-lobes acute, scarcely longer than the tube. - Mountains of Virginia and southward.

Var. grandiflorus. Somewhat pubescent; flowers larger ; calyx-lobes longer and taper-pointed. - Virginia and southward, near the mountains. May - July. - A tall shrub, with long and recurved branches: often cultivated.

P. coronarius, L., the common Mock Orange or Srringa of the gardens, with cream-colored, odorous flowers, in full clusters, the crushed foliage with the odor and taste of cucumbers, - has sometimes escaped from grounds.

\section{Parnásida, Tourn. Grass of Parnassus.}

Sepals 5 , imbricated in the bud, slightly united at the base, and sometimes also with the base of the ovary, persistent. Petals 5, veiny, spreading, at length deciduous, imbricated in the bud : a cluster of somewhat united gland-tipped sterile filaments at the base of each. Proper stamens 5, alternate with the petals: filaments persistent : anthers opening inwards. Ovary l-celled, with 4 projecting parietal placentæ: stigmas 4 , sessile, directly over the placentæ. Pod 4-valved, the valves bearing the placentae on their middle. Seeds very numerous, anatropous, with a thick wing-like seed-coat and little if any albumen. Embryo straight : cotyledons very short. - Percunial smooth herbs, with the leaves entire and chicfly radical, and the solitary flowers terminating the long naked sterns. P'tals white, with greenish or yellowish veins. (Named from Mount Parnassus : called Grass of Parnassus by Diuscorides.) In furmer edition placed between Druscracex and $\mathrm{H}_{y}$ pericacese.

1. P. parviflora, DC. Petuls sessile. little lunger than the calyx; sterile filuments about 5 in euch set, slender; leaves ovate or oblong, tapering at the base. - N. W. shore of L. Michigan (White-Fish Bay, Wisconsin, Henry Gillman), 
and westward. July. - More slender than the next, and the flower only half the size.

2. P. palustris, L. Prals sessile; mther longer than the calyx, fewveined; sterile filaments 9-15 in each set, slender; leaves heart-shaped. - Shore of Lake Superior, and northward. Aug. - Stalks $3^{\prime}-10^{\prime}$ high. Flower nearly (') I' broad. (Eu.)

3. P. Caroliniana, Michx. Petals sessile, more than twice the length of the caly x, many-veined; sterile filaments 3 in each set, stout, distinct almost to the base. - Wet banks, New England to Wisconsin and southward, especially along the mountains. July - Sept. - Leaves thickish, ovate or roundel, often heart-shaped, usually but one on the stalk, and that low down and clasping. Stalk $9^{\prime}-2^{\circ}$ high. Flower $1^{\prime}-1 l^{\prime}$ broad.

4. P. asarifolia, Vent. Petals alruptly contrarted into a clav at the base ; sterile filaments 3 in each set; laves rounded kidney-shaped: otherwise as in the foregoing. - High Alleghanies of Virginia and southward.

\section{A S TíLBE, Don. False Goatsmeard.}

Flowers diceciously polygamous. Calyx 4-5-parted, small. Petals 4-5, spatulate, small, withering-persistent. Stamens 8 or 10 . Ovary 2-celled, alınost free, many-ovuled: styles 2, short. Pod 2-celled, separating into 2 follicles, ench ripening few seeds. Seed-coat loose and thin, tapering at each end. Perennial herbs, with twice or thrice ternately-compound ample leaves, cut-lobed and toothed leaflets, and small white or yellowish flowers in spikes or racemes, which are disposed in a compound panicle. (Name composed of $\boldsymbol{a}$ privative and $\sigma \tau i \lambda \beta \eta$, a bright surface, because the foliage is not shining.)

1. A. decándra, Don. Somewhat pubescent; leaflets mostly heartshaped; petals minute or wanting in the fertile flowers; stamens 10. - Rich woods, Alleghanies of S. W. Virginia and southward. July. - Plant imitating Spiræa Aruncus, but coarser, $3^{\circ}-5^{\circ}$ high.

\section{SA Xífiga, L. Saxifrage.}

Calyx either free from or cohering with the base of the ovary, 5-cleft or parted. Petals 5, entire, imbricated in the bud, commonly deciduous. Stamens 10. Styles 2. Pod 2-beaked, 2-celled, opening down or between the beaks; or sometimes 2 almost separate follicles. Seeds numerous, with a close coat. Chiefly perennial herbs, with the root-leaves elustered, those of the stem mostly alternate. (Name from saxum, a rock, and fiango, to break; many species rooting in the clefts of rocks.)

* Stems prostrate, in tufts, leafy: leavrs opposite: calyx free from the pod.

1. S. oppositifoblia, I. (Mountain Saxufrage.) Leaves fleshy. ovate, keeled, ciliate, imbricated on the sterile branches (1" $-2^{\prime \prime}$ long); flowers solitary, large; petals purple, obovate, much longer than the 5-cleft-calyx. Rocks, Willoughby Mountain, Vermont, and northward. (Eu.)

* : Stems ascending, leafy : stem-teaves alternute: caly.r colierent brlow with the pod.

2. S. rivulàris, L. (Alpine Brook-S.) Smull; stems weak, 3-5flowered; lower leaves rounded, 3-5-lobed, on slender petioles, the upper lance- 
olate; petuls white, orate - Alpine region of Mount Washington, New Hamp shire (Oakes, \&c.) : rare. (Bu.)

3. 8. aizoldes, L. (Yellow Mountain-s.) Iow $\left(3^{\prime}-5^{\prime}\right.$ high), in tufts, with few or several corymbuse tlowers; laves linter-lanceolate, entire, fleshy, distantly spinulose-ciliate; peluls yellow, spotted with orunye, ollong. - Willoughtby Mountain, Vermont; near Oncida Lake, New York; N. Micligan ; aud northward. June. (Ea.)

4. S. tricuspidàta, Retz. Stems tofted $\left(t^{\prime}-8^{\prime}\right.$ high), naked alove; flowers coryunbose; leuves ollony or spatulute, with 3 rigid shurp teeth at the summir; petals abovite-ablong, yellow. - Shore of L. Superior and northward. (Eu.)

* Leaves clustered at the root: scape muny-flowered, ervet, dammy-pubescent.

$$
\text { - Petuls ull alike. }
$$

5. S. Aizòon, Jaet]. Leaves persistent, thick, spatu'ate, with white cartilayinous tonthed mugins; calyx partly allierens; petals obuvate, cream-color, oficu spotted at the base. - Muist rucks, Upper Michigan and Wisconsin; Willoughtly Mountain, Vermont (Mr. Bluke), and northward. - Scape $5^{\prime}-10^{\prime}$ high. (Eu.)

6. S. Virginiénsis, Miclix. (Early S.) Iow $\left(t^{\prime}-9^{\prime}\right.$ high); louces obovate or oval-sjalulate, narrowed intu a broad petiole, crenate-tuothed, shickish; flowers in a clustered cyme, which is at leugth open and loosely panicled; lobes of the nearly frue culys trect, not half the length of the oblung obluse (wohile) petals; pods 2, united merely at the bise, divergent, purplish. - Exposed rocks : common, especially northward. A pril-June.

7. S. Pennsylvánica, L. (SwamP S.) Large $\left(1^{\circ}-2^{\circ}\right.$ high); leaves odlunceolute, obscurcly toullied $\left(t^{\prime}-8^{\prime}\right.$ long), narrowed at the base into a short and broad petiole; cymes in a large oblung panicle, at tirst clustered; lobes of the nearly free calyx recurved, about the length of the linear-lunceolute (grennish) small petals; filuments avel-shuped: pods at length divergent.-Bogs: commou, especially northward. May, June. - A homely species.

8. S. erosa, Pursh. (Letruce S.) Leaves oblung or oblanceolate, obtuse, sharply toched, tapering into a margined petiole $\left(8^{\prime}-12^{\prime}\right.$ long $)$; seape slender $\left(1^{\circ}-3^{\circ}\right.$ high) ; panicle elongated, loosely flowered; pedicels slenter; calyx reflexed, entircly free, newly as long as the ovul obluse (white) petals; filannents chabshaped; pods 2, nearly separate, diverging. - Cold mountain brooks, Pennsylvania (near Bethlehem, Mr. Wolle), and throughout the Alleghanies, southward. June.

++ Pelals unequal, with clanes, white, all or some of them with a pair of yellow spots near the buse: leaves oblong, wodlye-shaped or spatulate; calyx fice and reflexed.

9. S. leucanthemifolia, Lapeyronse, Michx. Leaves coarsely toothed or cut, tapering into a jetiule; scapes $\left(5^{\prime}-18^{\prime}\right.$ high $)$ bearing one or more leaves or leafy briuts and a luuse, spruading corymbose or paniculate cyme; pelcals lanceolate; the 3 linger ones with a heart-shaped base and a pair of spots; the 2 smaller with a tapering base and no spots. - Salt Pund Mountain, Virginia ( $W_{\text {a. }} M$. Canby), and southward in the Alleghanies.

10. S. stellàris, L., var. comosa, Willd. Leaves wedge-shaped, more or less toothed; scape $\left(t^{\prime}-5^{\prime}\right.$ high) bearing a small contracted panicle; many 
or most of the flowers changed into little tufts of green leaves; petals all lanceolate and tapering into the claw. - Mount Katahdin, Maine (Kev. J. Blake) and high northward. (Eu.)

\section{BOYKÍNIA, Nutt. BOYKINIA.}

Calyx-tube top-shaped, coherent with the 2-celled and 2-beaked pod. Stamens 5, as many as the deciduous petals, these mostly convolute in the bud. Otherwise as in Saxifraga. - P'erennial herbs, with alternate palmately 5 - 7Jobed or cut petioled leaves, and white flowers in cymes. (1)edicated to the late $D r$. Boykin of Georgia.)

1. B. aconitifolia, Nutt. Stem glandular $\left(6^{\prime}-20^{\prime}\right.$ high); leaves deeply 5-7-lobed. - Mountains of S. W. Virginia, and southward. July.

\section{SULLIVÁ N T IA, Torr. \& Gray. Sullivantia.}

Calyx bell-shaped, cohering helow only with the base of the ovary, 5-cleft. Petals 5, entire, acutish, withering-persistent. Stamens 5, shorter than the petals. Pod 2-celled, 2-beaked, many-secied, opening between the beaks : the seeds wing-margined, imbricated upwards. - A low and reclined-spreading perennial herb, with rounded and cut-toothed, or slightly lobed smooth leaves, on slender petioles, and small white flowers in a branched loosely cymose panicle, raised on a nearly leafless slender scape $\left(6^{\prime}-12^{\prime}\right.$ long). Peduncles and caly $\mathbf{x}$ glandular: pedicels recurved in fruit. (Dedicated to the distinguished bryologist who discovered the only spccies.)

1. S. Ohionis, Torr. \& Gr. (Gray, Chloris Bor.-Am., pl. 6.)-Limestone cliffs, Highland County, Ohio, Sullivant; Wisconsin River, Lapham. June.

\section{HEÙ CHERA，L. ALum-root.}

Calyx bell-shaped, the tube cohering at the hase with the ovary, 5-cleft. Petals 5, spatulate, small, entire. Stamens 5. Styles 2, slender. Pod 1-celled, with 2 parietal many-sceled placentr, 2-beaked, opening between the beaks. Seeds oval, with a rongh and close seed-coat. - Perennials, with the round heart-shaped leaves principally from the rootstock; those on the scapes, if any, alternate. Petioles with dilated margins or adherent stipules at their base. Flowers in small clusters disposed in a prolonged and narrow panicle, greenish or purplish. (Named in honor of John Henry Heucher, a German botanist of the beginning of the 18th century.)

* Flowers small, looseiy panicled: stamens and styles exserted: calyx regular.

1. H. villosa, Michx. Scapes $\left(1^{\circ}-3^{\circ}\right.$ hich $)$, petioles, and veins of the acutely 7 -9-lobed leaves bencath villous with rusty hairs; calyx $1 \frac{1}{2}$ "long; petals spatulate-linear, about as long as the stamens, soon twisted. - Rocks, Maryland, Kentucky and southward, in and near the mountains. Ang. - Scpt.

2. H. Americàna, L. (Common $\Lambda$ uum-roor.) Scapes $\left(2^{\circ}-3^{\circ}\right.$ high), \&c. glandular and more or less hirsute with short hairs; lenves roundish, with short rounded lobes and crenate teeth; calyx broad, $2^{\prime \prime}$ long, the spotulate petals not longer than its lobes. - Rocky woodlands, Connecticut to Wisconsin and southward. June.

$$
\text { G } \mathbf{M}-8
$$


* Flowers lurger : calyx ( $3^{\prime \prime}-4^{\prime \prime}$ long) more or less oblique: stamens short : panide very narrow: leaves rounded, slightly 5-9-lobed.

3. H. híspida, Pursh. Hispid or hirsute with long spreading hairs (occasionally almost glabrous), scarcely glandular; stamens soon exserted, longer then the spatulute petuls. (H. Richardsonii, $R . B r$.) - Mountains of Virginia. Also Illinois (Dr. Mead) and northwestward. MIay -July, - Scapes $2^{\circ}-4^{\circ}$ high.

4. H. pubéscens, Pursh. Scape $\left(1^{\circ}-3^{\circ}\right.$ high) and petioles granulurpubescent or ylundulur aboce, not lairy, below often glabrous; stamens shorter than the lobes of the cullyx and the spatulate petals. - Rich woods, Lancaster, Penn. to Virginia and Keutucky, aloug the mountains. June, July.

\section{Mitélia, Tourn. Mitre-woht. Bishor's-Cap.}

Calyx short, coherent with the base of the ovary, 5-cleft. Petals 5, slender, pinnatitid. Stamens 10, included. Styles 2, very shurt. Pod short, 2-beaked, 1-celled, with 2 parietal or rather basal several-seeded placente, 2-valved at the summit. Sceds smooth and shining. - Low and slender perennials, with round heart-shaped alternate leaves on the rootstock or runners, on slender petioles; those on the scapes, opposite, if any. Flowers small, in a simple slender raceme or spike. (Name a diminutive from $\mu$ iт $\rho$ a, a mitre or cup, alluding to the form of the young pod.)

1. M. diphýlla, L. Ilairy, leaves heart-shaped, acute, somewhat 3-5lobed, toothed, thuse on the many-flowered-scipe 2, opposite, nearly sessile. - Hillsides in rich woods: common, especially westward and northward. May. Flowers white, in a raceme $6^{\prime}-8^{\prime}$ long.

2. M. nùda, L. Small and slender; leaces rounded or kidney-form, deeply and doubly crenite; scape usually leafless, few-fluwered, very slender $\left(t^{\prime}-6^{\prime}\right.$ high). (M. cordifulia, Lam. M. prostrata, Mlickx.)-1)eep moist woods in moss, Maine to Penn., Ill., and northward. Maty - July. - A delicate little plant, sending forth runners in summer. Blossoms greenish.

\section{Ti A R ÉLA， L. False Mitre-wort.}

Calyx bell-shaped, nearly free from the ovary, 5-parted. Petals 5, with claws, entire. Stamens 10, long and slender. Styles 2. Pod menblranaceous, 1-celled, 2-valved; the valves uneegual. Seeds few, at the base of each parietal placenta, globular, smootl. - Perennials: flowers white. (Name a diminutive from Tiâpa, a tiara, or turban, from the forn of the pod, or rather pistil, which is like that of Mitella, to which the name of Mitre-wort properly belongs.)

1. T. cordifolia, L. Leaves from the rootstock or summer runners heartshaped, sharply lubed aud toothed, sparsely hairy above, downy beneath; scape leafless $\left(5^{\prime}-12^{\prime}\right.$ high) ; raceme simple; petals oblong. - Rich rocky woods: common northward, and southward along the mountains. AYril, May.

\section{CHRYSOSPLENIUM, Tourn. Goldex SAXIFlage.}

Calyx-tube coherent with the ovary; the blunt lohes $4-5$, yellow within. Petals noue. Stameus 8-10, very short, inserted on a conspicuous disk. 
Styles 2. Pod inversely heart-shaped or 2-lobed, flattened, very short, 1-celled, with 2 parietal placentr, 2-valved at the top, many-secded. - Low and sinall smooth herbs, with tender succulent leaves, and small solitary or leafy-cymed flowers. (Name compounded of $\chi \rho v \sigma o$ s, golden, and $\sigma \pi \lambda \dot{\eta} \nu$, the spleen, probably from some reputed medicinal qualities.)

1. C. Americanum, Schwein. Stems slender, spreading and forking; leaves principally opposite, roundish or somewhat heart-shaped, obseurely crenate-lobed ; flowers distant, inconspicuous, nearly sessile (greenish tinged with yellow or purple.) - Cold wet places : common northward. $\Lambda$ pril, May.

\section{Order 36. Chassulàchas. (Orine Fami,y.)}

Succulent herbs, with perfectly symmetrical flowers: viz. the petals and pistils equalling the sepals in number $(3-20)$, and the stamens the same or double their number, - technically difierent from Saxifragex only in this complete symmetry, and in the carpels being quite distinct from each other, but even this does not hold in two N. American genera. Also, instearl of a perigynous disk, there are usually little scales on the receptacle, one behind each carpel. Fruit dry and dehiscent; the porls (follicles) opening down the ventral suture, many- rarely few-seeded. - Stipules none. Flowers usually cymose, suall. Leaves mostly sessile, in Penthorum not at all fleshy.

* Not succulent : the carpels united, forming a 5-celled pod. Transition to the Saxifrage Family.

1. Penthorum. Sepals 5. Petals none. Stamens 10. Pod 5-beaked, many-seeded.

* * Leaves, \&c., thick and succulent. Carpels distinct.

2. Tillrea. Sepals, petals, stamens, and pistils 3 or 4 . Secds few or many.

3. Sealum. Sepals, petals, and pistils 4 or 5. Stamens 10-8. Seeds many.

\section{PÉ N THORUM, Gronov. Ditch Stone-crop.}

Sepals 5. Petals rare, if any. Stamens 10. Pistils 5, united below, forming a 5-angled, 5-horned, and 5-celled pod, which opens by the falling off of the beaks, many-seeded. - Upright weed-like perennials (not fleshy like the rest of the family), with scattered leaves, and yellowish-green flowers loosely spiked

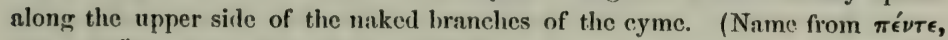
five, and opos, a rule or mode, probably from the quinary order of the flower.)

1. P. sedoldes, L. Leaves lanceolate, acute at both ends. - Open wet places, everywhere. July - Oct. - Parts of the flower rarely in sixes or sevens.

\section{TIL工市A, L. Tillea.}

Sepals, petals, stamens, and pistils 3 or 4 . Pods 2-many-sceded. - Very small tufted annuals, with opposite entire leaves and axillary flowers. (Named in honor of Michol. Angelo Tilli, an carly Italian botanist.)

1. T. simplex, Nutt. Rooting at the base $\left(1^{\prime}-2^{\prime}\right.$ high) ; leaves linearoblong; flowers solitary, nearly sessile; calyx half the length of the (ereenishwhite) petals and the narrow 8-10-secelel pods, the latter with a scale at the base of cach. (T. ascéndens, Euton.) - Muddy river-banks, Nantucket to Mr ryland. July-Sept. 


\section{Síd IM, Tourn. Stone-Crop. Orpine.}

Sepals and petals 4 or 5 . Stanens 8 or 10 . Pods many-seeded; a little scale the base of each. - Chictly peremial, smooth, and thick-leaved herbs, with the flowers cymose or one-sided. Petals almost always narrow and acute or pointed. (Name from sedeo, to sit, alluding to the manner in which these plants fix themselves upon rocks and walls.)

* Flowers perfect und sessile, as it were spiked along one side of sprcading flowering branches or of the divisions of a scorpioid cyme, the first or central fluwer mostly 5-merous and 10-andious, the others often 4-merous and 8-andious.

1. S. Acke, L. (Mossy Stunk-ciror.) Spreading on the ground, moss. like; leaves very small, alternate, almost imbricated on the branches, ovate, very thick; petals yellow. - Eiscaped from cultivation to rocky roadsides, \&c. July. (Adv. from ku.)

2. S. pulchéllum, Michx. Stems ascending or trailing $\left(4^{\prime}-12^{\prime}\right.$ high); leaves terete, linear-filiform, much crowded; spikes of the cyme several, densely flowered; petuls rose-purple. - Virginia to S. Illinois, Kentucky, and southward; also cultivated in gardens. July.

3. S. Névii, Gray. Stems spreading, simple $\left(3^{\prime}-5^{\prime}\right.$ high $)$; leaves all alternate, those of the sterile shoots wedye-obotate or spatulate, on flowering stems linear-spatulate and flattish; cyme about 3-spiked, densely flowered; petuls white, more pointed than in the next; the flowering 3 or 4 weeks later; leaves and blossoms smaller. - Mountains of Virginia (Salt Pond Mountain, W. M. Canby) to Alabama (R. D. Nevius).

4. S. ternatum, Michx. Stems spreading $\left(3^{\prime}-6^{\prime}\right.$ high $)$; leaves flut; the lower whorled in threes, wedge-obovate, the upper scattcred, oblong; cyme 3-spiked, leafy; petals white. - Rocky woods, l'enn. to Illinois and southward: common in gardens. May, June.

* * Flowers in a terminal naked and regular cyme or cluster, more or less pedunclod: leaves flal, obovate or oblong, mostly alternate.

+ Flowers perfect, 5-merous, 10-androus.

5. S. telephioldes, Michx. Stems ascending $\left(6^{\prime}-12^{\prime}\right.$ high $)$, stout, leafy to the top; leaves oblong or oval, entire or sparingly toothed; cyme small; petals flesh-color, ovate-lanceolate, taper-pointed; pords tapering into a slender style. - Iry rocks, Alleghany Mountains, from Maryland southward, and sparingly tin New Jersey? W. New York? and Indiana. June. - Too near the next.

6. S. Telèpitum, L. (Garden Orpine or Live-for-ever.) Stems ereet (20 high), stout; leaves oval, obtuse, toothed; cymes compound; $p$ tals purple, oblong-lanceolate; pods abruptly pointed with a short style. - Rocks and banks, escaped from cultivation in sonne places. July. (Adv. from Eu.)

$$
\text { + + Flowers diweions, mosily 4-merous and 8-androus. }
$$

7. S. Rhodiola, DC. (Roseroot.) Stems erect $\left(5^{\prime}-10^{\prime}\right.$ high); leaves oblong or oval, smaller than in the preceding; flowers in a close cyme, greenishyellow, or the fertile turning purplish. - Pennsylvania, on elifts of Delaware River, below Easton! (Proficssors Porter \& Green) ; Quodily Ilead, Maine (Prof. Verrill), and northward. May, June. (Eu.) 


\section{Order 37. Tamameinceze. (Witch-Hazel Family.)}

Shrubs or trees, with alternate simple leaves and deciduous stipules; flowers in heads or spikes, often polygamous or monæcious; the calyx cohering with the base of the ovary; which consists of 2 pistils united below, and forms a 2-beaked, 2-relled woorly porl, opening at the summil, with a single bony seed in each cell, or several, only one or two of them ripening. - Petals inserted on the calyx, narrow, valvate, or involute in the bud, or often none at all. Stamens twice as many as the petals, and half of them sterile and changed into scales, or numerous. Seeds anatropous. Embryo large and straight, in sparing albumen: cotyledons broad and flat.

Trlbe I. HAM AMLLEAE. Flowers with a manifest calyx or calyx and corolla, and a single ovule suspended from the summit of each cell.

1. Hamamelis. Petals 4, strip-shaped. Stamens and scales each 4 , short.

2. Fothergilln. Petals none. Stamens about 24 , long : filaments thickened upwards.

Tribe 11. BA LSA MIFIUAS. Flowers naked, with barcly rudiments of a calyx, and no corolla, crowded into catkin-like heads. Ovules several or many in each cell.

3. Liquidambar. Monœutious or polygamous. Stamens very numerous. Pods consoli. dated by their bases in a dense head.

\section{H A M A M ELI S, L. Witch-HAzeL.}

Flowers in little axillary clusters or heads, usually surrounded by a scale-like 3-leaved involucre. Calyx 4-parted, and with 2 or 3 bractlets at its base. Petnls 4, strap-shaped, long and narrow, spirally involute in the bud. Stamens 8, very short; the 4 nlternate with the petuls anther-bearing, the others imperfect and scale-like. Styles 2, short. l'od opening loculicidally from the top; the outer coat separating from the inner, which encloses the single large and bony $\because$ seed in each cell, but soon bursts elastically into two picces. - Tall shrubs, with

straight-veined leaves, and yellow, perfect or polygamous flowers. (From ä $\mu a$,

like to, and $\mu \eta \lambda$ is, an apple-tree; a name ancicntly applied to the Medlar, or some

other tree resembling the Apple, which the Witch-Hazel docs not.)

L 1. H. Virgínica, L. Lcaves obovate or oval, wavy-toothed, somewhat lowny when young. - Damp woods: blossoming late in autumn, when the leaves are falling, and maturing its seeds the next summer.

\section{FOTHERG ILLA, L. f. Fothergilla.}

Flowers in a terminal catkin-like spike, mostly perfect. Calyx bell-shaped, the summit truncate, slightly 5-7-tonthed. Petals none. Stamens about 24, borne on the margin of the ealyx in one row, all alike: filaments very long, thickened at the top (white). Strles 2, slender. Pod cohering with the base of the calyx, 2-lobed, 2-celled, with a single bony seed in each cell. - A low shrub; the oval or obovate leaves smonth, or hoary underneath, toothed at the summit; the flowers nppearing rather hefore the lenves, each partly covered by a scalc-like hract. (1)edicated to the distinguished Dr. John Fothergill.)

1. F. alnifolia. L. f. - Low grounds, Virginia and southward. April, May. 


\section{L I Q U I d Á M B A R, L. Sweet-Gum Tree.}

Flowers usually moncecious, in globular heads or catkins; the sterile arranged in a conical cluster, naked: stancens very numerous, intermixed with minute scales: filaments short. Fertile flowers consisting of many 2-eelled 2-beaked ovarics, subtended by minute scales in place of a caly $x$, all more or less colcring together and hardening in fruit, forming a spherical catkin or head; the pods opening between the 2 awl-shaped beaks. Styles 2, stigmatic down the inner side. Ovules many, but only one or two perfecting. Seeds with a wing-angled seed-coat. - Catkins racemed, nodding, in the bud enclosed by a 4-leaved deciduous involucre. (A mongrel name, from liquidus, fluid, and the Arabic umbur, amber; in allusion to the fragrant terebinthine juice which exudes from the tree.)

1. I. Styraciflua, I. (Sweetr Gum. Bilsted.) Leaves rounded, deeply 5-7-lobed, smooth and shining, glandular-serrate, the lobes pointed:Moist woods, from Connecticut to Illinois, and southward. April. - A large and beautiful tree, with fine-grained wood, the gray bark commonly with corky ridges on the branchlets. Tacaves fragrant when bruised, turning deep crimson in antum. 'I'he woody pods filled mostly with abortive seeds, resembling sawdust.

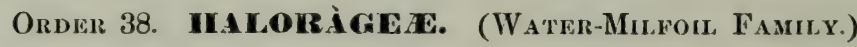

Aquatic or mursh plants (at least in northern countries), with the inconspicuous symmetrical flowers sessile in the axils of leaves or bracts, calyx-tube colcerent with the ovary, which consists of 2-4 more or less united carpels (or in Mippuris of only one carpel), the styles or sessile stigmas distinct. Limb of the calyx obsolete or very short in fertile flowers. Petals small or none. Stamens 1-8. Fruit indehiscent, 1-4-celled, with a single anatropous seed suspended from the summit of each cell. Embryo in the axis of fleshy albumen : cotyledons minute. - Formerly attached as a suborder to Onagracex, but now deemed quite distinct.

1. Mryriophyll um. Flowers monocious or polygamous, the parts in fours, with or withuut petals. Stamens 4 or 8 . Inmersed leaves pinnately dissecterl.

2. Proserpinaca. Fluwers perfect, the parts in threes. Petals noue. Inmersed leaves pinuately dissected.

3. Hippuris. Flowers usually perfect. Petals none. Stamen, style, and cell of the ovary only one. Leaves entire.

\section{MYRIOPHÝ LLU M, Vaill. WATER-MilforL.}

Flowers monecious or polygamous. Calyx of the sterile flowers 4-parted, of the fertile 4-toothed. Petals 4, or none. Stumens 4-8. Fruit nut-like, 4-

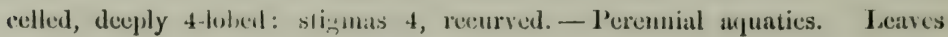

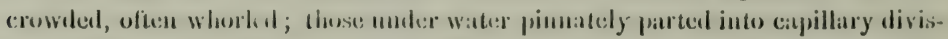
ions. Flowers sessile in the axils of the upper leatves, ustally aloove water in summer; the uppermost staminate. (Name fiom $\mu v p i o s, ~ a ~ l h o u s a n d$, and $\phi u ́ \lambda$ -

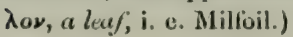


- Strumens 8: petals deciduous: carpels even: leaves whorled in thees or fours.

1. M. spicatum, L. Leaves all pinnately parted and capillary, except the floral ones or bracts; these ovate, entire or toothed, and chiefly shorter than the flowers, which thus form an interrupted spike. - Deep water: common. (Lu.)

2. M. verticillatum, L. Floral leaves much longer than the flowers, pectinate-pinnatifid: otherwise ncirly as No. 1.-Ponds, \&c. northward. (Eu.)

* Stamens 4 : petals rather persistent: carpels 1-2-rielyed and roughened on the back: leaves whorled in fours and fives, the lower with capillary divisions.

3. M. heterophyllum, Michx. Stem stout; floral leaves ovate and lancedate, thick, crowded, sharply serrate, the lowest pinnatifid; fiuit obscurely roughened. - Lakes and rivers, from N. New York westward and southward.

4. M. scabràtum, Michx. Stem rather slender; lower leaves pinnately parted with fow capillary divisions ; floral leaves linear (rarely scattered), pectinatetoothed or cut-serrate: carpels strongly 2-ridged and roughened on the back. - Shallow ponds, from S. New England and Ohio southward.

* * Stamens 4 : petals rather persistent: carpels even on the back: leaves chiefly scattered, or wanting on the flowering stems.

5. IM. ambiguum, Nutt. Immersed lenves pinnately parted into about 10 very delicate capillary divisions; the energing ones pectinate, or the upper floral linear and sparingly toothed or entire; flowers mostly perfect; fruit (minute) smooth. - Var. 1. NATANs : stems floating, prolonged. Var. 2. CAPILLACEUM : stems floating, long and very slender; leaves all immersed and capillary. Var. 3. LIMósum : small, rooting in the mud; leaves all linear, incised, toothed, or entire. - Ponds and ditehes, Massachusetts to New Jersey, Pennsylvania, and southward, near the coast.

6. M. tenéllum, Bigelow. Flowering stems nearly leafless and scupe-like, $\left(3^{\prime}-10^{\prime}\right.$ high), erect, simple; the sterile shoots ereeping and tufted; bracts small, entire; flowers alternate, monxcious; fruit smooth. - Borders of ponds, N. New York, New England, and northward.

\section{PROSERPI NÀ A, L. Mermaid-weed.}

Flowers perfect. Calyx-tube 3-sided, the limb 3-parted. Petals none. Stamens 3. Stiginas 3, cylinirical. Fruit bony, 3-angled, 3-celled, 3-sceded, nutlike. - Low, perennial herbs, with the stems ereeping at the base (whence the name, from proserpo, to creep), alternate leaves, and small flowers sessile in the axils, solitary or 3-4 together, in summer.

1. P. palústris, L. Leaves lanceolate, sharply serrate, the lower pectinate when under water; fruit sharply angled. - Wet swamps : not rare.

2. P. pectinàcea, Lam. Leaves all pectinate, the divisions linear-awlshaped; fruit rather obtusely angled. - Sandy swamps, near the coast.

\section{H I P P Ù RIS, L. Mare's TaIL.}

Flowers perfect or polyganous. Calyx entire. Petals none. Stamen one, inserted on the edge of the calyx. Style single, threal-shaped, stigmatic down one side, received in the groove between the lobes of the large anther. Fruir 
nut-like, 1-celled, 1-seeded. - Perennial aquatics, with simple entire leaves in

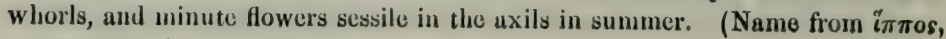
a horse, und ovipá, a tail.)

1. H. vulgàris, I. Leaves in whorls of 8 or 12, linear, acute - Ponds and springs, New York to Kientucky and northward: rare. Stems simple, $1^{\circ}$ $2^{\circ}$ high. Flowers very inconspicuous. (Eu.)

\section{Order 39. onagticeat. (Evening-Primrose Family.)}

Merbs, with 4-merous (sometimes 2-3-or 5-6-merous) perfect and symmetrical flower's; the tube of the calyx cohering with the 2-4-celled ovary, its lobes valvate in the bud, or obsolete; the pelals convolute in the bud, sometimes wanting; and the stumens as many or twice as many as the petals or calyx-lobes, inserted on the summit of the calyx-tube. Style single, slender: stigma 2-4-lobed or capitate. Pollen grains often connected by cobwebby threads. Seeds anatropous, small, without albumen.

* Purts of the flower in twog.

1. Cireder. Petals 2 , obcordate or 2 -lobed. Stanens 2. Druit 1 - 2-seeded, bristly.

* Purts of the fluwers in fours or more.

- Fruit dry and indehiscent, mostly becoming 1-celled, 1-4-seeded.

2. Gaura. Petals 4. Stamens 8 and with the long style turned downwards.

- + Fruit a many-seeded pod, usually loculicidal.

3. Epllobium. Stamens 8. Petals 4. Seeds with a large downy tuft at the apex.

4. Euothera. Stumens 8 and petals 4 on the prolonged ealyx-tube. Seeds naked.

5. Jussiaea. Stamens 8-12. Petals 4-6. Calyx-tube not prulonged beyond the ovary.

6. Ludwigia. Stamens 4. Petals 4 or more. Calyx-tube not prolunged beyond the ovary.

\section{Circ 瞒 A, Tourn. Enchanter's Nightshade.}

Calyx-tube slightly prolonged, the end filled by a cup-shaped disk, deciduous; lobes 2, reflexed. Petals 2, inversely heart-shaped. Stamens 2. Fruit indehiscent, small and bur-like, bristly with hooked hairs, 1-2-eelled: cells 1-seeded. - Low and inconspicuous pereunials, in cool or damp woods, with opposite thin leaves on slender petioles, and small whitish flowers in racemes, produced in summer. (Named from Circe, the enchantress.)

1. C. Lutetiàna, I. Taller $\left(1^{\circ}-2^{\circ}\right.$ high $)$; leaves ovate, slightly toothed; bracts none; hairs of the roundish 2-celled fruit bristly. - Very common. (Eu.)

2. C. alpina, L. Low $\left(3^{\prime}-8^{\prime}\right.$ high $)$, smooth and weak; leaves heart-shaped, thin, shining, coarsely toothed; bracts minute; hairs of the obovate-oblong 1-celled fruit soft and slender. - Deep woods : common northward. July. (Eu.)

\section{Ga U̇ R A, L. Gaura.}

Calyx-tube much prolonged beyond the ovary, deciduous; the lobes 4 (rarely 3), reflexed. Petals clawed, unequal or turnel to the upper side. Stamens mostly 8 , often turned down, as is also the long style. A small scale-like appendage before the base of each filanent. Stigma 4-lobed, surrounded by $\mu$ ring or cup-like border. Fruit hard and nut-like, 3-4-ribbed or angled, inde- 
hiscent or nearly so, usually becoming 1-celled and 1-4-seeded. Seeds naked. - Leaves alternate, sessile. Flowers rose-color or white, changing to reddish in fading, in wand-like spikes or racemes; in our species quite small (so that the name, from yaûpos, superb, does not seem appropriate).

1. G. biénnis, L. Soft-hairy or downy $\left(3^{\circ}-8^{\circ}\right.$ high $)$; leaves oblong-lanceolate, acnte, denticulate; fruit oval or oblong, nerrly sessile, ribbed, downy. Dry banks, from New York westward and southward: common. Ang.

2. G. fillipes, Spach. Neurly smooth; stem slender $\left(2^{\circ}-4^{\circ}\right.$ high); leaves limar, mostly toothed, tapering at the base; branches of the panicle very slender, naked ; fruit obovate-club-shaped, 4-angled at the summit, slender pedicelled. - Open places, Virginia to Ohio, Illinois, and southward. Aug.

\section{EPII Ò B I U M, L. WILLOW-HerB.}

Calyx-tule not prolonged beyond the ovary; the limb 4-cleft, deciduous. Petsla 4. Stamens 8 : anthers short. Pod linoar, many-seeded. Seeds with a tuft of long hairs at the end. - Perennials, with nearly sessile leaves, and violet,

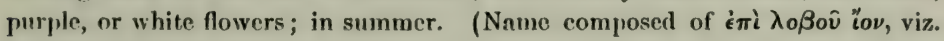
a violet on a pod.)

* Flouers large in a long spike or raceme : petals widely spreading, on claws, entire: stumens and style turned downwards : stigma of 4 long lobes: leaves scattered.

1. E. angustifólium, L. (Great Willow-heris.) Stem simple, tall !) :. $\left(4^{\circ}-7^{\circ}\right)$; leaves lanceolate. - Low grounds, especially in newly cleared land : r common northward. - Flowers pink-purple, very showy. (Eu.)

* Flowers rather large, rigular: petals obcordate: stumens and style erect: stigma of 4 long linear lobes: leaves mostly opposite.

2. E. mirsutum, L. Soft-hairy, branching $\left(3^{\circ}-5^{\circ}\right.$ high $)$; leaves lanceoblong, scrrulate; flowers in the upper axils or in a leafy short raceme; petals rose-purple, 6" long. - Spontancous in waste grounils, New Bedford, Mass. (T. A. Greene) and Roxbury (D. Murray); and in a ravine near Albany, New York (C. II. Peck). (Nat. from Eu.)

* * Flowers small, corymbed or panicled: petals (mostly notched at the end), stamens, and style erect: stigma club-shaped, nearly entire: lower leaves opposite, entive or denticulate.

3. E. alpinum, L. Low $\left(2^{\prime}-6^{\prime}\right.$ high $)$, nearly glubrous; stents ascending from a stoloniferous base, simple; leaves elliptical or ovate-oblong, obtuse, nearly entire, on short petioles; flowers few or solitary, drooping in the bud ; petals Iurple; prods long, glabrous. - Alpine summits of the White Mountains of New Hampshire, and Adirondack Mountains, New York. (Eu.)

Var. màjus, Wahl. Taller; upper leaves more or less acnte and toothed, pod glabrous or somewhat pubeseent. (E. alsinifolium, Vill. E. origanifolium, Lam.) - With the typical form: also upper Wisconsin and Michigan. (Eu.)

4. E. palústre, L., var. lineàre. Erect and slender $\left(1^{\circ}-2^{\circ}\right.$ high), branched above, minutely hoary-pubescent; stem roundish; leares narrinly lancenlate or linear, nearly entire ; flower-luds somewhat nodding ; petals purplish or white; pods hoary. (E. lineare, Muhl E. squamatum, Nutt.)-Bogs, N. 
England to Penn., Illinois, and northward. There is also a small an simple 1 -few-flowered form $\left(4^{\prime}-9^{\prime}\right.$ high), less hoary or nearly glabrous, with shorter leaves (E. oligánthum, Michx.), found in N. New York, White Mountains of New Hampshire, and northward. This is E. nutans, Sommerf. \& E. lineare, Fries, but the pods are usually a little hoary. (Eu.)

5. E. mólle, Torr. Soft-downy all over, strietly erect $\left(1^{\circ}-21^{\circ} \mathrm{high}\right)$, at length branching; leaves crowded; linear-oblong or lunceulate, blunt, mostly petioled; petals rose-color, notched $\left(2^{\prime \prime}-3^{\prime \prime}\right.$ long). - Bogs, Rhode Island and Pennsylvania to Michigan, and northward. Sept.

6. E. coloràtum, Muhl. Glubrous or nearly so; stem roundish, not angled, much branched $\left(1^{\circ}-3^{\circ}\right.$ high), many-flowered ; leaves lanceulate or ovateoblong, acute, denticulate, often pclioled, not at all decurrent, thin, usually purple-veined; flower-buds erect ; petals purplish, 2-cleft at the summit $\left(1 \frac{1}{2}{ }^{\prime \prime}-2^{\prime \prime}\right.$ long). - Wet places : conmon. July - Sept.

\section{Cen othira, L. Evening Primrose.}

Calyx-tube prolonged beyond the ovary, deciduous; the lobes 4 , reflexed. Petals 4. Stamens 8 : anthers mostly linear and versatile. Pod 4-valved, many-seeded. Seeds naked. - Leaves alteruate. (Nane from oivos, wine, and O'jpa, a hunt or euger pursuit, given to some plant the roots of which were eaten to provoke a relish for wine.)

\$1. Tube of the culyx filiform or cylindrical and much prolonged beyond the ovary: stamens nearly equal: anthers lineur: stigna of 4 filiform or linear divergent lobes.

* Annuals or biennials: flowers nocturnal, odorous, yellow, withering the next day: pods fusiform or cylindicul, closely sessile.

1. Ф. biénnis, L. (Common Evening-Primrose.) Erect, mostly hairy ; leaves ovate-lanceolate, acute, obscurely toothed; flowers in a terminal rather leafy spike; calyx-tube much prolonged; petals inversely heart-shaped (light yellow); pods ollong, somewhat tapering above. - Varies greatly; as Var. 1. Muricata, with rough-bristly stem and porls, and petals rather longer than the stamens. Var. 2. GRANDiflókA, with larger and more showy petals. Var. 3. Parviflóra, with petals about the length of the stamens. Var. 4. crucrdrA, with singularly sinall and narrow lincar-oblong petals, shorter than the stamens, and smooth pods. Var. 5. OАкквıגмa ((E. Oakesiana, Rolkins), with a minute and wholly appressed pubeseence, or almost glabrous: otherwisu as Var. 3. - Fields and waste places : very common. June-Sept.

2. CE. rhombipétala, Nutt. Petuls rhombic-ovate, acute; calyx-tube very slender, extended an inch longer than the short eylindrical ovary : otherwise resembling a smoothish or rather hoary narrow-leaved state of No. 1. - Sandy вoil, Illinois, Wisconsin, and westward. July-Sept.

3. F. sinuata, L. Hairy, low, ascending, or at length procumbent; leaves oblong or lanceolate, sinuate-toothed, often pinnatifid, the lower petioled; Howers (small) axillary; petals not longer than the stamens (palle yellow, rose-color in fading); pods cylindrical, elongated. - Sandy fields, New Jersey and southward, priucipally a dwarf state. Juns. 
* Biennials or perennials : flowers diurnal (opening in sunshine), yellow : pods clubshaped, with 4 strong or winged angles and 4 intermediate ribs.

4. CE. glaùca, Michx. Very glabrous, glaucous; leaves ovate or ovatelanceolate; pods obovoid-oblong, 4-winged, almost sessile; root perennial. - Mountains of Virginia, Kentucky, and southward. May-July.-Leaves broader and flowers larger than in the next.

5. CE. fruticosa, I. (SUNmRor.) Ilairy or nearly smooth $\left(1^{\circ}-3^{\circ}\right.$ high) ; laves lanceolate or oblong ; raceme corymbel, naked below ; petals broadly obcordate, longer than the calyx-lobes and stamens; pods oblong-club-shaped, 4winged, longer than the pedicels; root perennial. - Open places, S. New England to Illinois, and southward. June-Aug. - Corolla $1 \frac{1}{2}$ ' broal.

6. G. ripària, Nutt. Scarcely pubescent; leaves linear-lincolate, elongrited, tapering below and somewhat stalked; flowers (large) in a rather leafy at length elongated raceme; petals slightly obcordate; pods oblong-club-shaped, slender-pedicelled, scarcely 4-winged; root biennial. - River-banks and swamps, Quaker Bridge, New Jersey, to Virginia and sonthward.

7. CF. lineàris, Michx. Slender, minutcly hoary-pubescent; leaves linear; flowers (rather large) somewhat corymbed at the end of the branches; pods obovate, hoary, scarcely 4-winged at the summit, tapering into a slender pedicel. - Montauk Point, Long Island, to Virginia and southward. June, July. - Plant $1^{\circ}$ high, bushy-branched : flowers 1 ' wide.

8. G. chrysántha, Michx. Slender, smooth or pubescent; leaves lanceolate, rather blunt; flowers crowded or at first corymbed; petals obovate, notched at the end (orange-yellow), longer than the stamens: pods all pedicelled, oblong-clubshaped, scarcely wing-angled; root biennial? - Banks, Oswego, New York, to Wisconsin and northward. July. - Stem 12'-15' high; flowers larger than in No. 9, from which it may not be distinct.

9. CF. pùmila, L. Almost smooth, small ; leaves lanceolate or oblanceolate, mostly obtuse; flowers in a loose and prolonged leafy raceme; petals obcordate (pale yellow), scarcely longer than the stamens; pods almost sessile, oblong-clubshaped, strongly wing-angled; root perennial or biennial ? - Dry ficlds : common northward, and southward along the Alleghanies. Junc. - Stems mostly simple, $5^{\prime}-12^{\prime}$ high : the corolla $\frac{1^{\prime}}{2}$ broad.

\$ 2. Tube of the calyx funnel-form, strongly 4-nerved, and shorter than the cylindrical ovary, its lobes kerled with the midrib: filaments opposite the petals shorter: anthers oblong, versatile: stigma disk-shaped, almost entire: flowers opening in sunshine or daylight.

10. CF. serrulata, Nutt. Stems low, slightly woody at the base; leaves lance-linear, oblanceolate or linear-spatulate, sharply serrulate or toothed; flowers axillary mostly small; petals yellow, obovate, wavy-crenulate, much longer than the stamens; pods cylindrical, puberulent. - Falls of St. Anthony, Wisconsin (Lesquereux, T.J Hale), and westward.

\section{J USSI 市A, L. JUSSIXA.}

Calyx-tube elongated, not at all prolonged beyond the ovary; the lobes 4-6, herbaceous and persistent. Petals 4-9. Stamens twice as many as the petals. 
Pod 4-6-cellel, usually long, opening between the ribs. Seeds very numerous. - Herbs (ours glabrous perennials), with mostly entire and alternate leaves, and axillary yellow flowers, in summer. (1)edicated to Bernard de Jussieu, tho founder of the Natural System of Botany, as fureler developed by his illustrious nephew.)

1. J. decúrrens, DC. Stem erect $\left(1^{\circ}-2^{\circ}\right.$ high $)$, branching, winged by the decurrent lanceolate leaves ; calyx-lobes 4 , as long as the petals ; pod ublungclub-shaped, wing-angled. - Wet places, Virginia to Illinvis, and southward.

2. J. rèpens, L. Stem cretping, or fluting and rooting; leaves oblong, tapering into a slemder petiole; Howers large, long-peduncled; calyx-lobes and obovate petals 5; prod cyliudrical, with a tapering base. - In water, Illinvis, Kontucky, and southward. Also nat. near Philadelphia.

\section{L U D W Í I A, I. False Loosestrife.}

Calyx-tube not at all prolonged beyond the ovary ; the lobes 4, usually persistent. Petals 4 , uften small or wanting. Stamens 4 . Pod short or cylindrical, many-seeded. Seeds minute, naked, - Perennial herbs, with axillary (rarely capitate) flowers, producel through summer and autumn. (Nanned in houor of Christian G. Lulwiy, I'rofissor of Butany at Leipsic, coutemporary with Liunæus.)

* Leaves all alternate, sessile or nearly so.

- Flowers palunded in the "pper axils, with conspicuous yellow petuls ( 4 " - 8" long), equalling the ovate or lancealate foliaceous lubes of the calyx.

1. L. alternifolia, L. (SEED-13OX.) Smouth or ncarly so, branched ( $3^{\circ}$ high); leures lancealute, acute or pointed at luth ends; pods cubical, rounded at the base, wing-angled. - Swanps : common, especially near the coast. - Puds opening first by a livle where the style falls off, afterwards splitting in pieces.

2. L. hirtélla, Raf. IIsiry all over; stems nearly simple $\left(1^{\circ}-2^{\circ}\right.$ high $)$; leaves ullong, or the upper lancealute, Ulunt at buth ends: pods nearly as in the last, but scarcely wing-angled. - Muist pine barrens, New Jersey to Virginia, and southward. - Fascicled roots often tuberous-thickened.

+ + Fluwers small, sessile (solitury or sometimes clustered or crowded) in the axils, with very small greenish petuls (in No. 5) or mostly none: leaves mastly luncealute or linear on the erect stems $\left(1^{\circ}-3^{\circ}\right.$ high) and nunnerous branches; but prastrute or creeping sterile shouts or stolons are often produced from the base of the stem, these are thickly besct with stiorter obviate or spatulate leaves. (Our species yla. brous, except No. 3.)

3. L. sphærocárpa, Ell. Minutely pubescunt, especially the calyx, or nearly glabrous; leaves lanceolate or lincar, acute, tapering at the base; those of the rumers olowate with a welfre-shaped batse aud glandular-denticulate;

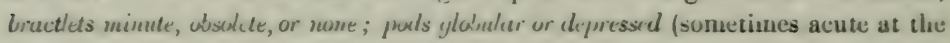
base), not longer than the calyx-lubes (less than 2" long). - Water or wet swamps, E. Miss., S. New York, New Jursey, Penn., and southward. - Bark of lower part of the stem uften spungy-thickened.

4. L. polycárpa, Short \& Peter. Leaves narrowly lanceolate, acute at buth ends; those of the runners oblong-spatulate, acute, entire; bructlets linear- 
avol-shaped, and conspicuous on the base of the 4-sided somewhat top-shaped pod, which is longer than the ealyx-lobes. - Swamps, Michigan to Illinois, Kentucky, and southward.

5. L. linearis, Walt. Slender, mostly low ; leaves narrowly linear, those of the short runuers obovate; minute petals usually present; bractlets minute at the base of the elongated top-shaped 4-sided pod, which is $3^{\prime \prime}$ long and much longer than the ealyx-lobes. - Bogs, pine barrens of New Jersey and southward.

6. L. cylindrica, Fil. Much branched; leaves oblong- or spatulatelanceolate, much tapering at the base, or even petioled ; bractlets very minute at the base of the cylindrical pod, which is $3^{\prime \prime}$ long, and several times exceeds the calyx-lobes. - Mound City, S. Illinois, Dr. Vasey, and southward.

* Leaves all opposite: stems creeping or floating.

7. L. palústris, Ell. (Water Purslane.) Smooth: leaves ovate or oval, tapering into a slender petiole; petals none, or small and reddish when the plant grows out of water; calyx-lobes very short; pods oblong, 4-sided, not tapering at the base, sessile in the axils (2" long). (Isnárdia palustris, L.) Ditches : common. (Eu.)

8. L. arcuata, Walt. Smooth, small and creeping; leaves oblanceolate, nenrly sessile; flowers solitary, long-peduncled; petals yellow, exceeding the calyx ( $3^{\prime \prime}$ long); pods oblong-club-shaped, somewhat curved ( $t^{\prime}$ long). Swamps, Eastern Virginia and southward.

\section{Order 40. MELAs'Tomàcea. (Melastoma Family.)}

Plants with opposite 3-7-ribbed leaves, and definite stamens, the anthers opening by pores at the apex; otherwise much as in the Evening-Primrose Family. - All tropical, except the genus

\section{RHEXIA, L. Deer-Grass. Mendow-Benutr.}

Calyx-tube urn-shaped, coherent with the ovary below, and continued above it, persistent, 4-cleft at the apex. Petals 4, convolute in the bud, oblique, inserted, along with the 8 stamens, on the summit of the calyx-tube. Anthers long, 1-celled, inverted in the bud. Style 1: stigma 1. Pod invested by the permanent calyx, 4-celled, with 4 many-seeded placentre projecting from the central axis. Seeds coiled like a snail-shell, without albumen. - Low perennial herbs, often bristly, with sessile 3 - 5 -nerved and bristle-edged leaves, and large

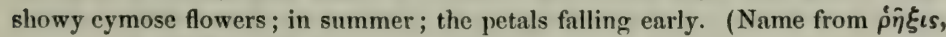
a rupture, applied to this genus for no obvious reason.)

* Anthers linear, curved, with a minute spur on the back at the attachment of the flament above its base: flowers cymose, peduncled.

1. R. Virgínica, L. Stem square, with wing-like angles; leaves oval'anceolate, acute; petals bright purple. - Sandy swamps, E. Massachusetts to Penn., Wisconsin, Illinois, and southward.

2. R. Mariana, L. Stems cylindricul ; lenves linear-oblong, narrowed below; petals paler. - Sandy swamps, New Jersey, Kentucky, and southward. 
* * Anthers oblong, straight, without any spur : flowers few, sessile.

3. R. ciliosa, Michx. Stem square, glabrous; leaves broadly ovate, ciliate with long hristles; calyx glalorous. - Maryland and southward.

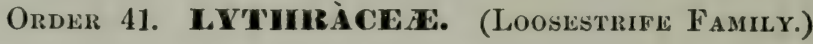

Herbs, with mostly opposite entire leaves, no stipules, the calyx enclosing but free from the 1-4-celled many-seeded ovary and membranous pod, and bearing the 4-7 deciduous petuls and 4-14 stamens on its throat; the latter lower down. Style 1: stigma capitate, or rarely 2-lobed. - Flowers axillary or whorled, rarely irregular, perfect, sometimes dimorphous or even trimorphous, those on different plants with filaments and style reciprocally longer and shorter. Petals sometimes wanting. Pod often 1-celled by the early breaking away of the thin partitions: placente in the axis. Seeds anatropous, without albumen. - Branches usually 4-sided.

* Flowers regular, or nearly so.

1. A mmannia. Calyx short, 4 -iugled, not striate. Potals 4 , or none. Stamens 4 , rarty 2.

2. Lу пуим. Calyx tubular-cylindrical, atriate. Petals 5-7. Staneus 5-14.

3. Neswa. Calyx short-cimpanulate or hemispherical. Staneus $10-1 \pm$, exserted.

* Flowers irregular : petals unequal.

4. Cuphea. Calyx spurred or enlarged on one side at the base. Stamens 12.

\section{A M M Á N N I A, Ilouston. Ammannia.}

Calyx globular or bell-shaped, 4-angled, 4-toothed, usually with a little hornshaped appendage at each sinus. Petals 4 (purplish), small and deciduous, sometimes wanting. Stamens 4, rarely 2, short. Pod globular, 2-4-celled. - Low and inconspicuous smooth herbs, with opposite narrow leaves, and small greenish flowers in their axils, produced all summer. (Named after Paul Ammann, a German botanist anterior to Linnaus.)

\$1. Calyx with manifest tooth-like or horn-shaped appendages at the sinuses : pod 4celled: plants of low or wet ground; ours are annuals.

1. A. hùmilis, Michx. Leaves tapering at the base or into a short petiole, linear-oblanecolate or somewhat spatulate ; flowers solitary or 3 together in the axils of the leaves, sessile; style very short. - Massachusetts to Michigan, Illinois and southward.

2. A. latifolia, L. Leaves linear-lanceolate $\left(2^{\prime}-3^{\prime}\right.$ long), with a broad auricled sessile base; style sometimes very short, sometimes slender. - Ohio, Illinois, and southward. Ship-yards, Philadelphia, an immigrant from the south, C. F. Purker.

§2. HYРOBRÝCHIA, M. A. Curtis. Appendages at the sinuses of the calyx mere callous points or none: petuls none: pod 2-celled.

3. A. Nuttállii, Gray. Submersed ąquatic, or sometimes terrestrial, rooting in the mud; leaves linear, when inmersed clongated, thin, and closely sessile by a broad base, when out of water shorter and contracted at the base; flowers mostly solitary in the axils, sessile, small ; calyx with broad triangular lobes; style very short. (Péplis diandra, Nutt., but stamens usually 4. Hypo- 
brichir Nuttallii, M. A. Curtis.) - Wisconsin and Minnesota (T. J. Hale), Illinois (Buckley, Vasey, IIall, \&c.), and southward. - When in deep water the stems are $1^{\circ}-3^{\circ}$ long, very leafy, the flowers and pods not larger than a pin's head : when terrestrial $2^{\prime}-6^{\prime}$ long, larger-flowered, reseinbling depauperato specimens of No. 1, with obsolete projections at the sinuses.

\section{L $\mathbf{Y} T H R U M$, L. Loosestrife.}

Calyx cylindrical, striate, 5-7-toothed, with as many little processes in the sinuses. Petals 5-7. Stamens as many as the petals or twice the number, inserted low down on the calyx, commonly nearly equal. Pod oblong, 2-celled. - Slender herbs, with opposite or seattered mostly sessile leaves, and purple (rarely white) flowers; produced in summer. (Name from $\lambda \dot{v} \theta \rho o \nu$, blood; per. haps from the crimson blossoms of some species.)

* Stumens und petals 5-7: flowers small, solitary and nearly sessile in the axils of the mostly scattered upper leaves: proper calyx-teeth ofien shorter than the intermediate processes: plants smooth.

1. L. Hyssopifolia, L. Low annual $\left(6^{\prime}-10^{\prime}\right.$ high), pale; leaves oblonglincar, obtuse, longer than the inconspirnous fluwers; petals (pale-purple) 5-6. Marshes, coast of New England and New Jersey. (Eu.)

2. L. alatum, Pursh. Tall and wand-like perennial; branches with margined angles; leaves from oblong-ovate to lanceolate, the upper not longer than the flowers ; petals (decp purple) 6. - Michigan, Wisconsin, and sonthward.

3. L. lineare, L. Stem slender and tall $\left(3^{\circ}-4^{\circ}\right.$ high $)$, bushy at the top, two of the angles margined; leaves linear, short, chinfly opposite, obtuse, or the upper acute and searecly execeling the flowers; calyx obscurely striate; petals (whitish) 6. - Brackish marshes, New Jersey and southward.

* * Stumens 12, twice the number of the petals, 6 longer and 6 shorter: flowers large, crowded and whorled, in an interrupted wand-like spike.

4. L. Salicària, L. (Spiked Loosestrife.) Leaves lanceolate, heartshaped at the base, sometimes whorled in threes. - Wet meadows, Eastern New England, and Orange County, New York : also cultivated. - Plant more or less downy, tall : flowers large, purple, trimorphons, as to respective length of style and filaments in 3 different kinds of individuals.

\section{N ES 妾 A, Commerson, Juss. Swamp Loosestrife.}

Calyx short, broadly bell-shaped or hemispherical, with 5-7 erect tecth, and ns many longer and sprealing horn-like processes at the sinuses. Petals 5. Stamens 10-14, exserted, of two lengths. Pod globose, 3-5-celled. - Perennial herbs or slightly shrubby plants, with opposite or whorled leaves, and axillary flowers (these probably dimorphous or trimorphous).

1. N. verticillàta, H. B. K. Smooth or downy; stems recurved $\left(2^{\circ}\right.$ $8^{\circ}$ long), 4-6-sided; leaves lanceolate, nearly sessile, opposite or whorled, the upper with clustered flowers in their axils on short pedicels; petals 5, weigelanceolate, rose-purple ( $\frac{1}{2}$ ' long); stamens 10, half of them shorter. (Décodon verticillatum, Gmelin.). - Swampy grounds : common eastward. July-Sept. 


\section{C Ù PHE A, Jacq. Cupriea.}

Calyx tubular, 12-ribled, somewhat inflated below, gibbous or spurred at the base on the upper side, 6-toothed at the apex, and usually with as many little processes in the sinuses. Petals 6 , very unequal. Stannens mostly 12, approximate in 2 sets, included, unequal. Ovary with a curved gland at the base next the spur of the calyx, 1-2-celled : style slender: stigma 2-lobed. Pod ublong, few-seeded, early ruptured through one side. - Flowers solitary or racemose, stalked. (Name from кuфós, yibbous, from the shape of the calyx, \&c.)

1. C. viscosíssima, Jacq. (Clasm Curhea.) Aunual, very viscidhairy, branching: leaves ovate-lanceolate; petals ovate, short-clawed, purple. - Dry ficlds, fiom Connecticut to Illinois, and southward. Aug. - Secels flat, borue on one side of the placental, which is carly forced out the ruptured pod.

\section{Order 42. LoAsiceate. (Loasa Family.)}

Herbs, with a rough or stinging pubscence, no stipules, the calyx-tube adherent to a 1-celled ovary with 2 or 3 parielal placenta;-represented here only by the genus

\section{MENTZìla, Plumier. · (Bartònia, Nutt.)}

Calyx-tube cylindrical or club-shaped; the limb 5-parted, persistent. Petals 5 or 10 , regular, spreading, flat, convolute in the bud, deciduous. Stanens indefinite, rarely few, inserted with the petals on the throat of the ealyx. Styles 3 , more or less united into one: stigmas terminal, minute. Pod at length dry and opening irregularly, few - many-seeded. Seeds flat, anatropous, with little albumen. - Stems erect. Leaves alternate. Flowers terminal, solitary or cymose-clustered. (Dedicated to $C$. Mentzel, an early German botanist.)

1. M. oligospérma, Nutt. Rough and adhesive $\left(1^{\circ}-3^{\circ}\right.$ high $)$, much branched, the brittle branches spreading; leaves ovate and oblong, cut-toothed or angled ; flowers yellow $\left(7^{\prime \prime}-10^{\prime \prime}\right.$ broul), opening in sunshine; petals wedgeoblong, pointed; stanens 20 or more: filaments tilitorm: pod small, about 9seeded. - Prairies and plains, Illinois, and on the western plains; - where $\mathbf{M}$. OnNATA and MI. NUDA, with large white flowers, are showy representatives of the genus.

\section{Ordia 43. Cacticente. (Cactus Family.)}

Fleshy and thickened mostly leafless plants, of peculiar aspect, globular, or columnar and many-angled, or flallened und jointed, usually wilh prickles. Flowers solitary, sessile; the scpals and petals numerous, imbricated in several rows, adherent to the 1-eelled ovary. - Stamens numerous, with long and slender filaments, inserted on the inside of the tube or cup formed by the union of the sepals and petals. Style 1 : stigmas numerous. Fruit a 1-celled berry, with nunerous campylotropous seeds on several parietal placentre. - Represented east of the Misolssippi only by the grenus 


\section{OPÚ N T a, Tourn. Prickly Pear. Indian Fig.}

Sepals and petals not united into a prolonged tube, spreading, regular, the inner roundish. Berry often prickly. Seeds flat and margined. Fmbryo coiled around albumen : cotyledons large, foliaceous in germination. - Stem . composed of joints, bearing very small awl-shaped and usually deciduous leaves arranged in a spiral order, with clusters of barbed bristles and often spines also in their axils. Flowers in our species yellow, opening in sunshine for more than one day. (A name of Theophrastus, originally belonging to some different plant.)

I. O. vulgaris, Mill. (Cactus Opuntia, L.) Low, prostrate or spreading, pule, with flat and broally ohovate joints; the minute leaves ovale-sululute and appressed; the axils bristly, rarely with a few smull spines; flowers sulphur-yellow; herry nerrly smooth, pulpy, catable. - Sandy ficlds and dry rocks, from Nantucket, Mass., southward, usually near the coast. June.

2. O. Rafinésquii, Engelm. Joints (deep green) and flowers larger than in the preceding, the latter often with a red centre, and with more numerous $(10-12)$ petals; lenees spreadin!, longer and narrower $\left(3^{\prime \prime}-4^{\prime \prime}\right)$; axils some of them hearing a few small spines and a single strong one $\left(9^{\prime \prime}-12^{\prime \prime}\right.$ long). Wisconsin to Kentucky and westward. June.

3. O. Missouriensis, DC. Prostrate; the joints brondly obovate and flat $\left(2^{\prime}-4^{\prime}\right.$ long), tuberculate; leaves minufe; axils armed with a tuft of strawcolored bristles and 5-10 slender radiating spines $\left(1^{\prime}-2^{\prime}\right.$ long); flowers light yellow; berry dry, prickly. - Borders of Wisconsin and westwarl. May-July.

\section{Order 44. Passifuoràcea. (Passion-Flower Family.)}

Herls or woody plants, climbing by tendrils, with perfect flowers, 5 monadelphous stamens, and a stalked 1-celled ovary free from the calyx, with 3 or 4 parictal placenta, and as many club-shaped styles;-represented by the typical genus

\section{PASSIFLÒRA, L. Passion-Flower.}

Calyx of 5 sepals united at the base into a short eup, imbricated in the bud, usually colored like the petals, at least within; the throat crowned with a double or triple fringe. Petals 5, on the throat of the calyx. Stamens 5: filaments united in a tube which sheathes the long stalk of the orary, separate above: anthers large, fixed by the middle. Berry (often edible) many-seeded; the anatropous albuminous seeds invested by a pulpy covering. Secd-coat brittle, grooved. - Leaves alternate, gencrally palmately lobed, with stipules. Peduncles axillary, jointerl. Ours are perennial herbs. (Name, from passio, passion, and flos, a flower, given by the early missionaries in South America to these blossoms, in which they fancied a representation of the implements of the crucifixion.)

1. P. Iutea, L. Smooth, slender; teaves obtusely 3-lolsed at the summit, the lobrs entire; petioles glandless; flowers greenish-yellow ( $1^{\prime}$ broad). - Damp thickets, S. Penn. to Ill. and southward. July - Sept. - Fruit $\frac{1}{2}$ in diameter, I. \& $\mathrm{M}-28$ 
2. P. incarnàta, L. Nearly smooth; leaves 3 -cleft; the lobes sernate; petiole bearing 2 glands; flower large ( $2^{\prime}$ broad), nearly white, with a triple purple and flestr-colored crowu; iuvolucre 3-leaved. - Dry soil, Virginia, Kentucky, and southward. May-July. - Fruit of the size of a hen's egg, oval, called Mitypops.

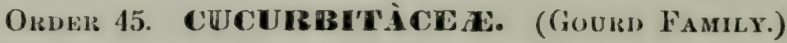

Mostly succulent herls wilh temilils, dicecious or monxcious (offen mono. pilculous) flowers, the calys-tube coltering with the 1-3-celled ovary, and the 5 or usuctly $2 \frac{1}{2}$ stamens. (i. e. one with an one-eelled and 2 with two-celled anthers) commonly united by their often tortuous anthers, and sometimes ulso by the filcments. Fruit (pepo) fleshy, or someimes membranaceous. Limb of the calyx and corolla usually more or less combined. Stigmas 2 or 3. Seeds large, usually llat, anatropous, with no albumen. Cotyleilous leaf-like. Leaves alternate, palmately lobed or veined. - Mostly a tropical or subtropical orler; represented in cultivation by the Gourd (LA-

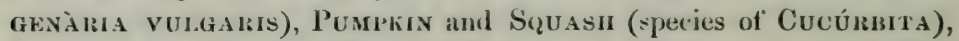
Muskmelon (Cúcumis Mreo), Cucumbers (C. sativus), and WaTEkmelon (Citú́lius veliàrs); while as wild plants, there are only the three following :-

1. Sieyos. Corollis of the sterile flowers flat and spreading, E-lobed. Fruit prickly, judchiscent, 1-cullut, 1 -scciled.

2. Echinocystis. Curulla of the sterile flowers flat and sprealing, 6-parted. Pod prickly, 2-celled. t-sceded, hursting at the top.

3. Melothria. Corollat of the sterile flotvers somewhat canpanulate, 5-cleft. Berry smooth, many-sected.

\section{Sí CY O S, L. One-Seeded Stak-Cucumier.}

Flowers monocious. Petals 5, united below into a bell-shaped or flattish corolla. Anthers colering in a mass. Ovary l-celled, with a single suspended ovule: style slender: stigmas 3. Fruit ovate, dry and indehisent, filled by the single seed, covered with barbed prickly bristles which are readily detached. Climbing annuals, with 3-forkerl tendrils, small whitish flowers; the sterile and fertile mostly from the same axils, the former corymbed, the latter in a capitute cluster, long-peduncled. (Greek name for the Cucumber.)

1. S. angulàtus, I. Leaves roundish heart-shaped, 5-angled or lobed, the lobes pointed; plant clammy-hairy. - River-banks; and a weed in damp yards. July - Sept.

\section{ECHI N O CÝ S T I , Torr. \& Gray. Wild Balsam-aplie.}

Flowers moncecions. Petals 6 , lanceolate, united at the base into an open spreading corolla. Anthers more or less united. Ovary 2 celled, with 2 ereet ovules in each cell : stigma broad. Fruit fleshy, at length dry, clothed with weak prickles, bursting at the summit, 2-celled, 4-seeded, the inner part fibrousnetted. Seeds large, with a thickish hard coat. Tall climbing plants, nearly smooth, with 3-furked tendrils, thin leaves, and very numerous small greenish- 
white flowers; the sterile in compound racemes often $1^{\circ} \mathrm{long}$, the fruitful in small elusters or solitary, from the same axils. (Name composed of éXivos,

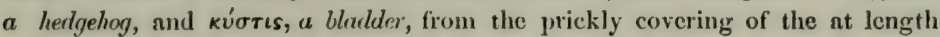
bladdery fruit.)

1. E. lobàta, Torr. \& Gr. Root annual; leaves decply and sharply 5lohed; fruit oval (2' long); secds flat, dark-colored. (Sicyos lobatus, Michx. Momórdica echinata, Mfuhl.) - Rich soil along rivers, W. New England to Wisconsin and Kentucky : also cult. for arbors. July-Oct.

\section{MELÒTHRIA, L. MeLotiria.}

Flowers polygamons or monocious; the sterile campanulate, the corolla 5lobed; the fertile with the calyx-tube constricted above the ovary, then campanulate. Anthers more or less united. Berry small, pulpy, filled with many flat and horizontal seeds. - Tendrils simple. Flowers very small. (Altered from $M \dot{\eta} \lambda \omega \theta \rho o \nu$, an ancient name for a sort of white grape.)

1. M. péndula, I. Slender, from a perennial root, climbing; leaves small, roundish and heart-shaped, 5-angled or lobed, roughish; sterile flowers few in small racemes; the fertile solitary, greenish or yellowish; berry oval, green. - Copses, Virginia and southward. June-Aug.

\section{Order 46. umbechíferde. (Parsley Familt.)}

Herbs, with small flowers in umbels (or rarely in heads), the calyx entirely adhering to the 2-celled and 2-ovuled ovary, the 5 petals and 5 stamens inserted on the disk that crouns the ovary and surrounds the base of the 2 styles. Fruit consisting of 2 seed-like dry carpels. Limb of the calyx obsolete, or a mere 5-toothed border. Petals either imbricated in the bud or valvate with the point inflexed. The two carpels (called mericarps) cohering by their inner face (the commissure), when ripe separating from each other and usually suspended from the summit of a slender prolongation of the axis (carpophore) : each carpel marked lengthwise with 5 primary ribs, and often with 5 intermediate (secondary) ones; in the interstices or intervals between them are commonly lorlged the oil-tubes (vitta), which are longitudinal canals in the substance of the fruit, containing aromatic oil. (These are best seen in slices made across the fruit.) Seeri suspended from the summit of the cell, anatropous, with a minute embryo in hard albumen. - Stems usually hollow. Leaves alternate, mostly compound, the petioles expanded or sheathing at the base: rarely with true stipules. Umbels usually compound; when the secondary ones are termed umbellets : each often subtended by a whorl of bracts (that under the umbel is the involucre; that of the umbellet, involucel). - In many the flowers are dichogamous, i. e. the styles are protruded from the bud some time before the anthers develop, - an arrangement for cross-fertilization. - A large family, some of the plants innocent and aromatic, others with very poisonous (acrid-narcotic) properties; the flowers much alike in all, 
- therefore to be studied by their fruits, inflorescence, \&c., which likewise exhibit comparatively small diversity. The family is therefore diflicult for the young student.

I. Inner face of each seed flat or nearly so (not hollowed out).

- Umbels or heads simple or irregularly cumpound, sometimes pruliferous (i. e. one from the summit of another).

1. Hydrocotyle. Fruit smooth, orbicular or shicld-shaped, flattened laterally. Ieave with an orbicular or roundish blade.

2. Crantzia. Fruit smooth, globular, corky. Leaves are thread-shaped or awl-shaped petioles, with no true blade.

3. Sanicula. Fruit clothed with hooked prickles, globular. Flowers polygamous, cupitute in the unbellets.

4. Eryngium. Fruit clothed with appressed scales or tubercles, top-shaped. Flower perfect, in dense heads.

* * Umbels compound and perfect ; i. e. its rays regularly bearing umbellets.

- Fruit beset with bristly prickles, not flat.

5. Daucus. Fruit beset with weak prickles in single rows on the ribs.

- + Fruit smooth, strongly flattened on the back, and single-winged or margined at the junction of the 2 carpels (next to the commissure).

6. Polytaenia. Fruit surrounded with a broad and tumid corky margin thicker than the fruit itself, which is nearly ribless on the back.

7. Hexacleum. Fruit broadly wing-margined : the carpels minutely 5-ribbed ou the back : lateral ribs close to the margin. Flowers white, the marginal ones radiant.

8. Pastinaca. Fruit wing-margined : ribs of the carpels as in No. 7. Flowerd yellow, tho marginal ones perfect, not radiant.

9. Archemora. Fruit bruadly winged : the 5 ribs on the back equidistant; the 2 lateral ones close to the wing. Flowers white. Leaves pinnate or 3-foliolate.

10. Tiedemannia. Fruit winged, much as in No. 9. Leaves simple, long and cylindrical, hollow, with some cross partitions.

- + - Fruit smooth, flat or flattish on the back, and double-winged or margined at the edge, each carpel also 3-ribled or sometimes 3 -winged on the back.

11. Angelica. Carpels with 3 slender ribs on the back; a siugle oil-tube in each interval. Seed not loose.

12. A rehangelica. Carpels with 3 rather stout ribs on the back, and $2-\mathbf{3}$ or more oiltubes in each interval adhering to the loose seed.

13. Confoselinum. Carpels with 3 wings on the back narrower than those of the margins.

- + - Fruit smooth, not flattened either way, or only slightly so, the cross-section nearly orbicular or quadrate ; the carpels each with 5 wings or strong ribs.

14. REthusa. Fruit ovate-globose : carpels with 5 sharply keeled ridges, and with single oil-tubes in the intervals.

15. Ligusticum. Fruit elliptical : carpels with 5 sharp almost wiuged ridges, and with several oil-tubes in each interval.

16. Thasplum. Fruit elliptical or ovoid : carpels 5-winged or 5-ribbed, and with single oil-tubes in each interval. Flowers yellow or dark purple.

$+\ldots++$ Fruit smuoth, flattened latterally or contracted at the sides, wingless.

17. Zizia. Flowers yellow Fruit oval, somewhat twin: the carpels narrowly 5-rilbed : oiltubes 3 in each interval. Leaves compound.

18. Bupleurum. Flowers yellow. Fruit ovoid-oblong : the carpels somewhat 5-ribbed. Leaves all simple.

19. Discopleura. Flowers white. Fruit ovoid: the lateral ribs united with a thick corky margio. Leaves cut into capillary divisions. 
20. Cienta. Flowers white. Fruit subglobose, twin: the carpels strongly and equally 5ribbed. Leaves twice or thrice ternate.

21. Slum. Flowers white. Fruit ovate or globular : the carpels 5-ribbed. Leaves all simply pinnate.

22. Cry ptotoon Ia. Flowers white. Fruit oblong. Leaves 3-parted. Umbel irregular.

II. Inner face of the seed hollowed out lengthwise, or the margins involute, so that the cross-section is semilumar. (Umbels compound.)

23. Chrerophy $11 \mathrm{um}$. Fruit linear or oblong, nnrrowed or beaked at the apex.

24. Osmorrhiza. Fruit linear-club-shapel, tapering below : ribs bristly.

25. Conlum. Fruit ovate, flattened at the sides : ribs prominent, wavy.

26. Eulophns. Fruit ovoid, somewhat twin, nearly destitute of ribs.

1II. Inner face of the seed hollowed in the middle, or curved inwards at the top and bottom, so that the section lengthwise is semilunar.

27. Erigenia. Fruit twin : carpels nearly kidney-form. Umbellets few-flowered.

\section{HY DROCÓTYLE, Tourn. Water Pennyort.}

Calyx-tecth obsolete. Fruit flattened laterally, orbicular or shield-shaped; the carpels 5-ribbed, two of the ribs enlarged and often forming a thickened margin: oil-tubes nonc. - Low, mostly smooth, marsh or aquatic perennials, with slender creeping stems, and round shicld-shaped or kidney-form leaves, with scale-like stipules. Flowers small, white, in simple umbels or clusters, which are either single or proliferous, appearing all summer. (Name from vँ $\omega \rho$, unter, and коти́ $\eta$, a flat cup, the peltate leaves of several species being somewhat cup-shaped.)

* Peduncles much shorter than the petioles: pedicels short or none: leaves not peliate.

1. H. repánda, Pers. Petioles $\left(2^{\prime}-9^{\prime}\right.$ long $)$ and peduncles $\left(1^{\prime}-2^{\prime}\right.$ long $)$ clustered on the creeping stems or runners; leaves ovate-heart-shaped with a shallow open sinus, repand-toothed, thickish; flowers $2-4$ in a head or cluster, with a conspicuous 2-leaved involucre; ripe fruit ribbed, reticulated between the ribs. - Maryland (W.M. Canby) and southward. - Probably a variety of H. Asiática, $L$.

2. H. ranunculotdes, L. Petioles $\left(2^{\prime}-9^{\prime}\right.$ long $)$ and peduncles $\left(\frac{1^{\prime}}{2}-1^{\prime}\right.$ long, in fruit reflexed) from long commonly floating creeping stems; leaves orbicular or kidney-form, 3-7-cleft, the lobes broad and crenate; flowers 5-10 in a capitate umbel; fruit smooth, scarcely ribbel. - Pennsylvania to Virginia, and southward.

3. H. Americàna, L. Stems, filiform, branching, spreading and creeping; Inaves rounded kidney-form, crenate-lobed and the lobes crenate, thin, very smooth and shining, short-petioled ; the few-flowered umbels of minute flowers in their axils almost sessile. - Shady damp places : common northwart.

* * Peduncles scape-like, as long as the slender petioles, all from slender runners or rootstorks creeping in the mud: lenves orlicular, centrally pellate, simply or doubly crenate: fruit sharp-margined.

4. H. umbellata, L. Umbel many-flowered and simple or sometimes proliferous ( 2 or 3 , above one another); pedicels slender $1 \frac{1}{2}{ }^{\prime \prime}-3^{\prime \prime}$ long); fruit 
notched at base and apex. - Massachusetts on the coast, to Penn. (on the Juniata River, Prof. Purler), and southward. - Petioles and peduncles $3^{\prime}-8^{\prime \prime}$ high: leaves $l^{\prime}-2^{\prime}$ wide.

Vur. ? ambigua. Uubels 3-4; pedicels only once or twice the length of the fruit. - Marylund, $W^{\top} . M$. Cunby. Intermediate between H. umbellata and H. vulgaris : differs from the next by the distinctly pedicelled fruit.

5. H. interrúpta, Muhl. Unbels or rather little leads few-flowered, proliferous and forming an interrupted spike; pedicels scarecly auy, the broadly margined fruit acutish at the base. - Missiachusetts to Virginia and southward, along the coast. - Usually smaller than No. 4.

\section{CR Á N TZIA, Nutt. Crantzia.}

Calyx-tecth obsolete. Fruit globose; the carpels corky, 5-ribbed : an oil-tube in each interval. - Minute perennials, creeping and rooting in the mud, like Hydrocotyle, but with fleshy and hollow eylindrical or awl-shaped petioles, in place of leaves, marked with cross divisions. Unbels few-flowered, simple. Flowers white. (Named for Prof. IIenry Jolen Crantz, an Austriau botanist of the 18th century.)

1. C. lineàta, Nutt. Icaves somcwhat club-shaped, very obtuse $\left(1^{\prime}-2^{\prime}\right.$ long); lateral ribs of the fruit projecting, forming a corky margin. - Brackish marshes, from Massachusetts southward along the coast. July.

\section{SA N Í CULA, Tourn. Sanicle. Black SNakeroot.}

Calyx-teeth manifest, persistent. Fruit globular; the carpels not separating spontaneously, ribless, thickly clothed with hooked prickles, each with 5 oil-tubes. - Perennial rather tall herbs, with palmately-lobed or parted leaves, those from the root long-petioled. Umbels irregular or compound, the flowers (greenish or yellowish) capitate in the umbellets, perfect, and with staminate ones intermixed. Involucre and involucels few-leaved. (Name from sano, to heal.)

1. S. Canadénsis, L. Leaves 3-5- (the upper only 3-) parted; stcrile flouers few, scarcely pedicelled, shorter than the fertile ones; styles shorter than the prickles of the fruit. - Copses. June-Aug. - Plant $1^{\circ}-2^{\circ}$ high, with thin leaves; their divisions wedge-ohovate or oblong, sharply cut and serrate, the lateral mostly 2-lobed. Fruits few in each umbellet.

2. S. Marilándica, I. I.caves all 5-7-parted; sterile flowers numcrous, on slender pedicels, about the length of the fertile; styles clongrted and conspicuous, recurved. - Woods and copses : common. - Stem $2^{\circ}-3^{\circ}$ high; the leaves more rigid and with narrower divisions than in the former, with almost cartilaginous teeth. Fruits severial in each unbellet.

\section{ERÝ NGI U M, Tourn. Eryngo.}

Calyx-teeth manifest, persistent. Styles slender. Fruit top-shaped, covered with little seales or tulucreles, with no ribs, and scarcely any oil-tubes. - Chiefly perenuials, with coriaceous, toothed, cut, or prickly leaves, and blue or white bracted flowers closely sessile in dense heads. (A name used by Dioscorides, of uncertain origin.) 
1. E. yuccæfolium, Michx. (Rattuesnake-Master. Button Snakenoor.) Lewes linear, taper-pointed, rigid, grass-like, nerved, bristly-fringed; leaflets of the involuere mostly entire and shorter than the hearls; root perennial. (E. nquaticum, $L$., in part, but never aquatic.) - Jry or damp pine-barrens or prairies, New Jersey to Wisconsin, and southward. July, Aug.

2. E. Virginiàum, Lam. Lites lincar-lanceolate, serrate with hooked or somewhat spiniy trith, veiny; leaflets of the involucre cleft or spiny-toothed, longer than the cymose whitish or bluish heads; root biennial. - Swamps, New Jersey and southward near the coast. July.

\section{D A Ù C U S, Tourn. CArrot.}

Calyx 5-toothed. Corolla irregular. Fruit ovoid or oblong; the carpels scarcely flattened on the back, with 5 primary slender bristly ribs, two of them on the inner fice, also with 4 equal and more or less winged secondary ones, cach hearing a single row of slender bristly prickles : an oil-tube under each of these ribs. - Biennials, with finely 2 -3-pinnate or pinnatifid leaves, cleft involucres, and concave umbels, dense in fruit. ('The ancient Grcek name.)

1. D. Canóta, L. (Сомmon Carrot.) Stem bristly ; involucre pinnatifid, equalling the umbel. - Spontaneous in old fields. July-Sept. - Flowers white or crenm-color, the central one of each umbellet ahortive and dark-purple. Umbel in fruit dense and concave, resembling a birl's nest. (Adv. from Eu.)

\section{POLYT 宛 NA, DC. Polytenia.}

Calyx 5-toothed. Fruit oval, very flat, with an entire broad and thick corky margin, the impressed back very obscurely ribbed : oil-tubes 2 in each interval, snil many in the corky margin. - A smooth herb $\left(2^{\circ}-3^{\circ}\right.$ high $)$, resembling a Parsnip, with twice-pinnate leaves, the uppermost, opposite and 3-cleft, no involucres, briatly involucels, and bright yellow flowers. (Name from moxús, many, and ratvia, a fills, alluding to the numerous oil-tubes.)

1. P. Nuttâllii, 1)C. - Barrens, Michigan, Wisconsin, and southwestward. May.

\section{H E R A C L U U, L. Cow-PARsnir.}

Calyx-tecth minute. Fruit as in Pastinaca, but the oil-tubes shorter than the carpels (reaching from the summit to the middle). Petals (white) inversely heart-shaped, those of the outer flowers commonly larger and radiant, appearing 2-cleft. - Stout perennials, with broad sheathing petioles and large flat umbels. Involucre decidnous : involucels many-leaved. (Dedicated to Hercules.)

1. H. lanàtum, Michx. Woolly; stem grooved; leaves 1-2-ternately compound ; leaflets somewhat heart-shaped ; fruit obovate or orbicular. - Moist rich ground : most common northward. June. - A very large, strong-scented plant, $4^{\circ}-8^{\circ}$ high, in some places wrongly called Masterwort.

\section{PASTIN À CA, Tourn. PAnsmir.}

Calyx-tceth obsolete. Fruit oval, flat, with a thin single-winged margin; the carpels minutely 5-ribbed; three of the ribs equidistant on the back, the lateral 
ones distant from them and near the margin : an oil-tube in each interval, of the length of the fruit. Petals yellow, roundish, entire; none of the flowers radiant. - Chicfly biennials, with spind!c-shaped roots, and pinnatcly-compound leaves. Involucre and involucels small or none. (The Latin name, from pastus, fuod.)

1. P. sativa, I. (Common P.uisnir.) Stem grooved, smooth; leaflets ovate or oblong, obtuse, cut-toothed, somewhat shining above. - Fields, \&c. July. (Adv. from Eu.)

\section{ARCH Ǵm RA, DC. Cowbane.}

Calyx 5-toothed. Fruit with a broal single-winged margin, oval, flatish: the carpels with 5 obtuse and approxinated equidistant ribs on the convex back. oil-tubes one in each interval, and $4-6$ on the inner face. - Smooth perennials, with rather rigid leaves of 3-9 lanceolate or linear leaflets. Involucre nearly none: involucels of numerous small leaflets. Flowers white. (Name applied to this poisonous unbelliferous plant in fanciful allusion to Archemorus, who is said to have died fiom eating parsley. $D C^{\prime}$.)

1. A. rígida, DC. Leaves simply pinnate; leaflets 3-9, varying from lancelate to ovate-oblong, entire or remotely toothed, or, in Var. AMBfiUA, linear, long and narrow. - Sandy swamps, New Jersey and W. New York to Michigan, Illinois, and southward. Aug. - Stem $2^{\circ}-5^{\circ}$ high.

\section{TI I DEM Á N N I A, DC. False Water-Dropwort.}

Calyx 5-toothed. Fruit with a single-winged margin, obovate, fluttish; the carpels with 5 equidistant slender ribs on the convex back : oil-tubes one in cach interval, and 2 on the inner face. - A smooth and erect aquatic herb, with a hollow stem $\left(2^{\circ}-6^{\circ}\right.$ high $)$, and cylindrieal pointed and hollow petioles (the cavity divided by cross partitions) in place of leaves. Involucre and involucels of few subulate leaflets. Flowers white. (Dedicated to the distinguished anatomist the late Prof. Ticdemann, of Heidelberg.)

1. T. teretifolia, DC. Virginia (IIarjer's Ferry) and southward. Aug.

\section{A N GÉLICA, L. Angelica.}

Calyx-tecth obsolete. Fruit flattened, with a double-winged margin at the commissure; i. e. the lateral rib of each oval carpel expanded into a wing; their flattish backs each strongly 3-ribbed: an oil-tube in ench interval, and $2-4$ un the inner lace. Seed anllerent to the pericarp. - Stout perennial herbs, more or less aromatic, with first teruately, then once or twice pinnately or ternatcly divided leaves, toothed and cut ovate or oblong leaflets. large terminal umbels, scanty or no involucre, and small many-leaved involucels. Flowers white or greenish. Petioles membranaceous at the base. (Named angedic from its cordial and medicinal properties.)

1. A. Curtísii, Buckley. Nearly glabrous; leaves twice ternate or the divisions quinate; leaflets thin, ovate or ovate-lancevate, pointed, sharply cut and toothed; involucels of small subulate leaflets; wings of the fruit broad. -Mountains of Pennsylvania (Piof. Porter), Virginia, and southward in the Allaghanies. Aug. 


\section{A RCHA NGEL i CA, Hoffm. Archangelica.}

Calyx-tceth short. Seed becoming loose in the pericarp, coated with numerous oil-tubes which adhere to its surface. Otherwise as in Angelica, from which the species have been seprated, with hardly sufficient reason.

1. A. hirsùta, Torr. \& Gr. Woolly or downy at the top $\left(2^{\circ}-5^{\circ}\right.$ high $)$, rather slender; leaves twice pimnately or ternately divirled; leaflets thickish, ovate-oblong, often blunt, serrate; involucels as long as the umbellets; peduncles and fruit douny, broadly winged. (Angélica triquinàtn, Nutt.) - Dry open woods, New York to Michigan, and southward. July. - Flowers white.

2. A. atropurpurea, Hoffm. (Grent ANGeLjCA.) Smooth; stem dark purple, very stout $\left(4^{\circ}-6^{\circ}\right.$ high), hollow; lenves 2 -3-termately compound; the leaflets pinnate, 5-7, sharply cut serrate, acute, pale benenth; petioles much inflated; involucels very short; fruit smooth, winged. (Angélica triquinàta, Michx.) - Low river-banks, New England to Penn., Wisconsin, and northward. June. - Flowers grcenish-white. Plant strong-scented.

3. A. Gmélini, 1)C. Stern a little downy at the summit $\left(1^{\circ}-3^{\circ}\right.$ high $)$; leaves 2-3-ternately divided; the leaflets ovate, acute, cut-scrrate, glabrous; involucels about as long as the umbellets; fruit oblong with 5 thick and corky winglike rils to each carpel, the marginal ones little broader than the others. (A. peregrína, Nutt., \& ed. 2.) - Rocky coast of Massachusetts Bay and northward. July. - Flowers greenish-white. Plant little aromatic. Fruit so thick and so equally ribbed, rather than winged, that it might be taken for a Ligusticum.

\section{CO N I OSELì N U M, Fischer. Hemlock-Parsley.}

Calyx-tecth obsoletc. Fruit oval: the earpels convex-flattish and narrowly 3-winged on the back, and each more broadly winged at the margins : oil-tubes in the substance of the pericarp, $1-3$ in ench of the intervals, and several on the inner face. - Smooth perennials, with fincly 2-3-pinnately compound thin leaves, inflated petioles, and white flowers. Involucre scarcely any : leaflets of the involucels awl-shaped. (Name compounded of Conium, the Hemlock, and Selimum, Milk-Parsley, from its resemblance to these two genera.)

1. C. Canadénse, Torr. \& Gr. Leaflets pinnatifid; fruit longer than the peclicels. - Swamps, Vermont to Wisconsin northward, and southward through the Alleghanies. Aug. - Herbage resembling the Poison Hemlock.

\section{4. 府TH U̇ $\mathbf{S}$, L. Fool's Parslex.}

Calyx-tecth obsolete. Fruit orate-globose; the carpels each with 5 thick sharply-kecled ridges: intervals with single oil-tubes. - Annual, poisonous herbs, with 2-3-ternately compound and many-cleft leaves, the divisions pinnate, and white flowers. (Name from a $\theta \omega \omega$, to burn, from the acrid taste.)

1. 尼. CrNipium, L. Divisions of the leaves wedge-lanceolate; involucre none: involucels 3-leaved, long and narrow. - About cultivated grounds, New Jenglanil to Penn. July. $-\Lambda$ fetirl, poisonous herb, with much the nspect of Poison Hemlock, hut with dark-green foliage, long hanging involucels, and unspotted stem. (Adv. from Eu.) 


\section{LIG Ú STICUM, L. Lovage.}

Calyx-teeth small or minute. Fruit elliptical, round on the cross-section, or slightly flattened on the sides; the carpels each with 5 sharp and projecting or narrowly winged ridges : intervals and inner face with nuny oil-tubes. - Perennials, with aromatic roots and fruit, 2-3-ternately compound leaves, and whito flowers. (Named from the country Liguria, where the officinal Lovage of the gardens, L. Levisticum, abounds.)

1. L. Scóticum, L. (Scotcu Lovagk.) Very smooth; stem (20 high), simple; leaves 2-ternate; leaflets rhombic-ovate, coarsely toothed or cut; leaflets of the involucre and involucels linear; calyx-teeth distinct; fiuit narrowly oblong.

- Salt marshes, from Rhode Island northward. Aug. - (Eu.)

2. L. actæifölium, Michx. (Nondo. Angelico.) Smooth; stem (3$6^{\circ}$ high) branched above; the numerous umbels forming a loose and naked somewhat whurled panicle, the lateral ones mostly barren; leaves 3-ternate; leaflets broally ovate, equally serrate, the end ones often 3-parted; calyx-tecth minute; ribs of the short finit wing-like. - Rich woods, Virginia, Kentucky, and southward along the mountains. July, Aug. - Root large, with the strong aromatic odor and taste of Angelica. (Michaux's habitat, "Banks of the St. Lawrence," is probably a mistake.)

\section{TH Á S P U M, Nutt. Meadow-Parsnip.}

Calyx-tecth obsolete or short. Fruit ovoid or oblong, somewhat flattish or contrated at the sides (the cross-section of each seed orbicular and somewhat angled or 5-angular); the carpels each with 5 strong and equal ribs or wings, the lateral ones marginal : oil-tubes single in each interval. - Perennial herbs, with 1-2-ternately divided leaves (or the root-leaves simple), umbels with no involucre, minute few-leaved involucels, and yellow or sometimes dark-purple flowers. (Name a play upon Theysia, a genus so ealled from the island of 'Thap)sus.) I include in this genus Zizia, Koch, - because the same species has fruit either ribbed or winged, - and retain the name of ' Zizia for $Z$. integerpina, $D($.

* Stems loosely branched, $2^{\circ}-5^{\circ}$ high, mostly pubescent on the joints: calyx short but manifest: corolla light yellow: leaves all ternutely compound.

1. T. barbinode, Nutt. Leaves 1-3-ternate; leaflets voate or lance-ovate and acute, mostly with a walge-shaped base, above decply cut-serrate, often 2 -3-cleft or parted, the terminal one long-stalked $\left(1^{\prime}-2^{\prime}\right.$ long $)$; fruit oblong, 6-10-winged ( $3^{\prime \prime}$ long), some of the dorsal wings often narrow or obsolete. - River-banks, W. New York to Wisconsin, and southward. July.

2. T. pinnatífidum, Gray. Branchlets, umbels, \&c. roughish-puberulent; leaves 1-3-ternate; lenglets 1-2-pinnatifid, the lobes linear or oblong; fruit oblong, narrowly 8-10-winged ( $1 t_{2}^{\prime}$ long), the intervals minutely scabrous. (Zizia pinnatifida, Buckley. Thaspium Walteri, Shutllew., excl. syn. Wult.) - Barrens of Kentucky (Short), and southward in the mountains.

* * Stems somewhut bianclied; the whole plant glabrous : calyx-teuth obscure.

3. T. aùreum, Nutt. Leaves all 1-2-ternately divided or parted (or rarely nome of the root-leaves simple and heart-shaped) ; the divisions or leyflets obloney- 
lanreolate, very sharply cut-sermete, with a wedge-shaped entire base; flowers deep yellow; fruit oblong-vval, with 10 winged ridges. - Moist river-banks, \&c. June.

Var. ápterum. Fruit with strong and sharp ribs in place of wings. (Smýrnium aureum, L. Zizia aurea, Koch.) - With the winged form.

4. T. trifoliatum. Rool-lenves or some of them round and heart-shaped; stem-lenves simply termate or quinete, or 3-purted; the divisions or leaflets ovutelimerolale or roundish, mostly alorupt or heart-shaped at the base, crenatcly toothed; flowers deep yellow; fruit globose-ovoid, with 10 winged rilges. - Rocky thickets, Vermont to IVisconsin, and southward : rare eastward. June.

Var. atropurpùreum, 'Torr. \& Gr. Petals decp dark-purple. ('Thápsin trifoliata, L. Smyrniun cordatum, Wolt. 'Thaspium atropurpureum, Nutt.) - From New York westward and sonthward.

Var. ápterum. Petrls yellow : fruit with sharp ribs in place of wings. (Zizia cordata, Koch, Torr.) With the preceding form.

\section{ZÍZIA, DC. partly. (ZizIA § Tenfois, Torr. \& Gr.)}

Calyx-teeth obsolete. Fruit ovoid-oblong, contracted at the junction of the carpels so ns to become twin, the cross-section of each secd nearly orbicular: carpels somewhat fleshy when fresh, with 5 slender ribs (which are more conspicuous when dry) : oil-tubes 3 in each interval and 4 on the inner face. $-A$ perennial smooth and glaucous slender herb $\left(2^{\circ}-3^{\circ}\right.$ high $)$, with $2-3$-ternately compound leaves, the leaflets with entire margins; umbels with long and slender rays, no involnere, and hardly any involucels. Flowers yellow. (Named for I. B. Ziz, a Rhenish botanist.)

1. Z. integérrima, DC. - Rocky hillsides : not rare. May, June. •

\section{B U P LE U R U M, Tourn. Thoroveir-wax.}

Calyx-teeth obsolete. Fruit ovate-oblong, flattened laterally or somewhat twin, the carpels 5-ribbed, with or without oil-tubes. Plants with simple entire leaves and yellow flowers. (Name from ßoôs, an ox, and $\pi \lambda \epsilon u p o ́ v, a$ rih.)

1. B. rotunnffólum, L. Leaves ovate, perfoliate; involucre none; involucels of 5 ovate leaflets. - Fields, New York to Virginia : rare. (Adv. from Eu.)

\section{DI SCOPLE Ù RA, DC. Mock Brsior-weed.}

Calyx-tecth awl-shaped. Fruit ovoid; the carpels each with 3 strong ribs on the back, and 2 broad lateral ones united with a thickened corky margin : intervals with single oil-tubes. - Smooth and slender branched annuals, with the leaves finely dissected into bristle-form divisions, and white flowers. Involucre

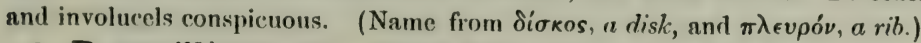

1. D. capillacea, DC. Umbel ferv-rayed ; leaflets of the involucre 3-5cleft; involucels longer than the umbellets; fruit ovate in ontline. - Brackish swamps, Massachusetts to Virginia, and sonthward. July-Oct.

Var. ? costata, I)C. I arger ; rays and divisions of the involucre numerous; ribs of the fruit stronger. - S. Illinois (Vasey) and southwestward.

2. D. Nuttallii, DC. Umbel many-rayed ; leaflets of the involıce entire and shorter; fruit globular. - Wet prairies, Kentucky and southward. 


\section{CI C Ù T A, L. Water-HemLock.}

Calyx minutely 5-toothed. Fruit subglobose, a little contracted at the sides the carpels with 5 flattish and strong ribs: intervals with single oil-tubes. Marsh perennials, very poisonous, smooth, with thrice pinnately or ternately compound leaves, the veins of the lanceolate or oblong leaflets terminating in the notches. Involucre few-leaved: involucels many-leaved. Flowers white; in sumner. ('The ancient Latin name of the Hemlock.)

1. C. maculàta, L. (Shotted Cowbane. Musquasil Root. Beaven-Poison.) Stem streaked with purple, stout; leuflets oblong-lanceolate, coursely serrate, sometimes lobed, pointed. - Swamps : common. Aug. Plaut $3^{\prime}-6^{\circ}$ high, coarse; the root a deadly poison.

2. C. bulbifera, L. Leaflets lincar, remotely toothed or cut-lobed; upper axils bearing clustcred bulblets. - Swamps : common northward : scldom firuiting.

\section{Si U M, L. Wateir-Pairsip.}

Calyx-teeth small or none. Fruit oblong, ovate or globular, flattish or contracted at the sides; the carpels with 5 mostly strong rilss : intervals with 1 several oil-tubes. - Marsh or ayuatic perennials, smooth, poisonous, with sharpangled or grooved stems, simply pinnate leaves, and serrate or incised leaflets, or the immersed leaves more compound. Involuere several-leaved. Flowers white; in summer. (Name supposed to be from the Celtic siu, water.)

* Pericarp thin between the strong projecting ribs: lateral ribs marginal.

1. S. lineàre, Michx. 'T'all $\left(2^{\circ}-4^{\circ}\right)$; leaflets linear, lanceolate, or oblonglanceolate, tapering to a sharp point, very sharply serrate; calyx-teeth none or obsolete; fruit globular, with corky and very salient rils, or rather wings ; oil-tubes $1-3$ in the very narrow intercals. (S. cicutafolium, Gmelin, of Siberia is probably the same, and if so, the older name.) - In water or wet places : conmon.

S. Latifóliun, L., of Europe (for which broal-leaved forms of our plaint have been mistaken), if ever found in this country, will be known by its blunt or less tapering leaves, slender calyx-tecth, and much less projecting or winglike ribs to the more oval fruit.

2. S. Carsonii, Durand, ined. Smaller $\left(1^{\circ}-2^{\circ}\right.$ high $)$, lranched; leaflets 3-7, thin, varying from lincar to oblong, acute, sharply serrate; calyx-teeth none or obsolete; fimit oroid-ylubular, with strong filiform rils, the broad interrals with 1-3 conspicuous oil-tubes. - Wet lanks of streams, or in flowing water (when the submersed or floating leaflets are very thin, sometimes redued to the terminal one, ovate or oblong, and usually laciniate-toothed or dissected : in this state it was doubthully referred to IIslosciàtium nodiflorum, Koch, in ardend. to ed. 2). - Pennaylvania, around the Pocono Mountain, Prof. Traill Green, Prof. T. C. P'orter, 1r. Carson. Counceticut, Prof. D. C. Eaton.

* Ribs inconspicuous or confluent in the thick texture of the pericarp, concealing the numerous oil-tubes, the lateral ones not quile murginal. (Bérula, Kuch.)

2. S. angustifolium, L. Low $\left(9^{\prime}-20^{\prime}\right.$ high); leaflets varying from oblong to linear, mostly cut-toothed and cleft or even pinnatifid; peluncles short; fruit ovate; calys-teeth searely any. - Wet places, Massachusetts ( $\mathbf{I}$. A. Cutis in lierb Durand), Michigan, Illinois (Dr.Vusey), and westivard. (Liu.) 


\section{CRYPTOT 寉NIA, DC. Honewort.}

Calyx-tecth obsolete. Fruit oblong, contracted at the sides; the carpels equally and obtusely 5-ribbed : oil-tubes very slender, one in each interval and one under each rib. Seed slightly concave on the inner face. $-\Lambda$ perennial smooth herb, with thin 3 -foliolate leaves, the umbels and umbellets with very unequal rays, no involucre, und few-leaved involucels. Flowers white. (Name

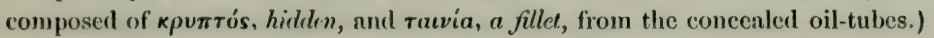

1. C. Canadénsis, DC. - 'Thickets : common. June-Sept. - Plant $2^{\circ}$ high. Leaflets large, ovate, pointed, doubly serrate, the lower ones lobed.

\section{C H 开 ROPHÝ PLUM, L. Chenvil.}

Calyx-tecth obsolete. Fruit linear or oblong, pointed or short-beaked, contracted at the sides; the carpels 5-ribbed, at least at the apex: inner face of the seed deeply grooved lengthwise: intervals usually with single oil-tubes. Chiefly annuals or biennials : leaves ternately decompound; the leaflets lobed or toothed : involucre scarcely any: involucels many-leaved. Flowers chiefly white. (Name from $\chi a i p \omega$, to gladden, and $\phi \dot{u} \lambda \lambda o v$, a lenf, alluding to the agreenble sromatic odor of the foliagc.)

1. C. procúmbens, Lam. Stems slender $\left(6^{\prime}-18^{\prime}\right)$, sprealing, a little hairy ; lobes of the pinnatifid leaflets obtuse, oblong; umbels few-rayed (sessile or peduncled) ; fruit narrowly oblong, with conspicuous narrow ribs, not beaked.

- Moist copses, New Jersey to Illinois and southward. May, June.

2. C. satrudu, Lam. (Garinen Cuenvil.) Taller; lobes of the leaves ovate and pinnatifid ; fruit oblong-lincar, ribless, but tapering in to a ribbed beak shorter than the seed. (Anthriscus Cerefolium, Iloffim.) - Rarely seen in gardens (as a sweet herb), but thoroughly spontancous in ficlels and copses near Lancaster, Penn., Prof. T. C. Porter. (Nat. from Eu.)

\section{OSMORRHì ZA, Raf. Sweet Cicely.}

Calyx-tecth obsolete. Fruit linear-oblong, angled, tapering downwards into a stalk-like base, contracted at the silles, crowned with the styles; the carpels with sharp "1pwarlly bristly ribs: inner face of the nearly terete seed with a deep longitudinal channel : oil-tubes none. - l'erennials, with thick sweet-aromatic roots, and large 2-3-ternately compound leaves; the leaflets ovate, pinnatifid-toothed. Involucre and involucels few-leaved. Flowers white. (Name from $\dot{\sigma} \sigma \mu \dot{\eta}, a$ scent, and $\hat{\rho} i \zeta \zeta_{a}, a$ root, from the anise-like flavor of the latter.)

1. O. longístylis, DC. (Smootuer Sweet Cicely.) Styles slender, nearly as long as the ovary; lenflets sparingly pubescent or smooth when old, shortpointed, cut-toothed, sometimes lobed. - Rich moist woods : commonest northward. May, June. - Plant $3^{\circ}$ high, branching : stem reddish.

2. O. brevístylis, DC. (HAiry Sweer Ciceny.) Styles conical and not longer than the breadth of the orary; fruit somewhat tapering at the summit; leaflets downy-hairy, taper-pointed, pinnatifid-cut. - Common : root less sweet.

\section{CONIUM, L. Porson Немlock.}

Calyx-teeth obsolete. Fruit ovate, flaftened at the sides, the carpels with 5 prominent wavy ribs, and no oil-tubes: inner face of the seed with a deep nar 
row longitudinal groove. - Biennial poisonous herbs, with large decompound leaves. Involucre and involucels 3-5-leaved, the latter 1-sided. Flowers white.

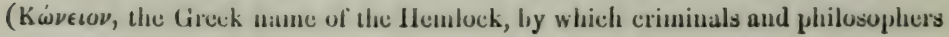
were put to death at $\Lambda$ thens.)

1. C. Maculdtum, L. Simooth; stem spotted; leaflets lanceolate, pinnatifid: involucels shorter than the umbellets. - Waste places. July. - A large branching herb: the pale green leaves exhale a disagreeable odor when bruised. A virulent narcotico-acrid poison, used in medicine. (Nat. from L̀u.)

\section{EÙLOPHUS, Nutt. Eulorius.}

Calyx-teeth small. Fruit ovoid, contracted at the sides and somewhat twin; the carpels smouth, inclistinctly ribbed, and with a close row of vil-tubes: inner face of the seed longitudinally channelled, the cross-section semiluuar. - A slender, smooth peremial : leaves 2-ternately divided into narrow linear leaflets. Involucre scarcely any: involucels bristle-form. Flowers white. (Name firumi $\epsilon \dot{v}$,

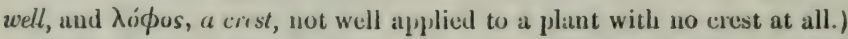

1. E. Americànus, Nutt. - 1) atloy platins, near Columbus, ()his (Sullivant), Illinois, and sunthwestward. July. - Root a cluster of small tubers.

\section{ER I G È I A, Nutt. IIAhingen-of-Spring.}

Calyx-tecth obsolcte. I'etals obovate or spatulate, flat, entire. Fruit twin; the curpels incurved at top and bottom, nearly kiduey-form, with 5 very slender ribs, and several small oil-tubes in the interstices: imner face of the seed hollowed into a broad deep cavity. - A small and smooth verual plant, producing from a deep round tuber a simple stem, bearing one or two 2-3-ternately divided leaves, and a somewhat imperfect and leafy-bracted compound umbel. Llowers

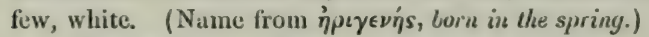

1. E. bulbòsa, Nutt. - Alluvial soil, Western New York and Penn. to Wisconsin, Kentucky, \&c. Mareh, A pril. - Stem $3^{\prime}-9^{\prime}$ high.

\section{Order 47. aralidicede. (Ginseng Family.)}

IIerbs, shrubs, or trees, with much the same charucters as Umbellifirx, but with usually more than 2 styles, and the fruit a feus-several-celled drupe. (Albumen mostly fleshy. Petals not inflexed.) - Represented here only by the genus

\section{A R À L I A, Tourn. Ginseng. Wild Sargapariula.}

Flowers more or less polygamous. Calyx-tube coherent with the ovary, the teeth very short or almost olssolete. Petals 5, cpigynous, oblong or obovate, lightly imbricated in the bud, deciduous. Stamens 5, epigynous, alternate with the petals. Styles $2-5$, mostly distinct and slender, or in the sterile flowers short and united. Ovary $2-5$-celled, with a single anatropous ovule suspended from the top of each cell, ripening into a berry-like drupe, with as many seeds as cells. Embryo minute. - Leaves compound or decompound. Flowers white or greenish, in umbels. Roots (perenuial), bark, fruit, \&e. warm and aromatic. (Derivation obscure.) 
8 1. ARALIA, L. Flowers monacionsly polygamous or perfect, the umbels usually in corymbs or panicles: stylss und cells of the (bluck or durk purple) fiuit $5:$ stems herbaceous or woody: ullimate divisions of the leaves pinnnte.

* Umbels very numerous in a large componnd panicle: leaves very large, quinately or pinnately decompound.

1. A. spinósa, L. (Angelica-tree. Hercules' Cuub.) Shrub, or a low tree; the stout stem and stulks mrickly; leaflets ovate, pointed, serrate, pale beneath. - River-banks, Penusylvania to Kentucky and southward : common in cultivation. July, August.

2. A. racemosa, L. (Srikenarn.) Iterbaceous; stem widcly branched; lerflets heart-ovate, pointed, doubly serrate, slightly downy; umbels racemose; styles united. - Rich woodlands. July. - Well known for its spicy-aromatic large roots. 'There are traces of stipules at the dilated base of the leafstalks.

* Umbels 2-7, corymbed: stem short, somewhat woody.

3. A. híspida, Michx. (Bristly Sarsaparilla. Wild Elder.) Stem $\left(1^{\circ}-2^{\circ}\right.$ high), brisly, leafy, terminating in a peduncle bearing several umbels; leaves twice pinuate; leaflets oblong-ovate, acute, cut-serrate. - Rocky places: common nofthward, and southward along the mountains. June.

4. A. nudicaùlis, L. (Wud Sarsapanula.) Stem scarcely rising out of the ground, smooth, bearing a single long-stallied leaf and a shorter naked scape, with 2-7 umbels; leaflets oblong-ovate or oval, pointed, scrrate, 5 on each of the 3 divisions. - Moist woodlands; with the same range as No. 3. May, June. The aromatic horizontal roots, which are several feet long, are employed as a substitute for the officinal Sarsaparilla. Leafstalk $1^{\circ}$ high.

§ 2. (ifNSENG, Decaisne \& Planchon. (Panax, $\left.I_{\text {.. }}\right)$ Flouers dixciously polygumous : styles and cells of the (red or reddish), fruit 2 or 3 : stem herbaccous, low, simple, benring at its summit a. whorl of 3 palmutrly 3 - 7-foliolule. leaves (or perheps rather a single and scssile twice-compond loaf), and a single umbel on a slender naked neduncle.

5. A. quinquefolia. (Ginseng.) Ront large and spindle-shaped, often forked $\left(4^{\prime}-9^{\prime}\right.$ long, aromatic); stem $1^{\circ}$ high; leceflets long-stallied, mostly 5 , large and thin, ohovate-ohlong, pointed; styles mostly 2 ; frit bright red. (Panax quinquefolium, L.) - Rich and cool woods: becoming rare. July.

6. A. trifolia. (Dwarf Ginsenc. Ground-nut.) Root or tuber globular, dcep in the ground (pungent to the taste, not aromatic); stems $4^{\prime}-8^{\prime}$ high ; lenf; lets $3-5$, sessile at the summit of the leafstalk, narrowly oblong, obtuse; styles usually 3 ; fruit yellowish. - Rich woods : common northward. A pril, May.

Hènera HèLix, the European Ivy, is almost the only other representative of this family in the northern temperate zone.

\section{Order 48. Cornàcere. (Dogwoon Famitu.)}

Shrubs or trees (rarely herbaceous), with opposite or alternate simple leaves, the calyx-tuhe coherent with the 1-2-celled ovary, its limb minute, the petals (valvate in the burl) and as many stamens borne on the margin of an epigynous disk in the perfect flowers; slyle one; a single analropous ovule hany- 
ing from the top of the cell; the fruil a 1-2-seeded drupe; embryo nearly the lenglh of the alloumen, with larye and foliaceous cotyledons. - A small family represented by Cornus, and by a partly apetalous genus, Nyssa. (Bark bitter and tonic.)

\section{Có R N U S, Tourn. Cornel. Dogwood.}

Flowers perfect (or in some foreign species dioceious). Calyx minutely 4toothed. l'etals 4, oblong, spreading. Stamens 4 : filaments slender. Style slender : stigma terminal, flat or capitate. Drupe small, with a 2-celled and 2seeded stone. - Leaves opposite (except in one species), entire. Flowers small, in open naked cymes, or in close heads which are surromeded by a corolla-like involucre. (Name from cormu, a horn; alluding to the hardness of the wood.)

\$1. Flowers greenish, in a head or close cluster, which is surrounded by a large and showy, 4-leaved, corolla-like, white or rarely pinkish involucre: fruit bright red.

1. C. Canadénsis, L. (Dwark Connel. Bunchi-beiris.) Stems low and simple $\left(5^{\prime}-\tau^{\prime}\right.$ high) from a slender creeping and subterranean rather woody trunk; leaves seareely petioled, the lower scale-like, the upper erowded into an applarent whorl in sixes or fours, ovate or oval, pointed; leteves of the incolucre ovale; fruit globular. - 1)amp cold woods: common northward. June.

2. C. flórida, L. (Flowening Dogwoov.) Leaves ovate, pointed, is acutish at the base; lcaves of the involucre inversely heart-shaped or notched (1 $1 \frac{11}{2}$ long); fruit oval. - Rocky woods: more common southward. May, June. 'Tree $12^{\circ}-30^{\circ}$ high, very showy in flower, scarcely less so in fruit.

§2. Flowers white, in open and flut spreading cymes: involucre none: fruit spherical. * Lcaves all opposite: shrubs.

3. C. circinàta, L'iler. (Round-teaved Colnel or Dogwood.) Branches greenish, warty-dotted; leaves round-oval, abruptly pointed, woolly beneuth $\left(2^{\prime}-5^{\prime}\right.$ broad) ; cymes flat; fruit light blue. - Copses; in rich soil. June.Slurub $6^{\circ}-10^{\circ}$ high. Leaves larger than in any other species.

4. C. sericea. L. (Sifik X Cornet. Kinnikinnik.) Branches purplish; the Iranchlets, stalks, and lower surfuce of the narrowly ocute or elliptical pointed leaves silky-downy (often rusty), pale and dull ; cymes flat, close ; calyx-teerh lanceolate; fruit pale blue. - Wet places : common. June. - Shrub $3^{\circ}-10^{\circ}$ high.

5. C. stolonífera, Michix. (Red-osier Dogwood.) Branches, especially the osier-like commul shoots, bright red-parple, smooth; leaves ocate, rounded at the , lase, abruptly short-pointed, roughish with a minute close pubesecnee on both sides, whitish underneath; cymes small and flat, rather few-flowered, smooth; fruit white or lead-color. - Wet places: common, especially northward. Multiplies freely by prostrate or subterranean suckers, and forms broad clumps, $3^{\circ}-6^{\circ}$ high. June.

6. C. asperifolia, Michx. (Rovgh-Leaved Dogwood.) Branches brownish; the brunchlets, fic. rough-pubescent; leaves ublong or ovule, on very short petioles, pointed, rough with a harsh pubescence above, and downy bencuth; caly $\mathrm{x}$ teeth minute. - Dry or sandy soil, Illinois and southward. May, June.

7. C. strícta, Lain. (STIFF Cornes..) Branches brownish or reddish, smooth ; leaves ocate or ovate-lanceolate, taper-pointed, acutish at the base, glabrvus, 
of nearly the same hue both sides; cymes loose, fattss ; anthers and fruit pale blue.

8. C. paniculàta, L'Her. (PANicien Connez.) Branches gray, smooth; leaves ovnte-lanceolute, taper-pointed, acute at the base, whitish beneath but not downy; cymes convex, loose, often panicled; fiuit white, depressed-globose. Thickets and river-banks. June. - Shrub $4^{\circ}-8^{\circ}$ high, very much branched, bearing a profusion of pure white blossoms.

* * Leaves mostly alternate, crovded at the ends of the branches.

9. C. alternifolia, L. (Arternate-Lenved Connei.) Branches greenish strenked with white, alternate; leaves ovate or oval, long-pointed, acute at the basc, whitish and minutely pubescent underneath; fimit deep blue on redilish stalks. - Ilillsides in copses. May, Junc. - Shrub or tree $8^{\circ}-20^{\circ}$ high, with flattish top, and very open, broad cymes.

\section{N Ý S S A, L. Tupelo. Peppenide. Sour-Gum Tree.}

Flowers dixciously polygnmons, elnstered or rarely solitary at the summit of axillary peluncles. Stam. $\mathbf{F}$. numerous in a simple or compound dense cluster of fascicles. Calyx small, 5-parted. Petals as in fertile flower or none. Stamens 5-12, oftener 10, inserted on the otitside of a convex disk : filaments slender : anthers short. No pistil. Pist. Fl. solitary, or 2-8, sessile in a bracted cluster, much larger than the staminate flowers. Calyx with a very short repand-truncate or minutely 5-toothed limb. Petals very small and fleshy, deciduous, or often wanting. Stamens 5-10, with perfect or impertect arthers. Style elongated, revolute, stigmatic down one side. Ovary one-celled. Drupe ovoid or oblong, with a bony and grooved or striate 1-celled and 1 -seerled stone. Trees with entire or sometimes angulate-toothed leaves, which are alternate, but mostly crowded at the end of the branchlets, and greenish flowers appearing with the leaves. ('The name of a Nymph: "so called because it [the original species] grows in the water.")

1. N. multiflora, Wang. (Turelo. Pepreringe. Buck or Sour Guм.) Leaves oval or obovate, commonly acuminate, glabrous or villous-pubescent when young, at least on the margins and midrib, shining above when old $\left(2^{\prime}-5^{\prime}\right.$ long $)$; fertile flowers $3-8$, at the summit of a slender peduncle; finit ovoid, bluish-black (about $\frac{1}{2}$ 'long). (N. sylvática, Marsh. N. villòsa, Willd, \&c.) Rich soil, either moist or nearly dry, Massachusetts to Illinois, and southward. $\Lambda$ pril, May. - $\Lambda$ middle-sized tree, with horizontal branches and a light flat spray, like the Beech: the wood firm, close-grained and very unwedgeable, on account of the oblique direction and crossing of the fibre of different layers. Leaves turning bright crimson in autumn.

2. N. uniflora, Walt. (LARe Tupelo.) Leaves ohlong or ovate, sometimes slightly cordate at the base, long-petioled, entire or angulate-toothed, pale and downy-pubescent beneath, at least when young $\left(4^{\prime}-12^{\prime}\right.$ long $)$; fertile flower solitary on a slender peduncle; fruit oblong, blue (1' or more in length). (N. denticulàta, Ait. N. tomentiosa, nul angìlisnns, Mirkr. N. grandirlentàtı, Michx. f.) - In water or wet swamps, Virginin, Kentucky, and southward. $\Lambda$ pril.- Wood soft: that of the roots very light and spongy, used for corks. 


\section{Division II. MONOPÉTALOUS EXÓGENOUS PLANTS.}

Floral envelopes consisting of both caly $x$ and corolla, the latter composed of more or less united petals, that is, monopetalous.*

\section{Order 49. Capriforiàcea. (Honeysuckle Family.)}

Shrubs, or rarcly herbs, with opposite leaves, no (genuine) stipules, the calyx-tube coherent with the 2-5-celled ovary, the slumens as many us (or one fewer thun) the lobes of the tubulur or wheel-shaped corolla, and inserted on its tube. - Fruit a berry, drupe, or pod, 1 -several-seeded. Seeds anatropous, with a small embryo in fleshy albumen.

Taibe I. LONICERIEAs. Curollas tubular, uften irregular, sometimes 2-lipped. Style slender: stigma capitate.

1. Linnaca. Stantus 4 , one fewer than the lubes of the corulla. Fruit dry, 3-celled, but only 1-seeded; two of the cells sterile.

2. Symphoxicurpus. Stimens 4 or 5 , as many as the lobes of the bell-shaped regular corolla. Berry t-eclled, but maly 2 -scected; two of the cells sherile.

3. Lonfcera. Stimens 5 , ats many as the lobes of the tubuliar and more or less irregular corulla. Berry several-seeded; all the 2 or 3 culls fertile.

4. Diervilla. Stamens 5. Corolla fumel-form, nearly regular. Pod 2-celled, 2-valved, many-seeded, slutuder.

5. Triosteum. Stamens 5. Corolla gibbous at the base. Fruit a 3-celled drupe.

Tribe II. SA MBUCEF. Coralla wheel-shaped or uru-shajped, regular, deeply 5-lobed. Stigmas $1-3$, rarely 5 , sessile. Vlowers in broad cymes. '

6. Sambucus. Fruit berry-like cuntuining the small seud-like nutlets. Leaves pinnate.

7. Viburnum. Fruit a 1-celled 1-secded drupe, with a compressal stone. Leaves simple.

\section{LIN N 安 A, Gronov. Linnda. Twin-rlower.}

Calyx-teeth 5, awl-shaped, deciluous. Corolla narrow bell-shaped, almost equally j-lubed. Stamens 4, two of them shorter, inserted toward the base of the corolla. Ovary and the small dry pod 3-celled, but only 1-seeded, two of tho cells having ouly abortive ovules. - A slender creeping and trailing little evergreen, somewhat hairy, with rounded-oval sparingly crenate leaves contracted at the base into short petioles, and thread-like upright perluncles forking into 2 pedicels at the top, each bearing a delicate and frigrant nodding flower. Corollat purple and whitish, hatry inside. (1)edieated to the immortal Linneus, who first pointed out its characters, and with whom this pretty little plant was a special favorite.)

1. L. boreàlis, Gronov. - Moist mossy woods and cold bogs : common northward, but towards the south of rare occurrence as far as New Jersey, and along the mountains to Maryland. June. (Eu.)

* In certain families, such as Fricacea, \&c., the petals in some generib are nearly or quite separate. In Compusitue and some others, the cialy $x$ is unstly relucel to a pappus, or to scales, or a mere border, or eveu to nothing more than a covering of the surface of the ovary. The student might look for these in the first or the third division. But the artificial analysis prefixed to tho volume provides for such unumalies, asd will lead the student wo the projer order. 


\section{SYM PHOR I CÁ R PS, Dill. SNowberr.}

Calyx-teeth short, persistent on the fruit. Corolla bell-shaped, regularly 45-lobed, with as many short stumens inserted into its throat. Ovary 4-celled, only 2 of the cells with a fertile ovule; the berry therefore 4-celled but only 2 seeded. Seeds bony. - Low and branching upright shrubs, with oval shortpetioled leaves, which are downy underneath and entire, or wavy-toothed or lobed on the young shoots. Flowers white tinged with rose-color, in close short spikes or clusters. (Name composed of $\sigma \nu \mu \phi o \rho \epsilon ́ \omega$, to bear together, and

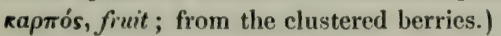

1. S. occidentàlis, R. Brown. (WoLfrenRy.) Flowers in dense terminal and axillary spikes; corolla much bearded within; the stamens and style protruded; berries white. - Northern Michigan, Illinois, and westward. - Flowers larger and more funnel-form, and stamens longer, than in the next.

2. S. racemosus, Miclix. (SNownerry.) Flowers in a loose and somewhat leafy interrupted spike at the end of the branches; corolla bearded inside; berries large, bright white. - Rocky banks, W. Vermont to Pennsylvania and Wisconsin : common in cultivation. June-Sept. - Berries ripe in autumn.

Var. pauciflorus, Robbins. Low, diffusely branched and spreading; leaves smaller (about l' long), the spike reduced to one or two flowers in the axils of the uppermost. - Rocky woods of L. Superior, Dr. Robbins, and northwestward. Alleghanies of Pennsylvania, J. R. Lowrie, Mr. Böcking.

3. S. vulgàris, Michx. (Indin Cunrant. Coral-merry.) Flowers in smâll close clusters in the arils of nearly all the leaves; corolla sparingly bearded; berries small, dark red. - Rocky banks, W. New York and Penn. to Illinois and southward: also cultivated. July.

\section{L O N I C È A, L. Honeysuckle. Woonbine.}

Calyx-tecth very short. Corolla tubular or funncl-form, often gibbous at the base, irregularly or almost regularly 5-lobed. Stamens 5. Ovary 2-3-eelled. Berry several-seeded. - Leaves entire. Flowers often showy and fragrant. (Named in honor of Adam Lonizer, latinized Lonicerus, a German herbalist of the 16th century.)

§ 1. CAPRIFÒIUM, Juss. Twining shrubs, with the flowers in sessile whorled clusters from the axils of the (often connote) upper leaves. and forming interrupted terminal spikes: calyx-teeth persistent on the (red or orange) berry.

* Corolla trumpet-shaped, almost regularly and equally 5-lobed.

1. L. sempérvirens, Ait. ('Trumpet Honeysuckre.) Flowers in somewhat distant whorls; leaves oblong, smooth; the lower petioled, the uppermost pairs united round the stem. - Copses, New York (near the city) to Virginia, and sonthward: common also in cultivation. May-Oct. - Leaves deciduous at the North. Corolla scentless, nearly $2^{\prime}$ long, leep red outside, yellowish within or rarely throughont.

* Corolla ringent : the lower lip narrow, the upper lroad and 4-lobed.

2. L. gràta, Ait. (American Woodbine.) Lfaves smooth, glaucous beneath, obovate, the 2 or 3 upper pairs united; flowers whorled in the axils of 
the uppermost leaves or leaf-like connate bracts; corolla smooth (whitish with a purple tube, fading yellowish), not gibbous at the base, fragrant. - Rocky woodlands, New York, Peun., and westivard : also cultivated. May.

3. L. flàva, Sims. (Yellow Honexsuckite.) Leaves smooth, very pale and glaucous buth sides, thickish, ubovate or oval, the $2-4$ upper pairs united into round enp-like disks; flowers in approximate whorls; tube of the smooth (light yellow) corolla somewhat gibbous ; tilanents almost or quite smooth. - Rocky banks. Catskill mountains (l'ursh), Ohio to Wisconsin (a form with rather short flowers), and southward along the Alleghany Mountains. June.

4. L. parviflora, Lam. (SMall Honersuckise.) Leaves smooth, ob long, yreen above, very yluucous beneath, the upper pairs united, all elosely sessile; flowers in 2 or 3 closely approximate whorls raised on a peduncle; corolla gibbous at the buse, smooth outside (grecnish-ycllow tinged with dull purple), short (9" long); filaments rather hairy below. - liocky banks, mostly northward. Maty, June. - Stem commonly bushy, only $2^{\circ}-4^{\circ}$ high.

Var. Douglásii. Leaves greener, more or less downy underneath when young, or ciliate; corolla crimson or deep dull purple. (L. Douglasii, LC:) Northern Ohio to Wisconsin and northward.

5. L. hirsùta, katon. (Hani Honersuckic.) Leaves not glaucous, downy-hairy beneuth, as well as the branches, and slightly so above, veiny, dull, broadly oval; the nppermost united, the lower short-petioled; flowers in approximate whorts ; tube of the (orenge-yellow) chemmy-pubescent corolle gibbous at the base, slender. - Damp copses and rucks, Maine to Wisconsin northward. July. - A coarse, large-leaved species.

§2. XYLÓS'TEON, Juss. Upright bushy slirubs: leaves all distinct at the lase: peduncles axilluriy, single, 2-flowered at the summit; the two berries somatimes united into one : calyx-teeth not persistent.

* The two flower's involucrute by 4 conspicuous and broad foliaceous bracts.

6. L. involucràta, Banks. Pubesecut, or becoming glabrous; branches 4-angular; leaves $\left(3^{\prime}-6^{\prime}\right.$ long) ovate-oblong, mostly pointed, petioled, and with a strong midrib, exceding the peduncle; corolla yellowish, viscid-pubescent, cylindraceous $\left(6^{\prime \prime}-8^{\prime \prime}\right.$ long); ovaries and globose berries distinct. - Deep woods, Lake Superior (C. G. Loring, Jr., Dr. Robbins) and westward. June.

* * Bracts (2 or sometimes 4) at the base of the ovaries minute.

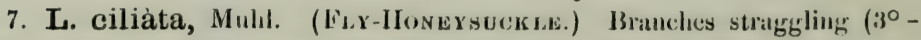
$5^{\circ}$ high) ; leanes oblong-ovale, often heart-shepred, petioled, thin, downy bencath; filiform peduncles shorter than the leaves; corolla funnel-form, almost spurred at the base (greenish-yellow, ${ }_{4}^{3}$ long), the lobes nearly equal ; berries sepurute (red). - Rocky woods, Mass. to Penn., Wisconsin, und northward. May.

8. L. cærùlea, L. (Monstain E.) Low $\left(1^{\circ}-2^{\circ}\right.$ high); branches upright; beaves ovel, downy when young; pedtuncles very short; bracts awh-shutpecl, longer than the ovaries of the two (yellowish) flowers, which are united into one (blue) berry. (Xylósteun villosum, Mlichx.) - Mountain woods and bogs, Rhode Isl and to Wisconsin, northward. May. (Eu.)

9. L. oblongifolia, Muhl. (Swamp F.) Branches upright; leaves oblong, downy when young, smooth when old; peduncles long and slender; bracts 
minute or deciduous; corolla deeply 2-lipped ( $\frac{1}{2}{ }^{\prime}$ long, yellowish-white); berries (purple) united or nearly distinct. - Bogs, Northern New York to Wisconsin. June. - Shrub $2^{\circ}-5^{\circ}$ high. Leaves $2^{\prime}-3^{\prime}$ long.

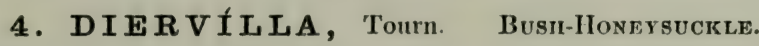

Calyx-tube tapering at the summit; the lobes slender, awl-shaped, persistent. Corolla funnel-form, 5-lobed, almost regular. Stanens 5. l'od ovoid-oblong, pointed, 2-celled, 2-valved, septicidal, mıny-secded. - Iow, upright shrubs, with ovate or oblong pointed serrate leaves, and cymoscly 3 -several-flowered peduncles, from the upper axils, or terminal. (Named in compliment to $M$. Dierville, who brought it from Canada to 'Tournefort.)

1. D. trífida, Moench. Leaves oblong-ovate, taper-pointed, petioled; peduncles mostly 3-flowered; pod long-beaked. (1). Canalénsis, Muhl.)-Rocks: common, especially northward. June- $\Lambda \mathrm{ng}$. - Flowers honey-color, not showy, like the Japanese species cultivated under the name of WEIGEIA.

、 D. sessılifòlı, Buckley, of the mountains of North Carolina, may occur in those of S. W. Virginia.

\section{TRIÓ S T E U M, L. Fever-wort. Honse-Gentian.}

Calyx-lobes linear-lanceolate, leaf-like, persistent. Corolla tubular, gibbous at the base, somewhat equally 5-lobed, scarcely longer than the calyx. Stamens 5. Ovary mostly 3-celled, in fruit forming a rather dry drupe, containing as many angled and ribbed 1 -seeded bony nutlets. - Coarse, hairy, perennial herbs, leafy to the top; with the ample entire pointed leaves tapering to the base, but connate round the simple stem. Flowers sessile, and solitary or

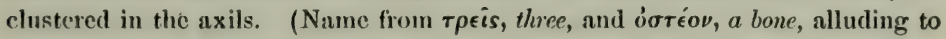
three bony seeds, or rather nutlets.)

1. T. perfoliàtum, I. Sofly hairy $\left(2^{\circ}-4^{\circ}\right.$ high $)$; leaves oval, abruptly narrowed below, downy beneath; flowers brownish-purple, mostly clustered. Rich woodlands : not rare. June.-Fruit orange-color, $\frac{1}{2}$ long.

2. T. angustifblium, L. Smaller ; bristly-hairy; leaves lanceolate, tapering to the base; flowers greenish-cream-color, mostly single in the axils. - S. Pennsylvania to Illinois, and southward. May.

\section{S A M B Ù CU S, Tourn. Elder.}

Calyx-lobes minute or obsolete. Corolla open urn-shaped, with a broadly spreading 5-cleft limb. Stamens 5. Stigmas 3. Fruit a berry-like juicy (') drupe, containing 3 small sced-like nutlets. - Shrubhy plants, with a rank smell when bruiscl, pinnate leaves, serrate pointed leaflets, and numerous small . and white flowers in compound cymes. (Naune from $\sigma \alpha \mu \beta \dot{k} \eta$, an ancient muJsical instrument, supposed to have heen made of Elder-wood.)

1. S. Canadénsis, L. (Соммок Emmer.) Stems searcely woody ( $\left(5^{\circ}-10^{\circ}\right.$ ligh) ; leuflets 7-11, oblong, mostly smooth, the lower often 3-parted; cymes flat; fruit black-purple. - IRich soil, in open places. June. - Pith white.

2. S. pübens, Michx. (Red-Berried Elder.) Stems woody $\left(2^{\circ}-18^{\circ}\right.$ high), the bark warty; leaflets 5-7, ovate-lanceolule, downy underneath; cymes 
panicled, convex or pyramidul; fruit bright red (rarely white). - Rocky woods; chiefly northward, and sonthward in the momtains. May : the fruit ripening in June. - P'ith brown. - Var. with dissected leaves, Lako Superior, Lewis f'uote, Di. Riobbins.

\section{VIBÚ R N U M, L. Arrow-woov. Laurestinus.}

Calyx 5-toothed. Corolla spreading, deeply 5-lobed. Stamens 5. Stigmas 1-3. Fruit a l-eelled, I-seeded drupe, with soft pulp and a thin-crustaceous (flattened or tumid) stone. - Shrubs, with simple leaves, and white flowers in flat compound cymes. Petioles sometimes bearing little appendages which are evidently stipules. Leaf-buds naked, or with a pair of scales. (The classical Latin name, of unknown meaning.)

§1. F'lowers all alike and perfect.

* Leaves finely serrate or entire, bright grcen; veins not prominent: no stipular appendages: whole plant glabrous or with some minute rusty scurf: fruit black or with a blue bloom, sweet; the stone very flat and even, broally oval or orlicular.

1. V. Lentàgo, L. (Sweet Viburnum. Shép-вkikx.) Leaves voute, strongly pointed, closely and very sharply serrate; petioles long and margined; cyme sessile; fruit oval, $\frac{1}{2}$ ' or more long, ripe in autumn, edible; tree $15^{\circ}-30^{\circ}$ high. - Copses, \&c. : common, especially northward. May, Jume.

2. V. prunifolium, L. (BLACK HAW.) Leaves voul, obtuse or slightly pointed, fincly and sharply serrate, smaller than in the preceling $\left(1^{\prime}-2^{\prime} l o n g\right)$; fruit similar or rather smaller; cyme sessile. - Dry copses; Commecticut to Illinois, and common southward. May. - A tall shrub or small tree.

3. V. nùdum, L. (WrThe-1zov.) Leaves thickish, oval, oblong or lanceolate, not shining, the margins entire, repand, or crenate; cyme short-peduncled; fruit round-ovoid ( $3^{\prime \prime}$ long). - Var. 1. Claxtòn has the leaves nearly entire, the veins somewhat prominent underneath, and grows in swamps from Massachusetts, near the coast, to Virginia and southward. Var. 2. cassinotoes (V. pyrifolium, Pursh, fc.) has more opaque, often toothed leaves; and grows in cold swamps from P'ennsylvania northward. May, Junc. - Shrub $6^{\circ}-10^{\circ}$ high.

4. V. obovàtum, Walt. Laves obovate or spatulate, obtuse, entire or denticulate, thickish, small $\left(1^{\prime}-1 \frac{1}{2}^{\prime}\right.$ long $)$, shining; cymes sessile, small; fruit ovoidoblong. - River-banks, Virginia and southward. May. - Shrub $2^{\circ}-8^{\circ}$ high.

* * Leaves (with buse inclined to heart-shaped) coarsely toothed, prominenlly pimately veined, the veins straight and simple or sparingly forked: no rusty scurf: fruit small, ovoid, blue or purple; the stone tumid and groved: cymes peduncled.

5. V. dentàtum, L. (Aккоw-woov.) Smooth; leaves broudly ovate, very numerously sharp-toothed and strongly veined, on slender petivles; fruit bright Ulue; the turgid stone decply excavated on one fuce; cross section of the seed between kidney-ard horseshoe-shuped. - Wet places, common northward. June - Shrub $5^{\circ}-10^{\circ}$ high, with ash-colored bark; the pale leaves often with hairy tufts in the axils of the straight veins.

6. V. mólle, Michx. Leaves broudly oval, dovate or ovate, scarcely pointed, coarsely crenate or repand-toothed, the lower surfice, rather slender petioles, brunchkts and cymes soft-downy, the latter with stellate pubescence; fruit oily (Lin. 
gelm.), the stone as in No. 5, but less deeply excavnted on the face. (V. dentatum, var. senbréllum, Torr. \& $G$ r.) - Rich woods, Kentucky and southward.

7. V. pubéscens, Pursh. (I) acute or taper-pointed, the veins and tecth fewer and less conspicuous than in No. 5, the lower surface und very shert petioles soft-dowmy, at lenst when young; fruit dark-purple; the stone plano-convex and 3-4-grooved on the flat face. Rocks, \&c., W. Vermont to New Jersey, Kentucky, Wisconsin, and northward. June. - A low, straggling shrub.

* * Leaves coarsely toothed and someuhat 3-lohed, roundish, the base mostly iruncate or somewhat heart-shaped, 3-5-ribbed from the base, the ribs and veins prominent benenth: stipular appendages bristle-shaped: rymes small, slenderpeduncled : fruit red; the stone flattened.

8. V. acerifolium, L. (Marle-Lenved A. Dockmackie.) Leaves f soft-downy bencath, 3-ribbed, the pointed lobes diverging, unequally toothed; I stamens exserted ; fruit crimson turning purple; the lenticular stone undulately 2-grooved on one face and 3-grooved on the other. - Rocky woods: common. Mry, June. Shrub $3^{\circ}-6^{\circ}$ high.

9. V. pauciflorum, Pylaie. Leaves glabrous or loosely pubescent beneath, 5-ribbed at buse, unequally serrate nearly all round, with 3 short lobes at the summit; cyme few-flowered ; stamens shorter than the corolla ; fruit red, sonr, globular; the stone very flat and even. (V. Oxycóccus, var. eradiàtum, Oakes.) Cold woods, Northern N. Hampshire, New York, Wisconsin, and northward.A low straggling shrub, most related to the next; the leaf-buds similar.

\$2. Marginal flowers of the ryme destitute of stamens and pistils, and with corollas many times larger than the others, forming a kind of ray, as in Hydrangen: stipular appendages conspicuous on the petiole.

* Fruit spherical, pleasuntly ucid, lright red; the stone very flat, smooth and even, nearly orbiculur: lenf-burls enclosed in one or two puirs of scales.

10. V. Ópulus, L. (CrAnBerny-Trev.) Nearly smooth, upright (50$10^{\circ}$ high) ; leaves 3-5-ribbed, strongly 3 -lobed, broadly wedge-shaped or truncate at the base, the spreading lobes pointed, mostly toothed on the sirles, entire in the sinuses; petioles bearing 2 glands at the apex, cymes peduncled. (V. ()xyeóccus and V. élule, Pursh.) - Low grounds, along streams: common northward, and southward in the Alleghanies to the borlers of Maryland. June, July. - The acid fruit is a substitute for cranberries, whence the name Iligh Cranberry-bush, \&c. - The well-known SNow-Bati, Tree, or GuelnerRose, is a cultivated state, with the whole cyme turned into showy sterile llowers. (En.)

* * Fuit ovoil, red, turning darker; the stone tumid, 6-qroored: buds wholly naked.

11. V. lantanoldes, Michx. (IIomne-rusir. Amkrican WATFarING-TREE.) Leaves round-ovate, abruptly pointed, heart-shaped at the base, closely serrate, pinnately many-veined; the veins and veinlets underneath along with the stalks and hranchlets very rusty-senrfy; cymes sessile, very broad and flat. - Cold moist woods, New England to P'enn. and northward, and sonthward in the Alleghanies. May. $-\Lambda$ straggling shrub; the reclining branches often taking root. Flowers handsome. Lenves $4^{\prime}-8^{\prime}$ across. 


\section{Order 50. hubiaceat. (Madder Family.)}

Shrubs or herbs, with opposile entire leaves connected by interposed stipules, or in whorls wilhout apparent stipules, the calyx colterent with the 2-4-celled ovary, the stamens as many as the lobes of the regular corolla (3-5), and inserted on its tube. - Flowers perfect, but often dimorphous (as in Mitchella and IIoustonia). Fruit various. Seeds anatropous or amphitropous. Embryo commonly pretty large, in copious hard albumen. - A very large family, the greater part, and all its most important plants (such as the Coffice and Peruvian-Bark trees) tropical; not sufficiently represented in our district to render it worth while to note the tribes and the larger systematic divisions.

\section{STLLLATA. Leaves in whorls : no apparent stipules.}

1. Galium. Corolla wheel-shaped, 4-(or rarely 3-) parted. Calyx-teeth obsolete. Fruit twin, separating into 2 indchiscent one-seeded carpels.

II. CINCIIONEA, \&c. Leaves rarely in whorls, with stipules.

* Ovules and seeds solitary in cach cell.

- Eluwers axillary, separate. Eruic diy when rips. Ilerbs.

2. Spermacoce. Corolla funsel-form or salver-form : lobes 4 Fruit scparating when ripe into 2 carpels, one or buth of them opening.

3. Diodia. Fruit separating into 2 or 3 closed and indehiscent carpels : otherwise as No. 2.

- Hlowers in a close and globose long-peduncled liead. Fruit dry. Shrubs.

4. Cephalauthus. Corolla tubular : lobes 4 Fruit inversely pyraraidal, 2-4-seeded.

+++ Flowers twin; their ovaries united into one. Fruit a 2 -eyed herry.

5. Mitchella. Corolla funnel-form; its lobes 4. - A creeping herb.

* *vules and seeds many or several in each cell of the (loculicidal) pod.

6. Oldenlandia. Corolla whecl-shaped in our species, 4-lubed. Seeds very numerous and minute, angular.

7. Houstomia. Corolla salver-form or funnel-form, 4-lobed. Seeds rather few, thimbleshaped or saucer-shaped.

\section{G À L I U M , L. Bedstraw. Cleavers.}

Calyx-teeth obsolete. Corolla 4-parted, rarely 3-parted, wheel-shaped, valvate in the bud. Stamens 4, rarely 3, short. Styles 2. Fruit dry or fleshy, globular, twin, separating when ripe into the $\mathbf{2}$ seed-like, indehiscent, 1 -seeded carpels. - Slender herls, with small eymose flowers (produced in summer), square stems, and whorled leaves : the roots often containing a red coloring matter. (Nane from yá $a$, milk, which some species are used to curdle.)

* Annual: leaves ahout 8 in a whorl: peduncles 1 -2-flowered, axillary.

1. G. Aparine, T. (Cheavens. Goose-Grass.) Stem weak and reclining, bristle-prickly backwards, hairy at the joints ; leaves lanceolate, tapering to the base, short-pointed, rough on the margins and midrib $\left(1^{\prime}-2^{\prime}\right.$ longr); flowers white ; fruit (large) lristly with hookel prickles. - Muist thickets. Doubiful if truly indigenous in our district. (Eu.)

* Perennial, ascending; leaves 4-6 or 8 in a whorl, with prominent midrib, but no lateral nerres: flow.rs white, few or numerous, on slender pedicels : fruit smouth. 
+ Flouers very abundant, the small clusters or cymes panicled on the branches.

2. G. Mollưgo, L. Stems $\left(1^{\circ}-3^{\circ}\right.$ long) very sinonth; leaves mostly in uhorls of 8 , oblanceolate or oblong-linear, barely rough on the margins, slender-pointed; flowers forming a long panicle. - Washington Heights, near New York, W. W. Denslow. (Adv. from Eu.)

3. G. aspréllum, Michx. (Rovgit Bunstraw.) Stom weak, much branched, rough backwards with hooked prickles, leaning on bushes $\left(3^{\circ}-5^{\circ}\right.$ high); leaves in whorls of 6 , or $4-5$ on the lranchlets, oval-lanceolate, pointed, with almost prickly margins and midrib; peduncles short, 2-3 times forked. - Low thickets : common northward.

4. G. coneinnum, Torr. \& ( ir. Stems low and slender $\left(6^{\prime}-12^{\prime}\right.$ high $)$, with minutely roughened angles; leaves all in whorls of 6, linear, slighty point,d, veinless, the margins upwardly roughened; peduncles slender, 2-3 times forked, diffusely panicled at the summit; pedicels short. - Dry ground, Pennsylvania from the Susquehanna, to Virginia, Michigan, Illinois, and Kentucky. - Leaves not blackening in drying.

\section{+ + Flowers few, lateral or terminating the branches, not panicled.}

5. G. trifidum, L. (Sмall Bedstraw.) Stems weak, ascending (5'$20^{\prime}$ high), branching, mostly roughened backwards on the angles; leaves in whorls of 4 to 6, linear or oblanceolate, obtuse, the margins and midrib rough ; corolla-lobes and stamens often only 3.- Var. 1. Pusflud : stems rather simple, $5^{\prime}-8^{\prime}$ high, nearly smooth; leaves only $3^{\prime \prime}-4^{\prime \prime}$ long, all in fours, soon reflexed; peduncles 1-3-flowered. (In deep sphagnous swamps, northward.) Var. 2. TINCTòrum : stem taller and stouter, and with nearly smooth angles; peduncles 3-7-flowered, the corolla-lobes and stamens 4, Var. 3. LАт́ғònum ((3. obtusum, Biyel.): stem smooth and widely branched; leaves oblong or elliptical, quite rough on the midrib and margins. - Swamps: common, and very variable. (Lu.)

* * Perennial, prorumbent: Ieaves 6 or rarely 5 in a whorl, with prominent midrib and no lateral nerves: flowers grecnish: fruit bur-like, beset with hookrd bristles.

6. G. triflorum, Michx. (Sweet-scented Benstraw.) Stem (10$3^{\circ}$ long) bristly-roughened backwards on the angles; leaves elliptical-lanceolate, bristle-pointed, with slightly roughened margins $\left(1^{\prime}-2^{\prime}\right.$ long); peduncles 3-flowered, the flowers all pedicelled. - Rich woodlands : common. - Sweet-scented in drying. (Eu.)

*** Perennial, ascending or upright: leaves all in fours, more or less 3-nerved: peduncles loosely or remotely 3 - several-flowered: corolla dull-purple, brownish, or rarely cream-color; the lobes pointed or bristle-tipped: fruit, except in No. 10, bur-like, beset with hooked bristles.

7. G. pilòsum, Ait. Hairy; leaves oval, dotted, hairy (1' long), scurcely 3 nerved; peduncles twice or thrice 2-3-forked, the fluvers all pedicelled. - Dry copses, Rhode Island and Vermont to Illinois and southward. - Var. PUNCTieu cosoum is a nearly smooth form (G. puncticulosum, Michx.): Virginia and sonthward.

8. G. circæezans, Michx. (Win Liquonicn.) Smooth or downy (10 high); leaves oval, varying to ovate-oblong, mostly obtuse, 3-nevved, ciliatr $\left(1^{\prime}-1 \frac{1}{2}{ }^{\prime}\right.$ long); peduncles usually once forked, the branches elongated and widely diverging in L \& M-29 
fruit, bearing severul vemote flowers on very short latersl pedisels, reflexed in fruit; lobes of the corolla hairy outside above the middle. - Rich woods: common. The var. montanum is a dwarf, broad-leaved form, from mountain woods.

9. G. lanceolàtum, Torr. (WiL. Liquonice.) Leaves (except tho lowest) lanccolate or ovute-lanceolute, tupering to the apex (2' long); corollu glabrous: otherwise like the last. - Woodlands : common northward.

10. G. latifolium, Michx. Smooth $\left(1^{\circ}-2^{\circ}\right.$ high $)$; leuves lanceolate or ovate-lnnepolate, acute, 3 -nerved below; the nidrib and margins rough; cymes panicled, loosely many-flowered, the purple flowers all on slender spreading pedicels; fruit smooth. - Dry woods, Merecrsberg, Penn. (Prof. Porter), Marylaud, and southward in the Alleghanies. (Also Arkansas, Engdmann.)

****** Perenrial, ercet: leaves 4 or 8 in a whorl; flowers very uumerous and crowded in a nurrow and compact termmal punicle, white or yellow.

11. G. boreàle, L. (Nontukin Beostraw.) Smooth $\left(1^{\circ}-2^{\circ}\right.$ high); leaves in fours, lin-ar-lunceulate, 3-nerved; flowers white; fruit minutely bristly, sonnetimes smooth. - Rocky banks of streams: common, especially northward. (Eu.)

12. G. vìnua, L. (Yellow Benstraw.) Leaves in eights for some in sixes), lincer, grooved above, roughish dellexed; flowers yellow; fruit smooth.Dry fields, li. Massachusctts. (Adv. fiom Lu.)

\section{S PERM A CÒ E E, L. Butron-wend.}

Calyx-tube short; the limb parted into 4 teeth. Corolla funnel-form or salver-form; the lobes valvate in the bud. Stamens 4. Stigmu or style 2-eleft. Fruit small and dry, 2-celled, 2-seeded, splitting when ripe into 2 carpels, one of them usually carrying with it the partition, and therefore closed, the other open on the immer face. - Small herbs, the bases of the leaves or petioles conneeted by a bristle-bearing stipular membrane. Flowers small, crovded into sessile axillary whorled clusters or heads. Corolla whitish. (Name compounded

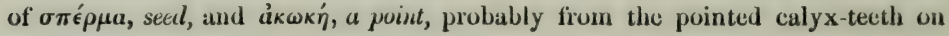
the fruit.)

1. S. glabra, Michx. Glabrous perennial; stems spreading $\left(9^{\prime}-20^{\prime}\right.$ long $)$; leaves oblong-lanceolate; whorled leads many-flowered ; corolla little excecting the calyx, bearded in the throat, bearing the anthers at its base; filanents and style hardly any. - River-banks, S. Ohio, Illinois, aud southward. Aug.

\section{DIÓDI A, I. BUTTON-WEẺ.}

Calyx-teeth 2-5, often une(ual. Fruit 2- (rarely 3-) eelled; the crustaceous carpels into which it splits all closed and indehiscent. Otherwise resembling Spermacoce. Flowering all summer. (Name fiom diodos, a thorouyhfure; the species often growing by the wayside.)

1. D. Virgínica, L. Smooth or hairy perennial; stems spreading $\left(1^{\circ}-\right.$ $2 \circ$ long); leaves lanceolate or oblong-lanceolate, sessile; flowers $1-3$ in each axil; corolla white ( $\frac{1}{2}$ long), the slender tube abruptly expanded into the large limb; style 2-parted; firit oblong, strongl! furrowed, crowned mostly with 2 slender calyx-teeth. - River-banks, Maryland, and southward. Also naturalized ncar Philadelphia, C. $\boldsymbol{b}$. Parker. 
2. D. tères, Walt. Hairy or minutely pubescent annual; stem spreading 3'-9' long), nearly terete; leaves linear-lanccolate, closely sessile, rigid ; flowers $1-3$ in each axil; corolla funnel-form $\left(2^{\prime \prime}-3^{\prime \prime}\right.$ long, whitish), with short lobes, not exceeding the long bristles of the stipules; style undivided; fruit obovateturbinate, not furvowed, crowned with 4 short calyx-teeth. - Sandy fields, from New Jersey and Illinois southward.

\section{CE $\mathbf{P}$ H A L Á T TH U S, L. Button-bush.}

Calyx-tube inversely pyramidal, the limb 4-toothed. Corolla tubular, 4. toothed; the tecth imbricated in the bud. Style thread-form, much protruded. Stigma capitate. Fruit dry and hard, small, inversely pyramislal, 2-4-celled, is at length splitting from the base upward into 2-4-closed 1-secled portions. -

$\therefore$ Shrubs, with the flowers densely aggregated in spherical peduncled heads. Flow-

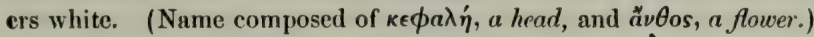

1. C. occidentàlis, L. Smooth or pulescent; leaves petioled, ovate or lanceolate-oblong, pointed, opjosite or whorled in threes, with short intervening stipules. - Wet places: common. July, Aug.

\section{Mitchélla, L. Partridee-berry.}

Flowers in pairs, with their ovaries united. Calyx 4-toothed. Corolla funnel-form, 4-lobed; the lobes spreading, densely bearded inside, valvate in the bud. Stanens 4. Style 1: stigmas 4, linear. Fruit a berry-like double drupe, crowned with the calyx-tceth of the two flowers, each with 4 small and seed-like bony nutlets. $-\Lambda$ smooth and trailing small evergreen herb, with round-ovate and shining petioled leaves, minute stipules, white fragrant flowers often tinged with purple, and scarlet edible (but nearly tasteless) dry berries, which remain over winter. Flowers occasionally 3-6-merous, always dimorphous; all those of some individuals having exserted stamens and included stigmas; of others, included stamens and exserter style. ('This very pretty plant commemorates Dr. John Mitchell, an early correspondent of Linnæus, and an excellent botanist, who resided in Virginia.)

1. M. rèpens, L. - Dry woorls, creeping about the foot of trees : common. June, July. - Leaves often variegrated with whitish lines. Rarcly the two flowers are completely confluent into one, with a 10-lobed corolla.

\section{OLdE N L Á N D I A, Plumier, L. Oldenlanda.}

Calyx 4- (rarely 5-) lobed, persistent. Corolla short, in our species wheclshaped; the limb 4- (rarely 5-) parted, valvate in the bud. Stamens 4 (rarely 5) : anthers short. Style 1 or none: stigmas 2. Pod thin, 2-celled, manyseeded, opening loculicidally across the summit. Seeds concave, very numerous, minute and angular. - Low herbs, with small stipules united to the petioles. (Dedicated, in 1703, to the memory of Oldenland, a German physician and botanist, who died early at the Cape of Good Hopc.)

1. O. glomerata, Michx. An inconspicuous, pubescent or smoothish, branched and spreading annual $\left(2^{\prime}-12^{\prime}\right.$ high $)$; leaves oblong; flowers in sessi'e 
axillary clusters; corolla nearly wheel-shaped (white), much shorter than the calyx. (O. uniflora, L. Hedyotis glomerata, Ell.) - Wet places, S. New York to Virginia near the coast, and southward.

\section{HOUSTÓNIA, L. Houstonia.}

Calyx 4-lobed, persistent; the lobes in fruit distant. Corolla salver-form or funnel-form, usually much longer than the calyx-lobes, 4-lobed, the lubes valvate in the bud. Stamens 4: anthers linear or oblong. Style 1: stigmas 2. Uvary 2-celled. Pod top-shapied, globular, or didymous, thin, its summit or upper half free from and projecting beyond the tube of the calyx, loculicidal across the top. Seeds rather few ( $4-20$ in each cell), peitate and saucer-shaped or glubular-thimble-shaped. pitted. - Small herbs, with short entire stipules connecting the petioles or narrowed bases of the leaves, and cymose or solitary and peduncled flowers. These are dimorphous, in some individuals with the anthers borne high up on the tube of the corolla and projecting fiom its throat, while the style is short and the stigma therefore included: in the other sort the anthers are luw down in the corolla and the style long, the stigmas therefore protruding; - an arrangement for cross-fertilization. (Named for $D_{i}$. W $/$. Ilouston, an Euglish botanist who collected in Central America.) 'The genus, formerly merged in Oldenlandia, merits restoratiou.

* Erect, mostly perennial herbs $\left(6^{\prime}-20^{\prime}\right.$ hiy hl), with stem-leaves sessile, and flourrs in terminal small cymes or clusters: corolla funnd-form, purplish, often hairy inside: seeds meniscoiclul, with a ridge across the hollowed inner fuce.

1. H. purpùrea, L. Pubescent or smooth $\left(8^{\prime}-15^{\prime}\right.$ high); leaves varyiny from roundish-ocate to lanceulute, 3-5-ribbed; calyx-lobes longer than the hulf fiee glubular pod. (Iloustonia purpurea, L. II. varians, Miche. Oldenlaudia purpurea, ed. 2.) - Woodlands, WV. Pennsylvania to Illinois and southward. May - July. - Varying wonderfully, as into :-

Var. longifolia. Leaves varying from oblong-lanceolate to linear, narrowed at the base, 1-ribbed; caly x-lobes scarcely as long as the pod; stems $5^{\prime}$ 12' high. (Honstonia longifulia, Willd.) - Maine to Wisconsin and southward. - A narrow-leaved, slender form is H. tenuifulia, Nutt.

Var. ciliolàta. More tufted stems $3^{\prime}-6^{\prime}$ ligh; root-leaves in rosettes, thickish and eiliate; calyx-lobes ahont as long as the pod. (Houstonia ciliolata, Torr.) - Along the Great Lakes and rivers, from N. New York to Wiscunsin.

2. H. angustifolia, Michx. Stems tufted from a hatd or woody root; leaces nurrowly lineur, acute. 1-ribbed, many of them fascicled; flowers crowded, short-pedicelled; lobes of the corolla densely bearded inside; pod vbarvid, acute at the base, only its summit free from the calyx, opening first across the top, at length through the partition. (O)deulandia angustifulia, ed. 2. Hedyotis stenophylla, Torr. \&. Gray.) - Plains and banks, from Illinois southwart. June - Aug.

* * Sinall and delicute, chiefly unnuals or biennials, vernal-fluwering : peduncles 1-flow. ered: corollu sulver-form : upper half of the broal and somewhat 2-lobed pul frce: seeds globulur, with u. very deep round cavity occupying the inner fuce.

3. H. mínima, Beck. Scabrous; stems at length much branched and spreading $\left(1^{\prime}-4^{\prime}\right.$ high $)$; lowest leaves ovate or spatulate, the upper oblong or 
nenrly linear; earlier peduncles elongated and spreading in fruit, the later oncs short; tube of the purplish corolla not longer than its lobes nor than the ample calyx. lobes ( $1 \frac{1}{2}^{\prime}$ long). - Dry hills, IV. Illinois and southwestward. March-May.

4. H. cærùlea, L. (Buvets.) Glabrous; stems erect, slender, sparingly branched from the base $\left(3^{\prime}-5^{\prime}\right.$ high $)$; leaves oblong-spatulate $\left(3^{\prime \prime}-4^{\prime \prime}\right.$ long); peduncle filiform, erect; corolla with tube much longer than its lobes or than those of the coly.x. (Oldenlandia carulen, ed. 2.) Moist and grassy places; produeing from early spring to midsummer its delicate little flowers, light blue, palo lilac, or nearly white with a yellowish eye.

H. serpytifold , Michx., - with similar flowers, but with slender crecping stems, abounding in the mountains of $\mathrm{N}$. Carolina, - may occur in those of Virginia.

H. Rotundfólı, Michx., - nlso crecping, but with much larger roundish leaves, and axillary peluncles nodding in fruit, - belongs to the low country of the Southern States, and may occur in S. E. Virginia.

\section{Order 51. Vacerianicese. (Valerian Family.)}

Herbs, with opposite leaves and no stipules; the calyx-tube coherent with the ovary, which has one fertile 1-ovuled cell and two abortive or empty ones; the stamens distinct, 1-3, fewer than the lobes of the corolla, and inserted on its tube. - Corolla tubular or funnel-form, often irregular, mostly 5lobed, the lobes imbricated in the bud. Style slender: stigmas 1-3. Fruit indehiscent, 1-celled (the two empty cells of the ovary disappearing), or 3-celled, two of them empty, the other 1-sceded. Seed suspended, anatropous, with a large embryo and no albumen. - Flowers in panicled or clustered cymes. (Roots often odorous and antispasmodic.) - Represented by only two genera.

\section{VALERI ì NA, Tourn. VaLerian.}

Limb of the caly $\mathrm{x}$ of several plumose bristles (like a pappus) which are rolled up inwards in flower, but unroll and spread as the seed-like 1-celled fruit matures. Corolla commonly gibbous near the base, the 5-lobed limb nearly regular. Stamens 3. - Perennial herbs, with thickened strong-seented roots, and simple or pinnate leaves. Flowers in many species imperfectly dinecious, or dimorphous. (Name from valere, to have efficacy, alluding to the medicinal qualities.)

$$
\text { * Root filrous: leaves thin. (Stems } 1^{\circ}-3^{\circ} \text { high) }
$$

1. V. pauciflora, Michx. Smooth, slender, surculose; root-leaves ovate, heart-shaped, toothed, pointed, sometimes with 2 small lateral divisions; stemleaves pinnate, with $3-7$ ovate toothed leaflets; branches of the panicled cyme few-flowered; tube of the (pale pink) corolla long and slender ( $\frac{1}{2}$ ' long). - Woodlands, and alluvial banks, Penn. (near Lancaster, Prof. Porter) and Ohio to S. Illinois and southward. Jnne.

2. V. sylvática, Richards. Smooth or minutely puhescent; root-leaves ovate or oblong, entire, rarely with 2 small lobes; stem-leaves pinnate, with 5-11 
oblong-ovate or lanceolate nearly entire leaflets; cyme at first close, manyflowered ; corolla inversely conical ( $3^{\prime \prime}$ long, rose-color or whitc). - Cedar swamps, Western Vermont to Wisconsin and northward. June. (Probably a form of V. dioica, $L$.)

* Root spindle-shuped, large and deep $\left(6^{\prime}-12^{\prime}\right.$ long $)$ : leaves thickish.

3. V. édulis, Nutt. Sinooth, or ninutely downy when very young; stem straight $\left(1^{\circ}-4^{\circ}\right.$ high $)$, few-lcaved; leaves commonly minutely and densely ciliate, those of the root spatulate and lanceolate, of the stem pinnately parted into $3-7$ long and narrow divisions; flowers in a long and narrow interrupted panicle, nearly dicecious; corvlla whitish, obconical (2" long). (V. ciliäta, Torr. \& $G r$.) - Alluvial ground, Ohio to Wisconsin, and westward. June.

\section{Fidia, Girtn. Corn Salad. Lamb-Lettuce.}

Limb of the calyx obsolete or merely toothed. Corolla funnel-form, equally or unequally 5 -lobed. Stamens 3 , rarely 2 . Fruit 3 -eelled, two of the cells empty and sometimes confluent into one, the other 1-seeded. - Annuals and biennials, usually smooth, with forking stems, tender and rather succulent leaves (entire or cut-lobed towards the base), and white or whitish cymose-clustered and bracted small flowers. (Name of uncertain derivation.) - Our species all have the limb of the calyx obsolete, and are so much alike in aspect, flowers, \&c., that good characters are only to be taken from the fruit. They all have a rather short corolla, the limb of which is nearly regular, and therefore belong to the section (by many botanists taken as a genus) VALERIANÉLLA.

1. F. olıtóna, Vahl. Fruit compressed, oblique, at length broader than long, with a corky or spongy mass at the back of the fertile cell nearly as large. as the (often confluent) empty cells; flowers bluish. - Fields, New York and Penn. to Virginia : rare. (Adv, from Eu.)

2. F. Fagopỳrum, Torr. \& Gr. Fruit ovate-triangular, smooth, not grooved between the (at length confluent) empty cells, which furm the anterior angle, and are much smaller than the broad and flat fertile one; flowers white. - Low grounds, from Western New York to Wisconsin and Kentucky. May, June. - Plant $1^{\circ}-2^{\circ}$ high.

3. F. radiàta, Michx. Fruit ovoid, downy (rarely smooth), obtuscly and unequally somewhat 4-angled; the empty cells parallel and contiguous, but with a deep groove between them, rather narrower than the futtish fertile cell. - Low grounds, Peun. to Michigan, and soutliward. - 1'laut $6^{\prime}-15^{\prime}$ high.

4. F. umbilicàta, Sulliv. Fruit globular-ovate, smooth; the much influtd sterile cells wider and many times thicker than the fluttish fertile one, contiguous, and when young with a common partition, when grown, indented with " deep circulur depression in the mildle, opening into the confluent sterile ectls; bracts not ciliate. - Moist gromuls, Colunnbus, Ohio, Sullivent. (Sill. Jour. Jan. 18t2.)

5. F. patellària, Sulliv. Fruit smooth, circular, platter-shaped or disk-like, slightly notehed at hoth ends, the flattencd-concave sterile ctlls widely divergent, much broader than the fertile one, and forming a kind of wing around it when ripe. - Low grounds, Colunbus, Ohio, Sullivant. - I'lant $1^{\circ}-2^{\circ}$ high, resembling the last, but with a very different fruit. 


\section{Order 52. Dipsàceie. (Teasel Family.)}

Herbs, with opposite or whorled leaves, no stipules, and the flowers in dense heads, surrounded by an involucre, as in the Composite Family; but the stamens are distinct, and the suspended seed has albumen. - Represented by the Scabious (cultivated) and the genus

\section{D I PS A C US, Toum. Trastr.}

Involucre many-leaved, longer than the chaffy leafy-tipped and pointed bracts among the densely capitate flowers : each flower with a 4 -leaved calyx-like involucel investing the ovary and fruit (achenium). Calyx-tube coherent with the ovary, the limb cup-shaped, without a pappus. Corolla nearly regular, 4-cleft. Stamens 4, inserted on the corolla. Style slender. - Stout and coarse biennials, hairy or prickly, with large oblong heads. (Name from $\delta \iota \psi a ́ \omega$, to thirst, probably because the united cup-shaped bases of the leaves in some species hold water.)

1. D. Bylvéstris, Mill. (Wilv Teasez.) Prickly ; leaves lance-oblong; leares of the involucre slender, longer thin the head; bracts (chaff) tapering into a long flexible awn with a straight point. - Roadsides : rather rare. (Nat. from Eu.) Suspected to be the original of

2. D. Fuldònu, L., the cultivated Furmer's Tenser, which has a shorter involucre, and stiff chaff to the heads, with hooked points, used for raising a nap upon woollen cloth: it has escaped from cultivation in some places. (Adv. from Eu.)

\section{Order 53. Compósicke. (Composite Family.)}

Flowers in a close heal (the compound flower of the older botanists), on a common receptacle, surrounded by an involucre, with 5 (racely 4) stamens inserted on the corolla, their anthers uniled in a tube (syngenesious). - Calyx-tube united with the 1-celled ovary, the limb (called a pappus) crowning its summit in the form of bristles, awns, scales, teeth, \&c., or cup-shaped, or else entirely absent. Corolla either strap-shaped or tubular; in the latter chiefly 5 -lobed, valvate in the bud, the veins bordering the margins of the lobes. Style 2-cleft at the apex. Fruit seed-like (achenium), dry, containing a single erect anatropous seed, with no albumen. - An immense family, in temperate regions chiefly herbs, without stipules, with perfect, polygamous, monæcious, or dincious flowers. The flowers with a strap-shaped (ligulate) corolla are called rays or ray-fowers: the head which presents such flowers, either throughout or at the margin, is radiale. The tubular flowers compose the disk; and a head which has no ray-flowers is said to be discoid. When the head contains two sorts of flowers it is sail to be heterógamous; when only one sort, homógamous. The leaves of the involucre, of whatever form or texture, are termed scales. The bracts or scales, which often grow on the recep- 
tacle among the flowers, are called the chaff: when these are wanting, the receptacle is said to be naked. - The largest order of Phrnogamous plants. It is divided by the corolla into three suborders, only two of which are represented in the Northern United. States. The first is much the larger.

\section{SUBORDEII I. 'TUBULIFLOKAE.}

Corolla tubular in all the perfect flowers, regularly 5- (rarely 3-4-) lobed, ligulate only in the marginal or ray-llowers, which when present. are either pistillate only, or neutral (with neither stamens nor pistil).

The technical characters of the five tribes of the vast suborder Tubulifturce, taken from the styles, require a magnifying-glass to make then out, and will not always be clear to the student. The following artificial analysis, founded upon other and more obvious distinctions, will be useful to the beginner. ('The numbers are those of the genera.)

\section{Artificial Key to the Genera of this Suborder.}

1. Rays or ligulate towers none: corollas all tabular (or raroly nono).

* Flowers of the head all perfect aud alike.

Pappus composed of bristles ;

Double, the outer of very short, the inner of longer bristles $\quad$ - $\quad . \quad$. $\quad$ No. 1.

Simple, the bristles all of the same sort.

Heads few-flowered, theinselves aggregated into a compound or dense cluster. . . 2

lleads separate, few-Howered or many-flowered.

Receptucle (when the flowers sre pulled off) bristly-hairy . . . . 67, 68, 70 .

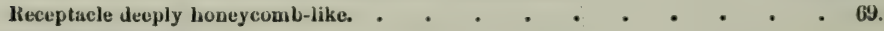

Receptacle naked.

Pappus of plumose or bearded stiff bristles. Flowers purple. . . . . . 4.

Pappus of very plumose bristles. Flowers whitish. . . . . . . 5 .

Pappus of slender but rather stiff rough bristles. - . . . . 6, 7, 8, 20 .

Pappus of very soft and weak naked bristles. . . . . . . 62,63 .

Pappus composed of scales or chalf.

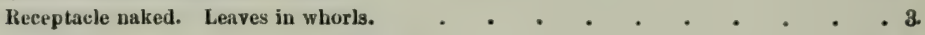

Receptacle naked. Leaves alternate. • . . . . . . • . . 45

Receptrcle buring chaff among the flowers. $\quad$. . . . . . . 49 . 4

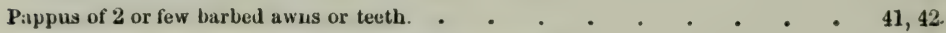

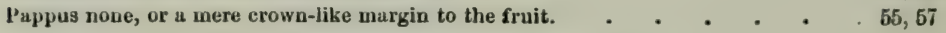

* Flowers of two kinds in the same head.

Mlarginal flowers neutral and sterile, either conspicuous or inconspicuous. 65, 66

Uarginal flowers pistillate and fertile.

Receptacle elonguted and bearing broad chaff among the flowers. $\quad$ - . $\quad$ - 60 .

Receptacle naked or bearing no couspicuous chaff.

Pappus of capillary bristles. Involuere imbricated. . . . . . . 23, 58, 59.

Pappus of capillary bristles. Involucre merely one row of scales. $\quad . \quad$. 14,61.

Pappus obsolete or none.

Achenia becoming much longer than the involucre. $\quad$. . . . . 11

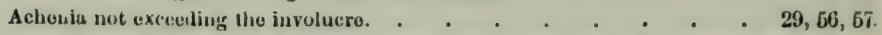

* * Flowers of two kinds in separate heads, the one pistillate, the other staninate.

Heads diocious ; in both kinds many-flowered. Pappus capillary. . . . . 24, 59.

Ifeads moncecious ; the fertile 1-2-flowered and closed. Pappus none. . . . . 80, 31 
12. Rnys present ; 1. e. the marginnl flowers or some of them with ligulate corollas.

* Pappus of capillary bristles. (Rays all pistillate.)

Rays occupying severul rows.

Rays in one maryinal row, and

White, purple or blue, never yellow. ․ . . . . . . . 12-15.

Yellow, of the sime color as the disk.

Pappus double, the outer sbort and minute. - . - . - . . 21.

Pappus simple.

Scales of the Involucre equal and all in one row. Leaves alternate. _ . 63.

Scales of the involucre in two rows. Leaves opposite. . . . . . . 64 .

Scales of the involucre imbricated. Lenves alternate. . . . . . . 19, 22

* * Pappua a circle of ehaffy scales, dissected into bristles. . . . 44.

* * Pappus a circle of thin chaffy scales or shurt chaffy bristles.

Heads several-flowered. Receptacle chaffy. - . . . . . . . . 50.

Heads 8-10 flowered. Receptacle naked. . . . . . . . . . . . 18.

Heads many-flowered. Receptacle deeply honeycombed. . . . . . . 48

Heads many-flowered. Receptacle naked. . . . . . . . . 45t, 46, 47.

* * Pappus none, or a cup or crown, or of 2 or 3 awns, tecth, or chaffy scales corresponding with the edges or angles of the achenium, often with intervening minute bristles or acales.

+ Receptacle naked.

Achenia flat, wing-margined. Puppus of separnte little bristles or awns. . . . . . 16. Achenia flat, marginless. Pappus none. Receptacle conical. . - . . . . 17. Achenia terete or angled. Pappus none. Receptacle flattish. . . . . . . 64 . Achenia angled. Pappus a little cup or crown. Receptacle conical. . . . . 55. + - Receptacle chaffy.

Rays neutral (rarely pistillate but sterile); the disk-flowers perfect and fertile.

Receptacle elevated (varying from strongly convex to columnar), and

Chaffy only at the summit; the chaff deciduous. Pappus none: . . . . 51 .

Chnffy throughout. Achenin flattened laterally if at all. . . . . 86-40.

Receptacle fint or flutish. Achenia flattened parallel with the scales or chaff. . 41, 42.

Rays pistillate and fertile ; the disk-flowers also perfect and fertile.

Achenir much flattened laterally, 1-2-awned. . . . . . . . . . 48.

Achenin fluttened parallel with the acales and chaft. Pappus none. - . - 58.

Achenia 3-4-angular terete or laterally flattish, awnless.

Receptacle convex or conical. Leaves alternate dissected. . . . . . 52

Receptrele conical. Lenves opposite simple.

Achenia obovold. Involucre a leafy cup - . . . . . . . 32 .

Achenin 4-angular. Involucre of separate scales. . . . . . . 85.

Receptacle flat. Leaves opposite and simple. . . . . . . . 38, 34,

Rays pistillate and fertile the disk -flowers staminate and sterile (pistil imperfect).

Receptacle chaffy. . . . . . . . . . . 25-28.

\section{Systematic Synopsis.}

Tribe I. VFT NONIACAE. Heads discoid; the flowers all alike, perfect and tubu. lar. Branches of the style long and slender, terete, thread-shaped, ninutely bristly-bairy all over. - Lenves alternate or scattered.

1. Vernonla. Heads several-many-flowered, separate. Involucre of many scales. Pappus of many capillary bristles

2. Elephantopug. Heads 3 - 5 -flowered, several crowded together into a compound head. Involucre of 8 scales. Pappus of several chaffy bristles.

Trlbe It. EUPATORIACER. Heads diseold, the flowers all alike, perfect and tubular; or in a few cases dissimilar, and the outer oues ligulate Branches of the style thlckened upwards or club-shaped, obtuse, very minuwly and uniformly pubescent ; the stigmatic lines indistinct.

G $M-10$ 
Subtribe 1. Eupatortev. Flowers all perfect and tubular, never truly yellow.

* Pappus a row of hard scales.

8. Selerolepls. Head many-flowered. Scales of the iuvolucre equal. Leaves whorled. * Pappus of slender bristles.

4. LIatris. Achenia many-ribbed. Bristles of the pappus plumose or barbellate. Corollas red-purple, strougly 5-lobed.

5. Kuhuin. Achenia many -ribbed. Bristles of the pappus very strongly plumose. Corollas whitish, 5-toothed.

6. Eupatorium. Achenia 5-angled. Bristles of the pappus roughish. Scales of the involucre many or several. Receptacle of the 5-many flowers flat or barely convex.

7. Mikunia. Achenia and pappus no No. 6. Scales of the involucre and flowers only 4.

8. Соnоclinium. Acheuia, pappus, \&c. as No.6. Receptacle conical.

Subtribe 2. Tussilaginea. Flowers (8onetimes yellow, more or less monceious or diœcious) of 2 sorts in the same bead.

* Outer flowers of each (many-flowered) head pistillate and ligulate. Scape leaflese.

9. Naxdosmiu. Hleads corymbed. Flowers somewhat dioecious. Pappus capillary.

20. Tussilago. Ilead siugle; the outer pistillate flowers in many rows. Pappus capillary.

* Flowers all tubular. Sten leafy.

11. Adenocanlon. Head few-fluwered; the outer tluwers pistillate. Pappus none.

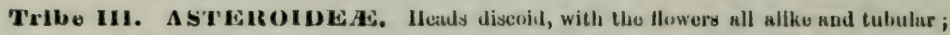
or else radiate, the outer ones ligulate and pistillate. Branches of the sty le in the perfect flowers flat, smooth up to where the conspicuous marginal stiguatic lines abruptly terminate, and prolenged above this into a flatteneel lance-shaped or triangular appendage which is evenly hairy or pubescent outside. - Leaves alteruate. Heccptuclo uaked (destitute of chaff) in all our species.

Subtribe 1. Asteriueae. Flowers of the head all alike and perfect, or the marginal ones ligulate und pistillate. Anthers without tails at the base.

* Ruy-flowers white, blue, or purple, never yellow.

- Pappus of numerous long and capillary bristles : receptacle flat.

12. Sericocarpus. Heads $12-15$ Howered : rays 4 or 5. Involuere oblong or club-shaped, imbricated, cartilagimous. Ac euia short, narrowed downwards, silky.

13. Aster. Leads many-flowered. Involucre loosely or closely iubricated. Achenia flattish. Pappus simple, copious.

14. Erigeson. Ifeads many-flowered. Involucre of narrow scales, little imbricated. Achenia flattened. Pappus simple and rather scauty, or with some outer minute scales.

15. Diplopappus. Ilcads many-flowered. Iuvolucre imbricated. Pappus double; the outer obscure, of minute stilt bristles.

+ + Pappus of very short rigid bristles, or none : receptacle conical or hemispherical.

16. Boltonia. Achenia flat and wing-margined. I'uppus very short.

17. Hells. Achonia marginless. P'appus noue. Receptacle conical.

* Ray-flowers yellow (in one species of Solidago whitish), or sometimes none at all.

18. Brachyehreta. Ilsads 8-10-Howered, clustered: rays 4 or 5. Puppus a row of minute bristles shorter than the achenium.

19. Solidugo. Heals few - uany-tlowered : rays 1 - 16. Pappus simple, of numerous sleu. der and equal capillary bristles.

20. Bigelovia. Ifeads 3-4-flowered : rays none. Receptacle awl-shaped. Pappus simple, a single row of eapillary bristles.

21. Chrysopsis. IJeals nuny-tlowered : rays numerous. Pappus double; the outer of very suall chaffy bristles, much shorter than the inner of copious capillary bristles.

Subtribe 2. Inulex. Anthers with tails at their base : otherwise as Subtribe 1.

22. Inula. Heads mauy-Howered. Rays many. Pappus capillary and copious. 
Bubribe 3. Bncehnrlaters trarchonnnthere. Flowers of the head nll tubur lar, either dincrious or monocious, namely, the etaminate and pistillate flowers either in different heals on distinct plants, or in the same head. Corolla of the pistillate fertile flowera a very slenrler tube sheathing the style, and truncate at the summit.

23. Pl wehen. Heads contrining a few perfect but sterile flowers in the centre, and many pistillate fertile ones around them. Anthers tailed at the base. Pappus capillary.

24. In ceharis. Ifends dinecious, some all pistillatc, others all staminate, on different plants. Anthers tuilless. Puppus capillary.

Trlbe IV. SEN ECIONIDEA. II 1 ads various. Branches of the style in the fertile flowers linear, thickiah or convex externally, flat internally, hairy or pencil-tufred at the npex (where the stigmatic lines terminats: ahruptly), and either trunente, or continued beyond Into $n$ briatly-hniry nppeniluge. - Jeaves either opposite or ulternate.

Subtribe 1. Melnmpodinese. Flowers none of them truly perfect, but either ataminate or pistillate; the two sorts either in the same or in different heads. Anthers tailless. Pappus, if any, never of bristles.

* Heads containing two kinds of flowers, the marginal ones pistillate, the central and tubular staminate flowers having a style, but always sterile.

+ Fertile flowers with a lizulate corolla (rarely wanting in No. 25) receptacle chaffy.

25. Polymuin. Achonia thick nut turghi, roumlish. Рлирия ионе.

26. Chrysogon um. Achenia flattish. Pappus $\Omega$ ne-sided 2 3-tonthed chaffy crown.

27. SII phimm. Achenia flat, wing-margined, numerous in several rows: rays deciduous.

28. Parthenium. Achenia flat, slightly margived: rays very short, persistent.

+ + Fertile fiowers with tubular or no corolla: no pappus.

29. Ivn. Achenia short and thick : receptacle with narrow chafr.

57. A rtemisis, in part. Achenia short and small: receptacle naked.

11. Adenocaulon. Achenia elongated, braring stalked glands : receptacle naked.

* * Ifends of two serts, one contilining staminate, the other pistillate flowers, both borne on the same plant; the pistillate only 1 or 2 , in a closed involucre resenbling an achenium or a bur; the atrminate several, in an open cup-shaped involucre.

30. Ambrosin. Fertile involucre (fruit) small, 1-flowered, pointed and nften tubercled.

31. Xanthium. Fertile involucre (fruit) sn oblong prickly bur, 2-celled, 2-flowered.

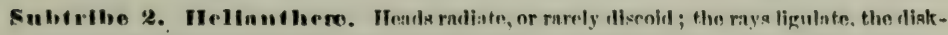
flowers all perfect and fertile. Receptacle chaffy. Anthers hlackish, tailless. Pappus none, or a crown or cup, or of one or two chafty awne, never capillary, nor of several uniform ehaffy scales. - Leaves more commonly opposite.

* Rays pistillate and fertile : achenia 3-4-sided, slightly if at all flattened. - Involuere double; the outer forming a cup.

32. Tetragonotheca. Outer involucre 4-leaved. Achenia obovoid. Pappus none. + + Invilucre of one or more rows of separate seales.

33. Fellpta. Receptacle flat; its chaff bristle-shaped. Pappus obsolete or none.

34. Borrleh Ia. Receptacle flat, its chaft scale-like and rigid. Pappus an obscure crown.

35. Hellopsis. Receptacle conical; its chaff linear. Pappus none or a mere border.

* * Rays sterile (either entirely neutral or with an imperfect style), or occasionally none ; achenia 4-angular or flattened laterally, i. e. their edges directed inwards and outwards, the chaff of the receptacle embracing their outer edge.

- Receptacle elevated, conical or columnar. Pappus none or a short crown.

36. Echinncen. Rays (very long) pistillate, but sterile. Achenia short, 4-sided.

37. Rudbeckin. Rays neutral. Achenia 4-sided, flat at the top, marginless.

38. Le pachy. Rays few, neutral. Achenia fiattened laterally and margined.

+ + Receptacle flattish or conical. Pappus chaffy or awned.

39. Helinnthus. Achenia flattened, marginless. Pappus of 2 very deciduous chaffy scales.

40. Actluomeris. Achenia very flat, wing-margined, bearing 2 persistent awns. 
** * Rays sterile, neutral : achenia obcompressed, i. e. flattened parallel with the scales of the involucre, the faces looking inwards and outwards. Involucre double; the outer spreading and often foliaccous. Receptacle flat.

41. Coreopsis. Pappus of 2 (or rurely more) scales, teeth, or awns, which are naked or barbed upwards, sometimes obsolete or a mere crown.

42. Bideus. Pappus of 2 or more rigid aud persistent downwardly barbed awns or teeth.

**** Rays pistillate or fertile (rarely none): acheuia laterally flattened, 2-awned.

43. Verbesina. liays few aud suall, or rarely none. Heceptacle convex. Achenia sometimes winged.

Subtribe 3. Tagetineae. Heads commonly radiate; the rays ligulate; the disk-flowers all perfect and fertile. Heceptucle uaked, flat. Scales of the involucre united into a cup. Pappus various, - Herbage strong-scented (as in Tagetes of the gardeus), being dotted with large pellucid glauds contisining a voliatile oil.

44. Dy sodia. P'appus a row of chaffy scales dissected iuto mauy bristles.

Subtribe 4. Helenieae. Ifeads radiate or sometimes discoid; the disk-flowers perfect. Pappus a circle of several chatfy scales. Auchers tailless.

* Receptacle naked (not chaffy nor honeycombed.)

45. Hymenopappus. Ha) 8 none. Receptacle flut. Scales of the involucre colored.

45. Actinella. Rays pistillate, merely toothed. Receptacle elevated. Fuvolucre appressed.

46. HelenIum. Rays jistillate, 3 b-cleft. Receptacle elevated. Iuvolucre amall, rellexed.

47. Leptopoda. Rays neutrul or sterile: otheriviso as No 46.

* Receptacle deeply pitted, like hone, comb.

48. Baldwinia. Kays numerous: neutral, elongated. Involucre much imbricated.

*** lieceptacle chafly.

49. Marshallia. Rays none. Involucre of many narrow and foliaceous seales.

50. Galinsoga. Ratys 4 or 5 , short, pistillate, whitish; the disk jellow. Involucre of 4 or 5 ovate and thin scales.

Subtribe 5. Anthemideae. Heads radiate or discoid; the perfect flowers sometimes infertile, and the pistillate flowers rarely tubular. Pappus a short crown or none. Otherwise nearly as Subtribe 4 .

* Receptacle chaffy, at least in part: rays ligulate.

51. Maruta. Rays neutral. Acheuia ohovoid and many-ribbed. Pappus none.

52. Anthemis. Rays pistillate. Achenia terete or 4 angular. Pappus minute or none.

53. Achillea. Rays pistillate, short. Achenia flattened and margined.

* Receptacle naked.

54. Leucanthemum. Rays numerous. pistillate. Receptacle flattish. Achenia striate or ribled. Pappus none.

55. Matricaria. IRays pistillate, or none, and then all the flowers perfect. Receptacle conical. Pappus crown-like or noue.

56. Tanacetum. Tays none, but the marginal flowers pistillate. Achenia broad at tho top. lappus a short crown.

57. A rtemisia. Rajs none; some of the outer flowers often pistillate. Achenia narrow at the top. Pappus none.

Subtribe 6. Guaphalinere. Heads all discoid, with tubular corollas; those of the fertile flowers filiform. Anthers with tails at their base. Pappus of capillary bristles. Flocculent-woolly herbs: leaves aiternate.

58. Guaphalium. Heceptacle nated, flat. Iteads containing both perfect and pistillate flowers. Bristles of the pappus all slender.

59. Antemuaria. Receptacle naked, flat. Heads diocious, or nearly so. Pappus of tho staminate flowers thickened or club-shaped at the summit.

60. Filago. Receptacle columuar or top-shaped, chalfy. P'uppus of the inner flowers capil lary, of the outer often none. 
Snbtribe 7. Sencelonero. IIends rndinte or diseold; the central flowers perfect. Anthers tnilless. Pappus capillary. Receptacle naked. (Scales of the involucre commonly in a single row.)

* Herds discoid. Leaves alternate.

61. Erechthites. Heads man, flowered: flowers whitish; the marginal ones pistillate and with filiform corollas.

62. Cnealla. Hends 5-many-flowered : flowers white or cream-color, all tubular and perfect.

63. Senecio. Heads many-flowered: flowers yellow, all perfect.

* Hends radiate, bany-flowered.

- Rays conspicuous and in a single row : flowers all fertile, yellow.

63. Senecio. Puppus fine and soft. Leaves alternatic.

64. A rnica. Pappus of more rigid and rough-denticulate bristles. Ienves all opposite.

+ + Rays narrow or sunall, in more than one row, nt least in fertile henda. Laves all radical.

9. Nurdosmia. Flowers whitish or purplish. Schpe bearing several heads.

10. Tussilago. Flowers yellow. Scape benring a single head.

Tribe V. CYNA REA. Ileads (in our apecies) discold, with the flowers tubular, or some of the outer corollas enlarged and appearing like rays but not truly ligulate. Style thickened or thickish near the summit; the branches stigmatic to the apex, without any appendage, often united below. (Hends large.)

* Marginal flowers mostly neutral or sterile. Pappus not plumose.

65. Centauren. Achenia flat. Pappus of short naked bristles, or none. Marginal neutral flowers commonly enlarged or ray-like.

66. Cuicus. Achenia terete, bearing 10 horny teeth and a pappus of 10 long and 10 shorter rigid naked bristles. Marginal flowers inconspicuous.

* * Flowers all alike in the (or oid or globular) head.

67. CIrslum. Achenia smooth. Pappus of plumose bristles. Receptacle clothed with long and soft bristles or hairs.

68. Cnxduns. Pappus of naked bristlea : otherwise as No. 67.

69. Onoporion. Achenia wrinkled transversely, 4-augled. Pappus not plumose. Receptacle honey combed.

70. Lnppa. Achenia wrinkled, flattened. Pappus of short and rough bristles. Receptacle bristly.

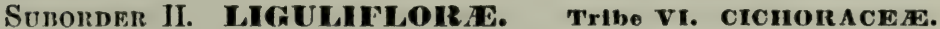

Corolla ligulate in all the flowers of the head, and all the flowers perfect. - Herbs, with milky juice. Leaves alternate.

* Pappus none.

71. Lnm paann. Involucre cylindrical, of 8 scales in a single row. 8-12-flowered.

* * Pappus chaffy, or of both chaff and bristles.

72. Clehoxium. Pappus a small crown of many bristle-form scales. Involucre double.

73. Krigia. Pappus of 5 broad chaffy ecales, and 5 slender bristles.

74. Cy whia. Pappus double; the outer short, of many minute chaffy scales, the inner of numerous long eapillary bristles.

*** Pappus plumose.

75. Leontodon. Bristles of the pappus several, chafy-dilated at the base, tarny.

**** Pappus composed entirely of capillary bristles, not plumose.

- Achenia not flattened nor distinctly beaked, columnar or terete, often slender: pappus rather stif, mostly tawny or dirty-white.

76. Troximon. Involucre loosely imbricated, many-flowered: corolla yellow. Achenia 10-ribbed. Pappus very copious and unequal.

7. Herncium. Involucre more or less imbricated, 12-many-flowered : corolla yellow. Achenis short. Pappus of rather scanty and tawny roughish bristles. 
78. Nabalus. Involuere cylindrical, of $5-14$ linear equal scales in a single row and a fow little scales at base, 5 - many-flowi-red : corolla whitish, crean-color, or purplish. Achebiat rather short mad blunt. P'ippus of very copious tawny or brown roughish bristles.

79. Lу удсdевын Involucre as the preceling, 5-10-flowerod : corolla rone-purple. Achevia long and slender, tipering ut the summit. Pappus of copious whitish bristles.

+ + Achenia terete or nearly so, ribbed, rouphish above, abruptly slender-beaked. Yappus soft, fine, und flaccid. Iuvolucte cylindrical, of geveral liueur seales in a single row and soue suall short ones at the base. Corolla yellow.

80. Chondrilla. Involucre few-flowered. Pappus white. Stems branching, leafy.

81. Pyrihopappus. Involucre many-tlowered. Pappus reddish or rusty. Stems branching, leafy below.

82. Taraxacum. Involucre many-flowered. Pappus whitish. Scape naked, simple.

+++ Achenia flat or liattish. luvolucre somewhat imbricated, mostly many-flowered.

83. Lactuca. Achenia abruptly long and slender-beaked, very flat: pappus bright white.

84. Iulgedium. Achenia flattish, and with a short and thick beak:

85. Somelıus. Acheuia tlattish, beakless. Pappus white. Flowers yellow.

\section{VER N Ò I A, Schreb. IRon-WEed.}

Heads 15-many-flowered, in corymbose cymes; flowers all perfect. Involacre shorter than the flowers, of many appressed closely imbricated scales. Receptacle naked. Achenia cylindrical, ribbed. Pappus double; the outer of minute scale-like bristles; the inner of copious capillary bristles. - Perennial herbs, with alternate leaves and mostly purple flowers. (Naned in honor of a Mr. Vernon, an early linglish botanist who travelled in this country.)

1. V. Noveboracénsis, Willd. Scules of the incolucre tipped with a long bristle-form or awl-shapul spreuding appendage or awn; in some varicties merely pointed. - Low grounds near the coast, Maine to Virginia; and river-banks in the Western States, from Wisconsin southward. Aug. - A tall coarse weed with lanceolate or oblong leaves.

2. V. fasciculata, Michx. Scales of the involucre (all but the lowest) rounded and obtuse, without appendage. - Prairies and river-banks, Ohio to Wisconsin and southward. Aug. - Leaves narrowly or broally lanceolate : heads mostly crowded. Very variable, and manifestly passing iuto No. 1.

\section{ELEPHÁ NTOPUS, L. Elemilant's-Foot.}

Heads 3-5-flowered, several together clustered into a compound head : flowers perfect. Involucre narrow, flattened, of 8 oblong dry scales. Achenia many-ribbed. Pappus of stuut bristles, chaffy-dilated at the base. - P'erennials, with alternate leaves aud purplish flowers. (Name composed of $\tilde{\epsilon} \boldsymbol{\lambda} \epsilon \phi a s$, elephant, and $\pi$ ov̂s, foot.)

1. E. Caroliniàuus, Willd. Somewhat hairy, corymbose, leafy; leaves ovate-oblong, thin. - 1)ry soil, Pemsylvania to Illinois and soutliward.

\section{SCLERÓlEPIS, Cas. Screrolepis.}

Ifead many-flowered : flowers perfect. Scales of the involucre linear, equal, in 1 or 2 rows. Corolla 5-tuothed. Achenia 5-angled. 1'appus a single row of alınost horny oval and obtuse scales. - A smooth perennial, with simple stems, rooting at the base, linear entire leaves in whorls of 5 or 6 , and a terminal head 
of flesh-colored flowers. (Name of $\sigma \kappa \lambda \eta p \rho o ́ s$, hard, and $\lambda \epsilon \pi i s, a$ scale, from the pappus.)

1. S. verticillata, Cass. - In water : pine barrens, New Jersey and southward. Aug.

\section{I I A T I I S, Schreb. Button Snakeroot. Blazing-Star.}

Head several-many-flowered : flowers perfect. Scales of the involucre imbricated, appressed. Receptacle naked. Corolla 5-lobed. Achenia slender, tapering to the base, about 10-ribbed. Pappus of 15-40 capillary bristles, which are manifestly plumose, or only barbellate. - P'erennial herbs, often resinous-dotted, with rigid alternate entire leaves (these sometimes twisted so as to become vertical), and heads of handsome rose-purple flowers, spicate, racemose, or panicled-cymose, appearing late in summer or in autumn. (Derivation of the name unknown.)

§1. Stem usually wand-like and simple, fiom a globular or roundish corm or tuber (impregnated with resinous matter), very leafy: leaves narrow or grass-like, 1 5-nerved: heads spicate or racemed: involucre well imbricated: lobes of the corolla long and slender.

* Pappus very plumose; scales of the 5-fowered involucre with ovate or lanceolate spreading petal-like (purple or sometimes white) tips, excecding the flowers.

1. L. élegans, Willd. Stem $\left(3^{\circ}-5^{\circ}\right.$ high $)$ and involucre hairy ; leaves short and spreading; spike or raceme compact ( $1^{\circ}$ long). - Barren soil, Virginia and southward.

* * Puppus very plumose: scalrs of the cylindrical many-flowered involucre imbricated in many rows, the tips rigid, not petal-like: corolla hairy within.

2. L. squarrosa, Willd. (BLAzing-Star, \&c.) Often hairy $\left(1^{\circ}-3^{\circ}\right.$ high); leaves linear, elongated; heads few ( $1^{\prime}$ long) ; scales of the involucre mostly with elongated and leaf-like spreading tips. - Dry soil, Pennsylvania to Illinois and southward.

3. L. Cylindràcea, Michx. Commonly smooth $\left(6^{\prime}-18^{\prime}\right.$ high $)$; leaves linear; heads few $\left(\frac{1}{2}-\frac{2}{3}\right.$ ' long) ; scales of the involucre with short and rounded appressed tips. - Dry open places, Niagara Falls to Wisconsin, and sonthwestward.

* * Pappus not obviously plumose to the naked eye: corolla smooth inside.

4. I. scariosa, Willd. Stem stout $\left(2^{\circ}-5^{\circ}\right.$ high) pubescent or hoary; leaves (smooth, rough, or pubescent) lanceolate; the lowest ollong-lanceolate or obovate-oblong, tapering into a petiole; heads few or many, large, 30-40-flowcred; scales of the broad or depressed involucre olovate or sputulate, very numerous, with dry and scarious often colored tips or margins. - Dry soil, New England to Minnesota, and southwarl. - Widely variable : heads $l^{\prime}$ or less in diameter.

5. L. piloss, Willd. Beset with long scattered hairs; stem stout; leaves linear or linear-lancrolate, clongated; heads few, 10-15-flowered; scales of the top-shaped or bell-shaped involucre slightly margined, the outer narrouly oblong, very obtuse, the innermost linenr. - Mountains of Virginia and sonthward : rare and olscure. Perliaps a remarkable state of the next; but the flowers as largo as in the preceding. 
6. L. spicata, Willd. Smooth or somewhat hairy; stems yery leafy $\left(2^{\circ}-5^{\circ}\right.$ high $)$; leaves linear, the lower $3-5$-nerved; heads 8 - 12 -flowered $\left(f^{\prime}-\right.$ $\frac{\delta^{\prime}}{2}$ long), crowded in a long spike; seales of the cylindricul-bell-shaped involucre oblony or vecul, obtuse, appressed, with shight margins; achenia pubescent or smoothish. - Moist grounds: common fiom S. New York to Wisconsin and southward. Involucre somewhat resinous, very smooth.

7. L. graminifolia, Willd. Hairy or smoothish; stem $\left(1^{\circ}-3^{\circ}\right.$ high $)$ slender, leafy ; leaves linear, elongated, 1-nerved; heads several or numerous, in a spike or raceme, 7-12-flowered; scales of the obconical or obovoid involucre spatulate or oblong, obtuse, or somewhat pointed, rigid, appressed; achenia huiry. Virginia and southward. - Infloreseence sometimes panicled, especially in

Var. dùbia. Scales of the involucre narrower and less rigid, oblong, often ciliate. (L. dubia, Burton.) - Wet pine barrens, New Jersey and southward.

8. L. pycnostàchya, Michx. Hairy or smoothish; stem stout $\left(3^{\circ}-5^{\circ}\right.$ high), very leafy; leaves linear-lanceolate, the upper very narrowly linear; spike thick and dense $\left(6^{\prime}-20^{\prime}\right.$ long); heads about 5-flowered ( $\frac{1}{2}^{\prime}$ long); scales of the cylindrical involucre oblong or lanceolate, with recurved or spreading colored tips. - Prairies, from Indiana southward and westward.

§ 2. Stem simple or branched above, not from a tuber: heads small, corymbed or panicled, 4-10-flowered: involucre little imbricated: lobes of the corolla orate: pappus not plumose.

9. L. odoratíssima, Willd. (VAnilla-plantr.) Very smooth; leaves pale, thickish, obovate-spatulate, or the upper oval and clasping; heads corymbed. - Low pine barrens, Virginia and southward. - Leaves exhaling the odor of Vanilla when bruised.

10. L. paniculata, Willd. Viscid-hairy; leaves narrowly oblong or lanceolate, smoothish, those of the stem partly clasping, heads panicled. - Virginia and southward.

\section{K Ù H N I A, L. KunNiA.}

Heads 10-25-flowered: flowers perfect. Scales of the involucre few and loosely imbricated, lanceolate. Corolla slender, 5-toothed. Achenia cylindrical, many-striate. Pappus a single row of very plumose (white) bristles. - A perennial herb, resinous-dotted, with mostly alternate lanceolate leaves, and paniculate-corymbose leads of cream-colored flowers. (Delicated to Dr. Kuhn, of Pennsylvania, who brought the living plant to Linnæus.)

1. K. eupatorioides, L. Leaves varying from broadly lanceolate and toothed, to linear and entire. - Dry soil, New Jersey to Wisconsin and southward. Sept.

\section{EU PATÒ R I M , Tourn. THonođghwort.}

IIcads 3-many-flowered : flowers perfect. Involucre cylindrical or bellshaped. Receptacle flat or barcly convex. Corollin 5-toothed. Achenia 5angled. Pappus a single row of slender capillary barely roughish bristles. Perennial herbs, often sprinkled with bitter resinous dots, with generally corymbose heads of white, bluish, or purple blossoms, appearing near the close of 
summer. (Dedicated to Eupator Mithidates, who is said to have nsed a species of the genus in medicine.)

* IIeads cylindrical, 5 - 15-fowered; the purplish scales numerous, closely imbricated in several rows, of unequal length, slightly striale: stout herbs, with ample mostly whorled leaves, and flesh-colored flowers.

1. E. purpùreum, L. (Joe-Pye Ween. Trumpet-Weed.) Stems tall and stont, simple; leaves $3-6$ in a whorl, oblong-ovate or lanceolate, pointed, very veiny, roughish, toothed; corymbs very dense and compound. - Varies greatly in size $\left(2^{\circ}-12^{\circ}\right.$ high $)$, \&c., and with spotted or unspotted, often dotted stems, \&c., - including several nominal species. - Low grounds : common.

* Heads 3-20-flowered: involucre of 8-15 more or less imbricated and unequal scales, the outer ones shoiter: flowers white.

+Leaves all alternate, mostly dissected: heads panicled, very small, 3-5-flowered.

2. E. fconiculàceum, Willd. Smooth or nearly so, paniculatcly muchbranched $\left(3^{\circ}-10^{\circ}\right.$ high $)$; leaves 1 -2-pinnately parted, filiform. - Virginia, near the const, and southward. Adv, near Philadelphia.

+ + Leaves mostly opposite and sessile: heads 5-8-flowered, corymbed.

3. F. hyssopifolium, L. Minutely pubescent $\left(1^{\circ}-2^{\circ}\right.$ high $)$; leaves narrow, linear or lanceolate, elongated, obtuse, 1-3-nervel, entire, or the lower toothed, often crowded in the axils, acute at the base; scalss of the involucre obtuse. - Sterile soil, Massachusetts to Virginia, E. Kentucky and southward.

4. E. leucólepis, 'Torr. \& Gr. Minutely pubescent, simple $\left(1^{\circ}-2^{\circ}\right.$ high $)$; leaves linear-lanceolute, closely sissile, 1-nerved, obtuse, serrute, rough both sides; corymb hoary; scules of the involucre with white and scarious acute tips. - Sandy bogs, Long Island, New Jersey, and southward.

5. E. parviflórum, Ell. Minutely velvety-pubescent, branching $\left(2^{\circ}-3^{\circ}\right.$ high); leaves lancelate or oblong, triple-ribled and veiny, scrrate above the middle, tapering to the base, the lower slightly petioled; scales of the short involucre obtuse. (Leaves sometimes whorled in threes, or the upper alternate.) - Damp soil, Virginia and southward.

6. F. altíssimum, L. Stem stout and tall $\left(3^{\circ}-7^{\circ}\right.$ high), downy; leaves lanceolate, tapering at both ends, conspicuously 3-nerred, entire, or toothed abore the mildle, the uppermost alternate; corymbs dense; scales of the involucre obtuse, shorter than the flowers. - Dry soil, Pennsylvania to Illinois and Kentucky. Leaves $3^{\prime}-4^{\prime}$ long, somewhat like those of a Solidago.

7. E. álbum, I. Roughish-hairy ( $2^{\circ}$ high) ; leares oblong-lunceolate, coarsely toothed, veiny; heads clustered in the corymb; scales of the involucre closely imbricated, rigid, narrowly lanceolate, pointed, white and scarious above, longer than the fouers. - Sandy and barren places, pine barrens of New Jersey to Virginia and southward.

8. E. teucrifolium, Willd. Rooghish-pubescent $\left(2^{\circ}-3^{\circ}\right.$ high); leaves ovate-oblong and ovate-lancenlate, obtuse or truncate at the hase, slightly triplenerved, veiny, coursely toothed or incised towards the base, the upper ones alternate: branches of the corymb few, unequal; scales of the involucre ollong-lancrolute, rother obtuse, at length shorter than the flowers. (E. verhenxfolium, Michx.)-Low grounds, Massachusetts to Virgınia and southward near the coast. 
9. E. rotundifolium, L. Downy-pubescent $\left(2^{\circ}\right.$ high $)$; leaves roundish ovate, obtuse, truncate or slightly heart-shaped at the base, deeply crenate-toothed, triple-nerved, veiny, roughish ( $1^{\prime}-2^{\prime}$ loug) ; corymb large and dense; scales of the (5-flowered) involucre linear-fanceolate, slightly pointed. - Dry soil, Khodo Island to Virginia, near the coast, and southward.

10. E. pubéscens, Muhl. Pubescent: leaves ovate, mostly acute, slightly truncate at the base, serrate-toothed, somewhat triple-nerved, veiny; scules of the 7-8-flowered incolucre lenceolate, acute. (L. ovàtum, Bigel.) - Massachusetts to New Jersey, near the coast, and Kentucky. - Like the last, but larger.

11. E. sessilifolium, L. (U1'LAN1) Buntestr.) Stem tall $\left(4^{\circ}-6^{\circ}\right.$ high), smooth, branching; leaves lanceolute or ovate-lanceolate, lapering fiom near the rounded sessile buse to the sharp point, serrate, veiny, smooth ( $3^{\prime}-6^{\prime}$ long); corymb very compound, pubescent ; scales of the 5- (or 5-12- ?) flowered involucre oual and ablony, obtuse. - Copses and banks, Massachusetts to Illinois, and southward along the mountains.

+++ Leaves opposite, clusping or united at the base, long, widely spreading: heads mostly 10-15-flowered: corymbs very compound and larye.

12. E. resinosum, 'Torr. Minutdy velvely-downy $\left(2^{\circ}-3^{\circ}\right.$ high $)$; leaves lincar-lanceulate', deneguted, serrate, perdly clasping, tapering to the point, slightly veiny beneath $\left(4^{\prime}-6^{\prime}\right.$ long $)$; scales of the involucre oval, obtuse. - Wet pine barrens, New Jersey. - Name from the copious resiuous globules of the leaves.

13. E. perfoliàtum, L. (Thonovgnwort. Boneset.) Stem stout $\left(2^{\circ}-4^{\circ}\right.$ high), hairy; leaves lanceolate, united at the base around the stem (connateperfoliate), tapering to a slender point, serrate, very veiny, wrinkled, downy beneath $\left(5^{\prime}-8^{\prime}\right.$ long); scales of the involucre linear-lanceolate. - Low grounds: common and well-known. - Varies with the heads $30-40$-flowered.

++++ Leaves long-peioled, the upper ones alternate: heads 12-15-flowered, in compound corymbs.

14. E. serótinum, Michx. Stem pulverulent-pubescent, bushy-branched $\left(3^{\circ}-6^{\circ}\right.$ high $)$; leaves ovate-lanceolate, tapering to a point, triple-nerved and veiny, coursely serrate $\left(5^{\prime}-6^{\prime}\right.$ long $)$; involucre very pubescent. - Alluvial ground, Maryland to Illinois and southward.

*** Heads 8-30-flowerod; the scales of the involucre nearly equal and in one row: leaves opposite, ovate, petioled, tiiple-nerved and veiny, not resinons-lotted: flowers white.

15. E. ageratoides, L. (Wurte SNake-root.) Smooth, brunching

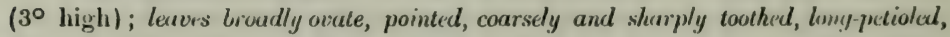
thin $\left(4^{\prime}-5^{\prime}\right.$ long) ; corymbs compound. - Rich woods : common northward.

16. E. aromáticum, I. Smooth or slightlly downy; stems nearly siuple; leaves on short petiules, onute, rather obtustly toothed, not pointral, thickish. Copses, Massachusetts to Virginia and southwarl, near the coast. - Lower and more slender than No. 15, with fewer, but usually larger heads.

\section{M I K À N I A, Willd. Chimbing Hemp-weed.}

Heads 4-flowered. Involucre of 4 scales. Receptacle small. Flowers and achenia, \&c., as in Eupatorium. - Twining perennials, climbing bushes, with 
oppoxite mommonly heart-shaped and petioled leaves, and corymbose-panicled flesh-colored flowers. (Named for Prof. Mikan, of Prague.)

1. M. scándèns, L. Nearly smooth, twining; leaves somewhat trianguIrr-heart-shaped or halberd-form, pointed, toothed at the base. - Copses along streams, E. New England to Kentucky and southward. July-Sept.

\section{CONOCLINIU M, DC. Mist-Flower.}

Heads many-flowered. Involucre bell-shaped, the nearly equal linear-awlshaped scales somewhat imbricated. Receptacle conical! Otherwise as in Eupatorium, of which it is rather a section. - Perennial erect herls, with opposite petioled lenves, and violet-purple or blue flowers in crowled terminsl corymbs. (Nume formed of kôvos, $a$ cone, and $\kappa \lambda i v \eta, a$ bed, from the conical receptacle.)

1. C. cœlestinum, DC. Somewhat pubescent $\left(1^{\circ}-2^{\circ}\right.$ high $)$; leaves triangular-ovate and slightly heart-shaped, coarsely and bluntly toothed. - Rich soil, Pennsylvania to Michigan, Illinois, and southward. Sept.

\section{N A R D Ó S M I A, Cass. Sweet Coltsfoot.}

Heads many-flowered, somewhat dicecious : in the sterile plant with a single row of ligulate pistillate ray-flowers, and many tubular ones in the disk; in the fertile plant with many rows of minutely ligulate ray-flowers, and a few tubular perfect ones in the centre. Scales of the involucre in one row. Receptacle flat. Achenia terete. Pappus of soft capillary bristles, longer and copious in the fertile flowers. - Perennial woolly herbs, with the leaves all from the rootstock, the scape with sheathing scaly bracts, bearing heads of purplish or whitish fra-

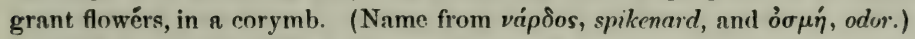

1. N. palmàta, Hook. Leaves rounded, somewhat kidney-form, whitewoolly beneath, palmately and deeply 5-7-lobed. the lobes tootherl and cut. (Tussilngo palmata, Ait. T. frigirla, Bigel.) - Swamps, Mainc and Massachusetts to Michigan and northwestward : rare. $\Lambda$ pril, May. - Full-grown leaves $\left(6^{\prime}-10^{\prime}\right.$ broad).

\section{TUSSILÀ G O, Tourn. Contsfoot.}

Head many-flowered; the ray-flowers narrowly ligulate, pistillate, fertile, in many rows; the tubular disk-flowers few, staminate. Scales of the involucre nearly in a single row. Receptacle flat. Fertile achenia cylindrical-oblong. Pappus capillary, copious in the fertile flowers. - A low perennial, with horizontal creeping rootstocks, sending up simple scaly scapes in early spring, bearing a single head, and producing rounded-heart-shaped angled or toothed leaves later in the serson, woolly when young. Flowers yellow. (Name from tussis, a congh, for which the plant is a reputed remedy.)

1. T. FArfara, L. - Wet places, and along brooks, New England, New 'York, and Pennsylvania; thoroughly wild. (Nat. from Eu.)

\section{A D E N C A Ù L O N, Hook. Adenocaulon.}

Heads 5-10-flowered; the flowers all tubular and with similar corollas; the marginal ones pistillate, fertile; the others staminate. Scales of the involucre 
equal, in a single row. Achenia elongated at maturity, club-shaped, beset with stalked glands above. Pappus none. - Slender perennials, with the alternate thin and petioled leaves smooth and green above, white woolly beneath, and few small (whitish) heads in a loose panicle, besct with glands (whence the name,

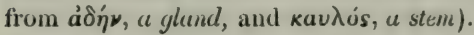

1. A. bícolor, Hook. Leaves triangular, rather heart-shaped, with angular-toothed inargins; petioles margined. - Moist woods, shore of Lake Superior, and westward.

\section{S ER I C O C Á R U S, Nees. White-topped Aster.}

IIeads 12-15-flowered, radiate; the rays about 5, fertile (white). Involucre somewhat cylindrical or club-shaped; the scales closcly imbricated iu several rows, cartilaginous and whitish, appressed, with short and abrupt often spreading green tips. Receptacle alveolate-toothed. Achenia short, inversely pyramidal, very silky. Papjus simple, of numerous capillary bristles. - Perenuial tufted herbs $\left(1^{\circ}-2^{\circ}\right.$ high), with sessile somewhat 3-nerved leaves, and small heads mostly in little clusters, disposed in a flat corymb. Disk-tlowers pale

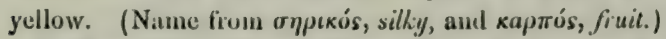

1. S. solidagíneus, Necs. Sunouth, slunder; laves linear, rigid, obtuse, entire, with rough margins, tapering to the base; heads narrow (3" long), in close clusters, few-flowered; petprus white. - Thickets, S. New England to Virginia, near the coast. July.

2. S. conyzoides, Nees. Someivhat pubescent; leaves oblong-lanceolute or the lower spululute, mostly serrate towards the apex, ciliate, veiny; heads rather loosely corymbed, obconical $\left(t^{\prime \prime}-6^{\prime \prime}\right.$ long); pappus rusty-color. - Dry ground: common. July.

3. S. tortifolius, Nees. Hoary-pubescent; leaves obovate or oblong-spatulate, short, $\left(\frac{1^{\prime}}{2}-1^{\prime}\right.$ long), turnerl edlyewise, both sides alike, nearly veinless; heads rather loosely corymbed, obovoid (4" $4^{\prime \prime}$ long); pappus white. - Pine woods, Virginia and southward. Aug.

\section{3. Á S T ER, L. Starwort. Aster.}

Heads many-fluwered, radiate; the ray-flowers in a single series, fertile. Scales of the involucre more or less imbricated, usually with herbaceous or leaflike tips. Receptacle flat, alveolate. Achenia more or less flattened. I'appus simple, of capjillary bristles. - l’erential herbs (or annual only in $\$ 6$ ), with corymbed, panicled, or racemose heads; flowering in autumn. Rays white, purple, or blue: the disk yellow, of ten changing to purple. (Name áoríp, a star, from the appearance of the radiate lieads of flowers.)

§ 1. BIO'TIA, I)C. Iniolwe abovoid-bell-shaped; the scales regularly imbricutal in several rows, appressed, nearly destitule of herbaccous lips: rays 6-15 (uhite or nearly so): achenia slender: lower leaves large, heart-shaped, petioled, coarsely serrate: heads in open corymbs.

1. A. corymbosus, Ait. Stem slender, somewhat zigzag; leaves thin, smoothish, cuursely and unequally serrate with sharp spreading teeth, sharp-pointed, ovate or ovate-lanceolite, all but the uppermost heart-shaped at the base and on 
slender naked petioles; rays 6-9. - Woodlands : common, especially northward. July, Aug. - Plant $1^{\circ}-2^{\circ}$ high, with smaller heads, looser corymbs, rounder and less rigid exterior involucral scales, and thinner leaves than the next; not rough, but sometimes pubescent.

2. A. macrophýllus, L. Stem stout and rigid $\left(2^{\circ}-3^{\circ}\right.$ high); leaves thickish, rough, closely servute, somewhat pointed ; the lower heart-shaped $\left(4^{\prime}-10^{\prime}\right.$ long, $3^{\prime}-6^{\prime}$ wide), long-petioled ; the upper ovate or oblong, sessile or on margined petioles; heads in ample rigid corymbs; rays $12-25$ (white or bluish). Moist woods : common northwarl, and southward along the mountains. Aug., Sept. - Involucre $\frac{1}{2}$ 'broud ; the outer scales rigid, oblong or ovate-oblong, the innermost much larger and thinner.

§ 2. CALLIASTRUM, Torr. \& Gr. Scales of the involucre imbricated in several rows, coriaceous, weth short herbuceous tips: rays 12-30, violet or blue: achenia narrow (smoothish) : pappus of rigid bristles of unequal thickness: stem-leaves all sessile; lower ones not heart-shaped: heads few, or when several corymbose, large and showy. (Allied to $§ 1$, and to Sericocarpus.)

3. A. Rádula, Ait. Stem simple or corymbose at the summit, smooth, many-leaved $\left(1^{\circ}-3^{\circ}\right.$ high $)$; leaves oblong-lanceolate pointed, sharply serrate in the middle, very rough both sides and rugose-veined, closely sessile $\left(2^{\prime}-3^{\prime}\right.$ long), nearly equal; scales of the bell-shaped involucre bblong, appressed, with very short and slightly spreading herbaceous tips; achenia smooth. - Bogs and low grounds, Delaware to Maine and northward, near the coast. Also Pocono Mountain, Penn. (Prof. T. Green); and a dwarf variety, with lincar-lanccolate leaves, at White Moun tains, New Hampshire. Aug. - Rays light violet. Involucre nearly smooth, except the cilinte margins.

4. A. surculosus, Michx. Stems slender $\left(\frac{1}{2}^{\circ}-1^{\circ}\right.$ high $)$, from long and slender, or here and there tuberous-thickencd, creeping, subterranean shoots or suckers, roughish-pubescent above, 1-2- or corymbosely several-flowered; leaves roughish, obscurely toothed, lanceolate or the lower spatulate; involucre obconical or bell-shaped ( $\boldsymbol{b}^{\prime}-\frac{1^{\prime}}{2}$ long), the whitish and coriaccous scales with short herbaceous tips, the outer ones shorter; achenia slightly pubescent. - Var. GRACuLs (A. gracilis, $N u t t$.) is a form with the scales of the narrower obconical involucre successively shorter and with very short and scarcely spreading green tips, resembling a Sericocarpus. - Moist grounds, pine barrens of New Jersey and southward. Sept. - Rays about 12 , violet, 6 " long.

5. A. spectábilis, Ait. Stems $\left(1^{\circ}-2^{\circ}\right.$ high $)$ minutcly rough and glandular-pubescent at the summit; leaves oblong-lancenlate, voughish, obscurely toothed, tupering to the buse; scales of the short and almost hemispherical involucre linear-oblong, with conspicuous spatulate glandular-rlowmy tips, the outrmost scarcely shorter; achenia slightly pubescent. - Sandy soil, Massachusetts to ${ }^{\circ}$ New Jersey, near the coast, and southward. Sept. - Nov. - One of the handsomest of the genus, though the heads are few. The rays, about 20 , are narrowly lanceolate, nearly I' long, very deep violet-blue. Involucre $\frac{1}{2}$ long and wide.

6. A. Hérveyi, n. sp. Stcon slender $\left(1^{\circ}-2^{\circ}\right.$ high $)$, nearly smooth, the summit and peduncles of the several corymbose heads minutely glandular-pubescent; leaves thinnish, roughish, obscurely serrate, oblong-lanceolate, very acute, all but 
the uppermost taper-pointed, and also tapering below into a narrowed base or winged petiole; heads small (less than $\frac{1}{2}$ ' long, exclusive of the narrow rays); involucre between bell-shaped and top-shitpeil; the scules obscurdy glandulur, linear, or tho slourt outer ones oblong, with greenish appressed tips; achenia linear, slightly pubescent. - Burders of vak woods, in rather moist soil, New Bedford, Mass., E. $\boldsymbol{W}$. Hervey. Sept. - An anuliguous member, and the smallest-flowered, of the section. Pappus whitish, finer than that of the preceding.

\$3. ASTER, proper. Scales of the involucre imbricated in various degrees, with herbuceous or leaf-tike summits, or the outer ones entirely foliaceous: rays mumerous: pappus soft and nearly uniform: achenia flutlemed. (All flowering late in summer or in autumn.)

* Letwes whitenal, silcriy-silhy both sides, all sessile and entire, mucronulate: involucre imbricated in 3 to several rou's: rays showy, purple-violet.

7. A. sericeus, Vent. Stems slender, branched ; leaves silver-white, lanceolate or oblong; heads mostly solitary, terminating the short branchlets; scales of the globular involucre similar to the leaves, spreading, except the short coriaceous base; achenia smooth, many-ribbed. - Prairies and dry banks, Wisconsin to Kentucky and southward. - Ileads large : rays 20-30.

8. A. cóncolor, L. Stems wand-like, nearly simple; leaves crowded, oflong or lanceolate, appriessed, the upper reduced to little bracts; heads in a simple or compound wand-like raceme; scales of the obovoid involucre elosely imbricated in several rows, appressed, rather rigid, silky, lanceolate; achenia silky. - 1)ry sandy soil, pine barrens of New Jersey and southward. - Plant $1^{\circ}-3^{\circ}$ high, with the short leaves $\mathbf{1}^{\prime}$ or less in length, grayish-silky both sides.

* * Lower leaves not heart-shaped; the upper all sessile and more or less clusping by a heurt-shaped or auricled buse: heads showy: scules of the inversely conical or bell-shuped involucre reyularly imbricuted in several rows, the outer successicely shorter, appressed, coriaccous, whitish, with short herbaceous tips: rays large, purple or blue.

9. A. pàtens, Ait. Rough-pubescent; stem loosely panicled above $\left(1^{\circ}-3^{\circ}\right.$ high), with willely spreading branches, the heads mostly solitary, terminating the slender branchlets; leaves oblong-lanceolate or ovate-oblong, often contracted below the middle, all clusping by a deep auricled-heart-shaped base, rough, especially above and on the margins, entire; scales of the minutely roughish involucre with spreading pointed tips; achenia silky. - Var. PHLOGIrònus is a form which the plant assumes in shady inoist places, with larger and elongated thin scarcely rough leaves, downy underneath, sometimes a little toothed above, mostly much contracted below the midlle. - Dry ground: common, especially southward. Heads $\frac{1}{2}$ broad, and with showy deep blue-purple rays.

10. A. læevis; L. Vory smooth throughout; heads in a close panicle; leaves thickish, lanceolate or ovate-lanceolate, chiefly entire, the upper more or less elasping by an anricled or leart-shaped base; scales of the short-abovid or hemispherical involucre with appressed green points; rays sky-blue; achenia smoolh. A variable and elegant species, of which the two best-marked forms are :-

Var. lævigatus. Scarcely if at all glaucous ; leaves lanceolate or oblong ; involucre nearly hemispherical; the scales lanceolate or linear, with narrow und 
sente green tips tapering down on the midnerve. (A. lævis, $L$. $\Lambda$. levigatus, Willd.) - Dry woodlands : rather common.

Var. cyaneus. Very smooth, but pale or glancous; lcaves thicker; tho upper often oblong or ovate-lanceolate, clasping by a heart-shaped base; involuere narrowed at the base, of broader and more coriaccons scales with shorter

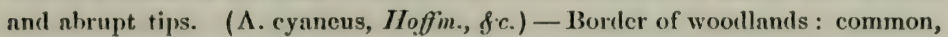
especially northward.

11. A. turbinéllus, Lindl. Very smooth; stem slender, paniculately branched; leaves lanceolate, tapering to each end, entire, with rough margins; involucre elongated-obconical or almost club-shaped ( $\left.\frac{1}{2}^{\prime} \mathrm{long}\right)$; the scules linear, with very short and blunt green tips; rays violet-blue; wrlemia nearly smooth. J)y hills, \&c., Illinois and sonthwestward. - Well-marked and handsome.

* * Lower leaves all heart-shuped and petioled, the upper sessile or petioled: involucre imbricuted much as in the last division, but the heads smaller, very numerous, racemosed or panicled.

+ Lenves entire or slightly serrate: heads middle-sized: rays bright-blue.

12. A. azùreus, Lindl. Stem rather rough, erect, racemose-compound nt the summit, the branches slender and rigid ; leaves rough; the lower ovate-lanceolate or oblong, heart-shaped, on long often huiry petioles; the others lanceolate or linear, sessile, on the branches awl-shaped; involucre inversely conical. - Copses and prairies, Niagara Falls (Clinton), and Ohio to Wisconsin and southward. Involucre much as in A. lævis, but much sinaller, slightly pubescent; the rays bright blue.

13. A. Shórtii, Boott. Stem slender, sprealing, ncarly smooth, bearing very numerous hends in racemose panicles; leaves smooth abore, minutely pubescint underneath, lanceolate or ovate-lanceolate, elongated, tapering gradually to a sharp point, all but the uppermost more or less heart-shaped at the base, and on naked prtioles; involucre bell-shaped. - Cliffs and banks, Ohio to Wisconsin and southwnrd. $-\Lambda$ pretty species, $2^{\circ}-4^{\circ}$ high; the leaves $3^{\prime}-5^{\prime}$ long.

14. A. undulatus, L. Pale or somewhat hoary with close pubescence; stem spreading, bearing numerous heads in racemose panicles; leuves orate or ovate-lanceolate, with wavy or slightly toothed margins, ronghish above, downy underneath, the lowest heart-shaped on margined petioles, the others alnuptly contracted into short broadly winged petioles which are diluted and clasping at the base, or directly sessile by a heart-shaped base; involucre obovoid. (A. diversifolins, Michx.) - Dry copses : common.

+ + Leaves conspicuously serrate: hands small : rays pale hilue or nearly white.

15. A. cordifolius, L. Stem much branched above, the sprending $m$ diverging branches bearing very numerous panicled hro/s; lower leaves all heartshaped, on slender and mostly naked ciliate petioles; scales of the inversely conical involucre all appressed and tipped with short green points, obfuse or acutish. Woodlands : very common. - Varies with the stem and leaves either smooth, roughish, or sometimes hairy. Hearls profuse, but quite small.

16. A. sagittifblius, Willd. Stem rigid, erect, with nscending branches bearing numerous racemose heads; leaves ovate-lanceolate, pointed; the lower hcart-shaped at the base, on margined petioles; the upper lanceolate or linear, 
pointed at both ends; scales of the oblong involucre linear, tapering into awl-shaped stender and loose tips. - Dry ground, New York and Penn. to Kentucky and northward. - Usually more or less hairy or downy; the heads rather larger than in the last, almost sessile. - $\Lambda$. 1)rummondii, Lindl., which probably grows on the Illinois side of the Mississippi, is a downy-leaved variety of this.

**** Leaves none of them heurt-shuped; those of the stem sessile, nurrow, rigid, entire: incolucre imbricated in several rows: the coriactous scales appressed and whitish at the buse, with abrupt and conspicuous spreading herbaceous tips : hauds small and very numerous, paniculute-racemuse; rays white.

17. A. ericoides, L. Simouth or sparingly hairy $\left(1^{\circ}-1 \frac{1}{2}^{\circ}\right.$ high); the simple branchlets or peduncles racemose along the upper side of the wand-like spreading branches; lowest leaves oblong-spatulate, sometimes toothed; the others linear-lanceolate or linear-awt-shaped, acute at both ends; scales of the invalune broudest at the base, with acute or uwl-shaped green lips. - Vur. villosus is a hairy form, often with broader leaves; chictly in the Western States. - Dry open places, S. New England to Wisconsin and southward.

18. A. multiflorus, Ait. Pule or hoary with minute close pubescence (10 high), much branched and bushy; the heads much crowded on the spreadiug racemose branches; laves crowdal, lincer; spreading, with rough or ciliate nargins, the upper somewhut diluted and parlly clasping at the base; scales of the involucie with spatulate spreading green tips broader than the lower portion, the outer obtuse. - Dry gravelly or sandy soil : common.

***** Leaves none of them heart-shaped; those of the stem tapering at the buse, sessile; involucre imbricated; the scales unequal, with short and narrow appressed or rather loose greenish tips: heads small or middle-sized: rays white or bluish-purple.

+ Heads small. (Involucre 2" -4 "long.)

19. A. dumosus, L. Smooth or nearly so, racemosely compound, the scattered heads mostly solitary at the end of the spreading branchlets; leaves linear or the upper oblong, crowded, entire or slightly serrate, with rough margins; scales of the closcly imbricatal involucre linear-spatulate, obtuse, in 4-6 rows. Thickets : commou. $-\Lambda$ variable species, $1^{\circ}-3^{\circ}$ high, loosely branched, with small leaves, especially the upper, and an inversely conical or bell-shaped involucre, with more alorupt green tips than any of the succeeding. Rays pale purple or blue, larger than in the next. Runs into several peculiar forms.

20. A. Tradescánti, L. Smooth or smoothish; the numerous heads closely racemed along one side of the erect-spreading or diverging branches; leaves lanceolate-linear, elongated, the larger ones remotely serrate in the middle with fine sharp tecth; scales of the imolncre narrowly linear, acute or acutish, in 3 or 4 rows. - Var. Frifius has the leaves entire or nearly so, except the lowest, the heads more scattered. - Moist banks : very common. - Stems $2^{\circ}-4^{\circ}$ high, bushy: heads very numerous, smaller than in the last. Rays white or nearly so.

21. A. miser, L., Ait. More or less hairy, much branched; the branches usually diverging, bearing racemose often scuttered heads; leaves lanceolate or ollong-lanceolate, tapering or pointed at each end, sharply serrate in the middle. 
scales of the involucre linear, acute or vather obtuse, imbricated in 3 or 4 rows. 'Thickets, fields, \&c. : very common, and extensively variable. - I caves larger thun in either of the preceding $\left(2^{\prime}-5^{\prime}\right)$; the involucre intermediate between them, as to the form of the seales. Rays mostly short, pale bluish-purple or white.

++ Heuds middle-sized. (Involucre $3^{\prime \prime}-5$ "long.)

22. A. simplex, Willd. Smooth or nearly so $\left(3^{\circ}-6^{\circ}\right.$ high $)$, much branched; the brunches and scattered heads somerhat corymbose at the summit; leaves lanceolute, pointed, the lower serrate; scales of the involucre linear-awl-shaped, loosely and sparingly imbricuted. - Shady moist banks : common. - Rays pale. Approaches in its different forms the preceding and the two following.

23. A. tenuifólius, L. Nearly smooth; stem much branched $\left(2^{\circ}-3^{\circ}\right.$ high); the heads somewhat panicled or racemed; leaves narrouly lanceolate, tapering into a long slender point $\left(2^{\prime}-6^{\prime}\right.$ long), with rough margins, the lower somewhat sovate in the middle; scales of the hemispherical involucre lincar-awl-shaped, very slender-pointed, numerous, closely imbricated. - Low grounds, New York to Wisconsin, and southward. Rays short and narrow, pale purple or whitish.

24. A. cárneus, Nees. Smooth, or the branches rough or pubescent; leaves lanceolute, somewhat pointed, or the upper short and partly clasping; heads racemose along the ascending leafy branches; scales of the obovate involucre lanceolate, abruptly acute, closely imbricated. - Moist soil : common. Leaves firm in texture, smooth, or rough above. Rays rather large, bluish, purplish, violet-purple, or almost white. - On a thorough revision of the genus, older names will be found and verified for this and No. 22, which here cover a multitude of forms. A mutábilis, L., is probably one of them.

****** Stem-laves sessile, the upper more or less clasping: scales of the henispherical involucre loosely more or less imbricuted, somewhat rqual, with herbaceous tips, or the outer often entirely herlucems : hrads middle-sized or large: rays blue or purple. ('The species of this group are still perplexing.)

25. A. æstivus, Ait. Stem slender, rough, bushy-branched; leuves narrowly lancelate-linear, elongrted, taper-pointed, entive, with rough margins; heads corymbose, loose; scales of the involucre linerr, loose; rays large, apparentiy light blue. (A. laxifolius, Nes.) - Var. Lxtrfionus has very slender branches and leaves, and the scales of the involucre uncqual and more appressed. Moist shady places. Ohio to Wisconsin and northward. - Heads about as large as in A. puniceus, in some forms appearing more like $A$. carneus. Leaves $4^{\prime}-$ $7^{\prime}$ long, $f^{\prime}$ to $\frac{1^{\prime}}{2}$ widc.

26. A. Novi-Bélgii, L. Niarly smooth; strm stout; leaves oblong-lancenlate, pale or somewhat gluucous, serrate in the middle, acute, tapering to each end; scules of the involucre ruther closely imbricated, with broudish acute herbaceons tips; rays pale blue or purplish. - Low grounds, not clearly known in a wild state. The plant here in view is intermediate between No. 24 and No. 27. - Heads smaller and less showy than in the next.

27. A. longifolius, Lam. Smooth or nearly so ; stem branched, corymhose-panicled at the summit ; Ienves lanceolute or linear, or the lower ovate-lanceolate, entire or sparingly serrate in the middle, taper-pointed, shining above; scales L \& M-30 
of the involucic imbricutel in 3-5 rows, linear, with acute or awl-shaped spreading or recurved green tips; rays large and numerous, bright purplish-blue. - Muist places, along streams, dec. : cominon castward. $-1^{\prime}$ lant $1^{\circ}-5^{\circ}$ high, with laggo and showy leads; very variable in the foliage, involucre, \&c.; its multiform varieties including A. thyrsiflorus, IIoffin., A. láxus, Willd. (a form with unore leafy involucres), A. pritáltus, Pvir., A. eludes, Torr. g. (ir. : also A. sulicifulius, Scholler, the oldest name of all.

28. A. puníceus, L. Stem tall and stout, rough-lusiry all over or in lines, usually purple below, panicled ahove; lenes oblong-lancevlate, clasping by an auricled buse, sparing'y serrate in the midule with appressed leeth, rough above, nearly smooth underineath, pointed; scules of the involucie nurvowly linear, acute, linase, equal, in about 2 rows; rays long and showy (lilac-blue, paler or whitish in slade). - Low thickets and swamps, very common. - Stems $3^{\circ}-6^{\circ}$ high, in open grounds rough with rigid bristly hairs.

Var. vimíneus ( $\Lambda$ vimincus, $\mid V i l l d$.) is a variety nearly smooth through out; growing in shade.

29. A. prenanthoides, Muhl. Stem low $\left(1^{\circ}-3^{\circ}\right.$ high $)$, corymbose-pani-

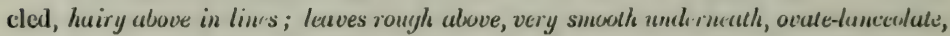

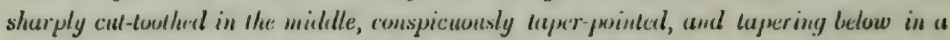
long contracted entire portion, which is abruptly diluted into an anriched-heart-shaped clasping base; scales of the involucre narrowly linear, with recurved-spreading tips; rays light bluc. - Burders of rich woods, W. New York to Wisconsin, and southwards to Virginia.

******* Leaves entire, thuse of the stem sessile, the buse often clasping: heads solitary terminuting the branches or somewhut corymbed, showy: scules of the inovlucre very numervus, with loose and spreading or recurved mostly fuliuceous tips, usually moie or less glindular or viscid, as are the branchlets, \&c.

+ Involucic imbricated, the scales in sevicial or many ranks.

30. A. grandiflorus, L. Kough with minute hispil huirs; stems slender, loosely much branched $\left(1^{\circ}-3^{\circ}\right.$ high $)$; leaves very smull $\left(f^{\prime}-1^{\prime}\right.$ long $)$, oblouglinear, obtuse, rigid, the uppermost passing inte scales of the hemisplericul squarrose many-ranked involucre; rays bright violet (1' long); achenia hairy. - Dry open places, Virginia and soutliward. - Heads large and very showy.

31. A. oblongifòlius, Nutt. Minutely glendular-puberulent, much branched above, rigid, paniculate-corymbose $\left(1^{\circ}-2^{\circ}\right.$ high); leaves narrowly allong or lanceolcte, mucronate-pointed, partly chasping, thickish ( $1^{\prime}-2^{\prime}$ long by $2^{\prime \prime}-5^{\prime \prime}$ wide) ; seales of the involuere broully linear, appressed at the base; rays violet-purple; achenia canescent. - Banks of rivers, fiom l'ennsylvania (Huntingdon County, Prof. Porter!) and Virginia to Wisconsin, Kentucky, and westward. - Heads middle-sized or smaller.

32. A. amethýstinus, Nutt. T'aller than the foregoing $\left(2^{\circ}-5^{\circ}\right.$ high $)$, more upright, with more hirsute and not at all glandular or viscid pubescence; heads more racenose on the branches and smaller; involucre only about $3^{\prime \prime}$ in diancter, the tips of the scales less spreading; rays light clear bluc. - Moist grounds, Massachusetts (near Salem, Cambridge, \&c., Nutlall, Dr. Robbins, \&c. : Amherst (Prof. Tuckernum), Illinois (E'. Hall), and Wisconsin. 
+ + Invoiucre of many very slender equal scalesuppearing like a single row.

33. A. Novæ-Ángliæ, L. Stem stout, hairy $\left(3^{\circ}-8^{\circ}\right.$ high $)$, corymbed at the summit ; leaves very numerous, lanceolote, entire, acuir, auriculate-rlasping, clothed with minute pubescence; scales of the involucre linear-aul-shaped, loose, glandular-viscid, as well as the branchlets; rays violet-purple, in var. noseus rose-purple (A. roseus, Desf.), very numerous; achenia hairy. - Moist grounds: common. Ileads large, corymbed. Var. ? with white rays, Carroll Co., III., II. Shimer.

******** Hcads, fcc., as in the preceding group; but foliage as in ***.

34. A. anómalus, Engelm. Somewhat hoary-pubescent; stems slender $\left(2^{\circ}-4^{\circ}\right.$ high $)$, simple or racemose-branched above; leaves ovate or ovate-lanceolate, pointed, entire or nearly so, the lower cordate and long-petioled, the upper small and almost sessile; scales of the hemispherical involuere imbricated in several rows, appressed, with linear spreading leafy tips; achenia smooth. Limestone cliffs, W. Illinois (and Missouri, near St. Louis), Engelmann. - Heads as large as those of No. 31 : rays violet-purple.

\$4. ORITROPIIIUM, Kunth. Scales of the involucre narrow, nearly equal and almost in a single row, more or less herbaccous : puppus of soft and uniform capillary bristles: mostly low peremials, bearing solitary or few heads.

35. A. graminifolius, Pursh. Slightly pubescent, slender $\left(6^{\prime}-12^{\prime}\right.$ high $)$; leaves very numerous, narrowly linear; branches prolonged into slender naked peduncles, bearing solitary small heads; rays rose-purple or whitish. - Northern borders of New England, Lake Superior, and northward.

§ 5. OR'THÓMERIS, Torr. \& Gr. Scales of the involucre regularly imbricated, unequal, often carinute, with membranaceous margins, entirely destitute of herbaceous tips : pappus of soft and unequal capillary bristles.

36. A. acuminatus, Michx. Somewhat hairy; stem (abont $1^{\circ}$ high) simple, zigzag, panicled-corymbose at the summit; peduncles slender; leaves oblong-lanceolate, conspicumssly pointed, conrsely toothed above, welge-form and entire at the base; scales of the involucre few and loosely imbricated, linear-lanceolate, pointed, thin $\left(3^{\prime \prime}-5^{\prime \prime}\right.$ long $)$; heads few or several ; rays $12-18$, white, or slightly purple. - Cool rich woods : common northward and southward along the Alleghanies. Ang. - There is a depauperate narrow-leaved variety on the White Mountains of New Hampshire.

37. A. nemoràlis, $\Lambda$ it. Minutely roughish-pubescent; stem slender, simple or corymbose at the summit, very leafy $\left(1^{\circ}-2^{\circ}\right.$ high $)$; leaves small $\left(1^{\prime}-\right.$ $1 \frac{1}{2}$ long), rather rigid, lanceolate, nearly entire, with revolute margins; scales of the inversely conical involucre narrowly linear-lanceolate, the outer passing into awl-shaped bracts; rays lilac-purple, elongated. - Bogs, pine barrens of New Jersey to Maine along the coast, and northwarl. Also White Mountains of New Hampshire; a small form, with solitary heads. Sept.

38. A. ptarmicoldes, Torr. \& Gr. Smooth or ronghish; stems clustered $\left(6^{\prime}-15^{\prime}\right.$ high $)$, simple; leaves linear-lanceolate, acute, rigid, entire, tapering to the hase, 1-3-nerved, with rough margins ( $2^{\prime}-4^{\prime}$ long); heads small, in a flut corymb; scales of the involucre imbricated in 3 or 4 rows, short; rays white $\left(2^{\prime \prime}-3^{\prime \prime}\right.$ long). - Dry rocks, W. Vermont to Illinois and Wisconsin along the Great Lakes, and northward. Aug. 
\$6. OXYTRIPÒLIUM, DC. Scales of the involucre imbricated, without herbaceous tips, usually very acute, the outer passing into scule-like bracts : pappus soft and capillary: achenia striate.

39. A. flexuosus, Nutt. Stem zigzag, rigid, forked $\left(6^{\prime \prime}-20^{\prime}\right.$ high $)$; the branches bearing larye solitary heads ; laves linear, thick and fleshy, pointed, entire; scales of the bell-shaped incolucre imbricuted in many rous, ovate-lanceolate with awl-shaped points; rays numerous, large, pale purple. - Salt marshes on the coast, Maine to Virginiat. Sept.

40. A. linifolius, I. Annual; stem much branched $\left(6^{\prime}-24^{\prime}\right.$ high $)$, the branches bearing numerous racemose or panicled small heads; leaves linear-hanceolate, pointed, entire, flat, on the branches awl-shaped; scales of the oblong incolucre linear-awl-shaped, in few rows; rays somewhat in two rows, short, not projecting beyond the disk, more numerous than the disk-fluwers, purplish. (A. subulatus, Michx.) Silt marshes, on the coast, Maine to Virginia. Aug. - Oct.

41. A. angùstus, Torr. \& Gr. (Tripolium angustum, Lindl. T. frondusum, Nutt. Also in Siberia, Conyza Altaica, $D C$., and Brachyactis ciliata, $L e d b^{b}$ ) An annual species related to the last, but with broader leaves, very many minute rays, and more copious papjus : comes from the northwest to near the borders of Wisconsin.

\section{ERÍgeron, L. Fleabane.}

Ifeads many-flowered, radiate, mostly flat or hemisplerical; the narrow rays very numerous, pistillate. Scales of the involucre narrow, nearly equal and little imbricated. Receptacle flat or convex, naked. Achenia flattened, usually pubeseent and 2-nerved. Pappus a single row of capillary bristles, with minuter ones intermixed, or with a distinct short outer pappus of little bristles or chaffy scales. - IIerbs, with entire or toothed and generally sessile leaves, and solitary or corymbed heads. I)isk yellow; ray white or purple. (Name from $\grave{\eta} \rho$, spring, and $\gamma \dot{\epsilon} \rho \omega \nu$, an old man, suggested by the hoary appearance of some of the vernal species.)

§1. CÁNÒTUS, Nutt. Rays inconspicuous, in several rows, scarcely longer than the pappus: pappus simple: chiefly annuals and biennials.

1. E. Canadénse, L. (Honse-weed. Butter-weev.) Bristly-hairy; stem erect, wand-like $\left(3^{\circ}-5^{\circ}\right.$ high) ; leaves linear, mostly entire; those from the root cut-lobed; heads very numerous and small, cylindrical, panicled. - Waste places; a common weed, now widely diffused over the world. July-Oct.Ligules much shorter than their tube, white. (Nat. in Eu. \&c.)

2. E. divaricàtum, Michx. Diffise and decumbent $\left(3^{\prime}-6^{\prime}\right.$ high) ; leaves linear or awl-shaped; heads loosely corymbed; rays purple: otherwise like No. 1. Illinois, Kentucky, and southward.

3. E. acre, L. Sparsely hairy or smoothish ; stem erect $\left(10^{\prime}-20^{\prime}\right.$ high) ; leaves lanceolate or the lower spatulate-oblong, entire; heads several or rather numerous, racemose or at length corymbose, nearly hemispherical $\left(4^{\prime \prime}-5 \prime\right.$ long); rays purplish or bluish, equalling or a little exceeding the copious pappus. - Shores of Lake Superior (Dr. Rabbins, Prof. Portcr, \&c.), and northwestward. (Eu.) 
§2. EUERTGRRON, Torr. \& (ir. Rays elonguted, crowdrd in one or more rows:

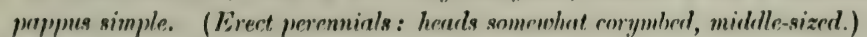

4. E. bellidifolium, Muhl. (Ronin's P'LANTAN.) Ilsiry, producing offsits from the base: stem simple, rather nakd above, bearing few (1-9) large heads on slender peduncles, root-leaves obovate and spatulate, sparingly toothed; those of the stem distant, lanceolate-oblong, partly clasping, entire; rays (about 50) rather broad, light bluish-purple. - Copses and moist banks: common. May.

5. E. Philadélphicum, L. (Common Flesane.) Hairy; stem leafy, corymbed, bearing several small heads; leaves thin, with a broad midrib, oblong; the upper smoothish, clasping by a heart-shaped base, mostly entire; the lowest spatulate, toothed; rays innumerable and very narrow, rose-purple or fleshcolor. (E. purpiureum, Ait.) - Moist ground : common. June-Aug.

§ 3. S'TENAC'TIS, Cnss. Outernost bristles of the pappus short and minute, or rather chuffy, forming an external series: otherwise as $§ 2$.

6. F. glabéllum, Nutt. Stem $\left(6^{\prime}-15^{\prime}\right.$ high) stout, hairy above, the leafless summit bearing $1-7$ large heads; leaves nearly glabrous, except the margins, entire, the upper oblong-lanccolate and pointed, closely sessile or partly clasping, the lower spatulate and petioled; rays (more than 100 , purple) more than twice the length of the hoary-hispid involucre. - Plains N. Wisconsin, and westward. June.

§ 4. PHALACROLÒMA, Cass. Rays nummons, but nearly in a single row, conspicuous : puppus plainly double, the outer a crown of minute chaffy-bristle-form scales; the inner of scanty cupillary bristles which are diciduous, or entirely wanting in the ray: annuals and biomials.

7. E. ánnuum, Pers. (Mirsy Finanane. Sweet Scamous.) Stem stont $\left(3^{\circ}-5^{\circ}\right.$ high), branched, beset with spreading hairs; leaves coursely and sharply toothed; the lowest ovate, tapering into a margined petiole; the upper ovate-lanceolate, acute and entire at both ends; heads corymhed; rays white, tinged with purple, not twice the length of the bristly involuere. (E. heterophýllum, Muhl. F. strigòsum, Bigel.) - Ficlds and waste places : a very common weed. June-Aug. (Nat. in Eu.)

8. E. strigósum, Muhl. (Dмisy Fuenвane.) Stem panicled-corymhose at the summit, roughish like the leaves with minute appressed hairs, or almost simnoth; leaves entire or nearly so, the upper lanceolate, scattered, the lowest oblong or spatulate, tapering into a slender petiole; rays white, twice the length of the minutely hairy involucre. (E. integrifolinm, Bigel.) - Fields, \&c. : common. June-Aug. - Stem smaller and more simple than the last, with smaller heads bnt longer rays. - Var. Discofdeum, Robbins, has the rays minute, scarcely exceeding the involucre. - Uxbridge, Massachusetts, and adjacent parts of Connecticut and Rhode Island, $\mathrm{Dr}$. Robbins.

§5. ERIGERfDIUM, Torr. \& Gr. Rays about 30, in a single row, rather brond: pappus simple: achemia mostly 4-nerved: root perennial.

9. F. vérnum, Torr. \& Gr. Glabrous; leaves clustered at the root, oval or spatulate; scape leafless, slender $\left(1^{\circ}-2^{\circ}\right.$ high), bearing $5-12$ small corymbed heads; rays white. (E. nudicaule, Michx. $\Lambda$ ster vernus, L.) - Low grounds, E. Virginia and southward. May. 


\section{DI PI O P Á P U S, Cass. Double-bristled Aster.}

Heads many-flowered, radiate; the rays $8-12$, pistillate. Scales of the invo. lucre imbricated, appressed, narrow, 1-nerved or keeled, destitute of herbaceous tips. Receptacle flat, alveolate. Achenia flattish. Pappus double; the outer of very short and sinall stiff bristles, the inner of capillary bristles as long as the disk-corolla. - Perennials with corymbose or simple heads: disk-flowers

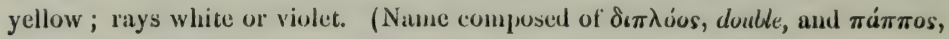
pappus, the character which distinguishes the genus from Aster.)

\$1. Rays violet, showy: head sulitury, pretty large: involucre much imbricated: achenia silky: bristles of the inner pappus all alike.

1. D. linarifolius, Hook. Stems $\left(6^{\prime}-20^{\prime}\right.$ high) several from the same woody root, mostly simple, very leafy ; leaves rigid, spreading, linear, strongly 1-nerved, smooth, rough-margined. - Dry soil : common. Sept., Oct.

§2. Rays white: heuds small, corymbed: involucre shorter than the disk, imbricated in about 3 rows: achenia smouthish: bristles of the imer pappus unequal, some of them thickened at the tip : leaves rather large, scattered, meirbranactous, veiny, entire.

2. D. umbellatus, Torr. \& Gr. Sinooth, leafy to the top $\left(2^{\circ}-6^{\circ}\right.$ high $)$; leaves lanceolate, elongated, taper-pointed and tapering at the base $\left(3^{\prime}-6^{\prime}\right.$ long); heads very uunerous in compound flat corymbs; scales of the involucre rather close, obtusish. - Moist thickets: common, especially northward. Aug.

3. D. amygdálinus, 'Torr. \& Gr. Smouth or roughish above, leafy; leaves ovate-lanceolate, acure, abruptly narrowed at the base; scales of the involucre loose, obtuse. - Low grounds, New Jersey, Penn., and southward. Aug. Too near the last; but lower, rougher, and with broader and shorter leaves.

4. D. cornifolius, Darl. Stem $\left(1^{\circ}-2^{\circ}\right.$ high) pubescent, bearing few heads on divergent paluncles; leaves elliptical or avate-lanceolate, conspicuously pointed at both ends, ciliate, hairy on the veins underneath. - Woodlands, E. Massachusetts to Kentucky, and southward along the mountains. July-Sept.

\section{BOLTONIA, L'Her. Boltonia.}

Heads many-flowered, radiate; the rays numerous, pistillate. Scales of the hemispherical involuere imbricated somewhat in 2 rows, appressed, with narrow membranaceous margins. Receptacle conical or hemispherical, naked. Aclienia very flut, obovate or inversely heart-shuped, margined with a callous wing, or in the ray 3-wingel, crowned with a pappus of several minute bristles and usually 2-4 longer awns. - Perennial and busliy-branched sinooth herbs, palo green, with the asject of $\Lambda$ ster: the thickish leaves chiefly eutire, often turned edgewise. Flowers antumual : disk yellow : rays white or purplish. (Dedicated to James Bolton, an Euglish botanist of the last century.)

* IIeads middle-sized, loosely corymbed.

1. B. asteroides, L'Ifer. Leaves lanceolate; achenia broadly oval ; pappus of few minute bristles and no awns. - Moist places along streams. Pennsylvania (Bartram), and southward along the Alleghanies : rare. Oct. - I'lant usually $6^{\circ}$ high. 
2. B. glastifolia, L'IIer. Lenves lanceolate, ascending; achenia obovate, broadly winged; pappus of several short bristles and 2 or 3 short awns. - Rich soil, Pennsylvania to Illinois und southward. Sept., Oct. - Plant $2^{\circ}-4^{\circ}$ high.

* Heads smull, panicled on the slender branches.

3. B. diffùsa, I'Her. Steın diffusely branched; leaves lance-linear, those on the branchlets very small and awl-shaped; pappus of several very short bristles and 2 short awns. - Prairies near Centralia, Illinois (Vasey), and southwestward. Aug. - Oct.

\section{B ÉLLIS, Tourn. DAISY.}

Heads many-flowered, radiate; the rays numerous, pistillate. Scales of the Involucre herbaccous, equal, in about 2 rows. Receptacle conical, naked. Achenia obovate, flattened, wingless, and without any pappus. - Low herbs (all but our single species natives of the Old World), either stemless, like the true Daisy, B. perennis, or leafy-stemmed, as is the following. (The Latin name, from bellus, pretty.)

1. B. integrifolia, Michx. (Wrstern DAssx.) Annual or biennial, diffusely branched $\left(4^{\prime}-9^{\prime}\right.$ high), smoothish; leaves lanceolate or oblong, the lower spatulate-obovate; heads on slender peduncles; rays pale violet-purple. Prairies and banks, Keritucky and southwestward. March - June.

\section{BRACHYCH ł TA, Torr. \& Gr. False Golden-Rod.}

Heads and flowers nearly as in Solidago, except the pappus, which is a row of minute rather scale-like bristles, shorter than the achenia. - A perennial herb, with romiled or ovnte serrate leaves, all the lover ones heart-shiped; the small yellow heads in sessile elusters racemed or spiked on the branches. (Name composed of $\beta$ saxús, short, and Xair $\eta$, bristle, from the pappus.)

1. B. cordata, Torr. \& Gr. (Solidago cordata, Short.) Wooled hills, F. Kentucky and southward. Oct. - J'lant $2^{\circ}-4^{\circ}$ high, slender, more or less pubescent.

\section{SOLIDÁGO, L. Golnen-rod.}

Heads few - many-flowered, radiate; the rays $1-16$, pistillate. Scales of the oblong involucre appressed, destitute of herbaceous tips (except No. 1). Receptacle small, not chaffy. Achenia many-ribbed, nearly terete. Pappus simple, of equal capillary bristles. - Perennial herbs, with mostly wand-like stems and nearly sessile stem-leaves, never heart-shaped. Heads small, raccmed or clustered : flowers both of the disk and ray (except No. 2) yellow. (Name from solido, to join, or make whole, in allusion to reputed vulnerary qualities.) Flowering in sutumn.

81. CHRYSASTIRUM, Torr. \& Gr. Scales of the much imbricated and rigid involucre with abruptly spreading herbaceous tips: heads in clusters or glomerate racemes, disposed in a dense somewhat leafy and interrupted wand-like compound spike.

1. S. squarròsa, Muhl. Stem stout $\left(2^{\circ}-5^{\circ}\right.$ high), hairy above; leaves large, oblong, or the lower,spatulate-oval and tapering into a murgined petiole, 
scrrate, veiny; disk-flowers $16-24$, the rays 12-16. - Rocky and wooded hills, Maine and W. Vermont to P'cnnsylvania, and the mountains of Virginia: rather rare.

\$2. VIRGAUREA, 'Tourn. Sailes of the involucre destitute of hertuceous tips: rays mostly fewer than the disk-flower's: heuls all more or hess pedicelled.

* IItuds clusterad in the uxils of the feuther-veined leuves.

2. S. bícolor, L. Iluary or grayish with soft hairs; stem mostly simple; leaves oblong or elliptical-lanceolate, acute at both ends, or the lower oval and tapering into a petiule, slightly serrate; clusters or short racemes fiom the usils of the upper leaves, forming an interrupted spike or crowded panicle; rays small, cream-culor or nearly white. - Var. cóncolor has the rays yellow. - Dry copses and banks: the var. in Pennsylvania and westward.

3. S. latifolia, I. Smooth or ncarly so, stem anyled, zigzag, simple or paniculate-branched $\left(1^{\circ}-3^{\circ} \mathrm{high}\right)$; leaves liroully ovcute or oval, very strongly and sharply serrate, conspictuously pointed at both ends (thin, $3^{\prime}-6^{\prime}$ long); heals in very sliort axillary elusturs, or somewhat prolonged at the end of the brauches. Moist shaded banks : common northward, and along the mountains.

4. S. càsia, I. Smooth; stem tercte, mostly gluncous, at length much branched and difluse; laves lanceulate or oblong-lanceolate, scrrate, pointed, sessile; heads in very short clusters, or somewhat racemose-panicled on the branches. - Moist rich woodlands : common.

* * Racemes terminul, erect, either somcwliat simple and uxind-like, or compound and panicled, not one-sided: leaves feather-erined. (Not maritime.)

+ Hoculs small: Iraves nerrly entive, except the lowermost.

5. S. virgàta, Michx. Viry smooth throughout; stem strict and simple, wandlike $\left(2^{\circ}-4^{\circ}\right.$ high $)$, slender, beset with small and entire alpressed lanceolate-oblong thickish leaves, which are gradually reduced upwards to mere bracts; the lowest oblong-spatulate; heads crowded in a very nurrow compound spicale raceme; rays 5 - 7. - Damp pine barrens, New Jersey and southward.

6. S. pubérula, Nutt. Stem $\left(1^{\circ}-3^{\circ}\right.$ high, simple or branched) and panicle minutely houry; stem-leatcs lanceolute, acute, tapering to the base, smoothish; the lower werlge-lanceolate and speringly toothed; hexds very nuncrous and crousled in compact short racenus forming a prolonged and dense narrow or pyramidal panich ; scales of the involucre lineur-awl-shaped, appressed; rays about 10. - Sundy soil, Maine to Virginia and southward, near the coast.

7. S. strícta, $\Lambda$ it. $V_{c r y}$ smooth throushout; stem simple, strict $\left(2^{\circ}-3^{\circ}\right.$ high); leaves lancechate, pointed, the lower tapering into winged petioles, partly sheathing at the base, minutely serrate above with appressed tecth; racemes much crowded and appressed in a drnse wand-like panicle; scales of the involucre linearollong, obtuse; rays 5-6, small. - I'eat-logers, Maine to P'ennsylvania, W'isconsin, and northward. liout-leaves $6^{\prime}-10^{\prime}$ long. Flowers carlier tham most species, beginning in July.

$$
\text { + + Iteuls rather large, at liast for the size of the plant. }
$$

8. S. speciosa, Nutt. Stem stout $\left(3^{\circ}-6^{\circ}\right.$ ligh $)$, smooth; leaves thickish, smooth with rough margins, oval or viate, slightly serrate, the uppermost oblonglanceolate, the lower contracted into a margined petiole; heuds somewhat 
crowded in numerous erect racemes, forming an ample pyramidal or thyrsiform panicle; peduncles and pedicels rough-hairy; scales of the cylindrical involucre ohlong, obtuse; rays about 5, large. - Var. Angustits is $\Omega$ dwarf form, with the racemes short and clustered, forming a dense interrupted or compound spike. - Copses, Maine to Wisconsin and southwarl. - A very handsome species; the lower leaves $4^{\prime}-6^{\prime}$ long and $2^{\prime}-4^{\prime}$ wide in the larger forms.

9. S. petiolàris, $\Lambda$ it. Minutely hoary or downy; stem strict, simple, $\left(1^{\circ}-\right.$ $3^{\circ}$ high) ; leaves small $\left(\frac{1}{2}{ }^{\prime}-2^{\prime}\right.$ long), oval or oblong, mucronate, veiny, rough-ciliolate; the upper entire and almuptly very short-petioled, the lower often serrate and tapering to the base; heads few, in a wand-like raceme or panicle, on slender bracted perlicels; rays about 10, elongated: scales of the pubscent involucre lanceolate or linear-awl-shaped, the outer ones loose and sprearling, more or less foliaceous, - especially in var. sQuARRULòsA, Torr. \& Gr. - S. W. Illinois (Dr. Engelmann), and southward. - The name is misleading, as the leaves are hardly petioled.

10. S. Virga-aùrea, L. Pubescent or nearly glabrous ; stem low $\left(6^{\prime}-18^{\prime}\right.$ high) and simple; lentes lanceolute or oblanceolate, or the lowest sputulate or ellipticalolow te and petioled, serrate with small appressed teeth or nearly entire; racemes thyrsoid or simple, narrow; scales of the involucre lanceolate or linear, acute; ruys 8-12. - An extremely variable species in the Old World and in our northern regions; perhaps including several. (Eu.)

Var. alpina, Bigel. Dwarf $\left(\mathrm{l}^{\prime}-8^{\prime}\right.$ high), with few $(1-12)$ pretty large hearls $\left(3^{\prime \prime}-4\right.$ " long, becoming smaller as they increase in number); lenves thickish, mostly smooth; scales of the involucre lanccolate, acute or acutish; rays abont 12. - Alpine region of the mountains of Maine, New Hampshire, and New York; and shore of Lake Supcrior.

Var. humilis. Low $\left(6^{\prime}-12^{\prime}\right.$ high $)$ and smooth, bearing several or numerous loosely thyrsoid smaller heads, which, with the peduncles, \&c., are mostly somewhat glutinous; scales of the involucre obtuse; rays $6-8$, short; leaves varying from narrowly lanceolate and nearly entire to oblanceolate and serrate. (S. humilis, Pursh, Torr. \& Gr.) - Rocky banks, W. Vermont, and along the Great Lakes northward. Also on islands in the Susquchanna, near Lancaster, l'enn., Prof. Porter! Great Falls of the Potomac, Virginia, Dr. Robbins l-At the base of the White Mountains of New Ilumpshire, on gravelly banks of streams, occurs x form, with the minutely pubesent stout stem $1^{\circ}-2^{\circ}$ high, the leaves larger and broader, and the heads very numcrous in an ample compound raceme; the rays occasionally almost white.

11. S. thyrsoldea, E. Meyer. Stem stout $\left(1^{\circ}-4^{\circ}\right.$ high $)$, wand-like, puivescent near the summit, simple; leaves thin, ovate, irregularly and conrscly serrate with sharp salient teeth, laige ( $1^{\prime}-4^{\prime}$ long), all but the uppermost abruptly contracted into long and maigined petioles; heads larye (5" -6 "long), many-flowered, crowded in an oblong or wand-like raceme or contracted panicle $\left(2^{\prime}-18^{\prime} \mathrm{long}\right)$; scales of the involucre loose and thin, long, lanceolate, taper-pointed ; rays 810, clongated; achenia smooth. (S. Virga-auren, I'ursh. S. Jeiocarpa, DC.) Wooded sides of mountnins, N. Maine to New York (sonth to the Catskills), shore of Lake Superior, and northward. - Very near an European form of $\mathbf{S}$. Virga-aurea. 
* * Heads in a compound corymb terninating the simple stem, not at all racemose: leaves mostly with a strung midrit.

12. S. rigida, I. Liongh und somewhat houry with a minute pubescence; btem stuut ( $3^{\circ}-5^{\circ}$ high $)$, very leafy ; corymb dense; leaves oval or ablong, copiously feather-veined, thick and rigid; the upler closely sessile by a broad base, slightly serrate, the uppermost entire; heads large, about 34 -flowered; the rays 7-10. - Dry soil, Connecticut to N. Wisconsin and southward.

13. s. Ohioénsis, Riddell. Very smooth throughout; stem wand-like, slender, leafy $\left(2^{\circ}-3^{\circ}\right.$ high $)$; stem-leaves ablong-lanceolate, flat, entire, obscurely feather-veined, closely sessile; the lower and radical ones elongated, slightly serrate towards the apex, tapering into long margined petioles; heads numerous, on smooth pedicels, smatl, $16-20$-tlowered; the rays 6 or 7. - Moist meadows or prairies, IV. New York to Ohio and Wisconsin. - liout-leaves $1^{\circ}$ long; the upper reduced to $1^{\prime}-2^{\prime}$, with rough margins, like the rest.

14. S. Riddéllii, lirank. Simouth and stout $\left(2^{\circ}-4^{\circ}\right.$ ligh $)$, very leafy, the branches of tho dense corymb and pedicels rough-pubescent; leaves linear-lanceolate, elonyated ( $4^{\prime}-6^{\prime}$ long), entire, acute, partly clasping or sheathing, conduplicate and mostly recurved, the lowest elongated-lanceolate and tapering into a long keeled petiole, obscurely 3-nerved; heads very numerous, clustered, 20-24-flowered; the rays 7 -9. - IVet grassy prairies, Ohio to Wisconsin and Illinois. Heads larger than in the last, $2 " 1$ - 3 " long. Stem-leaves upright and partly sheathing at the base, then gradually recurved-spreading.

15. S. Houghtonii, 'Torr. \& Gray. Smouth; stem rather low and slender $\left(1^{\circ}-2^{\circ}\right.$ high $)$; leuves scuttered, lineur-lanceolute, acutish, flut, entire, tapering in to a narrowed slightly clasping base, or the lower into margined petioles; hads few or several, 20 -30-flowered; the rays 9 or 10. - North shore of Lake Michigan; collected in the Mïchigan State Survey. Swanıss at West Bergen, Genesee Co., New York, J. A. Puine, \&c. July, Aug. - Leaves rough-nargined, $2^{\prime}-5^{\prime}$ long, $2^{\prime \prime}-4^{\prime \prime}$ wide, 1-nerved, or the lower obscurely 3 -nerved above; reins obscure. Heads large, nearly $\frac{1^{\prime}}{2}$ long. Scales of the involucre obtuse.

**** Ileuds in one-sidid more or less spreuding or recurved racemes: leaves veiny, not 3-riblied, but sometimes obscurely triple-neried.

- Leaves thickish, very smooth, entire, clungatcd, wscurely viny: hads rather large.

16. S. sempérvirens, L. Smooth and stout $\left(1^{\circ}-6^{\circ}\right.$ high $)$; leaves flchy; lanecolate, slightly clasping, or the lower ones lanecolate-oblong, obscurely triple-nerved; racemes short, in an open or contracted pauicle - Varies, in less brackish swamps, with thinner elongated lincar-lanceolate leaves, tapering to each end, and more erect racemes in a narrower panicle. - Salt marshes, or rocks on the shore, Maine to Virginia. - Heads showy : the golden rays 8-10.

+ + Leaves usually ample, serrate, loosely feuther-veined, or rarely slightly triplenerved: heads midlle-sized.

17. S. elliptica, Ait. Smovth; stem stotit $\left(1^{\circ}-3^{\circ}\right.$ high $)$, vcryllufy; leutes elliptical or oblung-linceolute, acutc ( $2^{\prime}-3^{\prime}$ long), cluscly sessile, blightly scrratt, strongly veined, thick, smouth both sides, shining abreve; hauls in dense spreading racemes which are crowded in a close pyramidal panicle; peduncles and achenia strigose-pubescent. - Swamps (fresh or brackish) near the coast, Mass. to New Jersey and southward. - Heads showy, $3^{\prime \prime}$ long; the rays 8-12. 
18. .S. neglécta, Torr. \& Gray. Smooth; stem stout $\left(2^{\circ}-3^{\circ}\right.$ high $)$; leaves thirkish, smooth both sides, opaque; the upper oblong-lancoolate, mostly acuto and nearly entire; the lower orrete-lawcenlete or ob/onq, shaply serrate, tupering into a petiole; racemes shomt and dense, at lenelle spmending, disposed in an elongated or pyramidal close panicle; peduncles and achenia nearly glabrous. - Swamps, Maine to Penn. and Wisconsin. - Hearls rather large, crowded; the racemes at first erect anil scurcely one-sided.

19. S. pátula, Muhl. Słem strongly angled, smooth $\left(3^{\circ}-5^{\circ}\right.$ high $)$; leaves $\left(4^{\prime}-8^{\prime}\right.$ long) ovate, acute, serrate, pale, very smonth and veiny undernenth, but the upper surfuce very rough, like shagreen; racemes rather short and numerous on the sprearling branches. - Swamps : common.

20. S. argùta, Ait. Smooth throughout $\left(1^{\circ}-4^{\circ}\right.$ high); radical and lower stem-lerners elliptical or lancrolute-oval, sharply serrute with spreading teeth, pointed, tapering into winged and ciliate petioles; the uthers lancoolate or oblong, slightly triple-nerved, tapering to each end, the nppermost entive; racemes dense, naked, at length elongated and recurved, forming a crouded and flot corymb-like panicle: rays 8-12, small. - Var. 1. Júncea has the leaves narrower and less serrite, or all the upper entire. - Var. 2. sCArRéLLA is somewhat roughish-pubescent (Wisconsin, \&c.). - Copses and banks : common, especially the first variety. - Well distinguished by its long or droojing racemes, and the closely appressed rigid scales of the involucre, small rays, \&c. But the name is a bad one, as even the root-leaves are seldom much toothed.

21. S. Muhlenbérgii, Torr. \& Gr. . Smooth; stem angled; leaves (large and thin) orate, and the upper elliptical-lanceolate, very sharply and strongly serrate, pointed at both inds, the lowest on margined petioles; racemes pubescent, spreseding, disposed in an slonguted open panirle; rays 6-7, large. - Copses and moist woots, New IInmpshire lo P'enn. - Rncemes mush shorter and looser than in the last; the involucral seales thin and more slender.

22. S. linotdes, Solander. Smooth; stem slender, simple $\left(10^{\prime}-20^{\prime}\right.$ high $)$; leaves lanceolate, serrate with small appressed tecth, narrowed at the base, the lower tapering into margined ciliate petioles, the uppermost oblong; racemes short, crouded in one or 3-4 small one-sided panicles (3'-4' long); hends small and few-flowered; rays 1-3.-Bogs, New England (ncar Boston and Providence), to the pine barrens of New Jersey.

+ + + Learrs broad, not large, sessile or short-petioled, conrsely and sharply serrate, copiously fenther-veined and conspicuously reticulated: heads small: rays short.

23. S. altíssima, L. Rough-huiry, especiully the stem $\left(2^{\prime}-7^{\prime}\right.$ high) ; leaves ovate-lanceolate, elliptical or oblong, often thickish and very rugose ; racemes panicled, spreading; scales of the involucre linear; rays 6-9; the disk-flowers 4-7. Borders of fields and copses : very common, presenting a great varicty of forms : but instear of the tallest, as its name denotes, it is usually one of the lowest of the common Golden-rods. It flowers early. Aug. - Sept.

24. S. Ulmifolia, Muhl. Stem smonth, the branches hairy; leaves thin, elliptical-ovate or oblong-lancrolute, pointer, taprring to the base, lonsely veined, beset with soft hairs beneath; racemes paniclel, recurved-spreading; scales of the involucre lanceolatc-oblong; rays about 4. - Low copses : common. - Too near the last; distinguished only by its smooth stem and thin larger leaves. 
25. S. Drummóndii, Torr. \& Gr. Stem $\left(1^{\circ}-3^{\circ}\right.$ high $)$ and lower surface of the broadly ovate or oval somewhat triple-ribled leaves minutely velvety-pubescent, some of the leaves ahmost entire; racemes panicled, short; scales of the involucre oblong, obtuse; rays 4 or 5 . - Rocks, Illinois opposite St. Louis, and southwestward.

+++ + Leaves entire or wearly so, thickish, reticulate-veiny, but the veins obscure.

26. S. pilosa, Walt. Stem stout, upright $\left(3^{\circ}-7^{\circ}\right.$ high $)$, clothed with spicuching hairs, often panicled at the summit; leaves oblong-lanceolate, roughish, hairy beneuth, at least on the midrib, serrulate, the upper ovate-lanceolate or oblong and entire, closely sessile; racenes many, recurved, crowded in a dense pyramidal panicle; rays 7 - 10, very short. - Low grounds, pine barrens of New Jersey to Virwinia, and southward.

27. S. odora, Ait. (SweET Golden-Rod.) Smooth or nearly so throughout; stem slender $\left(2^{\circ}-3^{\circ}\right.$ high) often reclined; leaves linear-lanceolate, entire, shining, pellucid-dotted; racemes spreading in a small one-sided panicle; rays $3 \mathbf{3 - 4}$, rather large. - Border of thickets in dry or sandy soil, Vermont and Maive, to Kentucky and southward. - The crushed leaves yield a pleasant anisate odor. But an oceasional form, var. Inodòr A, is nearly secntless.

+++++ Lereves more or less grayish or houry, thickish, feather-veinal and slighlly triple-nerved, obscurdy serrate or entire; houds middle-sized.

28. S. nemoràlis, Ait. C'iothed with a minute and close grayish-houry (soft or roughish) pubescence; stem simple or coryuhed ut the sumnit $\left(\frac{1}{2}{ }^{\circ}-22^{\circ}\right.$ high); leaves oblanceolate or spatulate-oblong, the lower somewhat crenatetoothed and tapering into a petiole; racemes numerous, dense, at length recurved, forming a large and crowled compound raceme or panicle which is usually turned to one side; scales of the involucre lincar-oblong, appressed; rays $6-9$. - Dry sterile fields : very common. - Flowers very bright yellow, beginning early in Aug.

29. S. rádula, Nutt. Stem and oblongr or obovate-spatulate leaves rigid and very rough, not hoary, the upper sessile; scales of the involucre oblung, rigid; rays 3-6: otherwise nearly as in S. nemoralis, of which it is most probahly a greener and rongh varicty. - Dry IItls, Weshern Illinois and oouthwestward.

*****Hads in one-sided sprrading or recurved racemes, forming an ample panicle; laves plainly 3-ribbed, or triple-ribbed.

+ Scales of the incolure thickish and rigid, closely imbricated, and with somewhat greenish tips or midrib: leaves rigid, smooth and shinin!).

30. S. Shórtii, 'Torr. \& Gr. Stem slender, simple $\left(1^{\circ}-3^{\circ}\right.$ high $)$, minutely roughish-pubescent; leanes oblorg-lanctolute, acute, the lower sharply serrate above the middle with seattered fine teeth; racemes mostly short in a crowded panicle; achernia silliy-putesecent. - Rocks at the Falls of the Ohio, \&c. -A handsome species : hcads $3^{\prime \prime}$ long, narrow.

31. S. Missouriénsis, Nutt. Smooth throughout $\left(1^{\circ}-3^{\circ}\right.$ high $)$; leaves linear-lanceolate, or the lower broadly lanceolate, tapering to both ends, with very rough margins, the lower very sharply serrate; heals and dense crowiled racemes nearly as in No. 20; achenia nearly glabrous. - Iry prairies, from W is consin and Illinois soutliward and westward. - Heads $1 \frac{1}{2}{ }^{\prime \prime}-2^{\prime \prime}$ long. 
+ + Scales of the involucre narrow, thin and membranaceous : racemes mostly elongated and numerous, forming a crowded ample panicle. ('These all present intermediate forms, and should rather be regarded as one polymorphous species.)

32. S. rupéstris, Raf. Stem smooth and slender $\left(2^{\circ}-3^{\circ}\right.$ high $)$; leaves linear-lancelate, tapering to both ends, smonth and glatrous, entire or nearly so; panicle narrow; heads very small; rays very short. - Rocky river-banks, Kentucky and Indiana.

33. S. Canadénsis, L. Stem rough-hairy, tall and stout $\left(3^{\circ}-6^{\circ}\right.$ high $)$; leaves lunceolate, pointed, shurply serrate (sometimes almost cutire), more or less pubescent beneuth and rough above; heads small; rays vary shent. - Borrers of thickets and fields : very common. - Varies greatly in the roughness and hairiness of the stem and leaves, the latter oblong-lanceolate or elongated linearlanceolate; - in var. Pròcers, whitish-woolly underneath ; and in var. sCA Bra ulso very rongh ahove, often entire, and rugose-veined.

34. S. serótina, $\Lambda$ it. Sirm very smorth, tall and stout $\left(4^{\circ}-8^{\circ}\right.$ high $)$, often fluncons; Icuves lanceolate, pointed, serrate, roughish whove, smooth except the veins underneath, which are more or less hairy; rays short. - Thickets and low grounds : common. - Intermediate in character, and in the size of the heads and rays, between the last and the next.

35. S. gigantea, Ait. Stem stout $\left(3^{\circ}-7^{\circ}\right.$ high $)$, smooth, ofien glaucous; leares quite smooth both sides, lanceolate, taper-pointed, very sharply serrate, except the narrowed base, rough-ciliate; the ample panicle pubescent; ruys rather long. - Copses and fence-rows : common : - presenting many varicties, but with decidedly larger heads and rays than in the preceling. Seldom very tall.

§ 3. EUTIAMMIA, Nutt. Corymbosely much branched: heads small, sessile, in little clusters which are crowded in flat-topped corymls; the closely "ppreserd scales of the involucre somewhat glutinous: recptucle fimbrillute: rays $6-20$, short, more numerous than the disli-flowers: laves narrow, entire, sessile, crowded or fascicled in the axils.

36. S. lanceolàta, L. Leaves lancolate-linear, 3-5-nerved; the nerves, margins, and angles of the branches minutely rough-pubescent ; heads obovoidcylindrical, in dense corymbed clusters; rays 15-20. - River-banks, \&c., in moist soil : common. - Stem $2^{\circ}-4^{\circ}$ high : leaves $3^{\prime}-5^{\prime}$ long.

37. S. tenuifolia, Pursh. Smooth, slender; leaves very narrowly linear, mostly 1-nerved, dotted: heads obovoid-club-shaped, in numcrons clusters of 2 or 3 , disposed in a loose corymb; rays 6-12. - Sandy ficlds, Massachusetts to Illinois, and southward : common near the coast.

\section{BIGELÒ VIA, DC. RAYLESG Goldin-rod.}

Heads 3-4-flowered, the flowers all perfect and tubular : rays none. Invelucre club-shaped, yellowish ; the rigid somewhat glutinous senles linear, closely imbricated and appressed. Receptacle narrow, with an awl-shaped prolongution in the centre. Achenia somewhat obconical, hairy. Pappus a single row of capillary bristles. $-\mathbf{A}$ smooth perennial; the slender stem $\left(1^{\circ}-2^{\circ}\right.$ high $)$ simple or branched from the base, naked above, corymbose at the summit, bearing 
small heads in a flat-topped corymb. Flowers yellow. Leaves scattered, oblanceolate or linear, 1-3-nerved. (Dedicated by DeCandolle to Dr. Jucol Bigelow, author of the Florula Bostoniensis, and of the American Medical Botany.)

1. B. nudata, DC. - Low pine barrens, New Jersey (rare), and southward. Sept.

\section{CHRYSÓ PSIS, Nutt. Golden Aster.}

IIeads many-flowered, radiate; the rays numerous, pistillate. Scales of the invorucre linear, imbricated, without herbaceous tips. Receptacle flat. Acheniat obovate or linear-oblung, flattened, hairy. P'appus in all the flowers double, the outer of very short and somewhat chaffy bristles, the inner of long capillary bristles. - Cinefly perennial, low herbs, woolly or hairy, with rather large often corymbose heads terminating the branches. 1)isk and ray-flowers yellow. (Name composcd of $\chi \rho$ voris, gold, and ő $\psi(s$, aspect, from the golden blossoms.)

* I e wes nurrowly lanceolate or linear: achenia linear.

1. C. graminifolia, Nutt. Silvery-silky, with long close-pressed hairs; stem slender, often with rumers from the base, naked above, bearing few hearls; leaves lanceolate or linear, elongated, gruss-like, nerval, shining, entire. - Dry sandy soil, Delaware to Virginia, and southward. July - Oct.

2. C. falcàta, Ell. Stems $\left(t^{\prime}-10^{\prime}\right.$ high) very woolly; leaves crowded, lineer, rigid, ubout 3-nereed, entire, somewhut recurced or scylhe-shuped, huiry, or smooth when old, sessile; heads (small) corymbed. - Dry sandy soil on the coast, pine barrens of New Jersey to Nantucket and Cape Cod, Mass. Aug.

* *euves oblong or lanccolate, entire or slighlly serrate, mostly sessile, veined, not nerved; achenia obovute, flattened.

3. C. gossýpina, Nutt. Densely woolly all over; leaves oblong, ob/use (1' $2^{\prime}$ long); heads larger than in the next. - Pine barrens, Virginia and southward. Aug. - Oct.

4. C. Mariàna, Nutt. Silky with long and weak huirs, or when old smoothish; leaves oblong; heads corymbed, on glandular peduncles. - Dry barrens. from S. New York and Penn., southward, near the coast. Aug. - Oet.

5. C. villosa, Nutt. Hirsute and villous-pubescent; stem corymboscly branched, the branches terminated by single short-peduncled heads; haves nar,owly oblong, hoary with rongh mubescence (as also the involucre), bristly-ciliute toward the base. - Dry plains and prairics, Wisconsin to Kentucky, and westward. July-Sept.

\section{2. Í N U L A, L. Elecampane.}

Outer scales of the involucre sometimes leaf-like. Achenia terete or 4-sided. Pappus simple, of capillary bristles. Anthers with 2 tails at their base. Otherwise much as in the last genus. (The ancient Latin name)

1. I. Helènium, L. (Commov Elecampane.) Stout perennial $\left(3^{\circ}-5^{\circ}\right.$ high); leaves large, woolly beneath; those trom the thick root ovate, petioled, the others partly elasping; ray's very many, narrow. - Roadsides, esciuped from gardens. Aug. - Heads very large. Root mncilaginous. (Nat. from Lu.) 


\section{PLÙ CHEA, Cass. Marsi-Fueabane.}

Heads many-flowered; the flowers all tubular; the central perfect, but sterile, few, with a 5-cleft corolla; all the others with a thread-shaped truncate corolla, pistillate and fertile. Involucre imbricated. Anthers with tails. Achenia grooved. Pappus capillary, in a single row. - Ilerbs, somewhat glandular, emitting a strong or camphoric odor, the heads in close compound corymbs. Flowers purplish, in summer. (Dedicated to the Abbé Pluche.)

1. P. camphoràta, DC. (Salt-marsir Fleabane.) Annut, minutely viscid, pale $\left(1^{\circ}-2^{\circ}\right.$ high $)$; leaves scarcely petioled, oblong-ovate or lanceolate, thickish, obscurely veiny, serrate; corymb flat; involucre viscid-dlowny. (Conỳza camphorata, Bigel. C. Marylándica, Pursh.) - Salt marshes, Massachusetts to Virginia and southward.

2. P. fótida, DC. Perenniul, almost smooth $\left(2^{\circ}-4^{\circ}\right.$ high $)$; leaves distinctly petinled, veiny, oval-lanceolate, pointed at both ends, serrate; corymbs panicled; involucre smooth. River-banks, Ohio to Illinois, and southward.

3. P. bifrons, DC. Perennial; leaves closely sessile or half-clasping by a somewhat heart-shaped base, lance-oblong, sharply denticulate, veiny (only $2^{\prime}$ $3^{\prime}$ long); heads clustered in a corymb; involucre smooth. - Salisbury, Maryland ( $\boldsymbol{W} . \boldsymbol{M}$. Canby), and southward.

\section{B Á C CH A R I S, L. Grodndsel-Trev.}

Hearls many-flowered; the flowers all tubular, diøcious, viz. the pistillate and staminate flowers in separate heads borne by different plants. Involucre imbricated. Corolln of the pistillate flowers very slender and thrend-like; of the staminate, larger and 5-lobed. Anthers tailless. Achenia ribbed. Pappus of slender capillary bristles, in the sterile plant scanty and tortuous; in the fertile plant very long and copious. - Shrubs, commonly smooth and resinous or glutinous. Flowers whitish or yellow, autumnal. ('The name of some shrub) anciently dedicated to Bacchus.)

1. B. halimifolia, L. Smooth and somewhat scurfy; branches angled; leaves ohovate and wedge-form, coarsely toothed, or the upper entire; heads scattered or in leafy panicles; scales of the involucre acutish. - Sea beach, Massachusetts to Virginin, and southward. - Shrub $6^{\circ}-12^{\circ}$ high ; the fertile plant conspicuous in autumn by its very long and white pappus.

2. B. glomeruliflòn, Pers. Leaves spatulate-oblong; heads larger, sessile in the axils or in clusters; scales of the bell-shaped invalucre broader, very obtuse : otherwise like the last. - Pine barrens, E. Virginia and southward.

\section{POLÝ M I A, L. LEAF-CuP.}

Heads many-flowered, radiate: the rays several (ravely abortive), pistillate; the disk-flowers perfect but sterile. Scales of the involucre niwo rows; the outer about 5 , leaf-like, large and spreading; the inner small and membranaceous, partly embracing the thick triangular-ohovoid achenia. Receptacle flat, with a membranaceous chaff to each flower. Pappus none. - Tall branching 
perennial herbs, viscid-hairy, exhaling a heavy odor. Leaves large and thin, opposite, or the mpermost alternate, lobed, and with dilated appendages liko stipules at the base. Hearls in panicled corymbs. Flowers light yellow; in summer and autumn. (I)edicated to the Muse, Polylymnia, for no obvious reason, as the plants are coarse and inelegant.)

1. P. Canadénsis, L. Clanmy-hairy; lower leaves deeply pinnatifid, the uppermost triangular-ovate and 3-5-lobed or angled, petioled; heads small; rays few, obovate or wedyc-form, shorter than the involucre, whitish-yellow. - Moist shaded ravines, W. New York (and Wcehawken, New Jersey, Dr. A/len) to l'enn., Wisconsin, and southward along the mountains. - Var. DIscoìdé has the corolla of the ray-flowers reduced to a mere ring around the base of the style. Mt. Carroll, Illinois, Menry Shimer.

2. P. Uvedàlia, I. Romylish-hairy, stout $\left(4^{\circ}-10^{\circ}\right.$ high $)$; leaves broadly ovate, angled and toothed, nearly sessile; the lower palnatcly lobed, abruptly narrowed into a winged petiole; outer involucral scales very large; ruys 10-15, linear-ablong, much longer than the inner scales of the incolucre, yellow. - Rich soil, W. New York and New Jersey to Illinois and southward.

\section{CH R Y SÓ GO N U M, L. Chrysogonum.}

Heads many-flowered, radiate; the rays about 5, pistillate and fertile; the disk-flowers perfect but sterile. Involucre of alwot 5 exterior leat-like oblong scales, which exceed the disk, and as many interior shorter and chaff-like concave scales. Receptacle flat, with a linear chaff to each disk-flower. Achenia all in the ray, obovate, obcompressed, 4-angled, each one partly enclosed by the short scale of the involuce behind it; those of the disk-flowers abortive. P'appus a suall chafty crown, $2-3$-toothed, and split down the inner side. $-\mathbf{A}$ low $\left(2^{\prime}-6^{\prime}\right.$ high), hairy, perennial herb, nearly stemless when it begins to flower, the flowerless shoots forming runners. Leaves opposite, ovate or spatulate, crenate, long-petioled. Heads single, long-peduncled. Flowers yellow. (Nane composed of $\chi \rho v \sigma o ́ s$, golden, and yónv, knee.)

1. C. Virginiànum, L. Dry soil, from Pennsylvania (Mercersburg, Prof. Porter) and Illinois southward. May - Aug. - Rays $\frac{1}{2}$ long.

\section{Sí I PHIUM, L. Rosin-Plant.}

Heads many-flowered, radiate; the rays numerous, pistillate and fertile, their broad flat ovaries imbricated in 2 or 3 rows; the disk-flowers apparently perfect, hut with undivided style, and sterile. Scales of the broad and flattish involucre imbricated in several rows, broad and with loose leaf-like summits, exeept the innermost, which are small and resemble the linear chaft of the flat recejptacle. Achenia broad and flat, obeompressed, surromeded by a wing which is notched at the top, destitute of pilppus, or with 2 teeth confluent with the winged margin: achenia of the disk sterile and stalk-like. - Coarse and tall rough perennial herbs, with a copious resinous juice, and large corymbosepanicled yellow-flowered heads. ( $\Sigma$ i̇ $\phi \iota 0 \nu$, the ancient name of a plant which produced some gum-resin, perhaps assalietida, was transferred by Linuæus to this American genus.) 
- Strm terete, nuked above, alternate-lenved near the base (root very large and thick).

1. S. laciniatum, L. (Rosin-weed. Compass-Pinnt.) Rough-lristly thronghout; stem stout $\left(3^{\circ}-6^{\circ}\right.$ high), leafy to the top; lenves pinnutely parted, petioled but dilated and clasping at the base; their divisions lancenlate or limeur, acute, cut-lobed or pinnatifid, rarely cntire; heads few $\left(1^{\prime}-2^{\prime}\right.$ broad $)$, somewhat racemed ; scales of the involuere orate, tapering into long and sprending rigid points; nchenin broully winged and deeply notched. - Prairies, Michigan and Wisconsin, thence southward and westward. July. - Lower and root-leaves vertical, 12. $-30^{\prime}$ long, ovate in outline; on the wide open prairies disposed to present their edges north and south; hence called Compass-Plant.

2. S. terebinthinàceum, L. (РRагiw Dоск.) Stem smooth, slender $\left(4^{\circ}-10^{\circ}\right.$ high), panicled at the summit and bearing many (small) heads, leatless except towards the base; leaves ovate and ovate-oblong, somewhat heart-shaped, serrate-toothed, thick, rongh, especially beneath $\left(1^{\circ}-2^{\circ}\right.$ long, on slender petioles); scales of the ineolucre roundish, obtuse, smooth; achenia narrowly winged, slightly notehed and 2-toothed. - Var. PinNatfrinum has the leaves deeply cut or pinnatifid, but varies into the ordinary form. - Prairies and oak-openings, Ohio and Michigan to Wisconsin and southward. July-Sept.

* * Stem terete or slightly 4-angled, leafy! : leaves undivided (not large).

3. S. trifoliàtum, I. Stem smooth, ofen glencous, rather slender $\left(4^{\circ}-6^{\circ}\right.$ high), branched aloove; stem-leaves lanceolate, pointed, entire or scarcely servate, rough, short-petioled, in whorls of 3 or 4, the uppermost opposite; hends loosely panicled; achenia rather broally winged, and sharply 2-toothed at the top. 1)ry plains and banks, W. New York to Wisconsin and southward. Aug.

4. S. Asteríscus, L. Stem hispid $\left(2^{\circ}-4^{\circ}\right.$ high) ; leaves opposite, or the lower in whorls of 3, the upper alternate, oblong or ounl-lencrolute, coarsely toothed, rarely entire, rongh-hairy; heads nearly solitary (large); achenia obovate, winged, 2-toothed. - Dry sandy soil, Virginia and sonthward.

5. S. integrifolium, Michx. Stem rough, rather stont $\left(2^{\circ}-4^{\circ}\right.$ high), rigid, 4-angular and grooved; lerves all opposite, rigid, lanceolute-ovale, entire, tapering to a sharp point from a roundish heart-shaped and partly clasping base, rough-pubescent or nearly smooth, thick $\left(3^{\prime}-5^{\prime}\right.$ long) ; heads in a close forking corymb, short-peduncled; achenia broadly winged, decply notehed. - Var. riviv has the stem and leaves smooth or nearly so. - Prairics, Michigan to Wisconsin, and southward. Aug.

** Stem square: leaves opposite, connate (thin and large, $6^{\prime}-15^{\prime} \mathrm{long}$ ).

6. S. perfoliatum, I. (CUP-PLANT.) Stem stout, often branched above $\left(4^{\circ}-8^{\circ}\right.$ bigh) ; leaves ovate, coarsely toothed, the upper united by their bases and forming a cup-shaped disk, the lower abruptly narrowed into winged petioles which are connate by their bases; hearls corymbose; achenia winged and variously notched. - Rich soil along streams, Michigan to Wisconsin, and southward : common. Also escaped from gardens eastward. July.

\section{PARTH $\mathrm{E}$ I U M, L. PARtienium.}

Heads many-flowered, inconspicuously radiate; the 5 ray-flowers with very short and broad obcordate ligules not projecting beyond the woolly disk, pistil- 
late and fertile; the disk-flowers staminate with imperfect styles, sterile. Invo. lucre hemispherical, of 2 ranks of short ovate or roundish scales. Receptacle conical, chatly. Achenia only in the ray, obcompressed, surrounded by a slender callous margin, erowned with the persistent ray-corolla and a pappus of 2 small chaffy scales. - Leaves alternate. Heads small, corymbed; the flowers whitish. (An ancient name of some plant, from $\pi a \rho \theta \epsilon$ vos, virgin.)

1. P. integrifolium, L. Rough-pubescent perennial $\left(1^{\circ}-3^{\circ}\right.$ high $)$; leaves oblong or ovate, crenate-toothed, or the lower $\left(3^{\prime}-6^{\prime}\right.$ long $)$ cut-lobed below the middle; heads many in a very dense flat corymb. - Dry soil, Maryland to Wisconsin and southward. June-Aug.

\section{9. İ V A, L. Marsi Elder. Highwater-shrob.}

fleads sever:al-flowered, not radiate; the pistillate fertile and tho staminato sterile flowers in the same heads, the former few $(1-5)$ and marginal, with a small tubular or no corolla; the latter with a funnel-form 5-toothed corolla. Authers nearly separate. Scales of the involucre few, roundish. Receptacle small, with narrow chaff among the flowers. Achenia obovoid or lenticular. Pappus none. - Herbaceous or shrubby contse plants, with thickish leaves, the lower opposite, and small greenish-ivhite heals of flowers; in summer ans autumn. (Name of unknown derivation.)

\$1. Fertile flowers with a small tubular corolla: involucre simple (heads nodding in the axils of lecef-like bracts, forming spikies or racemes).

1. I. frutéscens, L. Slurublyy at the hase, nearly smooth $\left(3^{\circ}-8^{\circ}\right.$ high); leaves oval or lanceolate, coarsely and sharply toothed, rather fleshy, the upper reduced to linear bracts, in the axils of which the heads are disposed, in leafy panicled racemes; fertile flowers and scales of the involucre 5. - Sult marshes, coast of Massachusetts to Virginia, and southward.

2. I. ciliàta, Willd. Aunual $\left(2^{\circ}-8^{\circ}\right.$ high $)$, rough and hairy; leaves ovate, pointed, coarsely toothed, downy beneath, on slender ciliate petioles; heads in dense spikes, with conspicuous ovate-lanceolate rough-ciliate bracts; scales of the involuere and fertile fluwers $3-5$. - Moist grouml, from Illinois southward.

\$2. LUPIIRÓSYNE, 1)C. Fertile flowers 5, in the axils of as many thin membranaceous scales of the involucre, which bosely enwrap the achenia, their corolls a mere rudimentary ring or none.

3. I. Xanthiifolia, Nutt. Annual, tall, roughish; leaves nearly all oppor site, hoary with minute down, ovate, rhombic, or the lowest heart-shaped, doubly or cut-toothed, or obscurely lobed; heads small, crowded in spikes or clusters disposed $\mathrm{h}$ axillary and terminal panicles; bracts inconspicuous. $-\mathrm{N}$. W. Wisconsin (T.J. Hale), and northwestward.

\section{A IM B R ÒSI A, Tourn. RAGWEed.}

Sterile and fertile flowers occupying different heads on the same plant; the fertile 1-3 together and sessile in the axil of leaves or bracts, at the base of the racemes or spikes of sterile heads. Sterile involucres flattish or top-shaped, composed of 7-12 scales united into a cup, containing 5-20 funuel-form stam- 
innte flowers, with slender chaff intermixed, or none. Anthers almost separate. Fertile involucre (fruit) oblong or top-shaped, closed, pointed, resembling an achenium, and usually with 4-8 tubercles or horns near the top in one row, enclosing a single flower which consists of a pistil only ; the elongated branches of the style protruding. Achenia ovoid : pappus none. - Homcly und conrse weeds, with opposite or alternate lobed or dissected leaves, and inconspicuous greenish or whitish flowers, produced throughout Inte summer and autumn : our species are all annuals. ('A $\mu$ Bpovia, the food of the gods, an ill-chosen name for these miscrable ẉeeds.)

\$1. Sterile heads sessile, crowded in a dense cylindrical spike, the top-shaped involucre with its truncute murgin extended on one side into a large, lanceolute, hooded, recurved, bristly-hairy tooth or appendage; fertile involucre oblong and 4-angled.

1. A. bidentata, Michx. Hairy $\left(1^{\circ}-3^{\circ}\right.$ high $)$, very leafy ; leaves alternate, lanceolate, partly clasping, nearly entire, except a short lobe or tooth on each side near the base. - Prairies of Illinois and southward.

§2. Sterile heads in single or panicled racemes or spikes, the involucre regular.

* Leaves opposite, only once lobed: sterile involucre 3-ribbed on one side.

2. A. trifida, I. (Great Ragweed.) Stem stout $\left(4^{\circ}-12^{\circ}\right.$ high), roughhairy, as are the large decply 3 -lobed leaves, the lobes oval-lanceolate and serrate; petioles margined; fruit obovate, 5-6-ribbed and tubercled. - Var. INTEGRIFòtA is only a smaller form, with the upper leaves, or all of them, undivided, ovate or oval. - Moist river-banks : common.

* Leaves many of them alternate, all once or twice pinnatifid.

3. A. artemisiæfolia, L. (Roman Wormwoon. Hog-weed. BrtTER-weEv.) Much branched $\left(1^{\circ}-3^{\circ}\right.$ high), hairy or roughish-pubescent; leures thin, twice-pinnatifid, smoothish above, palcr or hoary beneath ; fruit obovoid or globular, armed with about 6 short acute teeth or spines. - Waste places everywhere. - An extremely variable weed, with fincly cut lenves; rarely tho spikes bear all fertile hends.

4. A. psilostàchya, DC. Paniculatc-branched $\left(2^{\circ}-5^{\circ}\right.$ high $)$, rough and somewhat hoary with short hispid hairs; leaves once pinnatifid, thiclish, the lobes acute, those of the lower leaves often incised; fruit obovoid, without tubercles or with very small ones, pubescent. (A. coronopifolia, Torr. \& Gr.)-Prairies and plains, Wisconsin, Illinois, and southwestward.

\section{XÁ NTH I U M, Tourn. Cocklebur. Clotbur.}

Sterile and fertile flowers occupying different heads on the same plant; the latter clustered below, the former in short spikes or racemes above. Sterile inrolucres and flowers as in Ambrosia, but the scales separate. Fertile involucre closed, coriaccous, ovoid or oblong, clothed with hooked prickles so as to form a rough bur, 2-celled, 2-flowered; the flowers consisting of a pistil with a slender threar-form corolla. Achenia oblong, flat, destitute of pappus. - Coarse and vile weeds, with annual roots, low and branching stout stems, and alternate toothed or loberl petioled leaves; flowering in summer and autumn. (Namo from $\xi$ ávӨos, yellow, in allusion to the color the plants are said to yield.) 


\section{X. strumàrium, L. (Соммом CоскцевUr.) Rough; stems unarmed;} leaves dilated-triangular and more or less heart-shaped, on long petioles, toothed and cut or obscurely lobed; fruit oval or oblong $\left(\frac{1}{2}-\frac{y^{\prime}}{3}\right.$ long $)$, pubescent on the lower part of and between the hooked prickles, and with two strong and usually straight beaks at the summit. - Barn-yards, \&e. (Nat. from Lu.) - Varies into forms with more spotud stems, and often larger fruit $\left(\mathbf{g}^{\prime}-\mathbf{1}^{\prime}\right.$ long), which is either glabrous, glandular, or glandular-hairy, the prickles longer and the beaks often incurved. (X. Canadense, Mill., \&e.) - River-banks, \&c., common westward; apparently indigenons. And this passes into

Var. echinàtum. (X. echinatum, M/ur, \&c.) Fruit turgid ( $\left.1^{\prime} l o n g\right)$, thickly clothed ivith long prickles, glandular-hispid, the beaks commonly incurved. - Sandy sea-shore, and along the Great Lakes and rivers. P'erhaps an immigrant from farther south. Now widely scattered over the warmer parts of the world.

2. X. Spinosum, I. (Spiny Clotbur.) Hoary-pubescent; stems slender, with slender yellow 3-parted spines at the base of the lanctolute or ovate-lanctolute leaves; these taper into a short petiole, are white-downy beneath, often 2 3-lobed or cut; fruit ( $f^{\prime}$ long) pointed with a single short beak. - Waste places on the sen-board and alomg rivers, sonthward. (Nat. from 'Trop. $\Lambda$ mer. ?)

\section{TETRAG ONOTHE CA, Dill. Tetragonotheca.}

IIeacls many-flowered, radiate; the rays 6-9, fertile. Involucre double; the onter of 4 large and leatly ovate seales, which are united below by their margins into a 4-angled or winged cup; the inner of as many small and chaffy scales as there are ray-flowers, and partly clasping their achenia. Receptacle convex or conical, with narrow and membranaceous chaff between the Howers. Achenia roundish and obovoid, flat at the top. Pappus none. - An erect perennial herb, viscidly hairy when young, with opposite and coarsely toothed oval or oblong leaves, their sessile bases sometimes comnate, and large single heads of pale yellow flowers, on terminal peduncles. (Name compounded of $\tau \in \tau$ pázw⿻s, fourangled, and $\theta \dot{\eta} \kappa \eta$, a case, from the shape of the involucre.)

1. T. helianthoides, L. - Saudy soil, Virginia and southward. June.

\section{ECLÍPTA, L. Echita.}

IIeads many-flowerel, ruliate; the rays short, fertile; the disk-flowers perfect, 4-toothed. Scales of the involuce 10 -12 , in 2 rows, leaf-like, ovate-lanceolate. Receptacle flat, with ahmost bristle-form chaff between the flowers. Achenia short, 3-4-sided, or in the disk laterally flattened, roughened on the sides, hairy at the summit; the pappus none, or an obseure denticulate crown. - Annual or biemial rough herbs, with slender stems and opposite lanceolate or ublong leaves. Heads solitary, small. Flowers whitish: anthers brown. (Name from $\dot{\epsilon} \kappa \lambda \epsilon i \pi \omega$, to be deficient, alluding to the absence of pappus.)

1. E. procúmbens, Michx. Rough with close appressed hairs; stems procumbent, creeping, or ascending ; leaves oblong-lanceolate, acute at each end, sessile, slightly serrate; peduncles muny times longer than the head. - Var. BRACHÝPODA has the peduneles not more than twice the length of the heads. - 
Wet river-banks, Pennsylvania to Illinois, nnd sonthward. June-Oct. $-\Lambda 11$ belong to a wide-spread and variable species of the warmer regions, the oldest specitic name of which is E. ALBA.

\section{BOR RÍtiA, Adans. SeA Ox-eye.}

Heads many-flowered, radiate; the rays fertile. Scales of the hemispherical involucre imbricated. Receptacle flat, covered with lanceolate rigid and persistent chatf. Achenia somewhat wedge-shaped, 3-4-angled. Pappus a short 4-toothed crown. - Shrubby low maritime plants, coriaceous or fleshy, with opposite nearly entire leaves, and solitary peduncled terminal heads of yellow flowers : anthers blackish. (Named for Olof Borrich, a Danish botanist.)

1. B. frutéscens, DC. Whitened with a minute silky pubescence $\left(6^{\prime}-\right.$ $12^{\prime}$ high) ; leaves spatulate-oblong or lanceolate, often toothed near the base; chaff rigidly pointed. - Virginia and southward.

\section{HELIÓ PSIS, Pers. OX-eYe.}

Heads many-flowered, radiate; the rays 10 or more, fertile. Scales of the involucre in 2 or 3 rows; the outer leaf-like and somewhat spreading, the inner shorter than the disk. Receptacle conical : chaff linear. Achenia smooth, 4angular. Pappus none, or a mere border. - Perennial herbs, like Helianthus. Heads showy, peduncled, terminating the stem or branches. Leaves opposite, petioled, triple-ribbed, serrate. Flowers yellow. (Name composed of $\eta^{n} \lambda \iota s$, the sun, and oै $\psi(s$, appearance, from the likeness to the Sunflower.)

1. H. lævis, Pers. Nearly smooth $\left(1^{\circ}-4^{\circ}\right.$ high $)$; leaves ovate-lanceolate or oblong-ovate. - Var. schrra has ronghish foliage, and the involucre somewhat hoary. - Banks and copses : common. Aug.

\section{ECH I N À CEA, Monch. Purter Cone-flower.}

IIcads many-flowered, radiate; the rays very long, drooping, pistillate but sterile. Scales of the involucre imbricated, lanceolatc; spreading. Receptacle conical ; the lanceolate spiny-tipped chaff longer than the disk-flowers. Achenia thick and short, 4-sided. Pappus a small toothed border. - Perennial herbs, with the stout and nearly simple stems naked above and terminated by a single large head; the leaves chiefly alternate, 3-5-nerved. Rays rose-purple, rather persistent: disk purplish. (Name formed from 'Exivos, the Hedgehog, or Seaurchin, in allusion to the spiny chaff of the disk.)

1. E. purpùrea, Monch. Leaves rough. often scrrate; the lowest orate, 5-nerved, veiny, long-petioled; the others ovate-lanceolate; involucre imbricated in 3-5 rows; stem smooth, or in onc variety (E. serótina, $D C$.) rongh-bristly, as well as the leaves. - Prairies and hanks, from W. Penn. and Ohio southward and westward. July. - Rays 15-20, dull purple (rarely whitish), $1^{\prime}-2^{\prime}$ long. Root thick, black, very pungent to the taste, used in popular medicine under the name of Black Sampson. - Probably varies into

2. E. angustifolia, DC. Leaves, as well as the slender simple stem, bristly-huiry, lanceolate and linear-lanceolute, 3-nerved, entive; involucre less imbricated ; rays $12-15\left(2^{\prime}\right.$ long $)$, rose-color or red. - Plains from Illinois and Wisconsin southwestward. June-Aug. 


\section{R U D B É C K I A, L. CONE-FLower.}

Heads many-flowered, radiate; the rays neutral. Scales of the involucre leaf-like, in about 2 rows, spreading. Receptacle conical or columnar; the short clsaft' concave, not rigid. Achenia 4-angular, smooth, not margined, flat at the top, with no palplus, or a minute crown-like border. - Clietly perenuial herbs, with alternate leaves, and showy leads terminating the stem or branches; the rays gencrally long, yellow. (Naned in honor of the Professors Rudheck, father and son, predecessors of Linnixus at Upsal.)

* Disk columnar in fruit, dull greenish-ycllow: leaves divided and cut.

1. R. laciniàta, L. Stem sinuoth, branching $\left(3^{\circ}-7^{\circ}\right.$ high $)$; leaves smooth or roughish, the lowest pinnate, with 5-7 cut or 3-lobed leaflets ; upper leaves irregularly 3-5-parted; the lubes uvate-lanceolate, pointed, or the uppermost undivided; heads long-peduncled; chatf truncate and downy at the tip; rays linear $\left(1^{\prime}-2^{\prime}\right.$ long $)$, drooping. - Low thickets : common. July - Sept.

* * Dish glubuiar, pule brownish: lower leaves 3-parted: receptacle swet-scented.

2. R. subtomentosa, l'ursh. Stem branching alsove $\left(3^{\circ}-4^{\circ}\right.$ high $)$, downy, as well as dhe luwer side of the vvate or valte-lanceulate serrate leares; heads short-peduncled; chafl duwny at the blunt apex. - Prairies, Wiscousin, Illinois, and southward.

*** Disk broaully conical, dark purple or broun: leares undivided, except No. 3.

3. R. tríloba, 1. Hairy, biennial, much branched $\left(2^{\circ}-5^{\circ}\right.$ high), tho branches slender and spreading; upper leaves ovute-lunceulute, sparingly toothed, the lower 3-lobed, tapering at the base, coarsely-sericule (those from the root pinnately parted or undivided); reys 8, ocal or cblong; chaff of the black-purple disk smooth, awned. - Iry soil, Penn. to Hlinvis, and southward. Aug.Heads small, but numerous and showy.

4. R. speciosa, Wenderoth. Roughish-hairy $\left(1^{\circ}-2^{\circ}\right.$ high $)$, branched; the branches upright, clongated and naked above, terminated by single large leads; leaves lancrolute or ovatc-tanceolate, printed at both ends, petioled, 3-5-nercid coarsely and unequally touthed or incised; involucre much shorter than the numerous elongated $\left(1^{\prime}-1 \frac{1}{2}^{\prime}\right)$ ray's; chaff of the dark purple disk acutish, smouth. Dry soil, W. Penn. to Olio and Virginia. July.

5. R. fúlgida, $\Lambda$ it. Hairy, the branches naked at the summit and bearing single heads; leaves spululate-oblong or lanceulate, parlly clasping, triple-nervod, the upper cotire, mostly olinsts; rays abont 12, ecqualling or exceeding the involucre; chaff of the dark purple disk nearly smooth and blunt. - Dry soil, Pennsylvania to Kentucky and southward. - Variable, $1^{\circ}-3^{\circ}$ high : the rays orangeyellow. Nearly approaches the next.

6. R. hírta, L. Very rungh and bristly-hatiry throughout; stems sinuple or branclied near the base, stuut $\left(1^{\circ}-2^{\circ}\right.$ high), naked alsove. bearing single large heads; leaves nearly cutire; the npper allong or lanceolute, sessile; the luwer spatulate, triple-nerved, petioled; rays (about 14) more or less exceeding the involucre; chate of the dull lrown disk hairy at the th, acutish. - Dry soil, W. New York to Wisconsin and sunthward. Now common eastward, as a weed in menduws, of recent intruduction, with clover-seed from the West. JuneA acr. 


\section{L苗 P A Y $\mathbf{S}$, Rnf. (Oreliscaria, DC.)}

Heads many-flowered, radiate; the rays few, neutral. Scales of the involucro few and small, spreading. Receptacle oblong or columnar : the chaff truncate, thickened and bearded at the tip, partly embracing the flattened and margined achenia. Pappus none or 2 teeth. - l'eremial herbs, with alternate pinnate leaves; the growed stems or branches naked above, terminated by single showy heads. Rays yellow or party-colored, drooping; the disk grayish. (Name from $\lambda \in \pi i s, a$ scule, and $\pi a \chi u ́ s$, thick, from the thickened tips of the chaff.)

1. L. pinnàta, Torr. \& Gr. Hoary with minute appressed hairs, slender (4० high), branching; leaflets $3-7$, lanceolate, acute; disk oblong, much shorter than the large and drooping light-yellow rays (which are $2^{\prime}$ long). Dry soil, W. New York (Dr. Sartwell), to Wisconsin and southward. July. The receptacle exhales a pleasant anisate odor when bruised. Achenia slightly margined on the inner edge, obscurely 2 -toothed at the top.

\section{HELI Á N T H U, L. Sunflower.}

Heads many-flowered, radiate; the rays several or many, neutral. Involucre imbricated. Receptacle flattish or convex; the persistent chaff embracing the 4-sided and laterally compressed achenia, which are neither winged nor margined. Pappus very deciduous, of 2 thin chaffy scales on the principal angles of the achenium, and often 2 or more little intermediate scales. - Coarse and stout herbs, with solitary or corymbed heads, and ycllow rays; flowering to-

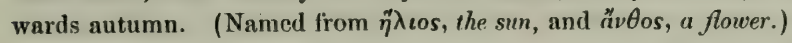

§. Root annual: leaves alternate: receptacle fat: disk brounish.

1. H. Annues, I. (Сommon Sunflower.) 'Tall, rongh; leaves tripleribbed, ovate or the lower heart-shaper ; heads in cult. plant very broad, and rays many. - Escaped from cult. into waste grounds. (Adv. from trop. Amer.)

$\$ 2$. Root perennial, the creeping rootstocks sometimes tuberous-thickmed or tuberif rous.

* Disk convex, dark purple: leaves mainly opposite: heads small, excrpt No. 4.

2. H. angustifolius, L. Stem slender $\left(2^{\circ}-6^{\circ}\right.$ high); leaves long and linear, sessile, entire, with revolute margins, 1-nerved; heads loosely corymbed, long-peduncled; scales of the involucre tapering into narrow and spreading herbaccous tips. - Low pine barrens, New Jersey to Kentucky and southward.

3. H. atrorubens, L. Rough-hairy; stem slender $\left(2^{\circ}-5^{\circ}\right.$ high $)$, smooth, and naked and forking above; leares thin, orate or oral, or the lowest heartshaped $\left(3^{\prime}-6^{\prime}\right.$ long), serrate, abruptly contracted into a margined petiole; heads small, corymbed; scales of the involncre ovate, obtuse, regularly imbricated, appressed, destitute of herbaceous tips; rays 10-16; pappus of 2 fringed scales. - Dry soil, Virginia, Illinois, and southward.

4. H. rígidus, Desf. Stem stout $\left(1^{\circ}-3^{\circ}\right.$ high $)$, simple or sparingly branched, rough; lenves very thick and rigid, rough both sides, oblong-lanceolate, usually pointed at both ends, nearly sessile, slightly serrate, the lowest oval; heads nearly solitary, pretty large; scales of the involucre ovate or lance-oblong, obtuse, ciliute, appressed, destilute of herbucrous tips; rays 20-25; pappus of 2 large and often several small scales. - Dry prairies, Michigan to Illinois, and westward. 
* * Disk convex, yellow: scales of the involucre regularly imbricated and appressed, with somewhat spreading and acute (but not fuliaccous) lips: leaves chiefly opposite.

5. H. lætiflorus, 1'ers. S'tout and rough $\left(3^{\circ}-4^{\circ}\right.$ high), branching above; leaves oval-lanceolute, very rough loth sides, narrowed into short petioles, serrate, taperpointed, the uppermost alternate and nearly entire; heads single or corymbed, on naked peduncles; scales of the involucre ovate-lanceolate, pointed, ciliate. Dry open places, Ohio to Illinois, and southward. - Leaves almost us thick as in II. rigidus. Rays showy, $1^{\prime}-2^{\prime}$ long.

6. H. occidentàlis, liiddell. Sornewhat hairy; stem slender, simple, nakted above $\left(1^{\circ}-3^{\circ}\right.$ hight, sending out runners from the base), bearing $1-5$ small heads on long peduncles; lowest leaves ocal or lanceolate-ovate, 3-nerved, obscurely scrrate, roughish-pubcscent beneath, abruptly contracted into long hasiry petioles; the upper smull cend remote, entire; seales of the involucre oval-lanceolate, pointed, ciliate. - Dry barrens, Ohio to Wisconsin, Kentucky, and southward.

7. H. cinèreus, var. Sullivántii, Torr. \& Gr. Gray with a cluse roughish pubescence; stem branching above, hairy; leaves ovate-oblong, sessile by a narrowed buse, acute, obscurcly scrate; the upper small and remote; peduncles slender ; scales of the involucre lanceolate, hoary. - Darby Plains, Ohio, Sullivant. Stem $2^{\circ}-3^{\circ}$ high, bearing few heals, as large as those of the next.

8. H. móllis, Latm. Stem clothed with suft white hairs, simple, leafy, to the top $\left(2^{\circ}-4^{\circ}\right.$ high) ; leaves ocate, with a boad heart-shaped and clasping base, pointed, nearly entire, houry above, very soft white-uoolly and reticulated underneath; seales of the involucre lanceolate, downy. - Barrens and Prairies, Ohio to Illinois, and westward.

* * Ileads very small (about 4 " broad) : scales of the involucre few, shorter than the yellow disk, irregulaily imbricuted, appressed, the outer with spreading foliaceous pointed tips: rays $5-8$, slender: leaves all but the uppermost opposite.

9. H. microcéphalus, Torr. \& Gr. Stem smooth $\left(3^{\circ}-8^{\circ}\right.$ high), with numcrous slender branches above; leaves thin, ovate-lanceolute, taper-pointed, somewhat serrate, veiny, petioled, rough above, downy or lutiry underneath; peduncles slender, rough; scales of the involucre ovate and ovate-lanceolate, ciliate. - Thickets, Pennsylvania to Illinois, and southward.

10. H. lævigàtus, Torr. \& Gr. Stem slender $\left(1^{\circ}-4^{\circ}\right.$ high $)$, simple or sparingly branched, very smooth and glabrous throughout, as well as the slightly serrate lanceulate leaves. - Dry soil, Alleghany Mountains, west of the Warm Springs of Virginia, and southward.

* * * Heads midlle-sized or large: scales of the involucre irregularly imbricated, loose, with spreutiny folinceous tips, as long as the yrllow dish or longer.

- Leaves chiefly alternatc or seattered, feather-veined, some limes obscurely triple-ribbed.

11. H. gigantèus, I. Stem hairy or rough $\left(3^{\circ}-10^{\circ}\right.$ high $)$, luanclied above; liaves hinceulat', pointed, serrate, very rough above, rough-hairy bencath, narrowed and ciliate at the base, but nearly sessile; scales of the involucre long, linear-lanceolate, pointed, hairy, or strongly ciliate. - Var. A muf fivus has most of the leaves opposite and closely sessile by an obtuse base, and approaches No. 14. - Low thickets and swamps: common. Heads somewhat corymbed : tho pale yellow rays $15-20$. 
12. H. grosse-serràtus, Martens. Stem smooth and glaucous, at lenst helow $\left(5^{\circ}-10^{\circ}\right.$ high $)$; leuves elongated-ianceolate or ovate-lanceolate, taperpointed, serrate, rough alove, rounded or acutc at the base, petioled, honydowny beneath; scales of the involncre lance-awl-shaped, slightly ciliate. - Dry plains, Ohio to Illinois, and southwestiward. - 1'robably runs into the last.

13. H. tomentosus, Michx. Stem hairy, stout $\left(4^{\circ}-8^{\circ}\right.$ high); leaves oblong-lanceolete, or the lowest ovate, taper-pointed, obscurely serrate, large (5' 12' long), somewhat petioled, very rough alover, sof -towny bruecth ; seales of the involucre with very long and spreading tips, hairy; the chaff and tips of the disk-flowers pubescent. (1)isk $1^{\prime}$ broad; rays $12-16$ about $1^{\prime}$ long.) - Rich woods, Illinois? Virginia and southward along the mountains.

++ Leaves opposite, or the uppermost alternate, 3-nerved or triple-ribbed.

14. H. strumosus, L. Stem $\left(3^{\circ}-4^{\circ}\right.$ high) smooth below ; leaves ovateIanceolate, tapering gradually to a point, serrate with small appressed tieth, abruptly contracted into short margined petioles, rough above, whitish and naked or minutely downy underneath; seales of the involucre broadly lanceolate with spreading tips, equalling the disk; rays mostly 10. - Var. Mórurs has the leaves softly downy underneath. - River-banks and low copses . common, especially westward.

15. H. divaricatus, L. Stem simple or forked and corymbed at the top $\left(1^{\circ}-4^{\circ}\right.$ high) smooth; leuves all opposite and diruricule, ovate-luncelale, 3-nerved from the rounded or truncate sessile base, tapering gradually to a sharp point ( $3^{\prime}$ 6' long), serrate, thickish, rough both sides; scales of the involucre lanceolate from a broad base, pointed, equalling the disk; rays 8-12.-Thickets and barrens : common. - Disk 6" wide; rays 1' lowg.

16. H. hirsùtus, Raf. Stem simple or forked above, stont $\left(1^{\circ}-2^{\circ}\right.$ high), bristly-huiry; leaves more or less petioled, ovate-luncrolate, gradually pointed, slightly serrate, rounded or obtuse at the base, very rongh above, rough-hairy underneath ; scales of the involucre ovate-lanceolate, pointed, equalling the disk; rays about 12. - Dry plains, Ohio to Wisconsin, and southward. - Runs into the iast.

17. H. tracheliifólius, Willd. Stem loosely branched, tall, hairy; leaves thin, oute-lunceolate or oblong-lanccolate, taper-pointed. sharply serrate, smoothish or ronghish.pulurscent both sides, contracted into short petioles; scales of the involuere lancelate-linear, elongated and very taper-pointed, loose, exceeding the disk; rays 12-15. - Copses, Pennsylvania and Ohio to Illinois, and southward. - Probably runs into the next.

18. H. decapétalus, L. Stem branching $\left(3^{\circ}-6^{\circ}\right.$ high $)$, smooth below; leaves thin and green both sides, smooth or roughish, orate, coarsely serrate, pointed, abruptly contracted into margined petioles; scales of the involucre lanceolatelinear, elongated, loosely spreading, the outer longer than the disk; rays about 10. - Var. FRosdòsus has the outer involucral scales foliaceous or changing to leaves. - Copses and low banks of streams: common, especiully northward. (H. multiflorus, $L$., may be a cultivated state of this.)

19. H. doronicoldes, Lan. Stem stont $\left(5^{\circ}-g^{\circ}\right.$ high $)$, branching, roughhairy ulove; leaves ovate or oblong-lenceolate, pointed, serrate, strongly triple-veined, rough above, smoothish or downy underneath, the lower often heart-shaped and on L \& $\mathbf{M}-\mathbf{3}$ I 
margined petioles; scules of the involucre huear-ianceolate, pointed, scarcely exceeding the disk; rays 12-15. - River-bottoms, Pennsylvania to Illinois and southward. $-\Lambda$ coarse species, with ample leaves (the lower often $1^{\circ}$ long); the upper ones frequently alternate; rootstock thickening into elongated tubers. 'This is probably the original of

20. H. tubziosus, L., the Jenusalem Artrichoke, (i. c. Crirusale of the Italians, meaning the sane as sunflower, and corrupted in England into Jerusalem), which has all the upper leaves alternate. It has escaped fivm gardens into fence-rows, \&c. in some places.

\section{A CTINóm ERIS, Nutt. Actinonieris.}

Heads many-flowered; the rays few or several, neutral, or rarely none. Involucre foliaceous, nearly equal, in 1 to 3 rows. lieceptacle couvex or eonical, chaffy; the chaff embracing the outer margin of the flat (laterally compresse: 1) and winged achenia. Pappus of 2 smooth persistent awns. - ' 1 'all and branching pereunials, with serrate feather-veined leaves, tapering to the base and mostly decurrent on the stem. Heads corymbed : flowers chicily yellow. (Name from áxтis, a ray, and $\mu \in$ pis, a part; alluding to the imegularity of the rays.)

1. A. squarrósa, Nutt. Steme semecuht hairy and wingal above $\left(4^{\circ}-8^{\circ}\right.$ ligh) ; leaves alternate or the lower opposite, oblong or ovate-lanceolate, pointed at both ends; heads in an open corymbed panicle; seales of the ineoluce in 2 rows, the outer linear-spatulate, reflexd; rays 4-10, irregular; achenia broadly winged; receptacle globular. - Rich soil, Penn. and W. New York (Sartwell) to Michigan, Illinois, and southward. Sept.

2. A. helianthoides, Nutt. Stem hairy $\left(1^{\circ}-3^{\circ}\right.$ high $)$, widely winged by the ovate-lanceolate sessile alteruate leaves, which are rough above and softlairy bencath; heads fiew; scales of the involucre not spreading; rays 8-15, regulur; achenia oval, slightly winged, tipped with 2 fragile awns; receptacle conical. - Prairies and copses, Ohio to Illinois and southward. July.

\section{COREÓ PSIS, L. Tickseed.}

Heads many-flowered, radiate; the rays mostly 8 , neutral, rarely wanting. Involucre double; each of about 8 scales, the outer rather foliaceous and somewhat spreading; the inner broader and appressed, nearly mombranaceous. Receptacle sat, with membranaceous chaff deciduous with the fruit. Achenia flat, obcompressed (i. e. parallel with the scales of the involucre), often winged, not beaked or nurrowed at the top, 2-toothed, 2-awned, or sometimes naked at the summit, the awns not barbed downwardly. - Herbs, generally with opposite leaves, and yellow or party-colored, rarely purple, rays. (Name from

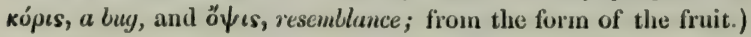

\$2. Branches of the style truncate: ratye rose-color: disk yellow: rool perennial.

1. C. rósea, Nutt. Stem branching, leafy, smooth $\left(6^{\prime}-20^{\prime}\right.$ high) ; leaves opposite, linear, entire; heads small, somewhat corymbed, on short peduncles; outer involucre very short; rays 3-toothed; achenia oblong, wingless; pappus an obscure crown-like border. - Sandy and grassy swamps, Plymouth, Massachusetts, to New Jersey, and southward : rare. Ang. 
\$ 3. Corolla of the ray and disk yellow or partly brown: branches of the style tipped with a pointed or acute appendage.

* Achenia nearly orbicular, broudly winged, incurved, furnished with a callons tubercle on the inside at the top and bottom, crowned with 2 small chaff-like denticulate teeth: outer involucre about the length of the imer: rays large, coarsely 3-5toothed: leuves opposite or the nppermost alternate: heads on long naked peduncles: root in our wild species perennial.

2. C. auriculata, Linn. Pubescent or glabrous; stems $1^{\circ}-4^{\circ}$ high, brunching, somctimes with runners; leaves mostly petioled, the upper ablong or ovallinceolute, entire; the lower oval or roundish, some of them variously 3-5-lobed or divided; scales of the outer involucre oblong-linear or lanceolate. - Rich woods and banks, Virginia to Illinois and southward. June-Sept.

3. C. lanceolàta, L. Smooth or hairy $\left(1^{\circ}-2^{\circ}\right.$ high $)$; stems short, tufted, branched only at the base; leaves all entire (or the lower rarely with a pair of small lateral lobes), lanceolate, sessile, the lowest oblanceolate or spatulate, tapering into petioles; scales of the outer involucre ovate-lanceolate. - Rich or damp soil, Michigan and Illinois to Virginia, and southward. July. Also cultivated in gardens. - Heads showy : rays l' long.

C. rincròria, Nutt., a native of the plains beyond the Mississippi, with the rays yellow above, and brown-purple towards the base, a common garden biennial or annual, is becoming spontaneous in a few places.

* Achenia oblong, narrowly winged, minutely or olscurely 2-toothed at the summit: scales of the outer involucre narrow, about the leng'h of the inner, all more or less united at the base: rays mostly entire and acute: leuves opposite, sessile, mostly 3divided, therefore appearing as if whorled: peremial $\left(1^{\circ}-3^{\circ} \mathrm{high}\right)$.

4. C. senifolia, Michx. Leaves each divided into 3 sessile ovate-lanceolate entire lenflets, therefore appearing like 6 in a whorl: plant minutely soft-pubescent. - Sandy woods, Virginia and southward. July.

Var. stellata, Torr. \& Gr. Glabrous, and the leaves narrower. (C. stellata, Nutt.) - Virginia, Kentucky, and southward.

5. C. delphinifolia, Lam. Glabrous or nearlý so; leaves divided into 3 sessile la flets which are 2-5-parled, their divisions lance-linear ( $1^{\prime \prime}-3^{\prime \prime}$ broad). rather rigid; disk brownish. - P'ine woods, Virginia and southward. July.

6. C. verticillata, L. Glabrous; leaves divided into 3 sessile leaflets which are 1-2-pinnately parted into narrowly linear or filiform divisions. - Damp soil, from Maryland and Michigan southward. Also cultivated in old gardens, but not showy. July - Sept.

7. C. palmàta, Nutt. Nearly smooth, simple; leaves broadly wedge-shaped, deeply 3-clef , rigid; the lobes broudly linear, entire, or the middle one 3-lobed. Prairies, Michigan to Wisconsin, and southwestward. July.

* * Achenia elliptical, narrowly winged, the narrowly notched summit of the wing minutely lacerate-toothed: scules of the outer involucre foliaceous, much smaller than the inner, all united at the base: rays obtuse, entire: leaves opposite, petioled, 3 5-divided: perennial.

8. C. trípteris, L. (TAll Coreopsis.) Smooth; stem simple $\left(4^{\circ}-9^{\circ}\right.$ high), corymbed at the top; leaflets lanceolate, acute, entire. (Chrysostémma, 
Less.) - Penn. to Michigan, Illinois and southward. Aug. - Sept. - Heads exhaling the odor of anise when bruised : disk turning brownish.

****Achenia wingless, flut, 2-awned, 2-toothed, or rarely truncate, 1-nerved or ridged on each fuce: scules of the outer involucre leafy, reflexed or spreading: leaves opposile, petivled, generally pinnately or ternaldy compound, the lavves or leaflets serrate: biennials or annuals, with the aspect of Bidens, intermediute between that genus and Coreopsis; - and certain ambignous (hybridized?) specimens, with the awns buibed some upuards and some downoards, comect the two.

+ Riuys conspicuous, golden-yellow.

9. C. aristósa, Michx. Somewhat pubescent; leaves 1-2-pinnately 57-divided, petioled; leaflets lanceolate, cut-toothed or pinnatifid; heads panicledcorymbose; outer involucre of 10-12 leafy bracts; achenia drovate, often obscurely wing-margined, bristly-ciliate, with 2 (rarely 4) long and slender diverying awns as long as the achenium itsclf. - Swamps, Olio to Michigan, Wisconsin, and southwestward. Aug. - Oct. - Var. Múrics has two short divergent teeth or points in place of the awns. - W. Illinois and southwestward, where a furm (C. involucràta, Nutt.) oceurs with the bracts of the outer involucre more lenfy, numerous, and hirsute. Mr. Fritchey sends, from near St. Louis, specimens with short awns and their barbs either spreading or retrorse, and others with long awns retrorsely barbed, - perhaps hybrids with some Bidens.

10. C. trichospérma, Michx. ('Tickseed Sunrlower.) Smooth, branched; leaves short-petioled, 5-7-divided; leaflets lauceolate or linear, cuttoothed, or the upper leaves only 3-5-cleft and almost sessile; heads panicledcorymbose; achenia nuirowly wedye-oblong or the inner ones wallye-linear, smooth or minutely appressed-hairy, marginless, crowned with 2 erect trianyular or awl-shaped stout teeth. - Swamps, Massachusetts to Virginia near the coast. Also Buffalo, New York (G. W. Clinton), and Illinois (Vasey), where forms with shorter achenia approach the Southern C. aurea. Aug.-Oct.

+ + Rays none, or rarely small and inconspicuous: outer involuere of few (usually 3-5) loose liafiy bracts commonly surpussing the hauds: achenia minutely appressed-pubescent: plants glabrous, $1^{\circ}-3^{\circ}$ high .

11. C. discoídea, Torr. \& Gr. Diffusely branched; leaves temately divided, slender-petioled; leaflets ovate-lanceolate, jointed, coarsely serrate; heads $2^{\prime \prime}-3^{\prime \prime}$ long; achenia linear-wedge-shaped ( $2^{\prime \prime}-3^{\prime \prime}$ long), bearing a pair of short and stout upwarlly-barbed awns of the length of the corolla. - Wet banks and swamps, Delaware (W.M. Canby) to Ohio, Illinois, and southward. July.

Anomalous specimens, from near Philadelphia (A. II. Smilh, de.), growing with lidens frondosa, differ from small forms of that only in the less rigid and upturned barts of the awns.

12. C. bidentoldes, Nutt. Paniculately branched; leaves undivided, lanceolate, coarsely toothed, taper-pointed, and the base tapering into a slender petiole; heads 6" - 10" long; achenia nearly subulate tapering downwards, bearing a pair of cery slender upwardly roughened awns surpassing the corolla ( $t^{\prime \prime}$ long), but shorter than the achenium, often also 2 minute teeth alternate with the awns. Shores of 1)elaware River, near Philadelphia, and in Delaware, Nutall, Durand, A. II. Smith, W. M. Canby. 


\section{BIDEN S, L. Bur-MArigold.}

Heads many-flowered; the rnys when present $3-8$, neutral. Involucre double, the outer commonly large and foliaceous. Receptacle flattish; the chaff deciduous with the fruit. Achenia flattened parallel with the scales of the involuere, or slender and 4-sided, crowned with 2 or more rigid and persistent awns which are downwardly barbed. - Annual or perennial herbs, with opposite various leaves, and mostly yellow flowers. (Latin, bidens, two-toothed.)

* Acheniu flat, not tapering at the summit. (All annuals?)

1. B. frondosa, L. (Соммом ВеgGni-тіскs.) Smooth or rather hairy, trll $\left(2^{\circ}-6^{\circ}\right.$ high) and branching; leaves 3-5-divided; the leuflets mostly stulked, lanceolate, pointed, conrsely toothed; outer lenfy involucre much longer than the hend, ciliate below; rays none or few and very small; achenia wedye-nhovate, 2-awned, the margins ciliute with upwardly-turned bristles, except near the summit. -Moist waste places : a coarse troublesome wced, the achenia, as in the other species, adhering by their retrorsely barbed awns to the dress, and to the flecee of animals. July - Oct.

2. B. connata, Muhl. (Swame Begann-ticks.) Smooth $\left(1^{\circ}-2^{\circ}\right.$ high) ; leaves lanceolute or oblong-lanceolate, pointed, sharply scrratc, tapering into margined petioles which are slightly united at the base; the lower ofen 3-divided, their lateral divisions united ut the buse and decurrent on the petiole; scales of the outer involucre longer than the heal, few, mostly obtuse; rays none; achenia narrowly wedge-form, 3- (2-4-) awned, the margins minutely retrorsely ciliate. (B. tripartita, Bigel.) - A thin-leaved more petioled form is B. petiolata, Nutt. - E. New England to Illinois, and sonthward. - Var. Comòs is stonter, the leaves commonly all simple, upper ones nearly sessile, the heads larger and with more numerous and leafy bracts. - Illinois, Kentucky, and westward. $\Lambda$ ug. - Oct.

3. B. cérnua, L. (Smitrer Bur-Marigotd.) Nearly smooth (5'-10' high); leaves cill undividal, lanceolnte, unequally serrate, scarerly connate; heads nodding, with or without (light yellow) rays : outer involuere longer than the head; achenia wedge-obovate, 4-awned, the margins downwardly barbed. Wet places, Virginia to. Wisconsin, and northward. July - Sept. - Rays, when present, smaller than in the next, the leaves irregularly toothed, and the outer involucre more leaf-like. (Eu.)

4. B. chrysanthemoldes, Michx. (LArger Bur-Mạigotn.) Smooth, erect, or reclining at the base $\left(6^{\prime}-30^{\prime}\right.$ high) ; leaves lancenlate, tapering at both ends, more or less connate, regularly serrate; onter involucre mostly shorter than the showy golden-yellow (1' long) muys; achenia wedge-shaped, with almost prickly downwardly barbed margins; awns 2, 3, or 4. - Swamps: common. Aug. Oct. - Northward it runs into No. 3.

* Achenia linear or aut-shaped, 4-sided, slender, tapering at the summit.

5. B. Béckii, Torr. (Water Marigold.) Aquatic, perhaps perennial, smooth; stems long and slender, bearing crowded immersed leaves many times dissected into fine capillary dirisions; the ferv emerging leaves lanceolate, slightly connate, toothed; heads single, short-peduncled; involucre much shmter thin the showy (godden yellow) rays; achenia linear, thickisli, smooth ( $f^{\prime}$ long), hearing 46 stout divergent awns which are un inch long and barbed only towards the 
apex. - Ponds and slow deep streams, Massachusetts to N. Jersey, Illinois, and northward. Aug. - Oct.

6. B. bipinnàta, L. (Spanish Needles.) Smooth annual, branched; leaves 1-3-pinnately parted, petioled; leaflets ovate-lanceolate, mostly wedge-shaped at the base; heads small, on slender peduncles; outer involucre of linear scales equalling the short pule ycllow rays ; achenia slender, 4-grooved and angled, nearly smooth, 3-4-awned. - Jry soil, Connecticut to Illinois and southward.

\section{VERBES I N A, I. Crownuedrd.}

IIeads several-many-flowered; the rays pistillate, few, or sometimes none. Scales of the erect involucre few, imbricated in 2 or more rows. Receptacle rather convex; the chuff concave. Achenia flat (compressed laterally), winged or wingless, 2-awned. - Perennial herbs ; the toothed or lobed leaves decurrent on the stem. ("Name metamorphosed from Verbena.")

1. V. Siegesbéckia, Michx. Stem tall, 4-winged; leaves opposite, ovate, triple-nerved, serrate, pointed at both ends, often pubescent beneath (large and thin); heads in compound corymbs; flouers yellow; rays 1-5, lanceolate; achenia wingless. - Rich soil, S. P'enn. to Illinois, and southward. July.

2. V. Virgínica, L. Stem narrowly or interruptedly winged, downypubescent, like the lower surface of the ovate-lanccolate feuther-veined alternate leaves; heads in compound corymbs; flowers white; rays 3-4, oval; achenia narrowly winged. - Dry soil, Pennsylvania? Illinois, and southward. Aug.

\section{DYSò Di A, Cav. Fetid Marigold.}

Heads many-flowered, usually radiate; the rays pistillate. Involucre of one row of scales united into a firm cup, at the base some loose bractlets. Receptacle flat, not chaffy, but beset with short chaffy bristles. Acheuia slender, 4angled. Pappus a row of chaffy scales dissected into numerous rough bristles. - Herbs, mostly annuals or biennials, dotted with large pellucid glands, which give a strong odor (as in Tagètes, the Frencil Manigold of the gardens, which belongs to the same group); the hearls terminating the branches: flowers yellow. (Name $\delta v \sigma \omega \delta i a$, an ill smell, which the plants exemplify.)

1. D. chrysanthemoides, Lag. Nearly smooth, diffusely branched $\left(6^{\prime}-18^{\prime}\right.$ high); leaves opposite, pinnately parted, the narrow lobes bristlytoothed or cut; rays few, scarcely exceeding the involucre. - Roadsides, and banks of rivers, from Illinois southward: a common weed; now migrating caktward, established at 13uffialo, N. Y., G. W. Clinton. Aug- - Oct.

\section{H Y M E N P P P PUS, L'Her. Hymenopapus.}

Heads many-flowered; the flowers all tubuiar and perfect. Scales of the involucre 6-12, loose and broad, thin, the upper part petal-like (usually white). Receptacle small, naked. Corolla with large revolute lobes. Achenia topshaped, with a slender base, striate. Pappus of 15-20 small and blunt scales in a single row, very thin (whence the name of the genus, from i $\mu$ inv, membrane, and $\pi a ́ \pi \pi v s$, pappus). - Bienniul or perennial herbs, with alternate mostly dissected leaves, and corymbed small heads of usually whitish flowers. 
1. H. scabiosieus, I'IIer. Somewhat flocenlent-woolly when young $\left(1^{\circ}-3^{\circ}\right.$ high $)$; leaves $1-2$-pinnately parted into linear or oblong lobes; scales of the involucre roundish, nearly all whitish. - Sandy barrens, Illinois and southward. May, June.

\section{$45 \frac{1}{2}$. A C T I N ELA, Pers., Nutt. Actinella.}

Heals many-flowered, radinte; the rays sereral, wedge-oblong, 3-lobed at the apex or 3-toothed, pistillate. Scales of the hemispherical involucre ovate or lanceolate, membranaccous or coriaccous, nearly equal, appressed in 2 or 3 ranks, littlo shorter than the disk. Receptacle hemispherical or conical, naked. Achenia top-shaped, densely silky-villous. Pappus of 5 or more ovate or lanecolnte very thin chaffy scales. - Low herbs, with narrow leaves, dotted or sprinkled with resinons atoms as in the next genus; the solitary heals terminating sapes or slender naked peduneles; flowers yellow. - Natives of the Western plains, \&.e., and harely entering our borders. (Name a diminutive of Actinea, from àktis, ray.)

1. A. scaposa, Nutt., var. glàbra. Tufted; leaves crowded on the summit of woolly rootstocks, lincar or somewhat spatulate, thickish, sparingly silky-hairy, becoming glabrous ; scape $\left(3^{\prime}-9^{\prime}\right.$ high) and involucre more woolly, the scales ovate and obtuse; chaffy scales of the pappus ovate, awnless. Joliet, Illinois, on an Indian mound (Dr. Scnmmon, W. Boott), and westward.

\section{H EL i N I U M, L. SNeEze-weed.}

IIcads many-flowered, radiate; the spreading wedge-shaped rays several, 35-cleft at the summit, fertile. Involucre small, reflexerl, the seales linear or awl-shaped. Receptacle globose or oblong, nakel. Achenia top-shaped, ribbed. Pappus of 5-8 thin and 1-nerved chaffy scales, the nerve usually extended into a bristle or point. - Erect, branching herbs, with alternate leaves decurrent on the angled stem and branches, which are terminated by single or corymbed (yellow, rarely purple) heads; often sprinkled with bitter and aromatic resinous globules. (Named after Hden, the wife of Menelaus.)

1. H. autumnàle, L. (SNEEZk-weEn.) Nearly smooth, perennial ; leaves lanecolate, toothed ; rays longer than the globular-disk. - Alluvial riverbanks : common (except in New England). Sept. - Plant $1^{\circ}-3^{\circ}$ high, bitter : the corymbed heads showy.

\section{IEPTÓPODA, Nutt. LePtopoda.}

Rays neutral. Otherwise nearly as in Helenium. - In the true species (of which $L$. puberula and $L$. brevifolia may be found in S. Virginia) the stems are simple, and naked above, like a long peduncle, and bearing a single head (whence the name, from $\lambda \in \pi$ rós, slender, and $\pi$ oús, foot); but the following is leafy to the top, and branched; and were hetter restored to Ilelenium.

1. L. brachypoda, Torr. \& Gr. Stem corymbed at the summit $\left(1^{\circ}-4^{\circ}\right.$ high); leaves oblong-lanceolate, decurrent on the stem ; disk globular, brownish; rays $\left(\frac{1}{2}\right.$ ' $-\frac{2 \prime}{3}$ long) yellow, or in one variety brownish-purple, sometimes with an imperfect stylc. - Damp soil, from Illinois southward. June-Aug. 


\section{B A L D W Í NIA, Nutt. BaLdwinia.}

Heads globular, many-flowered, radiate; the long and narrowly wedge-shaped rays neutral. Involucie sloort, of many thickish small scales inbricated in 3 or 4 rows, the outer obovate and obtuse. Receptacle strongly convex, with deep honeycomb-like eclls containing the olsconical or oblong silky-villous achenia Pappus of 7 -9 lance-oblong erect chatify seates. - A perennial herb, smoothish, with slender simple stems $\left(2^{\circ}-3^{\circ}\right.$ high $)$, bearing alternate oblanceolate leaves, and the long naked summit terminated by a showy large head. Rays yellow (1' long); the disk-flowers often turning dark purple. (Named for the late Dr. William Bulduin.)

1. B. uniflora, Nutt. - Borders of swamps, Virginia and southward. Aug.

\section{M A R SHÁ IIIA, Schrcb. Marsinalia.}

Heads many-flowered; the flowers all tubular and perfect. Scales of the involucre linear-lanceolate, foliaceous, erect, in one or two rows, nearly equal. Receptacle convex or conical, with narrowly lincar rigid chaff among the flowcrs. Lobes of the corolla slender, spreading. Achenia top-shaped, 5-angled. Pappus of 5 or 6 membranaccous and pointed chaffy scales. - Smooth and low perennials, with alternate and entire 3-nerved leaves, and solitury hearls (rebcubling those of a Scabious) terminating the naked summit of the simple stem or branches. Flowers purplish ; the anthers blue. (Named for Humphry Marshall, of 1'ennsylvania, author of Arbustrum Americanun, one of the earliest works on the trees and shrubs of this country.)

1. M. latifòlia, P’ursh. Stems lcafy; leavcs ovate-lanceolate, pointed, sessile. - Dry soil, Virginia and southward. (M. Lanceorata and M. anGustifolia may occur in S. Virginia.)

\section{G A LI N S Ò A, Ruiz \& Pav. Galinsoga.}

Heads several-flowered, radiate; the rays 4-5, small, roundish, pistillate. Involucre of 4 or 5 ovate thin scales. Receptacle couical, with narrow chatf anong the llowers. Achenia angled. Pappus of small oblong cut-finged chaffy scales (sometimes wanting). - Annual herbs, with opposite triple-nerved thin leaves, and small heads. disk-flowers yellow; rays whitish. (Named for (ialinsorga, a Spanish botanist.)

1. G. Parvifora, Cav. Sinoothish (10 high) ; leaves ovate, acute, somewhat toothed; scales of the pappus 8-16. - Waste places, especially castward; spreading from year to year. (Adv. from S. Amer.)

\section{M A R Ù T A, Cáss. MaY-weed.}

Heads many-flowered, radiate; the rays neutral. Involuce of many small somewhat imbricated scales, slerter than the disk. Receptacle conical, bearing slender chaff, at least near the summit. Achenia obovoid, ribbed, smooth. Pappus none. - Annual acrid herbs, with a strong odor, finely thrice-pinnately divided leaves, and single heads terminating the brauches Rays white, soon 
veflexed; the disk yellow. (Derivation unknown. - The genus not distinet enough from the next.)

1. M. Cótula, DC. (Common MaY-weed.) Scales of the involucre with whitish margins. (Anthemis Cotula, L.) - Roadsides : very common. (Nut. from Eu.)

\section{A N THEMIS, L. Синмомие.}

IIeals and flowers as in Maruta, but the rays pistillate. Achenia terete, striate or smooth. Pappus none, or a minute crown. - Ilerbs with aromatic or strong odor, 1-2-pinnately divided leaves, the branches terminated by singlo heads. Rays in ours white; the disk yellow. ('A $\nu \theta \epsilon \mu$ is, the ancient name, given in allusion to the profision of the flowers.)

1. A. arvénsis, L. (Corn Chamomile.) Puhescent annul or biennial, resembling May-weed, but not ill-scented; chaff of the receptacle lanceolate, pointed; pappus a minute border. - Waste places : rare. (Adv. from Eu.)

2. A. Nónitis, L. (Ganden Сиямомиц..) More downy and perennial, pleasantly strong-scented; sterile shoots depressed or crecping; leaves very fincly dissected; chaff of the receptacle blunt; pappus none. - Established near Lewiston, Delaware, Nuttall. ( $\Lambda$ dv. from Eu.)

\section{3. A CHILLEA, L. YARRow.}

Heads many-flowered, raliate; the rays few, fertilc. Involucre imbricated. \& Receptrcle chaffy, flattish. Achenia oblong, flattened, margined. Pappus none. - I'erennial herbs, with small corymbose heads. (So named because its virtues are suid to have been discovered by Achilles.)

1. A. Millefolium, I. (Common YArrow or Milfort.) Stems simple; leaves twice-pinnately parted; the divisions linear, 3-5-cleft, crowded ; corymb compound, flat-topped ; involucre oblong; reys 4-5, short, white (sometimes rose-color). - Ficlds and hills : common northwird. Aug. (Eu.)

2. A. PтÁmica, L. (Sneezewont.) Leaves simple, lance-linear, sharply serrate with nppressed teeth; corymb loose; rays 8-12, much longer than the involucre; flowers white. - Danvers, Massachusetts, \&c. ( $\Lambda \mathrm{dv}$ from Eu.)

\section{LEUCA NTHEMU M, Tourn. OX-EYE DAISY.}

Heads many-flowered, radiate; the rays numerous, fertile. Scales of the broad and flat involucre imbricated, with scarious margins. Receptacle flat or convex, naked. Disk-corollas with a flattened tube. Achenia of the disk and ray similar, striate, without pappus. - Perennial herbs, with toothed, pinnatifid, or divided leaves, and single or corymbed heads. Rays white : disk

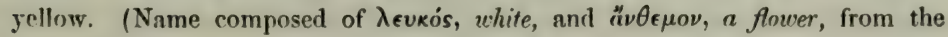
white rays.)

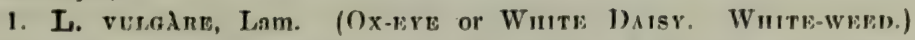
Stem ereet, nearly simple, naked above and bearing a sinele larege hend; rontleaves spatulate, petioled, the others partly clasping, all eut or pinnatifid-tonthed; scales of the involucre with rusty brown margins. (Chrysinthemum Leucanthemum, L. - Fields and mealows : too abundant. Juic, July. A pernicions

$$
\text { G } \mathrm{M}-12
$$


weed, with large and showy heads : in Connecticut is a variety with inconspicuous rays. (Nat. from Eu.)

2. I. Paktuènium, Gudron. (Fevereew.) Tall, branched, leafy; leaves twice-pinnately divided; the divisions ovate, cut; heads corymbed, rather small. (Matricaria Parthenium, L. P'yrethrum Parthenium, Smith.) - Escaped from gardens in some places. (Adv. from Eu.)

\section{5. M A tricì Ri A, 'Tourn. Wild Chamomile.}

Heads many-flowered; the rays pistillate, or wanting. Scales of the involucre imbricated, with scarious margins. Receptacle conical, at least in fruit, naked. Achenia angular, wingless. Pappus a membranaceous crown or border, or none. - Smooth and hranching herbs (ours annuals or biennials) with divided leaves und single or corymbed heads. Rays white or none: disk yellow. (Named for reputed medicinal virtues.)

1. M. Inovỏra, L. Leaves twice-pinnately divided into fine almost filiform lobes; heads lurge, naked-peduncled, and with many long rays; pappus a short crown or border. - (Wild far northward.) Ruadsides, Eastport, Maine, Prof.

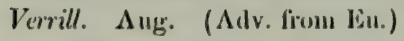

2. M. discoídea, 1)(. Low $\left(6^{\prime}-9^{\prime}\right.$ high $)$; leaves $2-3$-pinnately parted into short linear lobes; hads rayless, short-jeduncled; seales of the involucro oval, with broad margins, much shorter than the conical disk; pappus obsolete. - Banks of the Mississippi opposite St. Louis. I'robably an immigrant from Oregon, now extending eastward: also established in N. Europe. July - Sept.

\section{T A INACETUM, L. TANSY.}

IIcads many-flowered, nearly discoid, all fertile; the marginal flowers chiefly pistillate and 3-5-toothed. Scales of the involucre inbricated, dry. Reeep. tacle convex, naked. Achenia angled or ribbed, with a large flat top. Pappus a short crown. - Bitter and acrid strong-scented herbs (ours perennial), with 1-3-pinnately dissected leaves, and corymbel heads. Flowers yellow; in

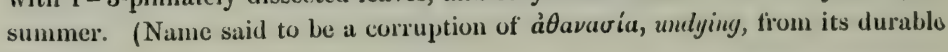
flowers.)

1. T. vulgire, L. (Common Tansy.) Stem $\left(2^{\circ}-4^{\circ}\right.$ high) smooth; leaflets and the wings of the petiole cut-toothed; corymb dense; pistillate flowers terete; pappus 5-lobed. - Var. cnfspum has the leaves more cut and crisped. - Escaped from gardens to roadsides. (Adv. from Lu.)

2. T. Huronénse, Nutt. Hairy or woolly when young, stout $\left(1^{\circ}-2^{\circ}\right.$ high); lobes of the leaves oblong; heads large ( $\frac{1}{2}-g^{\prime}$ wide) and usually few; pistillate flowers flattened, 3-5-cleft; pappus toothed. - St. John's Kiver, Maine (G. L. Goodule), shores of the upper Great Lakes, and westward.

\section{A RTEMÍSIA, L. Wormwood.}

Heals discoid, few-many-flowered; the flowers all tubular, the marginal गnes pistillate, or sometimes all similar and perfect. Scales of the involucre imbricated, with dry and scarious margins. Receptacle small and Hattish, na- 
kerl. Achenia obovoil, with a small summit and no pappus. - Ilerbs or shrubby plants, bitter and aromatic, with small heads in panicled spikes or racemes; flowering in summer. Corolla yellow or purplish. (Dedicated to Artemis, the (Greck Diana.)

\$ 1. Receptarle smooth: marginal flowers pistillate and fertile: disl-flowers perfect but sterile: root perennial, except in No. 4.

1. A. dracunculoides, Pursh. 'Tall $\left(3^{\circ}-5^{\circ}\right)$, somewhat woody at base, slightly hoary or glabrous; leaves linour and entive or the lower 3-cleft; houds small and numerous, panicled. - Sandy banks of streams, S. W. Illinois (Di. Vasey, Dr. Meud) and westwarl.

2. A. boreallis, Pallas. Imo $\left(3^{\prime}-6^{\prime}\right.$ high $)$, tufted, silky-villous or nearly smooth; lower laves 3-5-elef at the apex, or like the others 1-2-pinnately parled, the lobes lancenlate or linear; heuds fow, hemispherical, pretty large, spiked or racemed. - Shore of Lake Superior, and northward. (Eu.)

3. A. Canadénsis, Michx. Smooth, or hoary with silky down $\left(1^{\circ}-2^{\circ}\right.$ high); lower leaves twice-pinnntely divided, the upper 3-7-divided; the divisions linear, vather rigid; heads rather large, in panicled racemes. - Shore of all the Great Lakes, \&c., and northward. (Eu.)

4. A. caudata, Michx. Smonth $\left(2^{\circ}-5^{\circ}\right.$ high $)$; upper leaves pinnately, the lower 2-3-pinnately divided; the divisions threer-;orm, diverging; heads small, the racemes in a wand-like elongated panicle; root hienr ial. - Sandy soil, coast of New Hampshire to Virginia; also Michigan and Illineis.

§ 2. Receptacle smooth : flowers all fertile, a few pistillate, the others perfect. * Tall $\left(1^{\circ}-5^{\circ}\right)$ and branching perennials, whitened with fine and close-pressed wool: hends small, ovoid, crouded in lenfy panicles.

5. A. Ludoviciàna, Nutt. (Western Mugwort.) Whitened woolly throughout; leaves lancelate, the upper mostly entire, the lower cut-lobed, toothed or pinnatifid; heals larger than in the next, mostly sessile in narow panicles. - Dry banks, Lakes IIuron and Michigan, and southwestward; especially the var. GNAPIIALDDE, which has the elongated nearly entire leaves very woolly both sides.

6. A. vulgiris. L. (Сомmon Mugwort.) Teaves mostly glabrous and green alove, beneath and the branches white-woolly, all pinnatificl, with tho divisions often cut-lohed, linenr-lanceolate; heals small in open panicles. - Wasto places, near dwellings. ( $\mathrm{Adv}$. from $\mathrm{Eu}$.)

* * Less branched $\left(1^{\circ}-3^{\circ}\right)$ biennial or annual, glabrous : hends densely clustered.

7. A. biénnis, Willid. (Brenniar. Wormwoon.) Lower leaves twicepinnately parted, the upper pinnatifid; lobes linear, acute, in the lower leaves cut-toothed; heads in short axillary spikes or clusters, crowded in a narrow and glomerate leafy panicle. - Gravelly banks, Ohio to Illinois, and northwestward; rapidly extending castward by railroal to Buffalo, Philadelphia, \&c.

§ 3. Receptacle hairy; flowers all fertile, the marginal ones pistillate: heads nodding.

8. A. Absformium, I. (Сомmos Wonmwoov.) Rather shrubly (20$4^{\circ}$ high), silky-hoary ; lenves 2 - 3-pinnately parted, lohes lanceolate; heads hemispherical, panicled. - Roadsides, sparingly escaped from gardens. (Adv. from Fin.) 
9. A. frigida, Willd. Low $\left(6^{\prime}-20^{\prime}\right.$ high $)$, in tufts, slightly woody at the base, white-silky; leaves pinnately parted and 3-5-cleft, the divisions narrowlincar; heads globose, racemose. - Dry hills and rocks, I'alls of St. Anthony, Wisconsin (L. Lesquereux, T. J. IIale), Lake Superior, and northwestward.

\section{GINAPHÀIUM, L. Cudwed.}

IIeads many-flowered; the fluwers all tubular; the outer pistillate and very slender, the central perfect. Scales of the involucre dry and scarious, white or colored, imbricated in several rows. Reeptacle flat, naked. Pappus a single row of capillary rough lristles. - Woolly herbs, with sessile or decurrent leaves, and clustered or corymbed heals; fl. in summer and autumn. Corolla whitish or yellowish. (Name fiom quápadov, a lock of uool, in allusion to the floceoso down of the leaves.)

\$1. Achenia tcrete : pistillute flowers in several rows : bristles of pappus distinct.

1. G. decúrens, Ives. (Everuasting.) Stout, erect $\left(2^{\circ}\right.$ high) perennial, branched at the top, clammy-pubeseent, white-woolly on the branches, bearing numerous heals in dense corymbed clusters; leaves linear-lanceolate, purlly clesping, decurrent; seales of the (yellowish-ivlite) involuce oval, acutish. Ilillsiles, New Jersey and l'enn. to Maine, Michigan, and northward.

2. G. polycéphalum, Michx. (Common Everlastine.) Lirect, woolly annual (1'-2' high). frangrant ; laves lanceolate, tapering at the buse, with undulate margins, not decurrent, smoothish above; heads clustered at the summit of the panicled-corymbose branches, ovate-conical before expansion, then obovate; scales of the (whitish) involucre ovate and oblong, rather obtuse; perfect flowers few. - Old ficlds and woods: common.

3. G. uliginòsum, L. (Low Cudvesn.) Diffusily branched, woolly annual (3'-6' high); leaves lanceolate or linear, not decurrent; heads (smull) in terminal sessile capitute clasters subtended by leaves. - Low grounds by the roadside; common castward and northward: perhaps introduced. (Eu.)

§ 2. GAMOCH ANIA, Weddell. Achenia and flowers as $\$ 1$ : bristles of the pappus united at the very base into a ring, so fulling off all togaher.

4. G. purpùreum, L. (Punplish Cunweed.) Anual, simple or branched fiom the base, ascending $\left(6^{\prime}-20^{\prime}\right.$ high), woolly ; leaves oblong-spatulate, mostly obtuse, not decurrent, green above, very white with close wool underncath; herds in sessile chusters in the axils of the upper leaves, and spiked at the wand-like summit of the stem; scales of the involucre tawny, the inner often marked with purple. - Sandy ur gravelly soil, coast of Maine to Virginia, and southward.

§ 3. HOMALOTHECA, 1)C. Achenia fluttened: pistillute flowers in a single maryinal row: lristles of the pappus distinct and fulling separately, as in $\$ 1$.

5. G. supinum, Villars. (Mountain Cunweso.) Dwarf and tufted peremial (2' high); leaves linear, woolly; heads solitary or few and spiked on the slender simple flowering stems; scales of the involucre brown, laneeolate, acute. - Alpine summil of Mount Washington, New Hampshire : very rare. (Eu.) 


\section{A N T EN N A R I A, Gartn. EverLasting.}

IIcads many-flowered, dinccions or nearly so ; the flowers all tubular: pistilInte corollas very slender. Seales of the involucre dry and scarious, white or colored, imbricated. Receptacle convex or flat, not chaffy. Pappus a singlo row of bristles, in the fertile flowers capillary, and in the sterile thickened and club-shaped or barbellate at the summit. - Perennial white-woolly herbs, with entire leaves and corymbed (rarely single) heads. Corolla yellowish. (Name from the resemblance of the sterile pappus to the antennce of certain insects.)

1. A. margaritàcea, R. Brown. (Pennty Everuasting. Stem erect $\left(1^{\circ}-2^{\circ}\right.$ high $)$, corymbose at the summit, with many heads, lenfy ; leaves linearlanceolate, taper-pointed, sessile ; fertile heads often with a few imperfect staminate flowers in the centre; scales of the pearly-white involucre obtuse or rounded. - Dry hills and woods; common northward. $\Lambda$ ug.

2. A. plantaginifolia, Ilook. (Plantain-manved Evertastina.) Spreading ly offsets and nunners, low $\left(4^{\prime}-10^{\prime}\right.$ high); leaves silky-woolly when young, at length green above and hoary beneath; those of the simple and scapelike flowering stems small, lanccolate, appressed; the radical obovate or ovalsputulate, petioled, ample, 3-nerved ; heads in a small crowded corymb ; seales of the (mostly white) involucre obtuse in the sterile, and acutish and narrower in the fertile plant. - Var. Monocḱpun LA is an occusional state, with a single larger head. - Sterile knolls and banks : common. March-May.

\section{0. FIL À G O, Tourn. Cotton-Rose.}

IIeads many-flowered; the flowers all tubular, the central ones perfect, but often infertile; the others pistillate, very slender and thread-form. Scales of the involuere few and woolly. Receptacle elongated or top-shaped, naked at the summit, but chaffy at the margins or toward the base; the chaff resembling the proper involucral seales, each covering a single pistillate flower. - Pappus of the eentral flowers capillary, of the outer ones mostly none. $-\Lambda$ nnual, low, branching woolly herbs, with entire leaves, and small heads in capitate clusters. (Name from flum, a thread, in allusion to the cottony hairs of these plants.)

1. F. Germánios, L. (Henba Impia.) Stem erect, short, elothed with lanccolate and upright crowded leaves, producing a capitate cluster of woolly heads, from which rise one or more branches, each terminated by a similar head, and so on:- hence the common name applied to it by the old botanists, as if the offspring were undutifully exalting themselves above the parent. Dry fields, New York to Virginia. July-Oct. (Nat. from Eu.)

\section{ERECHTHİTES, Raf. Fineweed.}

Ileads many-flowered; the flowers all tubular and fertile; the marginal pis. tillate, with a slender corolla. Scales of the cylindrical involucre in a single row, linear, acute, with a few small bractlets at the base. Receptacle naked. Achenia oblong, tapering at the end. Pappus copious, of very fine and white soft hairs. - Frect and coarse annuals, of rank sincll, with alternate simple leaves, and paniculate-corymbed heads of whitish flowers. ('The ancient name of some species of Groundsel, probably called after Erechthens.) 
1. F. hieracifolia, Raf. (FInEweEn.) Often hairy; stem grooved $\left(1^{\circ}-5^{\circ}\right.$ high $)$; leaves lanceolate or oblong, acute, cut-toothed, sessile; the upper with an auricled clasping base. (Senècio hieracifolius, L.) - Moist woods: common, especially northward, and in recent clearings, where the ground has been burned over; whence the popular name. July-Sept.

\section{CA CÀ li A, L. Indian p'lantain.}

Heads 5-many-flowered; the flowers all tubular and perfect. Scales of tho involucre in a single row, with a few bractlets at the base. Receptacle naked. Corolla deeply 5-cleft. Achenia oblong, smooth. Pappus of numerous capillary bristles. - Smooth and tall peremuial herbs, with alternate often petioled leaves, and rather large heals, in flat corymbs. Flowers white or whitish. (An ancient name, of uncertain meaning.)

* Involucie 25-30-fluwered, with severul bracts at its base: receptacle flat.

1. J. suavèolens, L. Stem grooved $\left(3^{\circ}-5^{\circ}\right.$ high $)$; laves triangularlanceolate, halbe; ishaped, pointed, serrate, those of the stem on winged petioles. - Rich woods, Connecticut to Wisconsin and Kentucky : rare. Sipt.

* * Involucre 5-laweal and 5-jlowercel, its bracts minute or none: receplache beariny a more or less evident sculc-lik" pointal appendaye in the centre.

2. C. renifórmis, Muhl. (Great Indian l'lantan.) Stem (4-9o

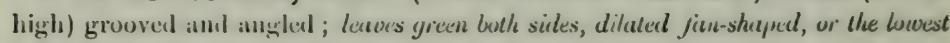
kidncy-jorm $\left(1^{\circ}-2^{\circ}\right.$ hroid), reprend-lcothed and angled, palumately veined, petioled; the teeth pointed; corymbs large. - Rich damp woods, New Jersey to Illinois, and southward along the mountains. Aug.

3. C. atriplicifólia, L. (Pale Induan P.) Stem terete $\left(3^{\circ}-6^{\circ}\right.$ highi;, and with the pulinutely veined and angulute-lobed leaves glaucous; lower leaves triangular-kidney-form or slightly heart-shaped; the upper rhomboid or wedge-form, toothed. - Rich woodlands, IV. New York to Wisconsin, and southward Aug.

4. C. tuberósa, Nutt. (Tuberous Indian P.) Stem angled and grooved $\left(2^{\circ}-6^{\circ}\right.$ high $)$, from a thick or tuberous root; lcaves green both sides, thick, strongly 5-7-nerved; the lower lance-ovate or oval, nearly entire, tapering into long petioles; the upper on short margined petioles, sometimes toother at the apex. - Wet prairies, de., Ohio to Wisconsin, and southward. June.

\section{SE NĖio, L. Groundsel.}

Heads many-flowered; the flowers all perfect and tubular, or mostly with radiate marginal ones; the rays pistillate. Scales of the involucre in a single row, or with a few bractlets at the base. Receptacle flat, naked. Pappus of numerous very soft and slemler capillary bristles. - Herlss, in the United States, with alternate leaves and solitary or corymbed heads. Flowers chiefly yellow. (Name from senex, an old man, alluding to the hoary hairs which cover many species, or to the white hairs of the pappus.)

* Root annnal or in No. 3 biennial: heads several or many in a corymb: herluge glabrous or saon becoming so. 
1. S. vuradris, L. (Common Groundser.) Low, corymbosely branched; leaves pinnatifid and toothed, clasping; rays none. - Waste grounds. July Sept. ( $\Lambda \mathrm{dv}$. from Eu.)

2. S. lobatus, lers. (Butren-weed.) Rather tall; leaves somewhat fleshy, mostly lyrute or pinnate, the divisions or leaflets crenate or cut-lobed, variable; hends small in a naked corymb; rays about 12, conspicuous. - Low banks of the Ohio and Mississippi, Illinois and southward. April-July.

3. S. palústris, Hook. Biennial, loosely woolly when young; stem stout, $6^{\prime}-3^{\circ}$ high; leaves oblong-lanceolate, irregularly toothed or laciniate, the upper with a heart-shaped clasping base; rays 20 or more, short, pale yellow ; pappus copious und becoming very long. - Wet ground, N. W. Wisconsin (T.J. Hule) aud northward. June. (Eu.)

* * Root perennial: heads small or middle-sized, in a naked corymb.

4. S. aureus, L. (Golden Ragwort. Squaw-weed.) Smooth, or floccose-woolly when young $\left(10^{\prime}-30^{\prime}\right.$ high $)$; root-leaves simple and rounded, the larger ones mostly heart-shaped, crenate-toothel, long-petioled; the lower stem-leaves lyrate; upper ones lanceolate, cut-pinnatifid, sessile or partly clasping; corymb umbel-like; rays 8-12. - Varies greatly, the leading forms being, - Var. I. onovitus, with the root-leaves round-obovate (growing in drier places). Var. 2. BALSAm IT E, with root-leaves oblong, spatulate, or lanceolate, sometimes cut-toothed, tapering into the petiole. Rocky places. - Var. 3. LANCEOLATus, Oakes, with the leaves all lanceolate-oblong, thin, sharply and unequally toothed, either wedge-shaped or somewhat heart-shaped at the basc, the upper merely pinnatifid-cut towards the base. (Cedar swamps, Vermont, Robbins.) - Common cverywhere: the primary form in swamps. May, June.

5. S. Fllióttii, Torr. \& Gr. Soon smooth, stem simple $\left(1^{\circ}\right.$ high $)$, often nearly leafless, bearing a small corymb; ront-lenves thickish, nhovate or roundish, narrowed into a short and winged petiole, or sessile, crenate-toothed, sometimes $1 y$ rate; stem-leaves small, cut-pinnatifid. - Rich soil, Virginia and southward along the inountains. May.

6. S. tomentósus, Michx. (WoorLy RAGwort.) Clothed with scarcely deciduous hoary wool $\left(1^{\circ}-2^{\circ}\right.$ high) ; root-lenves oblong, obtuse, crenate toothed, on slender petioles; the upper sessile; corymb flat-topped ; rays 12-15. - Mountains of Pennsylvania (Pursh), Maryland, and southward. May. - S. CdNus, Hook., which too closely resembles smaller forms of this, probably occurs within the northern borders of Wisconsin.

* * Root perennial: heads large and mostly solitary.

7. S. Pseudo-Árnica, Less. Looscly white.woolly, sometimes becoming glabrous; stem stout, $6^{\prime}-12^{\prime}$ high, leafy to the top; leaves oblong, repand, tapering into a narrow petiole-like base; heads 1-4, over an inch in diameter; rays 20 or more, large. - Grand Manan Island off Maine (Prof. Verrill) and northward.

\section{4. Á R N CA, I. ARnica.}

Heads many-flowerel, radiate; the rays pistillate. Seales of the bell-shaped involucre lanceolate, equal, somewhat in 2 rows. Receptacle flat, fimbrillate. 
Achenia slender or spindle-shaped. Pappus a single row of rather rigid and strongly roughened-denticulate bristles. - Perennial herbs, chiefly of mountains and cold northern regions, with simple stems, hearing single or corymbed largo heads and opposite leaves. Flowers yellow. (Name thought to be a corruption of Ptarmica.)

1. A. móllis, Hook. Soft-hairy; stem kafy $\left(1^{\circ}-2^{\circ}\right.$ high $)$, bearing 1 to 5 heads; leaves thin, eciny, smoothish when old, toothed; the upper ovate-lancedate, closely sessile; the lower narrower, tapering into a margined petiole; scales of the involucre pointed; pappus almost plumose. - Alpine rivulets, mountains of New Ilampshire and N. New York, shores of Lake Superior, und northwestward. July.

2. A. nudicaùlis, Ell. Hairy and rather glandular $\left(1^{\circ}-3^{\circ}\right.$ high $)$; leceses thickish, 3-5-nerved, ovate or oblong, all sessile, mostly entire and near the root, those of the nuked stem small and only one or two pairs; heads several, corymbed, showy. - Damp pine barrens, S. Penn. and southward. A pril, May.

\section{Cent a U R ì A, L. Star-Thistle.}

Heads many-flowered; the flowers all tubular, the marginal often much larger and as it were radiate, sterilc. Receptacle bristly. Iuvolucre imbricated, the scales margined or appendaged. Achenia compressed. Pappus wanting, or of a few bristles. - Herbs with alternate leaves and single heads. (Named fiom the Centuur, (hiron.)

1. C. Cỳnus, L. (Bluknotrle.) Scales of the globular involucre fringemargined; false rays large; pappus very short; laves linear, entive, or toothed at the base; root annual. - Roadsides, escaped from gardens. July. - Flowers blue, varying to purplish or white. (Adv. from Eu.)

2. C. Nigis, L. (KNAPwEed.) Scales of the globular involucre appendaged, and with a stiff black fringe; reys wanting; pappus very short; leates lanceolate, or the lower lyrate-angled, rough; root perenuial. - Waste plaees, E. New England. Aug. - Flowers purple. (Adv. from Eu.)

3. C. Calcfirapa, L. (Stan Tuistre.) Stem diffusely much branched; leaves pinnately lobed or spinulose-toothed; heads sessile, the middle scules of the. ovoid involucre spriny; pappus none; flowers purple; root annual. - Norfulk, Virginia, and Philadelphia. (Adv. from Eu.)

\section{8. CNICUS, Vaill. Buessed Tumste.}

Heads many-flowereel; the ray-flowers tubular and sterile, shorter than the rest, which are all tubular and perfect. Scales of the ovoid involucre coriaceons, appressed, extended into a long and rigid pinnately spinose appendage. Receptacle clothed with capillary bristles. Achenia terete, short, strongly striate, crowned with 10 short and horny teeth, and bearing a pappus of 10 elongated rigid bristles, and 10 short bristles alternate with the last in an inner row. $-A n$ annual smoothish herb, with clasping scarcely pinnatitid-cut leaves and largo bracted heads. Flowers yellow. (Name from $\kappa \nu i \zeta \omega$, to prick.)

1. C. Benenferes, L. - Rivadsides, southward: rare, scarecly naturalized (Adv. from Eu.) 


\section{CIRSIU M, Tourn. Common or Plumed Tinstle.}

Heads many-flowered; the flowers all tubular, perfect and similar, or rarely imperfectly dicecious. Scales of the ovoid or splerical involucre imbricated in many rows, tipped with a point or prickle. Receptacle thickly clothed with soft bristles or hairs. Achenia oblong, flattish, not ribbed. Pappus of numerous bristles united into a ring at the base, plumose to the middle, deciduous. - Herbs, with sessile alternate leaves, often pinnatifid, and prickly. IIeads large, terminal. Flowers reddish-purple, occasionally yellowish, white, or cream-color; in summer. (Name from kipoos, a swelled vein, for which the Thistle was a reputed remedy.)

* Scules of the involucre all tipped with spreading prickles: root biennial.

1. C. eanceontum, Scop. (Соmmon Timstie.) Leaves decurrent on the stem, forming prickly lobed wings, pinnatifid, rough and bristly above, woolly with deciluous webby hairs beneath, prickly ; flowers purple. - Pastures and roadsides, everywhere, at the North. (Nat. from Eu.)

* Scales of the involucre appressed; the inner ones not prickly: filaments hairy.

+ Leaves white-woolly beneuth, and sometimes also above: outer scales of the involucro successively shorler, and tipped with short prickles.

2. C. Pitcheri, Torr. \& Gr. White-woolly throughout, perennial, low ; stem stout, very leafy ; leaves all pimately panted into rigid narrowly linear and elonyated divisions, with revolute margins; flowers cream-color. - Sandy shores of Lakes Michigan, Huron, and Superior.

3. C. undulàtum, Spreng. White-uoolly thronghout. biennial, low nnd stout, lenfy; lemes lancrolule-oblong, partly claspingr, undulate-pimmatifiel, with prickly lobes; Howers reddish-purple. - Islands of L. Huron and Michigan; thence westwatd.

4. C. díscolor, Spreng. Biennial; stem grooved, hairy, branched, tall, lenfy; leaves all dreply finuatifid, sparingly hairy and green above, whitened with chose wool beneuth; the diverging lobes 2-3-cleft, linear-lanceolate, prickly-pointel ; flowers pale purple, rarely white. - Meadows and copses.

5. C. altíssimum, Spreng. Stem downy, branching $\left(3^{\circ}-10^{\circ}\right.$ high $)$, lenfy quile to the herds: Iruves roughish-hairy shove, whitened with close wool beneath, oblong-lanceolate simuate-toothad, undulute-pinnatifid, or undivided, the lobes or teeth prickly ; those from the base pinnatifid ; and their lobes short, oblong or triangulur; flowers chiefly purple. - Fields and copses, Penn. to Illinois and sonthward.

6. C. Virginianum, Michx. Stem woolly, slender, simple or sparingly branched $\left(1^{\circ}-3^{\circ}\right.$ high) ; the branches or long peduncles naked: leaves lanrcolate, green ahove, whitened with close wool beneath, ciliate with prickly bristles, en. tire or sparingly sinuate-lubed, sometimes the lower deeply simuate-pinnatifid ; outes scales of the involucre scarcely prickly; heads small; flowers purjle. - Woods and plains, Virginia, Ohio, and sonthward.

Var. filipéndulum. Stem stouter, more leafy, corymbosely brancheir above; the heads on shorter peduncles; leaves pinnatifid; roots tuberous, en. larged below. (C. filipendulum, Engelm.)-Prairies of S. Illinois and south. westward. 
+ + Leaves green both sides, or only with loose colweldy hairs underneath: scales of the involucre scarcdy prickly-pointed: heads larye.

7. C. mùticum, Michx. (Sivasr 'Tinstıe.) Sten tall $\left(3^{\circ}-8^{\circ}\right.$ high), angled, smoothish, panicled at the summit, the branches sparingly leafy and bearing single or few rather large nakal hoads; leaces somewhat hairy above, whitened with lonse wehly hairs beneath when joung, doeply pinnatifid, the divisions lancelate, acute, cut-lobed, prickly-pointed; scales of the webby and glutinous involucre closely appressed, pointless or barely mucronate; flowers purple ; root perennial. - Swamps and low woods : common.

8. C. pùmilum, Spreng. (Pasture 'Tuistle.) Stem low and stuut $\left(1^{\circ}-3^{\circ}\right.$ high), hairy, bearing $1-3$ very large haeds ( $1_{2}^{\prime}$ broad), which are somewhat leafy-bracted at the base; leaves green, lanceolate-oblong, partly clasping, somewhat hairy, pimatifil, with short and cut very prickly-margined lobes; outer scales of the involucre prickly-pointed, the inner very slender; flowers purple or rarely white (fragrant, 2' long); root bienuial. - Dry fields, Maine to Penu., near the coast, Illinois and westward : common.

9. C. horridulum, Michx. (Yellow 'Thiste.) Stem stout $\left(1^{\circ}-4^{\circ}\right.$ high), webl,y-haired when young; leaves partly clasping, green, soon smooth, lanceolate, pinnetifid, the short loothed and cut lobss tery sping with yellowish

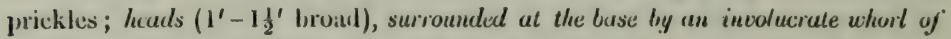
laf-like and very prichly bracts, which equal or exceed the narrow and unarmed scules of the involucre; flowers pale yellow or purple. - Sandy fields, Massachusetts to Virginia, und southward, near the coast.

* * Outer scales of the appressed involucre bardy prickly-pointed: filuments nearly smooth : heads imperfoctly diacions, small and numerous.

10. C. anvénse, Scop. (Canaida Tiustel.) Perenuial, the roots extensively creeping; leaves oblong or lanceolate, smooth, or slightly woolly bencath, sinuate-pinnatifid, prickly-maryined; flowers rose-purple. - Cultivated fields, pastures, and roadsides : common at the North; a most troublesome weed, extremely difficult to eradicate. (Nat. from Eu.)

\section{C Á R D U S Tourn. Puumeless Thistle.}

Bristles of the pappus naked (not plumose), merely rough or denticulate. Otherwise as in Cirsium. (The aneient Latin name.)

1. C. nùtans, I. (Musk 'Thistle.) Biennial ; leaves decurrent, sinuate, spiny; heads solitary, drooping; flowers purple. - Ficlds near IIarrislurg, Peunsylvania, Prof. Porter. (Adv. from Eut.)

\section{O N O PÓRDON, Vaill. Cotton or Scotcu Tustle.}

Heads and flowers nearly as in Cirsium. Scales of the involucre coriaceous. tipped with a lanceolate prickly appendage. Receptacle deeply honeycombed. Achenia 4-angled, wrinkled trausversely. Bristles of the pappus numerous, slender, not plumose, united at the hase into a horny ring. - Coarse, branching annuals, or biennials, with the stens winged by the decurrent base of the lobed and touthed somewhat prickly laves. Heads large: flowers purple. ('The ancient Greek name of the plant.) 
1. O. AofNTriUM, L. Stem $\left(2^{\circ}-4^{\circ}\right.$ high) and leaves cotton-woolly; scalea linear-awl-shaped. - Roadsides and waste places: rather rare. July-Sept. (Adv. from Eu.)

\section{0. LÁ P P A, Tourn. Bundock.}

IIeads many-flowered ; the flowers all perfect and similar. In rolucre globular; the imbricated scales coriaceous and appressed at the base, tipped with an abrupt and spreading awl-shaped hook-pointed appendage. Receptacle bristly. Achenia ohlong, flattened, wrinkled transversely. Pappus short, of numerous rongh bristles, not united at the base, deciduous. - Coarse biennial weed, with large unarmed and petioled leaves, and small solitary or clustered heads: flowers purple, rarely white. (Name from $\lambda \alpha \beta \epsilon i v$, to lay hold, the involucre forming a hooked bur which holds tenaciously to the dress, or the fleece of animals.)

1. L. officindus, Allioni. - Waste places and around dwellings, in manured soil. - The var. MA.Jon (CоммON Bunbock) has the involucre smoothish; leaves loosely whitish-cottony beneath or becoming smooth, the upper ovate, lower heart-shaped. - Var. томentosa has the involucre cottony, and is rare. - Var. Minor has smaller heads with smooth involucre, and smaller smoothish leaves, often tapering at the base; occasionally cut-toothed or laciniate-lobed. (Uxbridge, Mass., Dr. Robbins.) July-Oct. (Nat. from Eu.)

\section{Suborder II. higullelòr a. (Cichoracese.)}

\section{L Á M P A N A, Tourn. Niprle-wort.}

Heads 8-12-flowered. Scales of the cylindrical involucre 8, erect, in one row. Receptacle naked. Achenia oblong. Pappus none. - Slender branching annuals, with nngled or toothed leaves, and loosely panicled small hends: flowers yellow. ('The $\Lambda a \mu \psi(i ́ v \eta$ of Dioscorides was evidently a wild Mustard.)

1. L. соммùnıs, L. Nearly smooth; lower leaves ovate, sometimes lyreshaped. - Roadsides, near Boston, Buffalo, \&c. (Adv. from Eu.)

\section{CI CH Ò R U M, Tourn. Sreconx or Cichonx.}

Heads several-flowered. Involucre double; the outer of 5 short spreading scales, the inner of $8-10$ scales. Achenia striate. Pappus of numerous small chaffy scales, forming a short crown. - Branching perennials, with deep roots; the sessile heads 2 or 3 together, axillary and terminal. Flowers bright blue or varying to purple, showy. (Altered from the Arabian name of the plant.)

1. C. Intrius, L. Stem-leares oblong or lanccolate, partly clasping, the lowest runcinate, those of the rigid flowering branches minute. - Roadsides: common near the coast, especially in E. Mass. July - Oct. (Nat. from Eu.)

\section{KRIGIA, Schreher. DWARF DANIELon.}

Heads 15-20-flowered. Scales of the involucre several, in alout 2 rows. Achevia top-shaped, many-striate or angled. Pappus double; the outer of 5 
broad and rounded chaffy scales; the inner of as many alternate slender bristles. - Small anmuals or biennials, branched from the base; the leaves chicfly radical, lyrate or toothed; the small heads terminating the naked scapes or branches. Flowers yellow. (Named after D. Krieg, an early German botanical collector in this comntry.)

1. K. Virgínica, Willd. Stems or seapes several $\left(1^{\prime}-10^{\prime}\right.$ high $)$; earlier leaves roundish and entire, the others narrower and often pinnatifid. - Var. Dicnótoss is a branched and leafy summer state. - New Eugland to Illinois and southward. April- $\Lambda$ ug.

\section{CÝ NTHIA, Don. Crntira.}

IIeads many-flowered. Scales of the involuere several, somewhat in 2 rows. Achenia short, striate. P'appus double; the outer of mumerous very suall chatfy bristles; the inner of nunerous capillary elongated bristles. - Low perennial herbs, nearly smooth and glaucous, with scattered or radical leaves; the scapes or naked peduncles (often bristly at the apex) bearing rather showy single heads. Flowers yellow. (Perhaps named after Mount C'ynthus.)

1. C. Virgínica, Don. liouts filuous; stem-luwes 1-2, oblong or linceolate-spatulate, clasping, mostly entire; the ralical ones on short winged petioles, often toothed, rarely pinnatifid; peduncles 2-5. - Moist banks, New York to Michigan aud southward. June. - Stem $1^{\circ}$ high, or more.

2. C. Dándelion, DC. Scapes leafless, from a tuberous root $\left(6^{\prime}-15^{\prime}\right.$ high $)$; leaves varying from spatulate-oblong to linear-lanceolate, entire or few-lobed. Moist ground, Maryland to Kícntucky and southward. March-July.

\section{LEONTODON, I., Juss. Hiwíit. Fill Dindelion.}

Heads many-flowered. Involucre scarcely imbricated, but with several bractlets at the base. Achenia spindle-shaped, striate, all alike. Pappus persistent, composed of plumose bristles which are enlarged and flattened towards the base. - Low and stemless peremials, with toothed or pimnatitid root-leaves, and seapes boatring one or more yellow lieads. (Name fiom $\lambda e^{\prime} \omega \nu$, a hon, and ỏooús, a looth, in allusion to the toothed leaves.) - The following belongs to the subgenus Opokínia, with a tawny pappus of a single row of equal bristles.

1. L. autuanale, I. (Fall Dandelion.) Leaves laciniate-toothed or pinnatifid; scape branched; peeluncles thickened at the summit and furnished with small sealy bracts. - Meadows and roadsides: conmon in E. New England. July - Oct. (Nat. from Eu.)

\section{TRÓXIMON, Nutt. Troximon.}

Head many-flowered. Scales of the bell-shitped involucre ovate or lanceolate, pointed, loosely imbricated in 2 or 3 rows. Achenia smooth, 10-ribbed, not beaked. Pappus longer than the achenium, white, of copious and unequal rigid capillary lisistes, some of the larger gradually thickened towvirds the batse. - Perennial herbs, with elongated linear tufted root-leaves, and a simple naked neape. Heads solitury, large : flowers yellow. (Name fiom $\tau \rho \omega \dot{\xi} о \mu a \iota$, to eat, first applied to some plant with an edible root, like Salsify.) 
1. T. cuspidatum, Pursh. Lenves Innceolnte, elongated, tapcring to a sharp point, woolly on the margins; seales of the involucre lanceolate, sharppointed. - Prairies, Wisconsin, N. Illinois, and westward. $\Lambda$ pril, May.

\section{7. H I ER À C I U M, Tourn. HヘwKwend.}

IIeads 12-many-flowered. Involucre more or less imbricated. Achenia short, oblong or columnar, striatc, not beaked. Pappus a single row of tawny and fragile capillary rough bristles. - l'erennial herbs, with entire or toothed leaves, and single or panicled heads of mostly yellow flowers; in summer ani carly autumn. (Name from iépa $\xi$, a hauk.)

* IIeads large and broad: involucre imbricated: achenia tapering towards the buse.

1. H. Canadénse, Michx. (Canada Hawkweed.) Stems sim!li, leafy, corymbed at the summit $\left(1^{\circ}-3^{\circ}\right.$ high $)$; leaves sessile, lanceolate or ovato oblong, neute, remotely and very coarsely toothed, somewhat hairy, the uppermost slightly clasping. - Dry woods, northward.

* Hcads small: involucre cylindrical, scarcely imbricated.

2. H. scàbrum, Michx. (Rovgir H.) Stem rather stout $\left(1^{\circ}-3^{\circ}\right.$ high), leafy, rough-hairy; the stiff panicle at first racemose, at length rather corymbose; the thickish peduncles and the hoary 40-50-flowered involucre densely clothed with dark glandular bristles; achenic columnar, not tapering at the summit; leaves obovate or oval, nearly entire, hairy. - Dry open woods ; common.

3. H. longípilum, Torr. (Long-Bennded H.) Stem wand-like, simple, stout $\left(2^{\circ}-3^{\circ}\right.$ high $)$, very leafy towards the base, naked above, and bcaring a small racemed panicle ; the lower portion and both sides of the oblong-lanceolate or spatulate entire leaves thickly clothed with very long and upright bristles (often 1'long); peduncles and 20-30-flowered involucre glandular-bristly; achenia spindle-shaped, narrowed at the apex. - Prairies, Michigan to Wisconsin and southwestward. - IIeads intermediate between the last and the next.

4. H. Gronóvii, L. (Hиiry H.) Stem wand-like, mostly simple, lenfi) and very hairy below, naked above and forming a long and narrow panicle; leaves oblong or obovate, nearly entire, hairy; the slender peduncles and the 20-30. flowered involucre sparingly glandular-bristly; achenia spindle-shaped, with a very taper summit. - Dry sterile soil : common, especially southward. - Varica from $1^{\circ}-4^{\circ}$ high. The small heads and almost beaked fruit distinguish the largest forms from No. 2, and small naked-stemmed states from the next.

5. H. venosum, L. (RAtrlesnake-ween.) Stem or scrpe $\left(1^{\circ}-2^{\mathrm{C}}\right.$ high) naked or with a single leaf, smonth and slender, forking above into a spreadin? loose corymb ; root-leaves obovate or oblong, nearly entire, scarcely petioled, thin and pale, purplish and glaucous underneath (often hairy along the midrib), marked above with purple veins ; peduncles very slender; involucre 20-flowered; achenia linear, not tapering upwards. - Var. subCAULÉscens has the stem more or less leafy next the base. - Dry plains and pine woods : common.

6. H. paniculatum, L. (Panicued.II.) Stem slender, lenfy. diffisely branched, hairy below $\left(2^{\circ}-3^{\circ}\right.$ high) ; leaves lanccolate, acute at both ends, slightly toothed, smooth; heads in a loose panicle (very small), on slender and 
diverging peduncles, 12-20-flowered; achenia short, not tapering at the summit. -Open woods : rather common.

\section{N Á B A I US, Cass. Rattlesnake-Root.}

Heads few - many-flowered. Involucre cylindrical, of 5 to 14 linear seales in a single row, and a fiew small bractlets at the bise. Achenia short, linear-oblong, striate or grooved, not contracted at the apex. Pappus of copious strawcolor or brownish and rough capillary bristles.- Perennial lects, with upright leafy stems arising from spindle-shaped (extremely bitter) tubers, very variablo leaves, and racemose-panicled mostly nodding heads. Flowers greenish-white or yellowish, often tinged with purple; in late summer and autumn. (Name probably firon $\nu$ á $\beta \lambda a$, “ harp, in allusion to the lyrute leaves which these plants sometimes present.) Species of Prenánthes, $L$.

\section{* Involucre smooth or nearly so, 5-20-flowered.}

1. N. álbus, Hook. (White Lettuce. Ratrfesnake-Root.) Smooth and glaucous $\left(2^{\circ}-4^{\circ}\right.$ high $)$; stem corymbose-panicled at the summit : leaves angulate or triaugular-halloerd-form, sinuate-toothed, or 3-5-cleft; the uppermost oblong and undivided; involucre (purplish) of about 8 scals, 8-12-flowered; pappus deep cimemon-color. - Var. Senpentriria is a form with deeply divided leaves, their margins often rough-eiliate. - Borders of woods, in rich soil : common, especially northward. - Stouter and more corymbed than the next, with thickish leaves and often purplish hranches. Heals $6^{\prime \prime}$ long.

2. N. altíssimus, Hook. ('Trac W.) Smooth; stem tall and slender $\left(3^{\circ}-6^{\circ}\right.$ high $)$; the heads in small axillary and terninal loose clusters forming a long and wand-like leafy panicle: leaves membranaceous, all petioled, ovate, heart-shaped, or triangular, and inerely toothed or cleft, with naked or winged petioles, or frequently 3-5-parted, with the divisions entire or again cleft; involucre slender (greenish), of 5 scales, 5-6-flowered; pappus dirty white, or pale straw-color. - Rich moist woods : common northward.

3. N. Fràseri, DC. (Lion's-foot. Gall-of-tin-earth.) Nearly sinooth; slem corymbose-panicled at the summit $\left(1^{\circ}-4^{\circ}\right.$ high $)$; leaves mostly deltoid, roughish ; the lower variously $3-7$-lobed, on margined petioles; the upper oblong-lanceolate, mostly undivided, nearly sessile; involucie (greenish or purplish, sometimes slightly bristly) of about 8 scales, 8-12-flowered: pappus dull straw-color. - Varies greatly in foliage: the var. INTEGRIFólıus has the thickish leaves all undivided and merely toothed. - Dry sandy or sterile suil, S. New lingland to Virginia and southward.

4. N. nàuus, 1)C. Smooth; stem low and simple $\left(5^{\prime}-10^{\prime}\right.$ high); the heads in axillary clusters forming a narrow racemed panicle; leaves triangularhalberd-shaped and very variously loled or eleft, on slender petioles; involucre (livid) 10-13-floweral, of abont 8 proper scules and several very short bract-like ones, which are tricungular-ovate and appressed; pappus straw-color. - Alpine summits, White Mountains of New Hunpshire, and Adirondacks, N. New York.

5. N. Boóttii, DC. Stem simple, dwaif $\left(5^{\prime}-6^{\prime} \cdot\right.$ high $)$, pubescent at the summit; the heads in an almost simple raceme; lowest leaves halberd-shaped or heart-shaped, the middle oblong, the upper lanceolato, nearly entire, taper- 
ing into a margined petiole; involucre (livid) 10-18-flowered, of $10-15$ very obtuse proper scules, and several linerer and loose exterior ones nearly half the length of the former; pappus straw-color. - Higher upine summits of the mountains of Maine, New Ilampshire, and N. New York.

6. N. virgàtus, DC. (Shender Rattlesnake-root.) Smooth, slightly glancous; strm simple $\left(2^{\circ}-4^{\circ}\right.$ high), prolonged into a nuked and slender spiked raceme $\left(1 \frac{1}{2}{ }^{\circ}-2^{\circ} \mathrm{long}\right)$; heads clustered and mostly unilateral; leaves lanceolate, acute, closely sessile, the upper reduced to bracts, the lower toothed or pinnatifid ; imolucre (purplish) of about 8 scules, 8-12-flowered; pappus straw-color. Sandy pine barrens, New Jersey to Virginia, and southward.

* Involucre 12-40-flowered, hairy, as well "is the peduncles.

7. N. racemosus, Hook. Stem wand-like, simple $\left(2^{\circ}-5^{\circ}\right.$ high $)$, smooth, as well as the oval or oblong-lanceolate denticulate leaves; the lower tapering into winged petioles (rarely cut-pinnntifid,) the upper partly clasping; heads in clusters crouded in a long and narrow interruptedly spiked panicle; involucre about 12-fowered; pappus straw-color. - Plains, Ohio to Illinois and northward. Also IIackensack marshes, New Jersey. - Flowers flesh-color.

8. N. ásper, Torr. \& Gr. Stem wand-like, simple $\left(2^{\circ}-4^{\circ}\right.$ high $)$, roughpubescent, as well as the oval-oblong or broadly lanceolate toothed leaves; heads (mostly erect) in small clusters disposed in a long and narrow compound raceme: involucre 12-14-flowered; pappus straw-color. - Dry prairies and barrens, Ohio to Illinois, and southward. - Flowers larger than No. 7, cream-color.

9. N. crepidineus, DC. Somewhat smooth; stem stout $\left(5^{\circ}-8^{\circ}\right.$ high), bearing numerons nodding heads in loose clusters on the corymbose-punicled branches; lenves large $(6-12$ long), broadly triangular-onate or halberd-forn, strongly toothed, contracted into winger petioles; involncre 20-40-flowered; pappus brown. - Rich soil, Ohio to Illinois and southward. - Involucre blackish ; flowers cream-color.

\section{LYGOD自S M I A, Don. Lxgonesmia.}

Heads and flowers $(5-10)$ nearly as in Nabalus; the cylindrieal involucre more elongated, and the achenia long and slender, tapering at the summit. Pappus whitish. - Smooth, often glaucous, low perennials, with single erect he:uds of rose-purple flowers terminating almost leafless or rush-like stems or branches. (Name composed of $\lambda \dot{v} \gamma o s$, a twig for wickerwork, and $\delta \in \sigma \mu o ́ s, a$ bond, from the twiggy or rush-like stems.)

1. L. júncea, Don. Stems (10 high) tufted, branched, striate; lower leaves lance-linear, $1^{\prime}-2^{\prime}$ long, rigid, the upper awl-shaped and minute; heads 5-flowered. - St. Croix River, Wisconsin, T. .J. Hale, and westward. July.

\section{CHONDRÍlLA, Tourn. Chondrilla.}

Heads few-flowered. Involucre cylindrical, of several narrow linear equal scales, and a row of small bractlets at the basc. Achenia terete, scveral-ribbed, smooth below, roughened at the summit by little scaly projections, from among which springs an abrupt slender beak. Pappus of copious very fine and soft capillary bristles, bright white. - Herbs of the Old World, with wand-like 
branching stems, and small heads of yellow flowers. (A name of Dioscoridea for some plant which exudes a gum.)

1. C. JúxCEA, L. Bienuial, bristly-hairy below, smooth above $\left(1^{\circ}-3^{\circ}\right.$ high); root-leaves runcinate; sten-leaves few and small, linear; heads scattered on nearly leatless branches, $6^{\prime \prime}-8^{\prime \prime}$ long. - Fields and roaslsides, abundant near Alexandria, Virginia, M.J. Belb, A. H. C'urtiss; perhaps of recent introduction. Aug. ( $\Lambda$ dv. from Èu.)

\section{PyRRHo Pá P P US, DC. False Dandelion.}

Heals, \&c. nearly as in Taraxiscum, but the soft pappus reddish or rustycolor, and with a villous ring at the top of the long beak of the achenium. Mostly annual or biennial herbs, often branching and leafy below. Heads solitary, terminating the naked summit of the stem or branches. Flowers decp

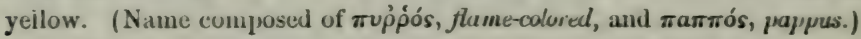

1. P. Caroliniànus, DC. Stem branching $\left(1^{\circ}-2^{\circ}\right.$ high $)$; leaves oblong or lanceolate, entire, cut, or pinnatifid, the stem-leaves partly clasping. - Sandy fields, from Maryland southward. April-July.

\section{TARÁ XACUM, Haller. DANDELION.}

Head many-flowered. Involucre double, the outer of short scales; the innet of long lincar scales, erect in a single ruw. Aclicnia terete, ublong, ribbed, and roughened on the ribs, the apex prolonged into a very slender thread-like heak, bearing the pappus of copious soft and white calpillary bristles. - Perennials or biennials, jroducing a tuft of piunatifid or runcinate radical leaves, and slender naked hollow scapes, bearing a single large head of yellow flowers. (Name from $\tau a \rho a ́ \sigma \sigma \omega$, to disquiet or disorder, in allusion to mediciual properties.)

1. T. Dens-leonis, Desf. (Common Dandelion.) Smooth, or at first pubescent; outer involucre reflexed. - Pastures and fields everywhere: probably indigenous in the North. A pril-Sept. - After blossoming, the inner involucre closes, the slender beak elongates and raises up the pappus while the fruit is forming; the whole involucre is then reflexed, exposing to the wind the naked fruits, with the pappus displayed in an open globular head. (Eu.)

\section{I A C T Ù C A, Tourn. Letruce.}

Ileals several-flowered. Scales of the involucre imbricated in 2 or more sets of unequal lengths. Achenia flat (compressed parallel to the scales of the involucre), abruptly contracted into a long thread-form beak, bearing a copious and fugacious pappus of very soft and white capillary bristles. - Leafy-stemmed herbs, with panieled heads; the fluwers of variable color, produced in summer and autumn. (The ancient name of the Lettuce, $L$. sativa; from lac, milk, in allusion to the milky juce.)

1. L. Canadénsis, L. (Wird Letrucr.) Biennial, mostly tall; leaves partly clasping, pale bene:ath; the upper lanceolate and entire; heads about 20flowered; achenia oval, rather longer than the heak, minutely rugose transversely and roughish, one-ribbed on each fuce. 'The typical form (L. elongata, Mull, 
nnd Fd. 2) is tall, with a thick and hollow very leafy stem $\left(4^{\circ}-9^{\circ}\right.$ high), smooth or nearly so ; leaves long, most of them runcinate-pinnatifid ; heads very numerous, in a long and narrow naked panicle; flowers mostly pale yellow. - Rich and damp soil, borders of fields or thickets : common, especially northward. The following are perhaps to be restored as species :-

Var. integrifolia, Torr. \& Gr. (L. integrifolia, Bigel.) Stem $3^{\circ}-6^{\circ}$ high ; leaves all undivided, either entire or sharply denticulate; panicle more open; flowers pale yellow, cream-color, or purple. - Open and dry or sterile soil, E. New England near the coast to Illinois and southward.

Var. sanguínea, Torr. \& Gr. (I. sanguinea, Bigel.) Lower and less stout $\left(2^{\circ}-5^{\circ}\right.$ high); leaves all runcinate-pinnatifid, the midrib beneath and lower part of the stem often sparsely bristly-hairy; heads fewer, in a loose open panicle; flowers yellow-purple, reddish with or without a yellow centre, or rarely white. - Open dry ground, Eastern New England to New Jersey, Illinois, and southward.

2. L. Scarłola, L. (Prickly Lettuce.) Annual or biennial; stem below sparsely prickly-bristly, as also the midrib on the lower face of the sagittate-clasping oblong or lanceolate spinulose-denticulate vertical leaves; panicle narrow; heads small, few-flowered ; achenia striate. - Waste grounds and roadsides, Cambridge, Massachusetts. (Adv. from Eu.)

\section{M U L G ì D I U M, Cass. False or Blue Lettuce.}

Heads many-flowered. Involucre, \&c. as in Lactuca. Achenia laterally compressed, striate or ribbed, the summit contracted into a short and thick (or in No. 1 slender) benk or neck of the same texture, expanded at the apex into a ciliate disk, which bears a copious rather deciduous pappus of soft capillary bristles. - Leafy-stemmed herbs, with the general aspect and foliage of Lactuca; ours glabrous or nearly so. Hearls racemed or panicled; the flowers chiefly blue; in summer. (Name from mulgeo, to milk.)

* Pappus lright white: flowers blue.

1. M. pulchéllum, Nutt. Perennial, pale or glaucous; stem simple, $1^{\circ}-$ $2^{\circ}$ high ; leaves sessile, oblong- or linear-lanceolate, entire, or the lower runcinate-pinnatifid ; heads few and large, racemose, erect : scales of the conical-cylindraceous involucre lanceolate, imbricated in 3 or 4 ranks; the peduncles scalybrncted; achenia tapering into a slender beak, almost as in Lactuca. - Upper Michigan (Prof. Porter, \&c.), probably in N. W. Wisconsin: common on the plains westward.

2. M. acuminatum, DC. Tall biennial $\left(3^{\circ}-6^{\circ}\right.$ high $)$, with many small heads in a loose panicle, on diverging peduncles; leaves ovate or ovate-lanceolate, pointed, barely toothed, sometimes hairy on the midrib beneath, contracted into a winged petiole, the lowest occasionally sinuate; achenia with a very short beak. - Borders of thickets, New York to Illinois, and sonthward. - Probably.only an entire-leaved state of the next.

3. M. Floridànum, DC. Leaves all lyrate or runcinute, the upper often with a heart-shaped clasping base; panicle larger: otherwise as No. 2. - Rich soil, Pennsylvania to Illinois and southward.

$\mathrm{L} \& \mathrm{M}-32$ 
* Pappus tawny : corolla pale blue, or cream-color turning bluish.

4. M. leucophæum, 1)C. Nearly smooth biennial; stem tall $\left(3^{\circ}-12^{\circ}\right.$ high), very leafy; lcaves irregularly pinnutifid, sometimes runcinate, connsely toothed, the uppermost often undivided and sometimes clasping; heads in a large and dense compound panicle. - Low grounds: rather common.

\section{Só N CH US, L. SuW-Thistle.}

Heads many-flowered, becoming tumid at the base. Involucre more or less imbricated. Achenia flattened laterally, ribbed or striate, not beaked. Pajpus copious, of very white exceedingly soft and fine capillary bristles. - Leafystenmed roarse weeds, chicfly smooth and glaucous, with corymbed or umbellate heads of yellow flowers; producel in summer and atumu. (The ancient Greck namuc.)

$$
\text { * Annual }\left(1^{\circ}-5^{\circ} \text { high }\right): \text { flowers pale yellow. }
$$

1. S. oleraceus, L. (Common Sow-Thistle.) Stum-leaves runcinatepinnatifid, or rarely undivided, slightly toothed with soft spiny teeth, clasping by a leart-shaped base, the auricles acute; involucre downy when young; uchenia striate, also wrinkled liansversely. - Waste places in manured soil and around dwellings. (Nat. firou Liu.)

2. S. Ásper, Vill. (Siriny-Leaved S.) Stem-leaves less divided and more spiny-toothed, the anrieles of the clasping lase rounded; achenia murgined, 3 nerved on euch side, smooth. - With and like the last. (Nat. firom Lu.)

* * Perennial, with creeping reotstucks: flowers bright yellow, in larye heads.

3. S. AkVÉxsis, L. (FiELD S.) Leaves runcinate-pinnatifid, spiny-toothed, clasping by a heart-shaped base; peduncles and involuere bristly ; achenia transversely wrinkled on the ribs. - Roadsides, \&c., New England and New York: becoming more commul. (Nat. from Eu.)

\section{Order 54. LOBELIACEA. (Lobelia Family.)}

Herbs with milhy juice, alternate leaves, and scattered flowers, an irregular monopelalous $\tilde{n}$-lobed corolla; the 5 slamens free from the corolla, and united into a tube commonly by their filaments and always by their anthers. - Calyxtube adherent to the many-seeded pod. Style 1 : stigma often fringed. Seeds anatropous, with a small straight embryo, in copious albumen. Acrid poisonous plants (rather to be regirded as a part of the next order), represented only by the genus

\section{I O B Ė I A, L. Lobelia.}

Calyx 5-cleft, with a short tube. Corolla with a straight tube, split down on the (apparently) upper side, sumewhat 2-lipped; the upper lip of 2 rather erect lobes, the lower lip sprealing and 3-cleft. Two of the anthers in our species bearded at the top. Pod 2-celled, many-seeded, opening at the top. - Flowers axillary or chicfly in bracted racemes; in summer and early autumn. (Dedicated to Matthias De l'Obel, an early Flemish herbalist.) 
* Flowers deep red, large: stem simple.

1. L. cardinalis, I. (CARninat-FLower.) Tall $\left(2^{\circ}-4^{\circ}\right.$ high), smooth. ish ; leaves oblong-Ianceolate, slightly toothed; raceme elongated, rather 1-sided ; the pedicels much shorter than the leaf-like bracts. - Low grounds: conmon. - Perennial by offsets, with large and very showy intensely red flowers, - rarely varying to rose-color! (Plymouth, Mr. Gilbert), or even to white !

* Flowers blue, or blue variegated with white.

- Stems leafy to the top, simple $\left(1^{\circ}-3^{\circ}\right.$ high $)$ from a perennial root; leaves oblong or ovate-lanceolate: sinuses of the calyx with conspicuous deflexed auricles: flowers crouded in a long spike or dense raceme.

2. L. syphilitica, I. (Great Loneun.) Somewhat hairy; leaves thin, ricute at both ends $\left(2^{\prime}-6^{\prime}\right.$ long), irregularly serrate ; flowers (nearly $\mathbf{l}^{\prime}$ long) pedicelled, longer than the leafy bracts; calyx hirsute, the lobes half the length of the corolla, the short tube hemispherical. - Low grounds: common. - Flowers light blue, rarely white.

3. L. pubérula, Michx. Finely soft-pubescent; leaves thickish, obtuse (1'$2^{\prime}$ long), with small glandular teeth; spike rather 1-sided; calyx-lobes (and ovate bracts) little shorter than the corolla, the hairy tube top-shaped. - Moist grounds, New Jersey to Illinois and southward. - Corolla bright blue, $\frac{1}{2}$ long.

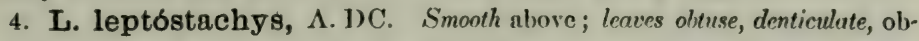
long-lanceolate, the upper gradually reduced to awl-shaped bracts ; raceme spikelike, long and dense; lobes of the calyx nearly equalling the corolla, the auricles in the form of 10 awl-shaped appendages as long as the hemispherical tube. Sandy soil, Illinois and southward. - Corolla $3^{\prime \prime}-4$ "long.

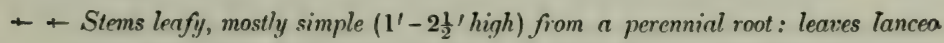
late or oblong-lanceolate: calyx-tube hemispherical, the sinuses destitute of auricles: flowers pretty large (g'-1' long) and showy, in a loose nearly 1-sided raceme: anthers sometimes bearded on the lack.

5. L. glandulosa, Walt. Sparingly pubescent: leaves, bracts, and usually the lobes of the calyx strongly glandular-toothed; calyx-tube densely hispid, rarely sparsely so, or smonthish. - Moist places, Virginia and southward.

6. L. amœna, Michx. Glabrous (rarely minutely pubescent); leaves and bracts usually glnndular-toothed; calyx-lobes entire and slender. - Shady moist places, Virginia and southward.

+++ Stems leafy: calyx with no auricles or appendnges at the sinuses: flowers small $f^{\prime}-\frac{1^{\prime}}{2}$ long, racemed: roots slender, annual or biennial, or perhaps sometimes perennial.

$\rightarrow$ More or less pubescent, at least below: leaves oblong or ovate: stems angled or striate: racemes spike-like: corolla pale blue.

7. L. inflàta, L. (INdian Toвасco.) Stems paniculately much branched from an annual root, pubescent with spreading hairs $\left(9^{\prime}-18^{\prime}\right.$ high); leaves ovate or oblong, toothed, gradually diminishing into leaf-like bracts, which exceed the lower short-pedicelled flowers, calyx-tuhe ovoid, the pod inflated. - Dry open fields : common. - Corolla only $1 \frac{1}{\prime \prime}-2^{\prime \prime}$ long. I'lant poisonous and a noted quack medicine. 
8. I. spicàta, Lam. Stem slender, strict and simple $\left(1^{\circ}-3^{\circ}\right.$ high) from a biennial or perhaps perennial root, below and the barely denticulate leaves minutely pubescent ; lower und root-leaves obovate or spatulate, the upper reduced to linear or club-shaped bracts; raceme long and naked, mostly dense and manyflowered; calyx-tube short, obconical or becoming alıost hemispherical. ( $L$. Claytoniàna, Michx. L. pallida, Muhl.) - Moist or dry, mostly gravelly or sandy soil : rather common, at least southward and westward. - A slender and smaller flowered variety (beginning to blossom in June) grows in swamps at Lancaster, Penn., Prof. Porter. - Corolla ordinarily 4" long.

+ + Glubrous or nearly so: leaves small, linear or lanceolate, only those from the root obovate or spatulate, the uppermost reduced to setaceous bracts, all entire or barely denticulate: stems very slender, simple or becoming paniculately branched above : racemes loosely severul-flowered.

9. L. Iuttállii, Roem. \& Sch. Stem very slender $\left(1^{\circ}-2^{\circ}\right.$ high $)$, terete; pedicels mostly longer than the bract and shorter than the flower, usually with very . minute bractlets near the base; calyx-tube very short, depressed-hemispherical in fruit, the globalar pod half free; corolla pale bluc, barely $3^{\prime \prime}$ long. - Sandy swamps, from Long Island, New Jersey, and the adjacent lower borders of Peunsylvania, southivard.

10. L. Kálmii, L. Stem mostly low $\left(4^{\prime}-18^{\prime}\right.$ high) minutely angled; pedicels filiform, not exceeding the linear or setuceous bructs but as long as the flower, mintitly 2-bracteolute or 2-ylundulur above the midlle; calyx-tube top-shaped or obo. void with an acute base, fully half the length of the lobes, in fruit rather longer than they, smooth, covering the whole pod; corolla bright light blue, $4^{\prime \prime}-5^{\prime \prime}$ long. - Wet limestone rocks and banks, Northern New England to Wisconsin and northward along the St. Lawrence and Great Lakes, and through New York southward to Lancaster, Penn. (Prof. Porter).

11. L. Cánbyi, n. sp. Stem strict $\left(1^{\circ}-2^{\circ}\right.$ high $)$, minutely angled; pedi. cels shorter than the bracts and mostly shorter than the flower, minutely roughened under a lens; Gractiets none; calyx-tube top-shaped, acute ut the base, and only half the length of the lobes (which, with the linear leaves, are sparsely glandular-denticulate along the margins), in fruit becoming oblong, covering the whole pod; corolla deep blue (furiy $5^{\prime \prime}$ long), more or less bearded in the throat. - Wet places, pine barrens of New Jer'scy, especially at Quaker Bridge, Win. M. Cumby, C. E. Smith, \&c. (Also Sosth Carolina, M. A. Curtis.) Aug., Sept. - Leaves I', rarely $1 \frac{1}{2}$ 'long, numerous, gradually diminishing in size up to the raceme, the largest $2^{\prime \prime}$ wide. Pod nearly $3^{\prime \prime}$ long.

++++ Stem simple from a peremial root, and nearly leafless, except at or near the base: flowers in a simple loose raceme, light blue: leuves fleshy: calyx-tube acute at the base, top-shaped: auricles none.

12. L. paludosa, Nutt. Nearly smooth; stem slender $\left(1^{\circ}-21^{\circ}\right.$ high $)$; leaves thickish but flat, scattered near the base, linear-spatulate or oblong-linear, glandular-denticulate, mostly tapering into a petiole; lower lip of the corolla bearded in the middle; calyx-tube about half the length of the short lobes, becoming hemispherical in fruit. - Wet bogs, Delaware (Nuttall) and southward.

- Corolla $5^{\prime \prime}-6^{\prime \prime}$ long. 
13. L. Dortmánna, L. (Water Lonelia.) Very smooth; scape thick. ish $\left(5^{\prime}-12^{\prime}\right.$ high), few-flouered; lenves all tufled at the root, linear, terete, hollow, with a partition lengthwise, sessile; lower lip of the corolla slightly hairy; calyx-tube about as long as the lobes, in fruit much longer. - In the gravelly borders of ponds, N. Penn. to New England, and northward. - Corolla 6" -8 " long. (Eu.)

\section{Order 55. Campanulàcea. (Campanula Family.)}

Herbs, with milky juice, alternate leaves, and scattered flowers ; the calyx adherent to the ovary; the regular 5 -lobed corolla bell-shaped, valvate in the bud; the 5 stamens free from the corolla and usually distinct. - Style 1, beset with collecting hairs above : stigmas 2 or more. Pod 2 -several-celled, many-seeded. Seed small, anatropous, with a straight embryo in fleshy albumen. - Flowers generally blue and showy. - Sparingly represented in America, and in the Northern States by only two genera.

\section{C A M P Á N U L A, Tourn. Bellflower.}

Calyx 5-cleft. Corolla generally bell-shaped, 5-lobed. Stamens 5, separate; the filaments broad and membranaceous at the base. Stigmas and cells of the porl 3 in our species, the short porl opening on the sides by as many valves or holes. - Herbs, with terminal or axillary flowers; in summer. (A diminutive of the Italian campana, a bell, from the shape of the corolla.)

* Indigenous species, perenniuls, except No. 2 and No. 4.

- Flowers loosely panicled (or rarely solitary), long-peduncled: pods nodding.

1. C. rotundifolia, I. (II nensec..) Slender, branching $\left(5^{\prime}-12^{\prime}\right.$ high), 1-10-flowered ; root-leaurs round-hent-shiperd or ovnte, mostly toothed or crenate, long-petioled, early withering nway; stem-leaves numerous, linear or narrowly lanceolate, entire, smooth; calyx-lobes aul-shaped, varying from $\frac{1}{3}$ to $\frac{2}{3}$ the length of the bright-blue corolla (which is $6^{\prime \prime}-9^{\prime \prime}$ long). - Rocky shaded banks : com. mon northward, and along the mountains. $-\Lambda$ delicate and pretty, but variable, species, with a most inappropriate name, since the round root-leaves are rarely. obrious. (Eu.)

Var. linifolia. Stems more upright and rather rigid; the lowest leaves varying from heart-shaped to ovate-lanceolate ; corolla $3^{\prime}-1^{\prime}$ long. (C. linifolia, Lam.) - Shores of the Great Lakes, and northwestward. (Eu.)

2. C. aparinoides, Pursh. (Marsi Bellflower.) Stem simple and slender, weak $\left(8^{\prime}-20^{\prime}\right.$ high), few-flowered, somewhat 3-angled, rough backwards on the angles, as are the slightly toothed adges and midrib of the linenr-lanceolati leaves; peduncles diverging, slender; lobes of the calyx triangular, half the length of the bell-shaped nearly white corolla. (C. erinoides, Muhl.) - Bogs and wet meadows, among high grass. - Plant with somewhat the habit of a Galium; the corolla barely 4 " long.

3. C. divaricata, Michx. Very smooth; stem loosely branched $\left(1^{\circ}-3^{\circ}\right.$ high) ; leuves oblong-lanceolute, pointed at both ends, coarsely and shurply toothed; 
flowers numerous on the branches of the large compound panicle, calyx-lubes aw2. shaped, about half the length of the pale-blue small corolla (of $3^{\prime \prime}$ long); style protruded. - Dry woods and rocks, mountains of Virginia, Kentucky, and southward.

+ + Flowers numerous and nearly sessile, crowded in a long more or less leafy spike: corolla ulmost wheel-shuped, deeply 5-lubed: jods erect.

4. C. Americàna, L. ('ílll Bellelower.) Stem mostly simple $\left(3^{\circ}-6^{\circ}\right.$ high); leaves ovate and ovate-lanceolate, taper-pointed, serrate, mostly on margined petioles, thin, somewhat hairy $\left(2 \frac{1}{2}^{\prime}-6^{\prime}\right.$ long); the slender style protruded and curved. - Moist rich soil, New York to Wisconsin, and southward. - Spike $1^{\circ}-2^{\circ}$ long. Curolla light blue, $1^{\prime}$ broad. Root annual.

* European species escaped from gardens into roadsides; both perennials.

5. C. glomelata, L. (Clusteied B.) Sumewhat huiry, stout and ereet, 10 high; stem-leaves oblong or lanceolate, cordate-clasping; flowers sessile, clustered in the upper axils, forming a leafy head; corolla open-bell-shaped, $1^{\prime}$ long. - Danvers, Mass., \&c. (Adv. from Eu.)

6. C. Rapunculoìnes, L. Smoothish, sleuder, erect; stem-leaves ovatelanceolate, pointed, the lower long-petioled and heart-shaped; flowers nodding, single in the axil of bracts, forming racemes; corolla oblong, $1^{\prime}$ long. - E. Massachusetts; and Richficld Springs, New York, G. W. Clinton. (Aḍ. from Lu.)

\section{S PECULÀRIA, Heister. Venus's Looking-glass.}

Calyx 5- (or 3-4-) lobed. Corolla wheel-shaped, 5-lobed. Stamens 5, separate: the membranaceous hairy filaments shorter than the anthers. Stigmas 3. Pod prismatic or elongated-oblong, 3-celled, opening by 3 small lateral valves. - Low annuals; the earlier flowers in the American species (\$ Triodallus, Raf.) minute and fruiting precociously in the bud, without expanding their inperfect corolla. (Name from Speculum Veneris, the early name of the common European species.)

1. S. perfoliàta, A. DC. Somewhat hairy $\left(3^{\prime}-20^{\prime}\right.$ high $)$; leaves roundish or ovate, elasping by the heart-shaped base, toothed ; flowers sessile, solitary or 2-3 together in the axils; the upper or later ones only with a conspicuous and expanding (purple-blue) corolla; pod oblong, opening rather below the middle. - Sterile open ground : common. May-Aug.

\section{Order 56. ericàceate. (Heati family.)}

Shrubs, sometimes herbs, with the flowers regular or nearly so: the stamens as many or twice as many as the 4-5-lobed or 4-5-petalled corolla, free from but inserterl with it: anthers 2-celled, commonly appendaged or opening by terminal clinks or pores, introrse (except in Suborder 3): style 1: ovary 3-10-celled. Pollen compound, of 4 united grains, except in Suborder 4. Seeds small, anatropous. Embryo small, or sometimes minute, in fleshy albumen. - A large family, very various in many of the charac. ters, comprising four well-marked suborders, as follows: - 


\section{Suborder I. VACCINIEA. Whortherbrry Family.}

Calyx-tube adherent to the ovary, which forms an edible berry or berry. like fruit, crowned with the short calyx-teeth. Anthers 2-parted. - Shrub or somewhat woody plants, with scaly buds.

1. Gnylussacia. Ovary 8-10-celled, with a single ovule in each cell. Fruit a berried drupe with 8 or 10 small seed-like nutlets.

2. Vaceluium. Berry 4-5-celled (or imperfectly 8-10-celled by false partitions), manyseeded. Auther-cells capering upward into a tube.

3. Chiogemes. Berry 4 -celled, many-seeded, its sumwit free. Anther-cells not prolonged into a tube, but each 2-poiuted.

\section{Suborder II. Eisicinede. Proper Heath Famiz.}

Calyx free from the ovary. Corolla monopetalous, or sometimes polypetalous, hypogynous. - Shrubs or small trees.

Tribe I. ARBUTEAC. Fruit indehiscent, a berry or drupe. Corolla deciduous.

4. Arctostaphylos. Corolla uru-shaped. Drupe berry-like, 5-10-seeded.

Trlbe IY. AND ROMEDE. Fe. Fruit a loculicidal pod. Corolla deciduous.

* Anthers upright in the bul. Corolla monopetalous.

- Anther-cells opening through their whole length; not appendaged.

5. Epigoen. Corolla salver-shaped. Caly $x$ of 5 separate dry and pointed sepals.

$\leftarrow$ - Anther-cells opening only at the top. Corolla not salver-shaped.

\# Calyx becoening enlarged und berry-like in fruit.

6. Gaultherla. Caly $\times 5$-cleft, in fruit enclosing the small pod. Anthers 4-awned at the top. +++ Caly $x$ dry, not becoming fleshy after flowering.

7. Henonthoe. Caly $x$ imbricated in the bud. Corolla cylindraceous, 5-toothed. Pod depressed, 5-lobed, the valves entire.

8. Cassandra. Caly $x$ imbricated in the bud. Corolla cylindracens, 5-tnothed. Pod splitting when ripe into an outer and inncr layer, the inner of 10 valves.

9. Cansiope. Calyx imbricnted. Corolla briadly campanulate, decply 4-5-cleft. Pod globular-ovoid, 1-5-valved, the valves 2 cleft.

10. A ndromealn. Caly $x$ valvate and very early open in the bud. Pod globular. Seeds mostly hanging on the central placenta.

11. Oxycleudrum. Calyx valvate and opening early in the hud. Pod oblong-pyramidal Seeds all ascending. 1

* Anthers turned over outwardly in the bud. Corolla of 5 separate petals.

12. Clethra. Sepals 5 Stamens 10 : anther-cells opening by a terminat hole or ehink. Style 3-cleft at the apex. Pod 3-valved.

Tribe IIT. FRICE F. Corolla persistent, becoming scarious after flowering.

13. Calluna. Corolla bell-shaped, 4-parted Pod opening septicidally.

Tribe IV. RHODOR EAE. Fruit a septicidal pod. Corolla deciduous.

* Anther-cells opening by a hole or chink at the top.

- Fowers not from sealy huils; the bracts leaf-like or coriaceous.

14. Phyllodoce. Corolla ovate or urn-shaped. Leaves narrow and heath-like.

15. Kalmin. Corolla broadly bell-shaped or wheel-shaped, with 10 pouches receiving as many anthers. Leaves oblong or linear.

_ Flowern developed from large scaly buds, the acales or bracts calucous.

16. Mrenziesin. Corolla globular-bell-shaprd, 4-toothed. Stamens 8 . Leaves decidunus

17. A zal ea. Corolla open funnel-form, 5-lobed. Stamens 5 . Leaves deciduous. 
18. Rhododendron. Corolla bell-ghaped or funnel-form. Stamens 10. Leaves evergreen

13. Rhod ora. Corolla irregular, two petals uearly aeparate. Stamens 10. Leaves deciduous.

20. Led um. Corolla regular, all 5 petals uearly separate. Stumens 5 - 10. Leaves evergreen.

* Anther-cells opening tengthwise. Leaves evergreen. Bud-scales firm and persistent.

21. Loiselenria. Corolla deeply 5-cleft. Stanens 5, included.

22 Leiophyllum. Curulla of 5 separate jetals. Stimpeus 10, exserted.

\section{Suborner ili. Pyeole.j. Pyrula Family.}

Calyx free from the ovary. Corulla polypetalous. Anthers extrorse in the bud. Seeds with a loose and translucent cellular coat much larger than the nucleus. - Nearly herbaceous and broad-leaved everyreens.

23. Pyrola. Flowers in a raceme. Petuls not widely spreading. Filaments arr-shaped. Sigle long. Valves of the pod culveluy on the eriges.

24. Moneses. Ylower single. Pctals willy gloruding. Yilanents not dilated in the middle: anthers cunspicuously 2-horued. Style straight, exscrtad : stigma 5-rayud. Valves of the pod smooth on the edges.

25. Chimaplilla. Ylowers corymbed or umbelled. Petals widely sprealing. Filaments dilated in the middle: anthers 2-horned. Style very short and wp-shaped, covered by a broul and orbicular stigana. Valves of the pod sacoth ou the ediges.

\section{Subordek IV. MONO'TROPEa. Indan-pipe Family.}

Flowers nearly as in Suborders 2 or 3, but the plants herbaceous, rootparasitic, entircly destitute of green foliage, and with the aspect of Beechdrops. Seeds as in Suborder 3.

* Corolla monopetalous : anthers 2-celled.

26. Pterospora. Corulla ovate, 5-twothed : anthers 2-awned on the back, opening lengthwise.

27. Sehweinitzia. Cunulla bruadly bell-shaped, 5-lubed : authers opeuing at the twp.

* Corulla of 4 or 5 separate petals : calyx imperfect or bract-like.

22. Monotropa. Petuls uarruw. Authera kiduey-shuped, upening acruss the top.

\section{G A Y L US S Á CI A, H. B. K. Huckleberry.}

Corolla tubular, ovoid, or bell-shaped; the border 5-cleft. Stamens 10 : anthers awnless; the cells tapering upward into more or less of a tube, opening by a chink at the end. Fruit a berry-like drupe, containing 10 seed-like nutlets. Brauching shrubs, with the aspect of Vaccinium, commonly sprinkled with resinous dots; the flowers (white tinged with purple or red) in lateral and bractud racenos. (Named for the distingruishorl (dhenist, Gay-Lussac.)

* Leaves thick und evergreen, not resinus-dolled.

1. G. brachycera, Gray. (Bux-HuскLевекв.) Very smooth (1high); leaves oval, finely crenate-toothed; racemes short and nearly sessile; pedicels very short; corolla cylindrical-bell-shaped. - Dry Woods, Perry Co., P'eunsylvania, near Bloonficld (Prof. Baird), and mountains of Virginia. May. - Leaves in shape and aspect like thuse of the Box.

* Leuves deciduous, entire, sprintled more or less with resinous or vaxy atoms.

2. G. dumosa, Torr. \& Gr. (Dwary Huckleberky.) Somewhat hairg and glandular, low $\left(1^{\circ}-5^{\circ}\right.$ high from a creuping basc), bushy; leaves obovate- 
oblong, mucronate, green both sides, rather thick and shining when old; racemes ulongated; bracts lenf-like, oval, persistent, as long as the pedicels; ovary bristly or glandulur; corolla bell-shaped; fruit black (insipid). - Var. HirtélLA has the young branchlets, racemes, and often the leaves hairy. - Sandy low soil, Maine to Penn. and Virginia, near the coast, and southward. June.

3. G. frondosa, 'Torr. \& Gr. (Blue Tangle. Dangleberry.) Smonth $\left(3^{\circ}-6^{\circ}\right.$ high $)$; branches slender and divergent; lraves obovate-oblong, blunt, pale, glaurous benrath: racemes slender, loose; lracts oblong or lineur, deciduous, shorter than the slender drooping pedicels; corolla globular-bcll-shaped; fruit dark blue with a white bloom (sweet and edible). - Low copses, coast of New England to Kentucky, and southward. May, June.

4. G. resindsa, Torr. \& Gr. (Внаск HuскцевеRrx.) Much branched, rigid, slightly pubescent when young $\left(1^{\circ}-3^{\circ}\right.$ high); leaves oval, oblong-ovate, or oblong, thickly clothed and at first clammy, as well as the flowers, with shining resinous globules; racemes short, clustered, one-sided; pedicels about the length of the flowers; bracts and bractlets (reddish) small and deciduous; corolla ovoid-conical, or at length cylindrical with an open mouth; fruit black, without bloom (pleasant, very rarely white). - Woodlands and swamps: common (except southwestward towards the Mississippi). May, June. - The common Huckleberry of the North.

\section{V A C I N I U M, L. Cranberry. Blueberry. Bilberry.}

Corolla various in shape; the limb 4-5-cleft, revolute. Stamens 8 or 10 : anthers sometimes 2-awned on the back; the cells scparate and prolonged upwards into $n$ tube, opening by a hole at the npex. Berry 4 -5-celled, many-seeded, or sometimes 8-10-celled by a false partition stretching from the back of ench cell to the placenta. - Shrubs with solitary, clustered, or racemed flowers: the corolla white or reddish. (Ancient Latin name, of obscure derivation.)

§ 1. OXYCÓCCUS, Tourn. Ovary 4-celled: corollu 4-parted, the long narrow divisions revolute: anthers 8 , awnless, tapering above into very long tubes: pedicels slender.

* Stems very slender, creoping or trailing: leaves small, entire, whitened beneath, ever. green: pedicels erect, with the pale rose-colored flower nodding on their summit: corolla deeply 4-purted: berries red, acid.

1. V. Oxycóccus, L. (Sмлt, Crannerry.) Stems very slender $\left(4^{\prime}\right.$ $9^{\prime}$ long) ; Iraves ovute, acute, with strongly revolute margins $\left(2^{\prime \prime}-3^{\prime \prime}\right.$ long) ; pedicels 1-4, terminal; filaments more than half the length of the anthers. (Oxyeoccus vulgaris, Pursh.) - Peat-hogs, New England and Pennsylvania to Wisconsin, and northward. June, - Berry $3^{\prime \prime}-4^{\prime \prime}$ broad, often speckled with white when young; scldom gathered for the market. (En.)

2.' V. macrocárpon, Ait. (Large or American Cranberry.) Stems elongated ( $1^{\circ}-3^{\circ}$ long), the flowering branches ascending; leaves oblong, obtuse, glancous underneath, less revolute $\left(4^{\prime \prime}-6^{\prime \prime}\right.$ long) ; pedicels several, becoming lateral; filaments scarcely one third the length of the anthers. (Oxycoccus macrocárpus, Pers.) - Peat-bogs, Virginia to Wisconsin, and everywhere northward, but scarcely westward. June. - Berry $\frac{1}{2}{ }^{\prime}-1$ ' long.

G $\mathrm{M}-13$ 
Stem upright and leaves deciduous, as in common Bluberries: flowers axillara and solitary: corollu deeply 4-cleft: berries turning purple, insipid.

3. V. erythrocárpon, Michx. Sinooth, divergently branched $\left(1^{\circ}-4^{\circ}\right.$ high); leaves oblung-lanceolate, taper-pointed, bristly scrrate, thin. - Wooded hills, mountains of Virginia and southward. July.

§ 2. VI'TIS-ID \̇A, Tourn. Ovary 4-5-celled: corolla bell-shaped, 4-5-labed: anthers 8-10, awnless: filaments hairy: flowers in short and bracted nodding racemes: leaves evergicen: berries red or purple.

4. V. Vitis-Idæ̀a, L. (Cowвеnкy.) Low $\left(6^{\prime}-10^{\prime}\right.$ high); branches erect from tufted creeping stems; leaves obovate, with revolute margins, dark green, smooth and shining above, dotted with blackish bristly points underneath; corolla bell-shaped, 4-cleft. - Higher mountains of New England, also on the coast of Maine, and at I)anvers, Massachusetts (Oakes), and northward. June. -Berries dark red, acid and rather bitter, mealy, barely edible. (Eu.)

§ 3. PICROCÓCCUS, Nutt. Ovary more or less 10-celled by fulse partitions: berries greenish, hardly edible, ripening few seeds: corvlla open-bell-shaped, 5-lobed: anthers 10, extended into very long nuch exserted tubes, 2-uwned on the buck: flowers on slender pedicels, singly in the axils of the upper leaves or leaf-like bructs, forming leafy racemes, not arliculated: leaves thin, deciduous.

5. V. stamíneum, L. (Deerberry. Squaw IIuckleberry.) Diffusely branched $\left(2^{\circ}-3^{\circ}\right.$ high), somewhat pubescent; leaves ovate or oval, pale, glaucous or whitish underneath; corolla greenish-white or purplish; berries globular or pear-shaped, large, greenish, mawkish.-Dry woods, Maine tw Michigan and southward, mainly eastward. May, June.

§4. BATODÉEDRON, Nutt. Ovary more or less 10-celled by fulse partitions: berries black: corolla short-bell-shaped, 5-toothed: anthers 10, included, conspicuously 2-awned on the back, and extended into slender tubes : filaments hairy: flower's on slender pedicels singly in the axils of coriaceous shining leaves, or racemed at the end of the branches, articulated just below the ovary!

6. V. arbodreum, Marshall. (FakkLE-BerRy.) Tall $\left(8^{\circ}-15^{\circ}\right.$ high), smoothish; leaves oval or obovate, entire or denticulate, mucronate; bright green and shining above, at the South evergreen; corolla white; berries mealy, insipid, ripening late. - Dry ground, Makanda, S. Illinois (Dr. Vusey), probably also in Virginia, and soutliward. Junc.

\$5. EUVACCINIUM. Ovary 4-5-celled, with no trace of fulse partitions : corolla urn-shaped or globular, 4-5-toothed: unthers 2-awned on the back: filuments smooth: flowers axillury, solitary, or 2 or 3 together: berries blue or black, edible: northern or alpine plants, with deciduous leaves.

* Parts of the flower mostly in fours: stamens 8.

7. V. uliginòsum, L. (Bog BıLerix.) Low and spreading $\left(4^{\prime}-18^{\prime}\right.$ high), tufted; leaves entirc, dull, obovate or oblong, pale and slightly pulescent underneath; flowers single or 2-3 together from a scaly bud, almost sessile; • corolla short, urn-shaped; berries black with a bloom, sweet. - Alpine tops of the high mountains of New England and New York, shore of Lake Superior, and northward. (Eu.) 
- Parts of the flower in fues: stamens 10 : leaves membranaceous: flowers solitary on short axillary peduncles, noddiny.

8. V. cæespitòsum, Michx. Dwarf $\left(3^{\prime}-5^{\prime}\right.$ high), tufted; leaves obovate, narrowed at the base, smooth and shining, serrate; corolla oblong, slightly urnshaped; berries blue. $-\Lambda$ lpine region of the White Mountains of New Hampshire; and high northward.

9. V. ovalifolium, Smith. Straggling, $3^{\circ}-10^{\circ}$ high; leaves dliptical, obhuse, nearly entire, pale, mostly glaucous beneath, smooth; coralla ovoid; berries blue. - P'eat-bogs, Keweenaw Co., Lake Superior, Dr. Robbins (and far westward). May.

10. V. myrtilloides, Hook. More erect, $1^{\circ}-4^{\circ}$ high ; branchlets somewhat angled; leaves mostly ovate and acute or pointed, sharply and closely serrulate, bright green, nearly smooth; border of the calyx almost entire; corolla depressedglobular, rather large; berries large, black, rather acid. - Woods and bluffs, Kieweenaw Co., Lake Superior, Dr. Rohbins. (Lake Huron, Dr. Todd: and nortliwestward.) May, Junc. - Pedicels $3^{\prime \prime}-6^{\prime \prime}$ long, drooping in flower, erect in fruit.

§ 6. CYANOCÓCCUS. Ovary more or less completely 10.celled by fulse partitions : corolle oblony-cylindricul or slightly win-shaped, 5-toothed: anthers 10, awnless: flaments hairy: beries Wue or black with a bloom (sweet): flowers in clusters or very short racemes from scaly buds separate from and ruther preceding the leaves, on short pedicels, appearing in early spring. (Leaves deciduous in the Northern species or proper Blueberries.)

11. V. Pennsylvánicum, Lnm. (Dwarf Blufberry.) Dwarf (6'15' high), smooth; leaves lanceolute or oblong, distinctly serrulate with bristle-pointd teeth, smooth and shining both sides for sometimes downy on the midrib underneath); corolla short, cylindrical-bell-shaped. - Var Anavstrfórum is a high mountain or boreal form, $3^{\prime}-6^{\prime}$ high, with narrower lanceolate leaves. (V. angustifolium, Ait.) - Dry hills and woods: common from Pennsylvania and N. Illinois far northward. - Branches green, angled, warty. Berries abundant, large and sweet, ripening early in July : the earliest blueberry or blue huckleberry in the market.

12. V. Canadénse, Kalm. (Cansda Bluebrrry.) Low $\left(1^{\circ}-2^{\circ}\right.$ high); leaces ablong-lanceolate or elliptical, entire, downy both sid's, as well us the crowded branchlets; corolla shorter: otherwise as the last, into which it seems to pass. - Swamps or moist woods, Maine to Wisconsin, and northward.

13. V. vacillans, Solander. (Low Blueberry.) Low $\left(1^{\circ}-2 \frac{1}{2}\right.$ high), glabrous; leaves obovate or oval, very pale or dull, glaucous, at least underneath, minutely ciliolate-serrulate or entire; corolla between bell-shaped and cylindraceous, the mouth somewhat contracted. - Dry woodlands, especially in sandy soil, New England to Virginia and N. Illinois. - Branches yellowish-green. Berries ripening later than those of No. 11.

14. V. corymbosum, I. (СоммоN or Swamp-Blueberry.) Tall $\left(5^{\circ}-10^{\circ}\right.$ high $)$; leaves oxcte, oval, oblong, or elliptical-luncenlute; corolla varying from turgid-ovate and cylindrical-urn-shaped to oblong-cylindrical. - Swamps and low thickets : everywhere common, except southwestwurd. - This yields 
the common Uweberry or Uue huchlderry of the latter part of the season. The typical form has the leaves entire and more or less pubescent, as least when young, as also the branchlets. 'The species ex hibits tlie gruatest variety of forms : the last of those here mentional is the mast remarkisble, and tho only one which has any claims to be rogardod as a species.

Var. glàbrum, is whully or ucarly glabruns throughout; the leaves entire.

Var. amcenum, has the leuves bristly-ciliate, shiniug above, green both sides, beneath somewhat pubescent on the veins. (V. amcenum, Ait., de.)

Var. pállidum, has the leaves mustly glabrous, pale or whitish, glaucuuz: especially underneath, senrulate with bristly tecth. (V. pallidum, Ait.)

Var. atrocóccum, lats the leaves entire, duwny or wuolly underneath even when uld, as also the branchlets; berries smuller, blatk, without bloom. (V. fuscàtum, $A \dot{u} . z \&$ Ed. 1.)

\section{CH I Ó G E E S, Salisb. Creepixg Snowberry.}

Calyx-tube adherent to the lower part of the ovary; the limb 4-parted. Co. rulla bell-shaped, deeply 4-cleft. Stamens 8 , includcel, inscrted on an 8-toothed epigy nous disk: tilanents very short and broal : anther-eclls ovate-oblung, quite sejurate, not awnel on ble bich, but each minntely 2-jointed at the apex, and opening by a large chiok down to the middle. Berry white, globular, crowned with the 4-toothed calyx, rather dry, 4-celled, many-sceled. - A trailing and creeping evergreen, with very slender and scarcely wooily stems, and small Thyme-like, ovate and pointcl leaves on short petioles, with revolute margins, smouth above, the lower surfate and the branches besut with rigid rusty bristles. Flowers very small, solitary in the axils, on short noulding perluncles, with 2

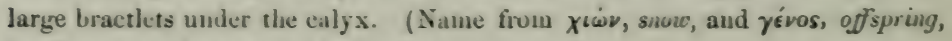
in allusion to the snow-w hite herrics.)

1. C. hispidula, Torr. \& Gir. - Peat-bogs, and mossy mountain woods, in the shate of evergreens; common northward, extending southwand in the Alleghanies. May. - Plant with the aromatic flavor of Gaulcheria or Birch.

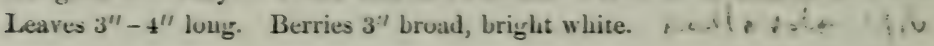

\section{A RCTOSTÁ P H Y L OS, Alans. Bearberky.}

Corolla ovate and urn-shaped, with a short revolute 5-toothed limb. Stamens 10, included : anthers with 2 retlexed awns on the back near the apex, opening by terminal pores. I)rupe berry-like, with 5-10 seed-like nutlets. - Shrubs, with alternate leaves, and scaly-bracted nearly white flowers in terminal racemes or clusters. Fruit austere. (Name composed of äpкros, a bear, and $\sigma \tau a \phi u \lambda \dot{\eta}$, a grope or berry, the Greck of the popular name.)

1. A. Uva-úrsi, Spreng. (BEArberrx.) Trailing; lenes thick and ever-1.. green, obovate or spatulate, entire, smouth; fivil red. (Arbutus Uva-ursi, L.) Rocks and bare hills, New Jersey to Wisconsin and northward. May. (Eu.)

2. A. alpina, Spreng. (Alpixe Besквевкx.) Dwarf, tufted and depressed; leaves deciduous, serrate, wrinkled with strong netted veins, obovate; fruit Ulack. - Alpine recrion of the White Mountains, New Hanpshire, Mouns Katahdin, Maine, and high northward. (Eu.) 


\section{E PIG 永A, L. Ground laurel. Trailing Árbutus.}

Corolla salver-form; the tube hairy inside, as long as the ovate-lanceolate pointed and scale-like nearly distinct sepals. Stamens 10, with slender filaments : anthers oblong; awnless, opening lengthwise. Style slender, its apex (as in Pyrola) forming a sort of ring or collar around and partly adnate to the 5 little lobes of the stigma. Pod depressed-globular, 5-lobed, 5-celled, many-seeded. A prostrate or trailing scarcely shrubby plunt, bristly with rusty hairs, with evergreen and reticulated rounded and heart-shaped alternate leaves, on slender petioles, and with rose-colored flowers in small axillary clusters, from scaly bracts. (Name composed of $\dot{\epsilon} \pi i, u p o n$, and $\gamma \hat{\eta}$, the earth, from the trailing growtlı.)

1. E. rèpens, L. - Sandy woorls, or sometimes in rocky soil, especially in the shade of pines : common in many places, especially eastward. - Flowers appearing in early spring, exhaling a rich spicy fragrance. In New England called Mayflower.

\section{GA ULTH È I A, Kalm. Aromatic Wintergren.}

Corolla cylindrical-ovoid or a little urn-shaped, 5-toothed. Stamens 10, included : anther-cells ench 2-awned at the summit, opening by a terminal pore. Pod depressed, 5-lobed, 5-celled, 5-valred, many-seeded, enclosed when ripe by the calyx, which thickens and turns fleshy, so as to appear as a globular red berry! - Shrubs, or almost herbaccons plants, with alternate evergreen leaves and axillary (nearly white) flowers: pedicels with 2 bractlets. (1)edicated by Kalm to "Dr. Gaulthier," of Qucbec; Limn. Amsen. Acad. 3, p. 15. The true orthography, as ascertained by Prof. Brunet from the old records in Quebec, is Gaultier; so that the orthography of the genus, if changed at all, should be Gaultiera.)

1. G. procúmbens, L. (Creering Wintergneen.) Stems slender and extensively erecping on or below the surfuce; the flowering branches nscending, lenfy at the summit $\left(3^{\prime}-5^{\prime}\right.$ high); lcaves obovate or oval, obscurely serrate; flowers few, mostly single in the axils, nodding. - Cool damp woods, mostly in the shade of evergreens especially northward, and southward along the Alleghanies. July. - The bright red berries (formed of the calyx) and the foliage have the well-known spicy-aromatic flavor of the Sweet Birch. In the interior of the country it is ealled Wintergreen, or sometimes Tea-beriy. Fastward it is called Cherkerherry or Paitridge-berry (names also applied to Mitchella, the latter especially so), also Boxberry.

\section{LEUCÓTHÖ̈, Don. LEUCOTнӧ̈.}

Calyx of 5 nearly distinct sepals, imbricated in the bud, not enlarged nor fleshy in fruit. Corolla ovate or cylindraceous, 5-tootherl. Stamens 10: anthers naked, or the cells with 1 or 2 erect awns at the apex, opening by a pore. Pod depressed, more or less 5-lobed, 5-celled, 5-valved, the sutures not thickened; valves entire : the many-secied placenta borne on the summit of the short columella, mostly pendulous. - Shrubs with petioled and serrulate leaves, and white scaly-bracted flowers crowded in axillary or terminal spiked racemes. ( $\Lambda$ mythological name.) 
§1. LEUCOTIIOi proper. Anthers awnless; the cells sometimes obscurely 2 pointed: stigma dypressed-capitute, 5-ruyjed: racemes sessile (dense), produced at the tine of flowering from sculy buds in the axils of the coriuceous and shining persistent leaves of the preceding yeur, shorter than they: bracts persistent: bractlets at the base of the short pedivels. (.Secd-coat lvose and cellular, winy-like.)

1. L. axillàris, Don. Leaves lanceolute-oblong or ocal, aliruptly pointed or acute, somewhat spinulose-serrulate, on very short yetioles; sepals broadly ovate. (Andromeda axillaris, Lam.) - Banks of streans, Virginia, in the low country, and southward. Feb. $-\Lambda$ pril. - Shrub $2^{\circ}-4^{\circ}$ high.

2. I. Catesbæi. Leaves ovute-lanceolate, tuper-pointed, serrulate with ciliatespinulose appressed teeth, conspicuously petioled ( $3^{\prime}-6^{\prime}$ long); sepals ovate-oblong, often acute. (Andr. Catesbai, Walt. A. axillaris, Michx. A. spinulosa, P'ursh. L. spinulosa, Don.) - Moist banks of streams, Virginia along the mountains, and southward. May. - Shrub $2^{\circ}-4^{\circ}$ high, with long spreading or recurved branches. Flowers exhaling the unpleasant scent of C'hestunt-blossoms.

§ 2. EÙBOTRYS, Nutt. Anthers awned: stiyma simple: bractlets close to the calyx, and, like the sepals, of a vigid texture, ovute or lanceolate, pointed: placente not pendulous: flowers very short-pedicelled, in long one-sided racemes, which mostly lcrminate the branches, formed with them in the summer, but the flower-buds not expranding till the following spring : bracts awh-shaped, deciduons: leaves membranaccous and deciduous, serrulate, the midrib and veins beneuth pubescent.

3. L. recúrva, Buckley. Branches and racemes recurved-spreading; leaves lanceolate or ovate, taper-pointed; sepals ovate; inther-cells 1-awned; pod 5-lobed; seeds flat and cellulur-winged. - Dry hills, Alleghanies of Virginia and southward. April. - Lower and more straggling than the next.

4. L. racemósa. Branches and racemes mosily erect; leaves oblong or ovallanceolate, acute; sepuls ovate-lunceolate; anther-cells each 2-awned; pod not lobed; seeds anyled and wingless. (Andromeda racemosa \& A. paniculata, L.) - Moist thickets, Massachusetts to Virginia, near the coast, and southward. May, June. - Shrub $4^{\circ}-6^{\circ}$ high. Corolla cylindrical.

\section{C A S S Á N D R A, Don. Leather-Leaf.}

Calyx of 5 distinct rigid ovate and acute sepals, imbricated in the bud, and with a pair of similar bractlets. Corolla cylindricul-oblong, 5-toothed. StaInens 10: anther-cells tapering into a tubular beak, and opening by a pore at the apex, awnless. Pod depressed, 5-eelled, many-seeded; the pericarp of 2 layers, the outer 5-valved, the cartilaginous inner layer at length 10-valved. Seeds flattened, wingless. - Low and much branched shrubs, with nearly evergreen and coriaceous leaves, which are scurfy, especially underncath. Flowers white, in the axils of the upper small leaves, forming small I-sided leafy racemes; the flower-buds formed in the summer and expanding early the next spring. (Cussandra, a daughter of Priam and Hecuba.)

1. C. calyculata, Don. Leaves oblong, obtuse, flat. (Andromeda calyculata, L.) - Wet bugs : common northward: rure westward to North Wisconsin. (Eu.) 


\section{CASS I O PE, Don. CAssiope.}

Calyx without bractlets, of 4 or 5 nearly distinct ovate sepals, imbricated in the bud. Corolla broadly campanulate, decply 4-5-cleft. Stamens 8 or 10 : anthers fixed by their apex; the ovoid cells each opening by a large terminal pore, and bearing a long recurved awn behind. Pod ovoid or globular, 4-5celled, 4-5-valved; the valves 2-cleft : placentre many-seeded, pendulous from the summit of the columella. Seeds smooth and wingless. - Small, arctic or alpine evergreen plants, resembling Club-Mosses or Heaths. Flowers solitary, nodding on slender erect peduncles, white or rose-color. (Cassiope was the mother of Andromeda.)

1. C. hypnoides, Don. 'Tufted and procumbent, moss-like $\left(1^{\prime}-4^{\prime}\right.$ high $)$; leavea needle-shaped, imbricated ; corolla 5-cleft; style short and conical. (Andromeda hypnoides, $L$.) $-A$ lpine summits of the Adirondack Mountains, New York (Dr. Parry), White Mountains of New Hampshire, Mount Katahdin, Maine (Mr. Young), and high northwurd. (Eu.)

\section{A N D RÓ MEDA, L. (in part). ANDromeda.}

Calyx without bractlets, of 5 ncarly or partly distinct sepals, valvate in the bud, but very soon separate or open. Corolla 5-toothed. Stamens 10: anthers fixed near the middle, the cells opening by a terminal pore. Pod globular, 5celled, 5-valved; the many-seeded placentæ borne on the summit or middle of the columella. - Shrubs, with umbelled, clustered, or panicled and racemed (mostly white) flowers. (Fancifully named by Linnæus for A. polifolia, in alJusion to the fable of Andromeda.)

§ 1. ANDRÓMEDA proper. Corolla globular-ırn-shrped: filaments bearded, not appendaged: anthers short, the cells cach surmounted by a slender ascending awn: seeds turned in all dirctions, oral, with a close and hard smooth coat: flowers in a terminul umbel: pedicels from the axils of orate persistent scaly bracts; leaves evergreen.

1. A. polifolia, L. Smooth and glancons $\left(6^{\prime}-18^{\prime}\right.$ high; leaves thick, lanccolate or oblong-linear, with strongly revolute margins, white beneath. Cold bogs, from Pennsylvania northward. May. (Eu.)

§ 2. POR'TÙNA, Nutt. Corolla oroid-urn-shaped and 5-angled: filaments not appendaged: anthers oblong, the colls each bearing a long reflexsd aun near the insertion: seeds mostly pendulous, and with a lonse cellular coat : flowers in axillary and terminal naked racemes, formed in summer, but the blossoms expunding the following spring: pedicels 1-sided, bructed and with minute bractlets, recurved: leaves thick and mergreen.

2. A. floribùnda, Pursh. Branches bristly when young; leaves lanceoblong, acute or pointed ( $2^{\prime}$ long), petioled, serrulate and bristly-ciliate ; racemes dense, crowded in panicles. - Moist hills, in the Alleghanies from Virginia southward. $\Lambda$ pril. $-\Lambda$ very leafy shrub, $2^{\circ}-10^{\circ}$ high, bearing abundance of handsome flowers.

§ 3. PIÈRIS, jon. Corolla ovoid-oblong or cylindruceous : filaments slender and aut-shaped, usually appenduged with a spreading or recurved bristle on each side 
at or below the apex: anthers oblong, awnless : sulures of the 5-angular pod with a more or less thicheneal line or ridye, which often fulls uway sepa, ately when the pod opens: seeds turned in all directions, oblong, with a thin and rather loose reticulated cout: flowers in umbel-like clusters vuriously arranyed.

3. A. Mariàna, L. (STAggen-Bush.) Nearly glabrous; leaves decidnous, but rather coriaceous, oval or oblong, veiny ; fluwers large and nodding, in clusters from axillary sealy buds, which are crowded on naked branclies of the preceding year; sepals leaf-like, deciduous with the leaves. - Sandy low places, Rhode Islaud to Virginia near the coast, and southward. May, June. - Shrub $2^{\circ}-4^{\circ}$ high : foliage said to poison lambs and calves.

§4. LYÒNIA, Nutt. Calyx 5-cleft: corolla glubular, pubescent: filaments and anther's destitute of uwns or appenduges, or the former sometimes 2-setose near the apex: pods prominently ribbed at the sutures, the ribs at length separuting or separable: seals stender, all pendulous, with a loose and thin cellular coat : flowers smull, mostly in clusters which are racemosed-panicled: bracts minute and deciduous : leaves pubescent or scurfy beneath.

4. A. ligustrina, Muhl. Leaves deciduons, not scurfy, smoothish when old, obovate-oblong varying to oblong-lanceolate; flowers racemose-panicled on branchlets of the preceding year. - Swamps and low thickets, New England to Penı., Virginia, and southward. June, July. - Slırub $4^{\circ}-10^{\circ}$ high.

\section{OXY DÉ N D R M, I) C. Sonml-tree. Sour-Wood.}

Calyx without bractlets, of 5 almost distinct sepals, valvate in the bud. Corolla ovate, 5 -toothed, puberulent. Stamens 10 : anthers fixed near the base, linear, awuless; the cells tapering upwards, and opening by a long chink. Pod oblong-pyramidal, 5-eelled, 5-valved; the many-seeded placenta at the base of the ecells. Seceds all ascending, slender, the thin and loose reticulated coat extended at both ends into awl-shaped appendages. - $\Lambda$ tree with deciduous, oblong-lanceolate, pointed, soon smooth, serrulate leatres, on slender petioles, and white flowers in long one-sided racenes clustered in an open panicle, terminating the branches of the season. Bracts and bractlets minute, deciduous. Fuliage sour to the taste (whence the name, from ókús, sour, and $\delta^{\epsilon} \nu \delta \rho o \nu, t r e e$ ).

1. O. arboreum, I)C. (Andromeda arborea, L.) - Rich woods, from Penn. and Ohio southward, mostly along the Alleghanies. June, July. - Tree $15^{\circ}-40^{\circ}$ high. Leaves in size and shape like those of the Peach.

\section{CLit th A, L. White Alder. Sweet Pepperiush.}

Calyx of 5 repals, imbricated in the bud. Corolla of 5 distinct obovate-ublong petals. Stamens 10, often exserted: anthers inversely arrow-shaped, inverted and reflexed in the bud, opening by terminal pores or short slits. Style slender, 3-cleft at the apex. Pod 3-valved, 3-celled, many-seeded, enclosed in the calyx. Shrubs or trees, with alternate and serrate deciduous leaves, and white Howers in terminal hoary racemes. Bracts deciduous. (K $\lambda \dot{\eta} \theta \rho a$, the ancient Greek name of the Alder, which this genus somewhat resembles in foliage.) 
1. C. alnifolia, L. Leaves wedge-obovate, sharply serrate, entire towards $\therefore$ the base, prominently straight-veined, smooth, green both sirles; racemes upright, panicled; bracts shorter than the flowers; filaments sinooth. - Wet copses, Maine to Virginia near the coast, and southward. - Shrub $3^{\circ}-10^{\circ}$ high, covered in July and August with handsome fragrant blossoms. - In the South are varieties with the leaves rather scabrous, and pubescent or white-downy beneath.

2. C. acuminata, Michx. Leaves oval or oblong, pointed, thin, finely serrate (5'-7' long), pale beneath; racemes solitury, drooping; bracts longer than the flowers : filaments and pods hairy. - Woods in the Alleghanies, Virginia and southward. July. - A tall shrub or small tree.

\section{C A LL Ù N A, Salisb. Heather.}

Calyx of 4 colored sepals. Corolla bell-shaped, 4-parted, much shorter and less conspicuous than the caly $x$, both becoming scarious and persistent. Stamens 8, distinct: anthers with a pair of deflexed appendages on the back, the cells opening each by a long chink. Pod 4-celled, septicidally 4-valved. Evergreen undershrub, with no sealy buds, opposite and minute leaves (mostly extended at base into 2 sharp auricles), crowded and imbricated on the branches. Flowers axillary, or terminating very short shoots and crowded on the branches, forming close mostly one-sided spikes or spikc-like racemes, rose-colored or sometimes white, small, bracted by 2 or 3 pairs of leaves, the innermost of which are more or less scarious. (Named from $\kappa a \lambda \lambda u ́ v \omega$, to brush or sweep, brooms being made of its twigs.)

1. C. vulgàris, Salisb. (C. Atlantica, Seemann, Jour. Bot. 4, p. 305, t. 53. Erien vulguris, L.) - Low grounds, Tewksbury, Massachusetts (.Jackson Dawson, \&c., a small patch); border of forc st on Cape Elizabeth, Maine ( $\mathrm{Mr}$. Pickard, from Dr. Wood); also Nova Scotia, Cape Breton, and Newfoundland; mostly local. (See various articles in Amer. Jour. Sci.) July, Aug. (Eu.)

\section{PHÝL Ó D O CE, Salisb. Phyllodoce.}

Corolla urn-sh"ped or bell-shaped, 5-toothed, deciduous. Stamens 10 : anthers pointless, shorter than the filaments, opening by terminal pores. Pod 5-celled, 5-valved, septicidal (as are all the succeeling), many-secled.-Iow alpine Heath-like evergreen undershrubs, clothed with scattered linear and obtuse rongh-margined leaves. Flowers usually nodding on solitary or umbelled peduncles at the summit of the branches. (" A mythological name.")

1. P. taxifolia, Salisb. Corolla oblong-urn-shaped, purplish, smooth; style included. (Menziesia exrùlen, Smith.) - N pine summits of the mountains of New Hampshire and Maine, and northward. July. (Eu.)

\section{KÁ L M I , L. American Laurel.}

Calyx 5-parted. Corolla between wheel-shaped and bell-shaped, 5-lobed, furnished with 10 depressions in which the 10 anthers are severally lodged; filaments long and thread-form. Pod globose, 5 celled, many-seeled. - Evergrcen mostly smooth shrubs, with alternate or opposite entire coriaceous leaves, 
naked buds, and showy flowers. (Dedicated to Peter Kulin, a pupil of Linnzus who travelled in this country about the middle of the last century, afterwards Professor at $\mathbf{A b c}$.)

§1. F'lower's in simple or clustered naked umbel-like corymbs: pedicels from the axils of small and firm foliaceous persistent bracts: calyx smaller thun the pod, persistent: leaves glabrous.

1. K. latifólia, L. (Calico-bush. Mountain Laurel. SpoonwOOD.) Leaves mostly alternate, bright green buth sides, ovate-lanceolate or elliptical, tapering to each end, petioled; corymbs terminal, many-flowered, clammypubescent; pod depressed, glandular. - Rocky hills and damp soil, rather common from Maine to Ohio and Kentucky, as a shrub $4^{\circ}-8^{\circ}$ high; but in the mountains from l'enn. southward forming dense thickets, and often treelike $\left(10^{\circ}-20^{\circ}\right.$ high). May, June. - Elowers profuse, large and very showy, varying from deep rose-color to nearly white, clammy.

2. K. angustifolia, L. (Shrep Laurel. Lambill.) Leaves commonly opposite or in threes, pale or whitish underneath, light green above, narrowly oblong, obtuse, petioled; corymbs luteral (appearing later than the shoots of the season), slightly glandular, many-flowered; pod depressed, nearly smooth; pedicels recurved in fiuit. - Hillsides : common. May, June. - Shrub $2^{\circ}-3^{\circ}$ high : the flowers more erimson and two thirds smaller than in the last.

3. K. glaùca, Ait. (Pale LaURer.) Branchlets 2-edged: lecuves opposite, nearly sessile, oblony, white-ylancous beneath, with recolute margins; corymbs terminal, few-fluwered, smooth; bracts large; pod ovoid, smooth. - Var. RosmanINı́olia has linear and strungly revolute leaves. - Cold peat-bogs and mountains, from P'eunsylvania northward. May, June. - Straggling, about $1^{\circ}$ high. Flowers $\frac{1}{2}$ ' broud, lilac-parple.

\$2. Flowers scattered, solitury in the axils of the leaves of the season: calyx leafy, larger than the pod, nearly equalling the corvllu, ut length deciduous: leaves (alternate and opposite) and branches bristly-hairy.

4. K. hirsùta, Walt. Branches terete; leaves oblong or lanceolate (4" long), becoming glabrous. - Sandy pine-barren sivamps, E. Virginia and southward. May-Sept. - Shrub $1^{\circ}$ high. Corolla rose-color.

\section{MENZIESIA, Sinith. Menziesia.}

Calyx very small and flattish, 4-toothed or 4-lobed. Corolla cylindraceousurn-shaped and soon bell-shaped, obtusely 4-lobed. Stamens 8, included : anther-cells opening at the top by an oblique pore. Pod ovoid, woody, 4-celled, 4-valved, many-secded. Siceds narrow, with a loose coat. - A low shrub; the straggling branches and the oblong-obovate alternate deciduous leaves (like those of Azalea) hairy and ciliate with rusty rather chaff-like bristles. Flowers small, developed with the leaves, in terminal clusters from scaly buds, greenishwhite and purplish, nodding. (Naned for Archibald Menzies, who in Vancouver's voyage brought the species from the Northwest Coast.)

1. M. ferrugínea, Smith, var. globulàris. Corolla rather shorter and broader than in the Oregon plant. - Alleghany Mountains, S. Pennsylvania to Virginia, \&c. (Also beyond Lake Superior.) June. 


\section{A Zа̀ L $\mathbf{A}$, L. False Honexgekle. Azalea.}

Calyx 5-parted, often minute. Corolla funnel-form, 5-lobed, slightly irregular; the lobes spreading. Stamens 5, with long exserted filaments, usually declined, as well as the similar style : anthers short, opening by terminal pores, pointless. Pod 5-celled, 5-valved, many-sceded. Sceds scalc-like. - Upright shrubs, with alternate and obovate or oblong deciduous leaves, which are entire, ciliate, and mucronate with a glandular point. Flowers large and showy, often glandular and glutinous outside, in umbelled clusters from large scaly-imbricated terminal buds. (Name from à $\zeta a \lambda \epsilon$ és, arid, - most inappropriate as applied to our species, which grow in swamps.)

\section{* Flowers appearing after the leaves.}

1. A. arboréscens, Pursh. (Sмоoтir Azarka.) Branchlets smooth; leaves obovate, obtuse, very smooth both sides, shining alove, glaucous beneath, the margins bristly-ciliate; culyx-lolies long and conspicuous; corolla slightly clammy ; stamens and style very much exserted. - Mountains of Penn. to Virginia, and sonthward. June. - Shrub $3^{\circ}-10^{\circ}$ high, with thickish leaves, and very fragrant rose-colored blossoms larger than in No. 3.

2. A. viscosa, L. (Сеamy A. White Swamp-Honeyguckle.) Branchlets bristly, as well as the margins and midrib of the oblong-obovate otherwise smooth leaves; caly.x-lobes mimute; corolla clammy, the tube much longer than the lobes; stamens and especially the style exserted. - Var. GuAùca has the leaves paler, often whitc-glancous underneath or both sides, sometimes roughhairy. - Var. NfTiDA is dwarf, with oblanccolate leaves green both sides. Swamps, Maine to Kentucky, mostly near the coast. June, July. - Shrub $4^{\circ}$ $-10^{\circ}$ high, with clammy fragrant flowers, white or tinged with rose-color.

\section{* * Flowers appearing before or with the leaces.}

3. A. nudiflora, L. (Purple A. Pinxter-flower.) Branchlets rather hairy; leaves obovate or oblong, downy unterneath; calyx very short; tube of the corolla srarcely longer than the ample lobes, slighly glandular; stamens and style much exserted. - Swamps, Massachusetts and New York to Illinois, and southward. April, May. - Shrub $2^{\circ}-6^{\circ}$ high; the showy flowers varying from flesh-color to pink and purple. There are numberless varieties, some of them with 10 stamens.

4. A. calendulàcea, Michx. (Flame-colored Azatea.) Branchlets and obovate or oblong leaves hairy; crlyx-lobes oblong, rather conspicuous; tube of the corolla shorter than the lobes, hairy; stamens and style much exserted. - Woods, mountains of Penn. to Virginia, Kentucky, and southward. May. - Shrub $3^{\circ}-10^{\circ}$ high, covered just when the leaves appear with a profusion of large orange blossoms, usually turning to flame-color, not fragrant.

\section{RHODODÉ NDRON, L. ROSE-BAY.}

Calyx 5-parted, minute in our species. Corolla bell-shaped or partly funnelform, sometimes slightly irregular, 5-lobed. Stamens 10 (rarely fewer), commonly declined: anthers, pods, \&c. as in Azalea. - Shrubs or low trees, with cvergreen entire alternate leaves, and ample showy flowers, in compact terminal 


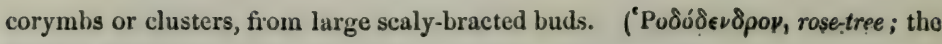
ancient name.)

1. R. máximum, L. (Great Lauiez.) Leuves ellipticul-ablong or lanceoblong, acule, narrowed towards the base, very sinooth, with somewhat revolute margins; pedicels viscid; corolla bell-shaped. - Damp deep woods, sparingly from Maine to Ohio, but very common along shaded water-courses through tha ? mountainous parts of Pennsylvania and sonthward. July. - Shrub or tree $6^{\circ}-$ $20^{\circ}$ high. Leaves $4^{\prime}-10^{\prime}$ long, very thick. Corolla an inch broad, pale roset color or nearly white, greenish in the throat on the upper side, and spotted with yellow or reldish.

2. R. Catawbiénse, Michx. Leaves oval or oblong, rounded at both ends, smooth, pale beneath ( $3^{\prime}-5^{\prime}$ long) ; corolla broadly bell-shaped, lilac-purple; pedicels rusty-downy. - High Alleghanies, Virginia and southward. June. Shrub $3^{\circ}-6^{\circ}$ high.

3. R. Lappónicum, Wahl. (Laplañ Rose-bay.) Divarf, prostrate; leaves elliptical, obluse, dotted (like the branches) with rusty scales; umbels fewflowered; corolla open bell-shaped, dotted; stamens 5-10. - Alpine summits of the mountains of Maine, New Hampshire, and New York. July. - Shrub 6t high, in broad tufts: leaves f' long. Corolla violet-purple. (Eu.)

\section{RHOD ÒRA, Duhamel. Riodora.}

Calyx minute, 5-toothed. Corolla irregular and 2-lipped; the upper lip usually 3-lobed or 3-cleft, and the lower two-parted or of 2 distinct spreading petals. Stanens 10, and with the slender style declined. Otherwise as in Azalea. (Nane from pódon, a rase, from the color of the showy flowers.)

1. R. Canadénsis, I. - Damp cold woods and swamps, New England to P'enn. and northward, or on mountains. May.-A handsome low shrub, with the oblong deciduous leaves whitish and downy underneath; the showy rose-purple (rarely white) flowers in umbel-like clusters, on short peduncles, appearing rather carlicr than the leaves.

\section{LEDUM, L. Labrador Tea.}

Calyx 5-toothed, very small. Corolla of 5 obovate and spreading distinct petals. Stamens 5-10: ąnthers opening by terminal pores. Pod 5-celled, splitting from the base upwards, many-seeded: placenta borne on the summit of the columella. - Low shrubs, with the alternate entire leaves clothed with rusty wool underneath, persistent, the margins revolute: herbage slightly fragrant when bruised. Flowers white, small, in terminal umbel-like clusters from large sealy buds: bracts or scales thin and caducous. ( $\Lambda \dot{\eta} \delta 0 \nu$, the ancient Greek name of the Cistus.)

1. I. latifolium, Ait. Leaves elliptical or oblong ; stanens $\mathbf{5}$, sometimes 6 or 7 ; pod oblong. - Cold bogs and damp mountain woods, New England to Peunsylvania, Wisconsin, and northivard. June. - Shrub $2^{\circ}-5^{\circ}$ high. (L. Palóstre, L., grows in British America. It is distinguished by its linear leaves, uniformly 10 stumens, and oval pods.) (Eu.) 


\section{Lo Iseleưria, Desv. Alpine Azalea.}

Calyx 5-parted, nearly as long as the rather bell-shaped and deeply 5-cleft regular corolla. Stamens 5, not declined, included : anthers opening lengthwise. Style short. Pod ovoid, 2-3-celled, many-sceded, 2-3-valved; the valves 2 cleft from the apex: placenta borne on the middle of the columella. $-\mathrm{A}$ small depressed evergreen shrubby plant, much branched and tufted, smooth, with coriaceous opposite elliptical leaves, on short petioles, with revolute margins. Flowers small, white or rose-color, $2-5$ in a cluster, from a terminal scaly bud; the scales or bracts thick and persistent. (Named for Loiseleur Delongchamps, a French botanist.)

1. L. procúmbens, Desv. (Azalea procumbens, L.)-Alpine summits of the White Mountains, New Hampshire, on rocks. June. (Eu.)

\section{LEIOPHÝ LLUM, Pers. Sand Mrrte.}

Calyx 5-parted. Corolla of 5 distinct obovate-oblong petals, spreading. Stamens 10, exserted: anthers opening lengthwise. Pod 2-3-celled, splitting from the apex downward, many-seeded. - A low much-branched evergreen, with the aspect, foliage, \&c. of the preceding genus, but the crowded leaves sometimes alternate, scarcely petioled. Flowers small, white, in terminal umbel-like clusters. (Name formed of $\lambda$ eios, smooth, and $\phi \dot{\lambda} \lambda \lambda_{o v}$, foliage, from the leaves.)

1. L. buxifolium, Ell. - Sandy pine barrens of New Jersey, and mountain-tops in Virginia? and southward. May. - Shrub $6^{\prime}-10^{\prime}$ high: leaves oval or oblong, smooth and shining, $3^{\prime}-6^{\prime \prime}$ long.

\section{Pí R OLA, Tourn. Wintergreen. Sitin-leaf.}

Calyx 5-parted, persistent. Petals 5, concave and more or less converging, deciduous. Stamens 10 : filaments awl-shaped, naked: anthers extrorse in the bud, but in the flower inverted by the inflexion of the apex of the filament, more or less 4-celled, opening by a pair of pores at the blunt or somewhat 2-horned base which by the inversion becomes the apparent apex! Style generally long: stigma 5-lobed or 5-rayed. Pod depressed-globose, 5-lobed, 5-celled, 5-valved from the base upwards (loculicidal); the valves cobwebly on the elges. Sceds minute, innumerable, resembling saw-dust, with a very loose cellular-reticulated coat. - Low and smooth perennial herbs, with running subterranean shoots, bearing a cluster of rounded and petioled evergreen root-leaves, and a simple raceme of nodding flowers, on an upright more or less scaly-bracted scape. (Name a diminutive of Pyrus, the Pear-tree, from some fancicd resemblance in the foliage, which is not obvious.)

\$1. Stamens ascending: style turned down and fowards the apex usually more or less curved upwards, longer than the campanulate-connivent or somewhat expanding petals : stigma much narrower than the truncate and somewhat excavated apex of the style which forms a sort of ring or collar, the 5 lobes at first very short and included, at length usually protruded. (Leaves denticulate or entire.)

1. P. rotundifolia, L. Leaves orbicular, thick, shining, usnally shorter than the petiole ; raceme elongated, many-flowered ; calyx-lobes lanceolate or oblong- 
lanceolate, acutish, with somewhat spreading tips, one half or one third the length of the roundish-olovate rather spreading (chiefly white) petuls; anther-cells nearly Ulunt. - Damp or sandy woods : common, especially northward. June, July. Scape $6^{\prime}-12^{\prime}$ high, many-bracted : flowers ${ }^{\prime}$ broad. - Exhibits many varieties, such as: Var. INCAKNATA, with flesh-colored flowers; calyx-lobes triangularlanceolate. - Var. ASAKIFÒLIA, with oblate or round-reniform leaves, and triangular-ovate calyx-lobes of about half the length of the white or flesh-colored petals. (P. asarifolia, Michx.) Coinmon northward. - Var. Uliginòsa, with roundish-oval or somewhat kidney-shaped smaller leaves $\left(1^{\prime}-1 \frac{1^{\prime}}{2}\right.$ wide), and ovate acute calyx-lobes, about one quarter of the length of the reddish or purple petals; flowers rather smaller, few or several. (P. uliginosa, Torr. \&. Gir.) Cold bogs, N. New England to Wisconsin, and northward. (Eu.)

2. P. elliptica, Nutt. (SHn-Leaf.) Leaves thin and dull, ellintical or olvoute-ocal, usuelly longer than the margined petivle; raceme many-flowered; calyxlobes ovute, acute, not one fourth the length of the obovate rather spreading (greenishwhite) petuls; anther-cells blunt. - Rich woods, New England to Pennsylvania, Wisconsin, and northward: common. June. - Scape and flowers nearly as large as in the preceding.

3. P. chlorántha, Swartz. Leaces small. (I'long), roundish, thick, dull,

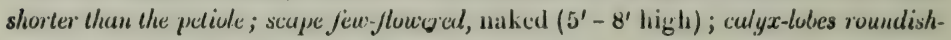
ovute, very short; the elliptical petals converging (greenish-white); anther-cells contracted below the orifice into a distinct neck or horn; style little exserted. - Open woods, New England to Penn., Wisconsin, and northward. June, July.

4. P. oxypétala, C. F. Austin, n. sp. Lecives orate, small ( $8^{\prime \prime}-12^{\prime \prime}$ long), shorter than the slender petiole; scape $\left(7^{\prime}-8^{\prime}\right.$ high) several-flowered; flowers on ascending pedicels, not nodding; calyx-lobes triangular-ovate, acute, short; petals lanceolate-oblony, acnminate, greenish; anthers conspicuously mucronute at the apex, obtusely 2-horned (as in No. 3) at the base, not inverted; style straightish, scarcely exserted. - Wooded hill near Deposit, Delaware Co., New York, June 1, 1860, C. F. Austin. - Stigutat as in No. 3; the calyx-lobes, \&c., different, so that it can hardly be a monstrosity of that species.

§2. Stamens regular: style straight, much narrower than the expanded depressed 5-rayed stigma: petuls erect and connivent.

5. P. secúnda, L. Subcaulescent; leaves ovate, thin, longer than the petiole, scattered, finely serrate; racemes dense and spike-iike, the numerous small (greenish-white) flowers all turned to one side, scarcely nodding; calyx-lobes ovate, very much shorter than the oblong oval petils ; style long, exserted. - Rich woods : common eastward and northwarl. July. - Scape $3^{\prime}-6^{\prime}$ high. (Eu.)

Var. pùmila ('́anc, Cat. I'l. Oneida Co.) is a remarkable form, growing in high peat-bogs from Otsegu Co., New York, Lake Superior, and northward (indicated by Chamisso in Russian Ancrica); leaves orbicular or broully ovel, very thin $\left(5^{\prime \prime}-12^{\prime}\right.$ long); scape $2^{\prime}-4^{\prime}$ high, 3 - 8 -flowered. July, Aug.

6. P. minor, L. Leaves roundish, slightly crenulate, thickish, mostly longer than the margined petiole; raceme spiked; calyx-lobes triangular-ovate, very much shorter than the nearly globose corolla; style short and included. - Woods at the base of the White Mountuins, New Hampshire, Lake Superior (L. Fout ), 
and northward. July, Ang. - Scape $5^{\prime}-10^{\prime}$ high. Flowers small, crowded, white or rose-color. (Eu.)

\section{MON is $\mathrm{MS}$, Salisb. One-flowered Prola.}

Petals 5, widely spreading, orbicular. Filaments awl-shaped, naked : anthers as in Pyrola, but conspicuously 2-horned. Style straight, exserted: stigma large, peltate, with 5 narrow and conspicuous radiating lobes. Valves of the pod naked, as in the next genus. (Parts of the flower occasionally in fours.) Scape 1-flowered. Otherwise as in Pyrola : intermediate between it and Chimaphila. (Name formed of $\mu$ óvos, single, and $\ddot{\sigma} \sigma \mathrm{s}$, delight, from the pretty and solitary flower.)

I. M. uniflora. (Pýrola uniflora, $L_{\text {. }}$ ) - Deep cold woods, from Penn. and New England northward. June. - A small perennial, with the rounded and reiny serrate thin leaves $\left(6^{\prime \prime}-9^{\prime \prime}\right.$ long), clustered at the ascending apex of creeping subterranean shoots; the 1 - 2 -bracted scape $\left(2^{\prime}-4^{\prime}\right.$ high) bearing a white or rose-colored terminal flower 6 " wide. (Eu.)

\section{CH I M Á PH I LA, Pursh. Pipsissewa.}

Petals 5, concave, orbicular, widely spreading. Stamens 10 : filaments enlarged and hairy in the middle: anthers as in Pyrola, but more or less conspicnously 2-horned. Style very short, inversely conical, nearly immersed in the depressed summit of the globular ovary: stigma broad and orbicular, diskshaped, the border 5-crenate. Pod, \&c. as in Pyrola, but splitting from the apex downwards, the edges of the valves not woolly. - Low, nearly herbaceous plants, with long running underground shoots, and evergreen thick and shining leaves, somewhat whorled or scattered along the short ascending stems: the fragrant (white or purplish) flowers corymbed or umbelled on a terminal pednncle. (Nnme from $\chi \in i \mu a$, vinter, and $\phi i \lambda \epsilon \omega$, to love, in allusion to one of the popular names, viz. Wintergreen.)

1. C. umbellàta, Nutt. (Prince's Pinf. Pipsisarwa.) Leaves wedgelanceolute, acute at the base, sharply serrate, not spoltcd; perluncles 4-7-flowered. - Dry woods : common. June. - Plant $4^{\prime}-10^{\prime}$ high, leafy : petals flesh-color: anthers violet. (Fn.)

2. C. maculàta, Pursh. (Srotted Wintergreen.) Leaves ovate-lanceolate, obtuse at the base, remotely toothed, the upper surface variegated with white; peduncles 1-5-flowered. - Dry woods: most common in the Middle States June, July - Plant $3^{\prime}-6^{\prime}$ high.

\section{PTERósPORA, Nutt. Pine-drops.}

Calyx 5-parted. Corolla ovate, urn-shaped, 5-toothed, persistent. Stamens 10: anthers 2-celled, awned on the back, opening lengthwise. Style short: stigma 5-lobed. Pod globose, depressed, 5-lobed, 5-celled, loculicidal, but the valves cohering with the columella. Seeds very numcrous, ovoid, tapering to each end, the apex expanded into a broad reticulated wing many times larger than the body of the seed. $-\Lambda$ stout and simple purplish-brown clammy-pubes- 
cent root-parasitic herb $\left(1^{\circ}-2^{\circ}\right.$ high $)$; the wand-like stem furnished towards the base with scattered lanceulate scales in place of leaves, above bearing many nodding (white) tluwers, resubling those of Andromeda, in a long bracted ra-

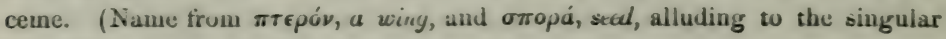
wing borue by the seerls.)

1. P. Andromedè, Nutt. - Hard clay soil, parasitic apparently on the roots of pines, from Vermunt, l'eekskill and Albany, N. Y., aud N. Penusylvania northward and westward: rare.

\section{SCHW in Ítzia, ell. Sweet Pine-sap.}

Calyx of 5 oblong-lanceolate acute scale-like sepals, erect, persistent. Corolla persistent, bell-shaped, rather fleshy, 5-lubed, slightly 5-giblous at the bare. Stamens 10: authers much shorter than the filaments, fixed near the summit, arnless; the two sac-shaped cells opening at the top. Pud ovoid, 5-celled, with a short and thick style, and a large 5 -angular stigma. Seeds innumerable. A low and smouth brownish plant, $3^{\prime}-4^{\prime}$ high, with the aspect of Munotropa, scaly-bracted, the fluwers several in a terninal spike, at tirst nodding, flesh-color, exhaling the fragrance of violets. (Naned for the late L. D. con Schueinitz.)

1. S. odoràta, Ell. - Wuvds, parasitic on the rovts of herbs, Maryland and southward: rare. April.

\section{MONÓtropa, L. Indian Pipe. Pine-8ap.}

Calyx of 2-5 lanceolate bract-like scales, deciduous. Corolla of 4 or $5 \mathrm{sep}$ arate erect spatulate or wedge-shaped scale-like jetals, which are gibbons or saccate at the base, and tardily deciluous. Stamens 8 or 10: filaments awlshaped: anthers hiduey-shajed, becoming l-celled, opening across the top. Style columnar: stigrua disk-like, 4-5-rayed. Pul ovoid, 8-10-grooved, 4-5celled, loculicidal: the very thick placentex covered with innumerable minute seeds, which have a very loose coat. - Iuw and fleshy herbs, tawny, reddish, or white, parasitic on routs, or growing on decomposing vegetable matter like a Fungus; the clusteral stems springing from a ball of matted fibrous ruotlets, furnished with scules or bracts in place of leaves, 1 -several-flowered; the fluwering summit at first nodding, in fruit erect. (Name composil of póvos, one, and трúmos, turn, from the summit of the stem turned to one side.)

§1. MONOTIR()I'A, Nutt. I'lant inodorous, with a single 5-petullud and 10-androus flower at the summit; the culye of $2-4$ irreyular scules or bructs: anthers transverse, opening by 2 chinks: style short and thick: stigma naked.

1. M. uniflora, L. (Ixuiax Pipl. Curise-Plant.) Smuoth, waxywhite (turning blackish in drying, $3^{\prime}-8^{\prime}$ high); stigma naked. - Dark and rich woods: common. June-Aug.

§ 2. HYPÓPITYS, Dill. Plant commonly fiugrant: flowors several in a sculy raceme; the terminal one usually 5-petalled and 10-undrous, while the rest are 4petalled and 8-androus; the bract-like sepuls mostly as many as the petals: anthers opening by a continuous line into 2 very unequal valves, the sinaller one ered and appeuring like a continuation of the jilument: style longer than the ovary, holluw. 
2. M. Hypópitys, L. (Pine-sar. Fane Breci-drors.) Somewhat pubescent or downy, tawny, whitish, or reddish $\left(4^{\prime}-12^{\prime}\right.$ high $)$; pod globular or oval; stigma ciliate. - Occurs in various forms: the more pubescent is $\mathbf{M}$. lanuginòsa, Michx. - Oak and pine woods : common. June-Aug. (Eu.)

\section{Order 57. Gatacínede. (Galax Family.)}

Character that of the following genus; which is kept as a distinct order until the true relationship is ascertained.

\section{1. Ġ̀ LA X, L. GALAX.}

Calyx of 5 small and separate sepals, persistent. Petals 5, hypogynous, obovate-spatulate, rather erect, deciduous. Stamens hypogynous : filaments united in a 10-toothed tube, slightly cohering with the base of the petals, the 5 teeth opposite the petals naked, the 5 alternate ones shorter and bearing each a roundish 1-celled anther, which opens across the top. Pollen simple. Style short: stigma 3-lobed. Pod ovoid, 3-celled, loculicidally 3-valved: columella none. Seeds numerous, the cellular loose coat tapering to each end. Embryo straight in fleshy alhumen, more than half its length. - Evergreen herb, with a thick matted tuft of scaly creeping rootstocks, beset with fibrous red roots, sending up round-heart-shaped crenate-toothed and veiny shining leaves (ahout $2^{\prime}$ wirle) on slender petioles, and a slender naked scape, $1^{\circ}-2^{\circ}$ high, bearing a wand-like spike or raceme of small and minutely-bracted white flowers. (Name from $\gamma^{\prime} \lambda a$, milk, - of no conceivable application to this plant.)

1. G. aphýlla, L. - Open woods, Virginia and southward. June.

\section{Order 58. aquifoliàcea. (Holly Family.)}

Trees or shrubs, with small axillary 4-8-merous flowers, a minute calyx free from the 4-8-celled ovary and the 4-8-seeded berry-like drupe; the stamens as many as the divisions of the almost or quite 4-8-petalled corolla and alternate with them, attached to their very base. - Corolla imbricated in the bud. Anthers opening lengthwise. Stigmas 4-8, or united into one, nearly sessile. Seeds suspended and solitary in each cell, anatropous, with a minute embryo in fleshy albumen. Leaves simple, mostly alternate. Flowers white or greenish. - A small family, here represented by only two genera (Prinos being placed under Ilex); related to the Celastracex, \&c., among the Polypetalous orders as much as to the following order.

\section{1. İ EX, L. (Ilex \& Prinos, L.) Holux.}

Flowers more or less diøciously polygamous. Calyx 4-6-toothed. Petals 1-6, separate, or united only at the base, oval or obovate, obtuse, spreading. Stamens 4-6. The berry-like drupe containing 4-6 little nutlets. - Leaves alternate. Fertile flowers inclined to be solitary, and the sterile or partly sterile flowers to be clustered in the axils. (The ancient Latin name of the Holly-Oak rather than of the Holly.)

L \& $M-33$ 
§1. AQUIFÒLIUM, 'T'ourn. Parts of the flower commonly in fours, sometimes in fives or sixes: drupe red, its nutlets ribled, veiny, or one-grooved on the back: leaves (mostly smooth) coriuceous and evergreen.

\section{* Leaves armed with spiny teeth: trees.}

1. I. opàca, Ait. (American Holly.) Leaves oval, flat, the wavy margins with seattered spiny tecth; flowers in loose clusters along the base of the young branches and in the axils; calyx-tecth acute. - Moist woodlands, Maine to Penusylvania, near the coast, and more common from Virginia southward. June. - Tree $20^{\circ}-40^{\circ}$ high; the deep green foliage less glossy, the berries not so bright red, and their nutlets not so veiny, as in the Luropean Holly (I. Aquiroliua, L.).

* * Leuvrs serrute or entire, not spiny: shrubs.

2. I. Cassine, L. (Cassena. Yaupon.) Leaves lunce-ovate or elliptical, crenate $\left(1^{\prime}-1 \frac{1}{2}^{\prime}\right.$ long) ; flower-clusters nearly sessile, smooth ; calyx-teeth obtuse. Virginia and soutliward along the coast. May. - Leaves used for tea by the people along the coast, as they were to make the eelebrated black drink of the North Carolina Indians.

3. I. myrtifolia, W:It. Lcaves linear-lanceolate or linear-oblong, sparingly and sharply serrute or entire ( 1 ' long); peduncles slender and 3-9-flowered, or the more fertile sliurter and 1-fiuwered, smooth; calyx-tecth acute. - Coast of Virginia and south wari. May. - Probably a var. or the next.

4. I. Dahoòn, Walt. (HAwoon Hol.t.y.) Leaves ollanceolate or oblong, entire, or sharply serrate towards the apex, with revolute margins $\left(2^{\prime}-3^{\prime}\right.$ long), the viditib and peduncles pubescent; calyx-teth acute. - Swainps, coast of Virginia and southward. May, June.

\$2. P'RINO)I) IS. P'urts uf the (pollygamous or diacions) flowers in fours or fives (rardy in sires) : diape red or purple, the nutlets striale-many-rilbuel on the back. leaves deciduous: shruls.

5. I. decídua, Walt. Leraves wedlye-oblong or lunce-obovate, obtusely serrate, downy on the midrib bencath, shining above, becoming thickish; peduncles of tha sterile flowers longer than the petioles, of the fertile short; calyx-tecth smooth, acute. - Wet grounds, Virginia, Illinois, and southward. May.

6. I. montícola, Gray. Leuves viate or lance-oblong, ample $\left(3^{\prime}-5^{\prime}\right.$ long $)$, taper-pointed, thin-membranaceous, smooth, sharply serrate; fertile flowers very short-peduncled; calyx ciliate. (I. ambígua, Torr. I. montàna, Ed. I, nő ['rinos montanus, S'u.) - 1)amp woods, Taconic and Catskill Mountains, and Cattaraugus Co., New York (G. W. Clinton), through Pennsylvania (east to Northampton Co. Mi. Wolle, Prof. T. Green), and southward along the Alleghanies. May.

7. I. móllis, Gray. Leaves suft downy leneath, oval, ovate, or oblong, taperbointed at both ends, especially at the apex, thin-membranateous, sharply serI ulate; sterile flowers very numerous in unhel-like clusters, the pedicels shorter than the petiole and (with the calyx) soft-downy, the fertile peduncles very short. (Prinos pubeseens, Michx. herb. P. ambiguns, Pursh, not Michx.) Burgoon's Gap, Alleghamies of P'ennsylvania (.J. R. Lonerie, Porker), and along the mountinins in the Sunthern States. - Rescinbles the last. 
§ 3. PRINOS, L. Parts of the sterile flowers in fours, fives, or sixes, thiose of the fertile flowers commonly in sixes (rarely in fives, sevens, or eights) : nutlets smooth and even: shiubs.

* Leaves deciduous : flowers in sessile clusters, or the fertile solitary : fruit bright red.

8. I. verticillata, Gray. (Brick Alder. Winternerry.) Leuves obovate, oval, or wedge-lanceolate, pointed, acute at the base, scrrate, downy on the veins beneath; flowers all very short-peduncled. (1'rinos verticillatus, L.) - Low grounds: common. May, June.

9. I. lævigata, Gray. (Smootir Winterberny.) Icaves lanceolate or oblong-lanceolate, pointed at both ends, appressed-serrulate, shining above, beneath mostly glabrous; sterile flowers long-peduncled. (Prinos lavigatus, Pursh.) - Wet grounds, Maine to the mountains of Virginia. June. - Fruit larger than in the last, ripening earlier in the autumn.

* * Leaves coriaceous, evergreen, shining above, often black-dotted beneath: fruit black.

10. I. glàbra, Gray. (Inkmenry.) Leaves wedge-lanceolate or oblong, sparingly toothed towards the apex, smooth; peluncles ( $\frac{1}{2}$ long) of the sterile flowers 3-6-flowered, of the fertile 1-flowered ; calyx-teeth rather blunt. (Prinos glaber, L.) - Sandy grounds, Cape Ann, Massachusetts, to Virginia and southward near the coast. June. - Shrub $2^{\circ}-3^{\circ}$ high.

\section{NEMOPÁNTHES, Raf. Mountain Holly.}

Flowers polygamo-diœcious. Calyx in the sterile flowers of 4-5 minute deciduous teeth; in the fertile ones obsolete. Petals 4-5, oblong-linear, spreading, distinct. Stamens 4-5: filaments slender. Drupe with $4-5$ bony nutlets, light red. $-\Lambda$ much-branched shrub, with ash-gray bark, alternate and oblong deciduous leaves on slender petioles, entire, or slightly toothed, smooth. Flowers on long and slender axillary peduncles, solitary, or sparingly clustered. (Name said by the anthor to mean "flower with a filiform peduncle," therefore prob-

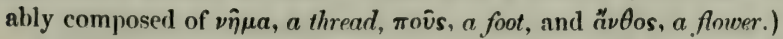

1. N. Canadénsis, DC. (Ilex Canadensis, Mich.x.) - Damp cold woods, from the mountains of Virginia to Maine, Wisconsin, and northward : common at the north. May.

\section{Order 59. EBenàcea. (Ebony Famity.)}

Trees or shrubs, with alternate entive leaves, and polygamous regular flowers which have a calyx free from the 3-12-celled ovary; the stamens 2-4 times as many as the lobes of the corolla, offen in pairs before them, their anthers turned invards, and the fruit a several-celled berry. Ovules 1 or 2, suspended from the summit of each cell. Seeds anatropous, mostly single in each cell, large and flat, with a smooth coriaceous integument; the embryo shorter than the hard albumen, with a long radicle and flat cotyledons. Styles wholly or partly separate. - Wood hard and dark-colored. No milky juice. - A small family, chiefly tropical, reprefested here only by the Persimmon. 


\section{Dios Pýros, L. Date-Plum. Persimmon.}

Calyx 4-6-lobed. Corolla 4-6-lobed, convolute in the bud. Stamens com. monly 16 in the sterile fluwers, and 8 in the fertile, in the latter imperfect. Berry large, globular, surrounded at the base by the thickish calyx, 4-8-celled, 4-8-seeded. - Flowers diceciously polyganous, the fertile axillary and solitary, the sterile sinaller and often clustered. (Name, $\Delta$ iós, of Jove, and $\pi v \rho o$ s, grain.)

1. D. Virginiàna, L. (Common Persimox.) Leaves ovate-oblong, smooth or nearly so; peduncles very short; calyx 4-parted; corolla between bell-shaped and urn-shaped; styles 4, two-lobed at the apex; ovary 8-celled. Woods and old ficlds, Rhode Island and New York to Illinois, and southward. June. - Tree $20^{\circ}-60^{\circ}$ high, with very hard blackish wood, thickish leaves, a pale yellow corolla, and a plum-like fruit, $\mathbf{l}^{\prime}$ in diameter, which is exceedingly astringent when green, yellow when ripe, and sweet and edible after exposure to frost.

\section{Order 60. Sapoticese. (Sappodilla Family.)}

Trees or shrubs, mostly with a milky juice, simple and entire alternate leaves (often rusty-downy beneath), small and perfect regular flowers usually in axillary clusters; the calyx free and persistent; the fertile stamens commonly as many as the lobes of the hypogynous short corvlla and opposite them, inserted on its tube, along with one or more rows of appendages and scales, or sterile stamens; anthers turned outwards; ovary 4-12-celled, with a single anatropous ovule in each cell; seeds large. - Albumen mostly none; but the large embryo with thickened cotyledons. Style single, pointed. A small, mostly tropical order, producing the Sappodilla or Star-apple, and some other edible fruits, represented in our district only by the genus

\section{B U M Élia, Swartz. Bumelia.}

Calyx 5-parted. Corolla 5-cleft, with a pair of internal appendages at each sinus. Fertile stamens 5 : anthers arrow-shaped. Sterile stamens 5, petal-like, alternate with the lobes of the corolla. Ovary 5 -celled. Fruit small, resembling a cherry, black, containing a large ovoid and erect seed, with a roundish scar at its base. - Flowers small, white, in fascicles from the axil of the leaves. Branches often spiny. Leaves often fascicled on short spurs. Wood very hard. (The ancient name of a kind of Ash.)

1. B. lycioides, Giertn. (Southern Buckthorn.) Spiny $\left(10^{\circ}-25^{\circ}\right.$ high); leaves wedye-oblong varying to oval-lanceolate, with a tapering base, often acute, reticulated, nearly glabrous $\left(2^{\prime}-4^{\prime}\right.$ long); clusters densely many-flowered; fruit ovoid. - Moist ground, Illinois, Kentucky, and southward. May, June.

2. B. lanuginossa, Pers. Spiny $\left(10^{\circ}-40^{\circ}\right.$ high $)$; leaves oblong-obovate or wedge-obovate, rusty-woolly beneath, obtuse $\left(1_{2}^{\prime}-3^{\prime}\right.$ long); clusters 6 - 12-flowered; fruit globular. (B. lanuginosa \& tomentosa, $A$. $D C$.) - Woods, lllinois, opposite St. Louis, and southward, - a variety with the leaves less woolly and rusty beneath (B. oblongifolia, Nutt.), passing towards No. 1. July. 


\section{Order 61. S'TYRACACEAE. (Storax FAmily.)}

Shrubs or trees, with alternate simple leaves destitute of stipules, and perfect regular flowers; the calyx either free or adherent to the 2-5-celled ovary; the corolla of 4-8 petals, commonly more or less united at the base; the stamens twice as many as the petals or more numerous, monatelphous or polyadelphous at the base ; style 1; fruit dry or drupe-like, 1-5-celled, the cells commonly 1-seeded. - Seeds anatropous. Embryo nearly the length of the albumen: radicle slender, as long as or longer than the flat cotyledons. Corolla hypogynous when the calyx is free: the stamens adherent to its base. Ovules 2 or more in each cell. - A small family, mostly of warm countries, comprising two very distinct tribes, which are sometimes separated as suborders or orders.

Trlbe I. STYRACER. Calyx 4-8-toothed or entire. Stamens 2-4 times as many as the petals : anthers linear or oblong, adnate, introrse. Ovules or part of them ascending - Flowers white, handsome. Pubescence soft and stellate.

1. Styrax. Calyx coherent only with the base of the 3-celled ovary. Corolla mostly 5 , parted. Fruit 1-celled, 1-seeded.

2. IInlesia. Caly $x$ coherent with the whole surface of the 2-4-celled ovary, which is 2-4, winger and 2-4-celled in fruit. Corolla 4-lobed.

Tribe I. STMPLOCINER. Culyx 5-cict. Stnmens usually very numerous : an thers short, Innate. Ovules pendulous. - Flowers yellow. Pubescence simple.

8. Symplocos. Calyx coherent. Petals 5, united merely at the base.

\section{ST⿱亠乂 RAX, Tourn. Stonax.}

Calyx truncate, somewhat 5 -toothed, the base (in our species) coherent with the base of the 3-celled many-ovuled ovary. Corolla 5-parted (rarely 4-8. parted), large; the lobes mustly soft-downy. Stamens twice as many as the lobes of the corolla: filaments flat, united at the base into a short tube: anthers linear, adnate. Fruit globular, its base surrounded by the persistent calyx, 1-celled, mostly 1-seeded, dry, often 3-valved. Seed globular, erect, with a hard coat. - Shrubs or small trees, with commonly deciduous leaves, and axillary or lenfy-racemed white and showy flowers, on drooping peduncles; produced in spring. Pubescence scurfy or stellate. (i $\Sigma \tau \dot{p} p a \xi$, the ancient Greek name of the tree which produces storax.)

1. S. grandifolıa, Ait. Leaves obovate, acute or pointed, white-tomentose beneath ( $3^{\prime}-6^{\prime}$ long) ; flowers mostly in elongated racemes; corolla ( $f^{\prime}$ long) convolute-imbricated in the bud. - Woods, Virginia and sonthward.

2. S. pulverulénta, Michx. Leaves oval or obovate (about 1'long), above sparingly puberulent, and scurfy-tomentose beneath; flowers ( $\left(\frac{1}{2}{ }^{\prime}\right.$ long) $1-3$ together in the axils and at the tips of the branches, fragrant. - Low pine barrens, Virginia (Pursh) and southward. - Shrub $1^{\circ}-4^{\circ}$ high.

3. S. Americana, Lam. Leaves oblong, acute at both ends (1- - $3^{\prime}$ long), smooth, or barely pulverulent beneath; flowers axillary or in 3-4-flowered racemes ( $\frac{1}{2}$ 'long); corolla valvate in the bud. (S. glahrum and S. leve, Ell.)-Mar. gin of swamps, Virginia and southward. - Shrub $4^{\circ}-8^{\circ}$ high. 


\section{HA Lìs I A, Ellis. SNowdrop or Silver-bell-Tree.}

Calyx inversely conical, 4-toothed; the tube 4-ribbed, coherent with the 2-4celled ovary. Petals 4 , united at the base, or oftener to the middle, into an open bell-shuped corolla, convolute or imbricated in the bud. Stamens 8-16: filaments united into a ring at the base, and usually a little coherent with the base of the corolla: anther's linear-oblong. Ovules 4 in each cell. Fruit large and dry, 2-4-winged, within bony and 1-4-celled. Seeds single, cylindrical. Shrubs or small trees, with large and veiny pointed deciduous leaves, and showy white flowers, drooping on slender pedicels, in clusters or short racemes, from axillary buds of the preceding year. l'ubescence partly stellate. (Named for Stephen Hales, author of Vegetable Statics, \&c.)

1. H. tetráptera, L. Leaves oblong-ovate; fruit 4-winged. - Banks of streams, upper part of Virginia, also on the Ohio River at Evansville (Short), and southwarl. Fruit $1 \frac{1}{2}$ long.

\section{SÝ M PLOCOS, Jacq. (HÒPEA, L.) Sweet-Lear.}

Calyx 5-cleft, the tube coherent with the lower purt of the 3-celled ovary. Petals 5, imbricated in the lud, lightly unisted at the base. Stamens very uumerous, in 5 clusters, one colering with the base of each petal : filaments slender: anthers very short. Fruit drupe-like or dry, mostly l-celled and 1-seeded. - Shrubs or small trees, tho leaves commonly turning yellowish in drying, and furnishing a yellow dye. Flowers in axillary clusters or racemes, yellow. (Name $\sigma \dot{u} \mu \pi \lambda$ okos, connected, from the union of the stamens.)

1. S. tinctoria, L'Her. (IIonse-Sugar, \&c.) Leaves elongated-oblong, acute, obscurely toother, thickish, almost persistent, minutely pubescent and pale beneath $\left(3^{\prime}-5^{\prime}\right.$ longs); flowers $6-14$, in close and bracted clusters, odorous. - Rich ground, Virginia and southward. April. - Leaves sweet, greedily eaten by cattle.

\section{Order 62. Plantacinàceate. (Plantain Family.)}

Chiefly stemless herbs, with regular 4-merous spiked flowers, the stamens inserled on the tube of the dry and membranaceous veinless monopetalous corolla, alternate with its lobes; - chiefly represented by the genus

\section{Pla i tiago, I. Plantain. Ribgrass.}

Calyx of 4 imbricated persistent sepals, mostly with dry membranaceous margins. Corolla salver-form, withering on the pod, the border 4-parted. Stamens 4, or rarely 2 , in all or some flowers with long and weak exserted filaments, and fugacious 2-eelled anthers. Ovary 2- (or in No. 5 falsely 3-4-) celled, with 1 several ovules in each cell. Style and long hairy stigma single, filiform. Pod 2-eelled, 2-several-seeded, opening all round by a transverse line, so that tho top falls off like a lid, and the loose partition (which bears the peltate seeds) falls away. Embryo straight, in fleshy albumen. - Icaves ribbed. Flowers whitish, small, in a bracted spike or head, raised on a naked scape. (The Latin name.) 
\$1. Flowers all perfect and alike, and with the 4 stimens and filiform stigma much exserted, but dichogamous, i. e. with the stigma exserted from the tip of the corolla a day or so before it expands and the anthers are hung out (an arrangement for crose. fertilization) : lobes of the corolla spreading or reflexed uffer flowering.

- Leaves 5-7-ribled, mostly broad: spike long and slender, smouth: secds not concave on the inner fuce: root peremial, or perhaps anmend in No. 2 and 3.

1. P. major, L. (Common Plantain.) Smooth or rather hairy, rarely roughish ; leaves ovate, oblong, oval, or slightly heart-shaped, often toother, abruptly narrowed into a channelled petiole; spike dense; pod 7-16-seeded. Moist grounds, everywhere near divellings. June - Sept. $-\Lambda$ small and rongher form in salt marshes. (Nat. from Eu., but probably indigenous high north.)

2. P. Камтscintica, Cham. Much resembles small forms of the preceding; but sepals and bract narrower, and pod 4-seeded. (P. Rugelii, Decaisne.) -Buffalo, N. Y., Mr. Day, and sparingly in the south. ( $\Lambda_{\text {pparently adv.) }}$

3. P. sparsiflora, Michx. Slender $\left(3^{\prime}-18^{\prime}\right.$ high), smoothish or hairy; leaves lancoolute or oblong, 3-5-nerved, tapering to hoth ends, denticulate or entirc ; spike spursely-fluwered, very slender: lobes of the corolla acute; pod 2-seeded. Mound City, Illinois (Dr. Vasey), and southwarrl. July - Sept.

4. P. cordàta, Lam. 'Tall, glabrous; leuves hoart-shuped or round-ovate $\left(3^{\prime}-8^{\prime}\right.$ long), long-petioled, the ribs rising from the midrib; spike at length loosely flowered; bructs round-ovate, ftrshy; pod 2-4-seodrd. - Along rivulets, New York to Wisconsin (rare), and southwarl. April-Jun\&.

* * Leaves linear, thick and fleshy, vithout ribs, or when dry obscurely 3-nerved: spike slender: tube of the corolla hairy below: seeds not hollowed.

5. P. maritima, L., var. juncoides. Smooth, or the ecape slightly pubescent; leaves flat or flattish and channelled, crect, nearly as long as the scape $\left(5^{\prime}-12^{\prime}\right)$, mostly entire; pod 2-celled or incompletely 3-4-celled, 2-4-sceded ; root on our coast annual or biennial. (P. juncoìles, Lnm.) - Salt marshes, from New Jersey northward. Near Boston a depauperate form, $2^{\prime}-5^{\prime}$ high, littlo fleshy, grows in sand beyond the influence of salt water (D. Murray). The perennial $\mathbf{P}$. maritima occurs in New Brunswick, \&c., perhaps in Maine.

* * Leaves 3-5-ribhed, narrow: spike thick and dense, at first or throughout very short: two of the sonvious sepals generally united into one: serels only 2 , hollowat on the inner fuce.

6. P. lanceolata, L. (Ribgrass. Ripplegrass. English Puantain.) Mostly hairy; scape grooved-angled, at length inuch longer than the lanceolate or lance-oblong leaves, slender $\left(9^{\prime}-2^{\circ}\right.$ high $)$; root perennial. - Dry fields : common castward. (Nat. from Eu.)

\$2. Flowers of two sonts on distinct plants, apparently polygamo-diocious; the mostly sterile with the usual large anthurs on long capillary. filmments, and the lobes of the corolla reflered or sprending; the truly, frrtile with minute anthers on short included filaments, and the corolla usurilly closing permanently over the apex of the fruit: seeds not hollowed on the fuce: small. annuals or biennials.

\section{* Stamens 4: spike dense.}

7. P. Virgínica, L. Hairy or hoary-pubescent $\left(2^{\prime}-9^{\prime}\right.$ high); leaves oblong, varying to obovate and spatulate-lanceolate, 3-5-nerved, slightly or 
coarsely and sparingly toothed; seeds usually 2. - Sandy grounds, Rhode Island to Illinois and southward. May-Sept.

* Stamers only 2 : leaves narrowly linear or thread-shaped, barely 1-ribbed: spike mostly slender, of few or muny crowded or scutterel small flowers.

8. P. pusílla, Nutt. Minutely pubescent $\left(1^{\prime}-4^{\prime}\right.$ high $)$; leaves entire; pod short-ovoid, 4-seeded, little exceeding the calyx and bract. - Dry hills, New York to Illinois, and southward. April-Aug.

9. P. heterophýlla, Nutt. Leaves rather fleshy, acute, entire, or soms of them below 2-4-lobed or toothed; pod ollong-convidal, 10-28-seeded, nearly twice the length of the calyx and bract. (P. pusilla, Decaisne, in DC.) - Low or sandy grounds, from Pliladelphia southward. April-June. - Plant $2^{\prime}-8^{\prime}$ high.

§ 3. Flowers all commonly fertile, but of 2 sorts on different plants; the more common with very small anthers on short filaments (perhups eurly and clase-fertilized) ; others with large anthers on lony-exserted filaments : corolla with broad round lobes permanenlly widcly spreading: seeds 2 (one in each cell), boat-shaped, deeply hollowed on the fuce: mostly annuls, with narrow and woolly or huiry leaces.

10. P. Patagónica, Jaç. Silky-woslly, or becoming naked; leaves 1 3-nerved; spike cylindrical or oblong, dense; sepals very obtuse, scarious, with a thick centre. (Found through almost the whole length of America.)

Var. gnaphalioldes, Gray. White with silky wool ; leaves varying from oblong-linear to filiform; spike very dense $\left(\begin{array}{lll}\frac{1}{4} & 4^{\prime} \\ \hline\end{array}\right.$ exceeding the calyx. (P. Lagòpus, Pursh. P. gnaphalioides, Nutt.) - Dry plains, W. Wisconsin aud southwestward. - Runs through var. SPINULOSA and var. NUDA into

Var. aristàta, Gray. Looscly hairy and green, or becoming glabrous; bracts awned, $2-3$ times the length of the flowers. (P. aristata, MFichx., \&c.) Illinois and southwestward.

\section{Ordeik 63. Plumbaginatceat. (Leadwont Family.)}

Maritine herls, with regular 5-merous flowers, a plaited calyx, the 5 stamens opposite the separate petals or the lobes of the corvlla, and the free ovary one-celled, with a solitary ovule hanging from a long cord which rises from the base of the cell. - The Staticis or Marsir-Rosemary Tribe only is represented in our region, in gardens by the Thrnft (Armiria vulGARIS), on the coast by a single species of

\section{S Tá T I C E, Tourn. Sea-Lavender. Margh-Rosemary.}

Flowers scattered or luosely spiked and 1 -sided on the branches, 2-3-bracted. Calyx funnel-form, dry and membranaceous, persistent. Corolla of 5 nearly or quite distinct petals, with long claws, the 5 stanens severally uttached to their bases. Styles 5, rarely 3, separate. Fruit membranous and indeliscent, 1-seeded, in the bottom of the caljx. Embryo straight, in mealy albumen. - Sea sido perennials, with thick and stalked radical leaves; the naked flowering stems or 


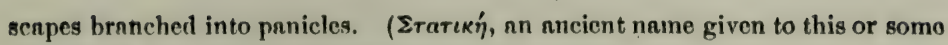
other herb, on account of its astringency.)

1. S. Limónium, L. Leaves oblong, spatulate, or obovate-lanceolate, 1ribbed, tipped with a deciduous bristly point, petioled; scape much-branched, corymbose-panicled $\left(1^{\circ}-2^{\circ}\right.$ high); spikelets I-3-flowered; caly $x$-tube hairy on the angles, the lobes ovate-triangular, with as many teeth in the sinuses. Root thick and woody, very astringent. Flowers lavender-color. (Eu.)

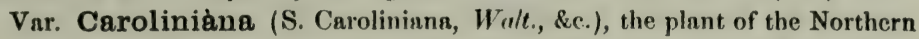
States, has a hollow scape, more erect brunches, at length scattered flowers, and sharper caly $\mathrm{x}$-lohes. - Salt marshes along the coast, extending northward (whero it passes into S. Bahusiensis, Fries). Aug., Sept. (Eu.)

\section{Order 64. Primulàcea. (Primrose Family.)}

Herbs, with simple leaves, and regular perfect flowers, the stamens as many as the lobes of the monapetalous (rarely polypetalous) corolla and inserted opposite them, a 1-celled ovary with a central fiee placenta rising from the base, bearing several or many sceds. - Calyx free from the ovary, or in Samolus partly coherent. (Corolla none in Glaux.) Stamens 4 or 5 , rarely 6 or 8 . Style and stigma one. Seeds with a small embryo in fleshy albumen, amphitropous and fixed by the middle, except in Tribe 4.

Tribe I. PRIMULEFE. Pod free from the calyx, opening by valves or teeth.

* Stemless : leares all in a cluster from the root.

1. Primula. Corolla funnel-form or salver-shaped, open at the throat. Stamens included.

2. Androsace. Corolla short, very small, constricted at the thront. Stamens included.

3. Dodecatheon. Corolla reflexed, ö-parted. Stamens exserted : filaments united.

* Stems leafy : corolla wheel-shaped (or in Glaux none).

4. Trientalis. Corolla mostly 7-parted. Stem lenfy only at the summit.

5. Lysimachia. Corolla 5-6-parted or 5-6-petalled. Stems leafy throughout.

6. Glnux. Corolla none: the calyx petal-like.

Tribe II. ANAGALLIDEA. Pod circumcissile. Otherwise as in Tribe I.

7. Anagallis. Corolla longer than the calyx, 5-parted. Leaves opposite.

8. Centunculug. Corolla shorter than the caly $x, 4-5$-cleft. Leaves alternate.

Tribe II. SAMOLER. Pod partly allherent to the calyx, opening by valves.

9. Samolus. Corolla bell-shaped and with 5 sterile filaments in the sinuses.

Tribe IV. HOTTONIEAE. Pod as in Tribe I. Seeds fixed by the base, anatropous.

10. Hottonila. Corolla salver-shaped. Immersed leaves pectinately dissected.

\section{Prím u La, L. Primrose. Cowsip.}

Calyx tubular, angled, 5-cleft. Corolla salver-shaped, enlarging above the Insertion of the stamens; the 5 lobes often notched or inversely heart-shaped. Stamens 5, included. Pod many-seeded, splitting at the top into 5 valves or 10 teeth. - Low perennial herbs, producing a tuft of veiny leaves at the root, and simple scapes, bearing the flowers in an umbel. (Name a diminutive of primus, from the flowering of the true Primrose in early spring.)

1. P. farinòsa, L. (Birn's-eye Primrose.) Leaves elliptical or obovate-lanceolat2, the lower surface and the 3-20-flowered involucre, fc. covered with 
a white mealiness: corolla pale lilac with a yellow eye. - Shores of Lakes St. Clair and Iuron; also Mount Kineo, Maine (A. H. Smith), and northward. June, July. - Scape $3^{\prime}-10^{\prime}$ high. (Eu.)

2. P. Mistassinica, Michx. Leaves spatulate or wedge-oblung, thin and veiny, not meuly; involucre 1-8-flowered; lobes of the Hesh-colored corolla broadly and decply obcordate. - Shores of the Upjer Lakes : also Crooked Lake (Saituell) and Anusville, Oncila County, New York (Knieshern and Vusey), Willoughby Mountain, Vermont (Wood, \&cc), and northward. May. - A pretty specics, $2^{\prime}-6^{\prime}$ high. (Eu.)

\section{A N D R ÓSACE, Tourn. Androsace.}

Calyx 5-cleft; the tule short. Corolla salver-shaped or funnel-form; the tube shorter than the calyx, contracted at the throat; the limb 5-parted. Stamens and style included. P'ud 5-valved. - Small herbs, with clustered root-leave8, and very small solitary or umbelled flowers. (An ancient and obscure name,

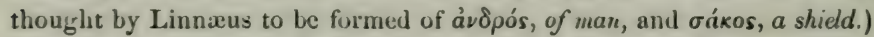

1. A. occidentàlis, I'ursh. Smovthish annual; scapes diffuse $\left(2^{\prime}-4^{\prime}\right.$ high), many-flowerel; leaves and leaflets of the involucre oblong-ovate, entire, sessile; calyx-lobes leafy, triangular-lanceolate, longer than the (white) corolla. - Bare hills on the Mississippi, Illinois, and northwestward.

\section{DOD ECÁ THEON, L. AMenican Cowslip.}

Calyx deeply 5-cleft; the divisions lanceolate, reflexed. Corolla with a very short tube, a thickened throat, and a 5-parted reflexed limb; the divisions long and narrow. Filaments short, monadelphous at the base: anthers long and linear, approximate in a slender cone. - Perennial smooth lerb, with fibrous roots, a cluster of oblong or spatulate leaves, and a simple naked scape, involucrate with small bracts at the sumnit, bearing an ample umbel of showy flowers, nodding on slender peduncles. Corolla rose-color, or sometimes white. (Name fancifully assumed from $\delta \dot{\omega} \delta \epsilon \kappa a$, twelve, and $\theta \in o i$, gorls.)

1. D. Meàdia, L. - Rich woods, Pennsylvania and Maryland to Wisconsin, and southwestward. May, June. - Very handsome in cultivation. In the West called Shouting-Stak.

\section{TR I E N T À L I S, L. ChickWeen-Wintergreen.}

Calyx mostly 7-parted; the divisions linear-lanceolate, pointed. Corolla mostly 7-parted, spreading, flat, without any tube. Filaments slender, united in a ring at the base: anthers ollong, revolute after flowering. Pod few-seeded. Low and smooth peremials, with simple erect stems, bearing a few alternate usually minute and scalc-like leaves below, and a whorl of thin veiny leaves at the summit. Peluncles one or more, very slender, bearing a delicate white and star-shaped flower. (A Latin name, meaning the third part of u foot, alluding to the height of the plant.)

1. T. Americàna, P'ursh. (Star-Flower.) Isaves elongated-lanceolate, tapering to both ends; petals fincly pointel. - Damp cold woods : common northward, and southward in the mountains. May. 


\section{I Y S I M À C H I A, Tourn. Loosegrrifk.}

Calyx 5-(rarely 6-7-) parted. Corolla wheel-shaped, 5- (or 6-7-) parted, or even of as many separate petals. Stanens as many. Pod globose, 5-10valved, few-many-seeded. - Leafy-stemmed perennials, with mostly yellow flowers, either axillary or in a terminal raceme. (Named in honor of King

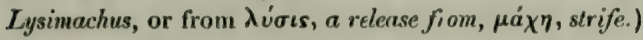

§1. NAUMBÚtrGIA, Monch. Lraves opposite, sessile, minutely glandular-dotted: parts of the flower not rarely 6, sometimes 7 ; the narrow petals almost or quile distinct, and with an interpnsed smoll tooth, sprinlded with purplish dots : filaments slender, distinct, equal: anthers short: pod few-spedod.

1. L. thyrsiflora, I. (TuFted Loosestrifk.) Simonth; stem simple $\left(1^{\circ}-2^{\circ} \mathrm{high}\right)$; lower leaves reluced to scalcs, the rest lanceolate, the axils of one or two pairs of the middle ones hearing a short-peduncled head-like or spikelike cluster of light yellow small flowers; divisions of the corolla lance-linear. (Niumburgia thyrsiflora, Reichenb., and Ed. 2.) - Cold wet swamps, from Penn. northward. June, July. (Eu.)

§ 2. TRIDÝNIA, Raf. Lrrves opposite or whorled, sessile, dotied: calyx and golden-ypllow corolla streaked with dark lines: filuments mostly unequal, plainly monadelphous at the base, with no interyosed sterile ones: anthers short: pod 5valved, ripening only $2-5$ seeds.

2. L. stricta, $\boldsymbol{\Lambda}$ it. Snonth, at length branched, very leafy ; Inves opposite Qr rarely alternate, lanceolate, acute at cach end; flowers on slender pedicels in a long raceme $\left(5^{\prime}-12^{\prime}\right)$, which is leafy at the base; or, in var. рRoDúcts, leafy for fully half its length : lohes of the corolla lance-oblong. - Low grounds : common. Junc-Aug. - Stems $1^{\circ}-2^{\circ}$ high, often bearing oblong or moniliform bulblets in the axils.

3. I. quadrifolia, L. Somewhat hairy; stem simple $\left(1^{\circ}-2^{\circ}\right.$ high $)$; if leaves whorled in fours or fives (rarely in threes or sixes) ovatc-lanceolate; foweers on long capillary peduncles from the axils of the lenves; lobes of the corolla ovate-oblong. - Moist or sandy soil: common. June. $-\Lambda$ variety has the leaves varying to opposite and partly alternate, some of the upper reduced to bracts shorter than the peluncles. Near New York, Washington, \&c.

§ 3. STEIRONEMA, Raf. Leaves opposite, not dolled, glabrous, mostly ciliate at the base: flowers nodding on slender poduncles from the axils of the upper leaves : corolla light yellow, not streaked nor dotterl; the lobes broadly ovate, pointed, with undulate or denticulate margins, little exceeding the sepals: filaments nearly equal, scarcely monadelphous, with the rudiments of a sterile set interpnsed at the base in the form of slender teeth or processes: anthers linar, at lenyth curved: pod 5-10valved, or bursting irregularly, 10 -20-seeded.

4. I. ciliàta, L. Stem erect $\left(2^{\circ}-3^{\circ}\right.$ high $)$; lenves lanceolate-ovnte $\left(3^{\prime}-6^{\prime}\right.$ ong), tapering to an acute point, rounder or heart-shaped at the base, all on long and fringed petioles; corolla longer than the calyx. - Low ground and thickets: common. July.

5. L. radicans, Hook. Stem slender, sonn reclined, the clongaterl branches Iften rooting in the mud; leaves ovate-lanceulate, mostly rounded at the base, on slen. 
der petioles: corolla about the length of the calyx. - Swampy river-banks, West Virginia (Aikin) and southward. - Leaves and flowers nearly one half smaller than in the last.

6. L. lanceolàta, Walt. Stem erect $\left(10^{\prime}-20^{\prime}\right.$ high) ; leaves lanceolate, varying to oblong und to linear, narrowed into a short maryined petiole or tapering base, or the lowest short and broad on long petioles. - Var. HÝ BRIDA is merely the broader-leaved form. Var. angustroòcı (I. angustifolia, Lam.) is a slender branching form, with the upper leaves narrowly lanceolate or linear, and acute at both ends. - Low grounds : not uncommon, especially westward and southward. June-Aug.

7. L. longifolia, Pursh. Sten erect, 4-angled, slender $\left(1^{\circ}-3^{\circ}\right.$ high), often branched below ; stem-leaves sessile, narrowly linear, elonyuted $\left(2^{\prime}-4^{\prime}\right.$ long, $2^{\prime \prime}-3^{\prime \prime}$ wide), smooth and shining, rather rigid, obtuse, the margins often a little revolute, the veins obscure; the lowest oblong or spatulate; corolla ( $8^{\prime \prime}-9^{\prime \prime}$ broad) longer than the calyx, the lobes conspicuously pointed. (L. revoluta, Nutt.) Moist soil, Western New York and Pennsylvania to Wisconsin and Illinois. July - Sept.

\section{§ 4. Introduced European species of true Lysimachia.}

8. L. numuldira, L. (Monerwort.) Smooth; stems trailing and creeping; leaves roundish, small, short-petioled; jeduncles axillary, 1-flowered; divisions of the corolla broally ovate, obtuse, longer that the lance-ovate calyxlobes and the stamens; filaments slightly monadelphous at the base. - Escaped from gardens into damp ground in some places. July-Sept.

\section{GLAÙ X, L. Sea-Milkwort.}

Caly $x$ bell-shaped, 5-cleft; the lobes ovate, petal-like. Corolla wanting. Stamens 5, on the base of the calyx, alternate with its lobes. Pod 5-valved, fewseeded. - A low and leafy fleshy perennial, with opposite oblong and entire sessile leaves, and solitary nearly sessile (purplish and white) flowers in their axils.

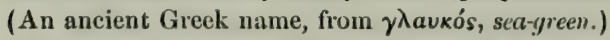

1. G. marítima, L. - Sea-shore of New England from Cape Cod northward. Also beyond the Mississippi northwestward. June. (Eu.)

\section{A N A G Á L L I S, Tourn. Pripernel.}

Calyx 5-parted. Corolla wheel-shaped, with almost no tube, 5-parted, longer than the calyx; the divisions broad. Stanens 5: filaments bearded. Pod membranaceous, circumcissile, the top falling off like a lid, many-seeded. - Low, spreading or procumbent herbs, mostly annuals, with opposite or whorled entire leaves, and solitary flowers on axillary peduncles. (The ancient Greek name, probably from ává, again, and a yá $\lambda \lambda \omega$, to delight in.)

1. A. arvénsis, L. (Common Pimpernel.) Leaves ovate, sessile, shorter than the peduncles; petals obovate, obtuse, fringed with minute teeth or stalked glands. - Waste sandy fields. June-Aug. - Flowers variable in size, scarlet, sometimes purple, blue, or white, quickly closing at the approach of bad weather; whence the English popular name of "Poor Man's Weather-gluss." (Nat. from Eu.) 


\section{CENTÚ N C U L U $\mathrm{S}$, L. Chaffwed.}

Calyx 4-5-parted. Corolla shorter than the calyx, 4-5-cleft, wheel-shaped, with an urn-shaped short tube, usually withering on the summit of the pod (which is like that of Anagallis). Stamens 4 or 5 : filaments beardless. Small annuals, with alternate entire leaves, and solitary inconspicuous flowers in their axils. (Derivation obscure.)

1. C. minimus, I. Stems ascending $\left(2^{\prime}-5^{\prime}\right.$ long $)$; lenves ovate, obovate, or spatulate-oblong; flowers nearly sessile, the parts mostly in fours. (C. lanceolatus, Michx.) - Low grounds, Illinois and southward. (Eu.)

\section{S Á m o lu S , L. Water Pimpernel. Brook-weed}

Calyx 5-cleft; the tube adherent to the base of the ovary. Corolla somewhat bell-shaped, 5-cleft, commonly with 5 sterile filaments in the sinuses. True strmens 5, on the tube of the corolla, included. Pod 5-valved at the summit, many-seeded. - Smooth herbs, with alternate entire leaves, and small white flowers in racemes. ("According to Pliny, an ancient Druidical name.")

1. S. Valerándi, L. Stem crect $\left(6^{\prime}-12^{\prime}\right.$ high $)$, leafy ; leaves obovatc; bracts none; bractlets on the mildle of the slender ascending pedicels; calyxlobes ovate, shorter than the corolla. (En.)

Var. Americànus, Gray. More slender, becoming diffusely branched; racemes often panicled, the pedicels longer and spreading; bractlets, flowers, and pods smaller. (S. floribúndus, H.B.K.) - Wet places : common. JuneSept.

\section{HOTtòn I A, L. Featierfoll. Water Violet.}

Calyx 5-parted, the divisions linear. Corolla salver-shaped, with a short tube; the limb 5-parted. Stamens 5, included. Pod many-seeded, 5-valved; the valves cohering at the base and summit. Seeds attached by their base, anatropous. - Aquatic perennials, with the immersed leaves pectinate, and the erect hollow flower-stems almost leafless. Flowers white or whitish, whorled at the joints, forming a sort of interrupted raceme. (Named for Prof. Ilotton, a botanist of Leyden, in the 17 th century.)

1. H. inflata, Ell. Leaves dissected into threarl-like divisions, scattered on the floating and rooting stems, and crowded at the base of the cluster of peduncles, which are strongly inflated between the joints (often as thick as one's finger); pedicels short. - Pools and ditches, New England to Kentucky, and southward. June-Ang.

\section{Order 65. CENTIBULÀCEAE. (Bladnerwort Family.)}

Small herbs (growing in water or wet places), with a 2-lipped calyx, and a 2-lipped personate corolla, 2 stamens with (confluently) one-celled anthers, and $a$ one-celled ovary with a free central placenta, bearing several anatropous seeds, with a thick straight embryo, and no albumen. - Corolla deeply 2-lipped, spurred at the base in front ; the palate usually bearded. Ovary 
free: style very short or none: stigma 1-2-lipped, the lower lip larger and with a prominent palate. Pod often bursting irregularly. Scapes 1-few-flowered. - Consists mostly of the two following genera:-

\section{U T R I C U L À R I A, L. BLADDerwort.}

Lips of the 2-parted calyx entire, or nearly so. Corolla personate, the palate on the lower lip projecting, often elosing the throat. Anthers convergent. Aquatic and immersed, with capillary dissected leaves bearing little bladders, which are filled with air and flout the plant at the time of flowering; or rooting in the mud, and sometimes with few or no leaves or bladders. Scapes 1-fewflowered; usually flowering all summer. (Name from utriculus, a little bladder.)

* Upper lenves in a whorl on the otherwise naked scape, flouting by means of large bludders formed of the influtul petioles; the lower leaves dissected and capillary, bearing little bladders : rootlcts few or none.

1. U. inflàta, Walt. (Inflated Bladderwort.) Swimming free; bladder-like petioles oblong, pointed at the ends, and branched near the apex, bearing fine thread-like divisions; flowers 5-10 (large, yellow); the appressed spur half the length of the corolla; style distinct. - l'onds, Maine to Vigriaia, and southward, near the coast.

* * Saupes maked (except some small scaly lructs), from immersed branching stems, which commonly swim free, and bear capillary dissected leaves furmished with small air-l/hulders on thicir lubes: roots few and not affixed, or none. (Mostly perenniai, propayated from year to year by a sort of burls.)

- Flowers all alike, yellow, several in a raceme: pedicels nodding in fruit.

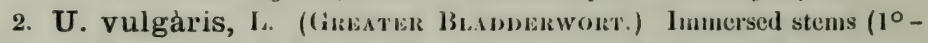
$3^{\circ}$ long) crowded with 2-3-pinumlely many-parted capillary leaves, bearing many bladders; scapes 5-12-flowered $\left(6^{\prime}-12^{\prime}\right.$ long $)$; corolle closed $\left(6^{\prime \prime}-9^{\prime \prime}\right.$ broad, the sides reflexed; spur conical, rather shorter than the lower lip, thick and blunt in the European and the high northern plant; in the common Var. Americana (U. macrorhiza, LeConte), less thick and rather acute. - Common in ponds and slow streams. (Eu.)

3. U. minor, L. (Smaller B.) Loaves scattered on the thread-like immersed stems, 2-4 times forked, short; scapes weak, 2-8-flowered ( $3^{\prime}-7$ ' high); upper lip of the gaping corollin not longer than the depressed palate; spur very shont and blunt, or almost none. - Shallow water, Rhode Island to Illinois and northward. - Corolla $2^{\prime \prime}-3^{\prime \prime}$ bruad. (Eu.)

++ Flowers of 2 sorts; viz. the usual sort $(3-7)$ in a raceme, their pedicels ascending, the corolla yellow; and more fertile ones solitury and scattered alony the hajy stems, on short soon reflexud poduncles, fruiting in the bud, the corolla minute and never expanding.

4. U. clandestina, Nutt. Ieaves numerous on the slender immersed stems, several times forlicel, capillary, copiously bladder-bearing; scapes slender $\left(3^{\prime}-5^{\prime}\right.$ high $)$; lips of the corolla nearly equal in length, the lower broader and 3-lobed, somewhat longer than the approximate thick and blunt spur. Pouds, E. New Lingland, IV. New York, and New Jersey. 
+++ Flowers all alike, fow $(1-5)$ : pedicels erect in fruit. .

+Corolla yellow: scupe and pedicels filiform: spur ascending or horieontal.

5. U. intermedia, Hnyne. Leaves crowded on the immersed stems, 2-ranked, 4-5 times forked, rigid; the divisions linear-awl-shaped, minutely bristle-toothed along the margins, not bladder-bearing, the bladders being on separate leafless branches; upper lip of the corolla much longer than the palate; spur conical-oblong, ucute, uppressed to the very broad $\left(6^{\prime \prime}-8^{\prime \prime}\right)$ lower lip and nearly as long as it. - Shallow pools, New England and New Jersey to Ohio, Wisconsin, and northward. - Leafy stems $3^{\prime}-6^{\prime}$ long. Scapes $3^{\prime}-7^{\prime}$ high. (Eu.)

6. U. striata, LeConte. Leaves crowiler or whorled on the smsll immersed stems, several times forked, capillary, bladder-benring; flowers 2-5 (6" broad), on long pedicels; lips of the corolla nearly equal, broad and expanded; the upper undulate, concave, plaited-striate in the middle; spur nearly linear, olyuse, "pronoching and almost equalling the lower lip. - Shallow pools in pine barrens, Jong Island, New Jersey, and sonthward. - Scape $8^{\prime}-12^{\prime}$ high.

7. U. biflora, Lam. Srape $\left(2^{\prime}-5^{\prime}\right.$ high) $1-3$-fowered, at the base bearing somewhat elongated submersed branches with capillary root-like leaves and numerous bladders; spur oblong, equalling the lower lip; sceds scale-shaped; otherwise resembles the next. - Shallow water, Illinois and southward.

8. U. gíbba, 1. Scape $\left(1^{\prime}-3^{\prime}\right.$ high $), 1-2$-fovered, at the base furnished with very slender short branches, bearing sparingly dissected capillary root-like leaves and scattered bladders; lips of the corolla broad and rounded, nearly equal; the lower with the sides reflexed (4" -5 "long), exceeding the very thick and blunt conical gibbous spur. - Shallow water, Virginia to Massachusetts, $\mathrm{N}$. New York and N. Illinois.

$$
++ \text { Corolla violet-purple. }
$$

9. U. purpurea, Walt. ? Jenves whorled slong the long immerserl freo flonting stems, petioled, decempomd, cupillary, bearing many bladers; Aowers 2-4 (6" wide) ; spur appressed to the 3-lobed 2-saceate lower lip of the corolla nnd abont half its length. (U. saccàta, LeConte.) - Ponds, Maine to Virginia, and sonthward. - Scape $3^{\prime}-6^{\prime}$ high, not scaly below.

* * Scrpe solitary, slender and naked, or with a few small scales, the base rooting in the mud or soil: leaves small, awl-shaped or grass-like, often raised out of the water, commonly few or fugacious: air-bladders few on the lenves or rootlets, or commonly none.

- Flower purple, solitary: leaves bearing a few delicate lobes.

10. U. resupinata, Greene. Scape $\left(2^{\prime}-8^{\prime}\right.$ high) 2 -bracted above; leaves thread-like, on delicate creeping branches; corolla (4" - 5" long) deeply 2-parted; spur oblong-conical, very obtuse, shorter than the dilated lower lip and remote from it. both ascendin! , the flower resting transversely on the summit of the scape. - Sandy margins of ponds, E. Maine to Rhode Island.

++ Flowers 2-10, (chiefly) yollow: leaves entire, rarely scen.

11. U. cornùta, Michx. Stem strict $\left(3^{\prime}-10\right.$ high $), 2-10-$ fowered ; pedicels not longer than the colyx; lower lip of the corolla large and lielmet-slinped, its centre very convex and projecting, while the sides are strongly reflexed; upper lip obovate and much smaller; spur awl-shaped, turned doumward and outward, 
about as long as the lower lip. - Peat-bogs, or sandy swamps : common both northward and southward. - Flowers close together, large.

12. U. subulàta, L. Stem eapillary $\left(3^{\prime}-5^{\prime}\right.$ high $)$; pedicels capillary; lower lip of the coiolla flut or with its margins recurved, equally 3 -lobed, much larger than the ovate upper one; spur cblong, acute, straight, appressed to the lower lip, which it nearly equals in length. - Sandy swamps, pine-barrens of New Jersey, Virginia, and southward. June. - Corolla $2^{\prime \prime}-4^{\prime \prime}$ broad.

U. - Walter characterizes his U. purpurea as with "floribus purvis." Elliott mentions that he once saw, near Savanuah, a small terrestrial species, like U. subulata, but purple-flowered, which he took for Walter's plant. Mr. J. A. Paine, Jr. fuund in the pine barrens of New Jersey, in Sept., 1866, a few minute specinens of this sort, with "faint pink-purple corolla, not larger than a pin's head." It is left for further investigation.

\section{PI N G U Í C L A, L. Butterwort.}

Upper lip of the calyx 3-cleft, the lower 2-cleft. Corolla with an open hairy or spotted palate. - Small and stcmless perenuials, growing on damp rocks, with I-fluwered seapes, aud hroal and entire leaves, all clustered at the root, soft-lleshy, mostly greasy to the touch (whence the name, from pinguis, fat).

1. P. vulgàris, L. Leaves ovate or elliptical; scape and calyx a littlo pubescent; lips of the violet corolla very unequal, the tube funnel-form; spur straightish. - Wet rocks, W. New York to Lake Superior, and northward. July. (Eu.)

\section{Order 66. Bignoniàce E. (Bignonia Family.)}

Woody or ravely levbaceous plants, monopetalous, didynumous or dian- drous, with the ovary commonly 2-celled by the meeting of. the two parietal placenta or of a projection fiom them, many-seeded: the large seeds with a flat embryo and no albumen. - Calyx 2-lipped, 5-cleft, or entire. Corolla tubular or bell-shaped, 5-lobed, somewhat irregular or 2-lipped, deciduous; the lower lobe largest. Stamens inserted on the corolla; the fifth or posterior one, and sometimes the shorter pair also, sterile or rudimentary: authers of 2 diverging cells. Ovary free, bearing a long style, with a 2-lipped stigma. - Leaves compound or simple, opposite, rarely alternate. Flowers large and showy. - Chiefly a tropical family: to which are appended several outlying groups, such as the PLDALINEs, represented by Martynia, \&c.

- Woody plants, with dry pods. Seeds transverse, very flat, winged; the broad and leaf-like cotyledons notched at both ends.

1. Bignomia. Pod flattened parallel with the partition. Leaves compound, tendril-bearing.

2. Tecoma. Pal flattish contrary to the partition. Leaves cumpound, without tendrits.

3. Catalpa. Pud as in No. 2. Fertile stamend only 2. Trees: leaves simple.

* Herbs. Fruit fleshy uutside, woody withiu. Seeds attached by one end, not winger ; the cotyledons thick and entire.

4. Marty nia. Fertile stamens 2 or 4 . Curolla bell-shaped 5-lobed. Fruit beaked. 


\section{BIG N Ò I A, Tourn. Bignonia.}

Calyx truncate, or slightly 5-toothed. Corolla somewhat bell-shaped, 5-lobed and rather 2-lipped. Stamens 4, often showing a rudiment of the fifth. Pod 2-celled, flattened parallel with the valves and partition. Seeds transversely winged. - Woody climbers, with chiefly compound leaves, terminating in a tendril. (Named for the Abbe Bignon.)

1. B. capreolata, L. Smooth; leaves of 2 ovate or oblong leaflets and a branched tendril, often with a pair of accessory leaves in the axil resembling stipules; peduncles few and clustered, 1-flowered. - Rich soil, Virginia to S. Illinois and southward. April. - Stems elimbing tall trees; a transverse section of the wood showing a cross. Corolla orange, $2^{\prime}$ long. Pod $6^{\prime}$ long. Seeds with the wing $1 \frac{t^{\prime}}{}$ long.

\section{TÉ COMA, Juss. TRUMPET-FLower.}

Calyx bell-shnped, 5-toothed. Corolla funnel-form, 5-lobed, a little irregular. Stamens 4. Pod 2-celled, the partition contrary to the convex valves. Seeds transversely winged. - Woody elimbers, with compound leaves. (Abridged from the Mexican name.)

1. T. radicans, Juss. ('Trumper Creeper.) Climbing by rootlets; leaves pinnate; leaflets 5-11, ovate, pointed, toothed ; flowers corymbed; stamens not protruded beyond the tubular-funnel-form corolla. (Bignonia radicans, L.) - Rich soil, Pennsylvania to Illinois and southward; but cultivated farther north. July - Sept. - Corolla $2^{\prime}-3^{\prime}$ long, orange and scarlet, showy.

\section{CA T $\mathbf{A} L \mathbf{P A}$, Scop., Walt. Catalpa. Indian Bean.}

Calyx deeply 2-lipped. Corolla bell-shaped, swelling; the undulate 5-lobed sprending border irregular nnd 2-lipped. Fertile stamens 2, or sometimes 4; the 1 or 3 others sterile and rudimentary. I'od very long and slender, nearly cylindrical, 2-celled; the partition contrary to the valves. Seeds winged on each side, the wings cut into a fringe. ('The aboriginal name.)

1. C. bignonioldes, Walt. Leaves heart-shaped, pointed, downy beneath; flowers in open compound panieles. - S. Illinois ? and southward. Cultivated in the Northern States: a well-known ornamental tree, with large leaves, and showy flowers, which are white, slightly tinged with violet, and dotted with purple and yellow in the throat, appearing in July. Pods hanging till the next spring, often $1^{\circ}$ long.

\section{M A R T Ý N I A, L. UNICORN-PLANT.}

Calyx 5-cleft, mostly unequal. Corolla gibbous, bell-shaped, 5-lobed and somewhat 2-lipped. Fertile stamens 4, or only 2. Pod fleshy, the flesh at length falling away in 2 valves; the inner part woody, terminated by a beak, which at length splits into 2 hooked horns, and opens at the apex between the horns, imperfectly 5-celled, owing to the divergence of the two plates of each of the two partitions or placentæ, leaving a space in the centre, while by reaching and cohering with the walls of the fruit they form 4 other cells. Seeds several, wing- 
less, with a thickened and roughened coat. - Low branching annuals, clammypubescent, exhaling a lieavy odor: stems thickish: leaves simple, rounded. Flowers racemed, large. (Dedicated to Prof. John Muityn, of Cambridge.)

1. M. proboscídea, Glox. Leaves heart-shaped, oblique, entire, or undulate, the upper alternate; corolla dull white or purplish, or spotted with yellow and purple; endocarp of the fruit crested on one side, loug-beaked. - Bunks of the Mississippi in S. Illinois (probably indigenous) and southwestward. Also common in gardens. July - Oct.

\section{Ordeir 67. OIrobanchícede. (Broom-rape Famity.)}

IIerbs destitute of green foliuge (root-parasites) monopetalous, didynamous, the ovary one-celled wilh 2 or 4 parielal placenta; pod very manyseeded: seeds minute, with albumen, and a very mirnute embryo. - Calyx persistent, 4-5-toothed or parted. Corolla tubular, more or less 2-lipped, ringent, persistent and withering; the upper lip entire or 2-lobed, the lower 3-lobed. Stamens 4, didynamous, inserted on the tube of the corolla: anthers 2-celled, persistent. Ovary free, ovoid, pointed with a long style which is curved at the alex: stigma large. Pod 1-celled, 2-valved; the valves each bearing on their face one placenta or a pair. Seeds very numerous, minute, anitropous, the minnte embryo at the base of transparent albumen. - Low, thick or fleshy herbs, bearing scales in place of leaves, lurid yellowish or brownish throughout. Flowers solitary or spiked.

\section{* Elowers of two sorts: stems branching.}

1. Epiphegus. Upper flowers sterile, with a tubular corolla ; the lower fertile, with the corollis minute and not expandiug. Bracts inconspicuous.

* * Vluwers all alike and perfect : stems mostiy simple.

2. Conopholis. Fluwers spiked. Calyx with 2 bractlets, and split on the lower side. Stamens protruled. Corulla 2-lipped.

3. Phelipaca. Flowers spiked or panicled. Calyx with 2 bractlets, and regularly 5-cleft. Corolla 2-lipped. Stamens included.

4. Aphyllon. Fluwers solitary, without bractlets. Calyx regularly 5-cleft. Corolla with the border almost equally 5 -lobed. Stamens included.

\section{EPIPHËGUS, Nutt. Been-diops. Cancer-hout.}

Flowers racemose or spiked, scattered on the branches; the upper sterile, with a long tubular corolla and long filaments and style; the lower fertile, with a very short corolla which seldom opens, but is forced off from the base by the growth of the pod: the stamens and style very short. Calyx 5-toothed. Stigma calpitate, a little 2-lobed. I'od 2 -valved at the apex, with 2 approximate placenta on each valve. - Ilerhs sleuder, purplish or yellowish-brown, much branched, with small and scattered scales, $6^{\prime}-12^{\prime}$ high. (Name composed of '́ $\pi i^{\prime}$, upon, and $\phi \eta \gamma o$ s, the Berch, because it grows on the roots of that tree.)

1. E. Virginiàna, Bart. (E. Anericìnus, Nutt.)-Common under Beech-trees, parasitic on their roots. Aug. - Oct. - Corolla of the upper (sterile) flowers whitish and purple, $6^{\prime \prime}-8^{\prime \prime}$ loug, curved, 4-toothed. 


\section{CON Ó PHOLIS, Wallroth. Squaw-root. Cancer-root.}

Flowers in a thick scaly spike, perfect, with 2 bractlets at the base of the irreg. ularly 4-5-toothed calyx; its tube split down on the lower side. Corolla tubular, swollen at the base, strongly 2-lipped; the upper lip arched, notched at the summit; the lower shorter, 3-parted, spreading. Stamens protruded. Stigma depressed. Pod with 4 placenta, a pair on the middle of each valve. - Upper scales forming bracts to the flowers; the lower covering each other in regular

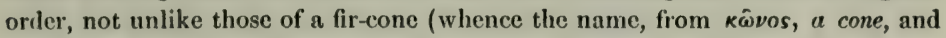

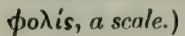

1. C. Americana, Wallroth. (Orobánche $\Lambda$ mericana, $L$.)-Oak woods : not rare, growing in cluste among fallen leaves. May, Junc. $-\Lambda$ singular plant, chestnut-colored or yellowish throughout, as thick as a man's thumb, $\mathbf{3}^{\prime}$ 6' long, covered with scales, which are at first fleshy, then dry and hard.

\section{P H ELIP 夜A, Tourn. Broom-RAPe.}

Flowers perfect, crowded in a spike, raceme, or clustered panicle, with a pair of bractlets at the base of the regular 4-5-eleft calyx. Corolla 2-lipped; the upper lip 2-lobed or notched; the lower 3-parted. Stamens included. Ovary with a gland at the base on the upper side. Iod with 4 placentac, two on the middle of each valve. - Stems rather thick, scaly. (Named for L.\&.J. Phelipeaux, patrons of science in the time of Tournefort.)

1. P. Ludoviciàna, Don. Glandular-pubescent, branched $\left(3^{\prime}-12^{\prime}\right.$ high); the flowers spiked in close clusters; corolla somewhat curved, twice the length of the narrow lanceolate calyx-lobes; the lips equal in length. - Illinois $(E$. Hall) and westward. Oct.

\section{A PHÝ LLON, Mitchell. NAKeD Broom-rape.}

Flowers perfect, solitary on long naked scapes or peduncles, without bractlets. Calyx 5-cleft, regular. Corolla with a long curved tube and a spreading border, somewhat 2-lipped; the upper lip deeply 2-cleft, its lobes similar to the 3 of the lower lip. Stamens included. Stigma broadly 2-lipped. Capsule with 4 equidistant placentre, 2 borne on each valve half-way between the midrib and the margin. Plants brownish or yellowish. Flowers (purplish) and scapes minutely glandular-pubescent. (Name from a privative and $\phi u ́ \lambda \lambda o v$, foliage, alluding to the naked stalks.) - Perhaps rather a section of Phelipaea.

1. A. uniflorum, Torr. \& Gr. (One-flowered Cancer-root.) Stem subterranam or nearly so, very short, scaly, often branched, each branch sending up 1-3 slender one-flowered scapes $\left(3^{\prime}-5^{\prime}\right.$ high); divisions of the calyx lanceaxl-shaped, half the length of the corolla. (Orohánche uniflora, L.) - Woods : not rare. $\Lambda$ pril, May. - Corolla $\mathbf{l}^{\prime}$ long, with 2 yellow bearded folds in the throat, the lohes obovate.

2. A. fasciculatum, Torr. \& Gr. Scaly stem erect and rising $3^{\prime}-4^{\prime}$ out of the ground, mostly longer than the crowded perluncles; divisions of the calyx triangular, very much shorter than the corolla, which has rounded short lobes. (Orobanche fasciculata, Nutt.) - Islands in Lake Michigan (Engelmann), N. Illinois (Vasey), and northwestward. May. 


\section{Order 68. SCROPHULARiàcere. (Figwort Family.)}

Chiefly herbs (rarely trees), with didynamous or diandrous (or very rarely 5 perfect) stamens inserted on the tube of the 2-lipped or more or less irregular corolla, the lobes of which are imbricuted in the bud: fruit a 2-celled and usually many-seedled pod, with the placentce in the axis: seeds anatropous, with a small embryo in copious albumen. - Style single: stigma entire or 2-lobed. Leaves and inflorescence various; but the flowers not terminal in any genuine representatives of the order. - A large order of bitterish, some of them narcotic-poisonous plants : the two principal groups generally distinguishable by the astivation of the corolla.

I. ANTIRRHINIDEE. Upper lip of the corolla covering the lower in the bud (with occasional exceptions in Mimulus, \&c.). Pod usually septicidal.

Tribe I. VERBA SCEAE. Corolla nearly whecl-shaped. Hlowers in a simple spike or raceme. Lenves all alternate.

1. Vexbaseum. Stumens 5 , all with anthers, and 3 or all of them with bearded filaments.

Tribe II. AN'TIRRHINEAs. Corolla tubular, with a spur or sac at the base below, the throat usually with a palate. Porl opening by chinks or holes. Flowers in simple racemes or axillary. Lower leaves usually opposite or whorled.

2. Lisaria. Corolla spurred at the base; the palate seldom closing the throat.

3. Antivhinum. Curolla merely saccate at the base; the palate closing the thront.

Tribe II C. CIELONER. Corolla tubular, or 2-lipped, not spurred nor saccate below. Pod 2-4-valved. Leaves opposite. Inflorescence usually compound the flowers in small clusters or cymes in the axils of the leaves or bracts, the clusters spiked or racemed; or when reduced to a single flower the peduncle 2-bracteate. Stamens 4, with mostly a rudiment of the filth.

4. Scrophularia. Corolla intlated, globular or ublong, with four erect lobes and one spresuling one. Rudinent of the sterile stamen a seule on the upper lip.

5. Collinsia. Corollia 2 -cleft, the short tube saccate on the upper side; the middle lobe of the lower lip sac-like and enclosing the declinel stamens.

6. Chelome. Corolla cubular, inflated ahove. Sterile stamen shorter than the others. Anthers very woolly. Seeds winged.

7. Pentstemon. Corolla tubular. Sterile stamen about as long as the rest. Seeds wingless.

Tribe IV. GRATIOLEAE. Corolla tubular, not saccate nor spurred. Pod 2-valved. Inflorescence simple; the flowers being single in the axil of the bracts or leaves, the peduncles bractless. Leaves all or the lower ones opposite. No rudiment of a fifth stamen.

* Stamens 4, all anther-beariug and sinilar.

8. Mimulus. Calyx prismatic, 5-angled, 5-toothed. Corolla elongated.

9. Comobea. Calyx 5-partel, the divisions equal. Corolla short.

10. Herpestis. Calyx 5-parted, unequal, the upper division largest. Corolla short.

* Auther-bearing stamens 2: usually also a pair of sterile flaments.

11. Gratiola. Caly $\times 5$-parted. Stamens incluiled; the sterile pair short or none.

12. Iysanthes. Calyx 5-parted. Stanens included; the sterile filaments protruded.

II. RIIINAN'TIIIDEE. Under lip or the lateral lobes of the corolla covering the upper in the bud. Pod commonly loculicidal.

Tribe V. SIB'THOPIEA, VERONICEZ, \&c. Corolla wheel-shaped, salvershaped, or bell-shaped. Stamens 2 or 4 , not approaching each other in pairs nor strongly didynamous : anthers 2-oelled. 
18. Mernnthemum. Calyx 4-toothed or cleft. Upper lip of corolla short or none. Sta mens 2, anterior : flaments with an appenilage. Leaves opposite. Flowers axillary.

14 Limosella. Calyx 5-toothed. Corolla open bell-shaped, 5-cleft, nearly regular. Stamens 4. Leaves alternate or fascicled, fleshy. Flowers axillary.

15. Synthyxis. Calyx 4-parted. Corolla bell-shaped, 2-4-lobed, irregular. Stamens 2 or 4. Leaves alternate. Flowers racemed.

16. Veronfea. Calyx 4- (rarely 3-5-) parted. Corolla wheel-shaped or salver-shaped, almost regular. Stamens 2. Leaves chiefly opposite or whorled. Flowers racemed.

Tribe VI. BUCHNEREA. Corolla salver-shaped. Stamens 4, approximate in pairs : anthers 1-celled. Upper leaves alternate. Flowers in a spike.

17. Buchmera. Caly $x$ tubular, 5 -toothed. Limb of the elongated corolla 5 -cleft.

Tribe VIX. GERA RDIEAC. Corolla inflated or tubular, with a spreading and slightly unequal 5-lobed limb. Stamens 4, approximate in pairs: anthers 2-celled. Leaves oppo site, or the uppermost alternate.

18. Seymerla. Stamens nearly equal. Tube of the corolla broad, not longer than the lobes.

19. Gerardia. Stamens strongly unequal, included.

Tribe VII. EUPHTASIEAG. Corolla tubular, 2-lipped; the upper lip narrow, erect or arched, enclosing the $\mathbf{4}$ usually strongly didynamous stamens.

* Anther-cells unequal and separated. Pod many-seeded.

20. Castillela. Caly $x$ tubular, cleft down the lower, and often also on the upper, side.

* Anther-cells equal. Pod many-several-seeded.

21. Schwalbea. Caly $x$ 5-toothed, very oblique, the upper tooth much the smallest.

22. Euphrasia. Calyx 4-cleft. Upper lip of the corolla 2-lobed. Pod oblong.

23. Rhinanthus. Caly $x$ inflated, ovate. Pod orbicular: seeds winged.

24. Pedicularis. Caly $x$ not inflated. Pod ovate or sword-shaped : seeds wingless.

* * Anther-cells equal. Pod 1-4-seeded.

25. Melampyrum. Caly $x$ 4-cleft. Ovary 2-celled, 4-ovuled. Pod flat, oblique.

\section{VERBÁ SCU M, L. MulleiN.}

Calyx 5-parted. Corolla 5-lobed, open or concave, wheel-shaped; the lobes broad and rounded, a little unequal. Stamens 5; all the filaments, or the 3 upper, woolly. Style flattened at the apex. Pod globular, many-seeded. Tall and usually woolly biennial herbs, with alternate leaves, those of the stem a. sessile or decurrent. Flowers in large terminal racemes, ephemeral; in summer. (The ancient Latin name, altered from Barbascum.)

1. V. Thápsús, L. (Cомmon Multein.) Densely woolly throughout; stem (tall and stout, simple, winged by the decurrent bases of the oblong acute leaves; flowers (yellow, very rarely white) in a prolonged and very dense cylindrical spike; lower stamens usually beardless. - Ficlds, \&c. : common. (Nat. from Eu.)

2. V. Blatтגia, L. (Мотн M.) Green and smoothish, slender; lower leaves petioled, oblong, doubly serrate, sometimes lyre-shaped, the upper partly clasping; raceme loose; filaments all bearded with violet wool. - Roadsides : not rare eastward. Corolla either yellow, or white with a tinge of purple. (Nat. from Eu.)

3. V. Lxchntris, L. (White M.) Clothed with a thin powdery woolliness; stem and branches angled above; leaves ovate, acute, not decurrent, greenish above; flowers (yellow, rarely white) in a pyramidal panicle; filaments with whitish wool. - Waste places, Penn. to New York : rare : hybridizes spontaneously with the common Mullein. (Adv. from Eu.) 


\section{LIN À RIA, Tourn. Tond-Flax.}

Calyx 5-parted. Corolla persunate, with the prominent palate often nearly closing the throat, spurred at the bise on the lower side. Stamens 4. Pod thin, opening beluw the summit by one or two pores or chinks. Seeds many. - Herbs, with at least all the upper leaves alternate: fl. in summer. (Namo from Linum, the Flax, which the leaves of some species resemble.)

* Leaves sessile, narrow: plant glabrous, erect, laify.

1. L, Canadénsis, Spreng. (Whlu Tond-Flax.) Slender amual or biennial, mostly simple, with scattered linear leaves; those from prostrate shoots oblong, crowded, and mostly opposite or whorled; flowers Ulue (very small), in a slender raceme, short-pedicelled; spur thread-shaped (oceasionally wanting). — Sandy soil : commou.

2. L. vulgais, Mill. ('Toan-Flax. Butter-and-eggs. Ransted.) Perennial, pale $\left(1^{0}-3^{\circ}\right.$ high $)$; leaves alternate, crowiled, lincar or lanceolate, acutish; flowers crowded in a dense raceme, yellow (1'long); spur awl-shaped; seeds flullened and maryined. - Old tields and roadsides : common eastivard, extending westward : a showy but pernicious weed. - The Peloria state, with a regular 5-cleft horder to the corolla, 5 sjurs, and 5 stanens, has been observed in Pennsylvania by Dr. Darlinglon. (Nat. from Èu.)

3. L. Genistifólia, Mill. Glaucuus pereniul, paniculate-branched; leaves lanceolate, acute, often partly clasping; flowers scullered, ycllow (smaller than in No. 2); seeds angleal and wrinkled. - Roadsides, New York, near the city (l'of. II. J. Clurk, Lesquereux). (Adv. from Eu.)

\section{* * Leaves petioled, broud, veiny, hairy: stems procumbent.}

4. I. Elf́tise, Mill. Branching annual; leaves alternate, ovate and halberd-shaped, mostly shorter than the slender axillary peduncles; flowers small, yellow and purjolish; sepals lanceolate, very acute. - Ficlds and bunks, eastward: scarce. (Adv. from Eu.)

\section{A N TIRRHİ U M, L. SNapdragon.}

Corolla sacente at the base, the throat closed by the large bearded palate. Seeds oblong-truncite. Otherwise nearly as Liuaria. Corolla commonly showy, resembling the face of an animal or a mask; whenee the name (from àvt, in comparison with, and $\dot{\rho} เ \nu$, a snoul.) Fl. summer and autumn.

1. A. Onóntios, I. A small flowered annual or biennial, low, erect; leaves lance-lincar; spike loose, leafy ; sepals longer than the purplish or white corolla. - About gardens, and old fields in Virginia. (Adv. from Eu.)

2. A. majus, L. (LARge Snapdragon.) A large-tlowered perennial, with oblong smooth leaves and a glamlular-downy raceme; sepals short ; corolla $1 \frac{1}{2}{ }^{\prime}-$ 2 long, purple or white. - Eastward escaping from gardens. (Adv. from Liu.)

\section{SCROPHULÀ R I , Tourn. Figwort.}

Calyx deeply 5-cleft. Corolla with a somewhat glubular tube; the 4 upper lobes of the short border erect (the two upper longer), the lower spreading. Stamens 4, declined, with the anther-cells trunsverse and confluent into vinc; 
the vestige of the fifth stamen forms a scale-like rudiment at the summit of the tube of the corolla. Pod many-seeded. - Rank herbs, with mostly opposite leaves, and small greenish-purple or lurid flowers in loose cymes, forming a terminal narrow panicle. (So called because a reputed remerly for scroficla.)

1. S. nodósa, L. Smooth perennial $\left(3^{\circ}-4^{\circ}\right.$ high $)$; stem 4 -sided; leaves ovate, oblong, or the upper lanceolate, cut-serrate, rounded or heart-shaped at the base. (S. Marilándica, L.) - Damp copses and banks. June-Aug. (Eu.)

\section{COLLÍNSIA, Nutt. Collinsia.}

Calyx decply 5-cleft. Corolla declined, with the tube saccate or bulging at the base on the upper side, deeply 2-lipped; the upper lip 2-cleft, its lobes partly turned backwards; the lower 3-cleft, its middle lobe keeled and sac-like, enclosing the 4 declined stamens and style. Fifth stamen a slender rudiment. Pod 4 - many-secded. - Slender branching annuals or biennials, with opposite leaves, and handsome party-colored flowers in umbel-like clusters, appearing whorled in the axils of the upper leaves. (Dedicated to the late Zaccheus Collins, of Philadelphia, an accurate botanist.)

1. C. vérna, Nutt. Slender $\left(6^{\prime}-20^{\prime}\right.$ high) ; lower lenves ovate; the upoer ovate-lanceolate, clasping by the heart-shaped base, toothed; whorls ahout 6-flowered; flowers long-peduncled; corolla (blue and white) twice the length of the culyx. - Moist soil, W. New York to Wisconsin and Kentucky. May, June.

2. C. parviflòra, Dougl. Small; lower leaves ovate or rounded; the upper oblong-lanceolate, mostly entire; whorls 2-6-flowed; flowers shortpeduncled; the small (blue) corolla scarcely exceeding the calyx - Shore of Lake Superior and westward.

\section{B. CHelò Ne, Tourn. Turtle-head. Snake-head.}

Calyx of 5 distinct imbricated sepals. Corolla inflated-tubular, with the mouth a little open; the upper lip broad and arched, keeled in the middle, notched at the apex ; the lower woolly-bearded in the throat, 3-lobed at the apex, the middle lobe smallest. Stamens 4 , with woolly filaments and very woolly heart-shaped anthers; and $\mathrm{n}$ fifth sterile filament smaller than the others. Seeds many, wing-margined. - Smooth perennials, with upright branching stems, opposite serrate leaves, and large white or purple flowers, which are nearly sessile in spikes or clusters, and closely imbricated with round-ovate concave bracts and bractlets. (Name from $\chi € \lambda \omega \dot{\omega} \eta, a$ tortoise, the corolla resembling in shape the head of a reptile.)

1. C. glàbra, L. Leaves very short-petioled, lanceolate or lance-oblong, pointed, variable in width, \&c. : the flowers white, rose-color, or purple. (Also C. oblìgua, L., \&c.) - Wet places : common. July - Sept. - Called also SHelLFLOWER, BALMONY, \&C.

7. PENTStim ON, Mitchell. Beard-tongue. Pentstemon.

Calyx 5-parted. Corolla tubular and more or less inflated, or bell-shaped, cither decidedly or slightly 2-lipped; the upper lip 2-lobed, and the lower 3-cleft. Stamens 4, declined at the base, ascending above; and a fifth sterile filament 
usually as long as the others, either naked or bearded. Seeds numerous, wingless. - Perennials, branched from the base, simple above, with opposite leaves, the upper sessile and mostly clasping. Flowers mostly showy, thyrsoid or ra. cemose-panicled. (Name from $\pi \dot{v} v \tau \epsilon$, five, and $\sigma \tau \dot{\eta} \mu \omega \nu$, stamen; the fifth stamen being present and conspicuous, although sterile.)

* Sterile filament beurded down one side: flowers numerous in a loose and somewhat clammy panicle, white or purplish.

1. P. pubéscens, Solander. More or less pubescent $\left(1^{\circ}-3^{\circ}\right.$ high $)$; stemleaves lanceolate from a clasping base, serrate or sometimes entire; corvlla 2 lipped, gradually widened upwards, somewhat flattened and one-ridged on the upper side, and with 2 infolded lines on the lower which are bearded inside; the throat almost closed; lower lip rather longer than the upper; sterile filament deusely yellow-bearded. - Varies greatly in the foliage, sometimes nearly glabrous, when it is P. lwvigàtus, Sulander, \&c. - Dry banks, Connecticut to Wisconsin, and southward. June-Sept.

2. P. Digitàlis, Nutt. Nearly glabrous $\left(2^{\circ}-4^{\circ}\right.$ high $)$; stem-leaves oblong-or ovate-lanceolate, clasping, serrulate or entire ; corolla abruptly inflated and almost bell-shaped from a narrow base, beardless, with the throat widely open, the spreading lobes nearly equal ; sterile filanent sparingly bearded. (Flowers more showy than in the preceding, mostly white, over I' long). - Rich soil, Alexundria, Virginia (A. H. Curtiss), to Illinois, and southward. June-Aug.

* * Sterile filament nearly beardlcss, diluted and hooked at the end (rarely wanting).

3. P. grandiflorus, Fraser. Very smooth and glaucous; stems simple $\left(1^{\circ}-3^{\circ}\right.$ high $)$; leaves thickish, ovate or rounded, the upper clasping; flowers (showy, $2^{\prime}$ long) on short pedicels, in a long and narrow raceme rather than panicle; corolla oblong-bell-shaped, almost regular, bluish or lilac-purple. Prairies, W. Wisconsin (Falls of St. Anthony, Lapham), and westward. June.

\section{MÍ M U L U S, L. Monkey-Flower.}

Calyx prismatic, 5-angled, 5-toothed, the upper tooth largest. Corolla tubular; the upper lip erect or reflexed-spreading, 2-lobed; the lower spreading, 3 lobed. Stamens 4. Stigma 2-lipped, the lips ovate. Seeds numerous. - Llerbs, with opposite leaves, and mostly handsome flowers on solitary axillary and bractless peduncles. (Name from $\mu \iota \mu \dot{\omega}$, an ape, on account of the gaping corolla.) * Erect from a perennial rout, glabrous: leaves feather-reined: corolla violet-purple.

1. M. ríngens, I. Stem square $\left(1^{\circ}-2^{\circ}\right.$ high $)$; leaves oblong or lanceolate, poinled, clasping by a heart-shaped base, serrate; peduncles longer than the flower; calyx-teeth taper-pointed, nearly equal. - Wet places : common. JulySept. - Flower $1^{\prime}-1 \frac{1}{2}^{\prime}$ loug, rarely white.

2. M. alàtus, Ait. Stem somewhat winged at the angles; leaves oblongovate, fapering into a petiole; peduncles shorter than the calyx, which has very short abruptly pointed teeth : otherwise like the last. - Low grounds, Conuecticut to Illinois, and southward.

* * Diffusely spreading: leaves several-nerved and veiny : corolla yellow.

3. M. Jamesii, Torr. Smooth or smoothish ; stems creeping at the base; stem-leaves roundish or kidney-shaped, nearly sessile, equalling the peduncles; 
caly $x$ ovate, inflated in fruit, the upper tooth inuch the largest. - In cool springs, N. Michigan, Wisconsin, Illinois, and westward. - Flowers small, little larger than in the cultivated M. Moschitus or Musk-Plant.

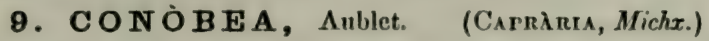

Calyx 5-parted, equal. Upper lip of the corolla 3-lobed, the lower 3-parted. Stamens 4, fertile: anthers approximate. Style 2-lobed at the apex, the lobes wedge-form. Seeds numerous. - Low branching herbs, with opposite leaves, and small solitary flowers on axillary 2-bractleted peduncles. (Name unexplained.)

1. C. multifida, Benth. Diffusely spreading, much branched, minutely pubescent, annual; leaves petioled, pinnately parted, divisions linear-wedgeshaped; corolla (greenish-white) scarcely longer than the calyx. - River-banks, Ohio to Illinois, and southward; also adventive below Philadelphia. July-Sept.

\section{HERPESTIS, Gartn. IIERPESTi8.}

Calyx 5-parted; the upper division broadest, the innermost often very narrow. Upper lip of the corolla entire, notehed or 2-cleft; the lower 3-lobed. Stanens 4, all fertile. Style dilated or 2-lobed at the apex. Sceds numerous. - Low herbs, with opposite leaves, and solitary axillary flowers; in summer: ours rather succulent perenniąls. (Name from í $\beta \pi \eta \sigma \tau \dot{\eta}$, a. creeping thing, the species being chiefly procumbent.)

* Upper lip of the blue corolla merely notched: leaves many-nerved.

1. H. rotundifolia, Pursh. Nearly smooth, creeping; leaves round-obovate, half chsping $\left(\frac{1}{2}^{\prime}-\mathrm{I}^{\prime}\right.$ long); peduncles twice or thrice the length of the calyx, the upper sepal ovate. - Wet places, Illinois and southward.

2. H. amplexicaùlis, Pursh. Stems hairy, creeping at the base; leaves oute, clusping; peduncles shorter than the calyx; upper scpal heart-shaped. - Wet plıces, New Jersey and southward. - Aromatic when bruised.

* Corolla (bluish) almost equally 5-cleft, the upper lip being 2-parted: calyx 2bracted: stamens almost equal: leaves nearly nerveless.

3. H. Monnièra, H. B. K. Smooth, somewhat creeping; leaves obovate or wedge-shaped. - Maryland and southward along the coast.

\section{GRATİOLA, L. Hedge-Hrssor.}

Calyx 5-parted, the divisions narrow and nearly equal. Upper lip of the corolla entire or 2-cleft, the lower 3-cleft. Fertile stamens 2, included, posterior; the anterior mere sterile fllaments, or wanting. Style dilated or 2-lipped at the apex. Pod 4-valved, many-seeded. - Iow herlss, mostly perennials, some apparently annuals, with opposite sessile leaves, and axillary 1-flowered peduncles, usually with 2 bractlets at the base of the calyx. Flowering all summer; all inhabiting wet or damp places. (Name from gratia, grace or favor, on account of supposed excellent medicinal propertics.)

§1. Anthers with a brond connective: the cells transverse: stems mostly diffusely branched, or creeping at base, sofl viscid-pubescent or smooth.

L \& $M-34$ 
* Sterile filaments minute or none: corolla whitish, with the tube yellowish.

1. G. Virginiàna, L. Sten clammy-puberulent above $\left(4^{\prime}-6^{\prime}\right.$ high); leaves lanceolate, narrowed at the base, sparingly toothed; peduncles almost equulling the leaves $\left(\frac{1}{2}^{\prime}-1^{\prime}\right.$ long); pod ovoid (2' long). - Very common.

2. G. sphærocárpa, Ell. Sinooth, rather stout $\left(5^{\prime}-10^{\prime}\right.$ high); leaves lance-ovate or oblong, tuothed; pedundes scarcely longer than the calyx and the large $\left(3^{\prime \prime}\right)$ globular pod. - N. Jersey to Illinois, and soutliward.

* * Sterile filaments struder, tipped with a lithte heud: leaves short $\left(\frac{1}{2}^{\prime}-1^{\prime}\right.$ long).

3. G. viscòsa, Schweinitz. C'lummy-pubescent or glundular; leaves ovata lincenlate or wlong, acute, toothed, mostly shorter than the peduncles; corolia whitish, yellow within. - Kentucky and southward.

4. G. aùrea, Muhl. Neaily glabrous; lenves lancedute or oblong-linear, entire, equalling the peduncles; corolla yolden-ycllow ( $2^{\prime}$ long). - Sandy swamps, N. Vermont and New Hampshire to Virginia, and southward.

§. Anthers with no bivud connectice; the cells verticul: hairy plunts, with erect rigid and more simple stems, from an apporently annual ront: sterile filaments tipped with a heud.

5. G. pilosa, Michx. Jeaves ovate or oblong, sparingly toothed, sessilo (b' long); flowers ncarly sessile; corolla white, scarcely exceeding the calyx. Low ground, Caunden Co., New Jerscy (C'. L'. Smilh, C'. F'. P'urker), Maryland, and southward.

\section{ILYSÁ N THES, Raf. (I.INDÉRNIA, MUhl.)}

Calyx 5-parted, nearly equal. Upper lip of the corolla short, erect, 2-lobed; the lower larger and spreading, 3-cleft. Fertile stamens 2, included, posterior; the anterior pair sterile, inserted in the throat of the corolla, 2 -lobed, without anthers; one of the lobes glandular; the other smooth, usually short and toothlike. Style 2-lipped at the apex. Pod ovate or oblong, many-seeded. - Small and smooth anuuals, with opposite leaves, and small axillary (purplish) flowers, or the upper racemed, produced all summer. (Name from ìús, mud, or mire, and ävOos, flower.)

1. I. gratiololdes, Benth. (False Pimpernez.) Much branched, diffusely spreading $\left(4^{\prime}-8^{\prime}\right.$ high $)$; leaves ovate, rounded, or oblong, sparingly toothed or entire, the upper partly clasping. (Caprària gratioloides, $L$. Lindernia dilatàta, \& L. attenuàta, Muhl.) - Wet places : common.

\section{MICRÁNTHEMUM, Michx. (Including Hemintuus, Nutt.)}

Calyx 4-lobed or 4- (rarely 5-) parted. Corolla short, 2-lipped, with the upper lip considerably shorter than the lower, or 1-lipped, the ıpper lip obsolete; lower lip 3-cleft, the middle lobe longest. Stamens 2, anterior, the short filament with a glandular (mostly basal) appendage: anthers 2-celled, didymous. No sterile filaments. Style short, its apex or the stigina 2 -lobed. Pod glubular, thin, with a very delicate or evaneseent partition, several-many-seeded. - Small, smooth, depressed and tufted or creeping annuals, in mud or shallow water, with opposite and entire rounded or spatulate sessile leaves, and minute 
white or purplish flowers solitnry in the axils of some of the middle leaves (usually one axil floriferous, that of the other leaf sterile). (Name formed of $\mu$ เopós,

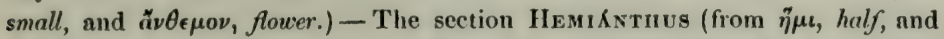
“ँdos, flower) includes the species like ours, of which there are several discovered by $\mathrm{C}$. Wright in Cuba, having the upper lip of the corolla very short or obsolete, and mostly slender or subulate stigmas.

1. M. Nuttállii. (Hemianthus micranthemoides, Nutt.) Branches ascending, $1^{\prime}-2^{\prime}$ high; leaves obovate-spatulate or oval; peduncles at length recurved, about the length of the calyx, which is bell-shaped, 4-toothed and usually split down on one side, in fruit becoming pear-shaped; middle lobe of the corolla linear-oblong, nearly twice the length of the lateral ones; appendage of the stamens nearly as long as the filament itself; stigmas subulate. Tidal muddy bunds of the Delaware River, and southwarp. Aug. - Oct.

\section{IIM OSÉLIA, L. MUdwort.}

Calyx bell-shaped, 5-toothed. Corolla short, widely bell-shaped, 5-cleft, nearly regular. Stamens 4 : anthers confluently 1-celled. Style short, club-shaped. Pod globular, many-seeded; the partition thin and vanishing. - Small annuals, growing in mud, usually near the sea-shore, creeping by slender runners, without ascending stems; ti:e entire fleshy leaves in dense clusters around the simple 1-flowered peduncles. Flowers small, white or purplish. (Name a diminutive of limus, mud, in which these little plants delight to grow.)

1. L. aquática, L. : var. tenuifolia, Hoffm. Leaves (with no blade distinct from the petiole) awl-shaped or thread-form. (L. tenuifolia, Nutt. L. subulata, Ives.) - In brackish tidal mud, from New Jersey northward. Aug., Sept. - Plant $1^{\prime}-2^{\prime}$ high. (Eu.)

\section{S $\mathbf{Y}$ T T Y RIS, Benth. SYNTIYnis.}

Calyx 4-parted. Corolla somewhat bell-shaped, variously 2-4-lobed or cleft. Stamens 2, inserted just below the sinuses on each side of the upper lobe of the corolla, occasionally with another pair from the other sinuses, exserted : anthercells not confluent into one. Style slender: stigma simple. Pod flattened, rounded, obtuse or notched, 2-grooved, 2-celled (rarely 3-lobed and 3-celled), many-seeded, loculicidal ; the valves cohering below with the columella. - Perennial herbs, with the simple scape-like stems beset with partly-clasping bractlike alternate leaves, the root-leaves rounded and petioled, crenate. Flowers in a raceme or spike, with bracter pedicels. (Name composed of $\sigma \dot{v} v$, together, and Oupis, a litlle door ; evidently in allusion to the closed valves of the pod.)

1. S. Houghtoniàna, Benth. Hairy ; root-leaves ronnd-ovate, heartshaped; raceme spiked, dense $\left(5^{\prime}-12^{\prime}\right)$; corolla not longer than the calyx, usually 2-3-parted. - High prairies and hills, Wisconsin, Houghton, Lapham. Michigan, Wright. Illinois, Meud. May. - Corolla greenish-white, for the most part deeply 2-parted, with the upper lip entire, a little longer and narrower than the lower, which is 3-toothed; but occasionally 3-parted, with the upper lip notched or 2-lobed. When there are 4 stamens the lower are later than the others. 


\section{VERó NICA, L. Speedwely.}

Calyx 4- (rarely 3-5-) parted. Corolla wheel-shaped or salver-shaped, the border 4-parted (rarely 5-parted); the lateral lobes or the lower one commonly narrower than the others. Stamens 2 , one each side of the upper lobe of the corolla, exserted: anther-cells confluent at the apex. Style entire: stigma single. Pod flattened, obtuse or notched at the apex, 2-celled, few-manyseeded. - Chiefly herbs: leaves mostly opposite or whorled : flowers blue, fleshcolor, or white. (Derivation doubtful; perhaps the flower of St. Veronica.)

\$ 1. Tall perennials, with mostly whorlcd leaves: racemes terminal, dense, spriked: bracts very smull: tube of the corolla longer them its limb and much longer than the culyx; buth sometimes 5-cleft. (Leptándra, Nutt.)

1. V. Virgínica, L. (Culver's-root. Culver's P'uysic.) Sinooth or rather downy; stem simple, straight $\left(2^{\circ}-6^{\circ}\right.$ high $)$; leaves whorled in fours to sevens, short-petioled, lanceolate, pointed, finely scrrate; spikes panicled; stamens much exserted. - Rich woods, Vermont to Wisconsin and southward: often cultivated. July, Aug. - Corolla small, nearly white. P'od oblong-ovate, not notehed, opening by 4 teeth at the apex, many-secded.

§ 2. Perennials with opposite usually serrate leaves: flowers in axillary mostly opposite racemes: corolla wheel-shaped (pale blue) : pod notched, many-seedad.

2. V. Anagállis, L. (Water Speedwell.) Smooth, creeping and rooting at the base, then erect; laves sessile, most of them clasping by a heurtshaped base, ovate-lanceolate, acute, serrate or entire $\left(2^{\prime}-3^{\prime} \mathrm{long}\right)$; pedicels spreading; pod slightly notched. - Brooks and ditches, especially northward: rare eastward. June-Aug. - Corolla pale blue with purple stripes. (Eu.)

3. V. Americàna, Schweinitz. (American Brookrime.) Sinooth, decumbent at the base, then erect $\left(8^{\prime}-15^{\prime}\right.$ high $)$; leaves mostly petioled, ovate or oblong, acutish, serrate, thickish, truncate or slightly heart-shnped at the base; the slender pedicels spreading; pod turgid. (V. Beceabunga, Amer. authors.) -Brooks and ditches: common. June-Aug.

\$3. Perennials, with difuse or ascending branches from a decumbent base: leaves opposile: racemes axillary, fiom alternate or sometimes opposite axils: curulla wheel-shaped: pod stiongly fluttened, seviral-seeded.

4. V. scutellàta, L. (Marsh SPEedwell.) Simooth, slender and weak (6'-12' high) ; leaces sessile, linear, acute, remotely denticulate; rucemes 1 or 2 , very slender and zigzag; flowers f $w$ and scattercd, on clongated spreading or reflexed pedicels; pod very flat, much broader than long, notched at both ends or didymous. - Bogs : common northward. June-Aug. (Eu.)

5. V. officinàlis, L. (Common SPEęiwell.) Pubescent; stem prostrate, rooting at the base; laves short-petioled, obovate-ellipticul or wedge-ablong, obtuse, serrate; racemes densely many-flowered; peelicels shorter than the calj $\mathbf{x}$; pod obovate-rriangular, broadly notched. - Dry hills and open woods. July. (Eu.)

\$4. Leaves opposite: fluwers in a terminal raceme, the lower bracts resembling the stem-leuvis: corolla wheel-shaped: pods flat, several-seeded.

* Perennials (mostly turning blackish in drying).

6. V. alpina, L. Stem branched from the buse, erect, simple $\left(2^{\prime}-6^{\prime}\right.$ high); leaves ellipticul, or the luwest rounded, entire or toothed; nearly sessile; 
raceme hairy, few-flowered, crouded; pod obovate, notched. - Alpine summits of the White Mountains of New Hampshire. (En.)

7. V. serpyllifolia, L. ('Tryme-Leaved Speenwel. at the creeping base, nearly smooth; branches ascending and simple ( $2^{\prime}-4^{\prime}$ high); leaves ovate or oblong, obscurely crenate, the lowest petioled and rounded, the upper passing into lanceolate bracts ; raceme loose; pod rounded, broader than long, obtusely notched. - Roadsides and fields : common : introduced and indigenous. May-July. - Corolla whitish, or pale blue, with deeper stripes. (Eu.)

* Annuals or biennials: floral leaves like those of the stem, so that the flowers appear to be axillary and solitary: corolla shorter than the calyx.

8. V. peregrina, L. (Neckweed. Purslane Speedwell.) Nearly smooth, erect $\left(4^{\prime}-9^{\prime}\right.$ high $)$, branched; lowest leaves petioled, oval-oblong, toothed, thickish ; the others sessile, obtuse ; the upper oblong-linear and entire, longer than the almost sessile (whitish) flowers; pod orbicular, slightly notched, manyseeded. - Waste and cultivated grounds: common : appearing like an introduced weed. April-June.

9. V. Arvensis, L. (Corn Spendert.) Simple or diffusely branched $\left(3^{\prime}-8^{\prime}\right.$ high), hairy; lonver lenves petioled, ovute, crenate; the uppermost sessile, lanceolate, entire; peduncles shorter than the calyx; pod inversely heart-shaped, the lobes rounded. - Cultivated grounds : rather common. (Nat. from Eu.)

§5. Annuals or biennials (prostrute-spreading, hairy): stem-lecuves opposite (all petioled), the upper alternate and bearing solitary peduncled fovers in their axils: corolla wheel-shaped: pod flat: seeds cup-shaped. Rare or local immigrants, and only near the coast, from Massachusetts to Virginia.

10. V. Agréstis, L. (Field Speedwel.) Leaves round or ovate, crennte-toothed; the floral somewhat similar, about the length of the recurved peduncles; calyx-lobes oblong ; flower small ; ovary mamy-mvuled, but the nearly orbicular and sharply notchrd pod 1-2-seeded. - Sandy ficlds. (Adv. from Eu.)

11. V. Buxвa Ùmi, Tenore. Leuces round or heart-ovate, crenately cuttoothed $\left(3^{\prime}-\mathbf{l}^{\prime}\right.$ long), shorter than the peduncles; flower large (nearly $\frac{1}{2}$ ' wide, blue); calyx-lobes lanceolate, widely spreading in fruit; pod obcordate-triangular, broadly notched, 16-24-seeded. - Waste grounds. (Adv. from Eu.)

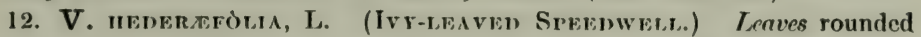
or heart-shaped, 3-7-tonthed or lobed, shorter than the prduncles; caly $x$-lobes somewhat heart-shaped; flowers small; pod turgid, 2-lobed, 2-4-seeded. - Shaded placés. April-June. (Adv. from Eu.)

\section{B Ú C H N E R A, L. Blue-Hearts.}

Calyx tubular, obscurely nerved, 5-toothed. Corolla salver-form, with a straight or curved tube, and an almost equally 5-cleft limb : the lobes oblong or wedge-obovate, flat. Stamens 4 , included, approximate in pairs : anthers onecelled (the other cell wanting). Stylc club-shaped and entire at the apex. Pod 2-valved, many-seeded. - Perennial rough-hairy herbs (doubtless root-parasitic), turning blackish in drying, with opposite leaves, or the uppermost alternate; the flowers opposite in a terminal spike, bracted and with 2 bractlets. (Named in honor of $J$. G. Buchner, an early German botanist.) 
1. B. Americana, L. Rough-hairy; stem wand-like $\left(1^{\circ}-2^{\circ}\right.$ high); lower leaves obovate-oblong, the others oblong and lanceolate, sparingly and coarsely toothed, veiny; the upermost linear-lanceolate, entire; spike interrupted; calyx longer than the bracts, one third the length of the deep-purplo corolla. - Plains, W. New York to Wisconsin and soutliward. June-Aug.

\section{S E Y M i R A, Pursh. Seymeria.}

Calyx bell-shaped, decply 5-cleft. Corolla with a short and broad tube, not longer than the 5 ovate or oblong nearly equal and spreading lobes. Stamens 4, somewhat equal: anthers approximate by pairs, oblong, 2-celled; the cells equal and pointless. Pod many-seeded. - Erect branching herbs, with the general aspect and character of Gerardia : leaves mostly opposite and üissected or pinnatifid, the uppermost alternate and bract-like. Flowers yellow, interruptedly racemed or spilhed. (Nanned for Henry Seymer, an English naturalist.)

1. S. macrophýlla, Nutt. (Muldein-Foxglove.) Rather pubescent $\left(4^{\circ}-5^{\circ}\right.$ high $)$; leaves large, the lower pinnately divided, with the broadly lanceolate divisions pinnatificl and incised, the upper lanceolate; tube of the corolla incurved, very woolly inside, as are the filaments except their apex; style short. dilated and notehed at the point; pod ovate, pointed. - Shady river-banks, Ohio to Illinois, and southwestward. July.

\section{GER ÁRDIA, L. Gerardia.}

Calyx bell-shaped, 5-toothed or 5-cleft. Corolla campanulate-funnel-form, or somewhat tubular, swelling above, with 5 more or less unequal spreading lobes, the 2 upper usually rather smaller and more united. Stamens 4, strongly didynamous, included, hairy : anthers approaching by pairs, 2-celled; the cells parallel, often pointed at the base. Style elongated, mostly enlarged and flattened at the apex. l'od globular or ovate, pointed, many-seeded. - Erect branching herbs (more or less root-parasitic): stem-leaves opposite, or the upper alternate, the uppermost reduced to bracts and subtending 1 -flowered peduncles, which often form a raceme or spike. Flowers showy, purple or yellow ; in late summer and autumn. (Dedicated to the celebrated herbalist, John Gerarde.)

\$1. GERARDIA proper. Calyx-teeth short: corolla purple or rose-color: anthers all alike, nearly pointless: leaves linear, entire. (Our species are all branching annuals. They still need revision, in connection with those of the Southern States.)

* Pediuncles shorter or moderately longer than the culyx: stem erect.

1. G. purpurea, L. (Purple Gerardia.) Stem $\left(8^{\prime}-20^{\prime}\right.$ high) with long and rigid widely spreading branches; leaves linear, acute, rough-margined; flowers large (1' long), bright purple, often downy; calyx-teeth sharp-pointed, shorter than the tube. - Low grounds, Maine to Wisconsin and southward, mostly towards the coast.

2. G. marítima, Raf. (SEA-Side G.) Low $\left(4^{\prime}-12^{\prime}\right.$ high), with shorter branches; lenves ruther.flishy and obtuse, as aie the short culyx-tcath; corolla $\frac{1}{2}$ ' long. - Salt marshes along the coast.

3. G. áspera, Dongl. Sparingly branched $\left(1^{\circ}-2^{\circ}\right.$ high $)$; leaves long and narrowly linear, rough ; pedicels once or twice the length of the calyx, which has 
lanceolate acute teeth nearly as long as the tube; corolla larger than in No. 1. Damp grounds, Illinois, Wisconsin, and westward.

* Peduncles long and fliform, commonly exceeding the leaves: stems diffusely branched, slender $\left(8^{\prime}-20^{\prime}\right.$ high $)$ : corolla light purple, $5^{\prime \prime}-7^{\prime \prime}$ long.

4. G. tenuifolia, Vahl. (SLEnder G.) Leaves narrowly linear, acute, the floral ones mostly like the others; calyx-teeth very short, acute; pod globular, not exceding the calyx. - Dry woods : common.

5. G: setàcea, Walt. Leaves bristle-shaped, as are the branchlets, or the lower linear; pod ovate, mostly longer than the caly. $x$, which has short setaceous teeth. (G. Skinneriana, Wood.) - Dry grounds, Penn. to Wisconsin, and southward.

\$ 2. DASÝSTOMA, Raf. Culyx 5-cleft, the lobes often toothed: corolla yellow; the tube elongated, woolly inside, us well as the anthers and filaments: anthers all alike, scarcely included, the cells awn-pointed at the base: leaves rather large, all of them or only the lower pinnatifid or toothed. (Perennials.)

6. G. flava, L. partly. (Downy False Foxglove.) Pubescent with a fine close down; stem $\left(3^{\circ}-4^{\circ}\right.$ high) mostly simple; leatss ouxte-lanceolate or $a b$ long, oltuse, entire, or the lover usually sinuate-toothed or pinnatifid; perluncles very short; calyx-lobes oblong, obtuse, rather shorter than the tube. - Open woods, especially in the Middle States. - Corolla I $\frac{1}{2}$ ' long.

7. G. quercifolia, Pursh. (Sмоoтu Fatan Foxniove.) Smooth and glausous $\left(3^{\circ}-6^{\circ}\right.$ high), usually branching; lower loaves commonly twice-pinnatifid; the upper oblong-lanceolate, pinnatifid or entire; peduncles ncarly as long as the calyx, the lance-linear acute lobes of which are as long as the at length inflated tube. - Rich woods, especially southward. - Corolla $2^{\prime}$ long.

8. G. integrifolia, Gray. Smooth, not glaucous; stem $\left(1^{\circ}-2^{\circ}\right.$ high) mostly simple; leaves lanceolate, acute, entire, or the lowest obscurely toothed; peduncles shorter than the calyx. (I)asystoma quercifolia, var.? in tegrifolia, Benth.) -Woods and barrens, l'ennsylvania to Illinois, and southward along the mountains. Corolla I' long.

9. G. grandiflora, Benth. Minutely downy; stem much branched $\left(3^{\circ}-\right.$ $4^{\circ}$ high); leaves ovate-lanceolate, coarsely toothed or cut, the lower pinnatifid; peduncles rather shorter than the calyx ; corolla ( $2^{\prime}$ long) 4 times the length of the brondly lancolate entire or toothed calyx-lobes. (D)asystomn Drummondii, I Benth.) - Oak openings, Wisconsin (Laphlum), Illinois (Vasey) and southward. - Intermediate between $G$. flava and the next.

10. G. pediculària, L. Smoothish or pubescent, much branched (20$3^{\circ}$ high, very leafy); lenves ovate-lanceolate, pinnatifid, and the lobes cut and toothed; peduncles longer than the hairy mostly serrate calyx-lobes. - Dry copses : common.

- §3. OTOPIIÝLLA, Benth. Calyx deeply 5-rlef, the loles unequal: corolla purple (rarely white), sparingly hairy inside, as well as the very uncqual slamens: anthers pointless, those of the shorter pair much smaller. (Annuals?)

11. G. auriculàta, Michx. Rough-hairy; stem erect, nearly simple (9'$20^{\prime}$ high); leaves lanceolate or ovate-lanceolate, sessile, the lower entire, the others with an oblong-lanceolate lobe on each side at the base; flowers nearly sessile in the axils ( $1^{\prime}$ long). - Low grounds, Penn. to Michigan, Illinois, and southward. 


\section{CastIILİ, Mutis. Panted-Cur.}

Calyx tubular, flattened, cleft at the summit on the anterior, and usually on the posterior side also; the divisions entire or 2 -lobed. 'T'ute of the corolla included in the calyx; its upper lip long and narrow, arched and keeled, flattened laterally, enclosing the 4 unequal stamens; the lower lip short, 3-lobed. Anthercells oblong-linear, unequal, the onter fixed hy the middle, the inner pendulous. Pod many-seeded. - Herbs (root-parasitic), with alternate entire or cut-lobed leaves; the floral ones usually dilated, colored, and more showy than the yellow or purplish spiked flowers. (Dedicated to Castillejo, a Spanish botanist.)

1. C. coccínea, Spreng. (Scarlet Panted-Cer.) Hairy biemial or annual; stem siuple; root-leaves clustercd; those of the stem incised; the floral 3-cleft, bright scurlet towards the summit (rarely yellow); calyx almost equally 2cleft, the lobes neaily entire, about the length of the pale yellow corolla. (E)uchioma coccinea, $N$ utt.) - Sandy low grounds : not uncommon. May-Aug.

2. C. pállida, Kunth. Sinooth or sparingly hairy perenuial; at the summit woolly; leaves often incised; the floral oblong or obovate, whitish, rarely tinged with purple; calyx cleft more deeply in fiont, the divisions 2-cleft, the ovateoblong lobes mostly shorter than the whitish corolla. (C. septentrionalis, Lindl.) - Alpine region of the White Mountains, New Hampshire, and Green Mountains, Vermont, Lake Superior and northwestward. Aug. (Eu.)

3. C. sessiliflóra, P'ursh. Ilairy and low perenuial $\left(6^{\prime}-9^{\prime}\right.$ high $)$; leaves mostly 3-cleft, with narrow diverging lobes; the floral broader, not colored: spiko many-flowered, crowded; calyx deeper cleft in front, the divisions deeply 2-clefi, shorter than the tube of the long and narrow greenish-yellow corolla; which has the lobes of the lower lip slender, pointed, about half the length of the upper. - P'rairies, Wisconsin (Lapham), Illinois, and westward. - Corolla 2 ' long.

\section{SCH W Á LBE A, Gronov. Chaff-seed.}

Calyx oblique, tubular, 10-12-ribled, 5-toothed; the posterior tooth much smallest, the 2 anterior united much higher than the others. Upper lip of the corolla arched, oblong, entire; the lower rather shorter, erect, 2-plaited, with 3 very short and broad obtuse lobes. Stamens 4, included in the upper lip: anther-cells equal and parallel, obscurely pointed at the base. Pod ovate, manyseeded. Seeds linear, with a loose chaff-like coat- - A pereunial minutely pubescent upright herb $\left(1^{\circ}-2^{\circ}\right.$ high $)$, with leafy simple stems, terminated by a loose spike of rather large dull purplish-yellow flowers; the leaves alteruate, sessile, 3-nerved, eutire, ovate or oblong, the upper gradually reduced into narrow bracts. Pedicels very short, with 2 bractlets under the calyx. (I)dicated to $C$. G. Schwalbe, an obscure German botanist.)

1. S. Americàna, L. - IVet sandy soil, Cape Cod at Sandwich (B. D. Greene), near Albany, New York, pine larrens of New Jersey, and southward near the coast. May-July.

\section{EU PHRÀ S I A, Tourn. Eyebight.}

Calyx tubular or bell-shaped, 4-cleft. Upper lip of the corolla erect, scarcely arched, 2-lobed, the lobes broad and spreading; lower lip spreading, 3-cleft, tho 
lohes obtuse or notched. Stamens 4, under the upper lip: anther-cells equal, pointed at the base. Pod oblong, fluttened. Sceds numerous. - Herbs with branching stems, and opposite toothed or cut leaves. Flowers small, spiked. (Name eủ申paria, cheerfulness, in allusion to its reputed medicinal properties.)

1. E. offleinalis, L. Low annual; léaves ovate or lanceolate, the lowest crenate, the floral bristly-toothed; lobes of the lower lip of the (whitish, yellowish, or bluish) corolla notched. - Nlpine summits of the White Mountains, New Hampshire (Oakes), Lake Superior, and northward. $\Lambda$ dwarf variety, $1^{\prime}-5^{\prime}$ high, with very small flowers. (E. pusilla, Godet, mss.) (Eu.)

\section{RHINÁ N THUS, L. Yeliow-Rattle.}

Calyx membranaceous, flattened, much inflated in fruit, 4-toothed. Upper lip of the corolla arched, ovate, obtuse, flattened, entire at the summit, but furnished with a minute tooth on eacli side below the apex; lower lip 3-lobed. Stamens 4, under the upper lip: anthers npproximate, hairy, transverse; the cells equal, pointless. Pod orbicular, flattened. Seeds many, orbicular, winged. Annual upright herbs, with opposite leaves; the lower oblong or linear; the upper lanceolate, toothed the floral rounded and cut-serrate with bristly teeth ; the solitary yellow flowers nearly sessile in their axils, and crowded in anesided spike. (Name composed of $\dot{\rho}^{\prime} \nu, a$ snout, and $\ddot{\nu} \nu 0 s, n$ flower, from the benked upper lip of the corolla in some species formerly of this gemus.)

1. R. Crista-gálli, L. (Common Yellow-Ratrte.) Leaves oblong or lanceolate; seeds broadly winged (when ripe they rattle in the inflated calyx, whence the popular name). - Plymonth, Mass. (probably introduced), White Mountains, N. Hampshire (Tuckerman), Lake Superior, and northward. (Eu.)

\section{PEDICULÀRIS, Tourn. Lovgewort.}

Calyx various. Corolla strongly 2-lipped; the upper lip areherl, flattened, often beaked at the apex; the lower erect at the base, 2-crested above, 3-lobed; the lobes commonly spreading, the lateral ones rounded and larger. Stamens 4, under the upper lip: anthers transverse; the cells equal, pointless. Pod ovate or lanceolate, mostly oblique, several-secded.-Perennial herbs, with chicfly pinnatifid leaves, the floral bract-like, and rather large flowers in a spike. (Name from pediculus, a louse; of no obvious application.)

1. P. Canadénsis, L. (Common Lousewort. Wood Betony.) -1 IIairy; stems simple, clustered $\left(5^{\prime}-12^{\prime}\right.$ high $)$; leaves scattered; the lowest pinnately parted; the others half-pinnatifid; spike short and dense; calyx split in front, otherwise almost entire, oblique; upper lip of the (dull greenish-yellow and purplish) corolla hooded, incurved, 2-toothed under the apex; pod flat, somewhat sword-shaped. - Copses and banks: common. May-July.

2. P. lanceolàta, Michx. Stem upright $\left(1^{\circ}-3^{\circ}\right.$ high $)$, nearly simple, mostly smooth; leaves partly opposite, oblong-lanceolate, doubly cut-toothed; spike crowded; calyx 2-lobed, leafy-crested; upper lip of the (pale yellow) corolla incurved and bearing a short truncate beak at the apex; the lower erect, so as nearly to close the thront; pod ovate, scarcely longer than the calyr. (P. pállida, Pursh.) - Swamps, Connecticut to Virginia and Wisconsin. Aug., Sept. 


\section{MELA M PÝ U M, Tourn. Cow-WheAt.}

Calyx bell-shaped, 4-cleft; the taper lobes sharp-pointed. Tube of the co. rolla cylindrical, enlarging above; upper lip arched, compressed, straight in front; the lower erect-spreading, biconvex, 3-lobed at the apex. Stamens 4, under the upper lip: anthers approximate, oblong, nearly vertical, hairy; the equal cells minutely pointed at the base. Ovary with 2 ovules in each cell. Pod flattened, oblique, 1-4-seeded. - Erect branching annuals, with opposite leaves, the lower entire, the upper mostly larger and fringed with bristly teeth at the base. Flowers seattered and solitary in the axils of the upper leaves in our species. (Name composed of $\mu \epsilon^{\prime} \lambda a s, b l a c k$, and $\pi v \rho o ́ s$, whent ; from the color of the seeds of ficld species in Europe, as they appear mixed with grain.)

1. M. Americàum, Michx. Leaves lanceolate, short-petioled, the lower entire; the floral ones similar, or abrupt at the base and beset with a few bristly teeth; calyx-tecth linear-atwl-shaped, not half the length of the slender tube of the pale greenish-yellow corolla. (M. pratense, var. Americanum, Benth.) Open woods: common. June-Scpt. - Plant 6'-12' high. Corolla 5" long, more slender than in M. pratense, sometimes tinged with purple.

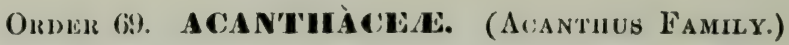

Chiefly herbs, with opposite simple leaves, didynamous or diandrous stamens, inserted on the tube of the more or less 2-lipped corolla, the lobes of which are convolute or imbricated in the bud; fruit a 2-celled and few- (412-) seeded pod ; seeds anatropous, without albumen, usually flat and supported by hooked projections of the placenta. - Flowers commonly much bracted. Calyx 5-cleft. Style thread-form: stigma simple or 2-cleft. Pod loculicidal, usually flattened contrary to the valves and partition. Seed with albumen in Elytraria of the Southern States, according to Dr. Feay. Cotyledons broad and flat. - Mucilagrinous and slightly bitter, not noxious. A large family in the warmer parts of the world : represented in gardens by TuUniengra, which differs fiom the rest by the globular porl and seeds, the latter not on hooks (retinacula); in the Northern States by only two indigenous genera.

\section{DIA N THERA, Gronov. Water-Whlow.}

Calyx 5-parted. Corolla deeply 2-lipped; the upper lip ereet, notched; the lower spreading, 3-parted, external in the bud. Stumens 2 : anthers 2-celled, the cells separated and somewhat unequal. Pod obovate, flattened, contracted at the base into a short stalk, 4-sceded. - Perennial herbs, growing in water or wet places, with entire leaves, and purplish flowers in axillary peduncled spikes

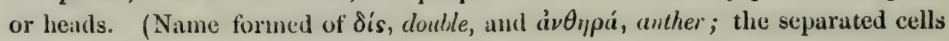
giving the appearance of two anthers on each filanent.)

1. D. Americàna, L. Leaves linear-lanceolate, elongated; spikes oblong, dense, long-peduncled. (Justícia pedunculòsa, Michx. Rhytiglossa, Nees.) - Borders of streams and ponds, N. W. Vermont to Wisconsin, Virginia, and southward. July - Sept. 


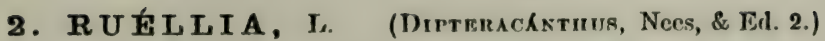

Calyx 5-parted. Corolla funnel-form, the spreading ample border almost equally and regularly 5-cleft, convolute in the bud. Stamens 4, included, didynamons: cells of the somewhat arrow-shaped anthers parallel and nearly equal. Pod narrow, in our species (of the scction Dipteracantuus) somewhat flattened, contracted and scedless at the base, above 8-12-sceded. Sceds with a mucilaginous coat, when wet under the microscope exhibiting innumerablo tapering short bristles, their walls marked with rings or spirals. - P'erennials, with rather large and showy blue or purple flowers, mostly in axillary clusters, sometimes also with small flowers precocionsly close-fertilized in the bud. Calyx often 2-bracteolate. (Named for the carly herbalist, ofohn Ruelle.)

1. R. ciliòsa, Pursh. Hirsute with soft whitish hairs $\left(1^{\circ}-3^{\circ}\right.$ high $)$; lenves nearly sessile, oval or ovate-oblong $\left(1^{\prime}-2^{\prime}\right.$ long) ; flowers $1-3$ and almost sessile in the axils; tube of the corolla $\left(1^{\prime}-1 \frac{1^{\prime}}{2}\right.$ long $)$ fully twice the length of the setaceous caly.r-Inlies; the throat short. (Dipteracanthus ciliosus, Necs.) - Dry soil, Michigan to Illinois, and southward. June-Scpt.

2. R. etrèpens, I. Glubrous or sparingly pubrsent $\left(1^{\circ}-4^{\circ}\right.$ ligh $)$; leaves narmwed at the base into a petiole, ovate, obovate, or most!y oblong $\left(2 \frac{1}{2}{ }^{\prime}-5^{\prime}\right.$ long); tube of the corolla (about 1 ' long) little longer than the dilated portion, slighly excerding the lanceolate or linear culyy-lobes. (I)ipteracanthus strepens, Ners.) Flowers $1-5$ in each axil, rarely on a slender peduncle, usually almost sessile; sometimes many and closely crowded, then mostly fruiting in the bud, (when it is D. micránthus, Engelm. \& Gr.). - Rich soil, Pennsylvania to Wisconsin, and southward. July - Sept.

\section{Order 70. Verienàcea. (Vhrvain Family.)}

Herbs or shruhs, with opposile leaves, more or less 2-lipped or irregular cornlla, and didynamous stamens, the 2-4-celled (in Phryma 1-celled) fruit dry or drupaceous, usually splitting when ripe into as many 1-seeded indehiscent nutlets; differing from the following order in the ovary not being 4-lobed, the style therefore terminal, and the plants seldom aromatic or furnishing a volatile oil. - Seeds with a straight embryo and little or no albumen. - A large order in the warmer parts of the world, sparingly represented in cool regions.

Tribe I. VER BEN E E. Ovary 2-4-celled, and with an erect anatropous ovule in each cell : radicle inferior.

1. Verbena. Flowers in spikes or heads. Calyx tubular. Fruit splitting into 4 nutlets.

2. Iippla. Flowers in spikes or heads. Calyx short, 2-cleft. Fruit splitting into 2 nutlets.

8. Callicarpa. Flowers in axillary cymes. Caly $x$ short. Fruit berry-like, with 4 nutlets.

Tribe II. PII Y MER. Ovary 1-cclled : ovule erect, orthotropous: radicle superior. 4. Phryma. Flowers in slender spikes. Calyx cylindrical, 2-lipped. Fruit an achenium.

\section{VERBìn A, L. Vertain.}

Calyx tubular, 5-toothed, one of the tecth often shorter than the others. Corolla tubular, often curved, salver-form; the border somewhat unequally 5-cleft. 
Stamens included; the upper pair occasionally without anthers. Style slender: stigma capitate. Fruit splitting into 4 seed-like nutlets. - Flowers sessile, in single or often panicled spikes, bracted; produced all summer. ('The Latin name for any sacred herb : derivation obscure.) - The species present numerous spontaneous hybrids.

§ 1. Anthers not appenduged: erect herbs, with slender spikes.

* Leaves undivided: root perennial.

1. V. angustifolia, Michx. Loir $\left(6^{\prime}-18^{\prime}\right.$ high), often simple; leaves narrowly lanceolate, tapering to the base, sessile, roughish, slightly toothed; spikes few or single; the purple flowers crowded, larger than in the next. - Dry soil, Amherst, Mass., to Wisconsiu and southward: rare northward.

2. V. hastàta, L. (BLUk Vkivain.) ' ''all $\left(4^{\circ}-6^{\circ}\right.$ high); leaves lanceolate or oblong-lanceolute, taper-pointerl, cut-serrate, pelioled, the lower often lobed and sometimes hulberel-shuged at the base; spikes linear, erect, densely flowered, corymbed or panicled. (V. paniculata, Lam., when the leaves are not lobed.) - Low and waste grounds: common. At the north probably immigrant from the south.

3. V. urticifölia, L. (NeTtLe-Leaved or White V.) Rather tall; leaves oval or oblong-ovale, acute, coursely serrate, petioled; spikes very slender, at length much elonguled, with the flowers remote, loosely panicled, very small, white. - Old fields and roadsides : apparently immigrant.

4. V. strícta, Vent. (Hodry V.) Downy with soft whitish huirs; stem nearly simple $\left(1^{\circ}-2^{\circ}\right.$ high $)$; leaves sessile, obovale or oblong, serrate; spilies thick and very densely floucerd, somewhat clustered, hairy. - Barrens, Ohio to Wisconsin, and southward. - Flowers blue, pretty large.

* * Leuves cleft or pinnatifid, narrowed at the base: root perennial?

5. V. officinilis, L. (European V.) Erect, loosely brauched $\left(1^{\circ}-3^{\circ}\right.$ high) ; leaves pinnatifid or 3-rlefl, oblong-lanceolate, sessile, smooth above, the lobes cut and toothed; spikes panicled, very slender; bracts small, much shorter than the very small purplish flowers. (V. spùria, L.) - Roadsides; chiefly southward: scarce. (Nat. from Eu.)

6. V. bracteosa, Michx. Widely spreading or procumbent, hairy; leaves wedye-lanceolate, cut-pinnatifid or 3-cleft, short-petioled; spikes single, remotely flowered ; lacts large and leafy, the lower pimnatifid, longer than the small purple flowers. - Waste places, Wisconsin to Kentucky and southward.

§2. Anthers of the longer stamens tipped with a glandular appendage.

7. V. Aublètia, L. Annuul, rather hairy, spreading or ascending; leaves obovate-oblong with a werlge-shaped base, 3-cleft and cut or pinnatifid; spikes peduncled, flat-topped in flower; bracts shorter than the calyx; flowers showy, light purple. - Prities and rocks, from Illinois southward. Also cultivated.

\section{LÍ P PIA, L. (ZAPANIA, Juss.)}

Calyx short, often flattened, 2-4-toothed, or 2-lipped. Corolla 2-lipped : upper lip notehed; the lower much larger, 3-lobed. Stamens included. Style slender: stigma obliquely caritate. Fruit 2-celled, 2-seeded. (Dedicated to Augustus Lippi, an Italian naturalist and traveller.) 
1. L. Ianceolàta, Michx. (Fog-fru1x.) Procumbent or creeping, roughish, green; leaves oblanceolate or wedge-spatulate, serrate above; peduncles axillary, slender, bearing solitary closely bracted heads of bluish-white flowers; calyx 2-cleft, the divisions sharply keeled. - River-banks, Pennsylvania to Illinois and southward. July-Sept.

\section{CALLICÁ R P A, L. Callicarpa.}

Calyx 4-5-toothed, short. Corolla tubular-bell-shaped, 4-5-lobed, nearly regular. Stamens 4 , nearly equal, exserted : anthers opening at the apex. Style slender, thickened upwards. Fruit a small berry-like drupe, with 4 nutlets. Shrubs, with scurfy pubescence, and small flowers in axillary cymes. (Name

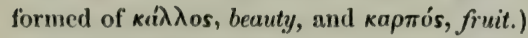

1. C. Americana, L. (Frencu Mulberry.) Leaves ovate-oblong with n tapering base, toothed, whitish beneath; calyx obscurely 4-toothed; fruits violet-color. - Rich soil, Virginia and southward. May - July.

\section{PH R Y M A, L. Lorseed.}

Calyx cylindrical, 2-lipper ; the upper lip of 3 bristle-awl-shaped teeth; the lower shorter, 2-toothed. Corolla 2-lipped; upper lip notehed; the lower much larger, 3-lobed. Stamens included. Style slender: stigma 2-lobed. Fruit dry, in the bottom of the calyx, oblong, 1-celled and 1-seeded! Seed orthotropous. Radicle pointing upwards: cotyledons convolute round their axis. - A perennial herb, with slender branching stems, and coarsely toothed ovate leaves, the lower long-petioled; the small opposite flowers in clongated and slender terminal spikes, reflexed in fruit, and bent close against the axis. Corolla purplish or pale rose-color. (Derivation of the name unknown.)

1. P. Leptostàchya, L. - Woods and copses : common. July. - Plant $\left(2^{\circ}-3^{\circ}\right.$ high) : leaves $3^{\prime}-5^{\prime}$ long, thin.

\section{Order 71. LABiatTe. (Mint Family.)}

Chiefly herbs, with square stems, opposite aromatic leaves, more or less 2lipped corollu, didynamous or diandrous stamens, and a deeply 4-lobed ovary, which forms in fruit 4 little seed-like nutlets or achenia, surrounding the base of the single style in the bottom of the persistent calyx, each filled with a single erect seed. - Nutlets smooth or barely ronghish and fixed by their base, except in the first tribe. Albumen mostly none. Einbryo straight (except in Scutellaria) : radicle at the base of the fruit. Upper lip of the corolla 2-lobed or sometimes entire; the lower 3-lobed. Stamens inserted on the tube of the corolla. Style 2-lobed at the apex. Flowers axillary, chiefly in cymose clusters, these often aggregated in terminal spikes or racemes. Foliage mostly dotted with small glands containing a volatile oil, upon which depends the warmth and aroma of the plants of this large and well-known family. (More abundant in the Old World than the New. One third of our genera and many of the species are merely introduced plants.) 
Tribe I. AJUGOIDEAE. Stamens 4, ascending (curved upwards) and parallel, usually projecting from the notch of the upper sile of the (not evidently 2-lipped) 5-lobed corolla. Nutlets reticulited and pitted, obliquely attached by the inside near the base.

* Lobes of the corvlla all declined (turned forwards) : stamens exserted.

1. Teucrium. Lower lobe of the corolla nuch larger than the others. Caly $x$ 5-toothed.

2. Trichostema. Lobes of the corolla scarcely unequal. Calyx 5-cleft, oblique.

* Lobes of the corolla almost equally spreading : stamens nearly included.

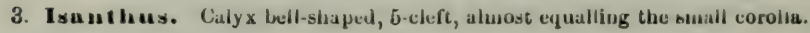

Tribe II. SA'TUR EIIfA. Stanens 4, the inferior pair louger, or onl; 2, distint, atraight, diverging, or converping uuder the upper lip : anthers 2 celled. Lobes of the corolla flat and spreading.

* Corolla not evidently 2-lipped, but almost eqtally 4-lobed, small. Stamens erect, distant.

4. Mentha. Fertile stauens 4, nearly equal.

5. Lусория. Fertile stumens 2 ; and often 2 sterile filaments without anthers.

* * Corolla more or less 2 -lipped; the tube naked (not bearded) within. - Stamens only 2 , distant : no rudiments of the upper pair.

6. Cunila. Calyx very hairy in the throat, equally 5-toothed. Corolla small. + Stamens 4 , all with anthers.

7. Hyssopus. Calyx tubular, 15-nerved, naked in the throat, equally 5-toothed. 8tamens exsertci, diverging.

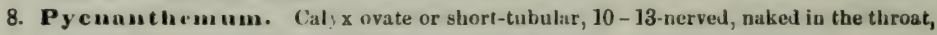
equally 5-toothed or somewhat 2-lipped. Flowers in dense heads or clusters.

9. Orign им. Caly $x$ ovate-bell-shaped hairy in the throat, 13-nerved, 5-tooched. Stamens diverging. Flowers spiked, and with large colored bracts

10. Thym us. Calyx ovate, notding in fruit, hairy in the throat, 10-13-nerved, 2-lipped. Stumens distant. Bracts minute. Leaves very small.

11. Satureia. Caly $x$ bell-shaped, naked in the throst. 10-nerved, equally 5-toothed. Stanens sonewhat ascending.

12. Calamiutha. Calyx tubular, often hairy in the throat, 18-nerved, 2-lipped. Tube of the corolla straight. Stanens connivent at the sumuit in pairs uuder the upper lip.

13. Mellisa. (Galj $x$ tubular-bell-shaped, 2 -lipped, flattish on the upper side. Tube of the corolla curved upwards. Stamens curved above, connivent under the erect upper lip.

+++ Stamens only 2 with anthers, ascending, and a pair of small sterile filanents.

14. Iledeoma. C'alyx gibbous ou the lower side, hairy in the throat. Flowers loose.

*** Corolla 2 -lipped and with a bearded ring inside at the bottom of the enlarged throat.

15. Colliusouia. Valy $x$ eularged and declined in fruit, 2-lipped. Lower lobe of the corolla nuch larger than the other four. Stumeus 2 or 4 , long, diverging.

Tribe III. MONARDEZC. Stamens 2 (sometimes also with mere rudiments of the upper pair), ascending and paraliel : anthers either apparently or really 1-celled. Corolla 2-lipped.

16. Salvia. Caljx 2-lipped. Anthers with a long connective astride the filament, bearing a linear cell at the upper end, and none or an imperfect cell on the lower.

17. Momardn. (alyx tubular and elougated, equally 5-toothed. Authers of 2 rells confluent into one; the connective inconspicuous.

18. Blephilia. Caly $x$ ovate-tubular, 2-lipped Anthers as in the preceding.

Tribe IV. NEPETEAS. Stamens 4, the superior (inuer) pair longer than the inferior! ascending or diverging. Corollis 2-lipped; the upper lip concave or arched, the lower spreading. Calyx mostly 15-nerved.

19. Lophanthus. Stameus divergent; the upper pair curved downwards ; the lower ascending : antlier-cells vearly parallel.

20. Nepeta. Stamens all ascending; the anthers approximute in pairs; the cells at length widely diverging. Calyx more or less curved. 
41. Drneecephnlum. Stamens nearly as in the preceding. Calyx straight, the upper lip or upper tooth commonly larger.

22. Cedronella. Stamens all ascending. Anther-cells parallel.

Tribe V. STACHYDEME. Stamens 4, ascending and parallel; the inferior (outer) pair longer than the superior, except in No. 33. Anthers usually approximate in pairs. Corolla 2-lipped; the upper lip concave or arched. Caly x 5-10-nerved.

* Calyx not 2-lipped, thin and membranaceous, inflated-bell-shaped in fruit.

23. Symandra. Calyx almost equally 4-lobed! Anther-cells widely divergent.

24. Physostegia. Caly $x$ 5-toothed or 5-lobed. Anther-cells parallel.

* * Caly x 2-lipped, closed in fruit.

25. IBrunella. Calyx nerved and veiny; upper lip flat, 3-toothed, the lower 2-cleft.

26. Scutellaxia. Caly $x$ with a helmet-like projection on the upper side; the lips entire.

** Caly $x$ not 2-lipped, nor the tube inflated, 5 -10-toothed.

- Stamens included in the tube of the corolla.

27. Marrublum. Calyx tubular, 5-10-nerved, and with 5 or 10 awl-shaped teeth.

++ Stamens projecting beyond the tube of the corolla.

$\leftrightarrow$ Anthers opening transversely by two unequal valves; the smaller valve cillate.

28. Galeopsis. Caly $x$ tubular-bell-shaped; the 5 teeth spiny-pointed.

++ Anthers opening lengthwise.

29. Stachys. Calyx tubular-bell-shaped. Nutlets rounded at the top. Stamens after shedding the pollen often turned downward.

30. L.сом urus. Caly $x$ top shnped, the rigid nnd spiny-pointed tecth soon sprending. Nutlets truncate and acutoly 3 -angled at the top.

31. Lamlum. Calyx-tceth not spiny-pointed. Nutlets sharply 3-angled, truncate at the top.

32. Bnllota. Calyx somewhat funnel-form, the $b-10$ teeth united at the base into a spreading border. Nutlets roundish at the top. Upper lip of the corolla erect.

83. Phlomis. Caly $x$ tubular, the 5 teeth abruptly awned. Upper lip of the corolla arched.

\section{T E Ù C R I U M, L. Germander.}

Calyx 5-toothed. Corolla with the 4 upper lobes nearly equal, oblong, turned forward, so that there seems to be no upper lip; the lower one much larger. Stamens 4, exserted from the deep cleft between the 2 upper lobes of the corolla : anther-cells confluent. (Named for Teucer, king of Troy.)

1. T. Canadénse, L. (American Germander. Wood Sage.) Herbaceous perennial, downy; stem erect $\left(1^{\circ}-3^{\circ}\right.$ high $)$; leaves ovate-lanceolate, scrrate, rounded at the base, short-petioled, hoary underneath; the floral scarcely longer than the oblique unequally-toothed calyx; whorls about 6-flowered, crowled in a long and simple wand-like spikc. - Low grounds: not rare. July - Sept. - Corolla pale purple, rarely white.

\section{TRICH OS Tì M A, L. Blue Currs.}

Calyx bell-shaped, oblique, decply 5-cleft; the 3 upper tecth elongated and partly united, the 2 lower very short. Corolla 5 -lobed; the lobes narrowly oblong, declined, nearly equal in length; the 3 lower more or less united. Stamens 4, with very long capillary filaments, exserted much beyond the corolla, curved : anther-cells divergent and at length confluent. - Low anuuals, somewhat clammy-glandular and balsamic, branched, with entire leaves, and mostly solitary 1-flowered pedicels terminating the branches, becoming lateral by the production of axillary branchlets, and the flower appearing to be reversed, 
namely, the short tceth of the calyx upward, \&c. Corolla blue, varying to pur ple, rarely white, small; in summer and autumn. (Name composed of $\theta_{p i} \xi_{1}$ huir, and $\sigma \tau \hat{\eta} \mu a$, stumen, from the capillary filaments.)

1. T. dichótomum, L. (BAstakd P'Ennyoyal.) Leaves lance-oblong or rhombic-lancrolute, rarely lance-linear, short-petioled. - Sandy fields, New England to Kentucky, and southward, chiefly castward. - Stamens $\frac{1}{2}$ long. Corolla blue : a pink variety near Hartford, Conn., C. HI. Olmstcad.

2. T. lineàre, Nutt. Leuves linear, nearly smooth. - Sandy pine barrens of New Jersey, and southward. - More slender and less forked than the last.

\section{3. is á N Th U S, Michx. False Pennyoyal.}

Calyx bell-shaped, 5-lobed, equal, enlarged in fruit. Corolla little longer than the calyx; the border bell-shaped, with 5 nearly equal and obovate spreading lobes. Stamens 4, slightly didyuamous, incurved-ascending, scarcely exceeding the corolla. - A low, much branched annual, clammy-pubescent, with nearly entire lance-oblong 3-nerved leaves, and small pale blue flowers on axillary 1 -3flowered peduncles. (Name from ioos, equal, and avbos, flower, referring to the ahmust regular corolla.)

1. I. cæruleus, Michs.-Gravelly banks and fields, Maine to Illinois, and southward. July, Aug. - Corolla 2" long.

\section{MÉntiha, L. Mint.}

Calyx bell-shaped or tubular, 5-toothed, equal or nearly so. Corolla with a short included tube; the bell-shiped border somewhat equally 4-cleft; the upper lobe broadest, entire or notched. Stmens 4, equal, erect, distant. - Odorous peremial herls, with the small flowers mostly in close clusters, forming axillary capitate whorls, sometimes approximated in interrupted spikes; producerl in summer; of two sorts as to the length of the stamens in most species. Corolla pale purple or whitish. (Miv $\theta \eta$ of 'Theophrastus, from a Nymph of that name, fabled to have been changed into Mint by the jealous Proserpine.)

* Inflorescence terminal, forming narrow spikes : lcaies sessile or nearly so.

1. M. rotundifólia, I. (Round-leaved Mint.) Softhluiry or downy; leaves round-ovate and somewhat heart-shaped, rugose, crenate-toothed. - Wet places, Maine, J. Blake, New Jersey and Penn., Porter. (Adv. from Lu.)

2. M. Vínids, L. (Si'EARMint.) Nearly smooth; leaves oblony-or ovutekenceolute, unequally serrate. - Wet places : common. (Nat. from Lu.)

* * Inflorrscence mostly terminal, forming interrupted spikes or heads : leaves petioled.

3. M. pipentit, I. (l'eppenmint.) Simoolh; leaves ovate-oblung, acute; spikes loose. - Var. sumirsuta, Benth., has the petioles, veins of the leaves, \&c. rather hairy. - Low grounds, and along brooks : less naturalized than the last; and like it multiplying rapidly by running under-ground shoots. (Nat. from Eu.)

4. M. aquatica, L. (Water Mint.) Pubescent or smoothish; leaves ovate or round-ovate; flowers in a terminal glubular or interrupted and oblong kead, often with one or more clusters in the axils of the upper leaves; calyx and 
usually the pedicels hairy. The common form has the stems hairy downwards. - Muddy shores, Nanticoke River, Delaware, W.M. Canby. - Var. g LA BrAta, Benth., a nearly smooth form, differing from Peppermint in the rounder leaves and spike of 2 or 3 rounded heads (M. citràta, Ehrh.). - Litchfield, Connecticut, Dr. T. F. Allen. (Nat. from Eu.)

* * Inflorescence axillary, the globular whorls or clusters all in the axils of the leaves, the uppermost axils not flower-bearing: leaves more or less petioled, toothed. (The species apparently run together.)

5. M. sativa, L. (Whorced Mint.) Stem hniry downwards; leaves ovate; calyx oblong-cylindrical with very slender teeth. Intermediate between the last and the next, apparently runs into both. - River-banks, N. Jersey \& Penn., Prof. Poiter. (Adv. from Eu.)

6. M. ARvénsis, L. (Corn Mint.) Lower and smaller-leaved than the last; calyx bell-shaped, the teeth shont and broader. - Moist ficlds : rare. (Adv. from $\mathrm{Eu}$.)

7. M. Canadénsis, L. (WILD Minr.) Leaves varying from ovatc-oblong to lanccolate, tapering to both ends; caly $\mathrm{x}$ oblong-bell-shaped, the tecth rather short; hairs on the stem when present not conspicuously reflexed. The commoner form is more or less hairy, and has nearly the odor of Pennyroyal. Var. grannitı, Benth. (M. borèlis, Michr.) is smoothish, "the scent pleasanter, more like that of Monarda." (Prof. Porter.) - Shady wet places, New England to Kentucky and northward.

\section{L Ý C O PUS, L. Water Horehound.}

Calyx bell-shaped, 4-5-toothed, naked in the throat. Corolla bell-shaped, scarcely longer than the calyx, nearly equally 4-lobed. Stamens 2, distant; the upper pair cither sterile rudiments or wanting. Nutlets with thickened margins. - Perennial low herbs, resembling Mints, with sharply toothed or pimatifid leaves, the floral ones similar and much longer than the dense axillary whorls of small mostly white flowers; in summer. (Name compounded of $\lambda$ úkos, a uolf, and $\pi 0 \hat{s}$, foot, from some fancied likeness in the leaves.)

1. L. Virgínicus, L. (Bugle-wered.) Stem obtusely 4 -angled $\left(6^{\prime}-18^{\prime}\right.$ high), producing long and slender runners from the base ; leaves oblong or ovatelanceolute, toothed, entire towards the base, short-petioled; calyx-tecth 4, ovate, bluntish and pointless. - Shady moist places: common, especially northward. Smooth, often purplish, with small capitate clusters of very small flowers. - The depauperate, few-flowered form, often tuberiferous at base (L. uniflorus, Michx., and L. pumilus, $V a h l)$, Lake Supcrior and northward. Plant very bitter.

2. L. Europæus, L. Stcm sharply 4-angled $\left(1^{\circ}-3^{\circ}\right.$ high $)$; leaves ovateoblong or oblong-lanccolate, sinuate-toothed or pinnatifid, usually more or less petioled; whorls many-flowered; calyx-teeth 5 , triangular-lanceolute, tapering to a rigid very sharp point; nutlets (smooth or glandular-roughened at the top) equalling or exceeding the calyx-tube. (Eu.) - Includes several nominal species (the sterile filaments variable); among them in our district is

Var. sessilifolius. Nearly smooth, producing slender leafy runners from the decumbent base ; leaves oblong-ovate, closely sessile or almost clasping, re 
motely toothed; sterile filaments minute and slender. - Atsion Creek, New Jersey, W. M. C'anby. - Nearest the var. parvifolius, Miquel, from Jupan : proba bly L. rubellus, Moench, is a closely related form.

Var. integrifolius. Stems often producing slender runners; leaves oblonglanceolate, varying to warrowly lanceolate (L. angustifolius, Nutt.), much acuminate at hoth euds $\left(2^{\prime}-4^{\prime}\right.$ long $)$, slender-petioled, sharply serrate. - Common westward.

Var. sinuàtus. (L. sinuatus, Benth. L. exaltatus \& L. sinuatus, Ell.) Much branched, smooth or smoothish; runners short or none; leaves mostly more tilpering to both ends than in the European furm, varying from cut-toothed to pinuatifid; sterile filaments mostly with a globular or spatulate tip. - Cummon in wet grounds.

\section{CUNİLA, L. Dittany.}

Calyx ovate-tubular, equally 5-toothed, very hairy in the throat. Corolla 2. lipped; upper lip ereet, flattish, mostly notched; the lower spreading, 3-eleft. Stamens 2, erect, exserted, distant: no sterile filaments.-Perenuials, with small white or purplish flowers, in corymbed cymes or clusters. (An ancient Iatin nume, of unknown origin.!

1. C. Niariàna, L. (Common Dittany.) Stems tufued, corymbosely much branclied ( $1^{\circ}$ high); leaves smooth, ovate, serrate, rounded or heart-shaped at the base, nearly sessile, dotted ( $1^{\prime}$ long $)$; cymes peduncled ; calyx striate. Dry hills, S. New York to Ohio, Illinois, and southward. July-Sept.

\section{HYSSÒPUS, L. HYssor.}

Calyx tubular, 15-nerved, equally 5-toothed, naked in the throat. Corolla short, 2-lipped; upper lip ercet, flat, obscurely notched; the lower 3-cleft, with the middle lobe larger and 2-cleft. Stamens 4, exserted, diverging. - A perennial herb, with wand-like simple branches, lanceolate or linear entire leaves, and blue-purple flowers in small clusters, crowded in a spike. (The aneient uame.)

1. H. orricisicis, L. - Roadsides, \&c., sparingly escaped from gardens. (Adv. from Eu.)

\section{PYCNÁ NTHEMUM, Michx. Mountain Mint. Basilo}

Calyx ovate-oblong or tubular, about 13-nerved, equally 5-toothed, or the three upper teeth more or less united, naked in the throat. Corolla short, more or less 2-lipped; the upper lip straight, nearly flit, entire or slightly notched; the lower 3-cleft, its lobes all ovate and obtuse. Stamens 4 , distant, the lower jair rather longer: antler-cells parallel. - Perennial uprigh herbs, with a pungent mint-like flavor, corymbosely branched ahove; the floral leaves often whitened; the many-fluwered whorls dense, crowded with bracts, and usually forming terminal heads or close cymes. Corolla whitish or purplish, the lips mostly dotted with purple Fl. summer and early autumn. - Varies, like the Mints, with the stamens exserted or included in different flowers. (Name com-

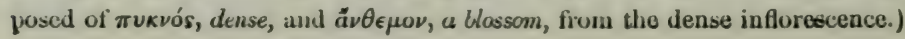


- Calyx sarrely at afl 2-iipped, the reeth and bracts aul-shaped and awn-pointed, rigid, naked, as long as the corolla : flowers in ruther dense mostly terminal heads : lenves rigid, slightly petioled.

1. P. aristatum, Michx. Minutely hoary-puberulent $\left(1^{\circ}-2^{\circ}\right.$ high $)$; leaves ovate-oblong and oblong-lanccolate, acute, sparingly denticulate-serrate (1'-2' long), roundish at the base. - Pine barrens, from New Jersey southward.

Var. hyssopifolium, Gray. Leaves narrowly oblong or broarly linear, nearly entire and obtuse. (P. hyssopifolium, Benth.) - Virginin and southward.

* Calyx 2-lipped from the greuter union more or less of the 3 upper teeth, which, with the bracts, are subulate and bearded with some spreading hairs: flowers in dense and compound futtened cymes, which become considerably exponded in fiuit. leaves membranaceous, petioled. (Species $2-5$ incline to run together.)

2. P. Túllia, Benth. Leaves greener and loosely softdowny, only the floral ones whitened, otherwise resembling those of the next; cymes dense; bracts much surpassing the flowers, their long awn-like points and the awn-pointed cnlyxtecth bearded with long loose hairs. - Dry ground, mountains of Virginia and southward.

3. P. incànum, Michx. Leaves ovate-oblong, acute, remotely toothed, downy alove and mostly hoary with whitish wool undernienth, the uppermost whitened both sides; cymes open; bracts linear-awl-shaped and, with the calyx-teeth, more or less awn-pointed. - Rocky woods and hills, New England to Michigan, and southward. - Plant $2^{\circ}-4^{\circ}$ high, the taste intermediate between that of Pennyroyal and Spearmint, as in most of the following species. Very variable.

4. P. clinopodioides, 'Torr. \& Gr. Leaves oblong-lanceulate, scarcely toothed, short-petioled, not whitened; the upper surface often smooth, the lower as well as the stem downy; cymes contiacted; bracts and calyx-teeth short-subulate, the latter nearly one half shorter than the tube. - Dry copses, S. New York to Pennsylvania. Connects No. 3 with No. 5.

* * Calyx usually almost equally 5-toothed: flowers crowded in loose heads or dense clusters at the end of the branches and in the uppermost axils; the bracts shorter than the 2-lipped corollas: leaves almost sessile.

5. P. Torrèyi, Benth. Somewhat pubescent; stem strict and nearly simple $\left(2^{\circ}-3^{\circ}\right.$ high); leaves thin, linear-lanceolate, tapering to both ends (mostly $2^{\prime}$ long and $2^{\prime \prime}-3^{\prime \prime}$ wide), nearly entire; the awl-shaped calyx-teeth and bracts canescent. - Dry soil, S. New York to Pennsylvania. - Intermediate in aspect between No. 4 and No. 8.

6. P. pilosum, Nutt. More or less douny with long and soft whitish hairs, much branched above; leaves lanceolnte, acute at both ends, or the lower ovate-lanccolate, nearly entire, the floral not whitened; calyx-tecth ovatc-lanccolate, acute, and with the bracts hoary-hairy. - Dry hills and plains, W. Pennsylvania to Illinois, and southward.

7. P. mùticum, Pers. Minutely hoary throughout, or becoming almost smooth, corymbosely much branched $\left(1^{\circ}-21^{\circ}\right.$ high) ; leaves ovate or brondly ovatelanceolate, varying to lanceolate, rather rigid, acute, rounded or slightly heart-shaped nt the base, mostly sessile and minutely sharp-toothed, prominently veined, green when old; the floral ones, bracts, and triangular or ovate caly $\mathrm{x}$-tceth, hoary with a 
fine close down. (Brachystemum verticillatum, Michx.) - Dry hills, Muine to Ohio, Kentucky, and southward. - Flowers in very dense clusters; the outer bracts orate-lanccolate and pointed, the others pointless.

**** Calyx equally 5-toothed: flowers collected in dense and globular, often fascicled, sinall und numerous heads, which are crowded in terminul corymbs: bructs rigid, closely appressed, shorter than the flowers: lips of the curolla very short: leaves narrow, stssile, entire, rigid, crouded and clustered in the axils.

8. P. lanceolàtum, Pursh. Smoothish or minutely pubescent $\left(2^{\circ}\right.$ high); reaves lancerlute or lance-lincur, obtuse at the base; hads downy; culyx-teeth short and trimgular: - Dry thickets : not rare.

9. P. linifòlium, Pursh. Smoother and leaves nurrower and heads less downy than in the last; the narrower bracts and lance-uzb-shaped culyx-tecth pungently pointed. - S. New England to Illinois, and southward.

***** Calyx equally 5-tonthed: fluwers collected in few and solitary larye and ylubular heads (terminal, and in the upper axils of the membranaceous petiolad leaves); the bracts loose, ciliate-bearded.

10. P. montànum, Michx. Stenn $\left(1^{\circ}-3^{\circ}\right.$ high $)$ und ovate- or oblonglanceolate serrate leaves glabrous; bracts very acute or awl-pointed, the outermost ovate and leaf-like, the inner linear; teeth of the tubular calyx short and acute. - Alleghanies, from S. Virginia southward. - Flavor warm and pleasant. Foliage and heads resembling Monarda.

\section{ORÍGA N U M, L. Wild MarJoram.}

Calyx ovate-bell-shaped, hairy in the throat, striate, 5-toothed. Tube of the corolla about the length of the calyx, 2-lipped; the upper lip rather erect and slightly notched; the lower longer, of 3 nearly equal spreading lobes. Stamens 4, exserted, diverging. - Peremials, with nearly entire leaves, and purplish flowers erowded in cylindrical or oblong spikes, imbricated with colored bracts. (An ancient Greck name, said to be composed of öpos, a mountain, and yávos, delight.)

1. O. vulgane, I. Upright, hairy, corymbose at the summit; leaves petioled, round-ovate; bracts ovate, obtuse, purplish. - Dry banks : scarce. JuneOct. (Nat. from Eu.)

\section{TH $\mathbf{Y}$ M U S, L. THYME.}

Calyx ovate, 2-lipped, 13-nerved, hairy in the throat: the upper lip 3-toothed, spreading; the luwer 2-cleft, with the awl-shaped divisions ciliate. Corolla short, slightly 2-lipped; the upper lip straight and flatti-h, notehed at the apex; the lower 3-cleft. Stanens 4, straight and distant, usually exserted. - Low pertnnials, with small and entire strongly-veined leaves, and purplish or whitish flowers. (The ancient Greek name of the Thyme, probably from Oíw, to burn perfume, because it was used for incense.)

1. T. Serpóllum, L. (Creeping Thyme.) Prostrate; leaves green, flat, ovate, entire, short-petioled, flowers crowded at the end of the branches. - Old ficlds, Eastern New England to Pennsylvania: rare. (Adv. from Eu.) Tho Gamene 'Tuyme is T. vulgamb, $\mathbf{l}$. 


\section{SATUREIA, L. SAvory.}

Calyx bell-shaped, 10-nerved, equally 5-toothed, naked in the throat. Corolla 2-lipped; the upper lip erect, flat, nearly entire, the lower 3-cleft. Stamens 4, somewhat ascending. - Aromatic plants, with narrow entire leaves, often clustered, and somewhat spiked purplish flowers. (The ancient Latin name.)

1. S. horténgis, L. (Summer Savory.) Pubescent annual; clusters fewflowered; bracts small or none. - Prairies of Illinois, and rocky islands at the Falls of the Ohio, Short: escaped from gardens. (Adv. from Eu.)

\section{CaIA $\mathrm{m}$ i N Tha, Monch. Calamintir.}

Calyx tubular, 13-nerved, mostly hairy in the throat, 2-lipped; the upper lip 3-cleft, the lower 2-cleft. Corolla with a straight tube and an inflated throat, distinctly 2-lipped; the upper lip erect, flattish, entire or notched; the lower spreading, 3-parted, the midldle lobe usually largest. Stamens 4, mostly ascending; the anthers usually approximate in pairs. - Percnnials, with mostly purplish or whitish flowers; produced all summer: infloresecnce various. (Name

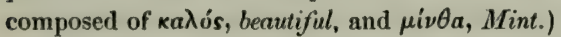

§1. CALAMfNTHA, Mnench. Calyx strinte, scarcely giblous at the lnse: clusters of flowers loose and peduncled in the axils of the leaves, and forming a raceme at the summit: bracts minute.

1. C. Népeta, Link. (Basil-Thyme.) Soft hairy; stem ascending $\left(1^{\circ}-\right.$ $3^{\circ}$ high) ; leaves petioled, broadly ovate, obtuse, crenate; corolla ( $3^{\prime \prime}$ long) about twice the length of the calyx. - Dry hills, Virginia, \&c. (Nat. frum Fu.)

§2. CALOMEIISSA, Benth. Calyx nearly as $\$ 1$ : whorls ferb-several-fowered, ssssile; flowers on slender naked pedicels; the bracts at their base linear or oblong, lenf-like.

2. C. glabélla, Benth. Smooth; stems diffuse or spreading $\left(1^{\circ}-2^{\circ}\right.$ long); leaves slightly petioled, oblong or oblong-linear, narrowed at the base $\left(8^{\prime \prime}-2^{\prime}\right.$ long), sparingly toothed, or nearly entire ; clusters 6-10-flowered ; corolla (purplish, $5^{\prime \prime}-6$ "long) fully twice the length of the calyx, the teeth of the latter awl-pointed. (Cunila glabella, Michx. Micromeria, Benth.)-Limestone banks, near Frankfort, Kentucky (Short), and southward.

Var. Nuttállii, Gray. Smaller; the flowering stems more upright (5'-9' high), with narrower mostly entire leaves and fewer-flowered clusters; while sterile runners from the base bear ovate thickish leaves only $2^{\prime \prime}-5^{\prime \prime}$ long. (C. Nuttallii, Benth. Micromeria glabella, var. angustifolia, Torr.) - Wet limestone rocks, Niagara Falls to Wisconsin, Central Ohio (Sullivant), and southwestward. - Appearing very distinct, but united by southwestern specimens.

§ 3. CLINOPODIUM, L. Caly, more or less giblous below: clusters sessile and many-flowered, dense, crowded with awl-shaped bracts.

3. C. Clinopodium, Benth. (BAsıL.) Hairy, erect $\left(1^{\circ}-2^{\circ}\right.$ high); leaves ovate, petioled, nearly entire; flowers (pale purple) in globular elusters; hairy bracts as long as the calyx. (Clinopodium vulgare, $L$.) - Borders of thickets and fields. Naturalized extensively : but apparently also indigenous about the upper Great Lakes and elsewhere. (Eu.) 


\section{MELÍSSA, L. BALM.}

Calyx with the upper lip flattened and 3-toothed, the lower 2-cleft. Corolla with a recurved-ascending tube. Stamens 4, curved and conniving under the upper lip. Otherwise nearly as Calamintha. - Clusters few-flowered, loose, one-sided, with few and inostly ovate bracts resembling the leaves. (Name from $\mu \eta \dot{\lambda} \iota \sigma \sigma a, a$ bee; the flower's yielding abundance of honey.)

1. M. Officinalis, I. (Comsion Balm.) Upright, branching; leares broadly ovate, crenate-toothed, lemon-secented ; corolla nearly white. - Sparingly escaped from gardens. (Nat. fiom Eu.)

\section{H E D E Ò A, Pers. Mock Pennyroyal.}

Calyx ovoid or tubular, gibbous on the lower side near the base, 13-nerved bearded in the throat, 2-lipped; the ujper lip 3-toothed, the lower 2-eleft. Corolla 2 -lipped; the upper lip erect, flat, notehed at the apex; the lower spreading, 3-cleft. Fertile stamens 2; the upper pair reduced to sterile filaments or wanting. - Low, odorous annuals, with small leaves, and loose axillary clusters of flowers (in summer), often forming terminal leafy racemes. (Altered from

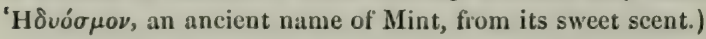

1. H. pulegioides, Pers. (American Pennyroyal.) Erect, branching, hairy; leaves petioled, oblong-ovate, olscurely serrate, the flural similar; whorls few-flowered; corolla (bluish, pubescent) scarcely execeding the calyx; sterile filaments tipped with a little head. - Open barren woots and fields. - The taste and odor ne:arly of the true Penuyroyal (Mentha Pulegium) of Europe.

2. H. híspida, Pursh. Erect, hairy $\left(2^{\prime}-5^{\prime}\right.$ highi); leaves sessile, linear, entire, the floral similar and exceeding the flowers; corolla scarcely longer than the ciliate hispid calyx. - Dry hills, W. Illinois and westward.

\section{COLLI NSÒN I A, L. Horse-BaLM.}

Calyx ovate, enlarged and declined in fruit, 2-lipped; upper lip truncate and flattened, 3-toothed, the lower 2-cleft. Corolla elongated, expanded at the throat, somewhat 2-lipped; the 4 upper lobes nearly equal, but the lower much larger and longer, pendent, toothed or lacerate-fringed. Stamens 2 (sometimes 4 , the upper pair shorter), much exserted, diverging: anther-ctells divergent. - Strongseented perennials, with large ovate leaves, and yellowish flowers on slender pedicels, in loose and panicled terminal racemes. (Named in honor of Peler Collinson, a well-known patron of science and correspondent of Linnaus, who introduced it into England.)

1. C. Canadénsis, I. (Ricir-weed. Stone-root.) Nearly smooth $\left(1^{\circ}-3^{\circ}\right.$ high $)$; leaves scrrate, pointed, petioled $\left(3^{\prime}-6^{\prime} \mathrm{long}\right)$; panicle loose; stamens 2. - Rich moist woods : common. July - Sept. - Corolla $8^{\prime \prime}-9^{\prime \prime}$ long, leruon-sceuted.

\section{SÁLVIA, L. SAGE.}

Calyx naked in the throat, 2-lipped; the upper lip 3-toothed or entire, the lower 2-cleft. Corolla deeply 2-lipped, ringent ; the upper lip straight or scytleshaped, entire or barely notclied; the luwer spreading or peudent, 3-lobed. the 
middle lobe larger. Stamens 2, on short filaments, jointed with the elongated transverse connective, one end of which ascending under the upper lip bears a linear 1-celled (half-) anther, the other usually descending bears an imperfect or deformed (half-) anther. - Flowers mostly large and showy, in spiked, racemed, or panicled whorls, produced in summer. (Name from sulvo, to save, in allusion to the reputed healing qualities of Sage.)

1. S. lyràta, L. (Lyre-teaven SAGE.) Low perennial $\left(10^{\prime}-20^{\prime}\right.$ high), somewhat huiry; stem nerrly simple and naked; root-lenurs olovate, lyre-shaped or sinuate-pinnatifid, sometimes almost entire; those of the stem mostly a single pair, smaller and narrower; the floral oblong-linear, not longer than the calyx; whorls loose and distant, forming an interrupted raceme; upper lip of the bluc-purple pubescent corolla short, straight, not vaulted. - Woodlands and meadows, New Jersey to Ohio, Illinois, and southward.

2. S. urticifolia, L. (Nettle-Lenved Sage.) Downy with clammy hairs, leafy; leaves rhombic-ovate, pointed, crenate, rounded or slightly heart-shaped at the base, narrowed into a short petiole, the floral nearly similar; whorls remote, many-flowered; upper lip of the blue corolla crect, one third the length of the lower; style bearded. - Woodlands, from Maryland southward. - Corolla 4" long; the lateral lobes deflexed, the middle notched.

\section{MON Á R D A, L. Horge-Mint.}

Calyx tubular, elongated, 15-nerved, nearly equally 5-toothed, usually hairy in the throat. Corolla elongated, with a slightly expanded throat, and a strongly 2-lipped limb; the lips linear or oblong, somewhat equal; the upper erect, entire or slightly notched; the lower sprealing, 3-lobed at the apex, the lateral lobes ovate and obtuse, the middle one narrower and slightly notehed. Stamens 2, elongated, ascending, inserted in the throat of the corolla : anthers linear (the livaricate cells confluent at the junction). - Odorous erect herbs, with entire or toothed leaves, and pretty large flowers in a few whorled heads, closely surrounded with bracts. (Dedicated to Nicnlus Monardes, author of many tracts upon medicinal and other useful plants, especially those of the New World, in the latter half of the 16th century.)

* Stumens and style exserted lieyond the narrow ucute upper lip of the corolla : root per. ennial: leaves lance-ovate or oblong, with a roundid or slightly heart-shaped base.

1. M. didyma, L. (Oswego Ten.) Somewhat hairy ( $2^{\circ}$ high); leaves petioled, pointed; the floral unes and the large outer bracts tinged with red; culyx smooth, incurved, nearly naked in the thront; corolla smooth (2' long), lright red. showy. - Moist woods by streams, New England to Wisconsin northward, and southward in the Alleghanies: often cultivated (under the name of Balm or Bce-Bulm). July, Aug.

2. M. fistulosa, L. (WILd BergnMot.) Smoothish or downy; leaves petioled; the uppermost and outer bracts somewhat colored (whitish or purplish) ; calyx slightly curved, very hairy in the throut; corolla purplish, rose-color, or almost white, smooth or hairy. - Woods and rocky banks, Vermont to Wisconsin, and southward, especially westward. July-Sept. - Very variable in appearanoe, $2^{\circ}-5^{\circ}$ high; the pale corolla smaller than in the last. 
3. M. Bradburiàna, Beck. Leaves nearly sessile, clothed with long soft hairs, especially underneath; the floral and the outer bracts somewhat heart-shaped, purplish; calyx smoothish, contracted above, very hairy in the throat, with awt-shaped awned teeth; corolla smoothish, bearded at the tip of the upper lip, scarcely twice the length of the calyx, pale purplish, the lower lip dotted with purple. - Oakopenings and woods, Ohio to Illinois, and westward. May-July.

* Stamens not excecding the upper lip of the short coiolla: annuals or biennials.

4. M. punctàta, L. (Horse-Mint.) Minutely downy $\left(2^{\circ}-3^{\circ}\right.$ high); leaves petioled, lanceolate, narrowed at the base; bracts lanceolate, obtuse at the base, sessile, yellowish and purple; teeth of the downy calyx short and rigid, awnless; corolla nearly smooth, yellowish, the upper lip spotted with purple, notehed at the apex, the tube scarcely exceeding the calyx. - Sandy fields and dry banks, New York to Illinois and southward. July - Sept. - Very odorous and pungent.

\section{BLEPHÍLIA, Raf. Blephilia.}

Calyx ovoid-tubular, 13-nerved, 2-lipped, naked in the throat; upper lip with 3 awned teeth, the lower with 2 nearly awnless teeth. Corolla inflated in the throat, strongly and nearly equally 2-lipped; the upper lip erect, entire; the lower spreading, 3-eleft, with the lateral lobes ovate and rounded, larger than the oblong and notched middle one. Stamens 2, ascencling, exserted (the rudiments of the upper pair minute or none): anthers, \&c. as in Monarda. - Perennial herbs, with nearly the foliage, \&c. of Monarda; the small pale bluish purple flowers crowded in axillary and terminal globose capitate whorls; in summer. (Name from $\beta \lambda_{\epsilon} \phi a p i s$, the eyelash, in reference to the hairy-fringed bracts and calyx-tecth.)

1. B. ciliàta, Raf. Somewhat downy $\left(1^{\circ}-2^{\circ}\right.$ high $)$; leaves almost sessile, oblong-ovate, narrouved at the base, whitish-downy underneath; outer bracts onate, acute, colored, ciliate, as long as the calyx; corolla hairy. (Monarda ciliata, L.) - Dry open places, Penn. to Kentucky and Wisconsin.

2. B. hirsùta, Benth. Hairy throughout; leaves long-petioled, ovate, pointed, rounded or heart-shirpecl at the base; the lower floral ones similar, the uppermost and the lracts linerir-cacl-shaped, shorter than the long-haired calyx; corolla smoothish, pale, with darker purple spots. (B. nepetoides, Raf. Monarda hir. suta, Pursh.) - Damp rich woods, E. Vermont to Wisconsin and Kentucky. Plant $2^{\circ}-3^{\circ}$ high, with spreading branches, and numcrous close whorls, the lower remote.

\section{LOPHÁ NTHUS, Benth. Grant Hrssop.}

Calyx tubular-bell-shaped, 15-nerved, oblique, 5-toothed, the upper teeth rather longer than the others. Corolla 2-lipped; the upper lip nearly erect, 2-lobed; the lower somewhat spreading, 3-cleft. with the middle lobe crenate. Stamens 4 , exserted; the upper pair declined; the lower and shorter pair ascending, so that the pairs cross. Anther-eells nearly parallel. - P'erennial tall herbs, with petioled serrate leaves, and small flowers crowded in interrupted terminal spikes; in

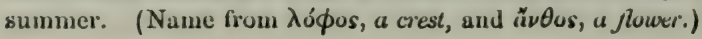


1. I. nepetoldes, Benth. Smooth, or nearly so; leaves ovate, somewhat pointed, coarsely crenate-toothed $\left(2^{\prime}-4^{\prime}\right.$ long); calyx-teeth ovate, rather obtuse, little shorter than the pale greenish-yellow corolla. - Borders of woorls, W. Vermont to Wisconsin, and southward. - Stem stout, $4^{\circ}-6^{\circ}$ high, sharply 4 -angled. Spikes $2^{\prime}-6^{\prime}$ long, crowded with the ovate pointed bracts.

2. L. scrophulariæfolius, Benth. Stem (obtusely 4-angled) and lower surface of the ovate or somewhat heart-shaped acute leaves more or less pubescent ; calyx-teeth lanccolate, acute, shorter than the purplish corolla (spikes $4^{\prime}$ - 15'long) : otherwise like the last. - Same geographical range.

3. L. anisatus, Benth. ( $\Lambda$ NISE IIrssop.) Smooth, but the ovate acute leaves glaucous-white underneath with minute down; calyx-tecth lanceolate, acute. - Plains, Wisconsin and northwestward. - Foliage with the scent of anise.

\section{N E PETA, L. CAT-MINT.}

Calyx tubular, often incurved, obliquely 5-toothed. Corolla dilated in tho throat, 2-lipped; the upper lip ereet, rather concave, notehed or 2-eleft; the lower sprending, 3-cleft, the midlle lobe largest, either 2-lohed or entire. Stamens 4, ascending under the upper lip, the lower pair shorter. Anthers approximate in pairs; the cells divergent. - Perennial herbs. ('The Latin name, thought to be derived from Nepete, an Etrurian city.)

§ 1. Cymose clusters rather dense and many-fouered, forming interrupted spikes or racemes : upper floral leaves small and bract-like.

1. N. Catגria, I. (Catnip.) Downy, erect, branched; leaves heartshaped, oblong, decply crenate, whitish-downy underneath; corolla whitish, dotted with purple. - Near dwellings : a very common weed. July-Sept. (Adv, from Eu.)

§ 2. GI,ECHOेMA, L. Leaves all alike: the axillary clusters lonsely frw-flowered.

2. N. Grecroma, Benth. (Grounn Ivr. Gis.) Creeping and trailing ; leaves petioled, round kidney-shaped, crenate, green both sides; corolla thrice the length of the calyx, light blue. (Glechoma hederàcea, L.)-Damp waste grounds near dwellings. May - Aug. - Anther-cells diverging at a right angle, each pair approximate and forming. a cross. (Adv. from Eu.)

\section{DR A C O CÉ P H A L U M, L. Dragon-Head.}

Calyx tubular, 13-15-nerved, straight, 5-toothed; the upper tooth usually much largest. Corolla 2-lipped; the upper lip slightly arched and notched; the lower spreading, 3-cleft, with its middle lobe largest and 2-cleft or notched at the end. Stamens 4, ascending under the upper lip ; the lower pair shorter. Anthers approximate by pairs, the cells divergent. - Whorls many-flowered, mostly spiked or capitate, and with awn-toothed or fringed leafy bracts. (Name from $\delta \rho a ́ \kappa \omega \nu, a$ drugon, and $\kappa \in \phi a \lambda \dot{\eta}$, head, alluding to the form of the corolla in the original species.)

1. D. parviflorum, Nutt. Annual or biennial ; stem erect, leafy ( $8^{\prime}$ $20^{\prime}$ high) ; leaves ovate-lanceolate, sharply cut-toothed, petioled ; whorls crowded in a terminal head or spike; upper tooth of the calyx ovate, nearly equalling L \& $\mathrm{M}-35$ 
the bluish small slender corolla. - Rocky places, from St. Lawrence Ca., New York, to Wisconsin along the Great Lakes, northward. May-Aug.

\section{CEDRONÉLIA, Munch. Cedronella.}

Calyx rather obliquely 5-toothed, many-nerved. Corolla ample, expanded at the throat, 2-lipped; the upjer lip thattish or concave, 2-lobed; the lower 3. cleft, spreading, the middle lobe largest. Stamens 4, ascending; the lower pair shorter. Anther-cells parallel. - Siwet-seented perennials, with pale purplish

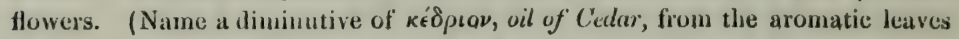
of the original species, C. triphylla, the Bulm-of-Gilead of English gardens.)

1. C. cordàta, Benth. Low, with slender runners, hairy ; leaves broadly heart-shaped, erenate, petioled, the floral shorter than the calyx; whorls few. flowered, at the summit of short ascending stems ; corolla hairy inside ( $1 \frac{1}{2}$ ' long); stamens shorter than the upper lip. (1)racocephalum cordatum, Nutt.) - Low shady banks, W. Penn. to líntucky, and soutliward along the mountains. June.

\section{SYNÁ N DRA, Nutt. SYnandra.}

Calyx bell-slaped, inflated, membranaceous, irregularly veiny, almost equally 4-toothed! Corolla with a long tube, much expanded above and at the throat; the upper lip slightly arched, entire; the lower spreading and 3-cleft, with ovate lobes, the middle one broadest and notehed at the end. Stamens 4, uscending : filaments hairy: anthers approximate in pairs under the upper lip; the two upper each with one fertile and one smaller sterile coll, the latter cohering with each other (whence the name; from $\sigma \dot{v} \nu$, togrther, and ả $\dot{\rho} \rho$, for anther).

1. S. grandiflora, Nutt. - Shaded banks, Ohio, Kentucky, and southward. June. - A pereunial ? hairy herb, $1^{\circ}$ high. Lower leaves long-petioled, broadly ovate, heart-shitped, crenate, thin; the floral sessile, gradually reduced to bracts, each with a single sessile flower. Corolla $1 \frac{1}{2}$ long, yellowish-white.

\section{PHY SOSTEg I A, Benth. False Dhagon-hea1).}

Calyx nearly equally 5-toothed, obscurely 10-nerved, short-tubular or bellshaped, more or less enlarged and slightly inflated in fruit. Corolla funnelform with a much inflated throat, 2-lipped; the upper lip crect, nearly entire; the lower 3-parted, spreading, small : its middle lobe larger, broad and rounded, notched. Stamens 4, ascending under the upper lip: anthers approximate; the cells parallel. - Smooth peremials, with upright wand-like stems, and sessile lanceolate or oblong mostly serrate leaves. Flowers large and showy, rose or flesh-color variegated with purple, opposite, crowded in simple or panicled terminal leafless spikes. (Nane from $\phi \hat{v} \sigma a, a$ bladder, and $\sigma \tau \hat{\gamma} \gamma \eta, a$ conering.)

1. P. Virginiàna, Benth. Corolla $\mathbf{l}^{\prime}$ or more long, gaping, the upper lip slightly arching; calyx-tube oblong-or obconical-bell-shaped. (Dracocephalum Virginianum, L.) - Wet banks, \&c., W. New York to Wisconsin and southward. July - Sept. - Varies from $1^{\circ}-4^{\circ}$ high, stout or slender; the leaves from olblong-obovate (the lewer) to narrowly lanceolate, and from very sharply toothed to nearly entire; the flowers cither crowded or scattered. 


\section{BRU N f́LA, Tourn. (Pruncla, L.) Selfinat.}

Calyx tubular-bell-shaped, somewhat 10-nerved and reticulated-veiny, flattened on the upper side, naked in the throat, closed in fruit, 2-lipped; the upper lip broad and flat, truncate, with 3 short teeth ; the lower 2-cleft. Corolla ascending, slightly contracted at the throat, and dilated at the lower side just beneath it, 2-lipped; the upper lip erect, arched, entire; the lower reflexedspreading, 3-cleft; its lateral lobes oblong; the middle one rounded, concave, crenulate. Stamens 4, ascending under the upper lip : filaments 2-toothed at the apex, the lower tooth bearing the anther. Anthers approximate in pairs, their cells diverging. - Low perennials, with nearly simple stems, and 3-flowered clusters of flowers sessile in the axils of round and bract-like membranaceous floral leaves, imbricated in a close spike or head. (Name said to be taken from the German braune, a disease of the throat, for which this plant was a reputed remedy.

2. B. vulgàris, I. (Common Sfef-ment or Hent-alt.) Lenves ovateoblong, cutire or toothed, petioled, hairy or sinoothish ; corolla (violet or fleshcolor, rmely white) not twice the length of the purplish enlyx. - Woods and fields : common. June-Sept. (Eu.)

\section{SCUT ELIÀRIA, L. SкULLCAP.}

Calyx bell-shaped in flower, 2-lipped ; the lips entire, closed in fruit, the upper with a helmet-like at length concave and enlarged appendage on the back (the upper sepal) ; calyx splitting to the base at maturity, the upper lip usually falling away. Corolla with an elongated curved ascending tube, dilated at the throat, 2-lipped; the upper lip arched, entire or barely notched; the lateral lobes mostly connected with the upper rather than the lower lip; the lower lobe or lip spreading and convex, notcher at the apex. Stamens 4 , ascending under the upper lip: anthers approximate in pairs, ciliate or benred ; those of the lower stamens 1-celled (halved), of the upper 2-celled and heart-shaped. - Bitter perennial herbs, not aromatic, with axillary or else spiked or racemed flowers; in summer: the short peduncles or pedicels chicfly opposite, 1-flowered, often 1-sided. (Name from scutella, a dish, in allusion to the form of the appendage to the fruiting calyx.)

* Flowers (blue) in terminal (single or panicled) racemes; the foral leaves, except the lower ones 'eing small, and reduced to bracts.

+ Lips short, nearly equal in length, the lateral lobs rather distinct, and almost as long as the straightish or scarcely incurved upper lip : leaves on slender petioles.

1. S. versícolor, Nutt. Soft hairy, the hairs of the inflorescence, \&c. partly viscid-glandular; stem mostly crect $\left(1^{\circ}-3^{\circ}\right.$ high $)$; leaves ovate or roundovate, chiefly heart-shaped, crenate-toothed, very veiny, rugose, the floral reduced to broadly ovate entire bracts about equalling the glandular-hairy calyx ; racemes mostly simple. - River-banks, \&c., Penn. to Wisconsin and sonthward. - Corolla 9" long, with a slender tube, below whitish, the lower lip purplespotted; the upper deep blue; the lateral lobes belonging as much to the lowcr as to the upper lip. - S. saxatilis, var. ? pilosior, Benth., is probably a smaller 
form of this, as is S. rugosa, Wood. ('The latter from IIarper's Ferry, Dr. Aikin according to Woud.)

2. S. saxátilis; Riddell. Sinoothish or slightly hairy; stem weak, ascending $\left(6^{\prime}-18^{\prime}\right.$ long $)$, often producing runners, branched; leaves ovate or ovate-oblohy and mostly heart-shaped, coarsely crenate-toothed ( $1^{\prime}-2^{\prime}$ long), thin, obtuse; upper bracts oblong or ovate, small; racemes loose. - Moist shaded banks, S. Ohio, Virginia, and Kentucky, and southward in the mountains. - Corolla $8^{\prime \prime}$ long, the lateral lobes connected with the straightish upper lip.

+ + Laterul lobes of the corolla smell, much shorter than the decidedly arched or in curved upper lip, and connected with it: stem erect: leaves moderately petioled, except in No. 6.

3. S. canéscens, Nutt. Sten branched $\left(2^{\circ}-4^{\circ}\right.$ high) above, with the panicled many-flowered racemes, flowers, and the lower surface of the ovate or lanceovate acute (at the base acute, obtuse, or cordate) crenate leaves whitish with fine soft down, often becoming rather glabrous; bracts oblong or lanceolate; upper lip of the corolla shorter than the lower. - Rich ground, Penn. to Illinois and southward. - Corolla 8 "long.

4. S. serrata, Andrews. Green and nearly glabrous; stem rather simple $\left(1^{\circ}-3^{\circ}\right.$ high $)$, with single looscly-flowered racemes; lcaves serrate, acuminate at both ends, ovate or ovate-oblong; calyx, \&c. somewhat hairy ; lips of the corolla equal in length (corolla 1 ' long, the tube more tapering below than in the last. which this resembles). -- Woods, Penn. to Illinois, and southward.

5. S. pilosa, Michx. Pubescent with spreading hairs; stem nearly simple $\left(1^{\circ}-3^{\circ}\right.$ high $)$; leaves ruther distant, crenate, oblong-ovate, obluse, varying to roundish-ovate, the lower abrupt or heart-shaped at the base and long-petioled, the upper on short margined jetioles, veiny; bracts oblong-spatulate ; racemes short, often branched ; corolla ( $6^{\prime \prime}-8^{\prime \prime}$ long) rather narrow, the lower lip) a little shorter. (S. hirsùta, Short, is a large form.) - Dry ground, S. New York to Michigan and southward.

6. S. integrifolia, L. Downy all over with a minute hoariness ; stem commonly simple $\left(1^{\circ}-2^{\circ}\right.$ high $)$; leaves oblong-lanceolate or linear, mostly entire, obtuse, very short-petioled; raceme often branched; corolla ( $1^{\prime}$ long) much enlarged above, the ample lips equal in length. - Borders of thickets, from Bridgewater, Mass. (Mr. Howard), to Pennsylvania and southward.

* * Flowers (blue or violet, short-peduncled) solitary in the axils of the upper mostly sessile leaves, which are similar to the lower ones.

- Corolla (2" $-3^{\prime \prime}$ long) seldom thrice the lenyth of the calyx; the short lips nearly equal in length, the upper lip concave.

7. S. nervosa, Pursh. Simooth, simple or branched, slender $\left(10^{\prime}-20^{\prime}\right.$ high) ; lower leaves roundish; the middle oncs orate, toothed, somewhat heurt-shapred ( $1^{\prime}$ long); the floral ovate-lanceolate, entire ; nerve-like veins prominent beneath. (S. gracilis, Nutt.) - Moist thickets, New York to Illinois and southward.

8. S. párvula, Michx. Minutcly downy, dwurf $\left(3^{\prime}-6^{\prime}\right.$ high $)$, branched and spreading; lowest leaves round-ovate; the others ovate or lance-ovate, obtuse, all entire or nearly so, sliyhtly heart-shaped ( $6^{\prime \prime}-8^{\prime \prime}$ long). (S. ambígua, Nutt.) Dry bauks, W. New Lingland to Wisconsin und southward. May, Junę. 
+ + Corolla (8" - 9" long), with a slender tube: lower lip large and rather longer than the somewhat arched upper lip: stem simple.

9. S. galericulata, L. Smooth or a little downy, erect $\left(1^{\circ}-2^{\circ}\right.$ high); leaves ovate-lanceolate, acute, serrate, roundish and slightly heart-shaped at the base (1'-2'long). - Wet shady places : common northward. (Eu.)

* * Flowers small (blue, $3^{\prime \prime}$ long), in axillary and offen also in terminal one-sided racemes; the lower floral leaves like the others, the upper small and bract-like.

10. S. lateriflora, L. Smooth; stem upright, much branched $\left(1^{\circ}-2^{\circ}\right.$ high) ; leaves lanceolate-ovate or ovate-oblong, pointerl, coarsely serrate, rounded at the base, petioled $\left(2^{\prime}-3^{\prime}\right.$ long $)$. - Wet shaterl places : common. $-\Lambda$ quack having formerly vaunted its virtues as a remedy for hydrophobia, this species bears the name of Mad-dog Skullcap.

\section{M A R R Ù B I U M, L. Horenound.}

Calyx tubular, 5-10-nerved, nearly equally 5-10-toothed; the tecth more or less spiny-pointed nnd spreading nt maturity. Upper lip of the corolla erect, notched; the lower spreading, 3-cleft, its middle lobe broadest. Stamens 4, included in the tube of the corolla. Nutlets not truncate. - Whitish-woolly bitteraromatic perennials, branched at the base, with rugose and crenate or cut leaves, and many-flowered axillary whorls. (A name of Pliny, said to be derived from the Hebrew murrob, a bitter juice.)

1. M. vulgare, L. (Сомmon Horemound.) Stems ascending; leaves round-ovate, petioled, crenate-toothed ; whorls capitate; calyx with 10 recurved tceth, the alternate ones shorter; corolla small, whitc. - Escaped from gardens into waste places. (Nat. from Eu.)

\section{GA LEÓ PSIS, L. IIemp-Netrue.}

Caly* tubular-bell-shaped, abont 5-nerved, with 5 somewhat equal and spinytipped teeth. Corolla dilated at the throat; the upper lip ovate, arched, entire; the lower 3-cleft, spreading ; the lateral lobes ovate, the middle one inversely heart-shaped; palate with 2 teeth at the sinuses. Stamens 4 , ascending under the upper lip : anther-cells transversely 2-valved; the inner valve of each cell bristlyfringed, tho outer ono larger and naked. - $\Lambda$ nnuals, with spreading branches, and several-many-flowered whorls in the axils of floral leaves which are nearly

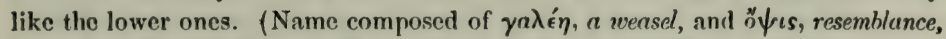
from some fancied likeness of the corolla to the hearl of a wensel.)

1. G. Tetranit, L. (Сommon Hemp-Netrue.) Stem swollen below the joints, bristly-hairy; leaves ovate, coarsely serrate ; corolla purplish, or variegated, about twice the length of the calyx; or, in var. GRANDIFLorA, $3 \div 4$ times the length of the calyx, often yellowish with a purple spot on the lower lip. Waste places : rather common. Aug., Sept. (Nat. from Eu.)

2. G. LAdanum, L. (Ren H.) Stem smooth or pubescent; leaves oblonglanccolate, more or less downy ; corolla red or rose-color (the throat often spotted with yellow), much exceeding the calyx. - Eastern New England : rare. Aug. (Adv. from Eu.) 


\section{ST À CH Y S, L. Hedge-Netre.}

Calyx tubular-bell-shaped, 5-10-nerved, equally 5-toothed, or the upper teeth united to form an upper lip. Corolla not dilated at the throat; the upper lip erect or rather spreading, often arched, entire or nearly so ; the lower usually longer and spreading, 3-lobed, with the middle lobe largest and nearly entire. Stumens 4, ascending under the upper lip (often reflexed on the throat after flowering): anthers approximate in pairs. Nutlets obtuse, not truncate. Whorls 2-many-flowered, approximate in a terminal raceme or spike (whence the name, from $\sigma \tau a \dot{\chi} v s$, a spike). Flowering in summer.

* Root annual: stems decumbent, low.

1. S. arvénsis, L. (Woundivort.) Hairy; leaves petioled, ovate, obtuse, crenate, heart-shaped at the base; axillary whorls 4-6-flowered, distant ; corolla (purplish) scarcely longer than the soon declined unarmed calyx. - Waste places, E. Massachusetts : scarce. (Adv. from Eu.)

\section{* * Root perennial: stem erect.}

2. S. palústris, L. Stem 4-angled $\left(2^{\circ}-3^{\circ}\right.$ high $)$, lèıfy, hirsute with spreading or reflexed hairs, especiaily on the angles; leaves sessile, or the lower short-petioled, oblong- or ovate-lanceolate, crenately serrate, rounded or heartshaped at the base, downy or hairy-pubescent, obtusish $\left(2^{\prime}-4^{\prime}\right.$ long), the upper floral ones shorter than the nearly sessile calyx ; whorls 6-10-flowered, the upper crowded into an interrujted spike; calyx hispid; the lance-subulate teeth somewhat spiny, half the length of the purple corolla, diverging in fruit. - Wet hanks of streans, \&c., mostly northward. (Eu.) - To this, for the present, we must refer all the following as varieties, different as some of them are:-

Var. áspera. (S. aspera, Michx.) Stem more commonly smouth on the sides, the angles beset with stiff reflexed bristles; leaves hairy or smoothish, jointed, the lower petioled, the lower floral as long as the flowers; spike often slender and more interrupted; calyx-tube rather narrower and the teeth more awl-shaped and spiny. - Common in wet grounds. - This passes into

Var. glàbra. (S. glabra, Riddell, suppl. sat. Ohio pl. 1836.) More slender, smooth and glabrous throughout, or with few bristly luairs; leaves oblong- or ovatelanceolate, taper-pointed, more sharply toothed, mostly rounded or truncate at the base, all petioled. - W. New York to Michigan and south ivestward.

Var. cordàta. (S. cordata, Riddell, l. c. S. Nuttallii, Shutlew.) Stem beset with spreading or reflexed bristly hairs; leaves hairy or smoothish, oblong, hrart-shaped at the narrowed base, all more or less petioled; calyx-teeth sometimes shorter. - Common westward and southward.

3. S. hyssopifolia, Michx. Smooth and glabrous, or nearly so ; stems slender $\left(1^{\circ}\right.$ high), the angles sometimes reflexed-bristly; lenves linear-ublong, or narrowly linear, sessile, olscurely toothed towards the apex; whorls 4-6-flowered, rather distant ; corolla (light purple) twice or thrice the length of the triangularawl-shaped spreading calyx-teeth. - Wet sandy places, Massachusetts to Virginia; also Michigan, Illinois and southward.

Betónica officinalis, the Wood Betony of Europe, - of a genus hardly distinct from Stachys, - was found by C. J. Sprague in a thicket at Newton, Massachusetts. 


\section{LEO N U RUS, L. Motherwort.}

Calyx top-shaped, 5-nerved, with 5 nearly equal teeth which are awl-shaper, and when old rather spiny-pointed and spreading. Upper lip of the corolla ob. long and entire, somewhat arched ; the lower sprealing, 3-lobed ; its middle lobo larger, broal and inversely heart-shaped, the lateral ones oblong. Stamens 4, ascending under the upper lip: anthers approximate in pairs, the valves naked. Nutlets truncate and sharply 3-angled. - Upright herbs, with cut-lohed leaves, and close whorls of flowers in their axils; in summer. (Name from $\lambda \dot{\epsilon} \omega \nu, a$ lion, and oúpá, tail, i. e. Lion's-tail.)

1. L. Cardaca, L. (Common Motuerwort.) Tall perennial; leaves long-petioled; the lower rounded, palmabely lobed; the floral wedge-shaped at the base, 3-cleft, the lobes lanceolate; upper lip of the pale purple corolla bearded. - Waste places, around dwellings. (Nat. from Eu.)

2. L. Marnubiяtrum, L. Tall biennial, with elongated branches; stemleaves oblong-ovate, coarsely toothed; corolla (whitish) shorfer than the ealyxteeth; the tube naked within; lower lip rather erect.-Roadsides, Pennsylvania: rare. (Adv. from Eu.)

\section{I A M I U M, L. Den D-Nettre.}

Calyx tubular-bell-shaped, about 5-nerved, with 5 nearly equal awl-pointed teeth. Corolla dilated at the throat; the upper lip ovate or oblong, arched, narrowed at the base; the middle lobe of the spreading lower lip broad, notched at the apex, contracted as if stalked at the base; the lateral ones small, at the margin of the throat. Stamens 4, ascending under the upper lip: anthers approximate in pairs, 2-celled, the cells divergent. Nutlets truncate at the apex. - Herbs, decumbent at the hase, the lowest leaves small and long-petioled, the middle ones heart-shaped and doubly toothed, the floral subtending the whorled clusters of flowers; produced from spring to antumn. (Name from $\lambda a u \mu o s$, the throat, in allusion to the ringent corolla.)

* Anmuals or biennials, low: fonwers small, purple, in few whorls or heads.

1. L. A MPLExicaùte, L. Ieaves rounded, deeply crenate-toothed or cut, the upper ones clesping; corolla clongated, upper lip bearded, the lower spotted;

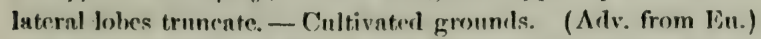

2. I. Purrimeum, I. Lenrs roundish or oblong, heart-shaped, crenatetoothed, all petioled. - Cult. grounds, Pennsylvania. (Adv. from Fu.)

\section{* * Perennial, taller: fnwers larger, in several axillary whorls.}

3. L. Áвuм, L. Hairy ; leaves ovate, heart-shaped, petioled; calyx-teeth very slender, spreading; corolla white, the tuhe curved upwards, obliquely contracted ncar the base, where there is a ring of hairs inside; lateral lobes of lower lip bearing a long slender tooth. - Waste ground near Boston, D. Murray. (Adv. from Eu.)

\section{BALLÒ TA, L. Fetid Hormound.}

Calyx nearly funnel-form; the 10-ribbed tube expanded above into a spreace. ing regular border, with 5-10 tecth. Anthers exserted beyond the tube of 
the corolla, approximate in pairs. Otherwise much as in Marrubium. (Tho Greek name, of uncertain origin.)

1. B. nigra, L. (Black Horenound.) More or less hairy, but green, erect; the root perennial; leaves ovate, toother ; whorls many-flowered, dense; calyx-teeth 5, longer than the tube of the purplish corolla. - Waste places, Massachusetts and Connecticut: scarce. (Adv. from Eu.)

\section{PHLÒmis, L. Jerusalem Sage.}

Calyx tubular, 5-10-ribbed, truncate or equally 5-toothed. Upper lip of the corolla arched; the lower spreading, 3 -cleft. Stamens 4 , ascending and approximate in pairs under the upper lip; the filaments of the upper pair with an awlshaped appendage at the base, longer than the others in P. tuberosa, \&c. : anthercells divergent and confluent. - Leaves rugose. Whorls dense and many-flowered, axillary, remote, bracted. (An old Greck name of a woolly species, of olscure derivation.)

1. P. тubenòsa, L. Tall peronnial $\left(3^{\circ}-5^{\circ}\right.$ high $)$, nearly smooth; leaves ovate-heart-shaped, crenate, petioled; the floral oblong-lanceolate; bracts awlshaped, hairy; upper lip of the purple corolla densely bearded with white hairs on the inside. - Shore of Lake Ontario near Rochester. June, July. (Adv. frum Lu.)

\section{Order 72. Borraginaceat. (Bohage Famil.y.)}

Chiefly rough-hairy herbs (not aromatic), with allernate entire leaves, ann symmetricul flowers with a 5-parted calyx, a regular 5-lobed corolla (except in No. 1), 5 stamens inserted on its tube, a single style and a deeply 4-lobed voury (as in Labiata), which forms in fruit 4 seed-like nutlets, each with a single seed. - Albumen none. Cotyledons plano-convex : radicle pointing to the apex of the fruit. Stigmas 1 or 2 . Calyx valvate, the corolla imbricated (in Myosotis convolute) in the bud. Flowers mostly on one side of the branches of a reduced cyme, initating a spike or raceme, which is rolled up from the end, and straightens as the blossoms expand (circinate or scorpioid), often bractless. (A rather large family of innocent, muciliginous, and slightly bitter plants; the roots of some species yielding a red dye.)

Tribe I. HORIRAGËE. Ovary decply 4-parted, forming as many separate 1-seceled nutlets is fruit; the style rising from the centre betireen them. (Rout frequently red)

- Corolla naked aud open (without scales) in the throat, somewhat irregular! Nutlets erect

1. Echium. Corvila funat-form, unequally 5-Jobed. Stumeus protruded.

* * Corolla with 5 sciles clusing the throat. Nutlets not prickly, erect ; the scar broad.

2. Lycopsis. Corolla funnt-form, slightly curved and oblique : scales blunt and hairy.

3. Symphy tum. Corulla tubular, and enlarged at the sumunit : seales awl-shaped.

* * Corulla opeu, with fulds rather than scales in the throat. Nutlets smouth, erect ; scar small. - Lobes of the tubular corolla imbricated in the bud.

4. Onosmodium. Nutlets stony, smooth. Lobes of the corolla acute and crect.

6. Lithospermum. Nutlets stony, smouth. Lobes of the corolla spreading, roundad. 
6. Mertengin. Nutlots fleghy, fixed hy the inner angic, Lobes of the corolla roanded.

- + Lobes of the short salver-shaped corolla convolute in the bud.

7. MyosotIs. Nutlets hard and smooth. Fluwers all or most of them bractless.

*** Corolla with 6 scales closing the throat. Nutlets prickly, laterally fixed to the central column or the base of the style, often recumbent.

8. Eehinospermum. Corolla salver-shaped. Nutlets emect, prickly on the margin.

9. Cy mоg $108 \mathrm{~mm}$. Corolla funnel-form. Nutlets oblique or depressed, prickly all over.

Tribe 1 I. HELIOTROPEAE. Ovary not lobed, tipped with the simple style : the fruit separating when ripe into 2 or 4 nutlets.

10. Hellotroplum. Throat of the short salver-shaped corolla npen. Nutlets 1-celled.

11. Hellophytum. Throat of the corolla contracted. Nutlets 2, each 2-celled, i. e. 4 in 2 pairs and sometimes a pair of empty false cells.

\section{1. È CHIU M, Tourn. VIPER's Bugloss.}

Corolla with a cylindraceous or funnel-form tube, and a more or less unequal spreading 5-lobed borler; the lobes rounded, the expanded throat naked. Stamens mostly exserted, unequal. S.tyle thread-form. Nutlets roughened or wrinkled, fixed by a flat base. ( $\Lambda$ name of I)ioscorides, from ë $\chi$ ‘s, $a$ viper.)

1. E. vulgare, L. (BLue-weed.) Rough-brintly biennial; stem erect ( $2^{\circ}$ high), mostly simple; stem-leaves linear-lanceolate, sessile; flowers showy, in short lateral clusters, disposed in a long and narrow raceme ; corolla reddishpurple changing to brilliant blue (rarely pale). - Roadsides and meadows : rather rare northward; but a troublesome weed in cultivated ficlds in Virginia. June. (Nat. from Eu.)

\section{I Y CÓPSIS, L. Bugross.}

Corolla funnel-shaped, with a curved tube and a slightly unequal limb; the thront closed with 5 convex obtuse bristly scales placel opposite the lobes. Stamens and style included. Nutlets rongh-wrinkled, erect, fixed by a hollowed-

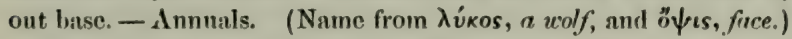

1. L. anvénsis, L. (Smale Bugloss.) Very rough-bristly ( $1^{\circ}$ high); leaves lanceolate; flowers in leafy raceme-like clusters; calyx as long as the tube of the small blue corolla. - Dry or sandy fields, New England to Virginia : scarce. ( $\Lambda$ dv. from Eu.)

\section{S $\mathbf{Y} \mathbf{M} \mathbf{P} \mathbf{Y} \mathbf{T} \mathrm{M}$, Tourn. CoMrrey.}

Corolla oblong-tubular, inflated above, 5-toothed; the short teeth spreading; the throat closed with 5 converging linear-awl-shaped scales. Stamens included: anthers elongated. Style thread-form. Nutlets smooth, ovate, ercet, fixed by the large hollowed hase, which is finely toothed on its margin. - Coarse perennial herbs, with thickened bitterish mucilaginous roots; the nodding raceme-like clusters either single or in pairs. (Name from $\sigma v \mu \phi \in i \nu$, to grow together, probably in allusion to its reputed healing virtues.)

1. S. officindee, L. (Сомmon Comfrey.) Hairy, branched, winged above by the decurrent leaves; the lower leaves ovate-lanceulate, tapering into a petiole, the upper narrower; corolla yellowish-white, rarely purplish. - Moist places; escaped from gardens. Junc. (Adv. from Eu.) 


\section{O N O S M Ò I U M, Michx. False Gromwell.}

Calyx 5-parted; the divisions linear and erect. Corolla tubular, or tubularfunnel-form, naked in the throat (the sinuses minutely hooded-inflexed); the $\mathbf{5}$ acute lobes converging or barely spreading. Anther's oblong-linear or arrowshaped, mucronate, inserted in the throat of the corolla. Style thread-form, much exserted. Nutlets bouy, ovoid, smooth, erect, fixed by the base; the scar minute, not hollowed out. - Chiefly perennial herbs, coarse and hispid, with oblong and sessile ribled-veined leaves, and white, greenish, or yellowish flowers, in at length elongated and exect leafy raceme-like clusters; in summer. Uur species all belong to true ONOsmovies, having the anthers all incluacel, smooth, and ou very short filaments; the corolla only once or twice the leseglis of the ealyx. (Named firum the resemblance to the genus Onosma, which neans ass-smell.)

1. O. Virginiànum, DC. Clothed all over with harsh and rigid appressed short bristles; stems rather slender $\left(1^{\circ}-2^{\circ}\right.$ high $)$; leaves narrowly obloneg, or oblong-lanceolate $\left(1^{\prime}-2 \frac{1}{2}^{\prime}\right.$ Jong), the lower narrowed at the base; lobes of the nurrow corolla lance-cuwl-shaped, sparingly bearded outside with long bristles. (O). hispidum, Michx. Lithospérmuin Virginianum, L.l) - Banks and hillsides, S. New England to Virginia aml soutliward.

2. O. Caroliniànum, 1)C. (excl. syn. Mlichx.) Shaggy all vaer with long and spreading bristly hairs; stem stout, upright $\left(3^{\circ}-4^{\circ}\right.$ high $)$; leaves ovate-lanceolate or oblong-lanceolate, acute; lobes of the rather broad corolla ovate-trianguhar or triangular-lanceolate, thickly hirsute outside. (O. múlle, Beck, \&c. Lithospermum Carolinianum, Lam.) - River-bauks, W. New York to Wisconsin and southward. - Perhaps passes into the next.

3. O. molle, Michx. Hoary with finer and soft mostly appressed hairs; leui's oblong-ovate, obtusish, strungly riblied, lobes of the rather nurow corolla triangular and sharp-pointed, thickly hirsute outside. - 1)ry grounds, Ohio to Ihinoir and southward.

\section{Litho}

Corolla funnel-form, or sometimes salver-shaped; the open throat vaked, or with a more or less evilent transverse fold or scale-like appendage oprosite each lobe; the spreading limb 5-cleft; its lobes rounded. Anthers oblung, almost sessile, included. Nutlets ovate, smooth or roughened, mostly bony or stony, fixed by the base; the scar nearly flat. - Herbs, with thickish and commonly red roots and sessile leaves; the flowers solitary and as if axillary, or spiked and leafy-bracted : sometimes dimorphous as to insertion of stumens and length of style. (Name formed of $\lambda i \theta o s$, stone, and $\sigma \pi \hat{\epsilon} p \mu a$, sced, from the hard nutlets.) $\S 1$. Nutlets tubercled or rough-wrinkled and pitted, gray and dull: throat of the (nearly white) corolla destitute of any evident folds or appenduges.

1. L. arvénse, L. (Corn Gromwele.) Minutely rough-hoary annual or biennial; stems erect $\left(6^{\prime}-12^{\prime}\right.$ high) ; leaves lanceolate or linear, veinless; corolla scarcely longer than the calyx. - Sandy banks and roadsides. MayAug. (Nat. fiom Liu.) 
\$2. Nutlets smooth and shining, mostly white like ivory, occasionully dotted with pores: corolla in our species greenish-uhite or cream-color, small, with 5 small but distinct pubescent scales in the throat. (Root perennial.)

2. L. angustifolium, Michx. Minutely and slightly hoary, roughish, much branched, erect or spreading $\left(6^{\prime}-15^{\prime}\right.$ high); leuves lineur, rigid, 1-nerved; corolla not longer than the calyx ; the short perluncles in fruit mostly recurved; nutlets more or less pitted when young, rarely bright white, but smooth and shining. - River-banks, from Illinois southward and westward. May.

3. L. officinale, L. (Сомmon GromwnL.) Much branched above, ercet $\left(1^{\circ}-2^{\circ}\right.$ bigh) ; lenes thinnish, broadly lemeolate, uente, with a few distinct veins, rough above, soft-pubescent beneath ; corollu exeed ling the crelyx ; nutlets very smooth end even. - Roadsides, \&c. : rather rare. (Nat. from En.)

4. L. latifòlium, Michx. Stem loosely branched, erect $\left(2^{\circ}-3^{\circ}\right.$ high $)$, rough ; leaves ornte and ovate-lennerolute, mostly taper-pointed (even the floral ones 2'-4' long), ribbrd-veined, roughish above, fincly soft-pubescent beneath, the root-leaves large and rounded; corollen shorler then the culy. $x$; nutlets very smooth or sparingly impressed-punctale, shining, turgid (2" longr). - Borders of woods, W. New York and Penn. to Wisconsin and southwestward. June.

\$ 3. В X'TSCIIIA, Ginclin. Nutlets smooth and shining: corollat large, salver-shaped or nearly so, derp orange-yfllon, somewhat pubsss:nt outside, the tube 2-4 times longer than the calyx, the throat more or less appendaged. (Roots perennial, long and deep, yielding a red dye.)

* Tube of the corolla from one half to twice longer than the calyx, not much longer than its ample limb, the lobes entive: the appendages glandular and adherent (especially when the stamens are at the base of the tube), or slightly arched.

5. L. hírtum, Lchm. (HAIRr Puccoon.) Hispid with bristly hairs $\left(1^{\circ}-2^{\circ}\right.$ high); stem-leaves lanceolate or linear, those of the flowering branches ovate-oblong, bristly-ciliate; corolla woolly-burevded at the buse inside; flousers dis linelly peduneled; fruiting calyx ( $\frac{1}{2}^{\prime}$ long) $3-4$ times longer than the nutlets. (Also L. sericeum, Lehm. Batschia Caroliniensis, Gmel. 13. Gmelini, Mich.) - 1)ry woods, New York to Wisconsin, Virginia, and sonthward and westward. $\Lambda$ pril-June. - Flowers crowded, showy : limb of the corolla $2_{3}^{\prime}-1^{\prime}$ broad.

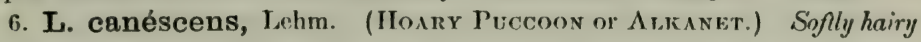
and more or less houry $\left(6^{\prime}-15^{\prime}\right.$ high) ; lemes o' hise, lincar-oblong, or the upper ovate-oblong, more or less downy benenth and ronghish with elose appressed hairs above; corolla naked at the base within; fowers sessile; finiting calyx ( 3 "long) barely twe the length of the nutlets. (Batschia caneseens, Michx.) - Open woods and plains, New York to Kentucky and northwestward. May. - Limb of the showy corolla smaller and the caly $\mathrm{x}$ shorter than in the last.

* * Tube of the corolla $2-4$ times the length of the culy.x and of its erose-toothed or crenulatelo'es, the appendages more projecting. (Pentálophus, A. DC.)

7. L. longiflorum, Spreng. Minutely strigose-hoary; stem simple (6'$18 \mathrm{high}$ ); leaves linear; tube of the corolla much longer than the calyx ( $8^{\prime \prime}$ $1 \frac{1}{2}$ long). (Batschia longiflora, Pursh. I. incisum, Lelm. Pentalophus longiflorus, A. DC.)-Prairies and plains, from W. Illinois and Wisconsin westward. May. 


\section{MERTÉ NSIA, Roth. Smooth Lungwort.}

Corolla trumpet-shaped or bell-funnel-shaped, longer than the deeply 5-cleft or 5-parted calyx, naked, or with 5 small glandular folds or appendages in the open throat. Anthers oblong or arrow-shaped. Style long and thread-form. Nutlets ovoid, fleshy when fiesh, smooth or wrinkled, obliquely attached next the base by a prominent internal angle; the scar small. - Smooth! or soft-hairy perennial herbs, with pale and entire leaves, and handsome purplish-blue (rarely white) flowers, in loose and short panicled or corymbed laceme-like clusters, only the lower one leafy-bracted: pedicels slender. (Named for Prof: Francis Charles Mertens, a Gierman botanist.)

\$1. Corolla perfectly nuked in the throat; the broad trumpet-mouthed limb almost entire: filaments slender, protruding, much longer than the anthers.

1. M. Virgínica, 1)C. (Vinginian Cowslip or Lunawont.) Very smooth, pale, erect $\left(1^{\circ}-2^{\circ}\right.$ high $)$; leaves obovate, veiny, those of the root $\left(4^{\prime}-\right.$ 6' long) petioled; corolla trumpet-shaped, $\mathbf{l}^{\prime}$ long, many times exceding the calyx, rich purple-blue, rarely white; lobes of the disk one on each side of the ovary. (Pulmonaria Virginica, L.) - Alluvial banks, W. New York to Wisconsin, Virginia, and southward. May. - Cultivated for ornament.

\section{§ 2. Corolla with 5 glandular folds or appendages at the throat; the limb 5-lobed.}

2. M. marítima, Don. (SEA Lunciwort.) Spreading or decumbent, smooth, glaucous; lawes fleshy, ovate or obovate, the upper surface becouning papillose; corolla bell-funnel-form, twice the length of the calyx ( $3^{\prime \prime}$ long); filaments longer and narower than the anthers; nutlets flattened. - Sea-coast, on rocks and sand, Cape Cod to Maine and northward: scaree. June-Aug. (Eu.)

3. M. paniculàta, Don. lionglish and more or liss hairy, erect $\left(1^{\circ}-2^{\circ}\right.$

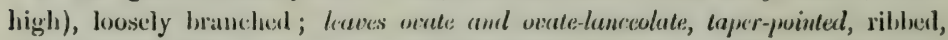
thin; corolla ( 6 "long) somewhat fumbelform, 3-4 times the length of tho lance-linear acute divisions of the caly ; filaments broader and shorter than the anthers. - Shore of L. Superior and northward and westward. July.

\section{- or Y OSÒTIS, I. Scorpion-grass. Forget-Mienot.}

Corolla salver-form, the tube about the length of the 5-toothed or 5-cleft calyx; the throat with 5 small and blunt arehing appendages opposite the rounded lobes; the latter convolute in the bud! Stamens included, on very short filaments. Nutlets smooth, compressed, fixed at the base; the scar minute. - Low and mostly soft-hairy herls, with entire leaves, those of the stem sessile, and with small flowers in naked (so called) racemes, which are entirely bractless, or oceasionally with one or two small leaves next the base, prolonged and straightened in fruit. Flowering thungh the season. (Name composed of $\mu$ v́s, munse, and oủs, $\omega^{\tau}$ ós, ear, in allusion to the aspect of the short and soft leaves in some species: one popular nane is MousE-E.Mr.)

* Calyx open in fiuit, ils hetirs appressed, none of them hooked nor glandular.

1. M. palústris, Withering. (TนU⿺ Forciér-ME-NoT.) Percmial; stems ascending from an oblique crecping basc $\left(9^{\prime}-20^{\prime}\right.$ high $)$, loosely branched, 
smoothish ; lenves rongh-pubescent, oblong-lanceolate or linear-oblong; calyx moderately 5-eleft, shorter than the spreading pedicels; corolla (rather large in the genuine plant) pale blue with a yellow eye. - Nat. from Eu. near Boston, escaping from gardens. - Varies into smaller-flowered forms, among which high anthorities rank M. caspitosa, and (with yet more reason) the intermediate

Var. láxa. (M. laxa, Lehm.) Creeping base of the stem slort ; flowers a third or half smaller; pedicels longer. - Vet places, northward. (Eu.)

* * Calyx closing or the lobes ercet in fiuit, clothed with sprunding huirs, a part of them minutely hooked or glandular at the apex: corolla small: root annual or biennial.

2. M. arvénsis, Hoffm. Hirsute with spreading hairs, erect or ascending $\left(6^{\prime}-15^{\prime}\right.$ high $)$; leaves oblong-lanceolate, acutish; racemes naked at the base and stalked; corolla blue, rarely white; pedicels spreading in fruit and longer than the 5-clef equal calyx. (M. intermedia, Link. M. scorpioides, var. arvensis, L.) -Fields, \&c. : not very common, perhaps not indigenous. (Eu.)

3. M. vérna, Nutt. Bristly-hirsute, branched from the base, erect (4'$12^{\prime}$ high); leaves obtuse, lincar-oblong, or the lower spatulate-oblong; racemes leafy at the base; corolla very small, white, with a short limb; pedicels in fruit erect and appressed at the bnse, usually abruptly bent outwarls near the apex, rather shorter than the derply 5-cleft unequenl (somewhat 2-lipped) very hispid calyx. (M. inflexa, Engelm.) - Dry hills : rather common. May - July.

4. M. versfcolor, Pers. More slender than the last, simple at the base; racemes loose, mostly naked at the base; flowers almost sessile; corolla pale yellow changing to blue or violet; calyx derply and equally 5-cleff. - Ficlds, Delaware, W. M. Canby. (Nat. from Eu.)

\section{ECH I N OSPÉRM U M, Swartz. STickseñ.}

Corolla salver-form, short, nearly as in Myosotis, hut imbrieaterl in the bud, the throat closed with 5 short scales. Stamens included. Nutlets erect, flxed laterally to the base of the style or central column, triangular or compressed, the lack armed with 1-3 marginal rows of prickles which are barbed at tho npex, otherwise naked:- Rongh-hairy and grayish herbs, with small blue flowers in bracted (so called) racemes; ours annuals or biennials, flowering all summer. (Name compounded of éxivos, a hedgehog, and $\sigma \pi \dot{\epsilon} \rho \mu \alpha$, seed.)

1. E. LAspuls, Lehm. Stem upright, branched above $\left(1^{\circ}-2^{\circ}\right.$ high); the short pelicels erect; leaves lanceolate, rough-hairy; nutlets each with a double row of prickles at the margins, and rongh-tubereled on the back. - Waste places : common. (Nat. from Eu.)

2. E. Redówskii, Lehm. Nutlets with a single marginal row stout prickles, and grannlate-roughened on the hack: otherwise much like the last. (E. patulum, Hook.) - St. Paul's, Minnesota, and on the plains westward.

\section{CYNOGLÓSS U M, Tourn. Hound's-Tongue.}

Corolla funnel-form; the tuhe about the length of th:3 5-parted calyx : the throat closed with 5 obtuse scales; the lobes rounded. Stamens included. Nut- 
lets depressed or convex, oblique, fixed near the apex to the base of the style, roughened all over with short barbed or hooked prickles. - Coarso herbs, with a strong scent and petioled lower leares; the mostly panicled (so-ealled) racemes naked above, usually bracted at the base. Fl. all summer. (Name from $\kappa \dot{\omega} \omega \nu$, a $\operatorname{dog}$, and $\gamma \lambda \hat{\omega} \sigma \sigma a$, tongue; from the shupe und texture of the leaves.)

1. C. officinale, L. (Comaon llognd'Tongue.) Bienuial ; cluthad with short soft hairs, leajy, panicled above; upper leaves lanceulate, closely sessile by a rounded or slightly heart-shaped base; racemes nearly bractless; corclla reddish-purple (rarely white); nutlets flat on the broad upper face, somewhat margined. - Waste grounds and pastures: a familiar and troublesome weed; the large nutlets adhering to the fleece of sheep, \&e. (Nat. from Lu.)

2. C. Virgínicum, L. (WiLv Comrrixy.) Perenuial; roughish with spreading bristly hairs; stem simple, few-leased $\left(2^{\circ}-3^{\circ}\right.$ high $)$; stem-leaves lanceolate-oblong, elaspiug by a deep heart-shaped bitse; racemes feev and corymbed, raisad on a long naked peduncle, bractless; corolla prele blue; nutlets strongly convex. - Rich woods: rather common, especially westward. - Elowers intermediate in size between the other two.

3. C. Morisóni, DC. (Beggan's Lick.) Biennial; stem hairy, viry broally branched, leafy ( $2^{\circ}-4^{\circ}$ high) ; leaves oblung-ovate, taper-pointed, also tapering at the base, thin, minutely downy underneath and roughish above; recemes panicled, forking, diverying, hairy, leufi-bracted at the base; flowers very small; corolla white or pale blue (minute); pedicels reflexed in firuit ; nuthets convex, the prickles with barbed points. (Myosiotis Virginica, L. Echinospérmum, Letom.) - Copses: a common and vile weed.

\section{HELIOTRÒ PI U M, Tourn. Helotrope.}

Corolla salver-shaped, short, 5-lohed; the sinuses more or less plaited in the bud; the throat open. Anther's nearly sessile. Style short: stigma conical, or capitate. Nutlets 4, when young united by their whole inner faces into a 4 celled ovary, but separating when ripe, cach 1-seded. - Ilerbs or low shrubly plants, the small flowers in one-sided spikes; in summer. (The ancient name,

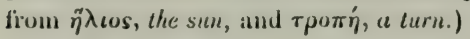

1. H. Eunoriedu, L. Erect annual $\left(6^{\prime}-18^{\prime}\right.$ high $)$, hoary-pubescent; leaves oval, long-petioled ; latcral spikes single, the terminal in pairs ; caly $\mathrm{x}$ spreading in firuit, hairy. - Waste places, southward : scarce. (Adv. from Eu.)

2. H. Curassávicum, I. Apparently annıal, glabrous; stenıs ascending; leaves lance-linear or spatulate, thickish, pale, almost veinless; spikes in pairs. - Sandy shores, Norfulk, Virginia, S. W. Illinois, and southward.

\section{H EL I Ó PHYTU M, Cham., I)C. Inman Helotrope.}

Corolla constrict:d at the throat. Style very short. Nutlets 2, cach 2-celled, i. e. 4, in pairs, and sometimes a pair of empty fialse eclls besides : otherwise nearly as in Ileliotropium. (Name, $\ddot{\eta} \lambda \iota s$, sinn, and qurón, plant.)

1. H. Índeum, 1)C. Frect and hairy ammual; leaves petioled, ovate or oval and somewhat heart-shaped; spikes single; fruit 2-cleft, mitre-shaped, with an empty false cell before each seed-bearing cell. (Ileliotropium Indi cum, L.) - Waste places, S. Illinois, and southward. (Adv. from India.) 


\section{Onder 73. HYDRopIYLLÀCEA. (WATERLEAF FamLY.)}

Herbs, commonly hairy, with mosily alternate leaves, regular 5-merous and 5-androus flowers, in aspect between the foregoing and the next orrler; but the ovary entire and 1-celled with 2 parietal 4-mumy-ovuled placentoe, or ravely 2-celled by the union of the placenta in the axis; style 2-cleft or 2 separate styles; fruit a 2-valved 4-many-seeded pod. - Seeds mostly reticulated or pitted. Embryo small in copions albumen. - Flowers chiefly blue or white, in one-sided cymes or rasemes, which are mostly bractless and coiled from the apex when young, as in the Borage Family. (A small order of plants of no marked properties, some cultivated for ornament.)

TrIbe I. HY DROPHYLYEAE. Ovary and pod 1-celled. Seeds amphitropous, pitted or reticulated, and with cartilaginous albumen. Leaves usually cut-tonthed, lobed or pinnate. Style 2-cleft.

- Ovary lined with the dilated and fleshy placentre, which enclose the ovules and sects (in our plants these are ouly 4 in number) like an imner porieurp.

1. Ilyalrophy 11 um. Stamens exserted : unthers linear. Calyx unchanged in fruit.

2. NemophIla. Stamens included : anthers shoit. Calyx with appendages at the sinuses.

3. Ellsin. Stamens included. Calyx destitute of appendages, enlarged in fruit.

* Ovary with narrow parietal placentac, in fruit projecting inwarls more or less.

4. Phacella. Coralla-lobes imbricated in the bud. Caly $\mathrm{x}$ destitute of appenilages.

Tribe II. H Y DROLEAE. Ovary and pod 2-celled, the placentie often projecting from the axis far into the cells. Seeds anatropous: albumen fleshy. Leaves undivided.

5. Hydrolea. Corolla between wheel-shaped and bell-shaped. Styles 2 . Leaves entire.

\section{HY DROPHÝLLUM, L. Waterleaf.}

Calyx 5-parted, sometimes with a small appendage in each sinus, early open in the bud. Corolla bell-shaperl, 5-eleft; the lobes convolute in the bud; the tube furnished with 5 longitudinal linear appendages opposite the lobes, which cohere by their middle, while their edges are folded inwards, forming a nectariferous groove. Stamens and style mostly exserted: filaments more or less bearded : anthers linear. Ovary bristly-hairy (as is usual in the family); the 2 fleshy placenta expanded so as to line the cell and nearly fill the cavity, soon free from the walls execpt at the top and bottom, each bearing a pair of oviules on the inner face. Pod ripening $\mathbf{1 - 4}$ seeds, spherical. - Perennials, with petioled ample leaves, and white or pale blue cymose-clustered flowers. (Name formed of $\tilde{\delta} \delta \omega \rho$, water, and $\phi \dot{\lambda} \lambda \lambda o \nu$, lraf; of no obvious application to these plants.)

* Calyx with minute if any appendages: rootstocks crerping, scaly-toothed.

1. H. macrophyllum, Nutt. Rough-hairy; leaves oblong, pinnate and pinnatifid; the divisions 9-13, ovate, obtuse, coarsely cut-toothed; peduncle very long; calyx-lobes lanceolate-pointed from a broad base, very hairy. - Rocky, shaded banks, Ohio, Indiana, Kentucky, and southward. July. - Root-leaves 10 long; flowers crowded in a globular cluster.

2. H. Virgínicum, L. Sinoothish $\left(1^{\circ}-2^{\circ}\right.$ high $)$; leaves pinnatcly divided; the divisions 5-7, ovate-lunceolate or oblong, pointed, sharply cut-toothed, the lowest mostly 2-parted, the uppermost confluent; peduncles longer shan the petioles of the upper leaves, forked ; calyx-lobes narrowly linear, bristly-ciliate - Damp woods. June - Aug. 
3. H. Canadénse, L. Neurly smooth (10 high); leaves palmately 5-7. lobed, rounded, heart-shaped at the bise, unequally toothed; those from the root sometimes with 2-3 small and scattered lateral leatlets; peduncles much shorter than the long petioles, forked, the crowded (nearly white) flowers on very short pedicels; calyx-lobes lincar-awl-shaped, nearly smooth. - Damp rich woods, W. New England to the mountaius of Virginia and northward. June-Aug. Rootstocks thickened and very strongly touthed in 2 rows by the persistent bases of the stout petioles: leaves $3^{\prime}-5^{\prime}$ broad.

* Calyx with a small reflexud appendaye in each sinus: stamens sometimes not exserted (probubly two forms of flowers, as in some Borrayinacen, \&c.).

4. H. appendiculàtum, Michx. Ifairy; stem-leaves palmately 5-lubed, rounded, the lobes toothed and pointed, the lowest pinnately divided; cymes rather loosely flowered; pedicels (at length slender) and calyx bristly-hairy. Open woods, New York to Virginia, Wisconsin, and westward. June, July.

\section{NEMÓ PH ILA, Nutt. Nemorilita.}

Calyx 5-parted, and with a reflexed tooth or appendage in each sinus, more or less enlarged in fruit. Corulla bell-shaped or almost wheel-sliaped ; the lobes convolute in the bud; the tube mostly with 10 small folds or scales inside. Stamens included: anthers ovoid or heart-shaped. Placenta (bearing each 2-12 ovules), pod, and seeds as in Itydrophyllum. - Diffuse and fragile annuals, with opposite or partly alternate pinnatitid or lobed leaves, and one-flowered peduncles; the corolla white, blue, or marked with purple. (Name composed of vépos, a grove, and $\phi \iota \lambda \epsilon \omega$, to love.) Some handsome sjecies are garden aunuals.

1. N. microcalyx, Fisch. \& Meyer. Small, roughish-pubescent; stems diffusely spreading $\left(2^{\prime}-8^{\prime}\right.$ lung $)$; leaves parted or decply cleft into $3-5$ roundish or wedge-obovate sparingly cut-lobed divisions, the upper leaves all alternate; peduncles opposite the leaves, shorter than the long petioles; flowers minute; corolla white, longer than the calyx; placentae each 2-ovuled; pod 1-2-secded. (Ellisia microcalyx, Nutt. Nemophila evanescens, Ihorby.) - Moist woods, Virginia (near Washington), and southward. April-June.

\section{3. eluísia, L. Ellisia.}

Calyx 5-parted, without appendages, enlarged and foliaceous in fruit. Corolla bell-shaped or cylindraceous, not longer than the calyx, 5-lubed above; the lobes imbricated or convolute in the bud, the tube with 5 minute appendages within. Stamens included. I'lacenter (each 2-oruled), fruit, and seeds much as in Ilydrophyllum. - Delicate and branching annuals, with lobed or divided leaves, the lower opposite, and small whitish flowers. (Named for John Ellis, a distinguished naturalist, :In English correspondent of Limnaus.)

1. E. Nyctèlea, L. Minutely or sparingly roughish-hairy, divergently branched $\left(6^{\prime}-12^{\prime}\right.$ high $)$; leaves pinnately parted into $7-13$ lanceolate or linearoblong sparingly eut-toothed divisions; peduncles solitary in the forks or opposite the leaves, 1 -flowered; calyx-lobes triangular-ovate lanceolate, pointed, about the length of the cylindraceous (whitish) corolla (in fruit becoming nearay $\frac{1}{2}$ long); pod penduluas. - Sharly damp places, W. New Jersey and E. Pemsjlvania to Virginiat. May-July. 
2. E. ambígua, Nutt. Later peluncles sometimes 2-3-flowered; corolla rather more bell-shaped, the upper part of tube 5-angular: otherwise like the preceding; of which it is probably a variety. - Illinois and westward.

\section{PH A C ÈLI A, Juss. (Phacelia \& Eutoca, R. Br.)}

Calyx 5-parted; the sinuses naked. Corolla open-bell-shaped, 5-lobed; the loles imbriented in the bud. Filamenty slender, often (with tho 2-cleft style) exserted : anthers ovoid or oblong. Ovary with 2 narrow linear placentro adherent to the walls, in fruit usually projecting inwards more or less, the two often forming an imperfect partition in the ovoid 4-many-sceded pod. (Ovules 2 - 30 on each placenta.) - Perennial or mostly nnnual herbs, with either simple, lobed, or divided leaves, and commonly handsome (blue, purple, or white) flowcrs in one-sided raceme-like clusters. (Name from фíkє $\lambda$ os, a fascicle.)

§1. PHACELIA. Seeds and ovules only 4 (two on each placentu) : corolla with narrow folds, appendages, or scules within, the lobes entire.

1. P. bipinnatiflda, Michx. Biennial; stem upright, much branched, hairy $\left(1^{\circ}-2^{\circ}\right.$ high); leaves long-petioled, pinnately $3-5$--livided; the divisions or leaflets ovate or oblong-ovate, acute, coarsely and often sparingly cut-lobed or pinnatifid; racemes elongated, loosely many-flowered, glandular-pubescent; perlicels about the length of the calyx, spreading or recurved. - Shaded banks, in rich soil, Ohio to Illinois and southward. May, June. - Corolla bright blue, 6" broad, with 5 pairs of longitudinal folds, covering as many externally kecled deep grooves. Stamens bearded below; these, with the style, are either somewhat included (P. brevístylis, Buckl.y) or exserted in different individuals.

§ 2. COSMANTHUS. (Cosmanthus, Nolte. Sect. Eucosmanthus, A. DC., in part.) Seerls and ovules only 4 : corolla naked within; its lobes benutifilly fringe-toothed: filoments villous-bearded below: lenves pinnatifid, the upper clusping at the base: flowers long-pedicelled: annuals or spring biennials.

2. P. Púrshii, Buckley. Sparsely hairy ; stem crect or ascending, branched $\left(8^{\prime}-12^{\prime}\right.$ high $)$; lobes of the stem-leaves $5-9$, oblong or linceolate, ante ; raceme manyflovered; calyx-lobes lance-linear; corolla light blue, varying to white (about $\frac{1}{2}$ in diameter). (P. fimbriata, Pursh., not of Michx. Cosmanthus fimbriatus, Nolte, $\& c$.) - Moist wooded banks, W. Pennsylvania to Illinois and southward. April-June.

3. P. fimbriàta, Michx. Slightly hairy, slender; stems sprending or ascending $\left(5^{\prime}-8^{\prime}\right.$ long), few-leaved ; lowest leaves 3 - 5-divided into roundish leaflets; the upper 5-7-cleft or cut-toothed, the lohes obtuse; ruceme 3-10-flovered; culy. $x$-lobes linear-oblong, obtuse, becoming spatulate; corolla white $\left(3^{\prime}-4^{\prime \prime}\right.$ broad). - Woods, high mountains of Virginia, and southward. May.

§ 3. EÙTOCA. (Eutoca, R. Br.) Serds (or at lenst the ovules) several or muny, rarely only 3 or 4 on each placenta : corolla usually with small and inconspicuous folds or appendages within, its lobes entire. (Ours are annuls or bimnials.)

4. P. parviflora, Pursh. Somewhat hairy, slender, difficsely spreading $\left(3^{\prime}-8^{\prime}\right.$ high) ; leaves pinnately cleft or the lower divided into $3-7$ short lobes; racemes solitary, loosely 5-15-flowered; pedicels filiform, at length several times 
longer than the oblong calyx-lobes; corvlla bluish-white $\left(3^{\prime \prime}-4^{\prime \prime}\right.$ broad); pod few-sected. - Shaded banks, S. Penn. to Virginia and southward. April-June.

5. P. Franklínii, Gray. Suft-hairy; stem erect $\left(6^{\prime}-15^{\prime}\right.$ high), rather stout; leaves pinnately parted int many lanceolate or oblong-linear lobes, which are crowded and often cut-toothed or pinnatitid; racemes short, dense, crouded into an ollony sprike; calyx-lobes linear; curolla blue; pod many-sceded. (Eutoca Franklinii, R. Br.) - Shores of Lake Superior, especially on Isle Royale; thence northward and westward.

\section{H Y DRÒLEA, L. HYDROLEA.}

Calyx 5-parted. Corolla short-campanulate or almost whecl-shaped, 5-cleft. Filaments dilated at the base. Styles 2, distinct. I'od globular, 2-eelled, and the cells often partly divided into 2 by the projection of the many-seeded placentie, thin-walled, 2-4-valved or bursting irregularly. Sceds minute, striateribbed. - Ilerbs or scarcely shrubby plants, growing in water or wet places (whence the name, from $v \delta \omega \rho, u x t e r)$, with entire leaves, often having spines in their axils, and clustered blue flowers.

1. H. affinis, n. sp. Glabrous throughout; stem ascending from a creeping base, armed with small axillary spines; leaves lanceolate, tapering into a very short petiole; fluwers in small axillary leafy-bracted clusters; divisions of the calyx lance-ovate, equalling the corolla and the irregularly-bursting globose pod. - Banks of the Ohio in S. Illinois, Mr. Fusey (and of the Missisippi at Memphis, A. Fendlex: also L. Texas, C. W'right: in addenda to ed. 2, referred to H. quadrivalvis, Halt., of the Southeastern States, from which it is distinguished by the smoothness and the broader sepals.

\section{Ordeir 74. Polemoniáce. (Polemonium Family.)}

Ilerts, with allernale or opposite leaves, regular 5-merous and 5-androus flowers, the lobes of the corolla convolute (in one tribe imbricated) in the bud, a 3-celled ovary and 3-lobed style; the pod 3-celled, 3-valecd, loculicidal, fewmany-seeded; the valies usually breaking atory from the triangular central column. - Seeds amplitropous, the coat frequently mucilaginous when moistened and emitting spiral threads. Embryo straight in the axis of copious albumen. Calyx persistent, usually imbricated. Corolla with a 5-parted border. Anthers introrse. (Insipid and innocent plants; many are ornamental in cultivation.)

Tribe I. POLEMIONIEAE. Caly $x$ 5-cleft. Corolla convolute in the bud. Filaments filifurm, inserted on the tube of the corsila : cells of the anther parallel, opening length. wise. Flowers cymuse-panicled or clustered.

1. Polemonium. Caljx and corulla open-bell-shaped. Filaments slenter, equal.

2. Phlox. Calyx uarrow. Curulla salver-shaped, with a lougr tube, includiug the unequally inserted flaments.

Tribe II. DIA PENSIEAE. Calyx of 5 sepals. Curulla imbricatid in the bud, and with the broad and flat tilaments in the sinuses. Anthers opeuiug transversely.

3. Diapensia. Anther-cells pointless, opening by an obliqucly transverse line.

4. Pyxidanthera. Auther-vills aw u-pointed uuderueath, opeuing struight acroes. 


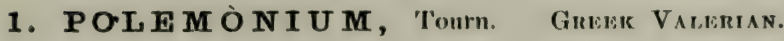

Calyx bell-shaped. Stamens equally inserted at the summit of the very short tube of the open-bell-shaped or short funicl-form corolla: filaments slender, declined, hairy-appendaged at the base. Pod few - several-sceded. - Perennials, with alternate pinmate Jeaves, the upper leaflets sometimes confluent; the (blue or white) corymbose flowers nearly bractless. (An ancient name, from $\pi$ ó $\lambda \epsilon \mu o s$, war, of doubtful application.)

1. P. réptans, L. Smooth throughout; stems weak and spreading $\left(6^{\prime}-\right.$ $10^{\prime}$ high, never creeping as the name denotes); leaflets $\mathbf{i}-11$, ovate-lanceolate 1 or oblong ; corymbs few-flowered ; flowers nodding; lohes of the calyx rather shorter than the tube; stamens and style not protruding heyourl the corolla, which is light blue, about $\frac{1}{2}^{\prime}$ wide; pods about 3-seeded. - Woods, W. New York to Wisconsin and sonthward. May, June.

2. P. cærùleum, L. (JACOB's LAdper.) Stem erect $\left(1^{\circ}-3^{\circ}\right.$ high); leaflets 9-21, linear-lanceolate, oblong- or ovate-lanceolate, mostly crowded; flowers numerous, in a thyrsus or contracted panicle; lobes of the caly $\mathrm{x}$ longe: than the tube; stamens and style mostly exserted beyond the bright blue corolla, which is nearly 1' broad; pod several-secded. - Swamps, about the sources of the Susqquehanna, New York: Fast of Charlottesville, Schoharie Co., 1)r. E. C. IIoue. Flk Creck, near Delhi, Delaware Co., B. 1). Gillort. Head of Littlo Lakes, Warren, Herkimer Co., G. IF. Clinton. Warren Co., New Jersey, A. P. Garber. Wild far northwestward. July. (Eu.)

\section{PHLOX, L. Priox.}

Calyx narrow, somewhat prismatic, or plaited and angled. Corolla salverform, with a long tube. Stamens very unequally inserted in the tube of the corolla, included. Pod ovoid, with (sometimes 2 ovules but ripening only) a single seed in each cell. - Perennials (except a few Southern species, such as P. Drummondii of the gardens), with opposite and sessile perfectly entire leaves, the floral often alternate. Flowers cymose, mostly bracted; the open clusters terminal or crowded in the upper axils. ( $\Phi \lambda \delta^{\prime} \xi$, flame, an ancient name of Lychnis, transferred to this North American genus.) Most of the species are cultivated in gardens.

* Stem strictly upright: panicle pyramidal $o$ oblong, many-fowered: peduncles and pedicels very short: lobes of the corolla entive. (Very common in gardens.)

1. P. paniculàta, L. Stem stont $\left(2^{\circ}-4^{\circ}\right.$ high $)$, smooth ; leaves oblonh lanccolate and ovate-lanceolate, pointed, large, tapering at the base, the upper often heart-shaped at the hase ; panicle ample, pyramidal-corymbed; calyx-tceth awnpointed. (P. undulata, Ait., \&c.) - Var. ACUmindta (P. acuminata, Pursh) has the broader and taper-pointed leaves beneath downy, like the stem, which is sometimes rongh-hairy and spotted below. - Rich woods, from Penn. to Illinois, and southward. June, July. - Flowers pink-purple varying to white.

2. P. maculata, L. (Wicd Sweet-Winicin.) Smooth, or barely roughish; stem spotted with purple, rather slender $\left(1^{\circ}-2^{\circ}\right.$ high); lower leaves lanceolate, the upper nearly ovatc-lanceolate, tapering to the apex from the broad 
and rounded or somewhat heart-shaped base; panicle narrow, oblong, leafy below: culyx-teeth tritingular-lanceolate, short, scurcely pointed; corolla purple (sometimes white, when it is $\mathrm{I}^{2}$. suatveolens, Ait.). Lower branches of the panicle rarely elongated, so as to become pyramidal, when it is P. pyramidalis, Smith. - Rich woods and river-banks, N. P'enn. to Wisconsin, and southward. June.

* * Stems ascending or upright, often from a dicumbent buse: fluwers in terminul corymbed eymes: the whole plant smooth and ylabrous: lobes of the corolla round and entire: culys-tecth short, triangular-lanceo'ute.

3. P. Carolina, L. Stems ascending $\left(\frac{1}{2}^{\circ}-2^{\circ}\right.$ high $)$, often from a prostrate base; leaves oblure-lanceolate, or the upper ovate-lanceolate, and sometimes heart-shaped at the base, acute or pointed; flowers crowded, short-peduncled; calyx-teeth acute. - Var. ovàs, Benth., has broader leaves (P. ovata, L.). Var. nftrda, Benth., has narrower leaves (P. nitida, Pursh), and verges to the next. - Woods, W. Pennsylvania to Michigan, Virginia, and southward. June, July. - Corolla $1^{\prime}$ long; the limb $1^{\prime}$ broad, pink-purple.

4. P. glabérrima, L. Stens slender, erect $\left(1^{\circ}-3^{\circ}\right.$ high $)$; leaves lineurlanceolate or raiely obiong-lanceolate, very smooth (except the rough and sometimes revolute margins), tapering grardually to a point ( $3^{\prime}-t^{\prime}$ lougr); cymes few-flowered and loosely corymbed; flowers peduncled (pink or whitish); calyx-lecth sharp-pointed. (P. carnea, Sims. P. revoluta, A ikin.) - Prairies and open woods, Ohio and Wisconsin to Virginia and southward. July.

* * Stems ascruding (or in No. 5 erect) fiom a spreuding or prostrate base, more or less clammy-pubescent, as well us the calyx and the oblong, lanceolate, or linear leaves: flowers in terminal corymbed cymes, mostly pedicelled: calyx deeply cleft, the tecth linear-awl-shaped or setuceous.

5. P. pilosa, L. Stems slender, nearly erect $\left(1^{\circ}-1 \frac{1}{2}{ }^{\circ}\right.$ high $)$, usually hairy, as ure the lanceolate or linear leaves, which commonly taper to a sharp point; cymes at length open; culy.c-tecth slender awl-shaped and awn-like, longer than the tube, loose or spreading; lobes of the pink-purple or rose-red (rarely white) corolla ohovate, entire. (I'. aristata, Michx. P. aristata \& pilosa in part, Benth. in $D($.) - Borders of thiclets and prairies, New Jersey to Wisconsin and southward. May, June. - Leaves $I^{\prime}-2 \frac{1}{2}$ ' long, $1^{\prime \prime}-3$ " wide.

6. P. procúmbens, Lehm. Stems ascending $\left(\frac{1}{2}^{\circ}-1 \frac{1}{2}^{\circ}\right.$ high $)$, mostly simple; leaves broadly linear, lanceolate or ovate-oblong, abruptly acute or blunt $\left(\frac{t^{\prime}}{2}-1 \frac{1}{2}^{\prime}\right.$ long, on sterile shouts often ovate); (yme mostly comproct and sessile, leafybrested; calyx-teeth awl-shaycd or linear, sharp-jointed, but seldom awned, rather longer than the tube, straight; lobes of the corolla oborate and entire (or rarely notched), purple, pink, or sometimes white. (P. pilosa, Walt., Michx., Ell., Benth. in part, not L. P. pilosa, var.? Walteri, Ed. 2. P. Wálteri, Chapman. P. procumbens, Lehin. is a small form.) - Dry hills and barrens, Kentucky, Virginia, and southward. May, June.

7. P. réptans, Michx. Runners creeping, bearing roundish-oborate smoothish and thickish lewes; flowering stems $\left(t^{\prime}-8^{\prime}\right.$ high $)$ and their oblong or ovate obtuse leaves ( $\frac{1}{2}$ ' long) pubrscent, often climnny ; cyme close, few-flowered ; calyxtecth lincar-awl-shiaped, about the length of the tulo; lobes of the reddish-purple corolla round-wovate, mostly entire. - Damp woods, I'ennsylvania, Kentucky, and 
southward. Mny, Junc. - Flowers showy : tube of the corolla an inch long; the limb nearly as broad.

8. P. divaricata, L. Stems spreading or ascending from a decumbent base $\left(9^{\prime}-18^{\prime}\right.$ high $)$; leaves oblong-ovate or the lower oblong-lanccolate ( $1 \frac{1}{2}^{\prime}$ long), acutish ; cyme corymbose-panicled, spreading, loosely-flowered; peduncles slender; calyx-tceth slender awl-shaped, much longer than the tube; lobes of the pale lilac or bluish corolla obcordate or wedge-obovate and notched at the end, or ofen entire (var. Laphamii, $W^{\prime}$ ood),$\frac{1}{2}{ }^{\prime}-\frac{3}{3}$ ' long, equalling or longer than the tube, with rather wide sinuses between them. - Rocky damp woods, mountains of Virginia to N. New York, Wisconsin, and northward. May.

9. P. bifida, Beck. Stems ascending, branched $\left(5^{\prime}-8^{\prime}\right.$ high $)$; leaves linear, becoming nearly glabrous $\left(\frac{1}{2}^{\prime}-1 \frac{1^{\prime}}{2}\right.$ long, $1 \frac{1^{\prime \prime}}{2}$ wide); flowers few, on slender peduncles; calyx-teeth awl-shaped, about the length of the tube; lobes of the pale purple corolla 2-cleft to or below the middle ( $4^{\prime \prime}$ long), equalling the tube, the divisions linear oblong. - Prairies of Illinois, Mead (and Missouri). May.

**** Stems creeping and tufted in broad mats, the short fowering stwots ascending, glandular-pubescent; the rigid narrow leaves crowded und fircicled.

10. P. subulata, L. (Ground or Moss Pink.) Depressed, in broad mats; leaves awl-shaped, lanceolate, or narrowly linear $\left(3^{\prime \prime}-6^{\prime \prime}\right.$ long) ; cymes few-flowered; calyx-teeth awl-shaped, rigid; corolla pink-purple or rose-color with a darker centre (sometimes white); the lobes wedge-shaped, notched, rarely entire. (P. setàcea, L.) - Dry rocky hills and sandy banks, S. New York to Michigan and southward. April, May. - Common in cultivation.

\section{DI A P É N I A, L. Diapensia.}

Calyx of 5 concave imbricated sepals. Corolla bell-shaped, 5 -lobed; the lobes rounded. Filaments broad and flat, adherent to the corolla up to the sinuses, short: anthers arlnate, of 2 ovoid pointless cells, diverging below, each opening therefore by a transverse-descending line. Pod enclosed in the calyx, cartilaginous; the cells few-seeded. - An alpine dwarf evergreen, growing in very dense convex tufts, with the stems imbricated below with cartilaginous narrowly spatulate mostly opposite leaves, terminated by a scape-like 1-flowered peduncle, 3 -bracted under the calyx. Corolla white ( $\frac{1}{2}$ ' wide). ( $\Lambda$ neient Greck name of the Sanicle, of obscure meaning, strangely applied by Linnæus to this plant.)

1. D. Lappónica, L. - Alpine summits of the White Mountains, New Hampshire, and Adirondack Mountains, N. New York. July. (Eu.)

\section{PYXIDA N T H E A, Michx. Prxinantiera.}

Anther-cells awn-pointed at the base, opening by a strictly transverse line. Otherwise much as in Diapensia. - $A$ small prostrate and creeping evergreen, with narrowly oblanceolate and awl-pointed crowded leaves, which are mostly alternate on the sterile branches, and somewhat hairy near the base. Flowers solitary and sessile, very numerous, white or rose-color. (Name from $\pi v \xi$ is, a small box, and divinpa, anther, the anther opening as if by a lid.)

1. P. barbulata, Michx. - Sandy pine barrens of New Jersey and southward. April, May. 


\section{Order 75. Convolvulàcea. (Convolvulus Family.)}

Chiefly twining or trailing herbs, often with some milly juice, with alternate leaves (or scales) and regular 5-andlrous flowers; a calyx of 5 imbricated sepals; a 5-plaited or 5-lobed corolla convolute or twisted in the bud; a 2celled (rarely 3-celled) ovary, or in one tribe 2 separate pistils, with a pair of erect ovules in each cell, the cells sometimes doubled by a fulse partition between the seeds, so becoming 4-celled; the embryo large, curved or coiled in mucilaginous albumen. - Fruit a globular 2-6-seeded pod. Flowers mostly showy, on axillary peduncles: pedicels articulated, often 2-bracted. (Many are cultivated for ornament, and one, the Sweet Potato, for its edible farinaceous roots: those of several species are cathartic; e. g. Jalap.) - There are three suborders, or rather strongly marked tribes.

Tribe I. CON VOLVULEAE. Leafy plants, mustly twiners. Ovary 2-4-celled. Pud usually septifragal. Embryo with broad and leaf-like cotyledons, crumpled in the seed.

* Style single and undivided.

- Calyx naked, i. e. not enclosed or surrounded by leafy bracts.

1. Qиаmoelit. Stamens and style exscrted. Corolla salver-shaped or nearly so. Stigma cispitate-2-lobed. Pod $t$-celled; the cells 1-secied.

2. Iромоха. Stimens ineluded. Corolla funucl-form or bell-shaped. Stigma capitate, often 2-3-lobed. Pod 2-3-celled; the eclls 2-seeded.

3. Couvolvulus. Stigmas 2, elongated, linear. Otherwise much as in I pomœa.

- Calyx surrounded and enclosed by a pair of broad leafy bracts.

4. Calystegia. Stigmas 2, linear or oblong. Pod imperfectly 2-celled, 4-seeded.

* * Style single and 2-cleft, or styles 2, rarely more. Prostrate or spreading herbs.

5. Bonamia. Styles 2 and undivided, or a single one 2 -cleft : stigmas capitute.

6. Evolvulus. Styles 2, an.l each 2-cleft : stigmas ubluse.

Tribe I. DICHONDIERA. Crecping plauts. Ovaries as well as styles 2 or more. Embryo, \&c. as in the precediug tribe.

7. Dichoudra. Corolla bell-shaped, 5-cleft. Pistils 2, one-seeded.

Tribe III. CUSCUTIN EA. Leafless parasitic twiners. Embryo spiral, slender, destitute of cotyleduns. Ovary 2.celled. Parts of the Hower rarely in fours '

8. Cuscuta. The vuly genus of the group.

\section{Qu Á M OCLIT, Tourn. Crpress-Vine.}

Sepals mostly mucronate or awned. Corolla cylindrical-tubular, with a small spreading border, not twisted in the bud. Stamens and style protruded. Stigma capitate-2-lobed. I'od f-celled; the cells 1-seceled. - Anmual twiners, with red or crimson flowers; in summer. (An aboriginal, probably Mexican, name.)

1. Q. coccfnes, Muench. Leaves heart-shaped, acuminate, entire, or angled; sepals awn-pointed; corolla light scarlet (1'long). (I pomoea coccinea, L.) - River-banks, \&c., Ohio to Illinois, Virginia, and southward. (Nat. from Trop. Amer. or Ind.)

2. Q. vulgàis, Choisy. (Crpress-Vine.) Leaves pinnately parted into lincar-thread-shaped delicate parallel lobes; peduncles 1-flowered; corolla narrow, scarlet-red, and a white variety. - Sparingly escaped from gardens soutl. ward. (Adv. from India.) 


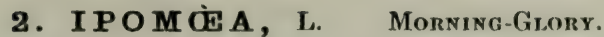

Calyx naked at the base. Corolla bell-shaped, funnel-form, \&c., twisted in the bud. Stramens included. Stigma capitate, often 2-3-lobed. Pod 2-celled, or in one group 3-celled; the cells 2-seeded. (Name, according to Linnæus,

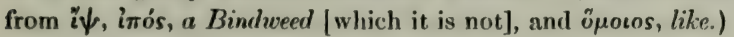

§ 1. PHÁRBITIS, Choisy. Pod 3-(rarely 4-) celled; the cells 2-seeded.

1. I. PUrpúrea, Lam. (Common Morning-Glory.) Annual; stems retrorsely hairy ; levves heurt-shuped, acuminate, entire; pertuncles long umbellately 3-5-flowered; calyx bristly-hairy below; corolla funnel-form (2' long), purple, varying to white. (Convolvulus purpureus, $L$. Pharbitis hispida, Choisy.) Around dwellings, escaping from cultivation. (Adv. from Trop. Amer.)

2. I. Nit, Roth. (Smaller M.) Stems retrorsely hairy ; leaves heart-shaped, 3-lobed, the lobes acute or acuminate; pedancles short, or rather long, $1-3$ flowcred; calyx densely hairy below; corolla white and purple or pale blue $\left(1^{\prime}-1 \frac{1}{2}^{\prime}\right.$ long). (Conv. Nil. \& C. hederàceus, L.) - Banks and near divellings, from Maryland southwarl. (Adv. from Trop. $\Lambda$ mer.?)

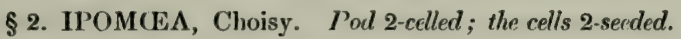

3. I. lacunosa, L. Annual; rather smooth; stem twining and creeping, slender; leaves henrt-shnped, pointed, entire or angled-lobed ; peduncles short, 1 3-flowered ; sepals lnnce-oblong, pointed, bristly-riliate or hairy, half the length of the sharply 5-lobed (white, $\frac{1}{2}{ }^{\prime}-1^{\prime}$ long) corolla. (C. micránthus, Riddell.) Woods and fields, Penn. to Illinois and southward. Aug.

4. I. panduràta, Meyer. (Wild Potato-vine. Man-of-tie-Eartir.) Perennial, smooth or nearly so when old, trailing or sometimes twining; leaves regulaly heart-shaped, pointed, occasionally some of them contracted at the sides so as to be fiddle-shaped; peduncles longer than the petioles; 1-5-flowered; sepnls smooth, ovate-oblong, very oltuse; corolla open-funncl-form $\left(3^{\prime}\right.$ long), white with purple in the tube. - Sandy ficlds and banks, from Connecticut to Illinois and sonthward. June- $\Lambda$ ug. - Stems long and stout, from a huge root, which often weighs 10-20 pounds. Flowers opening in bright sunshine.

\section{CON VÓLVULUS, L. Bindweed.}

Calyx naked at the base. Corolla open funnel-form or bell-shaped. Stamens included. Style 1: stigmas 2, lincar, often revolute. Pod 2-celled; the cells 2. sceded. - Stems twining, procumbent, or often erect-spreading. Flowers mostly opening at dawn. (Name from convolvo, to entwine.)

1. C. Arvénsis, L. (Bindweed.) Perennial; stem procumbent or twin. ing, and low ; leaves ovate-oblong, arrow-shaped, with the lohes at the base acutc; perluncles mostly 1-flowcred; bracts minute, remote; corolla (9" long) white or inged with reddish. - Ficlds, near the coast: likely to become a troublesome weed. June. (Nat. from Eu.)

\section{CALYSTEGIA, R. Br. Bracted Bindwed.}

Calyx enclosed in 2 large and mostly heart-shaped leafy bracts : sepals equal. Corolla bell-funnel-form, the border obscurely 5-lobed or entire. Stamens in- 
cluded. Style 1: stigmas 2, linear or oblong. Pod imperfectly 2-celled or 1celled, 4-seeded. - Peremials, with heart-shined or arrow-shaped leaves, and axillary 1-flowered peduncles; 11 . in summer. (Name from $k a ́ \lambda v \xi$, calyx, and $\sigma \tau \in \dot{\gamma} \omega$, to cover, alluding to the bracts enclosing the calyx.)

1. C. sèpium, R. Br. (HEdGe BindweEd.) Stem twining or sometimes truiling extensively; leaves triangular-hallerd-shaped or arrow-shaped, acute or 'pointed, the lobes at the base obliquely truncate and often somewhat toothed or sinuate-lobed; peduncles 4-angled; corolla white, or in the American plant more commonly light rose-color $\left(1 \frac{1}{2}^{\prime}-2^{\prime}\right.$ long) : the typical form glabrous throughout. (Convolvulus sepium, and C. repens, L.) - Varies greatly, often slightly pubescent: Var. Plisescens is a lowny form, in the young state approaching the next. (C. Catesbyana, Puish.) - Common, especially along the moist banks of streams. (Eu.)

2. C. spithamoea, l'ursh. Downy; stem low and mostly simple, upright or ascending $\left(6^{\prime}-12^{\prime}\right.$ long $)$; leaves oblong, with or without a heart-shaped or auricled base ; corolla white ( $2^{\prime}$ long). - Dry, mostly sandy ground : not rare.

\section{BO N Á MIA, 'Thouars. (Breweria, R. Br. \& Stylisma, Ruf.)}

Styles 2 , or rarely 3 , simple and distinct, or else united into one below : stigmas depressed-cipitate. Otherwise as Convolvulus and Evolvulus. - Perennial prostrate or diffusely spreading herbs (or in warmer regions sometimes shrubby); flowers small; in summer : corolla more or less hairy or silky outside. (Named for Francis Bonamy, author of a Flora of Nantes.)

1. B. humistràta, Gray. (Proceed. Amer. Acad. 5, p. 337.) Sparsely hairy or nearly smooth; leaves varying from oblong with a somewhat heartshaped base to linear, mucronate; peduncles 1-7-flowered; bracts shorter than the pedicels; sepals pointed, glabrous or nearly so ; corolla white; filunents hairy; styles united at the buse. (Convolvulus humistratus, Walt., who well distingurshes this from the next. Stylisma evolvuloides, Chois., in part. S. humistrata, Chapm.) - Dry pine barreus, Virginia (probably not in Ohio), and southward.

2. B. aqúatica, Gray. Minutely soff downy and somewhat hoary; sepuls silky; corolle pink or purple; filaments smooth; styles separate almost to the base: otherwise nearly as in the last. (Conv. aquaticus, Wult. Stylisma aquatica, Chapm.) - Margin of ponds, S. Virginia? and southward.

3. B. Pickeríngii, Gray. Soft-pubescent or smoothish; leaves very narrowly linear or the lowest linear-spatulate, tapering to the base, nearly sessile; peduncles 1-3-flowered; bracts resembling the leaves, mostly exceeding the flowers; sepals hairy: filaments (scarcely hairy) and styles (which are united fur above the middle) exserted from the oprn white corolla. (Stylisma Pickeringii, Ed. 2.) Rather dry sandy pine-barrens, New Jersey and southward. - Stems $1{ }^{\circ}-3^{0}$ long: leaves $1^{\prime}-1 \frac{1}{2}^{\prime}$ long. Corolla $4^{\prime \prime}-5^{\prime \prime}$ broad.

\section{EVó I U U US, I. Evorvulus.}

Calyx of 5 sepals, naked at the base. Corolla open funnel-form or almost wheel-shaped. Styles 2, each 2-cleft : stigmas obtuse. Pod 2-celled; the ce!!s 
2-secded. - Low and small herhs or suffruteseent plants, mostly diffuse, never twining (hence the name, from evolen, to unroll, in contrast with Convolvulus).

1. E. argénteus, Pursh. Many-stemmed from a somewhat woody base, dwarf, silky-villous all over; leaves crowded, broally lanceolate, sessile, or the Jower oblong-spatulate and short-petioled, about $\frac{1^{\prime}}{2}$ long; flowers almost sessile in the axils; corolla purple, $3^{\prime \prime}$ broad. - Potosi lead-mines, Missouri, probably also on the Illinois side of the Mississippi : common westward.

\section{DICHÓ N DRA, Forst. IICHONDRA.}

Calyx 5-parted. Corolla broadly bell-shaped, 5-cleft. Stamens included. Styles, ovaries, and the utricular 1-2-secded pods 2, distinct. Stigmas thick. - Small and creeping perennial herls, soft-pubescent, with kidney-shaped entire leaves, and axillary 1 -flowered bractless peduncles. Corolla small, yel-

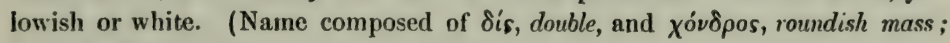
from the fruit.)

1. D. répens, Forst. : var. Carolinénsis, Choisy. Ieaves round-kid ney-shaped, pubescent, green both siles; corolla not exceeding the ealyx (1"1 $\frac{1}{2}$ " long). (1). Carolinensis, Michx.) - Moist ground, Virginia, near Norfolk, and southward. (Widely diffused in the Southern hemisphere.)

\section{CÚ S C U T A, Tourn. Donver.}

Calyx 5- (rarely 4-) cleft, or of 5 sepals. Corolla globular-urn-shaped, bellshaped, or somewhat tubular, the spreading border 5- (rarely 4-) cleft. Stamens furnished with a scale-like often fringed appendage at their base. Ovary 2-celled, 4-ovuled : styles distinct, or rarely united. Pod mostly 4-seeded. Embryo thread-shaped, spirally coiled in the rather fleshy albumen, destitute of cotyledons! sometimes with a few alternate scales (belonging to the plumule): germination occurring in the soil. - Ieafless herbe, chicfly nnmuals, yellowish or reddish in color, with thread-like stems, bearing a few minute seales in place of leaves; on rising from the ground becoming entirely parasitic on the bark of herbs and shrubs on which they twine, and to which they adhere by means of papilla developed on the surface in contact. Flowers small, cymose-clustered, mostly white; usually produced late in summer and in autumn. (Name of uncertain, supposed to be of Arabic, derivation.)

The following account of our species is contributed by Dr. FNGELMANN, whose monograph of the whole genus is published in Transactions of the St. Louis Academy of Science.

\$1. Stigmas elongated: pod opening regulurly around the buse by circumcissile dehiscence, leaving the partition behind. (Natives of the Old World.)

1. C. Erfunum, Weihe. (Fux Donder.) Stems very slender, low, flowers globular, sessile in dense scattered heads; corolla 5 -parted, short-cylinarical, scarcely exceeding the broadly ovate acute divisions of the calyx, left surrounding the pod in fruit; stamens shorter than the limb; scales short, broad, crenulate, shorter than the globose ovary. - Flax-fields; in Europe very injurious: sparingly introduced with flax-seed into the Northern States. June (Adv. from Eu.)

L \& $\mathrm{M}-36$ 
§2. Stigmas capilate: pods indehiscent, rarely bursting irregularly.

- Flowers more or less pedicelled: the scaly bracts few and distant: culyx 4-5-cleft. - Coralla cylindrical, in fruit coveriny the top of the pod.

2. C. tenuiflora, Engelm. Much branched, twining high, pale-colored; flowers at length peduncled and in rather loose cymes; tube of the corolk (ventricose after flowcring) tuice the length of its obtuse spreading lutres and of the ovate obtuse calyx-lobes ; scales ovate, cut-fringed; stamens shorter than the lobes of the corolla; pod depressed, membranaccous, thin, yellowish. (C. Cephaianthi, Engelm.) - Swamps, New Jersey to Illinois and westward; on Cephalanthus and other shrubs, and on various tall herbs. - Flower the narrowest of all our Northern species.

3. C. infléxa, Engclm. Flowers peduncled, in umbel-like cymes, 1" long; tube of the mostly 4-cheft flushy corolla as long as the ovate acutish and minutly crenate erect inflexed lobes and the acute keeled calyx-lobes; scales minute und few-tuethed, appressed; pod depressed, somewhat umbenate, of a thicker texture, brown, its top covered with the remains of the corolla. (C. Córyli, Enyelm. C. umbrusa, Beyrich, and Ed. 2.) - l'rairies and barrens, in rather dry soil, on Itazels, Ceano. thus, and orher shrubs or herbs; from Western Virginia and Illinois southward and westward.

4. C. decora, Chois., altered by Engehn. Flowers harger than in No. 3, from $1 i^{\prime \prime}$ to nearly 2 "long, loosely paniculate, broadly campanulate; corollu 5 clefi; the lobes ovate-lanceolate, acute; the scules large, lirondly ocul; pod enveloped by the remains of the corolla. (C. indecoura, Chois. C. neuropetala, Enyelm. C. pulcherrima, Schecte.) - Wet prairies, S. W. Illinois and southward; on various shrubs and herbs. - The nane changed hy 1)r. Engelmaun, because this is not a homely but the handsomest of our species.

$$
\text { + + Cirollu betl-shepped, persistent at the hase of the ripe pod. }
$$

5. C. arvénsis, Beyrich. Low ; flowers small, 5-parted, peduncled in loose umbel-like cymes; thbe of the corolia included in or little exceeding the broat-loted calyx, shorter than its lanceolate acuninate spreading or reflexed lobes; stamens much shorter than the lobes of the corolla; scales ovate, fimbriate, converging and often exceeding the tube; pod globose, thin, yellowish. (C. pentáyona, Éngelm.) - In fields, prairies, and barrens, from S. New York (C. F. Austin) to Virginia, Illinois, and southwestward; on smaller herbs, and flowering (in June and July) earlier than any other of our species. - Stens low, scarcely over a foot high ; flowers smaller than in any of our species, and quite variatle: when with a large 5-angled caly $\mathrm{x}$ it is $\mathrm{C}$. pentagona (Virginia): with a small one, it is vatr. microcalyx (Illinois): with a large and hemispherical one, var. calycima ('Texas) : with a tieshy verrucose calyx, it is C. verrucossa. Éngelm. ('Texass.)

6. C. chlorocárpa, Engelm. Low, orange-colored; flowers mostly 4-

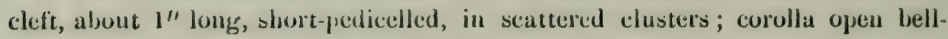
shaped, the tube nearly the length of the acute lobes and calyx-teeth; stanens as long as the lobes; scales small, appressed, incised, sometmes almost wanting; the thick styles as long as the large depressed ovary ; pod depressed, thin, greenish-yellow. (C. pulygonòrum, Lingchu.) - Low grounds, on P'olygunum 
and other herbs, Delaware to Wisconsin, and southwestward. - The large ovary fills the shallow tube of the corolla.

7. C. Gronóvii, Willd. Stems coarse, climbing high; flowers mostly 5 . cleft, peduncled, in close or mostly open paniculate cymes ; corolla bell-shaped, the tube longer than (or sometimes only as long as) the ovate obtuse entiro spreading lobes; scales large, converging, copiously fringed, confluent at the base ; pod globose, umbonate, brown. (C. Americàna, Pursh, \&c. C. vulgivàga, Engelm. C. umbròsa, Torr.) - Low, damp grounds, especially in shady pluces; everywhere common both east and west, and the principal species northward and eastward : chiefly on coarser herbs and low shrubs. - The close-flowered forms occur in the Northeastern States; the loosely-flowered oncs westward and southward; a form with 4-parted flowers was collected in Connecticut. C. Saururi, Engelm., is a form with more open flowers, of a finer texture, in the Mississippi valley.

8. C. rostràta, Shuttleworth. Stems coarsc, climbing high; flowers (2" $-3^{\prime \prime}$ long) 5-parted, peduncled, in umbel-like cymes; corolla deep bellshaped, the tube twice as long as the ovate obtuse teeth of the caly $x$ and its ovate obtuse entire spreading lobes; the large scales fimbriate, confluent at the base; styles slender, as long as the acute ovary; the large pod pointed. Shatly valleys of the Alleghanies, from Maryland and Virginia southward; on tall herbs, rarely on shrubs. Flowers and fruit larger than in any other of our species.

* * Flowers sessile in compact and mostly contınuous clusters: calyx of 5 separate sepals surrounded by mumerous similar bracts: remains of the corolla borne on the top of the globose somewhat pointed pod. (Lepidánche, Engeln.)

9. C. compácta, Juss. Stems coarse; lracts (3-5) and sepals orbicular, concave, slightly crenate, appressed, nearly equalling or much shorter than the cylindrical tube of the corolla ; stamens shorter than the oblong obtuse spreading lobes of the latter; scales pinnatifid-fringed, convergent, confluent at the base. C. coronata, Beyrich (C. compacta, Choisy) is the Eastern and Southern form, with a smaller, slenderer, more exserted corolla. C. (Lepidanche) adpressa, Engelm., is the Western form, with a larger, shorter, nearly included corolla. Both grow almost entirely on shrubs; the first from N. New York, and New Jersey southward; the latter from Western Virginia to the Mississippi and Missouri, in fertile shady bottoms. The clusters in fruit are sometimes fully $2^{\prime}$ in diameter.

10. C. glomeràta, Choisy. Flowers very densely clustered, forming knotty masses closely encircling the stem of the foster plant, much imbricated with scarious oblong bracts, their tips rerurved-spreading; sepals nearly similar, shorter than the oblong-cylindrical tube of the corolla; stamens nearly as long as the oblong-lanceolate obtuse spreading or reflexed lobes of the corolla; scales large, fringed-pinnatifid; styles slender, longer than the pointed ovary; the pointed pod mostly 1-2-seeded. (Lepidanche Compositarum, Engelm.) - Moist prairies, Ohio to Wisconsin and southward: growing commonly on tall Compositæ. - The orange-colored stems soon disappear, leaving only the close matted coils of flowers, appearing like whitish ropes twisted around the stems. 


\section{Order 76. Solaniceat. (Nightshade Family.)}

Herbs (or rarely shrubs), with a colorless juice and alternate leaves, regular 5-merous and 5-androus flowers, on bractless pedicels; the corolla imbricate, convolute, or valuate in the bud, and mostly plaited; the fruit a 2-celled (rarely 3-5-celled) many-seeded pod or berry. - Seeds campylotropous or amphitropous. Embryo mostly slender and eurved in fleshy albumen. Calyx usually persistent. Stamens mostly equal, inserted on the corolla. Style and stigma single. I'lacente in the axis, often projecting far into the cells. (Foliage rank-scented, and with the fiuits mostly narcotic, often very poisonous, while some are edible.) - A large fumily in the tropics, but very few indigenous in our district. It shades off into Scrophulariacex, from which the plaited regular corolla and 5 equal stamens generally distinguish it.

* Corolla wheel-shaped, 5-parted or 5-lobed ; the lobes valvate and their margins usually turned inwarls in the bud. Authers connivent. Fruit a berry.

1. Solanum. Anthers opening by pores or chinks at the tip.

* Corolla various, not wheel-shaped, nor valvate in the bud. Anthers separate.

- Eruit a berry, enclosed in the bladdery-inflated caly x. Curolla widely expanding.

2. Physalis. Calyx 5-cleft. Curolla 5-lobed or nearly entire. Berry juicy, 2-celled.

3. Nicandra. Calyx 5-parted. Corolla nearly entire. Berry dry, 3-5-celled.

+ - Hruit a berry with the unaltered calys persiatent at ito base.

4. Lycium. Corolla funucl-form or tubular, not plaited. Berry small, 2-celled. + - Eruit a pod.

5. Hy oscyamus. Calyx uru-shaped, enclosing the smooth 2-celled pod, which opens by the top falling off as a lid. Corolla and stamens somewhat irregular.

6. Datura. Calyx prismatic, 5-touthed. Pod prickly, naked, more or less 4-celled, 4-valved. Corulla fantitl-form.

7. Nicollasa. Calyx tubular-bell-bliaped, 5-cleft. Pud cuclosed in the talyx, 2-celled.

\section{S OL À N U M, Tourn. Nightshade.}

Calyx and the wheel-shaped corolla 5-parted or 5-cleft (rarely 4-10-parted), the latter plaited in the bud, and valvate or induplicate. Stamens exserted: filaments very short: anther's converging around the style: opening at the tip by two pores or chinks. Berry usually 2-celled. - Herbs, or shrubs in warn climates, the larger leaves often accompanied by a smaller lateral (rameal) one; the peduncles also mostly lateral and extra-axillary. $-\boldsymbol{A}$ vast genus, chiefly in the warmer regions, including the Potato (S. Tubenosum) and the Eggplant (S. Melongèna); while the Tomoto (Lcopérsicum esculéntum) is hardly of a distinet genus. (Name of unknown derivation.)

* Anthers blunt. (Plants not prichly, smoath or nearly so.)

1. S. Dulcamàra, L. (Brttersiveet.) Stem shublby, scuicely climbing; leaves orute-heart-shaped, the upper halberd-shaped, or with two eur-like lobes at the base; flowers (purple or blue) in small eymes; berries oval, red. - Moist banks and around dwellings. June-Sept. (Nat. from Eu.)

2. S. vigizu, L. (Comion Nightshant.) Anunal, low, much branched and oftun spreading, rough on the angles; leuces ovate, wavy-twothed; Alower's 
(very small, white) in small and umbel-like lateral clusters, drooping; berries globular, black. - Shaded grounds and fields: common. July - Sept. - A homely weed, said to be poisonous. (Nat. from Eu.)

* * Anthers elongated, lanceolate, pointed. (Plunts mostly prickly.)

3. S. Carolinénse; L. (Ilonse-Netrue.) Perennial, low (1० high); stem erect, prickly; leaves ovate-oblong, acute, sinuate-toothed or angled, ronghish with stellate pubescence, prickly along the midrib, as also the calyx ; flowers (pale blue or white, large) in simple loose racemes; berries globular, orunge-yellow. - Sandy soil, Connecticut to Illinois and southward. JuneAug. (S. Virginianum, $L$., is not here identified as distinct.)

\section{PHÝ SALIS, L. Ground CherrT.}

Calyx 5-cleft, reticulated and enlarging after flowering, at length much inflated and enclosing the 2-celled globular (edible) berry. Corolla between wheel-shaped and funnel-form, the very short tube marked with 5 concave spots at the base; the plaited border somewhat 5-lobed or barely 5-10-toothed. Stamens 5, erect : anthers scparate, opening lengthwise. - Herbs (in this country), with the leaves often unequally in pairs, and the 1-flowered nodding pe-

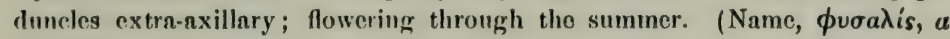
bladder, from the inflated calyx.)

* Root annual $\therefore$ anthers tinged with blue or violet: stems $1^{\circ}-3^{\circ}$ high. + Corolla white, large.

1. P. grandiflora, Hook. Clammy-pubescent, erect; leaves lance-ovate, pointed, entire or nearly so ; corolla $1^{\prime}-2^{\prime}$ wide when expanded, almost entire, and with $\Omega$ woolly ring in the throat; fruiting calyx globular, apparently nearly filled by the berry. - Upper Michigan, shore of Lake Superior (Dr. Robbins, \&c.) and northward, springing up in new clearings.

\section{+ + Corolla pale or greenish-yellow, small or smallish.}

2. P. Philadélphica, Lam. Almost glabrous, erect; leaves ovate or oblong-ovate, oblique at base, entire, repand, or very sparingly angulate-toothed; corella brownish-or violet-spotted in the centre, 7" -10 " broad; calyx at maturity glohose and completely filled by the large reldish or purple berry and open at the mouth. - Rich grounds, not rare, especially southward : also cult.

3. P. angulàta, L. Glabrous or nearly so, erect, much branched; leaves ovate or ovate-oblong, sharply and irregularly lacininte-fonthed; perluncles filiform ; corolla unspotted, very small ( $3^{\prime \prime}-6^{\prime \prime}$ brosd when cxpanded) ; fruiting calyx conical-ovate with a truncate or sunken base, 10-angled, loosely inflated, but at length well filled by the greenish-yellow berry. - Cult. and waste grounds.

4. P. pubéscens, L. Pubescent or clammy-hariry (rarely smoothish) diffisely much branchrd or at length decumbent; leaves ovate or heart-shaped, angulate- or repand-toothed ; coroll $a$ spotted with brown-purple in the centre, 5 " - 6" broad when expanded, obscurely 5-10-toothed; fruiting calyx ovate from a truncate or impresserl base, pointed, sharply 5-angled, loosely enclosing the yellow or greenish berry. (P. hirsuta, Dunal. P. obscurn, Michx. in part.) Low grounds : common, especially southward and westward. 
* Root perennial: stems mostly from slender creeping rootstocks, usually low (6 $6^{\prime}$ $20^{\prime}$ high): anthers ycllow: fruiting calyx loosely inflated, 5-angled, much laiger than the berry.

- Wild species: corolla greenish-yellow and commonly brown or purplish in the crntre, the border 5-angled or barely 5-10-toothed, 6" -12" broad.

5. P. viscosa, L. C'lunmy-pubescent, diffuscly much branched and widely spreading, or at first erect; leaves ovate or slightly heart-shaped, sometimes oblong, repand or obtusely tootled, rarely entire; corolla daik brown in the centre; fruiting caly $\mathrm{x}$ ovate, barcly concave or truncate at base, sharply 5angled; berry orange or reddish, glutinous. (1). heterophylla, Nees. P. nyctaginea, \& P. viscido-pubescens, Dunul ?) - Light or saudy soil : common.

6. P. Pennsylvánica, L. Minutely hirsute-pubescent (not clanımy), or nearly glabrous; leaves ovate, oblong, or oblong-lanceolate and tapering at the base, entire or sparingly repand-toothed; corolla merely durker or purplish-veiny in the contre ; fruiting caly $\mathrm{x}$ conical or globular ovate, pointed, and with an inpressed base; berry red.-Var. Laxceolata ; the narrower-leaved and pubescent form $\left(5^{\prime}-15^{\prime}\right.$ high), especially the state with a hairy calyx. (P'. lanceolata, Michx. P. marítima, M. A. Curtis.) - Dry, often sandy soil, from Peunsylvania southward and westward, even northwestward to the Winipeg valley. Fruiting calyx $1^{\prime}-1 \frac{1}{2}^{\prime}$ long. Shape of calyx-lobes very variable.

+ + Intioducal: corolla greenish-white, unspotted, 5-lobed.

7. P. Alkekéngi, L. (Strawerery Tomato.) More or less pubes. cent; sparingly branched ; leaves deltoid-ovate, pointed ; calyx-teeth awl-shaped; fruiting calyx broadly ovate, turning red; the berry bright red, pleasant. - Cult. and waste grounds, eastivard. (Cult. \& Adv. from Eu.)

\section{N I Cá N D R A, Adans. Apple of Peru.}

Calyx 5-parted, 5-angled, the divisions rather arrow-shaped, enlarged and bladder-like in fruit, enclosing the 3-5-celled globular dry berry. Corolla with border nearly entire. Otherwise much like Physalis. - An annual smooth lerb $\left(2^{\circ}-3^{\circ}\right.$ high $)$, with ovate sinuate-toothed or angled leaves, and solitary pale blue flowers on axillary and terminal peduncles. (Named after the poet Nicander of Colophon.)

1. N. Physaloìdes, Gærtn. - Waste grounds. (Adv. from Peru.)

\section{I Ý CI U M, L. Matrimony-Vine.}

Calyx 3-5-toothed or cleft, not enlarging, persistent at the base of the berry. Corolla funnel-form or salver-shaped, 5-lobed, the lobes inbricated and not plaited in the bud. Stamens 5 : anthers opening lengthwise. Style slender: stigma capitate. Berry small, 2-celled. Shrubby, often spiny plants, with alternate and entire small leaves, and mostly axillary small fluwers. (Named from the country, Lycia.)

1. L. volgais, D)unal. (Comson M.) Slirul, with long sarmentose recurved-drooping branches, smooth, sparingly if at all spiny; leaves oblung- or spatulate-lanceolate, often fascicled, narrowed into a short petiole; flowers on slender peduncles fascicled in the axils; corolla short funnel-form, greenish- 
purple; style and slender filaments equalling its lohes; berry oval, orange-red. (I. Bárbarum, $L$., in part.) - About dwellings ; and escaped into waste grounds in Pennsylvania, \&c. June-Aug. (Adv. from Eu.)

\section{H Y O SCỲ A M US, Tourn. Henbank.}

Calyx bell-shaped or urn-shaped, 5-lobed. Corolla funncl-forgn, oblique, with a 5-lobed more or less unequal plaited border. Stamens declined. Pod enclosed in the persistent calyx, 2-celled, opening transversely all round near the npex, which falls off like a lid. - Clammy-pubescent, fetid, narcotic herbs, with lurid flowers in the axils of angled or toothed leaves. (Name composed of ṽs, vós, a hog, and kúapos, a bean; said by Elian to be poisonous to swine.)

1. H. Nìter, L. (Black Henbane.) Biennial or annual ; leaves clasping, sinuate-toothed and angled ; flowers sessile, in one-sided leafy spikes; corolla dull yellowish, strongly reticulated with purple veins. - Escaped from gardens to roadsides. (Adv. from Eu.)

\section{D A T Ù R A, I. Jamestown-Weed. Thorn-Aprle.}

Calyx prismatic, 5-toothed, separating transversely above the base in fruit, the upper part falling away. Corolla funncl-form, with a large and spreading 5 -10-toothed plaited border. Stigma 2-lippel. I'od globular, prickly, 4-ralved, 2-celled, with 2 thick placentre projected from the nxis into the middle of the cells, and connected with the walls by an imperfect false partition, so that the pod is 4-celled except near the top, the placentas as if, on the middle of these false partitions. Seeds rather large, flat.-Rank weeds, narcotic-poisonous, with ovate leaves, and large and showy flowers on short peluncles in the forks of the branching stem; produced all summer and autumn. (Altered from the Arubic name, Tatoruh.)

1. D. Stramonium, L. (Common Stramonum or Thorn Apple.) Annual, glabrous; leaves ovate, sinuate-toothed or angled; stem green; corolla white ( $3^{\prime}$ long), the border with 5 teeth. - Waste grounds : a well-known weed. (Arlv. from Asia.)

2. D. Tátula, L. (Purree T.) Mostly taller; stem merple; corolla pale violit-perple. Thought to he specifically distinct from the last, on account of the behavior of the cross-brecls. ( $\Lambda \mathrm{dv}$. from tsop. $\Lambda$ mer.?)

\section{NICOTIÀ NA, L. Tobacco.}

Calyx tubular-bell-shaped, 5-cleft. Corolla funnel-form or salver-form, usually with a long tube; the plaited borrler 5-lobed. Stigma capitate. Pod 2 celled, 2-4-valved from the apex. Sceds minute. - Rank acrid-narcotic herbs, mostly clammy-pubescent, with ample entire leaves, and racemed or panicled flowers. (Named after.John Nicot, who was thought to have introduced the Tobacco (N. TAвасUM, L.) into Europe.)

1. N. Rústica, L. (WiL) Toracco.) Annual; lenves ovate, petioled; tube of the dull greenish-ycllow coroll: cylindrical, two thirds longer than the calyx, the lobes rounded. - Olil fields, from New York westward and southward : a relic of cultivation by the Indians. (Adv. from Trop. Amer.) 


\section{Order 77. Gentianacea. (Gentian Family.)}

Smooth herbs, with a colorless bitter juice, opposite and sessile entire and simple leaves (except in Tribe II.) without stipules, regular flowers with the stannens as many as the lobes of the corolla, which are convolute (raicly imbricated and sometimes valvate) in the bud, a 1-celled ovary with 2 purietal placenta, or nearly the whole inner fucce of the ovury uvuliferous; the fruit usually a 2-ialved and septicilal many-seedcl pod. - Flowers solitary or cymose. Calyx persistent. Corolla mostly withering-persistent; the stamens inserted on its tube. Seeds anatropous, with a minute embryo in fleshy albumen. (Bitter-tonic plants.)

Tribe I. GENTIAN EAE. Inbes of the corolla convolute in the bud (with the sinuses mostly plaited), or in Ulwolaria imbricated. Leaves almost always opposite or whorled, entire, thuse of the stem seysile. Seeds very small and uumerous, with a cellular coat; in Obolaria, Bartonia, and severabl Guntians, the ovules and seeds coveriug the whole face of the pericarp!

* Style distinct and slender, deciduous.

1. Sabbutia. Corollia wheel-shapetl, 5-12-parted : anthors at length recurved.

2. Erythraea. Corolla funnel-furu or salver-shaped, 4-5-cleft: authers soon spiral.

* Style (if any) and stigmas persistent : authery straight.

3. Frasera. Corulla 4-parted, whed-shaped ; a fringed glandular spot on each lobe.

4. Halenia. Corolla 4-5-cleft, bell-shaped, and 4-5-spurred at the base.

5. Cicmtiana. Corolla funucl-or bell-shaped, mostly plaited in the sinuses, not spurred.

6. Bartonia. Corolla ducply 4-cleft, bell-shaped: no plaits. Calyx 4-parted.

7. Obolaria. Corolla tubular-bell-shaped, t-lobed, with no plaits, the lubes imbricated in the bud! Calya 2-leaved.

Tribe II. MEN A NTHEAE. Lobes of the corolla valvate in the bud, with the edges turned inwards. Stem-leaves alternate, petioled. Sced-cuat hard or bony.

8. Menyanthes. Corclla bearded inside. Leaves 3-foliclate.

9. LImnanthemum. Corulla uaked or bearded on the margins only. Leaves simple, rouuded.

\section{SA B BÀt I A, Adang. American Centaury.}

Calyx 5-12-parted, the divisions slender. Corolla 5-12-parted, wheelshiıped. Stamens 5-12: anthers soon recurved. Style 2-parted, slender. Biemnials or annuals, with slender stems, and cymose-panicled handsome (white or rose-purple) flowers; in summer. (Dedicated to $L$. Sabbuti, an early Italian botanist.)

* Corolla 5-purted, or rarely 6-7-parted.

+ Corollu while, often turuing yellowish in diying: cymrs corymbed, many-flowered

1. S. paniculàta, 1'ursh. Stem bruchiutely much-brunched $\left(1^{\circ}-2^{\circ}\right.$ high): rather terete, but angled with 4 sharp lines; lenves linear or the lover ablong, ob. tuse, 1-nerved, nearly equalling the internodes; calyx-lobes linear-thread-form, much shorter than the corolla. - Low grounds, Virginia and southward.

2. S. lanceolàta, 'Torr. \& (ir. Stem simple $\left(1^{\circ}-3^{\circ}\right.$ high) bearing a flat' topped cyne; lenves ovate-lancolate or ovate, 3-nerved, the upper acute, much shorter than the internodes; calyx-lobes longer and flowers larger than in 
No. 1. (Chimnin Innecolntn, Wralt. S. corymbosn, Buldw.) - Wet pine bnrrens, from New Jersey southward.

+ + Corolla rose-pink, rarely white, with a yollowish or greenish oye: stem erect, $1^{\circ}-3^{\circ}$ high, pyramidally many-fowered: Irumchiss opposite : peduncles short.

3. S. brachiàta, Ell. Stem slightly angled, simple below $\left(1^{\circ}-2^{\circ}\right.$ high); leaves linear and linear-oblong, obtuse, or the upper acute; branches rather fewflowered, forming an oblong punicle; calyx-lobes nearly half shorter than the corolla. (S. concinna, Wood, ex char.) - Dryish grassy places, Virginia (Indiana, $\left.W_{o o d}\right)$, and southward. - Corolla rather smaller, and its lobes narrower than in the next.

4. S. angulàris, Pursh. Stum somexhat 4-winged-engled, much brnnched above $\left(1^{\circ}-2 \frac{1}{2}^{\circ}\right.$ high), mnny-flowered; lenves ovate, acutish, 5-nervel, with a somewhat heart-shaped clasping base; caly $\mathrm{x}$-lobes one third or half the length of the corolla. - Dry ground, New York to Illinois and southwaid. Corolla $1 \frac{1}{2}$ wide; the lobes obovate.

+++ Corolla rose-purple or white: stems $\left(5^{\prime}-20^{\prime}\right.$ high) slender, loosely and often altrmetely brenched, or merely forked, terete or scarcely 4-tungled: peduncles elongated and 1-fowered.

5. S. calycòsa, Pursh. Diffusely forking, pale; lenves oblong or lance-ob. long, nurrowed at the base; culyx-labes foliucrous, spatulate-lancelate (2'-1' long), exceeding the almost white corollu. - Marshes, E. Virginia, and southward.

6. S. stellàris, Pursh. Loosely branched and forking; leaves oblong-or ovatc-lanceolate, or the upper linear; calyx-lobes awl-shaped-linear, varying frome half to nearly the length of the bright rose-purple corolla. - Salt marshes, Massachu. setts to Virginia, and southward. Too near the next.

7. S. grácilis, Salisb. Stem very slender, at length diffusely branched; the branches and long perluncles filiform ; leares linear, or the lower lance-linear, the uppermost similar to the setaceous calyx-lolies, which equal the rose-purple corolla. (Chironia campanulatn, L.) - Brackish marshes, Nantucket (Oakes), banks of lower Delaware River (Mr. Cooley, Mr. I) iffenlanugh), and southward.

* * Corolla 9-12-parter, large (ahout 2' broad). (Lapíthea, Grisebach.)

8. S. chloroides, Pursh. Stem $\left(1^{\circ}-2^{\circ}\right.$ high $)$, loosely panicled above; the peduncles slender, 1-flowered; leaves oblong-lanceolate; calyx-lobes linear, half the length of the deep rose-colored (rarely white) corolla. - Borders of brackish ponds, Plymouth, Massachusetts, to Virginia, and southward. - One of our handsomest plants.

\section{ERYTHR发A, Pers. Centaury.}

Calyx 4-5-parted, the divisions slender. Corolla funnel-form or salver-form, with a slender tube and a 4-5-parted limb. Anthers exserted, erect, twisting spirally. Style slender, single: stigma capitate or 2-lipped. - Low and small branching annuals, chicfly with rose-purple or reddish flowers (whence the name, from é $\rho v \theta \rho o ́ s, r e d)$; in summer. All our Northern species were probably introduced, and occur in few localities.

1. F. Centa ùrium, Pers. (Centaury.) Stem upright, corymbosely branched above; leaves oblong or elliptical, acutish ; the uppermost linear; cymes clus- 
tered, flat-topped, the flowers all nearly sessile; tube of the (purple-rose-colored) corolla not twice the length of the oval lobes. - Oswego, New York. - Plant 6' $-12^{\prime}$ high : corolla $3^{\prime \prime}-4^{\prime \prime}$ long. (Adv. from Eu.)

2. E. ramostssima, Pers., var. I'ulchélla, Griseb. Low $\left(2^{\prime}-6^{\prime}\right.$ high) ; stem many times forked above and forming a diffuse cyme; leaves ovate-oblong or oval; flowers all on short pedicels; tube of the (pink-purple) corolla thrice the length of the elliptical-oblong lobes. (E. Muhlenbérgii, Griseb., as to Penn. plant. Exacum pulchellum, Pursh.) - Wet or shady places, Long Island to E. Virginia: scarce. - Flowers smaller than in No. 1. (Nat. from Eu.)

3. E. Spicata, P'er's. Stem strictly upright $\left(6^{\prime}-10^{\prime}\right.$ high $)$; the flowers sessile and spiked along one side of the simple or rarely forked brunches; leaves oval and oblong, rounded at the base, acutish; tube of the (rose-colored or whitish) corolla scareely longer than the calyx, the loles oblong. (E. 1'ickeringii, Oukes.) - Sandy sea-shore, Nantucket, Massachusetts, Oukes, and Norfolk, Virginia, Rugel. - Remarkable for the spike-like arrangement of the flowers. (Nat. from Lu. ?)

\section{Fràseran, Walt. American Columbo.}

Calyx deeply 4-parted. Corolla deeply 4-parted, wheel-shaped, each division with a glandular and fringed pit on the face. Filaments awl-shaped, usually somewhat monadelphous at the base : anthers oblong, versatile. Style persistent : stigma 2-lobed. Pod oval, flattened, 4-14-seeded. Seeds large and flat, wing-margined. - T'all and showy herbs, with a thick root, upright and mostly simple stems, betring whorled leaves, and numerous peduncled flowers in open cymes, which are disposed in an ample elongated panicle. (Dedicated to John Fraser, an indefatigable collector in this country towards the close of the last century.)

1. F. Carolinénsis, Walt. Smooth biemnial or triennial $\left(3^{\circ}-8^{\circ}\right.$ high $)$; leaves mostly in fours, lance-oblong, the lowest spatulate, veiny; panicle pyramidal, loosely flowered; divisions of the corolla oblong, mucronate, longer than the narrowly lanceolate calyx-lobes, each with a large and round gland on their middle; pod much flattened parallel with the flat valves. - Rich dry soil, S. W. New York to Wisconsin and southward. July. - Root very thick and bitter. Corolla $\mathbf{l}^{\prime}$ broad, light greenish-yellow, marked with small brownpurple dots.

\section{H A I E I I a, Borkh. Srurred Gentian.}

Calyx 4-5-parted. Corolla short bell-shaped, 4-5-cleft, without folds or fringe, prolonged at the base underneath the crect lobes into spurs, which are glandular in the bottom. Stigmas 2 , sessile, persistent on the oblong flattish pod. Seeds rather numerous, oblong. - Small and upright herbs, with yellowish or purplish panicled-cymose flowers. (Name of unknown meaning.)

1. H. defléxa, Grisebach. Leafy anmual or bieunial $\left(9^{\prime}-18^{\prime}\right.$ high), simplê or branched above; leaves 3-5-nerved, the lowest oblong-spatulate and petioled ; the others oblong-lanceolate, acute ; spurs cyliudrical, obtuse, curved, descending, half the length of the acutely 4-Jobed corolla. (Swértia corniculata, 
I., purtly.) - Damp woods, from the northern parts of Mnine, to Wisconsin, and northward. July, August.

\section{GENTI À N A, L. Gentiak.}

Calyx 4-5-cleft. Corolla 4-5-lobed, regular, usually with intermediate plaited folds, which bear appendages or teeth at the sinuses. Style short or none: stigmas 2, persistent. Pod oblong, 2-valved; the innumerable seeds either borne on placentse at or near the sutures, or in most of our species covering nearly the whole inner face of the pod. (First shown by Prof. H.J. Clark!) - Flowers solitary or cymose, showy, in late summer and autumn. (Name from Gentius, king of Illyria, who used some species medicinally.)

§ 1. AMARELLOII)ES, Torr. \& Gr. Corolla tubular-funnel-form, without crown or plaited folds, and with the lobes naked: anthers separate, fixed by the middle, introrse in the bud, but reftexed after the flower opens : sceds wing. Liss: anmunls.

1. G. quinqueflora, Lam. (Frve-floweried G.) Stem rather slender, branching ( $1^{\circ}$ high); leaves ovate-lanceolate from a partly clasping and henrt-shaped base, 3 - 7-nervel, tipped with a minute point; branches racemed or panicled, about 5-flowered nt the summit; lobea of the small 5-cleft calyx awl-shaped-linear; lobes of the pale-blue corolla triangular-ovate, bristle-pointed, one fourth the length of the slender obconical tube. - Var. occidentA Lis has linear-lanceolate calyx-lobes, more leaf-like, about half the length of the corolla. - Dry hilly woods, Maine to Wisconsin and southward, especially along the Alleghanies: the var. is the common form in the Western States. - Corolla nearly 1 'long; in the variety proportionally shorter.

§ 2. CROSSOPETALUM, Frol. Coiolla funnel-form, gland-hearing between the bases of the filaments, without crown or plaited folds; the loles fringed or toothed on the margins: anthers as in $\$ 1$ : pod somewhut stulked: seeds wingless, clothed with little scales: annuals or biennials.

in: 2. G. crinita, Frœl. (Fringed G.) Flowers solitary on long peduncles terminating the stem or simple branches; lemes lancenlate or ornte-lanceolate from a parlly heart-shaped or rounded base; lobes of the 4-cleft calyx unequal, ovate and lanceolate, as long as the bell-shined tube of the sky-blue corolla, the Inbes of Pi which are wedge-obovite, and strongly fringed around the summit; ovary lanceolnte. N - Low grounds, New Fingland to Kentucky and Wisconsin : rather common. Plant $1^{\circ}-2^{\circ}$ high: the showy corolla $2^{\prime} \operatorname{long}$.

3. G. detónsa, Fries. (Smatefen Fringen G.) Stem simple or with slender branches, terminated by solitary flowers on very long perluncles; leaves linear or lancelute-linear : lobes of the 4-(rarcly 5-) cleft caly $\mathrm{x}$ unequal, ovate or triangular and lanceolate, pointed; lobes of the sliy-bluce corolla spatulate-oblong, with ciliate-fringed margins, the fringe shorter or a/mosi obsolete at the summit; ovary elliptical or obovate. - Moist grounds, Niagara Falls to Illinois and northwestward. Passes into the last. (Eu.)

\$ 3. PNEUMONÁN'TIIE, Necker. Corolla bell-shaped or obconical, 5-lobed, with plaited folds which project into appendages in the sinuses: anthers erect. 
fixed by the deep sagittate base, extrorse, often cohering with each other in a ring or tube: pod stalked: perennials, mostly autumn-flowering.

* Flowers ncarly sessile, clustcral or raidy solitary, 2-bracteolate. + Seeds wingless: anthers unconnected.

4. G. ochroleùca, Frol. (Yellowish-White G.) Stems ascending, mostly smooth; the flowers in a dense terminal cluster and often also in axillary clusters; leaves obovale-oblong, the lowest broadly obovate and obtuse, the uppermost somewhat lanceolate, all narroucd at the base; calyx-lobes linear, unequal, much longer than its tube, rather shorter than the greenish-white open corvlla, which is painted inside with green veins and lilac-purple stripes; its lobes ovate, very much excecding the small and sparingly toothed oblique appendages; pod included in the persistent corolla. - Dry grounds, S. l'eunsylvania (rare) to Virginia, and common southward.

+ + Sculs wingul: unthers connivent and usually more or cohering.

5. G. álba, Muhl. Cat.! (Wıiтsıı G.) Stems upright, stout, and very smooth; flowers closely sessile and inuch crowded in a dense terminal eluster, sometimes also clustered in the upper axils; leaves ovate-lanceolate from a neartshaped closely clasping base, gradually tapering to a point; calyx-lobes ovate, shorter than the top-shaped tube, and many times shorter than the tube of the corolla, reflexen-spreading; corvllu white more or less tinged with greenish or yellowish, inflated-club-shaped, at length open, its short and broad ovate lobes nearly twice the length of the twothed apperdinges; pod nearly included; seeds broally winged. (G. Alávida, Gray, in Sill. Jour. G. ochrolenca, Sims., Darlingt., Grisebuch, in part.) - Glades and low grounds, S. IV. New York to Virginia along tho Alleghanies, and west to Illinois and Lake Superior. Bugins to flower in July, far earlier than the two next.

6. G. Andréwsii, Griscl). (Crosen G.) Stems upright, smooth; flowers closely sessile in terminal and "pper axillary clusters; leaves ovate-fanceolate and lanceolute from a narrower base, gradually pointed, rough-margined; calyxlobes ovate or oblong, recurvel, shorter than the top-shaped tube, and much shorter than the influted club-shuped and truncate mostly blue corolla, which is closed at the mouth, its proper lobes obliterated, the apparent lobes consisting of the broad fringe-toothed and notehed appendages; pod finally projecting out of the persistent corolla; seeds broadly winged. (G. Saponaria, Froel, not of L.) - Moist and rich soil : common, especially northward. - Corolla an inch or more in length, striped inside, the folds whitish; occasionally pure white thronghont.

7. G. Saponària, I. (SoApwort G.) Stem erect or ascending, smooth; the flowers clustered at the summit and more or less so in the axils ; leaves ovatelanceolate, oblong, or lancenlate-obovate, with rough margins, narrowed at the base; calyx-lobes linear or spotulate, acute, equalling or excceding the tube, half the length of the corolla; lules of the club-bell-shaped light-blue corolla obtuse, erect or converying, short and broul, lut distinct, and morc or liss lonyer than the conspicuons 2-clefi and minutely toothal appendages; seeds acute, narrowly winged. (G. Catesbeei, W $W^{\top}$ (lt.) - Moist woods, New Jersey and S. Penu. to Virginia, Illinois, and southward: flowering late. 
Var. lineàris. Slender, nearly simple $\left(1^{\circ}-2^{\circ}\right.$ high $)$; lenves linear or lance-linear $\left(2^{\prime}-3^{\prime}\right.$ long $)$, acutish ; "ppendages of the corolla shorter and less cleft, or nlmost entire. (G. Pneumonánthe, Amer. auth., \& Ed. 1. G. lincaris, Frol.) - Mountain wet glades of Marylaind and Penn., to Lake Superior, Northern New York, New Hampshire (near Concord), and Maine (nenr Portland) : beginning to blossom at midsummer. - Seems to pass on one side into G. Saponaria, on the other into G. Pncumonanthe of Europe.

8. G. pubérula, Michx. Stems erect or ascending $\left(8^{\prime}-16^{\prime}\right.$ high $)$, mostly romgh and minutely pubescent above; leaves rigid varying from linear-lanceolute. (1) oblong-lanceolute, rough-margined ( $1^{\prime}-2^{\prime}$ long) ; flowers clustered, rarely solitary; calyx-lobes lanceolate, not longer than the tube, much shorter than the bell-funnel-form open bright-blup corolla, the spreading ovate lobes of which are acutish and twice or thrice the length of the cut-toothed appendages. (G. Catesbiei, Ell. G. Saponaria, var. puberula, $E d$. 1.) - Dry prairies and barrens, Ohio to Wisconsin, and southward. Flowering near the end of summer. Corolla large for the size of the plant, $1 y^{\prime}-2$ ' long. Secls (also in G. P'neumonanthe) not covering the walls, as they do in the rest of this division.

* Flowers 1-3, peduncled: seeds wingless: anthers separate.

9. G. angustifolia, Michx. Stems slender and ascending $\left(6^{\prime}-15^{\prime}\right.$ high); leaves linear or the lower oblanceolate, rigid ; corolla open-funnel-form, azurebluc, also a grcenish and white varicty ( $\left.2^{\prime} \mathrm{long}\right)$, about twice the length of the thread-like calyx-lobes, its orate spreading lobes twice the length of the cuttoothed appendages. - Moist pine barrens, New Jersey, and southward.

\section{B A R T Ò N I A, Muhl. (Centaunélla, Michx.)}

Calyx 4-parted. Corolla decply 4-cleft, destitute of glandls, fringes, or folds. Stamens short. Pod oblong, flattened, pointed with a large persistent at length 2-lobed stigma. Seeds minute, innumerable, covering the whole inner surface of the pod. - Small annuals or biennials $\left(3^{\prime}-10^{\prime}\right.$ high $)$, with threul-like stems, and little awl-shaped scales in place of leaves. Flowers small, white, peduncled. (Dedicated, in the year 1801, to Prof. Benjamin Smith Barton, of Philadelphin.)

1. B. tenélla, Muhl. Stems branched above; the branches or peduncles mostly opposite, 1-3-flowered; lobes of the corolla oblong, acutish, rather longer thun the culyx, or sometimes twice as long; anthers roundish; ovary 4-nngled, the cell somewhat cruciform. - Open woods, New England to Wisconsin and southward. Aug. - Centaurella Moseri, Grisebuch, is a variety with the scales and peduncles mostly alternate, and the petals acute.

2. B. vérna, Muhl. Stem 1 -few-flowered; lobes of the corolla spatulate, obtuse, spreading, thrice the length of the caly, ; anthers oblong ; ovary flat. - Bogs near the coast, Virginia and southward. March. - Flowers $3^{\prime \prime}-4^{\prime \prime}$ long, larger than in No. 1 .

\section{O BOL $\mathbf{A} \mathbf{R I A , ~ L . ~ O b o l a r i a . ~}$}

Calyx of 2 spatulate spreading sepals, resembling the lenves. Corolla tubular-bell-shaped, withering-persistent, 4-cleft; the lobes oval-oblong, or with age 
spatulate, imbricated in the bud! Stamens inserted at the sinuses of the corolla, short. Style short, persistent: stigma 2-lipped. Pod ovoid, 1-celled, the cell cruciform : the seeds covering the whole face of the walls. - A low and vory smooth purplish-green perennial $\left(3^{\prime}-8^{\prime}\right.$ high), with a simple or sparingly lianched stem, opposite welge-obovate leaves; the dull white or purplish Howers solitary or in clusters of three, terminal and axillary, nearly sessile; in spring. (Name from $\dot{\beta} \beta$ 入ós, a small Greek coin; to which, however, the leaves of this plant bear no manifest resemblance.)

1. O. Virgínica, I. (G'ray, Chlor. Bor.-Am., t. 3.) - Rich soil, in woods, from New Jersey to Illinois, and southward : rather rare.

\section{MENYÁ N THES, Tourn. Buckiean.}

Calyx 5-parted. Corolla short funnel-form, 5-parted, deciduous, the whole upper surface white-bearded, valvate in the bud with the margins turned inward. Style slender, persistent : stigma 2-lobed. Pod bursting somewhat irregularly, many-seeded. Seed-coat hard, smooth, and shining. - A perennial alternateleaved herb, with a thickish creeping rootstock, sheathed by the membranous bases of the long petioles, which bear 3 oval or oblong leaflets at the summit; the flowers racemed on the naked scape $\left(1^{\circ} \mathrm{high}\right)$, white or slightly reddish.

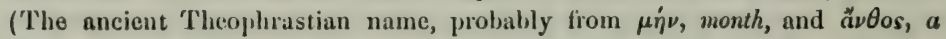
flower, some say from its flowering for about that time.)

1. M. trifoliàta, L. - Bogs, New England to Pennsylvania, Wisconsin, and nortliward. May, June. (Eu.)

\section{L I M N Á N T H E M M , Gmelin. Floating Heart.}

Calyx 5-parted. Corolla almost wheel-shaped, 5-parted, the divisions fringed or bearded at the base or margins only, folded inwards in the bud, hearing a glandular appendage near the base. Style short or none: stigma 2-lobed, persistent. Pod few - many-secded, at length bursting irregularly. Seed-coat hard. - Perennial aquatics, with rounded floating leaves on very long petioles, which, in most species, bear near their summit the umbel of (polygamous) flowers, along with a cluster of short and spur-like roots, sometimes shooting forth new leaves from the same place, and so spreading by a sort of proliferous stolons : flowering all summer. (Name compounded of $\lambda i \mu \nu \eta, a$ marsh or pool, and ${ }^{*} \nu \theta \epsilon \mu \nu \nu, a$ blossom, from the situations where they grow.)

1. L. lacunosum, Grisebach (partly). Leaves entire, round-heart-shaper ( $1^{\prime}-2^{\prime}$ broad), thickish ; petioles filiform; lobes of the (white) corolla broadly oval, naked, except the crest-like yellowish gland at their base, twice the length of the lanceolate calyx-lobes; style none; seeds smooth and even. (Villársia lacunosa, Vent. V. cordàta, Ell.) - Shallow water, from Maine and N. New York to Virginia and southward.

2. L. trachyspérmum, Gray. Leaves larger $\left(2^{\prime}-6^{\prime}\right.$ broad), and rounder, thicker, often wavy-margined or crenate, roughish and dark-punctate or pitted beneath; petioles stouter; seeds glandular-roughened. (Menyanthes trachysperma, Michx.) - Ponds, Maryland (W. M. Canby) and southward. 


\section{Order 78. Loganiacea. (Logania Famliy.)}

Herhs, shrubs, or trees, with opposite and entire leaves, and stipules or a stipular membrane or line between them, and with regular 4-5-merous 4-5androus perfect flowers, the ovary fiee from the calyx : a connecting group between Gentianacex, Apocynacex, Scrophulariacex (from all which they are known by their stipules) and Rubiaces, from which they differ in their free ovary : our representatives of the family are all most related to the Rubiacem, to which, indeed, they have been appended.

* Wooly twincrs: Icaves evergreen.

1. Gelsemium. Corolla large, the 5 lobes inbricated in the bud. Style slender : stigmas 4

$$
\text { ** Ilerbs. }
$$

2. Poly premum. Corolla 4-lobed, not longer than the calyx, imbricated in the bud.

3. Splgella. Corolla 5-lobed, valvate in the bud. Style single, jointed in the middle.

4. Mitreola. Corolla 5-lobed, valvate in the bud. Styles 2 , short, converging, united at the summit, and with a common stigma.

\section{GELSÉ M I U M, Juss. Yellow (False) Jessamine.}

Calyx 5-parted. Corolla open-funnel-form, 5-lobed; the lobes imbricated in the bud. Strmens 5, with oblong sagittate anthers. Style long and slender. Stigmas 2, each 2-parted; the divisions linear. Por elliptical, flattened contrary to the narrow partition, 2-celled, septicidally 2-valved. Seeds many or several, winged. Embryo straight in fleshy albumen; the ovate flat cotyledons much shorter than the slender radicle. - Smooth and twining shrubby plants with opposite and entire ovate or lanceolate leaves, minute stipules, and showy yellow flowers, of two sorts as to relative length of stamens and style. (Gelsemino, the Italian name of the Jessamine.)

1. G. sempérvirens, $\Lambda$ it. (Yezrow Jessamine of the Sonth.) Stem climbing high; leaves short-petioled, shining, nearly persistent; flowers in short axillary clusters; perlicels sealy-bracted ; flowers very fragrant (the bright yellow corolla $1^{\prime}-1 \frac{1}{2}{ }^{\prime}$ long); pod flat, pointed. - Low grounds, Eastern Virginia and southward. March, April.

\section{POLY PR E U M, I. Polvirium.}

Calyx 4-parted; the divisions awl-shaped from a broad scarious-margined base. Corolla not longer than the calyx, almost wheel-shaped, bearded in the throat; the 4 lobes imbricated in the bud. Stamens 4 , very short: anthers globular. Style 1, very short: stigma ovoid, entirc. Pod ovoid, a little flattered, notched at the apex, 2-celled, loculicilally 2-valved, many-secded. - A smooth, diffuse, much-branched, small annual, with narrowly linear or awlshaped leares, connected at their base across the stem by a slight stipular line; the small flowers solitary and sessile in the forks and at the ends of the branches; corolla inconspicuous, white. (Name altered from $\pi \circ \lambda u ́ \pi \rho \epsilon \mu \nu$ s, many-stemmed.)

1. P. procúmbens, L. - Dry fields, mostly in sandy soil, Maryland and southward; also adventive at Philadelphia. June-Oct. 


\section{S PIG亡LIA, L. Pink-root. Worm-grass.}

Calyx 5-parted; the lobes slender. Corolla tubular-funnel-form, 5-lobed at the sumnit, valvate in the bud. Stamens 5 : anthers linear. Style 1, slender, hairy above, jointed near the middle. Pod short, 2-celled, twin, laterally flattened, separating at maturity from a persistent base into 2 carpels, which open loculicidally, few-seeded. - Chietly herbs, with the pair of leaves united by means of the stipules, and the flower's spiked in one-sided cymes. (Named for Adrian Spiegel, latinized Sprigdius, who wrote on botany at the beginning of the seventecuth eentury, and was perhaps the first to give directions for preparing an lierbarium.)

1. S. Marilándica, L. (Maryland Prnk-root.) Stems simple and erect from a pereunial root $\left(6^{\prime}-18^{\prime}\right.$ high $)$; leaves sessile, ovate-lanceolate, acute; spike simple or forked, short; tube of the corolla 4 times the length of the calyx, the lobes lanceolate; anther's and style exserted. - Rich woods, Pennsylvania to Wisconsin and southward: not common northward. June, July. - Corolla $1 \frac{1}{2}$ long, red outside, yellow within. - A well-known officinal anthelmintic, and a showy plant.

\section{MITREOLA, L. Mithewont.}

Calyx 5-parted. Corolla little longer than the calyx, somewhat funnel-form, 5-lobed, valvate in the bud. Stamens 5, included. Ovary at the base slightly aduate to the bottom of the calyx, 2-celled: styles 2, short, converging and united above; the stigmas also united into one. Pod projecting beyond the calyx, strongly 2-horned or mitre-shaped, opening down the inner side of each horn, many-seeded. - $\Lambda$ munal smooth herbs, $6^{\prime}-2^{\circ}$ high, with small stipules between the leaves, and small white flowers spiked along one side of the lranches of a terminal petioled cyme. (Name, a little mitre, from the shape of the pod.)

1. M. petiolàta, Torr. \& Gray. Leaves thin, oblong-lanceolate, petioled. - Damp soil, from Eastern Virginia southward.

2. M. sessilifolia, Torr. \& Gray, with thickish sessile and roundish leaves, probably occur's as far north as Virginia.

\section{Order 79. APOCYNÁCEAs. (Dogbane Family.)}

Plants almost all with milky acrid juice, entire (chiefly opposite) leaves without stipules, regular 5-merous and 5-androus flowers; the 5 lobes of the corolla convolute and lwisted in the bud; the filaments distinct, inserted on the corolla, and the pollen granular; the calyx entirely free from the two ovaries, which (in our genera) are distinct (and forming pods), though their styles or stigmas are united into one. - Seeds amphitropous or anatropous, with a large straight enbryo in sparing albumen, often bearing a tuft of down (comose). - Chicily a tropical family (of acrid-poisonous plants), represented in gardens by the Oleander and Periwinkle, and among wild plants by three genera :- 
1 Amson In. Beeds naked. Corolla with the tube henrded Inside. Anthers longer than the finments. Leaves alternate.

2. Forsteronla. Seeds comose. Cornlla funnel-form, not appendaged. Filaments slender. Caly $x$ glandular inaide. Leaves oppogite.

8. A poey num. Seeds comose. Corolla bell-shnped, appendaged within. Filaments short. broad and flat. Caly $\mathrm{x}$ not glandular. Leaves opposite.

\section{A M S ÒnIA, Walt. Amsonia.}

Calyx 5-parted, small. Corolla with a narrow funnel-form tube bearded inside, especially at the throat; the limb divided into 5 long lincar lobes. Stamens 5 , inserted on the tube, included : anthers obtuse at both ends, longer than the filaments. Ovaries 2 : style 1 : stigma rounded, surrounded with a cup-like membrane. Pod (follicles) 2, long and slender, many-sceded. Seeds cylindrical, abrupt at both ends, packed in one row, naked. - Perennial herbs, with ulternate leaves, und pale blue flowers in terminal panicled cymes. (Said to be named for a Mr. Charles Amson.)

1. A. Tabernæmontàna, Walt. Loosely somewhat pubescent or hairy when young, or soon glabrous ; leaves varying from ovatc-lanccolate to linearlanceolate, taper-pointed; calyx-lobes short, awl-shaped; tube of the bluish corolla little longer than the lobes, the upper part either hairy when young or glabrous. - Low grounds, Illinois, Virginia? and southward. May, June.

\section{For S TER Ò I A, Meyer. Forsteronia.}

Calyx 5-parted, with $3-5$ glands at its base inside. Corolla funnel-form, not appendaged; the limb 5-lobed. Stamens 5, included : filaments slender: anthers arrow-shaped, with an inflexed tip, adhering to the stigma. Pods (follicles) 2, slender, many-seeded. Seeds oblong, with a tuft of down. - Twining plants, more or less woorly, with opposite leaves and small flowers in cymes. (Named for $\mathbf{M r} . \boldsymbol{T}, \boldsymbol{F}$. Forster, an English botanist.)

1. F. diffórmis, $\Lambda .1)$ C. Nearly herbaceous and glabrons; leaves ovallanceolate, pointed, thin; calyx-lobes taper-pointed; corolla pale yellow. Damp grounds, Virginia, S. Illinois, and southward. April.

\section{A PÓCY N U M, Tourn. Dogbane. Indian Hemp.}

Calyx 5-parted, the lohes acute. Corolla bell-shaped, 5-cleft, bearing 5 triangular appendages in the throat opposite the lobes. Stamens 5, inserted on tho very base of the corolla: filaments flat, shorter than the arrow-shaped anthers, which converge arouml the ovoid obscurely 2 -lobed stigma, and are slightly adherent to it by their inner face. Style none: stigma large, ovoil, slightly 2 . lobed. Fruit of 2 long and slender follicles. Seeds comose with a long tuft of silky down at the apex. - P'erennial herbs, with upright branching stems, opposite mucronate-pointed leaves, a tough fibrous bark, and small and pale cymose flowers on short pedicels. (An ancient name of the Dogbane, composed of inó, from, and $\kappa \dot{v} \omega \nu, a d o g$, to which the plant was thought to be poisonous.)

1. A. androsømifòlium, L. (Sprending Dogbane.) Smooth, branched above; branches divergently forking; leaves ovate, distinctly petioled; 
cymes loose, spreading, mostly longer than the leaves; corolla (pale rose-color, 4" broad) open-bell-shaped, with revolute lobes, the tube much longer than the orute pointed divisions of the calyx. - Varies, with the leaves downy underneath. Borders of thickets : common northward. June, July. - Pods $3^{\prime}-4^{\prime}$ long, pendent.

2. A. cannábinum, L. (Indian Hemp.) Stem and branches upright or ascending, terminated by erect and close many-fluvered cymes, which are usually shorter than the leaves; corolla (greenish-white) with nearly erect lobes, the tube

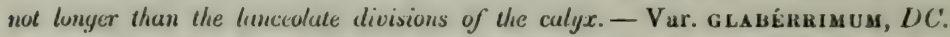
Entirely smooth; leaves oblong or oblong-lanceolate, on short but manifest petioles, obtuse or rounded, or the uppermost mostly acute at both ends. Var. P'UBÉscéns, $I C$ '. Leaves oblong, oval, or ovate, soft-downy underneath or sometimes on both sides, as well as the cymes. (A. pubescens, R. Br.) Var. HYPERicifòliusr. Leaves more or less heart-shaped at the base and on very short petioles, commonly smooth throughout. (A. hypericifolium, Ait.) - River-banks, \&c. : common. July, Aug. - Plant $2{ }^{\circ}-3^{\circ}$ high, much more upright than the last; the flowers scarcely half the size.

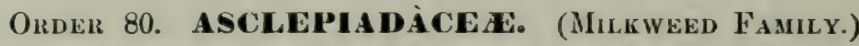

Plants with milly juice, and opposite or whorled (rarcly scattered) entire leaves; the follicular pods, seeds, anthers (connected with the stigma), sensible properties, \&c., just as in the last family; from which they differ in the commonly valvate corolla, and in the singular connection of the anthers with the stigma, the cohesion of the pollen into wax-like or granular masses, \&c., as explained under the first and typical genus.

Tribe I. ASCIEPIA DEAs. Filaments monalelphous. Pullen-mases 10, waxy, fixed to the stigma in patirs l,y a flimu, hauging vertically.

1. Aselepias. Caly $x$ and corulla reflexed, deeply 5 -parted. Crown of 5 horded fleshy boulies (nectaries, L.), with an incurved horn rising from the cavity of each.

2. Acerates. Calyx and corulla reflexed or merely spreading. Crown as in No. 1 , but without a horn inside.

3. Eusleuia. Caly $x$ and corolla ereet. Crown of 5 membranaceous flat bodies, terminated by a 2-cleft tuil or awn.

4. Vincetoxicum. Calyx and wheel-shaped corolla spreading. Crown a fleshy 5-10lohed ring or disk.

Tribe II. GONOIOBE E. Filaments monadelphous. Pullen-masses 10, aflixed to the stigma in pairs, horizontal.

5. Gonolobus. Corolla wheel-shaped. Crown a wavy-lobed fleshy ring.

Tribe III. PEIR I POCE E. Filaments distiuct or nearly so. Polleu-masses granular. separately applied to the stigma.

6. Pexiploca. Corulla wheel-shaped, with 5 awned scales in the throat.

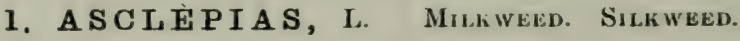

Calyx 5-parted, persistent; the divisions small, spreading. Corolla deeply 5-parted; the divisions valvate in the bud, reflexed, deciduous. Crown of 5 hooded bodies (nectaries, L.) seated on the tule of stamens, each containing 
an incurved horn. Stamens 5, inserted on the base of the corolla: filaments united in a tube which encloses the pistil : anthers adherent to the stigma, each with 2 vertical cells, tipped with a membranaceous appendage, each cell containing a flattened pear-shaped and waxy pollen-mass; the two contiguous pollen-masses of adjacent anthers, forming pairs which hang by a slender prolongation of their summits from 5 cloven glands that grow on the angles of the stigma,extricated from the cells by the agency of insects, and directing copious pollen-tubes into the point where the stigma joins the apex of the styles. Ovaries 2 , trjering into very short styles: the large depressed 5-angled fleshy mass which takes the place of stigma common to the two. Follicles 2, one of them often abortive, soft, ovate or lanceolate. Sceds anatropous, flat, margined, downwardly imbricated all over the large placenta, which separates from the suture at maturity, furnished with a long tuft of silky hairs (coma) at the hilum. Embryo large, with broad foliaceous cotyledons in thin albumen. - Perennial upright herbs, with thick and deep roots : peduncles terminal or lateral and between the petioles, bearing simple many-flowered umbels : flowering in summer. (The Greek name of Esculapius, to whom the genus is dedicated.)

* Leaves opposite (or some of them in No. 5-7 in threes or fours.)

- Stem simple or nearly so, leafy the top, and bearing lateral umbels us well as a terminal one: leaves ovate or oblong: flowers whitish, pinkish, or dull purple.

+ Pods beset with soft spinous projections : flowers $6 "$ - 9" long when open, greenishpurple, numerous in dense umbels.

1. A. Cornuti, Decaisne. (Common Mrikweed or Silkweed.) Stem tnll and stout; leaves oval-oblong $\left(4^{\prime}-8^{\prime}\right.$ long), contracted at base into a short petiole, pale, minutely downy beneath, as well as the peduncles, \&c.; hoods of the crown ovate, obtuse, with a lobe or tooth on each side of the short and stout claw-like horn; pods ovate, covered with weak spines and woolly. ( $\Lambda$. Syrìaca, L., but the plant belongs to this country only.) - Rich ground, everywhere.

2. A. Sullivántii, Engelm. Very smooth thronghout, tall ; leaves ovateoblong with a somewhat heart-shaped base, nearly sessile; hoods obovate, entire, obtusely 2-eared at the base outsile; flowers larger $\left(9^{\prime} \mathrm{long}\right)$ and more purple than in the preceding; pods obscurely soft-spiny, chicfly on the beak, ovate-lanceolate. - Low grounds, Columbus, Ohio (Sullivant) to Illinois.

+ Pods even, not warty-roughened, mostly glabrous.

3. A. phytolaccoldes, Pursh. (Роке-Mukween.) Stem $\left(3^{\circ}-5^{\circ}\right.$ high) smooth; leaves broudly ovale, or the upper oral-lancrolate and pointed at both ends, short-petioled, smooth or slightly downy underneath $\left(5^{\prime}-8^{\prime}\right.$ long $)$; lateral umbels several; pedicels loose and nodding, mumerous, Inng and slender ( $1^{\prime}-3^{\prime}$ long), equalling the peruncle, many times longer than the onate-oblong divisions of the (greenish) corolla; hoods of the crown (white) truncate, the margins 2-toothed at the summit, the horn with a long projecting aul-shaped point; pods minutely downy. - Moist copses ; flowering early in summer. - Flower $6^{\prime}$ long.

4. A. purpuráscens, L. (Purple M.) Stem rather slender $\left(1^{\circ}-3^{\circ}\right.$ high); leaves elliptical or ovate-oblong, the upper taper-pointed, minutely veleetydowny underneath, smooth above, contracted at the base into a short petiole; pedicels 
shorter than the peduncle, 3-4 times the lenyth of the dark purple lanceolateovate divisions of the corclla; hoods of the crown oblong, abruptly narrowed ubove; the hoin broadly scythe-shaped, with a nurrow and ubriptly inflexed horizontal point. (A. anienal, L., J/ichx.) - Borders of woods, \&c., New England to Illinois and southward. - Fluwer's 6 "long.

5. A. variegàta, L. (VAlikgated M.) Neurly glabrous $\left(1^{\circ}-2^{\circ}\right.$ high); leaves ovate, oval, or bbucute, somewhat wavy, contiuctud into short petioles; pedicels (numerous and crowded) and peduncle short, downy; divisions of the corolla ovate (white); hoods of the crown orbicular, entire, purplish or reddish, the horn semilunar wich a horizontal point; pods slightly downy. (A. nívea, $L$., in part. A. hýbrida, Miche.) - Dry woods, S. New York to Wisconsin and southward. July. - Remarkable for its compact umbels of nearly white flowers. Leaves 4-5 pairs, the middle ones sometimes whorled.

6. A. ovalifolia, Decitisne in DC. Low $\left(6^{\prime}-18^{\prime}\right.$ high $)$, soft-downy, especially the lower surface of the ovate or lanceolate-oblong acute short-petioled leaves; unbels loosely $10-18$-flowered, either sessile or peduncled; pedicels slender; hoods of the crown oblong, obtuse, yellowish, with a small horn, about the length of the oval greenish-white divisions of the corolla (which are tinged with purple outside); pods downy. (A. lamuginosa, Ed. 1, probably not of Nutt. A. Vaseyi, ('arey). - I'rairies and vak-openings, N. Illinois, Vasey, Wisconsin, Lapham, and northwestward. June. - Leaves $1 \frac{1}{2}{ }^{\prime}-3^{\prime}$ long, smoothish above, the upper somctimes scattered; the middle rarely in threes. Flower $4^{\prime \prime}-5$ " long.

7. A. quadrifollia, Jacq. (Four-Leaved M.) Neurly smooth; stem slender $\left(1^{\circ}-2^{\circ}\right.$ high $)$, mostly leafless below, bearing usually one or two whorls of four in the middle and one or two pairs of ovate or ovate-lanceolate taperpointed petioled leaves $\left(2^{\prime}-4^{\prime}\right.$ long); pedicels slender; divisions of the (pale pink) corolla oblong; hoods of the white crown elliptical-ovate, the incurved horn short and thick; pods linear-lanceolate, smooth. - Dry woods and hills: not very common. June. - Flowers 4 "long.

+ + Stem brinching, lcufig to the lop, bearing luteral as well as terminal umbels: leaves petiolad: Jlowers small (3" lony) : pods smooth and ylabrous.

8. A. perénnis, Walt. Ncarly glabrous; stems $\left(1^{\circ}-2^{\circ}\right.$ high) persistent or somewhat wovly at the base; leaves lanceolate or lanceolate-ovate, tapering to both ends, thin, rather slender-petioled; flowers white, small; the small hoods of the crown shorter than the needle-shaperl horn; seeds sometimes destitute of a coma! (A. parviflora, P'ursk, and Ed. 2.) - Low grounds, S. Indiana, Illinois, and southward.

9. A. incarnàta, L. (Swamp MrLkweed.) Smooth, or nearly so, in the typical form, the stem with two downy lines above and on the branches of the peduncles $\left(2^{\circ}-3^{\circ}\right.$ high $)$, very leafy; lecuves oblong-lenceolute, acute or pointed, abluse or abscurcly heart-shaped at base; flowers rose-purple; hoods of the crown scarcely equalling the slender needle-pointed horn. - Var. 1'úlenis has broader and shorter-petioled leaves, more or less hairy-pubescent, as well as the stem. (A. pulchra, Willd.) - Wet grounds; the smooth form very common northward; the hairy variety more so southward. - Milky juice scanty. 
+ + + Stem perfectly simple, produring only a single conspicuously-peduncled tarminal umbel of dull-colored largish ( $6^{\prime \prime}$ long) flowers: hoods and lobes of the co. rolla broad: pods smooth: whole plant glabrous or nearly so, and pale or glaucous : leaves closely sessile, transversely veiny.

10. A. obtusifolia, Michx., Stem tall $\left(2^{\circ}-3^{\circ}\right.$ high $)$; leaves wavy, oblong with a heart-shoped clasping base, very obtuse or retuse $\left(2 \frac{1}{2}^{\prime}-5^{\prime}\right.$ long); peduncle $3^{\prime}-12^{\prime}$ long ; corolla pale greenish purple; hoods of the crown truncate and somewhat toothed at the summit, shorter than the slender awl-pointed horn. Sandy woods and fields: not rare, especiully southward:

11. A. Meádii, Torr. (in Ed. 2, addend.) Stem slender $\left(1^{\circ}-2^{\circ}\right.$ high; ; leaves vvate or oblong-ovate, not wavy, obtuse or acutish $\left(1 \frac{1}{2}^{\prime}-2 \frac{1}{2}^{\prime}\right.$ long); peduncle only twice the length of the upper leaves; pedicels rather short; corolla greenish-white; hoods of the crown rounded-truncate at summit, and with a sharp tooth at each margin, somewhat exceeding the stouter horn; pod unknown. Augusta, Illinois, Dr. S. B. Mead. Clinton, Iowa, Dr. Vasey. June.

++++ Stem simple or mostly so $\left(2^{\circ}-4^{\circ}\right.$ high $)$, beuring $2-5$ panicled umbels on a naked terminul peduncle, and sometimes single axillary ones: flowers pink-red, rather large (over $6^{\prime \prime}$ long): crown conspicuously elevated above the base of the corolla: pods smooth: whole plant glabrus or nearly so.

12. A. rubra, L. Leaves ovute or lanceolate and tapering fiom a rounded or heart-shaped base to a very acute point, sessile or nearly so $\left(2^{\prime}-6^{\prime}\right.$ long, $\frac{1}{2}^{\prime}-2 \frac{1}{2}^{\prime}$ wide), bright green; umbels many-flowered ; divisions of the corolla and hoods of the crown oblong-lanceolate, purple-red ; the horn long and slender. (A. laurifolia, Mirhx. A. acuminata, Pursh.) - Wet pine-barrens, \&c., New Jersey and Penn. to Virginia and southward.

13. A. paupércula, Michx. Stem slender $\left(2^{\circ}-4^{\circ}\right.$ high $)$; leaves elongated lanceolute or linear $\left(5^{\prime}-10^{\prime}\right.$ long), tapering to both ends, slightly petioled; umbels 5-12-flowered; divisions of the red corolla narrowly ollong; the bright orange hoods broadly oblong, obtuse, much exceeding the incurved horn. - Wet pine-barrens on the coast, New Jersey, Virginia, and southward.

* Lenves scattered, or some opposite: milky juice little or none: flowers orange-red.

14. A. tuberosa, L. (Butterfly-ween. Pleurisy-root.) Roughish-hairy; stems crect or ascending, very leafy, branching at the summit, and bearing the umbels in a terminal corymb; leaves varying from linear to oblonglanceolate, sessile or slightly petioled ; divisions of the corolla oblong (greenishorange); hoods of the crown narrowly oblong, bright orange, scarcely longer than the nearly erect and slender awl-shaped horns; pods hoary. (A. decuimbens, L.) - Dry hills and fields: common, especially southward. - P'lant $1^{\circ}$ $2^{\circ}$ high, leafy to the summit, usually with numerous and corymbed shortpeduncled umbels of showy flowers.

* * Leaves ncarly all whorled, rarely alternate, crowded: flowers white, small.

15. A. verticillàta, L. (WhorLed M.) Smoothish; stems slender, simple or sparingly branched, very leafy to the summit; leaves very narrowly linenr, with revolute margins $\left(2^{\prime}-3^{\prime}\right.$ long, $1^{\prime \prime}$ wide), $3-6$ in a whorl; umbels small, lateral and terminal; divisions of the corolla ovate (greenish-white): 
hoods of the crown roundish-oval, about half the length of the incurved claw. shaped horus; pods smooth.-Dry hills: common, especially southward.

\section{A C E R À T ES, Ell. Green Milkweed.}

Nearly as in Asclepias; but the hoods of the crown destitute of a horn (whence the name, from a privative and képas, -atos, a horn). - Flowers greenish. Leaves varying from opposite to irregularly alternate, short-petioled or sessile. Pollen-masses slender-stalked.

\$1. Dicisions of the corulla reflexcl, oblong: hoorls of the crown erect and concave: umbels compactly many-yluwerid: pods not muricute, stender.

* Crown not elevated; its hoods oblony, neurly exuulling the anthers.

1. A. viridiflora, Ell. Minutely suft-lowny, becoming smoolhish; stems ascending $\left(1^{\circ}-2^{\circ}\right.$ high); leaves varying from oval to linear, thick $\left(1 \frac{1}{2}^{\prime}-4^{\prime}\right.$ long $)$, umbels neurly sessile, laterul, dense and globose; flower (when the corolla is reHexed) nearly $\frac{1}{2}$ long, short-pedicelled. - Dry soil : common, especially southward. July - Sept.

2. A. lanuginossa, Decaisne. Huiry, low $\left(5^{\prime}-12^{\prime}\right.$ high $)$; leaves lanceolate or orate-lanceolate; umbles solitary and terminal, pedineled; flowers not larger than in the next; peetects stender. (1'robably Aselepias lanuginosa, Nutt. : cortainly A. Nuttalliana, T'orr. Acerates monocephala, Lapham, in Ld. 2, addend.) - Prairies, Wisconsin (Laphum) and westward. July.

* * Crown short-stalked, i. e. elecated above the base of the corolla; its hoods oval, stiongly concuve, and decidcdly shorter thun the tips of the anthers.

3. A. longifolia, Eil. Minutely roughish-hairy or smoothish; stem erect $\left(1^{\circ}-3^{\circ}\right.$ high $)$, very leafy; leaves mostly alternate-scattered, linear $\left(3^{\prime}-7^{\prime}\right.$ long); umbels lateral, on peduncles of about the length of the slender pedicels; flower's $3^{\prime \prime}$ long when exprated. - Moist pratiries, Ohio to Wisconsin and southward. July - Oct.

§2. ANAN'THERIX, Nutt. Divisions of the corolla ascending or barely spreading: hoods of the crown widcly spreading and somewhat incurved, slipper-shaped and laterally compressed, the cuvity dicided at the "ipex by a crest-like partition: umbels solitary and terminal or corymbed, loosely-jlowered: pods oblony or ovate, often somewhut muricate with soft spinous projections.

4. A. paniculàta, Decaisne. Almost glabrous; stems short ( $1^{\circ}$ high); leaves alternate, short-petioled, clongated-oblong, $1^{\prime}-22^{\prime}$ wide; umbels several in a cluster, short-peduncled; flowers large ( $1^{\prime}$ in diameter), green, with a purplish crown. - Prairies, Illinois (Vasey, Bcbb), and southward. June.

\section{E NSLÉ N I A, Nutt. Énslemia.}

Calyx 5-parted. Corolla 5-jarted; the divisions ereet, ovate-lanceolate. Crown of 5 free membranatceous leaflets, which are truncate or obscurely lobed at the apex, where they hear a pair of flexuous awns united at their base. Anthers nearly as in Asclepias: pollen-masses oblong, obtuse at both ends, fixed below the summit of the stigma to the descending glands. Pods oblong-lanceolate, smooth. Seeds with a tuft, as in Asclepias. - A peremial twining herb, 
smooth, with opposite heart-ovate and pointed long-petioled leaves, and small whitish flowers in raceme-like clusters, on slender axillary perluncles. (1)edicated to A. Enslen, an $\Lambda$ ustrian botanist who collected in the Southern United States early in the present century.)

1. E. álbida, Nutt. - River-banks, Ohio to Illinois, and southward : common. July - Sept. - Climbing $8^{\circ}-12^{\circ}$ high : leaves $3^{\prime}-5^{\prime}$ wide.

\section{VI N CETÓXICU M, Monch. Vincetoxicum.}

Calyx 5-parted. Corolla 5-parted, wheel-shaped. Crown flat and fleshy, disk-like, 5-10-lobed, simple. Anthers smooth, pods and secds much as in $\Lambda$ sclepias. - Herbs, often twining. (Name composed of Vinca, the Periwinkle, and toxicum, poison.)

1. V. Nlgrum, Moench. (BLACK V.) More or less twining, nearly smooth; leaves ovate or lance-ovate; flowers small, dark purple, in an axillary cluster, on a peduncle shorter than the leaves. - Cambridge, Mass., \&c. : a weed escaping from gardens. ( $\Lambda \mathrm{dv}$. from Eu.)

\section{GON ÓLOBUS, Míchx. Gonolobus.}

Calyx 5-parted. Corolla 5-parted, whecl-shaped, sometimes reflexed-spreading; the lobes convolute in the bud. Crown a small and fleshy wavy-lobed ring in the throat of the corolla. Anthers horizontal, partly hidden under the flattened stigma, opening transversely. Pollen-masses 5 pairs, horizontal. Pods turgid, mostly muricate with soft warty projections, sometimes ribbed. Seeds with a coma. - Twining herbs or shrubs (ours herbaceous), with opposite heartshaped leaves, and corymbose-umbelled greenish or dark purple flowers, on peduncles rising from between the petioles. (Name composed of $\gamma \hat{\omega} \nu o s$, an angle, and $\lambda$ oßós, $a$ por, from the angled or ribbed follicles of some species.)

1. G. làevis, Michx. Nearly glabrous, or the stems and petioles sparingly hirsute and finely puberulent; calyx and corolla glabrous, the latter tapering-conical in the bud, the expanded divisions lanceolate, yellowish-green; pods ribbed, smooth. (Vincetoxicum gonocarpos, Wult. Periploca late-scandens, Clayt. G. macrophyllus, Michx., also Decrisne, excl. syn. Jacq. \& Bot. Mag. G. tiliæfolius, Decuisne.) - River-banks, Virginia, to Illinois and sonthward. July.

2. G. obliquus, R. Br. Stems, petioles and often the ribs of the leaves beneath hirsute with spreading viscid hairs ; culyx and corolla pubescent or puberulent outside, the latter narrow-conical-oblong in the bud, its divisions ligulatolinear or lanceolate, obtuse, dark dull crimson-purple within ; pods copiously muricate, ribless. (Cynánchum obliquum, Jacq., 1786. C. discolor, Sims, Bot. Mag. Gonolobus hirsìtus, Ed. 2, \&c. G. díscolor, R.\& S. G. macrophýllus, Decaisne in part.) - River-banks, Penn. to Virginia. Aug., Sept. - Lobes of the corolla nearly $6^{\prime \prime}$ long. Pod $5^{\prime}$ long.

3. G. hirsutus, Michx. (Apócynum hirsutum, Pluk.: perhaps Períploca Carolinensis, Dill., and P. late-scandens fl. ferrugineo, Clayt.; Vincetoxicum acanthocarpos, Walt. ; and clearly (ynanchum Carolinense, Jacq.) Known from the last by its short-ovate fower-buds, and the oval or oblong divisions of the purple corolla (only about $3^{\prime \prime}$ long); perhaps occurs in S. E. Virginia. 


\section{Períploca, L. Periploca.}

Calyx 5-parted. Corolla 5-parted, wheel-shaped, with 5 awned scales in the throat. Filanents distinct: authers coherent with the apex of the stigma, bearded on the back: pollen-masses 5, each of 4 united, singly aftixed directly to the glands of the stigma. Stigma hemisplericul. Pods smooth, widely divergent. Seeds with a silky tuft. - Twining shrubby plants, with smooth opposite leaves, and panicled-cymose flowers. (Name from $\pi \epsilon \rho \pi \lambda$ ok $\eta$, a coiling round, in allusion to the twining stems.)

1. P. Giries, L. Leaves ovate or ovate-lanceolate, shorter than the looselyflowered eymes; divisions of the brownish-purple corolla linear-oblong, very hairy above. - Near Rochester, \&c., New York. Probably hardly established. Aug. (Adv. fiom Eu.)

\section{OrDLik 81. OLEACAa. (OLIVE Family.)}

Trees or shrubs, with opposite and pinnate or simple leaves, a 4-cleft (or sometimes obsolete) calyx, a regular 4-cleft or nearly or quile 4-petalous corolla, sometimes apetalous; the stamens only 2 (rarely or accidentally 3 or 4); the ovary 2-celled, with 2 (rarely more) ovules in each cell. - Seeds anatropous, with a large straight embryo in hard fleshy afbumen, or without albumen. - The Olive is the type of the true Oleaces, to which belongs the Lilac (Syminga), \&c.; while the Jessamine (Jasminum) represents another division of the order.

Tribe I. OLEINEAs. Fruit a drupe or berry. Flowers perfect or polygamous, with both caly $x$ and corolla; the latter valvate in the bud. Ovules suspended. Leaves simple. mostly entire.

1. Ligustemm. Corolla funnel-form, its tubo longer than the calyx, 4-cleft.

2. Olea. Corolla short, bell-shaped or salver-shaped; the limb 4-parted.

3. Chionanthus. Corulla 4-parted or 4-petalous, the divisions or petals long and linear.

Tribe II. FRAXINEAE. Fruit dry and winged (a samara). Flowers dicecious or polygamous, mostly apetalous, aud sometimes also without a calyx. Ovules suspended. Leaves odd-pinuate.

4. Fraximus. The only genus of the Tribe.

Tribe III. FOR ESTI ER EAE. Fruit a drupe or berry. Flowers dicecious or perfect, apetalous. Ovules suspended. Leaves simple.

5. Foresticra. Flowers diceious, from a scaly catkin-like bud. Stamens 2-4.

\section{I I G Ú S T R M , Tourn. Privet.}

Calyx short-tubular, 4-toothed, deciduous. Corolla funuel-form, 4-lobed; the lobes ovate, obtuse. Stamens 2, on the tube of the corolla, included. Stigrma 2-cleft. Berry spherical, 2-celled, 2-1-seeded. - Shrubs, with entire leaves on short petioles, and small white flowers in terminal thyrsoid panicles. (The classical name.)

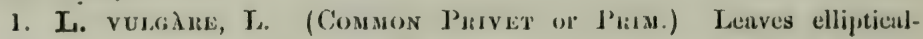
lanceolate, very smooth, thickish, deciduous; berrics black. - Used for low hedges : naturalized in copses by the agency of birds in E. New England and Pennsylvania. Junc. (Nat. from Eu.) 


\section{OेEA, 'Tourn. OLIVE.}

Caly $\mathrm{x}$ short, 4-toothed, rarely entire. Corolla with a short bell-shaped tube and a 4-parted spreading limb. Stamens 2. Jrupe with a bony stone, 2-1seeded. - Shrubs or trees, with opposite and coriaceous mostly entire leaves, and perfect, or (in our species) polygamous or dicecious small white flowers, in panicles or corymbs. ('The classical name of the Olive, O, Eurorisa.)

1. O. Americana, L. (DEviL-woov.) Leaves oblong-lanccolate, smooth and shining $\left(3^{\prime}-6^{\prime}\right.$ long $)$; fruit spherical. - Moist woods, coast of S. Virginia, and soutliward. May. - 'Tree $15^{\circ}-20^{\circ}$ high.

\section{CHIONA N T H U S L, L. Fringe-tree.}

Calyx 4-parted, very small, persistent. Corolla of 4 long and linear petals, which are barely united at the base. Stamens 2 (rarely 3 or 4 ), on the very base of the corolla, very short. Stigma notched. Drupe fleshy, globular, becoming 1-celled, 1-3-secled. - Low trees or shrubs, with deciduous and entire petioled leaves, and delicate flowers in loose and drooping graceful panicles, from lateral

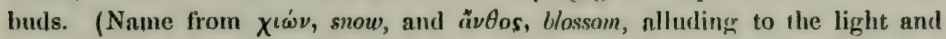
snow-white clusters of flowers.)

1. C. Virgínica, 1, Jeaves oval, ohloung, or ohovato-lanceolnte; flowers on slender pedicels; drupe purple, with n bloom, ovoirl ( $6^{\prime \prime}-8^{\prime \prime}$ long). - Riverbanks, S. Pennsylvania and southward: very ornamental in cultivation. Junc. - Petals 1 ' long, narrowly linear, acute, varying to $5-6$ in number.

\section{F R Á XI N US, Tourn, $\Lambda$ sн.}

Flowers polygamous or (in our species) diœcious. Calyx small and 4-cleft, toothed, or entire, or obsolete, Petals 4, slightly cohering in pairs at the base, or only 2, oblong or linear, or altogether wanting in our species. Stamens 2, sometimes 3 or 4 : anthers linear or oblong, large. Style single: stigma 2-cleft. Fruit a 1-2-celled samara or key-fruit, flattened, winged at the apex, 1-2seeded. Cotyledons elliptical : radicle slender, - Light timber-trees, with petioled pinnate leaves of $3-15$ either toothed or entire leaflets; the small flowers in crowded panicles or racemes from the axils of last year's leaves. (The chrssical Latin name, thought to be derived from $\phi \rho a \dot{\xi} \iota s, a$ separation, from the facility with which the wood splits.)

* Fruit winged from the apex only, barely nargined or quite terete touvurds the base: calyx minute, persistent; corolla none: lenflets stalkert.

1. F. Americana, I. (Wurre Asu.) Branchlets and petioles glabrous; leaflets 7-9, ovate- or lance-oblong, pointed, pale and cither smooth or pubescent underneath, somewhat toothed or entire; fruit terete and marginless bilow, abovo extended into a lemecolate, oblunceslute, or wedye-linear ving. (F. acuminata, and F. juglandifolia, Lrm. F. cpípteri, Michx.) - Rich or moist woods : common. $\Lambda$ pril, May. - $\Lambda$ large forest tree, with gray furrowed bark, smooth gray branchlets, and rusty-colored buds. ('The figure of the fruit in Michaux's Sylva is misplaced, apparently interchanged with that of the Green Ash.)

L \& $\mathrm{M}-37$ 
2. F. pubéscens, Lam. (REv AsH.) Brunchlets and petioles velvety-pubescent; leaflets 7-9, ovate or oblong-lanceolate, taper-pointed, almost entire, pale or more or less pubescent beneath ; fruit acute at the base, fluttish and 2-edycd, the edges gradually dilated into the long $\left(1 \frac{1}{2}^{\prime}-2^{\prime}\right)$ oblunceulate or linear-lanceolate wing. (F. tomentosa, Miclix.) - With No. 1: rare west of the Alleghanies: a smaller tree, less valuable for timber: passes by gradations into the next.

3. F. víridis, Michx. f. (Grees Asu.) Glabrous thionghout ; leaflets 5-9, ovate or oblong-lanceolate, of ten wedge-shaped at the base and serrate above, bright green both sides; finit acule at the buse, striate, 2-edyed or marginal, gradually dilated into an oblanceolate or linear-spatulate wing, much as in No. 2. (F.

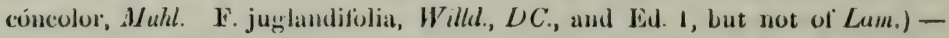
Near streans, New England to Wisconsin and southward; most common westward. - A small or middle-sizcd tree. (The figure of the fruit given in Michaux's Sylva evidently belongs to F. Americana.)

* * Fruit wingsd all round the sced-bearing pention.

- Calyx wanting, ut leust in the fertile jlowers, which are entirely naked!

4. F. sambucifolia, Lam. (Веаск or Water Ash.) Branchlets und petioles glabrous; leaflets $7-11$, sessile, oblong-lanceolate, tapering to a point, serrate, obtuse or rounded at the base, green and suooth both sides, when young with some rusty hairs along the midrib; fruit linear-oblong or nurrowly elliptical, blunt at both ends. - Swanps, Penn. to Kentucky, and everywhere northward. A pril, May. - Small tree; its tongh wood scparable into thin layers, used for cuarse basket-work, \&c. Bruised leaves with the odor of Elder.

++ Culyx prestnt, persistent at the base of the fruit.

5. F. quadrangulàta, Michx. (BLve Asir.) Branchlets square, at least on vigorous shoots, glabrous; leaflets $7-9$, short-stalked, oblong-ovate or lanceolate, pointed, sharply scrrate, green both sides; fiuit narrowly ollong, blunt, and of the same width at buth ends, or slightly narrowed at the base, often notched at the apex ( $1 \frac{1^{\prime}}{2}$ long, $y^{\prime}-\S^{\prime}$ wide). - Dry or moist rich woods, Ohio to Wisconsin, Illinois, and Kentucky. - Tree large, with timber like No. 1.

6. F. platycárpa, Michx. (Canorina Watek-Asu.) Branchlets tercle, glabrous or pubescent; leaflets $5-7$, ovate or oblong, acute at both cnds, shortstalked; fruit broully wingrd (not rarely 3-winged), oblong (9" wide), with a lapering buse. - Wet woods, Virginia and southward. March.

\section{FORESTIERA, Poir. (AvÈL1A, Michx.)}

Flowers dinecious, crowded in catkin-like scaly buds from the axils of last ycar's leaves, imbricated with seales. Corolla none. Calyx early deciduous, of 4 minute sepals. Stamens 2-4: anthers oblong. Ovary ovate, 2-celled, with 2 pendulous ovules in each cell : style slender: stigma somewhat 2-lobed. Drupe suall, ovoid, 1-celled, 1-seeded. - Shruls, with opposite and often fiascicled deciduons leaves and small flowers. Fertile peduncles short, 1-3-flowered. (Named for M. Forestier, a French physician.)

1. F. acuminàta, Poir. Glabrous; leaves thin, oblong-ovate or ovatelanceolate, acuminate at both ends, often serrulate; drupe oblong, usually pointed. - Wet river-bauks, W. Illinois and southward. April. 


\section{Division III. APÉTALOUS EXÓGENOUS PLANTS.}

Corolla none; the floral envelopes in a single series (calyx), or sometimes wanting altogether.

\section{Order 82. ARISTOLOCIIÁCEA. (Birthivort Family.)}

Twining shrubs, or low herbs, with perfect flowers, the conspicuons lurid culyx valvate in the bud and coherent (at least at the base) with the 6-celled ovary, which forms a many-seeded 6-celled pod or berry in fruit. Slamens 6-12, more or less united with the style: anthers adnate, extrorse. - Leaves petioled, mostly heart-shaped and entire. Seeds anatropous, with a large fleshy rhaphe, and a minute embryo in fleshy albumen. A small family of bitter-tonic or stimulant, sometimes aromatic plants.

\section{1. Ás A R U M, Tourn. Asaramaces. Wim Ginarí.}

Calyx regular; the limb 3-cleft or parted. Stamens 12, with more or less distinct filaments, their tips usually continned beyond the anther into a point. Pod rather fleshy, globular, bursting irregularly. Sceds large, thick. - Stemless herbs, with aromatic-pungent creeping rootstocks, bearing 2 or 3 scales, then one or two kidney-shaped or heart-shaped leaves on long petioles, and terminated by a short-peduncled flower, close to the ground; in spring. (An anciunt name, of obscure derivation.)

\$ 1. Calyx-tube wholly coherent with the ovury, the tips inflexed in bud: filaments slender, united only with the buse of the style, much longer than the short anthers: styles united into one, which is barely 6-lobed at the summit, and with 6 radiating thick stigmas: leaves unspotted, a single pair, with the peduncle between them.

1. A. Canadénse, L. Soft-pubescent; leaves membranaceous, kidneyshaped, more or less pointed $\left(4^{\prime}-5^{\prime}\right.$ wide when full grown); calyx bell-shaped, with the npper part of the short-pointed lobes widely and abruptly spreading, brown-purple inside; nt each sinus is usually a small awl-shaped appendago (abortive petal). - Hillsides in rich woods : common, especially northward.

§ 2. Calyx-tube inflated bell-shaped, somewhat contracted at the throat, only its base coherent with the lower half of the ovary; the limb 3-cleft, short: filuments very short or none: anthers oblong-linear: styles 6, fleshy, diverging, 2-cleft, euch bearing a thick extrorse stigmu below the clef : lenves thickish, persistent, usually only one each year, the upper surfuce often whitish-mottled: peduncle very short: rootstocks clustered, ascending.

2. A. Virgínicum, L. Nearly glabrous; leaves ront-heart-shaped (about 2' wide); calyx short, reticulated within; anthers pointless. - Virginia, and southward, in and near the mountains.

3. A. arifolium, Michx. Letres halherel-heurt-shaped $\left(2^{\prime}-4^{\prime}\right.$ long); calyx oblong-tubular, with very short and blunt lobes; anthers ubtusely short-pointed. Virginia and southward. 


\section{ARISTOLÒCHIA, Tourn. Bintuwort.}

Calyx tubular; the tube variously inflated above the ovary, mostly contracted at the throat. Stamens 6 ; the sessile anthers wholly adnate to the back of the short and fleshy 3-6-loled or angled stigma. Pod naked, 6-valved. Seeds very flat. - Twining, climbing, or sometimes upright perennial herbs or shrubs, with alternate leaves and lateral or axillary greenish or lurid-purple flowers. (Named from reputed medicinal propertics.)

\$1. Calyx-tube bent like the letter $S$, enlarged at the two ends, the small limb obtusely 3-lobed: anthers contiguous in pairs (making 4 cells in a row under each of the three truncate lubes of the stigma): low herbs.

1. A. Serpentària, L. (Virginia Snakeroot.) Stems $\left(8^{\prime}-15^{\prime}\right.$ high) branched at the base, pubescent; leaves ovate or oblong from a heart-shaped base, or halberd-form, mostly acute or pointed; flowers all next the root, shortpeduncled. - A narrow-leaved variety is A. sagittàta, Muhl., A. hastata, Nutt., \&c. - Rich woods, Connecticut to Indiana and southward : not common except near the Alleghany Mountains. July. - The fibrous, aromatic-stimulant root is well known in medicine.

\$2. Calyx-tube strongly curved like a Dutch pipe, contracted at the mouth, the short limb obscurely 3-lobed: anthers contiguous in pairs under each of the 3 short and thick lobes of the stigma: twining shrubs: flowcrs from one or two of the superposed accessory axillary buds.

2. A. Sipho, L'Her. ('Pine-Vine. Dutchian's Pipe.) Nearly glabrous; leaves round-kidney-shaped; peduncles with a clasping bract; calyx ( $1 \frac{1}{2}$ ' long) with a brown-purple abrupt flat border. - Rich woods, Penn. to Kentucky, and southward, along the mountains. May. - Stems sometimes $2^{\prime}$ in diameter, climbing trees : full-grown leaves $8^{\prime}-12^{\prime}$ broad.

3. A. tomentòsa, Sims. Downy or sofi-hairy; leaves round-heart-shaped, very veiny $\left(3^{\prime}-5^{\prime}\right.$ long $)$; caly $x$ yellowish, with an oblique dark purple closed orifice and a ruyose reflexed limb. - Rich woods, from S. Illinois southward. June.

\section{OHDER 83. NYCHATNACEAL. (FOUR-O'CLOCK FAMLY.)}

Herts (or in the tropics often shrubs or trees), with mostly opposite and entire leaves, stems tumid at the joints, a delicate tulular or funnel-form calyx which is colored like a corolla, its persistent base constricted above the 1-celled 1-seeded ovary, and indurated into a sort of nut-like pericurp; the stamens few, slender, and hypogynous; the embryo coiled around the outside of mealy albumen, with lroud foliaceous colylerlons. - Represented in our gardens by the Four-o'Clock, or Marvel of P'enu (Mníbilis JALÁPA), in which the caly $x$ is commonly mistaken for a corolla, the cuplike involucre of each flower exactly imitating a calyx; - and by a single

\section{OXÝ B A PH U S, Vahl. OxצвÁpHus.}

Flowers $1-5$ in the same 5-lobed membranaceous broad and open involucre, which enlarges and is thin and retienlated in fruit. Calyx with a very short 
tube and a bell-shaped (rose or purple) deciduous limb, plaited in the bud Stamens mostly 3. Style filiform : stigma capitate. Fruit achenium-like, several-ribbed or angled. - Herbs, nbonnding on the western plains, with very large and thick perennial roots, opposite leaves, und mostly clustered small flow-

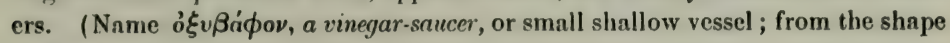
of the mvolucre.)

1. O. nyctagíneus, Sweet. Nearly smooth; stem repeatedly forked $\left(1^{\circ}-3^{\circ}\right.$ high $)$; leaves varying from ovate, or somewhat heart-shaped to laneeolate; involucres 3-5-flowered. - Rocky places, from Wisconsin and Illinois southward and westward. Jume-Aug.

\section{Order 84. PIIYTOLACCACEA. (Pokeweed Family.)}

Plants with alternate entire leaves and perfect flowers, having the general characters of Chenopodiaceæ, but usually a several-celled ovary composed of as many carpels united in a ring, and forming a berry in fruit; - represented only by the typical genus

\section{PHY TOLÁ CCA, Tourn. Poreweed.}

Calyx of 5 rounded and petal-like sepals. Stamens 5-30. Ovary of 5-12 carpels, united in a ring, with as many short separate styles, in fruit forming a depressed-globose 5-12-celled berry, with a single vertical seed in each cell. Embryo curved in a ring around the albumen. - Tall and stout perennials, with large petioled leaves, and terminal racemes which become lateral and op-

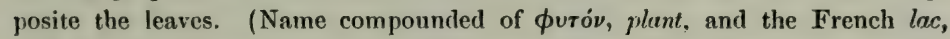
lake, in allusion to the crimson coloring matter resembling that pigment which the berries yield.)

1. P. decándra, t. (Common Poke or Scoke. Garget. PigeonBerny.) Stamens 10: styles 10. - Low grounds. July-Sept. - A smooth plant, with a rather unpleasant odor, and a very large poisonous root, often $4^{\prime}-6^{\prime}$ in diameter, sending up stout stalks (which are in early spring sometimes caten as a substitute for Asparagus), at length $6^{\circ}-9^{\circ}$ high. Calyx white: ovary green ; the long racemes of dark-purple berries filled with crimson juice, ripe in autumn.

\section{Order 85. Chenopodiàcea. (Goosefoot Family.)}

Chiefly herbs, of homely aspect, more or less succulent, with mostly alternnie leaves, and no stipules nor scarious bracts, minute greenish flowers, with the free calyx imbricated in the bud; the stamens as many as its lobes, or occasionally fewer, and inserted opposite them or on their base; the 1-celled ovary becoming a 1-seeded thin utricle or rarely an achenium. Embryo coiled intn a ring around the mealy albumen, when there is any, or else conduplicate, or spiral. - Calyx persistent, mostly enclosing the fruit. Styles or stigmas 2, rarely 3-5. (Mostly inert or innocent, weedy plants : several are pot-herbs, such as Spinach and Beet.) 
- Èmbryo coiled into a ring around copious central albumen. Leaves flat, not apiny nor fleshy.

- Flowers all alike and perfect, or merely polygamous by the want of stamens in some of them, clustered or panicled. Calyx obvious. Seed-coat crustaceous.

1. Cycloloma. Calyx 5-cleft, in fruit surrouuded by a horizontal continuous membranaceous wing. Seed horizontal.

2. Chenopodium. Calyx 3-5-cleft or parted, the lubes naked or merely keeled in fruit. Seed hurizintal, rarely vertical.

3. H1itum. Calyx of 3-6 sepals, mostly juicy or fleshy in fruit. Seed vertical.

- Flowers monoecious or dicecious, and of 2 distinct sorts; the staminate with a regular caly $x$, clustireal. the clusters mustly spiked.

4. A triplex. Fertile fluwery without calyx, enclused between a pair of appressed bracts.

+ + Flowers all perfect and alike, single in the axil of bracts, naked or 1-sepalled.

6. Corispermum. Fruil oval, liattened : pericarp adherent to the seed. Leaves linear.

* Embryo narrowly horseshoe-shaped or conduplicate : no albunen. Stem fleshy, jointed: leaves reduced to oppusite fleshy scales or teeth. Flowers deusely spiked, perfect.

6. Salfcornia. Fluvers sunk in hullows of the axis of the fleshy spike. Calyx utricle-like.

** Embryo coiled into a spiral : albumen mostly none. (Leaves alteruate.)

7. Sureda. Embryo flat-spiral. Calyx wingless. Leaves succulent.

8. Salsola. Eubryo conical-spital. Caly $x$ in fruit hurizoutally winged. Leaves gpinescent.

\section{Cyclolò Ma, Muquin. Wingled pigiwed.}

Flowers perfect, bractless. Calyx 5-cleft, with the concave lobes strongly keeled, enclosing the depressed fruit, at length appendaged with a broad and continuous horizontal scurious wing. Stamens 5. Styles 3. Seed horizontal, flat. Embryo encircling the mealy albumen. - An anual and much-branched coarse herb, with alternate sinuate-toothed petioled leaves, and small panicled

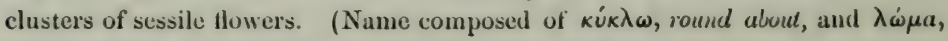
a border, from the encireling wing of the calyx in fruit.)

1. C. platyphýllum, Moquin. (Salsola platyphylla, Michx.) - Illinois. on sandy banks of the Mississippi, and northwestward.

\section{CHEN O P Ò D I U M, L. Goosefoot. Pigweed.}

Flowers perfect, all bractless. Calyx 5-cleft, rarely 2-4-cleft or parted, with the lobes sometimes keeled, but not appendaged nor becoming sueculent, more or less enveloping the depressed fruit. Stamens mostly 5 : filaneuts filiform. Styles 2, rarely 3. Seed horizontal (sometimes vertical in Nos. 3,7-9), lenticular; the coat crustaceous : cmbryo coiled partly or fully round the mealy albunen. - IVeeds, usually with a white mealiness, or glindular. Flowers sessile in small clusters collected in spiked panicles. (Named from $\chi \dot{\eta} v, a$ goose, and $\pi$ ous, fout, in allusion to the shape of the leaves.) - Our species are all annuals (except the last two), flowering through late summer and autumn, growing around dwellings, in mauned soil. cultivated grounds, and waste places.

§1. Smooth or menly, never glandulur nor sucet-scented: embryo a complete ring.

1. C. polvsímum, L. Low, often spreading, green and wholly destitule of menliness throughout: leates all entire, ollong or ovate and on slender petioles; flowers very small, the thin lobes of the calyx very incompletely enclosing the fruit; seed obtusc-edged. - In and around Buston : scarce. (Aiv. from Eu.) 


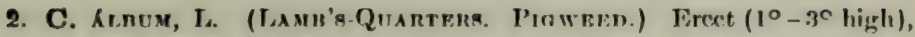
mealy und pale, sometimes green and the mealiness obscure; lenves varying fiom rhombic-ourite to lanceolate or the uppermost even linear, acute, all or only the lower more or less anqulute-tonthed; clusters spiked-panicled, mostly dense; seed with acute or bluntish margins. - Common, especially in cult. ground: extremely variable. - The genuine C. album is considerahly whitish-mealy, at least the inflorescence, which is dense; the caly $\mathrm{x}$ with strongly kecled lobes, and completely enclosing the fruit. A green form with somewhat entire leaves and less dense inflorescence is C. víride, $L$. (Nat. from Eu.)

Var. Bosciגsum. Loosely branched, more slender, the mealiness obscure or slight and only on the inflorescence, which is laxer, the flowers smaller; calyx incompletely covering the fruit. its lobes moderately or slightly if at all kecled; lesves inclined to be entire. (C. Boscianum, Moquin. C. Berlandièri, Moquin, „n intermediate form. C. polyspermum, var. spicatum, Ed. 2.)-More shady places, Pennsylvania and sonthward. In some forms appears as if a distinct speries; seemingly indigenous southwestwarl.

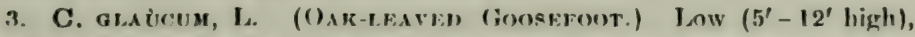
sprending, glaucous-mealy, leaves simutely pinmirifid-twothed, oblong, obtuse, pale green above; clusters spiked, small; calyx-lohes not at all keeled; seed sharpenlyed, often vertical. - Streets of towns: rather scarce. Brackish borders of Onondaga Iake. (Nat. from Eu.)

4. C. Únвicum, L. Rather pale or dull green, nearly destitute of mealiness, with erect branches $\left(1^{\circ}-3^{\circ}\right.$ high); leaves triangular, acute, caarsely and sharply many-toothed; spikes erect, crowded in a long and namow racemose, ranicle:

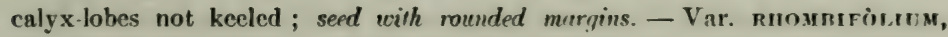
Moquin (C. rhombifolium, Muhl.), is a form with the leaves more or less wedgeshaped at the base, and with longer and sharper teeth. - Not rare eastward. (Nat. from Eu.)

5. C. MURALe, L. Resembles No. 4, but. Iess ereet, loosely hranched $\left(1^{\circ}-1 f^{\circ}\right.$ high) ; leaves rhombnid-ovate, acute, corrsely and shurply unequilly tontherl, thin, bright green ; spikes or rucemes diverging, somerchat corymbed ; caly $\mathrm{x}$-lobes scarcely kecled; sced sharp-edged. - Boston to Illinois : rare. (Adv. from Eu.)

6. C. IÝBRIDUM, L. (MATLe-teafen Goosfarot.) Bright green thmughout; stem widely much branched $\left(2^{\circ}-4^{\circ}\right.$ high $)$; loceses thin $\left(2^{\prime}-8^{\prime}\right.$ long), somewhat triangular and heart-shaped, taper-pointed, simuatr-angled, the angles extended into a few large and pointed testh; racemes diffusely and loosely panicled, leafless; caly $x$ not fully covering the fruit, its lohes kecled; seed sherpedped, the thin pericarp adhering closely to it. - Common. Heavy-scented, like Stramonium. (Nat. from Eu.)

§ 2. BOTRỲOIS, Moquin. (AмrRrsa, Moquin, in part.) Not mealy, hut more or less viscid-glandular and pleasant-nromatic: seed frequently vertical, obtuse-edged: embryo forming only two thirds or three quarters of a ring.

7. C. Bòtrys, L. (Jerusalem Oax. Featier Geranivm.) Glaniular-pubescent and viscid; leaves slender-petioled, oblong, obtuse, sinuate pinnatifid; racemes cymose-diverging, loose, lenfless; fruit not perfectly enclosed.Escaped from gardens. (Adv. from Eu.) 
8. C. ambrosioides, L. (Mexican Tea.) Smouthish; leaves slightly petioled, oblong or lanceolate, repand-toothed or nearly entire, the upper tapering to both ends; spikes densely fluwered, leafy, or intermixed with leaves; fruit perfectly enclosed in the calyx. - Waste places : common, especially southward. (Nat. from Trop. Amer.) - L'asses into

Var. antheláfticum. (Wormseed.) Root perennial (?); leaves inore strongly twothed, the lower sonctimes almost laciniate-pinnatifid; spikes mostly leafless. (C. anthelmínticum, L.) - Common in waste places southward. (Nat. from 'Trop. Amer.)

- 9. C. multrinum, L. Glandular-puberulent, diflusely branched; leaves once or twice pinnutifid, pale; flowers small in axillary clusters; culyx only 5 . cleft, coinpressed and completely closed over the ylandulur-douted utricle; seed always vertical. (Roubièva multitida, Mloquin, \& Ed. 2.) - W Waste places, City of New York (the station now secuningly extinct), and Philadelphia. Introduced in ballast from South America, not permanently estublished.

\section{BLIT TM, Tourn. Blits.}

Flowers perfect, bractless. Caly 3 3-5-parted, becoming fleshy or berry-like in fruit; the genus also mate to include some with calyx unchanged in fruit. Stamens 1-5: filaments filiform. Styles or stignas 2. Seed vertical, compressed-globular; the embryo coiled into a ring quite around the albumen. Herbs, with petioled triangular or halberd-shaped and mostly sinuate-toothed leaves. (The ancient Greek and Latin name of some insipid pot-herb.)

§1. MOROCÁRPUS, Munch. Glıbrous annuals or biennials, not menly: flowers in axillury heads, the upper ones oflen spiked: calyx in fruit commonly becoming fleshy or berry-like, neurly enclosing the utricle.

1. B. marítimum, Nutt. (COAst ButтE.) Stem angled, much branched; leaves thickish, triangular-lanceolate, tapering below into a wedge-shaped base and above into a slender point, sparingly and coarsely toothed, the upper linearlanceolate; chusters sculteral in axillary lenfy spikes; calyx-lobes 2-4, rather fleshy; stamen 1 ; seed shining, the margin acute. - Salt marshes, New Jersey to Massachusetts: salt springs, at Syracuse, New York (G. W. Clinton), and northwestward. Probably a variety of B. rubrum of Eu.

2. B. capitàtum, L. (Strawberky Blite.) Stem ascending, branching; leaves triangular and somewhat halberd shaped, sinuate toothed; clusters simple (large), interruptedly spiked, the upper leafless; stumens 1 -5 ; calyx betrylike in fiuit; seed ovoid, flattish, smooth, with a very narrow margin. - I)ry rich ground, common from IV. New York to Lake Superior, and northward. June. - The calyx becomes pulpy and bright red in fruit, when the large clusters look like Strawberries. (Eu.)

§ 2. AGATHÓPHYT'ON, Moquin. Someuhat mealy: root perennial: flowers in clusters crowded in a terminal spike: culy.x not fleshy, shorter than the halfnaked fiuit. Internediate between Blitum and Chenopodium.

3. B. Bonus-Hinkicus, Reichenbach. (Goon-King-Henry.) Leares triangular-halherd-form; stamens 5. (Chenopodium Bonns-Henricus, L.) Aruund dwellings: scarce. (Adv. from Liu.) 


\section{4. ÁTRIPLEX, Tourn. Orache.}

Flowers moncecious or diccious; the staminate like the flowers of Chenopodium, only sterile by the abortion of the pistil; the fertile flowers consisting simply of a naked pistil enclosed between a pair of appressed foliaceous (ovate or halberd-shaped) bracts, which are enlarged in fruit, and sometimes united. Seed vertical. Embryo coiled into a ring around the albumen. In one section, to which the Garden Orache belongs, there are also some fertile flowers with a calyx, like those of Chenopodium, but without stamens, and with horizontal seeds. - Herbs usually mealy or scurfy with bran-like scales, with triangular or halberd-shaped angled leaves, and spiked-clustered flowers; in summer and autunn. ('The ancient Latin name, of obscure meaning.)

1. A. pátula, L. Lrect or diffusely spreading, amnual, scurfy, green or rather houry, branching; leaves alternate or partly opposite, petioled, varying from triangular and halberd-form to lance-linear; fruiting bracts ovate-triangular or rhombic, entire or 1-2-toothed below, united to near the middle, their flat faces either even or sparingly warty-muricate; ralicle inferior or somewhat ascending. - The two extreme forms are, Var. илsтіти (A. hastata, L.), with the leaves nearly all triangular-halberd-shaped, entire or sparingly toothed. - Var. nitrordes (A. littoralis, L.), with lanceolate or linear mostly entiro leaves. - Salt marshes, bruckish river-banks, \&e., Virginia to Maine, and sparingly on the Great Lakes, and northward. The plant on the shore is more scurfy and hoary ; more inland, sometimes far from saline soil, it is greener and thinner-leaved. (Eu.)

2. A. arenària, Nutt. Silvery-mealy annual, diffusely spreading; leaves oblong, narrowed at the basc, nearly sessile; fruiting bracts broadly wedgeshaped, united, 2-3-toothed at the summit, and with a few prickly points on the sides; radicle superior. (Obìne arenaria, Moquin, \& Ed. 2.)-Sandy beaches, Massachusetts to Virginia and southward.

\section{COR I S P É R U M, Ant. Juss. Bug-seed.}

Flowers perfect, single and sessile in the axil of the npper leaves reduced to bracts, usunlly forming $n$ spike. Calyx of $n$ single deliente sepal on the inner side. Stamens 1 or 2 , rarely 5 . Styles 2. Fruit oval, flat, with the outer fince rather convex and the inner concave, sharp-margined, a ca,yopsis, i. e. the thin pericarp adherent to the vertical seed. Embryo slender, coiled around a central albumen. - Low branching annuals, with narrow lincar alternate 1-nerved leaves. (Name formed of kópıs, $a$ bug, and $\sigma \pi \epsilon ́ \rho \mu a$, serd.)

1. C. hyssopifolium, I. Somewhat hairy when young, pale; floral leaves or bracts awl-shaped from a dilated base or the upper ovate and pointed, scarious-margined ; fruit wing-margined. - Sandy beaches of the Great Lakes from Buffalo, a recent immigrant ( $G$. W. Clinton), Chicago (Dr. Scammon, \&c.), to Lake Superior and northwestward. Aug. - Oct. (Eu.)

\section{SALI Có R I A, 'Tourn. Glasswort. Samphire.}

Flowers perfect, 3 together immersed in each holiow of the thickened upper joints, forming a spike; the two lateral sometimes sterile. Calyx small and 
bladder-like, with a touthed or torn margin. at length spongy and narrowly wing-borlered, enclo-ing the tlattened thin utriele. Stamens 1 or 2. Styles 2, united at base. Sced vertical. Embryo thick, conduplicate : no albumen. Low saline plants, with succulcnt leafless jointed stems, and opposite branches; the flower-bcaring branclilets forming the spikes. (Name composed of sal, salt, and covnu, a loru; saline plants with horn-like branclics.)

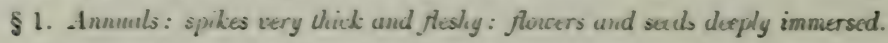

1. S. herbacea, L. Erext or at leugth sprcading $\left(6^{\prime}-12^{\prime}\right.$ high), grcen; scules docure und very lewh, wahing a truncate bardy cmarginate terminurion of the juints of stem or elongated spike; middle flower much higher than the lateral ones; sced oval or ullong. - Salt marshes of the coast and interior salt springs. Aug.-Oet. (Eu.)

2. S. Virgínica, I. (fl. Clayt.) Eroet, less branched, nahed beluw $\left(2^{\prime}-9^{\prime}\right.$ high). twiting rad in age; spske shurter and thicker; seules wucronutepoinded and conspicuous, espexially when dry; middle fluwer litde higher than

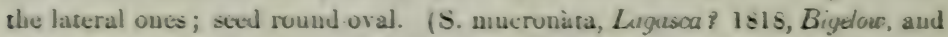
Ed. 2.) - Salt marshes, cuabt of Virginia to Maine. Sept., Oct. (Eu. ?)

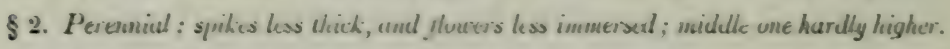

3. S. fruticosa, L., var. ambigua. (S. ambigua, Michr.) Numerous tufted stems $\left(3^{\prime}-12^{\prime}\right.$ long $)$ decumbent or ascending from a hard and rather woody creeping base or routstock, greenish, turning lead-colored; the cylindrical joints rather strongly notched at the end; scoul round-oval. - Sandy wet beaches, \&c., Massachusetts to Virginia and suuthward. Aug. - Oct. (Eu.)

\section{SU 宏DA, Forskal. Sea Blite.}

Flowers jerfoct, sulitary or elusterel in the axils of the leaves. Calys 5 -

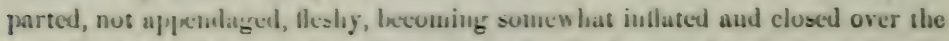
fruit (utricle). Stamens 5. Stignas 2 or 3. Secd vertical or horizontal, with a flat-spiral embryo, dividing the scanty albumen (when there is any) into 2 jortions. - Fleshy maricime glants, wish altcruate nealy terete linear leaves. (An Arabic name.) Cinsoronss, Muquin was founterl for those syecies, like ours, which have horizontal sects, - a wholly insufticient and inconstant ditierence.

1. S. marítima, Dumortier. Annual, smooth, diffusely much branched; leaves slender (1'lung), acute; caly $x$-lobes keeled; stigmas 2 ; seed horizuntal. (Chenopodina marítima, Moquin.) - Salt marshes of the sea-shure, and on the northwest plains. Aug. (Eu.)

\section{SALSÒLA, L. Saltwort.}

Flowers perfict, with 2 bractlets. Calyx 5-parted, persistent and enclosing the depressed fruit in its base; its divisions at length horizuntally winged on the lack, the wings forming a broad and circular scariuns lorder. Stancus mostly 5. Styles 2. Secd horizuntal, withumt allomen, filled ly the enbryo, which is coiled in a conical spiral (cochleate). - Herbs, or slightly slurubby branching flants of the sea-shore, with fleshy and rather terete or awl-shaped leaves, and 
sessile axillary flowers. (Name from sal, salt; in allusion to the alkaline salts these plants copiously contain.)

1. S. Kàli, L. (СоммоN SAтtwort.) Annual, diffusely branching, bushy, rongh or smoothish; leaves all alternate, awl-shaped, prickly-pointed; flowers single; caly $\mathrm{x}$ with the converging lobes forming a sort of beak over the fruit, the large rose or flesh-colored wings nearly orbicular and spreading. Sandy sea-shore: common. Aug. (Eu.)

\section{Order 86. AMARANTACEBE. (AMARANTH Family.)}

Weedy herbs, with nearly the characters of the last family, but the flowers mostly imbricated with dry and scarious persistent bracts; these often colored, commonly 3 in number; the one-celled ovary sometimes many-ovuled. (The greater part of the order tropical, but several have found their way northward as weerls.)

- Anthers 2 celled : Alamenta sepurate. Ovule nud secel sellenry.

1. Amarnutus. Flowers monocious or polygamous, all with a calyx of 3 or 5 distinct erect sepals, not falling of with the fruit.

2. Montella. Flowers dicecious. Caly $x$ none in fertile flowers. Utricle thin, circumcissile.

3. Acnlda. Flowers diøecious. Fruit fieshy, indehiscent, 3-5-angled.

* Anthers 1-cellerl. Ovule and seed solitary.

4. Iresine. Calyx of 5 sepals. Filaments unitel below into a cup.

5. Frollchla. Caly $\mathrm{x}$ 5-cleft at the apex. Filaments uniter throughout into a tube.

\section{A M A RÁ N T US, Tourn. AMARANTh.}

Flowers moncecious or polygamous, 3-bracted. Calyx of 5, or sometimes 3, equal erect sepals, glabrous. Stamens 5 , rarely 2 or 3 , separate : anthers 2 celled. Stigmas 2 or 3 . Fruit an ovoid 1 -seeded utricle, 2-3-benked at the apex, mostly longer than the calyx, opening transversely or sometimes bursting irregularly. Embryo coiled into a ring around the albumen. - Annual weeds, of coarse aspect, with alternate and entire petioled leaves, and small green or purplish flowers in axillary or terminal spiked clusters; in late summer and autumn. ('A rápavtos, unfuding, because the dry ealyx nnd hruets do not wither. The liomans, like the (ireeks, wrote $\Lambda$ inarantus, which the carly botanists incorrectly altered to Amaranthus.)

\$1. Utricle thin, circuncissile, the top fulling anory as a lid: Anvers polygamous. * Flowers in terminal and axillary simple or mostly panicled spikes: stem erect $\left(1^{\circ}-6^{\circ}\right.$ high $)$ : leaves long-petioled: stamens and sepals 5.

- Red Amaraxtis. Flowers and often lenes tinged with crimson or purple.

1. A. mypochondrticus, I. Smonth or smoothish; leaves oblong-lanceolate, acute or pointed; spikrs very obfuse, thick, croweled, the terminal one elongated and interrupted; bracts long-awned; fruit 2-3-cleft at the apex, longer than the calyx. - Rarely spontaneons around gardens. (Virginia, ex $L$. ; but doubtless adv. from Trop. Amer.)

2. A. PAxicdidus, I. Stem mostly pubescent; leaves oblong-ovate or ovate-lanceolate; spikes numrrous and slender, panicled, erect or spreading; bracts awn-pointel ; frait 2-3-toothed at the apex, longer than the calyx. - Flowers 
small, green, tinged with red, or sometimes crimson as in A. caudatus, $L$, the Prince's Featien of the gardens. (A. sanguíneus, L.) - In gardens, \&c. (Adv. from Trop. Amer.)

\section{— - Green Amarantis, Pigweed. Flowers green, rardy a little reddish.}

3. A. Retrofléxus, L. Roughish and pubescent, or smoothish; leaves dull green, long-petioled, ovate or rhombic-ovate, undulate; spikes crowded in a stiff or glomerate panicle; bracts awn-pointed, rigid, exceeding the calyx. - Var. culoróstacirys (A. chlorostachys, Willd.) is smoother, with bighter green leaves and less thick and croviled spikes, apparently passing into var. HÝBRIDUs (A. hybridus, L.), which is smooth and more loosely panicled, - perhaps not in our district. - Cultivated and manured soil, gardens, \&c. Probably indigenous southwestward. (Adv. firom Trop. Amer.?)

* * Flower's croudul in cluse and small axillary clusters: stems low, spreading or ascendiny: stamens and sepals 3, or the former only 2.

4. A. Álbus, L. Sinooth, pate green; slems whitish, mostly spreading next the ground; leaves long-petioled, obovate and spatulate-oblong, very obtuse or retuse; flowers greenish; sepals mucronate, half the length of the rugose fruit, much shorter than the rigid pungently pointed bracts. - Waste grounds, near towns, and roadsides: common. (Nat. from 'Trop. Amer.?)

§. Utricle thinnish, burstiny or innerfectly circuncissile: flowers monacious.

5. A. spinòsus, L. ('Thokiny Amarantu.) Smooth, bushy-branched; stem reddish; leaves rhombic-ovate or ovate-lanceolate, dull green, a pair of spines in their axils; upper clusters sterile, forming long and slender spikes; the fertile globular and mostly in the axils; flowers yellowish-green, small. Waste grounds, Peunsylvania, Ohio, and southward. (Nat. from Trop. Amer.)

§ 3. EÙXOLUS, Raf. Utricle rather fleshy, remaining closed or lusting irregularly: no spines: bructs inconspicuous.

6. A. Lfvidus, L. Simooth, somewhat succulent, much branched $\left(1^{\circ}-3^{\circ}\right.$ high) ; leaves livid-purplish, long-petioled, ovate or oval ; flower-clusters greenish, sessile in the axils and crowded in a terminal interrujted spike; stamens 3 ; sepels mostly 3, rather shorter than the ovate smoothish firuit. (Eùxolus lividus, Raf.) - Coast of Virginia, Clayton. Probably an introduced species, and to include $A$. oleraceus, $L$., and the next.

7. A. pùmilus, Raf. Low or prostrate; leaves roore fleshy and obovate, emarginate, the ribs stouter and transverse; flower-elusters small and axillary; stamens and sepals 5, the latter half the length of the obscurely 5-ribbed fruit: probably a maritime form of the preceding. (Euxolus pumilus, Raf.) - Sandy beaches, Rhode Island to Virginia and southward.

8. A. vfridis, L. Sinooth or minutely pubescent, spreading or ascending $\left(6^{\prime}-18^{\prime}\right.$ high $)$; leaves pale green, ovate or ovate-oblong, long-petioled; flowers much smaller than in the preceding, in axillary clusters and usually also in a terminal spike; sepuls und stumens :3, the latter thin, shorter than the small globose-ovate roughish fruit. (Euxolus deflexus, Ed. 2 ; but that has a larger and more elongated smooth 3-nerved utricle.) - Streets of Albany, New York: depauperate form with the terminal spike undeveloped. (Adv. from Ku.) 


\section{MONTELIA, Moquin (under ACNIDA).}

Flowers dinecious, 2-3-bracted. Staminate flowers of 5 thin oblong and mucronate-tipped sepals, longer than the bracts, and ns many stamens with oblong anthers; the cells of the latter united only at the middle. Pistillate flowers without any calyx, their lanceolate awl-pointed bracts longer than the 1-ovuled ovary : stigmas 2-4, very long, bristle-awl-shaped, plumosc-hispid. Fruit a thin and membranaceous globular utricle, smooth and even, opening transversely around the middle; the upper part falling off like a lid. Radicle of the annular embryo inferior. - An annual glabrous herb, mostly tall, with lanceolate or oblong-ovate alternate leaves, on long petioles, and small clusters of greenish flowers, usually crowiled into clongated and panicled interrupted spikes. (Probably a personal name.)

1. M. tamarfscina. (Amarantus tamariscinus, Nutt. A. altissimus \& Miamensis, Riddlll. Acnida nltissima, Mirhr. herb. A. rusocarpa, Mromin, \&c.) - Iow grounde und moist samily shores, Vermont to Wisconsin, Illinois, nnd southward, especially westward. Aug., Sept. - Var. Conchtendta is a form with the lower clusters in the fertile plant forming thickish distant heads $\left(5^{\prime \prime}-6\right.$ " in diameter) in the axils of the leaves; the stems often low and sprending or decumbent. $-\Lambda$ very variable plant, as 10 inflorescence, height $\left(1^{\circ}-6^{\circ}\right.$ hign $)$, the size and shape of the leaves $\left(1^{\prime}-5^{\prime}\right.$ long, the petioles often of the same length), the bracts more or less awl-shaped, cqualling or exceeding the fruit (which is that of Amarantus): but all are forms of one species. The sterile plant is Acnida rusocarpa, Mich.x., or was mixed with it in Michaux's coliection, but the fruit is neither obtuse-angled, rugose, nor indehiscent. That n\&me is unmeaning, perhaps a misprint of ruscocarpa.

\section{A C I İ D A, L. Water-IIEmr.}

Fruit a fleshy and indehiscent ntricle, 3-5-anglel, the angles often rugane or tubereled-crested. Stigmas 3-5, shorter than the ovary, linear-awl-shnped. Flowers in rather loose panicled spikes. Otherwise as in the preceding genus. (Name formed of a privative and $\kappa \nu i \delta \eta, a$ nettle.)

1. A. cannábina, L. Annual, tall $\left(2^{\circ}-6^{\circ}\right.$ high); leaves elongated-lan-

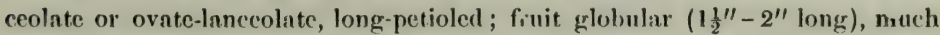
exceeding the pointless bracts. - Salt marshes on the coast; Massachusetts to Virginia and southward. Aug. - Oct. - Probably the only species; for A. rusocarpa, Michx., is certainly to be divided between this and Montelia tamariscina ; and A. tuberculata, Moquin, must be one or the other.

\section{I R E S İ N E, P. Browne. Iresine.}

Flowers mostly polygamons or dinecious, 3-bracted. Calyx of 5 sepals. Stamens mostly 5 : filaments slender, united into a short cup at the base : anthers 1-celled, ovate. Fruit a globular utricle, not opening. - Herbs, with opposite petioled leaves, and minute scarions-white flowers, crowded into clusters or spiked and branching panicles; the calyx, \&c. often bearing long wool (whence the

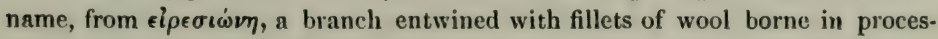
sions at festivals.) 
1. I. celosioldes, L. Nearly glabrous annual, ereet, slender $\left(2^{\circ}-4^{\circ}\right.$ high); leaves ovate-lanceolate; panicles narrow, naked; bracts and calyx silvery-white, the latter woolly at the base. - Dry banks, Ohio to Illinois and southward. Sept.

\section{FRCE LÍ C H I A, Mœnch. (OpLotiècA, Nutt.)}

Flowers perfect, 3-bracted. Calyx tubular, 5-cleft at the summit, below 2-5crested Jengthwise, or tubercled and indurated in fruit, enclosing the indehisent thin utricle. Filanents united into a tube, bearing 5 oblong 1 -celled anthers, and as many sterile strap-shaped appendages. - IIairy or woolly herbs, with opposite sessile leaves, and spiked scarious-bracted flowers. (Naned for J. A. Frölich, a German botanist of the last century.)

1. F. Floridàna, Moquin. Root annual; stem leafless above $\left(1^{\circ}-2^{\circ}\right.$ high); leaves lanceolate, silky-downy beneath; spikelets crowded into an interrupted spike; calyx very woolly. - Illinois, and southward. Aug.

\section{Ordir 87. POLYGonaceza. (Вuckwhedt Fami.y.)}

IIerbs, with alternate leaves, and stipules in the form of sheaths (ochrex, these sometimes obsulete) above the swollen joints of the stem; the flowers mostly perfect, with a more or less persistent culyx, a 1-celled ovary bearing 2 or 3 styles or stigmas, and a single erect orthotropous sect. Eubryo curved or straightish, on the outside of the albumen, or rarely in its centre; the radicle pointing from the hilum and to the apex of the dry seed-like fruit. Stamens $4-12$, inserted on the base of the $3-6$-cleft calyx. Leaves usually entire. (The watery juice often acrid, sometimes agreeably acid, as in Sorrel; the roots, as in Rhubarb, sometimes cathartic.) - West of the Mississippi are a great number of Erıogonke, having their flowers surrounded by an involucre. Our few genera are all of the true I'olygonacex, except the anomalous Brumnichia.

* Stipular slieaths (ochrece) manifest. Ovule erect from the base of the cell.

- Sepals 5, sometimes 4, scmewhat equal and erect in fruit.

1. Polуgомим. Enibryo curvert around one side of the albumen: cutyledons narrow.

2. Fagopyrum. Lubryo in the albumen, its very broad culyledous twisted-plaited.

+ Sepals 4-6, the outer row reflexed, the inner erect and enlarging in fruit.

3. Oxyxia. Sepals 4. Stignas 2. Fruit 2-winged, samara-like.

4. Rumex. Sepals 6. Styies 3. Fruit 3 -angled, enclosed by the inner sepals.

* Stipules obsolete. Ovule hanging from the apex of a slender stalk.

6. Brummichia. Calyx $\bar{y}$ parted, in fruit with a wing decurrent on the pedicel. Tendril. climber.

\section{POLYGON U M, L. KNOTwEed.}

Calyx mostly 5 -parted; the divisions often petal-like, all erect in fruit, withering or persistent and surrounding the lenticular or 3-angular uchenium. Stamens 4-9. Styles or stiprnas 2 or 3. Eubryo plined in a qroove on the outside of the albumen and curved half-way arombl it; the radicle and usually the cotyl- 
edons slender, - Pedicels jointed. Ours all herbaceous, flowering through late

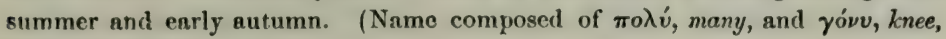
from the numerous joints.)

8 1. BISTÓRTA, Tourn. Calyx petal-like, deeply 5-clefl: stamens 8 or 9 : styles 3, slender: achenium 3-sided: stems low and simple fiom a thick and woody creeping rontstock: flowers in a spike-like raceme.

1. P. vivíparum, L. (Alpine Bistort.) Smooth, dwarf $\left(4^{\prime}-8^{\prime}\right.$ high), bearing a linenr spike of flesh-colored flowers (or often little red bulblets in their place); leaves lanccolate. - $\Lambda$ I pine summits of the White Mountains, New IIampshire, shore of Lake Superior, and northward. (Eu.)

§ 2. PERSICARIA, Tourn. Calyx petal-like, 5-parted: stigmas capitate: achenium lenticulur, or (when there are 3 stigmas) 3-sided: cotyledons accumbent and albumen hard and horny except in No. 2: roots fibrous: flowers crowded in spikes or spike-like racemes.

* Sheaths some of them with an alwupt spreading and more or less foliucrous (sometimes deciduous) border: tall brunching ammurls, with panicled and nodding dense cylindrical spikes: flowers rose or flesh-color: achenium fat.

2. P. orienther, I. (Princen's Frituen.) Softhairy; leaves ovate or oblong, pointed, distinetly petioled; flowers large, bright rose-color; stamens 7 ; style 2-cleft; cotyledons incumbent; albumen floury. - Sparingly escaped from gardens into waste grounds. ( $\Lambda \mathrm{dv}$. from India.)

3. P. Careyi, Olney. Stem $\left(3^{\circ}-5^{\circ}\right.$ high $)$ and peduncles glandular-bristly; ieaves lanceolate, roughish; flowers purplish; stamens mostly 5 ; style 2-parted. Shady swamps, Rhode Island to New Jersey, Pennsylvania, and northward.

* Sheaths all cylindrical and truneate, without a border.

- Annuals: spikes oblong or linear, densely flouered: flowers rose or flesh-color, or occusionally varying to white, slightly or not at all glandular-dotled: stamens 6-8: styles 2 or 2-cleft and achenium fluttened, except sometimes in No. 7, which alone. has the sheaths at all or more than slightly ciliate.

4. P. Pennsylvánicum, L. Stem $\left(1^{\circ}-3^{\circ}\right.$ high $)$, smooth below, the branches above, and especially the peduncles, beset with brislly-stalked glands; lenves lanceolate, roughish on the midrib and margins $\left(1 \frac{1}{2}^{\prime}-5^{\prime}\right.$ long); spikes oblong, oltuse ( $I^{\prime}-2^{\prime}$ long), erect, thick; stamens mosily 8, somewhat exserted; style 2-clef ; achenium with flat sides. - Moist soil, in open waste places : common.

5. P. incarnatum, Ell. Nearly glabrous $\left(3^{\circ}-6^{\circ}\right.$ high $)$; the peduncles; \&c. often minutely rough with scattered sessile glands; sheaths wholly naked and glabrous; leaves rough on the midrib and margins, elongated-lanceolate $\left(4^{\prime}-12^{\prime}\right.$ long, $1^{\prime}-3^{\prime}$ wille below), tapering gradually from towards the base to a narrow point; spikes linear, nodding, becoming slender $\left(1 \frac{1}{2}^{\prime}-3^{\prime}\right.$ long); stamens 6 and styles 2, both included; achenium with concaive sides. ( $P$. nodòsum, var. incarnatum, Ed. 2. P. lapathifolium, Amer. authors, \&c.) - Wet borders of ponds and streams; rather common everywhere, especially sonthward and westward. - Flowers smaller than in the last, lighter rose-color, or flesh-color, rarying to white.

6. P. lapathifolium, Ait., is lower, with shorter and much less pointed leaves; sheaths often somewhat hairy or ciliolate; spikes oblong and blunt; flowers 
pale or whitish; stigle 2-cleft, or not parted to the base. We have, sparingly, var. INCAxUM, Koch (P. incanum, Willd.), and only a depauperate form of it $3^{\prime}-6^{\prime}$ high ; leaves lanceolate, obtuse, white-downy beneath; spikes barely $6^{\prime \prime}$ long, erect. - Borders of Cayuga Lake, New York (Chickering and Brewtr), of Lake Superior (O. B. ITheder) and farther northward (Bouryeau). - The true P. nodosum, Pers., which comnects this species with the next, has not been detected. (Eu.)

7. P. P'tissicania, L. (Lanу's Túzв.) Nearly smooth and glabrous $\left(12^{\prime}-18^{\prime}\right.$ high $)$; shculhs more or less bristly-ciliute; leaves lanceolate, pointed, roughish, usually mailicel wilh a dark triangular or lunar spot near the midtle; spilies ovoid or ublony, dense, erect, on smooth (or at least not glandular) preduncles; stamens mostly 6 ; styles half 2-3-chff; achenium gibbous-flattened or sometimes triangular, smouth and shining. - Waste and damp places: very common. - Hlowers greenish-purple. (Nat. from Eu.)

+ + Anmuals or perennials: spikes slencter, filiform, loosely-fowered or interrupted: flowers greenish or whitish, sometimes purplish-tinged: sepuls dulted with conspicuous glands: haves pellucid-dolled: sheuths fringed with bristles: whole herbaye pungently acrid!

8. P. Hydrópiper, L. (Common SMartweed or Water-Pepper.) Annual, $1^{\circ}-2^{\circ}$ high, smooth; spikes nodding, usually short or interrupted; flowers mostly grcenish ; stamens 6 ; style 2-3-parted ; achenium dull, minutely striate, either flut or blustly triangular. - Moist or wet grounds; apparently introduced eastward, but indigenous northward. (Eu.)

9. P. àcre, H. B. K. (Water Smantwled.) Perenuial, nearly smouth; stems rooting at the decumbent base, $2^{\circ}-5^{\circ}$ high; leaves larger and longer than in the last, taper-pointed; spikes erect; flowers whitish, sometimes fleshcolor; stamens 8; style mostly 3-panted, and the achenium sharply trianyular, smooth and shining. (1'. punctìtum, Ell. P. hydropiperoides, Pursh.) - Wet places : common, especially southward.

+ + + Peremials, not acrid, aquatic or amphibious: sepals not glandular-dutted.

10. P. hydropiperoides, Michx. (Mild Water-l'epper.) Stern smooth $\left(1^{\circ}-3^{\circ}\right.$ high $)$, branching; the narrow sheaths hairy, finged with bristles ; leaves narrowly lanceolate; sometimes ublong; spikes ertet, slender, sometimes filiform, often intermupted at the base $\left(1^{\prime}-2 \frac{1^{\prime}}{2}\right.$ long $)$; flowers small, flesh-color or nearly white; stumens 8 ; style 3-cle $\Omega$; achenium sharply triungular, smooth and shining. (1'. mite, Pers., not of Schrank.) - Wet places, and in shallow water : common, especially southward.

11. P. amphíbium, L. (Water Persicaria.) Stems somewhat simple, and usually terminated by a single ovate or oblong and very dense spike (6" thick) of rather large bright rose-red flowers; sheaths not fringed with bristles; stamens 5 ; style 2-cleft; achenium biconvex; leaves varying greatly, frum elliptical or cordate-oblong to lance-ofate or lanceolate. - The typical plant is var. AQú́ticua, Willd. (Var. natans, Mancls. P. coccincum, Muld., \&e.), in water, nearly glabrous; leaves long.petioled, floating, elliptical or oblong, some. tines lieart-shaped at base; spikes short. - Var. TErkésthe, Willd., grows in shallow water, or in wet soil, or even "in sandy prairies" in Illinois 
(Dr. Mfard), either almost glabrons or strigose-hirante; leaves short-petioled, varying from elongated-lanceolate to lance-ovate and taper-pointed; spikes cylindrical $\left(1^{\prime}-3^{\prime}\right.$ long) often in pairs. - Common. (Eu.)

§ 3. TOVARIA, Adans. Calyx rather herbaceous (greenish), unequally 4-parted: stamens 5 : styles 2 , distinct, rigid and persistent on the smooth lenticular achenium : colyledons oblong, accumbent : peremial: flowers loosely disposed in naked long and slender spikes.

12. P. Virginianum, L. Almost smooth; stem teretc, upright $\left(2^{\circ}-4^{\circ}\right.$ high); leaves ovate, or the upper ovate-lanceolate, taper-pointed, rounded at the base, short-petioled, rough-ciliate $\left(3^{\prime}-6^{\prime}\right.$ long); sheatlis cylindrical, truncate, hairy and fringed; flowers $1-3$ from each bract, somewhat curved, the styles in fruit obliquely bent down, minutely hooked at the tip. - Thickets in rich soil : common.

\$4. PSEUDO-POLYGONEILA. Characters of the next section, except that the sheaths are truncate, naled and rigid; the flowers racemed, solitury from each truncate bract; pedicels jointed below the middle; culyx expanding and petaloid.

13. P. articulatum, L. (Jointweed.) Annual; stem upright, paniculately branched $\left(4^{\prime}-12^{\prime}\right.$ high), slenter; lenves linear-thread-form, deciduous; flowers rose-color, crowled in slender and spike-like panicled racemes, on recurved pedicels twice the length of the crowded joint-like bracts; stamens 8 ; achenium triangular, smooth and shining. (Polygonella articulata, Meisner, but has not the enlarged connivent inner sepals, nor the axile embryo of that genus.) - Dry, sandy soil ; along the coast and the Great Lakes, and in intermediate places in New York. - Singular for its many-jointed spikes or racemes, which are $1^{\prime}-3^{\prime}$ long; the lower bracts tooth-pointed on one side. Three inner filaments dilated at the base.

§4. AVICULARIA, Meisn. Calyx more or less petal-like, 5-parted: stamens $3-8$; the filaments awl-shaped, 3 of them broader at the base: stigmas 3, globose, nearly sessile: arhemiun 3-sided: colyledons incumbent : albumen horny: flowers inconspicuous, greenish-white, 2 or 3 together or sometimes solitary in the axils of the small leaves, appearing nearly sessile, sometimes more or less spiked along the leafless summits of the lwanches: ours all annuals or nearly so: sheaths scurious, usually 2-3-cleft or cut-fringed and torn.

14. P. aviculàre, I. (Kvotgrass, Goosf-ariss. Doon-weed.) Prostrate or spreading; leavrs sessile, lanceolate or oblong, pale; stamens chiefly 5 in the Amcrican, 8 in the European plant; achenium dull, minutely granular under a lens, enclosed in the calyx. - The commonest weed, in yards, waste places, \&c. (Eu.)

Var. eréctum, Roth. Stems upright or ascending; leaves broader (oblong or oval) and larger. (P. eréctum, L.) - In richer soil or more shaded places : common.

15. P. marítimum, L. (Const Knotgrass.) Prostrate, glancous, with a hard and sometimes woody and perennial root; stems very short-jointed; scarious sheaths large; leaves thickened, elliptical-lanceolate or narrow oblong; flowers larger than in the last; achenium very smooth and shininy. (P. glaueum, 
Nutt. P. aviculare, var. littorale, Ed. 2.) - Sandy sea-beach, Mass. to Virginia and southward: at the north apparently only annual. (Eu.)

16. P. ramosíssimum, Michx. Stems evect or ascending, much branched $\left(2^{\circ}-4^{\circ}\right.$ high), rigid, many-striate; leaves lanceolate or linear, tapering into a petiole; sheuths mostly short; calyx (drying yellowish) 6-parted and with 6 or 3 stamens, or 5-parted and with + or 5 stamens; ucheniun very smooth and shining. - Sandy shores and banks of streams, Michigan to Illinois and southwarl. Salt marshes, Rhode Island, Olney. - Larger leaves $2^{\prime}$ long.

17. P. ténue, Michx. Stem slender, upright, sparingly tranchod $\left(6^{\prime}-12^{\prime}\right.$ high), sharp-angled; leaves sessile, narrowly linear, very acute; sheaths capillary fringed; flowers axillary and loosely spiked on the filiform branches; wheniun smooth and shining. - Dry soil, and rocky hills.

§ 6. TINIÀRIA, Meisn. Calyx 5-parted (ravely 4-parted), greenish tinged with rose-color or white: stamens mostly 8 : styles or capitate stignas 3 and achenium 3-sided (except in No. 18) : leaves heurt-shaped or arrow-shapicd, petioled: sheuths semicylindrical.

* Annuals, erect or somewhat climbing by the reflexal prickles which beset the angles of the stem and patioles: divisions of the (pale rose-colurd or white) calyx not keeted: bracts chaff-like.

18. P. arifolium, L. (Halbern-leaved Tear-tudar.) Stem groovedangled; leaves halberd-shaped, taper-pointed, long-petioled; flowers somewhat racemed (few) ; peduncles glandular-bristly ; calyx often 4-parted; stamens 6 ; styles 2, very short; achenium lenticular (large). - Low grounds.

19. P. sagittàtum, L. (Arrow-leaved Tear-tuumb.) Stem 4-anyled; leaves arrow-shaped, short-petioled; flowers capitate; peduncles smooth; stamens mostly 8; styles 3, slender; achenium sharply 3-angled. - Low grounds : common. - Slender, smooth except the angles of the stem and midrib beneath : these are urned with a line of fine and very sharp saw-toothed prickles, which cut tho hand drawn against them.

* * Stems twining, not prickly: calyx with the 3 outer divisions keeled, at least in fruit: flowers in loose panicled racemes: bracts like the stipules.

20. P. Convólvulus, I. (Black Bindweed.) Amual; slems twining or procumbent, low, roughish, the joints nuked; leaves halberd-hcurt-shaped, pointed ; flowers in small interrupted corymbose racemes; outer culyx-lobis keelcd; achenium smoothish. - Cult. and waste grounds: common. (Nat. from Lu.)

21. P. cilindode, Michx. Perennial, minutely downy; the shaths fringed at the base with reflexed bristles; leaves heart-shaped and slightly halberd-shaped, taper-pointed; racemes panicled; calyx-lubes obscurely keeled; achenium very smooth und shining. - Copses and rocky hills. Climbing $3^{\circ}-9^{\circ}$ high.

22. P. dumetorum, L. (Climing False Вuскwilat.) Perennul, smooth; sheaths naked; leaves heart-shaped or slightly halberd-shaped, pointed; racemes interrupted, leafy; the 3 outer calyx-iobes strongly keeled and in fruit winged; achenium smooth and shining. (Eu.)

Var. scándens (P. scandens, L.) has more panicled flowers, and usually much broader wings to the fruiting calyx than the European. - Moist thickets. Twining $8^{\circ}-12^{\circ}$ high over bushes. 


\section{FAGOPỲ R U M, Tourn. Bucriment.}

Calyx petal-like, equally 5-parted, withering and nearly unchanged in fruit. Stamens 8. Styles 3 : stigmas capitate. Achenium 3-siled, longer than the calyx. Embryo large, in the centre of the albumen, which it divides into 2 parts, with very broad and foliaccous plaited and twisted cotylerlons. - Annuals, with triangular-heart-shaped or halberd-shaped leaves, semicylindrical sheaths, and corymbose racemes or panicles of white flowers, often tinged with green or rose-

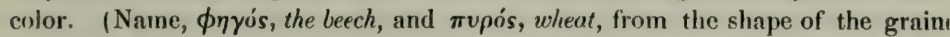
being that of the beech-nut; whence also the English name Buckwheat, from the German Buche, beech.)

1. F. esculéntum, Mœnch. (Buckwheat.) Smoothish; flower with 8 honey-bearing yellow-glands interposed between the stamens; the fruit acute and entire. (Polygonum Fagopyrum, L.) - Old fields, remaining as a weed after cultivation, and escaping into copses. June-Sept. (Adv. from Eu.)

\section{OXÝRIA, Hill. Mountain Sonnet.}

Calyx herbaccous, of 4 sepals; the two outer smaller and spreading, the two inner broader and erect (but unchanged) in fruit. Stamens 6. Stigmas 2, sessile, tufted. Achenium lenticular, thin, flat, much larger than the calyx, surrounded by a broad and veiny wing. Seed flattened in the opposite direction from the wing. Embryo straight, occupying the centre of the albumen, slender. - Low alpine perennials, with round-kidney-form and long-petioled leaves chiefly from the root, obliquely truncate sheaths, and small greenish flowers clustered in panicled racemes on a slender scape. (Name from ókús, sour, in allusion to the acid leaves, like those of Sorrel.)

1. O. dígyna, Campdera. Icaves all round-kidney-form, usually notched nt the end; fruit orbicular. - Alpine region of the White Mountains, New Hampshire, Oukes, \&c., and high northward. (Eu.)

\section{4. $\mathbf{R}$ Ù $\mathbf{M} \mathbf{X}$, L. Dock. Sornel.}

Calyx of 6 sepals; the 3 onter herbaceous, sometimes united at the base, spreading in fruit ; the 3 inner larger, somewhat colored, increasing after flowering and convergent over the 3 -angled achenium, veiny, often bearing a grainlike tubercle on the back (in fruit called valves). Stumens 6. Styles 3: stigmas tufted. Embry - slightly curved, lying along one side of the albumen, slender. - Coarse herbs, with small and homcly (mostly green) flowers, which are crowded and commonly whorled in panicled racemes; the petioles somewhat sheathing at the base. (The ancient Latin name of these plants; of unknown etymology.)

§ 1. Dоск. Finvers perfict or monxciously polygamous: herbage not sour: none of the leaves halberd-shaped. (Flowering through the summer.)

* Perennials, $2^{\circ}-7^{\circ}$ high: valves not bearing bristles.

-Valves (large, $3^{\prime \prime}$ broad, thin) all naked or one with a small grain.

1. R. Patíntia, I. (PAtimen Dock.) A very tall speciea, with ovateoblong and lanceolate leaves, those from the root $2^{\circ}-3^{\circ}$ long, and one of the 
heart-shaped nearly entire valves bearing a small grain, or its midrib thickened at the base, was found spontaneous at Amherst, Mass., by Prof. Tuckerman, in the form with undulate leaves, R. orientalis, Beinh. (Adv. from Eu.)

2. R. rovgifólics, DC. (R. domésticus, Hurtın, and too near R. aquaticus, L.), known by the rounded somewhat heart-shaped valves all without a grain, - is indigenous at the northwest, perhaps in Northern Wisconsin. (Eu.)

- Valves (smuller) onc or more of them conspicuously grain-beuring.

- Indigfnous: haves not uary, none heart-shuped, except the lowest of No. 6.

3. R. orbiculàtus, Gray. (Great Watel-I)ock.) Tall and stout $\left(5^{\circ}-6^{\circ}\right.$ high $)$; racemes upuright in a large compound panicle, nearly leatless; whorls crowiled; pedicels cupillury, nodding, about twice the length of the fruiting culyx; the culces orbirulur or round-ovate, very obtuse, ubscurely heart-shaped at base, nembranaceous, finely reticukated, entire or repand-denticulate $\left(2^{\prime \prime}-3^{\prime \prime}\right.$ lnoad), all grain-bearing; leaves oblong-lanceolate, rather acute at both ends, transversely veined, and with obscurely erose-crenulate nargins (the lowest, including the petiole, $1^{\circ}-2^{\circ}$ long, the midille rarely truncate or obscurely cordate

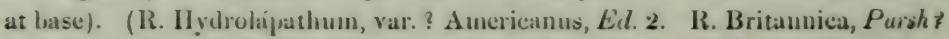

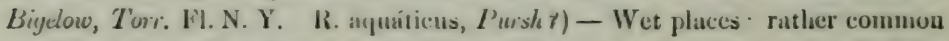
northward. - livot yellow. Jculncs occisionally abruptly contracted a little below the enlarging apex. Valves very unch rounder, thinner, larger in proportion to the grain, and more reticulated than in the European R. Hydrolitpathum, resentiling those of $\mathrm{R}$. longifulius except in bearing a conspicuous grain.

4. R. Británnica, L. (P.le Dock.) Rather tall $\left(2^{\circ}-6^{\circ}\right.$ high); racemes spike-like and panicled, nearly leafless; whorls crowded; pedicels nodding, shorter than the fruiting calyx; the valves braadly ovile or obscurcly heart-shaped, obtuse or acutish, entire, membranaceous, loosely reticulated (about 2" broad), one with a consjicuous grain, the others with a small grain or thickened midrib, or naked; leaves oicule-lunceolute or allong-lancedute, acute, pale, thickish, obscurely veiny (those of the stem $3^{\prime}-6^{\prime}$ long, contracted at base in to a short petiole), none heart shaped. (R. Claytòii, Campdera, which mane is to he alopted if we reject that inconsiderately assigned hy Linnaus, who transferred the ubscure Ilerba Britannica of the old writers to a Virginian species. R. xanthorhizus, IIoffinunsegg, ex Meisner. R. altissimus, Woul.) - Moist grounds, New York to Illinois and southward.

5. R. salicifolius, Weinmann. (Whiте Dоск.) Rather low $\left(1^{\circ}-3^{\circ}\right.$ ligh) ; root white; leaves narrowly or lineur-lancrolate, or the lowest oblong; whorls much crowded; pedicels much shorter than the fruiting culyx; ralves deltoidvicute, obtusish or acutish (aloout $1 \frac{1}{2}{ }^{\prime \prime}$ long), one, two or sometimes all three with a conspicuous often very large grain : otherwise nearly as in the preceding. ( $R$. pállidus, Bigeluev.) - Salt marshes, coast of New England; also far westivard and northward.

6. R. verticillàtus, L. (Swam Dock.) Rather tull $\left(3^{\circ}-5^{\circ}\right.$ high); racemes nearly leatless, clongated, louse; the whorls crowded or the luwer oncs distant; fruit-bearing pedicels slender, club-shuped, abuphly reflexed, 3-4 times lunyer thun the fruiting calyx; the valves dilated-rlumboid, ubtusely somewhat pointed, strongly rugasc-reticulated, cach bearing a very harge grain; leaves lanceolate or 
oblong-lanceolate, rather obtuse, thickish, pale-green, the lowest often heart shaped at the base. - Wet swamps: common.

++ Naturalized wecds : lower leaves mostly hart-shuped at the base.

7. R. crfspus, I. (Curted Dock.) Smooth; leaves with strongly wavyculled margins, lanceolute, acute, the lower truncate or scarcely heart-shaped at the base; whorls crouded in prolonged uand-like mermes, lenfless above; valves round-heart-shaped, obscurely denticulale or entire, mostly all of them grain-bearing. $-\Lambda$ very common weed in cultirated and waste grounds. Stem $3^{\circ}-4^{\circ}$ high, from a deep spindle-shaped yellow root. There is a hybrid of this with the next. (Nat. from Eu.)

8. R. obtusifólius, L. (Bitter Dock.) Stem roughish; lowest leaves orate-heurt-shaped, obtuse, rather downy on the veins underneath, somewhat wavymargined, the upper oblong-lanceolute, acute; whorls loose and distunt ; valves ovatehulberd-shuped, and with some sharp awl-shaped teeth at the base, strongly reticulated, one of them principally grain-bearing. - Fields, \&c. (Nat. from Eu.)

9. R. conoumendtua, Muray. (Sммisin (imben Dock.) Leaves oblong, pointed, slightly wavy-margined, the lower heart-shaped at the base; whorls distant, leafy; ; pediccls very short; valves linear-oblong, vather broader next the base; obtuse, entire, each bearing a single reddish grain. (R. acutus, Smith.) - Moist places; sparingly introduced. (Nat. from Eu.)

10. R. sangufneus, L. (Bloody-veined Dock.) Leaves lanceolate, wavymargined, the lowest heart-shaped at the base ; whorls distant, in long and slender leafless interrupted spikes; pedicels very short ; valves nurrowly oblong, obtuse, entire, one at least grain-bearing; reins of the leaf red, or, in var. vfRIDIs, green. Waste and cultivated grounds. (Nat. from Eu.)

* * Annuals, low: valves bearing long awns or bristles.

11. R. marítimus, L. (Golden Dock.) Minutely pubescent, diffusely branched; leaves lance-linear, wavy-margined, the lower auricled or heart-shaped at base; whorls excessively crowded in leafy and compact or interrupted spikes ; valves rhombic-oblong, lance-pointed, ench bearing 2-3 long awn-like bristles on each side, and a large grain on the back. (Also R. persicarioìdes, L.) - Seashore, Virginia to Massachusetts: also Illinois and westward. - Plant $6^{\prime}-12^{\prime}$ high; remarkable for the crowded and almost orange-colored fruiting calyx, the bristles usually longer than the width of the valves. (Eu.)

§ 2. Sorrel. Flowers dixcious, small, in a terminal naked panicle: herbage sour : some leaves hulberd-shaped: smooth perennials, flowering in spring.

12. R. Engelmánni, Ledeb. Stem simple, $1^{\circ}-2^{\circ}$ high; leaves nearly as in the next; pedicels jointed at or bolow the middle; vulves of the fruiting calyx round-heart-shaped, thin, finely reticulated, naked, many times larger than the achenium. (R. hastulatus, Buldwin.) - S. W. Illinois, thence southward and westward.

13. R. Acetosélla, L. (Field or Sheep Sorrel.) Low $\left(6^{\prime}-12^{\prime}\right.$ high) ; leaves lance-halberd-form, at least those of the root, the narrow lobes entire; pedicels jointed with the flower; valves scarcely enlurging in fruit, ovate, naked. An abundant weed in waste places and all sterile and worn fields. - The fertile panicles usually turn reddish in summer. (Nat. from Eu.) 


\section{BRUN N ÍCHIA, Banks. Brunnichia.}

Calyx 5-parted; the divisions somewhat petal-like, oblong, connivent and coriaceous in fruit. Stamens 8 : filaments eapillary : styles 3, slender: stigmas depressed-capitate. Ovule hanging on the sumnit of a sleuder erect funiculus: the seed erect, 6-grooved. Embryo in one of the angles of the inealy albumen, somewhat curved. Achenium obtusely triangular, partly 3-celled, enclosed in the indurated calyx, its base and almost the whole length of the pedicel winged on one side. (Named for L'. Brunuich, a Danish naturalist.)

1. B. cirrhòsa, Banks. - A somewhat shrubly smooth plant, with grooved sterns, climbing by tendrils extended fiom the ends of the branches. Leaves ovate or heart-shaped, pointed, entire: petioles dilated at base and partly clasping; but no distinct sheath or stipules. Flowers greenish, $2-5$ in a fascicle from the axil of un awl-shaped bract, these crowded in axillary and terminal racemes: pedicel jointed near the base. Fruiting calyx with the wing $\mathbf{l}^{\prime}$ long. - Pulaski Co., S. W. Illinois, Dr. F. Brendel: also southward.

\section{Order 88. haUtràceat. (Laurel Family.)}

Aromatic trees or shrubs, wilh alternate simple leaves mostly markied with minule pellucid dots, and flowers with a regular calyx of 4 or 6 colored sepals, imbriculed in 2 rows in the bud, free from the 1-celled and 1-ovuled ovary, and mostly fewer than the stamens; anthers opening by 2 or 4 uplifted valves. - Flowers clustered. Style single. Fruit a 1-seeded berry or drupe. Seed anatropous, suspended, with no albumen, filled by the large almond-like embryo. - A well-marked family, very numerous in the tropics, represented in our district by only five species, in four genera.

* Elowers perfect, panicled : stumens 12, three of them sterile.

1. Persea. Calyx persistent. Anthers 4-celled, those of three stameus turned outward.

* * Flowers divecious, or nearly so: stamens in the male flowers 9 .

2. Sagsafias. Flowers in corymb-or umbel-like racemes. Anthers 4-celled, 4-valved.

3. Lindera. Flowers in umbel-like clusters. Anthers 2-celled, 2-valved.

4. Tetranthera. Flowers few in involucrate umbels. Antliers 4-celled, 4-valved.

\section{PÉRSEA, Gartn. Alligator P'ear.}

Flowers perfect, with a 6-parted calyx, which persists at the base of the berrylike fruit. Stamens 12, in four rows; the 3 of the inmermost row sterile and re- duced to a sort of glands: the rest bearing 4-celled anthers (i. e. each of the two proper cells is divided transversely into two), opening by as many uplifted valves; the anthers of 3 stamens turned outward, the others introrse. - Trees, with persistent entire leaves, and small panicled flowers. (An ancient name of some Oriental tree.)

1. P. Carolinénsis, Nees. (Red BaY.) Ilonry at least when young with a tine down; leaves oblong, pale, soon becoming smooth above; peduncle bearing few flowers in a close cluster; sepals downy, the outer shorter; berries dark blue, on a red stalk. (Laurus (Curolinensis, Catesb. L. Borbonia, L.) Swamps, Delaware, Virginia, and southward. Junc. - A small tree. 


\section{SA S A F R A S, Nees. SAsgAFras.}

Flowers diæcious, with a 6-parted spreading calyx; the sterile kind with 9 stamens inserted on the base of the calyx in 3 rows, the 3 inner with a pair of stnlked glands at the base of each; anthers 4-celled, 4-valved: fertile flowers with 6 short rudiments of stamens and all ovoid ovary. 1)rupe ovoid (blue), supported on a club-shaped and rather fleshy reldish perlicel. - Trees, with spicy-nromatic bark, very mucilaginous twigs and foliage; the latter deciduous, often lobed. Flowers greenish-yellow, naked, in elustered and peduncled corymbed racemes, appearing with the leaves, involucrate with sealy bracts. Leaf-buds sealy. (The popular name, of Spanish origin.)

1. S. officinale, Nees. Leaves ovate, entire, or some of them 3-lobed, soon glabrous. (Laurus Sassafras, L.) - Rich woods: common. April. Tree $15^{\circ}-50^{\circ}$ high, with yellowish-green twigs.

\section{LI N D ERA, Thunberg. Wind Alspice. Fever-nusir.}

Flowers polygamous-diccious, with a 6-parted open calyx; the sterile kind with 9 stamens in 3 rows, the inner filaments 1 -2-lobed and gland-bearing at the base; anthers 2-celled and 2-valved : fertile flowers with 15-18 rudiments of stamens in 2 forms, and a globular ovary. Drupe obovoid, red, the stalk not thickened. - Shrubs, with deciduous leaves, and honey-yellow flowers in almost sessile lateral umbel-like clusters, appearing before the leaves (in our species); the clusters composed of smaller clusters or umbels, each of 4-6 flowers and surrounded by an involucre of 4 deciduous scales. Leaf-buds scaly. (Named for John Linder, a Swedish botanist of the early part of the 18th century. Benzoin, Nees, adopted in Ed. 2, is a much later name.)

1. L. Benzoin, Meisner. . (Spice-iusu. Benjamin-вush.) Nearly smooth; leaves oblong-obovite, pale underneath. (Laurus Benzoin, L. Benzoin odoriferum, Nees, \& Ed. 2.) - Damp woors : rather common. March, April. Shrub $6^{\circ}-15^{\circ}$ high.

2. L. melissæfolia, Blume. Young branches and buds pubescent; leaves oblong, obtuse or heart-shaped at the base, downy beneath; umbels few. (Laurus melissæfolia, Walt. L. diospyroides, Michx. Benzoin melissæfolium, Nees.) Luw grounds, Virginia, Illinois ? and southward. $\Lambda$ pril.

\section{TETRA N TH E $\mathbf{T} \mathbf{A}$, Jacq. Tetrantmera.}

Flowers diccious, with a 6-parted deciduous caly $\mathrm{x}$; the sterile with 9 stamens in 3 rows; their anthers all introrse, 4-celled, 4-valved: fertile flowers with 12 or more rudiments of stainens and a globular ovary. I)rupe globular. Shrubs or trees, with entire leaves, and small flowers in axillary clustered um-

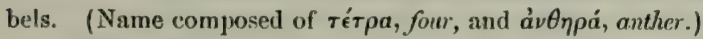

1. T. geniculáta, Nees. (Pond Sprce.) Flowers (yellow) appearing before the deciduous oblong leares, which are hairy on the midrib beneath; branches forked and divaricate, the branchlets zigzag ; involucres 2-4-leaved, 2-4-flowered; fruit red. (Laurus geniculata, Michx.) - Swamps, Virgini.ı and southward. April. 


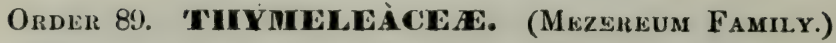

Shrubs, with acrid and very tough (not aromatic) bark, entire leaves, and perfect flowers with a regular and simple colored calyx, bearing usually twice as many stamens as its lobes, free fiom the 1-celled and 1-ovuled ovary, which forms a berry-like drupe in fruit, with a single suspended anatropous seed. Embryo large: albumen little or none. - A small family, represented in cultivation by Mapine Mezereum, and one or two other species; in Nurth America only by a single species.

\section{Dí R C A, L. Leatherwood. Moose-woód.}

Calyx petal-like, tubular-funncl-shaped, truncate, the border wavy or obseurely about 4-toothed. Stamens 8 , long and slender, inserted on the calyx above the middle, protruded, the alternate ones longer. Style thread-form : stigma eapitate. Drupe oval (reidish). - A unch-branclsed bush, with jointed branchlets, oval-obovate alternate leaves, at length smooth, deciduous, on very short petioles, the bases of which conceal the buds of the next season. Flowers light yellow, preceding the leaves, 3 or 4 in a cluster from a bud of as many darkhairy scales, forming an involucre, from which soon after proceeds a leafy branch. ( $\Delta i \rho \kappa \eta$, the name of a fountain near Thebes, applied by Limuas to this North American genus, for no imaginable reason, unless because the bush frequently grows near monntain rivulets.)

1. D. palústris, L. - Damp rich woods, seldom in swamps, New Eugland to Penn., Kentucky, and (especially) northward. A pril. - Shrub $2^{\circ}-5^{\circ}$ high; the wood white, soft, and very brittle; but the fibrous bark remarkably tough, used by the Indians for thongs, whenee the popular uames. In Northeru New England also called Wscory.

\section{Order 90. El angnàcede. (Oleaster Family.)}

Shrubs or small trees, with silvery-scurfy leaves and mostly dicecious flowers; further distinguished from the Mezereum Fanily by the erect or ascending albuminous seed, and the calyx-tube becoming pulpy and berry-like in fruit, and strictly enclosing the achenium; and from the following or by the calyx-tube not colering with the ovary, \&c. A small family, represented by only three North American species, only one strictly within our limits.

\section{SHEPH ÉRIA, Nutt. Shepherdi.}

Flowers diœcious; the sterile with a 4-parted calyx (valvate in the bud) and 8 stamens, alternating with as many processes of the thick disk; the fertile with an urn-shuped 4-eleft calyx, enclosing the ovary (the orifice closed by the teeth of the disk), and becoming berry-like in fituit. Style slender : stigma 1 -sided. - Leaves opposite, entire, deciduous; the small flowers nearly sessile in their axils on the branchlets, elustered, or the fertile solitary. (Named for John Stepherd, formerly curator of the Liverpool Botanic Garden.) 
1. S. Canadénsis, Nutt. (Canımin Sumperina.) Leaves elliptical or ovate, nearly naked and green above, silvery-downy and scurfy with rusty scales underneath; fruit yellowish-red, insipid. - Rocky or gravelly banks, Vermont to Wisconsin and northward. May. - Shrub, $3^{\circ}-6^{\circ}$ high; the branch. lets, young leaves, yellowish flowers, \&c., covered with the rusty scales.

2. S. argéntea, Nutt., the Buffalo-Berny of Upper Missouri, has narrower leaves, tapering at base, silvery on both sides, and edible, acid, scarlet fruit: probably in Minnesota: sometimes cultivated.

Fidengnus argéntica, Pursh, the Suver-Berrt, with oval silvery leaves, and silvery and mealy edible fruit, differing from Shepherdia in its perfect flowers with only 4 stamens, - abounds not far beyond our northwestern limits.

\section{Order 91. SAN'TaLàcede. (Sandalwood Family.)}

Herbs, shrubs, or trees, with entire leaves; the 4-5-clefl calyx valvate in the but, its tube coherent with the 1-celled ovary, which comains 2-4 ovules suspended from the apex of a stalk-like free central placenta which rises from the base of the cell, but the (indehiscent) fruil aluays 1 -seerled. - Seed destitute of any proper sced-coat. Fimbryo small, at the apex of copious albumen : radicle directed upward: cotyledons c:ylindric:al. Stamens equal in number to the lobes of the caly $x$, and inserted opposite them into the edge of the fleshy disk at their base. Style 1. A small order, the greater part belonging to warm regions, here represented only by the two following genera.

\section{COMA N DRA, Nutt. Bastand Tond-flax.}

Flowers perfect. Calyx bell-shaped or soon urn-shaped, lined above the ovary with an adherent disk which has a 5-lobed free border. Stamens inserted on the edge of the disk between its loles, opposite the lobes of the calyx, to the middle of which the anthers are connected by a tuft of thread-like hairs. Fruit drupelike or nut-like, crowned by the persistent calyx-lobes, the cavity filled by the globular sced. - Low and smooth perennials, with herbaceous stems from a rnther woody base or root, alternate and almost sessile lenves, and grecnish-white flowers in terminal or axillary small umbel-like clusters. (Name from kó $\mu \eta$,

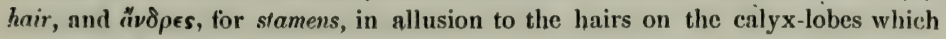
are attsched to the anthers.)

1. C. umbellata, Nutt. Icaves oblong, pale ( $\left.\mathbf{l}^{\prime} \mathrm{long}\right)$; pedincles several and corymbose-clusterd at the summit of the stem, several-flowered; caly $\mathrm{x}$-tube conspicuously continued beyond the ovary, forming a neck to the globular-urn. shaped fruit ; the lobes oblong; style slender ; fruit dry. - Dry ground : common. May, June. - Stems $8^{\prime}-10^{\prime}$ high, very leafy. Root forming parasitic attachments to the roots of trees (as shown by $M r$. Stauffer).

2. C. lívida, Richardson, Peduncles axillary, 3-5-fowered, shorter than the oval leaves; chlyx-tube not continued heyond the ovary, the lubes ovate; style short; fruit pulpy when ripe, red. - Sandy shores of Lake Superior: und northward. - Leaves larger than in the last.

$\mathrm{L} \& \mathrm{M}-38$ 


\section{Pyrulària, Michx. Oil-nut. Buffalo-nut.}

Flowers dioecious or polygamous. Calyx 4-5-cleft, the lobes recurved; a tuft of hairs at their base in the male fluwers. Stamens 4 or 5 , on very short filaments, alternate with as many rounded glauds. Fertile flowers with a pearshaped ovary invested by the adherent tube of the calyx, naked at the flat summit : disk with 5 gglands: style short and thick : stigrna capitate-flattened. Fruit fleshy and drupe-like, pear-shaped; the globose endocarp thin. Embryo small: albumen very oily. - Shrubs or trees, with alternate short-petioled and deciduous leaves; the small greenish flowers in short and simple spikes or racemes. (Name a diminutive of Pyrus, from the fruit, which in the original species looks like a small pear.)

1. P. oleífera, Gray. Shrub straggling $\left(3^{\circ}-12^{\circ}\right.$ high $)$, minutely downy when young, at length nearly glabrous; leaves obovate-oblong, acute or pointed at both ends, soft, very veiny, minutely pellucid-punctate; spike small and fervflowered, terminal; calyx 5-cleft. (P. pubera, Michx.; a little older than the other specific name, but much less appropriate. Hamiltònia oleifera, Muhl.) Rich woods, mountains of Penmsylvania, and southward through the Alleghanies. May. - Whole plant imbued with an acrid oil, especially the fruit, which is an inch long.

\section{Order 92. Lorranthàce a. (Mistletoe Family.)}

Shrubby plonls with coriacenus greenish foliage, parasitic on trees, represented in the northern temperate zone chiefly by the Mistletoe and its near allies; distinguished from the preceding family more by the parasitic growth and habit, and by the more reduced flowers, than by essential characters: represented by an American genus nearly allied to Viscum, or true Mistletoe, viz.

\section{PHoradéndron, Nutt. False Mistletoe.}

Flowers dioecious, in short and catkin-like jointed spikes, usually several under each short and fleshy bract or scale, and sunk in the joint. Calyx glolular, 3(rarely 2-4-) lobed: in the stiminate flowers a sessile anther is borne on the base of each lobe, and is transversely 2-celled, each eell opening by a pore or slit: in the fertile flowers the calyx-tube adberes to the ovary: stigma sessile, obtuse. Berry l-seeded, pulpy. Embryo small, half imbedded in the summit of mucilaginous albumen. - Yellowish-green woody parasites on the branches of trees, with jointed inuch-branched stems, thick and firm persistent leaves for orily scales in their place), and axillary small spikes of flowers. (Name composed of $\zeta \omega \rho_{1}$ a thief, and $\delta \dot{\nu} \nu \delta \rho o \nu$, tree; because these plants steal their food from the trees they grow upon.)

1. P. flavéscens, Nutt. (Аmemican Mistietoe.) Leaves obovate or oval, somewhat petioled, longer than the spikes in their axils, yellowish; borries white. (Viscum flaveseens, Pursh.) - New Jersey to Illinois and southward, on various deciduous-leaved trees. 


\section{Order 93. Sauteutràcea. (Lizard's-tall Family.)}

Herbs, with jointed stems, alternate entire leaves, and perfect flowers in spikes, entively destitule of any floral envelopes, and with 3-5 more or less separate or united ovaries. - Ovules few, orthotropons. Embryo heartshaped, minute, contained in a little sac at the apex of the albumen. - An offshoot of the (tropical) Pepper Family, and represented only by

\section{SAURÙRUS, L. LizarD'S-TAIL.}

Stamens mostly 6 or 7 , hypogynous, with distinct filaments. Fruit somewhat fleshy, wrinkled, of 3-4 pistils united at the base." Stigmas recurved. Seeds usually solitary, ascending. - Perennial marsh herbs, with heart-shaped converging-ribbed petioled leaves, without distinct stipules; flowers (each with a small bract) crowded in a slender wand-like and naked peduncled terminal spike or raceme (its appearance giving rise to the name, from oavpos, a lizard and ovjá, tail). Bract adnate to or borne on the pedicel.

1. S. cérnuus, L. Flowers white, in a dense spike nodding at the end; bract lanceolate; filaments long and capillary. - Swamps: common. June$\Lambda$ ug.

\section{Order 94. CERA'TOPHYLAACEAE. (Hornwort Family.)}

Aquatic herbs, with whorled finely dissected leaves, and minute axillary and sessile monœcious fowers without floral envelopes, but with an 8-12cleft involucre in place of a calyx, the fertile a simple 1-celled ovary, with a suspended orthotropous ovule: seed filled by a highly developed emlryo with 4 cotyledons! and a conspicuous plumule. - Consists only of the genus

\section{CERATOPHÝLLUM, L. Hornwor'.}

Sterile flowers of 12-24 stamens, with large sessile anthers. Fruit an achenium, beaked with the slender persistent style. - Herbs growing under water, in ponds or slow-flowing streams : the sessile leaves cut into thrice-forked thread-

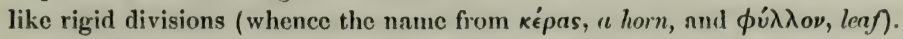

1. C. démersum, L. - Var. соммùse has a smooth marginless fruit beaked with a long persistent style, and with a short spinc or tubercle at the base on each side. - Var. Ecrindtum (C. echinatum, Gray) has the fruit mostly larger ( $3^{\prime \prime}$ long), rough-pimpled on the sides, the narrowly winged margin spiny-toothed. - Slow streams and ponds : common, but rarely seen in fruit. Probably there is only one species. (Eu.)

\section{Order 95. CALLITRICHÀCEAE. (WAter-Starworts.)}

Small annuals or perennials, mostly aquatics, with opposite entre leaves and axillary monocious, flowers without any proper floral envelopes, and with a 4-lobed and 4-celled 4-seeded fruit; - consisting only of the genus Callitriche (regarded by many botanists, perhaps with good reason, as repre- 
senting the most reduced form of the Haloragex, p. 174. The so-called perfect flower is considered to be a staminate and a pistillate, or two stạminate and one pistillate naked flowers in the same axil, each of a single stamen or pistil.)

The elaboration of our species is contributed by Dr. G. Engelmann.

\section{CALLítriche, L. Water-Starwort.}

Flowers monoecious, solitary or 2 or 3 together in the axil of the same leaf, wholly naked or between a pair of membranaceous bracts. Sterile flower a single stanen : filament bearing a heart-shapel 4-celled anther, which by confluence becomes one-celled, and opens by a single slit. Fertile flower a single 4-celled ovary, either sessile or pedicelled, bearing 2 distinct and filiform sessile, usually persistent stigmas. Ovule solitary in each cell. Fruit nut-like, compressed, 4lobed, 4-celled, separating at maturity into as many elosed 1-seeded portions. Seed anatropous, suspended, filling the cell : embryo slender, straight or slightly eurved, in the axis and nearly the length of the oily albunen. - Smooth, or beset with uinute stellate scales (visible only under the micruscope), with spatulate or

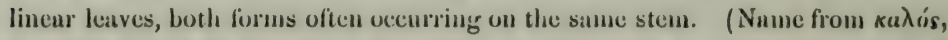
beantijul, and $\theta$ pi $\xi$, hair, from the almost cappillary and usually tufted stems of the commoner species.)

§1. Terrestrial species. Simall annuals, forming tufts on merely moist soil; destitute of stellate scales and of bracts: leaves uniform, very small, obovate or wedge-shaped, 3-nerved, crowded, provided with stomuta: filument not lengthening: carpels connate.

1. C. Austini, Engelm. Fruit small, broader than high, deeply notehed above and below, on a pedicel often nearly of its own length; lobes of the fruit narrowly winged and with a deep groove between them, wings denticulate; persistent stigmas shorter than the fruit, spreading or reflexed; leaves obovate. On damp soil in open woorls, fields and roads, New York and New Jersey (C. F . Austin) to Illinois, Missouri, 'Texas, Mexico, and South America. A pril -June. - Ilulf an inch or in inch high: leaves $1^{\prime \prime}-2^{\prime \prime}$ long : fruit $f^{\prime \prime}$ in diameter.

C. Plipuìdes, Nutt. and C. Nuttálit, Torr. (C. pedunculòsa, Nutt.), the former with subsessile curiously gibbous fruit, the latter with long-peduncled fruit with eversed keels, - are southwestern species of this section.

§2. Amphibious species. Perennials? with elungated stems (occasionally quite terrestrial as in the former, or wholly submersed as in the next section): leaves with stellate scales and stomata, the fluating ones ubovate and 3-nerved, the submersed linear: flowers usually letween a pair of bracts, rarcly nuked: pollen shed only in the air; the jilument elongating ufterwarls: curpels in frail connate.

2. C. vérna, L. liruit ( $\left(\frac{1}{2} "\right.$ long) higher tham broad, obovate, slightly obcordate, usually thicker at the base than upwards, sessile, its lobes sharply kecled or very narrowly winged upvastds, and with a wide groove between them; stigmas shorter than the fruit, almost creet, usually deciduous; floating leaves crowded in a tuft, ubovate, narrowed iuto a petiole. - Common in stagnaint waters, from Pemisjivania and Now Jersoy north and northwestivard. April - 
Ang. - From $n$ few inches to $n$ foot and moro in length: "upper leaves $3^{\prime \prime}-5$ " long; lower ones twice as long. A terrestrial form with smaller, narrower, and more uniform leaves (C. brevifolia, Pursh), occurs where the waters recede in summer and fall. (Fu.)

3. C. heterophylla, Pursh. Fruit smaller, as broad or broader than high, deeply emarginate, thick, almost ventricose, sessile or nearly so, its lobes obtusely angled, with a small groove between them; stigmas ns long as the fruit, erect, persistent; floating leaves crowiled in a tuft, broarly spatulate, often retuse, abruptly narrowed into a long petiole. (C. Asagrayi, Hegelmaier.) Stagnant water, New York to Illinois and southward: common. April-Aug. - Similar to the lnst, of same size, but with smaller leaves $\left(2^{\prime \prime}-4^{\prime \prime}\right.$ long), and fruit scarcely larger than in No. 1, but much thicker. A terrestrial form (which comes also under C. brevifolia, Pursh) and a submerged one, with linear leaves often an inch long (C. linearis, Pursh), are not rare.

§. Sunmensen arteris. Perennials, entively under usoter, with crowded and uniform linear 1-nerved leaves, wilhout scales or stomata : flowers bractless, fertilized under water: filament not elongating: carpels separate nearly to the axis.

4. C. autumnàlis, L. Fruit large, flattened, circular, deeply and narrowly notched, sessile or nearly so, its lobes brondly winged, and with a very decp and narrow groove between them; stigmas very long, reflexed, deciduous; leaves all linear from a broader base, retuse or notched at tip. - In the St. Lawrence River, near Ogdensburgh (G. W. Clinton), Lake Superior (C. G. Loring, $J r$.), and northwestward. Ang. - Sept. - Stems $3^{\prime \prime}-6^{\prime \prime}$ high: leaves $2^{\prime \prime}-5^{\prime \prime}$ long: fruit variable in size, usually $\mathrm{l}^{\prime \prime}$ or more in diameter. (Eu.)

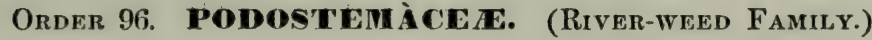

Aquatics, growing on stones in munning water, snme with the aspect of Sea-weeds or others of Mosses or Liverworts; the minute naked flowers bursting from a spathe-like involucre as in Liverworts, producing a 2-3celled many-seeded ribbed pod; - represented in North America by

\section{PODOSTEMON, Michx. Rivrer-wer.}

Flower solitary, pedicelled, from a tubular sac-like involucre, destitute of floral envelopes. Stamens borne on one side of the stalk of the ovary, with their long filaments united into one for more than half their length, and 2 short sterile filaments, one on each side: anthers 2-celled. Stigmas 2, awl-shaped. Pod oval, 8-ribbed, 2-celled, 2-valved. Seeds minute, very numerous on a thick persistent central placenta, destitnte of albumen. - Leaves 2-ranked. (Name from $\pi$ ovs, foot, and $\dot{\sigma} \dot{\gamma} \boldsymbol{\mu} \omega \nu$, strmen; the two stamens being apparently raised on a stalk by the side of the ovary.)

1. P. ceratophyllus, Michx. Leaves rigid or horny, dilated into a shcathing base, above mostly forked into thread-like or linear lobes. - Not rare in the bottom of shallow streams. July-Sept. - A small olive-green plant, of firm texture, resembling a Sea-weel, tenaciously attached to loose stones, in the manner of a Furus, by fleshy disks or processes in place of roots. 


\section{Order 97. EUPhoribiàceate. (SPURge Family.)}

Plants usually with a milky acrid juice, and monocious or dicecious flowers, mostly apetalous, sometimes achlamydeous (occasionally polypetalous or monopetalous); the ovary free and usually 3-celled, with a single or sometimes a pair of ovules hanging from the summit of each cell; stigmas or branches of the style as many or twice as many as the cells; fruit commonly a 3-lubed pod, the lobes or carpels separating elasticully from a persistent axis and elastically 2-valved; seed anatropous; embryo straight, almost as long as and the flat cotyledons mostly as wide as the fleshy or oily albumen. Stipules often present. - A vast family in the warmer parts of the world (the acrid juice poisonous); most numerously represented in Northern countries by the genus Euphorbia, which has very remarkable reduced flowers enclosed in an involucre that imitates a calyx. Our last genus belongs to the Box-Family, which some botanists of late separate from the Euphorbiacex, on account of the rhaphe being on the outer or dorsal sido of the suspended ovule, \&c.

\section{* Sceds anil ovules only one in each cell.}

- Staminate and pistillate flowers both destitute of caly $x$ as well as corolla, and contained in the same cup-shaped involucre, which imitates a calyx, - the whole liable to be mistaken for a single flower.

1. Euphorbia. Involucre surrounding many staminate flowers (each of a single naked stamen) and one pistillate flower (a 3-lobed pistil).

- - Staminate and pistillate flowers both with a calyx, not involucrate.

++ Stameus erect in the bud.

2. Jatropha. Flowers cymose or panicled. Calyx corolla-like, 5-cleft; the lobes imbricated in the bud. Stamens 10 or more.

8. Stillingia. Flowers in a spike, pistillate at the base. Caly $\times 2-3$-parted, the lobes imbricated in the bud. Stamens 2 or 3 . Stigmas or branches of the style 3 , simple.

4. A calypha. Flowers spiked or glomerate, the pistillate in the axil of bracts. Caly $x$ 3-6parted; in stamiuate flowers valvate in the bud. Stamens mostly 8 : anthers with 2 separate pendulous cells. Styley or stignas 3, dissected.

5. Tragla. Flowers in racemes, pistillate at the base. Calyx in staminate flowers valvate in the bud. Auther-cells united. Styles united at the base, simple.

+++ Stamens inflexed in the bud.

6. Croton. Flowers spiked or glomerate. Ovary and fruit 3- (rarely 2-4-) celled.

7. Crotonopsis. Flowers scattered on the branchlets. Ovary and fruit 1-celled.

* Seeds and ovules 2 in each cell. Calyx imbricated in the bud.

8. Phyllanthus. Flowers axillary. Stamens mostly 3 , and usually monadelphous.

9. Pachysandra. Flowers spiked. Caly $x$ 4-parted. Stamens 4 , separate.

\section{1. e U P H ó R i A, L. Spurge.}

Flowers moncecious, included in a cup-shaped 4-5-lobed involucre ( $f$ lower of older authors) resembling a calyx or corolla, and usually bearing large thick glands (with or without petal-like margins) at its sinuses. Sterile flowers numerous and lining the base of the involucre, each from the axil of a little bract, and consisting merely of a single stamen jointed on a pedicel like the filament : anther-eells globular, separate. Fertile flower solitary in the middle of 
the involuere, soon protruded on a long pedicel, consisting of a 3-lobed and 3 celled ovnry with no calyx, or a mere vestige. Styles 3 , ench 2 -cleft; the stigmas therefore 6. Pod separating into 3 one-seeded carpcls, which split elastically into 2 valves. Seed often caruncled. - Plants (herbs in the United States), with a milky acrid juice. Peduncles terminal, often umbellate-clustered; in the first section mostly appearing lateral, but not really axillary. (Named after Euphorbus, physician to King Juba.)

Genus newly elaborated for this work by Dr. Geores Engelmann.

A. APPENDICULAT A. Glunds of the involucre with potal-like, usually white or rose-colored, and entire or twothed margins or appendages; these almost obsolete in No. 1.

§ 1. ANISOPHÝLLUM. Leaves all similar, opposite, on short petioles, small, oblique at lase, furnishod with awl-shaped or sculy and often fringed persistent stipules: stems much branched, spreading or usually procumbent: involucres solitary in the forks of the brunches or in terminal or pseudo-lateral clusters, small, aluxays with 4 glands: seeds without a caruncle: oll our species are annuals, flowering throughout summer and autumn.

* Seeds smooth and even, ash-colored: leaves entire, glabrous, as is the whole plant, and pule green or glaucous.

1. E. polygonifolia, L. Prostrate-spreading; leaves oblong-linear, obtuse, mucronate, slightly cordate or obtuse at base $\left(4^{\prime \prime}-8^{\prime \prime}\right.$ long $)$; stipules setaccously divided; peduncles in the forks of the branches, as long as the petioles; lobes of the involucre longer than the minute not appenduged glands; pods obtusely angled; seeds ovate (over 1 "long, the largest of this section). - Sandy shores of the Atlantic and of the Great Lakes.

2. E. Géyeri, Engelm. Procumbent; leaves ollong-ovate, obtuse, slightly mucronate, mostly acutish at base, lowermost cordate $\left(3^{\prime \prime}-6^{\prime \prime}\right.$ long) ; stipules setaceously divided; peduncles as long as petioles, at length in loose foliaceous lateral clusters; glands of the involucre with narrow white or red appendages; pods acutely angled; seeds ovate, acute at one end ( $\frac{1}{2} "$ long). - Sandy soil, Illinois (Geyer, Vasey) to Wisconsin and Minnesota (T'. J. Hale).

The nearly allied E. гетA Lołnes, Engelm., of Kansas and Nebraska, extends into Western Missonri and Iowa, and may cross the upper Mississippi ; it is distinguished by its half-erect spreading growth; longer, narrower, and retuse or emarginate leaves; peduncles longer than petioles ; larger involucres, the broadly campanulate appendages much larger and conspicuous; capsule obtusely angled; secds nearly a line long.

3. E. sérpens, H. В. K. Stems filiform, prostrate, and often rooting; leaves round-ovate, obtuse or cordate at base (only $\frac{1}{2}{ }^{\prime \prime}-1 \frac{1}{2}{ }^{\prime \prime}$ long); stipules membranaccous, triangular; peduncles much longer than petioles, at length in loose foliaccous lateral clusters; glands of the very small involucre with minute crenulate appendages; pods acutely angled; seeds obtusely angled ( $\frac{1}{2}$ "long or less). (E. herniarioides, Nutt. and Ed. 2.) - In rich soil, Illinois, especially in the alluvions of the larger rivers, and southwestward: also adventive on ballast sand-banks of the Delaware near Philadelphia. (I. Martindule, C.F. Parker.) 
* Seeds minulely rouphened, or trunsversily urinliled, or pitted, ash-colored, or (in the last species) Ulaikish : leaves more or less serrulute, smooth or often hairy.

4. E. serpyllifolia, Pers. Glabruus, prostrate-spreading; haves obocuteoblong, narrowed at the very oblique base, sharply serrulate towards the obtuse apex $\left(3^{\prime \prime}-6\right.$ " long, often with a red spot $)$; stipules lanceolate, fimbriate; peduncles as long or longer than petioles, at length in loose fuliaceuto lateral clusters; glands of the snall involucre with narrow somew hat toothed appendages;

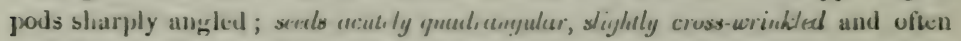
pitted (ncarly ă" lung). - Wiscunsin and Minncsutid, and sunthwestward.

5. E. glyptosperma, Eingelu. Glabruus (or vory rarely puberulent),

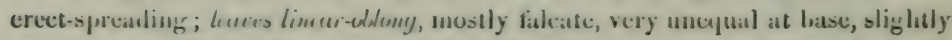
serrulate towards the ubluse upex ( $2 "$ " 5 " long); stipulus lanceulate, setaccously divided; peduncles as long as petioles, in deuse foliaceous lateral clustery; glands of the very small involucre with narrow crenulate appendages; pods sharply angled; seeds shurply 4 -tungled and with 5 or 6 sharp tiansverse wrinkles ( $\frac{1}{2}$ "long). - Wisconsin (Hale, Lapham) to Illinois, opposite St. Louis, where is also the pubescent form (Riehl), and southwestward.

6. E. máculata, L. Prostrate; stems puberulent or hairy ; leaves oblonglinear, very ublique at base, scrrulate upwards, more or less pubescent or sometimes smouthish $\left(4^{\prime \prime}-6^{\prime \prime}\right.$ long $)$, usually with a brown-red spot in the centre; stipules lanceolate, fimbriate; peduncles as long as perioles, in dense foliaceus lateral clusters; glands of the small involuce minute, with narrow slightly crenate (usually red) appendages; pods acutely angled, puberulent; seeds ovato (2" long), sharply 4 -angled and with about 4 shallow grooves across the concave sides. (E. thỵmifulia, Puish, not L. E. dopréssa, Turr.)-Upen places, roadsides, \&c. : werywhere.

7. E. humistràta, Engchu. P'rucumbent, puberulent or hairy; haers elliptical or weverte, very ubligue at base, serrulate towards the apes, sparsely lairy underncath ( $f^{\prime \prime}-y^{\prime \prime}$ long, sometimes with a brown spot above); stipules lanceolate, finbriate; peduncles rather shorter than petioles, in dense scarcely fuliaceous lateral clusters; incolucre de $\Omega$ on the hack, its (red or white) appeudages truncate or crenate; pods sharply angled, puberulent; secds ocute, oblusely angleal, minutely roughened ( $\frac{1}{2}$ " long). - Rich suil, in the alluvions of the Mississippi and lower Ohio and their tributaries; and also sonthward.

8. E. hypericifolia, L. Smooth or with scattered hairs, ascending or ercet $\left(1^{\circ}-2^{\circ}\right.$ high); leaves ollique at the ubtuse or slightly cordate base, ovate oblong or oblong-linear, sometimes falcate, serrate $\left(\frac{1}{2}^{\prime}-1 \frac{1}{2}^{\prime}\right.$ lung $)$, of then with a red spot or rul usargins; stipules triangular; puduncles longer than the petioles, collected in louse leafy cymes at the end of the branches; appenduges of the involucre entire, larecr and white, or smaller and somctimes rad; pod glabrous,

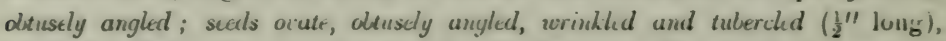
blackish. (This character is from the U. S. plant, E. Prislii, Gussone and Boissier, the E. hypericifulia, var. communis, Eingelm. The West Indian original E. hypericifolia, $L$. (lound also in Florida) has more compact and usually lateral inflorescence, smaller fluwers and small reddish seeds.) - Open places, cultivated soil: very common. 
§ 2. PETALÒMA. Uppermost or flowl Inves with conspicuons white petal-like margins, whorled or opposite, the others scuttered: erect annuals, with the leaves equal at the base and entire, and with lanceolute deciduous stipules: involucres mostly 5-lobed, collected in an umbel-like inflorescence: no carmele to the seed.

9. E. mangindta, P'ursh. Stem stout $\left(2^{\circ}-3^{\circ}\right.$ high $)$, erect, hairy; leaves sessile, ovate or oblong, acute; umbel with 3 dichotomons rays; glands of the involucre with broad white appendages. - Frequently cultivated in gardens for its showy broadly white-margined floral leaves: native of the plains of Kansas and Nebraska.

§3. TITHYMALÓPSIS. Only the uppermost or foral leaves whorled or opposite : erect perenvials, with entire leaves equal at the base: stipules none: involucres mostly 5-lobed, in the forks of the branches and terminal, in an umbelliform inflorescence: seeds without caruncle.

10. E. corollata, L. Glabrous or sometimes sparingly hairy $\left(2^{\circ}-3^{\circ}\right.$ high $)$; leaves ovato, lanceolnte, or linear, entire, obtuse; umbel 5- (3-7-) forked, and the forks ngnin 2-3- (or rarely 5-) forked; involucres long-peduncled; pod slender-pedicelled, smooth; seeds thick ( $l^{\prime \prime}$ long or more), ash-colored, the surface slightly uneven. - Rich or sandy soil, New York to Wisconsin and southward. July - Oct. - Conspicuous for the showy false lobes of the involuere, which appenr like five white petals, the true lobes minute and ineurved.

\section{B. EXAPIENDICULAT}

\section{§. POINSETTIA.}

often solitur'l cup-shaped glands: seed without a caruncle: ours erect annuals, with vuriable, entire, dentate, or sinuate leaves, all of them or only the upper ones opposite; the rppermost often colored, especially at the base: stipules small and glandular.

11. E. dentàta, Michx. Erect or ascending, hairy ( $1^{\circ}$ high $)$; leaves ovate, lanceolate, or lincar, petioled, coarsely toothed $\left(1^{\prime}-2^{\prime} \mathrm{long}\right)$, only the louest ones alternate, all others opposite, upper ones often paler at base; involucres almost sessile, with 5 oblong dentate lobes, and one or sometimes more short-stalked glands; seeds ovatc-globular, slightly tubercled. - Rich soil, Yenn. to Illinois and southward. July-Sept.

12. E. heterophýlla, L. Erect $\left(1^{\circ}-3^{\circ}\right.$ high $)$, glalorous; leaves alternate, petioled, ovate-fiddle-shaped and sinuate-toothed, or lanceolate or linear and entire, often only those of the branches linear; the upper ones usually with a red base; involucres about the length of the peduncle, with 5 ovate incised lobes and a single or few and almost sessile glands: sceds nearly globular, tubereled. (E. cynthóphorn, Jacq.) - Slopes snd rocky soil, W. Illinois and southward. July - Sept.

§ 5. TITHÝMALUS. Involucres in a terminal dichotomous or commonly umbelliform inflorescence, 5- or usually 4-lobed, with as many flat or convex entire or crescent-shaped glands: seeds mostly carunculate: ours ascending or erect, and glabrous (except No. 15) annuals or perennials; with entire or serrulate leaves, and no stipules.

* Perennials with entire lenves, all or only the upper ones opposite: involucres cong. 
peluncled in a dichotomous inflorescence, mostly with 5 obluse glands: seeds with. out caruncle.

3. E. Ipecacuánhæ, L. Stems many from a very long perpendicular root, erect or diffusely spreading $\left(5^{\prime}-10^{\prime}\right.$ long), forking from near the base; leaves varying from obovate or oblong to narrowly linear, almost sessile, glabrous; peduncles elungated $\left(\frac{1}{2}{ }^{\prime}-l^{\prime}\right.$ long); pod long-pedicelled, obtusely angled, nearly sinooth; secd ovate, white, sparsely marked with impressed dots. - Sandy soil, near the coast, New York to Virginia and southward. May-July.

* * Perennials or mostly annuals, with serrulate or raicly cntive scattered leaves, only the floral leaves in the umbelliform inflorescence uhorled or opposite and of different shape: glands of the involucre mostly 4, transiversely oval, obtuse.

+ Seeds smooth and even : pod warty or rough.

14. E. Darlingtonii, Gray. Tall perennial $\left(2^{\circ}-4^{\circ}\right.$ high $)$; leaves entire, minutely downy beneath; those of the stem lanceolate-oblong from a narrow base; the floral ones oval, very obtuse; the upper roundish-dilated with a truncate base; umbel 5-8-rayed, then simply forked; pod minutely warly; large globular seed with a small caruncle. (E. nemoràlis, Larl., not of Kiluibel.) - Cupses, I'enn. and southward along the mountains. July-Sept.

15. E. PLATYPHYLL, L. Erect annual $\left(8^{\prime}-18^{\prime}\right.$ high); upper stem-leaves lanceolute-oblong, acute, cordate at base, minutely serrulate, mostly with scattered lairs beneath; floral ones triangular-ovate, subcordate; umbel 5-rayed ; involucese with ciliate lobes und large sessile glands; styles longer than the ovary, united at the base, slighlly 2-cleft; pod covered with depressed warts. - Along the Great Lakes and the St. Lawrence to L. Champlain. June-Aug. (Adv. from Liu.)

16. E. obtusata, Pursh. Erect annual $\left(1^{\circ}-2^{\circ}\right.$ high); leaves oblong-sputulate, minutely serrulate, smouth, all obtuse; upper ones cordate at base; floral ones ovate, dilaterl, barely mucronate; umbel once or twice divided into 9 rays, then into 2; involucre with naked lobes and small stipitate glands; styles distinct and longer than the ovary, rect, 2 -cleft to the middle; pod beset with long warts. Damp woods, Virginia to Illinois. May - July.

\section{+ + Seeds rugose or reticulated: leaves serrulate: annuals.}

17. E. dictyospérma, Fischer \& Meyer. Stem erect $\left(8^{\prime}-18^{\prime}\right.$ high); lenves oblong-or ohovate-spatulate, smooth, all obtuse and obtusely serrate; upper ones cordate at base; floral ones roundish-ovate or obscurely heart-shaped, slightly mucronate; umbels onee or twice 3 -forked, then 2-forked; involucre with nearly naked lolses and small almost sessile glands; styles shorter than the ovary, spreading or recurved; pod waity; seeds delicately reticulated. (E. Arkansàna, Engelm. $\&$. Grọy.) - Prairies and roadsides, Kentucky (Short), and west and southwestward. May - July.

18. E. Hkıloscòrı, L. Stems ascending $\left\{6^{\prime}-12^{\prime}\right.$ high $)$, stout; leaves all obovate and very rounder or retuse at the end, finely serrate, smooth or a little hairy, those of the stem wedge-shaped; unbel divided into 5 rays, then into 3 , or at length simply forked; glands orbicular, stalked; pad smooth and even; seeds with coarse honeycomb-like reticulations. - Waste places, especially eastward and along the Great Lakes. July-Sept. (Nat. from Liu.) 
* * Perennials or annuals; ours wilh eutire and scrllered lenves, only the floral onea in the umbel-like inflorescence whorled or opposite and of different shape: glands of the involucre mostly 4, crescent-shaped or 2-hormed.

+ Seeds smooth and durk-colored: prremirls, with running rootstocks.

19. E. Esura, I. Stems clustered $\left(1^{\circ}\right.$ high); leaves lanceolute or linear; the floral (yellowish) broadly heor-shaped, mucronate; umbel divided into many rays, then forking; glands short-horned (brown); pods smoothish and granular. Essex County, Massachusetts, Oakes. June. (Adv. from Eu.)

20. E. Crparfssins, L. Stems densely clustered $\left(6^{\prime}-10^{\prime}\right.$ high); stem-tenies linear, croudin, the floval ones heart-shaped; umbel many-rayed; glands crescentshreper; pods granular. - Escaped from gardens to roadsides, in a few places in New England. (Adv, from Eu.)

$\leftarrow+$ Seeds sculptured, ash-colored: pod smooth: annurals or biennials.

21. E. Pípus, I. Erent or ascending $\left(5^{\prime}-10^{\prime}\right.$ high $)$; leaves petioled, thin, ro:ml-obovate, the upper floral ones ovats; umbel 3-rnyed, then forking; glands long-horned; lohes of the prol 2-ming-erested on the back; serds 2-grooved on the inner fuce, pitted on the back (scarcely ozer half a line long). - Waste places eastward : not common. July, $\Lambda$ ug.

22. E. commutata, Engelın. Stems branched from a commonly de. cumbent base $\left(6^{\prime}-12^{\prime}\right.$ high) ; leuves olvovate, obtuse; the upper all sessile, the "uper floral ones romdish-dilated, broaler than long; umbel 3-forked; glands with slender horns; pord obtusely angled, crestless; seuds orate, pitted all over (a line long). (E. Ohiótica, Studel \& Hochstetter.) - Along streams and shady slopes, from Virginia towards the mountains to Kentucky, Wisconsin, and westward. May, Junc. - Leaves often persistent over the winter on sterile shoots, turning rel. Larger in all its parts than E. Peplus, with which it has been confounded; but the characters of the pod and sceds readily distinguish it.

* ** A glahous annual or biemial, with entire opposite and decussate leaves, an unbelliform inflorescence, and short-hormed glands: sceds carunculate.

23. E. Lxtruxris, L. Stem stout $\left(2^{\circ}-3^{\circ}\right.$ high $)$; leaves thick, linear or oblong, the floral ones ohlong-ovate and heart-shaped; umbel 4-rayed, then forking.

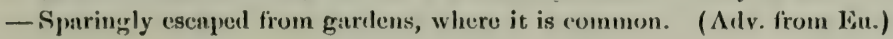

\section{JÁ TROPHA, I. (CNidoscolus, Pohl., Ed. 2.)}

Flowers monocious, rarely diøcious, in a terminal open forking cyme; the fertile ones usually in the lower forks. Calyx corolla-like, in the staminate flowers often salver-shajed, 5-lobed; in the pistillate, 5-parted, imbricated or convolute in the bud. Corolla of 5 ristinct or apparently united petals, or in our species none. Glands of the disk opposite the calyx-lobes. Stamens 10-30, in 2 or more whorls: filaments monadelphous at the base. Ovary mostly 3celled : styles 3, united below, their summits once or twice forked. Pod 3-celled, 3-sceled, separating into 3 two-valved carpels. Sced carunculate. - Perennial herbaceous or shrubby plants, chiefly tropical, with alternate mostly longpetioled palmately-veined leaves, and stipules. - Our species is of the seetion CNIDoscolus; of plants mostly armed with stinging bristles. (Name said by Linnæus to be formed of iarpóv, a remody, and $\phi a ́ \gamma \omega$, to eut.) 
1. J. ùrens, L., var. stimulosa, J. Müller. ('Tread-sortly. SpurgeNettce.) Herbaceous, from a long perennial root, branching $\left(6^{\prime}-2^{\circ}\right.$ high $)$; leaves roundish-heart-shinped, 3-5-lobed; the divisions toothed, cut, or even pinnatifid, often discolored; flowers slender; filaments 10, monadelphous only at the woolly base, or the outer set almost distinct. (J. stimulosa, Michx. Cnidoscolus stimulosus, $E d$. 2.) - Dry sandy soil, Virginia on the coust, and southward. June-Sept.

\section{S TiLLÍNGIA, Garden. Stillingia.}

Flowers monœcious, aggregated in a terminal spike. Petals and glands of the disk none. Calyx 2-3-cleft or parted; the divisions inbricated in the bud. Stamens 2 or 3 : anthers alnate, turned outwards. Style thick: stigmas 3 , diverying, simple. I'od 3-celled, 3-lobed, 3-secded. Seed carunculate. - Smooth upright plants, with the alternate leaves mostly 2-glandular at the base; the fertile flowers few at the base of the dense sterile spike (rarely separate); the bract for each cluster with a gland on each side. (Named for Dr. B. Stillingflect.)

1. S. sylvática, L. Herbaceuns $\left(1^{\circ}-3^{\circ}\right.$ high $)$; leaves almost sessilc, oblong-lanceolate, serrulate ; glauls of the spike saucer-shaped. - Sandy and dry soil, E. Virginia and southward. June-Sept.

\section{A C A L Ỳ PHA, L. Thrle-seeded Mercury.}

Flowers monocious; the sterile very small, clustered in spikes, with the few or solitary fertile flower's at their base, or sometimes in separate spikes. Calyx of the sterile flowers 4-parted and valvate in the bud; of the fertile 3-5-parted. Corolla none. Stamens 8-16: filaments short, monalelphous at the base: anther-cells separate, long, often worm-shaped, hanging from the apex of the filanent. Styles 3, the upper fice or stigmas cut-fringed (usualiy red). I'od separating into 3 globular carpels which split into 2 valves, rarely of only one carpel. - Herbs (ours annuals), or in the tropics often shrubs, with the appearunce of Nettles or Amaranths; the leaves alternate, petioled, with stipules. Clusters of sterile flowers with a minute bract; the fertile surrounded by a

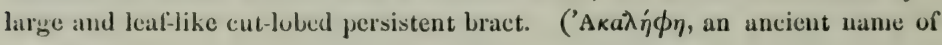
the Nettle.)

$$
\text { * Fruit smooth or merely pubescent: seeds nearly smooth. }
$$

1. A. Virgínica, L. Leaves ovate or oblong-ovate, obtusely and sparsely. serrate, long-petioled; sterile spike rather few-flowered, mostly shorter than the deeply palmately-cleft fruiting bracts. - Fields and open places : common. July - Sept. - A homely weed, $1^{\circ}-2^{\circ}$ high, smoothish or rather hairy, often turning purplish in autumn. Fertile flowers $1-3$ in each axil, along with the small and short-peduncled sterile spike: bracts large and leaf-like, unequally cut into 5-9 lanceolate lobes. - Passes by various forms (belonging to var. INTERMEDIA, .J. Mä̈l.) into

Var. grácilens, with lanceolate or even linear leaves, less toothed and shorter-petioled; the slender sterile spike often l' long, and much surpassing the less cleft or few-toothed fruiting bracts. (A. gracilens, Ed. 1 \& 2. A. Virginiana, var. gracilescens, J. Müll. A. monocócea, Enyelm., a reduced form with 
two cells of the ovary abortive.) - Sandy dry soil, Rhode Island to Illinois, and common southward.

* Fruit echinate with snft bristly green projections : seeds rough-urinkled.

2. A. Caroliniàna, Walt., Ell. I,eaves thin, ovatc-corrlate, sharply and closely serrate-toothed, abruptly ncuminate, long-petioled; sterile spikes short, axillary ; the fertile ones mostly terminal and elongated, its bracts decply cut into many linear lobes. (A. ostryæfolia, Riddell.) - New Jersey (Princeton, Torrey), Ohio, and southward.

\section{TR À G I A, Plumicr. Tragia.}

Flowers monœcious, in racemes, apetalous. Ster. Fl. Calyx 3-5- (chicfly 3-) parted, valvate in the bud. Stamens 2 or 3: filaments short: anther-cells united. Fert. F/. Calyx 3-8-parted, persistent. Style 3-cleft or 3-parted; the branches 3 , simple. Pod 3-celled, 3-lobed, bristly, separating into three 2-valved 1-seeded carpels. Sceds not carunculate. - Ereet or climbing plunts (perennial herls in U.S.), pubescent or hispid, sometimes stinging, with mostly alternate stipulate leaves; the small-flowered racemes terminal or opposite the leaves; the sterile flowers above, the few fertile at the base, all with small bracts. (Named for the early herbalist Bock, latinized Tragus.)

1. T. innócua, Walt. Erect, paniculate-branched, sofly hairy-pubescent $\left(6^{\prime}-12^{\prime}\right.$ high) ; leaves varying from obovate-oblong to narrowly linear, acute at the base, obtusely or sinuately few-toothed or lohed, sometimes entire, short-petioled or sessile, paler beneath ; stamens 2. (T. ùrens, L., having been discarded as a fulse name, the next oldest, and a good one, is adopted, rather than the recent one of T. díscolor, Mialler.) - Dry sandy soil, E. Virginia and southward. May - Aug.

2. T. urticæfolia, Michx. Erent or reclining or slightly twining, hirsute with stinging hairs; laves ovate-lanceolate or triangular-lanceolate, or the lower ovate, all somewhat cordate or truncute at the base, coarsely cut-toothed, short-petioled. - Virginia (Pursh), and common southward.

3. T. macrocárpa, Willd. Tivining, somewhat hirsute, not stinging; Aarrs derply cordute, ovate, sharply serrate ( $3^{\prime}$ long), all but the uppermost longpetioled (pod $\frac{1}{2}$ 'broad). ('T. cordata, Michx.) - Kentucky (Michaux,) and southward. - Apparently quite distinct.

\section{CRÓTON, L. Croton.}

Flowers monœcious, rarely diœcious, mostly in terminal spike-like racemes or spikes. Ster. Fl. Calyx 5-(rarely 4-6-) parted; the divisions lightly imbricated or nearly valvate in the bud. Petals usually present, but mostly small or rudimentary, hypogynous, as many as the divisions of the calyx. Glands or Jobes of the disk as many as and alternute with the petals. Receptacle usually hairy. Stamens 5 or more: filaments with the anthers inflexed in the bud. Fert. Fl. Calyx 5-10-cleft or parted, nearly as in the staminate flowers : but petals none or minute rudiments. Ovary mostly 3-celled, rarely 2-celled, with a single ovule in each cell : styles as many, from once to thrice 2-cleft. Pod 3(rarely $2-4^{-}$) celled, separating into as many 2 -valved 1-seeded carpels. Seeds 
carunculate. - Stellate-downy, or scurfy, or hairy and glandular plants, mostly strong-scented; the sterile flowers above; the fertile usually at the base of the same spike or cluster. Leaves alternate, or sometimes imperfectly opposite, with or without obvious stipules. (Koot $\dot{\nu}$, the Greek name of the Castur-vil Plant, of this family.)

§ 1. GLISELĖRIA, Klotzsch. Sterile flowers mostly with a 4-parted calyx, as many ovale-tanceulate petuls, a 4-rayed disk, and 8 stamens: fertile flunvers with a 5-parted calyx, und very minule awh-shaped rudincents of petuls; the 3 styles 2 -cteft.

1. C. glandulosus, L. Aumual, rough-hairy and glandular $\left(1^{\circ}-2^{\circ}\right.$ high $h$, somewhat unbellately brimclied; leaves oblong or lincar-vblung, ubtusely tooched, the base with a sancer-shaped gland on each side; fertile flowers capitate-clustered at the baste of the sterile spike, sessile in the forks and terminal. - Open waste places, Virginia, Illinois, and southward. July-Sept.

§ 2. PILINÓPHYTUM, Klotzsch. Sterile fluvers with the calyx equally 5parted, as many glands alternate with the petuls, and 10-14 stamens: fertile flowers with a 7-12-prarted calyx und willout petuls; the 3 styles twice or thrice 2-parted.

2. C. capitàtus, Michix. Annual, densely soft-woolly and somewhat glandular $\left(1^{\circ}-2^{\circ}\right.$ high $)$, branched; leaves long-petioled, lance-oblong or clongated-oblong, rounded at the base, entire; petals ubovate-lanceolate, densely fimbriate; fertile tlowers several, calpitate-crowded at the base of the short terminal sterile spike. - Barrens of Illinois, Kentucky, and southward. P'ine barrens of New Jersey, Kuieskern! July - Sept.

§3. GYNAMBLòsIS, Torr. (Engelmannia, Klutzsch.) Slerile flowers with an uncqually 3-5-purted culyx, and as menuy petuls und scale-like glands; the stamens varying from 3-11: fertile floners with an equally 5-parted caly.x, and with no petals, 5 iglends, and a 2-3-celled overy, crowned with as mamy sessile 2-parted stigmess.

3. C. monanthógynus, Michx. Amnual, whitish-stellate-pubesecnt and rusty-glandular; stems $\left(1^{\circ}-2^{\circ}\right.$ high $)$, slender, ereet, below often umbellately 3-4-forked, then repreatedly 2-3-forked or alternately branched; leaves oblungovate or narrowly oblung, entire, often acutish $\left(6^{\prime \prime}-12^{\prime \prime}\right.$ long, about twice the length of ther petioles); (lowers in the forks, the sterile few on the summit of a short and crect peduncle, the fertile few and clustered or mostly solitary on short recurved peduncles; stamens $3-8$; ovary 2-celled; fruit often by abortion l-eelled and 1-seedel; the seed broadly oval. (C. ellipticum, Nutu. Engelınannia Nutcalliania, Klotzsch. Gynamblosis monanthogyna, Torr.) Barrens and dry prairies, from Illinois and Kentucky southward and westward. June-Sept.

(C. eutufgrus, as it may he named, is the related Texan species, - with more silvery ilown, rounder leaves on longer petioles, $7-12$ stamens, more peduncled fertule flowers, and a 3-celled ovary generally ripening 3 oblong-oval sects, - mentioned by Torrey as a possible variety of this, and taken by Baillon and Miiller for C. elliptecus of Nuttall.) 


\section{CROTONÓPSIS, Michx. Crotonorsis.}

Flowers monocious, in very small terminal or lateral spikes or clusters, the lower fertile. Ster. Fl. Calyx equally 5-parted. Petals 5, spatulate. Stamens 5, opposite the petals: filaments distinct, inflexed in the bud, enlarged at the apex. Fert. Fl. Calyx unequally 3-5-parted. Petals none. Glands (petal-like scales) 5, opposite the sepals. Ovary 1-celled, simple, 1-ovuled, bearing a twice or thrice forked style. Fruit dry and indehiscent, small, 1-seeded. - $\Lambda$ slender low annual, with alternate or opposite short-petioled linear or elliptical-lanceolate leaves, which are green and smoothish above, but silvery hoary with starry hairs and scurfy with brownish scales underneath, as well as the branches, \&e. (Name compounded of K plant with the aspect and gencral character of Croton.)

1. C. lineàris, Michx. - 1)ry sandy soil, New Jersey (Knieskern, C. E. Smith), Bristol, Pennsylvanir (E. Diffenbaugh), Illinois, and southward. July Sept. The form with shorter and broader leaves is C. ellíptica, Willd., and C. argéntea, Pursh.

\section{PHYLLÁ N THUS, L. Phrlenntuus.}

Flowers monocious, axillary. Calyx usually 5-6-parted, imbricated in the bud. Petals none. Stamens mostly 3, erect in the bud, often united. Ovules 2 in each cell of the ovary. Pod depressed; each carpel 2-valved, 2-sceded. Seeds not carunculate. - Leaves alternate, 2-ranked, with small stipules. (Name com-

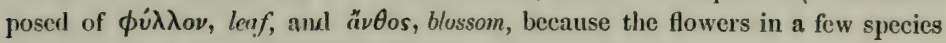
are borne upon leaf-like dilated branches.)

1. P. Carolinénsis, Walt. Aunutal, low and slender, branched; leaves obovate or oval, short-petioled ; flowers commonly 2 in each axil, almost sessile, one staminate, the other fertile; calyx 6-parted; stamens 3; styles 3, each 2-cleft; glands of the disk in the fertile flowers united in $\Omega$ cup. - Gravelly bauks, E. P'enn. to Illinois and southward. July-Scpt.

\section{PACH $\mathbf{Y}$ S Á N DA, Michx. Pacuysandra.}

Flowers monœcious, in naked spikes. Calyx 4-parted. Petals none. Ster. Fl. Stamens 4, separate : filaments long-cxserted, thick and flat : anthers oblong-linear. Fert. Fl. Ovary 3-celled : styles 3, thick, awl-shaped, recurved, stigmatic down their whole length inside. ()vules a pair in ench cell, suspended, with the rhaphe dorsal (turned away from the placenta). Pod deeply 3 -horned, 3 -celled, splitting into 3 at length 2-valver 2-seeded carpels. - Nearly glabrous, low and procumbent, perennial herbs, with matted creeping rootstocks, and alternate, ovate or obovate, coarsely toothed leaves, narrowed at the base into a petiole. Flowers each 1-3-bracted, the upper staninate, a few fertile ones at the base, unpleasantly scented: sepals greenish or purplish : filaments white (the size and thickness of the latter giving the name, from $\pi a \chi \chi^{i}$, thick, and ${ }^{2} \nu \delta \rho a$, used for stamen).

1. P. procúmbens, Michx. Stems $\left(6^{\prime}-9^{\prime}\right.$ long) bearing several ap. proximate leaves at the summit on slender petioles, and a few many-flowered spikes along the base; the intervening portion naked, or with a few small scales. 
(P. erécta, Raf., Buillon, is the same.) - Woods, mountains of Kentucky, W Virginia, and southward. March-May.

\section{Order 98. empétiticeat. (Crowberty Family.)}

Low shrubby evergreens, with the foliage, aspect, and compound pollen of Heaths, and the drupaceous fruit of Arctostaphylos, but the divided or laciniate stigmas, \&ce. of some Euphorbiacea : - probably only an apetalous and polygamous or dicecious degenerate form of Ericacex, - comprising three genera, two of which occur within the limits of this work, and the third farther south.

\section{1. ÉMPETRUM, Tourn. Crowberry.}

Flowers polygamous, scattered and solitary in the axils of the leaves (inconspicuous), scaly-bracted. Calyx of 3 spreading and somewhat petal-like sepals. Stamens 3. Style very short: stigma 6-9-rayed. Fruit a berry-like drupe, with 6 - 9 seed-like nutlets, each containing an erect anatropous seed. Embryo terete, in the axis of copious albunen, with a slender inferior radicle and very small cotyledous. (An ancient name, from $\dot{\epsilon} \nu$, upon, and $\pi \dot{\epsilon} T \rho o s, a$ rock.)

1. E. nigrum, L. (Black Crow berny.) Procumbent and spreading; leaves linear-oblong, scattered ; fruit black. - Alpine summits of the mountains of New Lingland and New York, Lake Superior, and northward. (Eu.)

\section{C O R E MA, Don. (Broom-Crowberry.)}

Flowers diøecious or polygamons, collected in terminal heads, ench in the axil of a scaly bract, and with 5 or 6 thin and scarious imbricated bractets, but no proper calyx. Stamens 3, rarely 4, with long filaments. Style slender, 3(or rarely 4-5-) cleft: stigmas narrow, often toothed. Drupe small, with 3 (rarely 4-5) nutlets. Seed, \&c. as in the last. - Diffusely much-branched little shrubs, with scattered or nearly whorled narrowly lincar heath-like leares. (Name к'́pqua. a lroon, from the bushy aspect.)

1. C. Conrádii, Torrey. Diffusely branched, nearly snooth ; drupe very small, dry and juiceless when ripe. (Empetrum, Torr. Tuckermánia, Klotzsch. Oakèsia, Tuckermann.) - Sandy pine baurens and dry rocky places, New Jersey; Long Island; Plymouth and Cape Corl, Massachusetts; Bath, and islands of Penobscot Bay, Maine. (Also Newfoundland.) April. - Shrub 6 ${ }^{\prime}-9^{\prime}$ high : the sterile plant handsome in flower, on account of the tufted purple tilaments and brown-purple anthers. (Gray, Chlor. Bor-Am.t. 1.)

\section{Order 99. URTicicea. (Nettle Family.)}

Plants with stipules, and monccious or dixcious, or rarely (in the Elm Family) perfect flowers, furnisherl with a regular calyx, free from the 1celled (rarely 2-celled) ovary which forms a 1-sceded fruit; the embryo in the albumen when there is any, its radicle pointing upwards; stamens as 
many as the lobes of the calyx and opposite them, or somctimes feiver. Cotyledons usually broad. Stipules often deciduous. - A large order (far the greater part tropical), comprising the following suborders, viz.:-

\section{Suborder i. ULMaceat. Elm Family.}

Flowers perfect or monceiously polygamous. Filaments straight or moderately incurved in the bud. Styles or stigmas 2. Fruit a samara or drupe. Seed suspended. - Trees, with a watery juice (no active or noxious properties), and alternate leaves.

\section{* Fruit dry, winged or crested (a samara): anthers extrorse.}

1. Ulmus. Flowers sometimes perfect. Ovary 2-ovuled. Fruit 1-celled, winged.

2. Planera. Flowers polygamous. Ovary 1-ovuled. Fruit wingless, nut-like.

* Fruit a drupe : anthers introrse.

3. Celtig. Flowers polygamous. Ovary 1-ovuled. Cotyledons curved and crumpled,

\section{Suborder II. Ait'Tucatepie. Bread-fruit \& Fig Family.}

Flowers monœcious or dicecious, crowded in catkin-like spikes or heads; the calyx, \&c. becoming fleshy or juicy in fruit, but the 1- (rarely 2-) celled ovary ripening as a dry achenium. Styles or stigmas commonly 2. - Mostly trees or shrubs, with a milky or yellow (acrid or poisonous) juice, and alternate (rough or smooth) leaves. - Stamens inflexed in the bud, and elastically spreading when the flower opens, in the Tribe More.e.

4. Morns. Fertile and sterile flowers in scparate spikes. Calyx berry-like in fruit.

\section{Suborder III. Uir'ticene. Nettle Family.}

Flowers monæcious or dicecious. Filaments transversely wrinkled and inflexed in the bud, straightening or spreading elastically when the flower opens. Style or stigma simple. Ovary always 1-celled, with an erect orthotropous ovule, forming an achenium in fruit. Embryo straight in the axis of albumen. - Ilerbs (or in the tropics often shrubs or trees), with a watery bland juice, a tough fibrous bark, and opposite or alternate leaves: many are armed with stinging hairs.

- Caly $x$ in the fertile flowers of 2-5 sepamte or nenrly keparato sepals. - Plant beset with stinging bristles.

5. Urtlea. Sepals 4 in both sterile and fertile flowers. Achenium straight and erect, en. closed by the 2 inner and larger sepals. Stigma capitate-tufted. Leaves opposite.

6. Ln porten. Sepals 5 in the sterile flowers, 4 in the fertile, or apparently only 2 , the two exterior minute and obscure. Arhenium very oblique and bent down, nearly naked. Stigma long and awl-shaped. Leaves alternate.

+ + Plant rholly destitute of stinging bristles.

7. Pllea. Sepals 3 or 4 , those of the fertile flowers unequal, all or all but one small. Achenium partly naked, straight and ereet. Stigma pencil-tufted.

* Caly $x$ of the fertile flowers tubular or cup-shaped, enclosing the achenium.

8. Bohmerin. Flowere monocious, glomerate, the clusters spiked, not involucrate. St, lo long and thread-shaped, stigmatic down one side.

9. Parletarla. Florers polygamous, in involucrate-bracted clusters. Stigma tufted. 


\section{Suborder IV. CanNa bine}

Flowers dicecious; the sterile racemed or panicled; the fertile in elusters or catkins. Filaments short, not inflexed in the bud. Fertile calyx of one sepal, embracing the ovary. Stigmas 2, elongated. Ovary 1-celled, with an erect orthotropous ovule, forming a glaudular achenium in fruit. Seed with no albumen. Embryo coiled or bent. - Herbs, with a watery juice, mostly opposite and lobed or divided leaves, and a fibrous inner bark (yielding bitter and narcotic products).

10. Cannabis. Fertile flowers spiked-clustered. Anthers drooping. Leaves 5-7-divided.

11. Humulus. Fertile towers in a short spike forming a membranaceous cutkin in fruit. Anthers erect. Leaves 3-5-lobed.

\section{1. Ú L M U S, I. E⿺.⿻.}

Calyx bell-shaped, 4-9-cleft. Stamens 4-9, with long and slender filanents. Ovary 2eelled, with a single anatropous ovule suspended fiom the summit of each cell, rarely 1 -celled: styles 2 , short, diverging, stigmatic along the inner edgre. Fruit (by obliteration) a l-eelled and I-seeded membranaceous samara, winged all around. Slbumen none: embryo stritight the cotyledons large.Flowers polygamous, purplish or yellowish, in lateral elusters, in our species preceding the leaves, which are strongly straight-veined, short-petioled, and oblique or unequally somewhat heart-shaped at the base. Stipules small, caducous. (The classical Latin name.)

* Flowers appearing nearly sessile: fruit orbicular, not ciliule: leaves very rough above.

1. U. fúlva, Mich. (Sirppery or Red Els.) Buds before expansion soft-downy with rusty hairs (large); leaves ovate-oblong, taper-pointed, doubly serrate $\left(4^{\prime}-8^{\prime}\right.$ long, sweet-scented in drying), soft-downy underneath or slightly rough downwards; branchlets downy; calyx-lobes and stamens 7-9; fruit $\left(8^{\prime \prime}-9^{\prime \prime}\right.$ wide) with the cell pubescent. - Rich soil from W. New England to Lake Superior and southward. March, April. - A small or middle-sized tree, with tough reddish wood, and a very mucilaginous inner bark.

* * Flowers on slender drooping peduncles or perlicels, which are jointed above the mildle: fruit ovate or oval, fringed-ciliate: leaves smooth above, or nearly so.

2. U. Americàna, L. (pl. Clayt.), Willd. (Aмеican or Wirte Elm.) Buds and branchlets glabrous; lranches not corky; leaves obovate-oblong or oval, abruptly pointed, sharply and often donbly serrate $\left(2^{\prime}-4^{\prime}\right.$ long $)$, soft-pubescent beneath, or soon glabrous; flowers in close fascicles; calyx with 7-9 roundish lobes; fruit glabrous except the margins ( $\left(\frac{1}{2}\right.$ long), its sharp points incurved and closing the notch. - Moist woods, especially along rivers, in rich soil. A pril. A large and well-known ornamental tree, variable, usually with spreading branches and drooping branchlets.

3. U. racemósa, Thomas. (Cонкх Write Elar.) Bud-scales downyciliate, and somewhat pubsesecut, as are the young branchlets; branches oflen with sonky ridges; leaves nearly as in the last, but with veins more simple and straight ; flowers racemed; fruit much as in the last, but rather larger. - River-banks, W. New England to Wisconsin and southward. April. 
4. U. alàta, Michx. (Wияноo or Winged Er.m.) Bud-scales and branchlets nearly glalnous; branches corky-winged, at least some of them; leaves downy beneath, ovate-oblong and oblong-lanceolate, acute, thickish, small ( $1^{\prime}-2 \frac{1}{2}$ ' long); calyx-lohes obovate; fruit downy on the face, at least when young. - Virginia to Illinois, and southward. March. - Wood fine-grained, valuable.

\section{PL $\mathbf{A} \mathbf{N} \mathbf{E} \mathbf{A}$, Gmelin. Planer-tree.}

Flowers monøciously polygamous. Calyx 4-5-cleft. Stamens 4-5. Ovary ovoid, 1-celled, 1-ovuled, crowned with 2 spreading styles which are stigmatose down the inner side, in fruit becoming coriaccous and nut-like, not winged. Albumen none: embryo straight. - Trees with small leaves, like those of Elms, the flowers appearing with them, in small axillary clusters. (Named for $J . J$. Planer, a German botanist.)

1. P. aquática, Gmel. Nearly glabrous; lenves ovate-oblong, small; fruit stalked in the calyx, beset with irregular rough projections. - Wet banks, Kentucky (Michuux) and southward. $\Lambda_{\text {pril. }}$

\section{C ÉLTIS, Tourn. Nettle-tree. Hackberry.}

Flowers monocciously polygaınous. Calyx 5-6-parted, persistent. Stamens 5-6. Ovary 1-celled, with a single suspended ovule: stigmas 2, long and pointed, recurved. Fruit a globular drupe. Embryo curved, nearly enclosing a little gelatinous albumen : cotyledons folded and crumpled. - Leaves pointed, petioled. Stipules caducous. Flowers greenish, axillary, the fertile solitary or in pairs, peduncled, appearing with the leaves; the lower nsually staminate only, in little fascicles, or racemose along the base of the branches of the season. (An ancient Greek name for the Lotus; the fruit of the European Nettle-tree supposed to have been the foorl of the Intophagi.)

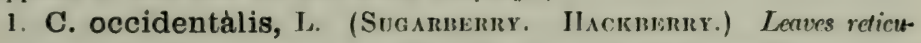
lated, ovate, cordate-ovate and ovate-lanccolate, taper-pointed, usually conspicuously and sharply so, more or less oblique at the base, sharply serrate, sometimes sparingly so or only towards the apex, scalorous but mostly glabrous ahove, usually soft-pubescent beneath, at least when young ; fruit reddish or yellowish, turning dark purple at maturity, its pelunele once or twies the length of the petiole. (Also C. Audibertiana, Spach., \&c.) - Woods and river-banks, New

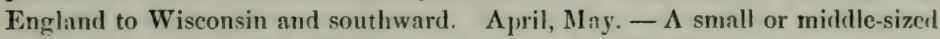
tree, with the aspect of an Elm, bearing sweet and edible fruits as large as birdcherries, at first obovate, ripe in autumn; the flesh thin.-Var. PÙmLA. Low and straggling $\left(4^{\circ}-10^{\circ}\right.$ high $)$; leaves thin when mature, and smooth, slightly acuminate. (C. pumila, Pursh.) Rirer-banks, on rocks, from Maryland southward. - Var. crassifòlia. $\Lambda$ tall or low tree; leaves thicker, usually serrate all round, and with a long tapering point, dull above, pale beneath. (C. crassifolia, Lam.) - Common southward and westward.

2. C. Mississippiénsis, Bose. Lraves entire, very long taper-pointed, rounded at the base, mostly oblique, thin, and smooth; fruit small. (C. integrifolia, Nutt.) -W. Kentucky, Illinois ? and southwestward. - Even this probably runs into the last. 


\section{MÒ RUS, Tourn. MulberRY.}

Flowers monœcious or diœeious; the two kinds in separate axillary and catkin-like spikes. Calyx 4-parted; lobes ovate. Stanens 4 : filaments elastically expanding. Ovary 2-eelled, one of the cells smaller and disappearing: styles 2, thread-form, stigmatic down the inside. Achenium ovate, compressed, covered by the sueculent berry-like calyx, the whole fertile spike thus becoming a thickened oblong and juicy (edible) aggregate fruit. - I'rees with milky juice and roundel leaves: sterile spikes rather slender. (Mopéa, the ancient name.)

1. M. rùbra, L. (Lís Mulikikx.) Leaves lieart-uvate, serrate, rongh atore, downy undermath, pointed (on young shoots often lobed); flowers frequently dicecious; fruit durk purple, long. - Rich woods, New England to lllinois and southward. May. - Small tree, ripening its blackberry-like fruit in July.

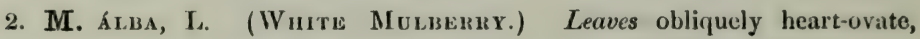
acute, serrate, sometimes lobed, smooth and shining; fruit whitish. - Spontancous near houses: introduced for feeding silk-worms. (Adv. from Eu.)

\section{U R Tíc A, Tuurn. Nettle.}

Flowers moncecious, or rarely diøecious; clustered, the clusters mostly in racemes, spikes, or loose heads. Ster: $F l$. Sepals 4. Stamens 4, inserted around the cup-shaped rudiment of a pistil. Fert. Fl. Sepals 4, in pairs; the 2 vuter smaller and spreading; the 2 inner flat or concave, in fruit membranaceous and enclosing the straight and erect ovate flattened achenium. Stigma sessile, capitate and pencil-tufted. - Herbs armed with stinging hairs. Leaves opposite: stipules in our species distinct. Flowers greenish; in summer. (The classical Latin name; from uro, to burn.)

* Perennials: flower-clusters in branching panicled spikes, often dioecious.

1. U. grácilis, Ait. Sparingly bristly, slender $\left(2^{\circ}-6^{\circ}\right.$ high $)$; leaves ovatelanceolate, pointed, serrate, 3-5-nerved from the rounded or scarcely heart-shaped base, almost glabrous, the elongated slender petioles sparingly bristly; spikes slender and loosely panicled. (U. procera, Willd.) - Fence-rows and moist ground : common. Sting's few.

2. U. DIolcA, L. Very bristly and stinging $\left(2^{\circ}-3^{\circ}\right.$ high $)$; leaves ovate, heartshaped, pointed, very deeply servate, downy underneath as well as the upper part of the stem; spikes much brunched. - Waste places and roadsides, chiefly castward. (Nat. from Eu.)

* * Anmuals : flower-clusters chirfly axillury and shorter than the petiole, andronynous.

3. U. ÙRENs, L. Leaves elliptical or ovate, very coarsely and deeply serrato with long spreading tecth, the terminal not longer than the lateral ones; flowerclusters 2 in each axil, small and loose. - Waste grounds, near dwellings, eastward: scarce. 1'lant $8^{\prime}-12^{\prime}$ high, with sparse stings. (Nat. from En.)

4. U. chamædryoides, Pursh. Lraves ovcute and mostly heurt-shaped, the upper ovate-lanceolate, coarsely serrate-toothed; floner-elusters glolular, $1-2$ in cach axil, and spiked at the summit. (U. gracilis \& U. verna, Raf. U. purpuráscens, Nutt.) - Alluvial sharled soil, Kentucky and southward. - Slender. $6^{\prime}-30^{\prime}$ high, sparsely beset with stings. 


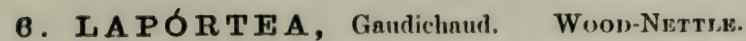

Flowers monnecious or diøecious, clustered, in loose cymes; the upper widely spreading and chiefly or entirely fertile; the lower mostly sterile. Ster. Fl. Sepals and stamens 5, with a rudiment of an ovary. Fert. Fl. Calyx of 4 sepals, the two outer or one of them usually minute, and the two inner much larger. Stigma elongated awl-shaped, hairy down one side, persistent. Achenium ovate, flat, extremely oblique, reflexed on the winged or margined pedicel, nearly naked. - Perennial herbs, with stinging hairs, large alternate serrate leaves, and axillary stipules. (Named for M. Lapurte.)

1. L. Canadénsis, Gaudichaud. Leaves ovate, pointed, strongly feather. veined $\left(3^{\prime}-7^{\prime}\right.$ long), long-petioled; fertile cymes divergent; stipule single, 2-cleft. (U. Canadensis and U. divaricata, L.) - Moist rich woods. July Sept. - Stem $2^{\circ}-3^{\circ}$ high.

\section{Píte A, Lindl. Richweed. Clearweed.}

Flowers monøecious or diocious. Ster. Fl. Sepals and stamens 3-4. Fert. F7. Sepals 3, oblong, more or less unequal : a rudiment of a stamen commonly hefore each in the form of a hooded scale. Stigma sessile, pencil-tufted. $\Lambda$ chenium ovate, compressed, erect, partly or nearly naked. - Stingless, mostly glabrous and low herbs, with opposite leaves and united stipules; the staminate flowers often mixed with the fertile. (Namerl from the shape of the larger sepal of the fertile flower in the original species, like the pileus, or felt cap, of the Romans, which partly covers the achenium. In our solitary species the three epals are nearly equal, small, and not hooded.)

1. P. pùmila, Gray. (Rrchweed. Ceesrween.) Low $\left(3^{\prime}-18^{\prime}\right.$ high); stems smooth and shining, pellncid; leaves ovate, conrsely toothed, pointed ; 3-ribbed and veiny ; flower-clusters much shorter than the petioles; sepals of the fertile flowers lanceolate, scarcely unequal. (Urtica pumila, $L$. Dubrueília pumila, Gaudichaud. Adice pumila, Raf.) - Cool and moist shaded places. July - Sept.

\section{BGH M E R I A, Jacq. False Nettle.}

Flowers monœcious or diøeious, clustered; the sterile much as in Urtica; the fertile with a tubular or urn-shaped entire or 2-4-toother calyx enclosing the ovary. Style elongated awl-shaped, stigmatic and papillose down one side. Achenium elliptical, closely invested by the dry and persistent compressed calyx. - No stings. (Named after G. R. Böhner, Professor at Wittenberg in the last century.)

1. B. cylíndrica, Willd. Perennial, smoothish; stem $\left(1^{\circ}-3^{\circ}\right.$ high $)$ simple; leaves chicfly oppositc, oblong-ovate or ovate-lanccolate, pointed, serrate, 3-nerved, long-petioled; stipules distinct; flowers dixcious, or the two kinds intermixed, the small clusters densely aggregated in simple and elongated axillary spikes, the sterile interrupted, the fertile often continuous. - $\mathbf{A}$ state with alternate leaves is B. lateriflòra, Muhl. - Moist or shady ground: very common throughout. 


\section{PA R I ét À Ria, Tourn. Pellitory.}

Flowers monociously polygamous; the staminate, pistillate, and perfect intermixed in the same involucrate-bracted cymose axillary clusters; the sterile much as in the last; the fertile with a tubular or bell-shaped 4-lobed and nerved calyx, enclosing the ovary and the ovoid achenium. Style slender or none: stigma pencil-tufted. - Homely, diffuse or tufted herbs. not stinging, with alternate entire 3-ribbed leaves, and no stipules. (The ancient Latin name, because growing on old walls.)

1. P. Pennsylvánica, Muhl. Low, annual, simple or sparingly branched, minutely downy; leaves oblong-lanceolate, thin, veiny, roughish with opaque dots; flowers shorter than the leaves of the involucre; stigma sessile. - Shaded rocky banks, Vermont to Wisconsin and soutliward. June-Aug.

\section{CÁ N N A B I S, Tourn. Hèr.}

Flowers diocious; the sterile in axillary compound racemes or panicles, with 5 sepals and 5 drooping stamens. Fertile flowers spiked-clustered, 1-bracted: the calyx of a single sepal enlarging at the base and folded round the ovary. Embryo simply curved. - A tall roughish annual, with digitate leaves of 5-7 linear-lanceolate coarsely toothed leaflets, the upper alternate; the inner bark of very tough fibres. ('The ancient name, of obscure etymology.)

1. C. Sativa, L. (Hemp.) - Waste and cultivated ground. (Adv. from Eu.)

\section{H Ù M U L S, L. Hor.}

Flowers diøcious; the sterile in loose axillary panicles, with $\mathbf{5}$ sepals and $\mathbf{5}$ erect stamens. Fertile flowers in short axillary and solitary spikes or catkins : bracts foliaceous, imbricated, each 2-flowered, in fruit forming a sort of membranaceous strobile. Calyx of a single sepal, embracing the ovary. Achenia invested with the enlarged scalc-like calyx. Embryo coiled in a flat spiral. Twining rough perennials, with stems almost prickly downwards, mostly opposite heart-shaped and palmately 3 - 7 -lobed leaves, with persistent ovate stipules between the petioles. (Name thought to be a diminutive of humus, moist earth, from the alluvial soil where the Hop spontaneously grows.)

1. H. Lùpulus, L. (Common Hop.) Leaves mostly 3-5-lobed, and commonly longer than the petioles; bracts, \&c., smoothish; the fruiting calyx, achenium, \&c., sprinkled with yellow resinous grains, giving the bitterness and aroma of the hop. - Allıvial banks: common northward and westward, where it is clearly indigenous, July. (Eu.)

\section{Order 100. Plateanicea. (Plane-tree Family.)}

Trees, with watery juice, alternate palmately-lobed leaves, sheathing stipules, and moncecious flowers in separate and naked spherical heads, destitute of calyx or corolla; the fruit merely cluls-shaped. 1-seeded nutlets, furnished with brislly down along the base: consists only of the following genus (of uncertain relationship). 


\section{PLATA N US, L. Pune-tree. Butronwoon.}

Stcrile flowers of numerous stamens, with club-shaped little scales intermixed: filaments very short. Fertile flowers in separate catkins, consisting of inversely pyramidal ovaries mixed with little scales. Style rather lateral, awl-shaped or thread-like, simple. Nutlets coriaceous, small, tawny-hairy below, containing a single orthotropous pendulous sect. Finbryo in the axis of thin albumen. ('The ancient name, from $\pi \lambda a \tau u ́ s$, lroad.)

1. P. occidentalis, L. (American Pline or Srchmore.) Learcs mostly truncate at base, angularly sinuate-lobed or toothed, the short lobes sharp-pointed; fertile heads solitary, hanging on a long peduncle. - Alluvial banks : very common, especially westward. May. $-\Lambda$ very large and wellknown tree, with a white bark, separating early in thin brittle plates.

\section{Order 101. JUGLandàcea. (Walnut Family.)}

Trees, uith alternate pinnate leaves, and no stipules; flowers monocious, the sterile in catkins (aments) with an irregular calyx adnate to the bract; the fertile solitary or in a small cluster or spike, with a regular 3-5-lobed calyx alherent to the incomplelely 2-4-celled but only 1-ovuled ovary. Fruit a kind of dry drupe, with a crustaceous or bony nut-shell, containing a large 4-lobed orthotropous seed. Albumen none. Cotyledons fleshy and oily, sinuous or corrugated, 2-lobed: radicle short, superior. Petals sometimes present in the fertile flowers. - A small family of important trees, consisting chicfly of the two following genera.

\section{J Ù GIA N S, L. Walnut.}

Sterile flowers in long and simple lateral eatkins from the wood of the preceding year; the calyx adherent to the entire bracts or scales, uncqually 3-6-cleft. Stamens 12-40: filaments frec, very short. Fertile flowers solitary or several together on a perluncle at the end of the branches, with a 4-toothed calyx, bearing 4 small petsls at the sinuses. Styles 2, very short: stigmas 2, somewhat club-shaped and fringed. Fruit with a fibrous-fleshy indehiscent epicarp, and a mostly rongh irregularly furrowed endocarp or nut-shell. - Trees, with strongscented or re:inous-aromatic bark, few-scaled or almost naked buds ( 3 or 4 sujerposed, and the uppermost far above the axil), odd-pinnate leaves of many serrate leaflets; and the embryo sweet and edible. 1'ith in plates. (Name contracted from Jovis glans, the nut of Jupiter.)

1. J. cinèrea, L. (Butrernut.) Lenflets oblong-lanceolate, pointed, rounded at the base, downy, especially underneath, the petioles and branchlets douny with clammy hairs : fiuit oblong, clammy, pointed, the nut deeply sculptured and rough with ragged rilges, 2-celled at the base. - Rich woods: common. May : fruit ripe in Sept. - Tree $30^{\circ}-50^{\circ}$ high, with gray bark and widely spreading branches; wood lighter brown than in the next.

2. J. nigra, L. (BцAск W A LNUT.) Lenves ovate-lanceolate, taper-pointed, somewhat heart-8haped or uncqual at the base, smooth above, the lower surface 
and the petioles minutely downy ; finit spherical, roughly dotted, the nut corrugated, 4-celled at top and bottom. - Rich woods; rare in the Eastern, very common in the Western States. May : the fruit ripe in Oct. - A large and handsomo tree, with brown bark, and valuable purplish-brown wood turning blackish with age. Seed less oily than the butternut, more so than in the European Walnut (J. rÈGIA).

\section{CÁ R Y A, Nutt. Hickorr.}

Sterile flowers in slender lateral and clustered catkins : calyx naked, adherent to the bract, unequally 2-3-parted. Stamens 3-10: filaments short or nome, free. Fertile Howers $2-5$ in a cluster or short spike, on a peduncle terminating the shoot of the season: caly $\mathbf{4}$-toothed: petals none. Stigmas sessile, 2 or 4, large, papillose, persistent. Fruit with a 4 -valved, firm and at length dry exocarp, fulling away from the sinooth and crustitcens or bony endocarp or nut-shell, which is incompletely 2 -celled, and at the base mostly 4 -celled. - Fine timber-trees, with hard and very tough wood, and scaly buds, from which in spring are put forth usually both kinds of flowers, the sterile below and the fiertile above the leaves. Nuts ripen and fall in October. (Kapúa, an ancicut name of the Walıut.)

§ 1. Sterile cathins fuscieled (no common preduncle or sometimes a very short one) from separate latercil scaly buds near the summit of shoots of the preceding year: budscales few: finit elongated-oblong: the thin-shelled unt 2-celled below: seed swet: leaflets short-stulhed, numerous.

1. C. olivæfórmis, Nutt. (P'ECan-Nut.) Minutely downy, becoming nearly smooth; leaflets $13-15$, oblong-lanceolate, tapering gradually to a slender point, falcate, serrate; nut olive-shaped. - River bottoms, from Illinois southward. - A large tree; its delicious nuts well-known.

\$2. Sterile catkins in thiees (or rarely more) on a common peduncle from the axil of the inner scules of the common bud, therefore at the base of the shoot of the season, which, then bearing 3 or 4 leaves, is terminated by the fertile flowers: fruit glabular or oval: nut 4-celled at base: leaflets sessile or nearly so.

* Bud-scalcs mumerous, alout 10, sucessively enwrapping; the imur ones accrescent, becoming thin and membranaceous and rather tardily deculuous: husk of the fruit splitting promptly into 4 thick (but variuble in this respect) and when dry hard or uoody valies: seed swect and delicious. (The hickory nuts of the market.)

2. C. álba, Nutt. (Shell-bank or Shag-bakk Hickony.) Bark of trunk shaggy, exfoliating in rough strips or plates; inner bud-scales becoming large and consjicuous, persistent till the flowers are fully developed; leaflets 5, when young minutely downy bencath, finely serrate, the three upper obovatelancoolate, the lower pair much smaller and oblongr-lanceolate, all taper-pointed; fruit globular or ilepressed; mut white, flattish-globular, barely mucronate, the shell thinnish. - Large and handsome tree, furnishing most valuable woor and the prineipal hickory nuts of the market.

3. C. microcápa, Nutt. (Smali-fiuited) Hickoky.) Nut as in the preceding, but sm:ller ( $7^{\prime \prime}-9^{\prime \prime}$ long), and the husk much thinner; while the folingre resembles that of No. 6 ; the lenflets $5-7$, oblong-lanceolate glundular under- 
nenth, and the bark of the trunk is said to be close : an uncertain species. - New York to Penn. and sonthwestward.

4. C. sulcata, Nutt. (Western Sirelt-nırk Ilickonx.) Bark, \&c. as in No. 1 ; levflets 7-9, more downy beneath; fruit oval or ovate, 4-ribbed above the middle, the husk very thick; nut large $\left(1 f^{\prime}-2^{\prime}\right.$ long) and usually angular, dull white or yellowish, thick-uralled, usually strongly pointed at both ends. - Pennsylvania to Wisconsin and southward. - Seed as sweet as in No. 1. IIeart-wood light-colored.

5. C. tomentósa, Nutt. (Mocker-nut. Wirte-ileart Hickory.) Bark close, rough, but not shaggy and exfoliating on old trunks; catkins, shoots, and lower surface of the leaves tomentose when young, resinous-scented ; leaflets 7-9, lance-obovate or the lower oblong-lanceolate, pointed; fruit globular or ovoid, with a very thick and hard husk; nut globular, not compressed, 4-ridged towards the slightly pointed summit, brownish, very thick-shelled, $\mathrm{I}^{\prime}$ in diameter or smaller. - Dry woods. New Fugland to Virginia, Kentueky and southward. Wood, \&e. $\mathrm{ns}$ in the lnst: secl more oily. $-\Lambda$ var. MAXIMA, of Nuttall bears "fruit as large as an apple," the husk exceclingly thick.

* * Bud-scales numerous or few; husk of the finit thin and rather friable at maturity, 4-valved only to the middle or tardily to near the base: seed more or less bitter: bark of old trunk not exfoliating.

6. C. porcina, Nutt. (PIG-Nut or Broom H.) Bud-scales nearly as in No. 5 , but smaller, caducous ; shoots, catkins, and leaves glabrous or nearly so; leaftets 5-7, oblong- or ohovate-lanccolate and taper-pointed, serrate: fruit pear-shaped, oblong, or oval ; nut oblong or oval ( $1 \frac{1}{2}$ to neurly $2^{\prime}$ long), with a thick lony shell; the oily seed at first sweet in taste, then bitterish. (C. glabra, Torr. \& Ed. 2. Juglans glabra, Wang., Muhl., \&c., is much the oldest name, but not quite clear in application. The ordinary forms of the present species are J. ovatn and J. obcordata, Wang.) - Woodlands : common. - Wood very tough : henrt-wood reddish or dark-colored : bark of trunk rough.

7. C. amara, Nutt. (BitTen-NuT or Swamp H.) Scales of the small yellowish buds abont 6 , valvate in pairs, caducous in leafing; catkins and young herbage more or less pubescent, soon becoming alınost glabrous ; lenflets 7-11, lanceolute or oblong-lanceolate; fruit globular, narrowly 6-ridged; nut ylobular, short-pointed, white (barely l' long), thin-walled; secd at first swecttasted, soon extremely bitter. - Moist soil : common. - Wood less valued, husk and nut-shell thinner and less hard than in other species: bark of trunk close and smooth.

\section{Order 102. Cupuliferde. (OAk Famity.)}

Trees or shrubs, with alternate and simple straight-veined leaves, very deciduous stipules, and monocious flowers; the sterile in catkins (aments) (or capitate-clustered in the Beech); the fertile solitary, clustered or spiked, furnished with an involucre which forms a cup or covering to the 1-celled and 1-seeded nut. Ovary more or less 2-7-celled, with 1 or 2 pendulous anatropous ovules in each cell; but all the cells and ovules except one 
disappearing in the fruit. Calyx adherent to the ovary, the minute teeth crowning its summit. Seed with no albumen, filled with the embryo: cotyledons thick and fleshy, in many edib?e : radicle short, superior. Stipules forming the bud-scales. Leaves usually conduplicate in the bud.

Tribe I. QEERCINERE. Sterile flowers with a distiuct 4-7-lobed calyx, including 3-20 stamens: filanents slender, free, exserted : anthers 2-celled. Fertile tlowers one or few enclosed in a cupule consisting of bracts variously consolidated. Ovary imperfectly 3-7-celled, crowned with 3-8 (mostly 6) calyx-teeth, forming a nut (gland), in fruit surrounded or enclused by tlie indurated scaly or prickly cupule.

* Sterile flowerd in sleuder cutkins.

1. Qucreus. Cupule 1-flowered, sealy, und entire: nut hard and terete.

2. Castanea. Cupulu 2 -4-llowcred, furning a prickly lard bur, 2 -4-valved when ripe.

* Sterile tlowers in a small head.

8. Fagus. Cupule 2-Howered, 4 -valved, contuining 2 sharply triangulaz nuts.

Tribe II. CA R PIN EAE. Sterile flowers destitute of true calvx, coneisting of several stamens included under and uore or less aduate to a bract : filaments short : anthers 1 celled. Fertile llowers in a short spike, catkin, or bead, two togetuer under each fertile bract, each with one or more bractlety, which form a foliaceous or membranaceous iuvoluere to the nut. Ovary inperfectiy 2-celied, 2-ovuled. Seed-cout single.

* Bract of stauinate fluwer furnished with n pair of bractlets inside.

4. Corylus. Involucre enclusiug the large bouy nut, leafy-coriaceous.

* Brict of stiminate flower simple : nut small, achenium-like.

5. Osırya. Each ovary and nut included in a bladdery and closed bag.

6. Carpiuus. Each nut subtended by an enlarged leafy bractlet.

\section{QUERCUS, L. OAK.}

Sterile flowers in slender and naked catkins: bracts caducous: calyx 2-8parted or lobed: staumens 3-12: anthers 2-celled. Furtile flowers seattered or somewhat clustered, comsisting of a nearly 3-celled and 6-ovuled ovary, with a 3-lobed stigna, enclused hy a scaly bud-like involucre which becomes an indurated cup (cupule) around the base of the rounded nut or acorn. Cotyledons remaining undergrount in germination : radicle very short, included. - Flowers greenish or yelluwish. Sicrile catkins single or often several from the same lateral scaly bud, filifurm and hanging in all our species. (The classical Latin name.) All flower in spring, and shed their nuts in October.

§1. ANNUAL-FRUITED; i. e. acorns perfected in the autumn of the first yeur, bonne therefore on the worrd of the scuson, usually in the uxil of the leaves, and oflen raiscd on a peduncle; the licrnel commonly swect-tusted: lubes or teeth of the leaves if any not bristle-pointed: abortive ovules persistent under the seed: sterile flowers mostly 4-6-parled and 8-androus.

* Wuste OAкs. Leaves lyrate or sinute-pinnatifid, pale beneath.

1. Q. álba, L. (Wнiть O^к.) Mature laves suowlh, pule or glaucous underneuth, bright green alove, obovate-oblong, obliguely eut into 3-9 oblong or linear and obtuse mostly cutire lobes; cup hemispherieal-sancer-shaped, rough or tubercled at maturity, nakid, much shorter than the ovvid or ablong acorn. - Rich woods : common. - A valuable lirege tree. I.obes of the leaves short and broad 3-5, or 5-9 decp and narrow. Acorn about 1' long; kernal cdible. 
2. Q. obtuafloba, Michx. (I'ost-()мк. Rovan or Box Wmite-OAк.) Leaves gruyish or yellowish-downy underneth, pale and rough above, thickish, sinuately cut into 5-7 rounded divergent lobes, the upper ones much larger and often 1-3-notched; cup deep sancer-shaped, naked, one third or half the length of the ovoid acorn. (Q. stellita, Willd.) - Sandy or sterile soil : common, especially southward. - A small tree, with very durable wood. $\Lambda$ corn $6^{\prime \prime}-9^{\prime \prime}$ long.

3. Q. macrocárpa, Michx. (Bur-OAK. Over-cup or Mossx-cup WIITE-OAк.) Leaves obovate or oblong, lyrately-pinnatifid or decply sinuatelobed, or nearly parted, irregular, downy or pale beneath; the lobes sparingly and obtusely toothed, or the smaller ones entire; cup deep, thick and woody, conspicuously imbricated with hard and thick pointed scales, the upper ones awned, so as usually to make a mossy-fringed border; acorn broadly oroid (1'-1 $\frac{1}{2}^{\prime}$ long), half immersed in or entirely enclosed by the cup. - Rich soil, W. New England to Wisconsin, Kentucky, and southwestward. - A handsome, middle-sized tree. Cup very variable, especially in size, from $9^{\prime \prime}$ to $2^{\prime}$ across.

Vnr. olivæfórmis (Q. olivaformis, Michx.) is apparently a mere state of this (figured by Michaux with unripe or imperfect fruit), with narrower and more deeply lobed leaves, and oblong acorns and cups.

* Chestnut-Onкs. Leaics coarsely sinuate-toothed, but not lobed, except slightly in No. 4, whitish and more or less downy beneath : cup hoary, hemispherical or a little depressed, about half the length of the oblony-ovoid edible acorn.

4. Q. bícolor, Willd. (SwaMp White OAк.) Leaves oborate or oblong-obovate, wedye-shaped at base, coarsely sinuate-crenate and often rather pinuntifid than toothed, soft-downy and white-hoary underneath, the main primary veins 6-8 pairs, lax and little prominent; fruiting peduncle much longer than the getiole; upper scales of the cup aw11-pointed, sometimes forming a mossy-fringed margin; acorn searcely $\mathbf{l}^{\prime}$ long. (Q. Prinus, var. tomentosa, Michx. Q. Prinus, discolor, Michx.f. \& Ed. 2.) - Low ground: common. A tall tree.

5. Q. Prinus, L. (Cinstsut-OAк.) Leaves varying, obovate or oblong, wilh an obtuse or acute base, undulately crenate-toothed, minutrily downy beneath, the main primary ribs $10-16$ pairs, straight, prominent beneath; fruiting peduncles shorter than the prtioles, ofton very short; cup thick (6" $-12^{\prime \prime}$ wide), mostly tuberculate with hard und stout scales; acorn 1' or less in length. - Dry or moist ground: common southward, scarce northward: a middle-sized or small tree.

Var. montícola, Michx. (Rock Curstnut-OAк.) (Q. montìna, Willd.) Connects with the next varicty, hut has large neorns; the cup is figured and deseribed as top-shaped : but I have not seen the like when the acorn is well grown. - From Vermont sonthward along the upper country. $\Lambda$ small tree.

Var. acuminàta, Michx. (Yes.ow Cimstnut-OAк.) (Q. Castánea, Muhl. \& Ed. 2.) Leaves slender-petioled, often oblong or even lanceolate, usually acnte or pointed, mostly ohtuse or roundish nt the base, alınost equably and rather sharply toothed; cup hemispherical, thin, of small appressed scales, $5^{\prime \prime}$ 7" broad; acorn 7" $7^{\prime \prime}$ long. - Rich soil, W. New England to Wisconsin: common in the Middle States. - Leaves more like those of Chestnut than any other; the primary veins very straight, impressed above, prominent beneath. A middle-sized tree. 
Var. hùmilis, Marsh. (Dwarf Chestnut- or Chinquapin-Oak.) (Q. pumila, Michx. Q. Prinus, var. Chincapin, Michx. f., A. DC. Q. pri. noides, Willd. \& Ed. 2.) Fuliage as in one other of the preceding forms; acorns and cups similar, but mostly smaller (abundant, sessile or nearly so); but is a shrub, only $2^{\circ}-4^{\circ}$ high; seemingly therefore a distinct species, but no good character is found. - l'oor soil, sandy barreus, \&e., S. New England and New York to Wisconsin and southward. (See p. 681.)

** Live Oaкs. Leuves coriaceous, everyreen, entire or rarely spiny-toothed.

6. Q. vírens, גit. (Live (OAK.) Leaves small, oblong or esliptical, hoary beneach as well as the branchlets; peduncle usually conspicuous, $1-3$ fruited; cup top-shaped; acorn oblong; cotyledons completely united into one mass. - Cuast of Virginia and southward. Farther south becoming a large tree: timber invaluable.

§2. BIENNIAL-FuUITED; i. c. acorns perfected in the autumn of the second yeur, therefore on old wood below the leaves of the seuson: preduncles short and thick or none: kernel bitter; the abortive ovules at the apex of the sted: culyx of sterile flowers 2-5-parted: stamens 3-5.

* Leaves entire or with a few teeth, or somewhat 3-5-lubed at the summit, coriaceous, inclined to be persistent southwurd, but none of them reully evergreen at the north, the tips or lobes commonly bristle-pointal: acorns globular, small, at most only $6^{\prime \prime}$ long. (Intermediate forms, in certain cuses probubly hybrids, occur between all these species and some of the next section.)

- Leaves not dilated upururds, generally entire: acorn globase.

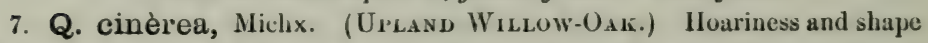
of the leaves as in No. 6, but commonly more lance-oblong or lanceolate, and rather more downy beneath, and the shallow cups and globular acorus as in the next. - Dry jine-barrens, from E. Virginia southward.

8. Q. Phéllos, L. (Willow-OАк.) Luves linear-lanceolute, narrowed to both ends, soon glubrous, light green $\left(3^{\prime}-4^{\prime}\right.$ long) ; cup saucer-shaped. - Sandy low woods, Long Island and New Jersey to Kentucky and southward. - Tree $30^{\circ}-50^{\circ}$ high, remarkable for the willow-like leaves.

9. Q. imbricària, Michx. (Laukel or Shingle OaK.) Leaves lanceolate-oblong, thickish, smooth and shining above, downy underneath, the down commonly persistent; cup between saucer-shaped and top-shaped. - Barrens and open woodlands, New Jersey to Wisconsin and southward. - Tree $30^{\circ}-50^{\circ}$ high; the wood used for shingles in the Western States, whence the specific naıne.

+. + Leaves thick, widening or oflen much diluted upucurds, when they are mare or less sinuate or someutut 3-5-lobed: acorns globular-ovoid.

10. Q. aquática, Cațesby. (WATER-OAK.) Leuves glabrous and shining, obovate-sputulale or narrowly wedlye-form, with a long tapering base, and an often obscurely 3-lobed summit, varying to oblanceolate; cup saucer-shaped or hemi spherical. - Wet grounds, around ponds, \&e., Maryland to Virginia and southward. - Tree $30^{\circ}-40^{\circ}$ high ; running into many varieties, especially southward; the leaves on seedlings and strong shoots often incised or sinuate-pinuatilid; then mostly bristle-pointed. 


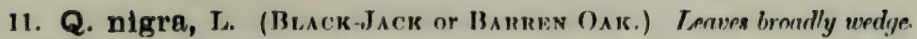
shaped, but sometimes roumled or obsenrely cordate at the base, widely dilated and somewhat 3-lobed (rarely 5-lobel) at the summit, occasionally with one or two lnternl conspicuously bristle-tipped lobes or teeth, rusty-pubeseent benenth, shining above, large $\left(4^{\prime}-9^{\prime}\right.$ long) ; cup top-shaped, conrse-scaly; acorn shortovoid. (Q. ferrugínea, Michx.) - Dry sandy barrens, New York to Illinois, and gouthward. - Tree $8^{\circ}-25^{\circ}$ high.

+++ Anomulous or occasional, probably some or all of them hybrid forms, derived wholly or in part from the foregoing species.

Q. TRIDentita, Engelm., arranged by DC. as a var. of $Q$. nigra, is just intermediate between it and Q. imbricaria. - Near St. Louis, Engelmann.

Q. QUINQuétoba, Engelm., is intermediate between, and probably derived from Q. nigra, and Q. coccinca, var. tinctoria. - St. Louis, Enyelmann.

Q. LEAna, Nutt. (LEA's $O_{\Lambda K}$ ), by its characters and by the foliage of the second generation, communicated by Mr. David Christy, is pretty elearly a hybrid between $Q$. imbricaria and $Q$. coccinea, var. tinctoria. $-\mathrm{S}$. Ohio and Illinois: two or three trees known.

Q. metkropúlta, Michx. (Bantran's OAK), lately rediscovered in Delaware and New Jersey, hy T. Merhan, C. E. Smith, \&e. - has laciniate leaves like those of vigorons young shoots of $Q$. aquatica, to which De Candolle refers it as a variety. It is as likely to be a state of $Q$. Phellos, with dilated and toothed or cut leaves.

** Black and Red Onкs. Leaves pinnutifid or lobed, and slender-petioled, not coriaceous, the tips of the lobes or teeth conspicuously bristle-pointed.

+ Mature leaves sofl-downy benrath: cup saucer-shaped with a somewhat top-shaped base, about half the length of the fully developed small acorn.

12. Q. ilicifollia, Wang. (Bear or Black Scrub-OnK.) Dwarf (3ㅜ$8^{\circ}$ high), straggling; leaves obovate, wedye-shaped at base, angulurly about 5- (3-7-) lobed, white-downy beneath; acorn ovoid, globular, 5" -6" long. - Sandy barrens and rocky hills, New England to Ohio and Kentucky. (Q. Banistèri, Michx.) Leaves $2^{\prime}-4^{\prime}$ long, thickish, with short and triangular spreading lobes.

13. Q. falcata, Michx. (SPANisi O.к.) Leaves grayjish-douny or fulvous undernealh, obtuse or rounded at the base, 3-5-lobed above; the lobes prolonged, mostly narrow and more or less scythe-shaped, especially the terminal one, entire or sparingly cut-toothed; acorn globose, 4 " -5 " long. - Dry or sandy soil, New Jersey to Illinois and southward. - A small or large trec, extremely variable in foliage; bark excellent for tanning. (Q. tríloba, Michx., scems to be a confusion of this and $Q$. nigra.)

+ + Mature Iraves glabrous on both sidrs or nearly so ; oval, oblong or somewhat obovate in outline, all except some of No. 14 varying from moderately sinuate-pinnatifid to deeply pinnatifid, turning various shades of red or crimson in late autumn: large trees; the wood renddish, coarse-grained. (Apparently these species all naturally intercross.)

14. Q. coccínea, Wang. (Scariet OAк.) Cup top-shaped, or hemispherical with a conical scaly base ( $" \prime \prime-9 "$ broad), coarscly scaly, covering half or more of the broadly or globular-ovoid acorn. - Leaves in the ordinary forms, at least on 
full-grown trees, bright green, shining above, turning red in autumn, deeply pinnatifid, the lobes divergent and sparingly cut-toothed; acorns 6" - 9" long, the kernel and the scar in the cup whitish or yellowish ; bark of the trunk gray, the interior reddish. - Moist or dry soil : common.

Var. tinctoria. (Quercitron, Yellow-barked, or Black Oak. (Q. tinctoria, Bartram.) Leaves, especially on young trees, often less deeply pinnatifid, sometimes barely sinuate, more membranaceous, commonly retaining some pubescence on the lower surface, turning brownish, orange, or dull red in antumn; bark of trunk darker-colored and rougher on the surface, thicker, and intermally orange, much more valuable for the tanmer and dyer; cup sometimes less top-shaped, rather hemispherical with a conical base, the scar inside orangecolored, the kernel yellowish. But the shape of the acorn-cup and the character of the bark do not always coincide: and in the figure of the younger Michaux, and in one of the two by the elder, the cup is just that of true coccinea. 'The foliage, in general, approaches that of Q. rubra. - Rich and poor soil.

Var. ambigua. (Lis Y OAK.) (Q. ambigua, or borealis, Michx. f.) Found along our northeastern borders to Lake Champlain and northward, figured and briefly characterized as with the foliage of Q. rubra and the fruit of Q. coccinea. The acorn in rising more out of the cup, also approaches the former. 'The Oak of Lake Superior, with " wood better than that of Q. rubra" (Dr. Robbins) has cup and acorn still more like this last.

A hybrid Q. coccinla-rlicifolia is found by Dr. Roblins at Northbridge, S. Massachusetts.

15. Q. rubra, L. (Red OAK.) Cup saucer-shaped or flat, with a narrow raised border ( $9^{\prime \prime}-12^{\prime \prime}$ in diameter), of rather fine elosely appressed scales, sessile or on a very short and abrupt narrow stalk or neck, very much shorter than the oblong-ovoid or ellipsoidal acorn, which is $1^{\prime}$ or less in length; leaves rather thin, moderately (rarely very decply) pinnatifid, turning dark red after frost; bark of trunk durk gray, smoothish. - Common both in rich and poor soil. - Tim ber coarse and poor. In Illinois and southward occurs a form with a deeper cup, more or less conical at base.

Var. runcinata, Engelm. Leaves with less deep and more ascending lobes; fruit nearly half smaller; acorn $7 "-9$ " long by 6 " broad; cup with a convex or obscurcly top-shaped base: approaches the next therefore in fruit, but not in foliage. St. Louis, in company with Q. rubra, palustris and imbricaria; probably a hybrid.

16. Q. palústris, Du Roi. (Swamp Spanisit, or Pin Oak.) Cup flutsaucer-shaped, sometimes contracted into a short scaly base or stalk; fine-scaled (5" - 7" broad), very much shorter than the ovoid-ylobose acom, which is $5^{\prime \prime}-7$ " long; leaves deeply pinnatifid with divergent lobes and broad rounded sinuses. - Low grounds: rather common. - A middle-sized tree: timber accounted better than of the last.

\section{CA S T $\mathbf{A} \mathbf{N}$ EA, Tourn. Chestrut.}

Sterile flowers interruptedly elustered in long and naked cylindrical catkins: calyx mostly 6-parted: stamens 8-20: filaments sleuder: unthers 2-celled. 
Fertile flowers few, usually 3 together in an ovoid scaly prickly involucre : caly $x$ with a 6-lobed border crowning the 3-7-celled 6-14-ovuled ovary: abortive stamens 5-12: stigmas bristle-shaped, as many as the cells of the ovary. Nuts coriaccous, ovoil, enclosed 2-3 together or solitary in the haril and thick very prickly 4-valved involucre Cotylerlons very thick, somewhat plaited, cohering together, remaining underground in germination. - Leaves strongly straight-veined. Flowers appearing later than the (undivided straight-veined) Jeaves; the catkins axillary near the end of the branches, cream-color; the fertile flowers at the base of the upper ones. (The classical name, from that of a town in Thessaly.)

1. C. vésca, L. (Chestnut.) Leaves oblong-lancrolate, pointed, scrrate with coarse pointed tecth, when mature smooth and green loth sides; nuts 2 or 3 in each involucre, therefore flattened on one or both sides: in the $\Lambda$ merican trec, var. Americdna, Michx., leaves acute at the hase, nuts smaller and sweeter. Rocky or hilly woods, Maine to Michigan and Kentucky and sonthwards, especially along the Alleghanies. June, July. - A large tree, with light coarsegrained wood. (En.)

2. C. pumila, Michx. (Cnrnguarin.) Lraves bllong, acute, serrate with pointed teeth, whitened.doun!y undernealh; nut solitary, not flattened. - Sandy woods, from (Long Island?) S. Penn. and Ohio, southwarl, where it ahounds. June. - Shrub or tree $6^{\circ}-20^{\circ}$ high. Involucres small, often spiked; the ovoid pointed nut scarcely half as large as a common chestnut, very sweet.

\section{F À G U S, Tourn. BeEch.}

Sterile flowers in small heads on drooping peduncles, with deciduous scale-like bracts : calyx bell-shaped, 5 -7-cleft : stamens $8-16$ : filaments slender: anthers 2-celled. Fertile flowers usually in pairs at the apex of a short peduncle, invested by numerous awl-shaped bractlets, the inner grown together at their hases to form the 4-lobed involucre: calyx-lobes 6, awl-shaperl: ovary 3-cellod with 2 ovules in each cell: styles 3, threal-like, stigmatic along the inner side. Nuts sharply 3-sided, usually 2 in ench urn-shaped and soft-prickly coriaceous inroluere, which divides to below the middle into 4 valves. Cotyledons thick, folded and somewhat united; but rising and expanding in germination. Trees, with a close and smooth ash-gray hark, a light horizontal spray, and undivided strongly straight-veined leaves. which are open and convex in the tapering bud, and plaited on the veins. Flowers appearing with the lcaves, the yellowish staminate flowers from the lower, the pistillate from the npper axils of the

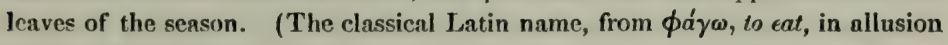
to the esculent nuts.)

1. F. ferrugínea, Ait. (American Bercir.) Leaves oblong-ovate, taper-pointed, distinctly and often coarsely toothed; petioles and midrib soon nearly naked; prickles of the fruit mostly recurved or spreading. (F. ferruginea and $\mathrm{F}$. sylvéstris, Mich $x, f$.) - Woods : common, especially northward, and along the Alleghanies southward. May. - Leaves longer, thinner, and less shining than in the European Bech, most of the silky hairs usually early deciduous; the very straight veins all running into the salient teeth. 


\section{CóryLus, Tourn. Hazel-xut. Filbert.}

Stcrile flowers in drooping cylindrical catkins consisting of 8 (half-) stamens with 1-celled anthers, their short filaments and pair of scaly bractlets echering nore or less with the inner face of the bract or scale of the catkin. Fertile flowers several in a scaly bud or ovoid catkin, each a single ovary in the axil of a scale or bract, and accompanied by a pair of lateral bractlets; the ovary tipped with a short limb of the adherent calyx, incompletely 2-celled, with 2 pendulous ovules, one of them sterile: style short: stigmas 2, elongated and slender. Nut ovuid or oblung, bony, cach enclosed in a leafy or partly coriaceous cup or involucre, consisting of the two bractlets eularged and often grown together, lacerated at the border. Cotyledons very thick (but raised to the surface of the soil in germination), ellible; the short radicle included. - Shrubs or small trees, with thimish doubly-toothed leaves, folded lengthwise in the bud, flowering in carly spring : sterile cattins single or fascicled from scaly buds of the axils of the preceding year, the fertile terminating early leafy shoots. (The classical name, probahly from kópvs, a helmet, from the involucre.)

1. C. Americàna, Walt. (WILd Hazel-nut.) Leaves roundish-huartshaped, pointed; involucre open above down to the globose nut, of 2 broud foliaceous cut-toothal almost distinct bicks, their lase coriaccons and downy, or with glamdular bristles intermixed. - Thickets : common. - T'vigs and petioles often glandularbristly. Nut sinaller and thicker-shelled than the European Hazel-nut.

2. C. rostràta, Ait. (BEAKED HAZEL-NUT.) Leaves ovale or ovate-nllong, somewhat heart-shuped, pointed ; involucre of united bracts, much prolonged above the ovoid nut into a nurrow tubular beak, densely bristly. - Common northward and along the Alleghanies. - Shrub $2^{\circ}-5^{\circ}$ high, with sleuder and mostly smooth branches.

\section{5. ÓSTRY A, Micheli. Hop-Hornieam. Iron-wood.}

Sterile flowers in drooping cylindrical catkins, consisting of several stamens in the axil of each bract: filaments short, often forked, or irregularly united, bearing 1-eelled (half-) anthers; their tips hairy. Furtile flowers in sliurt cathins; a pair under each deciluous bract, each of an incompletely 2-eelled 2 ovuled ovary, erowned with the short bearded border of the adherent calys, tipped with 2 long-linear stigmas, and enclosed in a tubular bractlet, which in fruit becomes a elosed bladklery oblong bag, very much larger than the small and smooth nut; these inflated involucres loosely imbricated to form a sort of strobile, in appearance like that of the Hop. - Slender trees, with very hard wood, brownish furrowed bark, and foliage resembling that of Birch: leaves open and concave in the bud, more or less plaited on the straight veins. Fluwers in spring, appearing with the leaves; the sterile catkins $1-3$ together from scaly buds at the tip of the branches of the preceding yeur; the fertile single, terminating short leafy shoots of the season. ('The classical name.)

1. O. Virgínica, Willu. (Amezican Hup-hohngeam. Lever-wood.) Leaves oblong-ovate, taper-pointed, very sharply doubly serrate, downy bencath, with 11-15 principal veins; buds acute; involucral sacs bristly-hairy at the basc. - Rich woods: common. Ilop.like fruit full grown in $\Lambda$ ug. 


\section{C A R P İ N U S, I. HornnenM. Iron-woon.}

Sterile flowers in drooping cylindrical catkins, consisting of several stamens in the axil of a simple and entire scale-like bract : filaments very shurt, mostly 2-forked, the forks bearing 1-celled (half-) anthers with hairy tips. Fertile flowers several, spiked in a sort of loose terminal eatkin, with small deciduous bracts, each subtending a pair of flowers, as in Ostrya ; but the involuere-like bractlets are open, enlarged in fruiting and foliaceous, merely subtending the small ovate several-nerved nut. - Trees, or tall shrubs, with a smooth and close gray bark, in this and in the slender luds and straight-veined leaves resembling the Beech; the leaf-buds and the inflorescence as in Ostrya. (The ancient Latin namc.)

1. C. Americana, Michx. (American Hornmeam. Brue or Water BeEcit.) Leaves orate-oblong, pointed, sharply doubly serrate, soon nearly smooth; bractlets 3-lobed, halberd-shaped, sparingly cut-toothed on one side, neutc. - Along streams: common. - Tree or shrub $10^{\circ}-20^{\circ}$ high, with a ridged trunk, and very hard whitish wood; also called InoN-wOoD.

\section{Order 103. MYricicea. (Sweet-Gale Family.)}

Monœcious or diœcious shrubs, with both kinds of flowers in short scaly catkins, and resinous-dotted ofien fragrant leaves, - differing from the Birch Family chiefly by the 1-celled ovary with a single erect orthotropous ovule, and the drupe-like nut. Involucre none. - Consists chiefly of the typical genus, from which our Sweet-Fern is not sufficiently distinct.

\section{M Y R İ C A, L. Bayberry. Wax-Myrtle.}

Flowers chiefly diœcious: the sterile in oblong or cylindrical, the fertile in ovoid catkins, from axillary scaly buds; both destitute of calyx and corolla, solitary under a scale-like bract and with a pair of bractlets. Stamens 2-8: filaments somewhat united below: anthers 2-celled. Ovary with 2-4 scales at its hase, and 2 thread-like stigmas. Fruit a small globular nut, or dry drupe, coated with resinous grains or wax. (Mvpik risk or some other shrub; perhaps from $\mu v \rho i \zeta \omega$, to perfume.)

1. M. Gàle, I. (Swert Gate.) Leaves wrdyc-lancolute, scrrate towards the apex; pule, later than the flovers; sterile catkins closply clustered; nuts in imbricated heads, 2-winged by the two thick ovate scales which coalesce with its hase. - Wet borders of ponds, New England to Virginia in the mountains, Penn. to Wisconsin, and northward. April. - Shruh $3^{\circ}-5^{\circ}$ high. (Eu.)

2. M. cerifera, L. (BАYвerny. WAX-Mrrtie.) Lenves oblong-lanceoIate, narrowed at the base, entire or wavy-toothed towards the apex, shining and resinous-dotted both sides, somewhat preceding the flowers; sterile cutkins scultered, oblong; scales werge-shaped at the base; nuts scattered and naked, bony, and incrusted with white wax. - Sandy soil on and near the sea-shore: also on Lake Erie. May. - Shrub $3^{\circ}-8^{\circ}$ high, with fragrant leaves : the catkins sessile along the last year's branches; the fruits sometimes persistent for 2 or 3 years. 


\section{CO M P T Ò I A, Solander. SweET-FERN.}

Flowers frequently monøecious; the sterile in cylindrical catkins, with kidneyheart-shaped pointed scale-like bracts, and 3-6 stamens; the fertile in glubular catkins, bur-like : ovary surrounded by 8 long linear-awl-shaped scales, persistent around the ovoid-oblong smooth nut: otherwise as in Myrica. - Leaves linearlanceolate, pinnatifid with many rounded lobes, thin, appearing rather later than the flowers. Stipules half heart-shaped. (Named after Henry Compton, Bishop of London a century ago, a cultivator and patron of botany.)

1. C. asplenifolia, Ait. (Myrica Comptonia, C'. DC'.) - Sterile hills, New Lingland to Virginia, Wisconsin, and northward. April, May. - Slirub $1^{\circ}-2^{\circ}$ high, with sweet-scented fern-like leaves.

\section{Order 104. Bétulàceat. (Birch Family.)}

Monocious trees or shrubs, with alternate simple mostly straight-veined leaves, both kinds of flowers in scaly catkins, 2 or 3 under each bract, and no involucre to the naked 1-celled and 1-seeded often winged small nut, which results from a 2-celled and 2-oculed ovary. Stipules often early deciduous. Stigmas 2, thread-like. Seed anatropous, suspended: no albumen. Cotyledons flattish, oblong, foliaceous in germination. - Comprises the two genera, Birch and Alder.

\section{BÉTULA, Tourn. Birch.}

Sterile flowers 3 , and bractlets 2 , under each shield-shaped scale or bract of the eatkins, consisting each of a calyx of one scale bearing 4 short filments with 1-celled anthers, or strictly of 2 two-parted filanents, each division bearing an anther-cell. Fertile flowers 2 or 3 under each 3-lobed bract, without bractlets or calyx, each of a naked ovary, becoming a broadly winged and scalelike nutlet or small samara crowned with the two spreading stigmas. - Outer bark usually separable in sheets, that of the branchlets dotted. 'Twigs and leaves often spicy-aronatic. Foliage mostly thin and light. Buds sessile, sealy. Sterile carkins long and drooping, terminal and lateral, formed in summer, remaining naked through the succeding winter, and expanding their golden flows's in early spring, with or preceding the leaves : fertile catkins oblong or cylindrical, usually terminating very short 2-leaved early lateral branches of the season. (The ancient Latin name.)

* Trees, with brown or yellow-gray bark on the trunk, sweet-aromatic as well as the twigs, meminanaceous and struight-veined Ilornbeum-like lcaves with a heartshaped or roundud base, on short petivles, and sessile very thick finiting cuthins : their about equally 3-clen scales rather persistent: wing of finit on each side not broader than the sead-bcaring body.

1. B. lénta, I. (Cheriz-I3. Siveet or Bzhck Brich.) Bark of trunk dark brown, close (outer layers scarcely laminate), very sweet-aromatic; leaves ovate or oblong-ovate fiom a more or less hent-shuped hase, ncuminate, sharply 
and finely doubly serrate all round, when muture shining or bright green nhove and glabrous except on the veins beneath; finiting calkins ollong-cylindrical ( $\mathrm{I}^{\prime}-1 \mathrm{f}^{\prime}$ long), the scales with short and divergent lobss. (13. carpinifolia, Ehrh., Mirhx.) - Moist woods, \&c. : common northward from New England to Illinois, and along the Alleghany region southward. - Rather large tree, reddish-bronzecolored on the spray, much as in the Garden Cherry : timber rose-colored, finegrained, valuable for cabinet-work.

2. B. lùtea, Michx. f. (Yelrow or Grax Bircir.) Baik of trunk yellowish-or silvery-qray, detuching in very thin filmy luyers, within and the twigs much less aromatic; leaves slightly or not at all heart-shaped and often narri rowish towards the base, duller-green above and usually more downy on the ${ }^{6}$ veins bencath ; fruiting catkins oblong-ovoid ( ${ }^{\prime}$ or less in length, $6 "$ " 9 " thick), . - the thinner scales $\left(5^{\prime \prime}-6^{\prime \prime} \mathrm{long}\right)$ twice as large as in No. 1, and with narrower burrly spreading lo'ses. (B. excélsa, Amer. authors, but not of Ait., Regel, \&c. The latter unaccountably fails to distinguish the present from the preceding speries.) - Moist woods, New England to I. Superior and northwarl. - Wood whiter and less valuable: tree not higher than No. 1. Leaves $3^{\prime}-5^{\prime}$ long.

* * Trees, with chalk:y-uhite lark of the trunk separable in thin shects, ovale or triancyular lenves of firmer texture, on long and slender petiolps: fruiting cutkins cylindrical, usually hunging on rather slender perluncles; their scales glabrous, with short diverging lobes, separating fieely from the axis: wing of the fruit much bronder than its body.

3. B. álba, var. populifollia, Spach. (American Wirte Birch.) Ifaves triangular (dcltoid), very taper-pointed, truncate or nearly so at the broad base, smasth und shining both sides, except the resinous glands when young. (B. populifolia, Ait.) - Common on poor soils, Penn. to Maine, near the coast. $\Lambda$ small and slender graceful tree $\left(15^{\circ}-25^{\circ}\right.$ high $)$, with bark much less separable into sheets rhan the next; the mostly very long-pointed leaves on petioles of fully half their length, tremulous as those of an $\Lambda$ spen. (Eu.)

4. B. papyràcea, Ait. (РАрег or Canoe Burcu.) Lraves ovote, taperpointed, heart-shaped or abrupt (or rarely wedge-shaped) at the base, smooth above, dull underneath. - Woods, New England to Penn. and Wisconsin, almost entirely northward, and extending far northwest. $-\Lambda$ large tree, with finegrained woorl, and very tough durable bark splitting freely into paper-like layers. Leaves dark-green above, pale, glandular-dotterl, and a little hairy on the veins underneath, sharply and unequally doubly serrate, 3-4 times the length of the petiole. - Var. MiNor, Tucksrman, in the alpine region of White Mountains, is a dwarf form, spproaching the var. occidentalis of N. W. Amer. an!l B. Davurica. In this country no transitions are secn between our White and the Paper Birch. ('The original B. excelsa, Ait., and of Regel, secms likely to belong here, or to have been mixed up with the next.)

** * Tree, with gremish-hrown bark, somewhat Iaminute, and reddish twigs, ovate leares whitish bmeath, and sofl-downy peduncled fruiting catkins.

5. B. nigra, I. (River or Ren BirCH.) Leaves rhomhic-ovate, acutish at both ends, irregularly doubly serrate, whitish and (until old) downy un(kerneath; petioles and peduncle of nearly the same length $\left(3^{\prime \prime}-7^{\prime \prime}\right)$ and with 
the oblong catkin tomentose; the bracts with oblong-linear nearly equal lobes; fruit broadly winged. (B. rubra, Mich x. f.) - Low river-banks, E. Massachusetts to Illinois and southward. - A rather large tree, with light-colored wood, and somewhat Alder-like leaves.

**** Shrubs, with brownish bark, rounded or wedye-shaped crenate and mostly small leaices of thickish or curiaceous texture, and ublong or cylindrical ylabrous and mostly erect catkins, on short peduncles.

6. B. pùmila, L. (Low Bircir.) Stems $\left(2^{\circ}-8^{\circ}\right.$ high) erect or ascending, not glanduler; young branches and lower face of young leaves mostly softdowny; leaves obovate, roundish, or orbicular ( $\left.6^{\prime \prime}-16^{\prime \prime} \mathrm{long}\right)$, pale beneath, veinlets on both faces finely reticulated; wing of the fruit mostly narrower than the body. Bogs, Conn. (Canaan, W. II. Leygetl) to N. Jersey and northward. - Leaves in one form resiniferous or glandular-dotted, usually not at all so.-B. Grayir, liegel, recently characterized on specimens of a shrub introduced from Central Ohio into the Cambridge Botanic Garden, since lost, appear's to be only a marked variety or luxuriant form of the present species, with shoots and young leaves beneath more tomentose, and wings of fruit (which are as wide as body in one Michigan specimen of B. pumila) here almost twice as wide!

7. B. glandulosa, Michx. (DwakF Bнксн.) Stems erect or mostly spreading $\left(1^{\circ}-4^{\circ}\right.$ high), or when alpine procumbent; branchlets glabrous, conspicuously dotted with resinous wait-like glands; leaves roundish wedge-obovate or sometimes orbicular $\left(6^{\prime \prime}-9^{\prime \prime}\right.$ long $)$, green both sides, less reticulated; fruiting catkins mostly shorter and oblong or oval; wing of the fruit narrower than or sometimes equalling the body. (B. nana, Ed. 2, not of $L$. A round-leaved alpine form is B. rotundifolia, Spach., and B. Littelliàna, Tuckerman.) - High mountains, Northern New England and New York, and shore of Lake Superior and northward. - The resinous-glandular branches chiefly distinguish some of the larger forms from B. pumila, and the small alpine ones from B. naua, $L$. of Lurope: probably they run together.

\section{2. Á I U U , Tourn. Alder.}

Sterile catkins elongated and drooping, with 4 or 5 bractlets and 3 (rarely 6 ) flowers under each short-stalked shield-shaped scale; each fower usually with a 3-5-parted calyx and as many stamens: filaments short and simple: anthers 2-celled. Fertile catkins ovoid or oblong ; the fleshy scales each 2-3-flowered, with a calyx of four little scales adherent to the scales or bracts of the catkin, which are thick and woody in fruit, wedge-obovate, truncate, or 3-5-lobed, and persistent. - Slirubs or small trees, with few-scaled leaf-buds, and solitary or often racemose-clustered eatkins, terminating leafless branchlets or peduncles. (The ancient Latin name.)

\$1. Flowers developed in spring with the leaves; the sterile from culkins which have remained naked over winter; while the fertile have been enclosed in a sculy bud: fruit with a conspicuous thin wing, as in Birch.

1. A. víridis, I)C. (Green or Mountain Alder.) Leaves roundoval, ovate, or slightly lieart-shaped, glutinous and smooth or softly downy underneath, serrate with very sharp and closely set teoth, on young slioots cften 
cut-toothed ; fertile catkins slender-stalked, clustered, ovoid. (A. undulàta, Willd. Betula crispa, Michx.) - On mountains and along streams descending from them, N. New England and New York, shore of L. Superior, and northward. $\Lambda$ lso in the Alleghanies southward. Shrub $3^{\circ}-8^{\circ}$ high. (Fu.)

\$2. Floures developal in tarliest spring, before the leaves, from mostly clustered catkins which (of both sorts) were forned the for going summer and have remained naked over winter; fruit wingless or with a nurrow coriaceous margin.

2. A. incàna, Willd. (SPECKLED or HoARY A.) Leaves Inoadly oral or ovate, rounded at the lase, sharply serrate, often coarsely tootherl, whitened and mostly downy underneath; stipules oblong-lanceolate; fruit orbicular. (A. glaìca, Michx.) - Shrub or small tree $8^{\circ}-20^{\circ}$ high, forming thickets along streams : the common Alder northward. - Var. GLAÙCA has the leaves pale, but when old quite smooth, beneath. (Eu.)

3. A. serrulata, Ait. (Ммооти A.) Leaves obonate, acute at the base, sharply serrate with minute tecth, thickish, green both sides, smooth or often downy beneath; stipules oval; fruit ovate. - Shrub $6^{\circ}-12^{\circ}$ high: the cummon Alder from S. New England to Wisconsin, Kentucky, and southward.

§ 3. Flowers in autumn (Sept.) from catkins of the season; the fertile mostly solitary in the axils of the leaves, ripening the fruit a year later: fruit wingless.

4. A. maritima, Muhl., Nutt. Sylv. t. 10. (SEA-sine A.) Glabrous ; leaves oblong, ovate, or obovate with a welge-shaped base, slender-petioled, sharply serrulate, bright green, or rather rusty beneath ; fruiting catkins large,

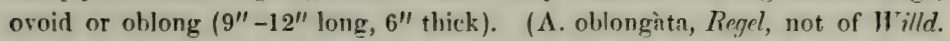
A. Japónica, Siebold \& Zuccarini, according to Regel.) - Along streams, Delaware and F. Maryland, Dr. Pirkering, W. Mr. Canby, \&c. Also, what is thought to be the same species in Japan! - Tree $20^{\circ}$ high.

\section{Order 105. SALicàceate. (Whllow Family.)*}

Dixecinus trees or shrubs, with both kinds of flowers in catkins, one under each bract, entirely destitute of floral envelopes (unless one or two gland-like bodies represent the (ealyx); the fruit a 1-celled and 2-valved porl, with 2 parinal or basal placentre, hearing numerous seerls furnished with a long silhy down. - Style short or none: stigmas 2, often 2-lobed. Seeds asc'endirg, anatropous, without albumen. Cotyledons flattened. - Leaves alternate, undivided, with seale-like and decilluous, or else leaf-like and persistent, stipules. Wood soft and light: bark bitter.

\section{SÀL I X, Tourn. Willow. Osier.}

Bracts (scales) of the catkins entire. Sterile flowers of 3-10, mostly 2, distinct or united stamens, accompanied by 1 or 2 little glands. Fertile flowers also with a small flat gland at the base of the ovary on the inner side : stig-

- This order was elaborated for the first edition by JoHs CARs, Esq.; whose acenunt is easentially preserved, peading the publication of Professor Andersson ' monograph in the fortheoming volume of DeC'andolle's Prodromus. 
mas short. - Trees or shrubs, generally growing along streams, with terete and lithe branches. Leaves mostly long and pointed, entire or glandularly toothed. Buds covered by a single scale, with an inner alherent membrane (separating in §2). Catkins appearing before or with the leaves. (The classical name, said to be derived from the Celtic sal, near, and lis, water.)

\$1. Catkins lateral and sessile, apparing bejore the leaves in April or Mary : stamens 2: scales dark red or brown becoming lluck, more or less huiry, persistent.

* Ovary stalked, downy, hairy, or woolly.

+ Calkins ovoid or cylindical: learies entire or obscurely wavy-toothed, hairy or urolly, with prominent veins and more or less revolute margins. Shrubs.

1. S. cándida, Willd. (Hosis Wilıow.) Lacaves narrowly lanccolate, taper-pointed, or the lowest obtuse, the upper suifuce and young bianches covered with a thin web-like wool more white and dense beneath; stipules small, lanceolute, toothed, about the length of the petioles; catkins cylindricul, elosely flowered; the fertile 1.!' -2' long at maturity; ovury densely woolly; style distinct; stigmas 2 cleft; scales oblong, obtuse. (S. incàna, Michi., not of Schrank.) - New York and New Jersey to Wisconsin and northward; in bogs. - Stems $2^{\circ}-5^{\circ}$ high: redlish twigs smooth and shining at maturity. The whole shrub very white in exposed situations, greener in shade.

2. S. trístis, Ait. (1) W.ик Gray W.) Leaves almost sessile, wedye-lanceolate, pointed, or the lower obtuse, grayish-woolly on both sides, the upper side becoming nearly smooth at maturity ; stipules minute, hairy, very early deciduous ; catkins small and very short, globular when young, loosely flowered; ovary with a long tupering benk, clothed with silvery hairs; style short; stigmas 2-lohed. - Bogs: common. - Shrub $1^{\circ}-1 \frac{1}{2}^{\circ}$ high, much branched : leaves thick, $1 \frac{1}{2}^{\prime}$ loug. Stipules seldom seen, often reduced to a mere gland. - Var. MenopuÝLA has very small and rigid contorted leaves.

3. S. hùmilis, Marshall. (I'rankis W.) Ierues petioled, lanceolate or obovate-lanceolate, acute or obtuse with an abrupt point, slightly downy above, more thickly so or sometimes grayish-woolly beneath; stipules small, semi-ocrute and entive, or larger and lunate with 2-4 tecth, shorter than the petioles; catkins ovoid or oblong, small, often recurved; ovary hairy; style distinct; stigmas 2cleft. (S. Muhlenbergiana, Betratt. S. conífera, Mluhl.)-1)ry plains and barrens: common. - Shrub $3^{\circ}-8^{\circ}$ high, varying much; the smatl forms sometimes scarcely distinguishable from No. 2; but leaves longer, thinner, and generally stipulate: the larger forms, with leaves $3^{\prime}-5^{\prime}$ long and $\not^{\prime}-1^{\prime}$ broad, resemble those of the next species, but retain more or less down beneath at maturity. - The species of this and the following section often bear cones on the ends of the branches, formed of closely imbricated leaves, probably oceasioned by the puncture of insects.

+ + Catkins cylindrical, large, clothed with very long glossy hairs: lcaves more or less serrut", smoth and shining above, glaucous bcnouth and at length smooth. Shruls or small tiees.

4. S. díscolor, Muhl. (Gravcous IV.) Leaves lanceolate, ovate-lanceolate, or oblong, acute, irregularly toothed on the sides, entire at the base and apex; stipules lunate, toothed; cathins crect; scales very hairy, oblanceulate; 
ovary densely silky. - Low mendows and river-banks : common. - A large shruh or small tree, $8^{\circ}-15^{\circ}$ high. Young lenves commonly obtuse and pubescent, at length becoming smooth and whitish-glnucons beneath. Stipules on vigorous shoots equalling the petiole, often inconspicuous. Young cutkins $1 \frac{1}{2}$ ' long, glossy, blackish with the conspicuous scales, elongating in fruit to $2 f^{\prime}$. $-\mathrm{S}$. eriocéphala, Michx., ndınitted in former editions, is of this species.

* * Orary stalked, silky-hoary and shining: cutkins with a few smull lenf-like bracts at their buse: leaves finely and evenly serrate, silky-gray or glaucous beneath, drying dark: stipules varying fiom linear to semilunar, toothed, very deciduous. Shruls, $3^{\circ}-10^{\circ}$ high .

5. S. serícea, Marshall. (SıLK W.) Leaves lanceolate, pointed, downy ahove, grayish underneath with short silky hairs; sterile catkins small, globular; the fertile rylindrical, closely flowered; scales obtuse, round-obovate, as long as the stalk of the densely-sillyy ornid orrny, stigma sessile. (S. grìsen, Willd.) - Sandy river-lonnks : common. Fertile entkins, nt length 1' long; the pods not spreading or elongnting in fruit, thus appearing sessile.

6. S. petiolàris, Sinith. (Y'erroced W.) Leaves lanceolate, pointed, smooth above, slightly silky beneath when young, at length smooth and glaucous; fertile catkins ovoid-cylindrical; scales acute, very hairy, scarccly as long as the stalk of the silky tupering ovary; style distinct; stigma 2-cleft. (S. rosmarinifolia, and S. fuscàta, Pursh.?)-Same situations as the last, which this resembles; but the mature leaves are not silky bencath, nor so blackish in drying; the scales not so dark, and clothed with longer white hair; fertile catkins shorter and broader; the pods spreading and showing the stalks.

* * Ounry sessile or almost so: downy: catkins bracted at the base. Small trees. + Filaments and offen the reddish anthers united, so as to appear as one.

7. S. PUrýtrea, L. (Purple W.) I,eaves oblanceolate, pointed, smooth, minutcly and sparingly toothed; catkins cylindrical; scales round and concave, very black; stigmas nearly sessile; ovary sessile. (S. Lambertiàna, Pursh.) Low grounds. - Twigs olive-colored or reddish. (Adv. from Ea.)

\section{+ + Filamen/s separate.}

8. S. viminilis, I. (Basket Osien.) Leaves lincar-lanceolate, very long, $\left(3^{\prime}-6^{\prime}\right)$, taper-pointed, entire or obseurely crenate, lustrous white and satiny beneath ; sterile catkins oblong, the fertile cylindrical, silky-hairy ; style elongated ; stigmas linear, mostly entire. - Wet mendows. - Considered the best species for basket-work. - S. Smithiana, Willd. (thought to be a hybrid of this with some other species), differing principally in the somewhat hroader leaves, is also occasionally met with. (Adv. from Eu.)

§2. Catkins lateral, with 4-5leafy bracts at the base, appearing with or before the leaves in May or.June: inner membrane of the scales of flowering buds scparating from the cartilaginous exterior, sometimes raised on the apex of the bursting catkins : ovary slender-stallied, smoth (rinder a lens gramulur, with occasionally a few shont huirs at the hase) : stamens 2 : scales dark or black, hairy, persistent.

9. S. cordàta, Muhl. (Insut-Lenved W.) Leaves lanceolate or ovatelancoolate, heart-shaped, truncate, or even acute at base, taper-pointed, sharply 
toothed, smooth, paler and with veinlets reticulated beneath; stipules kidneyshaped or ovate, toothed, often large and conspicuous, of the length of the (when young downy) petiole, or sometimes small and almost entire; catkins appearing with the leaves, leafy at base, cylindrical, the fertile elongating in fiuit; ovary lanceolate, tapering to the smmit. - Var. Rfoida las the leaves large and rigid, with coarser teeth, of which the lowest are somewhat elongated. (S. rigida, Muhl. S. 'Torreyana, Barralt, which has leaves of a deeper green beneath, appears to belong here.) - Var. mxiscolves has narrower leaves, neither heart-shaped nor truncate at the base. (S. myricoides, Muhl.) - Var. Angustita has lanceulate tapering fincly serrate leaves, acute at the base, and a more slender style. (S. angustata, Pursh, \& Ed. 2.) - Low or inundated places: common. - Slirub or sinall tree, with leaves $2 \frac{1}{2}{ }^{\prime}-6^{\prime}$ long.

\$ 3. Catkins lateral, with a few leafy lracts at the base, appearing with the leaves in May or June: ovary stalked, silky-hodiry: stamens 2: scales persistent.

10. S. lívida, Wahl., var. occidentàlis. (Lıviv W.) Leaves oblong or obovate-lanceolate, acute, obscurely toothed, downy above, mominently veiny, softly hairy and glaucous beneath; stipules semilunar, toothed; catkins cylindrical, the fertile becoming loose in fruit; ovary almost linear; style scarcely any; pods slender, tapering firm nar the base, their very stender stelk longer than the narrow scale. (S. rostrìta, Richardson, \& Ed. 2. S. vagans, cincrascens, var. occidentalis, Anders.) - Muist or dry ground, New Lngland to Penn., Illinois, and northward : common. - Shrub $3^{\circ}-15^{\circ}$ high. A transformation of the anthers into imperfect ovaries is frequently observable in this species.

11. S. chlorophýlla, Anders. (GiseEN W.) Gilabrous, except the catkins; leaves oblong-lanceolate or oblong, mostly entire, obtuse or acutish at both ends $\left(1^{\prime}-2^{\prime}\right.$ long $)$, shining above, pale or glaucous beneath; fertile eatkins dense, short-cylindrical ; ovary ovoid-conical; porl silky, very short-shlulked; style slender; scale dark-colored, villous. (S. phylicifolia, Ed. 2, not of $L$.) Moist ravines, on the alpine summits of the White Mountains, New Hampshire (Oukes, Tuckerman), and northward. - A low spreading shrub, with leaves of a coriaccous texture when old.

\$ 4. Catkins peduncled (long and loose), borne on the summit of lateral leafy brunches of the season, appearing in May and June: scales greenish-yellow, more or less hairy, falling before the pods are ripe: filaments hairy below. Sloruls and trees, with the branches very brittle at the base.

* Stamens 3-6 or sometimes more: ovary stalked, ylabrous.

12. S. lùcida, Muhl. (Suning W.) Lecuses oncte-oblong or lemerolute and narrow, usully with a long tepering point, smooth and shining on buth siles, serrate; stipules oblong and toothed; stamens commonly 5 , rarely $7-10$; porls tapering. - Along streams : rather common. - A beautiful species, sometimes flowering at the height of $3^{\circ}$, sometimes becoming a sinall bushy tree of $12^{\circ}$ 150. Probably the same as S. pentandra, L., of Eu.

13. S. nigra, Marsh. (Вi.sck WV.) Leaves narrowly lanceolate, pointed and tapering at each end, serrate, smooth (except on the petioles and midrib) and green on both sides; stipules small, deciduous; seales short and roundal, woolly; glands large, of the sterile flowers eleft, of the sterilo kidney-shaped; 
stamens 3-6; pods mostly short-ovete. (S. ambígun, Pursh.)-Var. FALCגTa has the leaves elongated, scythe-shaped, and the etipules large, broadly lunate, reflexed. (S. falcata, Pursh. S. Purshiànn, Spreng. S. ligustrìnn, Mirhx. f.) Tree $15^{\circ}-25^{\circ}$ high, with a rough black bark : frequent along streams, especially southward.

\section{* Stamens mostly 2 : ovary very short-stalked or nearly sessile, glabrous.}

14. S. Frioiris, L. (Britrue W.) Leares lanceolnte, taper-pointed, smooth, gleucous heneath (slightly silky when young), serrate with inflexerl teeth: stipules half-heart-shaped; pods tapering-conical. - Var. Decfriens has dark brown buds, and the lowest leaves on the branches broadly ohovate, very obtuse. (S. decipiens, Hoffin.) - Var. Russellidis has the leaves long and bright, strongly and very sharply serrate; the younger ones and upper branches of the annual shoots silky-downy towards autumn; stipules large and taper pointed. (S. Russelliana, Smith.) - Var. vfridis, has long and acute flexuous erect eatkins, tough pendulous branchlets, and firmer bright-green leaves. (S. viridis, Fries.) $-\Lambda$ tall and handsome tree, with smooth polished branches; cultivated for basket-work. ( $\Lambda$ dv. from Eu.)

15. S. ÁbA, L. (Wnite W.) Leaves lanccolate or elliptic-lanceolate, pointed, toothed, clothed more or less with white and silky hairs, especially beneath; stipules lanceolate; stigmas nearly sessile, thick and recurred. - Var. vitellina has yellow branches; leaves shorter and broader. (S. vitellina, Smith \& Borrer.) - Var. CXRÙLEA has the leaves nearly smooth at maturity, greenish or brownish, and greatly resembles the preceding species. (S. carulea, Smith.) $-\Lambda$ familiar tree, of rapid growth, attaining a height of $50^{\circ}-80^{\circ}$. (Adv. from Eu.)

16. S. Babrlónica, Tourn. (Weeping Willow), belongs to this section, and is planted for ornament. Only the fertile plant is known in the United States. - There is also a remarkable form of it with curled or annular leaves (S. annulàris, Forbes), well known in gardens as the Ring-Lenved or Hoop WiLLOW.

* * : Stamens 2 : ovary stalked, mostly silky or downy; the scule narrow.

17. S. longifolia, Muhl. (Long-LenveD W.) Leaves linear-lanceolate, very long, tapering at each end, nearly sessile, remotely denticulate with projecting teeth, clothed with gray hairs when young; stipules small, lanceolate, toothed; gland long, in the sterile flowers sometimes deeply 2-3-cleft; in the fertile longer than the short stalk of the ovary; stigmas very larige, sessile. liver-banks, rooting extensively in sand or gravel: common, especially westward. Varying greatly, $2^{\circ}-20^{\circ}$ high.

\$ 5. Catkins peduncled, borne on the lateral (or sometimes the terminal) leafy branches of the srason, appearing in .June: stipules deriduous or none: scales persistent. Small shrubs, mostly with underground spreading stems, sending up short erect or prostrate branches.

* Upright $\left(1^{\circ}-3^{\circ}\right.$ high $)$, not alpine: pod long-stalked: stamens 2.

18. S. myrtilloides, L. (Mrrtes W.) Very glabrous, except the scales of the catkin ; lenves elliptical, oblong, or linear-oblong, cntire $\left(1^{\prime}-2^{\prime}\right.$ long) reticulated, pale or glaucous beneath, somewhat coriaceous ; catkins ob- 
long, the fertile loose in fruit; stalk of the ovary slender, longer than the green ish-yellow scale. (S. pedicellàris, Pursh., more luxuriant than the European plant.) - Cold peat-bogs, New England to Wisconsin and northward. (Eu.)

* Prostrate or spreading and matted, alpine.

19. S. Cútleri, Tuckerman. (Cutwer's W.) Laves elliptical and pointed, or obuvate and obtuse, tapering at the base, slightly toothed, stiongly veiny, smooth and shining alove, pale and rather glaucous beneath; catkins mostly lateral, oblong-cylindrical ; ovury smooth, short-slulked; style distinct; stamen single; scales oblancevlate, entire, black, covord with long silky hairs. (S. Uva-Ursi, P'ursh, in part, \& El. 2.) Alpine summits of the high mountains of Mainc, New IIampshire, and New York.

20. S. argyrocárpa, Anders. (Silvekx-kuteded W.) Leaves lanceolate, acute, or the earliest obovate and obtuse, irregularly repand-crenate, smooth and green above, covered beneuth when young with long and shining deciduous hairs, at maturity smooth and glatucous; catkins ovoid, short; ouxy densely silvery-silky, stalked; style distiuct; stumens 2-3; gland sometimes double; scales obovate, obtuse, clothed with long hairs. (S. repens, Ed. 2, but is much nearer S. arbuscula, L.) - Moist alpine ravines of the White Mountains, New Hampshire. - Whole plant, when young, of a glossy satiny lustre; the leaves at length becoming quite smooth, with a white and prominent midrib, and slightly elevated veins.

21. S. herbàcea, I. (Herb-Like W.) Leaves roundish-aval, heart-shaped, notched at the apex, serrate, smooth and shining, with reticulated veins; autkins issuing from the terminal buds, small and few-flowered; oxary sessile, smooth; scales smooth, ciliate. - Alpine summits of the White Mountains of New Hampshire, and high northwarl. - A very small herb-like species, the stems seldom rising above an inch or two from the ground. (Eu.)

\section{Pó PULUS, Tourn. Poplar. Aspen.}

Bracts (scales) of the catkins irregularly cut-lobed at the apex. Flowers from a cup-shaper disk which is obliquely lengthened in front. Stamens 8-30, or more : filanents distinct. Stigmas elongated. - Trees, with broad and more or less heart-shaped or ovate-toothed leaves, and mostly angular branches. Buds scaly, covered with resinous varnish. Catkins long and drooping, appearing before the leaves. (The ancient name, called Arbor Populi, because it was used to decorate the public walks, or on account of the constant agitation of the leaves by every impulse.)

1. P. tremuloides, Michx. (American Aspen.) Leaves roundishheart-shaped, with at short sharp point, and small somewhat regular teeth, smooth on both sides, with downy margins; scales cut into $3-4$ dexp linear divisions, fringed with long hairs. - Woods : common. - Tree $20^{\circ}-50^{\circ}$ bigh, with smooth greenish-white bark. Ieaf-stalk long, slender, and laterally compressed, which accounts for the eontinual agitation of the foliage by the slight est breeze.

2. P. grandidentàta, Michx. (Langu-Toothè Aspen.) Ireaves roundish-ovate, urith herige and irreyular sinuale tath, when young densely covered 
whth white silky wool, at length smooth both sides; senles cut info 5 - 6 unequal cmall divisions, slightly fringed. - Woods : common, especially northward. A rather larger tree than the last, with a smoothish gray bark.

3. P. heterophýlla, I. (Iowny Popian.) Branches round; leaves hcart-shaped or roundish-ovate, obtuse, serrate, white-uonlly when young, at length nearly smooth, except on the elevated veins bencath. - Swamps, W. New England to Illinois and southward. - Tree $40^{\circ}-60^{\circ}$ high, with large, usually blunt leaves; the sinus, when heart-shaped, closed by the overlapping lobes which conceal the insertion of the nearly round leaf-stalk.

4. P. monilífera, Ait. (Cotton-wood. Neckice Poplar.) Young branches slightly angled, becoming round; leaves brondly deltoid, with spreading prominent nerves, slightly heart-shaped or truncate at the base, taper-pointed, scrrate with cartilaginous and incurved slightly hairy tecth; fertile catkins very long; scales lacerate-fringed, not hairy; stigmas nearly sessilc, toothed, dilated and very large. - Margins of lakes and streams, W. New England to Illinois and southward, especially westward. $-\mathrm{A}$ large tree, $80^{\circ} \mathrm{high}$ or upwards; the vigorous branches decidedly angled, bearing large leaves; the more stunted round, with smaller foliage. (P. Canadénsis, Michx. f. P. lavigàta, Willd.)

5. P. angulata, Ait. (ANGLed Cotron-wood.) Branches acutely angulur or winged; leaves broadly delloid or heart-ovate, smooth, crenate-serrate, or with obtuse cartilaginous teeth. - Low grounds, Pennsylvania to Wisconsin and sonthward. - Tree large as (and probably a mere variety of) the last, and lik it bearing very large heart-shaped leaves $\left(7^{\prime}-8^{\prime}\right.$ in length and breadth) on young plants and suckers : on full-grown trees only one fourth of that size, and commonly without the sinus.

6. P. balsamffera, L. (Balsam Porlar. Tacamanac.) Branches round ; leaves ovate, gradually tapering and pointed, fincly serrate, smooth on both sides, whitish and reticulately veined beneath ; scalcs dilated, slightly hairy; stamens very numerous. $-\mathrm{N}$. New England to $\mathbf{W}$ isconsin, and northward. $-\boldsymbol{\Lambda}$ tall tree, growing on the borders of rivers and swamps : its large buds varnished with copious fragrant resinous matter.

Var. cándicans. (ВАLм of GILEAD.) Leaves broader and more or less hent-shoped, pointed, serrate, whitish and reticulate-veined beneath; petiole commonly hairy. (P. candicans, Ait.) - N. New England to Lake Superior and Kentucky: rare in a wild state, but common in cultivation.

P. Nłars, I., was ndmitted hy the elder Mirhaux into his Florn, without any mention of its locality. It was afterwards published hy his son, moler the namo of $P$. Mudsonica : he, however, found it "only on the banks of the Iludson River, above Albany." Lastly, it was described as $I$ '. betulifolia by P'ursh, who further added as its station, "about Lake Ontario" It was probably introduced from Europe, and was latterly so considered by the younger Michaux himself.

P. dilatita, Ait, the well-known Lombardy Porlar (probably a form of P. nigra) has been extensively introduced as an ornamental tree.

P. Alra, L., the Abele or White Poplar of the Old World, is occasionally planted, when it spreads widely by the root, and becomes more common than is desirable: 


\section{SubClaSS II. GYMNOSPÉRM A.}

Pistil represented by an open scale or leaf, or else entirely want. ing; the ovules and seeds therefore naked (without a pericarp), and fertilized by the direct application of the pollen. Cutyledons often more than two.

\section{Order 106. Conifere ae. (Pine Family.)}

Trees or shrubs, with resinons juice, mostly awl-shaped or needle-shaped entire leaves, and monacions or rarcly diacious flowers in cuthins, destitute of calyx or corolla. Ovules orthotropous. Embryo in the axis of the albumen, nearly its length. (IVood destitute of ducts, composed chiefly of a homogeneous large woody fibre which is marked with circular disks on two sides.) Composes the three following Suborders:-

\section{Suborder 1. a bietinea. Proper Pine Family.}

Fertile flowers in catkins, consisting of open imbricated carpels in the form of scales in the axil of a bract; in fruit forming a strobile or cone. Ovules 2, adherent to the base of each carpellary scale, their orifice turned downward. Buds scaly.

\section{* Cones maturing the year after flowering.}

1. Pinus. Leaves $2-5$ in a eluster from the axil of a scale-like primary leaf, persistent

* * Cones maturing the same year.

2. Abies. Leaves all scattered on the branches and alike, perxistent.

3. Larix. Inaves many in a cluster, the primary ones similar to the others, deciduous.

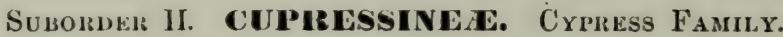

Fertile flowers consisting of few carpellary scales, without bracts, bearing single or several erect ovules on their base (the orifice upward), forming a closed strobile or a sort of diupe in fruit. Buds naked.

* Flowers monceious. Strobile dry, opening at maturity.

4. Thuja. Fruit of few imbricated oblong scales. Ovules 2. Leuves scale-like, closely $\mathbf{I m}^{*}$ bricated on the flattened branches.

5. Cupressus. Fruit of several shield-form thick scules united in a globulur woody cone. Seeds 2 or more on the stalk of each scale. Leaves scule-like or awl-shaped.

6. Taxodium. Fruit of several thick shield-shaped scales united in a globular woody cone. Seeds 2 on the base of each scale. Leaves linear, 2-ranked, duciduous.

* * Flowers chiefly diacious. Fruit berry-like, not opeuiug.

7. Juniperus. Fruit composed of $3-6$ coilescent 1-3-uvuled scales, becoming fleshy.

\section{Suborider Tit. Taxinea. Yha Family.}

Fertile flower solitary, consisting of a naked ovule, ripening into a rutlike or drupe-like seed. Carpel or seale entirely wanting. Buds scaly.

3. Taxus. Ovule erect, encircled at the base by an anuular disk, which in fruit forms a berry-like cup around the nut-like soed. 


\section{PI N U S, 'Tourn. PINE.}

Sterile catkins arranged in a spike at the base of the shoot of the same spring, involucrate by a nearly definite number of scales, consisting of numcrous stamens spirally inserted on the axis, with very short filaments and a scale-like connective: anther-cells 2, opening lengthwise. Pollen of 3 united grains. Fertile catkins solitary or aggregated immediately helow the terminal bud, or lateral on the young shoot, consisting of imbricated carpellary scales, each in the axil of a persistent bract, bearing a pair of inverted ovules at the base. Fruit a cone formed of the imbricated and woody carpellary scales, which are thickened at the apex (except in White Pines), persistent, sprealing when ripe and dry; the 2 nut-like seeds partly sunk in excavations at the base of the scale, and in separating carrying away a part of its lining in the form of a thin and fragile wing. Cotyledons $3-12$, linear. - Primary leaves of the shoots thin and chaff-like, merely bur-scales; from their axils immediately proceed the secondary leaves, which make the folinge, in the form of fascicles of 2 to 5 needleshaped evergreen leaves, from slender buds, some thin scarious bud-scales sheathing the base of the cluster. When there are only 2 leaves in the cluster they are semicylindrical and when dry channelled or concave; when more than 2 trinngular; their edges in our species serrulate. Blossoms developed in spring; the cones maturing only in the autumn of the second year. ('The classical Latin name.)

The species here arranged and characterized from notes contributed by Dr. Engelmann.

\$ 1. Leaves 2 or 3 in a close sheath: cones (except in No. 7) persistent after shedding the seed ; their woody scales thickened at the end, and usully spiny-tipped.

* Fertile catkins and cones lateral: scalcs much thickened at the end: leaves rigid. + Leuves in threes.

1. P. Tæ̇da, L. (Lonlolly or OLd-Fietd Piñe.) Traves long $\left(6^{\prime}-10^{\prime}\right)$, with elongated sheaths, light green; cones elongated-oblong $\left(3^{\prime}-5^{\prime}\right.$ long) and tapering; scules tipped with a stout incurved spine. - Barren light soil, Delaware (W. M. Canly), Virginia, and sonthward near the coast. - Tree $50^{\circ}-100^{\circ}$ high. Sterile catkins slender, $2^{\prime}$ long, their involuere of $10-13$ (rarely fewer) scales. Seeds with 3 strong and rough ridges on the under sicie: cotyledons 5 - 8 .

2. P. rígida, Miller. (P'itcir Pine.) Leaves (3:-5' long) dark green, from short shenths; cones ovoid-conical or ovate $\left(1^{\prime}-3 \frac{1^{\prime}}{}\right.$ long $)$, often in clusters ; the scales tipped with a short and stout recurved prickle. - Sandly or spare rocky soil, Maine to W. New York and southward: common. - Tree $30^{\circ}-70^{\circ}$ high, with very rough and dark bark, and hard resinous wood. Sterile catkins slender $\left(\frac{1}{2}{ }^{\prime}-1 \frac{1}{2}^{\prime}\right.$ long), with $6-8$ involucral scales. Seed with hardly any ridges : cotyledons about 5 .

\section{t- + Leaves in twos, or some of them in threes in $3 \& 6$.}

3. P. púngens, Michx. ('Tambe Mountain Pine.) Leaves stout, short $\left(1 \frac{1}{}^{\prime}-2 \frac{1^{\prime}}{2}\right.$ long), crowded, bluish, the sheath short (very short on old foliage); cones ovate ( $3 \frac{1}{2}{ }^{\prime}$ long), the scales armed with a strong hooked spine ( $f^{\prime}$ long). Alleghany Mountains, especially in the Blue Ridge, N. Carolina and Virginia 
(near Charlottesville, M. A. Curtis) to Penn., Prof. Porter, as far north as Port Clinton near Reading (T. Meehan). - Sterile catkins $6^{\prime \prime}-9^{\prime \prime}$ long, with $6-8$ involucral scales. Seed with 2 or 3 slight ridges: cotyledons about 7 .

4. P. ínops, Ait. (Jersex or Scrub PINe.) Leaves short $\left(1 \frac{1}{2}^{\prime}-3^{\prime}\right.$ long); cones oblong-conical, sometimes curved $\left(2^{\prime}-3^{\prime}\right.$ long $)$, the scales tipped with a straight or recurved awl-shaped prichle. - Barrens and sterile hills, New Jersey to Kentucky and southward. A straggling tree, $15^{\circ}-40^{\circ}$ high, with spreading or drooping branchlets : young shoots with a purplish glaucous bloom. Sterilo catkins lincar-oblong, 5 " -6 " Jong, with about 8 involucral scales.

5. P. Banksiàna, Lambert. (Gkay or Nortiern Scrub Pine.) Leaves short (1'long), oblique, divergent; cones conical, oblong, usually curved $\left(1 \frac{1}{2}{ }^{\prime}-2^{\prime}\right.$ long), smooth, the scales pointless. (P. rupestris, Michx.f.) - Rocky banks, N. Maine, N. Michigan and Wisconsin, and northward. - A straggling shrub or low tree $\left(5^{\circ}-2()^{\circ}\right.$ high $)$ : the sterile eatkins nearly as in No. 4 . Seed with 2 or 3 ridges on the inner side : cotyledons 4 or 5 .

6. P. mitis, Michx. (Yellow l'ine.) Laves in pairs or sometimes in threes, fiom long sheaths, slender $\left(3^{\prime}-5^{\prime}\right.$ long $)$; cones ovate- or oblong-conical (barcly 2' long); the scales tipped with a minute and weuk prickle. (I'. variálilis, Pursh.) - Dry or sandy soil, W. New England? and New Jersey to Wisconsin, and common southwarl. - T'ree $50^{\circ}-60^{\circ}$ high, straight, producing a durable, fine-grained, moderately resinous timber, valuable for flooring, \&c. Ieaves more soft and slender than in any of the preceding, dark green. 'The western form has more rigid leaves, and more tuberculate and spiny cones. Sterile catkins linear, 6"-9" long, with $9-12$ involucral scales. Seed with 2 or 3 rough ridges : cotyledons $5-7$.

* * Fertile catkins and cones terminal, the latter deciduous after sheuding the seed: their scules slightly thichened, pointless: leaves in twos, slender.

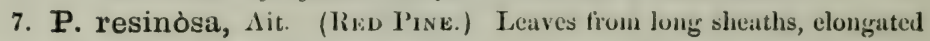
$\left(5^{\prime}-6^{\prime}\right.$ long), dark green; - cones ovate-conical, smooth (about $2^{\prime}$ Jong); sterile catkins oblong-linear $\left(6^{\prime \prime}-9^{\prime \prime}\right.$ long), subtended by about 6 involucral scales which are early deciduous by an articulation above their base; seeds slightly ridged on the lower surface; cotyledons 6 or 7 . (L'. rubra, Mich.e.f.) - Dry woods, Mass. to Penn., Wisconsin, and northward. - Tree $50^{\circ}-80^{\circ}$ high, with reddish and rather smooth bark, and compact, not very resinous wood. Wrongly called Norway Pine.

§ 2. Leaves 5 in a (loose-scaled entirely deciduous) shouth: cones terminal, deciduous ufhr shadding the secd; their seales slighlly if at all thicherned at the end and wholly destilute of prickle or point: buik smowh excipt on old trunks.

8. P. Stróbus, I. (IVinté Pine.) Leaves very slender, glaucous; sterile catkins oval $\left(t^{\prime \prime}-5^{\prime \prime}\right.$ long), with $6-8$ involucral scales at base; fertile catkins long-stalked, cylindrical; cones narrow, cylindrical, nodding, often curved (4'-6' lomer); seed smooth ; cotyledous 8-10. - Cool and damp woods; common northwarl fo llac Mississippi, and sondhwarl in the Mlleghunies. 'The White P'inc (called in lingland $W^{\prime}$ cymoulh $l^{\prime}$ 'ne) is our tallest tree, viten $120^{\circ}-160^{\circ}$ in a straght column in primitive forests, and is invaluable for ito soft and light white or yellowish wood, m large truuks nearly free from resin. 


\section{A BI ES, Tourn. Spruck. Frr.}

Sterile catkins scattered or somewhat clustered in the axils of leaves of the preceding year. Fertile catkins and cones lateral or terminal on branches of the preceding year: seales of the cone thin and even, not at all thickened nor prickly-tipped. Leaves all of one kind and foliaceons, scattered (not fascicled), short, persistent for two or more years. Flowering in spring, and cones maturing in autumn. Otherwise ncirly as in P'inus. ('The classical Latin name.) Of European species A. Excélsa, the Norway SPruce is most commonly, and A. Pectindta, the Silver Fir, occasionally planted.

§1. Spruce. (1'ices of $L i n k$, not of $L$. ABres, $L$. and others. These ancient names much transposed by moderns.) Cones hanging fiom or neur the end of a brunch; the scales persistent on the axis: anthers tipped with a roumded resurved appendug", their crlls distinct and opening lengtheise: pollen nearly as in Pine: lears needle-shaped and 4-sided, pointiny every uay.

1. A. nlgra, P'oir. (Bнаск or Dounle Spruce.) Leaves short (6" ( $^{\prime \prime}$ long), either dark green or glaucous-whitish; cones ovate or ovate-oblong $\left(1^{\prime}-1 \frac{1^{\prime}}{2}\right.$ long), mostly recurced, persistent, the rigid scales with a thin often eroded edge. - Swamps and cold mountain woods, New England to Wisconsin and northward, and southward along the mountains.

2. A. alba, Michx. (Wuite Spruce.) Leaves pale or glaucous; cones nodding, cylindrical (alout $2^{\prime}$ long), pale, deciduous, the thinner seales with an entire edge; a handsomer tree than No. 1, in aspect more like a Balsam Fir. Northern New England and New York to Lake Superior, and northward.

\$ 2. Hemlock-Spnuce. ('Tsuga, Endl.) Cones hanging on the end of declined branches of the preceding ycar, persistent, small; the scales persistent on the axis: sterile catkins small, of a few capitate anthers, their short confuent cells opening transversely: pollen-grains simple: lenes flut, uhitened beneuth, petioled, spreading in two directions so as to siem 2-rankd.

3. A. Canadénsis, Michx. (Нвмцock Spruce.) Leaves short-lineur, obtuse $\left(\frac{t^{\prime}}{2}\right.$ long) ; cones oval $\left(6^{\prime \prime}-8^{\prime \prime}\right.$ long), of few thin scales much longer than the bracts. - Ililly or rocky wools : very common northward, and rare southward in the Alleghanics. - A large tree, when young the most graceful of Spruces, with a light and spreading spray, and delicate foliage, bright greer abeve, silvery underneath. Timber coarse-grained and poor.

§ 3. Fir. (Abies of Pliny. PrCeA, L., not of Link.) Cones erect on the upper side of spreading branches; their scales and mostly exserted bracts deciduous from the persistent axis at maturity : serds and lark of tiee with balsam-learing vesi. cles: anthers tipped with a 1-2-pointed appenduge, their cells opening by lacer. ation; pollen neurly as in I'inc: lenves flut, with midril prominent on the whitened lower face, mostly sessile, on horizontal branches more or less spreading in two di. rections, so as to seem 2-ranked.

4. A. balsàmea, Marshall. (BАLsıм Fir.) Leaves narrowly linear, cones cylindrical, large $\left(2^{\prime}-4^{\prime}\right.$ long, $1^{\prime}$ thick), violet-colored; the bructs obovate, serrulate, tipped with an abrupt slender point, included or slightly projecting. Cold damp woods and swamps, New England to Penn., Wisconsin, and north 
ward. - A slender tree, of no value as timber, when young very bandsome, but short-lived. Leaves $6 "-10^{\prime \prime}$ in length, narrower and lighter green abovo than those of the European Silver Fir. Also called Balm-of-Gilead Fir. Canada balsam is drawn from blisters in the bark of this and the next species. - A subalpine state on the Green Mountains, \&c., has shorter or oblong, stunted cones, and approaches the next.

5. A. Fràseri, Pursh. (Friser's or Soutuern Balsam Fir.) Cones small (1'-2' long), oblong-ovate; the bracts oblong-wedye-shaped, the short-pointed upper part much projecting and reflexed. (A. balșamífera, Michx. Fl.)-Mountains of P'enu., Virginia, and southward on the highest Alleghanies. - Foliage, \&c. nearly as in the last.

\section{L À R I X, Tourn. LARCH.}

Catkins lateral, terminating short spurs on the branches of the preceding year, short or globular, developed in early spring; the sterile from leafless buds; the fertile mostly with leaves below. Anther-eclls openiug transversely. I'ollen-grains simple, globular. Cones as in Spruce, the scales persistent. - Leaves needle-shaped, soft, deciduous, all foliaceous, very many in a fascicle developed in early spring from lateral scaly and globular buds, and scattered along the developed shoots of the season. Fertile catkins crimson or red in flower. ('The ancient name.)

1. L. Americàna, Michx. (American or Brack Larch. Tamarack. Hackaатаск.) Leaves short ; cones ovoid $\left(6^{\prime \prime}-9^{\prime \prime}\right.$ long), of few rounded scales, arranged in $\frac{2}{5}$ order. (P’inus péndula, Ait. P. microcárpa, Lambert.) Sivamps, New Lingland to Penn. and Wisconsin, and (chiefly) northward. - A slender tree, with heavy, close-grained wood, horizontal branches, and more slender and usually shorter leaves than the Europeun Larch; - which is a handsomer tree, and has the scales of its larger cones arranged in the order $\frac{8}{21}$.

\section{THÙ J A, Tourn. Arbor Vite.}

Flowers mostly monocious on different branches, in very small terminal ovoid catkins. Stamens with a scale-like filament or connective, bearing 4 anthercells. Fertile catkins of few imbricated scales, fixed by the base, each bearing 2 erect ovules, dry and spreading at maturity. Cotyledons 2. - Small evergreen trees, with very flat 2-ranked spray, on which the sma'l and appressed persistent leaves are closely imbricated : these are of two sorts, on different or sucessive branchlets; the one awh-shuped ; the other seale-like, blunt, short, and

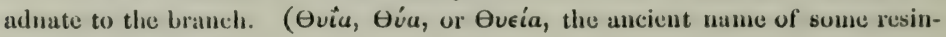
bearing evergreen.)

1. T. occidentàlis, L. (American Arbok Vita.) Leaves appressedimbricated in 4 lows on the e-eflyed branchlets; seales of the cones pointless; sceds broally winged all roumd. - Sivamps and cool rocky bauks : common from Penn. northward, where it forms extensive "cedar-swamps," and is called White Cedak: rare southward along the Alleghanies. May, June. - Treo $20^{\circ}-50^{\circ}$ high, yicldng a pungent aromatic vil : wood light, but very durable. 


\section{C U PRES S U S, Tourn. Crmes.}

Flowers monœcious on different branches, in terminal small catkins. Sterile catkins composed of shield-shaped scale-like filanents bearing $2-4$ anther-cells under the lower margin. Fertile cutkins globular, of shield-shaped seales bearing several erect bottle-shaped ovules. Cone globular, firmly closed, but opening at maturity; the scales thick, pointed or bossed in the middle; the few of several seeds attached to their contracted base or stalk. Cotyledons 2 or 3. Strong-scented evergreen trees, with very small and scale-like or some awlfhaped closely appressed-imbricated leaves, and exceedingly durable wood. ('The classical name.)

1. C. thyoides, L. (Wuite Cenar.) Leaves minute, pale, ovate or triangular-awl-shaped, often with a small gland on the back, closely imbricated in 4 rows; anther-cells 2 under each scale; cones small $\left(3^{\prime \prime}-5^{\prime \prime}\right.$ in diameter); sceds slightly winged. - Swamps, Massachusetts to Wisconsin, Virginia, and southward. May. - Tree $30^{\circ}-70^{\circ}$ high; the wood and fibrous shreddy bark, as well as the foliage, much as in Arbor Vita; but the spray more slender, the leaves finer and glaucous-green.

\section{TAX Ò I U M, Richard. BAL, Cyrress.}

Flowers monœcious, the two kinds on the same branches. Sterile catkins spiked-panicled, of few stamens: filaments scale-like, shield-shaped, bearing 2 5 anther-cells. Fertile catkins ovoid, in small clusters, scaly, with a pair of ovules at the base of each scale. Cone globular, closed, composed of very thick and angular somewhat shield-shaped scales, bearing 2 angled seeds at their base. Cotyledons 6-9.- Trees, with narrow linear 2-ranked light and deciduous leaves; a part of the slender leafy branchlets of the scason also deciduous in autumn. (Name compounded of Tákos, the Yew, and €́sos, resemblance, the leaves being Yew-like.

1. T. dístichum, Richard. (American Batd Crpress.) Leaves linear and spreading; also some awl-shaped and imbricated on flowering branchlets. - Swamps, Delaware, to S. Illinois, and southward, where it is a very large and valuable tree. Marcl, $\Lambda$ pril.

\section{JU N Í PERUS, L. JUniper.}

Flowers diocious, or occasionally monncious, in very small lateral catkins. Anther-cells 3-6, attached to the lower edge of the shicld-shaped scale. Fertile catkins ovoid, of 3-6 fleshy coalescent scales, each one-ovuled, in fruit forming a sort of berry, which is scaly-bracted underneath, black with white bloom. Seeds 1-3, wingless, bony. Cotyledons 2, - Evergreen trces or shrubs, with awl-shaped or scalc-like rigid leaves, often of two shapes in $\$ 2$. ('The classical name.)

\$1. Leares all in whorls and linear-aul-shaped, prickly-poin/ed, free, articulated witn the stem, with a midrib und rib-like margins.

1. J. communis, L. (Соммох Juniper.) Leaves in threes, with slender prickly point, spreading, bright green except the glaucous-white upper face, L \& M-40 
6"- $9^{\prime \prime}$ long ; berries large. - Dry sterile hills : common. - May, June. - Low shrub, aseending or spreading on the ground. (Eu.)

Var. alpina, L. (J. nana, Willd.), is a prostrate state, with shorter and less tapering, mostly ascending or incurved leaves. - Shores of upper Great Lakes, Maine, and northward. (Eu.)

§ 2. Leaves small, mostly opposite, not articuluted but comnate-decurrent on the stem of two somcwhat diffirent forms, i. e. awl-shaped and loose, and scal-shaped und appressad-imbricatal, the lather fluttened and oflen with a resiniferous gland on the back, and no distinct nerve or midilib.

2. J. Virginiàna, l. (Rei, Cebak or Savin.) Scale-shaped leaves acute or acutish; finit small, ereet on the short supporting branchlet. - Dry, mostly sterile or rocky soil : common. May. - Shrub, suall tree, or westward oiten a large tree, $60^{\circ}-90^{\circ}$ high ; with most durable, compact, reddish and odorous wood.

3. J. Sabina, L, var. procúmbens, P’ursh. Scale-shaped leaves obtuse or acutish, strongly appressed; fruit larger, nodding on the recurved pedunclelike branchlet; stems procumbent or prostrate, sornctimes extensively creeping. (J. Virginiana, var. humilis, Ed. 2.) - Rocky banks, borders of swamps, \&c., Maine to Wisconsin along and near the Great Lakes, and northward. May, June. (Eu.)

\section{TÁXUS, Tourn. YEW.}

Flowers mostly diøecious, or sometimes monucious, axillary from scaly buds; the sterile in small glubular catkins formed of a few naked stamens: anthercells $3-8$ under a shield-like somewhat lobed connective. Fertile flowers solitary, scaly-bracted at the base, consisting merely of an erect sessile ovule; with an annular disk, which becomes cup-shaped around its base, and at lengrth pulpy and berry-like, globular and red, and nearly enclosing the nutlike seed. Cotyledons 2. - Ictaves evergreen, flat, mucronate, rigid, scattered, 2-ranlied. ('The chassical uane, probably from $\tau$ ógov, a bow; the wood anciently used for lowss.)

1. T. baccàta, L., var. Canadénsis. (American Yew. Grotind Hemlock.) Stcms difluscly spreading; leaves linear, green both sides. ( $\mathrm{I}$. Canadensis, Willd.) - Moist banks and hills, near streams, especially in the shade of evergreens: common northward, extending southward mainly along the Alleghanies. April. - Our Yew is a low and straggling or prostrate bush, never forming an erect trunk like that of Europe and of Northwest America. (Lu.) 


\section{CLASS II. MONOCOTYLÉDONOUS OR EN- DÓGENOUS PLANTS.}

Stems with no manifest distinction into bark, wood, and pith; but the woody fibre and vessels in bundles or threads which are irregularly imbedded in the cellular tissue: peren-

- nial trunks destitute of annual layers. Leaves mostly parallel-veined (nerved) and sheathing at the base, seldom separating by an articulation, almost always alternate or scattered and not toothed. Parts of the flower commonly in threes. Embryo with a single cotyledon, and the leaves of the plumule alternate.

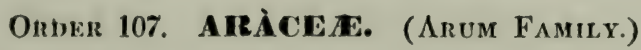

Plants with acrid or pungent juice, simple or compound often veiny leaves, and flowers crowded on a spadix, which is usually surrounded by a spathe. - Floral envelopes none, or of $4-6$ sepals. Fruit usually a berry. Seeds with fleshy albumen, or none but filled with the large fleshy embryo in Nos. 2, 4, and 5. A large family, chiefly tropical. Herbage abounding in slender rhaphides. - The genuine Aracex have no floral envelopes, and are almost all monæcious or diœcious : but the genera of the second section with more highly developed flowers are not to be separated.

* Spathe surrounding or subtending the spathe : flowers naked; i. e. without perianth.

1. A risrema. Flowers monnecious or dinecious, covering only the base of the spadix.

2. Peltnudra. Flowers monocious, covering the spadix ; nnthers nbove, ovaries below.

3. Calln. Flowers perfect (at least the lower ones), covering the whole of the short spadix. Spathe open and sprending.

* Spathe murrounding the spadix in No. 4, none or imperfect in the rest: flowers with a calys or perianth and perfect, cevering the whole spadix.

4. Eymplocarpus. Spadix globulnr, in a fleshy shell-shaped spathe. Stemless.

5. Orontlum. Spadix narrow, naked, terminating the terete scape.

6. A corus. Spadix eylindrical, borne on the side of a leaf-like scape.

\section{A RIS A M A, Martius. Indin Turnip. Dragon-Arem.}

Spathe convolute below and mostly arched above. Flowers moncecious or by abortion diœcious, covering only the base of the spadix, which is elongated and naked above. Floral envelopes none. Stcrile flowers above the fertile, each of a cluster of almost sessile 2-4-celled anthers, opening by pores or chinks at the top. Fertile flowers consisting each of a 1-celled ovary, tipped with a depressed stigma, and containing 5 or $\mathbf{6}$ orthotropous ovules erect from the base 
of the cell; in fruit a 1 -few-seeded scarlet berry. Embryo in the axis of albu. men. - Low perenuial herbs, with a tuberous rootstock or corm, sending up a simple scape sheathed with the petioles of the simple or compound veiny leaves, as if coalescent. (A play upon Arum, the ancient name; probably formed of äpov, Arum, and $\sigma \dot{\eta} \mu a, a$ sign or mark.)

1. A. triphýllum, Torr. (Indian Turnip.) Leaves mostly 2, divided into 3 elliptical ovate pointed leafets; spadix mostly divecious, club-shaped, obtuse, much shorter than the spathe, which is flattened and incurved-hooded at the summit. (Arum triphyllum, L.) - Rich woods: common. May. - Corm turnip-shaped, wrinkled, farinaceous, with an intensely acrid juice. Spathe with the petioles and sheaths green, or often variegated with dark purple and whitish stripes or spots (Arum atrorubens, Ait.); the limb ovate-lanceolate, pointed.

2. A. Dracóntium, Schott. (Green Dragon. Dragon-root.) Leaf usually solitury, pedately divided into 7-11 oblong-lanceolate pointed leaflets ; spadix often androgynous, tupering to a long and slender point beyond the oblong and convolute pointed spathe. (Arum Dracontium, L.) - Low grounds along streams. June. - Corms clustered. Petiole $1^{\circ}-2^{\circ}$ long, much longer than the peduncle. Spathe greenish, rolled into a tube, with a short erect point.

\section{PELTÁ N D R A, Raf. Anrow Arum.}

Spathe elongated, convolute throughout, wavy on the margin, curved at tho apex. Flowers monocious, thickly covering the long and tapering spadix throughout. Floral envelopes none. Anthers sessile, naked, covering all the upper part of the spadix, each of 5 or 6 cells imbedded in the margin of a thick and shield-shaped connective, opening by a terminal pore. Ovaries l-celled at the base of the spadix, bearing several amphitropous or nearly orthotropous ovules at the base: stigma almost sessile. Fruit a leathery or fleshy utricle, 1-3-secded. Seed olovate, surrounded by a tenacious jelly, the base empty, the upper part filled with a large and fleshy spherical embryo; no ulbumen. A stemless herl, with arrow-shaped leaves and simple scapes from the root of thick tufted fibres. Upper part of the spathe and the sterile portion of the spadix rotting away after flowering, leaving the fleshy base firmly enclosing the globular cluster of fruit. (Name composed of $\pi \hat{\epsilon} \lambda \tau \eta$, a taryct, and ávíp, for stamen, from the shape of the latter.)

1. P. Virgínica, Raf. (P. undulata, Raf. Arum Virginicum, L. Lecontia, Torr. Rensselæria, Beck.) - In shallow water: common. June. Leaves large, pointed; nerves reticulated next the margin. (It seems to have escaped attention that this plant has an exulbuminous corm-like embryo, nearly as in Symplocarpus.)

\section{Cál, I, L. Water Arum.}

Spathe open and spreading, ovate (abruptly pointed, the upper surface white), persistent. Spadix oblong, entirely covered with flowers; the lower perfect und 6-androus; the upper of teu of stamens only. Floral envelopes none. Filuments slender : anthers 2-eelled, opening lengthwise. Ovary l-celled, with 5-9 erect anatropous ovules: stigma almost sessile. Berries (red) distinet, few-sceded. 
Sceds with a conspicuons rhaphe nnd an embryo nenrly the length of the hard albumen. - A low perennial herb, growing in cold bogs, with a long creeping rootstock, bearing heart-shaped long-petioled leaves, and solitary scapes. (An ancient name, of unknown meuning.)

- I. C. palústris, I. - Cold hogs, New Englnnd to l'enn., Wisconsin, and fommon northward. Junc. - Seeds surrounded with jelly. (Eu.)

\section{S y m PLOCÁ R P S S, Salisb. Skunk Cabbage.}

Spathe hooded-shell-form, pointed, very thick and fleshy, decaying in fruit. Spadix globular, short-stalked, entirely covered with perfect flowers, which are thickly crowded and their (1-celled or abortively 2-celled) ovaries immersed in the fleshy receptacle. Sepals 4 , hooded. Stamens 4 , opposite the sepals, with nt length rather slender flaments : anthers extrorsc, 2-celled, opening lengthwise. Style 4-angled and awl-shaped : stigma small. Ovule solitary, suspended, anatropous. Fruit a globular or oval mass, composed of the enlarged and spongy spaclix, enclosing the spherical sects just beneath the surface, which is ronghened with the persistent and fleshy sepals and pyramidal styles. Seeds filled by the large globular and fleshy corm-like embryo, which bears one or several plumules at the end next the base of the ovary: albumen none. Perennial herb, with a strong odor like that of the skunk, and also somewhat alliaceous; a thick descending rootstock bearing a multitude of long and coarse fibrous roots, and a cluster of very large and broad entire veiny leaves, preceded in earliest spring by the nearly sessile spathes, which barely rise out of the

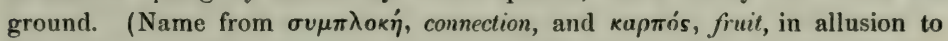
the coalescence of the ovaries into a compound fruit.)

1. S. fóetidus, Salisb. (İctòdes, Bigel.) - Bogs and moist grounds : common. - Leaves ovate and heart-shaped, $1^{\circ}-2^{\circ}$ long when grown, short-petioled. - Spathe spotted and striped with purple and yellowish-green, ovate, incurved. Fruit ripe in September, forming a roughened globular mass $2^{\prime}-3$ ' in diameter, in decay shedding the bulblet-like seeds, which are $4^{\prime \prime}-6^{\prime \prime}$ in diameter, and filled with the singular solid fleshy embryo.

\section{5. o R ó N T I U M, L. Golden-clur.}

Spathe incomplete and distant, merely a leaf-sheath investing the lower part of the slender scape, and bearing a small and imperfect bract-like blade. Flow. crs crowded all over the narrow spadix, perfect: the lower with 6 concave sepals and 6 stamens; the upper ones with 4 . Filaments flattened : anthers 2 celled, opening obliquely lengthwise. Ovary l-celled, with an anatropous ovule: stigma sessile, entire. Fruit a green utricle. Seed without albumen. Embryo thick and fleshy, "with a large concealed cavity at the summit, the plumule curved in a groove on the outside." (Torr.) - An aquatic perennial, with a deep rootstock, long-petioled and entire oblong-and nerred floating leaves, and the spadix terminating the elongated scape; its rather club-shaped emersed apex as thick as the spadix. (Origin of the name obscure.)

1. O. aquáticum, L. - Ponds, Massachusetts to Virginia, near the coast, and southward. May. 


\section{6. Á Corus, L. Sweet Flag. Calahus,}

Spadix cylindrical, lateral, sessile, emerging from the side of a simple 2-edged scape which resembles the leaves, densely covered with perfect flowers. Sepals 6, concave. Stamens 6: filaments linear: anthers kidney-shaped, 1-celled, opening across. Ovary 2-3-celled, with several pendulous orthotropous ovules in each cell : stigma minute. Fruit at length dry, gelatinous inside, $1-\mathrm{few}$ seeded. Embryo in the axis of albumen. - Pungent aromatic plants, especially the thick creeping rootstocks (calamus of the shops), which send up 2-edged sword-like leaves, and scapes similar to them, bearing the spalix on one edge; the upper and more foliaceous prolongation sometimes considered as a kind of

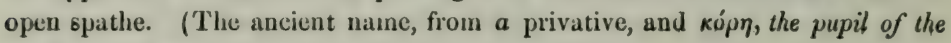
eye, having been used as a remedy for sore eyes.)

1. A. Cálamus, L. Scape leaf-like and prolenged far beyond the (yellowish-green) spadix. - Margin of rivulets, swamps, \&c. Probably truly indigenous nortliward. June. (Eu.)

\section{Order 108. Leminìcefe. (Duckweed Family.)}

Minute stemless plants, floating free on the water, destitute of distinct stem and foliage, being merely a frond, producing one or few moncecious flowers from the edge or upper surface, and commonly hanging roots from underneath: ovules rising from the base of the cell. Fruit a 1-7-seederl utricle. Seed large; the apex or radicular extremity of the seed-coat separable as an operculum or lid (as in Cabomba, \&c.) Embryo straight, surrounded by fleshy or sometimes very scanty albumen - The simplest, and some of them the smallest of flowering plants, propagating by the prolifurous growth of a new individual from a cleft in the edge or base of the parent frond, remaining connected for some time or separating, also by autumual fronds in the form of minute bulblets, which sink to the bottom of the water, but rise and vegetate in spring; the flowers (in summer) and fruit scarce, in some species hardly ever seen. Frond more or less cavernous; the upper surface furnished with stomata. - These plants may be regarded as a sort of very simplified Aracea.

Arranged from notes contributed by C. F. Austin, Esq., who is preparing a monograph of the American Lemnaceæ.

\section{LEm N A, L. Duckweed. Duck's-meat.}

Flowers produced from a cleft in the margin of the frond, usually three together surrounded by a spathe; two of them staminate, consistiug of a stamen only; the other pistillate, of a simple pistil; the whole therefore imitating a single diundrous flower. Ster. F\%. Filanent slenter: anther 2-celled, didymous; the cells dehiscent transversely : pollen-grains large, spherical, muricute. Fert. Fl. Ovary 1-celled: style and truncate or funnel-shaped stigma simple. Ovules and sceds 1-7. - Fronds producing rootlets underncath, proliferouts 
from a cleft in the margin towards the base, and at length stipitate; the tissue abounding with bundles of acicular rhaphides, as in Aracea. (An old Greek name, of uncertain meaning.)

§ 1. LEMNA, Schleiden. Root single: ovule one, half-anatropous or orthotropous.

1. L. trisúlca, L. Fronds oblong-lanceolate from a stalked base, thin, denticulate at the tip $\left(\frac{t^{\prime}}{2}-z^{\prime}\right.$ long), proliferous from one or both sides; seed half-anatropous. - Ponds and springy places; immersed and living through the winter, usually several generations remaining connected. Flowers found, for the first time in this country, by $C$. M. Booth, Rochester, New York. (Eu.)

2. L. Tórreyi, Austin, n. sp. Fronds oblong or obovate-oblong, usually somewhat fulcute (1" $-22^{\prime \prime}$ long), thin, faintly 1-nerved, cavernous to the apex, pule green both sides, commonly in groups of 4-8; utricle elongated-ovate, pointed by the Iong style, flattish, usually half the length of the frond; seed oblong and rather abruptly expanded below the middle, unequally cordate at the base, orthotropous, very obtuse, partly striate when dry ; testa fleshy, loosely adhering to the thickish and solid inner cont; operculum distinctly apiculate; allumen very scanly (a single layer of cells). - Pools, New Jersey (fertile) to Missouri and southward.

3. L. perpusilla, Torr. Fronds olvacate or roundish-ohovate, oblique (1" - $1 \frac{1}{2} "$ long), obscurely 3-nerved, grouped in circular patches (of 4-8); utricle ovate and at length oblique, tipped with a rather long ercentric style; sced ovate or oval, obtuse, oblique in the utricle, orthotropous, delicately many-striate when dry ; testa coriaceous, solid, firmly attached to the very thin inner coat ; operculum scarcely apiculate; albumen abundant. - New York to Wisconsin and southward : often fertile. - Var. trinérvis, Austin. Fronds largèr, distinctly 3-nerced, thin; utricle ovate, pointed with a rather long style; seed ovate, acutish, mostly straight, unequally cordate. - New York and Penn. (fertile) to Wisconsin.

4. L. minor, L. Fronds obovate or elliptical-olonate, thickish (1" $-2^{\prime \prime}$ long), often grouped and short-stalked, obscurely 3-nerved ; u/rirle short-urn-shaped and tipped with a short style; seed ovil or ovate, half-unatropous, horizonial, parallel with the margin of the frond. - Stagnant waters : common: rare in flower. (Eu.)

Var. obscùra, Austin. Fronds ohovate, convex on both surfaces, often purple underneath. - New York to Virginia : sterilc.

Var. orbiculata, Austin. Fronds nearly orbicular, fat ahove, convex and dark purple underneath, proliferous on very short includerl stalks. - New York to Wisconsin and sonthwarl : sterile. - This and the preceding variety have been taken for L. gibba by $\Lambda$ merican authors.

§2. SPIRÒDELA, Schlciden. Roots severul in a clustor: ouvles 2, anatropous.

5. L. polyrrbiza, I. Fronds round-obovate $\left(2^{\prime \prime}-4^{\prime \prime}\right.$ long $)$, thick, purple and rather convex heneath, dark green ahove, palmately (mostly 7-) nerved. Very common in ponds and pools; not found here in blossom. (Eu.)

§ 3. TELMATÓPI $\mathrm{CE}$, Schleiden. Roots single: ovules and seeds $2-\boldsymbol{7}$, anatropous: allumen hardly an!l in the mature socd.

6. L. gibba, L. Fronds obovate or almost orbicular $\left(1 \frac{1}{2}{ }^{\prime \prime}-3^{\prime \prime}\right.$ long), nearly flat above, much thickened and carernous-spongy underneath (almost hemispherical), proliferous on short and very fragile stalks, therefore seldom 
more than 2 or 3 in connection. - Occurs in Arizons and southward: but the true plant seems not to have been detected within our limits. (Eu.)

\section{W Ó I F F I A, Horkel, Schleiden.}

Flowers central, bursting through the upper surface of the globular (or in some foreign ones flat) and loosely cellular frond, only 2 ; one consisting of a singlo stamen with a one-celled 2-valved anther; the other of a globular ovary, tipped with a very short style and a depressed stigma. Ovule orthotropous, rather oblique in the cell. Utricle spherical. Albumen thin. - Fronds routess, proliferous from a cleft or funnel-shaped opening at the base, the offipring soon detached : no rhaphides. - The simplest and smallest of flowering plants, from $f^{\prime \prime}-z^{\prime \prime}$ long (a new $\Lambda$ firican and Cuban species much larger), floating as little grains on the water. (Named for John Fred. Wolff, who wrote on Lemna in 1801.)

1. W. Columbiàna, Karsten. Globose or globular, d" $d^{\prime \prime}-z^{\prime \prime}$ long, very loosely cellular, light green all over, not dotted; stomata $1-6$; the opening at the base circular and with a thin border. - Floating rather beneath the surface of stagnant waters, near Dutcher's Bridge, Salistury, Connecticut (Robbins, 1829), Orange Co., N. Y. (Austin), Lake Ontario (Puine), Detroit (J.M. Bigelow), Illinois (E. Hall, Engelmann, fertile), and Louisiana (Riddcll).

2. W. Brasiliénsis, Wedłlell. Oblong, smaller and more densely cellular, flattish and deep green with many stomata above, tumid and pale below, browndotted all over, anterior edge sharp, opening at base circular. - Growing with the last from Lake Ontario to Illinois, floating on the surface. (Char. of both by $G$. Engelmam.)

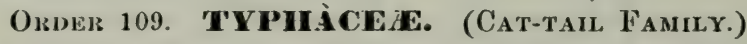

Marsh or aquatic herbs, with nerved and linear sessile leaves, and monocious flowers on a spadix or in heads, destitute of proper floral envelopes. Ovary tapering into a style and (usually elongated) 1-sided stigma. Fruit nut-like when ripe, 1-seeded, rarely 2-secled. Seed suspended, anatropous : embryo straight in copious albumen. Root perennial.

\section{Tỳ PHA, Tourn. Cat-tail Flag.}

Flowers in a long and very dense cylindrical spike terminating the stem; the upper part consisting of stanens only, intermixed with long hairs, and inserteal directly on the axis; the lower or fertile part consisting of ovaries, surrounded hy club-shaped bristles, which form the copious down of the fruit. Nutlets minute, very long-stalked. - Spathes mercly deciduous bracts, or none. Rootstocks creeping. Leaves long, sheathing the base of the simple jointless stems, crect, thickish. Flowering in sumucr. (Name from ripos, a fen.)

1. T. latifolia, L. (Common Cat-tal or lieed-mace.) Leaves fat: staminate and pistillate parts of the spike approximate. Common. (Eu.)

2. T. angustifolia, L. (Namow-Liaved or Sinlt C.) Leares channelled towards the base, narrouly linear; staminate and pistillate parts of the spike usually separated by an interval. A rarer and smaller plant. (Eu.) 


\section{SPARG À N I U M, Tourn. Run-Ren.}

Flowers collected in separate dense and spherical leafy-bracted heads, which are scattered along the summit of the stem; the upper ones sterile, consisting merely of stamens, with minute senles irregularly interposed; the lower or fertile larger, consisting of numerous sessile pistils, euch surrounded by $3-6$ scales much like a calyx. Fruit wedge-shaped or club-shaped. - Rootstocks creeping nnd stoloniferous: roots fibrous. Stems simple or brunching, sheathed below by the base of the linear leaves. Flowering through the summer. (Name from orúpyavov, a fillet, from the ribbon-like leaves.) By Dr. G. ENGELManN.

* Erect, with branched inflorescence of numerous heuds : pistil as long as the surrounding truncate scrles, attenuated into a short style bearing one or oflen two elongated stigmas : nuts sessile, werlye-shuped, angular: leaves for the greater part flat.and merely keeled, the base triungular with concave sides.

1. S. eurycárpum, Engelm. Fruit many-angled $\left(3 \frac{1}{2} "-4^{\prime \prime}\right.$ long) when fully ripe, with a broad and depressed or retuse summit $\left(2 \frac{1}{2}{ }^{\prime \prime}-3 \frac{1}{2}\right.$ " wide) abruptly tipped in the centre; fruit-heads 1 ' wide. (S. ramosum, in part, of most $\Lambda$ merican botanists.) - Borders of ponds, lakes, and rivers, from New England and Pennsylvania northward and westward. - Stems stout, $2^{\circ}-4^{\circ}$ high; heads 2 to 6 or more : the largest species known.

(S. RAmósum, Hudson, of Europe, has not yet been found on this continent: it is distinguished by smaller hears, and smaller, few-angled, usually 1 -seeded fruit, with a conical and long-pointed summit.)

* * Erect or rarely floating, with simple (or rrrely branched) inflorescence of numerous hends; the conspicuous style longer than the spatulate denticulate scales: stigmas always single, linear or oblong: nuts attenuated at both ends, and with a stalked base, nearly terete: stems rather slender: leaves (unless floating) triangular with fut sides in the lower half:

2. S. símplex, Hudson, genuinum. Erect $\left(9^{\prime}-15^{\prime}\right.$ high), slender; inflorescence simple, the lower heads supra-axillary, sessile or commonly peduncled $\left(7^{\prime \prime}-8^{\prime \prime}\right.$ wide); stigma linear, equal to the style; fruit more or less contracted in the mirldle. - New England and northward. (En.)

Var. Nuttállii. Like the last or type, but heads axillary; stigma linearoblong, shorter than the style; fruit less contracted. (S. Amcricanum, Nutt.) — From Pennsylvania nnd New England northward and northwestward. - Inflorescence rarely branched; heads $8^{\prime \prime}-9^{\prime \prime}$ wide.

Var. andrócladum. Stonter $\left(11^{\circ}-3^{\circ}\right.$ high) ; infloreseence branched below; branches bearing numcrous sterile (rarely also 1 or even 2 fertile) heads; stigma linear, as long as the style; fruit larger, not contracted, long-tapering upwards and downwards. (S. ramosum, in part, of American authors.) - From New England sonthward and especially westward. - Heads 10" -12 " wide.

Var. fluitans. Leaves floating; inflorescence branched; branches bearing fertile heads below; stigma oval, shorter than the style; fruit somewhat contracted and with a short stipe. (S. fluitans, Fries.) - Ponds at the base of the White Mountains, Oukes. - Heads 6" - 7 " wide. (Eu.)

Var. angustifolium. Leaves floating, longer and narrower than in the 
last; inflorescence simple; lower fertile heads usually supra-axillary, sessile or peduncled; stigma linear, about the length of the style; fruit smaller, shortstiped, contracted in the middle. (S. angustifolium, Michx. S. affine, Schnitzlein; said to te the true S. natans of Linnæus.) - Mountain lakes and slow streams, New York, New England, and northward. - Hcads 5" 7 7" wide. Dwarf states, growing nearly out of water, have shorwer erect leaves. (Eu.)

** Usually floating, with very slender stems and delicute a/ways flat and narrow leaves: inflorescence simple, of few small heads: stigma oval, about as long as the short style, scarcely surpussing the ovel or obovate denticulate scales: nuts ovul, with a very short stipe and short point.

3. S. minimum, Bauhin, Frics. Fertile heads solitary or usually 2, axillary, sessile or the lower one peduncled, fruit heads $4^{\prime \prime}-5^{\prime \prime}$ in diameter; nuts somewhat triangular, the lower third usually contracted; stems when out of water only $5^{\prime}-6^{\prime}$ high ; when submersed longer. (S. nàtans, of older authors, but not of Linnaus, according to Fries. S. angustifolium, Ed. 2.) - Northern New England to Wisconsin and northward. (Eu.)

\section{Order 110. Naiadicea. (Pondweed Famil.y.)}

Immersed aquatic plants, with jointed stems and sheathing stipules within the petioles, or with sheathing bases to the leaves, inconspicuous flowers, which are naked or with a free merely scale-like culyx; the ovaries solitary or 2-4 and distinct, 1-celled, 1-ovuled. Seed without albuinen, filled by the large embryo, often curved or hooked. Flowers usually bursting from a spathe, sometimes on a spadix.

* Flowers monocious or dicecious, axillary, naked, monandrous.

1. Naias. Pistils solitary and uatsed. Silgmar 2 or 4

2. Zannichellia. I'btils abuut 4 from a cup-blaped involucre or sheath.

8. Zostera. Pistils and anthers alteruately sessile in two rows on ono side of a linesr spadix enclosed in a luaf. Stiguar 2.

* * Flowers perfect, spiked or clustered.

4. Ruppla. Flowers naked (no perianth), each of 4 large anther-cells, and 4 ovaries.

6. Potamogeton. Flowers with sepals, stamens, and sessile ovaries each 4.

\section{NÀI A S, L. NAIAD.}

Flowers diœcious or monœcious, axillary, solitary and sessile; the sterile convisting of a single stamen enclosed in a little membranous spathe: anther at first nearly sessile, the tilument at length elongated. Fertile fluwers cunsisting of a single ovary tapering into a short style: stigmas 2-4, awl-shaped: orule erect, anatropous. Fruit a little seed-like nutlet, enclosed in a loose and separable membranous epicarp. Embryo straight, the radicular end downwards. Slender branching herbs, growing under water, with opposite and linear leaves, somewhat crowded into whorls, spinulose-toothed, sessile and dilated at the basc. Flowers very small, solitary, but often clustered with the branch-leaves in the axils; in summer. (Nä̈ás, unter-nymph; an ill-chuses name for these insignificant water-weals.) 
1. N. major, All. Icaves linear, rather broad, strongly repand-toothed, the back as well as the stem more or less beset with little spines, the shenthing base entire or nearly so; flowers dincious; anther 4-celled, 4-valved. - New York, Onondaga Lake, G. W. Clinton; Lake Ontario, near Rochester, C. M. Booth: recent discoveries. (En.)

2. N. fléxilis, Rostk. Leaves very narrowly linear and minutely serratc, as is thcir abrupt rounded sheathing base; flowers monoecious? (N. Canadénsis, Mich.x. Caulinia flexilis, Willd.) - Ponds and slow streams: common. (Eu.)

\section{ZA N N I CH它LIIA, Micheli. IIonnen Pondwen.}

Flowers moncecious, sessile, nnked, usually both kinds from the same axil; the sterile consisting of a single stamen, with a slender filament bearing a 2-4. celled nnther; the fertile of $2-5$ (usually 4) sessile pistils in the same cupshaped involuere, forming obliquely oblong nutlets in fruit, beaked with a shoit style, which is tipped by an obliquely disk-shaped or somewhat 2-lobed stigma. Seed orthotropous, suspended, stringht. Cotyledon taper, bent and coiled up. -Slender branching herbs, grotring under water, with opposite or alternatelong and linear thread form entire leaves, and sheatbing membranous stipules. (Named in honor of Zannichelli, a Venetinn botanist.)

1. Z. palustris, L. Style at least half as long as the fruit, which is flattish, somewhat incurved, even, or oceasionally more or less tootherl on the back (not wing-margined in our plant), nearly sessile; or, in var. Pedurculats, both the cluster and the separnte fruits evidently peduncled. - Ponds and slow streams : rather rare. July. (Eu.)

\section{ZOSTERA, L. Grass-wrack. Eel-grass.}

Flowers monœcious; the two kinds naked and sessile and alternately arranged in two rows on the midrib of one side of $n$ linear leaf-like spadix, which is hidden in $n$ long and shenth-like base of a leaf (spathe); the sterile flowers consisting of single ovate or oval 1-celled sossile anthers, as large as the ovaries, and contrining a tuft of threads in place of ordinnry pollen; the fertile of single ovate-oblong ovaries attached near their apex, tapering upward into an awlshaped style, and contrining a peudulous orthotropous ovule: stigmas 2, long and bristle-form, deciduous. Utricle bursting irregularly, enclosing an oblong longitudinally ribbed seed (or nutlet). Embryo short and thick (proper cotyledon almost obsolete), with nn open clink or cleft its whole length, from which protrudes n doubly curved slender plumule. - Crass-like marino herbs, growing wholly under water, from a jointed creeping stem or rontstock, sheathed by the bnses of the very long nnd linear, obtuse, entire, grnss-like, ribbon-shaped lenves (whence the name, from $\zeta \omega \sigma \tau \eta \dot{\rho}, a$ band).

1. Z. marina, L. Leaves obscurely 3-5-nerved. - Common in bays along the const, in wnter of $5^{\circ}-15^{\circ}$ deep. Aug. (Eu.)

\section{R Ú P P I A, L. Ditoh-grass.}

Flowers perfect, 2 or more approximated on a slender spadix, which is at first enclosed in the sheathing spathe-like base of a leaf, entirely destitute of flornl 
envelopes, consisting of 2 sessile stamens, each with 2 large and separate anther-cells and 4 small sessile ovaries, with a single campylotropous suspended ovule: stigma sessile, depressed. Fruit of little obliquely-ovate pointed drupes, each raised on a slender stalk which appears after flowering; the spadix itself also then raised on an elongated thread-form peduncle. Embryo ovoid, with a short and pointed plumule from the upper end, by the side of the short cotyledon. - Marine herbs, growing under water, with long and thread-like forking stems, and slender almost capillary alternate leaves, slieathing at the base. Flowers rising to the surface at the time of expansion. (Dedicated to $I I$. B. Iiuppius, a German botanical autior of the early part of the 18 th century.)

1. R. marítima, L. Leaves linear-capillary; nut ovate, obliquely erect; fruiting peduncles capillary $\left(\frac{1}{2}-1^{\prime}\right.$ long $)$. - Shallow bays, along the whole coast : also Onondaga Lake (near salt springs), New York, J. A. Paine. Chiefly a narrowly leaved variety with strongly pointed fruit, approaching $R$. rostellàta, Koch. June-Sept. (Eu.)

\section{POTAMOGETON, Tourn. Pondwed.}

Flower's perfect. Sepals 4, rounded, valvate in the bud. Stamens 4, opposite the sepals: anther's nearly sessile, 2-celled. Ovaries \& (rarely only one), with an ascending campylotropous ovule: stigma sessile or on a short style. Fruit drupe-like when fresh, more or less compressed : endocarp (nutlet) crustaceous. Embryo hooked, annular, or cochleate, the radicular end poiuting downwards. - Herbs of fresh, or one in brackish, ponds and streams, with jointed mostly rooting stems, and 2-ranked leaves, which are usually alternate or imperfectly opposite; the submersed ones pellucid, the floating ones often dilated, and of a firmer texture. Stipnles nembranous, more or less united and sheathing. Spikes sheathed by the stipules in the bud, mostly raised on a peduncle to the surface of the water. (An ancient name, composed of motapos, a river, and $\gamma \in i \tau \omega \nu, a$ neighbor, from their place of growth.)

The following account of the genus is contributed by Dr. J. W. Rosbins, of Uxbriclge, Mass. - By fruil, the full-grown fresh or macerated fruit is intended; by nutlet, that with the fleshy outer portion or epicarp removed. All exeept No. 15 flower in summer: the month mentioned indicates the season of the maturation of the fiuit, which, especially, should be collected.

§ 1. Diversifolix. Leaves of tur sorts; the flouting ones coriaceous, and different in form from the more delicate submersed ones.

* Submersed leaves mostly with no distinction of blade and petiole, being in fact bladeless more or less fluttened petioles, or phyllodia, sessile, grass-like, narrowly linear, or so attenuated as to become filiform or capillary.

- Stems rather stout : stipules fiee from the leaves : spikes all emersed, cylindrical and densely, fruited: fruits fleshy und turgid, obliquely obovate : embryo coiled into less or scurcely more than one turn.

1. P. nàtans, L. Stcm simple or sparingly branchul; floating leaves all tong-petioled, elliptical or ovate, somewhat cordate at base, obtuse but with a blunt point, 21 -29-nerved; upper submersed leaves lanceolate, early perishing, the lower (later in the season) very slender $\left(3^{\prime}-7^{\prime}\right.$ long, barely a line wide); 
upper stipulss very long, acute; peduncle about the thickness of the stem; spikes 1'-2' long; sides of the turgid nutlet with a small deep impression in the middle; embryo coiled into an incomplete elliptical ring. - Var. rroufxus, Koch. More slender; "pper leaves lanceolate, firequently submersed, acute; stem $\left(6^{\circ}-12^{\circ}\right)$, submersed leaves (sometimes $21^{\prime}$ ) and stipules very long. - Common in ponds and ditches : the var. in deep flowing water. Ang. (Eu.)

2. P. Oakesiànus, Robbins, n. sp. Stem more slender, much branched; floating leaves smaller $\left(1^{\prime}-1 \frac{1}{2}^{\prime}\right.$ long), ovate- or oblong-elliptical, obtuse, fewer- (17-23-) nerved; lowest submersed ones almost capillary (only $f^{\prime \prime}-\frac{1}{2}$ " wide), continuing through the flowering season; spikes shorter $\left(3^{\prime}-1^{\prime}\right.$ long), on pe. duncles much thicker than the stem; fruit smaller and more acute; sides of the tur. gid nutlet not at all impressed; curvature of the embryo nearly circular, its apex directed to a point above its base. - Ponds, and especially pools and stagnant ditches, not rare in E. Massachusetts. Aug.

3. P. Claytonii, Tuckcrman. Stems compressed, often simple from the creeping rootstocks; floating leaves chicfly opposite ( $1^{\prime}-1 \frac{1}{2}^{\prime}$ long), $11-17$. nerved, oblong, tapering into a short petiole, the lower gradually narrowing and passing into the submersed ones, which are very numerous and approximate, 2-ranked, linear $\left(2^{\prime}-5^{\prime}\right.$ long, and $1^{\prime \prime}-22^{\prime \prime}$ wide), 5-nerved, the lateral nerves slender and nearly marginal, the space within the inner nerves coarsely cellulurreticulated; stipules very obtuse; spikes numerous, about the length of the thickened peduncle; fruit round-obovate, flattish, 3-kceled when dry; nutlet distinctly impressed on the sides; curvature of the embryo transversely oval. (P. Nuttállii, Chamisso p) - Still or flowing water, and even in small streams: common. Perfectly distinct, and peculiar in the reticulation of the centre of the delicate grass-like submersed leaves. July, Ang.

++ Characters of the preconing sertion, lut all the parts small, slender and delicate as in the next, or as in No. 20 (and like it propagated by autumn buds), but with corinceous floating leaves.

4. P. Vàseyi, Robbins, n. sp. Very delicate; stem almost capillary ; flonting leaves obovate $\left(3^{\prime \prime}-5^{\prime \prime}\right.$ long) and about the length of their filiform petioles, with 5 nerves decply impressed beneath, cross-veins distinct; submersed leaves filiform-linear, very nttenuate $\left(1^{\prime}-2^{\prime}\right.$ long, $d^{\prime \prime}-f^{\prime \prime}$ wide) and acute; stipules not adnate, scarious; spikes all emersed and similar, few, interrupted-oblong, 3-5-flowered, on a thickish peduncle; fruit oblique roundobovate (?" long) compressed, slightly sharp-margined, tipped with a distinct recurved style, the sides impressed and face acute; upper portion of the embryo circularly incurved, its apex transverse to the fruit. - Illinois, near Ringwood, McHenry Co., Dr. G. Vasry. Apparently also in Quinsigamond Lake, Mass.

+ + + Stems slender or filiform and much branched: floating leaves sometimes wanting: stipules adnate to the base of the lenf: spikes of two kinds: one emersed, cylindrical and many-flowered, on a club-shriped pealuncle; the other submersed, globular and few-flowered: fruit fat, cochleate, with thin or scarcely uny flesh, and a thin nutlet: emlryo spiral.

5. P. Spirillus, Tuckerman. Floating leaves varying from oval to lance-oblong and lanceolate (the largest $10^{\prime \prime}$ long and $4^{\prime \prime}$ wide), usually obture 
about equalling the ruther diluted petioles, with 5-many nerves beneath deeply impressed; upper submersed leaves either with or without a lance-oblong or broad-linear proper blade; the numerous lower ones narow-linear, tapering towards the obtuse apex $\left(3^{\prime}-1 \frac{1}{2}\right.$ long, $t^{\prime \prime}-z^{\prime \prime}$ wide) ; stipules early lacerate; submersed flowers usully solitary on very short erect peduncles; shell-shuped fruit with the back either winged and with 4-5 distinct leeth or wingless and entire; embryo coiled 1 h hons. - Rivers, and even far up small streams, in company with the No. 3, or rarely with the following, Maine (.J. Bluke) to Lake Superior and Virginia. Jume-Aug. - Stem less slender than the next.

6. P. hýbridus, Michx. Floating leaves varying from oval to lanceoblong ; (the largest $10^{\prime \prime}$ long and $6^{\prime \prime}$ wide), often acute, longer than the filiform petioles, with about 5-7 nerves beneath deeply impressed; submersed leaves very numerous, almost setaceous, $\left(1^{\prime}-3^{\prime}\right.$ long, very rarely $\frac{1}{2} "$ wide); stipules obtuse; submersed spikes 1-4-flowered, their peduncles (of their own length) frequently recurved; fruit minute, about 8-touthed on the maryin; embryo coiled $1 \frac{1}{2}$ turns. (1'. diversifolius, Buiton. P. setaceus, Pursh.) - Shallow staynant waters. Jume Aug. - Emersed spikes $4^{\prime \prime}$ to (in var. spicatus, Engelm.) 7" long.

* * Submersed leaves lanceolate, rardy ocal or lincar, membranaceous.

7. P. ruféscens, Schrader. Stem simple, floating leavey foften wanting, P. obrutus, $W_{\text {ood }}$ ) rather thin, wedge-oldancenlate, narrowed into a short petiole, 11 17-nerved; submersed leaves almost sessile, lanceulate and lance-oblong, smooth on the margin, fewer-nerved; stipules broad, hyaline, obtuse, upper ones aeuminate; fruit obovate, lenticular, pitted when inmature, with an acute margin and pointed with the rather long style; embryo incompletely annular. - Rivers and streams, New England to Pennsylvania, Illinois, and especially noithward. - $\Delta$ ug. - Sept. - Spike often somewhat compound I (Eu.)

8. P. lonchites, 'Tuckerman. Stem often branching below; fluding leuves thinnish, lance-oblony or long-elliptical, often acute, lonig-petioled, 17-2:3nerved; submersed leaves very long $\left(3^{\prime}-12^{\prime}\right.$, by $2^{\prime \prime}-12^{\prime \prime}$ wide), lanceolate and lance-linear, 7-15-nerved, coarsely reticulated; peduncles somewhat thickened upwards; fruit obliquely obovate, obseurely 3 -kecled when fiesh and distinctly so when dry, the middle one winged above and sometimes with $3-5$ shallow indentations; the romuled slightly curved face surmounted by the short style; nutlet with the silles scarcely impressed; upper part of the embryo circulirly incurved. (1'-Americinus, Chamisso?) - Rivers and ponds, New England to Illinois. Aug., Sept. - More slender than the very similar P'. fluitans of Europe, its leaves longer petioled, the floating ones more abrupt at the base; stipules not bicarinate. Chamisso's name of this and No. 3 merely provisional.

9. P. púlcher, 'I'uckerman. Stem simple, black-spotted; leaves of three kinds; fluating ones becoming very large $\left(+\frac{1}{2}\right.$ by $\left.3 \frac{1}{2}{ }^{\prime}\right)$ roundish-ovate and cordute or ovate-oblong, 25-37-ncrved; all altwnate; upper submersal ones (3-5) usually lancoulale, acute at the base and very long-acuminate, 10-15-nerved, very thin, cellular cach sides of the midrib, undulate, short-petioled; lowest ( $2-4$ near tho base of the stem) thicker, plane, oval or oblong with a rounded base, or spatulateoblong, on longex petioles; stipules rather short and obtuse; peduncles thicker than the stem; fruit with a rounded back and angular face, pointed with the 
style, distinctly 3-keeled when fresh, sharply so when dry; nutlet marked on the back by two deep furrows and in front by a sinus below the angle; sides flat; upper portion of the embryo circularly much incurved. - Ponds ; found as yet only in Eastern Massnchusetts and "in ponds on hills north of St. Louis," Missouri, Enyelmann : also Georgia, Le Conte. - July, Aug.

10. P. amplifolius, Tuckerman. Stems simple, of very variable length ; flating leaves (sometimes wanting) large, oblong or lance-ovale, sometimes slightly cordate at base, abruptly acutish, 30-50-nerved, on rather long petioles; submersed leaves often very large (reaching $7^{\prime}$ by $2^{\prime}$ ), lanceolate or oval, acute at each end, usually much recurved, undulate, mostly on short petioles; stipules very long and tapering to a point, soon becoming loose; peduncles thickened upward, in deep water much elongated; fruit rather obliquely obovate, the back rounded and bluntly kecled; nutlet slightly impressed on the sides; upper portion of the embryo incurved into a ring. - Ponds and large rivers : not rare. - $\Lambda$ ug., Sept. - In very shallow water sometimes withont membranaceous lenves, and in deep water it may liave those only. - (Leaves on a radical ohoot in one specimon with adnate stipules!)

11. P. gramíneus, L. Stem slender, very branching below ; floating leaves mostly thin, variable, but with a short blunt point, 9-15-nerved; submersed ones usually lanceolate or linear-lanceolate, acuminate or cuspidate, narrowed towards the base, about 7-nerved on the stem and 3-nerved on the branches; upper ones petioled, lower sessile; stipules obtuse, loose; peduncles somewhat thickened upwards; fruit small, roundish, compressed, scarcely keeled; upper portion of the embryo annular. (P. heterophýllus, Schreber.) - Still or flowing water: common. - Varies exceedingly in its submersed leaves, peduncles, and otherwise. The ordinary forms are:-Var. Graminifólius, Fries. Submersed leaves lance-linear, attenuate at each end, flaccid, sometimes more than $4^{\prime}$ long by $3^{\prime \prime}$ wide; stem elongated. - Var. netenopurusus, Fries. Lower leaves shorter, lancelate, more rigirl : the commonest form. 'The following are doubtfully referred to this species. (Eu.)

Var.? spathulæformis. (P. spath:eformis, Tuckerman, in herb.) Branches senttered; floating leaves obovate or oblong, with a larger point ; submersed ones spatulate-oblong, obtuse, mucronate, sometimes recurved; spikes large and densely flowered. - Mystic Pond, near Boston, Tuckerman. The fruit is lacking to prove its rank.

Var. ? myriophýllus. Sending up from running rootstocks many short repeatedly dichotomous and densely leafy stems; fertile stems very slender; floating leaves small, delicate, lance-oblong, on long filiform petioles; submersed stem-leaves larger, early perishing; those of the branches (dcep green) linear-oblanceolate, very small $\left(f^{\prime}-1^{\prime}\right.$ long), acute, sometimes minutely serrulate; spike sleniler, loosely-flowcred, much shorter than the thickened peduncle. - Apponaug Pond, Rhode Island, without fruit.

§ 2. Conformifolix. Leaves all submersed and similar, mostly sessile, membranaceous and dilated, lancenlate, oblong, or oval. - (Stipules obtuse, becoming lonse.)

12. $\mathbf{P}$. lùcens, I. Stem thick, branching, sometimes very large; leaves more or less petiolsd, oval or lanceolate, mucronate, often rough-serrulate, frequently 
shining; fruit roumlish and compressed, with obtuse margins, slighly keeled; embryo circularly incurved above. - Ponds : not commun. Aug., Sept. (Eu.)

Var. minor, Noltc. Sinaller; upper leaves distinctly petioled and sometimes emersed, the others subsessile, all usually numerous, undulate and shining.

Var. ? Connecticuténsis. Stem flexuous; leaces all submersed, nearly sessile, lanceolate, acuminute, crisped, not shining; fruit larger, distinctly keeled; nutlet thick and hard. - Saltonstall's pond, East Haven, Connecticut, 1850.

13. P. prælóngus, Wulfen. Stem very long, branching, flexuous; leaves lance-oblong or lanceolate (sometimes 7 ' long), hulf-clasping, obtuse with a boatshaped cavity at the extremity, thence splitting on pressure; stipules scarious, very obtuse; spikes rather loose-flowered; peduncles very long (sometimes reaching $20^{\prime}$ ) ; fiuit obliquely obovate, compressed, sharply kiceled when dry ; style terminating the nearly straight face; curve of the embryo oval and longitudinal. Ponds and large rivers, E. New England, and along the Great Lakes to Lake Superior. Sept., Oct. - Stem white : foliage bright green. (Eu.)

14. P. perfoliàtus, L. Stem branching; leaves orlicular, ovate or lanceolate from a cordate-clasping base, usually obtuse and often minutely serrulate; peduncles short, cylindrical ; fruit irregularly obovate, obtusely margined; embryo incurved in an oval. - Ponds and slow streams : common. Sept., Oct. (Eu.)

Var. lanceolàtus. Larger; leaves long-lanceolate from a cordate-clasping base and acuminate, wavy, $3^{\prime}$ to sometimes $42^{\prime}$ long; peduncles thickencel upwards. - Along the Great Lakes. - This form seems peculiarly American.

15. P. críspus, L. Stem compressed; leaves linear-oblong, half-clasping, obtuse, serrulate, crisped-uavy, 3-nerved; fruit long-beaked; upper portion of the enbryo incurved in a large circle.-Flowing and stagmant waters, Delaware, Penn., and New Jersey, Tatnall, Porter, Mechan. June, July. (Eu.)

§3. Axgustrifolit. Leaces all submersed and similar, mostly membranaceuus and sessile, linear or setaceous. (No. 16, 17, and 20 are often gemmiparous, propugating by narrow terminal buds detached in autumn.)

* Stipules free from the sheathing base of the leaf.

16. P. compréssus, L. (ex Fries.) Stem lranching, wing-flattened; leaves linear and grass-like (commonly $4^{\prime}$ by $\left.1_{2}^{\prime \prime}\right)$, abruptly pointed, with many fine and 3 larger nerves; stipules (seen young) oblong, very obtuse ; spities cylindricul, 12 15-flowered, not half as long as the peduncle; fruit obliquely obovate, sumewhat keeled and with slight tecth on the back, the sides not impressed, the face arching and terminated by the short style; summit of the large cmbryo lying transverse to the finit. (P. zosterafolius, Schumacher.) - Still and slow-flowing waters, New Englind to Penn. and Wisconsin : not common. Aug., Sept. (Eu.)

17. P. obtusifolius, Mertens \& Koch. Stem flattened, very branching, beaves linear, tapering towards the base, obtuse and inucronate or very acute, 3 (rarely 5-) nerved ; stipules elongated, vary obtuse; spike ovate, continuous, 5-8flowered, about the lenyth of the pediencle; fruit oval, apiculate with the style, not keeled when fresh, upper portion of embryo coiled inward and lying transverse to the fruit. - Slow streams and ponds: very rare: Dillerville swamp, near Lancaster, Peun., Prof. Porter. Swamp of Beaver pond, near Central mine, and floating in Gratiot Lake, N. Michigan. Sept., Oct. (Eu.) 
18. P. Niagarénsis, Tuckerman. Stem fattencd, very branching; leaves linear, very acute, mucronate and much attenuate at the nearly sessile base, 3-5nerved, scarcely veiny $\left(1 \frac{1^{\prime}}{2}-3^{\prime}\right.$ long and at most $1^{\prime \prime}$ wide); midril) below dilated; stipules acutish (sometimes 8 "long), the numerons nerves early becoming bristles; peduncles short, club-shaped, compressed; spikes few, capitate, 8-12-fouered; fruit roundish, compressed, with a winged and tonthed keel and angled face; " seed convolute-uncinate." - Rapids above Niagara Falls, Tuckerman. Aug.

19. P. pauciflorus, Pursh. Stem filform, flattish and very branching, lenves narrow linear ( $1^{\prime}-2^{\prime}$ long and seldom $\frac{1}{2}$ " widc), acute, obscurely 3-nerved; stipules obtuse; spikes capitate, 1-4-usually 2-flowered, on short club-shaped peduncles; fruit roundish-lenticular; the back more or less crested; upper portion of the embryo incurved in a circle. - Still or stagnant waters: common. Aug., Sept. - Its largest forms are approached by the preceding.

20. P. pusíllus, L. Stem slender, flattish or nearly cylindrical, branching; leaves narrow- or setaceous-linear, obtuse or acute, furnished with trunslucent glands on each side at the base; stipules at first obtuse; spikes interrupted or capitate. 2-8-flowered, on rather long peduncles; fruit obliquely elliptical, scarcely keeled; apex of cmbryo incurved and directed obliquely downwards. - Pools and ditches: rather common, especially southward. - The principal forms are

Var. màjor, Fries. Stem less branching ; leaves broader (almost 1" wide), ofen 5-nerved; spikes interrupted. (P. mucronàtus, Schrader.) - This hardly passes into the following forms: rather rare. July. (Eu.)

Var. vulgàris, Fries. Slender, very branching; leaves 3-nerved, often obtuse ; spikes cylindrical and interrupted, or capitate and then but 1-3-flowered. -A rare form (E. Mass.) has sometimes lanceolate floating leaves of the length of the petioles, with 5 nerves impressed beneath, as in P. hybridus. A Swedish specimen in Fries. Herb. Norm. exhibits the same in the following variety, though in a slighter degree. July, Aug. (Eu.)

Var. tenuíssimus, Mertens \& Koch. Stem very slender and much branched; leaves almost setuceous, acute or cuspidate, obsoletely 3-nerved; spikes interrupted or capitate. - New England and New York: rather rare. July, Aug. - All three are rather sparingly furnished with reproductive buds: also the last two fruit freely, - the reverse of the fact in the following.

Var.? gemmiparus. Stem filiform and very branching, lenves thicker, perfectly setaceous and usually exrecdingly attenucte to the finest point, scarcely with a proper mirlrib; stipules long $\left(\frac{1}{2}{ }^{\prime}-1^{\prime}\right)$, ohtuse; spikes very few, always interrupted, 3-6-flowered, long-perluncled, proprigating burls very numerous; fruit watnting. (P. gemmiparus, Roblins in herb.) - Pools and slow-flowing waters : outlet of Mystic Pond, near Buston, Turlerman; valley of the Blackstone from Worcester to Providence. - This plant is annual, propagated exclusively by its gemmæ, the fruit not maturing.

21. P. Tuckermani, Robbins. Very slender and delicate from a creeping. rootstock, of a fine light green; stem filiform with several short and repeatedly dichotomous leaf-bearing branches; leaves thin and flat, but setrceous and tapering to near the fineness of a hair $\left(1^{\prime}-4^{\prime}\right.$ long and $j^{\prime \prime}$ extreme width), obscurely 1 3-nerved, with a few coarse reticulations; stipules rather persistent below, $b^{\prime}$ long, obtuse; peduncle solitary, very long, rather thickening upward; spike 4-8- 
flowered, in fruit continuous, wlong; fruit thick-lenticular, obscurely 3-keeled; nulles slightly impressed on the sides; shell thick and hard; embryo nearly annular. Cold ponds, White Mountains, New Hampshire, to Penn. June, July.

* * Slipules unitul with the sheathing base of the leaf.

22. P. pectinàtus, L. Stem filiform, repeatedly dichotomous; haves setaceous, attenuate to the apex, 1-nerved with a fíw transverse veins; spikes interrupted, on long filiform peduncles; firuit obliquely broad-obovate, compressed, bluntly keeled; shell of nutlet very thick; embryo nearly annular. - Lake Champlain w Lake Superior, and along the coast, both in fresh and salt water. Aug. - Oct. (Eu.)

23. P. Robbínsii, Oakes. Stem ascending from a creeping base, rigid, very branching, investal by the beses of the leaves and stipules; leaves crowded in two ranhs, recurved-spreading, narrow-lanceolate or linear $\left(3^{\prime}-5^{\prime}\right.$ loug and $2^{\prime \prime}-3^{\prime \prime}$ wide), acuminate, ciliate-serrulate with translucent teeth, many-nervel; stipules obtuse when young, their nerves soon becoming bristles; spikes numerous, loosely jewflowered, on short peduncles. A single, rather immature truit in l'rolessor 'Tuckerman's herbarium, from Prof. Eaton, is obliquely obovate, acutish at the base, 3-keeled on the back, the middle kecl winged, much arched on the thinuer face, compressed and impressed on the sides, and apiculate with the rather long style; superior portion of the large embryo circularly incurved and pointing obliquely downwards. - Oozy bottoms of ponds and slow streams: common in New Englizud: also in New York, l'ennsylvania, and Ohio. Flowering in June and July. Mature fruit not yet seen.

(P. DÉxsus, L. The plant upon which Schweinitz introduced this European species into the U. S. flora proves to be Anacharis Canadensis.)

\section{Ordek 111. Aisisidete. (Water-Plantain Family.)}

Marsh herbs, with scape-like flowering stems, and perfect or monocious flowers, not on a spadix, furnished with both calyx and corolla: sepals and petals each 3, distinct. Ovaries 3-many, distinct or partly so, or if united separating at maturily, forming as many 1-2-sected pods or achenia. Seed ascending or erect. Ĺmbryo without albumen. Stamens hypogynous, from 6 to many: anthers extrosse, 2-celled. Leaves sheathing at the base. - Comprises two very distinct suborders, viz. :-

\section{Subotder I. JUNCAfine Re. Arrow-grass Family.}

Calyx and corolla colored alike (greenish). Carpels more or less united. Seed anatropous, with a straight embryo. Leaves petiole-like, without a blade. (Flowers perfect.)

1. Triglochin. Ovaries $3-6$, united to the apex into one, but separating in fruit.

2. Scheuchzeria. Ovaries 3 , almost distinct, forming diverging pods in fruit.

\section{Suborder II. Alismede. Wateir-l'lantain Family.}

Calyx green and persistent. Corolla white, deciduous. Ovaries numerous, distinct. Seed campylotropous : embryo bent double or hook- 
shaped. Leaves or some of them commonly furnished with a blade. (Flowers perfect, monœecious, or sometimes diœcious.)

8. A IIsma. Flowern perfect, with definite, mostly 6 stamens. Carpels flattened, whorled.

4. Echlnodorus. Flowers perfort, with 6 -inany atsmens. Carpels eapitnte, ribbed.

6. Saglttnxin. Flowers monocious, rarely diøcious, with indefinite, rarely few stamens. Carpels capitate, flattened, winged.

\section{TRIGLÒCHIN, L. Arrow-Grass.}

Sepals and petals much alike (greenish), ovate, concave, deciduous. Strmens 3-6: anthers oval, on very short filaments. Pistils united into a 3-6-celled compound ovary: stigmas sessile : ovules solitary. Pod splitting when ripe into 3-6 carpels, which separate from a persistent central axis. - Perennials, with rush-like, fleshy leaves, below sheathing the base of the wand-like naked and jointless scape. Flowers small, in a spiked raceme, bractless. (Name composed of rpeis, thee, and $\gamma \lambda \omega \chi i v$, point, from the three points of the ripe fruit in No. 1 when dehiscent.)

1. T. palústre, L. Scape $\left(6^{\prime}-18^{\prime}\right.$ high) and leaves slender; fruit lincarclul-shoped; the 3 carpels when ripe separating from below upwards lenving a triangular axis, awl-pointed at the base.- Marshes, both fresh and brackish, New York to Illinois, and northiward. Ang. (Eu.)

2. T. maritimum, L. Scape $\left(12^{\prime}-20^{\prime}\right.$ high) and lmves thickish, fleshy, fruit ovate or oblong, ucutish, of 6 or rarely 5 carpels which are rounded at the base and slightly grooved on the back; the edges acute. - Salt marshes along the coast, also salt springs in the interior, shore of the Great Lakes, and northward. Var. ELATUM (T. elatum, Nutt.) grows in cold and fresh bogs, from W. New York to Wisconsin, often $2 \frac{1}{2}^{\circ}$ high, and has the angles of the carpels sharper, or almost winged. (Eu.)

\section{SCH EUCHZ ìr I A, L. Scheuchizeria.}

Sepals and petals oblong, spreading, nearly alike (greenish-yellow), but the latter narrower, persistent. Stamens 6 : anthers linear. Oraries 3, globular, slightly united at the base, 2-3-ovuled, bearing flat sessile stigmas, in fruit forming 3 diverging and inflated 1 - 2-sceled porls, opening along the inside. A low bog-herb, with a creeping jointed rootstock, tapering into the ascending simple stem, which is zigzag, partly sheatherl ly the bases of the grass-like conduplierte leaves, and terminated hy a loose raceme of a few flowers, with sheathing bracts. (Named for John and John.Jacol) Srhenchzer, distinguished Swiss botanists early in the 18 th century.)

1. S. palústris, L. - Peat-bogs, New England to Pennsylvania, Illinois, and northward. June, July. (En.)

\section{A L I S M A, L. Water-Plantain.}

Flowers perfect. Petals involute in the bud. Stamens definite, mostly 6. Ovarics many in a simple circle on a flattened receptacle, forming flattened coriaccous achenia, which are dilated and $2-3$-kceled on the back. - Roots fibrous. 
Leaves all from the root, several-ribbed, with connected veinlets. I Scape with whorled panicled branches. Flowers small, white or pale rose-color. (The Greek name; of uncertain derivation.)

1. A. Plantàgo, L., var. Americànum. Root perennial; leaves longpetioled, ovate, oblong, or lanceolate, pointed, mostly rounded or heart-shaped at the base, 3 -9-nerved; panicle loose, compound, many-flowered $\left(1^{\circ}-2^{c}\right.$ long); carpels obliquely obovate, forming an obtuscly triangular whor! in firui (A. trivialis and parviflora, Pursh.) - Shallow water. July-Sept. (Eu.)

\section{ECH I N Ó D OR US, Richard, Engelmann.}

Flowers perfect. Petals imbricated in the bud. Stamens 6-2l or more Ovaries several or many, imbricated in a head, forming thick and ribbed achenia in fruit, often beaked with a projecting persistent style. - Habit intermediate between the preceding genus and the following. Fl. summer and

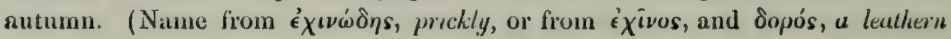
bottle, applied to the ovary, which is in most species armed with the persistent style, so as to form a sort of prickly head of fruit.)

Genus elaborated for this work by Dr. EnGLLManN.

1. E. párvulus, Lingchn. Leaves lanceculate or spatulate, acute $\left(\frac{1}{2}{ }^{\prime}-1 \frac{1^{\prime}}{2}\right.$ long, including the petiole); shoots often creeping and proliferous; scapes $\left(1^{\prime}-3^{\prime}\right.$ high) bearing a 2-8-flowered umbel; pedicels reflexed in fruit; stamens 9 ; styles much shorter than the vvary; achenia beakless, many-ribbed ; root annual. In unud, Cambridge, Mass. James, and Michigan to Ill. \&c. - Flower $3^{\prime \prime}$ broad.

3. E. rostràtus, Lingelm. Leaves broudly heart-shaped, abluse, nerved (1'$3^{\prime}$ long, excluding the pctiole); scupe erect, longer than the leaves, bearing a branched panicle of proliferous umbels; stamens 12 ; styles longer than the viary; achenia beaked, many-ribbed; root annual. (Alisma rostrata, Nutt.) - Swamps and ditches, Illinois and sonthward. - 1'lant from $3^{\prime}$ to $2^{\circ}$ high. Flower $5^{\prime \prime}$ wide. IIead of fruit ovoid, 3 " wide.

3. E. radicans, Engelm. Leaves somewhat truncately broadly heartshaped, obtuse, nerved $\left(3^{\prime}-8^{\prime}\right.$ broad, long-petioled $)$; stems or scapes prostrate, creeping $\left(2^{\circ}-4^{\circ} \mathrm{long}\right)$, proliferous, bearing many whorls of flowers; stamens alio:t 21; styles shorter than the ovary; achenia short-beaked, the keeled back denticulate. (Alisma radicans, Nutt.) - Swamps, Illinois and southward. Flowers $6 "-9^{\prime \prime}$ in diancter.

\section{SA G I T t A R I A, L. Arrow-head.}

Flowers monocious, or often diocious in No. 2, and polygamous in Nu. 3. P'etals imbricatel in the bud. Stamens indefinite, rarely few. Ovaries many, crowded in a splecieal or somewhat triangular depressed head on a glubular receptacle, in fruit forming flat membranaceous winged achenia. - Marsh or aquatic, peremial, stolonilerous herhs, with milky juice and fibrous roots; the seapes slicallical at the hase hy the bases of the long celluhar petioles, of which the primary ones, and sometimes all of them, are flattened, nerved, and destitute of any proper blade (i. e. are phyllodia): when present the blade is arrowshaped or lanceolate, nerved and with cross veinlets as in Alisma. Flowers 
produced all summer, mostly whorled in threes, with membranous bracts; the sterile above. (Name from sagitta, an arrow, from the prevalent form of the leaves.)

Genus newly elaborated for this edition by J)r. ENarimann.

* Filaments narrow, as long as the liwar-oblong anthers: scape simple or branched.

1. S. lancifolia, L. Scape $2^{\circ}-5^{\circ}$ high, with several of the lower whorls fertile; bracts ovate, acute or acuminate; pedicels slender, the fertile scarcely shorter than the sterile ones; filaments pubcscent; achenia obovate-falcate, pointed with an incurved beak; leaves lanceolate or lance-oblong, rarely linear, all with a tapering base, thick or coriaceous $\left(6^{\prime}-18^{\prime}\right.$ long and on a long and stout petiole, never sagittate), the nerves mostly arising from the very thick midrib. (S. falcata, Pursh, and Ed. 2.) - Swamps, Virginia and southward to the West Indies.

2. S. variábilis, Engelm. Scape $\left(4^{\circ}-4^{\circ}\right.$ high) angled, with one or more of the lower whorls fertile; bracts mostly pointed; pedicels of the fertile flowers about half the length of the sterile ones; petals with white claws; filaments glabrous, nearly twice the length of the anthers; achenia broadly obovate, with a long and curved beak $+-\frac{1}{4}$ its length; leaves very various, almost always sagittate. (S. sagittifolia Amer. auth. etc. - The European species has the fertile pedicels only or the length of the sterile; claws of the petals purpletinged; filaments not longer than the anthers; achenia almost orbicular, very broudly winged and with a short and straight beak.) - In water or wet places: very common. - Excessively variable in size and foliage : the following are the leading forms. - Var. ontusa (S. obtusa, Willd.) is large and diocious; the broadly sagittate leaves obtuse, $6^{\prime}-12^{\prime}$ long. - Var. LATIFòla (S. latifolia, Willd.) is large, monocious, with broad and acute sagittate leaves. - Var.

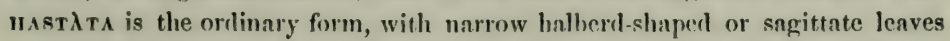
(including S. hastata, Pursh). - Var. DIversifóru, with some leaves lanceolate or ovate-lanceolate, others more or less sagittate. - Var. ANGUSTIFólia has the narrow leaves with long and linear diverging lobes. - Var. GRÁcilis (S. gracilis, Pursh) is the most slender form, with nearly linear leaves and lobes. - Var. PUBÉscens (S. pubéscens, Muhl.) : upper part of petiole and of seape and especially the orhicularovate obtuse bracts and sepals pubescent or woolly ; leaves obtusc or acute; beak of fruit (as also sometimes in some of the other forms) horizontal, so that the fruit-head appears compact and smoothish, while usually it has a squarrose surface, from the protruling and recurved beak, New Jersey and sonthward. - A state with double flowers has been found in Pennsylvania and Delaware.

3. S. calycina, Engelm. Scape weak $\left(3^{\prime} \cdots 9^{\prime}\right.$ high $)$, at length mostly procumbent; usually only the lowest whorl fertile, with perlicels as long as those of the sterile flowers, recurved in fruit; bracts orbicular, obtuse or rarely pointed ; caly. $x$ appressed to the fruit-hend and partly corering it ; filaments slightly rough, as long as the anthers; achenia obovate with a short horizontal style; leaves broadly halberd-shaped, obtuse or acutish, with wide spreading lobes, often wider than long, or lnnceolate or sometimes reduced to linear phyllodia. - Maine to Delaware, Wisconsin, and southward. - Var. spongiòss, with a loose or spongy texture and linear bladeless leaves submersed, occurs eastward; 
Var. FLỦrunas, with lance-linear floating leaves, has been found in Missouri and westward; and Var. G1ŔNDIs, with leaves $9^{\prime}-12^{\prime}$ wide and $9^{\prime}$ long, branched scape, and fruit-heads 9 "diameter, grows farther south. - 'This species shows 9-12 stamens in the fertile, and some sterile pistils in the sterile flowers; and thus connects with Echinodorus.

* Filaments very short, with enlarged mostly glandular base: scape more simple.

4. S. heterophýlla, P'ursh. Scape weak $\left(3^{\prime}-2^{\circ}\right.$ high $)$, at length procumbent; bracts roundish, obtuse; flowers of the lowest whorl fertile and almost sessile; the sterile on long pedicels; filaments glandular-pubescent; achenia narrowly obovate wich a long erect beak; leaves lanceolato or lance-oval, entire, or with one or two narrow basal sagittate appendages. - Rather common, at least southward. - Var. Ellferica has broad leaves (sometimes $6^{\prime}$ long and 5' wide), either obtuse or cordate at the base, or sagittate. - Vur, RfGiDA (S. rigida, Pursh, on the Niagara and along the Great Lakes), the tallest form, has stout petioles and rigid narrowly lanceolate blades, acute at both ends. Var. ANGUSTriolia has nearly linear leaves.

5. S. gramínea, Michx. Scape very slender, erect $\left(3^{\prime}-2^{2}\right.$ high $)$; the lower whorls furtile; bracts rather obtuse and usually comnate; pedicels ull slender, the sterile and firtile of equal length; filaments glandular-pubeseent; achenia small, narrowly obovate, almost beakless; leaves varying from ovatelanceolate to linear or reduced to broad and acute phyllodia (when it is S. acutifulia, Pursh); scarcely ever sagittate. (S. simplex of Amer. authors; not of Pursh, whose plant of this name is a dicecious form of $\mathrm{S}$. variabilis.) - Rather common, especially southward. - Flowers and fruit-heads sinaller than in any of the foregoing; except in the var. Platypirtla, which is found farther south, and has leaves $6^{\prime}-9^{\prime}$ long and $3^{\prime}-4^{\prime}$ wide; flowers $1^{\prime}$ wide, on pedicels $1 \frac{1^{\prime}}{2}-2^{\prime}$ long.

6. S. pusílla, Nutt. Scape (!'-3' high) weak, reclining in fruit; bract single, clasping; one or two whorls only, of which but a single flower is fertile, recurved in fruit; stamens about 7 , with glabrous filunents; achenia obovate, with an erect beak and three notehed dorsal ridges. (Alisina subulàta, Pursh.) - Inundated shores, from Eastern New Jersey (C. F. Austin) and P'hiladelphia southward near the coast.

S. NATANS, Michx., closely allied to the last, is only found farther south; it is a larger plant with long phyllodia, or oval floating leaves, glabrous filaments, and obovate short-beaked achenia, with 5 - 9 crenate angles, - by which structure it is nearly comnected with Echinodorus.

\section{Order 112. HYDTochateIdà CEAE. (Frog's-bit Family.)}

Aquatic herbs, with divecious or polygamous regular flowers on scape-like pedincles firom a spathe, and simple or double floral envelopes, which in the fertile flowers are united into a tube and coherent with the 1-3-celled ovary. Stancens 3-12, distinct or monadelphous: anthers 2-celled. Stigmas 3 or 6. Fruit ripening under water, indehisecnt, many-seeded. Seeds ascending, without albumen : embryo straight. 


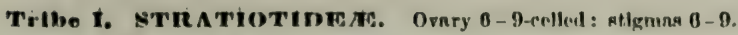

1. Limnoblum. Filamenta 6-12, unequally united in the sterile flowers : anthers linear.

Tribe it. VALLISN ERIRA. Ovary 1-celled with 3 parictal plecentro: stigmas 3.

2. A uncharis. Stem lenfy. Tube of tho perianth of the fortile flowers thrend-form.

3. Valls ancria. Stemless. Tube of the perianth not prolonged beyond the ovary.

\section{Li M N Ò BI U M, Richard. Americhe Frog's-bit.}

Flowers diœcious, (or monœcious?) from sessile or somewhat peduncled spathes; the sterile spathe 1-lenved, producing about 3 long-pedicelled flowers; the fertile 2-leaved, with a single short-pedicelled flower. Calyx 3-parted or cleft; sepals oblong-oval. Petals 3, oblong-linear. Filaments entirely united in a central solid column, bearing 6-12 linear anthers at unequal heights : there are 3-6 awl-shaped rudiments of stamens in the fertile flowers. Ovary 6-9celled, with as many placentæ in the axis, forming an ovoid many-seeded berry in fruit: stigmas as many as the cells, but 2-parted, awl-shaped (ovules orthotropous, Torr.). - A stemless perennial herb, floating in stagnant water, proliferous by runners, with long-petioled and round-heart-shaped leaves, which are spongy-reticulated and purplish underneath; rootlets slender, hairy. Sterile flowers rather small; the fertile larger; peduncle nodding in fruit. Petals white? (Name from $\lambda_{\iota \mu \nu} \beta_{\beta}$ เos, living in pools.)

1. L. Spóngia, Richard. (Hydrócharis Spongia, Bosc. H. cordifolia, Nutt.) - Lake Ontario (Dr. Bradley, Dr. Sartwell), Illinois, Dr. Vasey, and in the Southern States. Aug. - Leaves $1^{\prime}-2^{\prime}$ long, faintly 5-nerved. Peduncle of the sterile flower about $3^{\prime}$ long, thread-like; of the fertile, only $1^{\prime}$, stout.

\section{A NÁCHARIS (and Elodèa), Richard. Water-weed.}

Flowers polygamo-diøcious, solitary and sessile from a scssile and tubular 2cleft axillary spathe. Sterile flowers small or minute; with 3 sepals, barely united at the base, and usually 3 similar or narrower petals : filaments short and monadelphous at the base, or none; anthers 3-9, oval. Fertile flowers either pistillate or apparently perfect: perianth extended into an extremely long and capillary tube; the limb 6-parted; the small lobes (sepals and petals) obovate, spreading. Stamens 3-9, sometimes merely short sterile filaments, without anthers, or with imperfect ones, sometimes with oblong anthers Ovary 1-celled, with 3 parietal placenta, each bearing a few orthotropons ovules; the capillary style coherent with the tube of the perianth : stigmas 3, large, 2-lobed or notched, exserted. Fruit oblong, coriaceous, few-seeded. - Perennial slender herbs, growing under water, with elongated branching stems, thickly beset with pellucid and veinless, 1-nerved, sessile, whorled or opposite leaves. The staminate flowers (which are rarcly seen) commonly break off, as in Vallisneria, and float on the surface, where they expand and shed their pollen around the stigmas of the fertile flowers, which are raised to the surfice by the excessively prolonged calyxtube, varying in length according to the depth of the water. (Name formed of ày, throughout, and "xapes, without charms, being rather homely water-weeds.)

1. A. Canadénsis, Planchon. Leaves in threes or fours, or the lower opposite, varying from linear to oval-oblong, minutely serrulate; stamens 9 in 
the sterile flowers, 3 or 6 almost sessile anthers in the perfect flowers. (Elodèa Canadensis, Michx., and E. latifolia, Caspary, who has recently well illustrated this and the two related genera; all perhaps to be reduced to one, Hydrilla. Udora Canadensis, Nutt. Anacharis Alsinastrum (Bubington), Nuttallii, and Canadensis, also A paláuthe Schweinítzii, I'lenchon.) - Sluw streans and ponds: common. July. - Nat. in Lingland, where it is very truablesome by its raphid increase, filling navigable waters; but no inconvenience of the sort is complained of here in its native country.

\section{V A L L I S N E R I A, Micheli. Tape-girass. Eel-grass.}

Flowers strictly dicecious: the sterile numerous and crowded in a head on a conical receptacle, enclosed in an ovate at length 3-valved spathe which is borne on a very short scape: stamens mostly 3 . Fitrile flowers solitary and sessile in a tubular spathe which is borne on an exceedingrly long scape. Perianth (calyx) 3-parted in the sterile flowers; in the fertile with a linear tube coherent with the 1-celled ovary, but not extended beyond it, 3-lobed (the lobes obovate); also 3 linear small petals. Stigmas 3, large, nearly sessile, 2-lobed. Ovules very numerous, scattered over the walls, orthotropous. Fruit elongated, cylindrical, berry-like. - Stemless plants, with long and linear grass-like leaves, growing entirely under water. 'The staminate clusters being confined to the bottom of the water by the shortness of the scape, the flower-buils themselves spontaneously break away from their short pedicels and Hoat on the surface, where they expand and shed their pollen around the fiertile flowers, which are raised to the surface at this time: afterwards the thread-form fertile scapes $(2-4$ feet long, according to the depth of the water) coil up spirally, drawing the fruit under water to ripen. (Named for Ant. Vullisneri, an early Italian botanist.)

1. V. spiràlis, L. Leaves linear, thin, long and ribbon-like $\left(1^{\circ}-2^{\circ}\right.$ long $)$, obscurely serrulate, obtuse, somewhat nerved and netted-veined. - Common in slow waters. Aug. (Eu.)

\section{Order 113. hutranniàceat. (Burmania Family.)}

Small annual herbs, often with minute and scalc-like leaves, or those of the root grass-like; the flowers perfect, with a 6-cleft corolla-like perianth, the tube of which adheres to the 1-celled or 3-celled ovary; stamens 3 and distinct, opposite the inner divisions of the periunth; porl many-seeded, the seerls very minute. - A small, chiefly tropical family, of which only one species is found within our borders.

\section{B U R M Á N NIA, L. (Tripterélea, Michx.)}

Ovary 3-celled, with the thick placenta in the axis. Filaments 3, very short. Style slender: stigna capitate-3-lobed. I'od often 3-winged. (Named for J. Burmann, an carly Dutch botanist.)

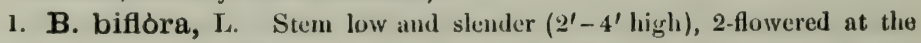
summit, or soon several-flowered ; perianth (2" $-3^{\prime \prime}$ long) bright blue, 3-winged. ('Tripterella carculea, Mlichx.) - l'enty bogs, Virginiat usd soutliward. 


\section{Order 114. Orchindèce. (Orchis Famrey.)}

Herbs, clearly distinguished by their perfect irregular flowers, with 6-merous perianth adnate to the 1-celled ovary, with innumerable ovules on 3 partetal placenta, and with either one or two gynandrous stamens, the pollen cohering in masses. Fruit a 1-celled 3-valved pod, with innumerable minute seeds, appearing like fine saw-dust. Perianth of 6 divisions in 2 sets; the 3 outer (sepals) mostly of the same petal-like texture and appearance as the 3 inner (petals). One of the inner set differs more or less in figure, direction, \&c. from the rest, and is called the labellum or lip: only the other two taking the name of petals in the following descriptions. The lip is really the upper or posterior petal, i. e. the one next to the axis, but by a twist of the ovary of half a turn it more commonly is directed forward, as if anterior, i. e. is next the bract. Before the lip, in the axis of the flower, is the column, composed of a single stanen, or in Cypripedium of two stamens and a sterile rudiment of a third, variously coherent with or borne on the style or thick fleshy stigma; the anther 2-celled; each cell containing one or more masses of pollen (pollinia or pollen-masses). Stigma a broad glutinous surface, except in $\mathrm{Cy}$ pripedium. - Perennials, often tuberbearing or tuberous-rooted ; some epiphytes. Leaves parallel-nerved, all alternate. Flowers often showy, commonly singular in shape, solitary, racemed, or spiked, each subtended by a bract, - in all arranged for fertilization by the aid of insects, very few capable of unaided self-fertilization. (See articles on Fertilization of Orchids, in Sill. Jour. 1862, $\left.1863,8 c^{.}\right)$- A vast family, but few in the United States.

I. Anther only one. (The 2 cells should not be mistaken for anthers !)

Tribe I. OPHRYDEF. Anther (of 2 separate cella) borne on and entirely adnate to the face of the stigma, erect or reclined. Pollen cohering into a great number of coarse grains, which are all fastened by elastic and cobwebby tissue into one large mass, and to a stalk that connects it with $\mathrm{a}$ gland or disk which was originally a part of the stigma. Flower In our epecies ringent, the lip with a spur beneath: one distinct gland to each pollen-mass

1. Orchis. The two glands or viseld disks enclosed in a common pouch.

2. Habenarla. The two glands or disks naked (without any pouch or covering), either npproximate or widely separated.

Trlbe II. NEOTTIEA. Anther dorsal and erect or Inclined, attached by its base only or by a short flament to the buck or summit of the column, persistent. Pollen in our genera lonsely cohering (mostly b; some delicate elastic thrinds) in 2 or 4 soft masees, and soon attached directly to a viscous gland on the beak of the stigma.

3. Good yera. Lip entire, free fom the column, without callosities at the base.

4. Splrnuthes. Lip ascending and embracing the column below, 2 callosities at the base.

5. Listera. Lp flat, spreading or pendulous, 2-lobed at the apex.

Trlbe II. ARETIUSER, MALAXIDEF, \&c. Anther terminal and inverted (except in No 12 like a lid over the stigma, deciduous.

* Pollen powdery or pulpy in 2 or 4 delicate masses : no gland

6. A rethusa. Lip bearded, its base adherent to the linear column. Pollen-mases 4.

7. Pogonia. Lip more or less crested, free from the club-shaped column. Pollen-masses 2 L \& $\mathrm{M}-41$ 
8. Calopogon. Lip bearded, stulked, free: column winged at the apex. Pollen-nasses 4

\section{* Pollen in 4-8 smooth waxy musres, \\ - Without stalks, attuchell directly to a large gland.}

9. Caly pso. Lip inflated and sac-like. Column winged and petal-like. Stem 1-flowered.

- + With stulks to the 2 or 4 pollen-masses, connecting them with a gland.

10. Tipularla. Lip short, flat, long-spurred beneath. Rameme many-llowered.

+. + + With stalks to the 8 polleu-masses, but no gland.

11. Bletia. Lip hooded, crested, spurless. Scape severul-Howered.

++++ Without fither stalks or glands to the 4 pollen-masses.

\#+ I'lats green and with ordinary leaves. Sepals spreading.

12. Microstylis. Column miuute, riund: autlier erect.

13. Liparis. Colum elongated, wargined at the apex : auther lid-like.

$\leftrightarrow+$ Plants tawny or purplish, leutless, or with a root-leuf only.

14. Corallorhiza. Periunth gibbuus at base, or with a spur adhereut to the ovary.

15. A plectrum. Perianth not gibbous nor spurred ut base. A green autumaal leaf.

II. Anthers two, or very rarely three.

Tribe IV. CYPIRIPDIEAS. The staucu which bears the unther in the rest or the order here usuall, forms a pelal-like sterile appendage to the columu. Pollen not in masses: no stalks nor glaud.

16. Сурхіреdím. Lip an inflated sac. Antbers 2 , one each side of the column

\section{1. ÓRCHIS, L. Orchis.}

Flower ringen:; the sepals and petals nearly equal, ull of them (in our species) converging upwards and arching over the colunn. Lip turned downwards, coalescing with the base of the column, bearing a nectariferous spur at the base underneath. Anther-cells contiguous and parallel. Pollen colering in numerous coarse waxy graius, which are collected on a cobweb-like elustic tissue into 2 large masses (one filling each anther-eell) borne on a slender stalk, the base of which is attached to a gland or sticky disk of the stigma, the two glands eontained in a common little pouch or hooded fold, placed just above the orifice of the spur or nectary. Flowers showy, in a spike. - These glands stick fast to the proboscis of a butterfly or some such insect introduced into the nectarbearing spur: when it flies to another flower, it drags out of the anther and carries with it the pollen-masses, and applies them to the stigma of the second or of several succeeding flowers, thus effecting cross-fertilization ("Opxts, the ancient name.)

1. O. spectábilis, L. (Showy Orcuss.) Root of thick fleshy fibres, producing 2 oblong-obovate shining leaves $\left(3^{\prime}-5^{\prime}\right.$ long), and a few-flowered 4 angled scape $\left(4^{\prime}-7^{\prime}\right.$ high); bracts leaf-like, lanceolate; sepals und petals all lightly united to form the vauled galea or upper lip, pink-purple, the ovate undivided lip white. - Rich woods, New England to Kentucky and (especially) northward. May.

\section{H A BEN À R I A, Willd., R. Br. Reın-Oremis.}

Gland:s or viscid disks (to which the pollen-masses are nttacher) naked and exposed, separate, sometimes widely separated (becoming attached, some to the probancis, others to the face or head of insects fecding upon the nectar of the 
spur, the pollen thns cnrried from one hlossom to another): otherwise nenrly as in true Orchis: the litural sepals, howcver, mostly spreading. (Name from hahena, a thong or rein, in nllusion to the shape of the lip or spur of some species.) - P'zatantuens, named primarily for the sfecies with the glinds and bases of the anther-cells widely divergent, nnd Gronsments, where these are approximate, are found to afford no wholly fixed or clear practical distinctions. Accordingly, in this edition, our species are restored to the older genus.

§1. GYMNADENIA, R. Br. Cells of the anther parallel and approximate, their glands therefore contiguous. (Appendayes of the stigmn in our species tuo or three and much developed, oblong or club-shaped.)

1. H. tridentata, Hook. Stem slender $\left(6^{\prime}-12^{\prime}\right.$ high), with a single oblong or oblanccolate obtuse leaf helow, nnd 2 or 3 small ones like bracts above; spike 6-12-flowered, oblong; flowers greenish or whitish, very small; lip werlge-oblong, truncate and with 3 short teeth ut the apex; the slender and slightly club shaped spur curved upwards, longer than the ovary. (Orchis tridentata, Muhl. Gymnadenia tridentata, Lindl.) - Wet woods : common northward and along the Alleghanies. June, July. - Root of few fleshy fibres. Appendages of the stigma (sterile stamens?) threc, oblong-(lub-shnperl, one outside each orbicular glund and one between them, rising as high as the anther-cell, their cellular viscid summits receiving pollen in the unopened flower, and penetrated by pollen-tubes!

2. H. Integra, Spreng. Stem several-leaved ( $15^{\prime}$ high), the 1 or 2 lower leaves elongated, oblong-lanceolate, acute; the others becoming smaller and bract-like; spike densely many-flowered, oblong-cylindrical ; flowers orange-yellow, small ; lip ovate, entire or slightly crenulate or wavy, shorter than the awlshaped descending spur. (Orchis integra \& flava, Nutt. H. Ellióttii, Beck. Gymnadenia flava, Lindl.) - Wet pine barrens of New Jersey, Virginia, and 8outhward. July. - Root of very fleshy fibres, one or two of them tuber-like. Appendages of the stigma two, lateral, oblong, fleshy: rostellum or middle appendage narrow.

\$2. PERULARIA, Lindl. Cells of the anther nearly parallel, separated by a broadish connective, narrowed towurds the base, the margins of which are $\mathrm{ex}$ tended so us to form the sides of a deep oblong groove or cavity (more thun semicircular in cross-section), which is lined by the dilated orbicular and incurvd gland.

(Flowers small, greenish, slender-spurred.)

3. H. viréscens, Spreng. Leaves orate-oblong or ohlong-lanceolate; the uppermost linear-lanceolute and pointed, passing into the bracts of the elongated raceme; petals ovate; flowers dull green; lip furnished with a tooth on each side and a strong nasal protuberance in the middle of the base, oblong, truncate-obtuse, about the length of the scpals, half the length of the slender club-shaped spur. (Orehis flava, L.! but the flowers are not yellow. $O$. virescens, Muhl., Willd. O. fuscéscens, Pursh., not of $L$. O. herbiola, Pursh. O. bidentàta, Ell. O. scutellatı, Nutt. H. herbiula, R. Br. H. flava, Gray. Platanthera flava, Gray.) - Wet places : common. June, July. - Stem 10'-20' high; the spike at first dense, with the bructs longer than the fiowers, at length 
elongated and often loose, the upper bracts shorter than the flowers; which are quite small, and with scarcely a tinge of yellow, drying brownish. - The Siberian H. (Perularia) fuscescens is clearly distinct.

§3. PLATANTHÈRA, Richard. Cells of the anther sometimes parallel, more commonly divergent, so that their tapering luses and the exposed glands are more or less distant. (lioot a cluster of Jleshy jibres, or tubcrous-thichened.)

* Flowers greenish or uhite, small, numerous in a clase spike: spur not longer than the entire or merely notched nurrow lip: andher-cells almost parallel, wholly adnate: stem leafy.

- Spur short and sac-like: the 3 sepals and 2 narrow petals erect: glands small, rather widely separuted. (Penístrues, Lindl.)

4. H. víridis, R. Br., var. bracteàta, Reichenbach. Lower leaves obovate, the upper ublong and gradually reduced to lanceolate acute bracts $2-4$ times the length of the green flowers; spike 10-30-flowered; lip oblong-linear or slightly spatulate, truncate and $2-3$-toothed or lobed at the tip, more than twice the length of the spur. (H. bracteata, $R$. $B r$.) - Stem $6^{\prime}-12^{\prime}$ higli. According to Mr. Darwin, in the common Luropean H. viridis each glaud is protected by a minute pouch : this is not yet verified in ours. - Danp woods, especially uorth ward. (Eu.)

+ - Spur slender, incurved, about as long as the gitire lip: lateral sepuls spreading.

5. H. hyperborea, $\mathrm{k}$. Br. Stein very leafy $\left(6^{\prime}-2^{\circ}\right.$ high) leaves lanciolate, erect; spike dense $\left(2^{\prime}-15^{\prime}\right.$ long); lower bracts lanceolate, longer than the (greenish) fluwers; lip and petals lanceolute, someuhlat equal, the latter spreading from the base; anther sonewhat overhanging the transversely dilated stigmu; glunds orbicular; stalk of the pollen-masses very slender and weak. ( 1 . hyperborea, Huronensis, \&c., Lindl.) - Peat-bogs and wet cold woods : common north. ward. June, July. (Eu.)

6. H. dilatàta, Gray. (That of Hook, Exot. Fl. is the preceding.) Resembles No. 5, but usually more slender, with narrower commonly linear leaves; flowers white; lip lunceulate from a rhomboidul-dilated buse, entire, its base with the bases of other petals and sepals erect-connivent, above spreading; anther-cells almost parallel; glands approximate, large and strap-shaped, verticul, nearly as long as the pollen mass and its short flat stalk together; stigma narrow; a trowelshaped conspicuous beak (rostellum) between the bases of the anther-cells. (Orchis dilatata, Pursh.) - Cold bogs : common northward. June, July.

* * Flowers greenish or white and purple, fẹ or several (5-15) in a lowse spike, rather large for the size of the plant: scape or stem naked above, 1-leared at the base $\left(5^{\prime}-9^{\prime}\right.$ high) : spur not longer than the lip: anther-cells wholly adnate.

7. H. rotundifolia, Richurdson. Leaf varying from almost orbicular to oblong $\left(1 \frac{1}{2}{ }^{\prime}-3^{\prime}\right.$ long $)$; fluvers rose-purple; or the hip white and spotted with purple, 3-lobed, and the larger middle labe dilated and 2-lobed or strongly notched at the summit $\left(4^{\prime \prime}-6^{\prime \prime}\right.$ long), excecding the ovate-oblong petals und sepals, and the olender depending spur; andher-cells contignous and parallel. (O. rotundilolia, Pursh.) - Damp woods and bogs, N. Maine, Mr. Goullich; Warren, Herkimer Co., New York, J. A. Paine: shore of L. Michigum in Wisconsin, Lewis troote, and nurthwurd. June. 
8. H. obtusata, Richardson. Ieaf ubovato or spatulate-oblong; flowers greenish-uhite; upper sepal very broad and rounded, the others and the petals lance-oblong ; lip entire, linear or lanceolute, deflexed ( 3 "long), about the length of the tupering and curving spur; anther-rells arcuete and videly spparated. (O. ohtusata, Pursh.) - Cold peat-bogs, \&e., northeastern coast of Maine, and on mountains of New England and N. New York to Lake Superior (chiefly subalpine), and northward. Junc. (Eu.)

* * Flovers white or greenish, numenous in a lonse spitip, on a nakrd scape, 2-leaved at the base: spur lonyer than the narrow entire lip: anther-cells widely diverging, their narrowed beak-like bases projerting forwards: base of the stalk of the pollenmass laterully affixed by a short intermediate body to the buck of the orbicular gland, the viscous fuce of which lonks obliquely inward (the space between the two brond enough to receive the head of a butterfly).

9. H. Hobkeri, Torr. Lcaves orbicular, spreading $\left(3^{\prime}-4^{\prime}\right.$ broad $)$; scape mostly naked $\left(\frac{1}{2}^{\circ}-1^{\circ}\right.$ high), bearing $10-20$ upright sessile yellowish-green flowers in a strict spike; sepals ovate-lanceolate; lip lanceolate, pointed, incurved, longer than the lance-aw/-shnped petals; spur slender, acute, alout the length of the ovary (nearly 1' long). (H. orbiculata, Hook.) - Woods, Rhode Island to Penn., Wisconsin and northward. June. - Var. oncongifólı, J. A. Paine. Leaves oblong $\left(3^{\prime}-5^{\prime}\right.$ by $\left.1 t^{\prime}-2^{\prime}\right)$. Little Falls, New York, J. A. Paine.

10. H. orbiculàta, Torr. ${ }^{0}$ Leaves very large $\left(4^{\prime}-8^{\prime}\right.$ wide), orbicular, spreading flat on the ground; scape bracted, bearing many spreading greenishwhite flowers in a lonse raceme; upper sepal orbicular, the lateral ovate; lip narrowly linear and slightly spratulate, ohtuse, drooping, nearly thrice the length of the oblong-lanceolate and falcate obtuse petals ; spur curved, slender (about $\mathbf{I}^{\prime}{ }^{\prime}$ long), gradually thickened towards the blunt apex, twice the length of the ovary; anthercells strongly projecting at the free beak-like base (the glands nearly $t^{\prime}$ apart). (H. macrophylla, Honk. Orchis orbiculatn, Pursh.) - Rich woods, especially of Coniferæ, Maine to Pennsylvania and Lake Superior, and southward along the Alleghanies. July. - Leaves very smooth, shining above, silvery underneath. Scape $1^{\circ}-2^{\circ}$ high.

*** (Fringed Orcurs.) Flovers several or many in an open spike, with mostly folincernus bruets: sten (rnther tall) leafiy: snur thread-shuped or scarcely sluh-slinped, Innger than the fringed, cleft, or dissected lip: anther-cells widely separated and usually diverging, their narrow beak-like bases, supported by the arms of the stigmn, strongly projerting foru:ards or partly upwards: base of the stalk of the pollen-mass mostly affixed more or less laterally to the gland.

- Lip pretinately fringed but undivided: flowers golden yellow or white: anther-cells widely divergent and beak-pointed, the orbicular glands as if raised on a tentacle murh projicting foruverds or slightly inwerds: ovary long, topering to the summit.

11. H. cristata, R. Br. Lower leaves lanceolate, elongrated; the upper gradually reduced to sharp-pointed bracts, nearly the length of the cronded (yellow) floxers; spike oblong or cylindrical; petals rounded, crenate; lip ovate, with a lacerate-fringed maryin, scarcely shorter than the slender obtuse incurved spur, which is not half the length of the ovary. - (O. cristata, Mirhx.) - Bogs, Penn. $(P$ ursh) to Virginia and southward. July. - Flowers only a quarter as large as in the next. 
12. H. ciliàris, R. Br. (Yellow Fringed-Orchis.) Leaves oblong or lanceolate; the upper passing into pointed bracts, which are shorter than the ovaries; spike oblong, rather closely many-flowered; flowers bright orange-yellow; lateral sepal rounded, reflexed; petals linear, cut-fringed at the apex; lip colong, about half the lenglh of the sprur, furnishad wath a very long and copious capillary. fringe. (U. ciliaris, L.) - IVet sandy places, New Lingland to Michigan, and especially sonthward: rare north of New Jersey. July - Sept. - Uur hatudsourest species, $12^{\circ}-2^{\circ}$ high, with a short spike of very showy llowers; the lip $\frac{1}{2}^{\prime}$ long, the cunspicuous fringe fully $z^{\prime}$ long on each side.

13. H. blephariglóttis, Hook. (White Fringed Orchis.) Leaves, \&e. as in the last; flowers white; petals spatulate, slightly cut or toothed at the apex; lip ovate- or lanceolate-oblong, with the irregular capillary fringe of the margins usually shorter than its disk, one third the length of the spur. Var. Holorétald (Platanthera holopetala, Lindl.) has narrower petals with the toothing obsulete, and the lip less fringed. - P'eat-bogs and borders of ponds, with the preceding, commonly taking its place in the northward. July. -A foot high, the flowers beautiful, but rather smaller than in the last.

+ + (Greenish Fringen-Orcuis.) Lip 3-purled above the stalk-like base, the divisions cut into capillary fringes: flowers greenish-or yellowish-white: anthercells not very divergent, the beaked bases, supported on the upper edge of the broud arms of the stigma, projecting forwards; the large glands oval or lanceolute, tratsverse, nearly facing each other: ovary short-tapering at the summit: the long spars gradually thickened downward.

14. H. leucophæa. Leaves oblong-lanceolate; the bracts similar, rather shorter than the (large) flowers; spike commonly elongated, loose; petuls abovate, minutely cut-toothed; divisions of the lip brocidly wallye-shaped or fun-shaped, many-cleft to the middle into a copions thread-like fringe; spur longer than the ovary (1'-1 $\frac{1}{2}^{\prime}$ long); glands transversely oval. (Orchis leucophaa, Nutt.)-Moist meadows, Ohio to Wisconsin and southwestward. July. - Stem $2^{\circ}-4^{\circ}$ high. Lip $7 " 10^{\prime \prime}$ long.

15. H. lácera, R. Br. (RAgGen Fringed-Orcuis.) Leaves oblong or lanceolate; raceme loosely many-flowered; petuls oblong-lineur, entire; divisions of the lip narrow, derply parted into a few long nearly capillary lobes; spur about the length of the ovary; glands lunceolute, as long as the stalk of the pollen-mass. (O. psycodes, Muhl., \&c., not of $L$. I'latanthera psychodes, Lindl. O. lacera, Michx.) - Bogs and moist thickets : common. July.

+ + + (Punple Fringed-Orcuis.) Lip, fan-shuped, 3-parted above the stalklike buse, the dilated dicisions erosely finged: flowers purple: anther-cells widely separatcd, but little diveryent, their tapering loases (supported as in the preceding) strongly projecting, the orbicular ylands looking obliguely, forwards and downuards: ovary contracted only at the summit: the lony curving spur somewhat thickened downward.

16. H. psycodes, Gray. Lcaves oblong or lanceolate, the uppermost passing into linear-lanceolate bracts; raceme cylindrical, densely many-flowered; lourer sepals round-oval, oltuse; petals wedlye-obovate or sputulute, denticulute ubove; divisions of the spreading lip, broadly wedgre-shnget, many-cleft into a short frimgs. 
(O. paycodes, L.l O. fimlurintn, Pursh, Bigelow. O.'incisa and O. fissn, Muhl. in Willd. Platanthera fimbriata, Lindl.) - Wet meadows and bogs: common. July, Aug. - Flowers short-pedicelled, crowded in a spike of $4^{\prime}-10^{\prime}$ in length, small, but very handsome, frngrant; lip short-stalked, harely $f^{\prime}$ broal and not so long; the middle lobe broadest and more closely fringed, but not so deeply cleft as the lateral ones.

17. H. fimbriata, R. Br. Lower leaves oval or ohlong, the upper few, passing into lanceolate bracts; spilce or raceme oblong, loostly-flowered ; lower sepals ovate, acute; petals oblong, toothed down the sides; divisions of the pendent large lip fan-shaped, more fringed. (O. fimbriata, Ait., Willd, Hook. Exot. F\%. \&c. O. grandiflora, Bigelow.) - Wet meadows, New England to Penn. and (chiefly) northeastward. June. - Flowers fewer, paler (or lilac-purple), and 3 or 4 times larger than those of the preceding; the more ample dilated lip ' ' to I' broad, with a deeper and almost capillary crowded fringe, differentshaped petals, \&c.

18. H. peramœ̇ona, Gray. Lower leaves oblong-ovate, the upper lanceolate; spike oblong or cylindrical, densely flowered; lower sepals round-ovate; petals rounded-obovate, raised on a claw ; divisions of the large lip very broadly wedge-shaped, irregularly eroded-toothed at the broadly dilated summit, the lateral ones truncate, the middle one 2-loled. (Platanthera peramœna, Ed. 2. P. fissa, Lindl. O. fissa, Pursh, not of Muhl.) - Moist meadows and banks, Penn. to Illinois, and southward along the Alleghanies. Aug. - Flowers large and showy, violet-purple; the lip paler and very ample, $8^{\prime \prime}-10^{\prime \prime}$ long: its divisions minutely and variably toothed, or sparingly cut along the terminal edge, but not fringed.

\section{GOOD Y íRA, R. Br. Rattesnake-Plantain.}

Lip sac-shaped, sessile, entire, and withont callosities at the base. Otherwise as Spiranthes. - Root of thick fibres, from a somewhat fleshy crecping rootstock, bearing a tuft of thickish petioled leaves, usually reticulated with white veining. Scape, spike, and the grcenish-white small flowers usually glandular-downy. (Dedicated to John Goodyer, an early English botanist.)

\$1. Lip strongly saccate-inflated and with a short sprending or recurved tip: anther short, borne on a distinct flament attached to the back of the short column, blunt: gland-bening tip or beak of the stigme very short.

1. G. rèpens, R. Br. Small $\left(5^{\prime}-8^{\prime}\right.$ high) and slender; leaves ovate,

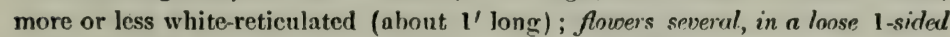
spilce; lip with an ovate recurved tip; sepals ovate. - Woods, under evergreens : common northward and through the Alleghanies. Ang. (Eu.)

2. G. pubéscens, R. Br. Larger; leaves strongly white-reticulated; seape $6^{\prime}-12^{\prime}$ high ; the numerous crouded fouers not one-sidel; tip of the globular lip rery short otherwise like the preceding, and too near it. - Rich woods, eastward and southward. July, Aug.

\$2. Lip burely saccute below, tupering and its sides involute above: anther ovate and long-pointed, borne on the base of the very short. proper column, which is continued above the stigma into a conspicuous long tapering aul-shaped gland-bearing beak. 
Aspect of Goodyera: structure of the flower nearly of Spiranthes, but the lip without callosities.

3. G. Menzièsii, Lindl. Leaves ovate-oblong, acute $\left(2^{\prime}-3^{\prime}\right.$ long), less white-reticulated than the preceding, some not at all so; scape $9^{\prime}-12^{\prime}$ high ; flowers rather numerous in a looser often 1-sided spike; Hower-buds less pubescent, elongated-ovate and pointed; lip with the saceate-conduplicate lower portion gradually tapering into the narrow barely spreading summit. (Spiranthes decípiens, Hook.) - Woods, Western New York to Michigan (confounded with G. pubescens), Lake Superior, and far westward. July.

\section{S Pir Á N THES, Richard. Ladieg' Tregses.}

Flower somewhat ringent, oblique on the ovary; the sepals and petals all narrow, mostly ereet or counivent, the three upper pieces sticking together more or less, the two lower covering the base of the lip. Lip oblong, short-stalked or sessile, the lower part involute around the column, and with a callous protuberance on each side of the base; the somewhat dilated summit spreading or recurved, crisped, wavy, or rarely toothed or lobed. Column short, oblique, bearing the ovate stigma on the front, and the sessile or short-stalked (mostly acute or pointed) 2-celled erect anther on the back. Pollen-masses 2 (one in each cell), ovate, cach 2-parted from the base (or even again divided) into thin and tender plates of granular pollen united by elastic threads, their summits together soon adhering to the narrow boat-shaped viseid gland of the stigma, which is set in the slender or tapering thin process or beak terminating the column, and is carried away on the proboscis of insects visiting the flower, with the pollen, to be deposited upon the stigma of mother flower. After the removal of the gland, the beak is left as a 2-toothed or 2-forked tip. - Roots clustered-tuberous : stem more or less naked atove, leaf-bearing below or at the bise. Flowers sinall (ours all white or greenish-white), bent horizontally, 1 -3ranked in a spike, which is commonly more or less spirally twisted (whence the

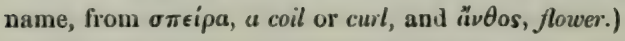

* Flowers in 3 ranks, crowded in a close spike. (Lenves at the root and base of the stem present at the flowering season.)

1. S. latifolia, Torr. Low; naked stem or scape $4^{\prime}-9^{\prime}$ high, smooth; leaves all next the base, oblong or lance-oblong $\left(1^{\prime}-3^{\prime}\right.$ long, $6^{\prime \prime}-8^{\prime \prime}$ wide), 3-5-nerved, contracted into at sheatling base; spike narrow $\left(1^{\prime}-2^{\prime}\right.$ long), flowers small; lip quadrate-oblong, thin, wavy-crisped at the very obtuse or truncate apex, the small callosities at the base oblong, marginal and adnate for their whole length; gland and beak of the stigma short. (S. plantaginea, Torr. in N. Y. Fl, not of Lindl. S. æstivalis, Oukes, Cut.) - Moist banks, Vermont and N. New York to Michigan, Penn. (near Lancister, Prof. Poiter), and Delaware, W. M. Cuntry. June. - Perianth $2^{\prime \prime}-3^{\prime \prime}$ long; lip jellowish on the face, not contracted in the middle nor the margins involute.

2. S. Romanzoviàna, Chamisso. Stem letefy below, and leufy-bructed ubove $\left(5^{\prime}-15^{\prime}\right.$ high) ; leaves varying from oblong-lanceol:ate to grassy-linear; spike dense, oblong or cylindrical $\left(1^{\prime}-4^{\prime}\right.$ long $)$; perianth curved and the summit manifistly ringent, the sepuls sud petals ull connivent in the upper portiou or 
gnlen; the lip ovale-oblong, contrarted below the rounded uravy-crenulate much re. curved summit, otherwise entire, the callositics at base glohular and smooth; gland oblong-linear and the 2-horned beak of the stigma short. (S. gemmípara, Lindl. (Neottia, Smith.) S. cernua, in part, Hook. \& Ed. 2.) - High and cool bogs, New York, from Herkimer and Otsego Co., to Lake Superior, and northwestward. July, Aug. - Perianth about 4" long, pure white, smonth or smoothish. (Eu. Bantry Bay, Ireland, only.)

3. S. córnua, Richard. Stem leafy below and leafy bracted above $\left(6^{\prime}-20^{\prime}\right.$ high) ; leaves linear-lanceolate, the lowest elongated $\left(4^{\prime}-12^{\prime}\right.$ long, $2^{\prime \prime}-4^{\prime \prime}$ wide) ; spike cylindrical, rather dense $\left(2^{\prime}-5^{\prime}\right.$ long) and with the flowers either pubescent or nearly smooth; perianth horizontal or recurving, the lower sepals not upturned or connivent with the upper; lip oblong and very obtuse when outspread, but conduplicate or the margins much incurved, wavy-crisped above the middle, especially at the flattish and recurved-spreading apex, the callosities at the base prominent, nipple-shaped, somewhat hairy ; gland of the stigma linear, in a long and, very slender beak. - Common in wet places, especially eastward and southward. Sept., Oct. - Very variable in size, foliage, \&c. : the commoner form, with pure white sweet-scented flowers, often nearly losing its root-leaves at flowering-time : a variety in dry ground has greenish-cream colored strongerscented flowers, and retains its root-lcaves. Perianth $4^{\prime \prime}-5$ "long.

* Flowers in one straight or spirally twisted rank.

- Stem bearing towards und at the base elonguted leuces, which mostly persist during the flowering season.

4. S. gramínea, Lindl., Var. Wálteri. Stem $9^{\prime}-2^{\circ}$ high ; lower and root-leaves linear or lance-lincar $\left(3^{\prime}-8^{\prime}\right.$ long, $2^{\prime \prime}-4^{\prime \prime}$ wide) gradually tapering to the base, the upper reduced to shcathing bracts; spike linear, dense $\left(2^{\prime}-5^{\prime}\right.$ long), usually much twisted, the axis, ovaries, \&c. downy-pubescent; bracts ovate and gradually, or rhombic-orate and abruptly taper-pointed, surpassing the ovary, the margins broadly haline; lip ovate-oblong when outspread, with rather small callosities at base, crisped at the rounded apex; anther and beak of the stigma very acute. (Limodorum procox, Walt. Neóttia tórtilis, Pursh, Barton, Fl., \&c. S. tortilis, Chapm.) - Wet, grassy places, S. New England to Virginin, and sonthward. July, $\Lambda$ ug., at the north. - Root of fleshy or somewhat tuberous thickened fibres. Perianth $3^{\prime \prime}$ long. - The original, West Indian S. tortilis (Swartz), Richnrd, has a smoother much less twisted spike, smaller bracts, and more leafless seape, the root-leaves seldom present at flowering-time : it is very like S. brevifolia, Chapm. (S. longilàbris, Lindl. ?). Our plant has a more acute tip to the anther and stigma than the Mexican.

+ + Scape very slender, merely bractrd; the leaves with a blade all in a cluster at the ground, orate or oblong, abruptly contracter into a petiole, commonly withering aux!y at or hefore flowering: flowers small, and whole plant gabrous or nearly so: bructs small, shorp-pointerl, not longer than the pod.

5. S. grácilis, Bigelow. Roots clustered, twherous-thickened; scape $8^{\prime}-18$ ' high, hearing a slender many-flowered one-sided or twisted spike; lip oral when outsprend, narrowly oblong in natural form, thickish and green above with thin white margins, the recurved obtuse or acutish apex wavy-crisped, the callosities 
at the base nipple-shaped. (Also S. Beckii, Lindl., at least us to the Northern plant.) - Hilly woods and sandy plains: common. July-Oct. - Perianth barely $1 \frac{1}{2} "-2^{\prime \prime}$ long.

6. S. símplex, n. sp. Root a solitury oblong or spindle-shaped tuber; no leaves at flowering time; scape $5^{\prime}-9^{\prime}$ high, bearing a small narrow (rarely 1 sided) spike of very short flowers (perianth 1 " $-1 \frac{1}{2}$ " long) ; lip thin, white, drovute oblong, the apex eroded and crisped, the callosities at the base slender. - Dry, sandy soil, E. Mass. (Nantucket, Dr. Rioblins), New Jersey (C. F. Austin, \&c.), and Delaware, Wm. M. Canby. Aug., Sept. - Spike $1^{\prime}-3^{\prime}$ long.

\section{LÍSTERA, R. Brown. TWaybude.}

Sepals and petals nearly alike, spreading or reflexerl. Lip mostly drooping, longer than the sepals, 2-lubed or 2-cleft. Column wingless: stigma with a rounded beak. Anther borne on the back of the column ut the summit, ereet, ovate: pollen powilery, in 2 masses, joined to a minute gland. - Roots filorous. Stem bearing a pair of opjosite sessile leaves in the middle, ant a spike or raceme of greenish or brownish-purple small fluwers. (Dedicated to Murtin Lister, an early and celebrated British naturalist.)

* Column very short. (Sepals ovate, reflexed: plants delicule, $4^{\prime}-8^{\prime}$ high.)

1. L. cordàta, R. Brown. Leaves round-ovate, somewhat heart-shaped $\left(\frac{1}{2}{ }^{\prime}-1^{\prime}\right.$ long) ; raceme smooth; flowers minute, crowded, on pedicels not longtr thun the ovary; lip linear, twice the length of the sepals, 1 -toothed on each side at the base, 2-cleft. - Daup cold woorls; from Penn. northward. June, July. (Eu.)

2. L. austràlis, Lindl. Leaves ovate; raceme loose and slender; flowers very small, on minutely glandular-pubescent pedicels twice the length of the ovary; lip linear, 3-4 times the length of the sepals, 2-parted, the divisions linear-selaceous. - Damp thickets, New Jersey to L. Virginial and southward. June.

* * Column longer, arching or straightrish.

3. L. convallarioides, Hook. Leaves oval or roundish, and sometimes a little heart-shaped $\left(1^{\prime}-1 \frac{1}{2}\right.$ long) ; raceme loose, pubescent ; flowers on slender pedicels; lip werlge-oblong, 2-lobed at the dilated apex, and 1-toothed on cach side at the base, nearly twice the length of the narrowly lanceolate spreading sepals, purplish, $f^{\prime}$ long. (Epipáctis convallarioides, Swartz.)-Damp mossy woods, along the whole Alleghany Mountains, to Penn., also Maine to Lake Superior, and northward. - Plant $4^{\prime}-9^{\prime}$ high.

\section{A R E T H Ù S A, Gronov. Aretrusa.}

Flower ringent; the lanceolate sepals and petals nearly alike, united at the base, ascending and arching over the column. Lip dilated and recurved spreading towards the summit. Column adherent to the lip below, petal-like, dilatud at the apex. Anther lid-like, terminal, of 2 approximate cells: pollen-masses powdery-gramular, 2 in cach cell. - Bcautiful low herbs, consisting of a slocathed scape from a globular solid bulb, terminated usually by a single large rose-purple flower. Leaf solitary, linear, nerved, hidden in the sheaths of the scape protruding after flowering. (Dedicated to the Nymph Arethusn.) 
1. A. bulbosa, L. Flower single, erect, with an entire lip recurved at tho apex and bearded-crested down the face. - Bogs, Virginia to Maine, N. Wisconsin, and northward : rather searce or local. May. - Flower $1^{\prime}-2^{\prime}$ long, very handsome, bright rose-purple; very rarely a pair of flowers.

\section{POG ÒNIA, Juss. Pogonia.}

Flower irregular, the sepals and petals scparate. Lip crested or 3-lobed. Column free, elongated, club-shaped, wingless. Anther terminal and lid-like,

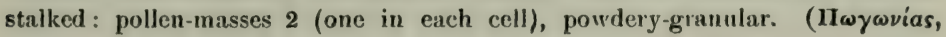
bearded, from the lip of some of the original species.)

\$1. Sepals and petals nearly equal and alike, pule rose-color; sometimes white.

1. P. ophioglossoldes, Nutt. Root of thick fibres; stem $\left(6^{\prime}-9^{\prime}\right.$ high) bearing a single oval or lance-oblong leaf near the middle and a smaller one or bract near the terminal flower, rarcly one or two others with a flower in their axil ; lip spatulate below, appressed to the column, beard-crested and fringed. In bogs. June, July. - Flower 1' long, sweet-seented. - An interesting monster of this, with two additional lips, and some other petaloid parts, was found in 'Herkimer Co., New York, by J. A. P'aine.

2. P. péndula, Lindl. Stem $\left(3^{\prime}-8^{\prime}\right.$ high) from oblong tuhers, bearing 3 to 7 alternate ovate-clasping very small $\left(3^{\prime \prime}-6^{\prime \prime}\right)$ leaves, the upper $1-4$ with drooping flowers in their axils on slenler perlicels; lip spatulate, somewhat 3 lobed, roughish or crisped above, crestless. ('Tríphora pendula, Nutt.)-Damp woods : rather scarce. Aug. - Y'erianth $\frac{1}{2}$ long, narrow.

§2. Sepals lineur, dingy or brownish, lonyer and much narrower than the erect or connivent petals: lip 3-lobed at the aptx, crested down the middle, beardless : flowers solitury (or rarely a puir), terminal: root a cluster of filves.

3. P. divaricata, $\mathrm{R}$. Br. Stem $\left(1^{\circ}-2^{\circ}\right.$ high) betring a lanceolate leaf in the middle, and a leufy bract next the flower, which is recurved on the ovary; but the sepals ascending or diverging, spatulate-linear, longer than the lanccolate-spatulate pointed and flesh-colored petals, these about $1^{\prime}-1 \frac{1}{2}^{\prime}$ long. - Wet pinebarrens, Quaker Bridge, New Jersey (IV. II. Leggett), Virginia, and southward. June, July.

4. P. vertioillata, Nutt. Stem $\left(6^{\prime}-12^{\prime}\right.$ high), nakerl, except some small scales at the base, and a whorl of mostly 5 obovate or obovate-oblong sessile leaces at the summit; flower dusky purplish, on a peduncle Imyger than the otary and pod; sepals move than twice the length of the petals, narrowly lincar, spreading from a mostly erect buse $\left(1 \frac{1^{\prime}}{2}-2^{\prime}\right.$ long $)$; lip with a narrow crest down the midrle. Low woods: rather rare, especially eastward. May, June. - Glancons when young. Stalk of pord alout $1 \frac{1}{2}$ ' long, more than half the length of the leaves.

5. P. affinis, C. F. Austin, n. sp. Somewhat smaller than the preceding; leaves paler and rather narrower; flowers (not rarely in pairs) yellowish or greenish; peduncle much shorter than the orary and pod; seporls nit twice the length of the petals, tapering to the base; lip crested over the whole face and on the middle of the lobes. - With the last, which it nearly resembles, but is much rarer. Southern New York and Northern New Jersey, C. F. Austin; and Connecticut, near New Haven, Edward Dana. 


\section{CALO PÒ GON, R. Br. Calopogon.}

Flower with the ovary or stalk not twisting, therefore presenting its lip on the upper or inner side. Sepals and petals nearly alike, lance-ovate, spreading, distinct. Lip spreading, distant from the column, raised on a narrowed base or stalk, dilated at the summit, strongly bearded aloug the upper side. Column free, slender, winged at the apex. Anther terminal and lid-like, sessile: pollenmasses 4 (two in each cell), of soft powdery grains, lightly connected by delicate threads. - Scape fiom a sinall solid bulb, sheathed below by the base of the grass-like leaf, naked above, bearing several flowers. Bracts minute. (Name composed of $\kappa u \lambda o ́ s$, beuutiful, and $\pi \dot{\omega} \gamma \omega \nu$, beurd, from the bearded lip.)

1. C. pulchéllus, R. Br. Leaf linear; scape about $1^{\circ}$ high, 2-6-flowered; lip as if hinged at the insertion, beantifully bearded towards the dilated summit with white, yellow, and purple club-shaped hairs. - Bogs: common. June, July. - Flowers I' broad, pink-purple.

\section{CALÝ PSO, Sulisb. Calypso.}

Sepals and petals nearly similar, ascending, spreading, lanceolate, pointed. Lip larger than the rest of the fluwer, sac-shaped, intlated (9" long), 2-pointed underneath the apex. Column broadly winged and petal-like, ovate, bearing the lid-like unther just below the apex: pollen-masses waxy, 2, each 2-parted, all sessile on a squire gland. - A little bog-herb; the solid bulbs producing a single ovate or slightly heart-shaped thin leaf, as in Aplectrum, and a short $\left(3^{\prime}-5^{\prime}\right.$ high) scape, sheathed below, bearing a large and showy (variegated purple, pink, and yellow) fluver. (Name from the gorldess Calypso.)

1. C. boreàlis, Salisb. - Cold bogs and wet woods, the bulbs resting in moss, Northern New England to Michigan, and northward. May. - A very local and beautiful plant. Lip somewhat resembling that of a Lady's Slipper, woolly-hairy inside. (Eu.)

\section{Ti f U là Ria, Nutt. Crane-fly Orchis.}

Sepals and petals spreading, oblong; the latter rather narrower. Lip prolonged underncath into a thread-like ascending spur twice or thrice the length of the flower (9"-12" Jung), 3-luhed; the middle lobe linear, a little wavy, as long as the petals, the side lobes short and triangular. Column narrow and wingless. Anther lit-like, terminal : pollen-masses 2, waxy, each 2-parted, connected by a linear stalk with the transverse small gland. - Herb with large solid bulbs connected horizontally, on a distinct petiole, producing in autumu a single ovate nerved and plaited leaf on a slender petiole, tinged with purple beneath; and in summer a long and naked slender scape $\left(10^{\prime}-18^{\prime}\right.$ high $)$, with 1 or 2 sheaths at the base, bearing a many-flowered racene of small greenish flowers tinged with purple. (Name from a fancical rescmblance of the fluwers to insects of the genus Tipula.)

1. T. discolor, Nutt. Lip blunt at the tip (which distinguishes it from a recently discovered Himalayan species). - Sandy woods, Massachusetts to Michigan and southward: very scarco. July. 


\section{BLEt T I , Ruiz \& Pnvon. Beetia.}

Sepals spreading, equal, rather exceeding the petals. Lip hooded, hinged as it were with the column, erested along the upper face, often 3-lobel. Column half-cylindrical; the fleshy anther forming a lid at its apex. P'ollen-masses 8, in pairs, with a stalk to each pair, waxy, becoming powdery. - Scnpe manyflowered from solid tubers. (Namerl for Louis Blet, a Spanish botanist.)

1. B. aphylla, Nutt. Leafless; scape $\left(1^{\circ}-2^{\circ}\right.$ high $)$ beset with purplish scales, the lower ones sheathing; flowers racemed, brownish-purple; lip not snccate. Rich woods, Kentucky and southward.

\section{M I CRÓSTYLIS, Nutt. ADDER'g-Moeth.}

Sepals spreading. Petals thread-like or linear, spreading. Lip auricled or ovate at the base, not tubercled, entire or nearly so. Column very small, terete, with 2 teeth or auricles at the summit and the erect anther between them. Pollen-masses 4 , in one row ( 2 in each cell), cohering by pairs at the apex, waxy, without any stalks, threads, or gland. - Little herbs, from solid bulbs, producing simple stems or scapes, which bear in our species a single leaf, and a raceme of minute greenish flowers. (Name composed of $\mu$ เxpós, little, and $\sigma \tau v \lambda$ is, a column or style.)

1. M. monophýllos, Lindl. Slender $\left(4^{\prime}-6^{\prime}\right.$ high); leaf shenthing the base of the stem, ovate-elliptical; raceme spiked, long und slender; pedicels not longer than the flowers; lip long-pointed. - Cold wet swamps, N. New England to Pennsylvania, Wisconsin, and northward. July. (Eu.)

2. M. ophioglossoldes, Nutt. Leaf near the middle of the stem, ovate, elasping; raceme short and obtuse; pedicels much longer than the flowers; lip 3toothed at the summit. - Damp woods : more common southward. July.

\section{Lf PARIS, Richard. Twayblat.}

Sepals and petals nearly equal, linear, or the latter thread-like, spreading. I ip flat, entire, often bearing 2 tubcrcles above the base. Column elongated, incurved, margined at the apex. Anther lid-like, terminal: pollen-masses 4, in one row ( 2 to each cell), slightly united in pairs, without stalk, threads, or gland. - Small, low herbs, with solid bulbs, producing 2 root-leaves and a low scape, which bears a raceme of few purplish or greenish flowers. (Name from $\lambda$ enapós, fat or shining, in allusion to the smooth or unctuous leaves.)

1. L. Liliifolia, Richard. Leares ovate; petals thread-like, reflexed; $/ \mathrm{p}$ large ( $\frac{1}{2}$ ' long) wedgc-obovate, abruptly short-pointed, broun-purplish. (Maláxis liliifolia, Suartz.) - Moist woodlands: commonest in the Middle States. June.

2. L. Lœsèlii, Richard. Leares elliptical-lanceolate or oblong, keeled; lip obovate or oblong (2" long), mucronate, yellowish-green, shorter than the linear unequal petals and sepals. (Malaxis Correàna, Barton.) - Bogs, New England to Penn., Wisconsin, and northward: rare. June. (Eu.)

\section{CORALLORHIZA, Haller. Coral-Root.}

Perianth somewhat ringent, oblique and gibbous or obscurely spurred at the base; the oblong or lanceolate sepals and petals nearly alike, the upper arching; 
the lateral sepals ascending, their bases with that of the lip forming the gibbosity or short spur which is mostly adnate to the summit of the ovary : lip slightly adherent to the base of the 2-edged straightish column, bearing a pair of projecting ridges on the face below, spreading or recurved at the apex. Anther terminal, lid like. Pollen-masses 4, obliquely incumbent, soft-waxy, free. Brownish or yellowish herbs, destitute of green foliage, with much-branched and toothed coral-like root-stocks (probably root-parasitical), sending up a simple scape, with sheaths in place of leaves, and bearing small and dull-colored flowers in a sjpiked raceme. (Name composed of кopá $\lambda \lambda_{\iota} \nu$, coral, and pija, root.)

§1. Simall spur or sac adnute to the summit of the veury: flowers small: lip whitish or purplish, often mottled with crimson.

1. C. innâta, R. Brown. Plant slender, light brownish or yellowish (3' 9' high), 5-12-flowered; pedicels very short; lip somewhat hastately 3 -lobed aboce the base, the lamellse thick and rather short; spur a very small protuberance; pod oval or elliptical ( $3^{\prime \prime}-4^{\prime \prime}$ long). (C. verna, Nutt.) - Swamps und damp woods. May, June. - Perianth only $2^{\prime}$ or $2 \frac{1}{2} 2^{\prime \prime}$ loug. (Eu.)

2. C. odontorhiza, Nutt. Piant light brown or purplish; sten rather slender, bulbons-thickenel at the base $\left(6^{\prime}-16^{\prime}\right.$ high $), 6$-20-flowered; pedicels rather slender; lip entive, or merely denticulate, thin; broadly ovate or obovate, abruptly contracted into a claw-like base, the lamella a pair of short projections; the spur represented by a small cavity wholly adnate to the summit of the ovary; nod at first very acute at the base, at length short-oval ( $4^{\prime \prime}$ long). (C. Wistariana, Conrad.) - Rich woods, New York to Michigan, and especially southward : rare northward. May, July. - Perianth about $3^{\prime !}$ long.

3. C. multiflora, Nutt. Plant purplish, rather stout $\left(9^{\prime}-18^{\prime}\right.$ high), $10-$ 30-flowered; lip deeply 3-lobed, with a short narrowed base and with prominent lamella: spur manifest and protuberant; pod oblong ( $6^{\prime \prime}-9^{\prime \prime}$ long), short-pedicelled-Dry woods : common. July - Sept. - Perianth $22_{2}^{\prime \prime}-4^{\prime \prime}$ long.

\$2. Spur none: the broadly gibbous somewhat saccate base of the perianth wholly fiee fiom the ocary: flowers large for the yenus, purple, unspotted, more expanding.

4. C. Macræi, Gray. Plant purplish, stout $\left(6^{\circ}-16^{\prime}\right.$ high), bearing $15-$ 25 large flowers in a crowded spike, on very short pedicels; lip oval or obovate, perfectly entire, concave, barely narrowed at the base, where it bears $1-3$ short lamella; all the parts of the perianth marked with 3 darker nerves; pod oblong (9" long). - Woods, from near Lake Eric (Caledonia Springs, Canada, W. F. Macrae), Mackinaw, C. Gr. Loring, Jr., Prof. Whitney, and westward to the Pacific. July. - Sepals, petals, and lip 6" or $7^{\prime \prime}$ long. - This is the Aplectrum aphyllum, Nutt. in herb.; and fiom the range and the size of the flowers it can hardly be other than C. striata, Lindl., but it does not at all agree with the character as to the lipe and spur.

\section{A L LE'TRUM, Nutt. Puttr-hoot. Adam-Ani-Eve.}

Perianth neither gibbous, nor with any trace of a spur or sac at the base. Lip free, the palate 3-rilged Otherwise the flowers and the scape (invested below with 3 greenish sheaths) as in Corallorhiza. But, instead of a coral-like 
root, $n$ slender naked rootstock produces ench yenr a thick, globular, solid bulb or corm, often $\mathbf{l}^{\prime}$ in diameter (filled with exceedingly glutinous matter), which sends up late in summer a large, oval, many-nerved and plaited, petioled, green lenf, lasting through the winter, and enrly in the succecding summer its seape, a foot or more high, is terminated hy a loose raceme of dingy rather large flowers. (Genus too near the last. The name composed of $a$ privative and $\pi \lambda \hat{\eta} \kappa \tau \rho \circ \nu$, a spur, from the total want of the latter.)

1. A. hyemàle, Nutt. - Woods, in rich mould: rather rare or local. Each corm lasts 2 or 3 years before it shrivels, so that 3 or 4 are found horizontally connected. Perianth greenish-brown, or the lip whitish, and somewhat speckled with purple, $5^{\prime \prime}-6^{\prime \prime}$ long.

\section{CYPRIPÈDIUM, L. LADY's SLIPPER. Moccason-Flower.}

Sepals spreading; all three distinct, or in most cases two of them united into one under the lip. Petals spreading, resembling the sepals but usually narrower. Lip a large influted sac. Column declined; on each side a fertile stamen, with its short filament bearing a 2-celled anther; the pollen loose and pulpy or powdery-granular; on the upper side a dilated-triangular, petal-like but thickish body, which answers to the fertile stanen of other Orchids, and covers the summit of the style; stigma terminal, broad, obscurely 3-lobed, moist and roughish (not smooth and viscid as in the rest of the order). Pollen in most of our species, especially in No. 6, exposed by the conversion of the face of the anther into a viscid, varnish-like film, which adheres to whatever touches it, carrying away some of the pollen. - Root of many tufted fibres. Leaves large, many-nerved and plaited, sheathing at the base. Flowers solitary or

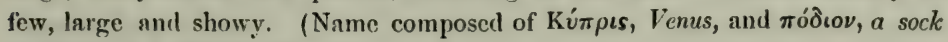
or buskin, i. e. Venus's Slipper.)

\section{\$1. The three sepals separate. (Stem leafiy, single-fowered.)}

1. C. arietinum, R. Brown. (RAM's-meaD I.) Upper sepal ovatelanceolate, pointed; the 2 lower and the petals linear and nearly alike (greenish-brown), rather longer than the red and whitish veiny lip, which is prolonged at the apex into a short conical deflexed point; leaves 3 or 4 , elliptical-lanceolate, nearly smooth. (Cryosńnthes, Rnf. Arietinum, Berk.) - Cold swamps and damp woods, Maine to New York, Wiseonsin, and northward: rare. June, - The smallest species: stem slender, $6^{\prime}-10^{\prime}$ high : lip only $6^{\prime}$ long.

\$2. Turo of the sepals united into one piece under the lip.

* Stem leafy to the top, 1-3-flowered: lip slipper-shaped or roundish, much inflated, horizontal, and with a rounded open orifice.

- Sepals and linerir uny-twisted petnls brownish, pointed, longer thun the lip.

2. C. cándidum, Muhl. (Smat., Wirte La1)y's Stipper.) Sepals ovate-lanceolate; lip white, flattish laterally, convex above; sterile stamen lanceolate; leaves lance-oblong, acute. - Bogs, Central and W. New Yurk (rarc) to Kentucky and Wisconsin. May, June. - Little larger than the foregoing species. slightly pubescent, 1-flowered : petals and sepals greenish, not much exceeding the lip, which is less than 1' long. 
3. C. parviflorum, Salisb. (Sadller Yellow L.) Sepals ovate or ovate-lanceolate; lip fluttish from above, bright yellow ( $l^{\prime}$ or less long); sterile stamen triangular; leaves oval, pointed. - Bogs and low woods; rather common. May, June. - Stem $1^{\circ}-2^{\circ}$ high. Flower fragrant: sepals and petals more brown-purple than in the next, into which, however, it seems to pass.

4. C. pubéscens, Willd. (Lakger Yellow L.) Sepuls ilongated-lanceolate; lip flattened laterully, very convex and gibbous above $\left(1 \frac{1}{2}^{\prime}-2^{\prime}\right.$ long, scentless, pale yellow. - Bogs and low woods: cominon northward and westward, and southward in the Alleghanies. May, June. - Stem $2^{\circ}$ high, pubescent, as are the broadly oval acute leaves.

+ + Siguls and poluls plane, rounded, white, not lonyer than the lip.

5. C. spectábile, Sivariz. (Sıowy L.) Sipuls round-ovate or orbicular, rather longer than the oblong petals ; lip much influted, white, pink purple in front ( $1 \frac{1^{\prime}}{2}$ long) ; sterile stamen lieart-ovate. - l'eat-bogs, Maine and W. New England to Illinois, and southward along the Alleghanis. July. - The most beautiful of the genus, downy, $2^{\circ}$ high. Lcaves ovate, pe uted.

* * Scape naked, 2-leaved at the base, 1-flowered; sepals and petals greenish, shorter than the dicoping lip, which has a closed fissure down its whole length in fiont.

6. C. acaùle, Ait. (Stringess L.) Sepals oblong-lanceolate, pointed, nearly as long as the lincar petals; lip obovoid or oblong, rose-purple (rarely white), nearly '2' long, veiny; sterile stamen rhomboid; leaves oblong. (C. hùmile, Salisb.) - Dry or moist woods, under evergreens : common, especially northward. May, June. - Plant downy: the scape $8^{\prime}-12^{\prime}$ high, with a green bract at the top.

\section{Order 115. AmarouLidàcez. (Amaryllis Family.)}

Chiefly bulbous and scape-bearing herbs, not scurfy or woolly, with linear flat root-leaves, and regular (or nearly so) and perfect 6-androus flowers, the tube of the corolline 6-parted perianth colterent with the 3-celled ovary; the lobes imbricated in the bud. - Anthers introrse. Style single. Pod 3-celled, several-many-seeded. Seeds anatropous or nearly so, with a straiglit embryo in the axis of fleshy albumen. - An order represented in our gardens by the Narcissus (N. POETricus), Jonquil (N. Jonquilla), and Duffodil (N. Pseudo-Narcissus), the Snowdrop (Galantius Nivalis) and the Snowfluke (Lkucounm VErNum), \&c., but with very few indigenous representatives in this country. Bulbs acrid. Differs from Liliacew chiefly in the inferior ovary.

* Pod 3-valved, loculicidal : anthers versatile : perianth funnel-shaped.

1. Amary 11is. Flower naked in the throat; the tube short or none. Bulbs coated.

2. Pancralium. Flower with a slender tube and narrow recurved lobes; a cup-shaped crown connecting the stimens. Bulbs coated.

3. Agave. Flower equally 6 -cleft, persisteut; no crown. Fleshy-leaved, not bulbous.

* * Pod indehiscent ; anthers sagittate.

4. Hy poxys. Perianth 6-parted nearly down to the ovary. Bulb solld. 


\section{A MAR Y LLIS, L. § ZEPHYRANTHES, Herb. AMARYxLI8.}

Perianth funnel-form, from a tubular base; the 6 divisions petal-like and similar, spreading above; the 6 stamens inserted in its naked throat: anthers versatile. Pod membranaceous, 3-lobed. - Leaves and scape from a coated bulb. Flowers 1 or 2, from a 1-2-leaved spathe. (A poetical name.)

1. A. Atamásco, L. (Aтамasco Lily.) Spathe 2-cleft at the apex; perianth white and pink ; stamens and style declined. - Penn. (Muhl.) Virginia, and southward. June. - Flower $3^{\prime}$ long, on a scape $6^{\prime}$ high.

\section{PA N C R À T I U M, L. Pancratium.}

Perianth with a long and slender tube, and an equal 6-parted limb; the lobes long and narrow, recurved; the throat bearing a tubular or cup-shaped corolline delicate crown, which connects the bases of the 6 exserted stamens. Anthers lineur, versatile. Pod thin, 2-3-lobed, with a few fleshy sceds, often like bulblets. - Scapes and leaves from a coated bulb. Flowers large and showy in an umbel-like head or cluster, leafy-bracted. (Name composed of $\pi a ́ \nu$, all, and кparís, powerful, from fancied medicinal properties.)

1. P. rotatum, Ker. I,eaves ascending, strap-shapel $\left(1^{\circ}-2^{\circ}\right.$ long); scape few-flowered; the handsome (white and fragrant) flower with a spreading large 12-toothed crown, the alternate teeth bearing the filaments. (Hymenocállis rotata, Herbert.) - Marshy banks of streams, Kentucky, Virginia, and southward. May. - Flowers opening at night or in clondy weather.

\section{A G À V E, L. Americhn Alok.}

Perianth tubular-funnel-form, persistent, 6-parted ; the divisions nearly equal, narrow. Stamens 6 : anthers linear, versatile. Pod coriaceous, many-seeded. Sceds flattened. - Leaves thick and fleshy, often with cartilaginous or spiny tecth, clustered at the base of the many-flowered scape, from a thick fibrousrooted crown. (Named altered from àyavós, wonderful, not inappropriate as applicd to $\boldsymbol{A}$. Americana, the Century-plant.)

1. A. Virgínica, L. (False Aloe.) Herbaceous; leaves entire or den iculate ; scape $3^{\circ}-6^{\circ}$ high ; flowers scattered in a loose wand-like spike, greenishyallow, fragrant. - Dry or rocky banks, Penn. ? Virginia to Illinois (Mr. Lummis), and sonthward. Sept.

\section{H Y PÓX Y S, L. STAR-grass.}

Pcrianth persistent, 6-parted, spreading; the 3 outer divisions a little herbacrous outside. Stamens 6 : anthers sagittate, erect. Pod crowned with the withered or closed perianth, not opening by valves. Seerls globular, with a crustaccous coat, ascending, imperfectly anatropous, the rhaphe not adherent quite down to the micropyle, the persistent seed-stalk thus forming a sort of lateral beak. Radicle inferior! - Stemless small herbs, with grassy and hairy linear leaves and slender few-flowereil scapes, from a solid bulb. (Name composed of inó, bencath, and ózús, sharp, it is thought because the pod is acute at the base.) 
1. H. erécta, L. Leaves linear, grass-like, longer than the umbellately 1-4-Howered scape; divisions of the perianth hairy and greenish outside, yellow within. - Mleadows and open woods : common. June - Aug.

\section{Order 116. HATMODORìceAE. (Bloodwort Family.)}

Herbs, with fibrous roots, usually equitant leaves, and perject 3-6-andious regular flowers, which are woolly or scurfy oulside; the tube of the 6-loled perianth colerent with the whole surface, or with merely the lower part, of the 3-celled ovary. - Anthers introrse. Style single, sometimes 3-partible; the 3 stigmas alternate with the cells of the ovary. Pod crowned or enclosed by the persistent perianth, 3-celled, loculicidal, 3-many-seeded. Ernbryo small, in hard or fleshy albumen. A suall family; chiefly of the Southern hemisphere.

* Ovary wholly adherent to the calyx-tube : style filiform : seeds peltate, amphitropous.

1. Luchnumbes. Stamens 3 , exserted: anthers versatilo. Leaves equitant.

* *vary free except at the base : style 3-partible : seeds anatropous.

2. Lophiola. Stameus 6 , on the base of the woolly 6 eleft periauth. Leaves equitant.

3. Aletris. Stamens 6 , in the throat of the warty-roughened and tubular 6-toothed perianth. Leaves flat.

\section{I A C H N Á N THES, L. RED-root.}

Periinth woolly outside, 6-parted down to the adherent ovary. Stamens 3, opposite the 3 larger or inner divisions : filaments long, exserted : anthers linear, fixed by the middle. Style thread-like, exserted, declined. Pod globular. Seeds few on each fleshy placentat, flat and rounded, fixed by the middle. Herb, with a red fibrous peremial root, equitant sword-shaped leaves, clustered at the base and seattered on the stem, which is hairy at the top, and terminated by a dense compound cyme of dingy yellow and loosely woolly flowers (whence

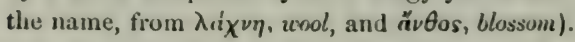

1. L. tinctòria, Ell. - Sandy swamps, from Rhode Island and New Jersey southward, near the coast. July-Sept.

\section{LOPHIOLA, Ker. LorHoLA.}

Perianth densely woolly, deeply 6-cleft; the divisions nearly equal, spreading, longer than the 6 stamens, which are inserted at their hase. Anthers fixed by the base. Pod ovate, free from the perianth except at the base, pointed with the awl-shuped style, which finally splits into $\mathbf{3}$ divisions, one terminating each valve. Seeds numerous, oblong, ribbed, anatropous. - A sleuder perennial herb, with creeping rootstocks and fibrous roots, linear and nearly smooth equitant leaves; the stem leafless and whitened with soft matted wool towards the summit, as also the crowded or panicled cyme. Perianth dingy yellow inside; the lohes naked unly towards the tip, each cholhed with a woolly tuft towards the base (whence the name from Xoquiov, a smull ciest.)

1. L. aùrea, Ker. (Conústylis Americana, Pursh.) - Buggy pine barrens, New Jersey to Virginia, and southward. June-Aug. 


\section{3. Átetris, i. Colic-root. Star-grass.}

Perianth cylindrical, not woolly, but wrinkled and roughened outside by thickly-set points, which look like seurfy mealiness, the tulie rohering below with the base only of the ovary, 6-eleft at the summit. Stanens 6 , inserted at the base of the lobes: filanents and anthers short, incluelerl. Style awl-shaped, 3-cleft at the apex: stigmas minutely 2-lobel. Porl ovate, enclosed in the roughened perianth; the dehiscence, seeds, \&c. nearly as in Lophiola. - Perennial and smooth stemless herbs, very bitter, with fibrous roots, nud a spreading cluster of thin and flat lanccolate leaves; the smull flowers in a wand-like spiked raceme, terminating a naked slender scape $\left(2^{\circ}-3^{\circ}\right.$ high $)$. Bracts awl-shaped, minute. ('A $\lambda \epsilon \tau$ pis, a female slave who grinds corn; the name applicd to these plants in allusion to the apparent mealiness dusted over the blossoms.)

1. A. farinosa, L. Flọwers oblong-tubular, white; lobes lanceolate-oblong. - Grassy or sandy woods : not rare. July, Aug.

2. A. aurea, Walt. Flowers bell-shaped, yellow (fewer and shorter); lobes short-ovate. - Barrens, New Jersey to Virginia, and southward. July.

\section{Order 117. Bromelaicea. (Pine-Apte Family.)}

Herbs (or scarcely woody plants, nearly all tropical), the greater part epiphytes, with persistent dry or fleshy and channelled crowded leaves, sheathing at the base, usually covered with scurf: 6-androus; the 6-cleft perianth adherent to the ovary in the Pine-APple, \&c, or free from it in

\section{TILLÁ N DSIA, L. Long Moss.}

Perianth plainly double, 6-parted; the 3 outer divisions (sepals) membranaceous; the 3 inner (petals) colored; all convolute bclow into a tube, spreading above, lanceolate. Stamens 6 , hypogynous! or the alternate ones cohering with the base of the petals : anthers introrse. Ovary free : style thread-shaped : stigmas 3. Pod cartilaginons, 3-celled, loculicidally 3-valved; the valves splitting into an inner and an outer layer. Seeds several or many in cach cell, anatropons, elub-shaped, pointed, raised on a long hairy-tufted stalk, like a coma. Embryo small, at the base of copious albumen. - Scurfy-leaved epiphytes. (Named for Prof. Tillands of Abo.)

1. T. usneoldes, L. (Сомmon Long Moss or Bцаск Moss.) Stems thread-shaped, branching, pendulous; lenves thread-shaped; peduncle short, 1flowered. - Dismal Swamp, Virginia, and southwarl; growing on the branches of trees, forming long hanging tufts. A characteristic plant of the Southern States, and barely coming within the limits of this work.

\section{Order 118. Iridacen. (Iris Family.)}

Herbs, with equitant 2-ranked leaves, and regular or irregular perfect flowers; the divisions of the 6-cleft petal-like perianth convolute in the bud in 2 sets, the tube coherent with the 3-celled ovary, and 3 distinct or monadelphous stamens, alternate with the inner divisions of the perianth and 
opposite the stigmas, with extrorse anthers. - Flowers from a spathe of 2 or more leaves or bracts, usually showy. Style single: stigmas 3, opposite the cells of the ovary. Pod 3-celled, loculicidal, many-seeded. Seeds anatropous: embryo straight in fleshy albumen. Rootstocks, tubers, or corms mostly acrid. - Represented in gardens by Crocus, Gladionus, Tigirida or Tigkr-Flower, and by three genera in the wild state.

1. Iris. Outer divisions of the perianth recurved; the inner erect: stigmas petal-like.

2. Pardanthus. Perianth equally spreading: filaments nearly distinct: stigmas dilated

3. Sisyrimchium. Perianth regular und equally spreading: filanents monadelphous to the top: stigmas thread-like.

\section{1. İ I I S, L. Flower-DE-LuCE.}

Perianth 6-cleft; the tube more or less prolonged beyond the ovary; the 3 outer divisions spreading or reflexed; the 3 inner smaller and erect. Stamens distinct; the oblong or linear authers sheltered under the overarching petal-like stignats (or rather branches of the style, bearing the true stigma in the form of a thin lip or plate under their apex): most of the style connute with the tube of the perianth. Pod 3-6-angled, coriatcous. Seeds depressed-fiattened. Peremuals, with sword-shaped or grassy leaves, and large slowy flowers; ours all with creeping and more or less tuberous rootstocks. ('Ipts, the rainbow deified, anciently applied to this genus on account of the bright and varied colors of the blossoms.)

* Stems leafy and rather tall $\left(1^{\circ}-3^{\circ}\right.$ high), from thickenerl rootstocks, often branching: tube of the perianth shorter than the divisinns, which are beardless and crestless, the erect inner ones (petuls) much smuller than the outer.

+ Flowers violet-blue, variegated with greenish, yellowish or white, and purple-veined.

1. I. versícolor, L. (Larger Brue Flag.) Stem stout, angled on one side; leaves sword-shaped ( $\mathbf{4}^{\prime}$ wide); ovary obtusely triangular with the siues flat; flowers $\left(2 \frac{1}{2}{ }^{\prime}-3^{\prime}\right.$ long) short-peduncled, the funnel-form tube shorter than the ovary; pod oblong, turgid, with rounded angles. - Wet places : common. May, June.

2. I. Virgínica, I. (Simnen Blue Flag.) Stem very slender, terete; leaves narrowly linear $\left(2^{\prime \prime}-3^{\prime \prime}\right.$ wide) ; flowers slender-peduncled (1 $\frac{1}{2}^{\prime}-2^{\prime}$ long $)$, the tube extremely short; ovary 3-angled, each side 2-grooved; pod sharply triangular. (I. prismática, Pursh. I. gràcilis, Bigel.)-Murshes, Maine to Virginia and southward, near the coast. June.

\section{+- + Flowers yeilowish or dull reddish-brown.}

3. I. cùprea, Pursh. Stem and leaves as No. 1; tube of the perianth eylindrical, as long as the 6-angled ovary; petal-like branches of the style narrow. - Sivamps near Cairo, S. Illinois (Dr. Vusey), and southward. May.

** Stems low (3'-6' high), fiom tufted and crepping slender (or here and there tulierous-thickened) rootstucks, 1-3-flowerch: tulse of the perianth long and slender; the violet-blue divisions neurly equal.

4. I. vérna, L. (1) wsır Inss.) Leaves linear, grass-like, rather glaucous; the thread-like tube of the perianth ubout the leugth of the divisions, which 
are oblong-obovate and on slender claws, the outer ones slightly hairy down the orange-yellow base, crestless; pod obtusely triangular. - Wooded hillsides, Virginin, Kentucky, and southward. April.

5. I. cristata, $\Lambda$ it. (Cnvaren D)wanr Inis.) Isaves lanceolate $\left(3^{\prime}-5^{\prime}\right.$ long when grown); those of the sprathe ovate-lanceolute, shorter than the threadlike tube of the perianth; which is $2^{\prime}$ long and much longer than the light blue obovate short-clawed divisions, the outer ones crested but beardless; pod sharply trinngular. - Mountains of Virginia, Kentucky, and southward. May. Creeping rootstocks pungently acrid.

6. I. lacústris, Nutt. (LAK घ DwARF IRIs.) Tube of the perianth rather shorter than the divisions (yellowish, $\frac{1}{2}{ }^{\prime}-\frac{3}{\prime}$ long), dilated upwards, not exceeding the spathe: otherwise as in the last, and too near it. - Gravelly shores of Lakes Huron and Michigan. May.

\section{PARDA NTHUS, Ker. Blackberry-Lily.}

Perianth 6-parted almost to the ovary; the divisions widely and equally spreading, all nearly alike, oblong with a narrowed base, naked. Stamens monadelphous only at the base : anthers oblong. Style club-shaped, 3-cleft, the narrow divisions tipped with a small dilated stigma. Pod pear-shaped; the valves at length falling away, leaving the central column covered with the globose black and fleshy-coated seeds, imitating a blackberry (whence the popular name). - Perennial, with rootstocks, foliage, \&c. of an Iris; the branching stems $\left(3^{\circ}-4^{\circ}\right.$ high) loosely many-flowered; the orange-yellow perianth mottled above

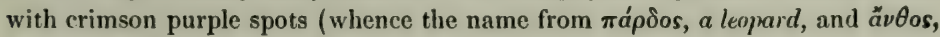
a flower).

1. P. Chinénsis, Ker. (Ixia Chinensis, L.) - Sparingrly escaped from gardens into waste places. July -Sept. (Adv. from China, \&c.)

\section{SIS Y R I N C H I U M, I. Bue-eYed Grass.}

Perianth 6-parted; the divisions alike, spreading. Stamens monadelphous to the top. Stigmas thread-like. Pod globular, 3-angled. Seeds globular. - Low slender perennials, with fibrous roots, grassy or lanceolate leaves, mostly branching 2-edgel or winged stems, and fugacions umbelled clustered sinall flowers from a 2-leaved spathe. (Name composed of $\sigma \bar{v} s, a$ hog, and ' $\dot{p}^{\prime} \gamma \chi x o s$, snout, from a fancy that the hogs are fond of rooting it up )

1. S. Bermudiana, L. Stem winged, naked, or 1-2-leaved; leaves narrow and grass-like; divisions of the perianth obovate, more or less notched at the end, and bristle-pointed from the notch. (Leaves of the spathe almost equal, shorter than the flowers.) - Var. AnCers (S. anceps, Cav.) has a broadly winged scape, and the outer leaf of the very unequal spathe longer than the flowers. Var. mucrondtum (S. mucronatum, Mich $x$.) has a slender and narrowly winged scape, very narrow leaves, those of the spathe sharp-pointed and unequal, one of them usually longer than the flowers. But there are various intermediate forms. - Moist meadows, \&c., among grass; common everywhere. June-Aug. Flowers small, delicate blue, changing to purplish, rarely whitish; or, in var. SLBIDUM (S. albidum, Raf.) pure white: Illinois, Kentucky, and westward. 


\section{Order 119. DIOSCoreàceate. (Yam Family.)}

Plants with twining stems from large tuberous roots or knotted rootstocks, and ribbed and netted-veined petioled leaves, small diocious 6-androus and regular flowers, with the 6-cleft calyx-like periunth adherent in the fertile plant to the 3-celled ovary. Styles 3, distinct. - Ovules 1 or 2 in each cell, anatropous. Fruit usually a membranaceous 3-angled or winged pod. Seeds with a minute embryo in hard albumen. - Represented chiefly by the genus

\section{DIOSCOREA, Plumier. YAM.}

Flowers very small, in axillary panicles or racemes. Stamens 6 , at the base of the divisions of the 6-parted perianth. Pod 3-eelled, 3-winged, loculicidally 3-valved by splitting thrungh the winged angles. Seeds 1 or 2 in each cell, flat, with a mernbranaceous wing. (Dedicated to the Greek naturalist, Dioscorides.)

1. D. villósa, L. (WILD Yam-Root.) Herbaceous; leaves mostly alternate, sometimes nearly opposite or in fours, more or less downy underneath, heart-shaped, conspicuously pointed, 9-11-ribled ; flowers pale greenish-yellow, the sterile in drooping panicles, the fertile in drooping simple racemes. - 'Thickets, New England to Wisconsin, and common southward. July. - Stems slender, from knotty and matted rootstocks, twining over bushes. Pods $811-10^{\prime \prime}$ long. $-\Lambda$ bad name, for the plant is never villous, and ofteu nearly sinooth.

\section{Order 120. Smilàcea. (Smilax Family.)}

Shrubby or rarcly herbaceous plants, climbing or supported by a pair of tendrils on the petiole of the ribled and netted-veined simple leaves; with dicecious small flowers; regular perianth of 6 (rarely more) similar greenish deciduous sepals, firee from the ovary; as many stamens as sepals, with introrse 1-celled anthers; ovary with 3 (rarely 1 or 4-6) cells and as many elonguted spreading sessile stigmas. Ovules one or a pair in each cell, suspended, orlhotropous. Fruit a small berry. Seed-coat close, firmly adherent to the hard horny albumen: embryo minute.-Order, as here limited, represented almost solely by the genus

\section{S Mì I $\mathbf{A}$, Tourn. Greenbrier. Catbrikr.}

Character as above. - Flowers in umbels on axillary peduncles, greenish or yellowish. Sier. Fl. Stamens inserted on the very base of the sepals: filanents linear: anthers linear or oblong, fixed by the base, 2-locellate. Fert. Fl. Filaments, if present, sterile. Stigmas thick and spreading, almost sessile. ('Tho ancient Greek name, of obscure meaning.)

\$1. Stems woodly, often prickly: ovules sulitury. (Ours all glabrous.)

* Leaves ovate or roundish, \&c., most of them rounded or heart-shaped at the base, and 5-9-nerved, the three middle nerves or ribs stronger and more conspicuous. 
- Peduncles shor or scarcely Innger than the petioles, fluttened; leaves thickish, inclining to be evergreen, ut lenst southuard, green both sides.

1. S. Walteri, Pursh. Stem low, somewhat angled, prickly near the

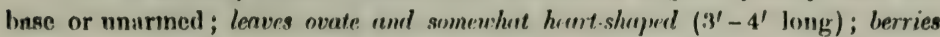
coral-red. (S. China, Wult.) - New Jersey, and southward. July.

2. S. rotundifolia, L. (Cомmon (GREEnzrier.) Stem armed with scattered prickles, as well as the teretc branches; branchlets more or less 4angular; leaves ovale or round-orate, often broader than long, slightly heartshaped, abruptly short-pointed $\left(2^{\prime}-3^{\prime}\right.$ long) ; berries blur-black, with a bloom. (S. cadùca, $L$., is only a more deciduous and thin-leaved form.) - Moist thickets : common, especially southward. June, July. - Plant yellowish-green, often high-climbing. - Passes into var. QUADRANGULÀrs, with the branches, and especially the branchlets, 4-angular, often square. (S. quadrangularis, Muhl.) Penn. to Illinois, and southward.

+ + Peduncles longer than, but seldom twice the length of the petiole, flattened: leaves tardily deciduous or parlly persistent : berries bluck, with a bloom.

3. S. glaùca, Walt. 'Terete branches and somewhat 4-angular branchlets armed with scattered stout prickles, or naked; leaves ovute, rurely subcordate, glaucous beneath and sometimes also above, as well as the branchlets when young (about $2^{\prime}$ long), abruptly mucronate, the edges smooth and naked. (S. Sarsaparilla, $L$., in part, but not as to the syn. of Bauhin, whence the name was taken. (S. cadùca, Willd. S. spinulòsa, Smith? Torr. $f$.) - Dry thickets, S. New York to Kentucky and southward. July.

4. S. tamnotdes, L. Branches and the angular (often square) branchlets sparsely armed with short rigid prick!es; leaves varying from round-heartshaped and slightly contracted above the dilated base to fidille-shaped and halberd-shaped or 3-lober, yreen and shining loth sides, cuspidatc-pointed, the margins often somewhat bristly-ciliate or spinulose. (S. Bona-nox, I., S. hastàta Willd., S. punduràta, Pursh, \&c, are all forms of this.) - 'Thickets, New Jersey to Illinois, and (chiefly) southward. July.

+++ Peduncles $2-4$ times the length of the petiole: lemes ample $\left(3^{\prime}-5^{\prime}\right.$ long $)$, thin or thinnish, green ioth sides: berries blurk: stem terete and lnrenchlets narly so.

5. S. híspida, Muhl. Rootstock cylindrical, elongated; stem (climbing high) below densely beset with long and weak blackish bristly prickles, the flowering branchlets mostly naked; leaves ovate and the larger heart-shaped, pointed, slightly rough-margined, membranucrous and deciduous. - Moist thickets, Penn. and W. New York to Michigan. Jume. - Peluncles $1 \frac{1}{2}-2^{\prime}$ long. Sepals lan. ccolate, almost $3^{\prime \prime}$ long.

6. S. Pseudo-China, I. Rootștock tuberous; stems and lnanches unarmed, or with very few weak prickles ; leaves ovate-heart-shaped, or on the branchlets ovate-oblong, cuspidate-pointed, often rongh-cilinte, bccoming firm in texture; peduncles flat ( $2^{\prime}-3^{\prime}$ long). - Dry or sandy soil, New Jersey to Kentucky, and southward. July.

* Leaves varying from oblong-lanceolate to linear, narrowed at the buse into a short petiole, 3-5-nerved, shining above, palor or glaucous beneath, many of them 
without tendrils: peduncles short, seldom exceeding the pedicels, terete; the umbels sometimes panicled: branches terete, unarned.

7. S. lanceolàta, L. Leuves thimish, rather deciduous, ovate-lanceolate or lance-oblong; stigmas 3 ; berries dull red. - Southeasteru Virginia and southward. June.

8. S. laurifolia, L. Leaces thick and coriaceous, evergreen, varying from oblong-lanceolate to linear $\left(2 \frac{1}{2}{ }^{\prime}-5^{\prime}\right.$ long $)$; stigma solitury; berries black when rije, 1-seeded. - P'ine barrens of New Jersey to Virginia and southward. July, Aug.

§ 2. COP'ROSMÁN'THUS, 'T'orr. Stem herbuceous, never prickly: flower's carrion-scented: ovules mostly in puirs in each cell: lates long-petioled, membranaceous, mucionate-tipped: berries bluish-black with a bloom.

9. S. herbàcea, L. (Cakion-Flowlr.) Stem erect and recurving, or climbing ; leaves ocate-ublony or rounded, mostly heurt-shaped, 7 -9-nerocal, sinooth; tendrils sometimes wanting; peduncles elongated $\left(3^{\prime}-4^{\prime}\right.$ long, or sometimes even $6^{\prime}-8^{\prime}$, and much longer than the leaves), 20-40-flowered. Var. Pulverulénta (S. pulverulenta, Michx. \& S. peduucularis, Muhl.) has the leaves more or less soft-downy underneath. A shorter-peduncled state of this appears to be $\mathrm{S}$. lasioneuron, Hook. - Moist meadows and river-banks : common. June. - Very variable, $1^{\circ}-3^{\circ}$, or even $6^{\circ}-8^{\circ}$ high : petioles $1^{\prime}-3^{\prime}$ long. Seeds 6.

10. S. tamnifolia, Michx. Stem upright or climbing; leaves hart-halberdshaped, 5-nerved, smooth; peduncles longer than the petioles. (S. tannoides, Pursh, not of L.) - P'ine barrens, New Jersey to Virginia and soutliward. Leaves abruptly narrowed above the dilated heart-shaped base, tapering to the apex. Berry 2-3-sceded.

\section{Order 121. Himicede. (Lily Family.)}

Herls, or rarely woorly plants, with regular and symmetrical almost always 6-androus flower:; the perianth not glumaceous, free from the chiefly 3celled ovary; the stamens one before each of its divisions or lobes (i. e. 6, in one instance 4), with 2-cellerl anthers; fruit a few-many-seederl poul or berry; the small emlryo enclosed in copious albumen. Seeds anatropous or amphitropous. Flowers not from a spathe, except in Allium; the outer and inner ranks of the perianth colored alike (or nearly so) and generally sinilar, except in Trillium. - A large family, as here extended, the principal divisions conmonly received as orders, but not well limited. For the present purpose they are best regarded as tribes.

Tribe I. TRILICDERE. Styles or sessile stiguas 3, separate down to the ovary. Fruit a several-many -seeded berry. Divisious or leaves of the perianth distinct, the 8 outer often foliaccous. Simple stem from a rootstock, nuked below; leaves all in one or two whorls above, broad, more or less conspicuously netted-veined!

1. Trillium. Perianth of two sorts, 3 foliaceous peristeut sepals and 8 colored petals. Anthers aduate, introrse. Leaves $(3)$ in a siugle whorl. Flower siugle.

2. Medeola. Periauth of 6 similar colored divisions, deciduous. Anthers fixed by the widdle, extrorse. Leaves in two whorls. Flowors Burorul. 
Tribe IT. M EI. A NTII TEF. Btylen or enaslle atigmna 8, apparnte down to the ovary. Fruit a several-many-seeded pod. Seede with a soft or looses cost. Anthers extrorse, except in No. 11. Perianth withering-persistent. Leaves parallel-veined and alternato Flowers often polygamous, sometimes diceious.

- Anthers henrt-shnped or kidney-shaped, confluently 1-celled, shield-shaped after openirg: pod 8-horned, and septicidal : reels flat, membranuceous-mnrgined.

- Sepals with one or two glands or spots on the upper face near the base.

8. Melauthlum. Flowers polygamoug. Sepals entirely free from the ovary, their long claws bearing the stamens.

4. Zygadenus. Flowers perfect or polygamous. Sepals nearly free from the base of the ovary : stamens free.

$\leftarrow$ - Sepals destitute of glands, and not raised on claws.

5. Stennuthium. Perianth below colierent with the base of the ovary; the sepals lanceolate, pointed, longer than the stamene. Racemes compound-punicled.

6. Verntrum. Perianth entirely free; the obovate or oblong sepals longer than the stamens. Flowers panicled, polygamous.

7. Amianthium. Perianth entirely free, the oval or obovate sepals shorter than the strmens. Flowers racemed, perfect.

* Anthers 2-celled, extrorse : pod loculicidal. Flowers racemed or spiked.

8. Xerophy $11 \mathrm{um}$. Flowers perfect. Cells of the globose-3-lobed pod 2-8eeded. Leaves very slender. Seeds 2 in each cell.

9. Helonlag. Flowers perfect. Cells of the giobose-3-lobed pod many-Beeded. Leaves lanceolate. Seape naked. Seeds numerous.

10. Chamaliffum. Flowers diœcious. Pod oblong, many-seeded. Stem leafy.

* * Anthers 2-celled, innate or introrze : pod septicidal, many-seeded.

11. Toftelda. Flowers perfect, spiked or racemed. Leaves equitant.

Tribe III. UVILARIEAE. Style 3-parted; i. e. styles 3 united into one only at the base. Fruit a few-seeded pod. Seed-cont soft or loose. Anthers more or less extrorse. Perianth 6-leaved, decilnous. Stems from a rootstock or fibrous roots, leafy. Leave alternate, broad, parallel-velned.

12. Uvularia. Pod 3-angular or 3-lobed. Anthers linear, adnate, on short filaments.

Tribe IV. A SPA A A G.IN EAE. Style 1, undivided (i.e. the 3 or rarely 2 styles united to the sumnit into one). Fruit a few-seeded berry. Seeds with a close coat and horny albumen. Stems from a rootstock. Leaves parallel-veined, chiefly alternate. Pedicels often articulated with the flower or in the middle.

* Plants with true leaves. Coat of the hard seed thin and membranous.

+ Anthers extrorsely attached to the filament. Stamens hypog!nous. Sepals diatinct.

13. Prosartes. Anthers linear-oblong, pointless. Flowers terminating the forked branches, on stright jointless pedicels.

14. Stre ptopus. Anthers arrow-shaped, pointed. Flowers lateral along the forked branches: pedicels bent about the middle.

15. Clintonia. Anthers oblong, pointles. Flowers terminuting a naked scape.

- Anthers introrfe. Filaments attached to the perinuth. Stem simple.

16. Convallaria. Perianth bell-shaped, 6 -lobed, bearing the stamens. Leaves all at the base of the naked scape, which bears the flowers in a simple raceme.

17. Smilnelna. Perianth 4-6-parted, spreading, the stamens borne at the base. Stem leafy. Flowers In a eimple or compound terminal raceme.

18. Polygonatum. Perianth tubular, 6-cleft, bearing the stamens above the middle. Stem leafy to the top. Flowers axillary.

* Plants with branching atems, their true leaves reduced to scales: leaf-like branchlets serving for foliage. Seed-coat hard and black.

19. Asparagus. Perianth 6 parted. The apparent leaves very narrow or threa 1-like. L. \& $\mathrm{M}-42$ 
Tribe V. LILIEAS. Style 1, undivided (i. e. the three united throughout into one or rarely a sessile stigma. Fruit a loculicidal pod. Seeds with a tleshy albumen. Anthers introrse or extrorse. Stem commonly from a couted or scaly bulb.

* Leafy-stemmed from a scaly bulb.

20. Lllimn. Periauth 6-leaved, deciduous. P'od obloug, many-seeded : seeds horizontal, that.

* Scape naked or nearly so, from a coated or rarely scaly bulb. Seeds mostly globular. + Perianth of 6 separate or ueurly separate divisions or sepals.

21. Erythronium. Flower siugle. Style club-shaped. Pod obovate.

22. Ornithogalum. Flowers corj mbed, never blue or reduish. Style 3-sided.

28. Scilla. Flowers racemel, purple or blue. Style thread like.

24. Alli uxm. H'lowers unbelled, from a spathe. Sepals 1-nerved.

+ + Perianth globular or ovoid, 6-toothed.

25. Muycarl. Vlowers in a dense raceme, numerous, siuall, mostly blue.

* * No bulb. Steur or scape several-flowered. Pod many-seeded.

26 IIemerocallis. Perianth large, funnel-shnped; the eepals united in a narrow tube below. Stamens and long $\times t$ le decined. Seeds globular, black.

27. Yucca. Perianth large, of 6 separate broad divisions. Stigmas sessile. Stem woudy and persistent: leaves persistent. Seeds flat, horizontal. Flowers pabieled.

28. Narthecium. Perianth 6-parted, the divisions narrow, Jellowish. Filaments woolly. Style slender. Flowers in a raceme. Leaves equitant. Sceds small, loog-tialed at both euds. ('Trunsition to Juncucese.)

\section{T R Í I L I U M, L. Three-leaved Nightshade.}

Sepals 3, lanceolate, sprealing, herbaceous, persistent. Petals 3, larger, withering in age. Stamens 6 : anther's linear, on short filaments, adnate, introrse; the cells opening down the margins. Styles (or rather stigmas) awlshaped or slender, spreading or recurved above, persistent, stigmatic down the inner side. Ovary 3-6-angled. Berry ovate, 3-celled (purple or red). Seeds horizontal, several in each cell. - Low perennial herbs, with a stout and simple stem rising from a short and pramor'se mber-like rootstock, maked, bearing ut the summit a whorl of 3 ample, commonly broadly ovate, more or less ribbed but netted-veined leaves, and a terminal large flower; in spring. (Name from trilix, triple; all the parts being in threes.) - Monstrosities are not rare with the calyx and sometimes the petals changed to leaves, or with the parts of the flower increased in number.

\$1. Flower sessile in the bosom of the leaves, erect: petuls varying from spatulute to lunceulute, 1'-2' long, litlle exceeding the sepuls, withering-persistent (stems $4^{\prime}-12$ ' high).

1. T. séssile, I. Lcaves sessile, ovate or rhomboidal, acute, often blotched or spotted ; sessile petuls erect-spreading (dark and dull purple, varying to greenish). - Moist woods, Pennsylvania to Wisconsin, and southward.

2. T. recurvàtum, Beck. Leaves contracted at the base into a petiole, ovale, oblong, or obovate: sepals reflexed, petals pointed, the base narrowal into a claw, dark purple. - Indiana to IVisconsin, and southward.

§ 2. Fluwer raised on a peduncle: prtuls withering au'ay afier Blossoming.

* Peduncte stcnder, ercct or inclincd: lawess rhombic-ovute, abruptly tuper-pointed, sessile or neurly so by a wedye-sluped or acute buse: petuls plane.

3. T. grandiflorum, Salisb. (Lalige White T. or Waкk Roвin.) Leaves rhomboid-olwvate, longer than broad, bately sessile; petuls dovate, 
Ipreading from an erect base, much larger than the sepals $\left(2^{\prime}-2 \frac{1^{\prime}}{2}\right.$ long), white, changing with age to rose-color. - Rich woods, Vermont to S. Penn., Kentucky, Wisconsin, and northward. June. - Flower erect, on a peluncle $2^{\prime}-3^{\prime}$ long, very handsome.

4. T. eréctum, L. (Punple T. or Binturoot.) Leaves dilated-rhomboidal, neurly as broad as long; petuls ovate, acutish, dark dull purple, spreading, little longer than the sepals $\left(1^{\prime}-1 \frac{1}{2}^{\prime}\right.$ long). (T. rhomboídeum, var. atropurpureum, Michx.) - Rich woods : common, especially northward. May. Peduncle $1^{\prime}-3$ ' long, usually rather inclined than erect.

Var. álbum, l'ursh. Petals greenish-white, or rarely yellowish; ovary mostly dull-purple. (T. péndulum, Ait., \&c.) - With the purple-flowered form, especinlly from New York westward.

Var. declinatum. Peduncle (fully half the length of the leaves) horizontal, or soon becoming so, or in fruit almost deflexed; petals white, rarely pink. Ohio to I. Superior (where it is the principal Trillium, Dr. Robbins), and northward. - Sometimes confounded with the next, if not passing into it.

* Peduncle from the first recurved under the short-petioled or almost sessile leaves, scarcely if at all longer than the wavy recurved-spreading petals.

5. T. cérnuum, L. (NoDning T. or Wark-Rosin.) Leaves broadly rhomboid, abruptly pointed; petals white, oblong-ovate, acute, rather longer than the sepals $\left(6^{\prime \prime}-9^{\prime \prime}\right.$ long); styles distinct. - Moist woods, especially eastward.

6. T. stylosum, Nutt. Leaves oblong, tapering to both ends, more distinctly ribbed; petals tinged with rose-color, oblong, much longer and broader than the sepals; styles united below the middle. - Virginia? and southward.

* * Peduncle erect or nearly so: leares distinctly petioled from a rounded base: petals merely spreading, longer than the sepals.

7. T. nivàle, Ridlell. (Dwarf Winte T.) Small $\left(2^{\prime}-4^{\prime}\right.$ high); leaves oval or ovate, obtuse ; petals oblong, obtuse, white, scarcely wavy, spreading from an erect base (as in No. 3), equalling the peduncle; styles long and slender. - Rich woods, Ohio to Wisconsin. April. - Leaves 1'-2', and petals 1' long.

8. T. erythrocárpum, Michx. (PAinted T.) Leaves ovate, taperpointed; petuls ovate or oval-lanceolate, pointed, wavy, widely spreading, white painted with purple stripes at the lase, shorter than the peduncle. ('T. pictum, Pursh.) - Cold damp woods and bogs, New England and Penn. to L. Superior and northward, and southward in the higher Alleghanies. May, June.

\section{MEDEOLA, Gronov. Indian Cucumbr-root.}

Perianth recurved, the 3 sepals and 3 petals oblong and alike (pale greenishyellow), deciduous. Stamens 6 : anthers shorter than the slender filaments, oblong, extrorsely attached above the base, but the line of dehiscence of the closely contiguous parallel cells lateral or slightly introrse. Stigmas, or styles stigmatic down the upper side, recurved-diverging from the globose ovary, long and thread-form, deciduous. Berry globose (dark purple), 3-celled, few-seeded. - A perennial herb, with a simple slender stem $\left(1^{\circ}-3^{\circ}\right.$ high, clothed with flocculent and deciduous wool), rising from a horizontal and tuberous white 
rootstock (which has the taste of cucumber), bearing near the middle a whorl of 5-9 obovate-lanceolate und pointed, sessile, lightly parallel-ribbed and netted-veiny, thin leaves; also another of 3 (rarely 4 or 5) much smaller ovate ones at the top, subtending a sessile umbel of small recurved flowers. (Named after the sorceress $M c d e a$, from the wholly imaginary notion that it possesses great medicinal virtues.)

1. M. Virgínica, L. (Gyròmia, Nutt.) - Rich danp woods. June.

\section{MEI Á N TH I U M, Gronov., L. Melantuum.}

Flowers monociously polygamous. Perianth of 6 separate and fiee widely spreading somewhat heart-shaped or oblong and halberd-shajed sepals, raised on slender claws, cream-colored, the base marked with 2 approximate or confluent glands, turning greenish-brown and persistent. Filaments shorter than the sepals, adhering to their claws often to near their summit, persistent. Anthers heart-shaped or kidney-shaped, confluently l-celled, shield-shaped after opening, extrorse. Styles 3, awl-shaped, diverging, tipped with simple stigmas. I'od ovoid-conical, 3-lobed, of 3 inflated membranaceotis earpels united in the axis, separating when ripe, and splitting down the inner edge, several-seeded. Secds flat, broadly winged. - Stem simple $\left(3^{\circ}-5^{\circ}\right.$ high $)$, from a somewhat bulbous base, roughish-downy above, as well as the open and ample pyramidal paniclo (composed chiefly of simple racemes), the terminal part mostly fertile. Leaves lanceolate or linear, grass-like, those from the root broader. (Name composed of

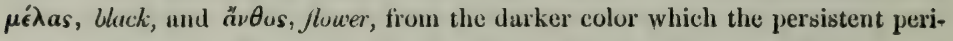
anth assumes after blossoming; but the name is hardly waranted.)

1. M. Virgínicum, L. (Bunch-roower.) (M. Virginicum \& racemosum, Michx. Leimanthium Virginicum, Willd. I. Virginicum \& hybridum, Roem. \&. Schult., (rroy, Melanth.) - Wet meadows, from Southern New York to Illiuvis, and common southward. July.

\section{ZYGA DE $\mathbf{H} \mathbf{S}$, Michx. ZYGadene.}

Flowers perfect or polygamous. Perianth withering-persistent, spreading; the petal-like oblong or ovate sepals 1-2-glandular next the more or less narrowed, but not unguiculate base, which is either free, or united and colierent with the base of the ovary. Stamens free from the sepals and about their length. Anthers, styles, and pod nearly as in Melanthium. Seeds margined or slightly winged. - Very smooth and somewhat glaucous peremials, with simple stems from ereeping rootstocks or coated bulbs, linear leaves, and pretty large panicled greenish-white flowers; in summer. (Name composed of לvyós, a yoke, and ǻn, a gland, the glands being in pairs.)

\section{* Glands on the perianth conspicuous.}

1. Z. glabérrimus, Michx. Stems $1^{\circ}-3^{\circ}$ high from a creeping rootstock, leaves grass-like, chunelled, conspicuously nerved, clongated, tapering to a point;

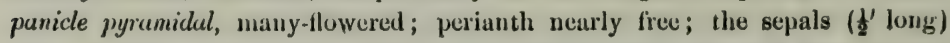
ovate, becoming lance-ovate, with a pair of orbicular glands ubore the short claw-like base. - Grassy low grounds, Virginia (Pursh) and southward. 
2. Z. glaucus, Nutt. Stem $1^{\circ}-3^{\circ}$ high from a voated bulb; leaves flat; panicle ruther simple and few-flowered; hase of the perianth coherent with the base of the ovary, the thin ovate or obovate sepals marked with a large obcondate

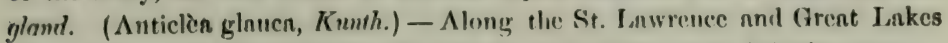
(Bergen Swamp, Gennesee Co., New York, G. T'. Iish) to N. Illinois : rare.

* Glainds of the periunth obscure. (Here also Amianthium Nuttallii, Gray.)

3. Z. leimantholdes. Stem $1^{\circ}-4^{\circ}$ high from a somewhat bulbous base, slender; leaves narrowly linear; flowers small ( $4^{\prime \prime}$ in diameter) and numerous, in a few crowded panicled racemes; only a yellowish spot on the contracted hase of the divisions of the free perianth. (Amianthiun leimanthoides, Gray.) Low grounds, pine barrens of New Jersey (Durand, Knieskern) and southward.

\section{STE $\mathbf{T}$ Á $\mathbf{N} \mathbf{T} \mathbf{H} \mathbf{I} \mathbf{U}$, Gray (under Veratrum).}

Flowers polygamous. Perianth spreading; the sepals narrowly lanceolate, tapering to a point from the broaler base, where they are united and coherent with the base of the ovary, not gland-bearing, persistent, much longet than fhe short stamens. Anthers, pods, \&c. nearly as in Nos. 4 and 6. Seeds nearly wingless. - Smooth, with a wand-like leafy stem from a somewhat bulbous base, long and grass-like conduplicate-kecled leaves, and numerous small flowers in compound racemes, forming a long terminal panicle; in summer. (Name com-

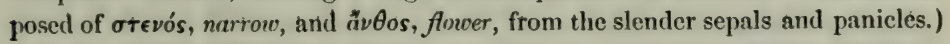

1. S. angustifolium, Gray. Leaves lincar, elongated ; flowers ( $ł^{\prime}$ long), white, very short-pedicelled, in slender racemes; the prolonged terminal one, ant often some of the lateral, fertile. (Veratrum angustifolium, Pursh. Helonias graminea, Bot. MFag.) - Low prairies and meadows, Penn. to Illinois and southward towards thé mountains. - Stem slender, $2^{\circ}-6^{\circ}$ high.

\section{V ER A TR U M, Tourn. False Hellebore.}

Flowers monueciously polygamous. Perianth of 6 spreading and separate olovatc-oblong (grecnish or brownish) sepals, more or less contracted at the base, entirely free from the ovary, not gland-bearing. Filaments free from the sepals and shorter than they, recnrving. Anthers, pistils, fruit, \&c. vearly as in Melanthium. - Somewhat pubescent perenials, with simple stems from a thickeried hase jroducing coarse fibrous roots (very poisonous), 3-ranked leaves, and racemed-panicled dull or dingy flowers; in summer. (Name formed of vere, truly, and ater, black.)

1. V. víride, Ait. (American White Hellebore. Indian Pore.) Strm stont, very lerify to the top $\left(2^{\circ}-4^{\circ}\right.$ high); leaves broadly oval, pointed, sheath clasping, strmgly plaited; panicle pyramidal, the dense spike-like racemes spreading; perianth yellowish-green, moderately sprearling. - Swamps and low grounds: common. (Much too near V. album of Europe.)

2. V. parviflorum, Michx. Stem slender $\left(2^{\circ}-5^{\circ}\right.$ high $)$, sparingly lenfy below, naked above; leaves scarcely plaited, glabrous, contracted into sheathing petioles, varying from oval to lanceolate; panicle very long and loose, the terminal raceme wand-like, the lateral slender and spreading; pedicels as long as the flow 
ors; sepals dingy-green, oblanceolate or spatulate $\left(2^{\prime \prime}-3^{\prime}\right.$ long $)$, those of the sterile flowers on claws, widely spreading. (Melanthium monoicum, Walt. Leimanthium monoicum, Gray.) - Mountains of Virginia and southward.

3. V. Woódii, Rubbins. Leaves lanceolate or oblong-lanceolate; pedicels $\left(1 \frac{1}{2} \prime-3^{\prime \prime}\right.$ long) shorter thun the flowers, the oblanceculate spreading sepuls ( $3^{\prime \prime}-4 \frac{1}{2}$ " long) dingy green turning brownish purple within: otherwise much as in the last, of which it may be a variety; but the tlowers are mostly double the size, and the pauicle stuuter. (1'lant $3^{\circ}-6^{\circ}$ high.) - Woods and hilly barrens, Green Co., Indiana, Wood. Augusta, Illinois, Mead.

\section{A MI Á N THIUM, Gray. Fly-Poison.}

Flowers perfect. Perianth widely spreading; the distinct and free petal-like (white) sepals oval or obovate, without claws or glauds, persistent. Filaments capillary, equalling or exceeding the periatuth. Anthers, pods, \&c., nearly as in Melanthium. Styles thread-like. Seeds wingless, oblong or linear, with a loose coat, $1-4$ in cach cell. - Glabrous, with simple stems fiom a bulbous base or coated bulb, scape-like, few-leaved, terminated by a simple dense raceme of handsone flowers, turning greenish with age. Leaves lincar, beeled, grass-like.

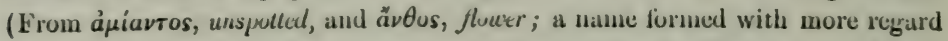
to euphony than to good construction, alluding to the glandless perianth.)

1. A. muscætóxicum, Gray. (Fly-Porson.) Leaves bruadly linear, elongated, obtuse $\left(\frac{1}{2}^{\prime}-1^{\prime}\right.$ wide); ruceme simple; pod abruptly 3-horned; seeds oblong, with a fleshy red coat. (Ifelonias erythrospérma, Michx.) - Open woods, New Jersey and I'enn. to Kentucky and soutliward. June, July.

\section{XEROPHÝLLUM, Michx. Xerophylem.}

Flowers perfect. Perianth widely spreading; sepals petal-like (white), oval, distinct, without glands or claws, at length withering, about the length of the awl-shaped filaments. Anthers 2-celled, short, extrorse. Styles thread-like, stigmatic down the inner side. Pod globular, 3-lobed, obtuse (small), loculicidal; the valves bearing the partitions. Seeds 2 in each cell, collateral, 3 -angled, not margined. - Herb with the aspect of an Asphodel; the stem simple, $1^{\circ}-4^{\circ}$ high, from a bulbous base, bearing a simple compact raceme of showy white flowers, thickly beset with needle-shaped leaves, the upper ones reduced to bristle-like bracts; those from the root very many in a dense tuft, reclined, a foot or more long, $\mathrm{l}^{\prime}$ wide below, rough on the margin, remarkably dry and rigid

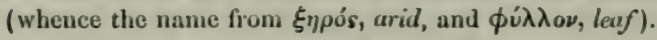

1. X. asphodeloides, Nutt. (X. tènax, Nutt. X. setifolium, Michx. Helonias asphodelioides, L.) - Pine barrens, New Jersey and southward: also far westward. June.

\section{HELONIA S, Y. Helonias.}

Flowers perfect. Puriauth of 6 spatulate-oblong purple sepals, persistent, turning green, shorter than the thread-like filaments. Anthers 2-celled, roundish-oval, bluc, extrorse. Siyles revoluk, stigmutic down the inner side. Pod 
obeordntely 3-lobed, loculieidally 3-valved; the valves divergently 2-loberl. Seeds many in each cell, linear, with a tapering appendage at both ends. - A smooth perennial, with many oblong-spatulate or oblanceolate evergreen fiat leaves, from a tuberous rootstock, producing in carly spring a hollow naked scape $\left(1^{\circ}-2^{\circ}\right.$ high), sheathed with broad bracts at the base, and terminated by a simple and short dense raceme. Bracts obsolete: pedicels shorter than the flowers. (Name probably from $\tilde{\epsilon}$ 入os, $a$ suamp, the place of growth.)

1. H. bullàta, I. (II. latifolia, Michx.) - Wet places, New Jersey and Pennsylvania to Virginia : rare and local.

\section{CHA M 尼LÍRI U M, Will DeviL's-Brt.}

Flowers dioccious. Perianth of 6 spatulate-linear (white) spreading sepals, withering-persistent. Filaments and (yellow) anthers as in Helonias: fertile flowers with rudimentary stamens. Styles linear-club-shaped, stigmatic along the inner side. Pod ovoid-oblong, not lobed, of a thin texture, loculicidally 3-valved from the apex, many-seeded. Seeds linear-oblong, winged at each end. - Smooth herb, with a wand-like stem from a (bitter) thick and abrupt tuberons rootstock, terminated by a long wand-like spiked raceme $\left(4^{\prime}-9^{\prime}\right.$ long) of stnall bractless flowers; fertile plant more leafy than the staminate. Leaves flat, lanceolate, the lowest spatulate, tapering into a petiole. (Name formed of $x a \mu a i$, on the ground, and $\lambda$ eiptov, lily; of no obvious application.)

1. C. lùteum. (Blazing-Star.) (C. Caroliniànum, Willd. Veratrum luteum, L. Helonias luter, Ait. H. dioica, Pursh.) - Low grounds, W. New England to Illinois and southward. June.

\section{TOFIÉLIA, Hudson. Fatse Asphodec.}

Flowers perfect, usually with a little 3-bracted involucre underneath. Perianth more or less spreading; the scpals (white or greenish) concave, oblong or obovate, without claws. Filaments awl-shaped : anthers short, innnte or somewhat introrse, 2-celled. Styles awl-shaped : stigmas terminal. Pod 3-angular, 3-partible or septicidal ; cells many-seeded. Seeds oblong. - Slender perennials, mostly tufted, with fibrous roots, and simple stems leafy only at the hase, bearing small flowers in a close raceme or spike. Leaves 2-ranked, equitant, linear, grass-like. (Named for Mr. Tofidd, an English botanist of the last century.)

$\$ 1$. Flowers in a simple spike-like raccme or head: anthers introrse: seeds not appendaged: plant smooth and glabrous.

1. T. palustris, Hudson. Scape leafless or nearly so $\left(3^{\prime}-6^{\prime}\right.$ high), slender, bearing a globular or oblong head or short raceme of whitish flowers; leaves tufted, I'long. - Isle Royale, \&c., Lake Superior, and northward. (Eu.)

§2. Flowers moconnse, but developing from above downuverds: short pedicels in threes from a little involucre of as many bracts: anthers innate: soods tail-pointed at both ends (as in many species of Juncus.)

2. T. glutinosa, Willd. Stem $\left(6^{\prime}-16^{\prime}\right.$ high) and pedicels very glutinous with dark glands; leaves broadly linear, short. - Moist grounds, Maine, Michigan, Wisconsin, and northward : also soutliward in the Alleghanies. June. 
3. T. pùbens, Ait. Stcm $\left(1^{\circ}-2^{\circ}\right.$ high) and pedicels roughened with minute glands; leaves longer and narrower. - Pine barrens, New Jersey to Virginia and southward. July.

\section{U V U LÀ RIA, L. Bellwort.}

Perianth nearly bell-shaped, lily-like; the 6 distinet sepals spatulate-lanceolate, with a honey-bearing groove or pit at the erect contracted base, much longer than the stamens, which barely adhere to their base, deciduons. Anthers linear, much longer than the filaments, aduate and extrorse, but the long and narrow eclls opening nearly along the margin. Style deeply 3-cleft; the divisions stigmatic along the inner side. l'od triangular or 3-lobed, loculicidally 3-valved from the top. Seeds ferv in each cell, obovoid, with a tumid or fungous rhaphe. - Stems rather low, from a rootstock, naked or scaly at the base, furking above, bearing oblong sessile or clasping flat and membranaceous leaves, and yellowish drooping flowers, in spring, solitary or rarely in pairs, on terminal peduncles which becone lateral by the growth of the branches. (Name "from the flowers hanging like the uvula, or palate.")

* Leaves clasping-perfoliate: sepuls pointed: porl truncate, 3-lobed: rootstock short.

1. U. granditlora, Smith. Stems $1^{\circ}-2^{\circ}$ high; flower $1 \frac{1}{2}^{\prime}$ long, pale greenish-y:llow, the sepals nearly smooth within; anthers blunt-pointed. - Rich woods, Vermont to Wisconsin and southwestward.

2. U. perfoliàta, L. Smaller; sepals yrunulur-roughened within; anthers sharper tipped; otherwise as No. 1. - Common castward and southward.

3. U. flava, Smith. Flower bright yellow, I long; sepals nearly smooth within ; anthers short-pointed. - New Jersey to Virginia : rare.

* * Leuves sessile: pod trianyulur : stems low $\left(6^{\prime}-12^{\prime}\right)$ : rootstock creeping.

4. U. sessilifolia, L. Leaves lance-oblong, pale, glaucous beneath, sessile or partly clasping by a narrow base; sepals blunt (9" long); anthers pointless; the ovoid and sharply triangular / ol stipitate. - Low woods : common. May.

5. U. pubérula, Michx. Slightly puberulent; leaves bright green both sides and shining, oval, with rough edges; styles separate to near the base, not exceeding the short-pointed unthers; pod ovate, not stipitate; otherwise like the last. - Mountains, Virginia, and southward.

\section{PROSÁRteS, Don. Prosartes.}

Perianth bell-shaped, the 6 sepals lanceolate or linear, deciduous. Filaments thread-like, much longer than the linear-oblong blunt anthers, which are fixed by a point above the base, and extrorse. Ovary with 2 ovules suspended from the summit of each cell : style one : stigmas short, recurved-spreading, or sometimes united into one! Berry ovoid or oblong, pointed, 3-6-seeded, red. Downy low herbs, divergently branched above, with elosely sessile ovate and membranaceous leaves, and greenish-yellow drooping flowers, on slender termi-

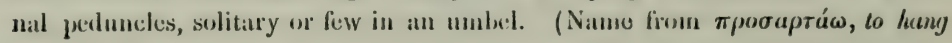
from, in allusion to the pendent ovules or flowers.)

1. P. lanuginòsa, Don. Leaves ovate-oblong, taper-pointed, rounded or slightly heart-shaped at the base, elosely sessile, downy underneath; flowers 
solitnty or in pairs ; sepals linenr-lanceolnte, tnper-pointed ( $f^{\prime}$ lorig), soon spreading, twice the length of the stamens, greenish; style smooth; stigmas 3. (Streptopus lanuginosus, Michx.) - Rich woods, Western New York to Virginia, Kentucky, and southward along the Alleghunies. May.

\section{STR E P T P U S, Michx. Twisted-Stalk.}

Perianth recurved-spreading from a bell-shaped base; the 6 distinct sepals lanceolnte, acute, the 3 inner keeled, deciduous. Anthers arrow-shaped, extrorse, fixed near the base to the short flattened filaments, tapering above to a slender entire or 2-cleft point. Ovary with many ovules in each cell: style and sometimes the stigmas one. Berry red, roundish-ovoid, many-seeded. Herbs, with rather stout stems, forking and divergent branches, ovate and taperpointed rounded-clasping menbranaceous leaves, and sinall (extra-) axillary flowers, either solitary or in pairs, on slender thread-like peduncles, which are abruptly bent or contorted near the middle (whence the name, from $\sigma \tau \rho \in \pi \tau o ́ s$, twisted, and $\pi$ oûs, foot or stalk.)

1. S. amplexifolius, DC. Leaves very smooth, glancous underneath, strongly clasping; flower greenish-white on a long peduncle abruptly bent above the middle; anthurs tapering to a slender entire point; stigma entire, truncate. (S. distórtus, Michx. Uvularia amplexifolia, L.) - Cold and moist woods, from Penn. northward. June. - Stem $2^{\circ}-3^{\circ}$ high, rough at the base, otherwise very smooth. Sepals $\frac{1}{2}$ long. - In this, as in the next, the peduncles are opposite the leaves, rather than truly axillary, and are bent round the clasping base under$\therefore$ neath them : they are rarely 2-flowered. (Eu.)

b. 2. S. roseus, Michx. Leaves green both sides, finely ciliate, and the branches $\rightarrow$ sparingly beset with short bristly hairs; flower rose-purple, more than half the Tength of the slightly bent perluncle; anthers 2-horned; stigme 3-cleft-Cold damp woods, northward, and in the Alleghanies southward. May.

\section{CLINTÒNIA, Raf. Cuntonis.}

Perianth of 6 separate sepals, bell-shaped, lily-like, deciduous; the 6 stamens inserted at their base. Filaments long and threal-like: anthers linear or oblong, extrorsely fixed by a point above the base, the cells opening down the margins. Ovary ovoirl-oblong, 2-3-celled : style long: stigmas 2 or 3 , or in ours united into one. Berry ovoid, blue, few-many-seeferl. - Stemless perennials, with slender crecping rootstocks, producing a nakerl scape shenthed at the base by the stalks of $2-4$ large ollong or oval ciliate leaves. Flowers rather large, umbelled, rarely single. (Declicated to De Witt Cliwton.)

1. C. boreàlis, Raf. Umbel few-(2-7-) flowred; ovules 20 or more. (Draciena horealis, Ait.) - Cold moist woorls, Massachusetts to Wisconsin and northward, and sonthward along the Alleghanies. June. - Scape and leaves $5^{\prime}-8^{\prime}$ long. Perianth over $\frac{1}{2}$ ' long, greenish-yellow, somewhat downy outside.

2. C. umbellàta, Torr. Umbel many-fowered; ovules 2 in ench cell. (C. multiflora, Beck. Convallaria umbellulata, Michx.) - Rich woods, S. W. New York, and southward along the Alleghanies. June, July. - Flowers half the size of the last, white, speckled with grcen or purplish dots. 


\section{CONVALLARIA, L. (in part). Lily of the Vallex.}

Perianth bell-shaped (white), 6-lobed, deciduous; the lobes recurved. Stamens 6, included, inserted on the base of the perianth: anthers introrse. Ovary 3-eelled, tapering into a stuut style: stigma triangular. Ovules 4-6 in each well. Berry few-seeded (red). - A low perennial herb, glabrous, stemless, with sleuder running rootstucks, sending up from a scaly-sheathing bud 2 oblong leaves, with their long sheathing petioles enrolled one within the other so as to appear like a stalk, and an angled scape bearing a one-sided raceme of pretty and sweet-scented nodding fluwers. (Altered from Liliun convallium, the jojpular name.)

1. C. majàlis, L. - High Alleghanics of Virginia, und southward. May. - Same as the Lurupean Lily of the VALLex of the gardens. (Eu.)

\section{S MILACìna, Desf. False Solomon's Seal.}

Perianth $4-6$-parted, spreading, deciduous (white), with as many stamens inserted at the base of the divisions. Filaments slemder: antliers short, introrse. Ovary 2-3-eelled, with 2 uvules in each cell: style short and thick: stigma obscurely 2-3-lobed. Berry glubular, 1-2-seeded. - Perenuial herbs, with simple stems fiom creeping or thickish rootstocks, alternate nerved leaves, and white, sometimes frayrant fluwers in a terminal and simple or compound raceme. (Name a diminutive of Similux, to which, however, these plants bear little resemblance.)

§ 1. SMIILACINA proper. Divisions of the perianth (oblongtunceolute) and stamens 6, the latter longer: ovary 3-celled: ovules colluteral: rowemes croculal in a compound raceme or clase paricle: rootstock stout, fleshy.

1. S. racemósa, 1)col. (Falsi Sinkisarb.) Minutely downy (20 high); leaves numerous, ublung or uval-lanceulate, taper pointed, ciliate, abruptly somewhat petioled. - Muist copses : common. June. - Berries pale red, speckled with purple, aromatic. (S. ciliàta, Ltsf., is a dwarf state of this.)

§ 2. ASTERANTHEMUM, Kunth. Divisions of the periunth 6, ollung-lanceoluke, longer thun the stumens: ovury 2-3-cellud: ovulcs one above the oulder: raceme single, 5-20-flowered: roolstock ruther slender.

2. S. stellata, Desf. Nearly glabrous, or the 7-12 ollong-tanceolute leares minutely duwny bencath when young, slightly clasping ; berrics Luchish. - Muist banks: common northward. May, June. - Plant $1^{\circ}-2^{\circ}$ high. (Eu.)

3. S. trifolia, Duf. Glabruus, dueverf $\left(3^{\prime}-6^{\prime}\right.$ highli); leates 3 (sometimes 2 or 4 ), oblong, tilpering to a sheathing lase ; berries red. - Culd logs, New Englaud to Peru., Wisconsiu, and northward. May.

§ 3. MAIÁNTHEMUM, Desf. Divisions of the reftexed-spreuling periunth (ooul) and the stamems 4 , of equal length: ovring 2-cellad: ovules coblaterul: ruceme single, mony-fluwered: crorping rootstuch s slemer.

4. S. bifolia, lier. (ilabrous, or somewhit pulnsecent, low $\left(3^{\prime}-5^{\prime}\right.$ lightı); leaves mustly 2 (sometimes 3), heart-shaped, petiulet, or in our plant (the var. CANADÉNSIs) One or buth uften scssile or nearly su and clasping. - Moist wouds: very conumon, especially northward. May. (Eu.) 


\section{POL Y GON A T U M. Tourn. Solomon's Seal.}

Perianth cylindrical, 6-lobed at the summit; the 6 stamens inserted on or nhove the middle of the tube, ineluded: anthers introrse. Ovary 3-celled, with 2-6 ovules in ench cell : style slender, decirluous by a joint: stigma obtuse or capitate, obscurely 3-lobel. Berry globular, black or hluc; the cells 1-2-secled. - Perennial herbs, with simple erect or curving stems, rising from creeping thick and knotted rootstocks, naked below, above hearing nearly sessile or halfclusping nerved leaves, and axillary nodding greenish flowers: pedicels jointed

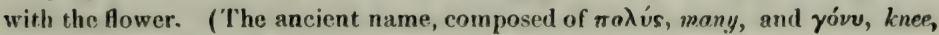
alluding to the numerous joints of the rootstocks and stems.) - Ours are all alternate-leaved species, and with the stem terete or scarcely angled when fresh.

1. P. biflorum, Ell. (Sмакцик Soromon's Senz.) Glabrous, except the ovate-oblong or lance-oblong noarly sessile lereves, which are commonly minutely pubescent, at least on the vicins (but sometimes smooth), as well as pale or y'ancons undernmih; stem slender $\left(1^{\circ}-3^{\circ}\right.$ high); peduncles $1-3$ - bul mostly 2-flowered; fluments prpillose-ronghened, inserted towards the summit of the cylindrical-oblong perianth. (Convallaria biflora, Walt. C. pubescens, Willd. Polygonatum pubescens, angustifolium, \& multiflorum, Pursh.) - Wooded banks: common. - Perianth $\frac{1}{2}$ long, grcenish.

2. P. gigantèum, Dietrich. (Grest S.) Glubrous thronghout; stem stout and mostly tall, terete; leaves ovate, partly clasping $\left(5^{\prime}-8^{\prime}\right.$ long $)$, or the upper oblong and nearly sessile, many-nerved; preduncles several- $(2-8-)$ flowered; filuments smooth and naked, or nearly so, inserted on the middle of the tube of the cylindrical-oblong perianth. (Convallaria canaliculata, Willd. Polygonatum canaliculatum, Pursh. P. comıntàtum, Dietrich.) - River-banks, in alluvial soil, $5^{\circ}-8^{\circ}$ high; in dry or less fertile soil $2^{\circ}-4^{\circ}$. June. (The stem not being at all channelled in the living plant, it is better to discard the carlier name of canaliculatum.) - Pedicels $4^{\prime \prime}-15^{\prime \prime}$ long: perianth $9^{\prime \prime}$ long. - Perhaps passes into the preceding.

3. P. latifolium, Desf. Upper part of the stem $\left(2^{\circ}-3^{\circ}\right.$ high $)$, the $1-5$ flowered peduncles, pedicels, and lower surface of the ovate or oblong mostly petioled leaves more or less pubescent; flluments glahinus. (1'. hirtum, Pursh. Convallaria hirta, Poir.) - Pennsylvania, Muhlenben!

(P. Moltiflonum, with hirsute filaments, I have never scen in this country.)

\section{A S PÁ RA G S, L. Asparagus.}

Perianth 6-parted, spreading above: the 6 stamens on its hase: anthers Introrse. Style short: stigma 3-lohed. Berry spherical, 3-celled; the cells 2-seeded. - Perennials, with much-branched stems from thick and matted rootstocks, and small greenish-yellow axillary flowers on jointed pedicels. The narrow, commonly thread-like, so-called leaves are really branchlets, acting as leaves, clustered in the axil of a little scale which is the truc leaf. (The ancient Greek name.)

1. A. officindeis, L. (Garben Asparaass.) Ilerbaceous, tall, busliybranched; leaves thread-like. - Sparingly escaped from gardens into wasto places on the coast. June. ( $\Lambda d v$. from Eu.) 


\section{LfLIUM, L. LiLy.}

Perianth funnel-form or bell-shaped, colored, of 6 distinct sepals, spreading ot recurved above, with a honey-bearing furrow at the base, deciduous; the 6 stamens somewhat adhering to their bases. Anthers linear, extrorsely inserted towards the middle to the tapering apex of the long filument, which is at first included, at length versatile; the cells dehiscent by a lateral or slightly introrse line. Style elongated, somewhat club-shaped: stigma 3-lobed. Pod oblong, containing numerous flat and horizontal (depressed) soft-coated seeds densely packed in 2 rows in each cell. - Bulbs scaly, producing simple stems, with numerous alternate-scattered or whorled short and sessile leaves, and from one to several large and showy flowers; in summer. (The classical Latin name, from the Greek $\lambda \epsilon i p t o \nu$.)

* Flowers erect, bell-shaped, the sepals narrowed below into claws.

1. L. Philadélphicum, L. (Wild Onange-red Lily.) Leaves linear-lanceulate; the upper chiegly in whorls of 5 to 8 ; flowers 1-3, open-bell-shanped, reddish-orange spotted with purplish inside; the linceolate sepals not recurved at the summit. - Dry or sandy ground: common. - Stem $2^{\circ}-3^{\circ}$ high: the flower $2 \frac{1}{2}$ ' long.

2. L. Catesbæ̀i, Wialt. (Soutukis Rev Lily.) Leaves lineur-lancealate, scattered; flower solitary, open-bell-shaped, the long-clawed sepals wavy on the margin and recurved at the summit, scarlet, spotted with dark purple and yellow inside. - Low sandy soil, Pennsylvania? to Kentucky and southward.

* * Flower's nulding, bell-shapred, the sessile sepuls revolute.

3. L. Canadénse, L. (Wan Ýlzow LiLY.) Leaves remulely whorled, lanecolate, strongly 3-nerved, the margins and nerves rough, flowers few, longpeduncled, oblong-bell-shaped, the sepals recurved-sprending above the middle, orange-spotted inside with brown. - Moist meadows and bogs, especially northward. - Stem $2^{\circ}-5^{\circ}$ high. Flower $2^{\prime}-3^{\prime}$ long.

4. L. supérbum, L. (Turk's-Cap LiLy.) Lower leaves whorled, lanceolate, pointel, 3-nervel, smouth; flowers often many $(3-20$ or 40$)$ in a pyramidal raceme; sepels strongly revolute, bright orange, with numerous dark purplo spots inside. - Rich low grounds. - Stem $3^{\circ}-7^{\circ}$ ligh : sepals $3^{\prime}$ long. I. Carolinianmm, Micke, aploirently belongs to this species, which also probably passes into the preceding.

\section{ERYTHRÒ I UM, L. Dog's-Tootu Violet.}

Perianth lily-like, of 6 distinct lanceolate sepals, recurved or sprealing above, deciduous, the 3 inner usually with a callous tooth on each side of the erect base, and a groove in the midille. Filaments 6 , awl-shitped : anthers oblong-linear, continuing erect. Style elongated. P'orl olovate, contracted at the base, 3-valved, loculicidal. Secels rather unurerons, ovoid, with a loose, menblomaceons tip. -

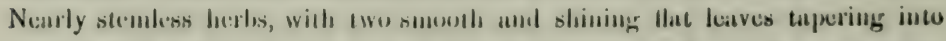
petioles and sheathing the base of the commonly one-flowered seape, rising from a deep solid-scaly bull). Flowers ratler large, nodding, in sprring. (Name from épvopós, red, which is inappropriate as respects the American species.) 
1. E. Americanum, Smith. (Yellow Ander's-tongeve.) Leaves elliptical-lanceolate, pale green, mottled and commonly dotted with purplish and whitish; perianth light yellow, often spotted near the base; style club-sliaped ; stigmens united into ono. - Low copses: common. May. - Scripe $6^{\prime}-9^{\prime}$ high: flower $1^{\prime}$ or more long. - E. mictedtum, Boott, from the Camel's Rump Mountain, Vermont, is probably only an accidental state, with a bract, such as the Western F. grandiflorum often has.

2. E. albidum, Nutt. (Wnite Dog's-тоотн Violet.) Leaves elliptical-lancenlate, less or not at all spotted, not dotted ; perianth bluish-white ; inner divisions toothless; style more slender except at the apex, bcaring 3 spreading stigmas. - Low thickets, New York (near Albany), and S. Penn. to Wisconsin and Illinois. - At Lake Superior, Dr. Robbins finds a plant like this but yellowflowered, a transition towards $\mathrm{E}$. grandiflorum.

\section{OR N I T H Ó G A L U M, Tourn. Star-of-Betnlenem.}

Perianth of 6 colored (white) spreading 3-7-nerved sepals. Filaments 6, flattened-awl-shaped. Style 3-sided: stigma 3-angled. Pod membranous, roundish-angular, with few dark and roundish seeds in cach cell, loculicidal. Scape and linear channelled leaves from a coated bulb. Flowers corymbed,

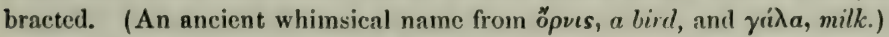

1. O. имnецLגтом, L. Flowers 5-8, on long and sprearling pedicels; sepals green in the middle on the outside. - Escaped from gardens into moist meadows, eastivard. June. (Nat. from Eu.)

\section{SCÍLLA, L. SQuill.}

Perianth of 6 colored (blue or purple) spreading sepals, mostly deciduons; the 6 awl-shaped filaments ut their base. Style thread-like. P'orl 3-nngled, loculicidal, 3-valved, with several black roundish secrls in cach cell. - Seape and linear leaves from a coated bulb: the flowers in a simple raceme, mostly bracted. (The ancient name.)

1. S. Fraseri. (Eastern Quanasi. Wild Hracintir.) Leaves long and linear, keeled ; raceme elongated ; bracts solitary, longer than the pedicels; stigma minutely 3-cleft ; pod triangular, śeveral-secded. (Phalạ́ngium esculéntum, Nutt. Scilla esculenta, Ker. Camássia Fraseri, Torr.) - Moist prairies and river-banks, Chio to Wisconsin and sonthwestward. May.-Bulb onionlike, eaten hy the Indians. Scape $1^{\circ}$ high. Sepals widely spreading, pale blue, 3-nerved, 6" long.

\section{4. ÁLIIU M, I. Onion. Garlic.}

Perianth of 6 entirely colored sepals, which are distinct, or united at the very base, 1-nerved, often hecoming dry and scarious and more or less persistent : the 6 filaments awl-shaped or dilated at their base. Style persistent, threadlike : stigma simple. Pod lohed, loculicilal, 3-valved, with 1 or few oroidkidney-shaped amphitropous or campylotropous black seerls in each cell. Strong-scented and pungent stemless herbs; the leaves and scape from a 
coated bulb flowers in a simple umbel, some of them frequently changed to bulblets; spathe 1-2-valved. (The ancient Latin name of the Gurlic.)

* Ovules and seeds single in each cell: leaves broad and flat, appearing in early spriny, and dying before the flowers are developed.

1. A. tricóccum, Ait. (W WLD Leks.) Scape nuked ( $9^{\prime}$ high from clustered pointed bulbs, $2^{\prime}$ long), bearing an erect many-flowered umbel; leaves lance-oblong $\left(5^{\prime}-9^{\prime}\right.$ long, $1^{\prime}-2^{\prime}$ wide); sepals oblong (white), equalling the simple filaments; pod strongly 3-lubed. - Rich woods, IV. New kinglaud to Wisconsin, Kentucky, and southward in the Alleghanies. July.

* Ooules mostly 2 in each cell: ovury crested with 6 teeth: leuves long and nurrow.

+ Umbel benting only flowers and ripening pods.

2. A. cérnuum, Riutlı. (W1LD ONion.) Sccupe nukal, angular $\left(1^{\circ}-2^{\circ}\right.$ high), often nodding at the apex, bearing a loose or drooping many-flowered umblat; leaves linear, sharply heelal ( $1^{\circ}$ long); sepals oblong-ovate, acute (rose-color), shorter than the simple slender filaments. - Stecp banks, Western New York to Wisconsin and southward. July, Aug.

3. A. stellàtum, Nutt. Scape terete, slender, bearing an erect umbel; leuves flat; sepals equalling the stamens: otherwise resembling the last, but usually not so tall ; the pod more crested. Ang. - Rocky slopes, Illinois (Engelmunn), and northwestward.

4. A. Schœonóprasum, L. (Chives.) Scape naked or leufy at the base $\left(6^{\prime}-12^{\prime}\right.$ high) bearing a globular capitale umblo of many rose-purple flowers; sepals lanceolate, pointed, longer than the simple downwardly dilated filaments; leaves awt-shaped, hollow. Var. with recurved tips to the sepals ( $\Lambda$. Sibiricum, L.) - Shore of Lakes IIuron, Superior, and northward. (Eu.)

+ + Umbel oflen densely bulb-bearing, with or without flowers.

5. A. vinedie, L. (Field Garic.) Scape slender, clothed with the sheathing bases of the leaves below the middle $\left(1^{\circ}-3^{\circ}\right.$ high $)$; leaves terete and hollow, slender, channelled above; filuments much dilated, the alternate ones 3-cleft, the middle division anther-bearing. - Moist meadows and fields: a vile weed eastward. June. - Flowers rosc-color and green. (Nat. from Eu.)

6. A. Canadénse, Kalı. (WiLd Garlic.) Scape leafy only at the base $\left(1^{\circ}\right.$ high); leases nurrowly linear, flutlish; umbel few-flowered; filaments simple, dilated below. - Moist meadows. May, June. - Flowers pale rose-color, pedicelled; or a head of bulbs in their place.

*** Ovules several in each cell: leaves long and linear. (Nothóscordum, Kunth.)

7. A. striatum, Jacc. Leaves narrowly linear, often convolute, striate on the back, about the length of the obscurely 3-augled natied scape $\left(6^{\prime}-12^{\prime}\right.$ long), filaments dilated below, shorter than the narrowly oblong sepals (which aro white with a reddish keel) ; ovules $4-7$ in cach eell. - Prairies and open woods, Virginia to Illinois and southward. May.

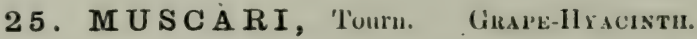

Perianth globular or ovoid, minutely 6-toothed (bluc). Stumens 6, included: anthers short, introrse. Siyle short. I'ud loculicidal, wich 2 black angular 
secds in each cell. - Leaves and scape (in early spring) from a coated bulb: the small flowers in a dense raceme, sometimes musk-sconted (whence the name).

1. M. Botryoldes, Mill. J.enves linear ; flowers globular $\left(1 \frac{1}{2} "-2^{\prime \prime}\right.$ long $)$, deep blue, nppenring like minute grupes; whence the popular mane. - Escuped from gardens into copses and fence-rows, E. Penn., \&e. (Ailv. from Eu.)

\section{HEMEROCÁLLIS, L. DAY-LILY.}

Perinnth funnel-form, lily-like; the short tube enclosing the ovary, the spreading limb 6-parted; the 6 stamens inserted on its thront. Anthers as in Lily, more or less extrorse. Filaments and style long and thread-like, declined and ascending : stigma simple. Pod (at first rather fleshy) 3-angled, loculicidally 3-valved, with several black spherical seeds in each cell. - Showy perennials, with fleshy-fibrous roots; the long and linear keeled lenves 2-ranked at the base of the tall scapes, which bear at the summit several bracted and large yellow flowers: these collapse and decay after expanding for a single day (whence the name, from in $\epsilon^{\rho} \rho a, a d a y$, and $\kappa a ́ \lambda \lambda o s$, beuuty).

1. H. FÚlVA, L. (Common DAY-Lily.) Inner divisions (petals) of the tawny orange perianth wary and obtuse. - Roadsides, escaped from gardens, where it is common (as is also the bright yellow-flowered H. FLAvA). July. (Adv, from Eu.)

\section{Y Ú C CA, L. Bear-Grass. Spanish Bayonet.}

Perianth of 6 petal-like (white) oval or oblong and acute flat sepals, withering-persistent, the 3 inner broader, longer than the 6 stamens. Stigmas 3, sessile. Pod oblong, somewhat 6-sided, 3-celled, or imperfectly 6-celled by a partition from the back, fleshy, at length loculicidally 3-valved from the apex. Seeds very many in each cell, depressed. - Stems woody, either very short, or rising into thick and columnar palı-like trunks, bearing persistent rigid linear or sword-shaped leaves, and terminated by an ample compound panicle of showy (often polygamous) flowers. (An aboriginal name.)

1. Y. flamentosa, L. (ADAm's Needer.) Trunk (from a running rootstock) rising for a foot or less above the carth, covered with the lanceolate unarmed corinceous lenves $\left(1^{\circ}-2^{\circ}\right.$ long), which bear filaments on their murgins; scape-like flower-stem $6^{\circ}-8^{\circ}$ high, erect. - Sandy soil, E. Virginia and southward. July.

\section{NARTH E C I U M, Mnhring. BoG-Asphodel.}

Sepals 6, linear-lanceolate, ycllowish, persistent. Filaments 6, woolly: anthers linear, introrse. Pod cylindrical-oblong, pointed with the undivided style and single stigma, loculicidal, many-secded. Seeds appendaged at each end with a long bristle-form tail, as in many species of Juncus. - Rootstock creeping, bearing linear equitant leaves (as in Tofieldia), and a simple stem or

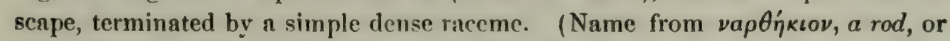
a box for fiagrant ointments, of obscure application.)

1. N. ossifragum, Huds. - Herb with scape about a foot high, longer than the leaves: pedicels mostly bracteolate. (Eu.) 
Var. Americànum. (N. Amcricanum, Ker.) Flowers rather smaller (scarcely $3^{\prime \prime}$ long) and leaves narrower than the European plant, which is limited to the Atlantic side of that continent, as is ours here: viz. in sandy bogs, on this side, where it is very local, in the pine barrens of New Jersey only. June, July.

\section{Order 129. JUNCגCEa. (Rush Family.)}

Grass-like or sedge-like herbs, with small flowers, a regular and hypogynous persistent periunth of 6 similar glumaceous sepuls, 6 or rarely 3 stamens with 2-celled anther's, a single short style, 3 filiform hairy stignus, ance an worry eilher 3-celled or 1-celled with 3 parielal placente, forming a loculicidal 3-valved pod. Seeds anatropous, with a minute embryo enclosed at the base of the fleshy albumen. - Rushes, with the flowe.s liliaceous in structure, but selge-like in aspect and texture, mainly represented by only two genera.

\section{L Ù Z U L A, DC. Wood-Rush.}

Pod 1-celled, 3-sceded, one seed to each parietal placenta. - Perennials, often hairy, usually in dry ground, with tlat and soft usually hairy leaves, and spikederowded or umbelled flowers. (Name said to be altered from the Italian luciolu, a glow-worm.)

\section{* Flowers loosely long-peduncled, umbelled or corymbed.}

1. L. pilossa, Willd. Leaves lance-linear, hairy ; umbel mostly simple; sepals pointed, shorter than the obtuse pod; seeds with a curved appendaye. Woods and hanks: comuon northward. May. - Plant 6'-9' high. (Eu.)

2. L. parviflora, 1)esv., var. melanocárpa. Nearly smooth $\left(1^{\circ}-3^{\circ}\right.$ high) ; leaves broatlly linear; corymb decompound, loase ; pedicels droopiny; sepals pointed, straw-color, about the length of the minutely pointed and brown pod. (L. melanocarpa, Desv.) - Mountains, Maine to Northern New York, und northward. July. (Eu.)

* * Flowers crowdel in spikes or close clusters. (Plants 6'-12' high.)

3. L. campéstris, DC. Leaves, flat, linear; spikes 4-12, somewhat umbelled, ovoid, straw-color, some of them lung-peduncled, others nearly sessile; sepals bristle-pointed, longer than the obtuse pods; seeds with a conical appendage at the basc. - Dry fields and woods ; common. May. (Eu.)

4. L. areuàta, Meyer. Leaies chunnelled, linear; spikes 3-5, on unequal often recurved pedencles, ovoid, chestnut-brown; bracts ciliate-finged; sepals taper-pointed, longer than the obtuse pod; secds not appendaged. - Alpine summits of the White Mountains, New IIampshire, and high northward. (Eu.)

5. L. spicàta, 1) csvatux. Leaves chunnelled, narrowly linear; flowers in sessile chusters, fonming a noddiny interruphed spitical punicte, brown; sepals bristlepointed, scarcely as long as the abruptly short-pointed pord; seeds merely with a roundish projection at the base. (Our plimt is L. racemosa, Desv.? according to Gudet.) With the last, and more common. (Eu.) 


\section{JÚ N C U S, L. Rush. Bog-Rusr.}

Pod many-seeded, 3-celled, or 1 -celled by the placenta not reaching the axis. Stamens when 3 opposite the 3 outer sepals. - Chicfly perennials, and in wet soil or water, with pithy or hollow and simple (rarely branching) stems, and panicled or clustered small (greenish or brownish) flowers, chicfly in summer. Plant never hairy. (The classical name, from jungo, to join, alluding to the use of the stems for bands.)

Contributed for this edition by Dr. ENGELMANN, who has recently published a monograph of the North American species in the Transactions of the St. Louis Academy of Science.

81. Thue Junc1; with naked and simple scapps from matted running rootstocks, many of them barren, furnished at base with short lenfless or rarely leaf-bearing sheaths : leaves, if any, terite, knotless and similar to the scape: flowers single or rarely clustered on the pedicels, in sessile panicles, produced apparently from the side of the scripe, the exterior sheuth or involucral lanf being similar to and contimuing the scupe. Flowering in early summer.

* Flowers single on the podicels or ultimute rumifications of the panicle.

- Sheaths at buse of the stem leafless.

+ Stamens 3.

1. J. effüsus, L. (Соммом or Soft Rusir.) Seape soft and pliant $\left(2^{\circ}-4^{\circ}\right.$ high); inuer sheaths awned; panicle diffusely much branched, manyflowered; flowers numerons, small (1 $11^{\prime \prime}$ long), grcenish ; sepals lanceolate, very acute, as long as the triangular-obovate retuse and pointless greenish-brown porl; anthers as long as filaments; style very short; sceds small (about f"long) with short pale points, delicately ribbed and cross-lined. - Var. cong Lomeratus (J. conglomeratus, $L_{\text {.) }}$ has the seape more distinctly striate, the panicle closely crowded, and the pod short-pointed. - Marshy grounds: very common; the var. in sphagnous swamps. (Eu.)

+4 Stamens 6.

2. J. fllifórmis, L. Scape very slender $\left(1^{\circ}-2^{\circ}\right.$ high $)$, pliant; panicle few-flowered, almost simple; flowers ( $1 \frac{1}{2}$ "long); sepals lanceolate, the inner a little shorter and less acute, longer than the broadly ovate obtuse but shortpointed greenish pod; anthers shorter than the filaments; style very short; seed (less than $\mathrm{f}^{\prime \prime}$ long) short-pointed at both ends, indistinctly reticulated. - N. New England and New York to Michigan and northward. (En1.)

3. J. Smithii, Engelm. Scape rather slender $\left(2^{\circ}-3^{\circ}\right.$ high $)$; panicle fewflowered. nearly simple; flowers brown (1 $1 f^{\prime \prime}$ long); onter sepals lanceolate and acute, inner a little shorter, ohtusish, shorter than the broally ovate rather triangular acute and pointed deep chestnut-brown pod; anthers as long as filaments ; style short, secds large ( $f$ " or more long) obtuse, with short nppendages at both ends, many-ribbed and reticulated. - Sphagnous swamps, on Broad Mountain, Pennsylvania, C. E. Smith.

4. J. Bálticus, Dethard. Scape rigid $\left(2^{\circ}-3^{\circ}\right.$ high $)$; panicle loose; flowers larger ( 2 "l long), chestnut-brown with green; sepals ovate-lanceolate, the outer sharp-pointed, the inner obtusish, as long as the elliptical rather triangular obtuse Ind pointed deep brown pod; anthers much longer than the 
broud filaments; style about the length of the ovary; seeds rather large ( $\xi^{\prime \prime}$ or more long), nearly obtuse, delieately ribbed and cross-lined. - Sandy shores of New England, the Great Lakes, and westward; also in swamps, Lancaster Co., Penn., Prof. Porter. (Eu.)

$$
\text { + + Innermost sheuths leaf-bearing: stamens } 6 .
$$

5. J. setàceus, Rostkovius. Scape slender $\left(1^{\circ}-3^{\circ}\right.$ high $)$; panicle loose, rather few-flowered; Howers greenish ( 2 "l long); sepals lanceolate, sharp-pointed, especially the 3 shining exterior ones, spreading in fruit, as long as the nearly globose beak-pointed greenish or light-hrown pod; anthers as long as filaments; style conspicuous; seeds ( $f^{\prime \prime}$ long) almost globose, ribbed and cross-lined. Pennsylvania (Rosthovius), Virginia? and North Carolina, southward near tho coast. - Duubtful if in our district.

* * Flowers in clusters, 6-androus: innermost sheaths ai base of stem leaf-bearing.

6. J. Rœmeriànus, Schecle. Scape stout and rigid $\left(2^{\circ}-3^{\circ}\right.$ high), its apex as well as the leaves pungent; panicle compound ; $3-6$ greenish or lightlrown llowers ( $1 \frac{1}{2}$ "long) in a cluster; outer sepals lanceolate, sharp-pointed, longer than the obtusish inner ones, as long as the elliptical rather triangular obtuse short-pointed brown pod; anthers much longer than the broad tilaments; styles shorter than the ovary; seeds ( $\xi^{\prime \prime}$ long) oval, obcuse, very delicately ribbed. (J. maritimus of Aner. authors.) - Brackish marshes, New Jersey (Pursh), Virginia and southward.

§ 2. GRASSY-LEAVED JUNCI; with simple or rarely branched stems, lenfy at base or throughout: leaves flut, or somewhut terte or seluccous and channelled, never knotted: panicle terminal.

* Flowers crowded in heads (produced in late summer).

+ Leaves thread-like, hollow: stems simple: hcads single or few: seeds large, the loose sced-coat produced into conspicuous tails : stamens 6.

7. J. stýgius, L. Stems slender $\left(6^{\prime}-16^{\prime}\right.$ high $)$ from slender branching rootstocks, 1-3-leaved below, naked above; heads 1 or rarely 2, of 3-4-flowers, about the length of the sheathing scarious awl-pointed bract; flowers pale and reddish $\left(2 \frac{1}{2}{ }^{\prime \prime}-3^{\prime \prime}\right.$ long $)$; sepals lanceolate, the inner obtusish, the length of the oblong acuminate pod, as long as the slender stamens; filaments many times longer than the oblong anthers; recurved stigmas shorter than the style; seeds oblong, with a very loose slightly striated coat prolonged at both ends ( $1 \frac{1}{2}$ "' long). - Peat-bogs bordering Perch Lake, Jefferson County, New York. N. Maine, G. L. Goodule. (New Brunswick. Mr . Fowler. North shore of Lake Superior, Mr. Wheter.) - Flowers larger and pod more abruptly pointed than in the European plant. (Eu.)

8. J. trífidus, L. Stems densely tufted from matted creeping rootstocks, erect $\left(5^{\prime}-10^{\prime}\right.$ high $)$, sheathed and mostly leafless at the base, $2-3$-leaved at the summit, the upper thread-like leaves subtending the sessile head of $1-4$ brown $\left(1 \frac{2}{2 \prime}-2^{\prime \prime}\right.$ long) flowers; sepals ovate-lanceolate, acute, equalling or rather shorter than the ovate beak-pointed deep brown pod; anthers inuch longer than the filaments; seeds few, oblong, angled ( 1 "long), faintly striate, short-talled. - Alpine summits of the nwuntains of New England, and N. New York, and ligh nortȟsard. (Eu.) 
$\leftarrow+$ Leaves flat and open, grass-like: stamens 3.

9. J. marginàtus, Rostkovius. Stem erect, from a bulbous and stoloniferous base $\left(1^{\circ}-3^{\circ}\right.$ high), flattened, leafy; lenves long-linenr; heads $3-8$ flowered, panicled ; flowers purplish with green ( $1 \frac{1}{2}$ "long); sepals oblong, the 3 outer acute and slightly awned, the inner longer and mostly obtuse and pointless. as long as the almost globular scarcely pointed pod; stamens exceeding the onter sepals; purple anthers shorter than filaments; style very short ; seeds $\left(t^{\prime \prime}-t^{\prime \prime}\right.$ long) slender, pointed at both ends and strongly ribbed. ( $J$. aristulàtus, Michx.) - Moist sandy places, S. New England to Illinois and sonthward. Var. paucicapitatus has smaller and less flattened stems, narrower leaves, and few large 8-15-flowered heads. Sandy coast of New Jersey and elsewhere. Var. BIFLorus has numerous and small 2-3-flowered heads, in much-branched panicles. (J. biflorus, Ell.) New Jersey to Illinois and southward.

10. J. rèpens, Michx. Stems flattened, ascending $\left(4^{\prime}-6\right.$ ! high) from a fibrous annual root, at length creeping or floating; leaves short. linear, those of the stem nearly opposite and fascicled; heads few in a loose leafy panicle, 3-12flowered ; flowers green ( $3^{\prime \prime}$ long) ; sepals rigid, lance-subulate, slender-pointed, the 3 outer as long as the linear triangular obtuse pod, the inner ones much longer; stamens as long as the outer sepals ; filaments many times longer than the oblong anther; sceds small ( $\frac{1}{5}$ "long), obovate, slightly pointed, very delicately ribbed and cross-lined. (Cephalóxys flabellàta, Desv.) - Miry banks, Maryland (W.M. Canby) and southward.

* Flowers single on the ultimate peduncles: stamens 6.

+ Stem branched: root annual.

11. J. bufonius, L. Stems low and slender $\left(3^{\prime}-9^{\prime}\right.$ high) from a fibrous root, leafy, often branched from the base; panicle spreading, mostly with onesided dichotomous branches; flowers remote, greenish (2" $-3 \frac{1}{2}$ " long); sepals linear-lanceolate, awl-pointed, 3 outer ones much longer than the inner and than the oblong obtuse pod; stamens short; filaments scarcely longer than anthers ; seeds elliptical, obtuse $\left(\mathrm{g}^{\prime \prime}-\frac{1}{6}{ }^{\prime \prime}\right.$ long), very delicatcly ribbed and crosslined. - Low grounds by roadsides: common, but not everywhere. JuneSept. - Var. FAsciculdTus, with flowers crowded at the end of the branchlets, is a southern form, which has been introduced about the Philadelphia Navy Yard. (Eu.)

+ + Stems slender, simple, tufted, leafy below: root perennial ( $f$. early in summer).

12. J. Gerárdi, Loisel. (BLıck-Grass.) Stems scarcely flattened, rigid $\left(1^{\circ}-2^{\circ}\right.$ high); panicle contracted, usually longer than the bracteal leaf; flowers chestnut-brown with green (13"long); sepals oval-oblong, obtuse, incurved, as long as the oval obtuse and mucronate pod; anthers much longer than the short filaments; style as long as the ovary; seeds (nearly $\mathbf{l}^{\prime \prime}$ long) obovute, short pointed at both ends, delicately ribbed and cross-lined. - Salt marshes: common along the const, especially northward; also in saline marshes of W. New York: rare along the Great Lakes. (Eu.) - The closely allied J. bulbosus, $L$. (to which this was referred in a former edition) has not yet been found in this country. 
13. J. ténuis, Willd. Stem wiry $\left(9^{\prime}-18^{\prime}\right.$ high) ; leaves flat or channelled; panicle shorter thun the involucral leaves, loose, or rarely crowded; flowers green (2' or more long); sepals lanceolate, very acute, spreading in fruit, longer than the ovoid retuse scarcely pointed green pod; anthers nearly equal to the filament; style very short; seeds small (about f $^{\prime \prime}$ long), white-pointed at both ends, delicately ribbed and cross-lined. - Low grounds, ficlds, and roadsides. (Eu.) - Var. secúxdes is a smaller plant, with smaller one-sided fluwers on tho forked branches of the panicle. New England to P'ennsylvania.

14. J. dichótomus, Ell. Stens rigid $\left(1 \frac{1}{2}{ }^{\circ}-2^{\circ}\right.$ high $)$ from a tumid base; leaves filiform, nearly terete, slightly grooved on the inner side; panicle loose, often with l-sided forked branches, mostly longer than the involucral leaf; flower's greenish ( 2 " or more long); sepals lanceolate, sharp-pointed, sprending in fruit, as long as the globular beaked light mahogany-colored pod; anthers nearly as long as filaments; style short ; seeds small ( $\frac{1}{6} " f^{\prime \prime}$ long), white-pointed at both ends, coarsely eross-lined. - Low sandy grounds, New Jersey (C. $\boldsymbol{F}$. Parker), Delaware (Prof: Leidy, Mr. Commons), and southward.

15. J. Greénii, Oakes \& Tuckerm. Stems rigid $\left(1^{\circ}-2^{\circ}\right.$ high $)$; leuves nearly terete, very decply chimnelled (almost iuvolute) on the inner side; panicle usually much shorter than the principal erect involucral leaf, dense; tho numerous crowded flowers often one-sided (1 1 "q long); sepals lanceolate, acute, light greenish-brown, appressed, shorter than the ovoid-oblong obtuse greenishbrown pod; anthers as long as filaments; style very short; seeds ovoid, tailpointed ( $f^{\prime \prime}-\frac{2}{5}{ }^{\prime \prime}$ long), ribbed and delicately cross-lined. - Sandy coast of New England, and on the Great Lakes near Detroit (Lolzer, J. M. Bigelow).

16. J. Vàseyi, Engelın. Stems rigid $\left(1^{\circ}-2 \frac{1}{2}{ }^{\circ}\right.$ high $)$; leaves nearly terete, very slightly channelled on the inner side; panicle longer than the involucras leaf, Joose; Howers few, often one-sided, greenish or light brown (2" or moro long); sepals lanceolate, acute, appressed, shorter than the oblong and retuse green-brown pod; anthers as long as the filaments; style very short; seeds slender, conspicuously tailed at both ends $\left(\frac{1}{2} "-\frac{2}{3} \prime \prime\right.$ long), closely ribbed. Michigan, with the last (near Detroit, Holzer, Bigelow) to N. Illinois (Vasey), and westward. June.

§ 3. KNotTr-Leaven Juncr; stems lenfy, simple or branching: leaves terete or sometimes laterally compressed, knotted by internal cross-partitions: panicís terminal, with flowers chiefly in heads.

* Seeds barely pointed, without tails.

+ Ileads comprosed of 2 or sometimes only simgle 6-androus flowers.

17. J. pelocárpus, E. Meyer. Stems slender and erect from a slender running rootstock $\left(6^{\prime}-18^{\prime}\right.$ high $)$, bearing few thread-like slightly knotted leaves, branching above into a compound spreading panicle, bearing in the forks and along one side of the branches single flowers or 2-flowered heads; often with the flower's or in place of them are tufts of leaves ; flowers small (1' - If' loug), greenish with red; sejals oblong, obtuse, the 3 inner ones longer, but shorter than tho oblong taper-beaked I-eelled porl; unthers much longer than the filaments ; stylo slender; seeds ( $t^{\prime \prime}$ long) obovate, short-pointed, delicately ribbed-reticulated. (J. vivíparus, Conrad. J. Conràdi, Tuckerm.) - Saudy, wet or swampy places 
Canada to Wisconsin, and from New England southward near the const. July, Aug. - The proliferous plants are usually sterile and much larger than the fertile ones, with larger and more diffuse panicles. - V nr. súntuLis (J. fluitans, Michx.), from Canadn, is a sinall sud creping or flonting form, inostly with single 2-flowered heals at the ends of the short stems.

++ Heads numerous, of 3-12 flowers (rardy more in No. 21), in early summer. - Stamens 6.

18. J. articulatus, L. Stems ascending or erect $\left(9^{\prime}-15^{\prime}\right.$ high), tufted from a short creeping rootstock, with 1 or 2 slender leaves; panicle short, spreading; the crowded heads 3 -8-flowered ; Howers brown, rarely pale (1 1 " 1 $f^{\prime \prime}$ long); sepals lance-oblong, acute or mucronate, or the 3 inner obtuse and a little longer, shorter than the ovate-oblong acute or abruptly mucronate-pointed incompletely 3-celled commonly decp chestnut-brown shining pod; anthers as long "is filaments; ovary attenuated into a short style; seeds (less than $\frac{1}{3}$ "long) obovate, attenuate below, abruptly pointed above, ribbed-reticulated. (J. lampocárpus, Ehrh.) - Wet grounds, New England to Western New York and 1) claware. (Eu.) - Var. onтusitus. Panicle crowded, level-topped; heads 5-flowered, green; sepals obtuse, of equal length, the outer mucronate; pod obtuse, mucronate. - Petty's Island, near Philadelphin, Mr. Diffenbaugh, Mr. Burke.

19. J. alpinus, Villars, var. insígnis, Fries. Stems erect $\left(9-18^{\prime}\right.$ high) from a creeping rootstock, with 1 or 2 slender leaves; panicle meagre, with erect branches bearing distant greenish or light-brown heads, each of 3-6 flowers (1 $f^{\prime \prime}-1 \frac{1}{2} "$ long); sepals oblong, obtuse, the outer mucronate or cuspidate and usually longer than the rounded inner ones, as long or shorter than the obtuse short-pointed incompletely 3-celled light-brown pod; anthers as long as filaments; style short; seeds ( $\mathbf{~}^{\prime \prime}$ or mofe in length) spindle-shaped, ribbed-reticulated. (J. pelocárpus, Ed. 1. J. articulatus, var. pelocarpus, Ed. 2.) - Wet sandy banks, from Lake Champlain (Robbins, Macrae,) and along the Great Lakes northward and westward. (Fu.)

20. J. militáris, Bigel. Stcm stont $\left(2^{\circ}-4^{\circ}\right.$ high) from a thick creeping rootstock, bearing a solitury stout erect leaf $\left(\frac{1}{2}{ }^{\circ}-3 \frac{1}{2}{ }^{\circ}\right.$ long) below the middle which overtops the crowded and rather contracted panicle; heads numerous, 5-12- (rarely 25-) flowered ; flowers brownish ( $1 \frac{1}{2} "$ long); sepals lanceolate, the outer onès awl-pointed, as long as the ovate-oblong triangular tapcr-beaked 1celled pod; anthers longer than filaments; ovary attenuated into a slender style, sceds ( $f^{\prime \prime}-\frac{1}{3}$ "long) glohose-obovate, obtuse, abruptly pointed, ribbed-reticulated. - In bogs and streams, Maine to Maryland. - Dr. Robbins finds that in flowThg water, at Uxbridge, Mass., this bears numberless capillary submersed leaves, $2^{\circ}-3^{\circ}$ long, from the rootstock.

\section{+ + Stamens 3.}

21. J. acuminàtus, Michx. Stems tufted, erect, bearing about 2 lenves and a loose spreading panicle; heads few - many-flowered, greenish, at length straw-colored or darker; sepals lance-awl-shaped, sharp-pointed, equal, as long ns or shorter than the triangular-prismatic short-pointed 1-celled pod; anthers a little shorter than the filaments; style almost none; seeds small ( $\xi^{\prime \prime}-f^{\prime \prime}$ long), 
acute at both ends, ribbed-reticulated. (J. palléscens, E. Meyer, as to the N. American plant.) - Earlier than other species which are likely to be confounded with it: May, June. - A very variable plant, the following forms of which have the appearance of distinct species, but are connected by various intermediate states.

Var. débilis. Stems slender $\left(9^{\prime}-18^{\prime}\right.$ high $)$; heads green, 3-6-flowered in a loose panicle; flowers smaller $\left(1 !^{\prime \prime}-1 \frac{1}{\prime \prime}\right.$ long); pod longer than the sepals. (.J. debilis, Gray, in former editions.) - Wet sandy soil, New Jersey to Kentucky and southward. - Stems sometimes decumbent and rooting.

Var. robústus. Stems stout, tall, $\left(2^{\circ}-4^{\circ}\right.$ high $)$, bearing numerous $5-8$ flowered light-brown heads in a large much-branched panicle; flowers small (1" $-1 \frac{1}{6} "$ long); ovoid pod scarcely longer than the sepals. - Deep swamps in the Mississippi Valley, from Illinois southward.

Var. legítimus. Stems slender $\left(1^{\circ}-2^{\circ}\right.$ long), bearing fewer and larger heads in a very loose spreading panicle; flowers 5-12 and often more in a head (11" 12 - $2^{\prime \prime}$ long); scpals as long as the straw-colored or light-brown pod. (J. acuminatus, Michx. J. paradóxus, E. Meyer. J. fraternus, Kunth. J. subverticillàtus, Mulll. J. Pondii, Wood.) - Comınon in wet places from S. New England southward and westward. - Ileads often proliferous in the autumn.

$$
+++ \text { Heuds few, crowded, of numerous flowers. }
$$

* Stamens 6.

22. J. nodòsus, L. Stem erect $\left(6^{\prime}-15^{\prime}\right.$ high), slender from a creeping thread-like and tuber-bearing rootstock, mostly with 2 or 3 slender leaves; heads few or several, rarely single, 8 -20-flowered $\left(3 \frac{1}{2} "-4^{\prime \prime}\right.$ wide), overtopped by the involucral leaf; flowers brown $\left(1 \frac{1}{2} \prime-2^{\prime \prime}\right.$ long) ; sepals lance-linear, awlpointed (the 3 outer mostly a little shorter), nearly as long as the slender triangular taper-pointed 1-celled pod; anthers oblong, shorter than the filament; style very short; sceds (about f' long.) obovate, abruptly mucronate. (J. Rostkovii, E. Meyer.) - Swamps and gravelly banks, from New England and Pennsylvania north and northwestward. July, Aug. - A very tall form ( $2^{\circ}$ high) occurs on the islands above Niagara, G. W. Clinton.

Var. megacéphalus, Torr. Stem stout $\left(1^{\circ}-3^{\circ}\right.$ high $)$, with thick leaves; heads few and large $\left(6^{\prime \prime}-8^{\prime \prime}\right.$ wide) $30-80$-flowered ; flowers pale green $\left(2 j^{\prime \prime}-\right.$ 23्9" long); onter sepals longer than the inner ones; anthers linear, shorter than the filanents. - From Western New York west and southweptward. Aug. An intermediate form, with numerous green heads in a compound panicle, occur's in Michigan and Northern Illinois.

\section{+ Stumens 3 .}

23. J. brachycárpus, Engelm. Stem erect $\left(1^{\circ}-2 \frac{1}{2}^{\circ}\right.$ high $)$, rigid from a thick white horizontal rootstock, bearing about 2 leaves and 2-10 densely flowered spherical heads $\left(t^{\prime \prime}-5\right)^{\prime \prime}$ wide) in a slightly spreading crowded panicle much exceeding the involucial leaf; flowers pale green (2" long); sepals lancelinear, uwl-pointed, the 3 outer much longer, and the ovoid pointed l-celled pod ruther shorter, than the inner sepals; anther's much shorter than filaments; style very short; seeds ( $\frac{1}{5}$ " long) abruptly apiculate, ribbed-reticulated. - Moist places in open woods and prairies, Ohio to Michigan, Illinois and southward May, June. 
24. J. scirpoldes, Lam. Stem erect $\left(1^{\circ}-3^{\circ}\right.$ high $)$, rigid, from a thick white horizontal rootstock, bearing about 2 leaves with wide and open sheaths, and a panicle of few or many densely-flowered pale-green splicrical hends much longer than the involucral leaf; sepals rigid, awl-shaped and (especially tho outer) bristly pointed, at length pungent, nearly equalling the oblong-triangular taper-pointed 1-celled porl; seeds ovoid, abruptly pointerl at each end, ribbedreticulated. (J polycćphalus, Michx.) - The following forms belong here.

Var. macrostemon. Rather slender; leaves terete; branches of the panicle ereet and often elongated; heads smaller ( $32^{\prime \prime}-4^{\prime \prime}$ wide), $15-40$-flowered; flowers $1 f^{\prime \prime}-1 f^{\prime \prime}$ long; outer sepals mostly longer than the inner, ns long as the stamens; anthers very small; scerls f"long. (J. cchinàtus, Muhl. J. macrostemon, (iay.) - Wet sandy soil, from Staten Island ( C. F. Austin) southward near the const.

Var. echinatus. Stouter; leaves terete; branches of the compact panicle short; heals larger (5" -6 " wide), 40-80-flowered; flowers (13" - 2" long); sepals narrower and more sharply pointed, the outer a little longer than the inner ones; stamens shorter and anthers longer than in the preceding, and scels rather smaller and more slender. (J. echinatus, Ell.) - From Maryland southward.

Var. polycéphalus. Much stouter; leaves laterally flattened ( $3^{\prime \prime}-6^{\prime \prime}$ wille); panicle spreading, branched, bearing many distant heads as large as those of the foregoing form ; flowers $2^{\prime \prime}-2 f^{\prime \prime}$ long; the 3 outer sepals the longer; unthers about as long as "the filaments; seeds larger ( $\frac{1}{3}$ " long). (J. polycephalus, Ell., Chapm.) - From North Carolina southward; and may be looked for in Southern Virginia.

* Sects trilid.

- Stumens 3.

25. J. Canadénsis, J. Gny. 'Tuftel stems erect, terete, smooth, bearing 2-3 leaves; heals few- or many-flowered, paniculate; sepals lanceolate, the 3 outer shorter than the inner ones, not much longer than the stamens, equal to or shorter than the triangular prismatic almost 1-celled usually short-pointed pod; style mostly short; seeds more or less distinctly tail-pointed, delicately many-ribhed. - Common in most districts. Ang., Sept. - One of the latest flowering species, and thus casily distinguished, even when quite immature, frum the similar but early J. acuminatus. This very variable species comprises the following forms.

Var. longicaudàtus. Stem stont and rigid $\left(1 \frac{1}{2}-3^{\circ}\right.$ high $)$, hearing in a decompound somewhat spreading panicle the numerous 5-50-flowered heals; flowers greenish or light brown (1 $\frac{1}{2} "-2^{\prime \prime}$ long); sepals awl-pointed mostly shorter than the abruptly short-pointed pod ; seeds slender (23" - 1" long), conspicuously tail-pointed. (J. paradoxus, Ed. 1 \& 2, Chapman, \&c.) - From S. New England southward along the const, and westward to Wisconsin and Northern Illinuis.

Var. subcaudàtus. Stem slender, often decumbent $\left(1^{\circ}-2^{\circ}\right.$ high), bearing in simpler spreading panicles fewer 8 -20-flowered heads; flowers greenish, as large as last; sepals awl-shaped, but not so rigid; pod mostly tapering; seeds 
large ( $2^{\prime \prime}-z^{\prime \prime}$ long), with short white membranaceous appendages. - From S. New England southward, especially in New Jersey. - Often confounded with forms of No. 21, from which it is readily distinguished by the large, delicately ribbed and not reticulated, appendaged seeds, and by the proportion of the inner and outer sepals.

Var. brachycéphalus. Stem slender $\left(12^{\circ}-22^{\circ}\right.$ high $)$, bearing numerous small and 3-5-flowered heads in a large and spreading panicle; flowers greenish or light brown $\left(14^{\prime \prime}-1 \frac{1}{2}{ }^{\prime \prime}\right.$ long $)$; sepals mostly obtuse, shorter than the brown abruptly short-pointed pod; style longer than in other forms; seeds smaller ( $f^{\prime \prime}-f^{\prime \prime}$ (ong), slender, with rather short appendages. - From Pennsylvania northwestward to Illinois and Wisconsill. - Sometimes confounded with No. 18, and with small-flowered forms of No. 21.

Var. coaretàtus. Stem slender, shorter $\left(9^{\prime}-18^{\prime}\right.$ high $)$, bearing fewer deepbrown 3-5-Howered heads in a somewhat erect contracted panicle; flowers as large as in the last; sepals acute, or rarely obtusish, much shorter than the prismatic abruptly pointed decp-brown pod; seeds as in the last, (J. acuminatus, Ed. 2, and of most American authors, but not of Michaux). - New England to Wisconsin and northward, southward to the mountaius of Pennsylvania.

+- Stamens 6.

26. J. asper, Engelm. Stems tufted, erect $\left(2^{\circ}-3^{\circ}\right.$ high $)$, terete, stout, rigid, and with the rigid leaves rough; panicle with rigid slightly spreading branches, bearing scattered lew- (2-6-) flowered heads; flowers greenish with brown ( $2 \frac{1}{2} "$ long) ; sepals ovate-lanceolate, awl-pointed, rigid and strougly nerved, the outer much shorter than inner ones, these a little shorter than the triangular-ovoid beaked incompletely 3-celled brown pod; ovary tapering into a conspicuons style; seeds large, oblong, delicately many-ribbed, with white or of ten reddish ilppendages (1 f" long). - Sphagnous swanps, New Jersey, Pickering, C. E. Similh. August.

\section{Order 123. Pon'tederiàcea. (Pickerel-weed Family.)}

Aquatic herbs, with perfect more or less irregular flowers from a spathe; the petal-like 6-merous perianth free from the 3-celled ovary; the 3 or 6 mostly unequal or dissimilar stamens inserted in its throat. - Perianth with the 6 divisions colored alike, imbricated in 2 rows in the bud, the whole togrether sometimes revolute-coiled after flowering, then withering away, or the base thickened-persistent and enclosing the fruit. Anthers introrse. Ovules anatropous. Style 1: stigma 3-lobed or 6-tootherl. Fruit a perfectly or incompletely 3-celled many-seeded pod, or a 1-celled 1-seeded utricle. Embryo slender, in floury albumen.

1. Pontederia. Perianth 2 -lipped, its fleshy persistent base enclosing the 1-seeded utricle. Stamens 6. Spike many-flowered.

2. Heternuthera. Periunth salver-shaped, withering-fugacious. Pod many-seeded Stancus 3, unequal, of 2 forms. Spathe 1 - few-flowered.

3. Sehollesa. Porianth alvor-shuped, regular. Slasions 8, uliko. Spatlis 1-towerod. 


\section{PONTEDERIA, L. Pickerel-wed.}

Perianth funnel-form, 2-lipped; the 3 upper divisions united to form the 3 lobed upper lip; the 3 lower spreading, and their claws, which form the lower part of the curving tube, more or less scparate or separable down to the base: after flowering the tube is revolute-coiled from the apex downwards, and its fleshy-thickened persistent base encloses the fruit. Stamens 6 ; the 3 anterior exserted on elongated filaments; the 3 posterior (often sterile or imperfect) with very short filaments, unequally inserted lower down : anthers oval, blue. Ovary 3-celled; two of the cells empty, the other with a single suspended ovule. Utricle 1-celled, filled with the single seed. - Stout herbs, growing in shallow water, with thick ereeping rootstocks, producing erect long-petioled mostly heartshaped leaves, and a 1-leaved stem or scape, terminated by a spike of violetblue ephemeral flowers. Root-leaves with a sheathing stipule within the petiole. (Dedicated to Pontedera, Professor at Padua at the beginning of the last century.)

1. P. cordata, L. Lcaves arrow-heart-shaped, blunt; spike dense, from a spathe-like bract. - Var. A NGustrfòla (P. angustifolia, Pursh) has triangular-elongated and tapering leaves scarcely heart-shaped at the base. - Common. July-Sept. - Calyx-tube in fruit crested with 6 toothed ridges. Upper lobe of the perianth marked with a pair of small yellow spots.

\section{HETERANTH É RA, Ruiz \& Pav. Mud-Plantain.}

Perianth salver-form with a slender tube ; the limb somewhat equally 6-parted, ephemeral, soon withering or decaying. Stamens 3 ; the 2 posterior filaments thickened in the middle and bearing ovate (yellow) anthers; the other longer, bearing a larger oblong or arrow-shaped (greenish) anther. Pod incompletely 3-celled, many-secded. - Creeping or floating low herbs, in mud or shallow water, with chicfly rounded long-petioled leaves, and a 1 - few-flowered spathe bursting from the sheathing side or base of a petiole. Flowers blue or white,

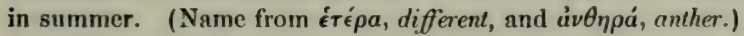

1. H. renifórmis, Ruiz \& Pav. Leaves round-kidney-shaped; spathe 3-5flowered; flocers white. - Connecticut to Illinois, and southward.

2. H. limòsa, Vahl. Leaves oblong or lance-oblong, obtuse at both ends; spathe 1-flowered; flowers blue. (Leptánthus ovàlis, Michx.) - W. Virginia to Illinois, and sonthward.

\section{SCH}

Perianth salver-form, with 6 nearly equal lance-linear divisions on a very long thread-like tube. Stamens 3, with similar oblong-arrow-shaped anthers (or rarely $a$ fourth which is abortive) : filaments nearly equal, awl-shaped. Pod oblong, invested by the withered perianth, 1-celled with 3 projecting parietal placentæ, many-seeded. - $\mathbf{\Lambda}$ grass-like herb, like a Pondweed, growing wholly under water, only the (small palc-yellow) flowers reaching the surface; the slender branching stems clothed with linear translucent sessile leaves, and bearing a terminal 1-flowered spathe : in summer. (Named after one Scholler, a German botanist.)

1. S. gramínea, Willd. (Leptánthus, Michx.) - In streams : common. 


\section{Order 124. Commelynìcefe. (Shiderwott Family.)}

Herbs, with fibrous or somelimes thickened roots, jointed and oflen branching leafy stems, and chiefly perfect and 6-androus, oflen irregular flowers, with the perianth free from the 2-3-celled ovary, and having a distinct calyx and corolla, viz.: Sepals 3, persistent, commonly herbaceous. Petals 3, ephemeral, decaying or deciduous. Stamens hypogynous, some of them often sterile: anthers with 2 separated cells. Style 1 : stigma undivided. Pod 2-3-celled, 2-3-valved, loculicidal, 3-several-seeded. Seeds orthotropous. Limbryo small, pulley-shaped, partly sunk in a shallow depression at the apex of the albumen. Leaves ovate, lanceolate or linear, paralletveined, flat, sheathed at the base; the uppermost often diss.milar and forming a kind of spathe. - A chiefly tropical family, not aquatic, here represented only by two genera.

\section{COM M EL Y N A, Dill. DaY-FLower.}

Flowers irregular. Sepals somewhat colored, unequal; the 2 lateral partly united by their contiguous margins. Two lateral petals rounded or kidneyshaped, on long claws, the odd one smaller. Stamens unequal, 3 of them fertile, one of which is bent inward : 3 of them sterile aud smaller, with inperfect cross-shaped anthers: filaments naked. Pod 3-celled, two of the ectls 2-seeded, the other 1 -seeded or ahortive. - Stems branching, often procumbent and rooting at the joints. Lcares contracted at the base into sheathing petioles; the floral one heart-shaped and clasping, folded together or hooded, forming a spathe enclosing the flowers, which expand for a single morning abd are recurved on their pedicel betore and afterwards. Petals blue. Flowering all summer. Ours all with peremial roots, or propagating by striking root from the joints. (1)elicated to the carly I)utch botanists $J$. and (i. Commelyn.)

1. C. erécta, L. Stem erect, rather stout $\left(2^{\circ}-4^{\circ}\right.$ high $)$; leaves large $\left(3^{\prime}-7^{\prime}\right.$ long, $1^{\prime}-2^{\prime}$ wide), oblong-lanceolate, the upper surface and margins rough backwards, sheuths fringed with rusty bristles; sputhes crowded and nearly sessile, hoodtd, lop-shaped in frinit; odd petal like the others but smaller, roundovate raised on a claw; pod 3.celled. (C. Virginica, Ed. 1. A hairy form is (: hirtella, Fahl.) - Alluvial and shaded river-banks, Penn. to Illinois and southward. - Our largest species, and the only one with a top-shaped spathe.

2. C. Virgínica, L. Stems slender, erect, or reclined and rooting towards the base; leaves oblong- or lincas-lanceolate; spulies mostly solitary or scattered, peduncled, condeplicule, round-hort-shaped when expanded, pointed, in fruit somewhat hood-like; vid petal usually inconspicuous and nearly sessile; pod 2-celled. (C. Virginca, L., as to syn. l'luk., which gave the name: Linnaus's detailed description apparently pertains to No. 1, which however must bear the name which he took from Dillenius, the authority for the species. C. angustifolia. Michx, is a narrow-leaved form.) - 1)amp rich woods and banks, S. New York to Michigan, Illinois, und southward.

3. C. Cayennénsis, lichard. Stems creeping, glabrous; lenves orateblong or lance-ublony, olluse, small ( $1^{\prime}-2^{\prime}$ long); spathes heart-uvate when ex- 
panded, pedincled, conduplicate, the luse not contracted in finit, 3-4-flowered; the odd petal round-ovnte, nearly sessile. (C. ngrària, Kunth.) - Alluvial banks, Illinois and southward. - The smallest-leaved and smallest-flowered species.

\section{TRA DESCÁ NTIA, L. SPIDERTort.}

Flowers regular. Sepals herbaceous. Petals all alike, ovate, sessile. Sta. mens all fertile: filaments bearded. l'od 2-3-celled, the cells 1-2-seeded. Pereunials. Stems mucilaginous, mostly upright, nearly simple, leafy. Leaves keeled. Flowers ephemeral, in umbelled clusters, axillary and terminal, produced through the summer: floral leaves nearly like the others. (Named for the elder Trudescuint, gardener to Charles the First.)

* Umbels sessile, clustered, usually involucrate by 2 leares.

1. T. Virgínica, L. (СоммоN SPInerwort.) Leaves lance-linear, elongated, tapering from the sheathing base to the point, ciliate, more or less open; umbels terminul, many-fowered. - Moist woods, from W. New York to Wisconsin, and southward: also commonly cultivated. - Plant either smooth or hairy ; the large flowers blue, in gardens often purple or white.

2. T. pilosa, Lehm. Laves broally lunceolate from a narrowed base, pointed, downy-hairy both sides, minutely ciliate; umbels many-flowered, in very dense terminal and axillary clusters; pedicels and calyx glandular-hairy. (T. flexuosa, Raf.) - Ohio, Illinois, Kentucky, and sonthward. - Stem stout, smooth below, $2^{\circ}-3^{\circ}$ high, often branched, zigzag above, forming a close cluster of small ( $8^{\prime \prime}-9^{\prime \prime}$ broad) lilac-blue flowers in all the upper axils.

\section{* Umbels long-peduncled, naked.}

3. T. rosea, Vent. Small, slender $\left(6^{\prime}-10^{\prime}\right.$ high $)$, smooth; leaves linear, grass-like, ciliate at the hase; umbel simple, or a pair; flowers (6" wide) rosecolor. - Sandy woods, Pennsylvania (?) to Kentucky, and southward.

\section{Order 125. XYridacere. (Yellow-eyed-grass Family.),}

Rush-like herbs, with equitant leaves sheathing the base of a naked scape, which is terminated by a head of perfect 3 -androus flowers, with extrorse anthers, glumacenus calyx, and a regular colored corolla; the 3-valved mostly 1-celled pod containing several or many orthotropous seeds with a minute embryo al the apex of fleshy albumen:- represented by Xyris. - But the anomalous genus Mayaca, consisting of a few moss-like aquatic plants, intermediate in character between this family and the last, may be introduced here.

\section{M A Y À C A, Aublet. (SrìnA, Schreber.)}

Flowers single, terminating a naked peduncle. Perianth persistent, of 3 herbaceous lanceolate sepals, and 3 obovate petals. Stamens 3 , alternate with the petals: Orary 1-celled with 3 parietal few-ovuled placentre: style filiform: stigma simple. Pod 3-valred, several-seeded. - Moss-like low herbs, creeping or floating in shallow water, densely leafy; the leaves narrowly linear, sessile 
1-nerved, pellucid, entire, notched at the apex: the peduncle solitary, sheathed at the base. (An aboriginal name.)

1. M. Michaùxii, Schott \& Endl. Peduncles not much exceeding th leaves, nodding in fruit; petals white. (Syena fluviátilis, Pursh.) - S. E. Vir: ginia, and southward. July.

\section{XìrIS, L. Yellow-eyed Grags.}

Flowers single in the axils of coriaccous scale-like bracts, which are densely imbricated in a head. Sepals 3 ; the 2 lateral glume-like, boat-shaped or kecled and persistent; the anterior one larger and membranaccous, enwrapping the corolla in the bud and deciduous with it. Petals 3, with claws, which cohere more or less. Fertile stamens 3, with linear anthers, inserted on the claws of the petals, alternating with 3 sterile filaments, which are cleft and in our species plumose or bearded at their apex. Style 3-cleft. Pod oblong, free, 1-celled, with 3 parietal more or less projecting placenta, 3-valved, many-seeded. - Flowers yellow, produced all summer. Ours apparently all perennials. (Iupis, an ancient name of some plant with 2-edged leaves, firom छupóv, a razor.)

1. X. flexuósa, Muhl., Chapm. Scape slender $\left(10^{\prime}-16^{\prime}\right.$ high $)$, barely flattened at the summit, often from a bulbons base, very smooth, much longer than the narrowly linear leaves, both commonly twisted with age; head roundishovoid (3"-4" long); lateral sepuls oblong-lanceolute, finely ciliate-scarious on the nurrow wingless keel, and usually with a minute bearded tuft at the very apex, shorter than the bract. (X. Jupacai, Michx. in part. X. Indica, Pursh. X. bulbòsa, Kunth, \& Ed. 2.) - Sandy or peaty bogs, from E. Massachusetts southward near the coast; also Illinois, Wisconsin, and Michigan.

Var. pusilla. Small and very slender, seldom twisted, $2^{\prime}-9^{\prime}$ high, the base not bulbous. (X. brevifolia, MIull, in part, \&c., not of Michx.) - From New Jersey and Pennsylvania northward to the base of the White Mountuins and Lake Supcrior. - Ilead $2^{\prime \prime}-3^{\prime \prime}$ long.

2. X. tórta, Smith. Scape terete, with one sharp ellge, slender, $9^{\prime}-20^{\prime}$ high, from a bulbous base, and with the linear-filiform rigid leaves becoming spirally twisted; head ovoid becoming spindle-shaped and acute $\left(5^{\prime \prime}-9^{\prime \prime}\right.$ long); sepals exceeding the bract; lateral sepuls winged on the kcel and firinged above the midtle. - P'ine barrens of New Jersey (near Batsto, D. C. Euton) and in the Southern States : in dry sand.

3. X. Caroliniàna, Walt. Scape flattish, 1-angled below, 2-edged at the summit, smooth, $1^{\circ}-2^{\circ}$ high, the base hardly bulbous ; leaves linear-sucord-shaped, flut; head globular-ovoid (5" $-7^{\prime \prime}$ long); lateral sepals obscurely lacenute-fringed above on the winged keel, rather shorter than the bract. (X. Jupacai, partly, Michx. X. anceps, Mull.) - Sandy swamps, \&c., Rhode Island to Virginia and southward, near the coast.

4. X. fimbriàta, Ell. Scape somewhat angled, 2-edged above, rough $\left(2^{\circ}\right.$ high), rather longer than the lincar-sword-shaped or strap-shaped leaves, the base not bulbons; liead oblong ( $6 "-10^{\prime \prime}$ long); latcral sepuls lanceolate-linear, nearly twice the length of the bract, above the middle conspicuously fringed on the wing-margined keel, and even plumose at the summut. - P'ine barrens of New Jersey to Virginia, and southward. 


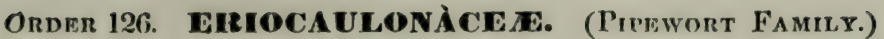

Aquatic or marsh herbs, stemless or short-stemmed, with a tuft of fibrous ronts, a cluster of linear and often lonsely collulur gruss-like leaves, and naked scapes sheatherl at the base, borring dense hends of monocious or ravely diocious small 2-3-merous fowers, each in the axil of a scarious bract; the perianth double or rarely simple, chaffy; anthers introrse; the fruit a 2-3-celled 2-3-seeded pod: the ovules, seeds, embryo, \&c. as in the preceding order. - Chiefly tropical plants, a few in northern temperate regions.

1. Erlocaulon. Perianth double, the inner (cornlln) tubular-funnel-form in the stnminnte flowers ; the stamena twice ns many as ita lobes (4 or 6). Anthers 2-celled.

2. Propalnuthus. Perinnth as in the lnst: the stanevs only as many as the lobes of the Inner series, or corolla (3). Anthers 2-celled.

8. Lachuncaulon. Perianth simple, of 3 sepals. Stamens 3 , monadelphous below. Anthers 1-celled.

\section{ERIOCA ÙLON, L. Pipewort.}

Flowers monœcious and androgynous, i. e. both kinds in the same head, either intermixed, or the central ones sterile and the exterior fertile, rarely diceious. Ster. Fl. Calyx of 2 or 3 kecled or boat-shaped sepals, usually spatulate or dilated upwards. Corolla tubular, 2-3-lobed, each of the lobes bearing a black gland or spot. Stamens twice as many as the lobes of the corolla, one inserted at the base of each lobe and one in each sinus: anthers 2-celled. Pistils rudimentary. Fert. Fl. Calyx as in the sterile flowers, often remote from the rest of the flower (therefore perhaps to be viewed as a pair of bractlets). Corella of 2 or 3 separate narrow petals. Stamens none. Ovary often sta!kerl, 2-3lobel, 2-3-celled, with $\Omega$ single ovule in each cell: style 1 : stigmas 2 or 3 , slender. Pod membranaceous, loculicidal. - Leaves mostly smooth, loosely cellular and pellucid, flat or concave above. Scapes or peduncles terminated by a single head, which is involucrate by some outer empty nracts. Flowers, also the tips of the bracts, \&c., nsually white-bearder or woolly. (Name compounded of Épiov, wool, and kaviós, a stalk, from the wool at the base of the scape and leaves of the original species. Excepting this and the flowers, our species aro wholly glabrous.) - The North American species are all stemless, with a depressed heal, and have the parts of the flowers in twos, the stamens 4.

1. E. decangulàre, L. (syn. Pluk. \&c.) Leaves obtuse, varying from linear-lanceolate to linear-awl-shaped, rather rigid; scapes $10-12$-ribbed $\left(1^{\circ}\right.$ $3^{\circ}$ high; head hemispherical, becoming globular (2" $-7^{\prime \prime}$ wirle); scales of the involucre acutish, straw-color or light brown; chuff (bracts among the flowers) pointed. (E. serótinum, Walt.) - Pine-barren swamps (New Jersey ?) Virginia, and sonthward. July - Sept.

2. E. gnaphalddes, Michx. Leaves spreading $\left(2^{\prime}-5^{\prime}\right.$ long), grassy-awlshaped, rigid, or when submersed thin and pellucid, tapering gradually to a sharp point, mostly shorter than the sheath of the 10-ribbed scape; scales of the involucre very obtuse, turning lead-color; chaff obtuse. (E. decangulare, $L$., in 
part, vir. as to $p l$. Clayt. E. compressum, Lam.) - I'ine-barren swamps, New Jersey to Vi.ginia, and southward. June-Aug.

3. E. septangulàre, Withering. Leuves short $\left(1^{\prime}-3\right.$ ! long), awl-shaped, pellucid, soft and very ccllular; scape 7 -striate, slender, $2^{\prime}-6^{\prime}$ high, or when submersed becoming $1^{\circ}-6^{\circ}$ long, according to the depth of the water; chaff acutish. (E. pellucidum, Michx.) - In ponds or along their borders, from New Jersey and Penn. to Michigan, and northward. Aug. - Head 2"-3" broad; the bracts, chaff, \&c. lead-color, except the white coarse beard. (Eu. Coast of Ireland, \&c. only.)

\section{P开PALÁ NTHUS, Mart. (Sp. of Eriocaulon of authors.)}

Stamens as many as the (often involute) lobes of the funnel-form corolla of the sterile flowers, and opposite them, commonly 3 , and the flower ternary throughout. Otherwise nearly as in Eriocaulon. (Name from $\pi a \iota \pi a ́ \lambda \eta$, dust or flour, and äptos, flower, from the meal-like down or scurf of the heads and flowers of many South American species.)

1. P. flávidus, Kunth. Tufted, stemless; leaves bristle-awl-shaped ( $1^{\prime}$ long) ; scapes very slender, simple, minutely pubescent $\left(6^{\prime}-12^{\prime}\right.$ high $), 5$ angled; bracts of the involucre oblong, pale straw-color, those among the flowers mostly obsolete; perianth glabrous; sepals and petals of the fertile flowers linear-lanceolate, scarious-white. (Eriocaulon flavidum, Michx.) - Low pine barrens, S. Virginia and southward.

\section{I A CH N OCA ÙLON, Kunth. Hairy PIPEwort.}

Flowers monœcious, \&c., as in Eriocaulon. Calyx of 3 sepals. Corolla none! Ster. $F$. Stamens 3 : filaments below coalescent into a club-shaped tube around the rudiments of a pistil, above separate and elongated: anthers 1-celled! Fert. $F l$. Ovary 3-celled, surrounded by 3 tufts of hairs (in place of a corolla). Stigmas 3, two-cleft. - Leaves linear-sword-shaped, tufted. Scape slender, simple, bearing a single head, 2-3-angled, hairy (whence the name from $\lambda \boldsymbol{\lambda a ́}_{\chi}$ vos, wool, and kaviós, stalk).

1. L. Michaùxii, Kunth. (Eriocaulon villosum, Michx.) - Low pine barrens, Virginia (Pursh), and southward.

\section{Order 127. Cypericeate. (Sedge Family.)}

Grass-like or rush-like herbs, with fibrous roots, mostly solid stems (culms), closed sheaths, and spiked chiefly 3-androus flowers, one in the axil of each of the glume-like imbricated bracts (scales, glumes), destitute of any perianth, or with hypogynous urisilles or scales in its place; the 1-celled ovary with a single erect anatropous ovule, in fruit forming an achenium. Style 2-cleft when the fruit is flattened or lenticular, or 3-cleft when it is 3-angular. Embryo minute at the base of the somewhat floury albumen. Stem-leaves when present 3-ranked. - A large, widely diffused fanily. (See Plates 1-6.) 
Tribe 1. SCIRPIN EAG. Flowera normally perfect and alike, rarely mome of them with stamens or pistil abortive : spikes all of one sort.

Subtribe 1. Cyperene. Scales of the spike strictly 2-ranked, conduplicate and keeled (in all our species). Bpikes usunlly nggregnted intn cluaters, heads, umbols. spikes, \&c.

* Flower dentituto of any briatles, nlao of any heak to the achenium.

1. Су perus. Spikes few-many-flowered, usually elongated or slender.

2. Ky llingla. Spises 1-Howered (but of 3 or 4 scales), glonierate in a sessile head.

- Flower furnished with bristles : achenium beaked by the persistent base of the style.

3. Dullchlum. Spikes 6 -10-fluwered, slender, clustered on an axillary peduncle.

Subtribe 2. Sefrpere. Scales of the spike or head imbricated all round, convex or ${ }^{\wedge}$ open, all or nearly all of them with a perfect flower in the axil.

* Flower with one or more inner'scales (either bractlets or perianth).

4. Fuirema. Scales of the spike awned below the apex. Flower surrounded by 3 stalked petal-like scales alternating with 3 bristles.

5. Lpocnrpha. Flower enclosed by 2 inner scales, one next the axis and the other next the awnless scale of the spike. No bristles.

6. Hemlearpha. Flower with a single very minute inner and thin scale next the axis of the spike: no bristles.

* * Flower without inner scales, either wholly naked or with some bristles (perianth).

+ Bristles generally present.

7. Fleocharis. Achenium with a tubercle jointed on its apex, consisting of the bulbous persistent base of the style. Spike solitary, terninating the leafless and bractless culm.

8. ScIrpus. Achenium naked at the apex, or pointed with the continuous simple base of the style. Culms often leafy at the base or apex. Spikes one or more.

9. Erlophorum. Achenium, \&c., as in Scirpus. Bristles after flowering exceedingly lengthened into cottony hairs.

$\leftarrow$ Bristles alwayg none.

6. Hemicnrpha will be looked for here when the minute inner scale is overlooked.

10. Fimbristylis. Style bulbous at the base, or constricted at the junction, deciduous from the achenium (with or rarely without the jointed bulb). Culms leafy at the base, and bracted at the summit, bearing usually several spikes.

Subtribe 3. Rhynchosporeae. Scales of the spike or head imbricated in few or several ranka, some of the lower commonly empty, and of the upper subtending abortive or staminate flowers. No inner acales.

11. Dich romenn. Spikes crowded into a leafy-involucrate head, laterally flattened, the scales more or less conduplicate and kecled. Achenium crowned with a beak or tubercle formed of the enlarged persistent base of the style. No bristles.

12. Rhywehosporn. Spikes terete or flattish, the scales convex, and either loosely enwrapping or regularly imbricated. Achenium crowned with a persistent tubercle or beak, and at the hase commonly surrounded by bristlea.

13. CIndium. Spikes terete, few-fowered, the scales, \&c. as in the preceding. Achenium destitute of tubercle. No bristles.

Tribe II. SCLERINEAF. Flowers monnecious; the staminate and pistillate in the same or in different clustered spikes. Achenium naked, bony or crustaccous, supported on a hardened disk.

14. Selerin. Spikes fow-flowered: lower scales empty. No bristles, \&c.

Tribe III. CA RICIN E RE. Flowers monocious in the eame (androgynous) or in separate spiken, or enmetimes dicecious. Achenium enclosed in a sac (perigynium), which answers to a single or a pair of inner scales or bractlets.

15. Carex. No bristle-form hooked appendage projecting from the sac which encloges the achenium. 


\section{Cy pitrus, L. Galingale. (PI. 1.)}

Spikes many - few-flowered, mostly flat, variously arranged, mostly in clusters or heads, which are commonly disposed in a simple or compound terminal umbel. Scales 2-ranked, conduplicate and keeled (their decurrent base below often forming margins or wings to the hollow of the joint of the axis next below), deciduous when old. Stamens 1-3. No bristles or inner scales. Style 2-3-cleft, deciduous. Achenium lenticular or triangular, naked at the apex.-Culms mostly triangular, simple, leafy at the base, and with one or more leaves at the summit, forming an involucre to the umbel. P'eduncles unequal, shcathed at the lase. All flowering in late summer or autumn. (Kúzєıрos, the ancient uane.)

§1. PYCRĖUS, Beauv. Style 2-cleft: achenium flattcnel: spikes flat, many-flowered: only the lowest scule empty. (Ours all annuals.)

1. C. flavéscens, L. Stumens 3 ; spikes becoming linear, obtuse, clustered on the $2-4$ very short rays (peduncles); scules obtuse, straw-yellow; achenium shining, orticular. - Low grounds, mostly new the coast. - Culms $4^{\prime}-10^{\prime}$ high; spikes $5^{\prime \prime}-8^{\prime \prime}$ long. Involucre 3-leaved, very unequal. (Eu.)

2. C. diándrus, 'Torr. Stamens 2, or sometimes 3 ; spikes lance-oblong, scattered or clustered on the $2-5$ very short or unequal rays; scules rather obtuse, pu'ple-trown on the margins or nearly all over; achenium dull, oblony-obovate: otherwise much like the last. - Var. castaneus, Torr. (C. castaueus, Bigel.) is ouly a form with browner scales. - Low grounds: common.

3. C. Nuttállii, Torr. Stamens 2; spikes lancelinear, acute and very flat $\left(\frac{1}{2}{ }^{\prime}-l^{\prime}\right.$ long $)$, crowded on the few very short (or some of them distinct) rays; srcisis oblong, yellowish-brown, rather loose; achenium oblong-obonute, very blunt, dull. - Salt or brackish marshes, Massachusetts to Virginia, and southward. - Culms $4^{\prime}-12^{\prime}$ high. - C. minimus? Nutt. (C. Cleaveri, Torr.) is a depauperate form of this, with a 1-leaved involucre, and only one or two spikes!

4. C. flavícomus, Michx. Stamens 3 ; spikes linear (4'-9" long), spiked and crowded on the whole length of the branches of the several-rayed umbel, spreading ; scales oncl, very obtuse, yellowish and brownish, broadly scarious(whitish-) margined; achenium obovate, mucronate, blackish; culm stout $\left(1^{\circ}-3^{\circ}\right.$ high); leaves of the involucre 3-5, very long. - Low grounds, Virginia and southward.

§ 2. PAPỲRUS, Thouars. Style 3-cleft: achenium triungular: stumens 3: spikes many-flowercd: the scarious winged margins of the joints of the axis early separating down to the base in the form of a pair of fice scales, which are persistent ufter the proper scule fulls away: othcrwise us in $\S 3$. (Ours annual.)

5. C. erythrorhizos, Muhl. Culm obtusely triangular $\left(3^{\prime}-3^{\circ}\right.$ high $)$; umbel compound, many-rayed; involucre 4-5-leaved, very long; involucels bristle-form; spikes very numerous, crowded in oblong or cylindrical nearly sessile heads or spikes, spreading horizontally, linear, flattish $\left(3^{\prime \prime}-6^{\prime \prime}\right.$ long), bright chestnut-colored ; scales lanceolate, mucronulate. - Alluvial banks, Penn. to Wisconsin? Illinois, and common southward. - Root fibrous, red. 
\$ 3. CYPERUS proper. Style 3-rleft: achonium trianyular: spiks many-fnowered, flat or almost terete; only the lowest scule empty; the joints of the axis wingmargined or naked.

* Stumen only one: spikes short and small $\left(2^{\prime \prime}-3^{\prime \prime}\right.$, or beroming 4" -5 "long), collected in globular heads, ocate or linear-oblong, compactly many-fowered: the scales merely ascending on the naked marginless axis.

- Low annuals: involucre 2-3-leaved: heads few: seales pointed.

6. C. infléxus, Muhl. Dwarf $\left(1^{\prime}-5^{\prime}\right.$ high $)$; spikes oblong lecoming linear, 7-13-flowered, in $\mathbf{1 - 5}$ ovute heads (either sessile and clustered or short-peduncled); scales nerved, tapering into a long recurved point; achenium obovate, obtuse. - Sandy wet shores : common. - Sweet-scented in drying.

7. C. acuminatus, Torr. Slender $\left(3^{\prime}-12^{\prime}\right.$ high $)$; spikes oute, becoming oblong, 16-30-flowered, pale; scules obscurely 3-nerved, short-tippd; achenium oblong, pointed at both ends. - Low ground, Illinois and southwestward.

+ + Tall perennial $\left(1^{\circ}-4^{\circ}\right.$ high $)$ : heads many, greenish: scales pointless.

8. C. vírens, Michx. Culm either sharply or obtusely triangular; leaves and involucre very long, keeled; umbel compound, many-rayed; spikes ovate or oblong; achenium oblong or linear; scales acutish, obscurely 3-nerved. (C. végetus, Torr.) - Wet places, Virginia and southward.

* Stamens 3: spikes 3-10 in a cluster at the summit of the culm or of each ray of an umbel, flat, oblong or linear, the crouded scales ascending, strongly keeled, ovete, with abruptly sharp-pointed slightly-spreading tips: achenium broadly olovate, sharply tringular.

9. C. compréssus, L. Low annual $\left(3^{\prime}-9^{\prime}\right.$ high), wi wh a single sessile or a few umbellate clusters of lineur green spikes (of $6^{\prime \prime}-10^{\prime \prime}$ long, 15-30-flowered), the axis naked. - Sterile ficlds, Somerset Co., Maryland, W. M. Canby (also adventive near Philadelphia Navy Yard), and southward.

10. C. dentatus, Torr. Perennial, with running rootstocks $\left(6^{\prime}-12^{\prime}\right.$ high) ; clusters several or many in a simple or twice or thrice compound umbel ; spikes ovate-oblong and rather few-flowered, or when well-developed linear and 15-30flowered $\left(3^{\prime \prime}-5^{\prime \prime}\right.$ long); the scales reddish-brown with green back; joints of the axis wing-margined. - Sandy swamps, Massachusetts to Northern New York (.I. A. Paine), and sonthward. - Spikes often abortive and changed into leafy tufts as in Juncus.

* * Strmens 3: spilies narrowly linenr, fett, scrillmed along the upper part of the rays of un open simple or somewhint compiound umlel: scales appressed, pointless: joints of the spike wing-margined: perennial by slender rumning rontstocks, which bear smull nut-like tubers, by which the plants multiply pestiferonsly in cultivated grounds.

11. C. rotúndus, L., var. Hýdra. (Nur-Grass.) Culm slender $\left(\frac{1}{2}^{\circ}-1 \frac{1}{2}{ }^{\circ}\right.$ high), longer than the leaves; umbel simple or slightly compound, about equalling the involucre; the few rays each bearing $\mathbf{4}-9$ dark chesinut-purple 12 - 40-flowered acute spikes (5" - 9" long); scales ovate, closely appressed, nerveless except on the keel. (C. Hydra, Michr.) - Sandy fields, Virginia and southward : and adventive near Philadelphia, C. F. Parker. (Eu.) 
12. C. phymatodes, Muhl. Cuhn $\left(1^{\circ}-2 \frac{1}{2}^{\circ}\right.$ high) equalling the leaves; umbel often compound, 4-7-rayed; much shorter than the long iuvolucre; spikes numerous, light chestnut or straw-color, acutish, 12 - 30-Howered ( $4^{\prime \prime}-7{ }^{\prime \prime}$ long) ; scules ablong, narrowly scurious-maryined, nerved, the acutish tips rather loose; acheniun oblong. (C. repens, Ell) - Low grounds, along rivers, \&c., Verinont to Wisconsin, and common southward.

**** Stamens 3: spikes nurrowly linear or slerder-awl-shaped, numerous and densely crowded or spiked on the summit of the ruys of the open simple or sometimes compound umbel, spreading or sometimes reflexed: scales erect-appressed, conduplicate or keeled, pointless: joints of the axis of the spike with scaly-winged margins partly emlrucing the achenium: involucie of 3 to several long leaves: annuals with fibrous roots, or sometimes apparently more or less perennial from a tuberous or bulbous thickened buse: no running rootstocks.

- Spikes flat, becoming straw-color $\left(\frac{1^{\prime}}{2}-1^{\prime}(0 n g)\right.$; the scales strongly conduplicate.

13. C. strigosus, L. Culm mostly stout $\left(1^{\circ}-3^{\circ}\right.$ high $)$; most of the rays of the umbel elongated $\left(1^{\prime}-5^{\prime}\right)$, their sheaths 2 -bristled; spikes 10-25-flowered, scales oblong-lanceolate, several-nerved, much longer than the oblong-linear achenium. - Damp or fertile soil : very common, especially southward. (C. stenólepis, Torr., is of this group and nearly rclated.)

$\leftarrow+$ Spikies slender and rather awl-shaped, almost terete, at least when mature; th: scales less conduplicute and more appressed to the axis.

14. C. Michauxiànus, Schultes. Culm stout, mostly low $\left(5^{\prime}-20^{\prime}\right.$ high $)$; rays of the umbel mostly all short and crowded; spikes 10-20-flowered, yellowishbrown at maturity $\left(3^{\prime \prime}-7\right.$ "long), the short joints of its axis wingod with very broad scaly margins which embrace the ovate triangular achnium; the scales ovate, obtusish, imbricately overlupping. - Low grounds and sandy banks : common. Root truly annual: stem scldom bulbous-thickened at the base.

15. C. Engelmánni, Steud. Rescmbles the foregoing; but the sprikes more slender and terete, somewhat remotely 5-15-flowered, the zigzag joints of the axis slender and narrowly winged, and the oblong or oval broadly scarious scules proportionally shorter, so as to expose a part of the axis of each joint, the successive scales rot reaching the base of the one above on the same side; achenium oblonglinear, very small. (C. tenùior, Enyelm.) - Low grounds and sandy banks, Virginia to Wisconsin and southward : also adventive at the Philadelphia Navy Yard. .

***** Stamens 3: spikes loosely or somewhat remotely 6-12-flowered, flattisn ard greenish, several crowded together in one sessile or in a few peduncled heuds or dense clusters; thir scules viate, convex on the back, many-nervod, applied to and little longer than the ovate or obovate und sharply triangular achenium: perennials, propagating from the hard clustered corms or bulb-like tubers at the base of the culins.

16. C. Schweinitzii, Torr. Culm rongh on the angles $\left(1^{\circ}-2^{\circ}\right.$ high $)$; leaves linear; umbel simple, 4-8-raycd; spikes crouded along the upper part of the mostly elongated rays, erect, loose $\left(4^{\prime \prime}-6^{\prime \prime}\right.$ long) ; scales aul-pointed; joints of the axis narrowly winged. - Dry sandy shores and ridges, from Lake Onturio to Ohio, Illinois, and northwestward. - Flowers rather large. 
17. C. Gràyii, Torr. Culm thread-form, wiry $\left(6^{\prime}-12^{\prime}\right.$ high); lenves almost bristle-shaped, channelled; umbd simple, 4-6-rayed; spikes 5-10 in a loose head, spreading ; joints of the axis winged; scales rather obtuse, gremish-chestnutcolor. - Barren sands, I'lymouth, Mass., to New Jersey, near the coast.

18. C. fllicúlmis, Vahl. Culm slender, wiry, often reclined $\left(8^{\prime}-15^{\prime}\right.$ high); leaves linear (1"-2" wide); spikes numerous and clustered in one sessile dense head, or in 1-7 additional looser heuds on spreading rays of an irregular umbel; joints of the axis naked; scales blunt, greenish. (C. mariscoides, Ell.) Dry sterile soil : common, especially southward.

\$4. MARfSCUS, Vahl. Style 3-cleft: the achenium triungular: stamens 3: spikes 1 -few-flowered, narrow or aul-shaped, with 2 lower scales short and empty, and inclined to persist on the common axis when the rest of the spike disarticulates and falls, croudd in dense hatds: otherwise nearly as in the penul. timate division of $\$ 3$. (Perennials with clustered small tuhers at base of the culms, as in the preceding division: spikes green, merely tawny with age.)

19. C. Lancastriénsis, T. C. Iorter, n. sp. Culm $\left(1^{\circ}-2^{\circ}\right.$ high) triangular; leaves rather broadly linear; umbel of $6-9$ mostly elongated rays; spikes very numerous in short-oblong or glohular dense heads, soon-reflexed, 3-6flowered, linenr-avel-sheped; the joints of the axis broally winged ; seales oblong, obtuse, twice the length of the linear-oblong achenium. - Rich soil, banks of the Susquehanna near Lancaster, Penn., Prof. Porter. - Most like the Southern C. Baldwinii, Torr.; but twice the size; the more numerous spikes 4 " -5 " long, more linear, less pointed, on a setaceous-bracted axis of $6^{\prime \prime}$ or $7^{\prime \prime}$ in length, with longer scales and achenium, \&c.

20. C. ovulàris, Torr. Culm sharply triangular $\left(6^{\circ}-12^{\prime}\right.$ high $)$; umbel 1-6-rayed; spiks $(50-100)$ in a globular very dense head, 2-4-flowered, oblong, blunt $\left(1 \frac{1}{2} "-2^{\prime \prime}\right.$ long); joints of the axis winged; scales ovate, obtuse, a little longer than the ohovate-oblong achenium. - Sandy dry soil, S. New York to Illinois and southward.

21. C. retrofráctus, Torr. Culm and leaves usually minntely downy and rough on the obtusish angles $\left(1^{\circ}-3^{\circ}\right.$ high); umbel many-rayed; spikes slender-awl-shaped, very numerous in obovate or oblong heads terminating the elongated rays, soon reflexed, 1 -2-flowered in the middle $\left(3^{\prime \prime}-5\right.$ "long); scales usually 4 or 5 , the two lowest ovate and empty, the fertile lanceelate and pointed, the uppermost involute-awl-shaped ; achenium lincar. (Scirpus retrofractus, L.) - Sandy fields, New Jersey to Virginia, and southward.

\section{K Y LLÍ NG I A, Rottböll. Krllingia. (PI. 1.)}

Spikes of 3 or 4 two-ranked scales, $1-1 \frac{1}{2}$-flowered; the 2 lower scales minute and empty, as in Cyperus, $\$ 4$, but style oftener 2-cleft, and achenium lenticular: the spikes denscly aggregated in solitary or triple sessile heads. Involucre 3-leaved. (Named after Peter Kylling, a Danish botanist of the 17 th century.i,

1. K. pùmila, Michx. Head globular or 3-lobed, whitish-green (about 4" broad); spikes strictly 1-flowered; upper scales ovate, pointed, rough on the keel; stamens and styles 2 ; leaves linear. - Low grounds, Ohio to Illinois and southward. Aug. - Culms '2'-9' high : root annual. 


\section{DULÍthIUM, Richard. Dulichium. (PI. 1.)}

Spikes many- (6-10-) flowered, linear, flattened, sessile in 2 ranks on axillary solitary peduncles emerging from the sheaths of the leaves: scales 2-ranked, lanecolate, decurrent, forming flat wing-like margins on the joint below. Peri. anth of 6-9 downwardly barbed bristles. Stamens 3. Style 2-cleft above. Achenium flattencel, linein-obloug, beaked with the long persistent style. - A perennial herb, with a turete simple culm $\left(1^{\circ}-2^{\circ}\right.$ high $)$, jointed and leafy to the summit; the leaves short and flat, linear, 3-ranked. ('The name of a Greek island; its singular application to an American plant unexplained.)

1. D. spathàceum, Pers. - Borders of ponds: common. July-Sept.

\section{FUIRE N A, Rottlü̈ll. UMbiklLA-Gikass. (Pl. 2.)}

Spikes many-flowered, terete, clustered or solitary, uxillary and terminal. Scales imbricated in many ranks, awned below the apex, all floriferous. Perianth of 3 ovate or heart-shaped petaloid scales, mostly on elaws, and usually with as many alteruating suall bristles. Stanens 3. Style 3-cleft. Achenium triangular, pointed with the persistent base of the style. Culms from a perennial root, obtusely triamgular. (Named for (r. F'uiren, a I)anish botanist.)

1. F. squarròsa, Michx. Stem $\left(1^{\circ}-2^{\circ}\right.$ high) lealy; leares and sheaths hairy ; spikes ovoid-oblong ( 6 "long), clustered in heads, bristly with the spreading awns of the scales; perianth-scales ovate and awn-pointed, the interposed bristles minute. - Var. l'ùmLA, Torr., is a dwarf form, $1^{\prime}-6^{\prime}$ high, with 2-6 spikes; perianth-seales orate-lanceolate and oblanceolate. - Sandy wet places, Massachusetts to Virginia, and southward; also Michigan: northward mostly the sinall variety. Aug.

\section{I I POCÁ RPHA, R. Br. Lirocarya. (Pl. 2.)}

Spikes terete, many-flowered, in a terminal close cluster, which is involucrate by leafy bracts. Scales spattulate, regularly imbricated all round in many ranks, awnless, deciduons, a few of the lowest empty. Inner seales (bractlets) 2 to each flower, thin, one between the scale of the spike and the flower, one butween the latter and the axis of the spike. Bristles or other perianth none. Stamens 1 or 2. Siyle 2-3-clelt. Achenium flattish or triangular, naked at the tip. -

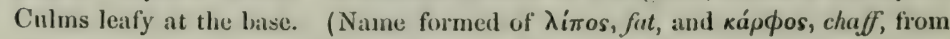
the thickness of the inner scales of some species.)

1. L. maculàta, 'Torr. Annual; culm ( $t^{\prime}-8^{\prime}$ ligh $)$ much longer than the linear concave leaves; spikes ( $1^{\prime \prime}-2^{\prime \prime}$ longr green and dark-spotted ; inner scales delicate; stamen one; achenium oblong with a contracted base. - Petty's Island, Philadelphia, I'rof. Leidy, frc. P'robably adventive from S. States.

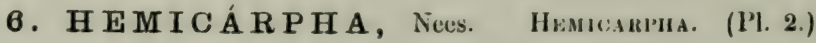

Spike, flowers, \&c. just ats in Siripus, exeept that there is a minute trans lucent scale (realily overlooked) letween the flower and the axis of the spike. Stamen only one. Style 2-cleft. Bristles or other perianth none. (Name from

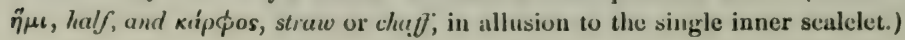


1. H. subsquarròsa, Necs. Dwarf or minute annual $\left(1^{\prime}-5^{\prime}\right.$ high); involucre 1-leaved, as if a continuation of the bristle-like culm, and usually with another minute leaf; spikes 2-3 (barcly 2" long); senles brown, tipped with a short recurved point. (Scirpus subsejuarosus, Mhhl.) - Snndy borders of ponds and rivers; often growing with Cyperus inflexus. July-Sept. - Var. Drummóndu (H. Drummondii, Necs.) is a form with single and paler or greenish heads: Illinois and southward.

\section{ELEÓCHA RIS, R. Br. SPIKe-Rush. (Pl. 3.)}

Spike single, terminating the naked culm, many-several-flowered. Scales imbricated all rond in many (rarcly in 2 or 3 ) ranks. Perianth of $3-12$ (commonly 6) bristles, usually rough or barbed downwards, rarely obsolete. Stamens 3. Style 2-3-cleft, its bulhous base persistent as a tubercle, which is jointed with the apex of the lenticular or triangular achenium. - Teafless, chicfly perennial, with tufted culms sheathed at the base, from matted or creep-

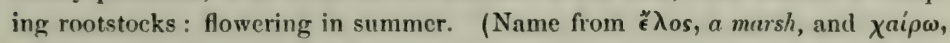
to delight in ; being marsh plants.)

\$1. Spike terete, hardly if at all thicker than the spongy-collular culm; the scales firmly persistent: style mostly 3-cleft : bristles of the periuth 6 (rarely 7 ), firm or rigid, mostly barbed downwardly, and equalling or surpassing the triangular or double convex achenium.

* Spike linear or lanceolate-awl-shaped, few-flowerd; the scales (only 3-9) few. ranked, convolute-clasping the long fattened joints of the axis, lanceolate, herbaceous (green) and several-nerved on the back, and with thin scarious margins.

1. E. Robbinsii, Oakes. Flower-bearing culms exrclly triangular, rather stout, erect $\left(8^{\prime}-2^{\circ}\right.$ high), also producing tufts of capillary abortive stems or fine leaves, which float in the water; sheath oblicuely truncate; acheniun oblong-obovate, triangular, minutely reticulated, about half the length of the bristles, tipped with a flattened awl-shaped tubercle. - Shallow water, from Pondicherry Pond, New Hampshire (Robbins), to New Jersey (C. E. Smith, \&c.), and southward. - Spike varying from 4 " to $10^{\prime \prime}$ long, by scarcely over a line wide; the long scales rather remote and sheath-like.

* * Spike cylindrical and many-flovered, 1'-2' lomg; the scales regulurly imbricated in several ranks, firm-coriaceous with a narrow scarious margin and no midril, pale, nerveless or fuintly striate: culms large and stout $\left(2^{\circ}-4^{\circ}\right.$ high $)$ : sheaths at the brase often leaf-bearing. (LinNócnLos, Nees.)

2. E. equisetoldes, Torr. Culm terete, knotted as if jointed by many cross partitions; achenium smooth, with a conical-beaked tubercle. - Shallow water, Rhode Island (O/ney), Michigan (Houghton). Delaware, and southward.

3. E. quadrangulàta, R. Br. Culm contimuous and sharply 4-angled; achenium fincly reticulated, with a conical fattened distinct tubercle. - Shallow water, New York (outlet of Oneida Lake, A. H. Curtiss) to Michigan and southward : rare.

\$2. Spike terete and Iurgid-orute, rery much thicker than the slender culm; the scales thin-coriaceous or firm-membranacoous and persistent, ovate : style 3 -clefl : bristles 
of the perianth stout, downwardly barbed, as long as the striated and pitted-reticulated triungular achenium and its tubercle; culms tufted from fibrous roots, about $1^{\circ}$ high.

4. E. tuberculosa, R. Br. Culms flattish, striate; spike $3^{\prime \prime}-6$ " long, many-flowered; tubercle fluttish-cap-shaped, as large us the body of the achenium. - Wet sandy soil, Mass. along the coast to Virginia and southward.

5. E. símplex, Torr. Culus sharply triangular, cupillary, twisting when dry; spike $2^{\prime \prime}-3^{\prime \prime}$ long, few-flowered; conical-beaked tubercle much smaller than the achenium. (E. tórtilis, S'chultes.) - Eastern shore of Maryland ( $\boldsymbol{W} . \boldsymbol{M}$. Cunby), and southward.

§ 3. Spike terte, much thislier then the rulm, nany-flowered; the scales imbricaled in meny or more then there renks, thin-membranaceous or scerious in texture, with a thicker midizb, usiully brownish or purplish, sometimes deciduous at muturity. (Elkógenus, Nees.)

* Achenium smooth and lenticular, and style 2-cleft, or in No. 6 more conmonly 3-cleft: culms slender or thread-form, terete or compressed.

6. E. obtùsa, Schultes. Culms nearly terete, tuited $\left(8^{\prime}-14^{\prime}\right.$ high) from fibrous roots ; spike glolsosp-ovoid and with age oblony, obtuse, rarely becoming acute (dull brown); the scales very obluse and numerons $(80-130)$, densely crowded in mony ranks; style 3 - (rarcly 2-) clef ; achenium olsovate, shining, tumid-margined, about half the length of the $6-8$ bristles, crowned with a short and very broad flattened tubercle. - Muddy places : most common.

7. E. olivàcea, Torr. Culms flattish, grooved, diffusely tufted on slender matted rootstocks $\left(2^{\prime}-4^{\prime}\right.$ high $)$; spike ovate, acutish, $20-30$-flowered ; scules ovate, obtuse, rather loosely imbricated (purple with a green midrib) and slightly scarious margins); achenium obovate, dull, abruptly beaked with a narrow tubercle, shorter than the 6-8 lristles. - Wet sandy soil, Mass. to New Jersey near the coast, and southward: also shore of Lake Ontario, J. A. Paine.

8. E. palústris, R. Br. Culms nearly terete, striate $\left(1^{\circ}-2^{\circ}\right.$ high), from running rootstocks; spike oblong-lanceolate, pointed, many-flowered; scales ovateoblong, loosely imbricated in several ranks, reddish-brown with a broad and translucent whitish margin and a greenish keel, the upper acutish, the lowest rounded and often enlarged; achenium obovate, somewhat shining, crowned with a short ovate or ovate-triangular flattened tubercle, shorter than the usuaily 4 bristles. - Var. gLaucéscens (S. glaucescens, Willd.!) : culms slender or filiform; tubercle narrower and acute, beak-like, sometimes half the length of the achenium. - Var. cflvA (E. calva, Torr.): bristles wanting; tubercle short, nearly as in the true E. palustris, but rather narrower (Watertown, New York, Dr. Crawe). - Very common, either in water, when it is pretty stout and tall; or in wet grassy grounds, when it is slender and lower. (Eu.)

9. E. compréssa, Sullivant. Culins flut, striute, erect $\left(1^{\circ}-2^{\circ}\right.$ high $)$; spike ovate-ublony, or at length lanceolate, $20-30$-flowered $\left(t^{\prime \prime}-7^{\prime \prime}\right.$ long); scales lancoolate-ovate, acute, dark purple with broad white pellucid margins and summit; achenium oborcte-peur-shaped, compressed, crowned with a small conical and pointed tubercle; bristles 1-4, very slender, fragile, shorter than or equalling the achenium, sometimes none or a single rudiment.) - Wet places, N. New York 
to Ohio and Illinois. - Culms tufted on running rootstocks, strikingly flat, often spirally twisted in drying.

* Achenium truangular or turgid: style 3-cleft.

+ Brisiles equalling or surpussing the smonth acheniun, downwardly luvbed, persistent.

10. E. rostellàta, 'Torr. Culms futtened and striute-grooved, wiry, crect $\left(1^{\circ}-22^{\circ}\right.$ high), the sterile ones reclining, rooting and moliferous from the apex $\left(1^{\circ}-2^{\circ}\right.$ high $)$, the sheath transversely truneate; spike spindle-shuped, $12-20$ flowered; scales ovate, obtuse (light-brown); achenium obovate-triangular, narrowed into the confluent pyramidal tubercle, which is overtopped by the 4-6 bristles. - Marshes, Rhode Island (Olney), E. Massachusetts (W. Boott), and Vermont (Tiukerman) to New Jersey (Dr. Allen), Alexandria, Virginia ( $A$. H. Curtiss), Michigan and southward.

11. E. intermedia, Schultes. Culms capillary, wiry, striate-grooved, densely tufted from fibrous roots, diffusely sprending or reclining $\left(6^{\prime}-12^{\prime}\right.$ long); spike oblong-ovate, acutish, loosely 10-20-flowered ( $2^{\prime \prime}-3^{\prime \prime}$ long); scales oblong, obtuse, green-kceled, the sides purplish-brown; achenium obovoid with a narrowed base, beaked with a slender conical-awl-shaped distinct tubercle, which nearly equals the 6 bristles. (E. reclinàta, Kunth.!) - Wet slopes : common from New York and Penn. to Illinois and northward.

12. E. microcárpa, Torr., var. Filicúlums, Torr. Like the preceding, but more capillary and heads smaller $\left(1 \frac{1}{2}{ }^{\prime \prime}-2^{\prime \prime}\right.$ long), sometimes proliferous, the one or more short new culms from the axil of its lowest scale, which persists as un herbaccous bract; achenium very much smaller, with sharper angles and a short conicul tubercle, which is hardly equalled by the 3-6 slender bristles. Wet pine barrens, New Jersey and southivard.

++ Bristles 2-4, shorter than the achenium, slender and fragile, or none.

13. E. ténuis, Schultes. Culms almost capillary, erest from running rootstocks, 4-angulur and flattish ( $1^{\circ}$ high), the sides concave; spike elliptical, acutish, 20-30-fowered ( $3^{\prime \prime}$ long); scules ovate, obtuse, chestnut-purple with a broad scarious margin and green keel; achenium obovate, roughish-wrinkled, crowned with $a$ small depressed tubercle, persistent after the fall of the scales; bristles half the length of the achenium, or wanting. (E. elliptica, Kunth.!) - Wet meadows and bogs: common, early-flowering; June.

14. E. melanocárpa, 'Torr. Culms flattened, grooved, wiry, erect $\left(9^{\prime}-\right.$ $18^{\prime}$ high); spike cylindricul-mnid or oblning, thick, obtuse, densely many-flowered ( $3^{\prime \prime}-6^{\prime \prime}$ long) ; scales closely many-ranked, roundish-ovatc, very obtuse, brownish with broad scarious margins: achenium smooth, obovate-top-shaped, obtusely triangular, the broad summit entively covered like a lid by the flat depressed tubercle, which is raised in the centre in to a short abrupt triangular point; bristles shorter than the (soon blackish) achenium, often ohsolete. - Wet sand, Plymouth, Massachusetts, to Virginia, and sonthward along the const.

15. E. tricostata, Torr. Culms fattish $\left(1^{\circ}-2^{\circ}\right.$ high); spike soon cylindrical, densely many-flowered ( $6^{\prime \prime}-9^{\prime \prime}$ long, thickish ; scales ovate, very obtuse, rusty brown, with hroad scarions margins; arhenium obovate, with 3 prominent thickened angles, minutely rough-vrinkled, crounod with a short-ronical acuto tubercle; bristles none. - Quaker Bridge, New Jersey (Knieskern), and southward. 
\$ 4. Spike more or less flattened, thicker than the slender or cupillary culm, few-manyflowered; the thin inembranuceous scales somewhat 2-3-ranked: style 3-cleft: bristles of the periunth 3-6, frayile or fingacious. Simall or delicate species, dif: fering from the last subdivision chiefly in the flattish spikes. (Cижrocro'ènus, Nees.)

* Achenium tumid, olscurely triangular, many-rilbed on the sides.

16. E. aciculàris, $\mathrm{R}$. Br. Culms finely capillary $\left(2^{\prime}-8^{\prime}\right.$ long), more or less 4-angular; spike 3-9-flowered; scales ovate-olblong, rather obtuse (greenish with purple sides); achenium obovate-oblong, with 3 -ribbed ungles and 2-3 times as many smaller intermediate ribs, also transversely striate, longer than the 3-4 very fugacious bristles; tuberele conical-triangular. (S. trichooles, Muhl., \&c.) - Muddy shores : common. (Eu.)

* * Achenium triangular, with smooth and even sides.

17. E. pygmæiea, Torr. Culms bristle-like, flattened and grooved $\left(1^{\prime}-2^{\prime}\right.$ high); spike ovate, 3-8-flowered; scales ovate (greenish), the upper rather acute; achenium ovoid, acutcly triangular, smooth and shining, tipped with a minute tubercle; bristles mostly longer than the fruit, sometimes wanting. (S. pusíllus, Vahl ?) - Brackish marshes and brackish river-banks.

\section{SCÍr PUS, L. Bulrush or Club-Rush. (Pl. 3.)}

Spikes several-many-flowered, solitary or in a terminal cluster which (except in No. 1) is subtended by a 1 -several-leaved iuvolucre (this when simple often appearing like a continuation of the culm), terete, the seales being regularly imbricated all round in many or several ranks, or rarely somewhat compressed, the fewer scales inclining to be 2-ranked. Flowers under all the scales, or all but one or two of the lowest, all perfect. Perianth of 3-6 (straight or rarely tortuous) bristles, or sonctimes wanting. Stamens mostly 3. Style 2-3-cleft, simple, not bulbous at the base, wholly deciduous, or sometimes leaving a tip or point to the lenticular or triangular achenium. - Culns sheathed at the base; the sheaths usually leaf-bearing. Perennials, except No. 8-9; flowering in summer. (The Latiu name of the Bulrush.)

§ 1. SCIRPUS proper (including IsóxepIs, which simply wants the bristles). Bristles when present vigid, not elonguted and contorted or exserted after flowering, mostly barbed downwards.

* Spike solitary, few-flowered, small, often flatlish: achenium trianyular, smooth.

+ No involucral leaf or bract and no lanes below: base of st!yle indurated and persistent, but continuons with the achenium. (Thrunsition to Eleocharis and Blysmus.)

1. S. pauciflorus, Lightfoot. Culms striate-angled, very slender $\left(3^{\prime}-9^{\prime}\right.$ high), scareely tufted, on slender running rootstocks, at the base with a short truncate sheath; scales of the ovate spike evidently 2-ranked, chestnutbrown, pointless, all fower-hearing, the two lower larger; bristles 3-6, downwardly bathed, abut the length of the conspicuously leak-pointed triangular achenium. (S. Bacothryon, Ehh. Blysums pauciflorus, Caruel.) - Very wet places, New York (Jefferson Co., Dr. Crume, \& IIcrkiner Co., J. A. Paine) to N. Illinois ' $D$. Visey), Michigan, and northwestward. (Eu.) 
+ + Involucre a short aul-shaped bract: culms tufted (3-12' high), filiform.

2. S. cæspitosus, L. Culms terete, wiry, densely shenthed at the base, in compact turfy tufts; the upper shenth bearing a very short awl-shaped leaf; spike ovoid, rusty-color; involueral brnet a rigid-pointed scale, resembling the lowest proper scale of the spike and scarcely surpassing it ; bristles 6, smooth, longer than the abruptly short-pointed achenium. - Alpine tops of the mountains of Maine, New Hampshire, and N. New York. On Roan Mountain, N. Carolina. Also, away from mountains, Bergen Swamp, Genesee Co., New York, G. W. Clinton, J. A. Paine. N. Illinois, Dr. Vasey. (Eu.)

3. S. Clintónii, Gray. Culms acutely trinngular, almost bristle-like ; sheaths at the base bearing a very slender almost bristle-shaped leaf shorter (usually very much shorter) than the culm; involucral bract awl-shaped, mostly shorter than the chestnut-colored ovate spike, which has pointless scales: othcrwise as the next. (S. planifolius, var. brevifolius, T'orr.) - Rather dry plains, New York, Jefferson Co., Dr. Crawe; near Buffalo, G. W. Clinton. June.

4. S. planifolius, Muhl. Cu/ms triangular, leafy at the base; the leaves linear, fut, us long as the culm, and like it rough-edged ; involucral bract a bristletipped scale usually overtopping the ovate or oblong chestnut-colored spike, the green midrib of the scales extended into sharp pnints; bristles of the perianth $u p$ wardly hairy, as long as the pointless achenimm. - Dry or moist ground, New England to W. New York (G. W. Clinton), Penn., and Delaware. June.

+++ One-leaved involucre more conspicuous, and as if continuing the culm.

5. S. subterminalis, Torr. Aquatic: culms $\left(1^{\circ}-3^{\circ}\right.$ long, thickish-filiform) partly and the shorter filiform leaves wholly submersed, cellular; the filiform green bract 6" -12 "long, much surpassing the oblong spike; scales somewhat pointed; bristles 6, bearded downwards, rather shorter than the abruptlypointed achenium. - Slow strenms and ponds, New Jersey and New England to Michigan and westward. - Var. Ternéstris, Paine, Cat. Less tall ; stem and leaves firmer; fully-fruiting spike more turgid : growing chicfly emersed, in a quaking morass, Litchficld, Herkimer Co., New York, J. A. Paine.

* Spikes clusterrd (ravely only one), appcaring lateral fiom the one-learcd involucre, which resembles the naked culm, sreming to be a continution of it.

- Culm sharply triangular, stout, chiefly from running rootstocks: spikes many-flowered, rusty brown, closely sessile in one cluster: sheaths at base more or less leafbearing. (Very rarely a second and smaller involucral lenf.)

6. S. púngens, Vahl. Running rootstocks long and stont; culm sharply 3-angled throughout $\left(1^{\circ}-4^{\circ}\right.$ high) with concave sides; leares $1-3$, elongated $\left(4^{\prime}-10^{\prime}\right.$ long), kceled and channelled; spikes $1-6$, capitate, ovoid, usually long overtopped by the pointed involucral leaf; scales ovate, sparingly ciliate, 2-cleft at the apex and awl-pointed from between the acute lobes; anthers tipper with an awl-shuped minutely fringed appendage; style 2-cleft (rarely 3-cleft); bristles 2-6, shorter than the obovate plano-convex and mucronate smooth achenium. (S. triquèter, Michx., not of $L$. S. Americànus, Pers.) - Borders of salt and fresh ponds and streams: very common. (Eu.)

7. S. Ólneyi, Gray. Culm 3-wing-angled, with deeply excavated sides, stout $\left(2^{\circ}-7^{\circ} \mathrm{high}\right)$, the upper sheath beuring a short triangular leaf or none; spikes 6-12, 
closely capitate, ovoid, obtuse, overtopper by the short involucral leaf; scales orbicular, sinooth, the inconspicuous mucronate point shorter than the scarious apex; anthers with a very short and blunt minutely bearded tip; style-2-cleft; bristles 6, scarcely equalling the obovate plano-convex and mucronate achenium. Salt inarshes, Martha's Vineyard (Oakes), and Rhode Island (Olney,, to Delaware, and common southward. - Cross-section of the stem strongly 3-rayed, with the sides parallel. - Much nearer than the last to the European S. TRIQUEter, which has similar anthers, and an abbreviated or almost abortive leaf; but its culm is wingless, and the cluster of spikes compound, some of them umbellate-stalked.

8. S. Tórreyi, Olncy. Rootstocks slender if any (so that the plant is readily pulled up from the mud); culm 3 -angled, with concave sides, rather slender $\left(2^{\circ}-4^{\circ}\right.$ high), leafy at the base; leures 2 or 3 , more than half the length of the culm, triangular-channclled, slender; spikes 1-4, oblong or spindle-shaped, acute, disfinet, pale chestnut-color, long overtopped by the slender ereet involucral leaf; scales ovate, smooth, entire, barely mucronate; style 3-cleff; bristles longer than the unequally triangular obovate very smooth and long-jointed achenium. (S. mucronatus, Pursh?, Torr. Fl. N. Y.) - Borders of ponds, both brackish and fresh, New England to Penn. and Michigan.

$\leftarrow+$ Culm triangular, tall and stout, from slender nunning rootstocks: spikes munyflowered loosely umbellate or corymbed, involusellate-bracted.

9. S. Cánbyi, Gray. Culın $\left(3^{\circ}-5^{\circ}\right.$ high $) 3$-angled, usually sharply so above, obtusely below, the sheath at the base extended into a long and slender triangular and channclled leaf; the involucral leaf similar, continuing the culn ; spikes oblong $\left(4^{\prime}-6^{\prime}\right.$ long), single or sumetimes proliferously 2 or 3 together, nodding on the apex of the 5-9 long filiform and flattened peduncles or rays of the dichotomous umbel-like corymb, or the central one nearly sessile; seales of the spike loosely imbricated, oblong-ovate, acute, pale, thin and searious, with a greenish nerved back; bristles of the perianth 6 , firm, furnished above with spreading hairs rather than barbs, equalling the slender abrupt beak of the obovate-triangular shining achenium. - In a mill-pond, near Salisbury, Maryland, A. Commons, W. M. Canby. - A remarkable species: leaf $2^{\circ}-4^{\circ}$ long: involucial leat $4^{\prime}-8^{\prime}$ long: rays or perluncles $12_{2}^{\prime}-3^{\prime}$ long, each subtended by a single involucellate leaf or bract, the lowest like that of the involuere but short, the uppermost reduced to scale-like bracts. Achenium $\left(1 \frac{1}{2}\right.$, and its beak $y^{\prime \prime}$ long.

+++ Culm terete, very tall and stout, from a deep running rootstork, nakerl; the sheaths at the base bariny a short and imperfect leaf or none: sprikes numerous and clustered in a one-sided compound umblitlike punicle, the principal rays of which mostly surpass the ineolucral leaf: involucellate bracts small, scale-tike and rusty-scurious: scules of the spike rusty or chestnut-brown, scurious, with a sulient midil extended into a mucronote point.

10. S. válidus, Vahl. (Gosat Bus.rusm.) ('ulm $3^{\circ}-9^{\circ}$ high, $f^{\prime}-1$. thick at batse; spikes ovite-oblong (3" - $4^{\prime \prime}$ long); scules mostly a little downy on the back and ciliate; style 2-cleft; achenium pule and dull, olonute with a narrowed base, plano-convex, mucronatc-pointel, usually overtopped by the 4-6 slender 
downvardly barbed bristles. (S. acùtus, Muhl. S. lacuistris, of Amer. authors and in former editions.) - Common everywhere in still fresh water. - Achenium ( $\$$ "long, half the size of that of the European S. lacustris, also narrower, pale, not shining. $-\Lambda$ slender variety with narrower hends, very smooth senles, and shorter or fragile bristles, was sparingly collected by Rev. J.W. Chickering at Havana, New York.

11. S. riparius, Presl., which largely takes the place of the preceding sonthwestward, probably within our limits, is known by the $2-4$ rather shorter and linear plumose scales, rather than bristles, of the perianth.

++++ Culms slender fiom an annual root, terete, plano-comer or olussly trinngular, naked; the sheaths at the base rarcly extended into a short Iraf: spikes friv or several, sometimes solitury, in a sessile cluster, murh overtopped by the involucral leuf: bristles of the perianth oflen few or urting.

12. S. débilis, Pursh. Culms obtusely triangular, with somewhat hollowed sides, $1^{\circ}-2^{\circ}$ high, yellowish-green; spikes $3-12$, capitate, ovate-oblong, obtuse ( $3^{\prime \prime}-4^{\prime \prime}$ long), chestnut-brown; involucral leaf often horizontal at maturity ; scales roundish ; stamens 3 ; style 2 -3-cleft ; bristles 6 , stout, downwardly barbed, equalling or two surpassing the obovate turgidly plano-convex (or bluntly 3-sided) abruptly mucronate-pointed smoothish achenium. (S. juncoides, Roxburgh.) - Swamps, Mass. to Virginia and southward. Ang., Sept.

13. S. Smithii, n. sp. Culms terete, slender, $3^{\prime}-12^{\prime}$ high, often leaf-bearing from the upper sheath, dull green as are the $1-3$ oblong-ovate acute spikes; involucral leaf always erect; scales oblong-oval; style 2-cleft; bristles 1 or 2 minute rudiments or none; achenium somewhat lenticular, smooth, deciduous with the scales. (S. debilis, Gray, Gram. \& Cyp. 135.) - Wet shores, Lake Ontario to Illinois and Delaware Bay (in tidal mud). July. - Named for C. E. Smith, who indicated and insisted on its distinctions.

14. S. supinus, L., var. Hállii. Culms filiform, $5^{\prime}-12^{\prime}$ high; upper kheath rarely distinctly leaf-bearing; spikes $1-7$ in a sessile or sometimes geminately proliferous cluster, ovate-oblong becoming cylindrical, greenish; scales ovate, strongly kecled, mucronate-pointed; stamens 2; style 2-cleft; bristles none; achenium obovate-orbicular, mucronate, plano-convex, strongly wrinkled transversely. (S. Hnllii, Gray, addend. ed. 2.) - Wet shores, Illinois, E. Hall, \&c., and southwestward. - In 'Texas occurs the normal S. supinus, with 3-cleft style and triangular achenium, as in Europe, where it sometimes has short bristles, as in No. 13. (Eu.)

* * Spikes clustered in simple or mostly compound umbellate or cymose-panicled clusters, many-flnwered, terete: involucre of mostly several obvious and flut leaves: culm tall, from tufled or running rootstocks; triangular, leafy, sedge-like: style mostly 3-cleft.

- Spikes large, 6" - 15" long: midrih of the scales extended beyond the mostly lacerate or two-cleft apex into a distinct awn.

15. S. maritimus, L. (Sea Club-Rusn.) Leaves flat, linear, as long as the stout $\mathrm{culm}\left(1^{\circ}-3^{\circ}\right.$ high), those of the involucre $1-4$, very unequal; spikes few - several in a sessile cluster, and often also with $1-4$ unequal rays bearing $1-7$ ovate or oblong-cylindrical (rusty-brown) spikes; awns of the 
scales soon recurved; achenium obovate-orbicular, compressed, flat on one side, convex or obtuse-angled on the other, minutely pointed, shining, longer than the $1-6$ unequal and deciduous (sometimes obsolete) bristles. - Var. масвовта́снуов, Michx. (S. robuistus, Pursh) is a larger form, with very thick oblong-cyliudrical heads, beconing $1^{\prime}-1 \frac{1}{2}^{\prime} \mathrm{long}$, and the longer leaf of the involucre often 10 long. - Salt marshes: common on the coast, and near salt springs in the interior (W. New York, \&c.). (Eu.)

16. S. fluviátilis, Gray. (River C.) Leares flat, broadly linear ( $\frac{1}{2}$ or more wide), tapering gradually to a point, the upper and those of the very long involucre very much exceeding the compound umbel; rays 5-9, elongated, recurvedspreading, each bcaring $1-5$ ovate or oblong-cylindrical acute heads; achenium dovate, shaiply and exuclly tritungular, conspicuously pointed, opaque, scarcely equalling the 6 rigid bristles. (S. maritimus var.? fluviatilis, Torr., exel. syn.) Borders of lakes and large streams, W. Vermont to Penn., Wisconsin and Illinois. - Culm very stout, sharply triangular, $3^{\circ}-5^{\circ}$ high. Leaves roughish on the margin, like the last; those of the umbel $3-7$, the largest $1^{\circ}-2^{\circ}$ long. Principal rays of the umbel $3^{\prime}-4^{\prime}$ long, sheathed at the base. Ifeads paler and duller than in the preceding; the scales less lacerate, and their awus less recurved, the fruit larger and very different.

+ + Spikes very mumcrous, small, 1'-3' long; their scales mucronate-pointed or blunt: umliel-like cymose panicle irregular, compound or decompound: culm $2^{\circ}-5^{\circ}$ high, unusually leafy; leaves broully linear, green and rather soft, rough on the edyes: bristles of the perianth very slender, often more or less tortuous and nuked below: - liansition to § Trichophorum.

17. S. sylváticus, L. Spikes lead-colored, clustcral 3-10 together at the end of the miostly slender ultimate divisions of the open decompound panicle, ovoid or lance-ovate, 2 " long ; scales bluntish ; bristles 6 , downwardly barbed throughout, rather excecding the triangular short-pointed acheniuı; style 3-cleft. Along brooks, E. Mass., W. Boott, to Albany, N. Y., C. H. Peck. (Eu.)

18. S. microcárpus, Presl. Like No. 17, but earlier, and with rather smaller heads, blunter scales, 2 stamens, a 2-cleft style, 4 bristles, and obovatelenticular achenium. (S. lenticularis, Torr.) - Near Boston, W. Boott, to New Hampshire, Oukes, \&c., and N. W.

19. S. atróvirens, Muhl. Leaves somewhat more rigid; spikes dull grernish-brown, densely conglomerate $(10-30$ together) into close heads, these also usually densely clustered in a less compound panicle; scales pointed; bristles sparisely and strongly downwarlly barbed above the middle, naked below, nearly straight, as long as the conspicuously pointed and obovate-oblong triangular achenium. (S. sylvaticus, var. atrovirens, Ed. 2, - Wet meadows and bogs, New England to Kentucky and northward: common.

20. S. polyphýllus, Vahı. Culm usually more leafy; spikes yellow-brown, ovate, becoming cylindrical, clusterse 3-8 together in small heads on the short ultimate divisions of the open decomponel umbel; scales mocronate; bristles fo, usually twice bent, soft-bubed towards the summit only, ubout twice the length of the achenium. (S. exaltàtus, Pursh. S. brúnneus, MUhl.) - Swamps and shatly borders of jonds, IV. New Eugland to Illinois, and common southward 
§ 2. TRICHÓPHORUM, Richard. Bristles capillary, naked, not barbed, elongaling, becoming tortuons and entangled, much longer than the triangular achenium, when old mostly projecting beyond the rusty-colored scales: culm, laves, \&c. as in the precedin! subdivision; umbel-like cymose panicle decompound.

21. S. lineatus, Michx. Culm triangular, leafy $\left(1^{\circ}-3^{\circ}\right.$ high $)$; leaves linear, flat, rather broad, ruigh on the margins; umbels terminal and sometimes axillary, loose, drooping, the terminal with a 1-3-leaved involucre much shorter than the long and slender rays; spikes oblong, becoming cylindrical $\left(2^{\prime \prime}-4^{\prime \prime}\right.$ long), on thread-like drooping pedicels; bristles at muturity scarcely exceeding the ovate green-kecled and pointed scales; achenium sharp-pointed. - Low grounds, W. New England to Wisconsin, and common southward.

22. S. Erióphorum, Michx. (Wool-Grass.) Culın nearly terete, very leafy $\left(2^{\circ}-5^{\circ}\right.$ high) ; leaves narrowly linear, long, rigid, those of the involucre 3-5, longer than the decompound cymose-panicled umbel, the rays at length drooping; spikes exceedingly numerous, ovate, clustered, or the lateral ones pedicelled, woolly at maturity $\left(1 \frac{1}{2} "-3^{\prime \prime}\right.$ long); the rusty-colored bristles much longer thun the pointless scales; achenium short-pointed. (Erióphorum cyperinum, $L$.) - Var. cyperinus (S. cyperinus, Kunth) is the form with nearly all the spikes conglomerate in small heads. - Var. LAxus (S. Eriophorum, Kunth) has the heads scattered, the lateral ones long-pelicelled. Various intermediate forms occur; and the umbel varies greatly in size. - Wet meadows and swamps: common northward and southward.

\section{ERIÓPHORUM, L. Cotton-Grass. (Pl. 3.)}

Spikes, scales, achenium, \&c. as in Scirpus. Bristles of the perianth of numerous (in one species few) flat and delicate capillary bristles, which lengthen greatly after flowering, much exceeding the scales, and forming of the capitate spike a (white or reddish) conspicuous cotton-like tuft in fruit. Stamens 1-3. Style 3-cleft. Perennials. (Name composed of épıov, wool or cotton, and popá, bearing.)

* Bristles of the flower only 6, crisped, white; spike single: small, involucre none.

1. E. alpinum, L. Culms slender, many in a row from a running rootstock $6^{\prime}-10^{\prime}$ high), scabrous, naked; sheaths at the base awl-tipped. - Cold bogs, New England to Penn., Wisconsin, and northward. June. (Eu.)

* Bristles very numerous, not crisped, forming dense cottony heads in fruit.

- Culm bearing a simple spike: involucre none.

2. F. vaginatum, L. Culms in close tufts $\left(1^{\circ}\right.$ high), leafy only at the base, above with 2 inflated leafless sheaths; root-leaves long and thread-form, triangular-channelled; scales of the ovate spike long-pointed, learl-color at maturity. - Cold and high peat-hogs, New Fingland to mountains of Penn. (Prof. T. Green), Wisconsin, and northward; rure. May, Junc. (Eu.)

(E. Russèoum, Fries, with copper-colored wool, found in New Brunswick by Rev. J. Fouler, may be expected in N. E. Mainc.)

+ + Culm leafy, hearing several umbellate-clustered heads, involucrate.

3. F. Virgínicum, L. Culm rigid $\left(2^{\circ}-4^{\circ}\right.$ high $)$; leares very narrowly linear, elongated, flat; spikes nearly sessile, crouded in a dense cluster or haud; 
wool rusty or copper-color, only thrice the length of the scale; stamen 1.-Bogs and low meadows: common. July, Aug.

Var. álbum, with the wool white. - Oswego and Jefferson Counties, New York, Di. Crawe, A. H. Curtiss.

4. E. polystáchyon, L. Culm rigid $\left(1^{\circ}-2^{\circ}\right.$ high), obscurely triangular; lcuves lincur, flu, or burcly channellal below, triangular at the point; involucre 2-3-leaced; spikes several (4-12), on nodding peduncles, some of them elongated in fruit; achenium obovate; wool white, very struight (1' long or more). - Var. Angustròium (E. angustifolium, Ruth, and of liuropean botanists, not of Amcrican, and the original E. polystachyon of $L$.) hats smooth peduncles.

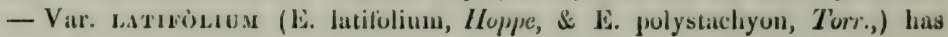
rough peduncles, and sometimes broader and flatter leaves. - Both are common in Logs, northward; often with the peduncles obscurely scabrous, indicating that the species should be left as Linnæus founded it. June, July. (Eu.)

5. E. grácile, Koch. Culm slender $\left(1^{\circ}-2^{\circ}\right.$ high $)$, rather triangular; leaves slender, channelled-triangular, rough on the angles; imvolucre short and scalelike, mostly 1-laved; peduncles rough or roughish-pubescent; achenium elliptical-linear. (E. triquètrum, Hoppe. E. angustifulium, Turr.) - Cold bugs, New England to Illinois, and northward. June-Aug. - Spikes 3-7, small, when mature the copious white wool $6 "-9^{\prime \prime}$ long. Scales brownish, severalnerved; or in our plant, var. raucríńrius, Engelm., mostly light chestuutcolor, and about 3-nerved. (Eu.)

\section{FIMBRÍSTYLIS, Vahl. (Pl. 3.)}

Spikes several - many-flowered, terete; the scales all floriferous, regularly imbricated in several rauks. Perianth (bristles, \&c.) none. Stamens 1-3. Style 2-3-cleft, often with a dilated or tumid base, which is deciduous (except in No. 4) from the apex of the naked lenticular or triangular achenium. Otherwise as in Scirpus. - Culıns leafy at the base. Spikes in our species umbelled, and the involucre 2-3-leaved. (Name compounded of fimbria, a fringe, and stylus, tho style, which is fringed with hairs in the genuine species.)

\$1. FIMBRISTYLIS proper. Style 2-cleft, flut and ciliate, fulling away, base and all, from the lenticular achenium ; scales of the many-floweral spike clusely imbricuted.

1. F. spadicea, Vahl., var. castánea. Culms $\left(1^{\circ}-2 \frac{1}{2}^{\circ}\right.$ high $)$ tufted from a perennial root, rigid, as are the thread-form convolute-channelled laties, smooth; spikes ovate-oblong becoming cylindrical, dark chestuut-color (2" thick); stamens 2 or 3 ; achenium very minutely striate and abscurely reticulated. (F. castanea, cylindrica, \&c., Vahl.) - Salt marshes along the coast, New Yurk to Virginia, and southward. July-Sept. - Spikes less dark-colored and scales mostly thinner than in the original Jamaica plant.

2. F. láxa, Vahl. Culıns slender $\left(2^{\prime}-12^{\prime}\right.$ highs) from an annual root, weak, grooved and thattish; leaves linear, flat, ciliate-dcrticulute, glaucous, sometimes hairy ; spikes ovate, acute ( $3^{\prime \prime}$ long) ; stamen 1 ; achenium ronspricuously 6 - 8 -ribbed on each side, and with finer cross lines. (F. Baldiviniana, Torr: F. brizoides, Nas, de.) - Luw, mustly clayey soil, P'enn. to Illinois and southward. July Sept. - Seales broater and less pointed than in E. unuแa. 
8. TRICHEIOS'TYISIS, Lestib. Style 3-reft and the achenium triangular: otherwise nearly as in $\$ 1$ : the spikes smull and fewer-finwered.

3. F. autumnalis, R(em. \& Schult. $\Lambda$ mnual $\left(3^{\prime}-16^{\prime}\right.$ high), in tufts; culms flat, slender, diffuse or (rect; leaves flat, acute; umbel compound ; spikes oblong, acute ( $1^{\prime \prime}-2^{\prime \prime}$ long), single or $2-3$ in a cluster; the seales ovate-lanceolate, mucronate; stamens $1-3$. (Scirpus autumnalis, L.) - Low grounds, Maine to Illinois, and southward. Aug. - Oct.

§ 3. ONCÓS TYLIS, Martius. Słyle 3-cleft, slender, its thickish base more turdily deciduous from the apex of the trianyular acheniun.

4. F. capillàris, Gray. Low annual, densely tufted $\left(3^{\prime}-9^{\prime}\right.$ high $)$; culm and leaves nearly capillary, the latter short; umbel compound or panicled; spikes (2" long) ovoid-oblong; stamens 2 ; achenium minutely wrinkled, very obtuse. (Scirpus capillaris, L.) - Sandy fields: common. Aug., Sept.

(F. congésta, Torr., a diminutive Southern species, with the 2-cleft style not ciliate, has been detected in ballast-sand at Camden, New Jersey, opposite Philadelphia, by C.F. Parker: probably only a waif.)

\section{D I CHRÒ ME NA, Richard. Dichromena. (Pl. 4.)}

Spikes aggregated in a terminal leafy-involucrate head, more or less compressed, few-flowered, all but 3 or 4 of the flowers usually imperfect or abortive. Scales imbricated somewhat in 2 ranks, more or less conduplicate or boatshaped, keeled, white or whitish. Stamens 3. Style 2-cleft. Perianth, bristles, \&c., none. Achenium lenticular, wrinkled transversely, crowned with the persistent and broad tubercled base of the style. - Culms lenfy, from creeping perennial rootstocks; the leaves of the involucre mostly white at the base (whence the name, from dis, double, and $\chi \rho \hat{\omega} \mu a$, color). - Differs (too little) from the next genus in the involucrate bracts and flattened spikes.

1. D. lexcocéphala, Michx. Culm triangular $\left(1^{\circ}-2^{\circ}\right.$ high $)$; leaves narrow; those of the involucre 4-7; achenium truncate, not margined. Damp pine barrens of New Jersey to Virginia and southward. Aug., Sept.

2. D. latifolia, Baldwin. Culm stouter, nearly terete; leaves broadly linear, those of the involucre 8-9, tapering from hase to apex; achenium round-obnvate, faintly wrinkled, the tubcrcle decurrent on its edges. - S. Virginia? and southward.

\section{RHY N CH ÓSPORA, Vahl. BЕлк-Rusir. (Pl. 4.)}

Spikes panicled or variously clustered, ovate, globular, or spindle-shaped, rerete, or sometimes flattish; but the scales open or barely concave (not boatshaped nor keeled); the lower ones commonly loosely imbricated and empty, the uppermost often subtending imperfect flowers. Perianth in the form of (mostly 6) bristles, or occasionally wanting. Acheniuın lenticular, globular, or flat, crowned with a conspicuous tuberele or beak consisting of the persistent and indurated base or even of the greater part of the style. - Chiefly perennials, with more or less triangular and lcafy culms; the spikes in terminal and

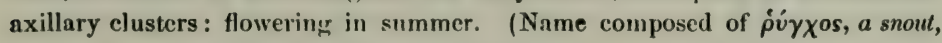
and $\sigma \pi$ oó, $a$ seed, from the beaked achenium.) 
§ 1. PSILOCARYA, Torr. Spikes ovate, terete, the numerous scales all ablke and reyularly imbricuted; a perfect flower under euch : stamens mostly 2 : styls 2-cleft; its base or the greater part of it enlarging and hardening to form the beak of the lenticulur or tumid more or less cross-wrinkled uchenium: bristles wholly wanting (whence the name).

1. R. scirpoides. Annual, $4^{\prime}-10^{\prime}$ high ; leaves flat; spikes in broad and open cymes, 20 - 30-flowered ; scales oblong-ovate, acute, chestnut-colored; achenium obscurcly wrinkled, beaked with the sword-shaped almost wholly persistent style, and somewhat margined. (Psilocarya scirpoides, Torr. \& Ed. 2.) - Inundated places, Rhode Island and Plymouth, Massachusetts.

(R. nìtens (Scirpus niteus, Vahl. Psilocarya rhynchusporoides, Torr.), like this, but with a more wrinkled and short-beaked achenium, takes its place in Southern States.)

§ 2. EURIIYNCHÓSPORA. Spikes terete or biconvex, few-many-flowerul; some of the lower scules ulmost always empty: stamens mostly 3 : style conspicuously 2-cleft, its base only forming the tubercle or bcak of the mostly lenticular achenium: bristles of the perianth usually present, and merely rough or barbeddenticulate (not plumose).

* Achenium trunsversely wrinkled: bristles mostly 6, upwardly denticulate.

2. R. cymòsa, Nutt. Culm triangular; leaves linear ( $f^{\prime}$ wide); cymes corymbose; the spikes crowded and clustered; achenium round-olovate, twice the length of the bristles, four times the length of the depressed-conical tubercle. Low grounds, Peun. and New Jersey to Virginia, and southward.

3. R. Torreyàna, Gray. Culm nurly terete, slender; leaves bristle-form; cymes panicled, somewhat loose, the spikes mostly pedicelled; achenitum oblongobovate, longer than the bristles, thrice the length of the hroad compressedconical tubercle. - Swamps; pine barrens of New Jersey, and soutliward.

4. R. inexpánsa, Vahl. Culm triangulur, slender; lenves narrowly linear; spikes spindle-shaped, mosily palicelled, in diooping panicles; achenium oblong, half the length of the slender loristles, twice the length of the triangular-subulate tubercle. - Low grounds, Virginia and southward.

\section{* * Achenium smooth and even.}

- Bristles of the perianth 6, long and conspicuous, upwardly denticulate.

5. R. fúsca, Roen. \& Schultes. Leaves bristle-form, channelled; spikes ovate-ablong, few, clustered in $1-3$ loose heads (dark chestuut-color); achenium olovate, half the length of the lristles, equalling the triangular-sword-shaped acute tubercle, which is rongh-serrulate on the hargins. - Iow grounds, New Jersey to Maine and Iake Superior : rare. - Culm 6 $-12^{\prime}$ high. (Eu.)

6. R. gracilénta, (iray. Lenves narrowly linear; spikes ovoid, in 2-4 small clusters, the lateral long-peduncled; achenium ovoid, rather shorter than the bristles, about the leugth of the flat awl-shaped tubercle. - Low grounds, S. New York, New Jersey, and southward. - Culn very slender, $1^{\circ}-2^{\circ}$ high.

+- +- Bristles none or 1-3 and minute: spikes pale, 1-flowered.

7. R. pállida, M. $\Lambda$. Curtis. Culı $\left(1^{\circ}-2^{\circ}\right.$ high $)$ acutely trimgrular; leaves and spikes as in the next species, but only a terminal dense cluster, which is less white or turns pale redilish-tawny; achenium obovate-lenticular, 
tipped with a minute depressed and apiculate tubercle; the delicate bristles four or five times shorter or obsolete - Bogs in pine barrens of New Jersey ( $W . M$. Canby, C. F. Parker), and in N. Carolina.

++ + Bristles long, denticulate dounwardiy, or both ways in No. 12.

+ Spikes white or whitish, beroming tawny uith age, perfecting only a single flower: stamens usually 2 : bristles $9-12$, or even 20

8. R. álba, Vahı. Culm slencler $\left(1^{\circ}-2^{\circ}\right.$ high $)$, triangular above ; leaves narrowly linear or almost bristle-form ; spikes lanceolate, densely crowded in a head-like terminal corymb and usually one or two lateral ones; achenium oblong-obovate with a narrowed base, scarecly longer than the flattened-awlshaped tubercle, shorter than the bristles. - Bogs, especially eastward. (Eu.) + Spikes chestnut-colored or darker in No. 11 and 12, few-several-flowered: stumens 3 : bristles usually 6.

9. R. capillàcea, Torr. Leaves bristle-form; spikes 3-6 in a terminal eluster, and commonly 1 or 2 un a remote axillary peduncle, oblong-lanceolate (pale chestnut-color, $3^{\prime \prime}$ long); achenium oblong-avoid, stipitate, very obscurely wrinkled, about half the length of the (6, rarely 12) stout bristles, and twice the length of the lanceolate-beaked tubercle. - Bogs and rocky river-banks, Penn. to N. Vermont, New York, and Michigan. - Culm 6'-9' high, slender.

10. R. Knieskérnii, Carcy. Leaves nurrowly linear, short; spikes numerous, crouded in 4-6 distant clusters, oblong-ovate (scarcely 1" long); achenium obovate, narrowed at the base, equalling the bristles, twice the length of the triangular flattened tubercle. - Pine barrens of New Jersey, on bog iron ore exclusively (Knieskern), and southward: rare. - Culms 6'-18' high, slender.

11. R. glomeràta, Vahl. Ieaves linear, flut; spikes numerous in distant clusters or heuds (which are often in pairs from the same sheath), ovoid-oblong; achenium obovate, margined, narrowed at the base, as long as the lance-awlshaped flattened tubercle, which equals the (always) downwardly barbed bristles. - Low grounds: common, especially eastward. - Culm $1^{\circ}-3^{\circ}$ high. $-\mathbf{A}$ state with small panicled clusters is R. paniculata, Gray.

12. R. cephalántha, Torr. Leaves narrowly lineur, flat, keeled; spikes very numerous, crowded in 2 or 3 or more dense globular heads which are distant (and often in pairs), oblong-lanceolate, dark brown; achenium orbicular-obovate, margined, narrowed at the base, about as long as the awl-shaped beak, half the length of the stout bristles, which are harbed downwards and sometimes also upwards. - Sandy swamps, Long Island to New Jersey, and southward. - Culm stout, $2^{\circ}-3^{\circ}$ high: the fruit larger than in the last, of which it may be only a marked variety.

§ 3. CERATOSCHĊNUS, Nces. Spikes spindle-shaped or lanceolate, acuminate, in fruit flattish, large, rymose-panicled, producing only one perfect and 1 to 4 staminate fowers; their scules few, the lower mostly empty: stamens 3 : Inistles of the perianth rigid, either short or slender, mimutely srubrous upurard: style simple or barely 2-toothed at the apex, filiform and yradually thickened downuards, in fruit almost all of it persistent as a very long, exserted, slender-awl-shaped, upwurdly roughened beak, several times longer than the smooth and flat obovate achenium: coarse perennials: spikes in flower 4", in fruit including the pro L \& M-44 
jecting bcak or style aboul 1' long. (This long beak gives the name, from кє́pas, a horn, anil $\sigma_{\chi}$ oivos, a rush.)

13. R. corniculàta, Gray. (HORned Rush.) Cymes dccompound, diffuse; bristles awl-shaped, stout, unequal, shorter than the achenium. - Wet places, Penn. to Illinois, and suuthward. - Culm $3^{\circ}-6^{\circ}$ high. Leaves about $6^{\prime \prime}$ wide.

14. R. macrostàchya, Torr. Cymes decompound, or in the northern form somewhat simple and smaller, and the spikes usually more clustered; bristles capillary, twice the length of the achenium. - Borders of ponds, Massachusetts, Rhode. Island, New Jersey, aud southward : rare. - Perhaps it runs into the pr*eding.

\section{CL À D I U M, P. Browne. Twıg-Rusis. (Plate 5.)}

Spikes ovoid or oblung, of several loosely inbricated scales; the lower ones empty, one or two alove bearing a staminate or imperfect flower; the terminal fluver perfect and fertilc. Perianth none. Stamens 2. Style 2-3-eleft, deciduous. Achenium ovoid or globular, somewhat corky at the sum ınit, por pointed. without any tubercle, in which it differs from Rhynchosiora. (Name from $\kappa \lambda$ áôs, a tweig or branch, perhaps on account of the twice branching styles of some sprecies.)

1. C. mariscoides, Torr. Peremial; culm obscurely triangular $\left(1^{\circ}-2^{\circ}\right.$ high) ; leaves narrow, channelled, scarcely rough-margined; cymes small; the spikes clustered in hends $3-8$ together on 2 to 4 peduncles; style once 3-cleft. - Bogss, New England to Jelaware, Illinois, and northward. July.

\section{S C L E R I A, L. Nut-Rusir. (I'l. 5.)}

Flowers monerious; the fertile spikes 1-flowered, usually intermixed with clusters of few-flowered staminate spikes. Sinles loosely imbricuted, the lower ones empty. Stunens 1-3. Style 3-cleft. Achenium globular, stony, hony, or enamel-like in texture. Bristles, \&c. none. Perennials, with triangular leafy culıns, mostly from creeping rootstocks: flowering in summer: all in low ground or swamps. (Name $\sigma \kappa \lambda \eta p i a$, hardness, from the indurated fruit.)

1. S. triglomeràta, Michx. Culm $\left(2^{\circ}-3^{\circ}\right.$ high) and broadly linear leaves roug! ish ; fitscicles of spikes few, terminal and axillary, in triple clusters, the lowermost peduncled; stamens 3; achenium smoolh and polished, on an obseure crustaceous ring or disk. - Vermont to Wisconsin, and common southward.

2 S. reticularis, Michx. Culms slender (10 high); leaves narowly Sinear; clusters loose, axillary and terminal, sessile or the lower on short slender peduncles; stamens 2; achenium globulur, reysularly pilled-reticulated, not huiry, resting on a double disk, each of three greenish appressed superposed culyx-like lobes, the inner larger. - Eastern Massachusetts to Virginia and southward: rare northivard.

3. S. láxa, Torr. Culms slender and weak $\left(1^{\circ}-2^{\circ}\right.$ high) ; leaves linear; clusters lonse, the lower mostly long-perluncled and drooping; acheniun globular, irregularly pitted-rcticulated or pitterl-rugose, towards the bise minutely hairy on tho somewhat spiral wrinkles : otherwise as in the foregoing. - L. Massachusetts to New Jersey, Pennsylvmia, and southward. 
1. S. pauciflora, Muhl. Somewhat downy or smoothish; culms slender $\left(9^{\prime}-18^{\prime}\right.$ high $)$; leaves narrowly linear; clusters few-flowered, the lower lateral ones when prosent pedunclerl; bracts cilinte ; stunens 3 ; as lirnium glolose, papillose-ronghened, white; the disk a narrow ring bearing 3 pairs of minute tubercles. -S. New Englanil to W. New York (rare), and more common southward.

5. S. verticillàta, Muhl. Smooth; culms simple, slender $\left(4^{\prime}-12^{\prime}\right.$ high), terminated by an interrupted spike of 4-6 rather distant sessile and small clusters; bracts minute; leaves linear; stamens 1 or 2 ; achenium rough-wrinkled with short elevated ridges, globular-triangular; the disk obsolete. - W. New York nnd Penn. to Michigan and southward: rare. - Plant faintly sweetscented; achenium small, $\mathbf{z}^{\prime \prime}$ long.

\section{CÀreX, L. Sedge. (PI. 5, 6.)}

Staminate and pistillate flowers separated (monccious), either borne together In the same spike (androgynous), or in separate spikes on the same stem, very rarely on distinct plants (diverions). Scales of the spikes equally imbricated around the axis, each subtending a single staminate or pistillate flower. Stamens 3, rarely 2. Ovary enclosed in an inflated sac (composed of either one or two inner scales (bractlets) united by their margins), forming a rounded or angular bladdery sac (prigyniun), which encloses the lenticular, plano-convex, or triangular achenium, tipper with more or less of the persistent (rarely jointed) base of the style. Stigmis 2 or 3, long, projecting from the narrow orifice of the perigynium. - Perennial herbs, chicfly flowing in spring and maturing in summer, frequently growing in wet places, often in dense tufts. Culms triangular, hearing the spikes in the axils of green and leaf-like or scale-like bracts, nnd terminal; commonly with sheaths at the base which enclose more or less of the stalks of the spikes. Lcaves grassy, usually rough on the mnrgins and keel. (A classical name, of obscure signification; derived by some from caren, to

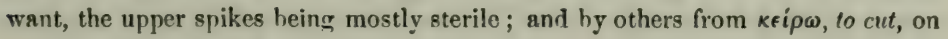
account of the sharp leaves.)

Contribnted for the first edition of this work, and revised for the second, by Jorn Caret, Fsq.; with some present arlditions, fiom recent discoveries, and n few alterations, chiefly from the subsequent investigations of the late $D_{R}$. Francis Bоotт, published in his magnificent Illustrations of the genus Carex, and from notes furnistod by $\mathrm{W}_{\mathrm{M}}$. Bootr, Esq.

\section{ARIDGED SYNOPSIS OF THE BECTIONS.}

A. Splke solitary and terminal, simple, diøcious or androgynous : bracts small, colored and scale-like. - (This division, retained for the convenience of students, is merely artificial, and combines species having no real natural affinity.) PSYLLOPHOR $\mathbb{E}$, Loiseleur.

1. Spike dicecious, or with a few staminate flowers at its base. No. 1-2.

2 Spike androgynous, staminate at the summit. No. 3-6.

Spike androgynous, staminate at the base. No. 36 and 138 may be sought here.

B. Spike solitary, single, androgynous, stuminate at the summit : hracts and scales of the ferthe flowers green and lenf-like. Stigmas 3. PHYLtostachYs, Torr. \& Ar. No. 7-9.

C. Bpikes severnl or numerous, androgynous (occasionally dinecious in No. 11 and 33), sessile, forming compact or more or less interrupted, sometimes paniculate, compound or detompound spikes. Stigmas 2. VIGNEA, Beaur. 
11. Spikes approximate, with staminate and pistillate flowers variously situated. No. 10-12

2. Spikes pistillate below, staminate at the sumınit. No. 13-28.

3. Spikes pistillate above, staminate at the base. No. $29-45$.

D. Staminate and pistillate flowers borne in separate (commonly more or less stalked) simple spikes on the same culm; the one or more stanninate (sterile) spikes constautly uppermost, having occasionilly more or less fertile flowers at base or apex; the lower spikes all pistillate (fertile), or sumetimes with staninate fluwers at the base or apex. Stigmas 3 (or only 2 in No. $46,53,65,150,8 c$.). CAREX proper.

* Perigynia with merely a minute or short point, scarcely ever prolonged into a beak.

61. Perigynia not inflated (slightly so in No. 55,56 ), smooth, nerved or nerveless, with a minute straight point, glaucous-green, becoming whitish, or more or less spotted or tinged with purple. Scales blackish-purple or brown. Stanninate spikes 1-3, or the terminal spike androgynous and staminate at the bast, the rest all fertile. No. 46-64.

2. Perigynia slightly inflated, smooth, nerved, obtuse aud pointless, or with a straight or oblique point. Scales brown, beconing tawny or white. Staminate spike solitary (except sometimes in No. 71) or andrugynous and pistillate above, the rest all fertile. No. $65-81$.

3. Perigynia slightly iuflated, hairy (in No. 83 smooth at maturity), terved, with a minute straight point. Terminal spike andrugynous, pistillate at the apex, the rest all fertile. No. $82,83$.

4. Perigynia not inflated, smooth, regularly striate, with a short, entire, ubliquoly bent or recurved point, remaining green at maturity. Staminate spike solitary. Bracts green and leaf-like (except in No. 84). No. 84-91.

6. Perigynia not inflated, smooth or downy, not striate, with a minute, obliquely bent, white and membransceous point, reddish-brown or olive-colored at maturity. Terminal spike all staminate or with 2-3 fertile flowers at the base; the rest all fertile, or with a few sterile flowers at the apex. Bracts reduced to colored sheaths, or with a short green prolongation. No. $92,93$.

* * Perigynia with a distinct beak, either short and abrupt, or more or less prolonged.

B. Perigynia not iuflated, hairy, with a rather abrupt beak, terminating in a membranaceous notched or 2-twothed orifice. Bracts short : culmy mostly low and slender; leaves all radical, long and narrow. Staminate spike solitary. No. 94-101.

7. Perigynia slightly inflated, hairy or smooth, with a short beak terminating in an entire or slightly notched orifice. Bracts long and leaf-like : culms tall and leafy. Staminate spike solitary (in No. 102 pistillate at the summit): fertile spikes erect (except in No. 102). No. 102, 103.

8. Perigynia slightly inflited, smooth and shining, green, few-nerved or nerveless, with a straight tapering beak terminatiug in 2 small membranaceous teeth. Stuminate spike solitary (often androgynous in No. 107): fertile spikes all on slender and pedulous stalks. No. 104-110.

8. Perigynia slightly inflated, smonth, nerved, with a tapering somewhat serrulate beak, terminating in 2 distinct menhranacenus teeth; becoming tawny or yellow at maturity. Staminate spike solitary. No. 111-115.

10. Perigynia slightly inflated, rough or puhescent, rarcly smouth, with an athrupt straight besk. Staminate spikes usually two or more. No. 116-119.

11. Perigynia moderately inflated, smooth or pubescent, conspicuously many-nerved, with a straight beak terminating in 2 rigid more or less spreading teeth. Staninate spikes 1-5. No. $120-127$.

12. Perigynia much inflated, smooth, conspicuously many-nerved, with a long tapering 2 toothed beak. Stuminate spike golitary. No. 128-136.

13. Parigyula mach inllates, obuvoild or obenic, amosth, few-nerved, with an extremely abrupt, very long, 2-towtheal beak, tawny or straw-colored at maturity, horizontally spreasing or deflexed. Terminal spike staminate, or androgynous and fertile at the apex. No. $137-138$.

14. Perigynia much inflated, smooth, shining and straw-colored at maturity, with a tapering and uore or less elongatel 2-toothed beak. Staminate spikes 2-5. No. 139-151. 
A. Spike solitary, simple; its scales or bracts small and scarious or colored (never green or foliaceous). Psyluópurona, Loiscleur.

\$ 1. Spike diacious, or the frrtile morrly with a frow staminate fonvers at the base.

1. C. gynócrates, Wormskiold. C'ulm und bristle-form rndienl lenves smooth, or minutely rough at the top; sterile spike linear; fertile spike ovoid, loosely flowered; perigynia oblong, short-beaked, with a white membranaceous obtusely 2-toothed apex, narrowed at the base, nerved throughout, smooth, sprealing horizontally at maturity, longer than the arute or acutish scale; stigmas 2. - Swamps, Wayne and Genesce Co., New York (Sartuell, \&e.), Michigan, and northward. (Eu.)

2. C. scirpoídea, Michx. Leaves flat; spike narrowly cylindrical ; perigynia ovoid, with a minute point, denscly hairy, clark purple at maturity, about the length of the pointed ciliate scale ; stigmas 3. (C. Wormskioldiàna, IIornem. C. Michaìxii, Schw.) - Alpine summits of the mountains of Maine and New IIampshire, Willoughby Mountain, Vermont (Iood), Drummond's Island, Michigan, and northward. (Eu.)

\section{§2. Spike androgynous, staminate at the summit. \\ * Stigmus 2 : leaves bristle-form.}

3. C. capitata, L. Spike small, roundish-ovoid ; perigynia broadly elliptical with a notched membranaceous point, compressed, smooth, spreading, longer than the rather obtuse scale. - Alpine summits of the White Mountains, New Hampshire, Robbins, Oakes. (Eu.)

* Stigmas 3 : leaves very narrow, shorter than the culm.

4. C. pauciflora, Lightfoot. Spike few-flowered; sterile flowers 1 or 2 ; perigynia awl-shaped, reflexed; scales deciluous. (C. leucoglochin, Ehrh.) Peat-bogs, from New England and W. New York northward. (Eu.)

5. C. polytricholdes, Muhl. Culm capillary; spiko very small, fewflowered; perigynia erect, alternate, oblong, compressch-triangular, obtuse, slightly nerved, entire at the apex, green, twice the length of the ovate scale. (C. leptàlen, Wuhl. C. microstàchya, Michx.) - Low grounds and bogs: very common.

* * Stigmas 3: leaves very (about $1^{\prime}$ ) broad, longer than the naked culm.

6. C. Fraseriàna, Sims. Pale or glaucous and glabrous; leaves without a midrib, many-nerved, smooth, with minutely crisped cartilaginous margins $\left(9^{\prime}-18^{\prime}\right.$ long), convolute below around the base of the scape-like culm: spike oblong, the fertile part becoming globular; perigynia ovoid, inflated, mucronatcly tipped with a minute entire point, longer than the scarious oblong obtuse scale; often enclosing a short appendage at the base of the achenium. - Rich woods, mountains of Pennsylvania ? Virginia, and southward : rare, and a most semarkable plant.

B. Spike solitary, simple, androgynous, staminate at the summit: bracts and scales of the pistillate flouers green, leaf-like, tapering from a broad base, the lowest much longer than the spike, the uppermost equalling the slightly inflated perigynia: style jointed at the base: stigmes 3. (Leaves long and grassy, much exceeding the short almost radical culms.) PuYlióstacirys, Torr. \& Gr. 
7. C. Willdenòvii, Schk. Slerile flawers 4-8, closely imbricated; perigynia 6-9, somewhat alternate, oblong, rough on the angles and tapering beak; achenium oblong, triangular, finely dotted; stigmas downy. - Cupses, Mass. to N. Virginia and westward.

8. C. Steudélii, Kunth. Sterile flowers 10-15, rather loosely imbricated into a linear (apparently distinct) spike; perigyric 2-3, roundish-obovoid, smooth, with a long and abrupt rough beak; achenium roumdish, obseurely triangular, very minutely dotted; stigmas downy. (C. Jamèsii, Schw.) - Woody hillsides, N New York to Illinois and Kentucky.

9. C. Báckii, Boott. Sterile flowers 3 , inconspicuous; perigynia 2-4, loose, globose-ovoid, with a conicul beal, smooth throughout; achenium globose-pyriform, scarcely dotted; stigmas sinooth. - Rocky hills, WV. Massachusetts (Mount 'Tom, Prof. Whituey), and N. New York to Ohio, Iake Superior, und northward. Culms gencrally shorter, and the leafy scules broader and more conspicuous, than in the last two.

C. Spikes scverul or numerous, androyynous (rarely diœcious), sessile, forming a compact or more or less interrupted sometimes paniculate-compound inflorescenco : stigmas 2: achenium lenticular. VIGNìA, Bcauv.

\$1. Spikes approximated, the staminate and pistillitte fluvers variously situated: perigyuia plano-convex, nerved, with a rough slightly toothed beak : bracts light brown, resembling the seales, or with a prolonged point, shorter than the (at maturity) brown and chaffy spikes. - Siccdras.

10. C. bromoides, Schk. Spikes 4-6, alternate, oblong-lanceolate, some of the centrul ones wholly fertile; perigynia erect, narrow-lanceolate with a tapering point, solid and spongy at the base, longer than the lanceolate scale; style juinted at the base. - Swamps : common. - Slender, oceasionally dicecious.

11. C. siccàta, Dew. Spikes 4-8, ellipsoid, the uppermost and commonly 1-3 of the lowest fertile below, the intermediate ones frequently all staninate; perigynia ovate-lanceolate, compressed, with a long rather abrupt beak, about tho length of the scale; style minutely hairy. (C. pállicla, C. A. Meyer.) - Sandy plains, New England to Illinois, and northwestward.

12. C. dísticha, Inds. Spikes numerous, short and ovoid, the upper or middle ones frequently almos: all staminate, the lower principally or entirely fertile; perigynia ovate-lanceolate, the margins not united to the top, leaving a deep eleft on the outer side; seale ovate, pointed, nearly the length of the perigynium. (C. intermèdia, Grood. C. Sartwéllii, Lew., and former editions.) - Seneca Co., New York (Sartwell) to Illinois, Wisconsin, and northward. (Eu.)

$\S 2$. Spikes pistillate below, staminate at the summit.

* Perigynia of a thick and corky texture, with a short 2-toothed roughly margined beak, nerved towards the hase, dark chestnut-brown and poli-hed at maturity: spikes decompound, paniculate: scales light brown, with white membranaceous margins; the bracts at the base resembling them, and with a short bristly prolongution. - Panicuidta.

13. C. teretiúscula, Good. Spikes with short appressed branches, crowded in a slemder spiked panicle; perigynia ovate, unequally bironvex, shortbtalked, with $3-5$ shoit nertes on the onter side mar the broul somewhat heart-shaped 
base; senle nente, rather shorter than the perigynium; achenium obovoid-pyriform, ditusely triangular. (C. paniculata, var. teretiuscula, Wuhl.) - Swamps, especially northward. (Eu.)

Var. major, Koch. Spikes more panicled; perigynin rather narmwer. (C. Ehrlartiann, IIoppe. C. prairien, Mrus.) - Bogs und low grounds, New England to Wisconsin, and northward. (Fin.)

14. C. decompósita, Muhl. Panicle large, with very numerous denselycrowded spikes on the rather short spreading branches; perigynia obovite, unequally bionnvex, sessile, with a short very abrupt beak, conspicionsly nowed on each side, about the length of the ovate pointed scale. (C. paniculata, var. decomposita, Dow.) - Swamps, W. New York (Sartudl) to Pennsylvania, Illinois, and southwestward.

* Perigynia small, compressed, 2-3-nerved, membranaceous, with a short 2-toothed rough beak, yellow or brown at maturity : spikes decompound, with numerwus small very densely-fowered hends: scales of the fertile spikes tawny, with the green keel prolonged into a rough point: bracts short and resembling them at the base, or often becoming green and bristle-shaped, and much exceeding the culm. - Murtiflòrs.

15. C. vulpinoídea, Michx. Spike oblong and dense, or more or luss interrupted $\left(1 \frac{1^{\prime}}{2}-2 \frac{1}{2}^{\prime}\right.$ long), of $8-10$ crowded clusters; perigynia ovate from a broad base, with a more or less abrupt beak, diverging at maturity. (C. multiflòra, Muhl. C. bracteòsa and C. polymórpha, Schw. C. microspérma, Wahl.) - Varies with the perigynium narrower, and the beak tapering and more strongly serrulate. (C. setacea, Dew.) - Low meadows : every where cornmon.

* * Perigynia on short stalles, plano-convex, without a margin, membranaccous, with a thick and spongy base and a long tapering 2-toothed rough beak, distinctly nevied (only obscurely so in No. 19 and 20), widely spreading and yellow at maturity : spikes dense, more or less aggregated, sometimes decompound: scales of the fertile spikes tawny, with a sharp point: bracts bristleshaped, shorter than the thick and triangular culms. - VuerteE.

16. C. crus-córvi, Shnttleworth. Spike very large, decompound, the lower branches long and distinct, the upper shorter and aggregated; bracts ofen 2-toother at the base: perigyniu attenuated f,om an ounte diluted and trunoute base into a very long slighly-vinged beak, murk exceding the scale; style.tumid at the base. (C. sicaformis, Boott. C. Hàlei, Dew.) - Swamps, Ohio to Wisconsin, and southwestward. - A conspicuous, very large species, with spikes $4^{\prime}-9^{\prime}$ long, often somewhat paniculate, and glaucous laves $6^{\prime \prime}$ wide.

17. C. stipata, Muhl. Spikes 10-15, aggregated, or the lower mostly distinct and sometimes compound; perigymia lanceolate, with a long beak tupering fiom a truncrite brox, many-nerved, much excenling the sorle; style slightly tumid at the buse. (C. vulpinoider, Torr., Cyp., not of Michx.) - Low grounds : common. - Culm flaceid : spikes pale.

18. C. conjuncta, Boott. Resembles the proceding; but the spikes (6-12) more simple; perigynia ovate froin a subcondate flat (not corky-tumid) base, shortheaked, fewer-nerved, longer and broader than the pointed scale; style bulbous at the base. (C. vulpina of former editions;-from which it 
differs in its flaccid culn, transversely wrinkled sheaths, orbicular aehenium, \&c.) - Ohio to Illinois and Kentucky.

19. C. alopecoídea, Tuckerman. Head of 8-12 aggregated spikes, oblong, dense; perigynia compressed, nerveless or very obscurely nerved, ovate from a broad truncate or somewhat heart-shaped base, a little longer than the scale; achenium pyriform; buse of the style not tumid. (C. cephalophora, var. maxima, Dew.) - Woods, W. New York to Peun., Michigan, \&c. - Resembles the last, but smaller, with shorter and more compact spikes; easily distinguished by the nearly nerveless perigynia, and the different achenium and style.

20. C. muricata, 1. Spikes 4-6, ovoid, upproxinate but distinct, the lowermost sometimes a little remote; perigynia ovate-lancelate, somewhat compressed, nerveless, or very ubscurely nerved towards the base, rather longer than the scale; acheniun orate; hase of the style not tumid. - Ficlds, Massachusetts (introduced?), Ohio, and Kentucky : rare. - Spikes mostly looser than in the last, the perigynia narrower, with a longer and more tapering beak. (Eu.)

****Periyynia sessile, plano-convex, compressed, more or less margined, membranaccous, with a rather short and rough (or wholly smooth in No. 26) 2-toothed beak, spreading and green at maturity: scales of the fertile spikes tawny or white : bracts bristle-shaped, commonly shorter than the culn. MuHLendergiande.

21. C. sparganioldes, Mull. Spikes 6-12, ovoid; the upper ones agyregated, the lower distinut and more or less distunt; perigynia broudly-ocute, nerveless, rongh on the narrow margin, about twice the length of the ovate-pointed scale; achenium roundish-ovute; style short, merely tumid at the base. - Var. Mìnon, Boott, is merely a reduced form. (C. cephalophora, var. Torr. C. muricata, var. cephaloidea, Dew. (.. cephaloidea, Dew. in part.) - Low rich grounds. A robust species, with rather wide palc-green leaves; sometimes with $1-2$ short branches of a few spikes each at the base of the compound spike (probably $\mathrm{C}$. divulsa, Pursh, not of Goorlenough).

22. C. cephaloidea, Dew. (in part), Boott. Spikes 5 or 6, contiguous; the broully ovate periygnia wing-margined, spongy at the base, shorter beaked, equalling or shorter than the cuspidate-tipped scale; style bulbous at the base. New York? Illinois ( Vasey). - Much resembles and has been confounded with the small form of the foregoing.

23. C. cephalóphora, Muhl. Spikes 5-6, small, and densely aggreyated in a short ovoid head; perigynia broadly ovate, with $3-4$ indistinct nerves on the outer side, scarcely longer than the ovate roughly-pointed scale; acheniun and style as in the last. (C. eephaloidea, Dew. (in part.) - Var. Angustriólia, Boutt, is a narrow-leaved, smaller form. (C. Leavenwórthii, Dew.) - Woods and ficlds : common.

24. C. Muhlenbérgii, Schk. Sprikis 3-9, closcly approximate, forming an oblong haul; perigynia orbicular-ovate, with a very short beak, prominently manynerved on loth sides, absut the length of the ovite roughly-pointed scule; achenium orbicular, with a very short bulbous style. - Fields : rather common, especially southward. - Culus 12' $-18^{\prime}$ high, and with the leaves pale and rigid: comamonly with a bract to ench spike. 
Var. enérvis, Boott. Scales sometimes pointless; perigynia nearly or wholly nerveless; spikes often bractless. - Hudson River, New York, J. L. Russell. Distinguished from C. cephaloidea by its rigid culm, narrower leaves, and firmer perigynium, spongy at the base.

25. C. rosea, Schk. Spikes 4-8, the 2 uppermost approximate, the others all distinct, and the lowest oflen remote; perigynia oblong (about 8-10 in each spike), narrow at the base, widely diverging at maturity, twice as long as the broadly orate obtuse scale. - Var. MiNor, Boott, has the 4-6 spikes smaller and more separated, the scales less obtuse and with a rough mucronate point; perigynia more erect; leaves narrower. - Var. radidta, Dew, is still more slender, almost capillary, and has only 3 or 4 remote and $3-4$-flowered spikes. (C. neglécta, Tuckerm.) - Moist woods and meadows : common.

26. C. retrofléxa, Muhl. Spikes 3-6, all approximute, the 1-2 lowest distinct but not remote; perigynia (about 5-7 in each spike) ovate, or ovate-lanceolate, smooth on the murgin and beak, not much exceeding the ovale-lanceolute pointed scale, widely spreading or reflexed at maturity. (C. rosea, var. retroflexa, Torr., Cyp.) - Copses and moist meadows: less common then the last, from which it is distinguished by the smaller approximate spikes, longer and sharper scales, and especially, from every species in this subsection, by the smooth perigynium.

***** Perigynia plano-convex, without a beak, of a thick and leathery texture, prominently nerved, smooth (except on the angles), with a minute and entire or slightly notched white membranaceous point : achenium conformed to the perigynium, crowned with the short thick style: bracts like the scales (brown), the lowest with a prolonged point: rootstock creeping. - CHORDorHizs.

27. C. chordorhiza, Ehrh. Culms branching from the long creeping rootstock $\left(4^{\prime}-9^{\prime}\right.$ high), smooth and naked above, clothed at the base with short appressed leaves; spikes in an ovoid head; perigynia ovate, a little longer than the scale. - Cold bogs, New York to Wisconsin, and northward. (Eu.)

28. C. tenélla, Schk. Spikes 2-6, very small, ruther remote, or the upper approximate, with 2 or 3, rarely 4, fertile flowers; perigynia ovate, twice as long as the scale. (C. loliàcea, Schk. suppl., not of $L$. C. dispérma, Dew. C. gracilis, El. 1, not of Ehrh.) - Cold swamps, New England to Penn., Wisconsin, and northward. - A slender species, $6^{\prime}-12^{\prime}$ high, with long grassy leaves, growing in loose tufts. (Eu.)

§ 3. Sprikes pistillate above, staminate at the base.

* Spikes roundish-onid, rnther small, more or less distant on the zigzag axis (closely aggregrated in No. 30) : perigyniu plano-convex, smooth, pale green, becoming whitish or silvery: scales white and membranaceous; the bracts resembling them, or prolonged and bristle-shaped. - Caniscéntes.

- Perigynin mostly somewhat thickened and lenthery, distinctly nerverl, and with a smooth or minutely serrulule short point, entive or slightly notched at the apex.

29. C. trisperma, Dew. Sprikes 2-3, very smmll, with uhout 3 fertile flou ers, remote, the lowest with a long bract; perigynia oblong, with numerous slender nerves, longer than the scale. - Cold swamps and woods, especially on mountains, New England to Penn., Michigan, and northward. - Resembling the last, but larger spikes and fruit, and weak spreading culms, $1^{\circ}-2^{\circ}$ long.

() M 2.5 
30. C. tenuiflora, Wahl. Spikes 3, few-flowered, closely approximated; perigynia ovate-olilong, about the length of the broadly ovate scale. - Cold swamps, N. New Euglaud to Wisconsin, and northward. (Eu.)

31. C. canéscens, L. (in part). Pale or glaucous; spikes 5-7 (about 12-20-fluwered), the upper approximaled, the rest distinct, the lowermost remote; perigynia ovate, equalling the pointed scale. (C. curta, Good. C. Ricliàdi, Michx.) - Marshes and wet meadows . common, especially northward. (Eu.)

Var. vitilis is a more slender and weak form, not glaucous, with smaller and roundish 6-15-flowered spikes, the more pointed perigynia spreading (and often tawny) at maturity: perhaps a good species. (Var. alpícola and var. spharostuchya, Ed. 1. C. tenella, Ehrh. C. Persoonii, Sieber. C. vitilis, F'vies. C. Gebhardi, Hoppe. C. sphwrostachya and C. Buckleyi, Dew.) - On mountains, and high northward. (Eu.)

32. C. Norvègica, Schk. Pale; stem $1^{\circ}$ or less high, angled; spikes $2-5$, rather approximate, oblong, short-bracted, with a few staminate flowers below the numerous fertile ones, or the terminal one all staminate; perigynia oval or oblong, lenticular, many-nerved, with a short entire beak, equalling the obtuse scule. - Salt marsh, Wells, Maine, Rev. J. Blake. (Eu.)

+ +Perigynia thin, spongy-thickened at the base, scarcely nerved, 2-toothed.

33. C. Deweyana, Schw. Spikes about 4 ; the 2 uppermost approximate, the others distinct, the lowest long-bracted ; perigynia oblong-lanceolate, tapering into a rough serrate-margined beak, rather longer than the sharply pointed or awned scale. - Copses, New England and New York to Wisconsin, and northward.

* * Spikes ovoid or obovoid, more or less clustered; perigynia concaice-convex, compressed, maryined or winged, nerved, with a rough 2-toothed beak, often tawny at maturity: scales tawny or white, awnless : bracts bristle-shaped, usually falling before the maturity of the spikes.

- Spikes snuall: perigynia usually (but not aluays) becoming spongy-thickened at the base, the margins rigid. - SteLldLAta.

+ Spikes completely or incompletely dicecious.

34. C. exilis, Dew. Spike commonly solitury and cylindrical, diocious or androgynous (staminate) and contracted below, often with $1-6$ small additional fertile spikes contiguous to the terminal larger one; perigynia veate-lanceolate, plano-convex, with a few fine nerves only on the convex side, spreading, turning brownish, longer than orate acute or obtuse scale; leaves involute-filiform. Swamps, L. New England to New Jersey, near the coast: also borders of mountain lakes, lissex County, New York.

35. C. stérilis, W'illd. Spikes 4-6, all staminate and rarely all pistillate on some plants, many androgynous, especially the lower spikes, all oblong or the fertile roundish; perigynia ovate from a broad somewhat hair-shaped sharply margined base, flat, diverging or the lower recurved, very aeutely 2-toothed at the apex, about equalling the acute or pointed scale; leaves marow, involute, fale. (C. stellulata, var. sterilis, of former ed.) - Swaups and wet meadows: common, especially northward. 
++ Spikes andongynous.

36. C. stellulata, L. Spikes 3-5, the uppermost much contracted at the base by the numerous staminate flowers; perigynia ovate or slightly heartahaped at the base, which has thickish or obtuse margins, the upex more minutely toothed; scales rather blunt and considerably shorter; leaves flatter and pale: otherwise nearly as in the last. - Lake Superior and northward. (Eu.)

Var. scirpoldes. Culms slender and weak $\left(9^{\prime}-20^{\prime}\right)$; leaves very narrow ; spikes contiguous, smaller; perigynia with a rounded or truneate base, planoconvex, nlmost twico the length of the obtuse scale. (C. scirpoides, Schk.) Wet places : common.

Var. angustata, is remarkable for the narrow lanceolate perigynia more than twice the length of the blunt scale and oblong acheniun: otherwise as in var. scirpoides. - Fairfield, New York.

+ + Spikes rather large: perigynia thickened and spongy on the angles, with a more or less dilated membranuctous margin or wing. - Ovì LEs.

37. C. sychnocéphala, Carey. Spikes densely clustered, forming a short compound spiked head, subtended by 3 very long and unequal persistent leufy bracts: periqynia tapering from an abruptly contracted ovate base into a long slender beak, somewhat excecling the lanceolate abruptly mucronate scale. (C. cyperoides, Dow., not of L.) - Jefferson County (Vresey \& Knisskern) and Iattle Falls, New York, Vasey. - Different in habit from the rest of this section; recognized at once by the ovoid compound spike, subtended by long leafy bracts, by which the lower spikes are partly concealed.

38. C. árida, Schw. \& Torr. Spikes 8-10, approximate (3' long), oblong. cylindrical, contracted at each end; perigynia narrowly lanceolate $(4-5$ lines in length), tapcring into a long beak more than twice the length of the ovate-lanccolate scale; achenium sessile, narrowly oblong. (C. Muskinguménsis, Schw.) - Wet mearlows, Ohio to Wisconsin and Kentucky. - In characters scarcely distinguished from the next, but strikingly different in appearance; much larger, with long, dry, and chaffy-looking spikes.

39. C. scoparia, Schk. Spikes 5-8, club-shaped, at length ovate, more or less approximate, sometimes forming a dense head; perigynia elliplical.lanceolate, tapering into a long slender beak, longer than the lanceolate pointed scale; achenium distinctly stalked, exactly oval. - Low meadows : everywhere common. - Spikes brownish or straw-colored when ripe. - Var. Minon, Boott. Spikes more rusty, smaller, contiguous; perigynia narrowly lanceolate. - Base of White Mountains, New Hampshire, and northward.

40. C. lagopodioldes, Schk. Spikes 10-15 or more, approximate, or the lower more separated; perigynia lancelate, nearly twice the length of the ovateoblong rather pointed scule; achenium narrowly oval, on a short stalk; leaves very tapering to the apex; their sheatlis loose, enlarging upwards, sharp-edged. Moist, rather shady places: common.

41. C. cristàta, Schw. Spikes smaller, 8-12 closely aggregated, globular, greenish; perigynia oblong or ocate, recurved at maturity ; senles olifuse; otherwise as in the last, of which in former editions it was taken for a variety. - Wet or moist ground: common. 
Var. mirábilis, Boott, has broadly ovate perigynia with a shorter beak, longer than the acute scale. (C. festucacea, var. mirabilis of former editions. C. mirabilis, Dew.) - Mass. to Ohio, \&c.

42. C. adústa, Boott (not of former ed.). Spilses 4-10, pale or brown, globular, or the upper club-shaped, the lower remole and sometimes compound; perigyniu ovul, onate, or roundish, gradually tapering to a beak, muny-nerved, with the narrow wing wider above the midlle, turgid at maturity, equalling the scale in length and breadth; achenium large, orbicular, sessile. (C. argyrántha, Tuckerm., is a very delicate form of this, found in rocky woods.) - Moist copses, \&e., from Rhode Island (Olney) and New Jersey (Kneiskern), northward and westward: rare.

43. C. fònea, Willd. Spikes 3-8, pale or silvery green, finally straw-colored, mostly approximate, ovoid, generally acute, the uppermost contracted or club-shaped at the sterile base; perigynia oval, orbicular or obvoate, short-beaked, broadly winged, appressed, transversely wrinkled, a little longer than the ovate or lanceolate white scale; achenium on a short stalk, oval. - Sandy and mostly salt or brackish marshes, \&e., along the coast, from New England southward.

Var.? ferrugínea, refirred here by 1)r. Boott, with rusty-colored acute spikes, and longer-beahed perigynia, generally acutish at base and exceeting the acute or mucronate sealc (Ohio, Sullicant), connects this with C. straminea.

Var.? sabulonum, also relerred here by 1)r. Boott, has 2-10 drooping rather remote spikes, more or less obovate or club-shaped, contracted at base, pale green turning stritw-color; perigynia broadly winged at base, slightly exceeding the pointed sciale: it is C. adústa of former editions, not of Boott. Sands of the sea-shore firom Maine southward. - Leaves narrow, often involute.

44. C. straminea, Schk. S'pikes 2-12, pale or kuwny, varying from obovate-globular to club-shaped, contiguous or rather remote; perigynia orbicularovate or oval, often heart-shaped at base, very flut, abruptly contracted into a short or tapering into a longer beak, winged, much wider and commonly longer than the usually acute or pointed scale; achenium nearly sessile, oval. - Open grounds and borders of woods: common, and very variable. The following are the varieties designated by 1)r. Boutt. - Var. TÝPICA, with 3-6 roundish spikes; perigynia spreading, broatly winged, rather longer and much broader than tho scale. - Vau. TÉneks, more slender and delicate, with 3-6 smaller oval or obovate spikes, more tawny; perigynia with a short and broad beak, rather longes and brvatder than the scale. (C. tenera, Dew. C. fistucacea, var. tenera, of former ed., in part.) - Var. AṔ́rTA. Spikes 4-8, tawny, tapering at base, drooping; perigynia long-beaked, thrice the length of the very sharp-pointed scale, loosely spreating in the spike. - Var. restucacea. Spikes 5-8, club. shaped, tawny or greenish; perigynia abruptly short-beaked and mostly narrowly winged, longer than the acute or mucronate scale; plant tall and rather rigid. (C. lestucacea, Sckk, aud former ed.) - Var. Ir Yalina, a chiefly Western form, approaching the ucxt species, with larger and thick pale spikes, usually 6 , all tapering at hase; perigynia greenish, with a wile spongy wing, and a long beak, alout ewice the length of the brown pointless scale; rather tall and stout, with broad leaves. (C. straminea, var. Crawei, Buott; but probably by some mistake said to be collected in Michigan by the late Dr. Crawe. C. hya- 
linn, Boott, is a small Texan form of it.) - Var. MEגolx (Illinois, Dr. Mead), resembles the last, but has rather smaller and rounder spikes, thinner wings to the perigynin, and long-tnpering or rongh awn-pointed seales.

45. C. alàta, Torr. Spikis 3-10, pule, lurgiet-ovoill, contiguons, mosılyy large $\left(6^{\prime \prime}-10^{\prime \prime}\right.$ long); perigynia dilated orbicular or obvale, brourlly winged, abruptly short-beaked, either heart-shaped or wedge-shaped at the base, longer and thrice broader than the lanceolate or ovate acute or rough awn-pointed scale; achenia stipitate. - W. New York (Sartwell) to Virginia and southward. - All these, from No. 38 to the present, run together variously.

D. Staminate and pistillate flowers borne in separate (rommonly more or less stalked) simple spikes on the same culm; the one or more staminato (sterile) spikes constantly uppermost, having occasionally more or less fertile flowers intermixed; the lower spikes all pistillate (fertile), or sometimes with staminate flowers at their base or apex : stigmas 3 : achenium sharply triangular (only usually 2 stigmas and the achenium lenticular in No. 46-56, 65, 149, 150). CAREX proper.

§ 1. Perigynia without a beak, or scarcely any, smooth, not inflated (slightly in No. $55,56)$, terminating in a minute, straight, entire or notched point, glaucous-green when young, becoming whitish, often spotted or tinged with purple, or occasionally nearly black at maturity: pistillate scalrs blackish-purple (barely brown in No. 55, 56. 64), giving a dark appearance to the spikes.

* Sterile spikes 1-3, stalked, often with more or less fertile flowers: pistillute spikes 3-5, fiequently with sterile flowers at the npex: bract of the lowest spike leaf-like, mostly with dark-colored expansions (auricles) at the base, and very minute sheaths or none. (Culm and leaves more or less glancous.)

+ Stigmas 2 (in No. 46 and $47^{\circ}$ sometimes 3 ) : perimynia Ienticular. - Acút ש. + Alpine, saxatile: pistillate scales pointless: leaves fat.

+- Scales anmless, mostly olifuse.

46. C. rigida, Good. Sterile spike solitary; the fertile 2-4, cylindrical, erect, rather loosely flowered, the lower on short peduncles; lowest bract about the length of the culm, with rounded auricles; stigmas $2-3$; perigynia elliptical, with an entire scarcely pointed apex, nerveless, about as long as the obtuse scale; culm rigid, nearly smooth except towards the top, about the length of the firm erect leaves. (C. saxátilis, $F l$. Dan., partly of L.) (Eu.) - Our plant is the

Var.? Bigelòvii (C. Bigclovii, Torr. C. Washingtònia, Dew.), with 3-5 longer and laxer fertile spikes, the lowest long-stalked, spreading, and sometimes remote; the sterile or terminal one often fertile at the top; perigynia more or less nerved : perhaps a distinct species. - Alpine summits of the mountains of New England, New York, and high northward.

+ Not alpine, paludose : pistillate scales awnless, single-nerved.

a. Leanes with imolute margins when dry; their sheaths not fibrillose.

47. C. vulgàris, Fries. Sterile spike $1-3$; the fertile $2-4$, approrimated, oblong, erect, densely-flowered, occasionally staminate at the apex, the lowest on a very short stalk; lowest bract barely the length of the culm, with small blackish rounded auricles; perigynia ovate-elliptical, stalked, nerved especially towards the base, with a very short abrupt entire or minutely notched point, longer than the obtuse appressed black scule; culm slender, sharply triangular, 
nearly smooth, except at the top. (C. acùta, var. vulgaris, $L$. C. cxspitòsa, of authors.) - Wet bianks, \&c. New England to Wisconsin and northward. Grows in small patehes (not in dense tufts like No. 50), and varies in height from $3^{\prime}$ to $18^{\prime}$, with narrow leaves shorter than the culn. (Eu.) The fullowing may be appended.

47². C. límula, Fries? Fertile spikes less approximate or rather remote; their bructs surpassing the culn (at least the lowest) and with rougher magins; leaves longer and more numerous at the base of the rougher culn; perigynia nerveless; stigmas often 3 : otherwise like C. vulgaris. - E. New England, near Boston, W. Boott, who rather doubtfully identifies it with the Lapland plant. The specimens in IIcrl. Suec. Norm. differ in their flat leaves, and narrower, longer, and even pointed sciales. (Eu.)

48. C. aquátilis, Wahl. Sterile spikes commonly $2-3$; the fertile $3-5$, cylindrical, inclining to club-shaped, erect, densely-jlowered, sessile, or the lower on very short stalks; bructs long, $1-2$ lowest exceding the culm; perigynia abovateellipticul, stalked, nerveless, with a very short entire point about the length of the lanceolate scale; culm smooth, not much exceeding the pale-green glaucous leaves. - Margins of lakes and rivers, New England to Wisconsin, and northward. - Robust, $2^{\circ}-3^{\circ}$ high ; the thick fertile spikes $1^{\prime}-3^{\prime}$ long. (Eu.)

b. Leaves with more or less revolute maryins when dry; sheaths at length filnillose, i. e. when old splitting up or resolved more or less into slinder parullel or lursely reticuluted fibres.

49. C. tórta, Boott. Sterile spikes $1-2$, commonly 1 , fertile 3-4, elanyated, narrowly-cylindical or slighllly club-shaped, loosdy few-flowered at the buse, occasionally more or less staminate at the apex, the lower on smooth slender stalks, spreading or drooping; bracts with oblong auricles, or very slightly sheathing, the lowest about the length of the culn, the rest bristle-shaped, shorter than their respective spikes; perigynia elliptical, short-stalked, tapering to a distinct point, with a minutely notched or jagged membranaceous orifice, very smooth, nerveless, the empty tips spreading or obliguely recurved at maturity, scarcely exceeding the narrow obtuse scale; achenium broadly obovate, much shorter than the perigynium; culm very smooth, leaves short, slightly rough on the margin only. (C. acuta, var. sparsiflora, Dew. ?) - Rills and wet banks, N. New Lingland, New York, \&c., and along the mountains from Penn. southward. - Well marked by is smooth flaccid culm $\left(12^{\prime}-18^{\prime}\right.$ high $)$, soft and short grassy leaves, und the tortuous empty apex of the perigynium.

50. C. apérta, Boott. Sterile spikes 1-2, oblong-cylindrical, acute; fersile 2-4, oblong, ereet, the uppermost approximate and sessile; the lower distunt and short-stalked, staminate at the apex, or often entirely fertile; lowest bract about the length of the culm, with oblong brown auricles, or very slightly sheathing, the upper bristle-shaped, shorter than the spikes; perigynia roundish-ovate, stalked, wilhout nerves, covered with very minute transparent dots, and sometimes very

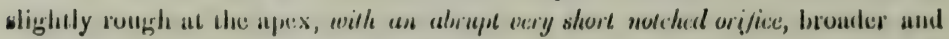
masch shorter than the lanceshate pointed brvewn scale; culus sharply triangular, smooth below, exceeding the rongh sharp-pointed leaves. - Wet mendows, Rhode Island and Mass. to Illinois and far westward. - Culm 10-20 high, with commonly 
2 fertile spikes $9 "-18^{\prime \prime}$ in length, nppearing somewhat bristly from the long and spreading scale. Differs from the next chiefly in the rounder perigynium and nearly smooth culm, ancl should perhaps be referred to it.

51. C. stritata, Lam. (not of (ioorl.) Sterilo spikes 1-3; the fertile 2-4, cylindical, slender, usually letren ut the summit, sessile, or the lower on a short stalk; lower bract with rounded or oblong brown auricles, seldom exceeding the culm ; periqynia ovate-acuminate or ellipticnl, nertelsss, or very obscurely fewnerved, often mimutely rough on the short, entire, or slightly notched point, usually shorter and broader than the narrow reddish-brown seale; culm slender, sharply triunular, rough, longer than the narrow and rigid rongh and glaucous leaves; their older sheaths with conspicunus reticulated fibres. (C. acìta, Mfuhl., \&c., not of $L$. C. Virginiàna, Smith in Rees, Cycl. C. acuta, var. crecta, Dew. C. angustàta, Boott.) - Var. stríction has shorter and more denscly flowererl fertile spikes, and perigynia equalling or somewhat exceeding the scale. (C. strictior, Dew.) - Wet meadows and swamps : very common. - Grows in large nnd very compact tufts: culms $2^{\circ}-2 \frac{1}{2} \circ$ high. Scales of the fertile spikes very variable; the lower commonly acute, the upper narrower and obtuse. (C. xcrocárpa, S. II. Wright, in Dew. Cut., scems to be a mere statc of C. stricta.)

52. C. lenticularis, Michx. Sterile spike single and mostly fertile at the top; the fertile $2-5$, erect, cylindrical $\left(6^{\prime \prime}-12^{\prime \prime}\right.$ long), sessile, or the lower shortpeduncled, densely-flowered; bracts exceeding the culm; perigynia ovate-oval, sessile, more or less nerced, abruptly short-pointed, the point entire, slightly exceeding the oblong and very obtuse scale; culm $\left(6^{\prime}-20^{\prime}\right.$ high $)$ and leaves smooth or nearly so, palc. - Wet gravelly banks and shores, N. Maine (J. Blake, C. E. Smith), N. New York (Torrey, Knieskern, J. A. Paine), Upper Michigan (Prof. Porter, \&c.), and northward.

++ Paludose or maritime: pistillate scales awned or pointed from the broad and strong more or less triple-nerved centre or midrib.

53. C. saltna, Wahl. Sterile spikes 2-3; the fertile 2-4, cylindrical, ered, often sterile at the apex, on more or less included stalks; bracts long, with rounded auricles, the two lowest commonly exceeding the culm ; perigynia orateelliptical, with a minute entire point, nerveless, rather shorter then the roughly-awned dark-brown scale; culm $\left(1^{\circ}-2^{\circ}\right.$ high) rough at the top, rather exceeding the leaves. - Salt marshes, Massachusetts (Gieene, W. Boolt), Mainc (G. L. Goodale), and far northward. (Fu.)

54. C. maritima, Vahl. Sterile and fertile spikes each 2-4 (the latter rarely 5 or 6$)\left(1^{\prime}-2^{\prime}\right.$ long), spreading or drooping on slender peduncles; perigynia nearly orbicular, with a short entire point, much shorter than the long-auned greenish scale; culm $\left(1^{\circ}-2^{\circ}\right.$ high) and the broad fat lenves smooth. (C. paleacea, Wahl.) - Salt marshes, Cambridge and Medford, Mass. (Greene, W. Boott), Wells, Maine, (J. Blake) and northward: rare. (Eu.)

55. C. crinita, Lam. Sterile spikes 1-2, often with fertile flovers wriously intermixed; the fertile 3-5, long-cylindrical ( $2^{\prime}-3^{\prime}$ long), densely flowered, often staminate at the apex, on exserted nodding stalks; bracts very long, exceeding the culm ; perigynia roundish-olovate, slightly inflated, ohscurely nerved, with a short entire point, shorter than the oblong mostly notched roughly-serrate auned 
light-brown scale; cum $\left(2^{\circ}-4^{\circ}\right.$ high) rough and sharply angled above, leafy below; the pale leaves $\left(3^{\prime \prime}-4^{\prime \prime}\right.$ wide), rough on the edges, their surface and the sheaths smooth. - Varies in siza (but usually tall); and with the lower fertile scales of ten very long-awned, the fruit imperfect and deformed (var. мо́квоDA, Carey in Sill. Jour. C. paleàcea of author's). - Wet grounds by streaus : common.

56. C. gynándra, Schw., Boott. Slucuths rough with minute hairiness; fertile spikes rather thicker and looser, and oftener staminute at the apex; perigynia more ovate or oblong and elliptical; the scales longer and less spreading but mostly shorter-awned: otherwise as in the preceeling, - to which it is very nearly related. - In similar situations, but less common, from New England to 1'enn. and Michigan.

+ + Slignus 3: perigynium obtusely triamgrular, indistinctly few-nerved, more or less compressed : pistillate spikes on filifurm drooping stalks. - Lr mòsw.

57. C. Barráttii, Schw. \& Torr. Sterile spike mostly single, sometimes 2 or even 3, dark purple; fertile mostly 2 or 3 , cylindrical, commonly staminate at the top; lower bract usually shorter than the culm; sheaths obsolete or minute; perigynia oval or ovel-lanceolate, obliquely divergent, scarcely notehed at the point, about the length of the ovate and blunt black-jurple scale; culın $\left(1^{\circ}-2^{\circ}\right.$ high) sharply triangular, nearly smooth, longer than the glaucous flat leaves; the old sheaths at base splitting into threads. (C. flácea, of former ed., and probably a mere geographical variety of that European species.) - Marshes, New Jursey near the coast, Collins, Kinieskern; and 'T'ownsend, Delaware, W. M. C'unby.

58. C. limosa, L. Stuninate spike solitiry; fertile 1-2, ablong, 10-20flowered, occasionally with staminate flowers at the apex; bructs very narrow, the lowest shorter than the culm; perigynia ovate, with a minute entire point, about equal to the ovate mucronate dull or purplish-trown scale. - Peat-bogs, New England to Pemsylvania, Wisconsin, and northward. - Culm $6^{\prime}-12^{\prime}$ high, ereet, sharply triangular, longer than the acute und rigid keeled leaves. (Eu.)

59. C. rariflora, Siuith. Resembles the last (of which it was thought to be a variety), but smaller, $4^{\prime}-9^{\prime}$ high ; culm obtuse-angled; leaves flatter and rather broader; pistillate spikes with only 5-10 less crowded flowers; perigynia very short-pointed or bluntish, rather shorter than and involved in the broadly-ovate black-purple scale. - Mt. Katahdin, Maine (G. L. Goodule), and northward. (Eu.)

60. C. irrígua, Smith. Staminate spike solitary; the fertile 2-4, ovoid or oblong, occasionally staminate at the apex, or with a few sterile flowers at the base; lowrst bract as wide as the leaves, longer than the culm; perigynia roundishwate or doevate, with un entire orifice, much shorter than the hipering and stenderpointed dark purple scule. (C. Magellánica, Lam., according tu Boott. C. limùsa, var. irrigua, Wahl. C. paupércula, Michx.)-Peat-bogs, New England to Punn., Wisconsin, and northward. - Taller than No. 58, growing in loose clumps, with weaker and nodding stems, often exceeded by the leaves. (Eu.)

* * Uppermust spike club-shaped, pistillute abve and staminate at the base; the rest all fertile or with a few sterile flowers below : lowest bract leaf-like, scarcely equalling the culm, with minute light-brown auricles and no sheaths : culm and leaves of a pale glancous-green.- ATrAta. 
- Scales of the spike decp-colored, purple or dark broun.

61. C. Buxbaúmii, Wahl. Spikes 3-4, obovoid or oblong, the uppermost short-stalked (rarely altogether staminate), the others neurly sessile, the lowest somewhat remote; perigynia elliptical, obtusely trinugular, compressed, obscurely nerved, with a distinctly notched orifice, scarcely cqualling the ovate sharp-pointed or short-awned (brown-purple) scale. (C. canéscens, $L$., in part.) - Peat-bogs: not rare. (Eu.)

62. C. atràta, L. Spikes 3-4, oblong-ovoid, approrimate, all on short fliform stnlks, at length drooping; perigynia ovoill, with a short notched point, about the length of the ovatc acute or dark brown-purple scale. - Alpine summits of the White Mountains, New Hampshire. - About 12'-15' high, with rather rigid leaves, nearly equalling the culm. Fruit at first pale straw-color, often becoming dark purple or nearly black. Stigmas sometimes 2. (Eu.)

63. C. alpina, Swartz. Sprikes 3-4, small, oval or globular, crouded into a head at the summit of the slender naked culm, nearly sessile, mostly overtopped by a foliaceous bract; perigynia orbicular or obovate, pointed with a small short beak, minutely notched at the orifice, roughish, longer than the ovate bluntish black-purple scale. (C. Váhlii, Schk.) Isle Royale, \&c., Lake Superior, Prof. Whitney, $\dot{C}$. G. Loring, Jr., and northward. - Culms in ours $1^{\circ}-2^{\circ}$ high, the leaves all at the base: spikes $2^{\prime \prime}-4^{\prime \prime}$ long. (Eu.)

++ Scales and spikes greenish turning straw-color.

64. C. Shortianan, Dew. Spikes 3-5, cylindrical, erect, more or less distant $\left(\frac{1^{\prime}}{2}-1 \frac{1^{\prime}}{2}\right.$ long), and the lowest rather remote, all andronynous and densely fowered; the terminal one about half staminate, the rest with only a few barren flowers at the base, the lower on short stalks ; perigynia brondly obovate, abmutly contracted at the base into a short stalk, with an extremely mimute entire point, little longer than the short-pointed somewhat ohovate scale. - Marshes, S. Pennsylvania to Illinois and southward. - Plant $1^{\circ}-3^{\circ}$ high : leaves flat, $3^{\prime \prime}$ wide.

§ 2. Perigynia without a beak (except in No. 67, \&c.), smooth, slightly inflated, bluntly triangular, nerved, with an obtuse and pointless mifice, or $a$ short (and straight or ohlique) entire or notched point : bracts leaf-like, sheathing: staminate spike solitury (except sometimes in No. 71), or andronynous and pistillate above; the rest ull fertile.

* Staminute spike on an elevated stalk (rarely short-stalked or sessile, or with 1 -2 small ones at its hase) : pistillate spikes $1-6$, crect, the upper on very short, the lower on more or less elongated exserted stalks (short and included in No. 73): bracts shenter than the culm (except in No. 65 and 72): perigynia with an entire and strright or obliquely hent point, glawrous-green whon young, becoming $c$ xam-colored or yellow at maturity, sometimes spotted with purple; pistillate scales dark-brown with white margins, fading to tawny. (Leaves mostly radieal, more or less glaucons.) - PANfCEx.

- Stigmas mostly 2 : perigynium wholly pointless, turgid-obovate.

65. C. aurea, Nutt. Fertile spikes 3-4, oblong, loosely flowered, the lowest often very remote; perigynia pear-shaped, obtuse, longer than the ovate acute scalc; achenium lenticular. (C. pyrifórmis, Schw.) - Wet grassy banks, sspecially on limestone, W. New England to Wisconsin, and northward. - A 
slender delicate species, $\mathbf{4}^{\prime}-8^{\prime}$ high, with long grassy leaves, and bracts exceeding the culm. Sterile spike often with some furtile flowers at the apex.

\section{- + Stiymas 3 : perigynium somewhat pointed and 3-sided.}

+ Staminate spike (or the cluster in No. 71) lony-stalked.

66. C. livida, Willd. Fertile spikes $1-2$, rarely with a third near the base of the culm, 10-15-jlucvered; periygnic ocvid-ublong, with fuint peliucid nerves, tipped with a straight obtuse poiut, rather longer than the ovate scale. (C. limosa, var. livida, W'ald. C. Grayana, Dew.) - Peat-bogs and wet pine barrens, New Jersey, Oneida Co., New York, and high northward. - Rarely with a single (sterile) spike, or with an additional terrile one on an erect stalk $t^{\prime}-9^{\prime}$ long, fiom the bise of the culm. Plant very glaucous, the leaves rigid and fincly tapering. (Lu.)

67. C. vaginata, Tausch. Stcrile spike with its stalk commonly bent to a right angle with the culı at Howering time, afterwards erect; fertile 2 or 3 , remote, erect, slender-peduncled, loosely flowered; bracts foliaceous, short, with dilated sheaths; perigynia short-ovate when mature and with a distinct terete beuk or beuk-like oblique point, enargiuate at the oritice, exceeding the ovate acute scale; culm slender $\left(1^{\circ}-2^{\circ} \mathrm{long}\right)$, weak and ruclining, nakcd, stoloniferous; the long-creeping sterile shoots bearing tutts of Hat green leaves $\left(2^{\prime \prime}-3^{\prime \prime}\right.$ wide) almost equalling the fertile culms. (C. sparsiflura, Fries. C. phatostachya, Simith.) - Mluist banks, Bergen swamp, Genesee Cu., New Yurk (J. A. F'uine), Lake Superior (R'sbins and P'orter), and northward. (Eu.)

68. C. panícea, L. Sterile spikite always erect ; fertile $1-3$, mostly 2 , erect, remote, oblong or short-cylindrical, rather loosely flowered, only the luwer slender-peduncled; sheaths of the short foliaceous bracts shorwe and narrower; perigynia lurged-ovate at maturity, obscurely nerved, tipped with a short bent entire point (mostly stratw-colored), lunger than the ovate b/unt scule. - Muist grounds, Massachusetts to Delatware (W.M. C'tuby) : rare. (Kiu.)

69. C. Meadii, Dew. Dittiers from the last only in the denser fertile spikes, the sterile one sometimes longer; and the perigynia more tiangular, less turgid, paler, less indistinctly nerved, the scules pointed; culms more rigid and roughish: the more slender forms elosely approach the next. (C. panicea, ehietly of former ed.) - Wet prairies, \&e., Ohio to Illinois and Wisconsin.

70. C. tetánica, Suhk. Fertile spikes 1-3, commonly 2, oblong-cylindiciai, loosely flowered, especially at the rapering base, remote; perigynia when youm pointed at auch end, at mufurity ohovoid, scarcely influthd, with a slightly bent print, longer than the ovate ohtuse and ofien abruptly mueronate or awn-pointed scale. (C. conoideal, Gray, Girum. g. ('yp., not of Sidk. C. Wvodii, Dew.) - Margins of lakes and rivers, W. Mass. to l'enn., Michigan, and southward.

71. C. Cráwei, Dew. Sterile spikes often 1 or 2 small ones at the base of the terminal, which is occasionally fertile at the apex; jertile spikes $3-6$, re-

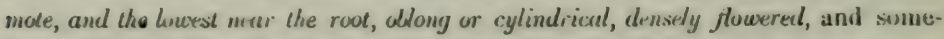
tines slightly compouml at the base; their short peduncles included, or the

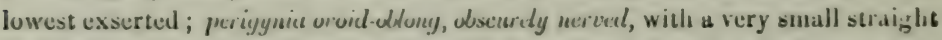
or slightly recurred point, longer than the ovate obtuse or acute or short-printed scale. (C. heterostichra, Torr.) - Wet places, S. Herkimer and Jeflirson 
Counties, New York, to Illinois, Michigan, and northwestward. - Variable, $4^{\prime}-12^{\prime}$ high; the taller forms resembling the next; but the perigynium is less round and with fewer and more indistinct nerves, the bracts do not exced the culm, and the staminate spike is long-peduncled.

+ Staminate spike nearly sessile: perigynium turgid, many-nerved, grenish.

72. C. granularis, Muhl. Sterile spike mostly shorter than the approximate uppermost of the 3 or 4 fertile; these cylindical, dense, the lowst remote and slender peduncled, sometimes from near the root; perigynia globular-ovoid, contracted into a short often slightly bent point, longer than the pointed scale; plant pale, glabrous; bracts long, exceeding the culm. - Wet meadows : common.

73. C. Tórreyi, Tuckerman. Sterile spike overtopping the 2 or 3 ovoid contiguous nearly sessile fertile spikes; perigynia obovate, strongly nerved, the very obtuse or retuse sumnit abruptly tipped with a very short cylindraceous beaklike point, longer than the ovate mostly acute or pointed scale; culm, leaves, and short sheathless bracts downy. (C. abbreviàta, Schw., Boott.)-Bethlehem, Pennsylvania, Schweinitz, New York? and high northward. - Probably overlooked from its close external resemblance to the next; but it is very distinct.

* Staminate spike sessile, or short-stalked (except in No. 75): pistillate spikes 2-5, erect, all on more or less exserted stalks; bracts longer than the culm (except in No. 75) : perigynia very obtuse, with an abrupt and minute or almost obsolete point, green and somewhat pellucid at maturity: pistillate scales tawny, fuding to white.-Palcescéntes.

74. C. palléscens, L. Fertile spilies 2-3, ovoid, densely flowered, approximate; perigynia obonoid-oblong, obscurely nerved, about the length of the scale. Var. under $\lambda \mathrm{TA}$ is a mere state with the lower bract at the base transversely wavy-lined. (C. undulata, Kinze.) - Meadows, New England to Penn. and northward. - Plant $8^{\prime}-18^{\prime}$ high : culm and leaves slightly pubescent. (Eu.)

75. C. conoidea, Schk. Staminate spike on a long stalk; fertile $2-3$, oblong, closely flowered, the lower distant ; perigynia oblony-conical, with impressed nerves, slightly oblique at the summit, rather longer (or sounctimes shorter) than the sharply pointed or awned scale; bracts not exceeding the culm. (C. tetanica, Schw. \& Torr., not of Schk.) - Moist meadows : rather common.

76. C. grisea, Wahl. Fertile spikes 3-6, oblong, rather loosely flowered, remote, or the 2 upper contiguous and the lowest distant; perigynia oblong, rather longer than the broadly ovate abruptly stromgly moned scale (the awn roughhispid ; style bulbous-thickened ; leaves light green, flat, ruther broal. (C. laxiflòra, Schk., not of Lam.) - Moist grounds : rather common.

77. C. flaccospérma, Dew. Differs from the preceding in having the flaceid leaves paler or glaucous: spikes longer, cylindrical (about $1^{\prime}$ long), witl: more numerous flowers, usually more distant, their bracts shorte:; perigynia larger (2" $-3^{\prime \prime}$ long), laxer, turning brownish, twice or thrice the length of the short-pointed or short-awn-pointed scale; style not thickened. (C. grisen, var. mìtica, of former ed. Prof. Dewey now proposes to change the name to xanthosperma, because flaccosperma is a hybrid word and "yellow-finited" was meant. But the fruit is not ycllow, nnd the original name has been adopted by Boott and Steudel.) - Low grounds, P'enn. and New Jersey, Knieskern (a dubious form), and common southward. 
* * * Uppermost spike fertile-flowered at the apex (rarely all staminate) : pistillate spikes 3-5, oblong or cylindrical, loosely flowered, distant, on exserted filiform stalks : bracts equalling or often exceeding the culm : perigynia oblong, with a short and abrupt notched point (obsolete in No. 80), green and membranaccous at maturity : pistillate scales tawny or white. - Gracflomas. - Fertule spikics nodding or pendulous.

78. C. Davísii, Schw. \& 'Torr. F'ertile spities oblony-rylindrical, ruther thich; perigynia somewhat contracted at each end, scarcely longer than the conspicnously awned scule. (C. aristàta, Dew., not of $R$. Bi. C. 'Torreyàna, Dew.) - Wet meadows, Massachusetts to Wisconsin, and southward. - Larger than the next $\left(1^{\circ}-2^{\circ} \mathrm{high}\right)$, and with stouter and longer spikes.

79. C. formòsa, Dew. F'ertile spikes oblong, short, all commonly with 2 or 3 barren flowers or empty scales at the base; perigynia somewhat contracted at each end, neurly twice ets long as the pointed or cuspidute scale. - Wet meadows, Massachusetts to W. New York.

80. C. gracíllima, Schw. Fertile spikes linear, slender; perigynia obtuse and slightly oblique at the orifice, longer than the oblong awned or awnless scale. (C. digitalis, Schw. \&. Torr, not of Willd.) - Wet meadows, New England to Kentucky, Wisconsin, and northward. -- When the uppermost spike is altogether staminate this resembles C. arctata; but is distinguished by the obtuse and sessile perigynium.

+ + Fertile spikes ncarly erect, all but the lowest short-peduncled or nearly sessile.

81. C. æstivàlis, M. A. Curtis. Spikes slender, loosely flowered; perigynia acutish at both ends, twice the length of the ovate obtuse or mucronute secule; achenium somewhat stipitate; sheaths of the lower leaves pubescent: otherwise nearly as the last, but smaller $\left(1^{\circ}-1 \frac{1}{2}\right.$ high). - Saldle Mountain, W. Massachusetts (Dewey), mountains of Penn., Virginia, and southward.

§3. Perigynia without a beak, hairy (in No. 83 becoming smooth at maturity), slightly influted, bluntly 3-angled, obtuse, conspicuously nerved, with a minute abrupt straight point: bracts narrow, with very short or obsolete sheathș, the lowest exceeding the culın; pistillate scales tawny or white; spikes 2-4, erect, the uppermost androgynous, fertile-flowered at the apex and club-shaped: the rest all fertile. - Vinescéntes.

82. C. viréscens, Muhl. Spikes oblony or cylindrical, on short stalks; perigynia ovoid, nearly entire at the orifice, rather longer than the ovate awned scale; leaces and sheaths hairy. (C. costàta, Schw.) - Rocky woods and hillsides, New England to Michigan, and sonthward. - Culus rough, slender, $1^{\circ}-2^{\circ}$ high : fertile spikes $6^{\prime \prime}-12^{\prime \prime}$ lung.

83. C. triceps, Michx. Spikes ovoid, nearly sessile, clasely approximate; perigynia troadly ubovoid, entire at the orifice, downy when young, smooth at maturity, rather longer than the pointed scale; sheuths very hairy; leaves more or less so. (C. hirsita, Willd. C. viridula, Schw. \&' T'orr., not of Mlichx.) Varies with the spikes rather longer and on stalks, and leaves nearly smooth. (C. hirsuta, var. pedunculàta, Schw. \& Torr.) - Woods and meadows : tho smoother form suuthward. - Culm $12^{\prime}-18^{\prime}$ high. Spikes $6^{\prime \prime}-9^{\prime \prime}$ long. 
§4. Perigynia without a beak, smooth, not inflated, 3-angled, regularly striate, terminating in a short, entive, ruther obliquely bent or recurved point, remaining green at maturity : pistillate scales memibrunaceous, mostly tipjed with a rough point or awn, brown or spotted, fuling to white: staminate spike solitary: pistillate spikes 2-5, more or less remote, the lowest often ncar the base of the culm.

- Sterile spike club-shaped : fertile spikes (erect, the uppermost commonly near the base of the sterile) all on stalks principally included within sheathing bracts, except sometimes the lowest, and shorter than the spikes or not much exceeding them: perigynia ovoid-triquetrous, narrowed at each end: culms numerous, diffuse and in fruit becoming prostrate: leaves all radical, very broud, finely and closely nerved throughout, with 3 distinct ribs. - PLANTAGfNex.

84. C. plantagínea, Lam. F'ertule spikes commonly 4, oblong, about 5-8flowered; bracts very short, dark purple, or the lowest greenish. (C. latifolia, Schk.) - Shady woods, mostly on hillsides in rich soil, New England to Penn., Wisconsin, and northward; and southward through the Alleghanies.

85. C. Careyàna, 'Torr. Fertile spikes 2-3, ovoid or oblong, about 3-5flowered; bracts green, the upper equal to the spikes, the lower somewhat exceeding them; perigynia large $\left(2^{\prime \prime}-2 \frac{1}{2} "\right.$ in length); leaves dark green. - In similar situations with the last, $\mathrm{N}$. New York to Penn. and Ohio: rare.

86. C. platyphylla, Carey. Fertile spikes 3, filiform, loosely 3-4-flowered; bracts as in the last; perigynia small; culms slender; leaves pale or whitish-green. - In similar situations with No. 84; and commoner southward.

* * Sterile spike short, club-shaped, pedunculate : fertile spikes 2-4, all on fil form exserted stalks, with long sheathing bracts resembling the leaves; the uppermost, as well as the leaves, exceeding the slender and at length prostrate culms : perigynia as in the last subsection. - Digrtales.

87. C. retrocúrva, 1)ew. Fertile spikes ovoid or oblong, compactly 3-8flowered, on lony drooping stalks, frequently with one or two staminate flowers at their base; leaves glaucous, 3-4 lines wide, with 3 prominent nerves. - Copses and hillsides, New England to W. New York, Virginia, and southward. - Closely approaching the next; perhaps only a variety of it.

88. C. digitàlis, Willd. Fertile spikes linear-oblong, loosely 6-9-flowered, on long stalks, the lowest sometimes drooping; leaves and bracts narrow, dark green ; perigynia smaller than in the last. (C. oligocárpa, Schw. \& Torr., not of Schk. C. Vanvléckii, Schw.) - Copses and hillsides : not rare. - Slender, $6^{\prime}-12^{\prime}$ high, growing in tufts, with numerous culms and long grassy leaves.

- * * Sterile spike linear, either conspicuously peduncled or smaller and nearly sessile in the same species: fertile spikes 2-6, erect; the 1-2 uppermost commonly near the base of the sterile, on an included stalk; the rest on exserted stalks, with long sheathing brats resembling the leaves; the uppermost exceeding the erect culm : perigynia with obtuse angles, about the length of the scale. - OLigochres.

+ Perigynia distinctly nerved, and with a hyaline orifice: style nearly even: scales of the pistillate spikes awnless or barely awn-pointed.

89. C. laxiflora, Lam. Fertile spikes slender and loosely several-many. flowered on a zigzag rhachis, cylindrical, or sometimes rather dense and oblong; 
perigynia oval-triangular, narrowed to each end, the point either strongly or sometimes slightly recurved. $-\Lambda$ most polymorphous species; very common in open woods, copses, \&c. The leading forms were collated by Dr. Boott as follows. - The typical form taken by him (C. strińtula, Mlichx.) has the leaves long and narrow ( $2^{\prime \prime}-4^{\prime \prime}$ wide), spikes about $1^{\prime}$ long and loosely Howered; perigynia with a slightly recurved or almost straight point, their scale except the lowest nearly pointless; sterile spike mostly conspicuous and long-peduncled. - Vu. stylofléxa, Boutt. (C. styluflexa, Dew. C. fusifórnis, C'hapman.) Slender, the weak tilifurm culms $1^{\circ}-2 \frac{1}{2}^{\circ}$ long; fertile spikes $2-4$, short, $5-10$ flowered, the lowest on a long sctaceous peduncle; bracts mostly shorter than the culn; perigynia more tapering or triangular-fusiforn, the point conmonly recurved. New Jersey (C'. F'. Austin), l'enn. (Prof: I'orter), and southward. - Var. plantacínel, Buott (var. patulitolia of former edition. C. plantaginea, Schk:), hats the root-leares 5" - 7" broad, otherwise as in the typical form. - Var. interiède, Buott (C. ánceps, Willd., Schk.), includes various slender, narrow-leaved forms, with loosely-flowered spikes, but otherwise as the next. -Var. blándi (C. blauda, $D(w$. C. laxiflora, var. striatula, $E d$. 2), includes narrow-leaved forms, $6^{\prime}-18^{\prime}$ high, with the sterile spike usually short or club-shaped and nearly sessile; the fertile oblong and dense, the uppermost approxinate; bracts much surpassing the culm; perigynia obovate with a slivert abruptly bent point; scale usually awn-pointed. - Var. Latifólia, Boott, has a broally and very sharp-angled culm, and very broad leaves und bracts (8" $-15^{\prime \prime}$ wide), inconspicuous sterile spike, the fertile ones cylindrical and loosely flowered, but the broad perigynium much longer than the truncate or abruptly short-pointed scale.

+- Perigynia densely striate, or as if finely wi inkled rather than nerved, of a firm texture, obscurely triangulur, with a cullous orifice: style thickened above the base: scale with the somewhat 3-nerved keel extended into a slout rough aun or point.

90. C. oligocárpa, Schk. Fertile spikes small, 3 -8-flowered; the point of the perigynium straight or slightly oblique, not recurved; leaves rough only on the ellge; sheuths smooth. (C. Sartwelliàna, Gay.) - Woods, W. New England to Illinois and Kentucky. - Culm slender, $6^{\prime}-12^{\prime}$ long.

91. C. Hitchcockiàna, Dew. Fertile spikes very loosely 3-5-flowered; apex of the perigynium recurved; sheuths and upper side of the leaves rouylly pubescent. - Woods, New England to Illinois and Kentucky. - Culm $1^{\circ}-2^{\circ}$ ligh, stouter, and fruit larger than in the last.

§5. Perigynium without a benk, smooth or downy, not influted, obovoid-triquetrous, with a minute obliquely bent white and membranaceous point, reddish-trown or olive-colored at maturity: bracts reduced to colored sheaths, or with a short green prolongation: leaves all radical, narrow or bristle-shaped. - Dicirìts.

92. C. eburnea, Boott. Sterile spike solitary; the fertile 3-4, erect, about 5-flowered, approximated and rlevated on lony stalks above the staminate spike: the lowest sometimes a little remote; perigynia obscurely nerved, smooth and shining, rather longer than the broad and obtuse membranaceous whitish scale. (C. alba, var. setifolia, Dew.) - Limestone rocks, N. New England to Kentacky, und northward. - A delicate species, with very slender culms, $t^{\prime}-10$ high, and 
bristle-shaped leaves, forming dense tufts. The fertile spikes $2^{\prime \prime}-3$ " in length, about I" brond.

93. C. pedunculata, Muhl. Spikes 3-5, commonly 4, the uppermost sterile with 2-3 frrile flowers at the base, the rest fertile with a few staninate fowers at the apex, all on long stalks, remote, $1-2$ of the lowest near the base of the culm; sheaths with green tips much shorter than the stalks; perigynia with a long attenuted buse and a minutely notched orifice, someuhat downy, especially on the angles, about the length of the broadly obovate abruptly awned or pointed dark-purple scale. - Dry woods and hillsides, E. New England to Penn., Wisconsin, and northward. - Culms $4^{\prime}-10^{\prime}$ high, prostrate at maturity, in tufts, partly concealed hy the very long and narrow grassy leaves.

\$6. Perigynia with a straight or slightly bent more or less abrupt. benk, hairy, not influted, terminating in a membranaccous notched or 2-toothed orifice: bracts short, either green and slightly sheathing or auriculate at the base, or small and resembling the scales : scales dark brown or purple with whitc margins, fading lighter or sometimes turning ncarly white: staminate spike solitary; the fertile 2-3, nearly sessile and erect, or the lower on a long radical peduncle. (Culms mostly low and slender : leaves all radical, long and narrow.) - Montine.

94. C. umbellata, Schk. Culms very short $\left(1^{\prime}-3^{\prime}\right.$, rarely $6^{\prime}$ high $)$, in close tufts; staminate spike sometimes with a few pistillate flowers; fertile spikes 4-5, ovoid, few-flowered; the upprermost conmonly close to the sterile spike and sessile, the rest on stalks arising from the base of the stem and of about equal height, nearly concealed by the long grassy leaves; perigynia ovoid, 3-angled, with a rather long abrupt beak, about the length of the ovate pointed scale. - Rocky hillsides, New England to Illinois, and northward.

95. C. Novæ-Ángliæ, Schw. Sterile spike sessile, short and usually inconspicuous; fertıle 2-4, greenish-purple, 3 -8-flowered, contiguous and sessile, or the lowest rather distant (sometimes even radical) and more or less peduncled; the lower or all the leafy bructs exceeding the culm; perigynia globularpear-shaped with a much attenuated base and a short conical 2-tonthel beak, minutely hairy, longer and broaler than the ovate mueronate-pointed purple scale (with green midrib and hyaline margins); achenium apiculate with the very short persistent base of the style; culms very slender $\left(4^{\prime}-10^{\prime}\right.$ long $)$, weak, soon reclined or procumbent. - Saddle Mountain, Massachusetts, Adirondack Mountains, New York, and high northward. - Too near C. pilulífera, L., of Europe and the following.

96. C. Emmónsii, Dew. Paler, and the spikes greenish, not purple, usually more crowded than in the forcgoing, otten a long-peduncled one from the base; bracts short, rarely equalling the culm; perigynia oval and more 3sided, hairy; and with a longer cylindrical beck; base of the style deciluous by an articulation. (C.. Noræ-Anglix, var. Emmonsii, Ed.2. C. Davísii, Dew., \&c.) - Dry woody hills . not rare.

97. C. Pennsylvánica, Lam. Sterile spike commonly on a short stalk; fertile 1-3, usually 2, approximate, nearly sessile, ovoid, 4-6-Alowered, the lowest cummonly uith a colord scale-tike long-auned bract; perigynia roundish-ovoid, with 
a short and abrupt minutely-toolhed beak about the length of the ovate pointed chestnut-colvied scule. (C. marginàta, Muhl.) - Dry woods and hills : common, especially northward.

98. C. vària, Muhl. Sterile spike sessile; fertile 2-3, mostly 3, distinct, on very short stalks, ovoid, 6-10-fluevered; the lowest and sometimes the 2 lower with green laj-like bracts; perigynia obocoid, with an abrupt distinctly toothed icuk, about the length of the ovate pointed light-bion scule. (C. P'ennsylvanica, var. Muhlenbergii, Gray, Gram. $\& \cdot(y / p$.) - I)ry wooded hills : common, especially northward. Closely resembles the last; but has wider, shorter, and more rigid glaucous leaves; also taller $\left(1^{\circ}-1 \frac{1}{2}\right)$ and more erect than No. 96, broaderleaved, and the spikes scattered. All these seem to run together.

99. C. Priscox, Jacq. Sicrile spike chub-shuped: fortile 2-3, oblong-ocoid, agyregated near the base of the sterile spike, sessile, or the lowest sometimies on a very short stalk, with a leaf-like bract scarcely exceeding the spike; perigynia ovoid-triangular, attenuated at the buse, with a short beak and neurly entire orifice, about equal to the ovate pointed dark-brown scale; achenium obovoid, with a prominent ring at the apex surrounding the base of the style; culm $3^{\prime}-6^{\prime}$ high ; leaves short, rather rigid. (C. verna, Villurs, Dew., not of Schk.) - Rocky hills, Salem and Ipswich, Massachusetts. (Nat. from Eu.)

100. C. Richardsónii, R. Br. Sterile spitie peduncled, cylindrical; fertile 1 or 2, scssile or short-stalked, approximate, oblong, longer than the scale-like brownish and mostly short-pointed bracts; perigynue obovoid-triangular, with a tapering base, obtuse, nearly brakless, the short point with an almost entire orifice, rather shorter than the ovate acutish brown or chestnut-colored scule; culm $\left(5^{\prime}-9^{\prime}\right.$ high) and rigid leaves rough. - 1)ry ground, near Rochester, New York (Dewey); prairies of Illinois (Mead); Wisconsin (Sartwell), and northward. A well-marked species, in aspect most like No. 97.

101. C. pubéscens, Muhl. Sterile spike usually sessile, fertile 3-4, oblong or cylindrical, loosely flowered, somewhat approximated, or the lowest a little remote, on a short stalk, with a narrow leaf-like bract about the height of the culm; fruit ovoid and sharply triangular, downy, attenunted at the base, with an abrupt slender beak nearly entire at the orifice, a little longer than the ovate abrupt$1 y$-pointed white scale; culm and flaccid flut leaves sofl-downy. - Moist woods and meadows, New England to Wisconsin and Kentucky. Differs from the other species of this section in its greater size and in aspect, and especially in the sharply angled perigynium.

§ 7. Perigynia slighlly inflated, with a short beak, terminating in an entire or sliyhlly notched orifice; staminate spike solitary, stalked (in No. 102 usually pistillate at the summit) : culms tall and leafy. (Two quite unlike species, artificially combined merely for convenience.) - ANómaLA.

102. C. miliàcea, Muhl. Staminate spike commonly fertile at the summit; fertile spikes 3 , cylindrical, rather slender, loosely flowered at the base, on filiform nodding stalks; hracts exceeding the culm, with short or nearly obsuleto sheaths; perigynia vevid-ticungulur, very smooth and thun, with an entire or very minutely notched orifiee, longer than the ovate short-awned white scale. (C. prasima, $W$ ahl.) - Rills und wet meadows: rather common. 
103. C. scabràta, Schw. Fertile spikes 4-5, cylindrical, erect, rather distant, densely flowered, the lower on long stalks; bracts without shenths, exceeding the culm; perigynia ovvid, contracted at the base, prominently jew-nervod, rough, spreading at maturity, with an ohliguely notehed beak, longer thun tho ovate slightly ciliate brown scale; culm leneves and bracts very rough. - Wet meadows and swamps, L. New England to Penn., Michigan, and northward.

\$8. Perigynia slightly inflated, 3-angled, smooth and shining (minutely pubescent in No. 104 and one form of 108), green, with a struight tapering beak (shortpointed in No. 107), terminating mostly in 2 small membranaceous teeth : lower bracts green and sheathing: pistillate scales tawny or white: staminate spike solitary, stalked : pistillate spilies 3-4, loosely flowered, all (except in No. 104) on filiform nodding stalks.

* Fertile spikes mostly slender, remote; perigyma somewhat nerved: bracts equalling or excceding the culm. - DÉriLes.

- Leaves and sheuths more or less sofi-pubescent: fertile sinikes nearly erect.

104. C. Sullivántii, Boott. Fertile spikes 3-5, commonly 4, narrowly cylindrical, erect, rather dense, the upper approximate, the lowest often remote, tapering towards the base and slightly compound, all on rough peduncles; bracts sheathing, not excecding the culm; perigynia elliptical, hairy, slightly stalked, very obscurcly nerved, with an entire or notehed orifice, rather longer than the ovate ciliate rough-awned or merely mucronate white scale. - Woods, Columbus, Ohio, Sullivant.

105. C. Knieskérnii, Dew. Less pubescent; fertile spikes 2 or 3, on longer and somewhat spreading peduncles; perigynia glabrous, more evidently nerved: otherwise like the preceding : too little known. - Copses, Oneida Co., New York, Dr. Knieskern, Dr. Vasry.

+ + Glabrous or nearly so: fertile spikes mostly nodding or spreading, loose.

106. C. arctàta, Boott. Fertile spikes slender-cylindrical, narrowed towards the base; perigynia ovate, short-stalked from a blunt base, short-beaked, longer than the pointed scalc. (C. sylvática, Dew., not of Hudson.) - Woods and meadows, New England to Pennsylvania, and northward.

107. C. glàbra, Boott. Fertile spikes oblong or short-cylindrical, rather dense and the terminal one oftener partly fertile; perigynia elliptical-oblong, not stalked, somewhat contracted at the base, and short-pointed at the apex, but nearly beakless, minutely and sharply 2-toothed at the orifice, prominently nerved, almost twice the length of the blunt brownish-margined scale. - Oneida Co., New York, Ir. Knieskern. Near Philadelphia, C. E. Smith. Probably not rare, but confoumded with the next: also resembling C. formosa.

108. C. débilis, Michx. Staminate spike occasionally fertile at the apex; fertile spikes slender-cylindrical, with loose alternate flowers on a somewhat sigzag rhachis; perigynia spindle-shaped or oblong-lanceolate, tapering into a slender beak with a hyaline 2-lobed tip, twice as long as the obtuse and pointless scale. (C. ténuis, Rudge. C. flexuòsa, Muhl.) - Moist mearlows : rather common, especially southward. - Perigynium often rusty-dotted :-in var. PÙBERA minutely pubescent and passing to C. venusta, Dew. of the Southern States. Bear Meadows, Centre Co., Penn., Prof. Portes.

$$
\mathrm{L} \& \mathrm{M}-\mathbf{4 5}
$$


* Fertile spikes short: periygnia ncrudess: lracts short. - FLÉxnı.es.

109. C. capillàris, L. F'rrile spikes commonly 3, mirute, with ubout 6 alter: nate flowers; periygnia blong-ovoid, contracted at the buse, tapering into a long slightly sericulate beuk, with an oblique nearly entire orifice, longer than the ovate scale. - Point de Tour, Lake Michigan; alpine summits of the White Mountains, New IIampshire; and high northward. - Au extremely deliente species, $4^{\prime}-6^{\prime}$ high, with spikes $3^{\prime \prime}-6$ "long, and a line or less in wistth. (Eu.)

110. C. fléxilis, Rudge. Sicrite spitie short and chlushthped; fertile spikes oblong or sometines with a few staminate flowers at the base and becoming club-shaped; the upper bracts short and scate-like, the lower bristle-shaped, very slightly sheathing; perigynia ovoid, olsscurely nerved, tapering into a beak alsout the length of the ovate hairy-fininged scele; leaves pate green and glaucous, and with the bracts soft-hairy. (C. blepharophora, Gray.) - Moist and shady places, Connecticut (near Salisbury), (cutral and Northern New York, Lake Superior, and Newfoundland : rare.

§ 9. Perigynia slightly inflated, obtusely 3-angled, nerved, smooth, tapering into a beak, with two mostly distinct tecth, becoming fawny or yellow at muturity : achenium obovate-triyuetrous, contracted at the base; staminate spike usually solitary. - FLÀ $\mathbf{L}$.

* Perigynin errct, slender-beaked: spikes remote; the staminate one usually longstulked: bructs not exceeding the culm, and with long sheuths.

111. C. lævigàta, Smith. Fertile spikes 3, cylindricul, on exserted nodding stalks; perizynia uroid, tapering into a 2-cleft beak, rather longer than the lightbrown or purplish pointed and awned scule; culm smooth. (C. Greeniàna, Dew.) - Massachusetts ('lewksbary" B. D. Greene). Introduced? (Eu.)

112. C. fúlva, livod. Fertile spikis $2-3$, oblong or ocoid, erent, the lowest on an exsertid stulk; perigynia ovoid, not much exceding the dark-brown scarcely pointed awnless scule; culin rough. (C. binérvis, Dew., not of Similh.) - Pond at Tewksbury, Massachusetts, B. D. Greene: not since found. (Eu.)

* * Perigynia ascending, short-beaked: spikes approximate or the lower remote; the staminate one sessile or nearly so; bructs much surpassing the culm; the upper nearly without shentls.

113. C. exténsa, Goot. Fertile spikes $2-4$. oblong, brown-green, very dense (5" $-10^{\prime \prime}$ long), the upper nearly sessile, the lowest on a short included stalk; perigynia ovate, the short conical beak sharply 2 toothed, longer than the ovate pointed purple scale; leaves and bracts long and narrow, involute, erect, rigid; culuns tufted, $8^{\prime}-20^{\prime}$ high. - Border of salt-marshes, const of Lung Islumd, New York, 1): 'T' I'. Allen. (Liu.)

* * Prigynia spreading or reflexed, honger than the sculs: spikes mostly approximate or crowded; the staninate mostly sessile or short-s/alked, often fertile at the apex or middle; the frrtile $(2-4)$ errct all or all but the lowest short-stalked or sessile: bracts much orcending the smosth culme, therir sheaths very short.

114. C. flàva, I. I'crtile spikes 2, roundish-ovoul, deuse, the upper approximated, the lowest often remote on a short exserted stilk; bructs spreading or reflexed; veriygnia lupering from an oroid contracted base into a slender recurved 
beak, widely spreading or reflexed at maturity. - Wet meadows, especially northward. - Wholo plant of a yellowish hue, $6^{\prime}-15^{\prime}$ high, with spikes about 6" in length. (11t.)

115. C. Ċderi, Ehrh. Fertile spikes oblong-onoid, closely nygrrgated, or the lowest rather remote, on very short stalks, densely flowered, sometimes staminate at the apex; leaves and bracts narrow, rigidly erect; perigynia ovoid, with a short and rather abrupt minutely notched beak, scarcely recurved at maturity. (C. virídula, Michx., not of Schw.\&. Torr. C. irregularis, Schu.) - Wet rocks and bluffi, coast of New England to Illinois, Lake Superior, and northward. Resembles the last; but the fertile spikes and perigynia are much smaller, and the beak more abrupt, shorter, and straight. (Eu.)

§ 10. Perigynia slightly inflated, ovoid or obtusely 3-angled, with an abrupt straight beak, nerved, densely pubescent or rough-puberulent, the pubescence nearly concealing the nerves, except in No. 119 : bracts leaf-like, with short sheaths: scales dark-purple or brown.

* Perigyma densely pubescent of a thick or somewhat leathery texture, ovoid, with 2 short and diverging membranaceous teeth: bracts much exceeding the nearly smooth culm: staminate spikes 2 or 3 , the uppermost stalked, the lower shore and sessile : fertile spikes $1-4$, usually 2 , ereet, remote, sessile or on very short gtalks. - LANUGiNis

116. C. flliformis, L. Fertile spikes oblong or ovoid; perigynia very short-beaked and with 2 sharp tecth; leaves and bracts narrow and involute; culm very slender $\left(1 \frac{1}{2}{ }^{\circ}-3^{\circ}\right.$ high $)$. - Peat-bogs, New England to Penn., Wisconsin, and northward. (Eu.)

117. C. lanuginosa, Michx Fertile spikes oblong or cylindrical; perigynia more hispidly pubescent; leaves and brasts flat, bronder and shorter; culm stouter $\left(1^{\circ}-2^{\circ}\right.$ high); staminate spikes usually shorter. (C. pellìta, Muhl.) Swamps and wet meadows. New England to Kentucky and northward.

* I erigynia thin, dowiny like the last or roughly granulate, or even smooth, ovoid, the beak terminuting in a thin and scarious oblique orifice, either entire or slightly notcher; bracts rigidly erect, shorter than the sharply triangular rough culm. - ScaRIÒs E.

118. C. vestita, Willd. Sterile spikes 1-2, the uppermost cylindrical, short-stalked ; fertile 1-2, approximate, sessile, ovoid or oblong, sometimes staminate at the apex ; prrigynin densely pubescent, with a short thick beak, a little longer than the ovate pointed scale; lenves fut, shorter than the stont and rigid culm. - Sandy soils, growing in tufts, New England to Penn. and southward. - Resembling the last in external appearance, but readily distinguished by the membratiaceous beak of the fruit, which is reddish at the hase and white and transparent at the orifice; and the style is twisted within the perigynimm.

119. C. polymorpha, Muhl. (in part.) Sterile spikes 1-4, the uppermost on a long stalk; the lower short, often with a few fertile flowers at the base; fertile spike solitury or rarely 2 , remote, cylindrical, sometimes staminate at the apex, erect, on partly exserted stalks; perigynia few- $(5-10-)$ nerved, very minutely roughened with granular dots, or smooth, abruptly contracted into \& slender 
cylindrical usually purplish beak, with a whitish hyaline entire orifice, longer than the ovate blunt purplish scalc. (C. IIalscyàna, Dew. \&. Ed. 1. C. striata, Torr. N. Y. Fl, not of Mich. .) - Varies considerably; in one form with the fertile spikes filiform, and the flowers alternate and very distant on the rhachis. Upland meadows, Rhode Island and Mass. to Penusylvania.

\$11. Perigynia moderately inflatcd, conspicuously many-nerned, smooth or pubescent, with a straight beak terminating in 2 rigid more or less spreading teeth: bracts leaf-like, with very short sheathing bases, equalling or exceeding the culm : staminate spikes $\mathbf{1}-5$.

* Perigynia with a short and thick beak, and short teeth. - IAcústres.

- Perigynia hairy, sometimes glalrate, turgid-ovate.

120. C. striàta, Michx. (not of Ed. 1). Sterile spikes 3, the uppermost slender-stalked; fertile spikes I-2, oblong, erect, remote, sessile or on short stalks (or the lower rarely on a slender stalk); perigynia minutely hairy or smoothish, or rarely smooth, ruther thin, longer than the blunt or pointed seale, the teeth usually scariously lobed at the base; leaves and bracts long and narrow, rather rigid, involute, with slender or setaceous rough extremities. (C. polymorpha, Ed. 1.) - Wet places, New Jersey to Virginia, and southward.

121. C. Houghtonii, Torr. Sterile spikes mostly 2 ; fertile $2-3$, oblong or cylindraceous, thicker and less distant, olive-colored; perigynia hairy, thickwalled, longer than the pointed or short-awn-tipped scale; the teeth at the orifice narrow and entire; leaves and bracts flat, shorter and broader, and culm lower $\left(9^{\prime}-15^{\prime}\right)$ than in the foregoing. - Wisconsin (Lake La Biche), Dr. Houghton; shore of Lake Ontario, Prof. Whitney; Medford above Bungor, Maine, J. Bluke; and northwestward.

++ Perigynia very smooth, very finely many-nerved.

122. C. ripària, Curtis. Sterile spikes $2-5$, the uppermost stalked ; fertile spikes 2-3, oblung-cylindrical, erect, remote, nearly sessile, or the lowest on a short stalk, large and thick $\left(2^{\prime}-3^{\prime}\right.$ long. $4^{\prime \prime}-6^{\prime \prime}$ wide), olive-colored; perigynia lanceolate-conical, coriaceous, tipped with rather slender short teeth, longer than the lance-ovate awned scale. (C. lacústris, Willd. and former ed.) - Borders of streams, ponds, and swamps: common. - Very robust, $3^{\circ}-5^{\circ}$ high : leaves $3^{\prime \prime}-5^{\prime \prime}$ wide, and sheaths nodose-reticulated. (Eu.)

123. C. paludosa, Good. More slender, with spikes smaller, leaves narrower, perigynia ovate, flattened, and more strongly nerved than the preceding, the orifice merely notched, and hardly exceeding the awned scale. - Border of a salt marsh at Dorchester, Mass., W. Boott. (Nat. from Eu. ?)

* * Perigynia with an elongated tapering bak and with long and setaceous or awnlike spreading or divergent tecth. - ARISTATAs.

- Staminate spikes 2-5 (rurely with some fertile flowers): fertile spikes remote, erect, rather loose, the uppermost almost sessile, without shauths, the lowest often on an exserted sometimes spreading peduncle: peringnia ascending.

124. C. aristàta, R. Br. Fertile spikes $2-4$, cylindricul; perigynia ovatelancecolate, smooth, tapering into a slender leak tipped with very slender at length diverging awn-like teeth, longer than the ovate-lanceolate awned and above hispid-ciliate scale; culm sinooth; sheuths and under surface of the leaves 
hairy. (C. ntheròdes, Spreng. C. miràta, Drw.) - Lake shores and river-banks, N. New York to Michigan, and northwestward. - Culm $2^{\circ}-3^{\circ}$ high: leaves $2^{\prime \prime}-3^{\prime \prime}$ widle. Fertile spikes $2^{\prime}-3^{\prime}$ long, often loosely flowered townrds the baso. (Eu. C. orthóstnchys.)

125. C. trichocárpa, Muhl. More slender; leaves and bracts rough, but not hairy; fertile spikes 2 or 3 , fewer-flowered; perigynia more ovate and with shorter and stouter teeth, downy-pubescent, the scale short-awned or awnless. (C. striata, Ed. 1, not of Michx.) - In water or wet ground: common, especially northward.

Var. imberbis. Perigynia glabrous; sheaths rather rough. Penn-Yan, New York, Sartwell. Illinois, Mend, E. Hall, and northwestward.

+ + Staminate spikes solitary, with a filiform bract; fertile 3-5, cylindrical, denselyflowered, on long exserted and at length drooping stalks, mostly approximute: perigynia widely spreading, reflexed at maturity.

126. C. comosa, Boott. Fertile spikes thick $\left(1^{\prime}-3^{\prime}\right.$ long, and $6^{\prime \prime}-7 \prime$ wide), the lowest sometimes very remote; perigynia tupering from a stalked ovoidtriangular base into a lony deeply 2 -forked beuk, the sharp elonguted teeth widely spreading or somewhat recurved; scales lanceolate, with a long bristle-shaped awn shorter than the mature fruit; culm rough and triquetrous. (C. furcàta, Ell., not of Lapeyr. C. Pseudo-Cyperus, Schw. \& Torr., Dew., \&c., in part, not of L.) -Wet places: common. $-\Lambda$ robust species $2^{\circ}-3^{\circ}$ high, formerly confounded with the next, which it greatly resembles; but it differs especially in the larger fertile spikes, longer beak of the fruit, and the longer, smooth and widely spreading teeth, giving to the spikes a comose or bristly appearance.

127. C. Pseudo-Cypèrus, L. Fertile spikes narrower and sometimes slightly compound at the base; perigynia as in the last, but with a shorter beak and shorter less spreading teeth; scale about the length of the mature fruit. - Border of lakes and in bogs, New England to Pennsylvania, and northward. (Eu.)

\$12. Perigynia much inflated, conspicuously many-nerved, smonth, with a long tapering 2-toothed beak: bracts leaf-like, much exceeding the culm: scales tawny or white: staminate spike stalked, always solitary. - Lurulin

* Bracts with very short or obsolete sheaths.

128. C. hystricina, Willd. Sterile spike often bearing a few fertile flowers at the base or apex; fertile spikes 2-4, oblong-cylindrical, densely flowered, the uppermost on a very short stalk, the others on long stalks and at length nodding, the lowest often very remote; perigynia spreading, tapering from an ovoid base into a long slender beak with sharp smooth teeth, longer than the awned scale. - A variety with shorter ovoid spikes, the lowest very remote on a filiform stalk, $4^{\prime}-6^{\prime}$ long, with rather smaller perigynia not much longer than the awn, is C. Cooleyi, Dew. - Wet meadows : common. - Plant pale or yellowish green, with fertile spikes $9^{\prime \prime}$ to $1 \frac{f^{\prime}}{2}$ long. Distinguished from the preceding by the more inflated less diverging fruit, its beak longer and tecth shorter; anil from the following by the smaller nodding spikes and many-nerved periginium, with longer and smooth tecth.

129. C. tentaculata, Muhl. Fertile spikes 2-3, ovoid, oblong, or cylindrical, densely flowered, approximate and diverging horizontally, the uppermost ses- 
sile, the lower on short exserted stalks; perigynia spreading, tapering from an ovoid few- (about 10-) nerved base into a long slender beuk with oblique orifice or short minutely serrulate teth, wuch longer that the lanceolute awned scale; achenium papillose-roue hened. (C. rostrara, Muhl., not of Michax.) - Wet meadows : very common. - Yar. Gidentss, Boutt, is a slender form with 2 much smaller fertile spilices ( $4^{\prime \prime}-12^{\prime \prime}$ lung, $3^{\prime \prime}-t^{\prime \prime}$ broad). - Var. A L.T10k, Bowth, is tall ( $2^{\circ}$ high), with more seattered large fertile spikes, and the more talpering beak of perigynium with longer teeth, perhaps a hybrid with C. lupuliua. Penn-Yan, New York, Surtwell, and Amherst, Mass., Tuchermen.

130. C. intuméscens, Rudge. Futile spilies 1-3, wooil, loosely fero- (5-8-) flowered, clasely approxinatual, sessile, or the lower on a very short exserted peduncle; perigynia exet-sprcaling, tapering from an ovoid 15-20-nerved base into a long sometimes rough beak. (C. folliculata, Schk., Michx., not of $L$.) - Wet meadows and swamps : very common - Culn slender, about $18^{\prime}$ high : fertile spikes usually contiguous : perigynia $6^{\prime \prime}-7^{\prime \prime}$ long, very ventricose.

131. C. Gràyii, Carey. Fertile spikes 2 (sometimes single), globose, densely (15-30-) fluvered, scpurate, on short exserted peduncles; perigynia ( 8 "long) spreading and deflexed, talering from an orvid 25 -30-nerved base into a long smooth and shining bouk. - River bottoms, Oneida Co., New York, to Ohio and Illinois : rather rare. - Culm robust, $3^{\circ}$ high; leares broader; and flowers in July, a month later than the last.

** Bracts all or all but the uppermost conspicuously sheathing.

- Fertile spiktes approcimate, or only the luwest one distant, erect, very large and turgid, many-fluwered: perigynia ascending, lony-beaked frow an ovale-ventricase base: sterile spikes rarely 2.

132. C. Iupulina, Muhl. Fertile spikes 2-4, cylindraceous or oblong $\left(1^{\prime}-2^{\prime}\right.$ long, $1^{\prime}$ thick), the lower on exserted stalks; perigynia $\left(6 \frac{1}{2}{ }^{\prime \prime}-7^{\prime \prime}\right.$ long) often raised on a short stalk-like base, smooth or with the beak rough above, much longer than the lanceolate rough awn-pointed scale; stem $\left(2^{\circ}-3^{\circ}\right)$ and long broailly linear leares and bracts smooth, the latter with rough margins ( $3^{\prime \prime}-t^{\prime \prime}$ wide). (C. lùrida, Wull.) - Wet grounds, common. - C. Canadénsis, and C. Bellavilla, Deac, appear to be depauperate and attenuated states of this, with more distant lax, and fewer-flowered spikes.

133. C. lupulifórmis, Surtwell. Fertile spikes $4-5$, cylindrical $\left(2^{\prime}-3^{\prime}\right.$ long), less approxinate; perigynia sessile $\left(i^{\prime \prime}-8^{\prime \prime}\right.$ long); achenium bruader. with manillated angles; scale more awned; otherwise as in the foregoing, of which it is probally a mere variety. (C. lupulina, var. polystachya, Schwo \& Torr.) - Swamps, New York to Delaware, \&c.

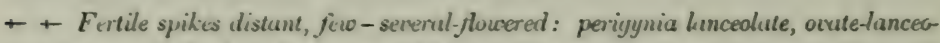
late or spindle-shaped, loose or widdly spreading at muturity : staminate spike smull, short-stallieal: oblusely angular culns and grassy soft leaves smooth.

134. C. folliculàta, L. Fertile spilies 3-4, remole, 12-20-flowered, all or the lowest on exserted peduncles, turning yellowish at maturity; perigynia tapering ovalt-henceolute from a broadish base, short-heakcal, at length wildely spreading, rather exceding the ovate white rough-aund soule. (C. xanthophysa, Wuld.) - Peat-logs, New England to Pemn., and northward, and in ono form 
touthward - Plant $2^{\circ}-4^{\circ}$ high, of yellowish appearance, with long foliaceous bracts, and leaves 4 " wide.

135. C. rostrata, Michx. More slender and smaller than the last $\left(10^{\prime}-\right.$ $15^{\prime}$ high), strictly erect, rather rigid ; leaves narrow; fertile spikes $1-3$, commonly 2 ; perigynia scarrely spreading at maturity, lancrolate, obtusely triangular, slender-beaked, about twice the length of the brownish blunt scale. - Cold bogs, mountains of N. New York, New England, and northward.

136. C. subulàta, Michx. Fertile spikes 3-5, rery remote, on included peduncles loosely few- (4-8-flowered, commonly with a few staminate flowers at the apex ; perigyniu awl-shaped, reflexed at maturity; the long slender beak deeply cleft or grooved down one side, tipped with 2 awn-like and at length rigidly deflexed teeth. (C. Collínsii, Nutt. C. Michaìxii, Dew.) - Celar swamps, Canada (Micliaux) to Rhode Island (Olney), and New Jersey near the coast: rare.

\$13. Perigyna much influted, ohovoil or obsonic, rather few-nerved, smooth, with a long and slender 2toothed beak abruptly produced from the obtuse or at maturity even retuse sunmit, tawny-hrown or straw-colored at maturity, spreading horizontally, or the lower deflexed, very densely aggregated in thick spikes: these, 1-7 in number, are either all androgynums, staminute at base, or the terminal wholly staminate, the others sometimes wholly pistillete: leaves and bracts flat, the latter much longer than the culm. - Squanross.

137. C. squarròsa, L. Spikes oflen only one, commonly 2-5, ghlular, ounid, or cylindruccous $\left(6^{\prime \prime}-7 "\right.$ thick), the terminal one with a slender-contracted base from the numerous staminate flowers, the others almost wholly fertile, on short slender peduncles, their bracts scarcely sheathing; perigynia sparingly nerved, longer than and conccaling the blunt or short-pointed scalis. (C. typhina, Michx.) - Low grounds, E. New England to Illinois and southward. - Remarkable for its dense, short and thick spikes, about ' ' long, to which the spreading beaks of the perigynia give a bristly appearance.

138. C. stenólepis, Torr. Spikes 5-7, the torminal one wholly staminate, or sometimes firtile at the top or throughout; the others with a few staminate flowers at the hase or sometimes none, cylindrical ( $l^{\prime}$ or more long), the upper approximated, nearly sessile on the zigzag stem, the lower remote on exserted stalks, their bracts sheathing; perigynia shorter than the long aron-like rough scales. (C. Frankii, Kunth. C. Shortii, Steud., not of Torr.) - Marshes, Pennsylvania (Prof. Porter) and Virginia to Illinois, and southwestward. - Somewhat resembling the last; but the spikes are narrower and more numerous, and of a still more bristly appearance from the projecting points of the scales.

\$ 14. Perigynia much influted, smooth and shining, lecoming straw-colored at maturity, with a tapering more or less elongated 2-toothed berk: bracts leaf-like, with very short or obsolete sheaths (conspicuously sheathing only in No. 139); scales brown or tawny: staminate spikes $2-5$, rarely 1 , stullied. - Vrsichrix.

* Perigynia conspuenously nerverl: brocts usully much excerding the culm.

- Fertile spiles oblony or eylindrical, many-flowered.

139. C. retrórsa, Schw. Sterile spikes 1-3, the uppermost occasionally with a few fertile flowers, the rest more or less pistillate at the base; fertile spikes 4-5, oblong-cylindrical, erect, the upper approximate and clustered on short or in- 
cluded stalks, the lowest remote on a long exserted stalk, and (with one or more of the others) often bearing $1-2$ short branches at the base; perigynia crowded, spreading and at length reflexed, strongly few-nerved, tapering from an ovoid contracted base into a conspicuously toothed beuk, much longer than the lanceolate scale. (C. revérsa, Spreng.) - Marshy border's of streams, New England to Penn., Wisconsin, and northwestward. - Culm nearly smooth $\left(1 \frac{1}{2}^{\circ}-22^{\circ}\right.$ high $)$ : leaves and bracts $3^{\prime \prime}-4^{\prime \prime}$ wide, much exceeding the thick spikes, which are $1^{\prime}-1 \frac{1}{2}$ long. Var. Hártı (C. Hartii, Dew.) is a slender state, with fertile spikes distant, the lower long-peduncled. - Yates Co., Now York, Di. Howt Wright.

140. C. gigantèa, liudge. Sterile spikes 1-5; sonctimes with a few fertile flowers; fertile spikes 3-5, cylindrical, somewhat erect, or spreading on exserted peduncles, distant or the upper contiguous, all or most of them staminate it the apex; perigynia ascending, at lenyth horizontal, many-nerved, abruptly tapering from a broadly or globular-ovate ventricose base into a long and slender sharply 2-toothed beak, much longer than the ovate-lanceolate mostly awn-pointed scale; achenium broader than high, strongly triquetrous, with coneave faces. - Swamps, Delaware ( $W . M$. Cunby), Kentucky (Short), and southward. - Allicd to the preceding and to No. 133. Culm $2^{\circ}-3^{\circ}$ high : perigynia about $6^{\prime \prime}$ long.

141. C. Schweinítzii, Dew. Sterile spikes commonly 2, the lower often pistillate at the base; fertile spikes 3-4, cylindrical, somewhut diooping, densely flowered, often staminate at the apex, and occasionally the lower rather compound at the base, on smooth nearly included stalks; periyynia ascending, oblong-ovoid, rather lightly fiw-nerved, tapering into a smooth short-toothed bcak, a little longer than the lanceolate roughly long-auned scule. - Wet swamps, New England, New Jersey, W. New York, and northward: not conmon. - Culm 10'-15' high, smooth : bracts and leaves $2^{\prime \prime}-3^{\prime \prime}$ wide, smooth except the margins, much exceeding the culn : fertile spikes $\left(2^{\prime}-3^{\prime}\right.$ long, rather narrow) and the whole plant turning straw-color. P'erigynia $2 \frac{1}{2} "-3^{\prime \prime}$ long, thin.

142. C. utriculàta, Buott. Sterilo spikes 3-4; fertile spikes 2-5, comtmonly 3, rather distant, sessile, or the lowest (sometimes loose and attenuated at the base), peduncled, cylindrical $\left(1 \frac{1}{2}^{\prime}-4^{\prime}\right.$ long) thick, and densely very manyflowcred; perigynia covate, either ventricose and abruptly or inclining to elliptical and more gradually contracted into a cylindrical smooth beak, longer than the lanceolute very acule or awn-pointed scale; culm stout and thick, obtusely angular, spongy at base $\left(2^{\circ}-3^{\circ}\right.$ high $)$; leaves flat $\left(3^{r}-4^{\prime \prime}\right.$ broad $)$, pale, nodose-reticulated. (C. ampullàcea, var. utriculata of former ed.) Swamps, New Eugland to P'enn., Michig:m, and common northward. - Fruit sometimes alnost that of C. vesicaria, sometines that of C. anpullaceat, into which it merges northward: the rongh mostly awn-like points of the seale usually distinguish it from both European species.

143. C. Vaseyi, Dew. Differs from the last in the slender culn with acute rongh angles; fertile spikes ( 2 or 3 ) looser and fewer-flowered; perigyuia more tapering into the batk, and scales less pointed; from C. vesicaria, $L$. of Europe (of which it is the nearest representative) in the more pointed scales and fewernerved perigynia tapering gradually into a longer beak; from the next (into which it probably passes) by the larger elongutul-ovate perigynia tapering into a slender beak (the ronghness of which, indicated by 1)r. Boott, is rarely obvious, 
the tecth, however, rough-scrrulntc). (C. monile, Dew. in 1845, not of Tuckerm. C. vesicaria, var. cylindràcea, Dew.) - Swamps, Yates Co., New York, Sartwell, to Illinois?

144. C. monile, Tuckermun. Sterile spikes 3 , rarely 2 or 4 ; fertile spikes mostly 2, rarcly 3 or solitary, cylindraceous or cylindrical $\left(1^{\prime}-2 \frac{1}{2}\right.$ long), mostly slender, slightly or the lower when remote longer-peduncled; perigynia globularovate, very ventricose, shining, abruptly contractal into a short smonth beak, longer than the ovate-lanceolate ncute or scarcoly pointed scale; culm slender $\left(1^{\circ}-3^{\circ}\right.$ high), sharply triangular, mugh on the angles; lenves narrow (barely 2 " wide).

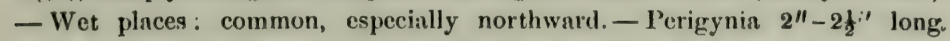
(C. vesicaria, var. alpígena, Fries, of N. Eu. appears to be a form of this.)

145. C. Ólneyi, Boott. Resembles the two preceding and C. vesicaria ; the fertile spikes denser and thicker, short-cylindrical $\left(1^{\prime}-1 \frac{1}{2}\right.$ long); perigynia $\left(2 \frac{1}{2} "-3^{\prime \prime}\right.$ long) turgid-ovate, with the short beak rough-serrate at the apex and on the awl-shaped teeth ; the scales acute or bluntish; leaves $\left(1^{\prime \prime}-2^{\prime \prime}\right.$ broad) rough. - Wet ground, Providence, Rhode Island, Olney.

146. C. Tuckermàni, Boott. Sterile spikes about 2 ; fertile spikes 2-3, commonly 3, oblong or cylindrical, stout, somewhat approximate, on rough stalks, the lowest often nodding; perigyna shining, thin and delicate, much inflated, ovate, nscending, tapering into a rather abrupt slender and cylindrical smooth beak, much longer than the ovate or lanccolate acute or short-pointed scale; the very long narrow bracts and leaves rough, much surpassing the rough-angled culm. (C. bullata of authors, not of Schl. C. cylindrica of former ed.; but the cylindrica of Schweinitz belongs mainly to the next or to some others, and is too much confused for preservation.) - Swamps, W. New England to Penn., Illinois, and northward. - Differs from the next in the more numerous and longer fertile spikes $\left(8^{\prime \prime}-2^{\prime}\right.$ long), and the larger, more inflated and membranaceous fruit ( $4^{\prime \prime}-5^{\prime \prime}$ long). with a smooth beak.

147. C. bullatta, Schk. Sterile spikes 2-3; fertile spikes most freguently only one, sometimes 2, approximated, oblong or rylindrical, stout, sessile or on short smooth stalks; perigynia spreading, shining, turgid-ovate, tapering into a long cylindrical rough beak, much longer than the lanceolate pointless scale; bracts and leaves narrow, about the length of the smooth or roughish culm. (C. cylíndrica, Schw., at least in part, Tuckerm., \&c.) - Wet swamps, New England to Penn. and southward, chicfly castward.

\section{+ + Fertile spikes globular or oblong, few-flowerrd.}

148. C. oligospérma, Michx. Sterile spikes 1-2, sleniler; fertile spikes 1-2, densely 6-18-flowered, the lower on a very short stalk; perigynia turgid

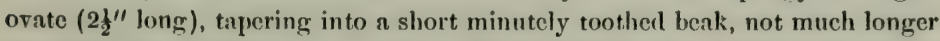
than the ovate awuless seale; culm very slender; leaves and bracts involute. (C. Orkesiàna, Dew.) - Wet horders of ponds, \&c., F. Mass. to Pennsylvania, Wisconsin, and northward, chicfly in cold or mountainous regions.

* * Perigynia nerveless or ncarly so bracts mostly shorter than the culm.

- Perigynia pointed with a very short smooth beak, minut,ly 2-tnothed at the apex: stigmas eithr 2 or 3 : fertile spikes 2 or sometimes one, dense, short, usually broun-purple or purplish, the upper almost sessile, the lower short-peduncled: ster: 
ile spikics I or 2, often solitury. ('The two following are very much ulike; and one or the oflaer is doubless C. miliaris, Michx. 'Tho first is regarded by Andersson as an extreme form of C. mupullacea, the second of C. vesicaria.)

149. C. rotundàta, Wahl.? Leuves and bructs involute, smoothish; fertile spikes oblong or cylindraceous, or the upper ovate or globular; perigynia shortovate, about the length of the broadly ovate (obtuse, or in our specimens acute or pointed) scale. - Gruvel-bars at the outlet of Mooschead Lake, N. Maine, C. E. \& A. H. Smith. - The specincus are a foot high, with one leaf on the obtusely ungular culn, and only' the lowest spike leafy-bracted: sterile spiko single the firuit not fully formed. (Eu.)

150. C. púlla, Good.? Laves and bracts flat, with a slender triangular apex, rough-margined; culm rather sharply triangular; perigynia inflated. ovate, mostly longer tham the ovate scale. (C. saxátilis, $L$., but that was in part C. rigida: the name is appropriate for that but not for this species, and is better discarded altogether.) (Eu.) - Var.? silıaris. Culm more slender, $1^{\circ}$ or more high ; fertile spikes paler $(1-3)$, ovoid or oblong, in our specimens staminate at the apex, each with a very rough leafy bratet, the lowest often surpassing the culın. (C. miliaris, Michx.) - Outlet of Moosehead Lake, with or near the preceding, July 29, C. E. \& A. II. Simith; and far northward.

+ + Perigynia abruptly cortracted into a very long and 2-toothed beak.

151. C. longiróstris, Torr. Sterile spikes usually 3 , at the sunımit of a long slender stalk; the lower often bearing some fertile flowers; fertile spikes 2-4, cylindrical, more or less distant, on long filiform at length drooping stalks, loosely flowered; perigynia globose-ovoid, smooth and shining, abruptly contracted into a slender cylindrical beak, which is longer than the body, rough on the margin, and 2-cleft at the membranaceous orifice, a little longer than the lanceolate light-colored or white scale. (C. Sprengèlii, Dew.) - Shady rocks, N. New England to Wisconsin, and northward.

\section{Order 128. Giramíneate. (Grass Family.)}

Grasses, with usually hollow stems (culms) closed at the joints, alternate 2ranked leaves, their sheaths split or open on the side opposile the blade; the hypogynous flouers mbricaled with 2-ranked glumes or bracts: the outer pair (ylumes proper) subtending the spikelet of one or several flowers; the imer pair ( palce or palets) enclosing each particular flower, which is usually furnished with 2 or 3 minute hypogynous scales (squamule, Juss., lodiculec, Beauv.). Stamens $1-6$, conmonly 3 : anthers versatile, 2-celled, the cells distinct. Styles mostly 2 or 2-parted: stigmas hairy or feathery. Ovary 1-celled, 1-ovuled, forming a seed-like grain (caryopsis) in fruit. Embryo small, on the outside and at the base of the floury albumen. Roots fibrous. Sheath of the leaves usually more or less extended above the base of the blade into a searious appendage (ligule). Spikelets panicled or spiked. Inner (upper) palet usually 2-nerved or 2-keeled, enclosed or partly covered by the outer (lower) palet. Grain sometimes free from, 
sometimes permanently adherent to, the palets. - A vast and most impor tant family, as it furnishes the cereal grains, and the principal food of cattle, \&c. ' (See Plates 7-14.)

Trlbe I. POA CE IC. R. Br. Spikelets 1 - many-fowered, when more than one-flowerod centripetal in development ; the lowest flowers first developing, uppermost, if any. imperfect or abortive, the rest all alike in the spikelet (perfect, or occasionally monnecious or dicecious); only in a few exceptional cases with the lowest of the several flowers less perfect than the upper (viz. staminate only in Arrhenatherum and Phragmites, neutral in Uniola, (tenium, \&c.).

Subtribe 1. Oryzere. Splkelets 1-flowered, in panleles, the flowers often monœcious Glumes abortive or wanting! Inner pales 8-nerved! Stanens 1-6.

1. Ieersla. Flowers perfect, strongly flattened contrary to the awnleas conduplicate palets.

2. Zixanin. Flowers monocious. Palets convex; the lower one awned in the fertile flowers.

Subtribe 2. Agrostidere. Spikelets 1-flowered, perfect, and occasionally with the rudiment or abortive pedicel of a recond fiower ahove, panicled, or clustered, sometimes so contracted as to form a sort of spike, but the spikelets are not directly borne on the common axis. Stamens $1-3$.

- PHLeOIDFs. Glumes equal, atrongl peeled, laterally flattened, boat-shaped, somewhat herbacrous, $n$ well as the palese. Inflorescence densely spiked!

3. Alopecurus. Glumes united at tho base. Lower palet bearing an $n$ wn on the back: the upper palet wanting.

4. Phleum. Glumes distinct, sharp-pointed, much larger than tho two thin and truncate awnless palets.

5. Cryps is. Glumes distinet, not longer than the palets; both awnless and pointless.

* AGRostiDEF proper. Glumes and palets both membranaceous, or the latter sometimes very thin and deliente. Inflorescence panicled or glomerate, sometines rather spike-like, but not contracted into a uniform cylindrical spike. Palets not surrounded by a tuft of hairs, or only with some very minute ones at the base.

- Flower perfectly sessile in the glumes : lower palet 1-nerved : awns none.

6. Vilfa. Fruit a caryopsis (seed adlierent to the pericarp, as in most grasses). Pavicle spiked or contracted.

7. Sporobolug. Fruit an utricle (seed loose in the thin pericarp). Panicle open or close.

+ - Flnwer alightly rriced in the glumes on a short sometimes stalk-like hase (rallus): lower palet 3-5-nerved; and this or the glumes awned or pointed, except in some species of No. 8 .

8. Agrostls. Glumes equal, or the lower one rather longer, pointless, exceeding the very thin blunt palets. Lower palet pointless, often awned on the back; the upper sometimes wanting. Panicle npen.

9. Puly yogon. Glumes nearly equal, long-awned, nuch longer than the palets, the lower of which is often short-awned below the apex. Stamens 3 . Panicle contracted.

10. Cinnn. Glumes acute, the lower about equalling and the upper slightly exceeding the similar palets. Stamen 1. Flowers raised on a distinct naked stalk, beardless : lower palet short-awned or bristle-pointed just below the tip; the upper 1-nerved.

11. Muhlenbergin. Lower glume mostly smnller Palets chiefly hairy-bearded at the base, the tip of the lower one mucrouate-pointed or awned. Stamens 3 .

12. Brnchy elytrum. Lower glume almost obsolete, and the upper minute. Lower palet long-awned from the tip; the upper gronved on the back and bearing a long and slender naked pedicel of an nbortive second flower. Stamens 2.

* - CAIA Magrostidex. Flower with a copious tuft of hairs at the base of the paletg: otherwas as in the foregoing subilivision.

13. Calnmagrostis. Lower palet mostiy awned on the back, shorter than the glumes. 
*** STIPEE. Palex coriaceous, or indurated in fruit, conmonly shorter than the mem. branaceous glumes, usually on a rigid base or callus; the lower iuvoluto, terete, closely enclosing the upper und the gruin, mostly 1-3-awned ut the apex. Inflorescence raceuose or panicled: spikelets usually liarge, the flower deciluous from the persistent glumes.

14. Oryzopsis. A irn simple, struight, deciluous from the palet or sometimes wantiug.

15. silpa. Awn simple, twisted below. Callus conspicuous, poiuted at the base.

16. Aristida. A wo triple. Upper palet small. Callus conspicuous, pointed at the base.

***** Palets coriaceous or cartilaginous, awnless. Ilere the followiog would be sought by the studeut who overlooked the pair of rudimentary flowers in No. 56, and was not ac. quainted with the recoudite theoretical structure of No. $5 \overline{7}$ and 53.

56. Phalaris. Spikelets laterally llattened. A rudiment at the buse of each palet.

57. Milium. Spikelets dorsally flittish, not jointed with the jedicels: flowers all alike.

68. Amphicarpum. Spikelets of two sorts, the fertile subterrauean, those of the panicle separating by a joint without ripeniug grain.

Subtribe 3. Chloxideve. Spikelets rarely 1-flowered, usually 2-several-flowered, with one or more of the upper llowers imperfect, disposed in oue-sided spikes! Glumes persistent, the upper one looking outward. Rhachis (axis) jointless. Spikes usually several and racemed or digitate. Stumens 2 or 3.

* Spikelets strictly 1-flowered.

59. Paspalum night be looked for here, having to all appearance merely 1-flowered spikelets

17. Spaxtisa. Spikelets much flatteued contrary to the glumes, imbricated in 2 ranks on the triangular rhachis of the straight spike.

* * Spikelets with one perfect and two or more imperfect or neutral flowers:

- The perfect flower intermediate.

18. Ctenium. Spikelets closely intbricated on one side of the axis of a single curved spl .e. ++ The perfect llower below the one or more neutral or rudimentary ones.

19. Bouteloun. Lower palet 3 cleft and pointed or 3 -awned at the apex. Spikes denso. 20. Gумиородия. Lower palet and the rudiment 1-awned. Spikes filiform, racemem. 21. Cymodon. Flower and the rudiment arnless. Spikes slender, digitato.

** Spikelets severil flowered; more than one of the lower flowers perfect and fertile. + Epikes digitate at the summit of the culu, denso.

22. Dactyloctenium. Glumes compressed-keeled; outer oue awned: lower palet pointed.

23. Eleusine. Glumes and palets both awnless and blunt.

$$
++ \text { Spikes racemed, slender. }
$$

24. Leptochloa. Spikelets loosely spiked. Luwer palct pointless or awned at the tip.

Subtribe 4. Festucineae. Spikelets several-(few-many-) flowered, panicled ; the uppermost flower often imperfect or abortive. P'ulets pointless, or the lower sometimes tipped with is straight (not twisted nor deeply dorsal) awn or bristle. Stamens 1-3. Culmo sometimes reed-like, but not woody.

* Lowest flowers of the spikelet perfect and fertile.

+ Grain free from the palets.

\# Joints of the rbachis of the spikelet at the insertion of each flower, or the whole rhachis, bearded. Glumes and convex palets membrauaceous.

25. Tricuspis. Spikelets 3-many-flowered. Lower palese hairy-fringed on the 3 nerves, one or all of which project into awus or mucronate tips, mostly from notches or clefts.

26. Graphephorum. Spikelets 2 -fow-flowered. Clunes and palety awnless or polntless t+ +1 Hhachis of the spikelet and bise of the flower not bearded.

a. Jowor palest 1-puinfed, awnes or aculo, the usrves whon probsit rumning into the polnt.

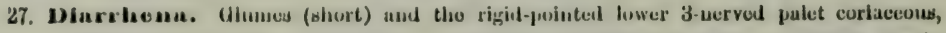
convex-boat-shaped. Stamens 2. l'ericarp cartilaginous, large. Paviolo locsely few-flowered. 
28. Dnety lis. Glumes (rather long) and lower palet awn-pointed, herbaceous, compressedkeeled. Panicle contrncted in one-sided clustera.

29. Koeleria. Glumes (nenrly as Inng na the apikelnt) and lowir palot membranacoous, keoled, neute or mucronnte, or ruther biunt. I'unfelo contructed, aplko-like.

87. Fentuen, with gruin sometimes free, miny bo lookod for hero.

b. Lower palet uwnless and pointleas, blunt (except one Glyceria), the nerves parallel.

1. Glumes extremely dissimilar, $1 \downarrow-3$-flowered.

30. Entoula. Lower glume linear; the upper broadly obovate and folded round the flowers.

2. Qlumes similar in shnpe, but often unequal in size.

31. Mellen. Iower palet fluttish-convex, many-nerved, membranucous at the top, harilenIng on the loose grain. Fertile flovers 1-3, the upper enwrapping deformed sterile ones.

32. G1ycexin. Lower palet convex or rounded on the back, 5 -7-nerved, kerions at the tip. Spikelets many-flowered; the flowers deciduous at maturity by the breaking up of the rhachis into joints.

33. Brixopyrum. Lower palet laterally much compressed and often keeled, acute, rigid, rather coriaceous, smooth, faintly many-nerved. Spikelets flat, spiked-clustered.

37. Festnca. Lower palet slightly if at all laterally compressed, not keeled, only 1 - 5-nerved, not cobwebby, and nearly without scarious margins, acutish : otherwise as in Poa.

34. Poa. Lower palet laterally compressed nnd mostly keelel, 5-nerred, membranaceous, scarious-nargined, the margins or nerves below often cobwebby or pubescent: the upper palet not remaining after the lower falls. Spikelets flattened.

35. Erngrogils. Lower palet 3-nerved, keeled, deciduous, lenving the upper persistent on the rhachis. Spikelets flat.

+ - Grain adherent to the upper palet.

36. Brizn. Lower palen rounded, very obtuse, pointless, innny-nerved, flattened parallel wo tho glumes, soon ventricose, scarious-mnrgined. Spikelets somewhat henrt-shnped.

37. Festmen. Lower palet convex on the back, acute, pointed, or awned at the tip, few-nerver. Spikelets terete or flattish. Styles terminal.

38. Brumus. Lower palet convex or kecled on the back, mostly awned or bristle-bearing below the 2-cleft tip, 5-9-nerved. Styles scarcely terminal.

* * Lowest flower of the spikclet neutral or staminate.

39. Uniola. Spikeleta very flat; the one or more lowest flowers neutral, of a single empty palet. Flowers strongly compressed-keeled, crowded, coriaceous.

40. Phrngmites. Spikelets strongly silky-bcarded on the rhachis, loosely-flowered, the lowest flower staminate or neutral. Palets membranaceous.

Subtribe 5. Bambuseae. Culms woody and commonly arborescent. Spikelets and flowers nearly as in the precelling Subtribe, awnless.

41. Aruminaria. Spikelets flattened, loosely 5-14-flowered, in depauperate panicles.

Sublribe 6. Horleineae. Spikelets 1-several-flowered, sessile on opposite sides of a rigzag jointed rhachis (which is excavated or channelled on one side of each joint), forming a spike. Glumes sometimes abortive or wanting. Otherwise as in Subtribe 4.

* Spikelets single at each joint of the rhachis.

42. Lepturns. Spikelets almost immersed in the excavations of the very slender rhachis, 1-flowered. The filiform enikes usually several.

43. Lollum. Spikelets many-flowered, placed edgewise on the rhachis of the solitary spike : glume only one, external.

14. Triticum. Spikeleta 3-seveml flowered, placed flatwise on the rhachis of the solitary вpike: both glumes present, transverse (right and left).

* Spikelets 2 or more nt each joint of the rhachis : spike solitary.

- Glumes nnterior, forming $n$ sort of involucre for the eluster of spikelets.

45. Hordenm. Spikelets 1-flowered, 3 nt ench joint, but the two lateral usually sterile.

46 El y mus. Spikelets 1 - severnl-flowered, all perfect and similar. 
- Glumes none or 1-2 awn-like rudiments in their place.

47. Gymnostichum. Spikelets few-Hlowerod, somewhat pedicelled, $1-3$ at esch joint.

Subtribe $\boldsymbol{\gamma}$. Aveneze. Spikelets 2-several-flowered, panicled; the rhachis or base of the flowery often villous-bearded. Glunes mostly equalling or exceediug the flowers Lower palet bearing a twisted, bent, or straight awn on its back or below its apex; tho upper palet 2-uerved. Stamens 3.

* F'lowers all perfect, or the uppermost rudimentary.

48. Danthouia. Spikelets several-flowered. Lower palet tirm and rigid, rounded on the back, several-nerved, the 3 midlle nerves running into the flattish twisted awn which proceeds from the cletit at the apex.

49. Avena. Spikelets 2 -several-flowered. Iower palet roundish on the back, and of firner texture than the glumes, several-nerved, sharply 2-toothed or 2-eleft at the tip, the bent or twisted awn rising only from the midnerve at or below the cleft.

50. T'risetum. Spikelets 2-several-1lowered. Lower palet laterally compressed and keeled, sharply 2-trothed or 2-pointed at the apex, the slender awn rising at or near the cleft, from the miduerve only.

51. A Ira. Spikelets suall, 2-flowered, with or without the rudineut of a third flower. Palets thin or scarious, the lower awned from towards the base.

* One of the flowers stuminate only.

52. A rrhenatherum. Lower flower stuminate; the perfect one commonly awnless; tho upperuost a rudiuent : otherwise as in Avena.

63. Holeuy. Lower flower perfect, awuless; the upper staminate and awned: rudimeut none : otherwise resembliug Aira.

Tribe II. PII A.A IRII) E. AG, T'riu. (not of Kunth). Spikelets 3-flowered; the uppermose or middlo (terminil) flower perfect: the two fower (one on each side) imperfect, either stąminate, neutral, or reduced to an iticouspicuous rudiment.

Subtribe 1. Anthoxunheve. Lateral flowers mostly awned, staminate or neutral, of 1 or 2 palets ; the upper one awnless and diandrous. Upper palet 1-nerved.

54. Ilics ochlou. Iateral flowers staminate aud triandrous, of 2 palets.

55. Anthoxuminum. Lateral flowers meutral, each of a single awod and hairy palet.

Subtribe 2. Phalaridea proper. Lateral flowers reduced to a small neutral rudiment or abortive pedicel on each side of the fertile one; which is awnless and triandrous.

56. Phalaris. Glumes boat-shaped, keeled, enciosing the coriaccous fertile flower.

Tribe III. PANICLIE. Spikelets 2-flowered; the lower flower always imperfect, either staminate or neutral; in the latter crse usually reduced to a single empty palet (placed next the lower glume, if that be present); the upper (termiual) flower (placed next the upper or inner glume) only fertile. Enbryo and groove (when present) on the outer side of the grain! (next the lower palet of the fertile flower). (Flowers polygamous, or henigamous (when the lower flower is neutral), or sometimes seemingly simple and perfect, from the suppression both of the lower glume and of the upper palet of the neutrul flower, sometines monucious, or rarely diccious. 1karely both glumes are wanting.)

Subtribe 1. Paspaleac, Griseb. Glumes and sterile palets herbaceous or membranaceous: palets of the fertile flower of firmer texture, coriaceous or chartaceous, awnless, not keeled, more or less flattened parallel with the glumes.

* Spikelets appearing as if simply 1-flowered, from the suppression of the lower glunie, the single neutral patet of the sterile llower apparently oceupying its place. (Awnless.)

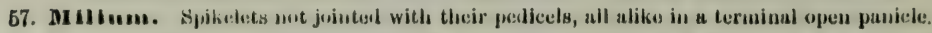

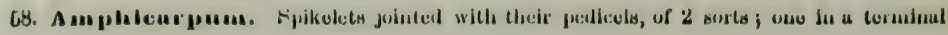
pauicle; the other subterranean, on rudical peduncles.

59. Paspa 1 um. Spikelets jointed with their short pedicels, ull ulike, plano-convex, in onesided spikes or spiked racemes. 
* Spikeleta manifestly $1 \frac{f}{2}-2$-flowered (polygamous, the lower flower staminate or often neutral, of one or both palets), the lower glume being present.

60. Pnnicum. Spikeleta not involuerate, nor the poduneles bristle-henring. Jower glume uaually amall or minute. Aterlle flower either atnminnto or neutrul.

61. Setnrin. Bpikeleta aplked or divse-panicled, the peiluncles continued into naked solitary briktles or awns : otherwiso as in Panicum.

62. Cenchrus. Spikeleta enclosed $1-5$ together in a hard and spiny or bristly and globular bur-like involucre.

Subtrlbe 2. Sncchnveze. Fertile palets membranaceous or scarious, always of thinner and more delicate texture than the (often inclurated) glumes, frequently awned from the tip. Spikelets usually in pairs or threes, panicled or epiked, some of them entirely sterile or rudimentary.

- Splkelets monœcinus, imbedded in the separable joints of the spike.

68. Tripsacum. Staminate spikelets above, in pairs at each joint: pistillate spikelets single in each joint: glumes indurated.

* Fertile spikelets with one perfect and one sterile (staminate or mostly neutral) flower: lower palet of the perfect flower awned.

64. Erinnthus. Both spikelets at each joint of the rhachis alike fertile, and involucrate with a silky tuft: otherwise as in the next.

65. A ndropogun. Spikelets a pair at each joint of the plumose-hairy spikes, one of them sessile and fertile; the other pedicelled and sterile or rudimentary.

66. Sorghum. Spikelets in open panicles, $2-3$ together, the lateral ones sterile or sometimes reduced to mere pedicels.

\section{LEERSIA, Solander. Whitr Grass. (PI. 7.)}

Flowers crowded in one-sided panicled spikes or racemes, perfect, but those in the open panicles usually sterile by the abortion of the ovary, those enclosed in the sheaths of the leaves close-fertilized in the buil and prolific. Spikelets 1-flowered, flat, more or less imbricated over each other, jointed with the short pelicels. Glumes wanting. Palets chartaceous, strongly flattened laterally or conduplicate, awnless, bristly-ciliate on the keels, closed, nearly equal in length, but the lower much broader, enclosing the flat grain. Stamens $1-6$. Stigmas feathery, the hairs branching. - Perennial marsh grasses: the flat leaves, sheaths, \&c., rough upwards, being clothed with rery minute hooked prickles. (Named after John Daniel Leers, a German botanist.)

* Spikelets narrowly oblong, rather loosely crouded.

1. L. Virgínica, Willd. (Wnite Grass.) Panicle simple; the spikelets clossly appressed on the slender branches, around which they are partly curved ( $1 \frac{1}{2}$ "long); stamens 2 (a third imperfect or wanting); palets sparingly ciliate (greenish-white). - Wet woods. Aug., Sept.

2. L. oryzoides, Swartz. (Rrce Cut-grass.) Panicle diffusely branched;

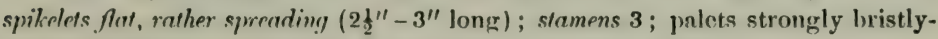
ciliate (whitish). - Very wet places: common. Ang. (Fu.)

* Spikelets broadly oral, imbricately conering each other $\left(2 \frac{1}{2} "-3\right.$ "long).

3. L. lenticulàris, Michx. (FLY-Catch Grass.) Smoothish; panicle simple; palets very flat, strongly bristly ciliate (said to close and catch flies); stamens 2: otherwise like the preceding. - Low grounds, Virginia, Illinois, and southward. 


\section{ZIZÀ N I A, Gronov. Water or Indian Rice. (Pl. 7.)}

Flowers moncecious; the staminate and pistillute both in 1-flowered spikelets in the same panicle. Glumes wanting, or rudimentary and forming a little cup. Palets herbaceo-membranaceous, convex, awnless in the sterile, the lower one tipped with a straight awn in the fertile spikelets. Stanens 6 . Stigmas pencil-form. - Large, often reed-like water-grasses. Spikelets jointed with the club-shaped pedicels, very deciduous. (Adopted from Zı jávıov, the ancient name of some wild grain.)

1. Z. aquática, L. (Indian Rice. Water Oats.) Annual; lover branches of the ample pyramidal panicle staminate, spreading; the upper erct, pistillute; pediecls strongly club-shaped; lower pala long-awned, rough; styles distinct; grain linear, slender. (Z. clavulosa, Michx.) - Swampy borders of streams and in shallow water: common, especially northwestward. Ang. - . Culms $3^{\circ}-9^{\circ}$ high. Leaves flat, $2^{\circ}-3^{\circ}$ long, lincar-lanceolate. Grain $6^{\prime \prime}$ long; largely gathered for food by the Northwestern Indians.

2. Z. miliàcea, Michx. Perennial; panicle diffuse, ample, the staminate and pistillate flowers intermixed ; awns short ; styles united ; grain ovate. Penn.? Ohio, and southward. Aug. - Leaves involute.

\section{ALOPECŨ US, L. Foxtall Grass. (PI. 7.)}

Spikelets 1-flowered. Glumes boat-shaped, strongly compressed und keeled, nearly equal, united at the base, equalling or exeeding the lower palet, which is awned on the back below the middle: upper palet wanting! Stamens 3 . Styles mostly united. Stigmas long and feathered. - Clusters contracted into a cylindrical and soft dense spike. Root perenuial. (Name from $a^{\lambda} \dot{\omega} \pi \eta \xi \xi$, fox, and oúpá, tail, the popular appellation, from the shaje of the spike.)

1. A. Praténsis, L. (Meadow Foxtail.) Culm upright, smooth $\left(2^{\circ}\right.$ high); palet equalling the acute glumes; awn exscrted more than half its length, twisted; the upper leaf much shorter than its inflated sheath. - Meadows und pastures, eastward. May. (Nat. from Eu.)

2. A. Geniculàtus, L. (Floating F.) Culm ascending, bent at the lower joints; palet ruther shorter than the oltuse glumes, the awn from nar its base and projecting half its length beyond it; anthers linear; the upper leaf as long as its sheath. - Moist meadows, castward. June-Aug. (Nat. from Eu.)

3. A. aristulàtus, Michx. (WILD F.) Glaucous; culm decumbent below, at length bent and ascending; palet rather longer than the obtuse glumes, scarcely exceeded by the awn which rises from just below its middle; anthers oblong. (A. subaristatus, Pers.) - In water and wet places: commun. JuneAug. Spike more slender and paler than in the last. (Eu.)

\section{- 4. PHLEU M, L. Cat's-tall Grass. (Pl. 7.)}

Palets both present, shorter than the mucronate or awned glumes; the lower one truncate, usually awnless. Styles distinct. Otherwise much as in Alopecurus. - Perennials. Spike very dense, harsh. (An ancient Greck name.)

1. P. preaténse, L. ('T'motux. Inzo'y-Grass in New England and New York.) 'Tall; spitice cylindricul, clongated; glumes ciliate on the back, 
tipped with a short bristle. - Mendows, commonly cultivated for hay. (Nat. from Eu.)

2. P. alpinum, L. Low; spike ovate-oblong; glumes strongly ciliate on the back, tipped with a rough awn about their own lrngth. $-\Lambda$ ppine tops of the White Mountains, New IIampshire, and high northward. (Eu.)

\section{CRÝ PSIS, Ait. Crypris. (PI. 7.)}

Spikelets 1-flowered, in clusters which are crowiled in a dense head or short spike bracted by the uppermost leaves. Glumes, palets, \&c. as in the next genus, or rather thinner. - Low and spreading tufted annuals, natives of the Fast ; with short leaves, the sheaths of the upper spathaceous. (Name, kpúqıs, concealment, the spikes at first partly hidden by the subtending sheaths.)

1. C. schonoldes, Lam. Leaves rather rigid, tapering to a sharp point; heads or spikes oblong, $7 "-20^{\prime \prime}$ long, thick. (C. Virgínica, Nutt., excl. syn.) - Waste places, strects of Philadelphia and vicinity, also of Wilmington, Delaware: becoming very common. (Nat. from Eu.)

\section{VÍLFA, Adans., Beauv. Rusi-Grass. (PI. 7.)}

Spikelets 1-flowered, in a contracted or spiked panicle. Glumes 1-nerved or nerveless, not awned or pointed, the lower smaller. Flower nearly sessile in the glumes. Pulets 2, much alike, of the same texture as the glumes (membranaceo-chartaceous) and usually longer than they, naked, awnless and mostly pointless; the lower 1-nerved (rarely somewhat 3-nerved). Stamens chicfly 3. Stigmas simply feathery. Grain (caryopsis) oblong or cylindrical, deciduous. - Culms wiry or rigid. Leaves involute, nsually bearded at the throat; their sheaths often enclosing the panicles. (Name unexplained.)

1. V. áspera, Beauv. Root perennial; culms tufted $\left(2^{\circ}-4^{\circ}\right.$ high); lowest leaves very long, rigid, rough on the edges, tapering to a long involute and thread-like point; the upper short, involute; sheaths partly or at first wholly enclosing the contracted panicle; pulets much longer than the unequal glumes; grain oval or oblong. ( $\Lambda$ grostis áspera, Michx. A. elandestìna \& A. involùta, Muhl. A. longifolia, Torr.) - Sandy ficlds and dry hills, especially southward. Sept. - Spikelets $2^{\prime \prime}-3^{\prime \prime}$ long. Palcts rough above, smooth or hairy below, of greatly varying proportions; the upper one tapering upwards, acute, and one half to twice longer than the lower, or else obtuse and equalled or even considerably excecled by the lower!

2. V. vaginæflora, Torr. Root annual; culms slender $\left(6^{\prime}-12^{\prime}\right.$ high), ascending; leaves involute-awl-shaped $\left(1^{\prime}-4^{\prime}\right.$ long); panicles simple and spiked, the lateral and often the terminal concealed in the sheaths; pulets somewhat equal, acute, about the length of the nearly equal glumes; only one third longer than the linear grain. ( $\Lambda$ grostis Virginien, Muhl., not of $\left.L_{\text {.. }}\right)-$ Barren and sandy dry fields: common, especially southward. Sept.

3. V. cuspidàta, Torr. Root perennial; culms and leaves more slender than in the preceding; panicle exserted, very simple and narrow; spikelets smaller, the glumes very acute, and the lower palet cuspidate. - Borders of Maino (on the St. John's River, G. L. Goodale), and northwestward. 
4. V. Virgínica, Beauv. Root perennial; culms tufted, slender $\left(5^{\prime}-12^{\prime}\right.$ long), often procumbent, branched; leaves convolute, rigid ; palets rather shorter than the nearly equal acuto glumes. (Agrostis Virginica, L.) - Sandy seashore, Virginia (Ciayton) and southward. - Spikelets much smaller and more numerous than in the others.

\section{SPORÓ BOLUS, R. Br. Drop-seed Grass. (PI. 7.)}

Spikelets 1- (rarely 2-) flowered, in a contracted or open panicle. Flowers nearly as in Vilfa; the palets longer than the unequal glumes. Stamens 2-3. Grain a globular utricle (hyaline or rarely coriaceous), containing a loose seed, deciduous (whence the name, fiom $\sigma \pi$ opá, seed, and $\beta a ́ \lambda \lambda \omega$, to cast forth).

* Glumes very unequal: panicle pyrumidul, open : ours perennials, except No. 3.

1. S. júnceus, Kunth. Leaves involute, narrow, rigid, the lowest elongated; culm $\left(1^{\circ}-2^{\circ}\right.$ high $)$ naked above, bearing a narrow loose panicle; glumes ovate, rather obtuse, the lower one half as long as, the upper equalling, the nearly equal palets. (Agrostis juncea, Michx. Vilfa juncea, Trin.) - Dry soil, Pennsylvania to Wisconsin, and (chiefly) southward. Aug. - Spikelets 1"-2"long, shining.

2. S. heterólepis, Gray. Lenves involute-thread-form, rigid, the lowest as long as the culn $\left(1^{\circ}-2^{\circ}\right)$ which is naked above; panicle very loose; glumes very unequal; the lower awt-shaped (or bristle-pointed from a broad base) and somewhat shorter, the upper ovate-oblong and taper-pointed and longer, than the equal palets. (Vilfa heterolepis, Gray.) - Dry soil, Connecticut, and New York to Illinois and Wisconsin. Aug. - Plant exhaling an unpleasant scent (Sullicont), stouter than the last, the spikelets thrice larger. Utricle spherical ( $\mathbf{I}^{\prime \prime}$ in diameter), shining, thick and coriaceous!

3. C. cryptándrus, Gray. Leaves flat, pale (2" wide); the pyramidal panicle bursting from the upper sheath which usually encloses its base, its spreading branches hairy in the axils; upper glume lanceolate, rather acute, twice the length of the lower one, as long as the nearly equal palets; sheaths strongly bearded at the throat; root annual? (Agr. \& Vilfa cryptandra, Torr.) - Sandy shores, coast of New England, and of the Great Lakes. Aug., Sept. - Culm $2^{\circ}-3^{\circ}$ high Panicle lead-color: spikelets I" long.

* * Glumes almost equal, shorter than the brond palets: panicle racemose-elongated, open, the pedicels capillary: sheaths nakd at the throut: spikitets not unfiequently tuco-flowered: root perennial. (Cocrodum?)

4. S. compréssus, Kinth. Very smooth, leafy to the top: culms tuffed, stout, very,flat: sheaths flattened, much longer than the internodes; leaves erect, narrow, conduplicate-chamelled; glumes acutish, about one third shorter than the obtuse palets. (Agrostis compressa, Torr. Vilfa, Trin.) - Bogs in the pine-barrens of New Jersey. Sept. - Forming strong tussocks, $1^{\circ}-2^{\circ}$ high. P'anicle $8^{\prime}-12$ ' long: spikelets I" long, purplish.

5. S. serótinus, Gray. Smooth; culıus very stender, fluttish $\left(8^{\prime}-15^{\prime}\right.$ high), fiw-leaved; leaves very slender, channelled; panicle soon much erserted, the diffuse capillary branches scattered; glumes ovate, obtuse, about half the length of the 
ralets. (Agr. \& Vilfa serotina, Torr. V. ténera, Trin. Poa? uniflora, Muhl. P. nodésta, Tuckerm.) - Strndy wet places, Maine to New Jersey and Michigan. Sept. $-\Lambda$ very delicate grass; the spikelets half a line Jong.

\section{A GRÓSTIS, L. 13ent-Grass. (11. 7.)}

Spikelets 1-flowered, in an open panicle. Glumes somewhat equal, or the lower rather longer, usually longer than the palets, pointless. Palets very thin, pointless, naked; the lower 3-5-nerved, frequently awned on the back; the upper often minute or none. Stamens chiefly 3. Grain (earyopsis) free. Culms usually tufted, slender; root commonly perennial. (Name from áypós, $a$ field, the place of girowth.)

§ 1. TRICHÒDIUM, Michx. - Upper palet alortive, minute, or none.

1. A. elàta, Trin. Culms firm or stout $\left(2^{\circ}-3^{\circ}\right.$ high $)$; leaves flat $\left(1^{\prime \prime}-2^{\prime \prime}\right.$ wide) ; upper ligules elongated (2" $-3^{\prime \prime}$ long) ; spikelets crouded on the branches of the spreading panicle above the middle ( $1 \frac{1}{2} "$ long); lower palet awnless, slightly shorter than the rather unequal glumes; the upper wanting. (A. Schweinítzii, Trin.? A. altissima, Tuckerm., excl. var. laxa. Trich. elatum, Pursh.) Swamps, New Jersey and southward. October.

2. A. perénnans, Tuckerm. ('Turn-(insas.) Culins slender, erect from a decumbent base $\left(1^{\circ}-2^{\circ}\right.$ high $)$; leaves flat (the upper $4^{\prime}-6^{\prime}$ long, $1^{\prime \prime}-2^{\prime \prime}$ wide) ; panicle at length diffusely spreading, pale green; the brancles short, divided and flower-hearing from or below the middle; lower palet awnless (rarcly short-awned), shorter than the unequal glumes; the upper minute or obsolete. (Cornucopia perennans, Walt. Trich. perennans, Ell. T. decúmbens, Michx. T. scabrum, Muhl. Agr. anómala, Willd.) - Damp shaded places. July, Aug. - Spikelets, \&c. as in No. 3 , into which it seems to vary.

3. A. scábra, Willd. (Harr-Grass.) Culms very slender, erect $\left(1^{\circ}-2^{\circ}\right.$ high); leaves short and narrow, the lower soon involute (the upper $\mathbf{l}^{\prime}-3^{\prime}$ long, less than 1" wide); panicle very loose and divergent, purplish, the long capillary branches fower-bearing at and near the apex; lower paiet awnless or occasionally short-awned on the back, shorter than the rather unequal very acute glumes; the upper minute or obsolete; root biennial? (A. laxiflora, Richard. A. Michauxii, Trin. partly. Trich. laxiflorum, Michx. T. montànum, Torr.)-Exsiccated places : common. June-Ang. - Remarkable for the long and divergent capillary branches of the extremely loose panicle; these are whorled, rongh with very minute bristles (under a lens), as also the keel of the glumes. Spikelets I' long. - A variety? from about the White Mountains, \&c. (var. montana, Tuckerm.), has a more or less exserted awn, thus differing from the T. montanum, Torr. (A. oreóphila, Trin.), which is a dwarfed form, growing in tufts in hollows of rocks, \&c.

4. A. canina, I. (Brown Bent-Grass.) Culms $8^{\prime}-2^{\circ}$ high; rootleaves involute-bristle-form, those of the culm flat and broader; paniclo loose; glumes slightly unequal, ovate-lanceolate, very acute; palet ersertly awned on the back at or below the middle; spikclets brownish or purplish, rarely pale or greenish (1" $-1 \frac{1}{2}{ }^{\prime \prime}$ long).-Meadows, sparingly naturalized eastward. A mountain form with shorter and more spreading panicle (A. Pickeríngii 
A. concinna, Tuckerm., A. canina, var. alpina, Oakes, \& Ed. 2., and essen. tially $\Lambda$. rubra, $L$. ex Wuhl., and A. borcalis, Ilartm.), is indigenous on mountain-tops, Maine to New York; also, an ampler form in the Alleghanies of Pennsylvania (J.R. Lowrie), and southward (A. rupéstris, Chapman, \&c.). July - Aug. (Lu.)

\section{§ 2. AGROSTIS proper. Upper palet munifest, but shorter than the lower.}

5. A. vulgàris, With. (Red-tor. Hend's-Grass of Penn., \&c.) Rootstocks creeping ; culm mostly upright $\left(1^{\circ}-2^{\circ}\right.$ high $)$; panicle oblong, with spreading slightly rough short branches (purple); leaves linear, flat; ligule very short, truncate; lower palet nearly equalling the glumes, chicfly awnless, 3-nerved; the upper about one half its length. (A. polymórpha, Huds., partly. - Varies with a rougher panicle (A. hispida, Willd.), and rarely with the flower shortawned.-Low meadows; naturalized from Eu., and apparently also native northward. (Eu.)

6. A. álba, L. (Fronin or White Bent-Grass.) Rootstocks more stoloniferous, and culms often decumbent at the base, ascending; ligule elongated, oblong or linear; panicle contracted after flowering, either greenish, purplish or brownish; otherwise as in the preceding, and equally variable; rarely with the lower palet short-awned, or even slender-awned below the tip. (A. stolonífera, L., partly.) - Meadows and ficlds, a valuable grass : nat. from Eu. : also indigenous on river-banks, N. New York and northward. (Eu.)

\section{POLY PÖ G N, Desf. Beard-Grass. (Pl. 8.)}

Spikelets I-flowered, in a contracted, mostly spike-like panicle. Glumes nearly equal, long-awned, much longer than the membranaceous palets, the lower of which is commonly short-awned below the apex. Stamens 3. Grain free. (Name composed of $\pi \circ \lambda \dot{v}$, much, and $\pi \dot{\omega} \gamma \omega \nu$, beurd ; from the awns.)

1. P. Monspeliénsis, Desf. Panicle interrupted; glumes oblong, the awn from a noteh at the summit; lower palet awned ; root annual. Hampton Beach, New IIanpshire (Kobbins), Virginia ? and southward. (Nat. from Eu.)

\section{CÍ N N A. Wood Reed-Grass. (Pl. 8.)}

Spikelets 1-flowered, much flattened, crowded in an open flaccid panicle. Glumes lanceolate, acute, strongly keeled, rough-serrulate on the keel; the lower rather smaller, the upper a little exeeding the palets. Flower manifestly stalked in the glumes, smooth and naked; the palets much like the glumes; the lower longer than the upere, short-awned or mucronate on the back below the pointless apex. Stamen one, opposite the l-nerved upper palet! Grain lincar-oblong, fice. - A perennial, rather sweet-scented grass, with simple and upright somewhat reed-like culms $\left(2^{\circ}-7^{\circ}\right.$ high $)$, bearing an ample compounả terminal panicle, its lranches in fours or fives; the broadly linear-lanceolate flut leaves $\left(4^{\prime \prime}-6\right.$ " wirle) with conspicuous ligules. Spikelets green, often purplish-tinged. (Nume unexplained.)

1. C. arundinàcea, L. - Moist woods and shaded swamps : rather common. July, Aug. - Panicle $6^{\prime}-15^{\prime}$ long, rather dense; the branches and pedi- 
eels spreading in flower, afterwards erect. Spikelets $2 \frac{1}{2} "-3^{\prime \prime}$ long. $\Lambda$ wn of the palet either obsolete or manifest.

Var. péndula, Gray. Panicle loose and more slender, the branches neurly enpillary and drooping in flower; pedicels very rongh; glumes and palets thinner, the former less unequal ; spikelets $11_{2}^{\prime \prime}-2^{\prime \prime}$ long ; upper palet obtuse. (C. pendula, Trin. C. latifolia, Griseb. C. expánsa, Link. Blýttia suavèolens, Fries.) - Deep damp woods, N. New England to Lake Superior and northward, and on mountains southward. $-\boldsymbol{A}$ slender variety of the last, as is shown by intermediate specimens, always monandrous. (Eu.)

\section{MUHLENBÉRGIA, Schreber. Drop-seed G. (Pl. 8.)}

Spikelets 1-flowered, in contracted or rarely in open panicles. Glumes mostly acute or bristle-pointed, persistent ; the lower rather smaller or minute. Flower very short-stalked or sessile in the glumes; the palets usually minutely bearded at the base, herbaceous, deciluous with the enclosed grain, often equal; the lower 3-nerved, mucronate or awned at the apex. Stamens 3. (Dedicated to the Rev. Dr. Henry Muhlenberg, a distinguished American botanist of the early part of this century.)

§ 1. MUHLENBERGIA proper. Panicles contracted or glomerate, terminal and axillary: perennials (in our species) with branching rigid culms, from scaly creeping rootstocks : leaves short and narrov.

* Lower palet barely mucronate or sharp-pointed. (Sp. of Cinna, Kunth, Trin.)

1. M. sobolifera, Trin. Culms ascending $\left(1^{\circ}-2^{\circ}\right.$ high $)$, rarely branching; the simple contructed panicle very slender or filiform; glumes barely pointed, almost equal, one third shorter than the equal pralets; lower palet abruptly short-mucronate. (Agrostis sobolifera, Muhl.) - Open rocky woods, Mass. to Michigan, Illinois, and southward. Aug. - Spikelets less than 1" long.

2. M. glomerata, Trin. Culms upright $\left(1^{\circ}-3^{\circ}\right.$ high $)$, sparingly branched or simple; panicle oblong-linear, contracted into an interrupted glomerate spike, longpeduncled, the branches sessile; glumes awned, nearly equal, and (with the bristle-like awn) about twice the length of the unequal very acute palets. (Agr. racemòsa, Michx. A. setòsa, Muhl. Polypògon racemosus, Nutt.)-Bogs : common, especially northward. Aug. - Panicle $2^{\prime}-3^{\prime}$ long.

3. M. Mexicàna, Trin. Culms ascending, much branched $\left(2^{\circ}-3^{\circ}\right.$ high $)$; panicles lateral and terminal, often included at the base, contracted, the branches densely spiked-clustered, linear (green and purplish); glumes awnless, sharp-pointed, unequal, the upper about the length of the very acute lower palet. (Agr. Mexicana, $\boldsymbol{L}$. A. lateriflora, Michx.) - Varies with more slender panicles (A. filifórmis, Muhl.) - Low grounds : common. Aug.

* Lower palet bristle-awned fiom the tip: flowers short-pedicelled.

4. M. sylvática, Torr. \& Gr. Culms ascending, much branched and diffusely spreading $\left(2^{\circ}-4^{\circ} \mathrm{long}\right)$; contracted panicles densely many-fowered; glumes almost equal, bristle-pointed, nearly as long as the lower palet, which bears an nwn twice or thrice the length of the spikelet. $(\Lambda \mathrm{gr}$. diffusa, $M u h /$.) - Low or rocky woods: common. Aug., Sept. - In aspect between No. 3 and No. 5. 
5. M. Willdenóvii, Trin. Culms upright ( $3^{\circ}$ high $)$, slender, simple or sparingly branched; contracted panicle slender, loosely flowered; glumes sliyhlly unequal, short-pointed, half the length of the lower palct, which bears an awn 3-4 times the length of the spikelet. (Agrostis tenuitlora, Willd.) - Rocky woods : rather common. Aug.

6. M. diffùsa, Schreber. (Drop-seed. Nimule Will.) Culms diffusely inuch branched $\left(8^{\prime}-18^{\prime}\right.$ high) ; contracted panicles slender, rather looscly many-flowered, terminal and lateral; glumes extiemely minute, the lower absolcte, the upper truncate; awn once or twice longer than the palet. (1)ilejyrum minutiflorm, Michx.) - 1ry hills and woods, from S. New England to Michigan, Illinois, and southward. Aug', Sept. - Spikelets only 1" long.

§2. TRICHÓCHLOA, DC. Panicle very loose and open, the long branches and pelicels capillary: leaves narrow, often convalute-bristle-form.

7. M. capillàris, Kunth. (HaIr-Grass.) Culm simple, upright ( $2^{\circ}$ high) from a fibrous root ; panicle capillary, expanding $\left(6^{\prime}-20^{\prime}\right.$ long, purple) ; glumes unequal, one third or half the length of the long-awned palets, the lower mostly pointless, the upper more or less bristle-pointed. - Sandy soil, W. New England to New Jersey, Kentucky, and southward. Sept. - Pedicels $1^{\prime}-2^{\prime}$ long, scarcely thicker than the awns, which are about l' long.

\section{B R A CH Y E I TRU M, Beauv. (Pl. 8.)}

Spikelets 1-flowered, with a conspicuous filiform pedicel of an abortive second flower about half its length, nearly terete, fow, in a simple appressed racemed panicle. Glumes unequal, persistent, usually minute, or the lower one almost obsolete. Palets chartaceo-herbaceous, involute, enclosing the linear-oblong grain, somewhat equal, rough with scattered short bristles; the lower 5-nerved, extended into a long straight awn; the upper 2-pointed; the awn-like sterile pedicel partly lodged in the groove on its lack. Stamens 2 : anthers and stig-. mas very long. - Perenuial, with simple culms $\left(1^{\circ}-3^{\circ} \mathrm{high}\right)$ from creeping rootstocks, downy sheaths, broad and flat lanceolate pointed leaves, and spike-

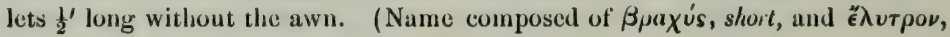
husk, from the minute glumes.)

1. B. aristàtum, Beauv. (Muhlenbergia erécta, Schreb. Dilepỳrum aristòsum, Michx.) - Rocky woods : common. Jume. - Var. Engelmánni, is a Western form, with the upper glume awn-pointed, nearly half the length of the palet.

\section{CA I A M A G Rós T IS, Adans. Reed Bent-G. (PI. 8.)}

Spikelets 1-flowered, and often with a pedicel or rudiment of a second abortive flower (rarely 2-flowered), in an open or spiked panicle. Glumes keeled or boat-shaped, often acute, commonly nearly equal, and exceeding the flower, which bears at the base copious white bristly hairs. Palets thin; the lower bearing a slender awn on the lack or below the tip, or sometimes awnless; the upper mostly shorter. Stamens 3. (irain free. - Peremials, with rumning rootstocks, and mostly tall and simple rigid culms. (Name compounded of

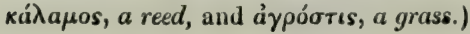


\$1. DEYEUXIA, Kunth. Rudiment of a second flower present in the form of $a$ plumuse or hairy small pedicel behind the upper palet (very rarely move developed and having palets or even stamens) : glumes and palets memhiranaceous, or the latter thin and delimte as in $\Lambda_{\text {grostis }}$ the lower 3-5-nermed and awn-bearing.

* Panicle loose and open, even uffer fowoming: the mostly purple-finged or lead-colored strigose-scabrous glumes not closing in fruit: copious hairs surrounding the flower about equalling the hyuline lower pulet, not surpassad by those of the rudiment : awn delicute, struight.

1. C. Canadénsis, Bcanv. (Buve Jornt-Grass.) Culm tall $\left(3^{\circ}-5^{\circ}\right.$ high); leaves flat when fresh, glancous; panicle oblong; glumes ovate-lenceolate, acute, $1 f^{\prime \prime}-1 \frac{1}{2}$ "long; awn from near the middle of the palet, not exceeding and scarcely stouter than the hairs around the flower. (Arundo Canadensis, Michx. C. Mexicana, $N_{i t t}$ ) - Wet grounds : common northward. July.

2. C. Langsdórffi, 'Trin. Spikelets larger, $2 \frac{1}{2} "-3$ " long; glumes lanceolate or oblong-lanceolate and grudually tuper-pointed; awn stouter: otherwise like the preceding. - White Mountains, New Hampshire, and northward. (Eu.)

* Panicle strict, its short branches appressed or erect afler flowering, and the glumes mostly closed: lower palet less delicate, roughish, sometimes of us firm texture as the glumes : awn stouter.

+ Leaves narrow, inclined to be involute: awn straight.

3. C. strícta, Trin. Panicle glomerate and lobed, strict ; glumes $1 \frac{1}{2} "-2$ " long, ovate-oblong, not acuminate; hairs scarcely or little shorter than the flower, and as long as those of the rudiment; awn from the milllle of the thin palea or lower, and barely exceeding it. - Lelges at Willoughby Lake, Vermont ( W. Boott), Lake Superior, and northward. (Eu.)

+ + Leaves brouder, flut : awn stouter, bent, divergent, or twisted when dry.

4. C. confinis, Nutt. Panicle elongated, its rather slencler branches spreading at flowering-time, afterwards appressed; glumes lance-oblong, very acute, 2 "long, pule; hairs of the flower copious, equal, slightly or one third shorter than the thin lower palet and than those of the rudiment; awn borne much below the middle of the palet, somewhat surpassing it; grain glabrous. (Arundo confinis, Willd.! C. inexpánsa, Giray.) - Swamps, N. and W. New York (especially Penn Yan, Sariwell) and Pennsylvania. July. - Culm tall.

5. C. Nuttalliàna, Steud. Culm stout $\left(3^{\circ}-5^{\circ}\right.$ high $)$; prnicle contracted and spike-like; glumes lanceolate and tapering into slender awl-shaped tips, $3^{\prime \prime}$ long; hairs on the lower side scant!y and barely half the length of the firm and kefled lower palet, on the other side longer and equalling the copious tuft on the summit of the rudiment; awn borne half-way between the middle and the tapering tip of the palet, stont, not twisted; grain bearded at the top. (C. Canadénsis, Nutt. C. coarctata, Torr., and of former ell.) - Moist grounds, E. New England to Pennsylvania, Virginia, und southward. Ang.

6. C. Pórteri, Gray. Culm slender $\left(2^{\circ}-4^{\circ}\right.$ high $)$; a woolly-bearded ring at the junction of the broadly linear leaves with the sheath; panicle long and narrow, with the branches appressed; glumes lanceolate, acute, pale, $2^{\prime \prime}$ to $2 \frac{1}{2}$ ' long; hairs of the flower and of the short rudiment scanty, and hoth reaching about to the middle of the flower behind the upper palet, but very short or none at the 
base of the firm-membranaceous lower palet, which bears near its base a twisted awn of its own length. - Dry woods, Pulpit Rocks and vicinity, Huntingdon Co., Penusylvania, I'rof:' 'I'. C'. P'viler.

7. C. Pickeríngii, Gray. Culm $1^{0}-1 \frac{1}{2}^{\circ}$ high ; leaves short; panicle pyramidal, purplish; glumes ovate-oblong, bluntish or bluntly pointed (1 1 " $-2^{\prime \prime}$ long); hairs both of the flower and of the rudiment viry short and scanty, one fourth or fifth the length of the flower, none behind the obtuse lower palet, which bears between its middle and base a short and stout (straight or bent, not twisted) awn. - White Mountains, New Hanpshire, in the alpine region of Mt. Washington (Dr. Pickering, \&c.); and a inore luxuriant form with smaller spikelets at Echo Lake, Franconili, IV. Buott. Sept.

§ 2. CALAMUVILIA. Gilimes and equal palets rather chartaceous, compressedkecled; the lower glume shorter than the upper and shorter than the palets, of which the lower is 1-nerval and entirely awnless: the upper strongly 2-keuled: ruliment of second flower wanting: panicle open and loose.

8. C. brevípilis, Gray. Branches of the diffuse pyramidal panicle capillary (purplish); ylumes ovate, mucronate; the upper slightly, the lower nearly one half shorter than the palets, which are above twice the length of the hairs and bristly-beurded along the keels. (Arundo brevipilis, Torr.) - Sandy swamps, pinebarrens of New Jersey : rare. Sept. - Culm $3^{\circ}-4^{\circ}$ high : leaves nearly flat.

9. C. longifolia, Hook. Culm $\left(1^{\circ}-4^{\circ}\right.$ high $)$ stout, from thick running rootstocks ; leaves rigid, elongated, mrolute above and tapering into a long threadlike point; branches of the pyramidal panicle smooth; glumes lanceolate, the upper as long as the similar palets, the lower one fuurth shorter ; the copious hairs more than half the length of the naked palets. - Sands, along the upper Great Lakes, from Illinois and Michigan northwestward. Aug. - Spikelets $2 \frac{1}{2}$ " long. Sheaths clothed with deciduous wool.

§ 3. AMMÓPHILA, Host. Rudiment of serond flover present and plumose alove: glumes nearly equal and ruther longer than the equal similar palets, scarious-characeous, lanceolute, compressed-keeled: lower palet 5-nerved, slightly mucronate or obscurely anowd nert the tip : the "upper 2-kepled: squnmulce lancrolinte, much longer than the ourry: pavicle spiked-contracted: spikelets large ( $\frac{1}{2}$ long).

10. C. arenària, Roth. (SEa Sand-Reko.) Culın stout and rigid $\left(2^{\circ}-3^{\circ}\right.$ high $)$ from firm running rootstocks; leaves long, soon involute; panicle contracted into a dense cylindrical spike $\left(5^{\prime}-9^{\prime} \mathrm{long}\right)$; hairs only one third of the length of the palet. (Arundo, L. Psamma, Beauv.)-Sandy beaches, New Jersey to Maine, and northward, and on the Great Lakes. Aug. (Eu.)

\section{ORYZÓPSIS, Michx. Mountain Rice. (Pl. 8.)}

Spikelets I-flowered, nearly terete. Glumes herbaceons or thin-membranaceous, several-nerved, nearly equal, commonly rather longer than the oblong flower, which is decilluous at maturity, and with a very short obtuse callus or Bcur-like luse Jower palct coriaceous, at length involute so as closely to encloso the upper (of the same length) and the oblong grain; a simple untwisted and deciluous awn jointed on its apex. Stumens 3. Siquamula 2 or 3, conspicnous. Stignas plumose. - Perennials, with rigid leaves and a narrow rucene or 
panicle. Spikelets greenish, rather large. (Name composed of "̋p $\rho \zeta$, rice, and bै $\psi(s$, likeness, from a fancied resemblance to that grain.)

* Styles distinct, short: culm leajy to the summit: leaves broud and fat.

1. O. melanocárpa, Muhl. Leaves lanceolate, taper-pointed; sheaths bearded in the throat; panicle simple or sparingly branched; awn thrice the length of the blackish palets (nearly 1' long). (Mílium racemosum, Simith. Piptathèrum nigrum, Torr.) - Rocky woods. Aug. - Culm $2^{\circ}-3^{\circ}$ high.

* Styles united below, slender: culms tufted, naked: Ieav's concrue or innolude.

2. O. asperifolia, Michx. Culms $\left(9^{\prime}-18^{\prime}\right.$ high) with sheaths bearing a mere rudimentary blade, overtopped by the long and rigid linear leaf from the base; very simple panicle or raccme fow-flowered; awn 2-3 times the length of the rather hairy whitish pulets. (Uráchne, Trin.) - Hillsides, \&c., in rich woods : common northward. May. - Leaves without keels, rough-edged, pale beneath, lasting through the winter. Squamula lanceolate, almost as long as the inner palet!

3. O. Canadénsis, Torr. Culms slender $\left(6^{\prime}-15^{\prime}\right.$ high), the lowest sheaths leaf-bearing; leaves involute-thread-shaped; panicle contracted $\left(1^{\prime}-2^{\prime}\right.$ long), the branches usually in pairs; palets pubescent, whitish; awn short and very deciduous, or wanting. (O. parviflora, Nutt. Stipa juncea, Michx. S. Canadensis, Poir. Milium pungens, Toır. Urachne brevicaudàta, Trin.) - Rocky hills and dry plains, W. New England to mountains of Penn., Wisconsin, and northward : rare. May. - Glumes 1" - 2" long, sometimes purplish.

\section{ST İ P A, L. Fentuer-Grass. (Pl. 8.)}

Spikelets 1-flowered, terete; the flower falling awav at maturity (with tne conspicuous obconical bearded and often sharp-pointed callus) from the membranaccous glumes. Lower palet coriaceous, cylindrical-involute and closely embracing the smaller upper one and the cylindrical grain, having a long and twisted or tortuous simple awn jointed with its apex. Stamens mostly 3. Stigmas plumose.-Perennials, with narrow involute leaves and a loose panicle. (Name from $\sigma \tau u ́ \pi \eta$, tow, in allusion to the flaxen appearance of the feathery awns of the original spccies. In our species the awn is naked.)

* Callus or base of the flower short and blunt: glumes pointless.

1. S. Richardsonii, Link. Culm $\left(1 \frac{1}{2}{ }^{\circ}-2^{\circ}\right.$ high $)$ and leaves slender; panicle loose $\left(4^{\prime}-5^{\prime}\right.$ long), with slender few-flowered branches; glumes nearly equal, oblong, acutish ( $2 \frac{1}{2}$ " long), about equalling the pubescent linear-oblong lower palet, which bears a tortuous awn $6^{\prime \prime}-8^{\prime \prime}$ long. - Pleasant Mountnin, near Sebago Lake, Maine, C. .J. Sprague, and northwestward. (Flowers rather smaller than in Richardson's plant, as described.)

* Cullus or bose of the fower pungently pointed, at maturity villous-bearded: lower palet slender and minutely bearded at the tip : glumes tuper-pointed.

2. S. avenàcea, L. (Вияск Омт-Grлss.) Culm slender $\left(1^{\circ}-2^{\circ}\right.$ high); leaves almost bristle-form ; panicle open ; palets blackish, nearly as long as the glumes (about 4"long); the awn bent above, twisted below ( $2^{\prime}-3^{\prime}$ long). - Dry or sandy woods, S. New England to Wisconsin, and southward. July.

3. S. spártea, Trin., not of Hook. (Porcupine Grass.) Culm rathe: L \& M-46 
stout $\left(1 \frac{1}{2}{ }^{\circ}-3^{\circ}\right.$ high); panicle contracted; palcts linear, $3^{\prime}-1^{\prime}$ long (including the long callus), pubescent below, shorter thun the lanceolate slender subulate-pointed greenish glumes; the twisted strong awn $\left(3 \frac{1}{2}^{\prime}-7^{\prime}\right.$ loug, pubescent below, rough above. (S. juncea, Pursh?) - Plains and prairies, from Illinois and N. Michigan northwestward. May-July.

\section{A R ÍSTI D A, L. Thiple-Awned Grass. (Pl. 8.)}

Glumes unequal, often bristle-pointed. Lower palet tipped with three awns; the upper much smaller. Otherwise much as in Stipa. - Culms branching: leaves narrow, often involute. Spikelets in simple or panicled racemes or spikes. Grain linear. (Name fiom arista, a beard or awn.) All grow in sterile, dry soil, and all ours lave the awns naked and persistent, and flower late.

\section{* A wns sepurute to the buse, not jointed with the paltet.}

- Awns very unequil; the much shorter or minute luterul ones erect; the elongated middle one horizontal or turned downwards: glumes equal or the upper one longer: low (5'-18' high) and branching, mostly tufled annuals.

+- Spikelets few in loose simple spikes or racemes: ylumes 3-5-nerved.

1. A. ramosíssima, Engelm. mss. Culms diffusely much branched; glumes $\left(9^{\prime \prime}-10^{\prime \prime}\right.$ long) rather shorter than the flower; middle awn 1 ' long, soon abruptly hooked-recurved, the lateral ones hardly $2^{\prime \prime}$ long; ligule truncate, bearded. - Dry prairies of Illinois (Engclinann, Vasey) and Kentucky (Michanx). - Var. uninistàta, with lateral awns wanting. Odin, S. Illinois, Vasey.

++ Spikelts more numerous: glumes ( $3^{\prime \prime}-4^{\prime \prime}$ long) carinately l-nerved.

2. A. dichótoma, Michx. (Poverty Grass.) Culms low, much branched throughout, ascending; spikelets in short narrow clusters; glumes nearly equal, longer than the flower, fully equalling its minute lateral awns, the soon reflext middle aum about the length of the palct. - Dry, sandy or gravelly ficlds: common, especially southward.

3. A. grácilis, Ell. Culms slender, $\operatorname{crect}\left(6^{\prime}-18^{\prime}\right.$ high), naked above and terminating in a sleniler raceme- or spike-like virgate panicle; glumes about the length of the Hower, the exserted lateral awns varying from one third to fully half the length of the horizontally bent middle one; or in var. DEPAUPERATA, from one fifth to one third its length. - Sandy soil, coust of Mass. and from Illinois southward. - Middle awn $6^{\prime \prime}-9^{\prime \prime}$ long, in the ordinary forms. In the var. which abounds on micaceous hills near Philadelphia (C. E. Simith), the flowers are much smaller, and awus shorter; but it passes into the larger form.

+ + Awns all diverging and alike, or the lateral ones moderately shorter. tr Glumes equal or the upper one longer.

4. A. strícta, Michx. Cuhns $\left(2^{\circ}-3^{\circ}\right.$ high $)$ densely tufted from a perennial root, bearing a $\left(1^{\circ}\right)$ long spiked panicle; leaves involute-thread-form, long, rigrid, sornetimes downy: awns about the length of the flower $\left(6^{\prime \prime}\right)$ or the lateral one third shorter. - Virginia and southward.

5. A. oligántha, Michx. Culms $\left(6^{\prime \prime}-20^{\prime \prime}\right.$ high $)$ tufted from an annual? root, bearing a loosely fiw-flowered raceme; leaves short, somewhat involuto when

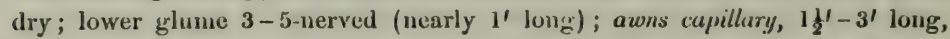
nuch exceeding the slender flower. - Virginiat to Illinois, and common southwestivard. 
++ Upper glume shorter than the lower: perennials, simple-stemmed, $2^{\circ}-4^{\circ}$ high.

6. A. purpuráscens, Poir. Glabrous; leaves rather involute; flowers in a $\left(10^{\prime}-18^{\prime}\right)$ long spiked panicle; awns much longer than the flower, the middle one about $\mathbf{I}^{\prime}$ long. (A. racemòsa, Muhl. A. Geyeriàna, Steud.)-Massachusetts to Michigan, Illinois, and southward: common.

7. A. lanàta, Poir. Tall and stout; leaves tardily involute, rough on the upper side, rigid; sheaths woolly; panicle $\left(1^{\circ}-2^{\circ} \mathrm{long}\right)$ spike-like or more compound and open; middle awn ( 1 'long) longer than the flower. - Salisbury, Maryland, W. M. Canby, and southward.

* Awns united below into one, jointed with the apex of the palet: root annual.

8. A. tuberculosa, Nutt. Culm branched below $\left(6^{\prime}-18^{\prime}\right.$ high), tumid at the joints; panicles rigid, loose; the branches in pairs, one of them short and about 2-flowered, the other elongated and several-flowered; glumes ( $1^{\prime}$ long, including their slender-awned tips longer than the palet; which is tipped with the common stalk (about its own length) of the 3 equal divergently-bent awns $\left(1 \frac{1}{2}{ }^{\prime}-2^{\prime}\right.$ long) twisting together at the base. - Sandy soil, E. Massachusetts to New Jersey ; also Wisconsin, Illinois, and southward.

\section{SPARTì N A, Schreber. Cond or Mansn Grass.}

Spikelets 1-flowered, without a rudiment, very much flattened laterally, spiked in 2 ranks on the onter side of a triangular rhachis. Glumes strongly compressedkeeled, acute, or bristle-pointed, mostly rough-bristly on the keel; the upper one much larger and exceeding the pointless and awnless palets, of which the upper is longest. Squamulx none. Stamens 3. Styles long, more or less united.Perennials, with simple and rigid reed-like culms, from extensively creeping scaly rootstocks, racemed spikes, very smooth sheaths, and long and tough leaves (whence the name, from $\sigma \pi a \rho \tau i \nu \eta, a c o r d$, such as was made from the bark of the Spartium or Broom.)

* Spikelets compactly imhricuted, very rough-hispid on the keels: spikes $\left(2^{\prime}-4^{\prime}\right.$ long $)$ more or less peduncled: culm and elongated lenves rigid.

1. S. cynosuroldes, Willd. (Fresi-water Cord-Grass.) Culn rather slender $\left(2^{\circ}-6^{\circ}\right.$ high) ; leaves narrow $\left(2^{\circ}-4^{\circ}\right.$ long. $\frac{1}{2}^{\prime}$ or less wide below $)$, tapering to a very slender point, keeled, flat, but quickly involute in drying, smooth except the margins; sprikes 5-20, scattered, spreading; rhachis rough on the margins; glumes awn-pointed, especially the upper, the lower equilling the lower palel, whose strong rongh-hispid midrib abruptly terminates below the membranous apex. (Trachynòtia cynosuroides, Michx. Limnètis, Pers.) - Banks of rivers and lakes, especially northward. $\Lambda$ ug. - Glumes strongly serrulate-hispid on the keel; the awn of the upper one about ${ }_{4}^{\prime \prime}$ long. Palets somewhat unequal. - Certainly distinct from the next, to which, in strictness, the Linnæan name belongs.

2. S. polystàchya, Willd., Muhl. (SALT Rerd-GrAss.) Culm tall and stout $\left(4^{\circ}-9^{\circ}\right.$ high, often $1^{\prime}$ in diameter near the base); leaves broad $\left(\frac{1}{2}^{\prime}\right.$ to $\left.1^{\prime}\right)$, roughish undernenth, as well as the margins; spikes 20-50, forming a dense oblong raceme (purplish); glumes barely mucronate, the lower half the length of the equal palets, of which the rough-hispid midrib of the lower one reaches to the apex. 
(Trachynotia polystachya, Michx. Dactylis cynosuroides, L.l in part, excl. var.) - Salt or brackish marshes, within tide-water, especially southward.

3. S. júncea, Willd. (Rush SAlT-Gisass.) C'ulms low $\left(1^{\circ}-2^{\circ}\right.$ high) and slender; leaves narrow and rush-like, strongly involute, very smooth; spikes $1-5$, on very short peduncles; the rhachis smooth; glumes acute, the lower scarcely half the length of the upper, not half the length of the lower palet. (Dáctylis patens, Ait.) - Salt marshes and sea-beaches. Aug. (Eu.)

* * Spikelets loosely imbricuted, or somewhat remote and alteinate, the keels only slightly hairy or roughish under a lens: spikes sessile and erect, soft: leaves, rhachis; \&c. very smooth: culm ruther succulent.

4. S. strícta, Roth. (Salt Marsil-Grass.) Culm $1^{\circ}-4^{\circ}$ high, leafy to the top; leaves soon convolute, narrow ; spikes few $(2-4)$, the rhachis slightly projecting at the summit beyond the crowded or imbricated spikelets : glumes acute, very unequal, the larger I-nerved, a little longer than the palets. - Salt marshes, Pennsylvania, \&c. (Muhl.) - Odor strong and rancid. (Eu.)

Var. glàbra. (S. glabra, Muhl., partly.) Culm and leaves longer; spikes $5-12\left(2^{\prime}-3^{\prime}\right.$ long) ; spikelets imbricate-crowded. - Common on the coast.

Var. alterniflòra. (S. alterniflora, Loisel. Dactylis cynosuroides, var., L.) Spikes more slender $\left(3^{\prime}-5^{\prime}\right.$ long), and the spikelets remotish, barely overlapping, the rhachis continued into a more conspicuous bract-like appendage: larger glume indistinctly 5-nerved (not so evidently as in the European and Tropical American plant): otherwise as in the preeding form, into which it passes. - Common with the last: also Onondaga Lake, J. A. Paine.

\section{CTÉ N I U M, Panzer. Toothache-Grass. (Pl. 9.)}

Spikelets densely imbricated in two rows on one side of the flat curved rhachis of the solitury terminal spike. Glumes persistent: the lower one (interior) much smaller; the other concave below, bearing a stout recurved awn, like a horn, on the middle of the back. Flowers 4-6, all but one neutral; the one or two lower consisting of empty awned palets : the one or two uppermost of empty awnless palets : the perfect flower intermediate in position; its palets membranaceous, the lower awned or mucronate below the apex and densely ciliate towards tho base, 3-nerved. Squamula 2. Stamens 3. Stigmas plumose. (Name Kreviov, a small comb, from the pectinate appearance of the spike.)

1. C. Americàum, Spreng. Culm $\left(3^{\circ}-4^{\circ}\right.$ high from a perennial root) simple, pubescent or roughish ; larger glume warty-glandular outside and conspicuously awned. (Monócera aromática, Ell.) - Wet pino barrens, S. Virginia and southward. - 'Taste very pungent.

\section{BOUTELOÙ A, Lagasca (1805). Muskft-Grass.}

Spikelets crowded and closely sessile in 2 rows on one side of a flattened rhachis, eonuprising one perfect flower below and one or more sterile (mostly neutrul) or rudimentary flusers. Gilumes convex-kecled, the lower one shorter. Perfect flower with the 3-nerved lower palet 3-toothed or eleft at the apex, the 2-nerved upper palet 2-toothed; the teeth, at least of the former, pointed or sub- 
tulnte-awned. Stamens 3: anthers orange-colored or red. Rudimentary flowers mostly 1-3-awned. Spikes solitary, racemed or spiked; the rhachis somewhat exteniled beyond the spikelets. (Named for Claudius Boutelou, a Spanish writer upon floriculture and agriculture.)

§1. CHONIOROSIUM, I)esv. Spikes pectinate, of very many spikclets, oblong or linenr, very dense, solitary and terminal or few in a raceme: sterile flowers $1-3$ on a short pedicel, neutral, consisting of $1-3$ scales and awns.

1. B. oligostàchya, Torr. Glabrons, perennial $\left(6^{\prime}-12^{\prime}\right.$ high); leaves very narrow; spikes $1-5$, the rhachis glabrous; glumes and lower fertile palet sparingly sof-hairy; the lobes awl-pointed; sterile flower copiously villous-tiffed at the summit of the naked pedicel, its 3 awns equalling the larger glume. (Atheropogon, Nutt.) - N. W. Wisconsin and westward. - Glumes obscurely if at all papillose along the keel. Mirdlle lobe of the lower palet 2-cleft at the tip. Sterile flowers often 2, the second mostly a large awnless scale, becoming hood-like and coriaceous. (Near B. gracilis: perhaps B. juncifolia, Laq.)

2. B. hirsùta, Lagasca. Tufted, annual ? $\left(8^{\prime}-20^{\prime}\right.$ high); leaves flat, lance-linear, pnpillose-hairy or glabrous; spikes 1-4; upper glume hispid with strong bristles from dark wurty glands; lower palet pubescent, 3-cleft into awlpointed lobes; sterile flower and its pedicel glabrous, the 3 auns longer than the glumes and fertile flower. (Atheropogon papillossus, Engelm. Chondrosium hirtum, H.B.K.) - Sandy plains, Wisconsin, Illinois, and southwestward.

\$2. $\Lambda$ THEROPȮGON, Muhl. Spikes short, numerous in a long and virgate one-sided spike or raceme, spreading or reflexed, each of few (4-12) spikelets: sterile flowers neutral, rudimentary.

3. B. curtipéndula, Gray. Culms tufted from perennial rootstocks $\left(1^{\circ}-3^{\circ}\right.$ high); sheaths often hairy; leaves narrow ; spikes $\frac{1}{2}^{\prime}$ or less in length, nearly sessile, 30 to 60 in number in a loose general spike $\left(8^{\prime}-15^{\prime}\right.$ long $)$; flowers senbrous; the lower palet of the fertile with 3 short awl-pointed teeth; sterile flower reduced to a single small awn, or mostly to 3 awns shorter than the fertile flower, and 1 or 2 small or minute scales. (B. racemòsa, Lagasca. Chloris curtipendula, Michx. Atheropogon apludioides, Muhl. Eutriana curtipendula, Trin.) - Dry hills and plains, S. New York to Wisconsin, and southward. July -Sept. - Passes by transitions into, Var. ARIstosa, with spikes shorter; sterile flower of a large saccate lower palet, awned at the 2-cleft tip and from the lateral nerves, the niddle awn exserted, and with a rudiment of an inner palet. (Eutriana affinis, J. D. Hook.) - Illinois (Geyer), and southward.

\section{GYMNOPÒGON, Benuv. Naked-beard Grass. (Pl. 9.)}

Spikelets of one perfect flower, and the rudiment of a second (consisting of an awn-like pedicel mostly bearing n naked bristle), sessile and remotely alternate on long and filiform rays or spikes, which form a crowderl naked raceme. Glumes lance-awl-shaped, keeled, almost equal, rather longer than the somewhat equal membranaceous palets; of which the lower is cylindrical-involute, with the midrih produced from just helow the 2-cleft apex into a straight and slender bristle-like awn: the upper with the abortive rudiment at its base. 
Stamens 3. Stigmas pencil-form, purple. - Root perennial. Leaves short and

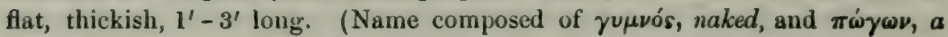
beard, alluding to the reduction of the abortive flower to a bare awn.)

1. G. racemosus, Beauv. Culms clustered from a short rootstock $\left(1^{\circ}\right.$ high $)$, wiry, leafy; leaves ollong-lanceolate; spikes flower-bearing to the buse $\left(5^{\prime}-8^{\prime}\right.$ long), soon divergent; awn of the abortive flower shorter than its stalk, equalling the pointed glumes, not more than half the length of the awn of the fertile Hower. (Anthopingon lepturvides, Nutt.) - Sandy pine-barrens, New Jersey to Virginia, and southward. Aug., Sept.

2. G. brevifölius, Trin. Filiform spikes long-peduncled, i. e. flower-bearing only above the middle; lower palet ciliate near the base, short-awned; awn of the abortive flower obsolete or minute; glumes acute. (Anthopògon brevifolius \& filifórmis, Nutt.) - Sussex County, Delaware, and southward.

\section{CÝNODON, Richard. Bermuda or Scutch-Grass. (PI. 9.)}

Spikelets 1-flowered, with a mere naked short-pedicelled rudiment of a second flower, imbricate-spiked on one side of a flattish rhachis; the spikes usually digitate at the naked summit of the flowering culms. Glumes keeled, pointless, rather unequal. Palets pointless and awnless; the lower larger, boat-shaped. Stamens 3. - Low diffusely-branched and extensively ereeping perennials, with short flattish leaves. (Nane composed of $\kappa \dot{\omega} \omega \nu, a$ dog, and ódoús, a tooth.)

1. C. 1) Sétryon, l'ers. Spikes 3-5; palets smooth, longer than the blunt rudiment. - P'eun. and southward; troublesome in light soil. (Nat. from Eu.)

\section{DactyloctèniUm, Willd. Egrptian Grass. (PI. 9.)}

Spikelets several-flowered, with the uppermost flower imperfect, crowded on ono side of a flattened rhachis, forming dense pectinate spikes, $2-5$ in number, digitate at the summit of the culm. Glumes compressed laterally and keeled, menbranaceous, the upper (exterior) one awn-pointed. Lower palet strongly keeled and boat-shaped, pointed. Stamens 3. P'eriearp a thin utricle, containing a loose globular and rough-wrinkled seed. - Root annual. Culms dif-

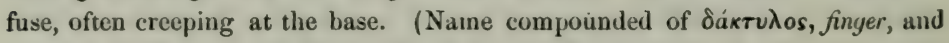
$\kappa \tau \in$ viov, a little comb, alluding to the digitate and pectinate spikes.)

1. D. Egyptìncum, Willd. Spikes 4-5; leaves ciliate at the baso. (Chloris mucronùtı, Mfichx.) - Cultivated fields and yards, Virginia, Illinoi», and southward. (Adv. from Afr.?)

\section{3. eleusìne, Gartn. Crab-Grass. Yard-Grass. (PI. 9.)}

Spikelets 2-6-flowered, with a terminal naked rudiment, elosely imbricatespiked on one side of a flattish rhachis; the spikes digitate. Glumes membranaceous, pointless, shorter than the flowers. Palets awnless and pointless; the lower ovate, kecled, larger than the upper. Stamens 3. Pericarp (utricle) containing a loose oval and wrinkled seed. - Low annuals, with flat leaves, and flowers much as in P'oa. (Name from 'E $\mathrm{\lambda} \in v \sigma$ i $\nu$, the town where Ceres, the goddess of harvests, was worshipped.) 
1. E. fodica, Gertn. (1)og's-t八iz or Wire Grass.) Culms ascending, fiattened; spikes 2-5 (about $2^{\prime}$ long, grecnish). - Yards, \&c., chicfly sonthward. (Nat. from Ind. ?)

\section{LEPT ÓCHLOA, Beauv (OxvB̀̀nis, Nüt.) (PI. 9.)}

Spikelets 3-many-fowered (the uppermost flower imperfect), loosely spiked on one side of a long filiform rhachis: the spikes racemed. Glumes membranarcous, keeled, often awl-pointed, the upper one somewhat larger. Lower palet 3-nerved, with the lateral nerves next the ciliate or hairy margins awnless, or bristle-awned at the entire or 2-toother tip, larger than the upper. Stamens 2 or 3 . Seed sometimes loose in the pericarp. - Ours annuals. Leaves flat. (Name composed of $\lambda \epsilon \pi r o ́ s$, slender, and $\chi^{\lambda}$ io grass, from the long attenuated spikes.)

§ 1. LEPTOCHLOA proper. Lower palet awnless or simply awned.

1. L. mucronata, Kunth. Sheaths hairy; spikes numerous (20-40, $2^{\prime}-\mathbf{4}^{\prime}$ in length), in a long panicle-like raceme; spikelets small ; glumes more or less mucronate, nearly equalling or exceeding the 3-4 awnless flowers. Ficlds, Virginia to Illinois, and sonthward. August.

§ 2. DIPLACHNE, Beauv. Lover pald bristlenowed from the 2-toothed apex; the marginal nerves often excurrent into lateral tecth or points.

2. L. fascicularis, Gray. Smooth; leaves longer than the geniculatedecumbent and branching culms, the upper sheathing the base of the crowded panicle-like raceme, which is composed of many strict spikes $\left(3^{\prime}-5^{\prime}\right.$ long $)$; spikelets slightly pedicelled, 7 - 11-flowered, much longer than the lanceolate glumes; palets hairy-margined towards the base; the lower one with 2 small lateral teeth and a short awn in the cleft of the apex. (Festuca fascicularis, Lam. F. polystàchya, Michx. Diplachne fascicularis, Benuv., Torr.) - Brackish meadows, from Rhode Island southward along the coast, and from Illinois southward on the Mississippi. Aug. - Sept. - Makes a direct transition to the next genus.

\section{TRI C ÚSPIS, Beauv. (P1. 10.)}

Spikelets 3-12-flowered, somewhat terete; the terminal flower abortive. Glumes unequal. Rhachis of the spikelet heariled below each flower. Palets membranaccous or somewhat chartaccous; the lower much larger than the 2toothed upper one, convex, 2-3-toothed or cleft at the apex, conspicuously hairy-bearded or villous on the 3 strong nerves, of which the lateral are marginal or nearly 80 and usually excurrent, as is the mid nerve especially, into a short cusp or awn. Stamens 3. Stigmas dark purple, plumose. Grain oblong, nearly gibbous. - Iseaves taper-pointed : slicaths bearderl at the throat. Panicle simple or compound; the spikelets often racemose, purplish. (Name from the Latin trimspis, three-pointed, allading to the lower palet.)

§1. TRICUSPIS proper. (IVindsoria, Nutt.) Glumes shorter then the enouded flowers : lower malet 3-mispidate by the projection of the nerves, and usually with intermediate membranaceous teeth; the upper palet naked. 
1. T. seslerioldes, Torr. (TALl Red-Top.) Perennial ; culm upright $\left(3^{\circ}-5^{\circ}\right.$ high $)$, very smooth, as are the flat leaves; panicle large and compound, the rigid capillary branches spreading, naked below; spikelets very numerous, 5-7-flowered, shining, purple ( $4^{\prime \prime}$ long); the flowers hairy toward the base: (Poa flava, L.l P. seslerioides, Michx. P. quinquélida, Pursh. Windsoria,

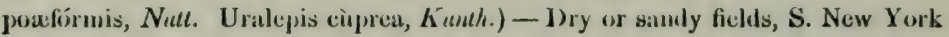
to Illinois and sonthward. $\Lambda$ ug. $-\Lambda$ showy gruss, with the spreading paniclo sometimes $1^{\circ}$ wide. I'oints of the lower palet almost eyual, scarecly execeding the intermediate tecth, thus appearing 5-toothed.

§2. TRHPLÀSIS, Beauv. (Diplòcea, Ruf. Urálepis, Nutt.) Glumes much shorter than the somewhat remote flowers: both palds stiongly fringe-bearded; the lower 2-ckft at the summit, its mid-nerve producud into un awn between the truncate or awn-pointed divisions.

2. T. purpùrea, Gray. (Sand-Gkass.) Culms many in a tuft from the same annual root, ascending $\left(6^{\prime}-12^{\prime}\right.$ high), with nunerous bearded joints; leaves involute-awl-shaped, mostly short; panicles very simple, bearing few 2 5-flowered spikelets, the terminal one usually exserted, the axillary ones included in the commonly hairy sheaths; awn much shorter than the palet, seldom exceding its erouled-lruncele or obluse listercal lobes. (Aira purpùrea, Walt. Diplòcea barbàta, Raf. Urálepis purpìrea and U. aristulàta, Nutt.) - In sand, Massachusetts to Virginia along the coast, and southward: also Lake Erie, near Buffalo, G. W. Clinton. Ang., Sept. - Plant acid to the taste.

(T. connutia (Uralepis cornuta, Ell., and 'Triplasis Americana, Beauv. l) may perhaps extend north to the borders of Virginia.)

\section{GR A P H É P H O R U M, Desv. (Duróntia, R. Br.) (PI. 10.)}

Spikelets 2-5-flowered, rather terete. Glumes nnembranaceous, mostly nearly equalling the remote flowers. $\Lambda$ cluster of villous hairs at the base of each flower. Palets thin and membranaceous or scarious; the lower one convex, scarcely keeled, faintly nerved, entire, pointless and awnless. Stamens 3. Stigmas plumose. Ovary glabrous. - P'erennial and northern or aretic grasses, with linear flat leaves, their sheaths closed at the base, the spikelets in a loose panicle. (Genus allied to the $\Lambda$ venea, but awnless; named from $\gamma$ pa $\phi i s, a$ pencil, and $\phi \dot{\epsilon} \rho \omega$, to bear, from the tufts of hair at the base of the flowers.)

1. G. melicoldes, Beauv. Culm $1^{\circ}-2^{\circ}$ high ; leaves roughish; panicle open; glumes uncequal, lanceolate, their midrib and the pedicels rough; joints of the rhachis unilaterally bearded between the 2-4 flowers. Graud Detour, Upper Michigan, Prof. Porter, Shore of Moosehead Lake, Maine, C. E. Smith, and northward : rare. - Var. м̇̀Jon, Gray (1)upontia Cooleyi, of former ed.), is a luxuriant form, $2^{\circ}-3^{\circ}$ high, with ampler panicle; found on the borders of a swamp, Washington, Macomb County, Michigan, by Dr. Cooley. Aug.

\section{D I A R R È NA, Raf. DLahriena. (Pl. 10.)}

Spikelets several-flowered, smooth and shining, one or two of the uppermost flowers sterile. Gilumes ovate, much shorter thath the flowers, coriaceous; the lower one much sinaller. Lower palet ovate, convex on the back, rigidly cori- 
accous, its 3 nerves terminating in a strong and abrupt cuspidate or awl-shaped tip. Squamule ovate, ciliate. Stamens 2. Grain very large, obliquely ovoid, ohtusely pointed, rather longer than the palets, the cartilaginous shining pericarp not adherent to the seed. - $A$ nearly smooth perennial, with running rootstocks, producing simple culms $\left(2^{\circ}-3^{\circ}\right.$ high) with long linear-lanceolate flat leaves towards the base, naked above, bearing a few short-pedicelled spikelets $\left(2^{\prime \prime}-3^{\prime \prime}\right.$ long) in a very simple panicle. (Name composed of dis, two, and äṕp $\dot{\eta}$, man, from the two stamens.)

1. D. Americana, Benuv. (Festuca diándra, Michx.) - Shaded riverbanks and woods, Ohio to Illinois and southward. Aug.

\section{DÁ CTyLIs, L. Orchard Grass. (PI. 10.)}

Spikelets several-flowered, crowded in one-sided clusters, forming a branching dense panicle. Glumes and lower palet herbaccous, keeled, awn-pointed, rough. eiliate on the keel; the 5 nerves of the latter converging into the awn-like point; the upper glume commonly smaller and thinner. Stamens 3. Grain lance-

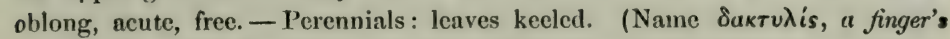
readeh, apparently in allusion to the size of the clusters.)

1. D. glomerits, L. Rough, rather glaucous $\left(3^{\circ}\right.$ high $)$; leaves broadly linear; branches of the panicle naked at the base; spikelets 3-4-flowered. Fields and yards, especially in shade. A varicty with downy spikelets, Medford, Mass., W. Boott. June. - Good for hay. (Nat. from Eu.)

\section{Koglitri.A, Pers. Keleria. (PI. 10.)}

Spikelets 3-7-flowered, crowded in a dense and narrow spikc-like panicle. Glumes and lower palet membranaceous, compressed-keeled, obscurely 3-nerved, barcly acute, or the latter often mucronate or bristle-pointed; the former moderately unequal, nearly as long as the spikelet. Stamens 3. Grain free.Tufted Grasses (allied to Dactylis and Poa), with simple upright culms; the sheaths often downy. (Named for Prof. G. L. Köller, or Koeler, an early writer on Grasses.)

1. K. cristàta, Pers. Panicle narrowly spiked, interrupted or lobed at the base; spikelets 2-4-flowered; lower palet acute or mucronate; leaves flat, the lower sparingly hairy or ciliate. - Var. onAcitis, with a long and narrow spike, the flowers usually barely acute. (K. nítirla, Nutt.) - Dry hills, Penn. to Illinois, thence northward and westward. (Eu.)

\section{EA T Ò I A, Raf. (Reboùles, Kunth.) (PI. 10.)}

Spikelets usually 2-flowered, and with an abortive ruliment or pelicel, numerous, in a contracted or sleniler punicle, very smooth. Flumes aomewhat equal in length, but very dissimilar, a little shorter than the flowers; tho lower narrowly linear, keeled, 1-nerved; the upper broadly obovate, folded round the flowers, 3-nerved on the back, not keeled, scarious-margined. Lower palet oblong, obtuse, compressed-boat-shaped, naked, chartaceous; the upper very thin and hyaline. Stamens 3. Grain linear-oblong, not grooved. - Perennial, slen- 
der grasses, with simple and tufted culms, and often sparsely downy sheaths, flat lower leaves, and smull greenish (or rarely purplish-tinged) spikelets. (Named for Prof. Amos Euton, author of a popular Manual of the Botany of the United States, which was for a long time the only general work available for students in this country, and of other popular treatises.)

1. E. obtusàta, Gray. Panicle dense and contracted, somewhat interrupted, rarely slender; the spikelets crowded on the short ereet branches; upper ylume rounded-aborate, truncute-obtuse, rough on the back; flowers lance-oblong. (Aira obtusàta, Michx. A. truncìta, Muhl. Koxleria truncata, Torr. K. paniculata, Nult. Reboulea gracilis, Kunth, in part. R. obtusata, Ed. 1. Eatonia purpuráscens, Ruef. Y) - Dry soil, N. Pennsylvania to Wisconsin, and southward. June, July.

2. E. Pennsylvánica, Gray. Panicle lony and slender, loose, the racemose branches somewhat elongated ; upper glume obtuse or bluntly somewhat pointed ; the 2 (rarely 3 ) flowers lanceolate. (Koeleria Pennsylvánica, DC. Aira mòllis, Muhl. Reboulea Pennsylvanica, Ed. 1.) - Varies, with a fuller panicle, $6^{\prime}-8^{\prime}$ long, with the aspect of Cinna (var. maJor, Torr.); and, rarely, with the luwer palet minutely mucronate-pointed! - Moist woods and meadows : common.

\section{MÉlica, L. Melic-Grass. (Pl. 10.)}

Spikelets 2-5-flowereil; the $1-3$ upper flowers imperfect and dissimilar, convolute around each other, and enwrapped by the upper fertile flower. Glumes ustally large, scarious-nargined, convex, obtuse; the upper 7-9-nerved. Pulets papery-membranaceous, diy and sometimes indurating with age; the lower rounded or flattish on the back, 7 -many-nerved, scarious at the entire blunt summit. Stamens 3. Stigmas branched-plumose. - l'erennials with soft and flat leaves. Panicle simple or sparingly branched; the rather large spikelets racemose-one-sided. (An old name, from $\mu \epsilon^{\prime} \lambda_{\iota}$, honey.)

1. M. mùtica, Walt. Punicle simple or branched; glumes unequal, the larger almost equalling the spikelet; fertile flowers 2 ; lower palet naked, glabrous minutely scabrous on the nerves. (M. glabra, Michx. M. speciòsa, Muhl.) - Var. glära (M. glabra, Pursh) has the panicle often few-flowered and rather simple, the lower palet very blunt. - Var. Difrèsa (M. diffusa, Pursh) is taller, $2 \frac{1}{2}^{\circ}-4^{\circ}$ high, with a more compound and many-flowered panicle; the lower palet commonly more scabrous and its tip narrower. - Rich soil, S. E. Pennsylvania to Wisconsin, and southward. June.

\section{GIX CERIA, R. Br., 'T'in. Manna-Giass. (P'l. I0.)}

Spikelets terete or flattish, several - many-flowered; the flowers mostly early deciduons by the breaking up of the thachis into joints, leaving the short and unequal 1-3-nerved membranaceous glumes belind. Pulets natied, of a rather firm texture, nearly equal ; the lowcr rounded on the back, scarious (and sometimes olsscurely toothed) at the blunt or rarcly acute summit, glabrous. 5-7nerved, the nerves parallel aud separate. Stamens 3 , or in the first section commonly 2. Stigmas plumose, mostly compound. Ovary smooth. Grain oblong, free. - Purennial, smooth marsh-grasses, mostly with creeping bases or 
rootstocks; the spikelets panicled. (Name from $\gamma \lambda$ ขKe pós, sweet, in allusion to the taste of the grain.)

§1. GLYCERIA proper. Lower palet conspicuously nerved: styles present: plumes of the stigma branched or toothed: grain grooved on the inner side: leaves flat, the sheaths nourly entire.

* Spikelets ovate, oblong, or linear-oblong, $1 "-3$ " in length,

- At length nodding in an open panicle, flattish laterally but turgid.

1. G. Canadénsis, 'Trin. (Ratruesnakk-Gnass.) P'anicle oblongpyramidal, at length drooping; spikelets ovate, at length very hroad and tumid, Briza-like, $2^{\prime \prime}$ long, pale, with purplish glumes ; lower palet acute or bluntpointed, firm, with not very prominent nerves, longer than the rounded upper one; culm stont, $2^{\circ}-3^{\circ}$ high ; leaves long, roughish. (Briza Canadensis, Mich $x_{\text {) }}$-Bogs and wet places : common from Penn. northward. July.

+ + Erect in a nowrow contracted panicle, somewhut flattened and turgid.

2. G. obtùsa, Trin. Panicle narrowly oblong, dense; $\left(3^{\prime}-5^{\prime}\right.$ long); spikelets 6-7-flowered; $2^{\prime \prime}-3^{\prime}$ long ; lower palet obtuse; culm stout, $1^{\circ}-2^{\circ}$ high, very leafy ; leaves long, smooth. (Poa obtusa, Muhl.) - Bogs, E. New England to Penn., near the coast.

3. G. elongata, Trin. Panicle nurrombly racemose, slonguted (10 long), recurving; the branches and 3-4-flowered spikelets appressed; Jower palet obtuse; leaves very lorig ( $1^{\circ}$ or more), rough. (Poa elongatu, Torr.) - Wet woods, New England to Michigan, and northward. July-Aug.

+++ Diffuse : lower palet truncate-obtuse, prominently 7-nerved; upper 2-tonthed.

4. G. nervata, Trin. (Fowl-Mkadow Grass, in part.) Branches of the loose panicle capillary, at length drooping, the very numerous small spikelets ovate-oblong, 3-7-flowered; leaves rather long. (Poa nervata, Willd. P. striàta, Michx. P. parviflòra, Pursh.) - Moist meadows : very common. June. - Culm erect, $1^{\circ}-3^{\circ}$ high. Spikelets $1^{\prime \prime}-2^{\prime \prime}$ long, commonly purplish.

5. G. pallida, Trin. Branches of the rather simple panicle slender, erectspreading, rough ; the spikelets usually few, somewhat appressed, oblong-linear, 5 - 9flowered (pale, 2": $-3^{\prime \prime}$ loug) ; lower palet minutely 5-toothed; the upper lanceolate, conspicuously 2-toothed; leaves short, sharp-pointed, pale: (Windsoria pallida \& Pon dentàta, Torr.) - Shallow water: common, especially northward. July. - Culms slender, $1^{\circ}-3^{\circ}$ long, ascending from a crecping base.

6. G. aquática, Smith. (Reed Mendow-Grass.) Panicle much branclied, aniple (8'-15' long); the numerous branches ascending, sprending with age; spikelets oblong on linear-oblong, 5-9-flowered (usually purplish, $2^{\prime \prime}-3^{\prime \prime}$ long); lower palet entire; leaves large $\left(1^{\circ}-2^{\circ}\right.$ long, $\frac{1}{3}^{\prime}$ to $\frac{1}{2}^{\prime}$ wide. - Wet grounds : common northward. July. - Culm stont, upright, $3^{\circ}-5^{\circ}$ high. (Eu.)

* Spikelets linen $\left(\frac{1}{2}{ }^{\prime}-1^{\prime}\right.$ long), pale, appressed on the brunchrs of the long and narrow racemose panicle, terete exrept during anthesis: pulets mimulely roughish, the upper 2-tonthed: squamula unilaterul or united: ligule long : culm flattened $\left(1^{\circ}-5^{\circ}\right.$ high), ascending from a rooting base. (Glyceria, $R$. Br.)

7. G. flùitans, R. Br. Spikelets 7-13-flowered; lower palet oblong, obtuse, or the scarious tip acutish, entire or obscurely 3 -lobed, usually rather longer 
than the blunt upper one. (G. plicàta, Fries.) - Shallow water : common. June- $\Lambda$ ug. - Icaves short and rather broad, very smooth. Panicle $1^{\circ}$ long: the simple branches nppressed, finally spreading helow. (Lu.)

8. G. acutiflora, 'Torr. Spikelets 5-12-flowered, few and scattered; lower palet oblong-lanciolute, acute, shorter than the long tapering point of the upper one. - Wet plices, l'enn. to Maine : rather rare. June. - Rescmbles the last; but the erect leaves smaller, the separate flowers twice the length (4" long), and less nerved.

§ 2. HELEÓCHLOA, Fries. (Scleròchloa, Ed. 1.) Lower palet inconspicuously or obsoletely 5-nerved: stigmes nearly sessile and simply plumose: grain hardly grooved: suline species : panicle contracted with age.

9. G. marítima, Wahl. (SEA SPEAR-Grass.) Sterile shoots procumbent, rumer-like; flowering culus erect $\left(1^{\circ}-1 \frac{1}{2}{ }^{\circ}\right.$ high $)$; branches of the panicle solitary or in pairs; spikelets oblong or linear, 4-8-flowered; lower palct rounded at the summit, slightly pubescent turads the base; leaves somewhat involute; ligule elongated. (1'oa maritima, Muds.) - Sea coast : not rare. (Eu.)

10. G. dístans, Wahl. Culins geniculate at the base, ascending, destitute of running shoots; branches of the panicle $3-5$ in a half whorl, spreading ; spikelets 3-6-flowered; lower palet truncate-obtuse; leaves mostly flat; ligule short. (P. fasciculàta, Torr.) - Salt marshes along the coast. - Too like the last. (Eu.)

\section{B R I Z O P Ỳ R U M, Link. SPike-Grass. (PI. í.)}

Spikelets and numerous flowers compressed, crowded in a densely spiked or capitate panicle. Glumes herbaccous or membranaceous; the lower faintly many-nerved. Lower palct rather coriaceous, laterally much flattened, indistinctly many-nerved, acute. Oviry stalked. - Flowers diocious, pretty large. Leaves crowded on the culms, involute, commouly rigid. (Name compounded of Briza, the Quaking.Grass, and mupós, wheat.)

1. B. spicàtum, Hook. Culms tufted from creeping rootstocks $\left(9^{\prime}-18^{\prime}\right.$ high) ; spike oblong, flattened ( $l^{\prime}$ long); spikelets ovate or oblong, 5-10-flowered; flowers smooth and naked; grain pointed. (Uniola spicata, L. P'oa Michauxii, K(unth.) - Salt marshes and shores. Aug. - Pistillate flowers more rigid and alnost keeled, with very long plumose stigmas; the sterile smaller and somewhat rounded on the back.

\section{Pòa, T. Meadow-Grass. Spear-Grass. (Pl. 10.)}

Spikelets ovate or lance-ovate, laterally compressed, several- (2-10-) flowered, in an open panicle. Glumes mostly shorter than the fluwers; the lower smaller. Lower palet membanteco-herbaccous, with a delicate scarions margin, compressed-keeled, pointless, 5-nerved (the intermediate nerves more obscure or obsolete), the principal nerves commonly clothed at und towards the base with soft hairs: upjer palct membranaceous, 2-toothed: base of the flower often cobwcbly. Stamens 2 or 3. Stigmas simply plumose. Grain oblong, froe. Culus tufted, from perenuial roots, except No. I. Lcaves smooth, usually tat and soft. (Пóa, an ancient Greck name for grass or folder.) 
* Low and spreading $\left(3^{\prime}-6^{\prime}\right.$ high $)$ from an annual or biennial root, flaccid: branches of the short panicle single or in puiv.

1. P. ánnua, L. (Low Srean-(insas.) Culms flattened; prnicle often 1-sided; spikelets crowded, very short-perlicelled, 3-7-flowered. - Cultivuted and waste grounds, everywhere : but doubtful if indigenous. April - Oct. (Eu.)

* Low; the culms $\left(6^{\prime}-20^{\prime}\right.$ long) geniculute-ascending from a minning rootstock, rigid, very much flattened: panicle simple and contracted.

2. P. compréssa, L. (Wine-(inass.) l'ule, as if glnucons; lenves short; panicle dense and narrow, somewhat onc-sided (1'-3' long), the short branches mostly in pairs; spikelets almost sessile, 3-10-(lowered, flat.-1)ry, mostly sterile soil, in waste places; rarely in woods: probably introduced with other and more valuable grasses: apparently indigenous northward. (Eu.)

* * Low alpine or alpestrine species, erect, in perennial tufts.

- Sof and flaccid, smooth or ncarly so, even to the branches of the panicle: leaves short and fat, short-pointed; liyule elongated.

3. P. alpína, L. Culms rather stout $\left(8^{\prime}-14^{\prime}\right.$ high) ; leaves broadly linear, especially those of the culm $\left(1 \frac{1}{2}{ }^{\prime}-2^{\prime}\right.$ long, $1 \frac{1}{2}{ }^{\prime \prime}-3^{\prime \prime}$ wide); panicle short and broud; spikelets broadly ovate, 3-9-flowered (nbout 3 "loug); lower palet villous on the midrib and margins. - Isle Royale, lake Superior, C. G. Loring, Jr., Prof. Porter, N. Maine? and northward. (Eu.)

4. P. láxa, Hanke. Culms slender $\left(4^{\prime}-9^{\prime}\right.$ high $)$; leaves narrow; panicle somewhat raceme-like, narrow, often one-sided and nodiling; spikelets 2-4-flowered, one half smaller. - Alpine mountain-tops of Maine, New Hampshire, and N. New York, and high northward. (Eu.)

+ + More strict and rigid, roughish, especially the panicle: ligule short.

5. P. cæ̀sia, Smith. Culms $6^{\prime}-20^{\circ}$ high ; leaves narrow, short, soon involute; branches of the panicle $2-5$ together, very scabrous; spikelets purplish (or sometimes pale), 2-5-flowered; glumes ovate-lancenlate and taper-pointed; flowers lanceolate, somewhat webby at the base; the lower palet villous on the keel and margins below the middle, its nerves obseure. (P. áspera, Giuudin.) - N. Wisconsin, I. A. Lapham; a form with loose open panicle (P. nemoràlis, $E d$. 2). - Var. strfetion, is $6^{\prime}-12^{\prime}$ high, with a contracted grayish-purple panicle, of smaller flowers. N. shore of Lake Superior, C. G. Loring, Jr., especially Isle Royale, Prof. Whitney, \&c., and northward. (Eu.)

**** Taller $\left(1^{\circ}-3^{\circ}\right)$, meadow or woodland grasses : panicle open.

+ Spikelets nostly very numerous and crouded on the rather short rough branches (usually in fives) of the oblong or pyramidal panicle, green, or sometimes violettinged: flowers acute, crowded, more or less webbed at base.

6. P. serótina, Ehrhart. (False Red top. Fowl Meadow-Grass.) Culms tufted without rumning rootstocks; leaves narrowly linear, soft and smooth; ligules elongated; spikelets 2-4- (rarely 5-) flowered (1" -2 "long), all short-pedicelled in an elongated panicle, often tinged with dull purple; flowers and glumes narrow; lourer palet very obscurcly nerrerl. (I'. nemoràlis, Pursh. P. crocat t, Mirhx.) - Wet mendows nnd low banks of streams: common, especially northward. July, Aug. - A good grass for moist mcarlows. (Eu.) 


\section{P. praténsis, I. (Green or Common Meadow-Grass. Kentucky} BLUL-Gikass.) Culms sending off copious running rootstorks from tho base, und the sheaths smooth; ligule short and blunt; panicle short-pyramidal ; spikelets 3-5flowered, crowded, and most of them almost sessile on the branches, ovate-lanceolate or ovate; lower pulet 5-nerval, hury ulong the margins as well as the keel. Common in dry soil: imported for pastures and meadows. Indigenous in mountain regions from N. Penn. northward. May - July. (Eu.)

8. P. thivialis; L. (Rovghisi Mkadow-Grass.) Culms erect from a somewhat decumbent base, but no distinct running rootstocks; sheuths and leaves more or less rough; ligule oblong, acute; panicle longer or with the branches more distant; spikelets mostly 3-flowered, broader upivards; lower palet prominently 5-nerced, naked at the margins: otherwise nearly as in the preceding. - Moist meadows, \&c., July. (Nat. from Eu.)

++ Spilielets fewer and more scattered, on slender pedicels: plants sof and smooth, flowering early. (No running rontstocks, except in No. 13.)

+r Spikelcts small (1"1-2"long), prale green, rather looscly 2-4-flowered: flower's oblong, obtuse: lower palet scarcely scarivus-tipped: culm-leaves lunce-tinear, acute, 1'-3' long.

9. P. sylvéstris, Gray. Culm flattish, erect ; branches of the oblong-pyramidil panicle short, numerous, in fives or more; lower palet villous on the keel for its whole length, and on the margins below the middle, sparingly webled at the base. - Rocky wouds and meadows, W. New York, Penu. and Virginia to Wisconsin, Kentucky, and southward. June.

10. P. débilis, Torr. Culms terete, weak; branches of the small panicle few and slender (the lower $1 \frac{1}{2}^{\prime}-2^{\prime}$ long to the few spikelets), in pairs and threes; flowers very dituse, smowth and glabrous, except a sparing web at their base. Rocky woodlituds, lihode Island and N. New York to Wisconsin. May.

+ + Spikelets 2" long, light green: oblong-lanceolute flowers and both glumes acute.

11. P. alsodes, Gruy. Leaves rather narrowly linear, acute, the uppermost $\left(2 \frac{1^{\prime}}{2}-4^{\prime}\right.$ long) often sheathing the base of the narrow and loose panicle, the capillary branches of which are appressed when young, and mostly in threes or fours; lower palet very obscurely nerved, villous on the keel below, and with a narrow cobwebby tuft at its base, otherwise glabrous. (P. nemoràlis, Torr. \& $E d .1$ : but wholly different from the European species of that name.) - Woods, on hillsides, New Eugland to Penn. and Wisconsin. May, June.

+++ Spikelets larger $\left(3^{\prime \prime}-4^{\prime \prime}\right.$ long), pale green, rardy purple-tinged, few and scattercd at the cetremity of the long and capillary branches (mostly in puirs or threes) of the very diffirse panicle: flowers 3-6, loose, oblong and olduse, as is the larger glume: lower palet conspicuously scarious at the aper, villous below the midille on the keel and margins: culms flattish, smooth.

12. P. flexuosa, Muhl. (not of Wahl.) Culms $1^{\circ}-3^{\circ}$ high, tufted; its leaves all linear $\left(2^{\prime}-5^{\prime}\right.$ lony) and gradually taper-pointad; panicle cery effuse (its branches $2^{\prime}-4^{\prime}$ long to the 4-6-flewered spikelets or first ramification); lower palet prominonily nerred, no web at the base. (1'. autumuàlis, Muhl. in E'll. $\mathbf{P}$. cámpyle, Sćchult.) - Dry woods, Virginia, Kentucky, and southward. Feb. May. - Wrongly confounded with the last, but near it. P. autumnalis is an 
Inapproprinte name, and there is now no obstacle to restoring to this species the earlier and unobjectionable (but not descriptive) name of $P$. flexuosa.

13. P. brevifolia, Muhl. Culms $1^{\circ}-1 \frac{1}{2}{ }^{\circ}$ high from running rontstocks, 2-3-leaved, the upper leaves very short $\left(2^{\prime}-2^{\prime}\right.$ long $)$, lancelate, all albuptly cuspidatetipped; branches of the short panicle mostly in pairs; spikelets 3-4-flowered; lower palet rather obscurely norved, colveblyy at the base. (P'. puingens, Nutt., cxcl. syn. Ell. P. cuspidàta, Barton. The older and more appropriate name is here restored.) - Rocky or hilly woodlands, Pennsylvania, Virginia, and sparingly westward. April, May. - Culm scarcely surpassing the long root-leaves.

\section{ERAGRóst IS, Beauv. Eragrostis. (PI. 10.)}

Spikelets 2-70-flowered, nearly as in Poa, except that the lower palet is but 3- (rarely 1-) nerved, not webby-haired at the base, and deciduous; and the upper one persistent on the rhachis after the rest of the flower has fallen. - Culms often branching. Leaves linear, frequently involute, and the ligule or throat of the sheath bended with long villous hairs. Panicle various. (An early name, probably from épa, earth, and Agrostis, in allusion to the procumbent habit of the original species.)

* Prostrate and creeping, much-branched: ront anrual: spilielets fat, imperfectly dixcious, clustered, almost sessile, in the more fertile plant almost capilate.

1. E. réptans, Nees. Spikelets linear-lanceolate, 10-30-flowered; flowers lance-ovate, acute; leaves short, almost awl-shaped. (Poa reptans, Michx.) - Gravelly river-borders : common. Aug. - Flower-branches $2^{\prime}-5^{\prime}$ high.

* * Diffisely spreading, or the flowering culms ascending, low $\left(6^{\prime}-15^{\prime}\right.$ high $)$ : spikelets large, densely-flowered, flut, forming a narrow crouded panicle.

2. E. Poxolnes, Beauv. Lower sheaths often hairy; leaves flat, smooth ; spikelets short-pedicelled, lance-linear or oblong-linear, 8-20-flowered, lead-colored (2" -5 " long); flowers ovate, obtuse, the lateral nerves evirlent. (Poa Eragrostis, L.) - Sandy wastc places, eastward : scarce. (Nat. from Eu.)

Var. MEgAstACnYA. Sheaths mostly glabrous ; spikelets larger $\left(3^{\prime \prime}-10^{\prime \prime}\right.$ long), becoming linear, whitish when old, 10-50-flowered. (E. megastachya, Link. Briza Eragrostis, L.) - Similar situations, and more common. Aug. - Emits a sharp, unpleasant odor. (Nat. from Eu.)

* * Erect, or in No. 3-5 diffusely spreading and ascending: panicle open, its branches capillary; the spikelsts proportionally small, sometimes minute. (Number of flowers in the spikelet very variuble, according to age, \&c.)

- Culms slender, branching and dreumhent or spreading at the base, from an annual root: leaves nurrow, flut, snf?: Inunches of the narrow pamile wither short and thickly-flowered, not beurded in the axils, excrpt sometimes the lowrst sparingly.

3. E. PILòsA, Beauv. Yanicle clongaterl-oblong, with rather erect branches (except at flowering-time); spikelets 5 - 12-flowered (2" $-4^{\prime \prime}$ long, purplish-leadcolor), becoming linear, about equalling their pedicels; glumes (small) and lower palet obluse, the latter brondly ovate, 1-neved (lateral nerves obsolete). ( $\mathrm{P}$. pilosa, L. P. Linkii, $K u n t h$.) - Sandy or gravelly waste places, S. New England to Illinois, and southward. Ang. - Plant $6{ }^{\prime}-12^{\prime}$ high. (Nat. from Eu.) 
4. E. Fránkii, Meyer. Much branched, diffuse $\left(3^{\prime}-8^{\prime}\right.$ high $)$; panicle ovate-oblong, rather icusc, sprealing; spikches 2-5-flowered (1"-18" long), on slender pedicels; glt:mess very acule; lower palct ovale, acute, rather obscurely 3-nerved. (E. erythrogrona, Nees, from the joints of the culm being mostly reddish.) - Low or sandy ground, S. Pennsylvania to Illinois, and southwestward. Aug.

5. E. Púrshii, (Beruh. ?) Schrader. Sparingly bramehed at the decumbent base, then ereet $\left(\frac{1}{2}^{\circ}-2^{\circ}\right.$ high) ; panicle elongated, the branches widely spreading, very loose; spikelets 5-18-flowered, oblong-lanceolate, at length linear $\left(2^{\prime \prime}-4 \frac{1}{2} \prime \prime\right.$ long), mostly much shorter than their cupillary pedicels; ylumes and lower pulet ovite and acute, or the lutter acutish, 3-nerved. (Poa tenella? Pursh. P. Caroliniàna, Spreng. P. pectinacea of authors, not of Mich.x.) - Sandy or sterile open grounds, New Jersey to Virginia, and southward.

+ + Culms simple or branching only at the very base, firm, erect from an anmual or perennial root, mostly forming thick tufts: leaces very long: panicle very lurge, compound, often longer than the culm, with elongated and loosely-flowered branches, their uxils often bearded. (Doubtful perennials, or No. 7 unnual.)

6. E. ténuis, Gray. Punicle virgately elonguted $\left(1^{\circ}-2 \frac{1}{2}^{\circ}\right.$ long), very loose, the spreading branches bearded in some of the lower axils, their remote divisions and long diverying pedicels capillary; spikelets 2-6- (sometimes 7-12) flowered, pale or greenish ; ylumes lanceolute or awlishaped, very acute ( $1 \frac{1}{2} "-2^{\prime \prime}$ long), membranaceous, as are the olkong-lunceolule acute flowers; lower pulet distinctly 3-nerval ; the upper ciliate-scabrous. (Poa tenuis, Ell. P. capillaris, Michx. P. trichòdes, Nutt. E. Géyeri, Steul.) - Sandy soil, Illinois, Virginia? and southward. Aug. - Oct. - Leaves rather rigid, $1 \frac{1}{2}-2^{\circ}$ long, glabrous or sparingly hairy : the sheaths hairy or glabrous; the throat strongly bearded. Flowers much larger than ia the next, fully $1 \mathbf{t}^{\prime \prime}$ long.

7. E. capillàris, Nees. Panicle widely expanding, usually much longer than the culm, its spreading branches (mostly naked in the axils) and long direrying pedicels capillary; spikielets rather terete, very small, 2-4-flowered, greenish or purplish; glunes and flowers ovate, acute (less than 1" long); lowtr pulet discurely 3-nerved, scarcely kecled; the upper rough-eiliate. (P'oa capillaris, $L$. P. hirsùta, Michx.) - Sandy dry soil and fields : common, especially southward. Aug., Sept. - Leaves and sheaths very hairy, or nearly glabrous; the former about $1^{\circ}$ long, not rigid. Panicle $1^{\circ}-2^{\circ}$ long, soon diffuse.

8. E. pectinàcea, Griay. Panicle widely diffuse, its rigid divergent main branches becurded in the arils; the rapillary pedicets more or less appressed on the secondary branches; spiketels flut, 5-15-llowered, hecoming linear, purple or purplish ; glumes and fluwers ovate or oblong-ovate, acutish ; luwer paltel strongly 3-nerved; the upper hirsute-ciliate. (P'on pectinacca, M/ich.e, ex char. I'. hirsuta, of Amer. authors. E. Unionis \& cognàta Steud. \}) - I eaves long, rigid, mostly hairy, the sheaths especially so. - Var. s'tectásinis. Iceaves and sheaths mostly glabrous; branches of the panicle (the lower retlexed with age) and pealicels shorter; spikeluts rather larger. (E. spectul,ilis, Ed. 1. l'oa spectabilis, Pursh.) - Sandly dry ground, from E. Mass. near the coast, and from Ohio and Illinois southward. Aug. - Oct. - Plant $1^{\circ}-3^{\circ}$ high. Spikelets $2^{\prime \prime}-3^{\prime \prime}$ long, $1^{\prime \prime}$ wide, closely flowered. 


\section{BRìzA, I. Qunkina Grass. (Pl. 10.)}

Spikelets many-flowered, ovate or heart-shaped, flattish-tumid; the flowers closely imbricated. Glumes roundish, meneat (purple). Lawer palet roundish and entire, flattened parallel with the glumes, ventricose on the back, heartshaped at the base, papery-membranaceous and becoming dry, scarious-margined, obscurely many-nerved; the upper palet much smaller, ovate, flat. Stamens 3. Stigmas branched-plumose. Grain flattened parallel with the palets, athering to the upper one. - Leaves flat. Panicle loose, diffuse, with the large and showy spikelets often drooping on delicate perlicels (whenee the nane, an ancient Greek appellation for some kind of grain, from $\beta \rho i \zeta \omega$, to slumber (Linn.), or $\beta$ pi $\theta \omega$, to bend downuards.)

1. B. мì̀ı, L. Panicle erect, the branches spreading; spikelets 5-9flowered ( $3^{\prime \prime}$ long); glumes shorter than the lower flowers; root perennial. -

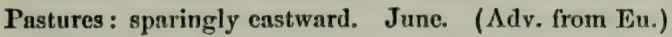

\section{FEST Ù CA, I. Fescue-Grass. (PI. 10.)}

Spikelets 3-many-flowered, panicled or racemose; the flowers not webby at the base. Glumes unequal, mostly keeled. Palets chartaceous or almost coriaceons, roundish (not kecled) on the back, more or lcss 3-5-nerved, acute, pointed, or often bristle-awnel from the tip, rarely blunt; the upper mostly adhering at maturity to the enclosed grain. Stamens 1-3. - Flowers, and often the leaves, rather dry and harsh. (An ancient Latin name.)

* Flowers awl-shaped, bristle-pointed or awned fiom the tip: panicle contracted.

+ Annuals or bionnials, slender, $5^{\prime}-18^{\prime}$ high: leaves convolutc-bristle-form.

1. F. Mrùnus, L. Panicle spike-like, one-sided; spikclets about 5-flowered; glumes very unequal; awn much longer than the palet, fully 6 " in length; stamen 1. - Dry fields, New Jersey, S. Penn., and southward. July. (Nat. from Eu.)

2. F. tenélla, Willd. Panicle spike-like, one-sided, or more compound and open; spikelets 7-13-flowered; awn 1"-3" long, shorter than or equalling the palet: stamens 2. - Dry, sterile soil, especially southward. June, July.

+- Perennial, tufled, 6'-24' high : stumens 3 .

3. F. ovina, L. (Sneer's Frescue.) Panicle somewhat one-sided, short, usually more or less compound, open in flowering; spikelès 3-8-flowered; nwn not more than half the length of the flower, often much shorter or almost wanting. - Indigenous in Northern New England, Lake Superior, and northward: naturalized farther south as a pasture grass. June. - Varies greatly. - Var. vivfrARA (which with us has running rootstocks), a state with the spikelets partially converted into leafy shoots, is found on the alpine summits of the White Monntains of New Ilampshire, and high northward. - Var. nurı úscuLA, (F. duriuscula, $I_{\text {. }}$ ) is a tall form, with spikelets rather larger, usually in a more compound panicle; culm-leaves often flat or less convolute, and the lower with their sheaths either smooth or hairy. New England to Virginia; nat., and indigenous northward. - Var. Rüви (F. rubra, L.) has running rootstocks and forms looser tufts; the leaves often reddish and pubescent above. Naturalized eastward : wild, Iake Superior, $I r$. Robbins, and northward. (Eu.) 
* Flowers oulong or lanceolate, awnless or nearly so $\left(11_{2}^{\prime \prime}-4^{\prime \prime}\right.$ long) : grain oflen free! (Root perennial: culins mostly tull: loaves flat.)

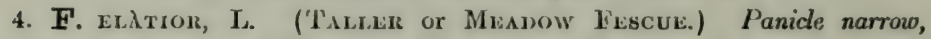
contracted before and after flowering, ercet, with short Uranches; spikelets crowded, 5-10-flowered; the flowers ruther remote, oblong-lanceolate; lower palet 5-nerved, scarious-margined, blunt, acute, or rarely with a distinct but very short awn. 'The type is large, $3^{\circ}-4^{\circ}$ high ; spikclets alout $6^{\prime \prime}$ long, in an ample and compound panicle. Rich grass-land. - Var. r'zAtéxsis (F.pratensis, Iluds.) is lower $\left(1^{\circ}-3^{\circ}\right.$ high $)$, with a simpler or close panicle, of smaller or narrower spikelets; and abounds in grass-lands. June-Aug. (Nat. from Liu.)

5. F. nùtans, Willd. l'unicle of several lony and slend $r$ spreading branches, mostly in pairs, drooping when old, rough, naked below, bearing near their extremity a few ovate $3-5$-flowered spikelets ( $3^{\prime \prime}$ long) on pretty long pedicels; fluwers ovate-oblony, rather obtuse, close together, coriaceous, smooth, very obscurely 5-nerved. - Rocky woods and copses. July. - Culın $2^{\circ}-4^{\circ}$ high, naked above : leaves broadly linear, taper-pointed, dark green, often rather hairy.

\section{BR Ò M U, L. Bromli-Grass. (P'l. 10.)}

Spikelets 5-many-flowered, panicled. Glumes unequal, membranaccous; the lower 1-5-, the upper 3-9-nerved. Lower palet cither convex on the back or compressed-kecled, 5-9-nerved, awned or bristle-pointed from below the mostly 2-eleft tip : upper palet at length adhering to the groove of the oblong or linear grain. Stamens 3. Styles attached below the apex of the ovary. - Coarse Grasses, with large spikelets, at length droojing, on perlicels thickened at the apex. ( $\mathrm{n}$ ancient name tor the ()at, from $\beta$ pópos, foud.)

\$. Lower palet convex on the buck; the flowers intricuthd over one another befure expansion: lower glume 3-5-nerved, the upper 5-9-nervod.

* Annuals or bieñnials, wads of cultivation, introduced into grain-fulds, or rarely in waste grounds, probubly all dericed from the European B. arvensis, $L$.

1. B. slcálinus, I. (Cinsat or Cmlss.) Panicle spreading, even in fruit, the drooping peduncles little branched; spikclets oblong-ovate, turgid, smooth, of 8-10 rather distant flowers; lower palet rather longer than the upper, shortawned or awnless; shcatlis nearly glabrous. - Too common in wheat-ficlds. June, July. (Adv. from Eu.)

2. B. machàsis, 1. (Uprigut Cuess.) Panicle erert, simple, rather narrow, contracterl in fiuit ; flowers closer, more imbricated; lower pulel decidedly exceeding the upper, berving an awn of its own length; culm more slender; sheaths sometimes hairy : otherwisc nearly as in the last, for which it is often mistuken in this country. (Adv, trom Eu.)

3. В. мóllis, L. (Sort Cuess.) Panicle erect, closely contracted in fruit; spikelets conical-ovate, somewhat flattened; the flowers closely imbricated, downy (as also the leaves, \&c.) ; lower pulet acule, long-awned. - Wheat-fields, New York to Virginia: scares. June. (Ailv. fiom Viu.)

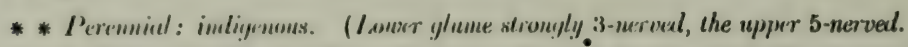

4. B. Kálmii, Gray. (W (Li) Chess.) Panicle simple, small $\left(3^{\prime}-4^{\prime}\right.$ long); spikelets drooping on capillary peduncles, closely 7 -12-flowered, densely silky 
nll over; awn only one third the length of the lance-oblong flower; lower palet 7-9-nerved, much longer and larger than the upper; culm slender $\left(1 \frac{1}{2}-3^{\circ}\right.$ high); leaves and shenths conspieuously or sparingly hairy. (B. cilintus, Muhl. 3. puírgans, Torr. Fl. N. Y.) - Dry ground: (ommon nortliwaril. June, July. - I'his is in the herbarium of Linnaxus under the name of B. cilintus, but is not the plant he described; thence has arisen much confusion.

§2. SCHEDÓNORUS, Beauv., Fries. Lower palet somewhat convex, but keeled on the back and laterally more or less compressed, at lenst above: flowers sonn separating from ench other: lower glume 1-nerved, the upper 3-neved, or with an obscure additional pair.

* Perennial, tall $\left(3^{\circ}-5^{\circ}\right.$ high $)$ : fowers oblong or lanceolate.

5. B. ciliatus, L. Panicle compound, very loose, the elongated branches at length dirergent, drooping; spikelets 7 -12-flowered; lower palet tipped with an awn half to three fourtlis its length, silky with appressed hairs near the margins, at least below (or rarely naked), smooth or smoothish on the back (B. Canadénsis, Michx. B. pubésecns, Muhl.); - or, in var. púngans (B. purgans, L.!), clothed all over with short and fine appressed hairs. - Riverhanks and moist woodlands: common. July, Aug. - Culm and large leaves $\left(3^{\prime \prime}-6^{\prime \prime}\right.$ wide) smooth or somewhat hairy ; the sheaths in the larger forms often hairy or densely downy near the top. Variable, comprising several forms, including both the Linnæan species; for which the present name is preferable to the inapplicable purgans, taken from Feuillée's South American specics.

6. B. Asper, L. Culm slender and panicle smaller; spikelets 5-9-flowered; lower palet linear-lanceolate, scarcely keeled, hairy near the margins, rather longer than the awn; shenths and lower leaves hairy or downy. - Bethel, Maine, in fields along the river-bank, W. Boott. (Nat. from Eu.)

* * Annual or biennial $\left(10^{\prime}-30^{\prime}\right.$ high $)$ : flowers slonder.

7. B. stérilis, L. Panicle open; spikelets of 5-9 rather distant and 7nerved roughish linear-awl-shaped long-awned flowers (awn $1^{\prime}$ long); leaves rather downy. - Waste places and river-banks, E. Massachusetts, New York, and Pennsylvania : rare. Junc. (Nat. from Eu.)

\section{U N İ L L, L. Spike-Grass. (PI. 11.)}

Spikelets closely many-flowered, very flat and 2-edged; one or more of the lowest flowers sterile (neutral) and consisting of a single palet. Glumes lanceolnte, compressed-keeled. Lower palet coriaceo-membranaceous, strongly latcrally compressed and kceled, striate-nerved, usually acute or pointed, entire, enclosing the much smaller compressed 2-keeled upper one and the free laterally flattened smooth grain. Stamen 1 (or in U. paniculata 3). - Upright smooth perennials, growing in tufts from strong creeping rootstocks, with broad teaves and large spikelets in an open or spiked panicle. (Ancient name of some plant, a diminutive of unio, unity.)

* Spikelets large $\left(\frac{1}{2}{ }^{\prime}-2^{\prime}\right.$ long), ovate or ollong, 9-30-flowered: panicle open.

1. U. paniculàta, I. Isnves narrow, when dry convolute; spikelets ovate, hort-pedicelled; flowers glabrous, bluntish, several of the lower sterile; the fer- 
tile with 3 stamens; culm and panicle elongated $\left(4^{\circ}-8^{\circ}\right.$ high $)$. - Sand-hills on the sea-shore, S. Virginia and southward.

2. U. latifolia, Michx. Leaves broad and flat (nearly $\mathbf{l}^{\prime}$ wide); spikelets at length oblong, hanging on long pedicels; flowers acute, ciliate on the keel, all but the lowest perfect and monandrous. - Shaded rich hillsides, S. Pennsylvania to Illinois and southwarl. A ug. - Culm $2^{\circ}-4^{\circ}$ high : paniclo loose.

* * Spikelets small: paniele contructul and ucund-like: perject jlowers long-pointud.

3. U. grácilis, Michx. Spikelts short-pedicellid (2" $-3^{\prime \prime}$ long), broadly wedge-shaped, acute at the base, $4-8$-fluwered; the flowers ovate and divergently beaked, long, the lowest one neutral. - Saudy soil, from Long Island to Virginia, near the coast, and southward. Aug. - Culm $3^{\circ}$ high, slender.

\section{PHRAGMITES, Trin. ReEd. (Pl. 11.)}

Spikelets 3-7-flowered; the flowers rather distant, silky-villous at their base, and with a conspicuous silky-bearded rhachis, all perfect and 3 -androus, except the lowest, which is either neutral or with $\mathbf{I}-3$ stamens, and naked. Glumes membranaceous, shorter than the flowers, lanceolate, keeled, sharp-pointed, very unequal. Palets membranaceous, slender; the lower narrowly awl-shaped, thrice the length of the upper. Squamula 2, large. Styles long. Grain frec. - Tall and stout perennials, with numerous broad leaves, and a large terminal

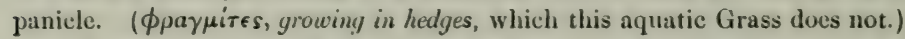

1. P. commùnis, 'Trin. Panicle loose, nodding; spikelets 3-5-flowered; flowers equalling the wool. (Arundo, L.) - Edges of ponds. Sept. Looks like Broom-Corn at a distance, $5^{\circ}-12^{\circ}$ high : leaves $2^{\prime}$ wide. (Eu.)

\section{ARUNDINÀria, Michx. Cane. (PI. 11.)}

Spikelets flattened, 5-14-flowered; the flowers somewhat separated on the jointed rhachis. Glumes very suall, membranaceous, the upper one larger. Palets herbaceous or somewhat membranaceous; the lower convex on the back, many-nerved, tapering into a mucronate point or bristle. Squamula 3, longer than the ovary. Stamens 3. Grain oblong, free.-Arborescent or shrubby Grasses, simple or with fascicled branches, and with large spikelets in panicles or racemes; the fluwers polygamous. (Name from arundo, a reel.)

1. A. macrospérma, Michx. (Large Cane.) Culms arborescent, $10^{\circ}-20^{\circ}$ high, rigid, simple the first year, branching the second, afterwards at indefinite periods fruiting, and soon after decaying; leaves lanceolate $\left(1^{\prime}-2^{\prime}\right.$ wide), smoothish; panicle lateral, comprosed of few simple racemes; spikelets purple, erect; lower palet lanec-ovate, pubescent, fringed ( $8^{\prime \prime}$ long). Chapman, under A. gigantea. - River-banks, S. Virginia? lientucky? and southward, forming cancbrakes.

2. A. técta, Muhl. (Smar.t. Cane.) Culms slender, $2^{\circ}-10^{\circ}$ high, branch-

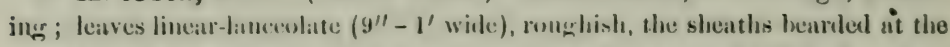
throut; spikelets solitary or in a simple raceme at the summit of the branches, or frequently on leatless radical culms; lower palet ( $6^{\prime \prime}$ long) ovate-lanceolate, smooth, fringed on the margins. Cherpman. (Arundo teeta, Wult.)-Swamps and n:oist coil, Virginia, Illinois, and southwarl. $A_{\text {pril. }}$ 


\section{LEPT Ù R S , R. Br. Lepturus. (Pl. 11.)}

Spikelets solitary on each joint of the filiform rhachis, nnd partly immersed in the excavation, 1-2-flowered. Glumes 1-2, including the 2 thin pointless palets. Strmens 3. Grain free, oblong-linear, cylindrical. - Iow and branching, often procumbent Grasses, chiefly annuals, with narrow leaves and slender

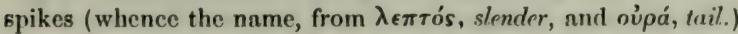

1. L. paniculàtus, Nutt. Stem slender $\left(6^{\prime}-20^{\prime}\right.$ long), naked and curved above, bearing 3-9 racemosely disposed thread-like and triangular apikes; glumes 2, transverse. - Open grounds and salt licks, Illinois (Mead), and westward. Aug.

\section{L Ó I U M, L. Darnet. (PI. 11.)}

Spikelets many-flowered, solitary on each joint of the continuous rhachis, placed edgewise; the glume, except in the terminal spikelet, only one (the up per) and external : - otherwise nearly as in Triticum. (Ancient Latin name.)

1. L. Perenne, L. (Common Darnet, Ray-or Rre-Grass.) Root perennial, glume shorter than the spikelet; flowers 8-15, awnless or sometimes shortawned. - Fields and lots: eastward. June. - A pretty good pasture-grass. (Nat. from Eu.)

2. L. temulentum, L. (Bennden Darnel.) Root annual ; culm taller, glume fully equalling the 5-7-flowered spikelet; awn lonyer than the flower ( $\frac{1}{2}$ 'long). - Grain-fields : rare. - Grain noxious; almost the only instance of the kind among Grasses. (Adv. from Eu.)

\section{TRÍ T I U M, L. Wheat. (Pl. 11.)}

Spikelets 3-several-flowered, single at each joint, and placed with the side against the rhachis. Glumes transverse (i. e. right and left), nearly equal and opposite, herbaceous, nerved. Lower palet rery like the glumes, convex on the back, pointed or awned from the tip : the upper flattened, bristly-ciliate on the nerves, free, or adherent to the groove of the grain. Stamens 3. (The classical name, probably from tritus, beaten, because the grain is threshed out of the spikes.) - The true species are annuals, with the glumes ovate-oblong, turgid and boat-shaped, as in common Wheat (T. vULGARE). Others are perennial, with nearly lanceolate glumes, and 2-ranked spikes, never furnishing bread-corn (§ AGROPY RON, Gærtn.) ; to which the following belong. Flowering in summer.

* Multiplying by long running rootstocks : awn shorter than the flower or none.

1. T. répens, L. (Coucr-, Quiтch, or Quick-Grass.) Spikelets 4-8flowered, glabrous or nearly so; glumes 5 - 7-nerved; rhachis glabrous, but rough on the edges; awns when present straight; leaves flat and often roughish or pubescent above. - Nat. in cultivated grounds, ficlds, \&c., and very tronblesome; indigenous northwestward. - Varies greatly. $\Lambda$ tall form, rather bright green (Var. NEMORALe, Andersson) bears awns nearly as long as the palet. A lower form is glaucous and mostly awnless or nearly so. A maritime form (nearly Var. intermèdiom, Fries, and approaching T. laxum, Fries, and T. acutum, DC.), collected by Prof. Tuckerman on the coast of Maine, is glaucous, rigid, with 
at length somewhat involute leaves, crowded spikelets, blunt und rigid glumos, and pointless or mucronate-tipped palets; the rhachis not disarticulating as in T. junceum, $L$. (Eu.)

2. T. dasystàchyum, Gray. Perhaps a remarkable variety of the last, but the glaucous leaves are narrow and often involute, and the 5-9-flowered spikelets densely downy-luiry all over. (T. repens, var. dasystachyum, Mook.) Sandy shores of Lakes Iluron and Superior, and northward. Ang.

* * No obvious running rootstocks, glabrous, or the flut and roughish leaves sometimes hairy above: glumes as well as flowers mostly awned or awn-pointed.

3. T. violaceum, IIornemamn. Spike dense, strict and rigid, usually tinged with violet or purple; spikelets 3-5-flowered; glumes conspicuously 5-nerved; awos struight, varying fiom half to nearly twice the length of the palet. ('T', Richardsònii, Schrader. 'T. pauciflorum, Schweinitz.) - Mountains of Penn. (Porter); in the alpine region of the White Mountains (Tuckerman), Wiscon$\sin$ (Lapham), and northward. - Intermediate in character between the last and the next. (Eu.)

4. T. caninum, I. (Awned Wheat-Grass.) Spike usually more or less nodding, at least in fruit, rather dense $\left(3^{\prime}-6^{\prime}\right.$ long); spikelets $3-5$-flowered; glumes 3-5-nerved; awns mostly somewhat bent or spreading, fully twice the length of the palet. - Sparingly naturalized in cult. ground and meadows. Indigenous along our northern borders, in a slender form, which approaches the northwestern T. divergens, Nees, or T. argilopoides, Turczuninow, which has narrow and convolute leaves, 5-7-nerved glunes, and widely diverging awns. (Eu.)

\section{HÓRDEUM, L. BarLeY. (H'l. 11.)}

Spikelets 1-flowered, with an awl-shaped rudiment on the inner side, three at, each joint of the rhachis; but the lateral ones usually imperfect or abortive, and short-stalked. Glumes side by side in fiont of the spikelets, 6 in number, forming a kind of involucre, slender and awn-pointed or bristle-form. Palets herbaccous, the lower (anterior) convex, long-awned from the apex. Stanens 3. Grain oblong, commonly adhering to the palets. Spike often separuting into joints. Ours are annuals or biennials, or scarcely perennial. (The ancient Latin name.)

1. H. jubàtum, L. (Squirrel-tail Grass.) Low; lateral flowers abortive, on a short pedicel, short-awned; the perfect flower bearing a capillary awn (2' long) about the length of the similar capillary glumes, all spreading. Sandy sea-shore, upper Great Lakes, and westward. Junc.

2. H. pratense, Iluls. Low $\left(6^{\prime}-18^{\prime}\right.$ high $)$; latcral flowers imperfect or neutral, awnless or mesely pinited; perfect flower with awn as long as those of the glumes $\left(3^{\prime \prime}-6^{\prime \prime}\right)$; spike linear, $1^{\prime}-2^{\prime}$ long. (II. pusillum, Nutt. and former ed.) - Plains, especially in saline soil, Ohio to Illinois and westward: also sparingly introduced, Virginia and southward along the coast. May, June. (Eu.)

\section{EIYMUS, I. Lyme-Grass. Wild RYe. (PI. 11.)}

Spikelets 2-4 at each joint of the rhachis, all fertile and alike, sessile, each 1 - 7-flowered. Glumes conspicuous, nearly side by side in front of the spikelets, 
2 for each spikelet, forming an involucre to the cluster. Palets coriaccous; the lower rounded on the back, acute or awned at the apex. Grain alherent to the involving palets (whence the name, an ancient one for some grain, from $e^{\prime} \lambda \dot{v} \omega$, to roll $u p)$.

* Glumes and flowers firm or rigid, both or only the latter awned: spikelets 1-5. flowered: perennials, with slender culms and rather hursh and broad flat leaves.

$$
\text { + Spike large and stout. }
$$

1. E. Virgínicus, L. Spike rigidly upright, dense $\left(2^{\prime}-3^{\prime}\right.$ long, $6^{\prime \prime}$ thick), on a short peduncle usunlly included in the shrath; spikelets 2-3 together, 2-3fowered, smooth, rnther short-awned, about the length of the thickened stronglynerved and bristle-pointed lanceolnte glumes. - River-banks: common. Aug. Culm stout, $2^{\circ}-3^{\circ}$ high.

2. E. Canadénsis, L. Spike soon nodding $\left(5^{\prime}-9^{\prime}\right.$ long), on an exserted peduncle; spikelets mostly in pairs, of 3-5 long-awned rough or rough-hairy flowers; the awl-shaped glumes tipped with shorter awns. (E. Philadelphicus, L. !) - Var. graverfórius (E. glaucifolius, Muhl.) is pale or glancous throughout, the flowers with more spreading awns ( $1 \frac{1}{2}$ l long). - River-banks : common.

$$
\text { - Spike more slender, as also the culm. }
$$

3. E. Sibiricus, L. Glabrous; spike wand-like (2'-6' long, about $3^{\prime \prime}$ thick), often somewhat nodding; spikelets in pairs, 3-6-flowered; glumes linear-lanceolate, 3-5-nerved, short-awned, shorter than the fowers, which are rather short-awnod. - South shore of Lake Superior (Porter), and northwestward. (Eu.)

4. E. striatus, Willd. More or less mubescent; spike dense and thirkish (2'-4' long), upright or slightly nodding; spikelets mostly in pairs, $1-2$ - (or rarely 3-) flowered, minutely bristly-hairy; glumes awl-shoped, bristle-awned, 1 -3nerved, about thrice the length of the fowers exclusive of the capillary awn (which is I' long). - Var. villósus (F. villosus, Muhl.!) has very hairy flowers and glumes, and villous sheaths. - Rocky woods and banks. July, Aug. - Palets only $3^{\prime \prime}$ long.

* Glumes and palets awnless and soft in texture: reed-like perennials.

5. E. móllis, Trin. (not of R. Br.) Culm ( $3^{\circ}$ high) velvety at top ; spike thick, erect $\left(8^{\prime}\right.$ long) ; spikelets 2 or 3 at each joint, 5-8-flowered; the lanceolate pointed 5-7-nerved glumes ( $1^{\prime}$ long) and the pointed palets soft-villous; rhachis of the spikelets separating into joints. - Shore of the Great Lakes, Muine, and northward. (Near E. arenarius.)

\section{GYMNÓSTICHUM, Schreb. Botrle-mrusir Grass. (Pl. 11.)}

Spikelets 2-3 or sometimes solitary on each joint of the rhachis, raised on a very short callous pedicel, loosely 2 -4-flowered (when solitary flatwise on the rhachis.) Glumes none! or small, awn-like, and deciduous (whence the name, from $\gamma v \mu \nu o ́ s$, naked, and $\sigma \tau i \chi x_{0 s}$, rank). Otherwise nearly as in Elymus.

1. G. Hystrix, Schreb. Spike loose $\left(3^{\prime}-6^{\prime}\right.$ long); the spreading spikelets 2-3 together, early deciduous; flowers smonthish or often rongh-hairy, tipped with an awn thrice their length (1'long); leares and sheaths smoothish; culm $3^{\circ}-4^{\circ}$ high; root perennial. (Elymus Hystrix, L.) - Moist woodlands. July, Aug. 


\section{DANTHÒNIA, DC. Wild OAT-Grass. (PI. 12.)}

Lower palet (oblong or ovate, rounded-cylindraceous, 7-9-nerved) bearing between the sharp-pointed or awn-like teeth of the tip an awn composed of the 3 middle nerves, which is flattish and spirally twisting at the base: otherwise nearly as in Avena. Glumes longer than the imbricated fluwers. Ours perennials, $1^{\circ}-2^{\circ}$ high, with narrow and soon involute leaves, hairy sheaths bearded at the throat, and a small simple panicle or raceme of about 7 -flowered spikelets. (Named for Danthoine, a French botanist.)

1. D. spicàta, Beáuv. Culms tufted, low; lcaves short, very narrow; spikelets few, $3^{\prime \prime}-5$ " long; lower palet loosely hairy, its teeth short and pointless. Dry and sterile or rocky soil. June-Aug.

2. D. serícea, Nutt. Taller and not tufted $\left(1^{\circ}-3^{\circ}\right.$ high $)$; leaves larger ; spikelets more numerous and panicled, $6 "-9$ " long; lower palet very silky-viilous, tipped with slender awn-pointed teeth. - Dry or moist sundy soil, Southern Massachusetts (Dr. Robbins), New Jersey (C.E. Smith, C. F. Parker), and southward: rarc. June.

\section{A V E N A, L. OAT. (Pl. 12.)}

Spikelets 2-many-flowered, panicled; the flowers herbaceo-chartaceous, or becoming harder, of firmer texture than the large and mostly unequal glumes; the uppermost imperfect. Lower palet rounded on the back, mostly 5-11nerved, learing a long usually bent or twisted awn on the back or below tho acutely 2-cleft tip proceeding from the midnerve only. Stamens 3 . Grain oblong-linear, grooved on one side, usually hairy at least at the top, free, but invested by the upper palet. (The classical Latin name.) - The Comson OAT (A. sativ A, L.) represents the large-flowered annual species of the Old World. The following are smaller-flowered, indigenous perenuials.

1. A. striàta, Michx. Glubrous and smooth throughout, slender $\left(1^{\circ}-2^{\circ}\right.$ high); leaves narrow; ligule short, truncate; panicle simple, loose; spikelets (6" long) on capillary pedicels, 3-6-flowered, much exeeding the scariousmargined purple acute glumes; the lower glume 1-, upper 3-nerved; rhachis smooth ; flowers short-bearded at the base; lower palet 7-nerved, much longer than the ciliate-finged upper one ( $4^{\prime \prime}$ long), mostly shorter than its soon bent or divergent awn, which rises just below the tapering very sharply euspidate 2-cleft tip. (Trisètum purpuráscens, Torr.) - Rocky, shaded hills, N. New England, New York, and northivestward. June.

2. A. Smíthii, T. C. Porter, n. sp. Taller $\left(2 \frac{1}{2}^{\circ}-4 \frac{1}{2}^{\circ}\right.$ high $)$, rather stout; leaves broadly linear ( $3^{\prime \prime}-6^{\prime \prime}$ wide) and taper-pointed, flat, and with the sheaths and culm retrorsely scabrous; ligule elongated, acute; panicle larger $\left(6^{\prime}-1.21\right.$ long), the few branches at length spreading; glumes slightly purplish, seabrous on the meros, of which there are 3 in the lower and 5 in the upper; rhachis minutely hispid; flowers $(3-5)$ not hairy-tufted at the hase; awn one third or half the length of the 7-nerved palet, straight. - Isle Royule, Keweenaw Point, Lake Superior, livbins. Woods near Sault Ste. Marie, C'. E. S'mith, for whom the species is named. April, May. - To be compared with the Siberian A. callosa, Turczaninow, which was referred to A. striata by Trinius. 


\section{TRISiTU M, Persoon. Trisetum. (Pl. 12.)}

Spikelets 2-several-flowered, often in a contracted panicle; the lower palet compressed-keeled, of about the same membranaceous texture as the glumes, hearing a bent or flexuous (rarely twisted) awn below the sharply 2-toothed or 2-pointed apex (whence the name, from tris, three, and seta, a bristle): otherwise nearly as in Avena. Ours are perennials.

1. T. subspicàtum, Beauv., var. mólle. Minutely sof-downy; panicle dense, much contracted, oblong or linear $\left(2^{\prime}-3^{\prime}\right.$ long); glumes about the length of the 2-3 smooth flowers; nwn diverging, much exserted. (Avena mollis, Michx.) - Mountains and rocky river-banks, N. New England to Wisconsin, and northward. July. - About $1^{\circ}$ high : leaves flat, short. (Eu.)

2. T. palústre, Torr. Smooth; panicle rather long and narrow ( $5^{\prime}$ long), loose, the Uranches capillury; spikelets flut ( $3^{\prime \prime}$ long); glumes shorter than the two smooth lanceolate flowers, of which the upper is on a slightly naked joint of the rhachis, and bears a slender spreading or bent awn next the short 2-pointed tip, while the lower one is commonly awnless or only mucronate-pointed. (Avena palustris, Michx, Aira pallens, Muhl.) - Low grounds, Southern New York to Illinois, and southward. June. - Culm slender, $2^{\circ}-3^{\circ}$ high : leaves flat, short. Spikelets yellowish-white, tinged with green.

\section{A İ RA, L. ILAin-Griss. (I'l. 12.)}

Spikelets small, in an open diffuse panicle, of 2 perfect flowers and often with the pedicel or rudiment of a third, all usually shorter than the membranaceous keeled glumes, and hairy at the base; the upper remotish. Lower palet thin and searious, 2-cleft or elso trunente nnd mostly denticulate or eroded at the summit, benring a slender bent or straight awn on its back, commonly near its base. Stamens 3. Styles plumose to the basc. Ovary glabrous. Grain oblong. (An ancient Greek name for Darncl.)

§ 1. DESCHÁMPSI $\Lambda$, Bcauv. Lower palet delicately 3-5-nerved, enoded or toothed at the truncate summit; the awn attacled mostly a little alnve the base: grain not grnoved, free: glumes about equalling the flowers : root perennial.

1. A. flexuósa, I. (Соммом IInr-Grass.) Culms slender, nearly naked $\left(1^{\circ}-2^{\circ}\right.$ high) above the small tufts of imolute bristle-form root-leaves ( $1^{\prime}-$ 6' long); branches of the small sprearling panicle capillary; awn longer than the palet, at length bent and twisted. - Dry places: common. Junc. (Eu.)

2. A. cæspitòsa, L. Culm tufted $\left(2^{\circ}-4^{\circ}\right.$ high $)$; leanes flal, linear; panicle pyramidal or oblong (6' long); awn straight, barely equalling the pulet. - Shores of lakes and streams : common northward. Junc, July. (Eu.)

\$2. AIROPSIS, Desv. Spikelets very small, of 2 closely approximate flowers, and with no rudiment of a third: lower palet of firmer terture, olscurely nerved, acutely 2-cleft at the apex: grain gronyd, alnate: low annuls, with short and setaceous loaves.

3. A. prixcox, I. Culms tufted, $3^{\prime}-4^{\prime}$ high ; liranches of the small and dense panicle appressed; nwn from lelow the mildle of the flower. (Avena praecox, Beauv.) - Sandy ficlds, New Jerscy to Virginia: rare. (Nat. from Eu.)

$$
\text { L \& } \mathrm{M}-47
$$


4. A. Caryopný lleea, L. Culms $5^{\prime}-10^{\prime}$ high, bearing a very diffuse paniclo of purplish and at length silvery srurious spikelets. - Dry fields, Nantucket : ulso Newcastle, Delaware, W. M. C'cubly. (Nat. from Liu.)

§3. VAHLÒDEA, Fries. Glumes boat-shaped, longer than the fluwers: lower pakt almost coriaceous, nerveless, its truncate-abtuse tip mostly entire; the awn borne at or alove the middle: grain grovicd, fluttish, fice: alpine perennial.

5. A. atropurpùrea, Wahl. Culms $8^{\prime}-15^{\prime}$ high, weak; leaves flat, sather wide; patnicle of lew spreading branches; awn stout, twice the length of the palet. - Alpine tops of the White Momitains, and those of Northern New , York. Aug. (Eu.)

\section{ARRHENATHERUM, Bcauv. OAT-Gkass. (Pl. 12.)}

Spikelets open-panicled, 2-flowered, with the rudiment of a third flower; the middle flower perfect, its lower palet barely bristle-pointed from near the tip; the lowest flower staminate only, bearing a long bent awn below the middle of the back (whence the name, from ä $\rho j \rho \eta \eta$, masculine, and $a \dot{\theta} \dot{\rho} \rho, a w n$ ):-otherwise as in Avena, of which it is only a peculiar modification.

1. A. avenachum, Beauv. Root perennial; culm $2^{\circ}-4^{\circ}$ high: leaves broad, flat; janicle elongated; glumes scarious, very unequal. (Avena elàtior, L.) - Meadows and lots: absurdly called Grass of the Andes. May-July. (Nat. from Eu.)

\section{HÓLCUS, L. (partly). Meadow Sort-Grass. (11. 13.)}

Spikelets crowded in an open panicle, 2-flowered, jointed with the pedicels; the boat-shaped membranaceous glumes enclosing and much exceeding the remotish flowers. Lower flower perfect, its papery or thin-coriaceous lower palet awnless and pointless; the upper flower staminate, otherwise similar, but bearing a stout bent awn below the apex. Stamens 3. Styles plumose to the base. Grain frec. (An ancient name, from ó $\lambda \kappa o ́ s$, attractive, of obscure application.)

1. H. lanatus, I. (Vklvet-Grass.) Perenuial, soft-downy and pale; panicle olslong; upper glume mucronate-awned under the apex; awn of the staminate flower curved. - Moist meadows. Junc. (Nat. from Ku.)

\section{HIERÓCHLOA, Gmelin. Holy Grass. (Pl. 13.)}

Spikelets 3-flowered, open-panicled; the flowers all with 2 palets; the two lower (lateral) flowers staminate only, 3-androus, sessile, often awned on tho middle of the back or near the tip; the uppermost (mildle) one perfect, shortpedicelled, scarcely as long as the others, 2-androus, awnless. Glumes equalling or exceding the spikelet, scarious: palets chartaccous. - Terennials : leaves flat. (Name composed of iepós, sacred, and $\chi^{\lambda}$ óa, grass; these sweet-scented Grasses being strewn before the church-doors on saints' days, in the North of Jiurope.)

1. H. boreàlis, liocm. \& Schultes. (Vanifla or Seneca Gikass.) Pau-

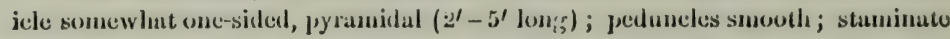
flowers with the lower palet nucronate or bristle-pointed at or near the tip; 
rootstock creeping. (Holcus odorìtus, L.) - Moist mendows, chiefly northward near the coast and along the Great Lakes. May. - Culm $1^{\circ}-2^{\circ}$ high, with short, lanceolate leaves. Spikelets chestnut-color; the staminate flowers strongly hairy-fringed on the margins, and the fertile one nt the tip. (Wu.)

2. H. alpina, Roem. \& Schultes. P'anicle contracted $\left(1^{\prime}-2^{\prime}\right.$ long); one of the staminate flowers barely pointed or short-awned near the tip, the other long-awned from below the middle; lowest leaves very narrow. - Alpine moun. tain-tops, New England, New York, and northward. July. (Eu.)

\section{ANTHOXÁnthum, L. Sweet Venal-Grass.}

Spikelets spiked-panicled, really 3-flowered; but the lateral flowers neutral, consisting merely of one palet which is hairy on the outside and awned on the back: the central (terminal) flower perfect, small, of 2 awnless chartaceous palets, 2-androus. Glumes very thin, acute, kecled; the upper about as long as the flowers, twice the length of the lower. Squamulx nonc. Grain ovate,

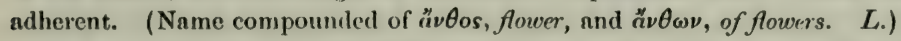

1. A. oporגтum, I. Spikelets (brownish or tinged with green) spreading at flowering-time; one of the neutral flowers bearing a bent awn from near its base, the other short-awned below the tip. - Menlows, pastures, \&c. Perennial: very sweet-scented in drying. May-July. (Nat. from Eu.)

\section{PHálaris, L. Canary-Grass. (Pl. 13.)}

Spikelets crowded in a clustered or spiked panicle, with 2 neutral mere rudiments (a scale or a pedicel) in place of lateral flowers, one on each side, at the base of the perfect one, which is flattish, awnless, of 2 shining palets, shorter than the equal boat-shaped and keeled glumes, finally coriaceous or cartilaginous, and closely enclosing the flattened free and smooth grain. - Stamens 3. -

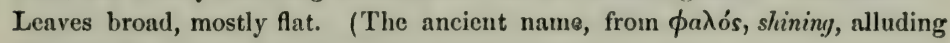
either to the palets or the grain.)

§1. PHALARIS proper. Panicle very dense, spike-like: glumes wing-keelad.

1. P. Canariénsis, L. (Canary-Grass.) Annual, $1^{\circ}-2^{\circ}$ high; spike oval; rudimentary flower a sinall lanceolate scale. - Waste places and roadsides, Massachusetts to Pennsylvania : rare. July - Sept. (Adv. from Eu.)

§2. DfGRAPHIS, Trin. Panicle branched, the clusters open in cinthesis : glumes not uinged on the back.

2. P. arundinàcea, I. (Reed C.) Perennial, $2^{\circ}-4^{\circ}$ high ; leaves flat $\left(3^{\prime \prime}-5\right)$ wide; glumes open at flowering, 3 -nerved, thrice the length of the fertile flower; rudimentary flowers reduced to a minute hairy scale or pedicel. - Wet grounds : common, especially northward. June, July. - Var. PfCTA, the leavcs striped with white, is the familiar Rrвmon-Grass of the gardens. (Eu.)

\section{Míl工U M, Millet-Grass. (P1. 13.)}

Spikelets diffusely panicled, not jointed with their pedicels, apparently consisting of 2 equal membranaceous convex nnd awnless glumes, including a single coriaceous awnless flower : but theoretica!ly the lower glume is wanting, whilo 
an empty single palet of the lower (neutral) flower, rescinbling the upper glume, fulfils its oftice, aud stands opposite the narrow upper palet of the terete fertile flower. Staneus 3. Stigmas brauched-plumose. Grain not grooved, enclosed in the palets, all deciduous together. ('The ancieut Latin name of the Millet (which however belougs to a different genus), probably from mille, a thousund, because of its fertility.)

1. M. effùsum, L. Smooth perenuial, $3^{\circ}-6^{\circ}$ high; leaves broud and flat, thin; panicle spreading $\left(6^{\prime}-9^{\prime}\right.$ long $)$; flower ovoid-oblong. - Cold and damp woods, New Englaud to Illinois and northward. June. (Eu.)

\section{8. A M P I C ÁR P M, Kunth. (Pl. 13.)}

Spikelets jointed with the apex of the pedicels, apjarently l-flowered, of two kinds; one kind in a terminal panicle, like those of Milium, except that the rudiment of the lowest glume is ordinarily discernilsle, and deciduous from the joint without ripening fruit, although the flower is perfect : the other kind solitary at the extrenity of olender runncr-like radical peduncles (which are more or less sheathed towards the base), much larger than the others, perfect and fertile, subterranean, fertilized in the bud; the enwrapping glume and similar empty palet many-nerved. Flower oblong or ovoid, pointed. Stamens 3 (small in the radical flowers). Stigmas plumose, deep purple. Grain nut grooved, in the radical flowers very large, the embryo next the lower palet. Neutral palet somewhat exceding the glume and the fertile flower. (Name frum á $\mu$ фiкарлоs, doully fruit-beuring.)

1. A. Púrshii, Kíunth. Annual or biennial ? erect, $1^{\circ}-4^{\circ}$ high; leaves lanceolate, copious on the lower part of the culm, hispid, especially on the sheaths; panicle strict, naked; grain ovoid or oblong (2"l-3" long), terete. (Milium amphicárpon, Pursh.) - Moist sandy pine-barrens, Niw Jersey, and in the Southern States. Sept.

\section{Pás Pa L U, L. Paspaluar. (PI. 13.)}

Spikelets spiked or somewhat racemed in $2-4$ rows on one side of a flattened or filiform continuous rhachis, jointed with their very short pedicels, planoconvex, awnless, apparently only one-flowered, as in Milium; but, on the other hand, differing from Panicum merely in the want of the lower glume; which, however, is occasionally present in some species, as a small scale. Glume and empty palet few-nerved. Flower coriaceous, mostly orbicular or ovate, flat on the inner sille, convex on the outer. Stamens 3. (Suid to have been a Greck name for Millet.)

* Spikes with a (1") Uroad and thin membranaceons or foliaceous and keeled rhachis, the incurved margins partly enclosing the small two-rowed spikelets. (Smooth, aquatic, or nearly so, decumbent or floating.)

1. P. flùitans, Kuntl. Annual; leaves lanceolate, flat $\left(3^{\prime \prime}-8^{\prime \prime}\right)$ broad; spikes numerous in a rexeme; the rhachis somewhat projecting heyond the minuto and slightly julnsecent spikelets into a tapering point, scabrous on the back. (Cerèsia fluitans, Ell.) - River-swamps, Virginia, S. Uhio, Illinois, and southward. Sept., Oct. 
2. P. Walteriànum, Schultes. Perennial; leaves linear, short; spikes $3-7$, the lowest partly included in the sheath of the uppermost leaf, the rhachis blunt; spikelets glabrous. (P. vaginutum, Ell.) - Iow or wet grounds, New Jersey (Cape Mny, Nutfall), I)elnware (T'atnall, C'(tnlyy), anil southward.

* * Spikes with a narrow wingless rhachis: perennials, or mostly so.

- Spikelets very obtuse, orbicular: spikes one terminal und often 1 - 5 lateral.

3. P. setàceum, Michx. Culm ascending or decumbent $\left(1^{\circ}-2^{\circ}\right.$ long), slender; lenves ( $2^{\prime \prime}$ wide, flat) and sheaths clothed with soft spreading hairs; spikes very slender $\left(2^{\prime}-4^{\prime}\right.$ long), smooth, mostly solitury on a long perluncle, and usually one fiom the sheaths of each of the upper leaves on short pedienclss or included;

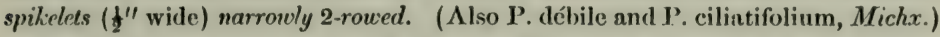
- Sandy fields: common from E. Mass. to Illinois, southward. Aug.

4. P. læeve, Michx. Culm upright, rather stout $\left(1^{\circ}-5^{\circ}\right.$ high $)$; the pretty large and long leaves with their flattened sheaths smooth or somewhat hairy; spikes 2-6, the lateral ones somewhat approximated near the summit of an elongated naked pedincle, spreading $\left(2^{\prime}-4^{\prime}\right.$ long), smooth, except a bearded tuft at their base; spikelets broadly 2-rowed (over 1" wide). - Moist soil, S. New England to Kentucky, and southward. Aug. - Fither glabrous or sometimes the lower shenths, \&c. very hairy. As here received this perhaps comprises two or more species.

+ + Spikelets acute: spikes always a pair at the summit of the naked peduncle.

5. P. dístichum, L. (Joint-Grass.) Nearly glabrous, rather glaucous ; culms ascending (about $1^{\circ}$ high) from a long creeping base; leaves linear-lanccolnte $\left(2^{\prime}-3^{\prime}\right.$ long); spikes short and closely-flowered ( $9^{\prime \prime}-2^{\prime}$ long), one shortpeduncled, the other sessile; rhachis flat on the back; spikelets ovate, slightly pointed (barely $1 \frac{1}{2}$ "long). - Wet fields, Virginia and southward. July-Sept.

6. P. Digitària, Poir. Culms ascending $\left(1^{\circ}-2 \frac{1}{2}^{\circ}\right.$ high $)$ from a creeping base; leaves lanceolate $\left(3^{\prime}-6^{\prime}\right.$ long, $4^{\prime \prime}-6^{\prime \prime}$ widc); spilies slender, rather sparsely flowered $\left(1^{\prime}-4^{\prime}\right.$ long), both sessile at the apex of the slender peduncle; spikelets ovate-lanceolate (2"long). (Milium paspalodes, Ell.) - Virginia and southward.

\section{0. PA N I C U M, L. Panic-Grass. (Pl. 13.)}

Spikelets panicled, racemed, or sometimes spiked, not involucrate, $1 \frac{1}{2}-2$-flowered. Glumes 2, but the lower one usually short or minute (rarely even wanting), membranaceo-herbaccous; the upper as long as the fertile flower. Lower flower either neutral or staminate, of one palet which closely resembles the upper glume, and sometimes with a second thin one. Upper flower perfect, closed, coriaceons or cartilaginous, usually flattish parallel with the glumes, awnless (except in $\$ 3$ ), enclosing the frce and grooveless grain. Stamens 3. Stigmas plumose, usunlly purple. (An ancient Latin name of the Italian Millet, P. Italicum (now Seturia Itnlica), thought to come from panis, breal; some species furnishing a kind of bread-corn.)

81. DIGITARIA, Scop. Spikelets crowded 2-3 together in simple and mostly 1-sided clustered spikes or spike-like racemes, wholly awnless and pointless: lower flower neutral, of a single palet - lower glume minute, sometimes obsolele or went. ing: root annual: plant often purplish. 
* Spikes erect; the rhachis filiform and nearly terete.

1. P. filifórme, L. Culms very slender $\left(1^{\circ}-2^{\circ}\right.$ high $)$, upright; lower sheaths hairy; spikes $2-8$, alternate, approximated, filiform; spikelets oblong, acute $\left(\frac{1}{2}\right.$ " long) ; lower glume almost wanting. - Dry sandy soil, Massachusetts to New Jersey along the coast, Illinois, and southward. Aug.

* Spikes spreading; the rhachis flat and thin.

2. P. Glänum, Gaudin. Culms spreading, prostrate, or sometimes erect (5'-12' long), glabrous; spikes 2-6, widely diverying, nearly digitate; spikelets ovoid (about I"long); upper glume equalling the flower, the lower one almost wanting. - Cultivated grounds and waste places : common, especially southward: in some places appearing as if indigenous. Aug., Sept. (Nat. from Eu.)

3. P. sanguindee, L. (Common Cirab-or Finger-Girass.) Culms erect or spreading $\left(1^{\circ}-2^{\circ}\right.$ high $)$; leaves and sheaths glabrous or hairy; spikes $4-15$, spreading, digitate; spikelets oblong ( $1 \frac{1}{2} "$ long); upper glume half the length of the fluwer, the lower one small. - Cultivated and waste grounds. A ug. - Oct. (Nat. from Eu.)

§ 2. PANICUM proper. Spikelets scuttered, in pranicls, awnless.

* Panicle elongated and racemose, wand-like or pyramidal ; the numerous and usually pointed spikelets short-pedicelled, excepting No. 7 and 8.

- Sterile flower neutrul and of 2 palets, fully twice the length of the lower glume: spikelets small (1" or $1 \frac{1}{2}$ "long) : root perennial.

4. P. ánceps, Michx. Culms flat, upright $\left(2^{\circ}-4^{\circ}\right.$ high $)$; leaves rather broadly lincar ( $1^{\circ}-2$ long, $4^{\prime \prime}-5^{\prime \prime}$ wide), smooth; panicle contracted-pyramidal; spikelets ovate-lanceolute, pointed, a little curved; upper glame 5-7-nerved; neutral flower one third longer than the perfect one. - Wet sandy soil, New Jersey and Penn. to Virginia, and southward. Aug. - Too near the next: spikelets and branches of the panicle longer.

5. P. agrostoides, Spreng. Culms flattened, upright $\left(2^{\circ}\right.$ high $)$; leaves long, and with the sheaths smooth; panicles terminal and often lateral, pyramidal $\left(4^{\prime}-8^{\prime}\right.$ long); the spikelets racemose, crowded and one-sided on the spreading branches, ovate-oblong, acute (purplish); upper glume 5-nerved, longer than the neutral flower which exeeds the perfect one; perfect flower bearded at the apex. (P. agrostidiforme, Lam.? P. multiflorum, Poir.) - Wet meadows and shorcs, E. Massachusetts and New York (Oneida Lake, A. H. Curtiss) to Illinois, and common southward. Aug.

+ + Sterile flower neutral and of a single palet, much longer than the lower glume; spikelets $\frac{1}{2} "-1 \frac{1}{2}$ "lony; annuals except No. 8: Laves flut; shealhs fattened.

+ Glubrous and smooth throughout; spikelets croucted, appressed, short-pedicelled.

6. P. prolíferum, Lam. Culms usually thickish and rather succulent, branched, geniculate and ascending from a procumbent base; sheaths flattened; ligule ciliate; panicles terminal and lateral, compound, pyramidal, the sleuder primary branches at length spreading; spikelets pale green, rarely purjolish; lower glume broad, of to the length of the upper; neutral flower little longer than the perfect one. - Marshy river-banks and shores, esjecially when brackjsh, hut also in the interior, from Mass. and Illinois southward. Aug. 
4+ Hispid or hairy on the shenths, at lenst the lower: spil onts mostly scrillered on slender or capillary pedicels in an ample, lonse, at lenyth very effiuse panicle: culms mostly branched from the buse, erect or ascending $\left(10^{\prime}-20^{\prime}\right.$ ligh $)$.

7. P. capillare, L. (Oro-witcr Grass.) Alt the sheaths and usually the leaves copiously huiry or hispid; panicle mostly very compound, the branches divaricate when old; spikelets varying fiom ovoid to narrowly oblong, pointed; lower glume half the length of the neutral polet which is longer than the elliptical obtuse perfort flower. - Sandy soil and cultivated fields everywhere. Aug. - Oct. - Varies extremely in size and appearance: in depauperate forms the spikelets only q $^{\prime \prime}$, in the larger forms $1 \frac{1}{2}$ " in longth.

8. P. autumnàle, Bose! Root perennial? lower sheaths and margins of the small narrow leaves more or less hairy, otherwise glahmus, except some bristly hairs in the main axils of the very effise capillary panicle, its much elongated divisions sparingly branched, or even simple and terminated with solitary spindleshaper spikelets; lower glume minute; perfect flower lancrolate-oblong and pointed, nearly equalling the lance-oblong ohtusish upper glume and the neutral palet. (P. nudum, Wult.? P. dichotomiflorum, Michx. 1'. divergens, Muhl, not of II. B.K. P. frágile, Kunth.) - Sand-hills, Mason County, Illinois (Mtad, E. Hall), and southward.

+ + + Sterile flower stuminate, of 2 palets: lower glume more than half the length of the upper: spikelets lurge (2" - 2f"long), ovate, pointed, as are the glumes, ffc.: perennials, glabrous, with tnll or stout and rigid upriglt culms.

9. P. virgàtum, L. Tall $\left(3^{\circ}-5^{\circ}\right.$ high $)$; leaves very long, flat; ligule silky-bearded; branches of the compound loose and large panicle $\left(9^{\prime}-2^{\circ}\right.$ long) at lenyth spreading or drooping; spikelets scattered, nsually purplish. - Moist sandy soil : common, especially southward. Ang.

10. P. amarum, Ell. Culms $\left(1 \frac{1}{2}^{\circ}\right.$ high) sheathed to the top; leaves involute, glaucous, coriaceous, the uppermost pxceeding the contracted panicle, the simple racemose branches of which are appressed ; spikelets pale. - Sandy shores, Connecticut (Barratt, Robbins), Virginia, and southward. Aug., Sept.

* Panicle loosdy spreading or diffuse, short or small : perennials.

- Lower (sterile) flouer neutral, or in No. 11, and sometimes in No. 14, staminate, formed of 2 palets, the upper one scurious and sometimes small and inonnspicuous.

+ Cilm-leaves broadly lancolate or wider, with $9-15$ principal neves.

11. P. latifolium, I. Culm $\left(1^{\circ}-2^{\circ}\right.$ high $)$ smooth; the joints and the orifice of the throat or margins of the otherwise smoth sheatls often benrded with sof woolly hairs; leaves broadly oblong-lancolate from a hourt-clasping lase (often 1' wille), taper-pointed, 11 - 15-nerred, smooth, or sparingly downy-hairy ; panicle more or less exserted ( $2^{\prime}-3^{\prime}$ long), usually long-perluncled, the branches spreading; spikelets oboute, $1 \frac{1}{2}$ " leng, downy; lower glume ovate, not half the length of the many-nerved upper one; sterile flower often (not always) with 3 stamens. (P. Wŕlteri, Poir.) - Moist thickets : common. June-Aug.

12. P. clandestinum, L. Culm rigid $\left(1^{\circ}-3^{\circ}\right.$ high $)$, very leafy to the top, at length producing appressed branches, the joints naked; sheaths rough with propille bearing very stiff and spreading bristly hairs; leaves oblong-lanceolate from a heart-clasping base, very taper-pointed; lateral and usually also the ter- 
minal panicle more or less enclosed in the sheaths, or with the terminal one at length long-peduncled (P. pedunculàtum, Torr.) :- otherwise resembling No. 11 ; but the spikelets more oroid, often smooth; the lower flower (always?) neutral. - Low thickets and river-banks: common. June-Sept.

13. P. microcárpon, Mulil. Culm and sheaths as in No. 11 ; the broadly lanceolate leaves nearly siuilar, but longer in proportion and less pointed, not dilated at the rounded bristly-ciliste lase, very rough-margined, the upper surface roughish ; panicle soon exserted on a slender peduncle, very many-flowered, narrowly oblong $\left(3^{\prime}-7^{\prime}\right.$ long $)$; spikclets only about $\frac{1}{2} \prime \prime$ long, ovoid, smooth or smoothish; lower glume orbicular and very small. (P. multiflorum, Ell. $?$ not of Puir.) - Dry or moist thickuts, Pennsylvania and Michigan to Illinois, and southward. July-Scpt.

14. P. xanthophysum, Gray. Culm simple, or at length branched near the base $\left(9^{\prime}-15^{\prime}\right.$ ligh $)$; sheaths hairy; leaves lanceolute, very acute $\left(4^{\prime}-6^{\prime}\right.$ long by $\frac{1}{2}$ ' wide), not diluted at the ciliate-bearded clasping base, smooth except the margins, strongly 9-11-nerved; panicle long-peduncled, very simple, the appressed branches bearing a few roundish-obovate spikelets (about $1 \frac{1}{2}$ "long); lower glume ovate, acutish, one third or half the length of the 9-nerved upper one. - Dry sandy soil, Maine to Wisconsin, and northward : rare. June. - Plant yellowish-green : spikelets minutely downy: sterile flower sometimes staminate.

15. P. víscidum, Ell. Culms upright or ascending, at length much branched, leariy to the top, densely velvely-doumy all over, as also the sheaths, with reflexed soft and often clanny hairs, except a ring below each joint; leaves likewise velvety, lanceolate ( $\frac{1}{2}{ }^{\prime}$ wide), 11 - 13-nerved; panicle spreading, the latcral ones included; spikelets obovate 1 " or $1 \frac{1}{2}$ "long, downy; the roundish lower glume scareely one fourth the length of the 7-nerved upper one. - Damp soil, New Jersey to Virginia, and southward. Aug.

16. P. pauciflorum, kll. ? Culms upright, at length much branched and reclining $\left(1^{\circ}-2^{\circ}\right.$ long $)$, roughish; leaves lanccolate $\left(3^{\prime}-5^{\prime}\right.$ long by $f^{\prime}-d^{\prime}$ wide $)$, rather faintly 9-nerved, hairy or smooth, fringel on the whole margin or next the base with long and stiff spreading hairs, the sheaths brisily throughout with similar hairs; panicle open, nearly simple, bearing few tumid-obovate hairy or smoothish spikelets about $1 \frac{1}{2}$ "long; lower glume roundish, about half or a quarter of the length of the upper one. - Wet meadows and copses, E. Massachusetts to Wisconsin, and southward. June, July. - Distinguished by its much larger spikelets, more nerved leaves, and coarser aspect, from any form of the next. It has probably been described under several names, some of them earlicr than Elliott's.

+t + Leaves lincar or leuceulute, wilh few or indistinct primary nerres.

17. P. dichótomum, L.! Culus $\left(8^{\prime}-20^{\prime}\right.$ high $)$ at tirst mostly simple, bearing a more or less exserted spreading componad penicle ( $1^{\prime}-3^{\prime}$ long), and lanceolate flut leaces (those tufted at the root usmally orate-lanceolate and very short, thickish); but commonly branching later in the scason, the branches often clustered, and bearing nearly simple und included small panicles; spikitets $\frac{1}{2}$ " to about 1" lomg; oblong-obovate, downy or smooth; louer ylume roundish, one third or a quarter the length of the 5-7-nervel upper one. - Founded on an autumnal state of the species, much forked and with densely clustered lateral branchlets 
and panicles. (P. nodiflorum, Lam.) - Exhibits an interminable diversity of forms; of which a shaggy-hairy and larger-flowered variety is $P$. pubescens, Inm.; and one with smaller spikelets is P. laxiflorum, I $\mathrm{Am}$.; while the varied smooth or smoothish states with shining leaves are P. nitilum, Iam., and (the more slender forms) P. barbulatum and P. ramulosum, Michx. \& c. Some of these may be good species. - Dry or low grounds : common. Junc-Aug.

18. P. depauperatum, Muhl. Culms simple or branched from the basc, forming close tufts $\left(6^{\prime}-12^{\prime}\right.$ high $)$, terminated by a simple and few-flowered contracted panicle, often much overtopped by the narrowly linear and elongated $\left(4^{\prime}-7^{\prime}\right)$ "pper leaves; spikelets $\mathbf{q}^{\prime \prime}-1 \frac{1}{2}$ " lony, oval-obovate, commonly pointed when young; the ovate lower glume one third the length of the 7-9-nerved upper one. (P. strictum, Pursh. P. rectum, Rom. \& Schult.) - Varies, with the leaves involute, at least when dry ( $\mathrm{P}$. involùtum, Torr.), and with the sheaths either beset with long hairs or nearly smooth : the panicle either partly included, or on a long and slender peduncle. - Dry woods and hills : rather common. June.

++ Lower sterile flower of a single palet, and neutral.

19. P. verrucosum, Muhl. Smooth; culms branching and spreading, very slender $\left(1^{\circ}-2^{\circ}\right.$ long $)$, naked above; leaves linear-lanceolate $\left(2^{\prime \prime}-3^{\prime \prime}\right.$ wide), shining; branches of the diffuse panicle capillary, few-flowered ; spikelets wartyroughened (dark green), oval, acute, $z^{\prime \prime}$ long; the lower glume one fourth the length of the obscurely nerved upper one. - Sandy swamps, New England to Virginia, near the coast, and southward. Ang.

§ 3. ECHINÓCHLOA, Beauv. Spikelets imbricated-spiked on the branches of the simple or compound raceme or panicle, usually rough with appressed stiff hairs : lower palet of the sterile flower awl-pointed or awned.

20. P. Crus-ghtei, L. (Barnyard-Grass.) Root annual; culms stout, branching from the base $\left(1^{\circ}+4^{\circ}\right.$ high); leaves lanceolate $\left(\frac{1^{\prime}}{2}\right.$ or more wide), rough-margined, otherwise with the sheaths smooth; spikes alternate $\left(1^{\prime}-3^{\prime}\right.$ long), crowded in a dense panicle; glumes ovate, abruptly pointed ; lower palet of the neutral flower bearing a rough awn of variable length. - Varies greatly; sometimes awnless or nearly so ; sometimes long-awned, especially so in the var. nfsrıdum (P. hispidum, Muhl., P. longisètum, Torr.), a very large and coarso form of the species with the sheaths of the leaves very bristy. - Moist, chiefly manured soil : the varicty in ditches, especially of braekish water; possibly indigenous. Aug. - Oct. (Nat. from Eu.)

\section{SETÀ I A, Bcauv. Bristly Fox-tanl Gra8s. (Pl. 13.)}

Spikclets altogether as in Panicum proper, and awnless, but with the short peduncles produced beyond them into solitary or clustered bristles resembling awns (but not forming an involucre). Inflorescençe a dense spiked panicle, or apparently a cylindrical spike. - Annuals, in cultivated or manured grounds, with linear or lanceolate flat leaves: properly to be regarded as meroly a subgenus of Panicum. (Name from seta, a bristle.)

* Bristles single or in pairs, roughened or barhed doumwards.

1. S. verticildita, Beauv. Spike cylimbical (2'-3' long, pale green), composed of apparently whorled short clusters; bristles short, adhesive. (Panicum verticillatum, L.) - Near dwellings. (Adv. from Eu.) 
* * Bristles in clusters, roughened or barbed upuards.

2. S. ghades, Beauv. (Foxtail.) Spike cylindrical, dense, tawny yollow (2'-4' long); bristles $6-11$ in a cluster, much longer than the spikelets; perfect flower transversely wrinkled. - Very conmon, in stubble, \&c. (Adv. from Eu.)

3. S. vfridis, Beauv. (Green Foxtail. Bottle-Grass.) Spike merty cylindrical, more or less compound, green; bristles few, longer than the spikelets; perfect flower striate lengthwise and dotted. - Cultivated grounds. (Adv. from Eu.)

4. S. Itálica, Kunth. Spike compound, interrupted at the base, thick, nodding (6' - 9' long, ycllowish or purplish); bristles 2 or 3 in a cluster, either unch longer or else shorter than the spikelets. (S. Germánica, Beauv.) - Sometimes cultivated under the name of MiLLET, or Bengal Grass : rarely spontancous. (Adv. from Eu.)

\section{CÉ NCHRUS, L. Hedgehog- or Bur-Grass. (Pl. 14.)}

Spikelets as in Panicum, awnless, but enclosed 1 to 5 together in a globular and bristly or spiny involucre, which becomes coriaceous and forms a deciduous hard and rigid bur: the involueres sessile in a terminal spike. Styles united below. (An ancient Greek name of Setaria Italica.)

1. C. tribuloides, L. Culms branched and ascending $\left(1^{\circ}-2^{\circ}\right.$ high $)$ from an annual root; leaves flat; spike oblong, of 8-20 spherical heads; involucre prickly all over with spreading and barbed short spines, more or less downy, enclosing 2 or 3 spikelets. - Sandy soil, on the coast, the Great Lakes, and the larger rivers. Aug. - A vile weed.

\section{Trípsacum, I. Gama-Grass. Sesame-Grass. (1'1. 14.)}

Spikelets monceious, in jointed spikes, which are staminate above and fertile below. Staminate spikelets 2, sessile at each triangular joint of the uarrow rhachis, forming a 1-sided and 2-ranked spike longer than the joints, both alike, 2-flowered : glumes coriaceous, the lower (outer) one nerved, the inner one boatshaped: palets very thin and membranaccous, awnless : anthers (turning orange or reddish-brown) opening by 2 pores at the apex. Pistillate spikelets single and deeply imbedded in each oblong joint of the cartilaginous thickened rhachis, occupying a boat-s aped recess which is closed by the polished and cartilaginous ovate outer glume, the inner glume much thinner and jointed, 2-flowered; the lower flower neutral, palets very thin and scarious, pointless. Styles united: stigmas very long (purple), hispid. Grain ovoid, free. Culms stout and tall, solid, from very thick creeping rootstocks. Leaves broad and flat. Spihes axillary and terminal, separating spontancously into joints at maturity. (Name from $\tau$ pi $\beta \omega$, to rub, perlaips in allusion to the polished fertile spike.)

1. T. dactyloides, L. Spikes $\left(t^{\prime}-8^{\prime}\right.$ long $) 2-3$ together at the summit (when their contiguous sides are more or less flattened), and also solitary from some of the upper sheaths (when the fertile part is cylindrical); sometimes, var. monostdenrum, the terminal spihe also solitary. - Moist soil, from Connecticut to Penusylvaniat, near the const, and from Illinois sonthward. Aug. - Culm $4^{\circ}-7^{\circ}$ high : the leaves like those of Indian Corn. - This is one of our largest and most remarkable Grasses: sometimes used for fodder at the South, where better is not to be had. 


\section{ERI Í T T US, Michx. Woolty BeArn-GrAss. (PI. 14.)}

Spikelets spiked in pairs upon each joint of the slender rharhis; one of them sessile, the other pedieclled; otherwise both alike; with the lower flower neutral, of one membranaceous palet; the upper perfeet, of 2 hyaline palets, which are thinner and shorter than the nearly equal membranaceous glumes, the lower palet awned from the tip. Stamens I-3. Grain free. - T'all und stout reer-like perennials, with the spikes crowded in a panicle, and clothed with long silky hairs, especially in a tuft around the base of each spikclet (whence the name, from ëpcov, uool, and "̈vOos, flower).

1. E. alopecuroldes, Ell. Culm $\left(4^{\circ}-6^{\circ}\right.$ high) woolly-bearded at the joints; panicle contructed; the silky huirs longer than the spikelets, shorter than the awn; stamens 2. - Wet pine barrens, from New Jersey and Illinois southward: rare. Sept., Oct.

2. E. brevibárbis, Michx. Culm $\left(2^{\circ}-5^{\circ}\right.$ ligh $)$, somewhat bearded at the upper joints; panicle rather open; silky hairs shorter than the spikelets. I.ow grounds, Virginia and southward.

\section{A N D ROPÒ GON, I. BenRd-Grass. (Pl. 14.)}

Spikelets in pairs upon each joint of the slender rhachis, spiked or racened; one of them pedicelled and sterile, often a mere vestige; the other sessile, with the lower flower neutral and of a single palet; the upper perfect and fertile, of 2 thin and hyaline palets shorter than the herbaceous or chartaceous glumes, the lower awned from the tip. Stamens 1-3. Grain free.-Coarse, mostly rigid perennials, mostly in sterile or sandy soil; with lateral or terminal spikes commonly clustered or digitate; the rhachis hairy or plumose-bearded, and often the sterile or staminate flowers also (whence the name, composed of $a \dot{v} \dot{\rho} \rho, \ddot{\nu} \nu \delta \rho p o s$, man, and $\pi \dot{\omega} \gamma \omega \nu, l_{f}$ ard).

* Spikes digtate, thickish, short-bearded, the sterile spikelet staminate: slamens 3.

1. A. furcatus, Muhl. Tall, $3^{\circ}-4^{\circ}$ high, rigid, the naked summit of the culm (and usually some lateral branches) terminated by $2-5$ rigill spikes; spikelets approximated, appressed; hairs at the base of the fertile spikclet, on the rhachis and on the stout pedicel of the awnless staminate spikelet short and rather sparse; awn of fertile flower long and bent; leaves flat, roughish, the lower ones long. - Common in dry sterile soil. $\Lambda$ ug. - Oct.

* Spikes with slender often zigzag rhachis, silky-villous,

- Single and scattered along the branches, with the silky hairs shorter than the flowers: sterile spikelet conspicuous but mostly nentrul; the fertile triandrous.

2. A. scopàrius, Michx. Culms slender $\left(1^{\circ}-3^{\circ}\right.$ high $)$, with numerous paniculate branches; lower sheaths and narrow leaves hairy; spikes slender, seattered, mostly peduneled ( $I^{\prime}-2^{\prime}$ long), very loose, often purplish, silky with lax dull-white hairs; sterile spikelet awn-pointed or awnless; the fertile about half the length of its twisted or bent awn. - Dry ground. July - Sept.

+ + In pairs or clustered; the copious soft-silky huirs much longer than the flowers: sterile spilielet a small neutral rudiment. (in No. 3), or altongether urenting on the summit of the very plumose-hairy prdicel: fertile flower momundrous, its awn capillary: leaves nurrow, the lower or their shcath ofien ruther hairy. 
3. A. argénteus, Ell. Culms rather slender $\left(1^{\circ}-3^{\circ}\right.$ high $)$; spikes in pairs (rarely in fours) on short mostly exserted ard loosely paniculate peduncles, densely floweral (1'-2' long), very silky with long bright whitehuirs. (A. argyræuus, Schultes. A. Ellióttii, ('hapm.) - Delaware (W.M. Canby), Virginia, near the coast, and southward. Sept., Oct.

4. A. Virgínicus, L. Culm flattish below, slender $\left(2^{\circ}-3^{\circ}\right.$ high $)$, sparingly short-branched aboe, sheaths smooth; spihes 2 or 3 together in distant appressed chusters, shorter than their sheathing bracts, weak ( $I^{\prime}$ long), the spikclets loose on the filiform rhachis, the soft hairs dull white. (A. vaginàtus, Ell., a form with larger and inflated shcaths.) - Sandy soil, E. Massachusetts to Virginia, Illinois, and southward. Sept., Oct.

5. A. macroùus, Michx. Culm stout $\left(2^{\circ}-3^{\circ}\right.$ high $)$, bushy-branched at the sunumit, loaded with very uunerous spikes forming thick leafy clusters; sheaths rough, the uppermost hairy; flowers nearly as in the preceding; the sterilo spikelet of each pair wholly wanting, its pedicel slender and very plumose. Low and saudy grounds, New York to Virginia, near the coast, and southward. Sept., Oct.

\section{6. S Ó RGHU MI, Pers. Вroom Corn. (Pl. 14.)}

Spikelets 2-3 together on the ramifications of an open paniele, the lateral ones sterile or often redueed merely to their pedicels; ouly the middle or terminal one fertile, its glumes coriaceous or indurated, sometimes awnless : otherwise nearly as in Andropogon. Stamens 3. (The Asiatic name of S. vUlaAre, the Indian Miflet, to which species belongs Guinea-Corn, Broom-Conn, the Sweet Sorgium, and other cultivated races.)

1. S. nùtans, Gray. (Indian Grass. Wood-Grass.) Root perennial; culn simple $\left(3^{\circ}-5^{\circ}\right.$ high $)$, terete; leaves lincar-lanceolate, glaucous; sheaths smooth; panicle narrowly oblong, crowded or loose $\left(6^{\prime}-12^{\prime}\right.$ long $)$; the perfect spikelets at length drooping (yellowish or russet-brown and shining), clothed, especially towards the base, with fawn-colored hairs, lanceolate, shorter than the twisted awn; the sterile spikelets small and imperfect, deciduous, or reduced to a mere plumose-hairy pedicel. (Andropogon nutans, L.)-Dry soil : common, especially southward, where it runs into several marked varieties or perhaps species (S. avenàceum, nutans, and secundum, Chaprnan). Aug. - Oct. 


\section{SERIES II.}

\section{CRYPTÓGAMOUS or FLOWERLESS PLANTS.}

Vegetables destitute of proper flowers (i. e. no stamens and pistils), producing, in place of seeds, minute bodies of homogeneous structure (called spores), in which there is no embryo, or plantlet anterior to germination.

\section{Class III. Á CR OGENS.}

Cryptogamous plants with a distinct axis (stem and branches), growing from the apex only, containing woody fibre and vessels (especially ducts), and usually with some kind of foliage.

\section{Order 129. Equisetàcea. (Iorsetail Family.)}

Leafless plants, with rush-like hollow and jointed stems, arising from running rootstocks, terminated by the fructification in the form of a cone or spike, which is composed of shield-shaped stalked scales bearing the spore-cases underneath. - Comprises solely the genus

\section{EQU I Sit U M. L. Horsetarl. Scouring Rushr. (Pl. 15.)}

Spore-cases (sporangia, thece) 6 or 7 , adhering to the under side of the angled shicld-shaped scales of the spike, 1-celled, opening down the inner side and dis. charging the numerous loose spores. To the base of each spore are attached 4 thread-like and club-shaped elastic filaments, which roll up closely around the spore when molst, and uncoil when dry. - Stems mostly from running rootstocks, striate-grooverl (in many the harel cuticle ahounding in silex), hollow, and also with an onter circle of smaller air-cavities corresponding with the grooves; the joints closed and solid, cach bearing instead of lcaves a sheath, which surrounds the base of the internode above, and is split into teeth corresponding in number and position with the principal rilges of the stem: the stomatn in tho grooves. Branches, when present, in whorls from the lase of the sheath, like the stem, but without the central air-cavity. ('The ancient name, from eques, horse, and sela, bristle.) 


\section{§1. Annual-stemmed, not surviving the winter. (Stomata scuttered.)}

* Fruiting in spring from soft and rather succulent pale or Irownish fertile stems, the sterile stems or branches appearing later, herbactous and very different.

+ Fertile stems remaining simple, soon perishing; the sterile producing copious branches.

1. E. Telmatèia, Ehrh. (Griat Honsetall.) Stems stout (as thick as the finger); the sheaths of the fertile ones $\left(1^{\prime}-12_{2}^{\prime}\right.$ Jong) enlarging upwards, deeply 20-30-toothed; sterile stem white, 20-30-furrowed; its branches simple, rough, usually 4-angled and again grooved on the angles. (Li. ebúrneum, liath., Schreber, and Ed. 2. E. fluviátile, Smith.) - Shore of the upper Great Lakes, and northwestward: rare. April, May. - Fertile stems $10^{\prime}-15^{\prime}$, the sterile $2^{\circ}-5^{\circ}$ high. (Eu.)

2. E. arvénse, L. (Соммом H.) Fertile stems $\left(4^{\prime}-10^{\prime}\right.$ high) with loose and usually distant about 8-12-toothed sheaths; the sterile slender (at length $1^{\circ}-2^{\circ}$ high), 10-14-furrowed, producing long and simple or sparingly branched 4-angular branches; their teeth 4, herbaceous, lanceolate. - Moist, especially gravelly soil : very common. March - Mity. - Rootstocks occasionally bearing copious little tubers like small peas (Illinois, S. A. Collier). - The var. senótinus, Meyer, an accilental state, in which the sterile plant produces a spike of fruit fiom its summit, is found in New Jersey by $C^{\prime} \cdot \boldsymbol{F}^{\prime}$. Austin.

+ + Fertile stems when older producing herbaceous 3-sidul branches, and lasting through the summer, except the naked top which perishes after fiuctificution.

3. E. praténse, Elurh. Sterile and finally also the fertile stems producing simple straight branches; sheaths of the stern with ovate-lanceulate short teeth, those of the branches 3-toothed: stems more slender and the branches shorter than in the last. (E. umbrosum, Willd. E. Drummóndii, Ilook.) - Michigan (Cooley, fcc.), Wisconsin, and northward. April, May. (Ëu.)

4. E. sylváticum, L. Sterile and fertile stems (about 12-furrowed) producing compound racemed branches; sheaths loose, with 8-14 rather blunt teeth, those of the branches bearing 4 or 5 , of the branchlets 3 , lance-pointed divergent teeth. - Wet shady places: common northward. May. (Lu.)

* * Fruiting in summer; the stems all of one kind, or the fertile contemporaneous with and like the sterile, erqully herbuceous, producing mostly simple branches, or sometimes nerrly naked.

5. E. palústre, L. Stems $\left(10^{\prime}-18^{\prime}\right.$ high $)$ slender, very deeply 5 -9-grooved, the grooves separated by narrow wing-like ridges, roughish, the lance-awl-shaped teeth whitish-margined; branches rather few in a whorl. - Wet places, Niagara River (G. W. Clinton), Wisconsin (C. F. dustin), and northward. June. (Eu.)

6. E. limosum, I. Stems $\left(2^{\circ}-3^{\circ}\right.$ high) slightly mony-furrowed, smooth, usually producing upright branches after fructification; sheaths appressed, with 10-22 (commonly ahout 18) dark-brown and acute rigid short teeth. (E. uliginòsum, Mhul.) - In shallow water : rather common. - Air-cavities none under the grooves, but smoll omes under the ridges. June, July. (Ein.)

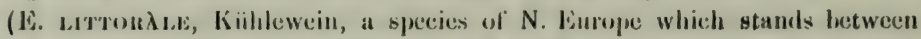
No. 5 and No. 6, is said by Milde to grow in Canada, on the anthority of a specimen in herb. Hook., and may be looked for northward.) 
\$2. Evergreen or perennial-stemmed, surviving the winter, mostly rough (the cuticle abounding in silex): fruiting in summer: spike tipped with a rigid little point. (Stomata in regular rouss, in our syecies 1-rowed on euch side of the groove.) .

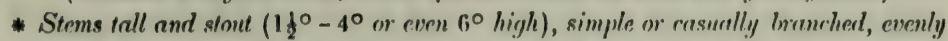
many- (15-40-) grooved: sheuths appressed. (Probably all forms of the Common Scouring Rush.)

7. E. lævigàtum, Braun. Stems $1 \frac{1}{2}^{\circ}-4^{\circ}$ high, sometimes with numerous branches; the ridges convex, obtuse, smooth or minutely rouglish with minute tubercles; shexths elongaled, with a narrow black limb and about 22 liner-awlshaped culucous teeth, 1-keeled below. - Dryish clay soil, Illinois and southward.

8. E. robústum, Braun. Stems $3^{\circ}-6^{\circ}$ high; the ridges narrow, rough with one line of tubercles: sheuths short, with a black girdle above the base, rarely with a black limb, and about 40 deciduous 3 -keeled teeth with ovate-aul-shapred points. - River-banks, Ohio to Illinois, and southward. - Passes by var. AFFine, Engelm. (smaller, with 20-25 awl-pointed more persistent teeth) into the next.

9. E. hyemalle, L. (Scouring-Rusn. Sirave-Grass.) Stems $1 \frac{1}{2}{ }^{\circ}-4^{\circ}$ high; the ridyes ronghened hy 2 more or less distinct lines of tubercles; sheaths elongated, with a black girdle above the base and a black limb, of about 20 (17 26) narrowly linear teeth, 1-kceled at the base and with awl-shaped deciduous points. Wet banks : common northward. Used for scouring. (Eu.)

\section{* Stems slender, in tufts, 5-10-grooved: sheaths looser.}

10. E. variegàtum, Schleicher. Stems ascending $\left(6^{\prime}-18^{\prime}\right.$ long), usually simple from a branched base, 5-10-grooved; shcaths green variegated with black above; the 5-10-teeth tipped with a decidnous bristle. - Shores or riverbanks, New Hampshire (Bellows Falls, Curey) and Niagara to Wisconsin and northward: rare. (Eu.)

11. E. scirpoldes, Michx. Stems very numerous in a tuf, filiform $\left(3^{\prime}-6^{\prime}\right.$ high), flexuous and curving, mostly 6-grnoved, with acute ridges; the shenths 3-toothed, the bristle-pointed tecth more persistent ; central air-cavity wanting. Wooded hillsides, New England to Pennsylvania, Michigan, and northward. (Eu.)

\section{Order 130. PímCES. (Ferns.)}

Leafy plants, with the leaves (fronds) usually raiser on a stalk or petiole (stipe), rising from a root, or mostly from a prostrate or assurgent or even erect rontstock, separately rolled up (circinate) in the bud (except in Suborder IV.) and bearing on the under surface, commonly on the veins or along the margins, the simple fructification, which consists of 1-celled spore-cases (sporangia), opening in various ways, and discharging the numerous minute spores. (Antheridia and pistillidia formed and fertilization effected on the seeding plantlet!) - Of the eight well-marked Suborders, into which the Ferns are divided, four are represented in the Northern United States.

The whole order has been elaborated for this edition by Prof. DANIEL C. EAton, of Yale College. 


\section{Suborder I. polypodiace. The True Ferns.}

Sporangia collected in dots, lines or variously shaped clusters (sori or fruit-dots) on the back or margins of the frond or its divisions, stalked, cellular-reticulated, the stalk running into a vertical incomplete-manyjointed ring, which by straightening at maturity ruptures the sporangium transversely on the imner side, discharging the spores. Fruit-dots often covered (at least when young) by a membrane called the indusium (or less properly the involucre), growing either from the back or the margin of the frond. (Plates 15-18.)

Tribe I. POLYPODIEA. Fructification on the back of the frned, in roundish or elongated fruit-dots (sori) placed on the veins or at tho ends of the veins, without indusium of any kind. Stipes urticulated to the rootstock, leuving a distiuct scar when separated. Veins free (not reticulated) in our species.

1. Polypodium. Sori round, in one or more rows each side of the midrib or of the segments of the frond.

Tribe II. PTERIDEAE. Fructification uarginal or intramarginal, provided with a general indusium formed of the (either altered or unchanged) margin of the frond. Stipes not articulated to the rootstock. Veins free in all our species.

* Sporangia at the ends of the veins, borne on a reflexed portion of the margin of the frond.

2. Adiantum. Midrib of the pinuules near the lower margin or none. Stipe black and polished.

* * Sporaugia borne on a continuous marginal vein-like receptacle, which connects the apices of the veins, and is covered by a delicate whitish indusium formed of the reflexed uargin of the pinnule.

3. Ptexis. Midrib of the pinnules central. Stipe light-colored.

* * Sporangia at or near the euds of the unconnected veius, borne on the under surface of the froud : indusium various.

4. Chellanthes. Sori minute, at the ends of the veins, indusium continuous or interrupted. Fronds mostly chaffy, woolly or pulverulent.

5. Pellsea. Sori on the upper part of the veins, distinct, or mostly forming a confluent submarginal band of sporangia. Indusium membranaceous, continuous, rarely altogether wanting. Sterile and fertile fronds not very unlike: stipes dark-colored : frouds surooth.

6. Allosorus. Sori roundish or elongated and extending far down the free veins, at first covered by the reflexed herbaceous margin of the segment, at length exposed and confluent. Sterile and fertile fronds very different : stipes light-colored : fronds smooth.

Tribe III. A SPLENIEAE. Sori more or less elongated, occupying one or both sides (but not the back) of the veins, covered by a special indusium which is attached by one pide to the fertile vein, and is free on the other. Stipes not articulated.

* Sori linear or oblong, borne on cross veins parullel to the midrib.

7. Woodwardia. Sori forming a chain-like row each side of the widrib or central veln. Veius reticulated.

* * Sori linear or oblong, borne on veins oblique to the midrib.

8. Asplenium. Sori on the upper side of the fertile veinlet, rarely on both sides of a veinlet. Veins free in all our species.

9. Scolopendrjum. Sori linear, confluent in pairs, each pair appearing like a single sorus with a double indusium opening down the uiddlo. Veins freo.

* * Sori borne partly on veins parallel to the midrib, partly on veius oblique to the midrib.

10. Camptosorus. Sori oblong or linear, the outer ones often approximating in pairs Veins reticulated. 
Trlbe IV. A SPIDIF. SE. Sori round or roundish, on the back or marely at the apex of the fertlle vein, provided with a special indusium, rarely naked. Stipes not articulated to the rootstock.

* Indusilum obsolete or none.

11. Phegopteris. Borl round, rather small. Veins free in our specles.

* Indusium evident, round or roundish, covering the sporangia, at least when young. Sterile and fertile fronds not very unlike. Veins free in our species.

12. Aspidlum. Indusium flat, orbicular or round-reniform, fixed by the centre, opening all round the margin.

13. Cystopteris. Indusium convex, fixed by a broad base partly under the sorus, commonly reflexed as the aporangin ripen.

** Indusium obscure, irregularly gemicircular. Fertile fronds much contracted and very unlike the sterile ones.

14. Struthlopteris. Fertile frond simply pinnate. Sterile frond with free veing.

15. Onoclea. Fertile frond twice pinnate. Sterile frond with reticulated veins.

*** Indusium roundish or stellate, placed beneath the sporangia, sometimes enclosing them and then bursting open from the top.

16. Woodsia. Indusium very delicate, cleft into Irregular lobes, or divided into a ciliate fringe. Veins free.

Tribe V. DA VALIERA. Sori roundish or transversely elongated, borne at the ends of the veins or on marginal cross-veinlets, with an indusium attached at the base or base and sides and opening towards the margin of the segment.

17. Dicksonla. Sori marginal, very small, the indusium cup-shaped, somewhat 2-valved, the under portion confluent with a lobule of the frond. Veins free.

\section{Suborder II. SCHIZAEACER.}

Sporangia ovate, sessile, having a complete transverse articulated ring at the apex, and opening by a longitudinal slit. (Pl. 19.)

18. Schixnea. Sporangia naked, fixed in a double row to the midrib of the narrow fertile segments. Sterile fronds rigid, simple or dichotomously branched.

19. Ly godium. Sporangia borne in a double row on narrow fertile regmente, each aporanglum seated on a separate veinlet, and provided with a special scale-like indusium. Fronds leafy, climbing.

\section{Suborder III. OSMUNDACEA.}

Sporangia naked, globose, mostly pedicelled, reticulated, with no ring or mere traces of one around the apex, opening into two valves by a longitudinal slit. (Pl. 19.)

20. Osmunda. Fertile pinne or fronds very much contracted, bearing the abundant and large sporangis upon the margins of the very narrow segments. Veins free.

\section{Suborder IV. ophioglossacede.}

Sporangia spiked, destitute of a ring, naked, coriaceous and opaque. not reticulated, opening by a transverse slit into two valves, discharging very copious powdery spores. Fronds straight, never rolled up in the bud! (Pl. 19.)

21. Botrychlum. Sporangia in pinnate or compound spikes, distinct. Veins free.

22. Ophlogloss nm. Sporangia cohering in a simple spike. Veins reticulated. 


\section{POLYPÒdIUM, L. Polypody. (PI. 15.)}

Fruit-dots round, naked, arranged on the back of the frond in one or more rows each side of the midrib or central vein, or irregularly scattered, each borne in our species on the end of a fiee veinlet. Rootstocks creeping, branched, often covered with chafiy scales, bearing scattered roundish knobs, to which the stipes are attached by a distinct articulation. (Name from $\pi \circ \lambda \dot{v}$, many, and $\pi$ ouss, foot, alluding to the branching rootstock.)

1. P. vulgàre, L. Fronds evergrcen, oblong, smooth both sides, $4^{\prime}-10^{\prime}$ high, simply and deeply pinuatifid; the divisions linear-oblong, obtuse or somewhat acute, remotely and obscurely toothed; veins once or twice forked; fruit-dots large, midway between the midrib and the maryin. - Rocks: common. July. (Eu.)

2. P. incànum, Swartz. Fronds evergreen and coriaceous, oblong, $2^{\prime}-$ 6' high, grayish and very scurfy underneath with peltate scules, simply pinnatitid; the divisions oblong-linear, obtuse ; fruit-dots rather small, near the margin; veins forking, frege in the N. American plant!-Rocks and trunks of trees, Virginia and Ohio to Illinois, and southward. Aug.

\section{A D I Á N T U M, L. MaInenhair. (Pl. 16.)}

Fruit-dots marginal, short; borne on the under side of a transversely oblong, crescent-shaped or roundish, more or less altered margin or summit of a lobe or tooth of the frond reflexed to form an indusium: the sporangia attached to the approximated tips of the free forking veins. - Main rib (costa) of the pinuules none, or at the lower margin. Stipes black and polished. ('The ancient name,

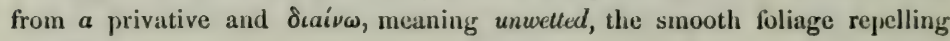
rain-drops.)

1. A. pedatum, L. Frond forked at the summit of the upright slender stalk $\left(9^{\prime}-15^{\prime}\right.$ high $)$, the recurved branches bearing on one side several slender spreading divisions, which bear numerous triangular-oblong and oblique shortstalked pinnules; these are as if halved, being entire on the lower margin, from which the veins all proceed, and cleft and fruit-beitring on the other.-Rich, moist woods. July. - A delicate and most graceful Fern.

\section{PTERIS, L. Brake or Bracken. (PI. 16.)}

Sporangia in a continuous slender line of fructification, occupying the entire margins of the fertile frond, and covered by its reflexel narrow edge, which forms a continuous nembranaceous indusium, attached to an uninterrupted transverse vein-like receptate which connects the tips of the forked and free veins. - Fronds once to thrice pinnate or decompound. (The ancient Greck

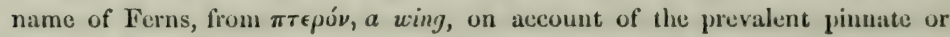
feathery fronds.)

1. P. aquilina, L. (Common Bıаке.) Frond dull green $\left(2^{\circ}-3^{\circ}\right.$ wide), ternate at the summit of an ereet stout stall $\left(1^{\circ}-20\right.$ high $)$, the widely spreading branches twice pinnate; pinnules oblong-lanceolate; the upper undivided; the lower more or less pinuatifid, with oblong obtuse lobes, margined all round with the indusium. - Thickets and hills: common. Aug. (Eu.) 


\section{CHEILÁ N THES, Swartz. Lip-FerN. (PI. 16.)}

Sporangia borne on the thickened ends of free veinlets, forming small and roundish distinct or nearly contiguous marginal fruit-dots, covered by a mostly whitish and membranaceous, sometimes herbaceous, common indusium, formed of the reflexed margin of separate lobes or of the whole pinnulc. - Low, mostly with 2-3-pinnate and hairy or chaffy fronds, the sterile and fertile nearly alike, the divisions not halved, the principal vein central. Some species with continuous indusium connect this genus very closely with the next. (Name com-

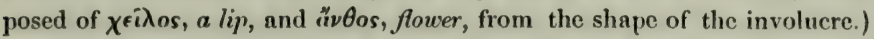

1. C. vestita, Swartz. Fronds $\left(6^{\prime}-15^{\prime}\right.$ high $)$, lanceolate-oblong, hirsute, as are the brown and shining stipes, with straightish prominently articulated rusty hairs, twice pinnate; pinnx rather distant, triangular-ovate; pinnules oblong, crowded (2" -4 " long), more or less incised, the ends of the roundish or oblong lobes refirxed and forming separate herbaceous involucres, which are pushed back by the ripened sporangia. (Nephròdium lanòsum, Michx.!)-Clefts of rocks, Island of New York ( $\boldsymbol{W} . \boldsymbol{W}$. Denslow), and New Jersey to Illinois, and southward.

2. C. tomentòsa, Link. Fronds $\left(12^{\prime}-20^{\prime}\right.$ high) lanceolate-oblong, densely tomentose with slender and entangled whitish obscurely articulated hairs, thrice pinnate; primary and secondary pinna oblong or ovate-oblong; pimules distinct, minute ( $\frac{1}{2} "-1$ " long), roundish-obovate, sessile or adnate-decurrent, the upper surface less woolly, the reflexed narrow margin forming a continuous somewhat membranacenus involucre. - Mountains of Virginia? and Kentucky ; thence westward and southward. - Stipe and rhachis rather stout, brown, covered with narrow chaffy scales and whitish hairs.

3. C. lanugindsa, Nutt. (in herb. IIook. \& Sp. Fil. 1851). Stipes slender, at first hairy, black or brown, shining; fronds $\left(3^{\prime}-6^{\prime}\right.$ high) ovatc-lanceolate, woolly with soft whitish distinctly articulated fattened hairs, becoming smoother above, twice or thrice pinnate; pinnx $\left(5^{\prime \prime}-6^{\prime \prime}\right.$ long) ovate, the lowest distant, the others contiguous; pinnules crenately pinnatifid, or mostly divided into minute and roundish densely crowded segments ( $2^{\prime \prime}-1$ "long), the herbaceous margin recurved forming an almost contimuous involucre. (C. vestita, Hook. C. lanosa, Eaton, Moore, excl. syn. C. gracilis, Mettenius, 1859. Myriópteris gracilis, Fée.) - In dense tufts, on dry rocks and cliffs, Wisconsin (T.J. Hale), Iowa (Vasey), Missouri (Nuttall, Engelmann), thence westward and southward.

\section{PELL㐫A, Link. Cliff-Brake. (Pl. 15.)}

Sporangia in roundish or elongated clusters on the upper part of the free veins, distinct or confluent laterally so as to imitate the marginal continuous line of fructification of Pteris, commonly covered by a broad membranaceous and continuous (rarely interrupted) general indusium, which consists of the reflexed and altered margin of the fertile pinnule or division. Small Ferns, with 13-pinnate fronds, the fertile ones with narrower divisions than the sterile, but otherwise similar. Stipes generally dark-colored, smonth and shining. (Name from $\pi \in \lambda \lambda$ ós, dusky, nlluding to the stipe.)

1. P. gràcilis, Ilook. Fronds smooth $\left(3^{\prime}-6^{\prime}\right.$ high), delicately membranaceous and slender, of few pinnx, the lower ones once or twice pinnately parted 
into $3-5$ decurrent divisions, those of the fertile frond oblong or linear-oblong, entire or sparingly incised; of the sterile ovate or ubovate, crenate or incised; veins of the fertile frouds mostly only once furked. (Pteris gracilis, Mlichx. Allosorus gracilis, Presl, and former ed. - Shaded calcareous rocks, Vermont and Northern and Central New York, to Wisconsin and northward: rare. July. - Rootstock very slender, ereeping : sti $\mathrm{i}_{-}$es polished, brownish, darker and sparingly chatry at the base.

2. P. atropurpùrea, Link. Smooth, except some bristly-chaffy hairs on the midribs and especially on the dark-purple and polished stalk and rhachis, 6' 15' high ; frond coriaceous, pale, once or below twice pinnate; the divisions broadly linear or oblong, or the sterile sometimes oval, chiefly entire, somewhat heartshaped or else truncate at the stalked base; veins about twice forked. (P'teris atropurpurea, $L$. Allosorus atropurpureus, Kunze, and former ed.) - Dry calcareous rocks : not common, but of wide range. July, - Rootstock short aud stout: stipes clustered.

\section{A LLOS S̀ U S, Bernhardi, Link. Rock-Brake.}

Fruit-dots rounlish or elongated and extending far down on the free forking veins. True involucre or indusium none, the herbaceous margins of the fertilo segments at first reflexed and meeting at the midrib, at length opening out flat and exposing the confluent sporangia. - Low, with smooth, 2 -3-piunate fionds, the fertile ones taller than the sterile, and with much nurrower divisions. (Name

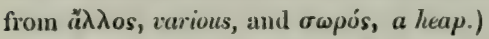

1. A. acrostichoides, Sprengel. Stipes densely tufted, struw-colored; frondy $2-3$-pinnate $\left(6^{\prime}-10^{\prime}\right.$ high $)$; fertile segrnents stalked, lincar or lincaroblong $\left(3^{\prime \prime}-5^{\prime \prime}\right.$ long), the sporangia in lines extending down the veins almost to the inidrib, confluent when ripe and covering the under surface of the now fully opened segments; sterile fronds on much shorter stipes, with ovate or obovate decurrent and crenately toothed or incised segments. (Cryptogrimmo acrostichoides, $R . B r$.) - Isle Royale, Lake Superior, thence westward and northward. - Very near A. crispus of Eu.

\section{W O O D W Á R I A, Smith. Cirain-Fern. (Pl. 16.)}

Fruit-dots oblong or linear, arranged in one or more chain-like rows on transverse anastomosing veinlets parallel and near to the midrib. Indusium fixed by its outer margin to the fruitful veinlet, free and opening on the side next the midrib. Veins more or less reticulated, free towards the margin of the frond. - Large Ferns, with pimnatilid or pinnate fronds. (Naned for Thomas .J. Woodward, an English botanist.)

§1. ANCIISSTEA, Presl. Sterile and fertile fronds alike: veins forminy only one row of meshies (areoles).

1. W. Virgínica, Smith. Fronds $\left(2^{\circ}-3^{\circ}\right.$ high) pinnate, with numerous lanceolate pinnatitid pinna; segments oblong; veins forming a row of narrow areoles along the midrib loth of the pinna and of the lobes, the outer veinlets free; fruit-lots oblong, one to each areole, confluent when ripe. - Wet swanns, Maine to Virginia, and southward. July. 
\$2. LORINSĖRIA, Presl. Sterile and fertile fronds unlike: veins of the steriie fronds forming many roms of meshes.

2. W. angustifolia, Smith. Fronds pimatifid; sterile one's $\left(12^{\prime}-18^{\prime}\right.$ high) with lanceolnte serrulate divisions united hy a broad wing; fertile fromis taller, with narrowly linear almost disconnected divisions, the areoles and fruitdots $\left(4^{\prime \prime}-5^{\prime \prime}\right.$ long) in a single row each sicle of the secondary midribs. (W. onocleoides, Willd. W. areolìta, Moore.)-Bogs, Massachusetts, near the coast, to Virginia, and southward : rare. Aug., Sept.

\section{A SPLENIU M, L. SPLEeNwort. (Pl. 17.)}

Fruit-lots oblong or linear, oblique, separate; the straight, or rarely curred, indusium fixed lengthwise by one edge to the upper (inner) side of the fertile vein:-in some species $\Omega$ part of the fruit-dots are double; the fertile vein bearing two indusia placed back to back. Veins free in all our species. (Named, from $a$ privative and $\sigma \pi \lambda \dot{\eta} \nu$, the spleen, for supposed remedial propertics.)

\$ 1. ASPLENIUM proper. Indusium straight or slightly curved, attached to the upper side of the vein, rarely doulle.

* Indusium Alat, or flattish, thin. (Fronds evergrcen.)

- Fronds pinnately lobed or parted, or simply pinnate.

1. A. pinnatifidum, Nutt. Fronds $\left(3^{\prime}-6^{\prime}\right.$ long $)$ lanceolate, pinnatifid, or pinnate below, tapering above into a slender prolongation, " the apex sometimes rooting." ; lobes roundish-ovate, obtuse, or the lowest pair long-acuminate ; fruit-dots irregular, those next the midrib often double, even the slender prolongation fertile. - Cliffs on the Schuylkill and Wissahickon, near Philadelphia, and southward along the Alleghanies; also sparingly westward: rare. July. - Resembles the Walking-Leaf (Camptosorus), but the veins are free. Stipes brownish, becoming green higher up, and so passing into the broad pale-green midrib.

2. A. ebenoldes, R. R. Scott. Fronds $\left(4^{\prime}-9^{\prime}\right.$ long) broadly lanceolate, pinnatifid, below pinnate, the apex prolonged and slender; divisions lanceolate from a broad base, the lower ones shorter, often proliferous, as is the apex of the frond; fruit-dots much as in the last; stipes black and polished, as is the lower part of the midrib, esperially beneath. - Limestone cliffs on the Schuylkill, near Philadelphia, R. R. Scott, F. Bourguin, \&c.: very scarce, growing with Camptosorus and Asplenium ebencum, of which Rev. M. G. Berkeley (Journ. Royal Horticult. Soc. July, 1866) considers it a probable hybrid.

3. A. Trichómanes, L. Fronds $\left(3^{\prime}-8^{\prime}\right.$ long $)$ in dense spreading tufts, linear in outline, pinnate; pinnce numerous, roundish-oblong or oval ( $3^{\prime \prime}-4^{\prime \prime}$ long), unequal-sided, obliquely wedge-truncate at the base, attached by a narrow point, the midvein forking and evanescent; the thread-like stipe and rhachis purplebrown and shining. (A. melanocaìlon, Willd.) - Sharled eliffs: common. July. (Eu.) A. viride, Huds., occurs in Canada, perhaps in N. New England.

4. A. ebèneum, Ait. Fronds upright $\left(8^{\prime}-16^{\prime}\right.$ high) pinnate, lance-linear in outline ; pinnae $\left(\frac{1}{2}^{\prime}-1^{\prime}\right.$ long) many, lanceolute, or the lower oblong, slightly scytheshaped, finely serrate, sessile, the dilated bnse anrieled on the upper or both sides; fruit-dots numerous on both sides of the elongated midvein; stipe and rhachis blackish-purple and shining. - Rocky, open woods : rather common. 
1- +- Fronds once or twice pinnate: pirna incised.

5. A. montànum, Willd. Fronds $\left(2^{\prime}-5\right)^{\prime}$ high $)$, ovate-lanceolate, pinnate; the ovate pinnce 3-7-prited (or the upper batrely cleft) and cut-toothed; fruit-lots very short, the lasal ones sometimes double. - Cliffs in the Alleghanies, Pennsylvania (Mr. Lea, Prof. Porter), to Virginia and southward. July. - Rhachis green, broad and flat: stipe brown at the base.

6. A. Ruta-murària, L. Fronds $\left(2^{\prime}-4^{\prime}\right.$ long) ovute in outline, 2-3-pinnate below, simply pinnate alove; the few divisions rhombic-wedye-shaped, toothed or incised at the apex; veins forking, diverging from the base; fruit-dots few, clongated, soon confluent. - Limestone eliffs, Vermout to Michigan, Virginia, and southward along the mountains: scarce. July. (Eu.)

* * Indusium slightly curved, strongly convex, thickish: fruit-dots very numerous and crowded. (Fronds tall, simply pinnate, decaying in autumn.)

7. A. angustifòlium, Michx. Fronds $\left(2^{\circ}-3^{\circ}\right.$ high $)$ thin, simply pimate; pinace numerous, short-stalked, linear-lanceolate, acuminate, entire or crenulato $\left(3^{\prime}-4^{\prime}\right.$ long $)$, those of the fertile frond narrower; fruit-dots linear, 20-40 each side the midvein. - Rich woods, W. New England to Wisconsin, and southward along the mountains. Sept.

*** Lower fruit-dots single, those towards the ends of pinna double: indusium straight, slightly convex, thinnish. (Fronds tall and ample, decuying in autumn.)

8. A. thelypteroides, Michx. Fronds $\left(2^{\circ}-3^{\circ}\right.$ high $)$ pinnate; pinuce deeply pinnatifid, linear-lanceolate $\left(3^{\prime}-5^{\prime}\right.$ long $)$; the lobes oblong, obtuse, minutely toothed, crowded, each bearing 3-6 pairs of oblong fruit-dots. - Rich woods : not rare. July - Sept.

§2. ATHÝRIUM, Roth. Indusium dilicate, curved, often crossing the vein, and attached to both sides of it, thus becoming reniform, or shaped like a horseshoe.

9. A. Filix-fóemina, Bernh. Fronds $\left(1^{\circ}-3^{\circ}\right.$ high $)$ ovate-oblong or broadly lanceolate, twice pinnate; pinnæ lanceolate, numerous; pinnules confluent on the secondary rhachis by a narrow margin, oblong and doubly serrate, or elongated and pinnately incised with eut-toothed segments; fruit-dots short, variously curved, at length confluent. (Aspidium Filix-fomina \& A. asplenioides, Swartz.) - A narrow form is Aspidum angústum, Willd. - Moist woods : common, and very variable. July. (Eu.)

\section{SCOLOPE N D I U M, Smith. HarT's-Tongue. (Pl. 17.)}

Fruit-dots linear, elongated, almost at right angles to the midrib, contiguous by twos, one on the upper side of one veinlet, and the next on the lower side of the next superior veinlet, thus appearing to have a double indusium opening along the middle. (The ancient Greek name, so called because the numerous parallel lines of fruit resemble the feet of the centipede, or Scolopendia.)

1. S. vulgàre, Smith. Frond oblong-lanceolate from an auricled-heartshaped base, entire or wavy-margined $\left(7^{\prime}-18^{\prime}\right.$ long, $1^{\prime}-2^{\prime}$ wide), bright green. (S. officinàm, Swartz, a later name.) - Shaded ravines and under limestone cliffs, Chittenango Falls, and near Jamesville, \&c., Onondaga Co., New York, Pursh, W. Cooper, Lewis Fuote, J. A. Paine: also in Canada West. (For a full account of stations, see Sillimun's Journal for May and September, 1866. (Ev.) 


\section{CAMPTOSÒR US, Link. Walking-Leaf. (PI. 17.)}

Fruit-dots oblong or linear, as in $\Lambda$ splenium, but irregularly scattered on either side of the reticulated veins of the simple frond, those next the midrib single, the outer ones inclined to approximate in puirs (so that their two indusin open face to face), or to become confluent at their ends, thus forming crooked lines (whence

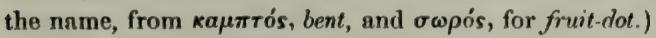

1. C. rhizophýllus, Link. (Asplenium rhizophyllum, L. Antigrámma, J. Smith, Torr. Also C. rumicifolius, Link.) - Shaded caleareous rocks, W. New England to Wisconsin, and southward: rare or local. July. - Fronds evergreen, growing in tufts, spreading or procumbent $\left(4^{\prime}-9^{\prime}\right.$ long), lanceolate from an auricled-heart-shaped or often hastate base, tapering above into a slender prolongation like a runner, which often roots at the apex and gives rise to new fronds, and these in turn to others; hence the popular name. $-\mathbf{A}$ singular form is found at Moint Joy, Penn., by Mr. Stauffer, having roundish fruit-dots and inconspicuous veins.

\section{PHegópteris, Féc. (Sp. of Polypodum, L.) Benen-Fern.}

Fruit-dots small, round, naked (no indusium), borne on the back of the veins below the apex. Stipe continuons with the rootstock. - Our species have free veins and bright-green membranaceous fronds, decaying in early autumn.

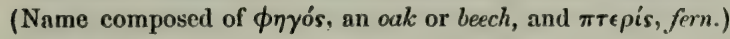

* Fronds twice pinnatifid: pinno all sessile, adnate to the winged rhachis.

1. P. polypodioides, Fée. Fronds triangular, longer than lroad $\left(4^{\prime}-9^{\prime}\right.$ long), hairy on the veins, especially beneath; pinnæe linear-lanceolate, the lowest pair deflexed and standing forwurds; their divisions oblong, obtuse, entire, the hasal ones decurrent and adnate to the main rhachis; fruit-dots all near the margin. (Ph. vulgaris, Mettenius. Polypodium Phegopteris, L., and former ed. P. connéctile, Michx.) - Damp woods: common northward. July.Rootstock slender, creeping, bearing a few distant slender stalks, rather longer than the fronds. (Eu.)

2. P. hexagonóptera, Féc. Fronds triangular, usually broader than long (7'-12' broad), slightly pubescent and often finely glandular beneath; pinna lanccolate; upper segments oblong, obtuse, toothed or entire, those of the very lirge lowest pinnce elonyated and pinnately lobed, basal ones very much decurrent and forming a continuous many-angled wing along the main rhachis; fruit-dots ne:ur the margin; some also between the sinus and the midrib. (Polypodium hexagonopterum, Michx.) - Rather open woods : common, especially southward. July. - Larger and broader than the last, which it often closely resembles.

* Fronds ternate, the three divisions petioled: rhachis wingless.

3. P. Dryópteris, Féc. Fronds smooth, broally triangular $\left(4^{\prime}-6^{\prime}\right.$ wide); the 3 triangular primary divisions widely spreading, 1 -2-pinnate; segments oblong, obtuse, entire or toothed ; fruit-dots near the margin. (Polypodium Dryopteris, L.) - Rocky woods : common northward. July. (Eu.) (ए. CALCAREA, which is more rigid, and minutely glandular-mealy, especially on the rhachis and midrib, is to be sought for northward.) 


\section{ASPÍdIUM, Swartz. Sheld-Fekn. Wood-Fern. (PI. 18.)}

Fruit-dots round, borne on the back or rarcly at the apex of the veins. Indusium covering the sporangia, flat or flattish, scarious, orbicular and peltate at the centre, or round-kidney-shaped and fixed either centrally or by the sinus, opening all round the margin. Stipe continuous (not articulated) with the rootstock. - Our species have free veins, and 1-3-pinnate fronds. (Nanne, aomiócov, a small shield, from the shape of the indusium.)

§ 1. DRYÓP'TERIS, Adauson. (Nephròdium, Rich., in part, Hook. Lástrea, Bory.) Indusium round-kidney-shapal, or orbicular with a narrow sinus.

* Veins simple or simply jorked and straight: fronds arnual, decaying in autumn, the stalks and slender crecping rootstocks nearly naked. ('Thelýpteris, Schott.)

1. A. Thelýpteris, Swartz. Fronds pinnate, lanceolate in outline; pinnæ horizontal or slightly recurved, linear-lanceolate, deeply pinnatifid, the lowest pairs scarcely smaller; lobes oblong, entire, obtuse or appearing acute when in fruit from the strongly revolute margins; veins mostly forked, bearing the (soon confluent) fruit-dots near their middle; indusium minute, smooth and naked. (Polypodium Thelypteris, L.) - Marshes: common. Aug. - Stalk $1^{\circ}$ long or more, usually longer than the frond, which is of thicker texture than the next, and slightly downy. (Eu.)

2. A. Noveboracénse, Swartz. Fronds pinnate, lanceolute in outline, tapering both ways from the middle; pinna lanceolate, the lowest 2 or more pairs gradually shorter and deflexed; lobes that, oblong, basal ones often enlarged and incised; veins simple, or forked in the basal lobes; fruit-dots distinct, near the margin; indusium minute, the margin glanduliferous. (Polypodium Noveboracense, L. A. thelypteroides, Swartz.) - Swamps and inoist thickets : common. July. - Frond pale-green, delicate and membranaceous, hairy beneath along the midribs and veins.

* * Veins, at least the lowest ones, more than once forked or somewhat pinnately branching; the fruit-bearing veinlets ofien obscure or vanishing above the fruitdot: fronds, at least the sterile ones, often remaining green through the winter: stalks and apex of the thickened rootstock scaly or cluffy, and often the main rhachis also.

+ Fronds small, pinnate: pinna pinnatifid: indusia very large, persistent.

3. A. fràgrans, Sivartz. Fronds $\left(4^{\prime}-12^{\prime}\right.$ high) glandular and aromatic, narrowly lanceolate, with linear-oblong pinnately-parted pinnæ; their crowcled divisions (2"long) oblong, obtuse, toothed or nearly entire, nearly covered beneath with the very lage thin imbricated indusia, which are orbicular with a narrow sinus, the margin sparingly glanduliferous and often ragged. - Falls of the St. Croix, Wisconsin, Dr. Purry; Wisconsin River, Lapham, Berlin Falls, N. Hampshire, $\boldsymbol{H}$. W'illey, Mt. Kinco, Maine, C. E. Smith, and northward. Rootstock stout, nearly erect, densely chalfy, as are the crowded stipes and rhachis.

+ + Large $\left(1^{\circ}-22^{\circ}\right.$ high), the fronds mostly twice pinnate with variously toothed and incised pinnules: indusia ruther small, shrivelled in aye, or deciduous.

4. A. spinulosum, Swartz. Stipes with a fiew pale-brown deciduous scales; frond ovate-lanceolate, twice pinnate; pinnce oblique to the rhachis, elongated-triun- 
gular, the lower pairs broadly triangular; pinnules set obliquely on the midribs, connected by a very narrow wing, oblong, acute, incisely serrate or pinnatifid with spinulosely-toothed lobes; indusium smooth and without marginal glands. (A. spinulosum, genuinum, Milde. Lastrea spinulosa, Presl,, Moore.) - In damp woods, Penn Yan, New York, Sartwell; Vermont, Frost; and probably northward. July.- The common European type, rare in North America. (Eu.)

Var. intermedium. Scales of the stipe few, brown with a darker centre; frond broadly oblong-ovate, twice or often thrice pinmate; pinne spreading, oblong-tanceolate, the lower ones unequally triangular-ovate; pinmules erowiled, ovate-oblong, spreading, pinnately divided; the oblong lobes spinulose-toothed at the apex; margin of the indusium denticulate and beset with minv'e stalked glands. (A. intermedium, Willd. Dryopteris intermedia, Ed, 1.) - Woods, everywhere.

Var. dilatatum. Scales of the stipe large, brown with a dark centre; frond broader, ovate or triangulur-ovate in outline, oftenest thrice pinnate; pinnules lanceoblong, the lowest ones often much elongated; indusium (in the North American plant) smooth and naked. (A. dilatatum, Swartz. A. campylópterum, Kunze.) - A dwarf state, fruiting when only $5^{\prime}-8^{\prime}$ high, answers to var. dumetorum. N. New England to Wisconsin, chiefly in mountain woods, and northward. (Eu.)

Var. Bobttii. Scales of the stipe pale-brown; fiond elongated-oblong or elongated-lanceolate in outline; pinnules broally oblong, very ohtuse, the lower pinnatifid, the upper and smaller merely serrate; indusium minuely glandilar. (A. Boottii, Tuckerm. Dryopteris rigida, Ed. 1; not A. rigidum, Swartz.) E, Massachusetts and Connecticut to New York, and northward. - The leust dissceted form, identicul with A. cristatum, var. uliginosum, of Milde, and intermediate in appearance between $\mathbf{A}$. spinulosum and $\mathbf{\Lambda}$. cristatum, but passing into the former,

+ + Large $\left(2^{\circ}-4^{\circ} \mathrm{high}\right)$ : fronds once pinnate, and the pinnoe decply pinnatifid, or nearly twice pinnate: fruit-dots not very near the margin; the indusia large, thinnish and flat, persistent.

5. A. cristatum, Swartz. Frond linear-ablong or lanceolate in outline $\left(1^{\circ}-\right.$ $2^{\circ}$ long) ; pinna short $\left(2^{\prime}-3^{\prime}\right.$ long), triangular-obiong, or the lowest ncarly triangular-ovate, from a somewhat heart-shaped base, acute, decply pinnatifid; the divisions (6-10 pairs) oblong, very obtuse, finely serrate or cut-toothed, the lowest pinnatifid-lobed; fruit-dots as near the midvein as the margin; indusium round-reni-

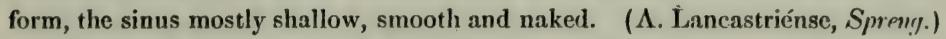
- Swamps, \&c. : common, July. - Stipes and the stout creeping rootstock bearing broad and deciduous chaffy scales. (Eu.)

Var. Clintonianum. Frond in every way much larger $\left(2 \frac{1}{2}^{\circ}-4^{\circ} \mathrm{long}\right)$; pinno oblong-lanceolate, broadest at base $\left(4^{\prime}-6^{\prime}\right.$ long, $1^{\prime}-2^{\prime}$ broad), deeply pinnatifid; the divisions (8-16 pairs) crowded or distant, linear-oblong, obtuse, obscurely serrnte or cut-toothed, the basal ones sometimes pinnately lobed; veins pinnately forking, the lowest anterior veinlets bearing the fruit-dots near the midvein; indusium orbicular with a shallow sinus, smooth and naked. - Swampy woods, New England to New Jersey, New York (G. W. Clinton, \&c.), and westward. July. - Rootstock stout, creeping, chaffy (like the stipes) with large bright-brown scales. $\mathbf{A}$ showy Fern, unlike any European form of A. cristatum, and often mistaken for A. Goldianum. 
6. A. Goldiànum, Ilook. Frond lroudly ovate, or the fertile ovate-oblong in outline ( $2^{\circ}-3^{\circ}$ long); pinme $\left(6^{\prime}-9^{\prime}\right.$ long) oblong-janceolate, broudest in the

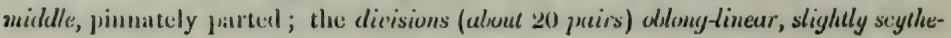
shaped $\left(9^{\prime \prime}-15^{\prime \prime}\right.$ longr), serrate with appressed teeth; veins pinuately forking and bearing the fruit-dots very ncar the midvein; indusium very large, onbicular with a deep narrow sinus, smooth and without marginal glands. - Rich and moist woods, from Connecticut to Kentucky, and northward. July. - A stately Fern, often $4^{\circ}$ high, the fronds growing in a circle from a stout ascending chaffy rootstock, and decaying in autumn. Indusium with the sides of the sinus often overlapping, thus appearing to be round and entire as in Polystichum.

$\leftarrow+++$ Large $\left(1^{\circ}-3^{\circ}\right.$ high $)$ : stipes very chaffy at the base: fronds twice pinnate, but the upper pinnulcs confluent, some of the lower pinnatifid-toothed: fruit-duts rather large: the indusiun convex, without maryinal glunds, persistent.

7. A. Filix-mas, Swartz. Frond lanceolate in outline $\left(1^{\circ}-3^{\circ}\right.$ high $)$; pinnæ linear-lanceolate, tapering from base to alpex; pinnules oblong, very obtuse, serrate at the apex, and ubscurely so at the sides, the basal ones incisely lobed, distinct, the upper confluent; fruit-lots nearer the midvein than the margin, and usually confined to the lower half of cach fertile pinuule. - Rocky woods, Keweenaw Peninsula, Lake Superior, Di. Robbins, and westward. Frond thickish but not surviving the winter. (Eu.)

8. A. marginàle, Swartz. Frond evergreen, sinooth, thickish and almost coriaceous, ovate-oblong in outline $\left(1^{\circ}-2^{\circ}\right.$ long); jinne lanceolate, broadest above the base; pinnules oblong or oblong-scythe-shaped, crowded, obtuse, entire or crenatcly-toothed; fruit-lots close to the margin. - Rocky hillsides in rich woods : common, especially northward. Aug.

§2. P’LYSTICIUM, Roth. (Aspidium, IIork.) Indusium orbiculer and entire, peltute, fixed luy the dcpressed centre: fronds rigid and coriaceous, everyreen, very chaffy on the rhachis, fre: pinme or pinnules auricled at the base on the upper side, crowded, the teeth or lobes bristle-tipped.

\section{* Fronds simply pinnate.}

9. A. acrosticholdes, Swartz. Frond lanceolate $\left(1^{\circ}-22^{\circ}\right.$ high $)$, stalked; pinnce linear-lanceulate, somewhat scythe-shaped, half-halberd-shaped at the slightly stalked base, serrulate with appressed bristly teeth; the fertile (upper) ones contracted and smaller, hearing contignous fruit-lots near the midrib, which are confluent with age, covering the surfice. (Nephrodium acrostichoides, Michx.) - Vau. unciswa (A. Sihweinitzii, Beck) is a stite with cut-lobed pinne, at not unfiequent case in the sterile fromls; sometimes the tips of almost all of then fertile more or less. - Ilillsides and ravines in woods: common northward, and southward along the Alleghanies. July.

10. A. Lonchitis, Swartz. Frond linear-lanceolite $\left(9^{\prime}-20^{\prime}\right.$ high $)$, scarcely stalked, very rigid; pinne lroudliy lanceolate-scythe-shuped, or the lowest triangular, strongly auricled on the upper side and wedge-truncate on the lower, densely spinulose-toothed ( $I^{\prime}$ or less in lang(h), copiously fruit-learing; fruit-dots contignons and near the margins. - Woods, southern dhore of Lake Superior, and northward. (Lu.) 
* Fronds bipinnate.

11. A. aculeatum, Swartz, var. Braunii, Koch. Frond spreading $\left(1 \frac{1}{2}^{\circ}-2^{\circ} \mathrm{long}\right)$, oblong-lanceolate in outline, with a trapering base, tho lower of the many pairs of oblong-lanccolato pinum gradually reduced in size and obtuse ; pinnules orate or oblong, obtuse, truncate and almost rectangular at the base, short-stalked, or the upper confluent, sharply toothed, beset with long and soft as well as chaffy hairs. (A. Braunii, Spenner.)-Deep woods, mountains of New Hampshire, Vermont, N. New York, and nortlıward. (Eu.)

\section{CYSTÓPTERS, Bornhmi. BrAmur-FEr.}

Fruit-dots roundish, borne on the back of a straight fork of the free veins; the delicate indusium hood-like or arched, attached by a broad base on the inner side (towards the midrib) partly under the fruit-dot, early opening free at the other side, which looks toward the apex of the lobe, and is somewhat jagged, soon thrown back or withering away. - Tufted Ferns with slender and delicate

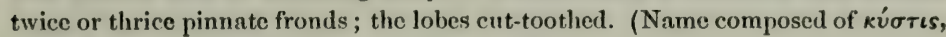
a bladder, and $\pi \tau \epsilon$ is, fern, from the inflated indusium.)

1. C. bulbifera, Bernh. Frond lancelate, elongated $\left(1^{\circ}-2^{\circ}\right.$ long), 2-pinnate; the pinnx lanceolate-oblong, pointed, horizontal $\left(1^{\prime}-2^{\prime}\right.$ long); the rhachis and pinnce oflen bearing bulblets underneath, wingless; pinmules crowded, oblong, obtuse, toothed or pinnatifid; indusium short, truncate on the free side. (Aspidium bulbiferum, Swartz. A. atomàrium, Muhl.!)-Shaded ravines, \&c. : common. July.

2. C. frágilis, Bernh. Frond oblong-lanceolate $\left(t^{\prime}-8^{\prime}\right.$ long, besides the stalk which is fully as long), 2-3-pinnate; the pinnze and pinnules ovate or lancolate in outline, irregularly pinnatifid or cut-toothed, mostly acute, decurrent on the margined or winged rhaclis; indusium tapering or acute at the free end. Var. DenTAta, Hook., is narrower and less divided, barely twice pinnate, with ovate obtuse and bluntly-toothed pinnules. ( $\Lambda$ spidium ténue, Swartz.) - Shaded cliffs: common, and very variable. July. (Eu.)

\section{STRUTHIÓPTERIS, Willd. Ostrici-Fern. (Pl. 15.)}

Fruit-dots round, on the pinne of a separate contracted and rigid frond, the margins of which are rolled backward so as to form a somewhat necklace-shaped or continuous hollow body enclosing the fruit : there are $3-5$ pinnate free veinlets from each primary vein, each bearing a fruit-dot on its middle : fruit-dots crowded and confluent; the sporangia borne on an elevated receptacle which is half-encircled at its base by a very delicate semicircular and ragged evanescent indusium. -Sterile fronds large, very much exceeding the fertile, pinnate, the pinna pinnatifid, all growing in a close circular tuft from thick and sealy matted rootstocks. Stipes stout, angular. P'innate veins free and simple. (Namo compounded of $\sigma \tau p o v \theta$ ós, an ostrich, and $\pi \tau \epsilon \rho i s, ~ a$ fern, from the plume-like arrangement of the divisions of the fertile frond.)

1. S. Germánica, Willd. Sterile fronds smooth, broadly lanceolate, the lowest pinnæ gradually much smaller; pinnæ very numerous, narrowly lanceolate, deeply pinnatifid; the lobes oblong, obtuse: fertile frond with somewhat 
necklace-shaped pinnæ, the lowest ones much smaller. (S. Pennsylvánica, Willd. Onoclea Struthiopteris, L., Hook.) - Alluvial suil ; not rare northward. - Fronds intermediate between the sterile and fertile condition (bearing a fer fruit-dots on contracted, but still herbaccous pinnw) are sometimes found; a condition analogous to the var. obtusiloba of Onoclea sensibilis. (Eu.)

\section{ONOCLEA, L. Sensizive Feren. (Pl. 18.)}

Fertile frond twice pinnate, much contracted ; the pinnules short and revolute, usually so rolled up as to be converted into berry-shaped closed involueres, filled with sporangia, and forming a one-sided spike or racems. Fruit-dots one on the middle of each strong and simple primary vein (with or without sterile crossveins), round, soon all confluent. Indusium very thin, hood-like, lateral, fixed by its lower side, free on the upper (towards the apex of the pinnule). - Sterile fronds rising separately from the naked extensively creeping rootstock, Jongstalked, broadly triangular in outline, deeply pinnatificl in to lance-oblong pinnx, which are entire or wavy-toothed, or the lowest pair sinuate-pinnatifid (decaying in autumn); veins reticulated with fine uneshes. (Name apparently from ô้vos, $a$ vessel, and $\kappa \lambda \epsilon i \omega, 10$ close, from the singularly rolled up fiructification.)

1. O. sensíbilis, I. - Moist or wet places, along streams: common. July. - A rare abnormal state, in which the pinna of some of the sterile fronds, becoming again pinnatifid and more or less contracted, bear some fruit-dots without being much revolute or losing their foliaceous character, is the var. овтusilobata, Torr., N. Y. Slate Fl. (Commecticut, New York, \&c.) This explains the long-lost O. obtusilubata, Schkukr (from Pennsylvania), which, as figured, has the sterile fronds thus 2-pinnately divided. (Ragiopteris, Prest., is founded on a young fertile frond of this species with the sterile frond of some Aspidium.)

\section{WO Ó DSIA, R. Brown. Woodsia. (PI. 18.)}

Fruit-dots round, borne on the back of simply-forked free veins; the very thin and often evanescent indusium attached by its base all around the receptacle, under the sporangia, either small and open, or else early bursting at the top into irregular pieces or lobes. - Small and tufted pinnately-divided Ferns. (Dedicated to Joseph Woods, an English botanist.)

§ 1. HYPOPÉLTIS, Torr. Indusium conspicuous, at first enclosing the sporangia, but early opening at the top, and splitting into scueral spreading jayged labes.

1. W. obtùsa, Torr. Frond broadly lanceolate, minutely glandular-hairy $\left(6^{\prime}-12^{\prime}\right.$ high $)$, pinnate, or nearly twice-pinuate; pinua rather remote, triugular-ovate or ublong ( $1^{\prime}-2^{\prime}$ long), bluntish, pinnately parted; segrments oblong, obtuse, crenately toothed, the lower ones pinnatifid with toothed lobes; vieins forked, and bearing the fruit-lots on or below the minutely toothed lobes. W. Perriniàna, Hook. \& Grev. Aspidium obtusum, Weber \& Mohr., Willd.) - Rocky banks and cliffs: common, esjeccially westward. July.

§2. WOOISSIA proper. Indusium minute or evanescent, open and flat from an early stage, and corcouled under the fruit-dot, its margin cleft into slender hairs or cilia. 
- Stipes obscurely jointed near the base; the withered fronds falling away at the joint: cilia of the indusium lony and inflexed over the sporangia.

2. W. Ilvénsis, R. Brown. Frond oblong-lanccolate $\left(2^{\prime}-6\right.$ ' long by 1 ' wide), smoothish and green above, thickly clothed underneath as well as the stalk with nisly bristle-like chaff, pinnate; the pinne crowiled, oblong, obtuse, sessile, pin nately parted, the numerous crouded segments oblong, obtuse, obscurely crenate, almost coriaceous; the fruit-dots near the margin, somewhat confluent when old. (Nephrodium rufidulum, Michx.)-Exposed rocks: common, especially northward, and southward in the Alleghanies. June. (Etr.)

3. W. glabélla, R. Brown. Smooth and naked throughout; fiond linent $\left(2^{\prime}-5^{\prime}\right.$ high), pinnate; pinno roundish or ovate, the lower ones rather remote, (2" $-4^{\prime \prime}$ long), cut into 3-7 rounded or somewhat wedge-shaped lobes. - Rocks, Little Falls, New York (Vasey); Willoughby Mountain, Vermont (Wood, C. C. Frost); and high northward. (Eu.)

* Stipes not jointed: ciliu of the indusium very short and hidden by the sporangin.

4. W. Oregàna, D. C. Eaton. Smooth; with fronds $\left(2^{\prime}-8^{\prime}\right.$ high, $8^{\prime \prime}-$ $12^{\prime \prime}$ wide) elliptical-lanceolate, pinnate, the fertile ones tallest ; pinna triangularoblong, obtuse, pinnatifid; segments oblong or ovate, obtuse, finely toothed, and in larger fronds incised; fruit-dots near the margin ; indusium very small, divided almost to the centre into a few necklace-like-jointed cilia. - Crevices of rocks, south shore of Lake Superior (Robbins), and westward.

\section{D I K KS ÒN IA, L'Her. Dicksonia. (PI. 17.)}

Fruit-dots small, globular, marginal, each placer on the apex of $a$ free vein or fork; the sporangia borne on an elevated globular receptacle, enclosed in a membranaceous cup-shaped indusium which is open at the top, and on the onter side partly adherent to a reflexed toothlet of the frond. (Named for Jumes Dickson, an English Cryptogamic botanist.)

1. D. punctilóbula, Kunze. Minutcly glandular and hairy $\left(2^{\circ}-3^{\circ}\right.$ high); fronds ovate-lanceolate and pointed in outline, pale green, very thin, with strong chaffless stalks rising from slender cxtensively creeping nakerl rootstocks, mostly bipinnate; primary pinna lanceolate, pointed, the secondary pinnatifid into oblong and obtuse cut-toothed lobes; fruit-dots minute, each on $\mathrm{n}$ recurved toothlet, usually one at the upper margin of each lobe. (I). pilosiúscula, Willd. Nephrodium punctilobulum, Michr. Dennstæeltia, Moore. Sitolobium, J. Smith.) - Moist, rather shady places : very common : pleasantly odorous. July.

\section{SCHIZ开A, Smith. ScHizdA. (Pl. 19.)}

Sporangia large, ovoid, striate-rayed at the apex, opening by a longitudinal cleft, naked, vertically sessile in a double row along the single vein of the narrow dirisions of the pinnate (or radiate) fertile appendages to the slender and simply linear, or (in foreign species) fan-shaped or dichotomously many-cleft fronds (whence the name, from $\sigma \chi i \zeta \omega$, to split).

1. S. pusílla, Pursh. Sterile fronds linear, very sleniler, flattened and tortuous ; the fertile ones equally slender ( $f^{\prime \prime}$ wide), but taller $\left(3^{\prime}-4^{\prime}\right.$ high), and bearing at the top the fertile appendage, consisting of about 5 pairs of crowded 
pinnæ (each $1^{\prime \prime}-1 \frac{1}{2}$ long). - Low grounds, pine barrens of New Jersey : very local. Sept.

\section{LyGòdi I M, Swartz. Climbing Fern. (Pl. 19.)}

Fronds twining or climbing, bearing stalked and variously lobed (or compound) divisions in pairs, with mostly free veins; the fructification on separute contracted divisions or spike-like lobes, one side of which is covered with a double row of imbricated hooded scale-like indusia, fixed by a broad baso to short oblique veinlets. Sporangia much as in Schizea, but oblique, fixed to the veinlet by the inner side next the base, one or rarely two covered by each indusium. (Name from $\lambda v \gamma \omega \dot{\omega} \eta \mathbf{s}$, flexille.)

1. L. palmàtum, Swartz. Very smooth; stalks slender, flexile and twining $\left(1^{\circ}-3^{\circ}\right.$ long), from slender running rootstocks; the short alternate branches or petioles 2 -forked; each fork bearing a round-heart-shaped palmately $4-7$-lobed frondlet; fertile frondlets above, contracted and several times furked, forming a terminal panicle. (Hydroglússum, Willd.) - Shaded or moist grassy.places, Massachusetts to Virginia, Kentucky, and sparingly southward: rare. Sept.

\section{OSM Ú N D A, L. Flowering Fern. (PI. 19.)}

Fertile fronds or fertile portions of the frond very much contracted, and bearing on the margins of the narrow rhachis-like divisions short-pedicelled and naked sporangia : these are globular, thin and retieulated, large, opening by a longitudinal cleft into two valves, and bearing near the apex a few parallel strix, the rudiment of a transverse ring. - Fronds tall and upright, from thickened rootstocks, once or twice pinnate; veins forking and free. Spores green. (Osmunder, a Saxon name of the Celtic divinity, Thor.)

\section{* Fronds twice pinnate, fertile at the top.}

1. O. regàlis, L. (Flowering Fern.) Very smooth, pale green (20 $5^{\circ}$ high); sterile pinnules $13-25$, varying from obloug-oval to lance-oblong, finely serrulate, especially towards the apex, otherwise entire, or crenately lobed towards the rounded, oblique and truncate, or even cordate and semi-auriculate base, sessile or short-stalked $\left(1^{\prime}-2^{\prime}\right.$ long $)$; the fertile racemose-panicled at the summit of the frond. (O. spectábilis, Willd. O. glaueéseens, Link, Mettenius.) - Swamps and wet woods: common. 'The cordate pinnules are commoner in Europe, but are sometimes found here. May, June. (Eu.) .

* * Sterile fronds once pinnate: pinno deeply pinnatifid; the lobes entire.

2. O. Claytoniàna, I. Clothed with loose wool when unfolding, soon perfectly smooth $\left(2^{\circ}-3^{\circ}\right.$ high $)$; pinme oblong-lenceulute, with oblong obtuse divisions; some ( $2-5$ puirs) of the middle pinnce fertile, theso entirely pinnute; sporangia greenish turning brown. (O. interrúpta, Michx., \&c.) - Low grounds : common. May. - Fruiting as it unfolds. - This, being Clayton's plant (as ascertained in 1839, both from the Claytonian and Linnæan herbaria), must hear the original Limman name, though wrongly described from young specinens in which the fructitication was thought to be terminal.

3. O. cinnamomea, L. (Cinnason-Fern.) Clothed with rusty wool when young; sterile fronds smooth when full grown, the lanceolate pinnæ pin- 
natifid into broadly oblong obtuse divisions; fertile fionds separate, from tho same rootstock, contracted, twice pinnate, covered with the cinnamon-colored sporangia. - Var. FrondòsA is a rare occasional state, in which some of the fronds are sterile below and more sparsely fertile at their summit. (O. Claytoniana, Courad, not of $L$. ) - Rarely such fronds are fertile in the middle. Swamps and low copses, everywhere. May. - Growing in large bunches; the fertile fronds in the centre, perfecting fruit as they unfold, $1^{\circ}-2^{\circ}$ long, decaying before the sterile fronds (at length $4^{\circ}-5^{\circ}$ high) get their growth.

\section{BOTRÝ CHIU M, Swartz. Moonwort. (11. 19.)}

Rootstock very short, erect, with clustered fleshy roots (which are full of starch, in very minute, irregular granules!); the base of the naked stalk containing the bud for the next year's frond: frond with an anterior fertile and a posterior sterile segment; the former mostly 1-3-pinnate, the contracted divisions bearing a donble row of sessile naked sporangia; these are distinct, rather coriaccous, not reticulated, globular, without a ring, and open transversely into two valves. Sterile segment of the frond ternately or pinnately divided or compound; veins all free. Spores copious, sulphur-color. (Name a diminutive of Bórpvs, a cluster of grapes, from the appearance of the fructification.)

* Sterile portion of the frond sessile or nearly so on the upper part of the common stalk.

1. B. Lunaria, Swartz. Sterile segment nearly sessile, borne near the middle of the common stalk, oblong, simply pinnate with 5-15 lunate or fan-shaped very obtuse crenate, incised or nearly entire, fleshy divisions, more or lezs ex, ised at the base on the lower or on both sides, the veins radiating from tho base and repeatedly forking; fertile segment panicled, 2-3-pinnate. - Lake Superior (Lnsquereux), and sparingly northward. - Plant $4^{\prime}-10^{\prime}$ high, very fleshy throughout. (Eu.)

2. B. simplex, Hitcheock. Fronds small $\left(2^{\prime}-4^{\prime}\right.$, rarely $5^{\prime}-6^{\prime}$ high), the sterile segment short-petioled from the middle or upper pait of the common stalk, thickish and fleshy, simple and roundish, or pinnately 3-7-lobed; the lobes roundishobovate, nearly entire, decurrent on the broad and flat indeterminate xhachis; the veins all forking from the buse; fertile segment simple or 1-2-pinnate. - Maine to New York, and northward : rare. (Eu.)

3. B. lanceolàtum, Angstrnem. Fronds small $\left(3^{\prime}-8^{\prime}\right.$ high); the sterile seginent closely sessile near the top of the long and slender common stalk, somewhat fleshy, in the smallest ones 3-lobed, in larger ones broadly triangular, ternatrly twice pinnatifid; the divisions lanceolate, incised or toothed; veins forking from a midvein; fertile part 2-3-pinnate. (B. simplex of former ed.) - New England and New Jersey (C.F.Austin) to Ohio and Lake Superior (II. Gillman). July. (Eu.)

4. B. Virginicum, Swart7. Fronds tull and ample; sterile segment sessile above the middle of the common s/alk, broadly triangular, thin and membranaccous, ternate; the short-stalked primary divisions once or twice pinnate, and then once or twice pinnatificl the oblong lobes cut-toothed towards the apex; rrins forking from a midiein; fertile part 2-3-pinnate. - Plant $1^{\circ}-2^{\circ}$ high, or often reduced to a few inches, when it is B. gracile, Pursh. - Rich woods : common. Junc, July. (Eu.) 
* * Sterile portion of the frond long-petioled from near the base of the common stalk.

5. B. lunarioides, Swartz. Sterile portion of the frond petioled from near the base, 2-3-teruate, or the ultimate divisious often pinnate or pinnately parted, broadly triangular in general outline; the lobes or divisions obovate, somewhat kidney-shaped, roundish or oblong, somewhat erenate; fertile stalk $3^{\prime}-6^{\prime}$ high; the fertilo part mostly 2-pinnate. (Bótrypus lunarioides, Michx. Botrychium funtarioides, Willd.) - Dry and rich woods, especially southward. July. - A state from Ilingham, Massachusetts (C. J. Sprajue), has the two lateral primary divisions of the sterile segment changed into loug-stalked fertile fronds.

Var. obliquum (B. oblicquum, MIhl.) is mostly larger $\left(6^{\prime}-17^{\prime}\right.$ high); the fructification more compound; the sterile segment with oblong or lanceolate divisions, either obtuse or oblique at the base, nearly entire, toothed, or irregularly pinnatifid. - New England to Wisconsin, and southward : rather scarce.

Var. disséctum (B. dissectum, MKuhl.) has the divisions of the sterile segment compoundly and laciniately cut into narrow small lobes and teeth: otherwise as the last, into which it passes, and with which it grows.

\section{OPHIOGLÓSSUM, I. Adder's-Tongue.}

Mode of growth much as in Botiychium; but the coriaceous sporangia connate and colierent in two ranks on the edges of a simple spike, which in our species is single and placed on a stalk rising fion tho base of the simple and reticulated-veined sterile segment. Spores copious, sulphur-color. (Name compounded of öфıs, a scrpent, and $\gamma \lambda \hat{\omega} \sigma \sigma a$, tongive.)

1. O. vulgàtum, L. Sterile segment ovate or elliptical-oblong $\left(2^{\prime}-3^{\prime}\right.$ Jong) rather fleshy, ohtuse, narrowed at the base, and sessile near the middle of the stalk of the fertile spike. - Bogs and meatows : not common. July. Stalk $6^{\prime}-12^{\prime}$ high, rising from a short oblique rootstock, the bud not enclosed in the base of the stalk. (Eu.)

\section{Order 131. LYcopodiàce. (Club-Mosg Family.)}

Low plants, usually of Moss-like aspect; with pretly large spore-cases (sporangia or sporocarps) sessile in the axil of simple and sessile, persistent, mostly awl-shaped or lanceolate leaves:- of three genera, including the aquatic and peculiar Isoëtes.

* Turrestrial, with erect or creeping stems : spore-cases free in the axils of the leaves.

1. Lycopodium. Spore cases all of one sort, coriaceous, mostly kiduey-shaped, 2-valved, filled with innumerable minute spores.

2. Seluginella. Spore-cuses of two sorts; one very smull, oblong or globular, 2-valved, filled with innumerable minute spores; the other larger, 3-4-valved, containing 3 or 4 large spores.

* Aquatic, with a corm in place of stem, covered ubove with the dilated bases of the tufted long and rush-like leaves, to which the spore-cases adhere.

3. Isoetes. Spore-cases of two sorts; one contuining uumorous large, the other numerous small spores. 


\section{L Y C O PÒ DI U M, L., Spring. Cuub-Moss. (P1. 20.)}

Spore-cases all of one kind (much like those of Ophioglossum, only larger), coriaceous, flattened, usually kidney-shaped, 1-celled, 2-valved, mostly by a transverse line round the margin, discharging the subtile spores in the form of a copious sulphur-colored inflammable powder. - Perennials, with evergreen onenerved leaves, imbricated or crowded in 4-16 ranks. (Name compounded of $\lambda$ úkos, $a$ wolf, and $\pi$ oús, foot, from no obvious resemblance.)

\$1. Spre-cases in the axils of the ordinary and uniform (dark-green and shining, rigid, lanceolate, sprrading, about 8-ranked) leaves.

1. L. Iucidulum, Michx. Stems thick, 2 or 3 times forked, the branches ascending $\left(6^{\prime}-12^{\prime}\right.$ high $)$; leaves widely spreading or reflexcd, acute, minutely toothed. - Cold, damp woods : common northward. Aug. - Little bulblets form in the axils of the leaves of young shoots (Austin, Rothrock).

2. L. Selàgo, L. Stems thick and rigid, erect, fork-branched, forming a level topped cluster $\left(3^{\prime}-6^{\prime}\right.$ high $)$ : laves pointed, entire. - Tops of high mountains, Maine to New York, on the Alleghanics southward, shore of Lake Superior, and northward: rare: both the variety with more erect, and that with widely spreading leaves. (Eu.)

\$2. Spore-cases only in the axils of the upper (bracteal) leaves, thus forming a spike.

* Leaves of the creeping sterile and of the upright fertile stems or branches, and those of the simple spike all alike, many-ranked (sporangia opening near the base).

3. L. inundatum, I. Dwarf; creeping sterile stems forking, flaccid; the fertile solitary $\left(\mathrm{l}^{\prime}-4^{\prime}\right.$ high), bearing a short thick spike; leaves lunceolate or lance-awl-shaped, acute, soft, spreading, naked, or sometimes bearing a few minute spiny teeth. - Leaves (curving upwards on the prostrate shoots) narrower in the American than in the European plant (perhaps a distinct species), and passing into the var. Bigelòvi, Tuckerm., which has fertile stems $5^{\prime}-7^{\prime}$ high, its leaves more awl-shaped and pointed, sparser and more upright, often somewhat teeth-bearing. (L. Carolinianum, Bigel., not of L.) - Sandy bogs, northward: rare: the var. E. New England to New Jersey and southward. Aug. (Eu.)

4. L. alopecuroides, L. Stems stout, very densely leafy throughout; the sterile branches recurver-procumbent and creeping; the fertile of the same thickness, $6^{\prime}-20^{\prime}$ high ; lenves narrowly linear-awl-shaped, spinulose-pointed, spreading, conspicuously bristle-toothed below the middle; those of the cylindrical spike with long setaceous tips. - Pine-barren swamps, New Jersey to Virginia, and southward. Aug., Sept. - Stems, including the dense leaves, $\frac{1}{2}{ }^{\prime}$ thick; the comose spike, with its longer sprending leaves, 's' to $1^{\prime}$ thick.

* * Leabes (bracts) of the catkin-like spike senle-like, imbricated, yellowish, ovate or heart-shaped, very different from those of the sterile strms and branches.

- Spikes sessile (i. e. branches equally leafiy to the top), single.

5. L. annótinum, L. Much branched; strms mostrate and creeping $\left(1^{\circ}-\right.$ $4^{\circ}$ long) ; the ascending lranches similar $\left(5^{\prime}-8^{\prime}\right.$ high), sparingly forked, the sterile ones making yearly growths from the summit; lenves equal, spreading, in about 5 ranks, rigid, lanceolate, pointed, minutely serrulate (pale green); spike soli- 
tary, oblong-cylindrical, thick. - Var. PúNGENs, Spring, is a reduced sub-alpine or mountain form, with shorter and more rigid-pointel erectish leaves. (Var. montunum, T'uckerm.) - Woods: common northward: the var. on the Whito Mountains, with intermediate forms around the biss. July. (Eu.)

6. L. dendroídeum, Michx. (Ground-Pine.) Stems upright $\left(6^{\prime}-9^{\prime}\right.$ high) from a sulterrancan creeping rootstock, simple below, and clothed with lomogeneous lanceolate-linear acute entire leaves appressed-erect in 4-6 rows, bushly-branched at the summit; the crowded branches spreading, fan-like, with the lower row of leaves shorter and the lateral spreading : - in var. овscùnus ap.pearing flat, from the leaves of the upper side being also shorter and alpressed. (L. obscurum, L.) - Moist woods. Aug. - Remarkable for its tree-like growth. Spike cylindrical, 4-10 on each plant.

+- Spikes peduncled: i. e. the leaves minute on the fertile branches.

+ Leaves homoyeneous and equal, many-ranked; stems terete.

7. L. clavàtum, L. (Cosson Club-Moss.) Stems creeping extensively, with similar ascending short and very leafy branches; the fertile terminated by a slender peduncle $\left(4^{\prime}-6^{\prime}\right.$ long), bearing about $2-3$ (rurely 1 or 4 ) linear-cylindrical spikes; leaves linear-awl-shaped, incurved-spreading (light green), tipped, as also the bracts, with a fine bristle. - Dry woods : common, especially north ward. July. (Eu.)

\section{+ Leaves of two forms, fev-ranked: stems or branches flattened.}

8. L. Carolinianum, L. Sterile stems and their few short branches entirely creeping (leafless and rooting on the under side), thickly clothed with broadly lanceolate acute and somewhat oblique 1-nerved lateral leaves widdy spreading in 2 ranks, and a shorter interinediate row appressed on the upper side; also sending up a slender simple peduncle $\left(2^{\prime}-4^{\prime}\right.$ lighl, clothed merely with small bract-like and appressed awl-shaped leaves), bearing a single cylindrical spikc. Wet pine-barrens, New Jersey to Virginia, ant southward. July.

9. L. complanàtum, L. Stems extensively creeping (often subterranean), the erect or ascending branches several times forled above; bushy branchlets crowded, flattened, all clothed with minute imbricated-appressed awl-shaped leaves in 4 ranks, with decurrent-united bases, the lateral rows with somewhat sprending tooth-like tips, those of the upper and under rows smaller, narrower, wholly appressed; peduncle slender, bearing $2-4$ cylindrical spikes. - Woods and thickets : common : the typical form with spreading fan-like branches, abundant southward ; - while northward, especially far northward, it passes gradually into var. sabinzeròlium (L. salhinafolium, Willd. L. Chamacyparíssus, Braun), with more erect and fascicled branches. (Eu.)

\section{SELAGINÉLLA, Beauv., Spring. (PI. 20.)}

Fructification of two kinds, namely, of spore-cases like those of Lycopodium, but minute and oblong or glolsular, containing reldish or orange-colored powdery spores; and of 3-4-valved tumid larger ones, filled by 3 or 4 (rarely 1 6) inuch larger globosc-anguliar spores (oophoridict); the latter either intermixed with the former in the sume axils, or solitary (and langer) in the lower axils of the leafy 4-ranked sessile spike. (Name a diminutive of Selago, an ancient nane of a Lycopodium, from which this genus is separated.) 
- Laves all alike and uniformly imbricated; those of the spike similar.

1. S. selaginotdes, I Link. Sterile stems prostrate or crecping, small and slender; the fertile thicker, ascending, simple ( $1^{\prime}-3^{\prime}$ high) ; Irares luncolute, acute, sprending, sparsely spindose-riliate. (S. spiniosn, Bemen. S. spinuliosa, Brvenn.) - Wet places, New Hampshire (Pursh), Michigan, Lake Superior, and northward : rare. - Lieaves larger on the fertile stems, yellowish-green. (Eu.)

2. S. rupéstris, Spring. Much lranched in close tuffs $\left(1^{\prime}-3^{\prime}\right.$ high); leaves densely aprressed-imbricated, linentanceslate, convex and with a grooved keel, mimutrly ciliutr, bristle-tipnd; those of the strongly qual-angular spike rather broaler; the two sorts of fructification in the same axils. (Lycoporlium rupestre, L.)-Dry and exposed rocks: very common.-Grayish-green in aspect, resembling a rigid Moss.

* Iates shorter alove and below, resembing slipules: the lateral larger, 2-ranked.

3. S. àpus, Spring. Stems tufted and prostrate, creeping, much branched, flaccid ; leaves pellucid-menbranaccous; the larger spreading horizontally, ovate, oblique, mostly obtuse; the smaller appressed, taper-pointed; those of the short spikes nearly similar; larger spore-cases copious at the lower part of the spike. (Lycopodium ápodum, L.) - Low, shady places : not rare, especially southward. - $\boldsymbol{\Lambda}$ delicate little plant, resembling a Moss or Jungermannia.

\section{ISÒ E ES, L. Quilswort. (Pl. 20.)}

Stem or trunk a fleshy more or less depresser corm, rooting just alove its 2lobed (or in many foreign species 3 -lubed) base, aloove covered with the dilated and imbricated bases of the awl-shaped or linear somewhat quadrangular leaves, which include 4 air-tubes, intercepted by cross partitions. Sporangia, or sporocarps, pretty large, orbicular or ovoid, plano-convex, very thin, sessile in the nxils of the leaves, and united at the back with their excavated bases (the thin edges of the excavation folding round partly cover them, forming the velum), traversed internally by transverse threads; those of the outer leaves filled with large spherical spores (macrospores), their whitish crustaccons integument marked by one circular, and on the npper surfuce by 3 radiating elevated lines (eireumscribing a lower hemisphere, and three upper segments which open valve-like in germination): those of the inner leaves filled with very minute and powilery grayish spores (mecrospores); these are always obliquely oblong and triangular. - Mostly small aquatics, grass-like or rush-like in aspect, some always submerged, others amphibious, a few living in merely moist soil, maturing their fruit in late summer and early autumn, except No. 7, and some forms of No. 6.

Genus much investigated of late by Prof. Durien and the late $J$. Gay of France, and by Prof. Braun of Berlin, newly elaborated for this edition by Dr. Georoe Englemann.

* Growing under water, only acridentally or in very dry seasons out of uater: leaves without stomata (exiept in some forms of No. 3), and without peripherical bastbundles.

1. I. lacústris, I. Leaves $\left(10-25\right.$ in number, $2^{\prime}-6^{\prime}$ long) durk green, rigid; sporocarps ovoinl or cireular, the upper third or less covered by the velum, free part pale and unspotted; both kint of spores the largest of our spe- 
cies; macrospores $\left(0^{\prime \prime} .32-0^{\prime \prime} .38\right.$ wide) covered with short and twisted crested ridges, which often anastomose; microspores $\left(0^{\prime \prime} .017-0^{\prime \prime} .020\right.$ long $)$ smooth. Mountain lakes, P'enn., New York, and New Eugland to Lake Superior, and northward often with No. 3. (Lu.) - The American is distinguished from the European plant by the larger inacrospores, therefore I. macróspora, Durieu.

2. I. Tuckermàni, Brau, n. sp. L.eaves $\left(10-30,2^{\prime}-3^{\prime}\right.$ long) very slender, awl-shaped, olive-green, the outer ones recurved; sporocarps ovoid or circular, the upper third covered by the velum, the free part sometimes brownishspotted; macrospores $\left(0^{\prime \prime} .22-0^{\prime \prime} .28\right.$ wide) on the upper segments covered with parallel and anastomosizing ridges, the lower half reticulated; microspores $\left(0^{\prime \prime} .013-0^{\prime \prime} .015\right.$ long $)$ snooth or very delieately papillose. - Mystic und other ponds near Boston, together with next, Tuckerman, W. Boott.

3. I. echinóspora, Durieu. Leaves slender, awl-shaped; sporocarps ovoid or circular; macrospores $\left(0^{\prime \prime} .20-0^{\prime \prime} .25\right.$ wide) beset all over with small entire and obtuse or slightly forked spinules. (Lu.) - In the European form, which has not yet been found in America, the leaves are very slenderly attenuated $\left(3^{\prime}-4^{\prime}\right.$ long $)$, the upper margin of the sporocarp only is covered with the narrow velum, the free part is unspotted, and the slightly papillose microspores are larger $\left(0^{\prime \prime} .015-0^{\prime \prime} .016\right.$ long). The following are the American forms of this species.

Var. Braunii. Leaves $\left(15-30\right.$ in number, $3^{\prime}-6^{\prime}$ long) dark and often olive-green, straight or commonly recurved, half or two thirds of the sporocurp covered by the velum, the firee part often with light brown spots; macrospores as in the species; microspores smaller $\left(0^{\prime \prime} .013-0^{\prime \prime} .014\right.$ long), smooth (I. Braunii, Durieu.) - P'onds and lakes, New England to New York, Penn., and uorthward, often with the two preceding. - Often with a few stomata, especially in Niagara specimens.

Var. muricàta. Leaves $\left(15-30,6^{\prime}-10^{\prime}\right.$ long $)$ straight or flaccid, bright green ; about one half of the almost circular sporocarp covered by the velum, unspotted ; macrospores $\left(0^{\prime \prime} .22-0^{\prime \prime} .27\right.$ wide) with shorter and blunter spinules; microspores as in the last variety, or rarely spinulose. (I. muricata, Durieu.) In some ponds north of Buston, W. Boott.

Var. Boóttii. Leaves $\left(12-20,4^{\prime}-5^{\prime}\right.$ high) awl-shaped, stiffly erect, bright green, with stomata; sporocarp as in last; macrospores as in the species, but a little smaller and with very slender spinules. (I. Buottii, Braun, in litt.) - Pond in Woburn, near Boston, partly out of water, W. Boott.

* * Groveng parlly out of waier, either by the pond drying up, or by the receding of the ab tide; leuves with stomula, and in 6 and 7 with jour or more peripherical bast-bundles.

4. I. saccharàta, Engelın., n. sp. Leaves (10-15, $2^{\prime}-3^{\prime}$ long) slender, olive-green, curved; sporocarps small, ovoid, only the upper edge covered by the velum, nearly unspotted; macrospores $\left(0^{\prime \prime} .20-0^{\prime \prime} .22\right.$ wille) minutely tuberculate; microspores (0".012 lomg) papillose. - On Wicomico River, castern shoro of Maryland, between high and low tide, $\boldsymbol{W}$. MI. Cunby.

5. I. riparia, Engelm. I Leaves $\left(15-30,4^{\prime}-8^{\prime}\right.$ long) slender, deep green, erect; sporocarps mostly oblong, upper margin to one third covered by the 
velum, the free part spotted; macrospores very variable in sizc $\left(0^{\prime \prime} .22-0^{\prime \prime} .30\right.$ wide), the upper segments covered by short crested ridges, which on the lower hemisphere run together forming n network; microspores larger thsn in nny other species except No. $1\left(0^{\prime \prime} .013-0^{\prime \prime} .016\right.$ long), mostly somewhat fuberenlated.-Gravelly banks of the Delaware, from above Philadelphia to Wilmington, betwcen flood and ebb tide; margins of ponds, New Fngland (Roblins, \&c.), and northward. - Distinguished from the nearly allied I. lacustris by tho stomata of the lenves, the spotted sporocarp, the smaller size of the spores and their reticulation on the lower half.

6. I. Engelmánni, Braun. Leaves long $\left(25-100, \Omega^{\prime}-20^{\prime}\right.$ long $)$, lighlıt green, erect or at last prostrate, flat on the upper side; sporocarps mostly oblong, unspotted, the velum very narrow; macrospores $\left(0^{\prime \prime} .19-0^{\prime \prime} .24\right.$ wide) covered all over with a coarse honcy-comb-like network; microspores $\left(0^{\prime \prime} .012\right.$ 0".014 long) mostly smooth. - Shallow ponds and ditches, froin Massachusetts (near Boston, W. Buott, II. Mann) to Pennsylvania and Delaware and (probably through the Middle States) to Missouri, - By far the largest of our species, often mature in July.

Var. gràcilis. Leaves few (8-12 only, $9^{\prime}-12^{\prime}$ long) and very slender; both kinds of spores nearly as in the species. - Southern New England, apparently in deep water.

Var. válida. Trunk large and stout (often $1^{\prime}-2^{\prime}$ wide); leaves (50-100, even $200,18^{\prime}-25^{\prime}$ long) with an elevated ridge on the upper side; sporocarps oblong or linear-oblong ( $4^{\prime \prime}-9^{\prime \prime}$ long), one third or one half or more covered by the velum; both kinds of spores very small, macrospores $0^{\prime \prime} .16-0^{\prime \prime} .22$ wide, microspores $0^{\prime \prime} .011-0^{\prime \prime} .013$ long, spinulose. - Delaware (W. M. Canby), and Pennsylvania (Prof. Porter). Sept.

7. I. melanópoda, J. Gay. Leaves $\left(15-50,6^{\prime}-10^{\prime}\right.$ long) very slender, keeled on the back, straight, bright green, usually with dark brown or black shining bases; sporocarps mostly oblong, with a very narrow velum, brown or spotted ; macrospores very small $\left(0^{\prime \prime} .14-0^{\prime \prime} .18\right.$ wide), smoothish, or with faint tubercles or ridges; microspores $\left(0^{\prime \prime} .010-0^{\prime \prime} .012\right.$ long) spinulose. - Shallow ponds, and wet prairies and fields, Central and Northern Illinois (E. Hall, Vasey), and westward. June, and sometimes again in Norcmber. - Trunk more spherical and more deeply 2-lobed, and both kind-of spores smaller than in any other of our species; leaves disappearing during the summer heat. Closely approaching the completely terrestrial species of the Mediterranean region.

Two other species, I. FLACcida, Shuttleworth, and I. Criapmani, Engelm., are found in Florida; and three more, I. Nuttalli, Braun, I. Californica, Engelm., and I PYgMis, Engelm., in the Pacific States.

\section{Order 132. IIYDROPTÉLIDES. (Mansiliace e, R. Br.)}

Aquatic cryptogamous plants, of diverse habit, with the fructification borne on submerged branches, consisting of two sorts of organs, contained in irregularly bursting involucres (sporocarps):- here represented by only two genera. 


\section{MARSília, L. MargiLia.}

Submersed or emersed aquatic plunts, with slender ereeping rootstocks, sending up elongated petioles, which bear at their apex a whorl of 4 nervose-veined leaflets, and at or near their base, or sometimes on the routstock, one or moro globular but someivhat ecentric sporocarps. 'These sporocurps or fruit ate 2celled vertically, and with many transverse partitions, and split or burst into 2 lobes at maturitj. On the partitions are inserted numerous short-stalked sporangia, of two sorts intermixed; the larger ones containing a single oval or ob. long spore, the smaller containing many very minute spores. (Named for Aloysius Marsili, an early Italian naturalist, - therefore to be written Marsilia, not Marsilea.)

1. M. quadrifolia, L. Leaflets broadly obovate-cuneate, glabrous; sporocarps usually 2 or 3 on a short peduncle from near the base of the petioles, pedicelled, glabrous or somewhat hairy. - In water, the leaflets commonly tloating on the surface; Bantam Lake, Litehfield, Connecticut, Dr. T. F. Allen. The only known habitat in America. (Eu.)

2. M. uncinàta, Braun., with hairy leaflets, and villous short-stalked or sessile sporocarps, solitary at the base of each petiole, will doubtless be found in the northwestern part of Wisconsin. It has been confounded with the very similar M. vestita, Hook and Grev., of the Southwest.

\section{A ZÓLLA, Lam. Azolla. (Pl. 20.)}

Plant floating free, pinuately branched, clothed with minute imbricated leaves, appearing like a small Jungermannia; fruetification sessile ou the under sido of the branches, of 2 sorts. Sporocarps covered at first with an indusiun of a single diaphanous membrane, ovoid: the smaller kind opening transversely all round, containing several roundish antheridia? peltately attached to the sides of a central erect column : the large or fertile kind bursting irregularly, filled with numerous spherical sporangia rising from the base on slender stalks, each containing a few globular spores. (Name said to come from ä $\zeta \omega$, to diy, and ö $\lambda \lambda \omega$, to kill, being destroyed by dryness.)

1. A. Caroliniàna, Willd. Leaves ovate-oblong, obtuse, spreading, reddish underneath, beset with a few bristles. - Still water, New York to Illinois and southward. Ilant forming little mats on the water, $6 "-12^{\prime \prime}$ broad.

Salvfin natans, T., saicl by Pursh to grow floating on the surface of small lakes in Western Neiv York, has not been found by any other person, and probably does not oceur in this country. It is therefore omitted. 


\title{
A D D E N D A.
}

\author{
JAN U A R X 1868.
}

To page 110.

Rota graviolens, L., Garnen Rue, is naturalized on rocky roadsides, Bedford Co., Virginia, according to $A$. $H$. Curtiss.

To prge 112, 113.

2. Vitis æstivalis, Michx. Original of the Clinton, Norton's Virginia Seedling, and some other wine grapes.

Var. ? cinerea, Engelm. "Branchlets and both sides of the almost entire leaves canescent, even when mature; berries very small, black and shining, very acid until after frost. - Rich bottom lands in the Mississippi Valley, Illinois, and southward." Engelmann.

3. V. cordifolia, Michx., according to Engelmann, " has the small berries black without bloom, the small seeds rounded above and with a prominent rhaphe. Unfit for cultivation."

$3^{\text {a }}$ V. riparia, Michx., Dr. Engelmann concludes should be restored as a species, with the following character. "Leaves larger, usually incisely 3-lobed, the lobes long-pointed; panicles small, rather simple; berrics larger and mostly with bloom ; seeds larger, obtuse or somewhat obcordate and with an inconspicuous rhaphe. - May, earlier than V. cordifolia. Thickets and river-banks, from Vermont to Michigan and Illinois. Several varicties in cultivation : the most esteemed white one is the Taylor-Bullit Grape. The celebrated claret-colored Delaware Grape seems also to belong here." Engelmann.

To page 126, after Genistr.

Cŕtisus (or Sarotukmus) scopdrues, Scotcir Broom, of Europe, which is often planted for ornament, has become naturalizel extensively in Virginia near Washington and southward, according to $\mathcal{A} . H$. Curtiss, so as to deserve a place in this work. May, June.

To page 130.

4. Petalostemon foliosus, Gray, in Proced. Amer. Acad. 7, p. 336. Smooth, very lenfy ; leaflets 16-29, lincar-ohlong, mucronate, the glands few and small; spikes cylindrical, short-peduncled; bracts slender-awned from a lanceolate base, exceeding the rose-purple flowers; calyx also glabrous, the teeth about half the length of the cylindraccous tube. - Banks of Fox River, Kane Co., Illinois, Mr. Burgess Truesdell. Also Nashville, Tenn., Mr. Hatch. "Like the other species pleasantly fragrant." Aug. 
To page 143.

6. Baptisia villosa, Ell. Sometimes soft-hairy, usually minutely pubescent when young, (rect, $2^{\circ}-3^{\circ}$ high, with divergent branches; leaves almost sessile; leaflets welge-lanceolate or obovate ; lower stipules lanceolate and persistent, those of the branchlets often small and subulate; racemes many-flowered; pedicels equalling oi longer than the calyx and the subulate mostly deciduous bracts; corolla yellow ; pods ovoid-oblong and taper-pointed, minutely pubescent. - Franklin, S. Virginia, W. M. Canby, and southward. May.

To page 150, at bottom.

2. Potèrium Sanguisórba, L. Garden Burnet. Stamens 12 or more in the lower flowers of the globular greenish head, with drooping capillary filaments, the upper flowers pistillate only; stems about $1^{\circ}$ high ; leaftets numerous, small, ovate, decply cut. - Fields and rocks, near Baltimore, P. V. Leroy. July. (Adv. from Eu.)

\section{To page 159.}

7. Rosa canina, L. Dog Rose. Resembles Sweet-Brier (No. 5), but more bushy, glabrous or nearly so, and nearly without glands, none on the lower surface of the leaflets, which are therefore inodorous. - Pennsylvania, abundant near Easton, Professors Green and Porter. (Nat. from Eu.)

To page 244.

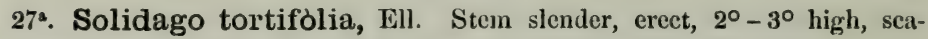
brous-puberulent above, thickly leafy to crowded panicle of racemes; leaves (often twisted at the base) linear, small $\left(\frac{1}{2}^{\prime}-2^{\prime}\right.$ long), sharply serrate with a few scattered small teeth, rough on the margins and midrib beneath, the veins very inconspicuous; heals small; the small rays and the disk-flowers each $3 \mathbf{- 5}$. - Northampton Co., E. shore of Virginia, and southward, W M. Canby. Heads like those of small forms of S. Canadensis : the leuves peculiar.

To page 266 , line 2.

Var. tubulifiórum, S. Tenney, in Amer. Nat. : an abnormal state of the WHTE-WEED, with the rays transformed into large and palmately or bilabiately 5-lobed (rarely 3-4-lobed) tubular corollas. - Fields, Pouglikeepsie, New York, Prof. Tenuey.

To page 292, before Chiogenes.

15. Vaccinium tenéllum, Ait. Between No. 14 and No. 11, taller than the latter $\left(1^{\circ}-3^{\circ}\right.$ high $)$, with firmer and obscurely serrulate leaves, and narrower cylindraceous corolla. - Pine-barren swamps, Franklin, S. Virominia, $\boldsymbol{W} \cdot \boldsymbol{M}$. Canby, and common southwarl. A pril, May.

To page 323 , before Phelipæa.

Orobánche minor, L., Lesser Broom-rape, is parasitic on Clover in the vicinity of Washington $(F . P e c h)$, and has been met with in New Jersey $\left(\boldsymbol{W} . \boldsymbol{M} . \mathrm{Canby}^{\prime}\right.$; but it may not long abide. The genus is known from Phelipar by its calyx of two sepals (either entire or 2-cleft) and no bractlets, the 
style persistent. This species is frot $6^{\prime}$ to $15^{\prime}$ high, light yellowish-brown, with some hluish-purple in the flowers, these in a loose spike from $3^{\prime}$ to $9^{\prime}$ long. (Aelv. from Fu.)

\section{To page 410.}

3. Atriptex kòsed, I. More hoary-mealy than $\Lambda$. patula ; leaves shortpetioled or the upper sessile, rhombic-orate or oblong with a wedge-shaped base, coarsely sinuate-toothed ; fertile flowers mostly clustered in the nxils ; fruiting bracts brond, cut-toothed and warty, united to the midlle, - $\Lambda$ lhany, New York, in streets and wasto pluces, Sept., C. M. Merk, $G . W$. Clinton. (Aiv. from Eu.)

To page 452.

5*. Quercus prinotdes, Willd. (Q. Prints, var. humilis, Marsh.), the Dwarf Cheatnet or Cinnevarin-OnK, is probably a quite distinct species. As noted by Mr. Emerson in Trees of Mass., some of the scales of the cup are apt to produce abortivo little acorns in their axils.

\section{To page 479.}

s. Lemna paucicostàta, Hegelmaier, in litt. "Fronds obliquely obovate ( 1 " $-1 \frac{1}{2}$ " long), thin, mostly grouped $3-5$ together ; fruit and style as in L. perpusilla ; seed marked with $12-14$ prominent (instead of $30-40$ delicate) ribs, between them (in both species) transversely striate. - Ponds, about St. Louis and southward into the tropies : frequently fertile, $\Lambda$ ug. - Oct." Engelmann.

\section{To page 483.}

3. Naias Indica, var. gracíllima, Braun, Mss, "Branches alternate; leaves very narrowly linear, nearly capillary, straight, serrate (with $20-40$ teeth consisting of 3 cells each), the rounded lobes of the sheathing base spinuloseciliate ; fruit linear, brown, impressed-dotted between the numerous (about 24) ribs. - In ponds, Albany, New York, C. H. Peck, Woburn, Massachusetts, $W m$. Boott, 1867, Missouri, Engelmann. - N. minor, not yet found in America, is dichotomous, with recurved leaves, few and stout spikes, and seeds transversely reticulated. $-\mathrm{N}$. flexilis has the leaves minutely serrate with teeth of single cells, their abrupt and rounded sheathing base toothed, the yellowishbrown seeds lance-oval, smooth and shining, \&c." Engelmann.

To page 491.

3. Triglochin triándrum, Michx. Seape anıl leaves slender $\left(6^{\prime}-12^{\prime}\right.$ high) ; flowers very small, with only 3 sepals and 3 stamens (instead of 6 as in the others) ; fruit globose-triangular, or when dry 3-lobed. - Sea-shore of Maryland and Virginia, W. M. Canby, and southward. Ang. - Oct.

\section{To page 499.}

2. Habenaria nivea, Spreng. Stem slender, $1^{\circ}-1 \frac{10}{2}$ high, manyleaved, the 1 or 2 lower leaves lance-linear and $4^{\prime}-8^{\prime}$ long, the others small and bract-like; spike cylindrical, loosely many-flowered ; flowers white, small ; petals and entire lip linear-oblong; spur thread-shaped, ascending, as long as the white ovary. - Pine-barren swamps, S. Delaware, W. M. Canby, and south. ward. Aug. Ovary not twisted: spur therefore looking towards the axis. 
To page.684.

57*. Carex glaucéscens, Ell. Sterile spike single, long-peduncled; fertile spikes $3-10$, cyliudricul $\left(1^{\prime}-2^{\prime}\right.$ longr), on slender drooping peduncles, most of them staminate at the summit; lowest bract usually exceeding the culm, the others shorter and bristle-like; perigynia ovate, compressed-3-angled, abruptly pointed with a short nearly entire beak, nerveless except at the angles, glaucous, longer than the chestnut-colored rough-awned scale ; culms $2^{\circ}-4^{\circ}$ high, above rough on the sharp angles; leaves glaucous, rigid, nearly equalling the culms, tapering gradually into a slender bristle-like apex. - I'ine-barren pouds, from Portsmouth, Virginia ( W. M. Canly) southward.

To page 591.

96. C. nigro-marginàta, Schıv. Culms some very short among the bases of the leaves, some $8^{\prime}-10^{\prime}$ high ; spikes 3 , rarely 4 or 5 , dark purple, the terminal sterile one sometimes inconspicuous annong the fertile, which are crowded into a head, or the lowest occasionally remote and peduncled; bracts scale-like and pointed, or the lowest rarely leafy and equalling or barely exeeding the culm; perigynia nerveless, pulsescent, stipitate, oval and unequally 3 -sided, pointed with an obliquely notched beak; scales ovate, obtuse, cuspidate, the lowest somewhat lanceolate, deep purple with greenish centre, scarcely equalling the perigynium. - Dry hillsides, New Jersey (and Penusylvania ?), C. F. Austin, C. F. Parker, Prof. Porter, C. E. Smith, and southward. Grows in close tufts, and has remarkably rigid long and curved leaves.

To page 615 , after line 25 .

$3^{\mathrm{a}}$. Calamagrostis Lappónica, Trin. Culm and rootstocks stouter than in C. stricta; the narrow panicle less defise, and purplish spikelets larger; glumes fully 2 " long, tapering to a point; awn from unch below the middle of the palet, stout. - Isle Royale, Lake Superior, Prof. T. C. Porter. Aug. (Lu.)

To page 650 , after No. 63.

\section{ROTT B'LÉLIA, L.}

Spikelets in pairs at each joint of a terete slender spike, awnless; one imperfect or rudimentary on a short and thick appressed pedieel; the other sessile and imbedded in an excavation of the joint of the rhachis, 2-flowered. Exterior glume hard and cartilaginous, with a hinge-like transverse depression next the base, the unner one boat-shaped and membranaceous. Palets thin and delicate, one for the lower and staminate or nentral flower, two for the upper and perfect flower. Stancus 3. Styles 2. - 'Tall, or coatse perennials, with rigid stems, and single cartilaginous spikes terminating the stem and axillary branches, chiefly subtropical. (Named for Prof. C. F. Ruttbell, an excellent Danish botanist, who wrote much upon Graminex, Cyperacea, \&c.)

1. R. rugosa, Nutt. Culın flattish, $2^{\circ}-4^{\circ}$ high ; leaves linear; spike.; $1^{\prime}-2^{\prime}$ long, the lateral ones on short elustererl branches in the axils, often partly included in the sheaths of the leaves; sterile flower neutral; lower glume transversely rugose. - Low pine-barrens, from S. Delaware (W. M. Canby) oouthward near the coast. Sept. - Oct. 


\section{N D E X.}

* The names of the Classes, Subclasses, and the Latin names of Orders, are in full capitala ; of the Suborders, Tribes, \&c., in small capitals ; of the Genera, \&c., as well as popular names and synonymes, in common type.

\begin{tabular}{|c|c|c|c|c|c|}
\hline Abele-tree & 467 & Alkanet & 363 & ANDROMFDER & 287 \\
\hline Ables & 471 & Alligator Pear & 422 & Andropogon & 651 \\
\hline A BIETINER & 468 & Allium & 533 & Androsace & 314 \\
\hline Abuttlon & 101 & Allosorus & 660 & A nemone & 36 \\
\hline Acacia & 131,145 & Allspice, Wild & 423 & Angelica & 192 \\
\hline Acalypha & 436 & Almond Family & 146 & Angelica-tree & 199 \\
\hline Acanthus Family & 838 & Alnus & 460 & Angelico & 194 \\
\hline ACA NTIIACE AE & 338 & Aloe & 513 & ANGIOSPERM $\mathbb{E}$ & 33 \\
\hline Acer & 118 & Alopecurus & 608 & Anise Uysaop & 353 \\
\hline Acerates & 397 & Alpine Aralea & 301 & Anisophyllum & 431 \\
\hline AOERINE & 117 & Alpine Bistort & 415 & ANONACEA & 50 \\
\hline Achillea & 285 & Alsine & 91 & Antennatria & 269 \\
\hline Acnida & 413 & ALSINERE & 87 & ANTIIEMIDER & 220 \\
\hline Aconitum (Aconite) & 46 & Alum-root & 169 & A NTHKMIS & 265 \\
\hline Acorus & 478 & Alther & 99 & ANTHOXANTIEE & 606 \\
\hline ACRUGENS & 653 & ALYSSINER & 63 & ANTHOXANTIUUM & $6+3$ \\
\hline Actren & 47 & Alyssum & 72 & Antigramma & 663 \\
\hline Actinella & 263 & Amuranth & 411 & A NTIRIRIINEAS & 324 \\
\hline Actinomeris & 258 & Amaranth Family & 411 & AntiRRHINIDEE & 324 \\
\hline Adaim-and-Eve & 510 & Amarantus & 411 & Antirrhinum & 326 \\
\hline Adam's Neetle & 535 & AMARANTACETE & 411 & Anychia & 96 \\
\hline Adder's-mouth & 509 & Amnrelloides & 387 & A palanthe & 496 \\
\hline Adder's-tongue & 633, 672 & AMARYLLIDACE A & 512 & Aphyllon & 323 \\
\hline Adelia & 402 & Amaryllis & 513 & A petalous Exogenous Pl. & 403 \\
\hline Adenocaulon & 227 & Amaryllis Family & 512 & $\Lambda$ pios & 140 \\
\hline Adenorhachis & 161 & Ambrina & 407 & A plectrum & 510 \\
\hline Adiantum & 658 & Ambrosia & 250 & APOCYNACEA & 392 \\
\hline Adice & 445 & Amelanchier & 162 & A pocynum & 393 \\
\hline Adlumia & 60 & American Aloe & 513 & Apple & 161 \\
\hline Arlonis & 48 & American Centaury & 384 & Apple of Peru & 382 \\
\hline Fschynommene & 134 & American Columbo & 386 & AQEIFOLACEA & 305 \\
\hline Eaculus & 117 & American Cowslip & 314 & Aquifolium & 306 \\
\hline Fthusa & 193 & American Frug's-bit & 495 & Aquilegia & 45 \\
\hline Agathophyton & 408 & American Ipecac & 150 & ARАВIDEN & 63 \\
\hline Agave & 513 & American Ivy & 113 & A rabis & 67 \\
\hline Agrimonia & 151 & Amianthium & ต25 & Arachen & 475 \\
\hline Agrimony & 151 & Ammadenia & 92 & Aralia & 198 \\
\hline Agropyron & 637 & Ammannia & 182 & ARALIACFA & 198 \\
\hline Agrostemma & 90 & Ammophila & 616 & Arbor Vitee & 472 \\
\hline Agrostidea & 603 & Amorpha & 130 & Arnuten: & 287 \\
\hline Agrostis & 611 & Ampelopsis & 113 & Arbutus & 292 \\
\hline Aflanthus & 110 & Amphicarpaca & 141 & A rbutus (Trailling & 293 \\
\hline Aira & 641 & Amphicarpum & 614 & Archangelica & 193 \\
\hline Airopsis & 641 & Amsonia & 393 & Archemora & 192 \\
\hline A JUGOIDER & 342 & AMYGDALEE & 146 & Arctostaphylos & 292 \\
\hline Aliter & 460 & Anacharis & 495 & A renaria & 90 \\
\hline Alder-Buckthorn & 115 & AN ACARDIACEF & 111 & A retlusan & 508 \\
\hline Alchemills & 151 & ANACALIINKS & 313 & A IEVTHUSRE & 497 \\
\hline Aletrig & 516 & Anfugullis & 316 & Argemone & 69 \\
\hline Alisma & 491 & Anantherix & 308 & A risaema & 475 \\
\hline ALISMACEA & 490 & Anchistea & 660 & Aristida & 618 \\
\hline A LISNREA & 490 & Androineda & 295 & A ristolochia & 404 \\
\hline
\end{tabular}




\begin{tabular}{|c|c|c|c|c|c|}
\hline ARISTOLOCHIACEAR & 403 & Basswood & 103 & Bladderwort Family & 317 \\
\hline A rmeria & 312 & Jesturil Pennymyal & $3 \pm 4$ & Blazing -Stur & 223,527 \\
\hline Arnica & 271 & Bastnri T'uad-flax & 425 & Blephilia & 352 \\
\hline Aromatic Wintergreen & $24: 3$ & Batexlendron & 240 & Blessed Thistle & 273 \\
\hline Arrhelatutherum & 642 & Batruchium & 40 & Jlletia & 609 \\
\hline Arrow Arum & 476 & Batschia & 36.3 & Blitum (Blite) & 408 \\
\hline Arrow-Grass & 491 & Bayberry & 457 & IBlool-rout & 60 \\
\hline Arrow-Grass Family & 490 & Beach Pea & 139 & Blondwort Family & 614 \\
\hline Arrow-head & 4923 & Jheak-1Kush & 667 & Blue Beech & 457 \\
\hline Arruir-wool & $204 ;$ & |3-:เแ1 & 140 & IHlueberry & 250 \\
\hline Arteuisiat & 260 & Be:erlwerry & 292 & Bluebottlo & $2 \pi \cdot 3$ \\
\hline AKTUCA KPKAS & $4 ! 1$ & Beard Ciriss & 612,651 & Blue Cohosh & 53 \\
\hline Aruncus & 150 & Bear-Grass & 535 & Blue Curis & 343 \\
\hline Arundinaria & $6: 36$ & lseard-tongue. & $3: 27$ & Blue Flag & 516 \\
\hline Arundo & $6: 36$ & Beaver-Poison & 196 & Blue-IItearts & 333 \\
\hline Asnrum & 403 & Beech & 455 & Bluets & 213 \\
\hline Asarabacca & 403 & Beech-drops & 322 & Blue-eyed Grass & 517 \\
\hline ASCLEPIA DACEA & 394 & Beech-Fern & 663 & Blue Grass & 600 \\
\hline ASCLEPIADE.E & 394 & Beet & 405 & Blue Joint-Gruss & 615 \\
\hline Asclepiias & 394 & Bedstraw & 208 & Blue Lettuce & 281 \\
\hline Ascyrum & 83 & Beggar's Lice & 366 & Blue Tangle & 289 \\
\hline Ash & 401 & Beggar-ticks & 261 & Blue-weed & 361 \\
\hline Ash-leaved Maple & 119 & Belltluiver & 285 & Blysmus & 560 \\
\hline Asimina & 50 & Bellis & 239 & Blyttia & 613 \\
\hline ASPARAGINEE E & $5 \div 1$ & Bellwort & 528 & Buchmeria & 445 \\
\hline Asparagus & $5: 31$ & Bengul Grass & 650 & Bog-Asphodel & 635 \\
\hline Aspen & 466 & Benjamin-Dush & $4: 23$ & Bog-Rush & 537 \\
\hline ASPIDIEA & 657 & Bent-Grass . & 611 & Bultonia & 238 \\
\hline Aspidium & 664 & Henzoin & 423 & Bonamia & 376 \\
\hline AsPLKSIIRAE & 656 & ЗEKISERIDACE玉 & 52 & Buncset & 228 \\
\hline Asplenium & 601 & Berberis & 52 & ВоRRAGEA & 360 \\
\hline Aster & $2 \cdot 28$ & Berchenia & 114 & Borrage Family & 360 \\
\hline Asteranthemum & 530 & Bergamot & 351 & BORRAGINACEF & 360 \\
\hline ASTERINE.E & 218 & Bermuda Grass & 622 & Borrichia & 253 \\
\hline AsTEROIDEA & 218 & Berula & 196 & Bottlebrush-Grass & 639 \\
\hline Astilbe & 167 & Betonica (Betony) & 358 & Bottle-Grass & 650 \\
\hline AstragaLeE & $12 t$ & Betony (Wood) & 337 & Botrychium & 671 \\
\hline Astragalus & 132 & Betula & 458 & Botryois & 407 \\
\hline Atamasco Lily & 513 & BETULACE巴 & 458 & Bouncing Bet & 88 \\
\hline Atheropogon & 621 & Biclens & 261 & Bouteloua & 620 \\
\hline Alhyrium & 662 & Bigelovia & 215 & lkowman's root & 150 \\
\hline Atragene & 35 & Bignonia & 321 & Boxberry & 293 \\
\hline Atriplex & 409 & BIGNONIACEE & 320 & Box-Elder & 115 \\
\hline Aurantiaceæ & 110 & Bignonia Family & 320 & Box Family & 430 \\
\hline A vena & 640 & Bilberry & 289 & Boykinia & 169 \\
\hline AVENEA & 606 & Bilsted & $17 t$ & Brachychæta & 239 \\
\hline Avens & 151 & Bindweed & 375 & Brachyelytrum & 614 \\
\hline Avicularia & 417 & Biotia & 228 & Bracted Bindweed & 375 \\
\hline Awlwort & 73 & Bireh Family & 458 & Brake, Bracken & 658 \\
\hline A wued Wheat-Grass & 618 & Birthront & 523 & Bramble & 156 \\
\hline Azalea & 249 & Birthwort & 404 & Brasenin & 55 \\
\hline \multirow[t]{2}{*}{ Azolla } & 677 & Birthwort Family & 403 & Brasiletto Family & 125 \\
\hline & & Bishop'z-Сap & 170 & Brassica & 70 \\
\hline BACCIARIDEAS - & 219 & Bistorta & 415 & BRASSICB.E & 63 \\
\hline Baccharis & 217 & Bitter-Cress & 66 & Breal-fruit Ramily & 441 \\
\hline Bald Cypress & 473 & Bittersweet & 116,380 & Bristly Foxtail-Grass & 649 \\
\hline Baldwinia & 264 & Bitter-weed & 251 & Briza & 633 \\
\hline Bullota & 359 & Black Alder & 307 & Brizopyrum & $6: 23$ \\
\hline Balm & 350 & Black berry & 157 & Brolne-Grass & 634 \\
\hline Billon of Gilead & 407 & IBlackberry-Lily & 517 & BROM ELIACE. & 515 \\
\hline Balmony & 327 & Black IBindweed & 418 & Brooklime & 332 \\
\hline Balsitun & 109 & Blinck-Gum-tree & 201 & Irocok-weed & 817 \\
\hline Balsaun Family & 106 & Black-Arass & 639 & Broum-Curn & 652 \\
\hline BALSAMIFIUA & 173 & Black IIaw & 206 & Bromu-Crowberry & 440 \\
\hline BALSAMINEAS & 100 & Black Horehound & 360 & Broum-rape & $3: 3$ \\
\hline BAMBUSEA & 605 & Black-Jack & 453 & Bเonn-rape Family & 322 \\
\hline Baneberry & 47 & Black Moss & 515 & Bromus & $6: 34$ \\
\hline Baptisia & 142 & Black-Mlustard & 71 & Brunella & 355 \\
\hline Barbarea & 69 & Black Oat-Grass & 617 & Brunnichia & $4: 22$ \\
\hline Barberry & 52 & Black Sinakeroot & 100 & Buchnera & $3: 33$ \\
\hline Babberry Vauily & 52 & Black Thoru & 148,100 & BUT'UNEKEA & $3: 25$ \\
\hline Burley & 638 & Blanliler-bern & 6417 & Bucklxean & 310 \\
\hline Barny iarl-(jrass & 040 & Blaulder Ketınia & 1022 & Bucklhorn & 114 \\
\hline Barren Struwberry & 1503 & Blatder-1iut & 117 & lBuckthorn Family & 113 \\
\hline Bartouia & 184,389 & Bladter-nut Family & 117 & Buckeye & 117 \\
\hline Basil & 346,349 & Blailder-pod & 73 & Buck wheat & 410 \\
\hline Basil Thyme & 349 & Bladderwort & 318 & Buckw beat Family & 414 \\
\hline
\end{tabular}


INIEX.

\begin{tabular}{|c|c|c|c|c|c|}
\hline Buffalo-berry & 425 & Cancer-root & 22,323 & Chelone & 827 \\
\hline Buffalo-nut & 426 & Cane & 636 & CHKLONEA & 321 \\
\hline Bugbane & 48 & CANNABINESE & 442 & CHLNOPODIACEAE & 403 \\
\hline Bagle-weed & 845 & Canuabis & 446 & Chenoportina & 410 \\
\hline Bugloss & 862 & Caper Funily & 75 & Chenoporlium & 400 \\
\hline Buk-seed & 409 & CAPVAKIDACEF & 75 & Cherry & 147 \\
\hline Buifush & 560 & Cajmaria & 329 & Chervil & 197 \\
\hline Bumelia & 808 & CAITIFOLIACEA & 202 & Chess & 634 \\
\hline Bunch-berry & 200 & Caprifolium & 203 & Chestnut & 451 \\
\hline Bunch-flower & 524 & Capsella & 73 & Cuichoraces & 221,275 \\
\hline Bupleurum & 195 & Carex & 571 & Chick weed & 92 \\
\hline Burdock & 275 & Cardumine & 66 & Chick weed-Wintergreen & 314 \\
\hline Bur-Arass & 650 & Cardinal Flower & 283 & Chimaphila & 303 \\
\hline Burmannia & 496 & Carduus & 274 & CIINCHONER & 208 \\
\hline BLIRMANNIACEAE & 496 & Caricineas & 551 & Chinquapin & 455 \\
\hline Bur-Marigold & 261 & Carnation & 88 & Chiogenes & 292 \\
\hline Burnet & 150 & Carolina Allspice. & 162 & Chionanthus & 401 \\
\hline Burning-bush & 116 & Carpet-weed & 97 & Chives & 534 \\
\hline Bur-reed & 481 & Carpinede & 450 & CHLORIDEA & 604 \\
\hline Bush-clover & 137 & Carpinus & 457 & Choke-berry & 161 \\
\hline Bush-Honeysuckle & 205 & Carrion Flower & 520 & Chondrilla & 279 \\
\hline Butter-and-egg & 826 & Carrot & 191 & Chondrosium & 621 \\
\hline Buttercup & 40 & Carya & 448 & Chrysanthemum & 265 \\
\hline Butterfly-Pea & 141 & CARYOPIIYLLACEE & 87 & Chrysastrum & 239 \\
\hline Butterfly-weed & 397 & Curyophyllata & 152 & Chrysogonum & 248 \\
\hline Butternut & 447 & Cushew Frumily & 111 & Chrysopsis & 246 \\
\hline Butter-weed & $2 \pi 1$ & Cassaudra & 294 & Chrysosplenium & 170 \\
\hline Butterwort & 320 & Cassena & 306 & Cichonacea & 221 \\
\hline Button-bush & 211 & Cassia & 144 & Cichorium & 275 \\
\hline Button Snakeroot & 191,223 & Cassiope & 295 & Cichory & 275 \\
\hline Button-weed & 210 & Castanea & 454 & Cicuta & 196 \\
\hline Buttonwood & 447 & Castilleia & 336 & Cimicifuga & 48 \\
\hline & & Catalpa & 321 & Cinchonea & 208 \\
\hline Cabomba & 55 & Catbrier & 518 & Cinna & 612 \\
\hline Cabomben & 54 & Catchfly & 89 & Cinnamon-Fern & 671 \\
\hline Cacalia & 270 & Catgut & 131 & Cinque-foil & 163 \\
\hline CACTACEA & 184 & Cat-mint & 353 & Circoea & 176 \\
\hline Cactus & 185 & Catnip & 353 & Cirsium & 273 \\
\hline Cactus Family & 184 & Cat-tail Family & 480 & Cissus & 113 \\
\hline Crenotus & 236 & Cat-tail Flag & 480 & CISTACEX & 80 \\
\hline CFSALPINIER & 125 & Cat's-tail Grass & 608 & Citrullus & 186 \\
\hline Cakile & 75 & Caulinia & 483 & Clatium & 570 \\
\hline Cakilinea & 64 & Caulophyllum & 53 & Cladrastis & 143 \\
\hline CAS.AMAGROSTIDËEB & 603 & Ceanothus & 115 & Claytonia & 98 \\
\hline Calamagrostia. & 614 & Cedar & 474 & Clearweed & 445 \\
\hline Calamintha & 849 & Cedronella & 354 & Cleavers & 203 \\
\hline Calaminth & 849 & Celandine & 59 & Clfmatidese & 34 \\
\hline Calamovilifa & 616 & Celandine Poppy & 59 & Clematis & 35 \\
\hline Calamus & 478 & CELASTRACEX & 115 & Clethra & 296 \\
\hline Calico-bush & 298 & Celastrus & 116 & Cliff-brake & 659,660 \\
\hline Calla & 476 & Celtis & 443 & Climbing Fern & 670 \\
\hline Calliastrum & 229 & Cenchrus & 650 & Climbing Fumitory & 60 \\
\hline Callicarpa & 341 & Centaurea & 272 & Climbing Jlemp-weed & 226 \\
\hline Callirrhoë & 100 & Centaurella & 389 & Clinoprodium & 349 \\
\hline CALLITRICHACEA & 427 & Centaury & 385 & Clintouia & $5: 29$ \\
\hline Callitriche & 428 & Centrosema & 141 & Clitoria & 141 \\
\hline Calluna & 297 & Centunculus & 317 & Clotbur & 251 \\
\hline Calomelissa & 349 & Century-plant & 513 & Cloud-berry & 157 \\
\hline Calopogon & 608 & Cephalanthus & 211 & Clover & 126 \\
\hline Caltha & 44 & Cephaloxys & 539 & Club-Moss & 673 \\
\hline CALYCANTHACEA & 162 & Cerastium & 93 & Club-Moss Family & 672 \\
\hline Calycanthus & 162 & Cerasus & 149 & Club-Rush & 560 \\
\hline Culycanthus Family & 162 & Ceratophyllacex & 427 & Cnicus & 272 \\
\hline Calycocarpum & 52 & Ceratoschoenus & 569 & Cnidoscolus & 435 \\
\hline Calypso & 508 & Cercis & 143 & Cocculus & 51 \\
\hline Calystegia & 375 & Chærophyllum & 197 & Cockle & 90 \\
\hline Cainassia & 633 & Chetncyperus & 560 & Cocklebur & 251 \\
\hline Camelina & 73 & Chnffseed & $33 \beta$ & Coffece & 208 \\
\hline CAMELINEA & 63 & Chaffweed & 274 & Cohosh & 53 \\
\hline Camellia & 103 & Chain-Fern & 680 & Colic-root & 515 \\
\hline CAMELLIACER & 103 & Chamalirium & 627 & Collinsia & 327 \\
\hline Campanula & 285 & Chamomile & 265 & Collinsonia & 350 \\
\hline CAMPANULACER & 285 & Charlock & 70 & Colpostium & 010 \\
\hline Campanula Famlly & 285 & Chent-(Iruss & 034 & Coltafout & 227 \\
\hline Campion & .89 & Checkerberry & 293 & Columbine & 45 \\
\hline Cainptosorus & 603 & Cheilanthes & 669 & Columbo & 380 \\
\hline Canary-Grass & 643 & Chelidonium & 59 & Comandra & 425 \\
\hline
\end{tabular}




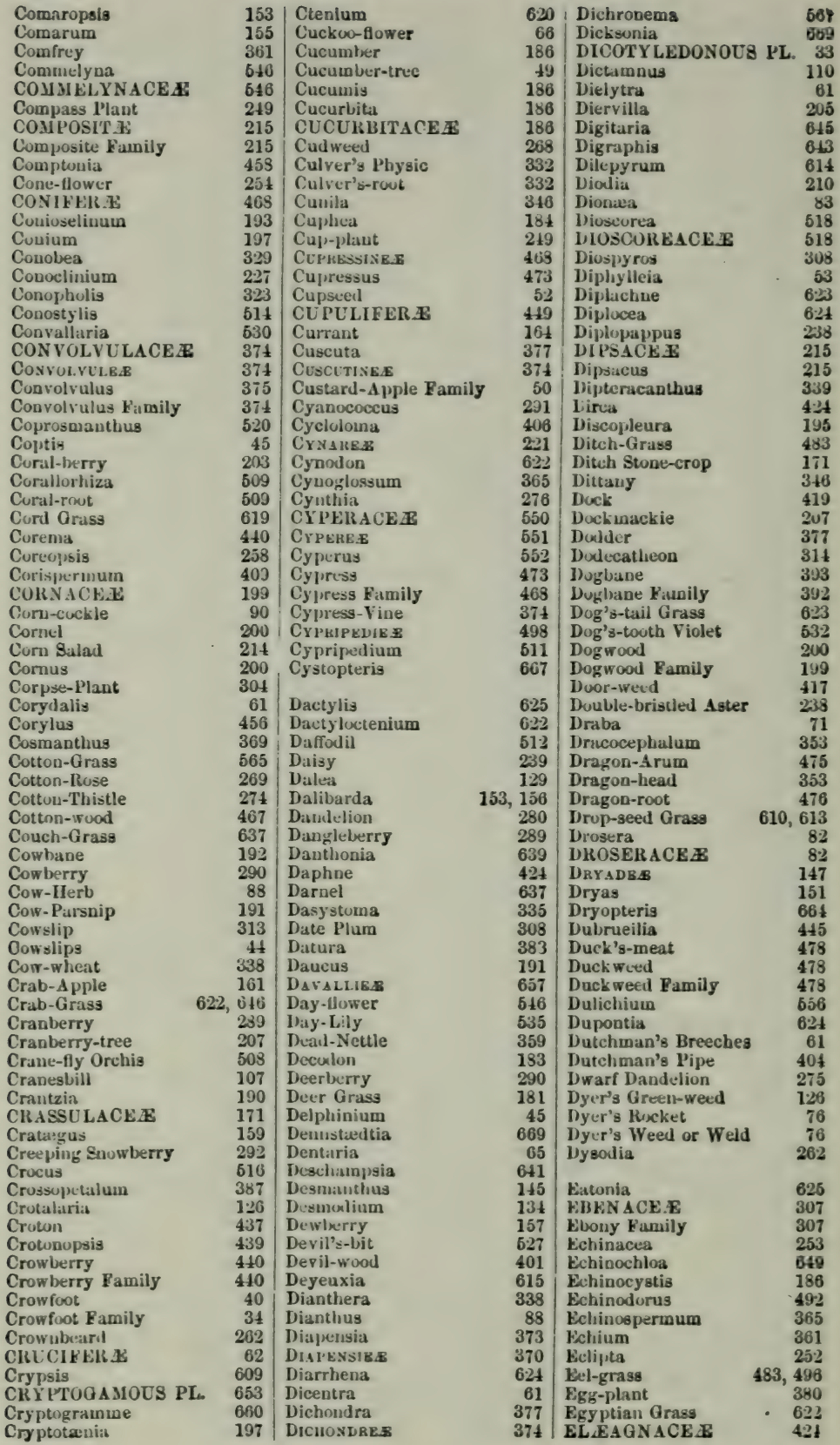




\begin{tabular}{|c|c|c|c|c|c|}
\hline ELongnus & 425 & Pagus & 455 & Fcxtail Grnss & 608,649 \\
\hline WLATINACER & 86 & Fall Danielion & 276 & Fragaria & 155 \\
\hline Blatine & 86 & False $\Lambda$ cacia & 131 & Fraugula & 115 \\
\hline Eluter & 205 & Fulse $\Lambda$ sphodel & b27 & Frasera & 386 \\
\hline Elecumpane & 240 & Fulae Becech-dlops & 305 & FrAXINER & 400 \\
\hline Klevelunris & 667 & Fulse Jughane & 39 & Fraxim.llı & 110 \\
\hline Hleogenus & 568 & False Dandelion & 280 & Fraximus & 401 \\
\hline Elephinatupus & $2 \cdot 2$ & False Dragon-lread & 354 & Frenels Marigolil & 262 \\
\hline Blephant's-foot ‥ & $2: 22$ & Vulse Flax & 73 & French Mulberry & 341 \\
\hline Ellisia & 368 & False Fuxglove & 835 & Fringel Polygala & 122 \\
\hline Elm & 442 & False Goatsbeari & 167 & Fringe-tree & 401 \\
\hline Fim Family & 441 & False Golden-r:d & 239 & Fruelichia & 414 \\
\hline Blodea & 495 & False Grumwell & 362 & Frog's-bit Family & 494 \\
\hline Bloxles & 86 & Falge Ilellebure & 6.25 & Frust-weed & 80 \\
\hline Eleusho & 622 & Frise Ilone ysuckle & 299 & Fuirena & 558 \\
\hline Wly uns & 639 & False Indigo & $130,1+2$ & Fumaria & 62 \\
\hline ЕМРЕТR ACEAE & 440 & False Lettuce & 281 & FUMARIACENG & 60 \\
\hline Empetrum & 440 & False Loosestrife & 180 & Fumitory & 62 \\
\hline ENDOUENOUS PLANTS & 475 & False Mallow & 100 & Fumitory Family & 60 \\
\hline Bnchanter's Nightsharle & 176 & Fulse Mermaid & 108 & & \\
\hline Boemion & 44 & False Mistletue & $4: 26$ & GAI,ACINEA & 305 \\
\hline Engelınannia & 438 & False Mitre-wort & 170 & Galactia & 142 \\
\hline Konslenia & 398 & False Nettle & 445 & Galanthus & 512 \\
\hline Fpigaea . & 293 & False P'impernel & 330 & Galax & 305 \\
\hline Epilobium & 177 & False Recl-top & 629 & Galax Family & 305 \\
\hline Epipactis & 506 & False Solomon's Seal & 530 & Galeghas & 124 \\
\hline Ejiphegus & 322 & False Spikenard & 630 & (Haleopsis & 357 \\
\hline WQUUSETACEA & 653 & False Water-Dropwort & 192 & Galingale & 552 \\
\hline Equisetum & 653 & Farkle-berry & 290 & Galinsoga & 264 \\
\hline Eragrogtis & 631 & Featherfoil & 317 & Gall-of-the-Earth & 278 \\
\hline Erechthites & 269 & Feather Geranium & 407 & Galium & 208 \\
\hline Erianthus & 651 & Feather Gruss & 617 & Gama-Grass & 650 \\
\hline ERICACEAE & 286 & Fedia & 214 & Garden Nasturtium & 105 \\
\hline Erickn & 287 & Ferns & 655 & Garget & 405 \\
\hline Fricinete & 287 & Fescue-Grass & 633 & Garlic & 533 \\
\hline Brigenia & 198 & Festuca & 633 & Gaultheria & 293 \\
\hline Erigeridium & 237 & Festucinea & 604 & Gaura & 176 \\
\hline Wrigeron & 236 & Fetid Horehound & 359 & Gaylussacia & 288 \\
\hline Driogoneas & 414 & Fetid Marigold & 262 & Geiseleria & 438 \\
\hline Eriocaulon & 549 & Fever-bush & 423 & Gelsemium & 391 \\
\hline ERIOCAULONACEA & 549 & Feverfew & 266 & Genista & 126 \\
\hline Briophorum & 665 & Fever-wort & 205 & Genistrax & 123 \\
\hline Brodium & 108 & Fig Family & 441 & Gentian & 387 \\
\hline Èrophila & 72 & Figwort & 326 & Gentiana & 387 \\
\hline Ervum & 139 & Figwort Family & 324 & GENTIANACEX & 384 \\
\hline Eryngium & 190 & Filago & 269 & IANER & 384 \\
\hline Eryngo & 190 & Filbert & 458 & Gentian Family & 384 \\
\hline Erythrea & 385 & FILICES & 655 & GEIR ANIACEX & 105 \\
\hline Wrythronium & 532 & Fimbristylis & 566 & NIERE & 105 \\
\hline Brysinum & 69 & Finger-Urass & 646 & Geranium & 107 \\
\hline KSCALLONIEA & 163 & Fiorin Grass & 612 & Geranium Family & 105 \\
\hline Kubotrys & 294 & Fir & 471 & Gerardia & 334 \\
\hline Bulophus & 198 & Fire-Pink & 89 & Gerardifie & 325 \\
\hline Kuonymus & 116 & Fireweed & 269 & Germander & 343 \\
\hline NUPATORIACE: & 217 & Five-finger & 153 & Geum & 151 \\
\hline butatorien & 218 & Flax & 104 & Giant IIyssop & 352 \\
\hline Eupatorium & 224 & Flax Family & 104 & Gill & 353 \\
\hline Kuphorbia & 430 & Fleabane & 236 & Gillenia & 150 \\
\hline BUPHORBIACE & 430 & Floating Ileart & 390 & Ginseng & 198,199 \\
\hline Euphrasia & 336 & Fluerkea & 108 & Ginseng Fumily & 198 \\
\hline EUPURASIEA & 325 & Flower-de-Luce & 510 & Girasole & 253 \\
\hline Kuphrosyne & 250 & Flowering Fern & 670 & Glade Mallow & 100 \\
\hline Eurhynchospora & 568 & FLOWERING PLANTS & 33 & olus & 516 \\
\hline Wuthamia & 245 & Flowering Wintergreen & 122 & Qlasswort & 409 \\
\hline Sutoca & 369 & FLOW ERLESS PLANTS & IS 653 & Glaucium & 60 \\
\hline Eutriana & 621 & tch Grass & 607 & & 316 \\
\hline Euvaccinium & 290 & Fly-1 & 526 & inma & 353 \\
\hline Euxolus & 412 & arsley & 193 & chia & 145 \\
\hline Svening Primmse & 178 & Foresticra & 402 & Qlobe-flower & 44 \\
\hline Evening l'rimrose Family & 176 & Forestiera. $x$ & 400 & Glyceria & 626 \\
\hline Fverlasting $\quad 268$. & 269 & Forget-me-not & 364 & Glycyrrhiza & 133 \\
\hline Everlasting Pea & 139 & Forked Chickweed & 96 & GNAPIIALINER & 220 \\
\hline Evolvulus & 376 & Forsteronia & 393 & Gnaphalium & 268 \\
\hline FXOGENOUS PLANTS & 83 & Fothergilla & 173 & Quat's-Beard & 150 \\
\hline \multirow[t]{2}{*}{ Eyebright } & 836 & Four-o'clock Family & 404 & Goat's Rue & 131 \\
\hline & & Fowl-meadow Arass & 27,629 & Golden Aster & 216 \\
\hline Dagopyrum & 419 & Foxglove & 335 & Golden-club & 477 \\
\hline
\end{tabular}




\begin{tabular}{|c|c|c|c|c|c|}
\hline Golden-rod & 239 & Hedge Bindweed & 375 & Iorse-Mint & 351 \\
\hline Gulden Saxifrage & 170 & Hedgehog-Grass & 650 & Horse-Nettle & 381 \\
\hline Gold-threiul & 45 & Hedge-IIyssop & 329 & Horseradish & 65 \\
\hline GunULUHEE & 391 & Iledge-Mustitrd & 70 & llorse-Sugar & 310 \\
\hline Gonolubus & 399 & Iledge-Nettle & 358 & Ilorsetail & 653 \\
\hline Good-King-Henry & 408 & HEDYSAKEE & 124 & Ilorsetail Family & 653 \\
\hline Goodyera & 503 & Hedysarum & 134 & IIottonia & 317 \\
\hline Gooseberry & 164 & IELENIEA & $2: 20$ & HUTTONIEA & 313 \\
\hline Goosefout & 406 & Iletenium & 2633 & Ilound'y-Tongue & 365 \\
\hline Choodefout Kamily & 405 & Ilcleochloa & 628 & II uustonia & 212 \\
\hline Unose-Cirass & 208,417 & HELIANTIEEE & 219 & Iluckleberry & 288 \\
\hline Gorilonia & 104 & Heliauthemum & 80 & Iluilsenia & 81 \\
\hline Quourd & 186 & Helianthus & 255 & Il umulus & 446 \\
\hline Giouril Fumily & 186 & IIELIOI'UYTLM & 366 & II untsman's Cup & 68 \\
\hline GRAMINEE & 602 & Ileliopsis & 253 & Ilydraugea & 165 \\
\hline Grape & 112 & II ELLOTKUPLA & 361 & IIYDKANGIEA & 163 \\
\hline Grape-IIyacinth & 534 & Heliotropium (Heliotr & ope) 360 & Ilydrastis & 47 \\
\hline Graphephoruin & $6: 24$ & Hellebore & 45 & IIYIROCHARIDACEX & 494 \\
\hline Qrusy of P'arnassus & 168 & IIelleborus & 45 & Ilydrocharis & 405 \\
\hline Girass of the Audes & 642 & Ilelonias & $5: 36$ & Ifydrocotyle & 189 \\
\hline Gruss-wrack & 483 & IIelosciadium & 190 & Ilydrulea & 870 \\
\hline Gratiola & 329 & IIemerocallis & 635 & III DHOLEA & 367 \\
\hline Gisatioleas & $32 t$ & Ilenianthus & 330 & Ily dropeltis & 65 \\
\hline Great Laurel & 300 & IJemicarpha & 556 & IIYUROPHYLLACEA & 367 \\
\hline Greek Valerian & 371 & Hemluck & 196,197 & II YDHOPHYLLEA & 367 \\
\hline Greenbrier & 518 & Hemlock-Parsley & 193 & Ilydrophyllum & 367 \\
\hline Green Dragon & $4: 26$ & Hemlock Spruce & 471 & HY DRO КTEHIDES & 676 \\
\hline Green Milkweed & 398 & Hemp & 446 & Ilymenopippus & 262 \\
\hline Green Viulet & 76 & IJemp Family & 442 & Ilyoscyanus & 383 \\
\hline Gromwell & 362 & Hemp-Nettle & 357 & HYPEKRICACEAS & 83 \\
\hline Girossularia & 161 & IIenbiane & 383 & Ily pericum & 84 \\
\hline GUSSLII.AHER & 163 & IEpatica & 38 & Hypul,rychia & 182 \\
\hline Grousd Cherry & 381 & Herachum & 191 & Hypopeltis & 668 \\
\hline Ground llemlock & 474 & Ilerb-liolvert & 107 & Ily poisitys & 304 \\
\hline Ground Ivy & $35 i 3$ & II. rcules's Club & 199 & Ilypoxis & 53 \\
\hline Ground Laturel & $29: 3$ & Ileril'y (irass & 608,512 & 11 ysiop & 346 \\
\hline (iroumd-nut & 140. 194 & Ilenpestis & 320 & Нувsория & $3 \pm 0$ \\
\hline Ground P'ine & 674 & Iивитетін & 68 & & \\
\hline Grounl P'ink & 373 & lletirauthera & 545 & Ictudes & 477 \\
\hline Oround Plum & 132 & Il.uchera & 169 & Ilex & 305 \\
\hline Groundsel & 270 & HIBISCER & 49 & ILLECEURKA & 87 \\
\hline Groundsel-Tree & 247 & llibiscus & 102 & llysanthes & 330 \\
\hline Guinea-Corn & 652 & Ilickory & 448 & Impatiens & 108 \\
\hline Gymnaudenia & 499 & Ilieracium & 277 & Inkberry & 307 \\
\hline (iy yonocladus & 144 & Ilighwater-slirub & 250 & Indisn Bean & 321 \\
\hline Cy mnopogon & 621 & Il ierochloa & 642 & Indian Chickweed & 97 \\
\hline GYMNOSPERMEA & 468 & IIPPOCASTANEE & 117 & Indian Cucumber-root & 523 \\
\hline Aymnostichum & 639 & IIippuris & 175 & Indiail Currant & 208 \\
\hline \multirow{3}{*}{ Gyromia } & 438 & Hoary Hea & 131 & Indiau Kig & 185 \\
\hline & \multirow{2}{*}{523} & II sbble-bush & 207 & Indiatu-Griss & 652 \\
\hline & & Ilog Pea-nut & $1+1$ & Indian Ileliotrope & 366 \\
\hline abenaria & 498 & Hog-weed & 251 & Indian Hemp & 393 \\
\hline Ilacklerry & 443 & IIolcus & $6+2$ & Indlan Mallow & 101 \\
\hline Ilackmatack & $47 \cdot 2$ & Ilolly & 305 & Indian Mlillet & 652 \\
\hline HAMUIODORACEF & $51 t$ & IJully Family & 305 & Indian Physic & 150 \\
\hline Itair-Urass $\quad 611$, & 614,641 & Ilolosteum & 93 & Indian Pipe & 304 \\
\hline Iialenia & 386 & Iloly Grass & 642 & Indian-pipe Eamily & 288 \\
\hline IIalesia & 310 & lloney-Locust & 145 & Indian Plantaín & 270 \\
\hline IIA LORAGEAE & $17 t$ & Honeysuckle & 203 & Indian Poke & 525 \\
\hline I A M A MELACEA & 173 & IIoneysuckle Family & 202 & Indian Rice & 608 \\
\hline HАMAMELE,E & 173 & IIonewort & 197 & Indian Tohacco & 283 \\
\hline II amamelis & 173 & IIonkenya & 92 & Indiau Turnip & 475 \\
\hline Hamilteni: & 426 & Hop & 446 & Inula & 240 \\
\hline Harbiuger-of-Spring & 198 & Ilopea & 310 & INUI.K.E & 218 \\
\hline Ilardhack & 149 & IIvp-IIornbeam & 456 & Iodantliug & 68 \\
\hline Ilar bell & 285 & Ilop-tree & 110 & Ipromuea & 375 \\
\hline Hart's-tongue & 662 & Ilordeuna & 638 & Iresine & 413 \\
\hline Hawkbit & 276 & 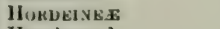 & 605 & IKIIDACEA & 515 \\
\hline Hawkweed & 277 & Horehound & 357 & Iris & 516 \\
\hline Haw thora & 159 & Hornbeam & 457 & Iris Family & 515 \\
\hline llazel-nut & 456 & Ilorned Pondweed & $48: 3$ & Iron-weed & 222 \\
\hline Ileal-all & 355 & Ilırned IRush & 670 & Iron-wood & 457 \\
\hline IIeart's Euse & 79 & Ilorn Popнy & 60 & Isanthus & 344 \\
\hline Heather & 297 & Ilornwort & $4: 27$ & Isoetes & 675 \\
\hline Itath Family & 286 & Ilorse-Balm & 350 & Isolepis & 560 \\
\hline Hedeoma & 350 & IIorsechestnut & 117 & Isopyrum & 44 \\
\hline Hedera & 199 & Horse-Geutian & 205 & Itea & $1 \mathrm{dS}$ \\
\hline
\end{tabular}


INDEX.

\begin{tabular}{|c|c|c|c|c|c|}
\hline Iva & 250 & Leatherwood & 421 & Logania Family & 391 \\
\hline Ivy & 199 & Lesveuworthis & 65 & Loiseleuria & 301 \\
\hline \multirow[t]{2}{*}{ Ixis } & 517 & Lechea & 81 & Lolium & 037 \\
\hline & & Lecontia & 476 & LOMENTACER & 64 \\
\hline Jacob's Ladder & 371 & Ledum & 300 & Long Mloss & 515 \\
\hline Jagged Chickweed & D3 & Leek & 534 & Lonicera & 203 \\
\hline Jamestown-weed & 883 & Leersia & 607 & INONICRHER & 202 \\
\hline Jasminum & 400 & LEGUMINOSE $\boldsymbol{X}$ & 123 & Loosestrife & 183,315 \\
\hline Jatropha & 435 & Leiophyllum & 301 & Loosetrife Family & 182 \\
\hline Jeffersonia & 53 & Lemina & 478 & Lophanthus & 852 \\
\hline Jerusalem Artichoko & 258 & LEMNACEA & 478 & Lophiola & 614 \\
\hline Jerusalem Oak & 407 & LENTIBLLACE $A R$ & 817 & Lopsced & 341 \\
\hline Jerusalem Sage & 360 & Leontodon & 276 & LORANTHACER & 426 \\
\hline Jessamine & 400 & Leonurus & 859 & Lorinserin & 681 \\
\hline Jewel-weed & 108 & Lepachys & 255 & Louservort & 337 \\
\hline Joe-Pye Weed & 225 & LEPIDINEA & 63 & Lovage & 104 \\
\hline Jointed Charlock & 75 & Lepidium & 74 & Lucerne & 128 \\
\hline Joint-Grass & 645 & Lepidanche & 379 & Ludwigia & 180 \\
\hline Joint-weed & 417 & Lepigonum & 95 & Lung wort & 364 \\
\hline Jonquil & 512 & Leptandra & 332 & Lupine & 126 \\
\hline Judas-tree & 143 & Leptanthus & 645 & Lupinus & 126 \\
\hline Juglans & 447 & Leptochloa & 623 & Luzula & 536 \\
\hline JUUGLANDACEA & 447 & Leptopoda & 263 & Lychnis & 90 \\
\hline JUNCACEZZ & 536 & Lepturus & 637 & Lycium & 882 \\
\hline JUNCAGINEA & 490 & Lespedeza & 137 & Lycopersicum & 880 \\
\hline Juscus & 637 & Lettuce & 280 & LYCOPODIACEA & 672 \\
\hline June-berry & 162 & Leucanthemum & 265 & Lycopodium & 673 \\
\hline Juniper & 474 & Leucojum & 512 & Lycopsis & 361 \\
\hline Juniperus & 473 & Leucothoẻ & 294 & Lycopus & 345 \\
\hline \multirow[t]{2}{*}{ Jussizea } & 179 & Lever-wood & 456 & Lygodesmia & 279 \\
\hline & & Liatris & 223 & Lygodium & 670 \\
\hline Kalmia & 297 & LIGULIFI.ORA & 221,275 & Lyonia & 296 \\
\hline Kentucky Blue-Grass & 630 & Ligusticum & 194 & Lysimachin & 815 \\
\hline Kentucky Coffee-tree & 144 & Ligustrum & 400 & LXTIIKACEA & 182 \\
\hline Kidney Bean & 140 & Lilac & 400 & Lythrum & 183 \\
\hline Kinnikinnik & 200 & LILIACEAE & 520 & & \\
\hline Knapweed & 272 & LILIEE & 522 & Madder Family & 208 \\
\hline Knатеl & 96 & Lilium (Lily) & 532 & Macrotys & 48 \\
\hline Knotgrass & 417 & Lily of the Valley & 530 & Magnolia & 49 \\
\hline Knotweed & 414 & LIMNANTHER & 106 & MAGNOLIACEA & 48 \\
\hline Kœleria & 625 & Limuanthes Family & 106 & Magnolia Family & 48 \\
\hline Kosteletzky a & 102 & Limnanthemum & 390 & Maianthemum & 530 \\
\hline Krigia & 275 & Limnetis & 619 & Maidenhair & 658 \\
\hline Kuhnia & 224 & Limnobium & 405 & MALAXIDER & 497 \\
\hline \multirow[t]{2}{*}{ Kyllingia } & 555 & Limnochloa & 557 & Mallow & 99 \\
\hline & & Limosella & 331 & Mallow Family & 98 \\
\hline 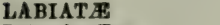 & 341 & LINACE $\overline{A S}$ & 104 & Malus & 161 \\
\hline Labrador Tea & 300 & Linaria & 826 & Malva & 99 \\
\hline Lachnanthes & 514 & Linden & 103 & MALVACEA & 98 \\
\hline Lachnocaulon & 550 & Linden Family & 103 & Malvastrum & 100 \\
\hline Ladetuca & 280 & Lindera & 423 & MALVEB & 99 \\
\hline Lady's Mantle & 151 & Lindernia & 330 & Mandrake & 64 \\
\hline Lady's slipper & 611 & Llnnæa & 202 & Manna-Grass & $62 \theta$ \\
\hline Lady's Thumb & 416 & Linum & 104 & Man-of-the-Barth & 875 \\
\hline Ladies-Tresses & 604 & Lion's-foot & 278 & Daple & 118 \\
\hline Lagenaria & 180 & Liparis & 509 & Maple Family & 117 \\
\hline Lambkill & 298 & Lip-Fern & 659 & Mare's Tail & 175 \\
\hline Lamb-Lettuce & 214 & Lipocarpha & 556 & Mariscus & 455 \\
\hline Lamium & 359 & Lippia & 340 & Marrubium & 857 \\
\hline Lampsana & 275 & Liquidambar & 174 & Marshallia & 264 \\
\hline Lapithea & 385 & Llquorice & 133 & Marsh Elder & 250 \\
\hline Laportea & 445 & Liriodendron & 50 & Marsh-Fleabane & 247 \\
\hline Lappa & 275 & Listera & 506 & Marsh Grass & 619 \\
\hline Larch & 472 & Lithospermum & 362 & Marsh-Mallow & 99 \\
\hline Larix & 472 & Live-for-ever & 172 & Marsh-Marigold & 44 \\
\hline Larkspur & 45 & Liver-leaf & 38 & Marsh-Rosemay & 312 \\
\hline Lastrea & 664 & Lizard's-tail & 427 & Marsh St. John's-wort & $B 8$ \\
\hline Lathyrus & 139 & Lzard'g-tail Family & 427 & Marsilia & 677 \\
\hline LAURACEAR & 422 & LOASACE $F$ & 184 & Marsillaceæ & 676 \\
\hline Laurel & 297 & Loasa Family & 184 & Martynia & 321 \\
\hline Laurel Family & 422 & Lobadium & 112 & Maruta & 264 \\
\hline Laurestinus & 206 & Iobelia & 282 & Marvel of Peru & 401 \\
\hline Lead-Plant & 130 & LOBELIACE $\pi$ & 282 & Masterwort & 191 \\
\hline Leadwort Family & 312 & Lobelia Family & 282 & Matricaria & 266 \\
\hline Leaf-Cup & 247 & Loblolly Bay & 104 & Matrimony-Vine & 382 \\
\hline Leather-Flower & 36 & Locust-tree & 130 & Mayacn & 547 \\
\hline Leather-leaf & 294 & LOGANIACER & 391 & May-Apple & 54 \\
\hline
\end{tabular}


May flower

Mlaypops

MIay-weed

Micadow-Beauty

Dleadow-Grass

Mleadow-l'arsuip

Meadow-liue

Meadow Soft-Grass

Meadow-Sweet

Medeola

Medicago (Medick)

MELAMPODINEA

Melannyrum

MELANTHIEA

MIelanthium

MELASTOMACEA

Melastoma Family

Melica

Melic Grass

Melilutus (Melilot)

Melissa

Melothria

MENISPERMACE里

Meuispermum.

Mentha

Mentzelia

Menyanthes

MEnyanterea

Menziesia

Mermaid-weed

Mertensia

Mexican Poppy

Mlexican Tea

Mezereum Family

Mlicranthemum

Microstylis

Miguonette

Mignonette Family

Mikania

Milfoil

Milium

Milk-Pea

Milkweed

Milkweed Family

Milkwort

Milkwort Family

Milk-Vetch

Millet-Grass

Mimosa Family

Mimosea

Mimulus

Min

Mint Family

Mirabilis

Mist-flower

Mistletoe

Mistletoe Family

Mitchella

Mitella

Mithridate Mustard

Mitreola

Mitrewort

Mitre-wort (Fulac)

Mocatson kluwer

Mlock Bishop-weed

Mocker-nut

Mock-Orange

Modiola

Mahringia

Mcenchia

Mol.luginese

Monarda

MONAKDEA

Muncses

Moneywort

Monkey-flower

Monkshood

\begin{tabular}{|c|c|c|c|c|}
\hline 293 & Monocera & 620 & Nettle-tree & 442 \\
\hline 186 & MONOCOTYLEDONOUS & & New Jersey Tea & 115 \\
\hline 201 & PLANTS & 475 & Nicandia & 382 \\
\hline 181 & Monopetalous Exogenous & & Nicotiuna & 883 \\
\hline $6: 28$ & Plauts & 202 & Niellia & 149 \\
\hline 194 & Monotropa & 304 & Nigella & 48 \\
\hline 38 & MONUTROPEA & 288 & Nightshade & 380 \\
\hline 642 & Montelia & 413 & Nightshade Family & 380 \\
\hline 149 & Moonseed & 51 & Ninble Will & 614 \\
\hline 523 & Moonseed Family & 51 & Nine-Bark & 149 \\
\hline 128 & Moonwort & 671 & Nipple-wort & 275 \\
\hline 219 & Moosewood & $4: 24$ & Nonesuch & 128 \\
\hline 338 & Moose-woud & 119 & Nondo & 191 \\
\hline 521 & MOREA & 441 & Nothoscordum & $53+1$ \\
\hline 524 & Morning-Glory & 375 & Nuphar & $56^{\prime}$ \\
\hline 181 & Morocarpus & 408 & Nut-Grass & 553 \\
\hline 181 & Morus & 444 & Nut-Rush & 570 \\
\hline 626 & Moss Campion & 90 & NYC'PAGINACEAE & $40 t$ \\
\hline 620 & Moss Pink & 373 & Nymplisea & 56 \\
\hline 128 & Motherwort & 359 & NYAIPHEACEA & 61 \\
\hline 350 & Mountain Ash & 161 & Nyssa & 201 \\
\hline 187 & Mountain Ilolly & 307 & & \\
\hline 51 & Mountain Mint & 346 & Oak & 450 \\
\hline 51 & Mountain Rice & 616 & Oakesia & 440 \\
\hline 344 & Mountain Sorrel & 419 & Oak Family & 449 \\
\hline 184 & Mouse-ear & 364 & Oat & 640 \\
\hline 390 & Mouse-ear Chiçkweed & 93 & Out-Grass & 612 \\
\hline 381 & Mouse-ear Cress & 70 & Obeliscaria & 255 \\
\hline 298 & Mouse-tail & 44 & Obolaria & 389 \\
\hline 175 & Mud-Plantain & 545 & Énothera & 178 \\
\hline 363 & Mudwort & 331 & Oil-nut & 420 \\
\hline 59 & Mugwort & 267 & Olil Witch Grass & 647 \\
\hline 408 & Muhlenbergia & 613 & Olilendandia & 211 \\
\hline 424 & Mulberry & 444 & Olea & 401 \\
\hline 330 & Mulgedium & 281 & OLEACEA & 400 \\
\hline 509 & Mullein & 325 & Oleander & $39 \cdot 2$ \\
\hline 76 & Mullein-Foxglove & 334 & Oleuster Family & 424 \\
\hline 76 & Mullugo & 97 & OLEINEA & 400 \\
\hline 226 & Muscari & 634 & Olive & 401 \\
\hline 265 & Muskit Grass & 620 & Olive Family & 400 \\
\hline 643 & Muskmelon & 186 & ONAGRACEAS & 176 \\
\hline 142 & Mlusk-Plant & 329 & Oncostylis & 567 \\
\hline 394 & Musquash-Root & 106 & Onion & 533 \\
\hline 394 & Mustard & 62 & Onoclea & 608 \\
\hline 120 & Mustard Family & 62 & Onopordon & 274 \\
\hline 120 & Myosotis & 364 & Onosinodium & 362 \\
\hline 132 & Myosurus & 44 & OPHIOGLOSSAOER & 657 \\
\hline 643 & Myrica & 457 & Ophioglossum & 672 \\
\hline 125 & MYRICACEA & 457 & OPHRYDEA & 497 \\
\hline 125 & Myriophyllum. & 174 & Oplotheca & 414 \\
\hline 328 & & & Opuntia & 185 \\
\hline 344 & Nabalus & 278 & Orache & 409 \\
\hline 341 & NAIADACEAE & 482 & Orange Family & 110 \\
\hline 404 & Naias (Naiad) & 482 & Orange-Qrass & 86 \\
\hline 227 & Naked-beard Graas & 621 & Orange-root & 47 \\
\hline 426 & Naked Brocnn-rape & 323 & Orchard Grass & 625 \\
\hline 426 & Napaa & 100 & ORCHIDACEA & 497 \\
\hline 211 & Narcissus & 512 & Orchis & 498 \\
\hline 169 & Nardosmia & 227 & Orchis Fumily & 497 \\
\hline 74 & Narthecium & 635 & Origanum & 348 \\
\hline 392 & Nasturtium & 64 & Oritrophium & 235 \\
\hline 392 & Naumburgia & 315 & Ornithogaluan & 533 \\
\hline 170 & Neckweed & 333 & ()ROBAN UIIACEA & 322 \\
\hline 611 & Negumblo & 118 & Orobanche & 323 \\
\hline 195 & Nelumbium & 65 & Orontium & 477 \\
\hline 449 & Nelumbo & 55 & Orpine & 172 \\
\hline 166 & Nelumbo Family & 55 & Orpiue Fanily & 171 \\
\hline 101 & NeLUMBUNEA & 55 & Orthomeris & 235 \\
\hline 91 & Nemopanthes & 307 & ORYZE.E & 603 \\
\hline 94 & Nemophila & 368 & Oryzopsis & 616 \\
\hline 88 & Neotties & 497 & Osier & 461 \\
\hline 351 & Nepeta & 353 & Osmorrhiza & 197 \\
\hline 342 & NEPKTE $N$ & 342 & OSMUNDACEA & 657 \\
\hline 303 & Nephrodium & 664 & Osmunda & 670 \\
\hline 316 & Nesæa & 183 & Ostrich-Fern & 667 \\
\hline 328 & Nettle & 444 & Ostrya & 456 \\
\hline 46 & Nettle Family & 440 & Озwego Tea & 851 \\
\hline
\end{tabular}


INDEX,

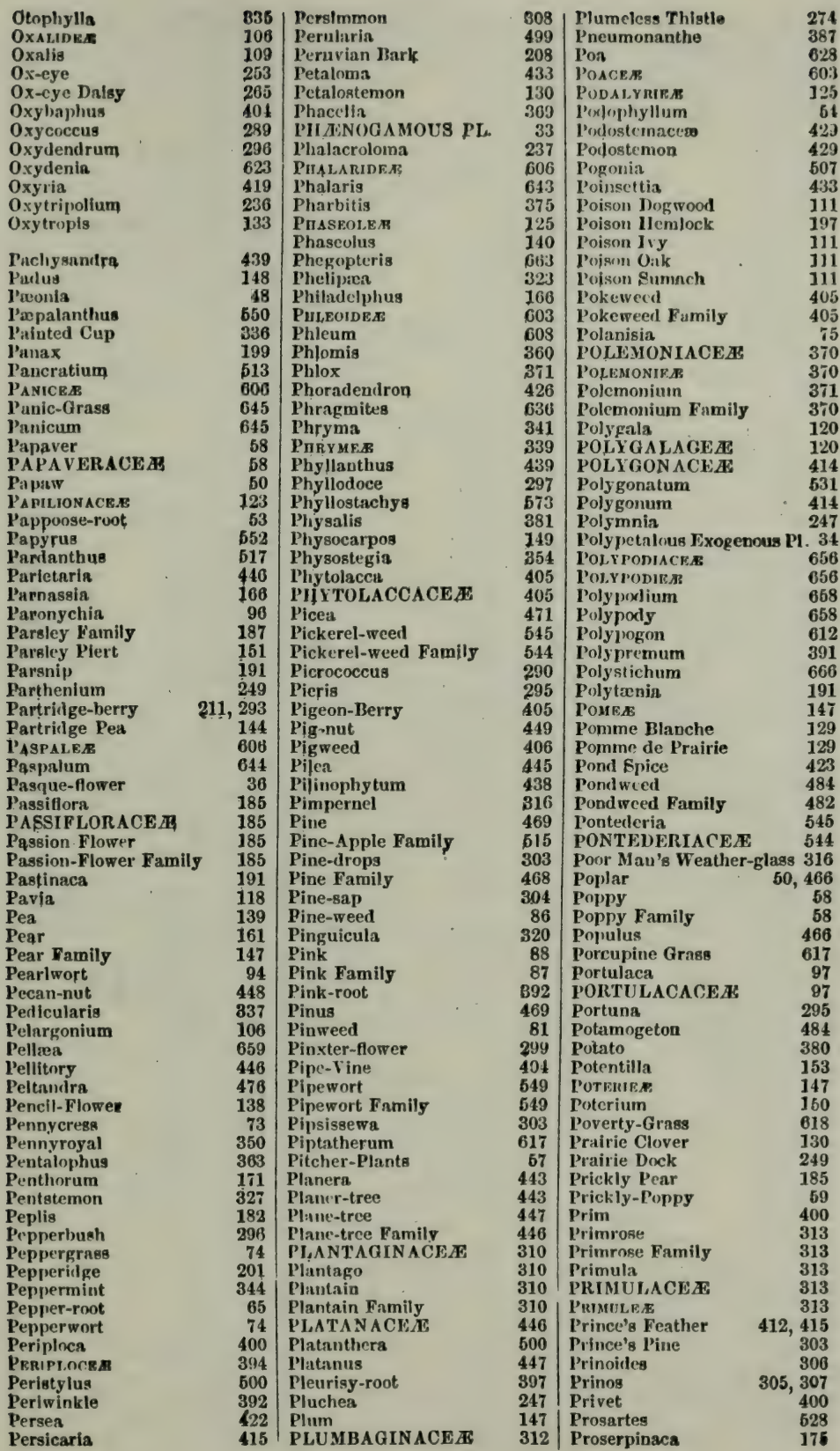




\begin{tabular}{|c|c|c|c|c|c|}
\hline Prunus & 147 & Rhinanthided & 321 & Sand-Myrtle & 301 \\
\hline P'seudu-Polygonella & 417 & Rhinanthus & 337 & Sand-Spurrey & \\
\hline Poilocarya & 568 & Rhodolendron & 299 & Sandwort & \\
\hline Psoralea & 128 & lihodora & 300 & Sanguinaria & \\
\hline J'SOHALIEAE & 124 & RHODOREA & 287 & Sauguisurba & \\
\hline Psyllophora & 573 & Rhubarb & 414 & Sauicle & \\
\hline P'telea & 110 & Rhus & 111 & Situicula & 19 \\
\hline PTEISIDEA & 656 & Rhynchosia & 142 & SAN'TALACEA & \\
\hline Pteris & 658 & Rhyuchuspora & 567 & SAPINDACEA & 16,11 \\
\hline P'terospora & 303 & RIIYNCUOSPOREAE & 651 & Sitponaria & \\
\hline l'uccoon & 362 & Ribes & 164 & SAPUTACEA & \\
\hline P'ulmonaria & 364 & Rilesia & 165 & Sappodilla Eamily & 30 \\
\hline l'ulsatilla & 36 & Rilygrass & 310 & Sarothra & \\
\hline l'ulse kamily & 123 & hice Cut-Grass & 607 & Sarracenia & \\
\hline P'umpkin & 186 & Rich-weed & 350,445 & SARRACENIACEAS & \\
\hline Yurple Cone-flower & 253 & Ripplegrass & 311 & Sarsaparilla 198 & 98,19 \\
\hline Purstane & 97 & River-weed & 429 & Sassafras & 43 \\
\hline Purslaue Fumily & 97 & River-weed Family & 429 & Satureia & 34 \\
\hline Putty-root & 510 & Robinia & 130 & SATUREIEE & 312 \\
\hline Pycuanthemum & 316 & liock.Cress & 67 & SAURURACEA & 427 \\
\hline Pycreus & $55 \div$ & Inock-1Rose & 80 & Saururus & 427 \\
\hline Pyrola & 301 & Rock-Rose Family & 80 & Saviu & 473 \\
\hline Pykolea (Pyrola Family) & 288 & Roman Wormwood & 251 & Savory & 349 \\
\hline Pyrrtsopappus & $2 S 0$ & Rugi (loose) & 158 & Saxifraga & $1+7$ \\
\hline Pyrularia & $4: 6$ & ROSEX & 147 & SAXIERAGACEZE & 163 \\
\hline Pyrus & 161 & JROSACEA & 116 & Saxifrage & 167 \\
\hline \multirow[t]{2}{*}{ Pyxidanthera } & 373 & Rose-Acacia & 131 & SAXIFRAGEX & 163 \\
\hline & & Buse-13ay & 299 & Saxifrage baunily & 163 \\
\hline Quaking-Gruss & $6 i 33$ & Ruse Family & 146 & Stabious & 215 \\
\hline Unamuash & $5: 3: 3$ & Rose-Mallow & 102 & Scherlonorus & $6: 13$ \\
\hline Qumunoclit & 374 & Rosceruot & 172 & Scheuchzeria & 491 \\
\hline Queen of the P'rairie & 149 & Rosiu-Plant & 248 & Schizaca & 669 \\
\hline QUEBCINEAB & 450 & Rosin-weed & 249 & SCHIZAACEAS & 657 \\
\hline Quercitron & $45 t$ & Roubieva & 408 & Schollera & 545 \\
\hline Quercus & 450 & Kowan Tree & 162 & Schrankia & 145 \\
\hline Queria & 96 & Rewhe & 147 & Schwalbea & 336 \\
\hline Quick - or Quitch-Grass & 637 & RUBIACEA & 208 & Schweinitzia & 304 \\
\hline \multirow[t]{2}{*}{ Quiliwort } & 675 & Rubus & 156 & Scilla & 533 \\
\hline & & liudbeckia & 251 & SCIRPEA & 651 \\
\hline Rarlish & 75 & Rue & 110 & SCIRPINEA & 551 \\
\hline Rugiopteris & 668 & Rue-Anemone & 38 & Scirpus & 560 \\
\hline Ragweed & 250 & Ruellia & 339 & Scleranthus & 96 \\
\hline Magwort & 271 & liumex & 419 & Scleria & 570 \\
\hline Rani's-head & 511 & Ruppia & 483 & SCLERINEA & 551 \\
\hline Ramsted & 326 & Rush & 637 & Selerochloa & 638 \\
\hline 11 A N UNCULACE $Z$ E & 34 & Rush Family & 536 & Sclerolepis & 222 \\
\hline RANUNCULEAE & 34 & Rush-Grass & 609 & Siuke & 405 \\
\hline Ranunculus & 40 & Ruta & 110 & Scolopendrium & 062 \\
\hline RAPIIANEAE & 64 & Rutabaga & 71 & Scorpion-grass & 364 \\
\hline Raphanus & 75 & IUTACE王 & 109 & Scotch Thistle & 274 \\
\hline Raspberry & 150 & Rye-Grass & 637 & Scouring Rush & 653 \\
\hline Kattle-box & $1: 26$ & & & Serophularia & 326 \\
\hline Rattlesnake-Grass & 627 & Sabbatia & $38 t$ & SCROLIIULARIACEA & $32 t$ \\
\hline Mattlesnake's-Master & 191 & SACCHARERE & 607 & Scutch-Grass & 622 \\
\hline Ikattlesuake-Plantain & 503 & Sacred Bean & 55 & Scutellaria & 355 \\
\hline Rattlesnake-root & 278 & Sage & 350 & Sea Blite & 410 \\
\hline Rattlesnake-weed & 277 & Sagina & 94 & Sea Lavender & 312 \\
\hline Ray-Grass & 637 & Sagittaria & 492 & Sea Milkwort & 316 \\
\hline Rayless Golden-rod & 245 & St. Andrew's Cross & 83 & Sea Ox-eye & 253 \\
\hline Reboulea & 625 & St. John's-wort & 84 & Sea Purslane & 97 \\
\hline Red bay & $42 \cdot 2$ & St. John's-ıvort Family & 83 & Se: Rocket & 75 \\
\hline Ked-bud & 143 & St. Peter's-wort & 83 & Sea Sand-Reed & 616 \\
\hline Jud Osier & 200 & SALICACHAS & 461 & Sea Spear-Qrass & 6.28 \\
\hline Red-root & 514 & Salicornia & 409 & Sedgo & 571 \\
\hline Jed-top & 612 & Salix & 461 & Serige Fumily & 650 \\
\hline Theed & 636 & S:alsola & 410 & Sedum & 172 \\
\hline Reed Bent-Grass & 614 & Saltmarsh-Grass & 620 & Seed-box & 180 \\
\hline Reed-mace & 480 & Sultwort & 410 & Selaginella & 674 \\
\hline Reed Meadow-Grass & 627 & Silvia & 350 & Self-heal & 355 \\
\hline Rein-Orchis & 493 & Stlvinia & 677 & Senebier: & 74 \\
\hline Itenssclacia & $47 i s$ & & 202 & Sentea Qriss & 642 \\
\hline Jeseda & 76 & S:unbucus & 205 & Sencen Snakeruot & 122 \\
\hline JESEDACEAS & 70 & SIM(II.EAS & 313 & Seneclo & 270 \\
\hline JIIAMNACEA' & 113 & & 317 & SHNECIONEA & 221 \\
\hline Rhamnus & 114 & Simphire & 409 & SENECIONIDEA & 219 \\
\hline Rheumatism-root & 54 & Sandalwood Family & 425 & Senna & 144 \\
\hline Khexia & 181 & Sand-Grass & 621 & Seusitive Brier & 145 \\
\hline
\end{tabular}


HNDEX.

\begin{tabular}{|c|c|c|c|c|c|}
\hline Sensitive Fern & 668 & Southern Buckthorn & 308 & StrATIOTIDER & 495 \\
\hline Sensitive Joint-Vet & etch & Sow Thistle & 282 & Strawberry & 155 \\
\hline Sericocarpus & 228 & Spauish-Bayonet & 635 & Strawberry IBlite & 403 \\
\hline Service-berry & 102 & Spanish-Needles & 262 & Strawberry Bush & 216 \\
\hline Sенаme-Uraso & 650 & Sparganium & 481 & Strawberry 'Tomato & 382 \\
\hline Sesuvium & 97 & Spartina & 619 & Screptopus & 629 \\
\hline Setaria & 649 & Spatter-Dock & 56 & Striped Dogwood & 219 \\
\hline Seymeria & 334 & Siear-Grass & 628 & Struthiopteris & 667 \\
\hline Sh:ul-bush & 162 & Spearmint & 344 & Stuartia & 204 \\
\hline Shave-Qrass & 655 & Spearwort & 41 & Stylipus & 152 \\
\hline Shcep-berry & 206 & Specularia & 296 & Stylisma & 376 \\
\hline Bhellflower & 327 & Speedwell & 332 & Stylophorum & 59 \\
\hline Shepherdia & 424 & Spergula & 96 & Styinsanthes & 138 \\
\hline Shepherd's Purse & 73 & Spergularia & 95 & STYIRACACEAS & 305 \\
\hline Shichl-fiern & 681 & Spermacoce & 210 & STYRACKA & 309 \\
\hline Slinin-leaf & 801 & Splec-bush & $42: 3$ & Styrax & 309 \\
\hline Shooting-Star & 314 & Spiderwort & $5+7$ & Susedı & 410 \\
\hline Shrubby Althaa & 102 & Spiderwort Family & 546 & Subularia & 73 \\
\hline Shrubby Bitter-8we & 116 & Spigelia & 392 & Succory & 275 \\
\hline Bhrubliy Trefoil & 110 & Syike-Grass & 628,635 & Sugarberry & 443 \\
\hline Bhrub Yellow-root & 47 & Spikenaril & 199 & Sullivantia & 163 \\
\hline Sibbaldia & 153 & Spike-Kush & 557 & Sumach & 111 \\
\hline BIBTHURPIEA & 324 & Spindle-tree & 116 & Summer IIaw & 160 \\
\hline Sickle-pod & 68 & Spirzea & 140 & Summer Savory & 349 \\
\hline Sicyos & 186 & Sirtr & 146 & Sundew & 82 \\
\hline Sidn & 101 & Spiranthes & 504 & Stundew Family & 82 \\
\hline Sid:-saldle Flower & 67 & Spirodela & 479 & Sundrops & 179 \\
\hline Sievergiı & 153 & Spleenwort & 661 & Sunflower & 255 \\
\hline Silene & 88 & Spoonwood & 298 & Supple-Jack & 114 \\
\hline SiLnenex & 87 & Sporobolus & 610 & Swainp lloneysuckle & 299 \\
\hline Siliculosa & 63 & Spotted Cuwbane & 196 & Swamp Lonsestrife & 183 \\
\hline BIL.IQU0sAs & 63 & Sputted Wintergreen & 303 & Sweet Buy & 49 \\
\hline Silkweed & 394 & Spring-IBeauty & 98 & Swect-Brier & 159 \\
\hline Silphium & 248 & Spruce & 471 & Sweet (jicely & 197 \\
\hline Silver-bell Treo & 310 & Spurge & 430 & Sweet Clover & 128 \\
\hline Silver-Berry & 425 & Spurge Family & 430 & sweet Coltsfoot & 227 \\
\hline Silver-Weed & 155 & Spurge-Nettle & 436 & Swetet-Fern & 458 \\
\hline Simarubaceæ & 111 & Spurred Butterfly-Pea & 141 & Swect Flagr & 478 \\
\hline Sinapis & 70 & Spurred Gentian & 386 & Swect-Gale Family & 457 \\
\hline SISYMBRte $\boldsymbol{N}$ & 63 & Spurrey & 96 & Sweet-Gum Tree & 174 \\
\hline Sisymbrium & 70 & Squash & 186 & Sweet-leaf & 310 \\
\hline Sisyrinchlum & 517 & Stjuaw-ront & 323 & Sweet lipporhush & 296 \\
\hline Sitolobium & 669 & Sqquaw-weed & 271 & Sweet P'ine-sitp & $30 t$ \\
\hline Sium & 196 & Squill & 533 & Sweet-Seentexl Shrub & 162 \\
\hline Skullcap & 355 & Styuirrel Corn & 61 & Sweet Vernal-Grass & 643 \\
\hline Skunk Cabhage & 477 & Squirrel-tail Grass & 638 & Swcet-William & 371 \\
\hline Sloe & 148 & IYDERS & 343 & Swine-Cress & 74 \\
\hline Smartweed & 416 & Stachys & 358 & Sycamore & 447 \\
\hline SMILACEF & 518 & Stagger-bush & 296 & Syena & 547 \\
\hline Smilacina & 530 & Staff-tree & 116 & Symphoricarpus & 203 \\
\hline Smilax & 518 & Staff-tree Family & 115 & Sympliytum & 361 \\
\hline Smilax Family & 518 & Staphylea & 117 & Syinplocatrus & 477 \\
\hline Strake-head & 327 & 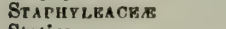 & $1: 7$ & SYMPLOCINER & 309 \\
\hline \multirow[t]{2}{*}{ Suake-root } & $190,191,223$, & Statice & 312 & Symplicos & 310 \\
\hline & 226,404 & Star-Cucumber & 186 & Syuandin & 351 \\
\hline Snapdragon & 326 & Star Flower & 314 & Syndesmon & 38 \\
\hline Sneeze-weed & 203 & & 513,515 & Synthyris & 331 \\
\hline Sncezewort & 265 & Star-of-Bethlehem & 533 & Syringa & 166,400 \\
\hline Snowberry & 203 & Star-Thistle & 272 & & \\
\hline Snowdrop & 310,512 & Starwort & 92,228 & Tacamahac & 467 \\
\hline Snowflake & 512 & Steeple-Bush & 149 & Trenirlia & 195 \\
\hline Soapberry Family & 116 & Steironema & 315 & Tagetes & 262 \\
\hline Soapwort & 88 & Stellaria & 92 & TAGETINGR & 220 \\
\hline SOLANACEA & 880 & Stellates & 208 & Talinum & 93 \\
\hline Solanum & 380 & & 237 & Tall Red-top & 624 \\
\hline Solea & 76 & Stenanthium & 525 & Tamarack & 472 \\
\hline Solidago & 239 & Stickseed & 365 & Tanacetum & 266 \\
\hline Solumon's Seal & 531 & Stillingia & 436 & Tansy & 266 \\
\hline Sonchus & 282 & Stipa & 617 & Tunsy-Mustard & 70 \\
\hline SOPHOREA & 125 & STIPFA: & 604 & Tape-grass & 496 \\
\hline Sorbus & 161 & Stitehwort & 92 & Taraxacum & 280 \\
\hline Sorghum & 652 & Stonc-crops & 172 & TARCHONA NTIER & 219 \\
\hline Sorrel & 419 & Stonc-ront & 350 & Tare & $1: 38$ \\
\hline Borrel Family & 100 & Ftorax & 309 & TAXINER: & 469 \\
\hline Sorrel-tree & 296 & Storax Family & 309 & Taxolium & 473 \\
\hline Sour-Gumtree & 201 & Storkshill & 108 & Taxus & 474 \\
\hline Bour-wood & 296 & Stramonium & 383 & Tea-berry & 293 \\
\hline
\end{tabular}


Tea-Plant

Tear-thumb

T'easel

Teisul-Vamily

Tecouna

Teluatophace

Tephrosia

TepHrosiak

TERNSTROUMIACEA

Tetragonotheca

Tetranthera

Teucrium

Thalictrum

Thaspium

Thermopsis

Thimbleberry

Thin-Grass

Thistle

Thlaspi

Tulaspideas

IThoru

Thoru-A pple

Thorough-wax

Thoroughwort

Thuce-leared Nightslade

'Three-seeded Mercury'

Three-thorned Acacia

Thrift

Thuja

Thuubergia

THYMELEACE AE

Thymus (Thyue)

Tiarella

Tickseed

Ticksed Sunflower

Tick-Trefoil

Tiedemanuia

Tiger-flower

Tigridia

Tilia

TILIACEAS

Tilla:

Tillandsia

Timothy

Tiniaria

Tipularia

Tithymalopsis

Tithymalus

Toad-Flax

Tobacco

Tofichilia

Tomato

Touthache-Grass

Tuothache-tree

Toothwort

Touch-me-not

Tovaria

Toiver-Mustard

Toxicodendron

Trachynotia

Tradescantia

Tragia

'Irailing Arbutus

Truatretteria

Treacle Mustard

Tread-softly

Tree of Ileaven

Trefuil

Trichelostylis

Trichochlou

Tricholium

Trichophorusn

I'richostema

Tricuspis

Tridynia

Trientalis

Tajroliefe
Trifolium

Triglochin

TuLl.IDEN

I'rillium

I'rlestiallus

Triosteum

Triplasis

Triple-awned Grass

Tripsacum

I'ripterella

Trisetumn

I'riticum

Trollius

Tropasolum

Troximon

Trumpel-Creeper

Trumpet-flower

Trumpets

Trumpet 4 weed

Tsuga

TUBULIFLORA

Tuckermanuia

Tulip-tree

Tupelo

'I'USSILAGINEAE

Tussilago

Turnip

Turritis

Turtle-head

Tirayblade

T'wig-kush

T'win-flower

Twin-leaf

Twisted Stalk

Typha

TYPHACEA:

Udora

ULMACEAE

UImaria

Ulinus

UMBELLIVER A

Umbrella-Grass

Umbrella-leaf

Uubrella-tree

Unicorn-plant

Uniola

Uralepis

Urtica

URTICACEA

URTICE $\mathbb{B}$

Utricularia

Uvularia

UVULARIEA

Vaccaria

V A ccinte. A

Vaccinium

Vahlorlea

Valeriaua (Valerian)

VALERIANACE

Valerianella

Valerian Vitmily

Vallisueria

VALLISNERIEAE

Vinilla Grass

Vanilla-plant

Velvet-leuf

Venus's Vly-trap

Venus's Looking-glass

Veratrum

Vi:HBASCREA

V(rb)iscum

Verbena

VERIBEN ACEA

VERBENEA

Verbesina

126

491

6.22

205

624

618

650

496

640

637

41

105

276

821

B21

58

895

471
216

440

50

201

218

227

71

68

606, 509

570

202

53

529

480

480

496

441

149

442

187

556

53

49

821

624

444

440

$4+1$

318

628

521

88

287

289,679

641
213

213

214

213

496
495

495

224

101

83

280

525

321

325

339 
White Cedar

White Daisy

White Grass

White Lettuce

White sunkeroot

White Thorn

White-topped Aster

White-weed

Whitlow Orass

Whitlow-wort

Whortleberry Family

Wicony

Wild Allsplce

Wild Balsam-apple

Wild Bean

Wild Bergamot

Wild Chamomile

Wild Comfrey

Wild Elder

Wild Ginger

Wild Iyacinth

Wild Liquorice

Wild Marjoram

Wild Oat-Grass

Wild Pink

Wild Potato-VIne

Wild Sarsaparilla

Wilt Sensitive-Plant

Willow

Willow Family

Willow-herb

Wind-flower

\begin{tabular}{|c|c|}
\hline 72,473 & Windsoria \\
\hline 265 & Winged Plgweed \\
\hline 607 & Winterberry \\
\hline 278 & Winter-Cress \\
\hline 228 & Wintergreen \\
\hline 159 & Wire-Cirass \\
\hline 228 & Wistaria \\
\hline 265 & Witch-IIazel \\
\hline 71 & Witch-Ilazel Family \\
\hline 96 & Withe-rod \\
\hline 287 & Woad-Waxen \\
\hline 424 & Wolfberry \\
\hline 423 & Wolffia \\
\hline 180 & Wolfabane \\
\hline 140 & Wood Betony \\
\hline 351 & Woodbine \\
\hline 266 & Wood-Fern \\
\hline 366 & Wood-Grass \\
\hline 199 & Wood-Nettle \\
\hline 40.3 & Wood Reed-Grass \\
\hline 532 & Wood-Rush \\
\hline 9,210 & Wood-Sage \\
\hline 348 & Woodsia \\
\hline 639 & Wood-Sorrel \\
\hline 89 & Woodwardia \\
\hline 375 & Wool-Grass \\
\hline 198 & Woolly Beard-Grass \\
\hline 144 & Worm-grass \\
\hline 461 & Wormseed \\
\hline 461 & Worm-seed Mustard \\
\hline 177 & Wormwood \\
\hline & Woundwort \\
\hline
\end{tabular}

\begin{tabular}{|c|c|c|}
\hline 623 & Xanthium & 251 \\
\hline 406 & Xerophyllum & 526 \\
\hline 307 & Xylosteun & 204 \\
\hline 69 & XYIIII) CCEX & 647 \\
\hline 293, 301 & Хугіs & 648 \\
\hline 623,629 & & \\
\hline 131 & Yam & 618 \\
\hline 173 & Yam Family & 518 \\
\hline 173 & Yard-Orass & 622 \\
\hline 208 & Yarrow & 265 \\
\hline 126 & Yaupon & 300 \\
\hline $20: 3$ & Yellow-eyed Grass & 548 \\
\hline 480 & Yellow-eyed Grass Family & 547 \\
\hline 46 & Yellow (False) Jessumine & 391 \\
\hline 337,358 & Yellow Pond-1́lly & 561 \\
\hline 113,203 & Yellow Puccoon & 47 \\
\hline 664 & Yellow-Rattle & 337 \\
\hline 652 & Yellow Rocket & 69 \\
\hline 445 & Yellow-wood & 143 \\
\hline 612 & Yew & 474 \\
\hline 536 & Yew Family & 468 \\
\hline 343 & Yucca & 535 \\
\hline $\begin{array}{l}668 \\
109\end{array}$ & & \\
\hline $\begin{array}{l}109 \\
660\end{array}$ & Zannichellia & 483 \\
\hline 660 & $\begin{array}{l}\text { Zatnthorhiza } \\
\text { Zanthoxylum }\end{array}$ & 47 \\
\hline 665 & Zanthoxylum & 110 \\
\hline 651 & Zatpania & 340 \\
\hline 392 & Zephy ranthes & 513 \\
\hline 408 & Zizania & 608 \\
\hline 69 & Zizia & 195 \\
\hline 266 & Zostera & 483 \\
\hline & Zygadenus (Zygadene) & 524 \\
\hline
\end{tabular}





\section{EXPLANATION OF THE PLATES.}

\section{Genera of Cyperaceæ or Sedges.}

\section{TAB. I.}

CYPERUS. - Small plant of C. diandrıs (1); a spike magnified (2); a piece of the rhachis with one scale enclosing its flower (3); a separate flower move magnified (4). C. erythrorhizos, a spike magnified, the lower scales and flowers have fallen, showing the little internal scales of the section Papyrus (5), formed of the winged margins of the joints of the rlachis detached; a separate one more enlarged (6); a flower ( 7 ); an achenium (8), cut in two. C. dentatus, a piece of the rhachis of a spike with lower part of one scale, showing how it is decurrent on the joint beneath (cut across) to form scalelike wings (9).

DULICHIUM. - Upper part of a plant (1); part of a spike somewhat enlarged (2); piece of rhachis and one scale decurrent on the joint beneath $(3)$; magnified flower (4).

KYLLINGIA. - Plant of K. pumila (1); one-flowered spike on a piece of the rhachis, enlarged (2); the same more enlarged and open (3); achenium (4), and section of same magnified (5).

\section{TAB. II.}

HEMICARPHA. - Plant (1), natural size; a spike enlarged, with its bract (2); magnified scale of the same (3); a flower (5), with its single stamen and minute internal scale, magnified; achenium (6), magnified.

LIPOCARPHA. - Upper part of plants with spikes (1); diagram of a flower, viz. of ovary between the two internal scales, and single stamen, scale of the spike on one side, axis of the spike on the other $(2)$; scale of spike detached (3); ? flower with its two inner scales (4); achenium magnified (5).

FUIRENA. - Upper portion of plants (1); scale of spike enclosing a flower (2); open scale of same (3); flower (4); one of the scales and one of the bristles of the flower (5), achenium (6), and section of same (7).

\section{TA 13. III.}

ELFOCHARIS. - Small plant of F. olivacea (1); the spike enlarged (2); detached scale (3); flower (4); rchenium and bristles (5). F. quadrangulata, spike (6); a scale (7); flower (8); achenium and bristles (9). E. tuberculosa; the achenium with its great tubercle, and bristles (10).

SCIRPUS. - Summit of plant of small S. debilis (1); a spike (2); a scale of tho eame (3), and flower (4); achenium with its bristles (5). S. (Trichophorum) 
Eriophorum; a small portion of the Inflorescence (6); a fower $(7)$; a spike in fruit $(8)$; achenium from the same, with the tortuous bristles much lengthened (9); section of the achenium (10).

ERIOPHORUM. - Small plant of E. alpinum, in flower (1); spike (2); a scale (3), and (4) a flower from the same; the spike in fruit, the bristles forming a cottony tuft (5); achenium and its bristles (6).

FIMBRISTYLIS. - Summit of a small flowering stem of F. laxa (1); a spike of the same (2); a detached scale (3), and (4) a flower of the same; acheniune (5). F. ('Trichelostylis) autumnalis; a spike, oularged (6); flower (7); acheuium (8), and (9) section of the sane.

\section{TAB. IV.}

DICHROMENA. - Head and involucre of D. latifolia (1); a scale from one of the spikes (2), and the same cut across (3); a flower (4); achenium with ita tubercle (5).

RHYNCHOSPORA. - Upper part of flowering stem of R. Torreyana (1); a spike (2); detached flower (3); achenium (4) with short bristles at its base; one of these bristles more magnified (5).

R. (\$ P'SILOCARYA): - P'art of plant (1), enlarged spike (2), detached scalo (3), flower (4), and achenium with its beak (5) of R. (Psilocarya) scirpoides.

R. ( $\$$ CERATOSCH(ENUS): - Upper part of fruiting plant (1), detached spike (2), flower (3), and beaked achenium with its bristles (4) of R. (Ceratoschœnus) macrostachya.

\section{TAB. V.}

CLADIUM. - Summit of a plant of C. mariscoides (1); detached spike (2); same, open, showing a staminate and a perfect flower (3); the nut-like achenium (4), and the longitudinal section of the same (5).

SCLERIA. - Summit of a flowering stem of S. reticularis (6); three spikelets from a cluster, the middle one pistillate, the lateral ones staminate $(\bar{\tau})$; staminate spikelet displaying four male flowers, the filaments of two of them have lost their anthers (8); pistillate spikelet displaying a single pistillate flower (9); achenium with the 3-lobed double cup underneath (10).

CAREX. - Plant of C. pauciflora (11); a staminate flower with its scale (12); scale (13), and mature pistillate flower, in its perigynium (14); cross section of perigynium and of the contained achenium (15); achenium on its stalk, style and stigmas (16). C. Steudelii, upper part of flowering plant (17); the spike enlarged (18); a staminate flower and its scale (19); pistillate flower in its perigynium (20); the same with half the perigynium cut away to show the contained achenium and style (21).

\section{TaB. VI.}

CAREX. - C. trisperma, upper part of a stem in fruit (1); enlarged spike displayed, with three staminate and two pistillate flowers (2); a scale (3) and a ripe perigynium (4), of the latter; with a section of the perigynium near the base, and of the contained perigynium (5). C. struminea, suminit of a fruiting plant (6); a spike cularged (7); scale of a pistillate flower (8); the winged perigynium and the contained achenium cut across (9); detached achenium with persistent style and stigmas (10). C. umbellata, whole plant (11); a perigynium and its scale (12); cross-section towards the base of perigynium and its contained achenium (13); detached achenium with its persistent style and stigmas (14). C. bullata; upper part of plant in fruit, with one pistillate and two staminate spikes (15); one of its staminate ftowers with the scale (16); a pistillate scale (17) and mature perigynium (18); longitudinal section of the latter, showing the achenium and its stylo (19), and cross section of the same (20). 


\section{Genera of Gramineæ or Grasses.}

\section{TAB. VII.}

LEERSIA. - Panicle of L. oryzoides, reduced in size (1); a branchlet of the sume with its spikelets, of the natural size (2); and an open spikelet in flower, enlarged (3).

ZIZANIA. - A staminate (1) and $\Omega$ pistillate (2) flower or spikelet of Z. aquatica; a magnified pistil with a pair of squamula or hypogynous scales $(3)$; a grain (4); and a magnified longitudinal section of the lower part of the same, showing the embryo at the ottside of the base of the albumen.

ALOPECURISS. - Part of a plant of A. geniculatus, in flower (1); a few spikelets from the spike-like inflorescence, moderately magnified (2); an open spikelet in flower, more magnified (3), and the single lower palet detached (4).

PHLEU.I. - A detached spikelet of $\Gamma$. pratense, having the flower with its palets raised above the glumes, magnified.

CRYPSIS. - Inflorescence (1) of C. schœnoides; a separate enlarged spikelet (2); and the same open, in flower (3).

VILFA. - An enlarged spikelet of V. vaginæflora (1); and the same displayed (2).

SPOROBOLUS. - A spikelet of S. cryptandrus, magnified (1); the same with the flower open, the palets raised above the glumes (2); and the fruit (3), more magnified, showing the seed loose in the pericarp (utricle).

AGROSTIS. - Panicle of A. vulgaris (1); with an enlarged open spikelet of the sames also (3) the rough pedicel and glumes of A. scabra, with the flower separated, tho latter having no upper palet.

\section{TAB. VIII.}

POLYPOGON. - Spike-like contracted panicle of P. Monspellensis (1); an enlarged detached spikelet, showing the long awns to the glunes (2); the same open in flower (3); and $n$ separate flower without the glumes (4).

CINNA. - A magnified spikelet of C. arundinacea (1); and the same open, displaying the palets, the single stamen, and the pistil (2).

MUHLENBERGIA. - A magnified closed spikelet of M. sylvatica (1); the same with the open flower raised out of the glumes (2). A magnified spikelet of M. diffusa (3); its minute and unequal glumes more magnified (4); and an open spikelet of the same (5).

BRACHYELYTRUM، - A spikelet of B. aristatum enlarged (1); the same displayed (2).

CALAM AGROSTIS. - An open spikelet of C. Canadensis, enlarged, displaying all the parts (1); the same with the flower raised out of the glumes, showing the hairy radiment behind the upper palet (2).

ORYZOPSIS. - An open magnifled spikelet of 0 . asperifolia (1); and the flower of the same removed from the glumes (2). Notice the remarkably long squamulæe or hypogynous scales, which here nearly equal the palets in length.

STIPA. - Glumes and flower (a little separated) of S. avenacea, enlarged.

A RISTIDA. - A spikelet of $\boldsymbol{\Lambda}$. purpurascens, enlarged.

TAB. IX.

SPARTINA. - Portion of the inflorescence of S. stricta, of the natural size (1); a spikelet enlarged (2); and the same displayed, the flower raised above the glumes (3).

CTENIUM. - Spike of C. Americanum (1); a single spikelet magnified (2); and the same displayed, the glumes separated (3).

BOUTELOUA. - A portion of the compound spike, of the natural size (1); and a spikelet displayed and magnified (2), the flowers raised out of the glumes. 
GYMNOPOGON. - Inflorescence of G. racemosus, reduced in size (1); and a mag. nified spikelet with the parts displayed (2).

CYNODON. - Inflorescence, of digitato spikes (1); a spikelet magnified and displayed, showing a perfect flower and a rudiment (2).

DACTYLOCTENIUM. - Inflorescence of D. Egyptiacum, of digitate spikes (1); one of the spikelets magnified (2); the fruit magnified (3), showing the seed loose in the thin pericarp (utricle); and (4) the wrinkled seed more magnified.

ELEUSINE. - One of the spikes from the digitate inflorescence of E. Indica (1); a magnified spikelet (2); the same with the flowers more displayed (3); a flower from the last showing its parts (4); the fruit magnified, showing the seed loose in the utricle (5); and the wrinkled seed detached (6).

LEPTOCHLOA. - Sinall portion of the inflorescence of L. fuscicularis (1); one of its spikelets displayed and magnified (2); an open flower of the sume (3).

\section{TAB. X.}

TRICUSPIS. - Magnified spikelet of ' $\mathrm{T}$. seslerioides (1); the same displayed and the lowest flower open (2); back view of the lower palets spread out (3).

GRAPHLPHORUM. - A magnified spikelet of G. melicoides, displayed (1); a part of the hairy rhachis and one flower of the same (2).

DIARRHENA. - A spikelet of D. Americana, enlarged (1); the grain and palets (2).

DACTYLIS. - A spikelet of D. glomerata magnified and displayed.

KELERIA. - A maguified spikelet of K. cristata, expanded, showing the glumes, the three flowers, and a rudiment (1); lower half of a lower palet, partly spread open (2); it is much more folded and keeled in its natural condition.

EATONIA. - A magnified spikelet of E. obtusata, expanded, showing the glumes, the two flowers, and a ruliment.

MELICA. - A magnified spikelet of M. mutica, expanded, showing the glumes, twa perfect flowers, and an abortive one.

GLYCERIA. - A magnined spikelet of G. nervata (1); a separate flewer with one joint of the rhachis $(2)$; and $(3)$ the lower half of a lower palet, showing its form (rounded on the back, not keeled.)

BRIZOPYRUM. - A pistillate spikelet of B. spicatum, enlarged (1); a flower from the same (2); and a flower from a staminate spikelet (3).

POA. - Panicle of P. compressa, reduced in size (1); a magnified spikelet (2); a separate flower more magnified (3); a lower palet cut across and somewhat outspread (4).

ERAGROSTIS. - A spikelet of E. pilosa, enlarged (1); the same, from which the glumes and all of six lower flowers except the upper palet have fallen away (2); a magnified flower, open (3); the lower palet of the same out. spread (4).

BRIZA. - A spikelet of B. media, enlarged (1); a separate flower (2).

FESTUCA. - A spikelet of F. elatior, enlarged (1); « separate flower (2); lowes part of a lower palet, outspread (3).

BROMUS. - A spikelet of B. secalinus, or Chess (1); and a separato flower, enlarged (2).

\section{TA13. XI.}

UNIOLA. - A spikelet of U. latifolia, of about the natural size (1); a flower, enlarged (2); empty lower palet of the lowest (sterile) flower (3).

PHRAGMITES. - A spikelet of P. communis, enlargerl (1); one of the perfect flowers, enlarged (2); and the lowest flower (3), which has stamens only.

ARUNDINAIRIA. - A spikelet of A. macrosperma (1); and a separate flower, magnified (2).

LEPTURUS. - Portion of the spike of L. paniculatus, onlarged (1); and a flower magnified (2). 
LOLIUM. - Portion of the spike of L. temulentum (1); and a separate flower, magnified (2).

TRITICUM. - Portion of the spike of T. repens, or Conch-Grass, of about the natural size (1); a flower, magnified (2).

HORDEUM. - The three one-flowered spikelets from one joint of the spike of H. jubatum, with their awn-like glumes, the lateral flowers abortive and neutral the middle one alone perfect (1); this perfect flower (with an awn-like rudiment) open and enlarged (2).

ELYMUS. - The two spikelets of one joint of the spike of E. Virginicus, about the natural size (1); the glumes and the flowers of one spikelet, enlarged and displayed (2); and an open flower, more magnified (3).

GYMNOSTICHUM. - A spikelet of G. Hystrix (1), and an expanded flower, magnified (2).

\section{TAB. XII.}

AIRA. - Panicle of A. flexuosa (1); a spikelet, magnified, the parts displayed (2); and one of the flowers detached and open (3).

DANTHONIA. - Panicle of D. spicata (1); a spikelet enlarged (2); and a separate flower from the same (3).

TRISETUM. - A spikelet of T. subspicatum, var. molle, expanded and magnified (1); and a separate open flower (2).

AVENA. - A spikelet of A. striata displnyed and magnified (1); and a separate flower (2).

ARRENATHERUM. - A spikelet of A. nvenaceum, displayed and magnified: 1 , the glumes; 2 , the flowers, the lower one staminate only, the next one perfect, and the third a rudiment.

HOLCUS. - A spikelet of H. lanatus magnified (1); the same displayed to show the two flowers, the lower one perfect and awnless, the upper staminate and awned (2).

\section{TAB. XIII.}

HIEROCHLOA. - A spikelet of H. borealis, enlarged (1): the same dispiayed, the flowers separated from the glumes, the two lateral ones with three stamens and no pistil; the middle or terminal one with a pistil and only two stamens (2).

ANTHOXANTHUM. - The spike-like inflorescence of A. odoratum (1); a spikelet magnified (2); another with the parts displayed, the flowers raised from the glumes, the lateral ones neutral, each of a single and awned palet, the middle one perfect and diandrous (3).

PHALARIS. - A spikelet of P. arundinacea enlarged (1); the glumes, and the perfect flower with a hairy rudiment on each side of it (2).

MILIUM. - Portion of the panicle of M. effusum (1); a closed spikelet magnified (2); and the same displayed (3).

AMPHICARPUM. - A spikelet from the panicle of A. Purshii, magnified (1); the same with the parts displayed (2); and a radical (fertile) spikelet, enlarged (3).

PASPALUM - Inflorescence of P. læve (1); a closed spikelet, enlarged (2); the same with the parts displayed (3).

PANICUM. - Part of a spike of P. (Digitaria) sanguinale (1); one of its spikelets magnifled (2); the same with the parts displayed (3): in this the lower flower is neutral and of a single palet. A spikelet of $P$. capillare, magnified (4), and the same displayed (5): the lower flower a single palet. A spikelet of $P$. clandestinum, nagnified (6), and the same displayed (7): the lower neutral, of two palets. A spikelet of $\mathrm{P}$. virgatum, magnified (8); the same displayed (9): the lower flower of two palcts and staminate.

SETARIA.- A magnified spikelet of S. glauca, with the accompanying cluster of bristles (1); the spikelet displnyed, showing the neutral lower flower of two palets and the perfect flower (2). 
TAB. XIV.

CENCHRUS. - Involucre of C. tribuloides, in flower, enlarged (1); longitudinal section of the sume (2); a spikclol displuyed (3): the stigmas should belong to the right-hand flower: the left-hand or lower flower is only staminate.

TRIPSACUM. - Piece of the spike (of the natural size), pi.stillate below, staminate above (1); a longitudinal section of one of the pistillate spikelets (2); a pistillate spikelet with its parts displayed (3); a staminate (two-flowered) spikelet, with its parts displayed (4).

ERIANTIUUS. - Part of the hairy inflorescence with two spikelets of E. alopecuroides, enlarged (1); one of the spikelets displayed (2).

ANDROPOGON. - Small portion of the spike of A. furcatus, enlarged, with one fertile and awned spikelet, and one starninate and awnless spikelet (1); the fertile spikelet (2); and the staminate spikelet (3) displayed.

SORGHUM. - A fertile spikelet of S. nutans, enlarged, with a sterile pedicel on each side (1); the spikelet displayed (2).

\section{Genera of Filices or Ferns.}

\section{TAB. XV.}

POLYPODIUM. - Plant; piece of the frond (1): a magnified sporangium with its stalk, and another bursting and discharging spores, of P. vulgare, L.

STRUTHIOPTERIS. - Pinna of the sterile frond (1) of S. Germanica, Willd. ; portion of a fertile frond (2); a piece of one pinna cut off to show the manner in which it is rolled up (3); and a portion of the last, magnified, with one side unrolled (4); towards the base of the sporangia all removed, to show how the fruit-dots are borne each on the middle of a vein.

PELLÆA. - Sterile and fertile plants of P. gracilis, and a portion of the fertile frond (1) enlarged, with a piece of the marginal indnsium turned back to display the fruit; the sporangia are all removed from the fruit-bearing tips of the two forks of the lower vein.

\section{TAB. XVI.}

PTERIS. - A pinnule of P. aquilina, L.; and a piece of one of the lobes, enlarged (2), the marginal indusium rolled back on one side, displaying the fruit; the sporangia all removed from the lower part to show the receptacle that bears them, viz. a cross line connecting the tips of the veins.

ADIANTUM. - Piece of the frond of A. pedatum, $L .(1)$; a pinnule somewhat enlarged (2); and a piece of one (3) more enlarged, with the indusium of one fruit-dot turned back to show the attachment of the fruit.

CHEILANTHES. - Small plant of C. vestita (1); and a fruit-bearing pinnule, enlarged (2).

WOODWARDIA. - Portion of the sterile (1) and of the fertile frond (2) of W. angustifolia; a piece of the latter enlarged (3); piece of the frond of W. Virginica (4); and part of a fruiting lobe $(5)$, enlarged.

\section{'I'A 13. XVII.}

CAMPTOSORUS. - Plant of C. rhizophyllus, Link.; and a portion of a frond, with fruit-dots, enlarged (1).

SCOLOPENDRIUM. - Tip of a fertile frond of S. vulgare; and (2) a piece enlarged, with two fruit-dots.

ASPLENIUM. - A pinna of A. thelypteroides, Michx. (1); and part of a lobe (2) in fruit, enlarged.

DICKSONIA. - P'inma of 1). punctilobula, Ilook. (1); portion of a pinnule (2), enlarged; and a fruit-dot in its cup-shaped indusium (3). 


\section{TAB. XVIII.}

CYSTOPTERIS. - Piece of the frond of C. bulbifera, Bernh. (1); a lobe in fruit (2), enlarged; and a small portion more magnified (3), bearing a fruit-dot with its indusium thrown back.

WOODSIA. - Small frond of W. glabella, $R . B r \cdot(1)$; a part of a fruiting pinna of the same (2), magnified; and a separate indusium (3), more magnified; a piece of a fruitful pinnule of W. obtusa, Torr. (4), enlarged; and a fruit with the opened indusium beneath (5), more magnified.

ASPIDIUM. - Pinna of A. (Dryopteris) marginale, Swartz (1); and n magnified fruiting portion (2); pieco of A. ('olystichum) nerostichoides (3); und " smnll fruiting portion (4), magnified.

ONOCLEA. - Sterile and fertile frond of $O$. sensibilis, $L$.; front view of $n$ fruiting contracted pinnule, enlarged (1); and the same laid open and viewed from the other side (2): on one lobe the sporangia are removed from the veins.

TAB. XIX.

SCHIZEA. - Plant of S. pusilla, Pursh., of the natural size; a (3rtile pinna with eleven sporangia (1), magnified; and a separate sporangium (2), more magnified.

LYGODIUM. - Summit of frond of L. palmatum, Swartz (1), with fertile and sterile divisions; a fruiting lobe enlarged (2), with two of the lower scales, or indusia, removed, displaying a sporangium under each; and a sporangium more magnified (3).

OSMUNDA. - Small piece of the frond of O. Claytoniana, $L$. (1), with a fertile and a sterile pinna; a portion of the fruit magnified (2); and one sporangium more magnified (3).

BOTRYCHIUM. - Plant of B. lunarioides, Swartz; and a portion of the fruit (1), with six sporangia, magnified.

OPHIOGLOSSUM. - Frond of $O$. vulgatum, $L . ;$ and a portion of the fruiting spike enlarged (1).

\section{Genera of Equisetaceæ, Lycopodiaceæ, \&c.}

\section{TAB. XX.}

EQUISETUM. - Upper part of fertile plant of E. limosum, $L$. (1); one of the shield-shaped scales or receptacles of the spike, with the six sporangia underneath (2), enlarged; same seen from below, discharging the spores (3); a magnified spore with the club-shaped filaments spreading (4); and (5) the same with the filaments coiled up.

LYCOPODIUM. - Plant of L. Carolinianum, $L_{*}$; and (1) a magnified scale of the spike removed, with the sporangium in its axil, discharging powdery spores.

SELAGINELLA. - Plant of S. rupestris, Spring; part of a fertile spike, enlarged (1); scale from the upper part of it (2), with its sporangium, containing innumerable powdery spores; scale from the base (3), with its sporangium containing few large spores; and (4) three large spores.

ISOETES. - Plant of I. lacustris (1); sporocarp containing the minute spores, cut across (2), enlarged; same divided length wise (5); s.porocarp with the large spores, divided length wise (3); and (4) three large spores more magnified.

AZOLLA. - Plant (1); a portion magnified (2), with two kinds of organs; sterile sporocarp, or antheridium, more magnified (3); fertile sporocarp more magnified (4); the same burst open, showing the stalked sporangia (5); one of the latter more magnified (6); another bursting (7); and three spores (8), beset with bristles. 



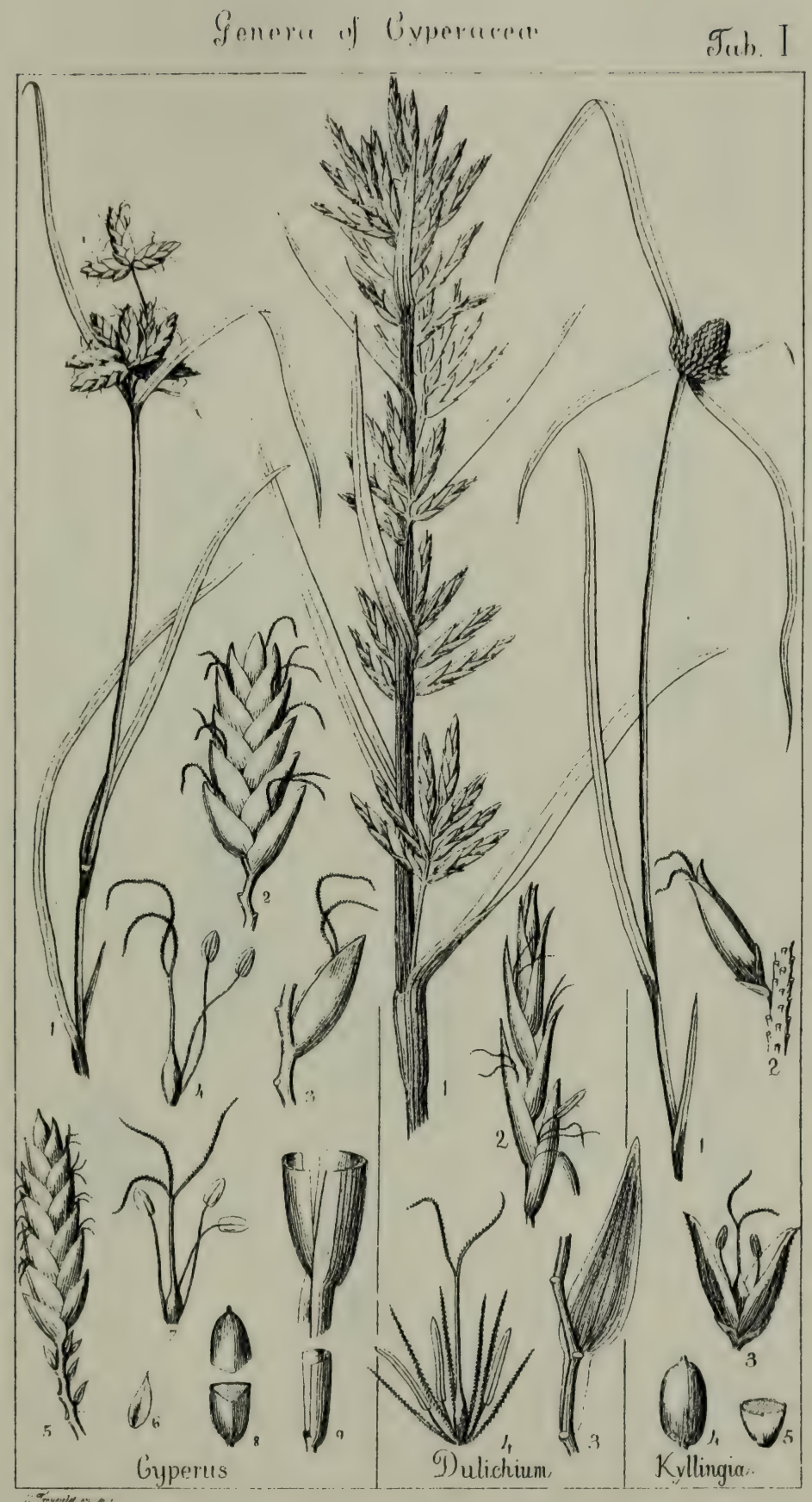



Senera of Cyperacece

gab. II

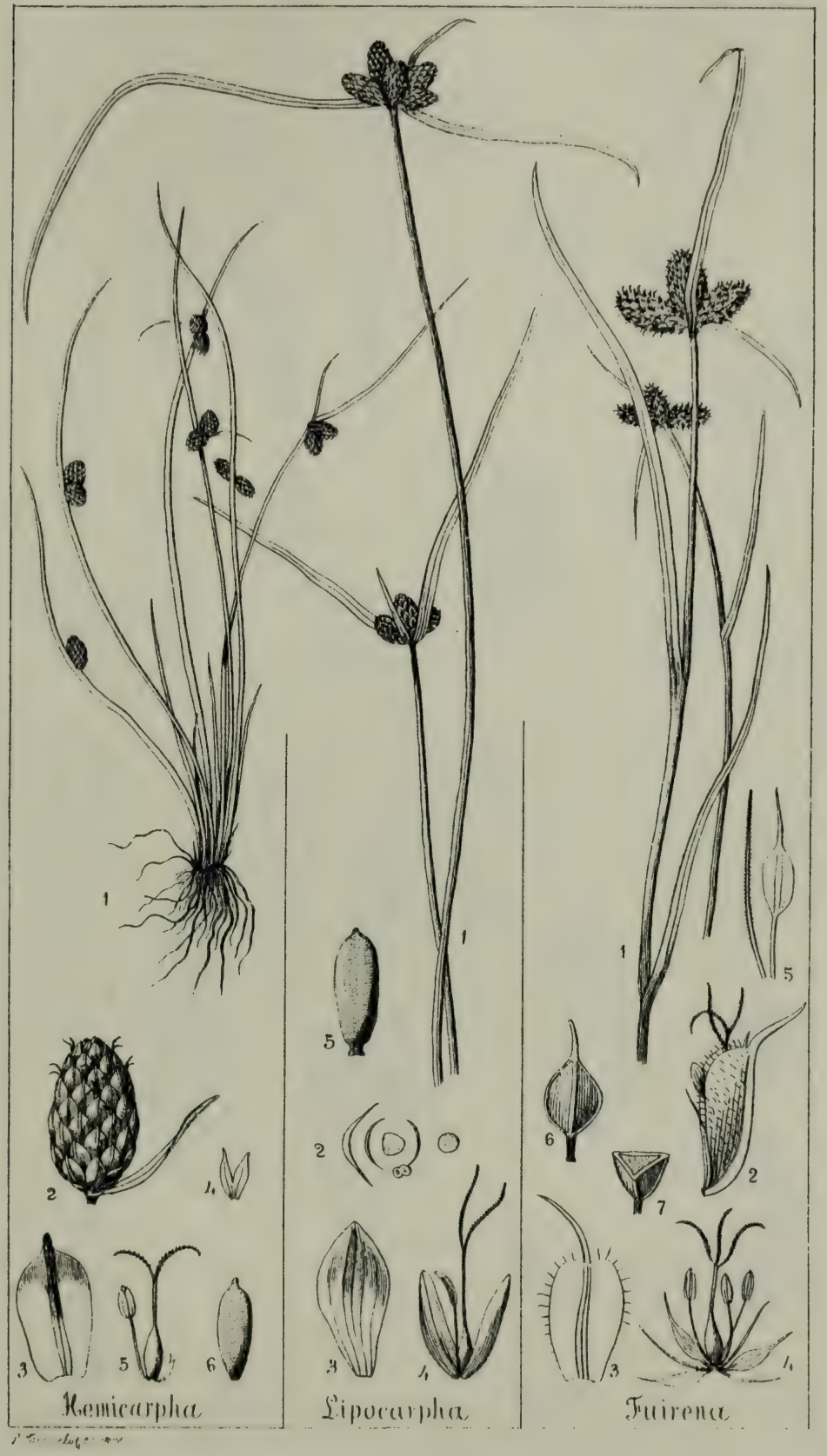





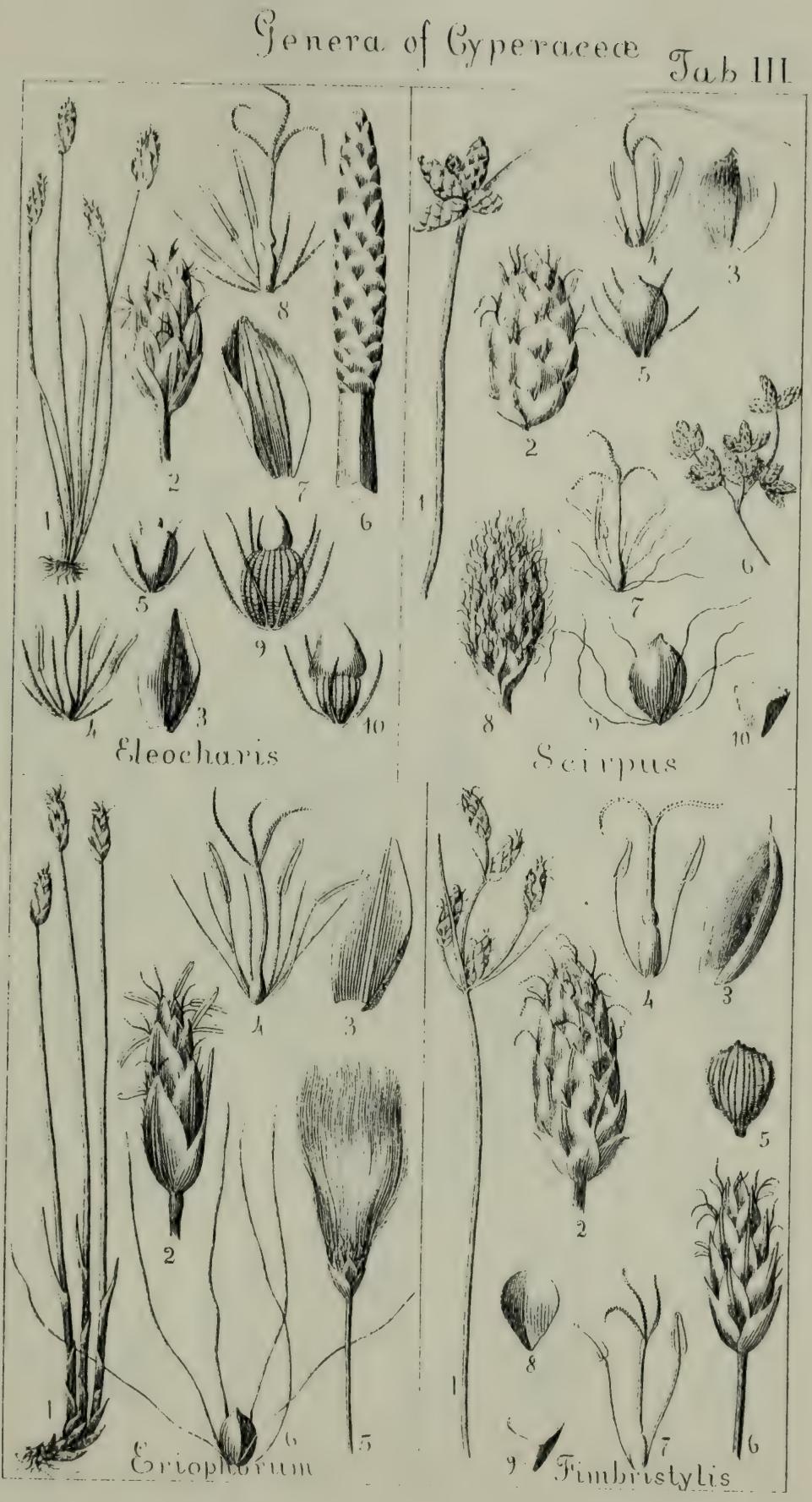





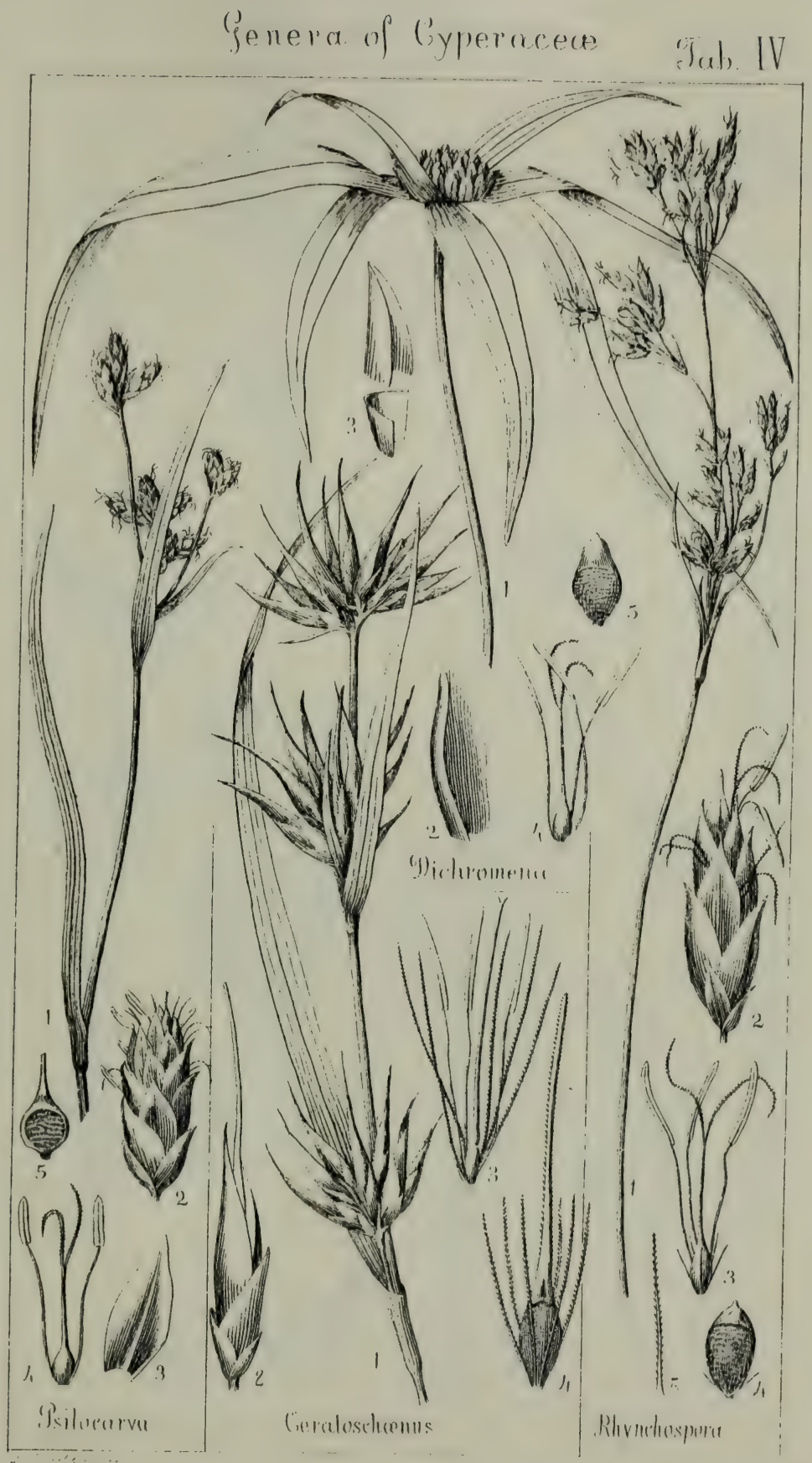





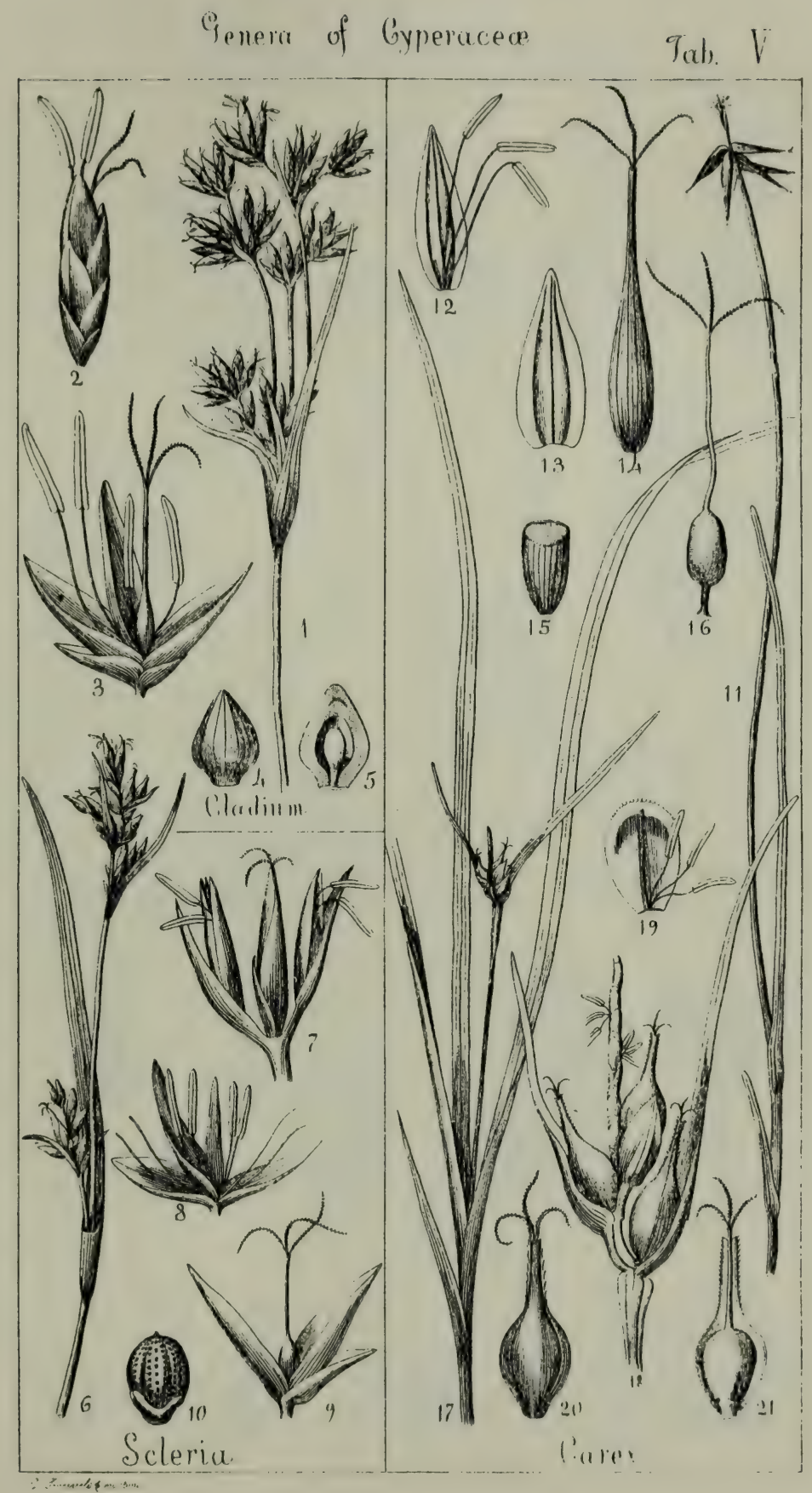





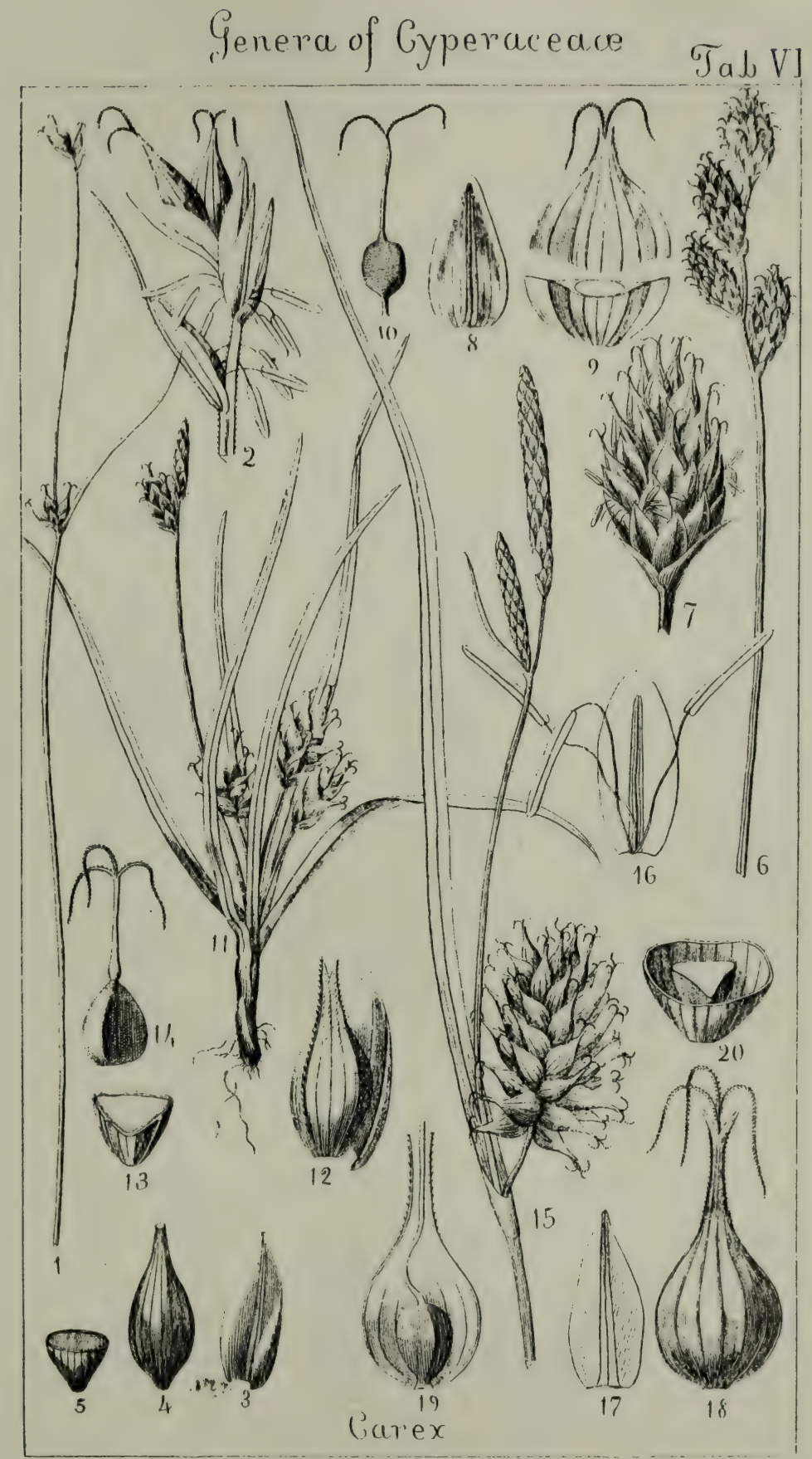





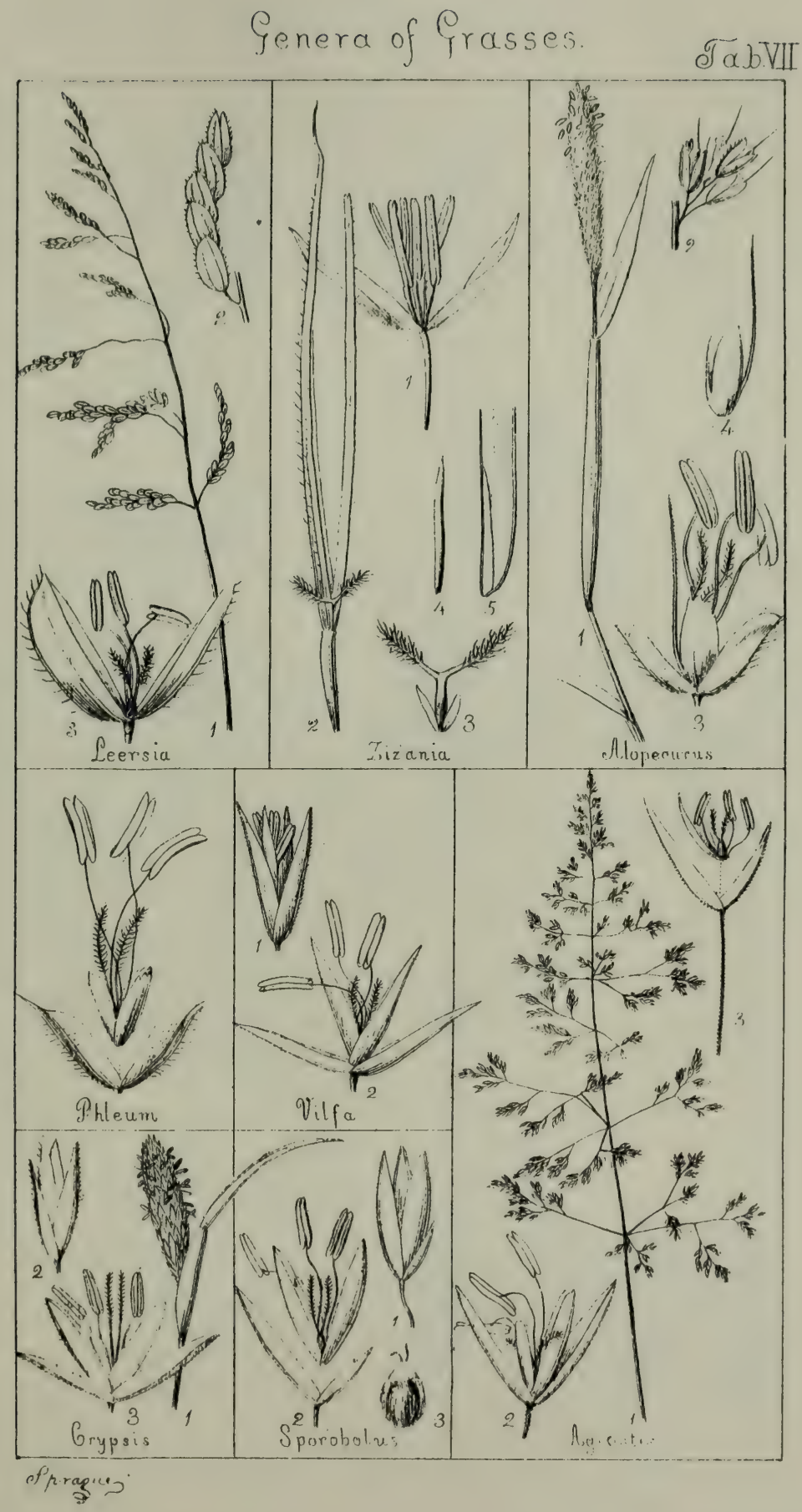





$$
\text { Genera "f Grassos Tabvili. }
$$

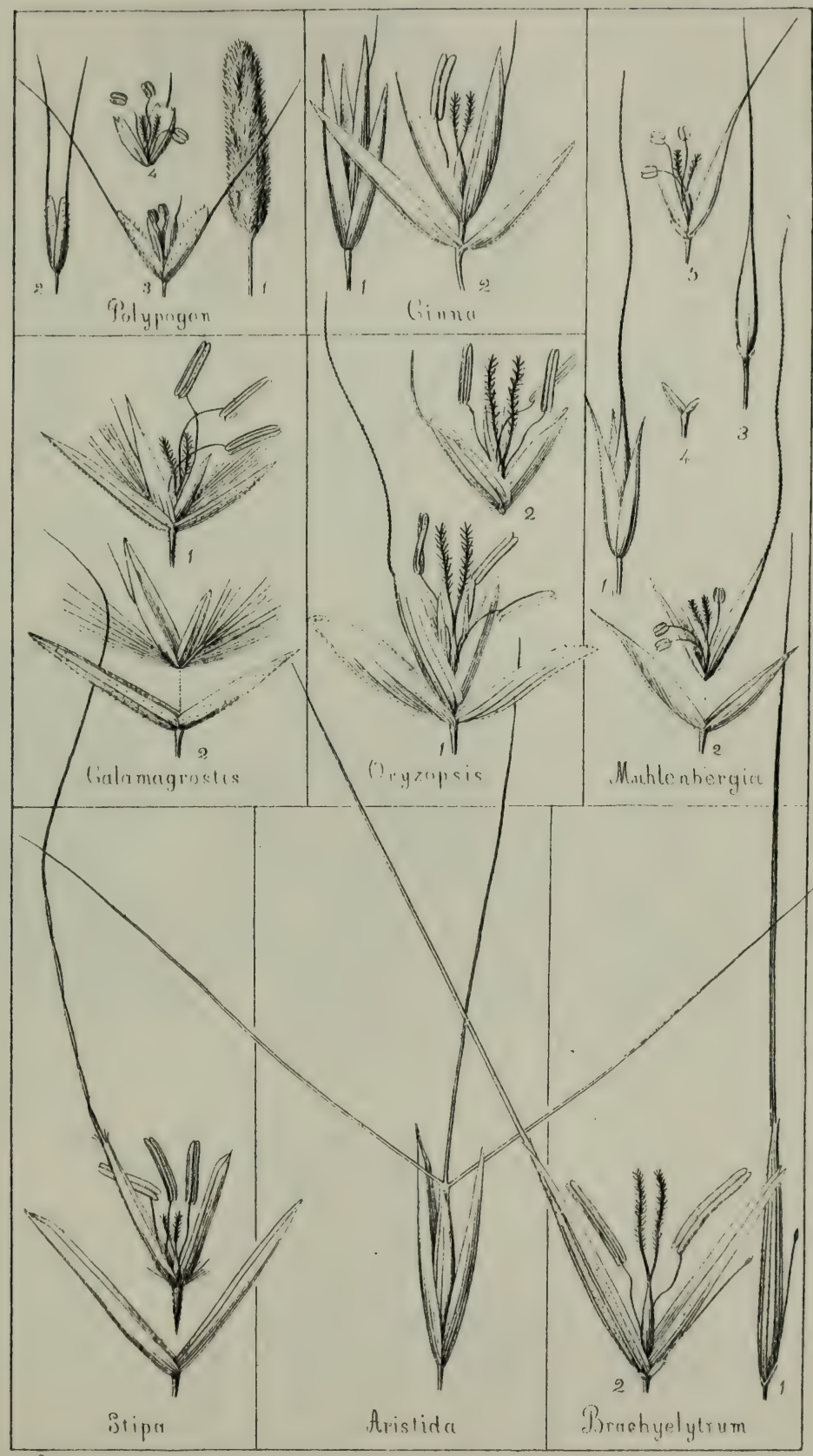

"थि, 



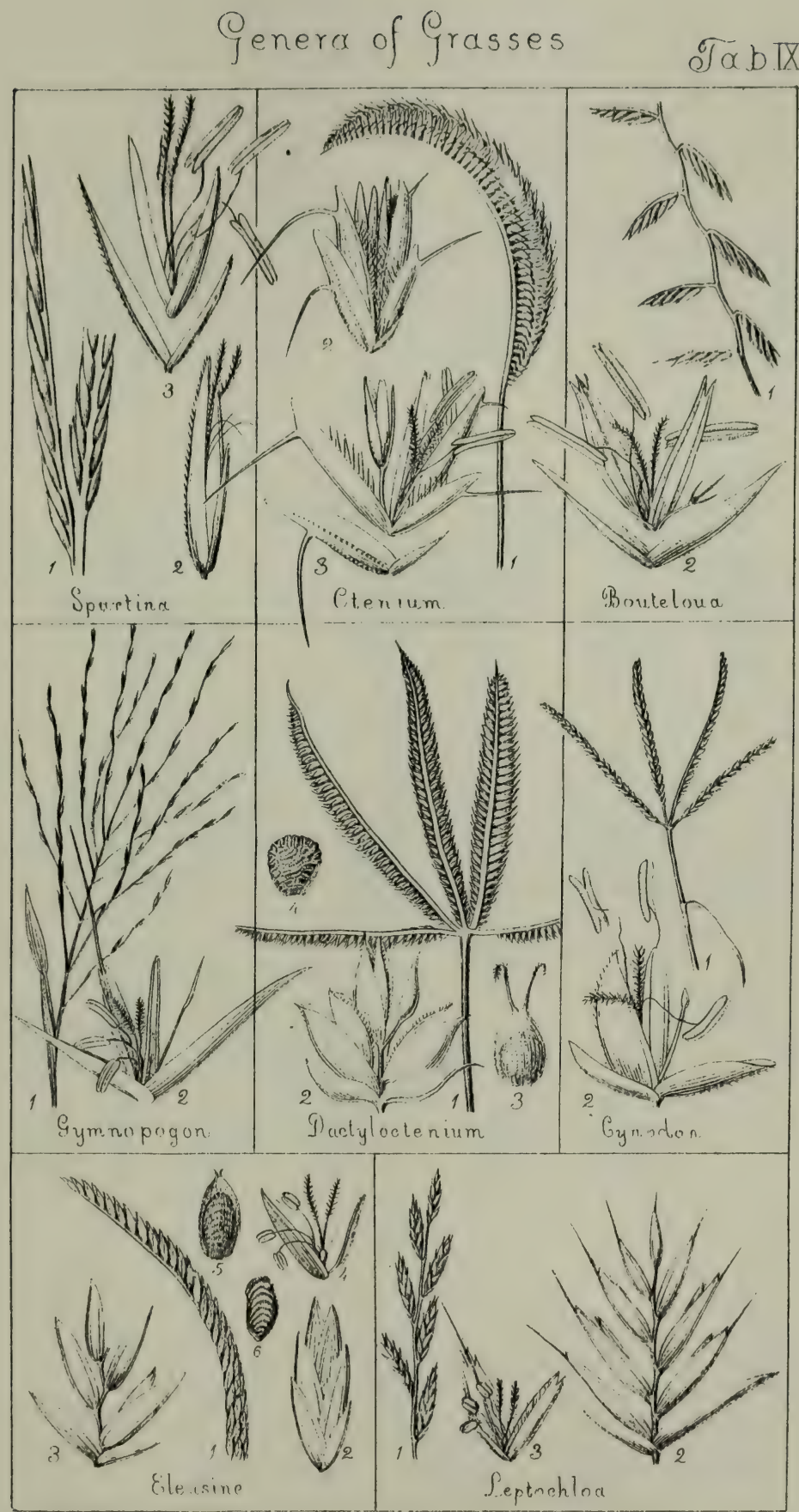





$$
\text { (i) pera of Jrasses. }
$$

ofis $+X$

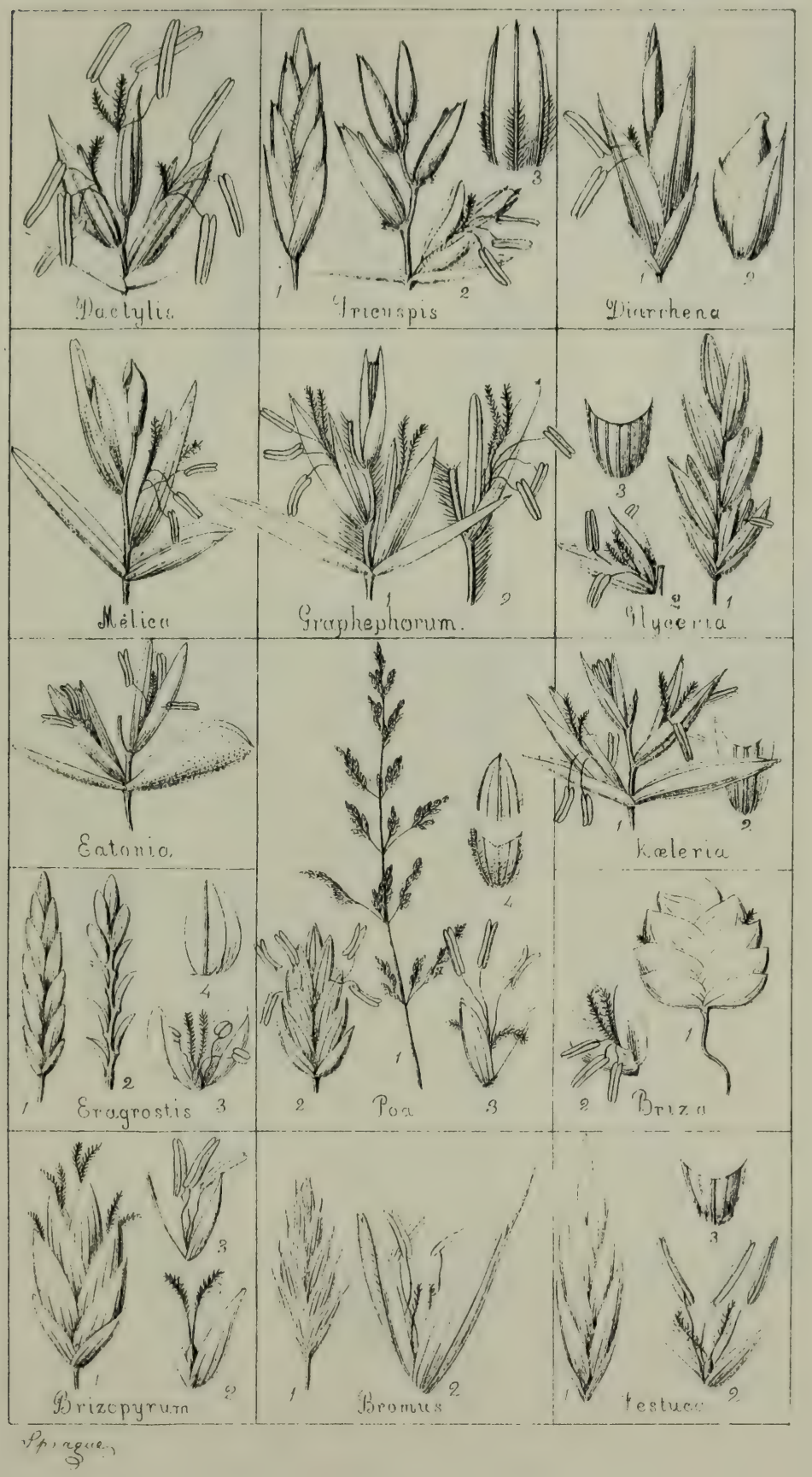





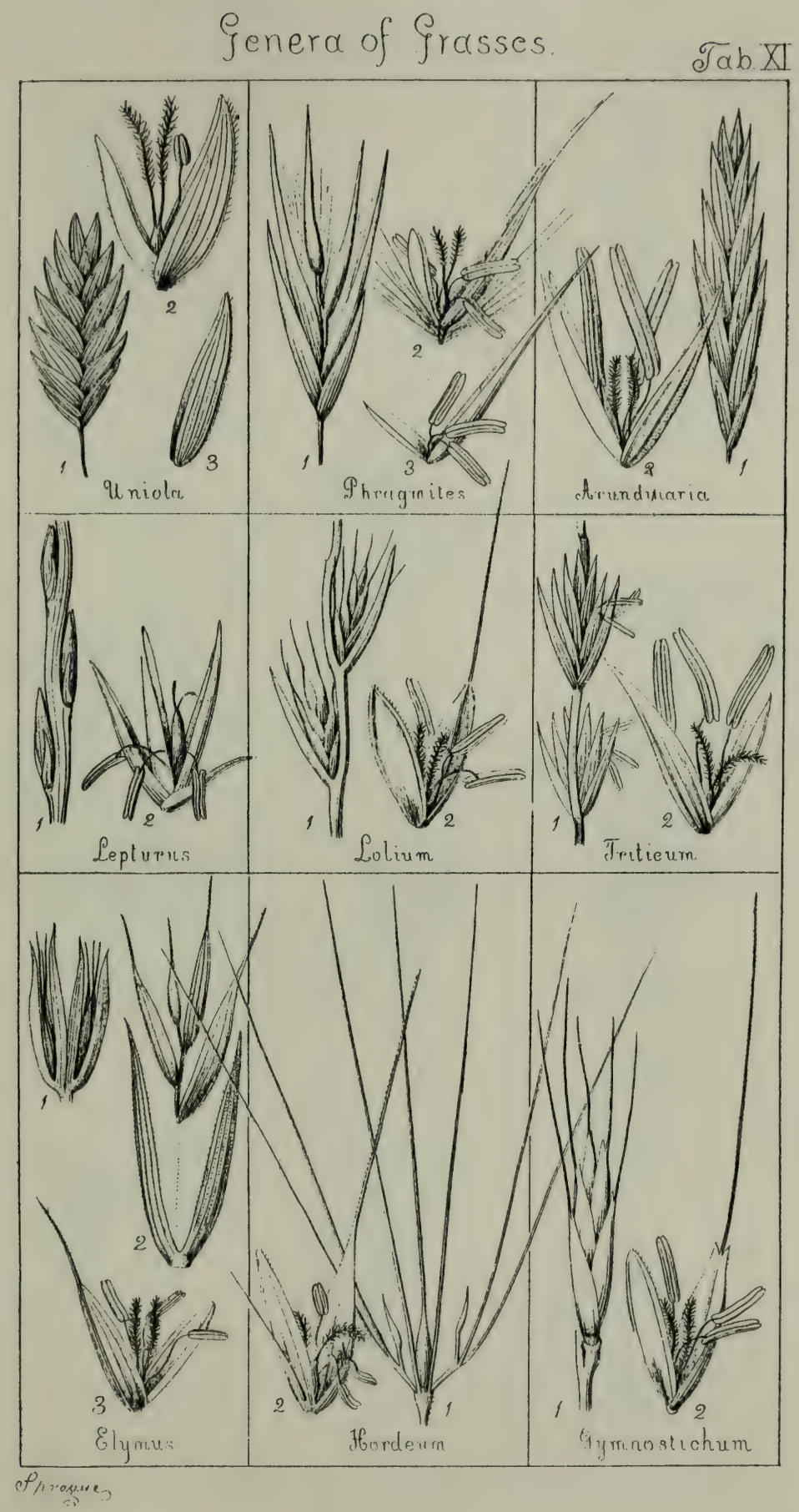





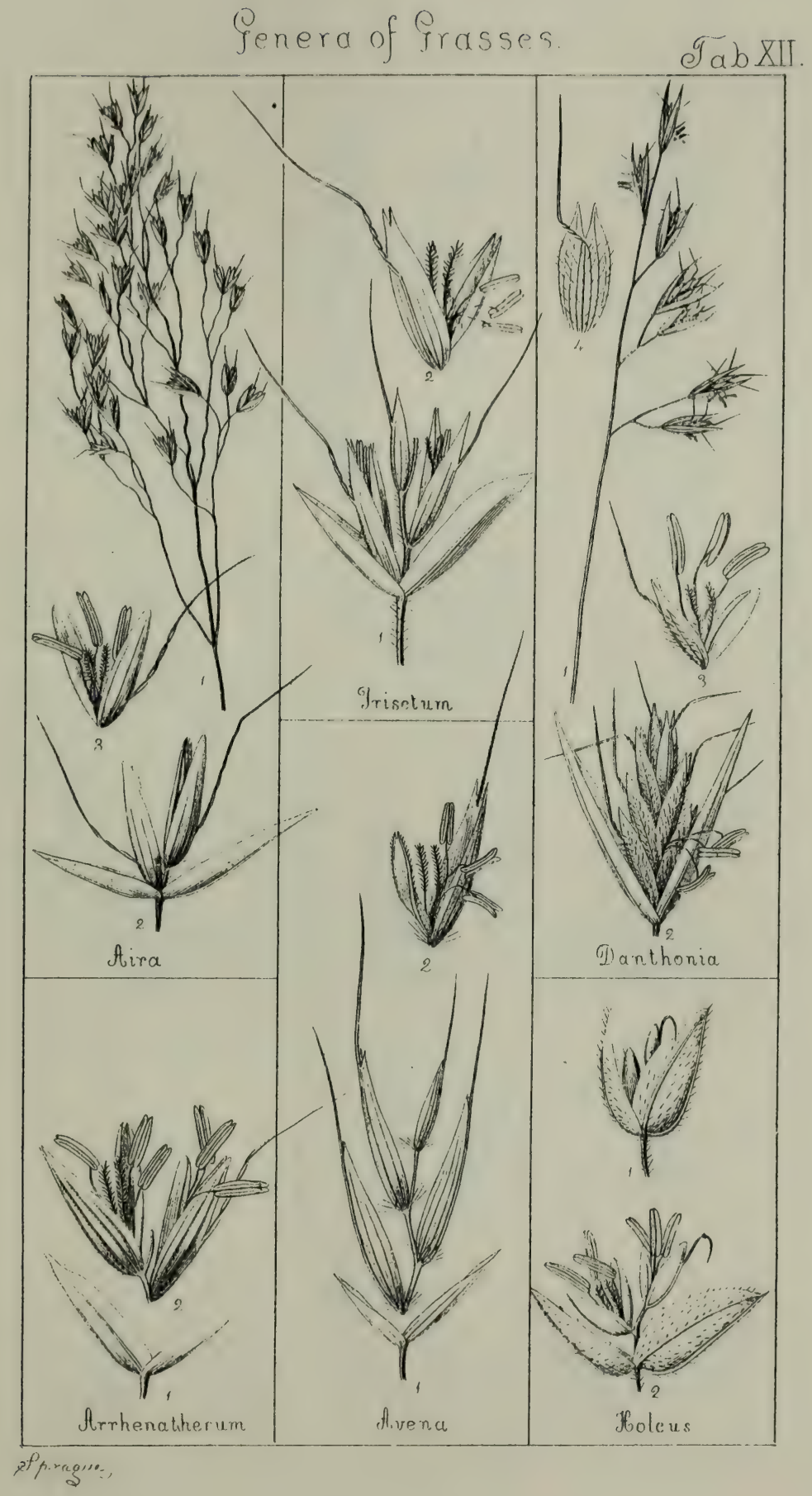





$$
\text { Gonora of Grassos }
$$

J (a.k XIII

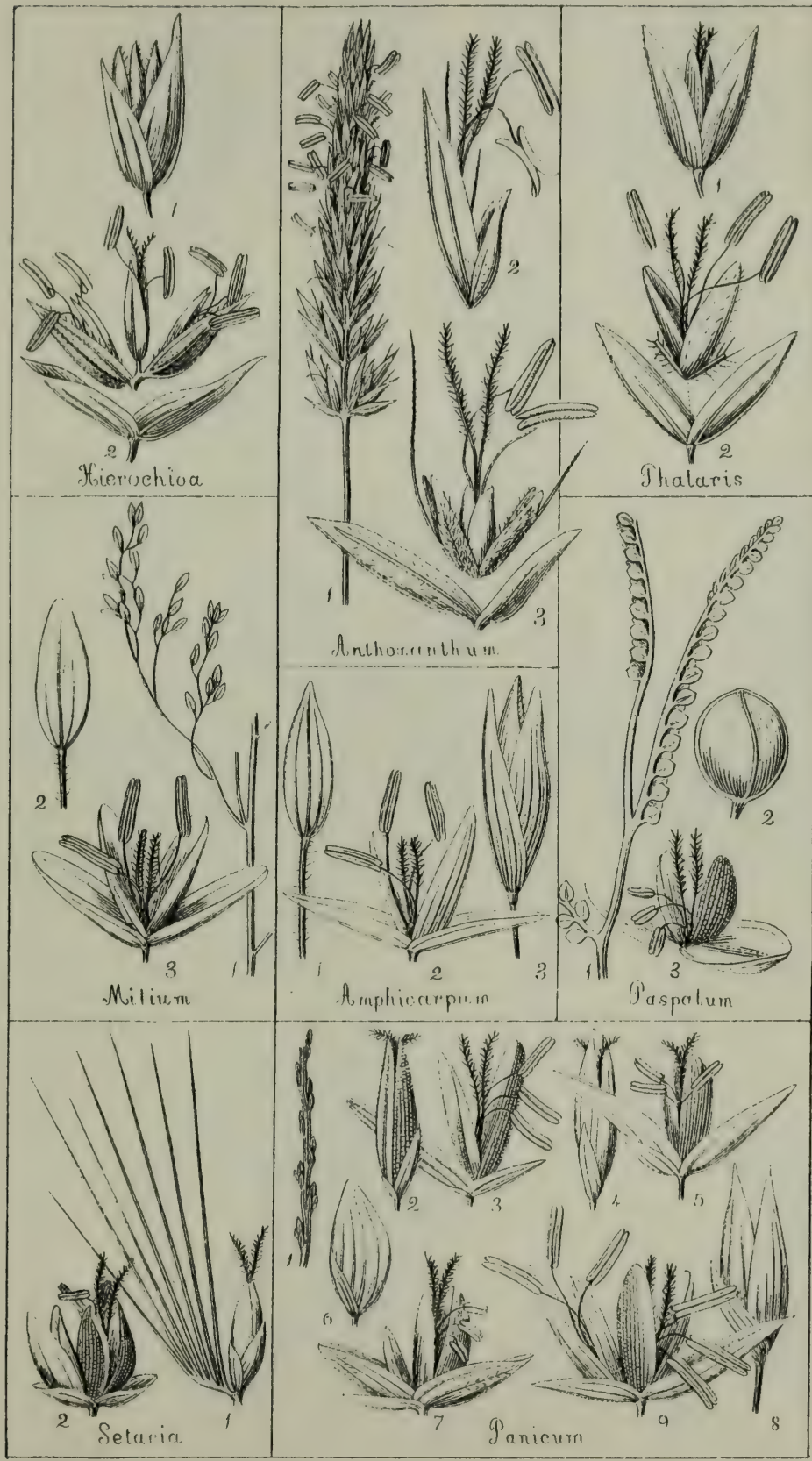

(Pprapue, 



\section{Genera of Grasses}

Tab XIV

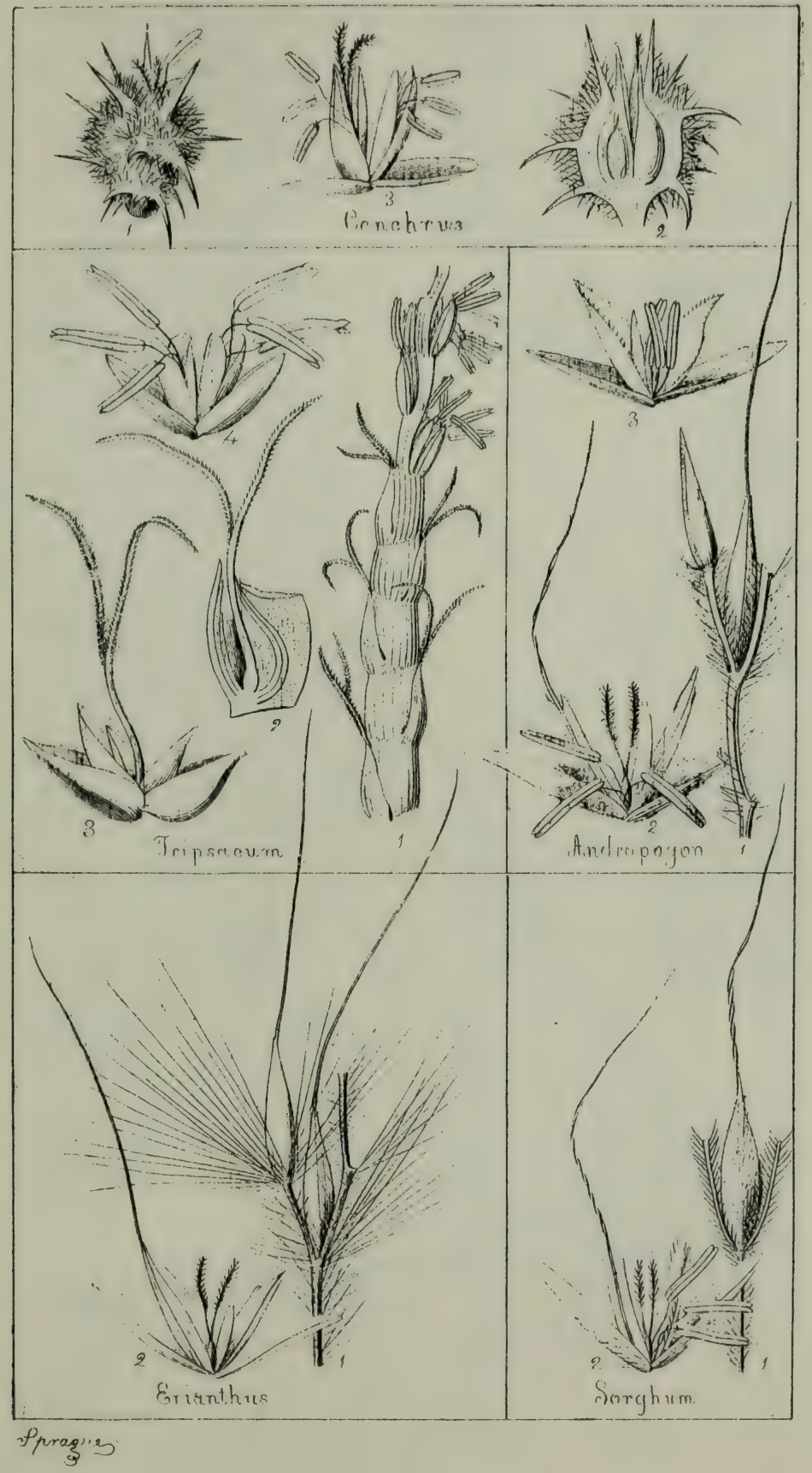





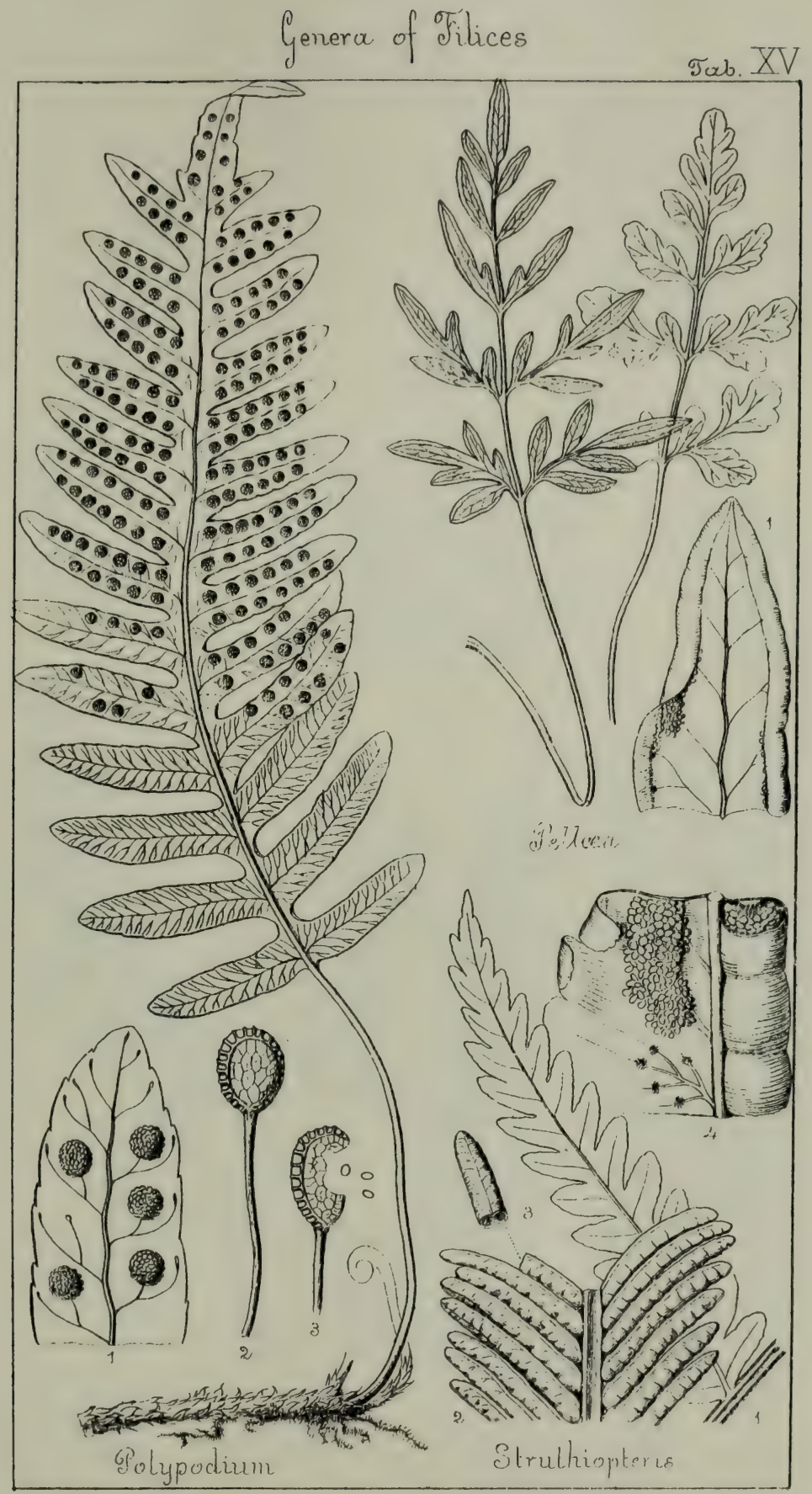

ippropace 



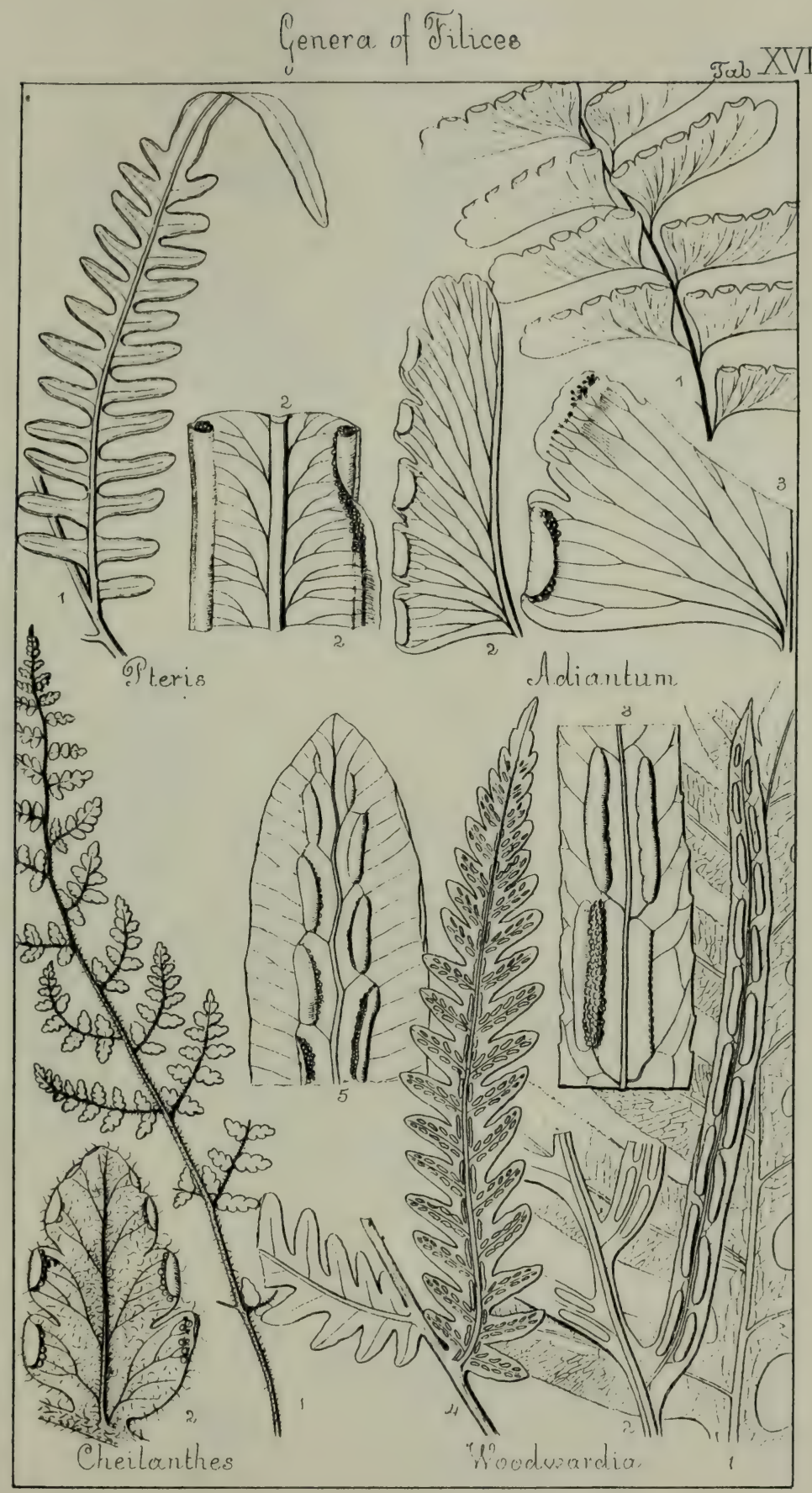

exprague 



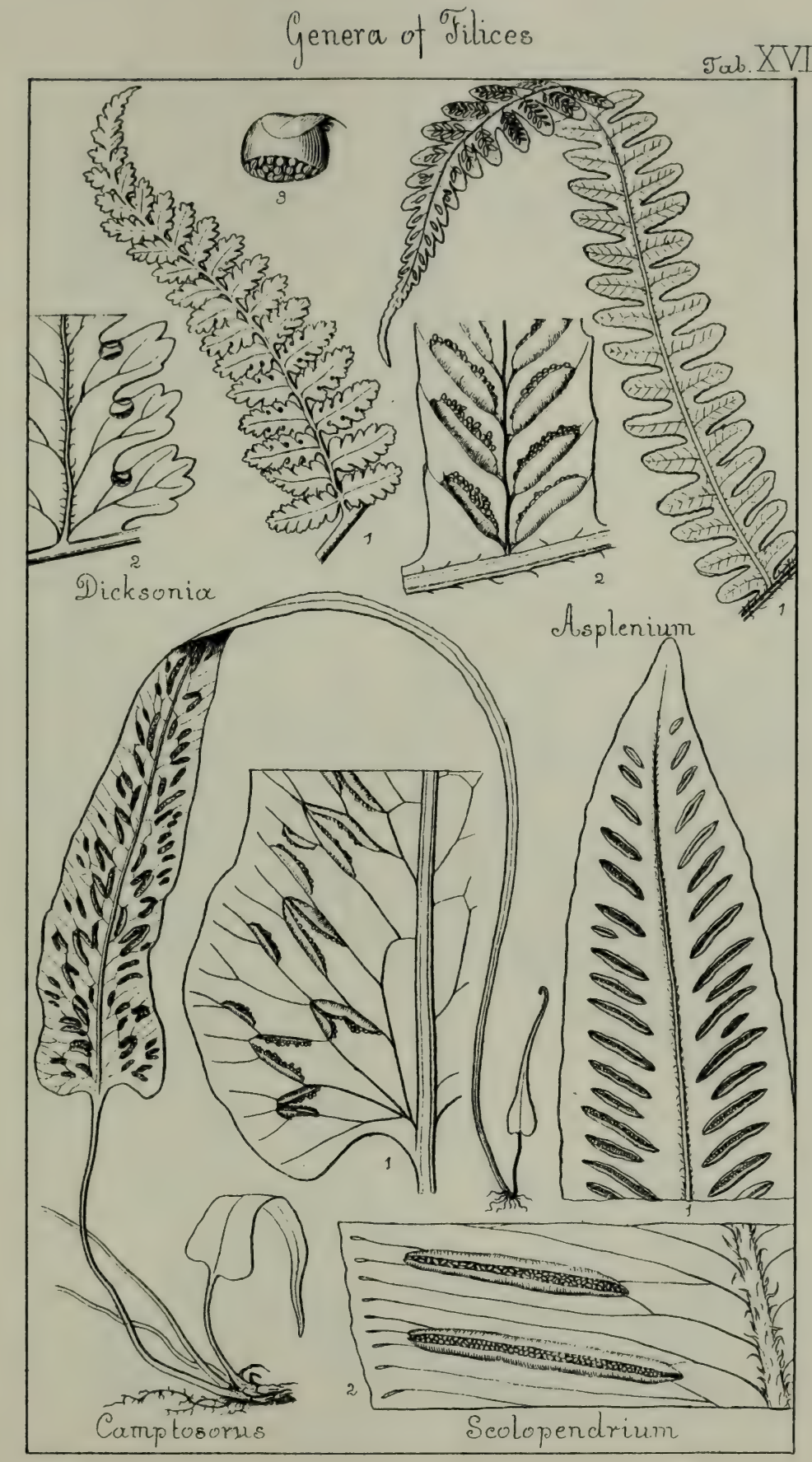





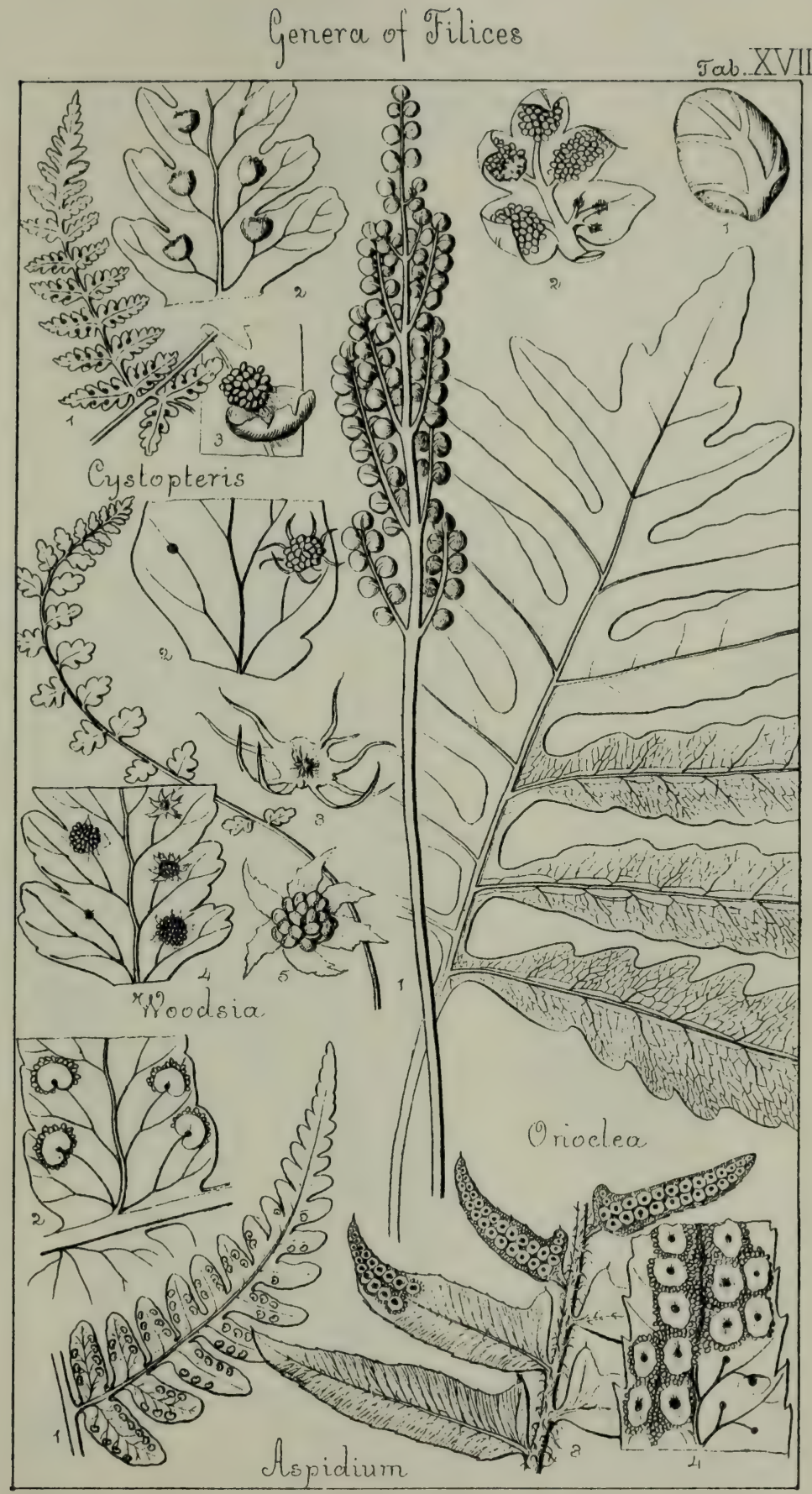

Dpragus 

Genera of dilices

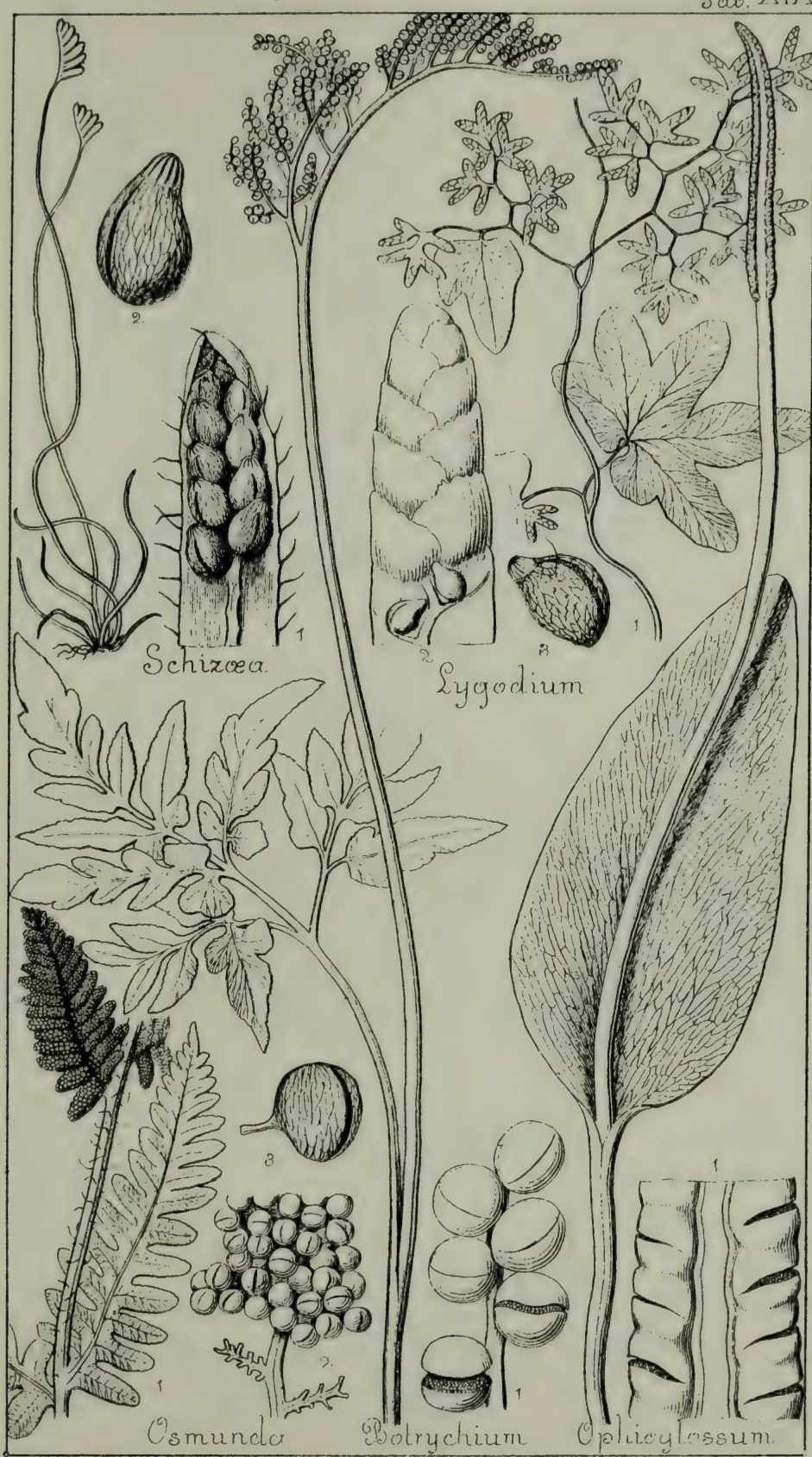

nPnrigue. 

Genera of Lycopodiacece, Squisetacese, \&cc.

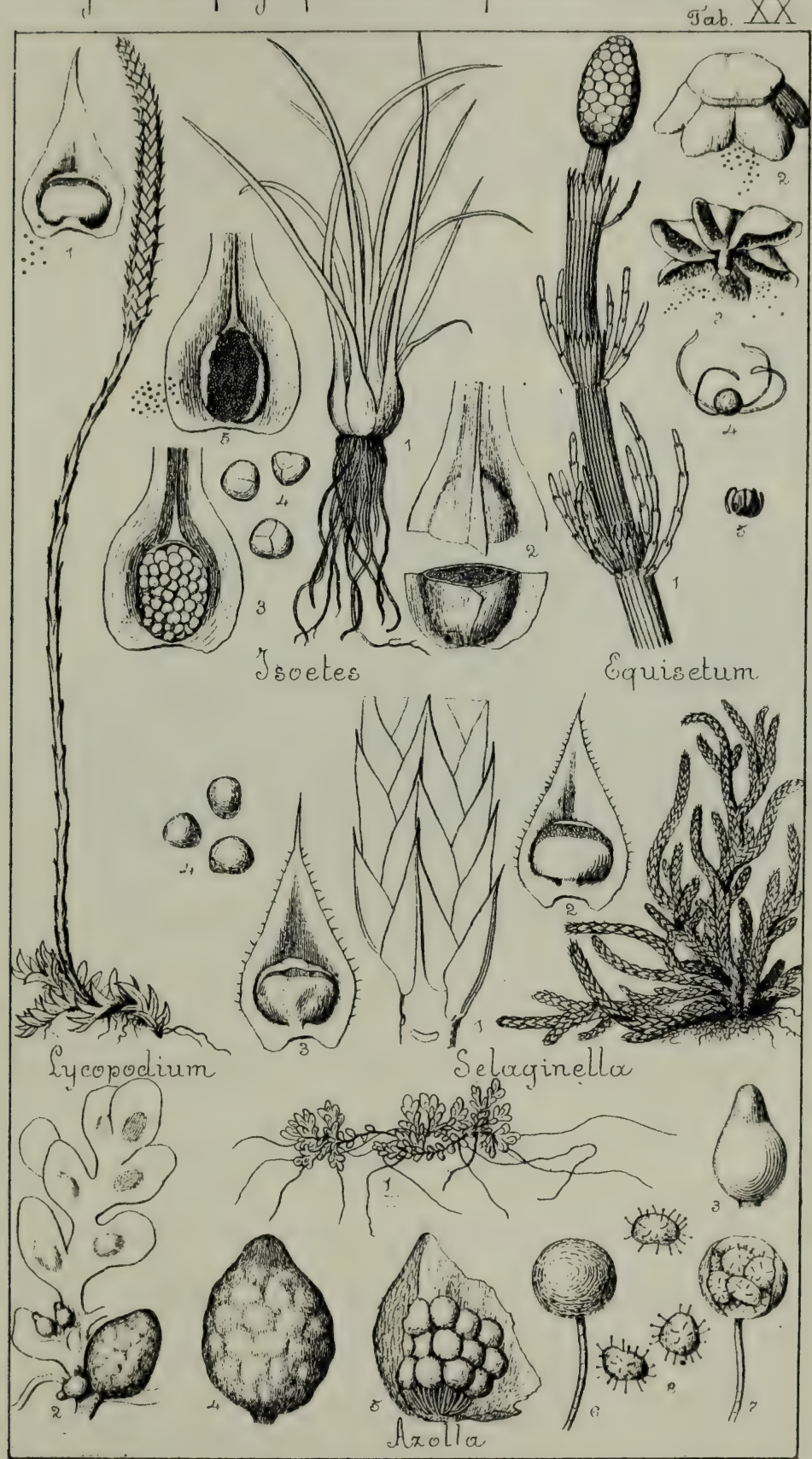

éfiragu 

Genera of Lycopodiacece, Gquisetacece, \&cc.

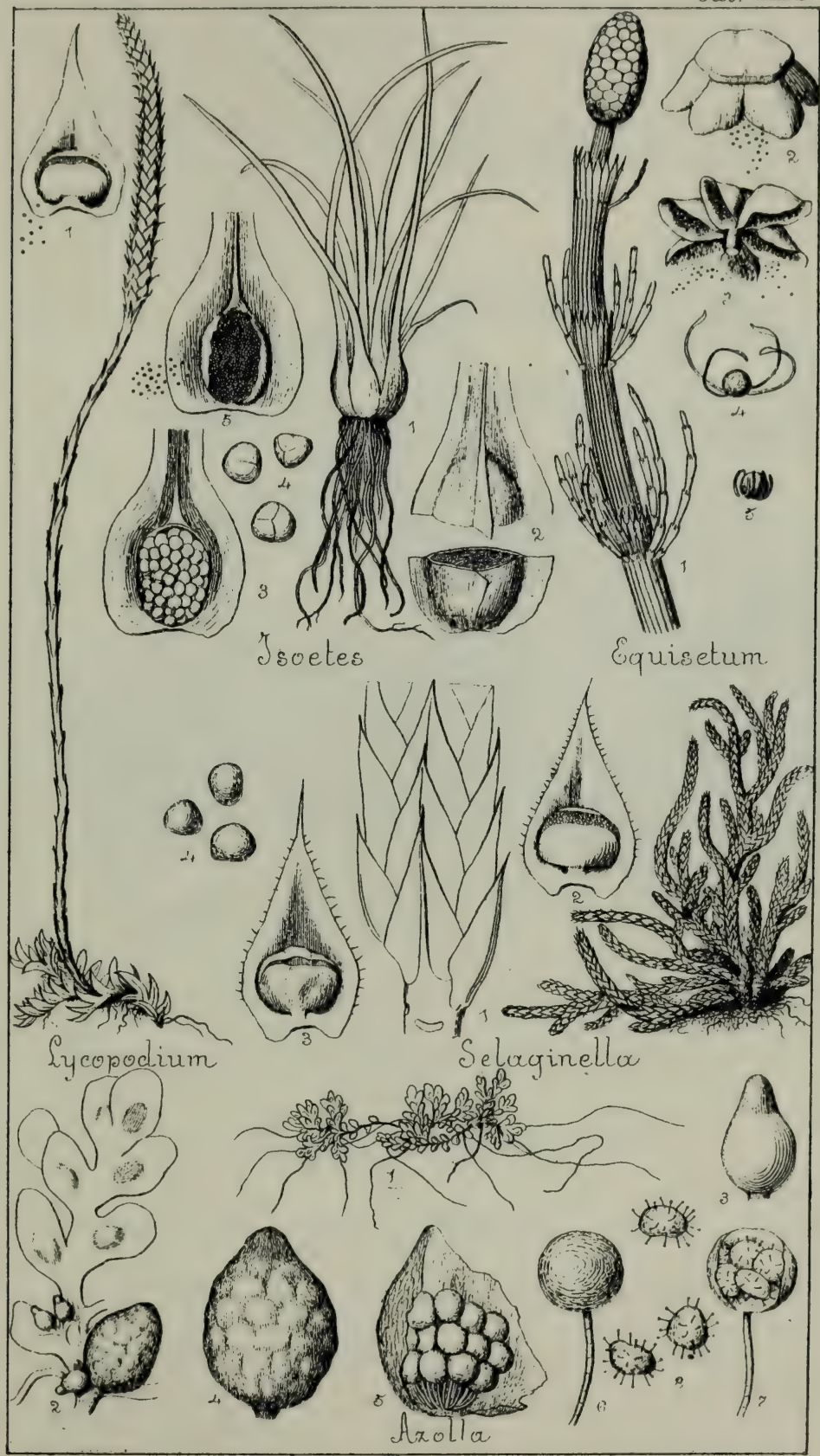

ífirez"u 



\section{GRAY'S}

\section{BotANIST'S MICROSCOPE.}

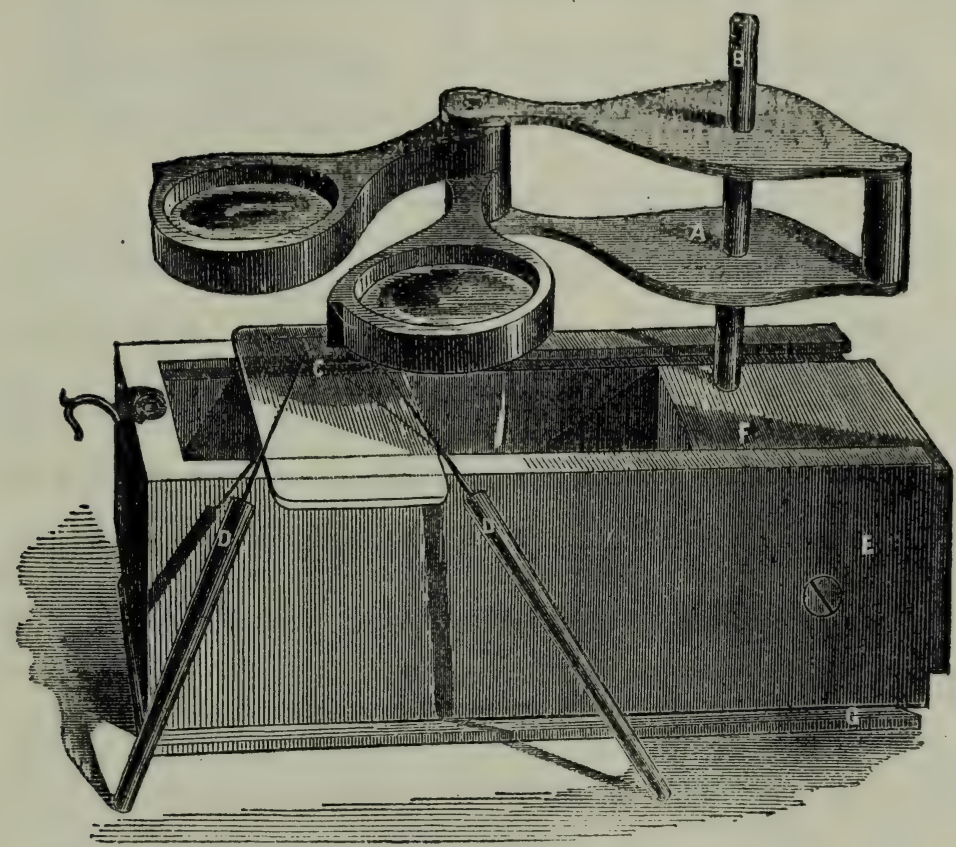

This Convenient Instrument, dcviscd and manufactured first for the use of the. Students in

\section{HARVARD UNIVERSITY,}

has given so great satisfaction there, and elsewhere, that we dcem it a duty to make it better known, and offer it at a price within the reach of all Students. 
It is attached to a box, one and a half inches high and less than four inches long, into which it is neatly folded when not in use. The needles are used for dissecting flowers, or other objects, too small to be otherwise handled for analysis. The lenses magnify about fifteen diameters; or. with three lonses, about one-third more.

A thousand things about forest, field or garden, afford objects of intense interest for daily study. Prof. ASA GRAY, of Harvard University, our popular American Botanist, says of it: "You are at liberty to call it the 'GRAY'S MICROSCOPE.' $I$ do not think anything better can be made for the money."

Price of Microscope, with two Lenses, - $\$ 200$ " " "three " - 250

Fior Sale by

\section{IVISON, Blakeman, Taylor \& CO.,}

N. Y., P. O. Box 1478.

Publishers of GRAY'S BOTANIES. 
A VALUABLE AID to the

$$
\text { STUDY OF BOTANY. }
$$

\section{PLANT ANALYSIS.}

By Hon. E. A. APGAR, Sup't Public Instruction of New Jersey; and Prof.A. C. APGAR, of the New Jersey State Normal School. Handsomely printed, and substantially bound in flexible cloth. Single copies will be sent by mail, on receipt of 70 cents.

17HE PLANT ANALYSIS will be found a valuable companion for students in the Science of Botany, and well adapted for use in connection with Gray's or any other series of Textbooks on the subject. By using this system of analysis in classes, pupils will become familiar with the meaning of botanical terms, and will learn how to apply these terms in botanical descriptions. They will also distinguish those characteristic features of a plant which are necessary to be known in making the analysis. The book will be found useful to teachers, as its written exercises afford an evidence of the work done by the pupils.

\section{Ivison, Rlakeman, Taylor \& Co.,} PUBLISHERS,

New Yorls. 


\section{WEBSTER'S}

\section{DICTIONARIES.}

UNABRIDGED QUARTO, NEW EDITION. 1928 Pager, 8000 Engravings. Over 4600 New Words and Meanings. Biographical Dictionary of over 9700 Names.

NATIONAL PICTORIAL, OCTAVO. 1040 Pages, 600 Illustrations. COUNTING-HOUSE DICTIONARY. With Illustrations.

ACADEMIC QUARTO. 834 Illustrations.

HIGH SCHOOL DICTIONARY. 297 Illustrations.

COMMON SCHOOL DICTIONARY. 274 Illustrations. PRIMARY SCHOOL DICTIONARY. 204 Illustrations. POCKET DICTIONARY. With Illustrations.

WEBSTER IS THE STANDARD FOR THE ENGLISH LANGUAGE, as is evidenced by the testimony of representative British and American Scholars and Writers.

TIE SAIE in this country is more than 20 times larger than that of any other Dictionaries, proof of which will be sent to any one on application.

WEBSTER IS THE AUTHORITY IN THE GOVERNMENT PRINTING OFFICE at Washington, and at THE U. S. MILITARY ACADEMY, WEST POINT.

W A R M L Y Recommended By W Bancroft, Prescotr, M OTley, Geo. P. Marsh, Halleck, W hittier, Willis, Saxe, Elihu Burritt, Daniel Webster, Rufus Choate, H. Colemidge, Smart, Horace Mann, Presidents Woolsey, Wayland, Hopkins, NotT, W ALKer, ANDERSon [more than FIFTY College Presidents in all], and the best American and European Scholars.

" THE best practical English Dic" tion:ry extant." - Lond on Quarterly Review, October, 1873.

" I HAVE looked, so that I might nut grow wrong, at Webster's Dictionary, a work of the greatest learning, research and ability."-LORD Chief Justice of ENGLAND, in 1863.

" T THE Courts look to it as of the 1 highest authority in all questions of definition."-Chirf Justica W AITE, U. S. Supreme Court.

" $\mathrm{IT}^{\mathrm{T}}$ has received the highest com1 mendations in the Courts of Englund, and its definitions have been universally followed in the Courts of this country."-Albany Law fournal. Fuly ro, 1875 .

Indorsed by State Superintendents of Schools in 35 States.

More than 32,000 copies of Webster's Unabridged have been placed in as many Public Schuols in the United States, by State enactments or School Officers.

PXE More than Ten Millions of volumes of School Books are annualiy published in the United States, rccognizing Welster as their general standard of orthography, while not a single school book publishing house in the country, as far as we are aware, has ever publicly recognized any other Dictionary than ivebster as its standard of orthograpliy, with the single exceptlon of the publishers of another Dictionary.- While in Etymology, Definitions, Illustrations, \&c., Webster stands unrivaled and alone.

Full descriptive circulars, showing superiority of Webster in Etymology, Defuitions, Illusirative Citallons, Orthograpliy, Pronunciution, Synonyms, Pictorial illnstrations, Usefui Tables, etc., etc., will be sent by application to the Publishers or their Agents.

$$
\begin{array}{r}
\text { Ivison, Blakeman, Taylor \& Co., } \\
\text { NEW YORK AND CHICAgo. }
\end{array}
$$


"Fully and handsomely illusirated; surpassing all others in excellence of manufacture, gradation and cheapness."

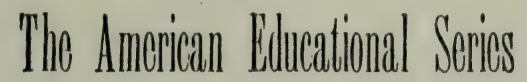

or

\section{New Graded Readers.}

AN ENTIRELY NEW SERIES, in FIVE Books, embracing many new features; compiled by several eminent educators who have acquired by a lice-long experience in the work of elementary education a familiarity with the wants of pupils and teachers in this department of instruction.

Of the dozen or more series of Readers in use in the Public schools of New York City, the New Graded are more used than all the others combined. They are more extensively used, generally, than any other series that have been issued within the past TEN years. They were adopted in June, 1878 , for exclusive use in the Public Schools of the City of Baltimore, upon a report of the Text-Book Committee of the Board of Education, from which the following is an extract :

"After considering with great care, and for a period of nearly two years past, the several series of Readers submitted for their examination, they have come to the conclusion, with en:ire unanimity, that the Educational Series of New Graded Readers, p iblished by Messrs. Ivison. Blakeman, Taylor \& Co., seems to combine a greater number of merits and advantages than any other series which the committee hive seen."

After one term's use, the high commendation of the Committee was emphasized by the following from the City Superintendent SHEPHERD, dated March 3rst, 1879 :

"Your Readers give general and decided satisfaction in Baltimore. I test them very frequently in my visits to our Schools, and with very satisfactory results. The introduc lon of a Reader with us has some significance; it is not merely placed upon a list to be used at discretion, but every,pupil in the grades into which it has been introduced, has and uses the series."

\section{CATHCART'S LITERARY READER.}

\section{TYPICAL SELECTIONS}

from the Best Authors, with Biographical and Critical Sketches, and numerous notes. Cloth. 438 pages.

* The above miy be had, as a rule, from any bookseller, but when not thus obtainable, we will supply them at liberal rates, free of transportation,

Descriptive circulars and price lists on application. The most liberal terms for introduction, exchange and examination.

\section{IVISON, BLAKEMAN, TAYLOR \& $\mathrm{CO}_{\text {", }}$}

Publishers,

New York and Chicago. 


\title{
Robinson's Progressive Course
}

OF

\section{MATHEMATICS.}

\section{RoBINSON'S PROGRESSIVE COURSE OF}

1 MATHEMATICS, being tho most conplete and scientific course of Mathematical Text-books published, is more extensively used in the Schools and Educational Institutions of the United States than any compeing series.

In its preparation two objects were kept constantly in view : First, to furnish a full and complete Series of Text-Books, which should be sufficient to give the pupil a thorough and practical business education; Second, to secure that intellectual culture without which the mere acquisition of book knowledge is almost worthless.

All the improvements of the best modern Text-Books, as well as many new and original methods, and practical operations not found in other similar works, have been incorporated into these books, and no labor or expense has been spared to give to the public a clear, scientific, comprehensive and complete system, not incumbered with unnecessary theories, but combining and systematizing real improvements of a practical and useful kind.

\section{-.. \\ Robinson's Shorter Course.}

In order to meet a demand from many quarters for a Series of Arithmetics, few in number and comprehensive in character, we have published the above course, in TWO books, in which Oral and Written Arithmetic is combined. These books have met with very great popularity, having been introduéed into several of the largest cities in the United States. They are unusually handsome in get-up, and are substantially bound in cloth.

** Desiriptive Circulars and Price Lists will be furwarded to Teachers and Educationists on "pplication. The most liberal terms will be made for introduction, exchange and examination.

\section{IVISON, BlakEMan, TaYLOR \& $\mathrm{Co}$,}

\author{
Publishers,
}

New York and Chicago. 


\section{STANDARD TEXT-BOOKS}

Bv

\section{Professor SWINTON.}

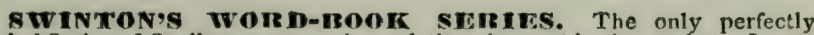
graded Series of Spellers evcr made, and the cheapest in the market. In use in more than 10,000 Schools.

Wórd Prlimer. A Beginner's Book in Oral and Written Spelling. 96 pages,

Word-isook of Spelliug. Oral and Written. Designed to attain practical results In the acquisition of the ordinary English vocabulary, and to serve as an introduction to Word Antlysis. 154 pages.

Word A nalysis. A Graded Class-book of English Derivative Words, with practical exercises in Spelling, Analyzing, Defining, Synonyms, and the Use of Words. I vol. 128 pages.

' S WINTON's IITTOKIIS. These books have attained great popularity. A new edition of the "Condensed" has just been issued, in wtich the work has been brought down to the present time, and six colored maps have been added.

Primary inistory of U. 8. First Lessons in our Country's History, bringing out the salient points, and aiming to combine simplicity with sense. I rol. square, fully illustrated.

Condensed School History of U. S. A Condensed School History of the United States, constructed for definite results in Recitation, and containing a new method of Topical Reviews. New edition, brought down to the present time. Illustrated with Maps, many of which are colored, Portraits and Illustrations. I vol. cloth. 300 pages.

Outllues of the World's IIstory. Ancient, Medixval and Modern, with special reference to the History of Mankind. A most excellent work for the proper Introduction of youth into the study of General IIistory. $1 \mathrm{vol}$, with numerous maps and illustrations, 500 pages, $12 \mathrm{mo}$.

SUVIN'TON'S GEOGIR TIIICA COURER. The famous "Two book series," the freshest, best graded, most beautitul and cheapest Geographical Course ever published. Of the large cities that have adopted Swinton's Geographies, we mention W Ashington, D. C., Rochester, N. Y. Trov, N. Y., Brooklyn, N. Y., New York City, Kingston, N. Y., Augusta, Me.. Charleston, S. C., LANCAster, Pa., Williamsport, Pa., MACon, Ga. In round numbers, they have been adopted in more than 1, 000 Cities and Towns in all parts of the country, and have, with marked prefirence, been made the bas's of Professional Training in the Leading Normal Schools of the United States.

Clementary Conrse in Ceography. Designed as a class-book for primary and intermediate grades; and as a complete Shorter Course for ungraded schools. iz pages, 8 vo.

Complete Conrce in Feography. Physical, Industrial and Political; with a special Geography for each State in the Union. Designed as a classbook for intermediate and grammar grades. 136 pages, 4 to.

The Maps in both books possess novel features of the highest practical value in education.

SWINTON:S IRAMIBCES AMONG WOIRD; Their Poetry, History and Wisdom. A Standard Work to all who love the riches of the English Language. By Winlam Swinton, M.A. Hands:mely bound in flexible cloth and marbled edges. 302 pages.

* The above may be had, as a rule, from any bookscller; but when not thus obtainable, we will supply them, transportation paid, at liberal rates. Descriptive Circulars and P'rice Lists will be sent on applicatton.

Very liberal terms for introduction, exchange and examination.

IVISON, BLAKEMAN, TAYLOR \& CO., Publishers, NEW YORK and CHICAGO. 


\section{Approved Text-Books}

FOR

\section{HIGH}

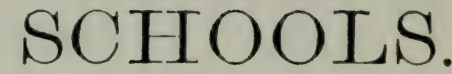

$\prod$

HERE are no text-books that require in their preparation so much practical scholarship, combined with the teacher's experience, as those compiled for use in High Schools, Seminaries and Colleges. The treatment must be succinct yet thorough; accuracy of statement, clearness of expression, and scientific gradution are indispensable. We have no special claims to make for our list on the score of the Ancient Classics, but in the modern languages, French, German and Spanish, in Botany, Geology, Chemistry and Astronomy. and the Iligher Mathematics, Moral and Mental Science, etc., etc., we challenge comparison with any competing books. Many of them are known to all scholars, and are reprinted abroad, while others have enjoyed a National reputation for many years.

WOODBURY'S GERMAN COURSE. Comprising a full series, from

"The Easy Lessons" to the most advanced manuals.

FASQUELLE'S FRENCH COURSE. On the plan of Woodbury's Method; also a complete series.

MTXERS MANUAL OF FRENCII POETRY:

LANGUELLIER dE MONSANTO'S HRENCU GRAMMAR.

UENNEQUIN'S FRE'VOU VERBS.

MONSANTO'S FRENCU STUDENT'S ASSISTANT.

MONSANTO \& LANGUELLIER'S SPANISH GRAMMAR.

GRA I'S BOTANICAL SERIES.

DANA'S WORKS ON GEOLOGY.

ELIOT E STORLI'S CIIEMISTRI:

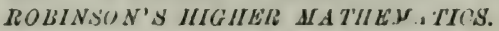

SWIVTON'S OUTLINES OF' IIISTORY.

WILLSON'S OUTLINES OF' IIISTORY.

CATIICART'S LITERARY READER.

HICKOK'S WORKS ON METAPIITSICS.

UUNT'S LITERATURE OF THE ENGLISH LANGUAGE.

WELLS' WORKS ON NATURAL SCIENCE.

KERL'S COMIREIIE.VSIVE E.VGLISH GRAMMAR.

WEBSTER'S ACADEMIO DICTIONARY.

TO WNSEND'S CIVIL GOVERNMEITT.

WHITE'S DISA WING.

TAYLOR-KL̈IINER'S GREEK GRAMMAR.

KIDULE'S ASTRONOMY.

SWINTON'S COMPLETE GEOGRAPHY. ELC. E'C.

** Descriptive Circulars and P'rice Lists will be sent to Teachers and Educationists on application. Libcral terms will be made for introduction, exchange and examination.

Ivison, Blakeman, Taylor \& Co., Publishers, NEW YOHK and CHICAGO. 
This preservation photocopy was made at BookLab, Inc. in compliance with copyright law. The paper meets the requirements of ANSI/NISO 239.48-1992 (Permanence of Paper)

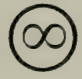

Austin 1996 






DATE DUE

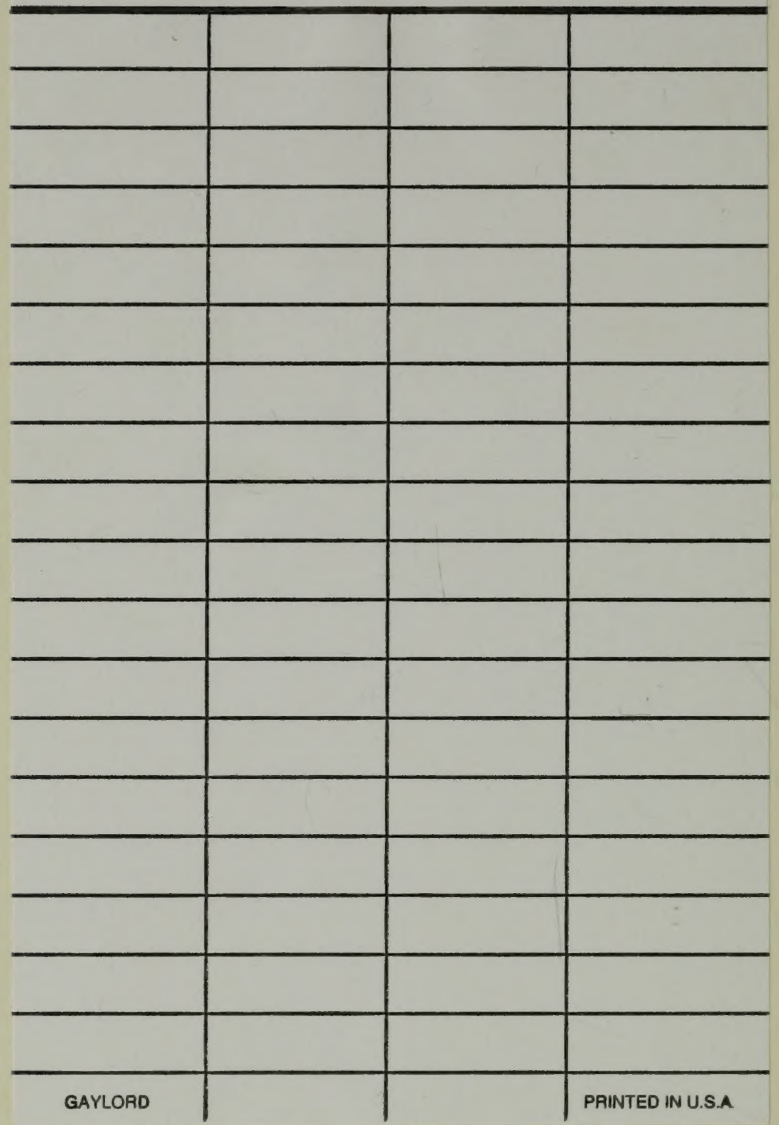




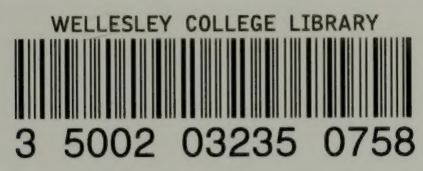

Science QK $117 . G 75 \quad 1881 a$

Gray, Asa, 1810-1888.

Gray'a lezeone in botany and vegetable phyelology 
